\title{
Johann Friedrich von Uffenbach. Sammler - Stifter - Wissenschaftler
}

\author{
Dissertation \\ zur Erlangung des philosophischen Doktorgrades \\ an der Philosophischen Fakultät der Georg-August-Universität Göttingen
}

\author{
vorgelegt von \\ Dietrich Meyerhöfer \\ aus Frankfurt/Main
}

Göttingen 2019 
Betreuer und Erstgutachter; Prof. Dr. Cartsten-Peter Warncke Zweitgutachter: Prof. Dr. Michael Thimann

Datum der mündlichen Prüfung: 28. Januar 2020 


\section{Inhaltsverzeichnis}

Johann Friedrich von Uffenbach...............................................................

Sammler - Stifter - Wissenschaftler …….................................................... 1

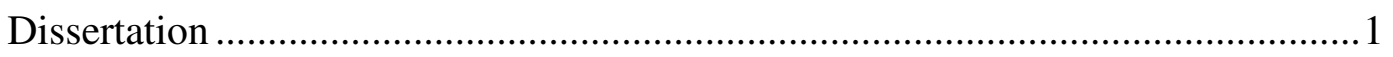

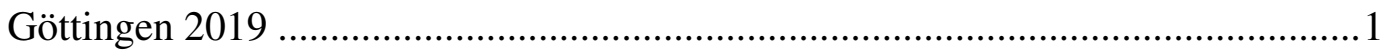

Betreuer und Erstgutachter; Prof. Dr. Cartsten-Peter Warncke..............................2

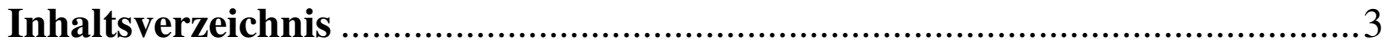

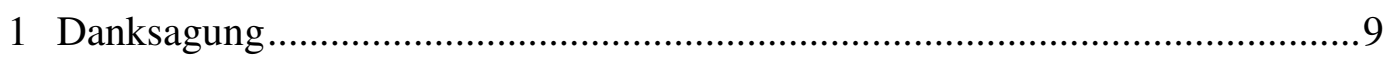

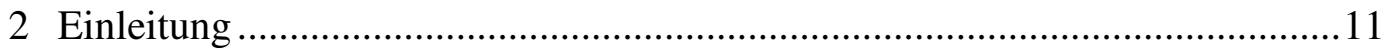

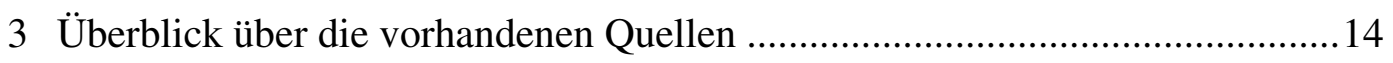

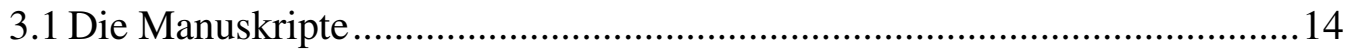

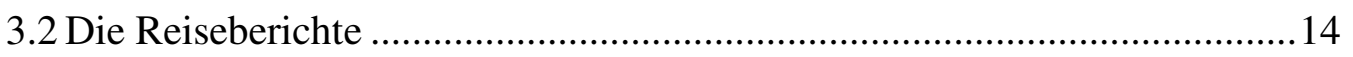

3.3 Das „Commercium Epistolicum“............................................................ 17

3.4 Quellen zur Bibliothek und zum graphischen Kabinett .............................. 18

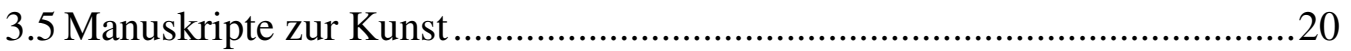

3.6 Die Protokolle der wissenschaftlichen Gesellschaft ................................21

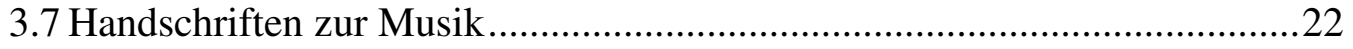

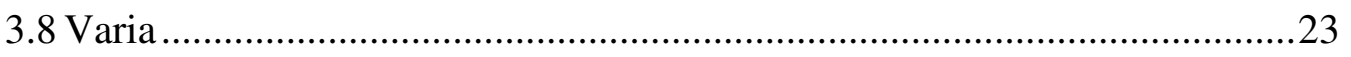

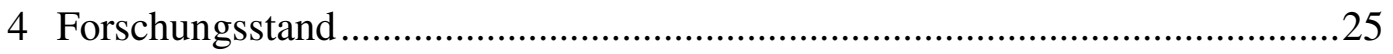

5 Lebenslauf des Johann Friedrich Armand von Uffenbach..............................29

5.1 Die Familie und Herkunft ....................................................................29

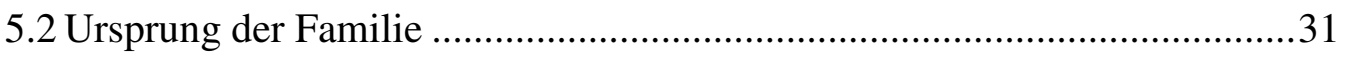

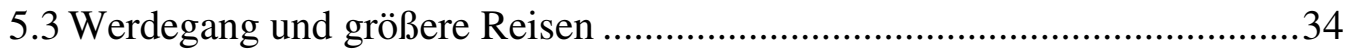

5.4 Privates und öffentliches Leben in Frankfurt am Main..............................55

5.5 Geschehnisse nach dem Tod von Johann Friedrich von Uffenbach ............83

6 Geschichte der Schenkung nach Göttingen................................................. 87

6.1 Uffenbach als Vollstrecker des Testaments von Zacharias Conrad.............87

6.2 Die Veräußerung der Bibliothek des Zacharias Conrad von Uffenbach......88

6.3 Uffenbachs Bindungen an Frankfurt am Main..........................................89

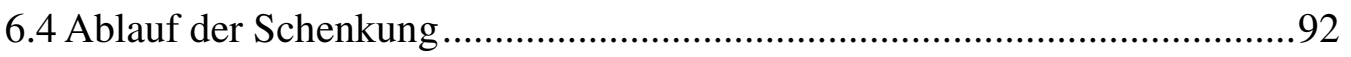


7 Der Sammler Johann Friedrich von Uffenbach ............................................113

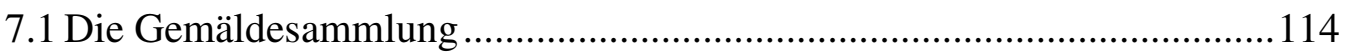

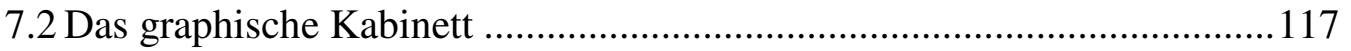

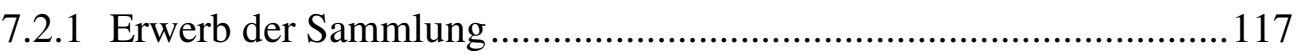

7.2.2 Die Ordnung des graphischen Kabinetts .........................................126

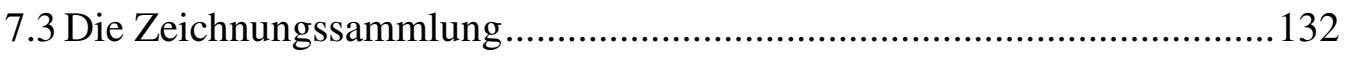

Abb. 25 Auktionskatalog Uffenbach 1771, S. 1 .............................................. 135

7.4 Die Sammlung der wissenschaftlichen Geräte........................................138

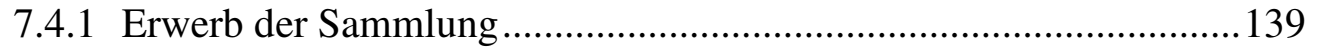

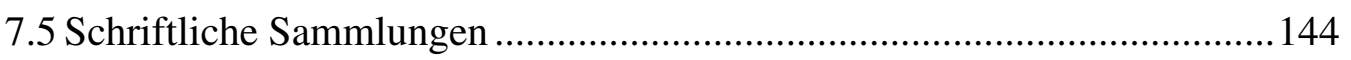

8 Uffenbachs Schriften zur Druckgraphik ................................................... 148

8.1 Die „Uhrsprüngliche Historie der gesamten Bildkunst auf Papier“............148

8.2 Die beiden Lexika der Monogramme …................................................. 150

9 Die wissenschaftliche Gesellschaft des Johann Friedrich von Uffenbach......157

9.1 Johann Friedrich von Uffenbachs „Vorberichte“......................................164

9.2 Die Statuten der wissenschaftlichen Gesellschaft...................................168

9.3 Die Wirkung der Gesellschaft nach außen .............................................169

9.4 Die Beiträge der einzelnen Mitglieder ................................................171

9.4.1 Die Beiträge von Johann Friedrich von Uffenbach ..........................171

„Kap. 1: Von dem Lobe und Alter der Astronomie............................................ 172

Kap. 3: Von der Altenmeinung, betreffendt die Welt=Ordnung........................172

Kap. 5: Von denen Einwürffen die denen Copernicanern gemacht werden........172

23. Kap.: Von denen Dingen so auf dem Erdeboden sind und geschehen. ..........174

9.4.2 Die Beiträge von Philipp Jacob Behaghel ......................................193

9.4.3 Die Beiträge von Albert Adolf Diesterweg ......................................196

9.4.4 Die Beiträge von Conrad Hieronymus Eberhard, gen. Schwind.......202

9.4.5 Die Beiträge von Johann Georg Kißner ........................................205

9.4.6 Die Beiträge von Wilhelm von Uffenbach....................................209

9.4.7 Die Beiträge von Johann Friedrich Ettling .....................................213 
9.5 Resümée

10 Welchem Typus von Sammler gehört Johann Friedrich von Uffenbach an? .219

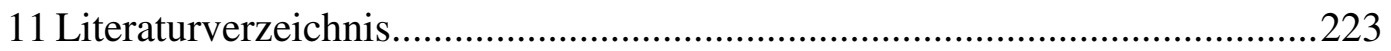

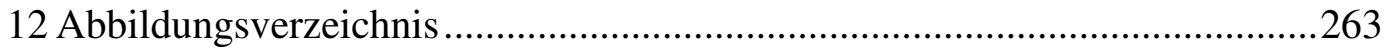

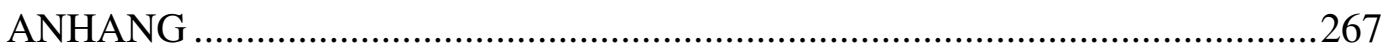

zu 267

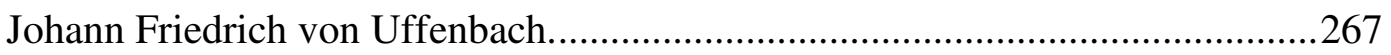

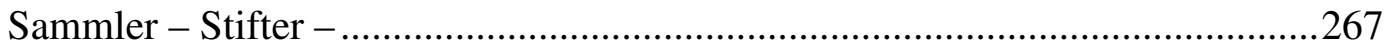

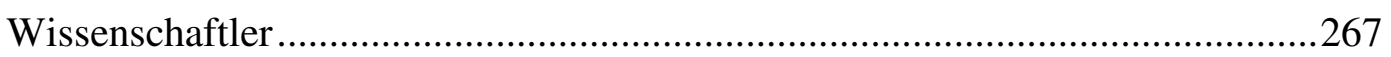

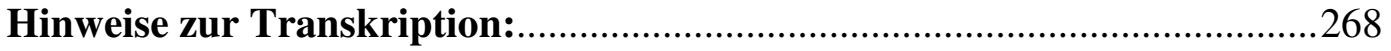

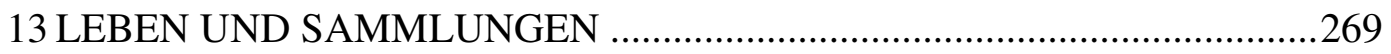

13.1 Eintragungen in den Taufbüchern und Totenbüchern der

Evangelischen Kirche.

13.2 Das Gutachten aus dem Jahre 1767 von Johann Friedrich von

Uffenbach zur Gründung einer Malerakademie in Frankfurt am Main .....273

13.3 Das Gegenschreiberbuch der Auktion von 1771 .............................227

13.4 Das Gegenschreiberbuch der Auktion von 1775 ...........................293

13.5 Die offizielle Schenkungsakte an die Georgia - Augusta in Göttingen

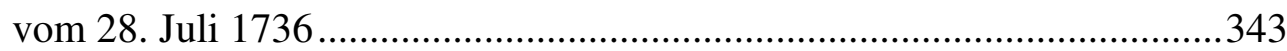

13.6 Das Uffenbachische Instrumenten-Inventar ....................................346

13.6.1 Darstellung des Uffenbachischen Instrumenten-Inventars................346

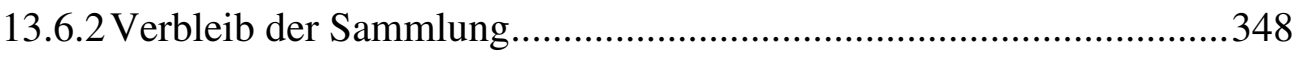

13.6.3 Transkription des Kataloges der Uffenbachischen Instrumente.........354

13.7 Das eigenhändige Inventar der Druckgraphik ................................401

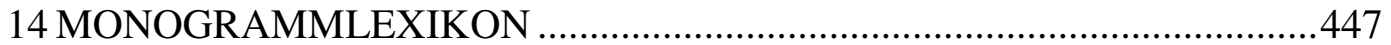

14.1 „Uhrsprüngliche Historie der gesamten Bildkunst auf Papier“ und zwei Referate zum Naturdruck.

14.1.1 Von dem Holz- oder Formschneiden ............................................449

14.1.2 Von dem Kupferstechen ...........................................................462

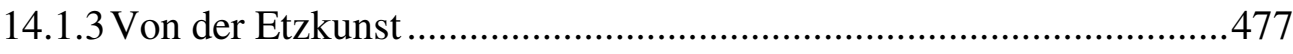


14.2 Lateinischer Text von Johann Friedrich von Uffenbach, gedacht als Vorwort bei der Veröffentlichung des Monogrammlexikons mit deutscher Übersetzung. .495

14.3 Johann Friedrich von Uffenbachs Aufsatzentwurf vom Januar 1736 an die Herausgeber der „Hamburgische Berichte von neuen Gelehrten Sachen“ 500

15 BRIEFE .507

15.1 Brief des Mechanikers und Feuerwerkers Johann Daniel Blümel aus Straßburg. .509

15.2 Drei Briefe von Johann Christian Kaller aus Amsterdam, einer der Kommissionäre, die für Johann Friedrich von Uffenbach tätig waren. .....511

15.2.1 SUB Göttingen Cod. Ms. Uffenbach 20/II, p. 301-302, Amsterdam, 17.Juni 1758 .511

15.2.2 SUB Göttingen Cod. Ms. Uffenbach 20/II, p. 303-304, Amsterdam, 06.Juli 1762 .513

15.2.3 SUB Göttingen Cod. Ms. Uffenbach 20/II, p. 384, Amsterdam 14.Juli 1762 .514

15.3 Sechs Briefe von Peter Heß, Steinschneider in Kassel. .515

15.3.1 SUB Göttingen Cod. Ms. Uffenbach 20/I, p. 445-446, 4. Januar 1751. 515

15.3.2 SUB Göttingen Cod. Ms. Uffenbach 20/II, p. 328-329, 24. Januar 1763. .518

15.3.3 SUB Göttingen Cod. Ms. Uffenbach 20/II, p. 330-331, 19. März 1763. 520

15.3.4SUB Göttingen Cod. Ms. Uffenbach 20/II, p. 332, 11. April 1763. .522

15.3.5 SUB Göttingen Cod. Ms. Uffenbach 20/II, p. 333-334, 28. Mai 1763. 523

15.3.6SUB Göttingen Cod. Ms. Uffenbach 20/II, p. 416-420, ohne p. 419, 28. November 1750 . 525

15.4 Drei Briefe von Johann Daniel Geysel an Johann Friedrich von Uffenbach 530 
15.4.1 SUB Göttingen Cod. Ms. Uffenbach 20/I, p. 108-112, Venedig, September 1750 .

15.4.2Cod. Ms. Uffenbach 20/II, p. 405-409, 9. März 1723 ......................538

15.4.3Cod. Ms. Uffenbach 20/II, p. 632-633, 5. Oktober 1723

15.5 Briefentwurf von Johann Friedrich von Uffenbach an den Leipziger

Professor Johann Friedrich Christ.

15.6 Antwortschreiben mit französischem Text von Johann Friedrich Christ aus Leipzig an Johann Friedrich von Uffenbach.

15.7 Zusammenfassung Uffenbachs von einem Brief des Leipziger

Verlegers Bernhard Christoph Breitkopf oder dessen Sohn, Johann Gottlob

Immanuel Breitkopf. .558

15.8 Zwei Kurzschreiben bezüglich der Auktion des graphischen Kabinetts von Johann Friedrich Christ aus Leipzig .559

16 DIE WISSENSCHAFTLICHE GESELLSCHAFT .561

16.1 Liste der Zusammenküfte der wissenschaftlichen Gesellschaft .563

16.2 Die Ordnung der Wissenschaftlichen Gesellschaft und die einzelnen Vorworte der Bände I - IV..... .576

16.2.1 Die Regeln, die sich die Gesellschaft gegeben hat: .576

16.2.2Die Vorworte:

16.3 Die Titel der Vorlesungen zur Astronomie von Johann Friedrich von Uffenbach.

16.4 Johann Friedrich von Uffenbach beschreibt einen Gehstock mit Schildpatthülle in der wissenschaftlichen Gesellschaft am 9. Dezember 1728587

16.5 Johann Friedrich von Uffenbachs Bericht zu seinen Versuchen mit Bleiweiß 589

16.6 Johann Friedrich von Uffenbachs Anmerkungen zu einem Verfahren des Mehrfarbendrucks .592

16.7 Die Rede Johann Friedrich von Uffenbachs zum Tod seines jüngeren Bruders Wilhelm von Uffenbach .594

17 Eidesstattliche Erklärung 



\section{Danksagung}

Ihr Zustandekommen verdankt diese Arbeit, die der Philosophischen Fakultät der Georg-August-Universität Göttingen 2019 vorlag, in großem Maße der Hilfsbereitschaft und dem Interesse zahlreicher Personen. An erster Stelle habe ich meinem Doktorvater, Professor Dr. Carsten-Peter Warncke, für seine langjährige und stete Anteilnahme und seine konstruktive Kritik zu danken, mit der er diese Dissertation betreute und unterstützte. Desweiteren gilt dieser Dank Dr. Gerd Unverfehrt †, ehemaliger Kustos der Kunstsammlung der Universität Göttingen, für seine große Geduld und Diskussionsbereitschaft. Während der Beschäftigung mit Johann Friedrich von Uffenbach hatte ich das Glück, in vielfachem persönlichen Gedankenaustausch zu stehen, wobei ich stellvertretend für andere Dr. Jochen Wagner $\dagger$, Professor Dr. Elisabeth Schröter $\dagger$, Professor Dr. Werner Heun $\dagger$, Ingelore Unverfehrt $\dagger$, Dr. Inke Beckmann (Göttingen), Dr. Karin Schrader (Bad Nauheim) und Dr. Anne-Katrin Sors (Göttingen) für ihre Anregungen sehr herzlich danke.

Mein Dank richtet sich auch an die Mitarbeiter und Mitarbeiterinnen des Kunstgeschichtlichen Seminars der Georg-August-Universität Göttingen und der Niedersächsischen Staats- und Universitätsbibliothek Göttingen, hier besonders Dr. Helmut Rohlfing, Barbara Mundt und Karsten Otte.

Ich danke herzlich PD Dr. Christof Boehringer, Archäologisches Institut Göttingen, Dr. Bernd Blisch, Stadthistoriker und Bürgermeister von Flörsheim am Main, und Bernhard Reichel, ehemals Archivar am Frankfurter Institut für Stadtgeschichte, zuletzt bis 2002 Leiter des Alten Archivs, für ihre bereitwillige Hilfe und Unterstützung.

Für die kritische Korrektur und die äußere Gestalt des Textes steht Annette Holzförster, der ich für ihre große Mühe meinen allerherzlichsten Dank ausspreche.

Ich widme diese Studie meinen Eltern Christiane $†$ und Günter, meiner Frau Daniela und meiner Tochter Dominique, ohne deren immerwährende Bereitschaft, mich und mein Vorhaben zu unterstützen, ich es sehr viel schwerer gehabt hätte. 


\section{Einleitung}

Die vorliegende Abhandlung setzt sich mit dem Frankfurter Patrizier Johann Friedrich von Uffenbach auseinander, der von 1686 bis 1769 gelebt hat. Dieser Mann und seine Sammlung mit diversen Schwerpunkten wie Graphik, Malerei, Skulptur, aber auch wissenschaftlichen Geräten der Optik, Astronomie, Arithmetik, Geometrie u. a. sollen hier eingehend beschrieben werden und in den Kontext Sammlung, Erwerb und Gebrauch im 18. Jahrhundert gestellt werden.

Über Uffenbach erschien bis zum heutigen Tage keine erschließende Auseinandersetzung. Bislang wurden nur kleine Ausschnitte seines Lebens und Schaffens dargestellt, so dass durch diesen selektiven Blick die umfassenden Intentionen des Sammlers nicht herausgearbeitet werden konnten. Im Gegenteil, bedingt durch diesen, kommt es in der Literatur teilweise $\mathrm{zu}$ unzutreffenden Schlussfolgerungen bzw. die Ergebnisse der Autoren sind verfälscht. Ausgehend von der Hinterlassenschaft Uffenbachs, die sich durch seine Stiftung im Jahre 1736 an die eben gegründete Königliche Universität in Göttingen zum größten Teil erhalten hat, kann ein geschlossenes Sammlerprofil entworfen werden.

Mit der Donation kamen viele Manuskripte dorthin, die Leben und Wirken des Sammlers, Architekten, Handwerkers und dilettierenden Künstlers erhellen. Um dieses Profil besser nachvollziehen zu können, ist es notwendig, zusätzlich die beiden gedruckten Auktionskataloge von 1771 und 1775 mit den beiden dazugehörigen, im Frankfurter Stadtarchiv erhaltenen Gegenschreiberbücher hinzuzuziehen. ${ }^{1}$

Vgl. Uffenbach 1771 und Uffenbach 1775.

Die beiden Gegenschreiberbücher galten seit dem Ende des zweiten Weltkriegs als verschollen, da sie 1944 verbrannt sein sollen, wie etwa annähernd die Hälfte des Bestandes des Frankfurter Stadtarchivs. Ich danke Bernhard Reichel, bis 2002 Archivar am Frankfurter Institut für Stadtgeschichte, herzlich für seine intensive Suche und das Auffinden der beiden Gegenschreiberbücher (ISG Frankfurt: Vergantungs-Register 1771/Uffenbach, und: Einundfünfzigerkolleg - Gegenschreiberbücher - 3079, [Verganthungs-Buch, angefangen den 1 ten $7 \mathrm{bre} 1774$ und gehet bis d. 30. May 1775, No. 5.]). Die Transkription der beiden Manuskripte wird im Anhang, S. 290-355 wiedergegeben (Nicht bei Ketelsen/Stockhausen 2002 aufgenommen).

Das 51-Kolleg, dem auf Lebenszeit gewählte Vertreter der gesamten Bürgerschaft angehörten, wurde 1732 durch kaiserliche Resolution in Frankfurt am Main eingerichtet. Damit erhielt die Bürgerschaft erstmals ein Organ zur umfassenden Kontrolle der Magistratshandlungen, vor allem derjenigen der finanziellen Aktionen. Dazu zählt auch die Einrichtung der bürgerlichen Gegenschreiberei, vgl. Koch 1983, S. 24-28; Kat. Frankfurt 1986, Bd. 1, S. 22-33, bes. S. 30, Bd. 2, Kat. Nr. III. 4-6. 
Durch die Vielzahl der Manuskripte, die im Folgenden vorgestellt werden, ist es möglich, dem Wirken und Wollen dieses Mannes $\mathrm{zu}$ folgen und somit, stellvertretend für andere, ein charakteristisches Bild eines patrizischen Sammlers der ersten Hälfte des 18. Jahrhunderts aufzuzeigen.

Die Darstellung des Lebenslaufes gliedert sich nach folgenden Schwerpunkten: Familie und Herkunft, Werdegang und größere Reisen, privates und öffentliches Leben in Frankfurt am Main und die Geschehnisse nach dem Tod von Johann Friedrich von Uffenbach. Hiernach folgt eine ausführliche Schilderung der Donation nach Göttingen.

Das nächste Kapitel setzt sich mit den verschiedenen Sammlungsgebieten Uffenbachs auseinander. Neben den Gemälden wird die etwa 9.400 Blatt Druckgraphik und 1.000 Blatt Handzeichnungen umfassende graphische Sammlung besprochen. An dieser Stelle wird der Umfang des Kabinetts, die Vorlieben, die Intentionen und der Umgang mit den Blättern durch den Sammler ausführlich dargestellt. Es folgt die Beschreibung der Sammlung an wissenschaftlichen Geräten und der schriftlichen Sammlungen. Anschließend wird beschrieben, wie intensiv Uffenbach seine eigene Sammlung an Druckgraphik genutzt hat.

Der hierauf folgende Exkurs setzt sich mit der Umsetzung seines Wissens auseinander. So gründete Uffenbach mit anderen Frankfurter Bürgern im Jahre 1725 eine wissenschaftliche Gesellschaft, die bis 1740 bestand. Anhand der erhaltenen, sehr ausführlichen Protokolle können sowohl eine der frühesten privaten, wissenschaftlich orientierten Gesellschaften vorgestellt werden, die Erfindungen auf ihre Umsetzbarkeit im Alltäglichen untersuchte, als auch sämtliche praktischen und theoretischen Kenntnisse aufgezeigt werden, die Uffenbach sich angeeignet hatte.

Darüber hinaus werden die anderen Tätigkeiten angesprochen, mit denen sich Uffenbach beschäftigt hat: Architekt und Feuerwerker, Kunstschriftsteller, Librettischreiber, Musiker, Dichter, Astronom und Erbauer von astronomischen und optischen Geräten und Dilettant im Zeichnen, Kupferstechen, Radieren, Schildkrötpressen, Drechseln, Metallbearbeiten und als Übersetzer. An dieser Stelle werden die verschiedenen Arten des Erwerbs sowohl der Gegenstände als auch der handwerklichen und künstlerischen Fertigkeiten anhand der verschiedenen Manuskripte aufgezeigt. Desweiteren wird geklärt, wie und woran Uffenbach sich orientierte, um seine diversen Sammlungsgebiete aufzubauen. 
In der Schlussbetrachtung wird ein kurzer Abriß der Sammlungsgeschichte von der Kunst- und Wunderkammer an bis zu dem Phänomen des Sammelns im 18. Jahrhundert vorangestellt, desweiteren wird die Sammlung Uffenbach in diesen Kontext gestellt. In diesem Resümee sollen die sammlerischen Intentionen von Johann Friedrich von Uffenbach dargestellt werden, wobei deutlich werden wird, dass die Sammlung weniger einem Connaisseur zum Vergnügen als einem Praktiker und Privatgelehrten zur Arbeit diente. 


\section{3 Überblick über die vorhandenen Quellen}

In einem ersten Teil werden die die Person Uffenbach betreffenden Manuskripte vorgestellt. Der zweite Abschnitt widmet sich den Publikationen, die sich mit Johann Friedrich von Uffenbach beschäftigen. Dabei soll nur ein kurzer Abriss der wichtigsten Literatur über Uffenbach zusammengestellt werden, da in den einzelnen Kapiteln auf die jeweilige Spezialliteratur eingegangen wird.

\subsection{Die Manuskripte}

Der größte Teil der erhaltenen Handschriften aus Uffenbachischem Besitz liegt heute in der Abteilung Spezialsammlungen und Bestandserhaltung der Niedersächsischen Staats- und Universitätsbibliothek Göttingen. ${ }^{2}$ Eine Auflistung befindet sich in Wilhelm Meyers drittem Band von „Die Handschriften der Universitätsbibliothek Göttingen.“3

Weitere Manuskripte Uffenbachs bewahren das Universitätsarchiv Göttingen, ${ }^{4}$ die Kunstsammlung der Universität Göttingen, sowie in Frankfurt am Main das Institut für Stadtgeschichte ${ }^{5}$ und die Universitätsbibliothek J.C. Senckenberg ${ }^{6}$ auf.

\subsection{Die Reiseberichte}

Die umfangreichste Gruppe der Handschriften bilden die ausführlichen Reiseberichte, die Uffenbach - zurückgekehrt nach Frankfurt am Main - anhand seiner Aufzeichnungen während der Fahrten angefertigt hat. Das umfangreichste Konvolut mit vier Bänden von insgesamt etwa 3100 Seiten stellt dabei seine Reise durch das Elsass, die Schweiz, Italien, Frankreich und die Niederlande in den Jahren von 1712 bis 1716 dar. ${ }^{7}$ Alste Horn-Oncken hat Anfang der siebziger Jahre des 20. Jahrhunderts eine maschinenschriftliche Transkription der Reise vom

2 Im Folgenden als SUB Göttingen gekennzeichnet.

Alle Signaturen, die mit „Cod. Ms. Uffenbach“ beginnen, sind dort aufbewahrt.

Meyer 1894.

Im Weiteren als Universitätsarchiv Göttingen bezeichnet.

Im Weiteren als ISG Frankfurt am Main bezeichnet.

Im Weiteren als UB Frankfurt am Main bezeichnet.

Cod. Ms. Uffenbach 29 I-IV (703 S., 774 S. 713 S., 881 S.). S. Kapitel „Lebenslauf.“ 
Elsass bis einschließlich Frankreich vorgenommen. ${ }^{8}$ Eine Übertragung der Abschnitte des Manuskripts, die die Anreise von Frankfurt nach Straßburg und den Aufenthalt im Elsass, den Aufenthalt in den Niederlanden und die Rückkehr nach Frankfurt am Main beschreiben, unterblieb bisher; ebenso fehlen die ausführlichen Register. Diese Teile sind von mir übertragen worden. Ebenso erfolgte eine überprüfende Durchsicht des maschinenschriftlichen Textes von Horn-Oncken anhand des Originals.

Eine vollständige Veröffentlichung dieser Reisetagebücher wurde bisher nicht unternommen, es sind bislang nur Ausschnitte im Druck erschienen. ${ }^{9}$ Eine weitere, von mehreren Schreibern angefertigte Kopie stammt aus der Bibliothek des älteren Bruders, Zacharias Conrad von Uffenbach, da jeder der vier Bände mit dessen Exlibris versehen wurde. Diese aus 2984 Seiten bestehende Kopie ging nach dem Tod des Bruders 1734 in den Besitz von Johann Friedrich über. ${ }^{10}$

Ein vier Bände umfassendes Manuskript mit 4110 Seiten beschreibt die Reise durch Niederdeutschland, die Niederlande und England, die Uffenbach als Begleiter seines Bruders Zacharias Conrad von 1709 bis 1711 unternommen hatte. ${ }^{11}$ Er übernahm dabei die Rolle des Schreibers und vor allem des Zeichners. Johann Georg Schelhorn gab mit Hilfe von Johann Friedrich dieses Reisetagebuch in den Jahren 1753 und 1754 in drei Bänden heraus, wobei einige Partien persönlichen Inhalts fehlen. ${ }^{12}$ Im Druck wurden beispielsweise die umfangreich von Zacharias Conrad abgeschriebenen Verzeichnisse der Handschriften ausgelassen, die sich in den besuchten Bibliotheken befanden; außerdem fehlt der verlängerte Aufenthalt Johann Friedrichs in den Niederlanden. Allerdings erfolgte die Edition nicht anhand des Göttinger Manuskripts, das Johann Friedrich sich für seine Bibliothek als Handexemplar von mehreren Schreibern hatte anfertigen lassen.

Es handelt sich dabei um die Übertragung des Textes ab S. 439 des ersten Bandes bis S. 692 des vierten Bandes;

Ein Exemplar der Abschrift befindet sich in der Abteilung Spezialsammlungen und Bestandserhaltung der Göttinger SUB: $8^{\circ}$ Uffenbach 29A.

Ich danke Christoph Boehringer, Archäologisches Institut Göttingen, ganz herzlich dafür, dass er mir ein weiteres zur Benutzung überlassen hat.

$9 \quad$ Allgemein: Preußner 1949; Baden: Rott 1917,2; Elsass: Polaczek 1922; Schweiz: HornOncken 1969, 1971 + 1973, Preisendanz 1918,2; Italien: Horn-Oncken 1978, Preisendanz 1918,1, Preisendanz 1920; Frankreich: Bode 1961; Niederlande: Schmidt 1969.

10 Cod. Ms. Uffenbach 4 I-IV.

11 Cod. Ms. Uffenbach 25 I-IV.

12 Schelhorn 1753. 
Das 297 Seiten umfassende, von anderer Hand geschriebene „Tagebuch einer Vergnügungsreise durch die Niederlande“,13 die die drei Brüder Uffenbach, Zacharias Conrad, Johann Friedrich und Wilhelm in Gesellschaft von Verwandten und Bekannten im Juli und August 1718 unternahmen, liegt seit 2017 vollständig veröffentlicht vor. ${ }^{14}$ Diese Fahrt diente, wie der Titel schon zeigt, lediglich dem Vergnügen. Für die Brüder Uffenbach war es hauptsächlich ein erneuter Besuch schon bekannter Orte.

In einem Band zusammengebunden finden sich zum einen die „Kurtze ReiseBeschreibung oder Tagebuch einer Spazierfahrt durch die Hessische in die Braunschweig Lüneburgische Lande, welche a. 1728 im August obhabender Geschäfften wegen gethan“,15 zum anderen die „Kleine Reise Beschreibung einer Spazierfarth durch die Pfalz a. 1731 im Sept. vom 4 - 11 abgeleget."16 Die Reise von 1728 unternahm Uffenbach wegen des von ihm verfassten Libretto „Pharasmanes“, das der Braunschweiger Kapellmeister Georg Caspar Schürmann vertonen und aufführen lassen wollte. ${ }^{17}$ Der Aufenthalt in der Pfalz 1731 diente Johann Friedrich von Uffenbach dazu, von dem Mannheimer Hofschreiner Franz Zeller die Verarbeitung des Schildpatts zu lernen.

Ein weiterer Band, der den Reisemanuskripten zuzurechnen ist, trägt den Titel „Kupfer Volumen zu allen Theilen der Reisz Diariorum“.18 Die 98 Blätter unterschiedlichen Formates zeigen Pläne und Ansichten von Städten und deren Denkmale der beiden längeren Reisen Uffenbachs. Die ersten 15 Blätter stammen von der Fahrt mit seinem älteren Bruder Zacharias Conrad von 1709 bis 1711,19 die übrigen von seiner eigenen Grand Tour von 1712 bis 1716.20

In allen Reisetagebüchern zeigt sich das Interesse Uffenbachs an der neuesten Architektur, der Musik - hier besonders der Oper -, den diversen Sammlungen

Cod. Ms. Uffenbach 46.

Vgl. Molen 2017 und Ausschnitte in: Schmidt 1969 und Molen 1994.

15 Cod. Ms. Uffenbach 33, S. 1-187, Das Manuskript wurde von Max Arnim übertragen und 1928 herausgegeben (= Arnim 1928,1).

Cod. Ms. Uffenbach 33, S. 188-244. Dieser Teil wurde ebenfalls von Max Arnim 1928 veröffentlicht (= Arnim 1928,2), s.u.

Cod. Ms. Uffenbach 18. Das Libretto wurde von Max Arnim 1930 veröffentlicht (= Arnim 1930,1); siehe auch weiter unten. Zu Schürmann und Uffenbach siehe Schmidt 1933.

18 Cod. Ms. Uffenbach 8.

19 Cod. Ms. Uffenbach 8, B1. 1-15.

20 Cod. Ms. Uffenbach 8, B1. 16-98.

Der Begriff „Grand Tour“ wurde erstmals 1760 in der französischen Übersetzung von Richard Lassels „The Voyage of Italy, or a Compleat Journey through Italy. In Two Parts“, Paris 1760 verwendet. 
und Bibliotheken. Er übernahm bei seinen Bibliotheksbesuchen von seinem älteren Bruder die Gewohnheit, so weit wie möglich den Bestand an seltenen Manuskripten und Drucken zu verzeichnen, obwohl er selbst kein ausgesprochen Bibliophiler war. Seine eigene Bibliothek unterschied sich von der stark historisch ausgerichteten seines Bruders Zacharias Conrad darin, dass er fachspezifische Bücher zur Mathematik, Technik, Architektur, Ikonographie, Topographie und zum Militärwesen besaß.21

\subsection{Das „Commercium Epistolicum“}

Ebenfalls erhalten hat sich sein insgesamt 1241 Blätter umfassendes „Commercium Epistolicum.“22 In den beiden Bänden mit seiner gesammelten Korrespondenz befinden sich zum einen einige Texte, die ihn zum Autor haben, wie beispielsweise seine „Uhrsprüngliche Historie der gesamten Bildkunst auf Papier“,23 zum anderen Briefe, die Uffenbach empfangen hat; ${ }^{24}$ es sind kaum Briefentwürfe Uffenbachs eingebunden. Die Schreiben hat er in folgende, sachliche Abteilungen geordnet:

Im ersten Band befinden sich die vier Rubriken

- „De re literaria“,

- „De re astronomica“,

- „De re architectonica“

- „De re optica“.

Der zweite Band gliedert sich in die sieben Sektionen

- „De re mechanica et instrumentis mathematicis“,

- „De re optificaria et artificaria“,

- „De re iconologica“,

- „De re pictoria et sculptoria“,

21 Vgl. Kind-Doerne 1986, S. 125; zu der Bibliothek von Zacharias Conrad s. Becker 1937, Bogeng 1922 und Franke 1965,1.

22 Cod. Ms. Uffenbach 20 I + II.

Da innerhalb der einzelnen Kapitel immer wieder auf Veröffentlichungen einzelner Briefe eingegangen wird, soll an dieser Stelle eine Aufzählung der zahlreichen Publikationen unterbleiben.

23 Cod. Ms. Uffenbach 20/II, B1. 255-285.

24 Es finden sich auch einige wenige Briefe darin, die nicht an Johann Friedrich adressiert sind, sondern an seine beiden Brüder, wie z.B. der Brief an Wilhelm von Uffenbach von dem französischen Flötenspieler Jacques Hotteterre (Cod. Ms. Uffenbach 20/I, B1. $258+$ 258a). Diese wenigen Briefe sind aber vom Inhalt her gesehen, Schreiben, die mit den Interessensgebieten Johann Friedrichs direkt zu tun haben. 
- „De re historia naturalis“,

- „De re poetica“

- „De re musica“.

Diese Unterteilungen spiegeln annähernd die Interessen Uffenbachs wider und zeigen in etwa die Ordnung seiner Bibliothek.

Das „Commercium Epistolicum“ ist das bisher von der Forschung am meisten benutzte Uffenbachische Manuskript. ${ }^{25}$ Allerdings interessierte dabei weniger der Empfänger als die Briefschreiber, bei denen es sich um Personen handelt, die Uffenbach entweder durch seinen Bruder Zacharias Conrad oder selbst in Frankfurt am Main und auf seinen Reisen kennengelernt hatte.

\subsection{Quellen zur Bibliothek und zum graphischen Kabinett}

Die StUB Frankfurt am Main bewahrt das Handexemplar des Verzeichnisses der Uffenbachischen Bibliothek und Sammlung auf, von dem der Katalog vom April 1736 und die drei Supplemente vom Oktober 1736, Oktober 1763 und November 1766 für die Göttinger Universitätsverwaltung abgeschrieben wurden. ${ }^{26}$ Uffenbach hat das Frankfurter Manuskript bis zu seinem Tode 1769 verwendet, da auch die zuletzt erworbenen Bücher verzeichnet sind. Er selbst vermerkte auf der Vorseite zu Blatt 1r: „NB wenn zu Ende jedes Abschnittes eine Linie zwischen noch folgenden Büchern vorkommt, so bedeutet es Sachen die nach der Verfertigung der ersten gottingischen Abschrift dazu gekommen“ und: „NB folgen derer Linien mehr, so ist es ein Zeichen daß die erstere bereits in einem Supplement nach Gottingen berichtet worden." 27 Innerhalb dieses Verzeichnisses sind nicht nur die Bücher aufgeführt sondern auch die Graphikmappen mit der Nennung der Anzahl der Künstler und die Aufzählung der wissenschaftlichen Instrumente.

Zur Bibliothek gehörten ebenfalls zwei Findbücher mit dem Titel: „Repertorium physico mathematico technicum oder alphabetische Anzeige aller Schrifft Stellen, welche dergleichen Materien theils umbständlich theils zufällig abhandeln, so zu eigenem Gebrauch aus seinem hierin enthaltenen Bücher Vorrath, den der vorgehende Catalogus enthält, mit eilender Feder entworffen. J.

\footnotetext{
25 S. weiter unten in den einzelnen Kapiteln.

26 StUB Frankfurt am Main Sign: Ms. Ff. J.F.v.UFFENBACH 1, SUB Göttingen Sign: Cod. Ms. Uffenbach 47, Cod. Ms. Bibl. Arch. A. 34c/2 und Cod. Ms. Bibl. Archiv A 34c.

27 StUB Frankfurt am Main Sign: Ms. Ff. J.F.v.UFFENBACH 1.
} 
F. ab U.“28 Uffenbach hat diesen Realkatalog im Sommer 1727 weitgehend abgeschlossen, ${ }^{29}$ benutzte ihn aber bis kurz vor seinem Tod, da sich Schriftstellen aus Büchern finden lassen, die erst 1768 erschienen sind. Auch verzeichnete er hier nicht nur Bücher seiner eigenen Bibliothek, sondern er fügte auch solche seines älteren Bruders Zacharias Conrad hinzu und kennzeichnete sie mit einer Unterstreichung des Buchtitels.

$\mathrm{Zu}$ den beiden Findbüchern muß noch das Manuskript „Ausgezogene Schriftstellen aus Büchern So zur Erläuterung der Naturlehre, Mathematic und künstlichen Handarbeit etwas beytragen angefangen 1733“30 hinzugerechnet werden. Der von unterschiedlichen Händen geschriebene Band umfaßt von den 370 Seiten insgesamt 352 beschriebene, meist Auszüge aus Zeitungen und Zeitschriften, weniger aus Büchern. Am Schluss befindet sich ein zwölfseitiges Register, desweiteren als Anhang: „Allerhandt Kunststïcke auß unterschiedlichen Künstlern undt Authoribus zusammengetragen." Uffenbach verwendete dieses bis ins hohe Alter; der letzte Eintrag stammt aus einer nicht genannten Zeitung vom 13. November 1767.

Mit der Übergabe der einzeln aufgelegten Graphik durch die Göttinger Bibliotheksverwaltung an die Kunstsammlung im Jahre $1845^{31}$ übernahm diese auch das Uffenbachische Verzeichnis der einzelnen und gebundenen Druckgraphik; es trägt den Titel: „Index Titulorum sive Artificum Pictorum vel Caelatorum Iconothecae insertorum." ${ }^{2}$ Dieser Index verzeichnet alle Künstlernamen, teilweise mit den Ligaturen, und die Anzahl der Blätter in den insgesamt 37 Mappen, in die die graphische Sammlung Uffenbachs ehemals eingelegt war. ${ }^{33}$

Cod. Ms. Uffenbach 10 I + II, Titel aus: Cod. Ms. Uffenbach 47, p. 123v + 124r.

Mit „der vorgehende Catalogus“ ist der in der StUB Frankfurt am Main liegende Katalog der Bücher gemeint.

Vgl. die Zusammenkunft am 31. Oktober 1727 in: Cod. Ms. Uffenbach 13/II, p. 54: „vorigen Sommers zu Ende gebrachtes Werck, so aus zwei Folianten bestehet, und den Tittul eines mechanischen und mathematischen Wegweisers führt.“

Cod. Ms. Uffenbach 9.

Der eindeutige Hinweis auf die Abtrennung des Kupferstichkabinetts von der Universitätsbibliothek im Jahre 1845 befindet sich in einem Brief von dem Maler und Professor für Kunstgeschichte Carl Oesterley (1805-1895) an das Universitätskuratorium vom 15. Mai 1845: , ,...] In Ansehung der Aufsicht über die Gemälde- und KupferstichSammlung dürfte eine Anordnung um so nötiger sein, als die letztere Sammlung von der Bibliothek getrennt wird. [...]“" (S. Universitätsarchiv Göttingen Kur. 5827, B1. 80-82).

2 „Index der Titel sowohl der Künstler, der Maler wie auch der Kupferstecher, die zu der Bildersammlung gehören.“

S. die Transkription im Anhang, S. 413-458. 


\subsection{Manuskripte zur Kunst}

Zwei Manuskripte Uffenbachs sind für sein Verständnis von Kunst und Künstlern besonders wichtig. Zum einen handelt es sich um ein „Alphabetisches Verzeichnüs Aller Mahler Bildhauer und Kupferstecher worinnen ihre Nahmen, Geburt Vaterland, Handzeichen, und übrige Lebensumstände, wie auch angezogene Schriftstellen anderer Bücher so über ihre Wercke urtheilen, zu finden sind. zusammengetragen von J. F. von U.“,34 zum anderen um die „Monogrammata oder Zeichen derer Mahler und Kupferstecher so noch ungedeutet oder unbekant sind." 35 Beide Manuskripte sind bisher noch nicht veröffentlicht und von der Forschung noch nicht beachtet worden.

Großes Verständnis und Einfühlungsvermögen gegenüber den Belangen der Künstler zeigte Uffenbach in seinem Gutachten von 1767 zur Gründung einer Malerakademie auf Frankfurts Boden. ${ }^{36}$ Er befürwortet hier das Zustandekommen einer freien Akademie und den Wegfall des Zunftzwanges der Künstler.

Auch das Manuskript „Encaustische Malerey oder Untericht zum Malen nach Art derer alten Zeiten, wobey angefüget ist ein sicherer und leichter Weg die Crayon Malereien und Handrisse von Rodstein und andern leichte, zu beschädigen seyenden Dingen verfertiget, feste und dauerhaft zu machen. herausgegeben von J. H. Müntz 1760 London aus dem Engeländischen übersetzet“ 37 zeigt sein Interesse an den Zeitströmungen der Malerei. Er beschreibt in einem vierseitigen Vorwort seine Beweggründe zu dieser freien, leicht interpretierenden Übersetzung, die er nach 1764 angefertigt haben muß. ${ }^{38}$ So hebt er hervor, dass die Wiederentdeckung der enkaustischen Malerei durch

Cod. Ms. Uffenbach 36. Zum alphabetischen Verzeichnis hinzuzurechnen sind die Beilagen, die extra gebunden unter der Signatur Cod. Ms. Uffenbach 36a zu finden sind.

Cod. Ms. Uffenbach 50. Auf diese Niederschriften wird im Kapitel 6.2 „Das graphische Kabinett" eingegangen werden.

36 Institut für Stadtgeschichte Frankfurt am Main: Handwerker Akten Nr. 618 (ehemals Ugb C 31 Z Nr.2): zur Maler Akademie, Bl. 27-28 r + v; s. im Kapitel „Uffenbach und die Kunst, die Transkription im Anhang, S. 286-289 und Valentin 1889, wo aber nur eine Teiltranskription des Gutachtens zu finden ist. Cod. Ms. Uffenbach 39.

Johann Heinrich Müntz (1727-1798).

Der Titel des Originals lautet: Johann H. Müntz, Encaustic or Count Caylus method of painting in the manner of ancients, London 1760 ( $8^{\circ}$ Bibl. Uff. 863). Im seinem Vorwort erwähnt er ein Buch, das erst 1764 erschienen war. 
den Grafen Anne-Claude-Philippe de Thubières, Comte de Caylus (1692-1765), ${ }^{39}$ die dieser an der französischen Akademie der Wissenschaften schon 1752 vorgetragen hatte, viele Künstler animierte, eigene Versuche mit der durch Plinius überlieferten Methode der Wachsmalerei anzustellen. Da nach Uffenbachs Meinung diese Versuche mit der Wachsmalerei größtenteils scheiterten und auch die Bestrebungen der Kunstschriftsteller, das Verfahren zu erklären, „mehrentheils schwürige, unangenehme und lästige Sudeleyen“ seien, war er von dem Buch von Johann Heinrich Müntz mit seinen ausführlichen Technikbeschreibungen angenehm angetan. ${ }^{40}$ Weiter führt er aus, dass viele seiner Landsleute der englischen Sprache nicht mächtig wären, weshalb er den Versuch unternommen hätte, das Werk zu übersetzen. Wenn man den Inhalt der „Vorrede“ interpretiert, muß man zu dem Schluss kommen, dass Uffenbach offensichtlich eine Veröffentlichung seiner Übertragung vorgehabt haben muß.

\subsection{Die Protokolle der wissenschaftlichen Gesellschaft}

Einen großen Handschriftenkomplex stellen die Protokolle der Wissenschaftlichen Gesellschaft dar. ${ }^{41}$ Diese Gesellschaft war auf Uffenbachs Initiative von insgesamt sechs Frankfurter Bürgern im November 1725 in Frankfurt am Main gegründet worden. ${ }^{42}$ Bei der bis nach 1739 existierenden Gesellschaft handelt es sich um die erste auf Frankfurts Boden und um eine der frühesten, rein bürgerlichen wissenschaftlichen Gesellschaften im deutschsprachigen Raum, die weder an einen Hof noch an eine Akademie gebunden war. Die fünf Protokollbände mit zusammen etwa 2600 Seiten tragen den programmatischen Titel „Wochentliche Sammlung der in Nützlichen Neben Stunden angestelten Untersuchungen der Natur und Kunst, welche zu einer Gemüths-Ergötzung dieienige Gesellschaft veranlasset, deren Denckspruch ist: Quo simplicius eo perfectius".43

Das Buch von Caylus: Mémoire sur la peinture a l'encaustique et sur la peinture a la cire, Genf, Paris 1755, befindet sich nicht in der Bibliothek Uffenbach.

40 Cod. Ms. Uffenbach 39, p. IV.

41 Cod. Ms. Uffenbach $13 \mathrm{I}-\mathrm{V}$. Von den Protokollen liegen keine längeren Veröffentlichungen vor. Es wurden immer nur einzelne Punkte herausgezogen.

42 Lange-Kothe 1960 unternahm eine erste, wenig geglückte Vorstellung dieser Gesellschaft; s.a. Meyerhöfer 1995.

43 Siehe Kapitel 8 „Die wissenschaftliche Gesellschaft des Johann Friedrich von Uffenbach.“ 


\subsection{Handschriften zur Musik}

Uffenbachs Kenntnisse und Vorlieben in der Musik galten hauptsächlich der Oper. Dies zeigt exemplarisch das Libretto „Der von Londinen zugleich geliebte und ungeliebte Pharasmanes König von Iberien in einem Sing-Spiel“, das er 1720 fertiggestellt hat. ${ }^{44}$ Bei dem Text handelt es sich um die Bearbeitung einer Episode aus einem Roman des Braunschweiger Herzogs Anton Ulrich (16331714) „Die Römische Octavia“, 45 weshalb Uffenbach sein Werk auch „deßen Durchlauchtem nunmehro Höchstruhmwürtig Regierendem Nachkommen in aller Unterthänigkeit überreichet."46 Spätestens seit 1725 kümmerte Uffenbach sich intensiv um eine Vertonung und Aufführung des Werkes am Braunschweiger Hof. Die Vertonung des Textes sollte der Braunschweiger Hofkapellmeister Johann Caspar Schürmann (ca. 1672-1751) vornehmen, mit dem Uffenbach diesbezüglich einen regen Schriftverkehr pflegte. ${ }^{47}$ Uffenbachs oben schon erwähnte Reise nach Braunschweig im Jahre 1728 sollte das Projekt unterstützen und vorantreiben. ${ }^{48} \mathrm{Ob}$ Schürmann die Vertonung fertiggestellt hat und die Oper tatsächlich aufgeführt wurde, kann nicht festgestellt werden. Auch der Musikwissenschaftler Gustav Friedrich Schmidt ${ }^{49}$ konnte eine Aufführung nicht nachweisen.

Für das auf kurmainzischem Gebiet liegendes Flörsheimer Landgut legte Uffenbach sich seinen eigenen zweibändigen Kirchenjahrgang „Der genesenen Vernunft zufällige Gedancken über alle sonn- und festägliche Evangelia in einem harmonischen Jahrgange verfaßet und vor 1 oder 2 Soprani theils mit einem begleitendem Instrumente theils mit blosem Basse in müßigen Stunden zu einer Haus Andacht in Music gebracht Johann Friedrich von Uffenbach“ an. ${ }^{50} \mathrm{Er}$ schreibt in dem Vorbericht zu dem Kirchenjahrgang: „Der offtere Aufenthalt auf meinem unter andern Glaubensgenossen gelegenen Landgute hat mich wie billig erinnert die eingefallene Sonn und Festage mit Ehrerbiethung zu begehen, und

Cod. Ms. Uffenbach 18; die Handschrift wurde von Max Arnim 1930 ediert (= Arnim 1930,1) und im gleichen Jahr von ihm einem größeren Publikum vorgestellt (Arnim 1930.2).

6 Bde., zuerst Nürnberg 1677. - Die Episode um Pharasmanes befindet sich im fünften Buch, S. 930-933. Welche Ausgabe Uffenbach verwendete, kann nicht festgestellt werden, da sich keine Ausgabe des Werks in seiner Bibliothek findet.

46 In Cod. Ms. Uffenbach 18, Vorwort.

47 Vgl. Cod. Ms. Uffenbach 20 II, Bl. 476-479, 603-614; die Transkription der Briefe s. Schmidt 1933, S. 91-99.

48 S.o.; Cod. Ms. Uffenbach 33, p. 1-185; Arnim 1930,1.

49 Schmidt 1933, Bd. I, S. 158-159, 263-264.

$50 \quad 2^{\circ}$ Bibl Uff. $562+563$. 
denenjenigen, so auch alda um mich sind $\mathrm{zu}$ anstößigen Gedancken keine Gelegenheit zu geben."51 Allerdings stammen weder Text noch Musik von ihm selbst, sondern er parodierte - also bearbeitete - Texte anderer Autoren und unterlegte sie mit Musikstücken vor allen von Georg Philipp Telemann (16811767), Christoph Graupner (1683-1760) und Gottfried Grünewald (1675-1739). ${ }^{52}$

\subsection{Varia}

$\mathrm{Zu}$ reinen Übungszwecken übersetzte Uffenbach aus dem Werk von dem Schriftsteller Tommaso Stigliani (1573-1651): „Arte del verso italiano, con le tavole delle rime di tutte le sorti copiosissime, Del Cav. Fr. Tommaso Stigliani, con varie giunte, e notazioni di Pompeo Colonna, Bologna o.J."53 das Reimregister, das sich dort auf den Seiten 246 bis 768 befindet. Diese Übersetzung mit dem Titel: „Fr. Tomaso Stigliani Rimario oder italienisches Reimregister vermehrt von Pompeo Colonna Principe di gallicano und mit einigen Zusätzen in das deutsche gebracht von Joh. Friedrich von Uffenbach.“"54 muß er nach 1730 angefertigt haben, da er in dem neunseitigen Vorbericht ein anderes Reimregister aus diesem Jahr erwähnt, welches er dem von Stigliani vorgezogen hätte, aber nicht zur Hand hatte. Schon 1727 hatte er versucht, sich über den Augsburger Wolfgang Jacob Sulzer d.J. (1685-1751) ein italienisches Reimlexikon zu besorgen, wobei dieser in seinem Brief vom 17. März 1727 an Uffenbach schrieb, dass er bis zu diesem Zeitpunkt keines erwerben konnte. ${ }^{55}$ Die Übersetzung muss mit Uffenbachs Interesse an der Oper, besonders der italienischen, in Beziehung gesetzt werden. Betrachtet man die Eintragungen in seinem italienischen Reisediarium, fällt auf, dass er sehr oft die Oper besuchte, vor allem 1715 in Venedig und Rom. ${ }^{56}$

Uffenbach erstellte nach 1729 ein „Alphabetisches Verzeichnüs derer ausländischen Bäume und Hölzer von allerley Arten so viel derer aus denen Schriften gelehrter Kräuter Verständigen wie auch Reisebeschreiber zu unserer Bekantschaft gekommen und in entfernten Welttheilen als ASIA AFRICA und 
AMERICA anzutreffen seyn mögen. $\mathrm{Zu}$ gemein nützigen, vornehmlich aber technischen Gebrauch gesamlet und entworfen“.57 Es gab zwei Gründe für ihn, sich eine detaillierte Beschreibung ausländischer Holzarten zusammenzustellen. Zum einen war er als Architekt darauf angewiesen, genaue Kenntnis der Baumaterialien zu besitzen. Zu diesem Zweck wollte er sich anfangs ein eigenes Kabinett mit Beispielen in- und besonders ausländischer Hölzer anlegen.

Da er aber von den Frankfurter Händlern betrogen worden wäre, wie er in einer Sitzung der wissenschaftlichen Gesellschaft bemerkte ${ }^{58}$, verlegte er sich auf das bescheidenere Mittel, eine Beschreibung der unterschiedlichsten Hölzer $\mathrm{zu}$ verfassen. Zum anderen hatte er auf seinen Reisen immer nur Sammlungen von Hölzern des jeweiligen Landes sehen können. Nach 1729 hatte er den Katalog „Zuverläßige Nachricht von demjenigen Holtz-Cabinet, Welches am 3. Jenner dieses 1729. Jahres In Ihro Königl. Majestät in Pohlen und Churfl. Durchl. zu Sachsen Vortreffliche Naturalien-Cammer. Nebst einem Verzeichniß aller und ieder darinnen befindlichen Holtz-Arten, in Latein. und Teutscher Sprache“59 von einem Buchhändler zugesandt bekommen, in welchem ausführlich auch ausländische Holzarten vertreten waren. Dieses dort beinhaltete Verzeichnis war weiterer Anlass zur Erstellung des Manuskripts durch Uffenbach, damit die „Verarbeiter“ von Holz über die Beschaffenheit dieses Stoffes nur nachschlagen müssen. ${ }^{60}$

\footnotetext{
Cod. Ms. Uffenbach 40.

Cod. Ms. Uffenbach 13/V, S. 72-73.

Dresden und Leipzig 1729 (ehemals $8^{\circ}$ Bibl. Uff. 403, wurde aber auf Veranlassung Uffenbachs an Cod. Ms. Uffenbach 40 angebunden).

60 Vgl. das Vorwort in Cod. Ms. Uffenbach 40 und auch Cod. Ms. Uffenbach 13/V, S. 72-73.
} 


\section{Forschungsstand}

In diesem Abschnitt werden nur die größeren Veröffentlichungen über Uffenbach, seine Sammlungen und Aktivitäten genannt. Publikationen, die sich direkt auf die verschiedenen Manuskripte beziehen, wurden im vorangegangenen Kapitel schon genannt. Kleinere Aufsätze und Schriften, in denen Uffenbach in einem weiter gefaßten Rahmen behandelt wurde, werden in den einzelnen Kapiteln dargestellt.

Eine erschöpfende Auseinandersetzung mit Johann Friedrich von Uffenbach sowohl mit seiner Person, wie seiner Tätigkeiten, Interessens- und Sammlungsgebiete - fand bis zum heutigen Tage nicht statt. Seine Person wurde hauptsächlich in Lexika behandelt, obwohl schon zu Lebzeiten eine Biographie über ihn erschien. ${ }^{61}$ Von den neueren Lexikonartikeln ist derjenige von Rudolph Jung in der „Allgemeinen Deutschen Biographie“ am detailliertesten. ${ }^{62}$

Auch wurde Uffenbach in Publikationen zur Geschichte der heutigen SUB Göttingen oder der Genese des Faches Kunstgeschichte ebendort gewürdigt. ${ }^{63}$ Hier ist der Aufsatz von Max Arnim über die Uffenbachische Schenkung in dem Sammelband „Beiträge zur Göttinger Bibliotheks- und Gelehrtengeschichte“64 aus dem Jahr 1928 herauszuheben. Ein weiterer, vertiefender Beitrag zur Donationsgeschichte wurde durch den Autor im Jahr 2000 veröffentlicht. ${ }^{65}$

Desgleichen erscheint Uffenbachs Name in der Literatur über seine Heimatstadt Frankfurt am Main im 18. Jahrhundert häufig. In dem von Heinrich Voelcker 1932 herausgegebenen Standardwerk „Die Stadt Goethes, Frankfurt am Main im XVIII. Jahrhundert“ ist von Uffenbach als herausragender Persönlichkeit der Stadt des Öfteren die Rede. 66

Aufgrund der Äußerungen Johann Wolfgang von Goethes in „Dichtung und Wahrheit" ${ }^{\text {67 }}$ wurde dem Musiker und Musikliebhaber Uffenbach vermehrt

\footnotetext{
$61 \quad$ Strodtmann 1757.

62 Vgl. u.a.: Jung 1895,1 (ADB), Hirsching 1812, Jung 1900, Frankfurter Biographie Bd. 2/1996, Stichwort „Johann Friedrich von Uffenbach.“.

63 Vgl. Pütter 1765, Meiners 1804, Hartmann/Füchsel 1937, Kempen 1951, Arndt 1986, Rohlfing 1998.

64 Arnim 1928,3.

65 Meyerhöfer 2000,1.

66 Voelcker 1932, s.a. Duchardt 1991, Hansert 1992, S. 38, 43-47.

67 Vgl. Goethe-Werke, I. Abt., Bd. 14, S. 83-84.
} 
Aufmerksamkeit gewidmet. Schon 1792 waren erste Würdigungen in Ernst Ludwig Gerbers „Lexicon der Tonkünstler“68 und in Johann Nicolaus Forkels „Allgemeine Litteratur der Musik“ 69 erschienen. Gerber hatte es sich als erster zur Aufgabe gemacht, die Veröffentlichungen Uffenbachs zusammenzutragen. Einen Gesamtüberblick über dessen Bedeutung für die Musikgeschichte gab Wolfgang Boetticher 1966 in seinem Artikel im Lexikon „Die Musik in Geschichte und Gegenwart."70 Sowohl Uffenbachs Grand Tour von 1712 bis 1716 als auch seine intensiven, hauptsächlich brieflichen Kontakte zu deutschen Komponisten des 18. Jahrhunderts, ${ }^{71}$ wie Georg Philipp Telemann, ${ }^{72}$ Georg Caspar Schürmann, ${ }^{73}$ Gottfried Grünewald, ${ }^{74}$ Christoph Graupner, ${ }^{75}$ Johann Friedrich Fasch $^{76}$ u. a., fanden hier Aufmerksamkeit. Die Autoren interessierte allerdings weniger die Person Uffenbach als die Musiker und die musikalischen Verhältnisse in den einzelnen Ländern und Städten. ${ }^{77}$ Hier ist als Autor besonders Willibald Nagel hervorzuheben, der Anfang des 20. Jahrhunderts Artikel über verschiedene Komponisten veröffentlichte, die mit Uffenbach in Kontakt standen. ${ }^{78}$

Auch Uffenbachs Erwiderungen zu Johann Christoph Gottscheds (1700-1766) Ablehnung über die Verwendung der deutschen Sprache in der Oper, die er in Lorenz Christoph Mizlers (1711-1778) „Neu eröffneten musikalischen Bibliothek“ 1752 veröffentlicht hat, stießen auf Interesse, da Uffenbach sich hier eindeutig gegen die Meinung Gottscheds stellt. ${ }^{79}$ Uffenbach hat diesen Artikel mit dem Titel „Von der Würde der Singgedichte oder Vertheidigung der Opern.“ schon vor 1733 fertiggestellt, da er sich in seinem Werk „Gesammelte NebenArbeit ..." als 46-seitige Vorrede findet. ${ }^{80}$ Johann Nicolaus Forkel war der erste,

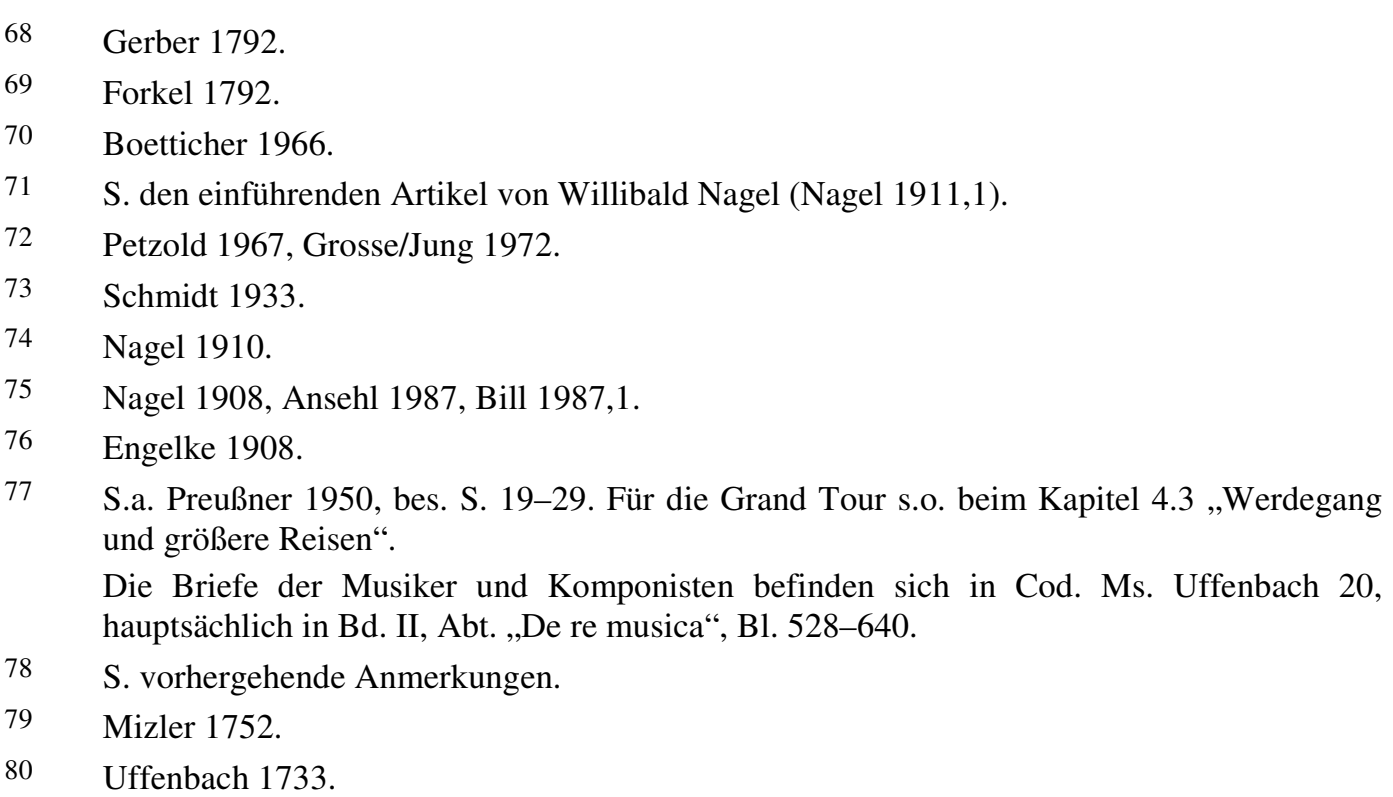


der diese Leistung 1792 herausstellte, die Hugo Goldschmidt 1915 wieder aufgriff. 81

Ein weiteres, wenn auch nicht sehr beachtetes Gebiet, mit dem sich die Forschung beschäftigte, waren die Interessen Uffenbachs in Bezug auf Kunst und Künstler. Es spielen zum einen die Umstände seines Portraitauftrages an Johann Georg Dathan (1701-1749) eine Rolle, ${ }^{82}$ zum anderen kommen Uffenbachs kunstpolitische Aktivitäten in Frankfurt am Main zum Tragen, wie z. B. das Gutachten zur Gründung einer Malerakademie ${ }^{83}$ oder seine Bauleitung beim Umbau der Alten Mainbrücke. ${ }^{84}$ Auch seine graphischen Versuche wurden am Rande immer wieder erwähnt. ${ }^{55}$ Innerhalb dieser Publikationen waren es besonders Uffenbachs Gemälde- und Graphiksammlungen, die auf Aufmerksamkeit stießen. ${ }^{86}$ In der Beziehung ist seine für die Frankfurter Lokalhistoriker unverständliche Stiftung nach Göttingen von Beginn an bis heute ein kritischer Punkt. Dabei kommt es immer wieder zu Übertreibungen und Verfälschungen, sowohl was die Person Johann Friedrich von Uffenbach als auch Quantität und Qualität seiner Sammlungen betrifft. ${ }^{87}$ Eine ausführlichere Zusammenstellung der Forschungsergebnisse zum Sammler Uffenbach gab Ulrich Schmidt 1960 in seiner Dissertation. ${ }^{88}$

Wie der Abriss der Veröffentlichungen bezüglich Johann Friedrich von Uffenbach zeigt, sind gewisse örtliche und auch zeitliche Schwerpunkte festzustellen. Zum einen beschränken sie sich hauptsächlich auf zwei Entstehungsorte: Seine Heimatstadt Frankfurt am Main und Göttingen als Standort seiner Schenkung. Zum anderen entstand die wichtigste Literatur über ihn in der ersten Hälfte des 20. Jahrhunderts. In dieser Zeit wurden die ersten Manuskripte, besonders durch Max Arnim in den zwanziger und dreißiger und Eberhard Preußner in den fünfziger Jahren, ganz oder auszugsweise veröffentlicht.

$81 \quad$ Forkel 1792, Goldschmidt 1915; s.a. Eitner 1904.

82 Das Portrait befindet sich heute im Historischen Museum Frankfurt am Main; Emmerling 1953, Döry 1958, Emmerling 1959.

83 Valentin 1889.

84 Müller 1912.

85 Hüsgen 1790, S. 350-355, Gwinner 1862, S. 265-266, Gwinner 1867, S. 118.

86 Holst 1930, Holst 1931.

87 Von Hüsgen 1780, S. 173-176 bis Frankfurter Biographie, Bd. 2/1996, Stichwort „Uffenbach, Johann Friedrich.“

88 Schmidt 1960, Stichwort „Sammlung Johann Friedrich von Uffenbach (1727).“ 
Ausgelöst wurde die vermehrte Zahl an Editionen wahrscheinlich durch den 1895 erschienenen, detaillierten Lexikonartikel von Rudolf Jung. ${ }^{89}$ 


\section{Lebenslauf des Johann Friedrich Armand von Uffenbach}

\subsection{Die Familie und Herkunft}

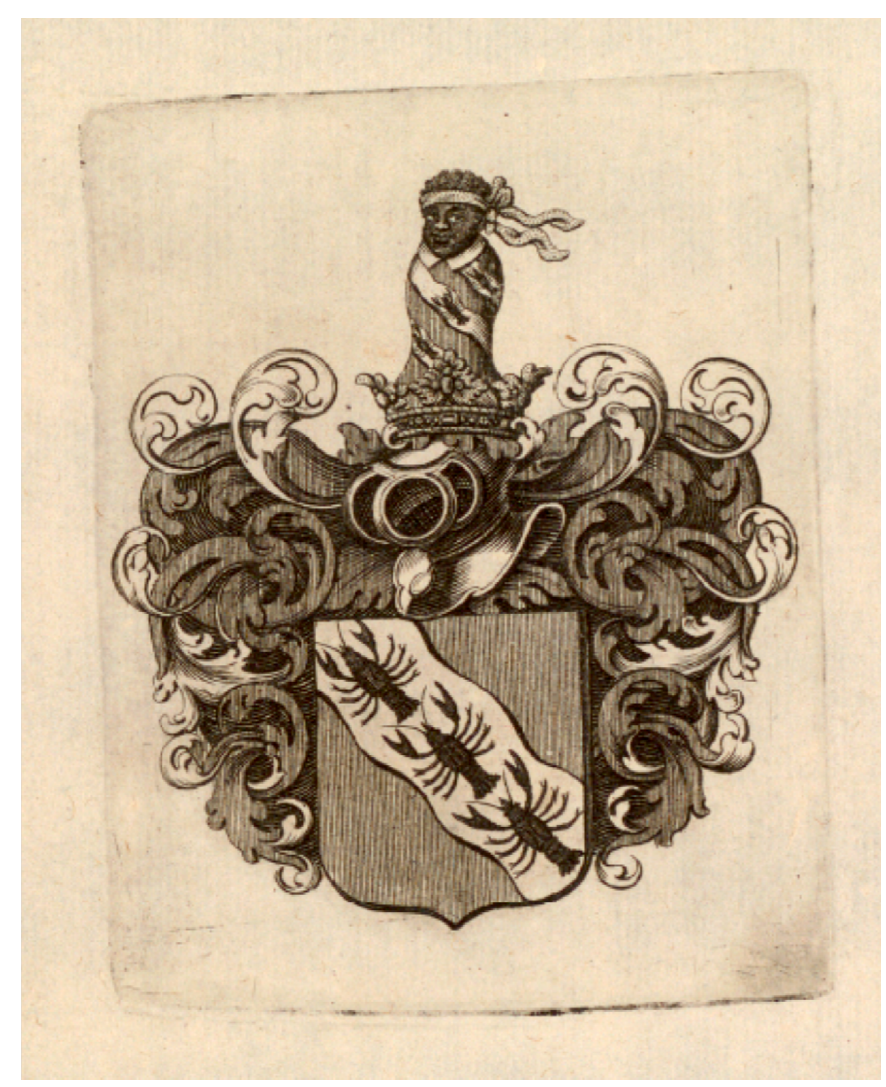

Abb. 1 Das Wappen der Familie von Uffenbach in: Cod. Ms. Uffenbach 29/I

Johann Friedrich von Uffenbach, der nach 1725 den dritten Vornamen „Armand“ hinzufügte, ${ }^{90}$ wurde am 6. Mai 1687 als zweiter Sohn des Frankfurter Rats- und Handelsmannes für französische Mode- und Galanteriewaren Johannes Balthasar (1641-1700) und dessen Frau Anna Sybilla, geb. Mayer (1656-1700), in der Freien Reichsstadt Frankfurt am Main, geboren. ${ }^{91}$ Die evangelische Taufe erfolgte vier Tage später, am 10. Mai. ${ }^{92}$ Er hatte einen älteren Bruder, den im

\footnotetext{
90 S. weiter unten.

91 Den Stammbaum und die Geburts- und Sterbedaten habe ich u.a. nach der handschriftlichen Fichardschen Geschlechtergeschichte, dem Taufbuch und dem Sterbebuch der Evangelischen Kirche, Frankfurt am Main, aus dem ISG Frankfurt erstellt, desweiteren wurden die Angaben aus Arnswaldt 1909 genutzt.

92 ISG Frankfurt, Taufbuch der Evangelischen Kirchen, Frankfurt am Main, 1686-1690, B1. 130v: Dienstags d. 10. dito [Mai 1687], H Johann Balthasar Uffenbach B.[ürger] u.
} 
Europa des 18. Jahrhunderts bekannten Bücher- und Handschriftensammler Zacharias Conrad (1683-1734); ${ }^{93}$ außerdem wurde elf Jahre später der Bruder Wilhelm am 16. September 1698 geboren, der aber schon im Alter von 37 Jahren am 24. Juni 1735 starb. ${ }^{94}$ Zudem hatte er noch eine Schwester, Anna Sibylla, die am 17. August 1675 geboren wurde ${ }^{95}$ und im Alter von sechzig Jahren ebenfalls 1735 starb. Die beiden Eltern verstarben innerhalb von drei Tagen im Jahre 1700, der Vater am 10. April, die Mutter am 13. des Monats - „wegen einer schweren zugeflossenen Kranckheit““.96 Durch das elterliche Erbe waren die Nachkommen finanziell unabhängig.

Johann Friedrich war zweimal vermählt. Am 6. August 1717 heiratete er die 1680 geborene Anna Elisabeth Lindheimer, Witwe des Frankfurter

Handelsmann alhier, uxor Fr. Anna Sibylla, ein Sohn Johann Friedrich, sub Herr Johann Friedrich Ammelburg, B. und Handelsmann alhier.

Jung 1895,1, S. 132; Polaczek 1922, S. 78 irrt also, wenn er schreibt: ,,[...] Uffenbach selbst war Katholik, allerdings ein ziemlich indifferenter. [...]“, Arnim 1928,1, S. VI. übernimmt Polaczeks falsche Angabe.

Dass Uffenbach nicht dem katholischen Glauben angehörte, läßt sich auch durch eine Textstelle im Vorbericht seines von ihm verfaßten „Harmonischen Jahrgange ... zu einer Haus Andacht in Music gebracht" belegen, den er für sein Landgut anlegte, das im katholischen, zum Mainzer Erzstift und Kurfürstentum gehörenden Flörsheim lag $\left(2^{\circ}\right.$ Bibl. Uff. 562 und 563); dort heißt es im ersten Band: „(S. 3r) [...] Der offtere Aufenthalt auf meinem unter andern Glaubensgenossen gelegenen Landgute hat mich wie billig erinnert die eingefallene Sonn und Festage mit Ehrerbiethung zu begehen, [...].“ Außerdem spottete er während seiner Reise durch Italien des Öfteren über die katholischen Riten.

93 S. ausführlich Franke 1965,1 und Franke 1965,2.

Ein Nachruf Johann Friedrichs auf Zacharias Conrad befindet sich zusammen mit der lateinischen Grabinschrift auf dem Frankfurter Friedhof von St. Katharinen im Commercium Epistolicum (Cod. Ms. Uffenbach. 20/I, p. 199a-c).

94 ISG Frankfurt, Taufbuch der Evangelischen Kirche in Frankfurt am Main 1686-1690, 375v: Donnerstags, den 26. dito [September 1689], Herr Johann Balthasar Uffenbach, Bürger und Handelsmann; Frau Anna Sibylla, uxori, geb. Mayerin; einen Sohn, Wilhelm, sub Johann Wilhelm Lehnemann p. [am linken Rand der Vermerk: +1735 [Zeichen für Venus od. Freitag] 24 Jun denat].

Johann Friedrich hält am 29. November 1735 ein längeres Ehrengedächtnis auf seinen Bruder Wilhelm in der wissenschaftlichen Gesellschaft (Cod. Ms. Uffenbach. 13/V, S. 536-543); S. Kapitel 8 ,Die wissenschaftliche Gesellschaft“; dort eine Kurzbiographie von Wilhelm von Uffenbach (Kapitel 8.4.6), und die Trauerrede Uffenbachs im Anhang, S. 606-612.

95 ISG Frankfurt, Taufbuch der Evangelischen Kirche in Frankfurt am Main 1667-1675, S. 495v: Dienstags, 17. Augusti [1675], Hr. Johann Balthasar Uffenbach, Bürger und Handelsmann, uxor Frau Anna Sibylla, eine Tochter Anna Sibylla, sub Frau Anna Sibylla; Wegl. Hrn. Johann Mayers, Bürgers und Handelsmanns Seel. Wittib, Ihr Mutter.

Anna Sybilla heiratete 1693 Johann Jost von Lindheim und war durch diese Verbindung die Großtante Goethes.

96 Uffenbach verfaßte lange nach dem Tod der Eltern im Jahre 1733 ein Lobgedicht mit dem Titel „Das Väterliche Andencken“, in dem er seinen Schmerz über den Verlust der Eltern beschreibt (Uffenbach 1733, S. 233-242).

Das Zitat: Uffenbach 1733, S. 242. 
Handelsmannes Franz Lehnemann (1665-1715), die am 5. November 1752 verstarb. Eine zweite Ehe ging er am 29. September 1755 mit Maria Magdalena von Bertram ein, die 1721 geboren worden war und ihn um 6 Jahre überlebte. Beide Ehen blieben kinderlos.

Aus der Ehe seines Bruders Zacharias Conrad mit Elisabeth Margarethe Perschberger $(\dagger 1734)$ gingen drei Kinder hervor, zwei Töchter und ein im Kindesalter verstorbener Sohn. Sein jüngerer Bruder Wilhelm blieb ledig, so dass dieser Zweig der Familie von Uffenbach im männlichen Stamm ausstarb, als Johann Friedrich Armand von Uffenbach am 10. April 1769 im Alter von 82 Jahren starb. ${ }^{97}$ Er wurde am 13. April auf dem Peterskirchhof in Frankfurt begraben. ${ }^{98}$

Die Familie von Uffenbach selbst erlosch aber erst 1799. Der Bruder des Vaters, der Handelsmann Zacharias Conrad (1639-1691), war in erster Ehe mit Anna Maria Werlin verheiratet $(\dagger 1683)$. Einer seiner Söhne, Nikolaus (16831744), ehelichte 1721 Margarethe Antonia von Lersner († 1751). Sie hatten zusammen insgesamt elf Kinder, von denen aber die meisten schon früh verstarben. Ihr drittes Kind war der 1725 geborene Johann Friedrich, der im Jahre 1799 ledig als „ultimus familiae“ verstarb. ${ }^{99}$ Um eine Verwechslung mit diesem zu vermeiden, fügte der ältere Johann Friedrich nach 1725 den dritten Vornamen „Armand“ zu.

\subsection{Ursprung der Familie}

Die Familie Uffenbach stammte ursprünglich aus Wetzlar. Wann genau der Urahn Johann Friedrichs, der Steindecker Peter Uffenbach ${ }^{100}(\dagger 1598)$, nach Frankfurt am Main übersiedelte, kann nicht festgestellt werden. ${ }^{101}$ Erstmals faßbar wird er am 7. Dezember 1552, als er die Goldschmiede- und Bürgerstochter Lucrezia Fleck heiratete, mit der er zwei Töchter und sechs Söhne hatte. Peter starb am 26. Mai 1598.102 Seinem vierten, am 28. November 1566 getauften Sohn,

Jung 1895,1, S. 132; Arnim 1928,1, S. XI

ISG Frankfurt, Totenbuch der Evangelischen Kirche in Frankfurt am Main 1668 - 1772, S. 198: „Donnerstag, d. 13. do [April 1769] von Uffenbach, S.T. Herr Johann Friedrich Armand, Ihro Röm. Kayßerl. Rath, würckl. Rath, ältester Schöff und des Raths alhier [...].“

99 Vgl. Fichards Geschlechtergeschichte, Arnswaldt 1909 und Jung 1900.

100 Oder ,Offenbach“.

101 Dietz 1897, S. 128; Donner-von Richter 1901, S. 8.

102 Nach Arnswaldt 1909, S. 42 hieß die Ehefrau mit Mädchennamen „Flicken“; die Kinder hießen: 1. Guda (get. am 08.07.1554), 2. Johann (get. am 25.06.1556), 3. Marx (get.
} 
ebenfalls mit dem Namen Peter (1566-1635), wurden vom Rat der Stadt Frankfurt am Main von 1589 bis 1597 finanzielle Mittel zur Verfügung gestellt, um in Straßburg, Padua und Basel Medizin zu studieren. 1597 wurde er in Basel zum Doktor sowohl der Philosophie als auch der Medizin promoviert. Noch im gleichen Jahr kehrte er nach Frankfurt zurück und erwarb sich als Arzt eine bedeutende Stellung - er wurde unter anderem zum „Physicus ordinarius“, das heißt zum Stadtarzt, ernannt. ${ }^{103}$ Er heiratete 1610 die Straßburger Ratstochter Maria Salome Birtsch und starb an der Pest in Frankfurt am 26. Oktober 1635, seine Frau verstarb am 20. Juli 1636. Der Arzt Peter war das erste Familienmitglied, das 1629 in die Frankfurter Patriziergesellschaft Frauenstein aufgenommen wurde. ${ }^{104}$

Der dritte Sohn des Arztes Peter Uffenbach war Achilles (1611-1677), der in Marburg die Rechte studierte. Am 6. Februar 1637 heiratete er Anna Ottilia Weyckart $(†$ 27.3.1670) und schwor im gleichen Jahr den Frankfurter Bürgereid. Er kam 1661 in den Rat und wurde 1670 zum Schöffen ernannt. Zudem war es ihm möglich, von Kaiser Ferdinand II. (1578-1637) den erblichen Adelstitel eines Freiherren zu erwerben; das Adelsprädikat erscheint allerdings erst 1711 in den

16.08.1562), 4. Heinrich (get. 22.05.1565), 5. Peter (get. 28.11.1566) und 6. ein Sohn, wahrscheinlich Johann (get. 02.02.1570).

Auf die Rückkehr des Dr. phil. et med. Peter Uffenbach aus Basel im Jahre 1597 wurde von Sebastian Prenner ein Lobgedicht verfaßt mit dem Titel: Clarissimo et literato ..., Straßburg 1597 ;

S.a. Kallmorgen 1936, S. 435.

Peter (Petrus) Uffenbach übersetzte und veröffentlichte mehrere Bücher, u.a.: Thesaurus chirurgiae, Petrus Uffenbach, Frankfurt a. M. 1610; Tractatus absolutissimus Ferdinandi Roderici Cardosi de sex rebus non naturalibus. Emendatus et in lucem emissus per Petrus Uffenbach, Frankfurt a. M. 1620; Wund Artzney, oder Arzneyspiegell Ambrosij Parei. Von Petro Uffenbach auß der Lateinischen Edition Jacobi Guillemeau tranferirt, Frankfurt a. M. 1601, das mehrere deutsche Auflagen hatte; Anatomia, Medicina Equorum Nova, Das ist Neuwes Roßbuch oder von der Pferden Anatomy, Natur, Cur, Pflegung und Heylung, ..., Auß deß Caroli Ruini Italienischer Edition, Durch Petrum Uffenbach ins Teutsch gebracht, Frankfurt 1603; Officina aurea: Das ist Güldene Werckstatt der Chirurgie oder Wundt Artzney, Joannes Andreas Cruce, Petrus Uffenbachius (Übersetzer), Frankfurt a. M. 1607; Kräuterbuch Dess uralten Unnd in aller Welt berühmten Griechischen Scribenten Pedacii Dioscodis Anazarbaei, .... Erstlich durch Joannem Danzium von Ast, der Artzney Doctorem, verteutscht, nun mehr aber von Petro Uffenbach, bestelten Medico zu Franckfurt auffs newe übersehen, verbessert, in ein richtige Form gebracht, und nicht allein mit vielen Figuren in Kupffer geziert, ..., Frankfurt a. M. 1610.

104 Zur Geschichte der Frauensteiner Patriziergesellschaft siehe: Lersner 1734, S. 100-117, Müller 1747, S. 112f.;

https://frankfurter-patriziat.de/node/26907 vom 19.06.2016; speziell zur Familie Uffenbach: https://frankfurter-patriziat.de/node/27135 vom 19.06.2016. 
Frankfurter Bürgerbüchern. ${ }^{105}$ Das Familienwappen zeigt heraldisch im Schild auf rotem Grund drei Flusskrebse von natürlicher Farbe in einem silbernen, von links oben nach rechts unten verlaufenden Querbalken mit dem Kleinod der neunkugeligen Krone als Zeichen des Freiherrnstandes (Abb.1). ${ }^{106}$ Achilles verstarb 1677, sieben Jahre nach dem Tod seiner Frau Anna Ottilia, und wurde in der Frankfurter Hospitalkirche begraben. ${ }^{107}$ Achilles Sohn', der Rat und Handelsmann Johann Balthasar, war der Vater Johann Friedrichs. ${ }^{108}$

Nahezu zeitgleich mit dem Steindecker Peter Uffenbach wanderte der Formenschneider Heinrich Uffenbach aus Muschenheim, einem Dorf bei Arnsburg in der Nähe von Wetzlar, in Frankfurt am Main ein. ${ }^{109}$ Dessen Sohn war der Maler und Stecher Philipp Uffenbach, der am 15. Januar 1566 getauft und am 6. April 1636 in Frankfurt am Main begraben wurde. ${ }^{110} \mathrm{Ob}$ ein Verwandtschaftsverhältnis - und wenn ja welches - zwischen Peter und Heinrich bestand, kann nicht festgestellt werden. Allerdings stand der Formenschneider Heinrich am 22. Mai 1565 Pate bei einem der Söhne des Steindeckers Peter.

Desweiteren unterschrieben der Arzt Peter Uffenbach und der Maler Philipp am 26. Mai 1598 zusammen eine Eingabe beim Rat der Stadt Frankfurt

105 Donner-von Richter 1901, S. 10 mit Anm. 1.; Oppitz 1992, Sp. 411; nach Hirsching 1812, Bd. 15, 1.Abt., S. 71. war die Familie schon Anfang des 17. Jahrhunderts durch Kaiser Rudolph II. geadelt worden;

in Fichards Geschlechtergeschichte wird über den Adelstitel der Familie Uffenbach folgendes ausgesagt: „Seine Söhne [d.h. die Söhne Johann Balthasars] schreiben sich von Uffenbach, ohne daß man damals wuste, warum, mann schrieb es ihrem Hochmuth und ihrer Prachtliebe zu“, und weiter, „In einem lateinischen Gedicht auf den Tod auf den Tod dreier Schöffen, des Joh. Hector v. Holzhausen, Hector Wilhelm v. Gunterrode u. Joh. Baltasar v. Uffenbach, wird ausdrücklich gesagt, daß sein Geschlecht (sein Großvater Peter) von K. Ferdinand II. geadelt worden.“

Franke 1965,1, S. 1236.

106 Das Wappen findet sich als Supralibros auf allen Einbänden der Manuskripte Johann Friedrichs, wo sie auf der Vor- und Rückseite auf grünem Leder in Gold geprägt erscheinen.

107 Fichards Geschlechtergeschichte berichtet weiter: „Er advozierte hier 24 Jahren lang und hatte dabei eine jährl. Rathsbestallung von mehreren Reichsständen, den Fürsten und Grafen v. Naßau, Grafen v. Isenburg, Büdingen und Hanau p.; wird als ein sehr rechtschafener Mann, der als Advocat sehr viele Prozeße durch gute Verträge beendiget zugleich als ein verständiger Rechts Gelehrter gerühmt.“

108 Fichards Geschlechtergeschichte: „lernt die Handlung in Franckreich u. Italien, wo er 8 Jahre zugebracht; verstand die Handlung sehr wohl. Handelte bis an seinen Tod mit französischen und Galanteriewaren, er hinterlies durch Sparsamkeit ein beträchtl. Vermögen.“

109 S.a. Donner-von Richter 1901, S. 6-17, der die verschiedenen Familien Uffenbach behandelt.

110 Fichards Geschlechtergeschichte: „Rubin und Diamantschneider alhier; muß bei Fettmilchs Aufruhr für sein Theil von dieser Zunft an der Bürgerstrafe 13 fl. 30 Xr erlegen, gut 1200 fl. im Vermogen lt. Specification bei dem Inquisitionsprozeß.“ 
„betreffend ein auf das Haus des Maurers Christoffel Müller von 'ihrem Vatter seligen' hypothezirtes Darlehen, von welchem der Schuldner behauptete, es schon bei Lebzeiten des Darleihers zurückbezahlt zu haben."111 Wenn die beiden aus Wetzlar und der Umgebung eingewanderten Handwerker tatsächlich Brüder gewesen sein sollten, dann wäre der Maler Philipp Uffenbach ein Großonkel Johann Friedrichs.

\subsection{Werdegang und größere Reisen}

Johann Friedrich von Uffenbachs Ausbildung fand zuerst durch Hauslehrer statt. Später besuchte er das öffentliche Frankfurter Stadtgymnasium, wo er in Griechisch und besonders in Latein als Sprache der Gelehrten ausgebildet wurde. ${ }^{112}$ Am 2. Mai 1704 immatrikulierte er sich an der Gießener Universität Ludoviciana, um Jurisprudenz zu studieren, und wechselte zum 23. September 1706 an die Friedrichs-Universität zu Halle, an der er Vorlesungen bei dem Philosophen und Mathematiker Christian Wolff (1679-1754) besuchte. In Halle wohnte er bei „H Engel in der Brüderstraße“. 113

Von November 1709 bis April 1711 unterbrach er für mehr als zwei Jahre das Studium, um seinen älteren Bruder, Zacharias Conrad, auf dessen ausgedehnter Reise durch Niederdeutschland, die Niederlande und England zu begleiten, wobei er die Aufgaben eines Zeichners übernahm. ${ }^{114}$ Auf und schon vor dieser Reise konnte Johann Friedrich die wissenschaftliche Vorgehensweise seines Bruders erlernen und für seine eigenen Bedürfnisse nutzen und ausbauen. Der Bruder war

111 Donner-von Richter 1901, S. 11.

112 Hirsching 1812, S. 72; Arnim 1928,1, S. VI.

Zum Frankfurter Stadtgymnasium: Liermann 1932, in: Voelcker 1932, S. 149-172, hier bes. S. 152-153.

113 S. den Briefentwurf Uffenbachs an Christian Wolff vom 10. März 1724 (Cod. Ms. Uffenbach, 20/I, p. 261r). Wolff hielt sich zu diesem Zeitpunkt gerade in Marburg auf, da er im November 1723 aus Halle als „Religionsverächter“ vertrieben worden war.

114 Eine für Johann Friedrich von Schreibern angefertigte Abschrift der Reisediarien befindet sich in der SUB Göttingen (Cod. Ms. Uffenbach 25 I-IV). Die Tagebücher dieser Reise wurden von Johann Georg Schelhorn (s. weiter unten) mit Hilfe von Johann Friedrich 1753 und 1754 leicht gekürzt dreibändig herausgegeben mit dem Titel: „Herrn Zacharias Conrad von Uffenbach merkwürdige Reisen durch Niedersachsen, Holland und Engelland“, Ulm, Memmingen 1753, 1754. U.a. lieferte er die Vorlagen zu den Kupfern. In der gedruckten Ausgabe fehlen z.B. die ausführlichen Bibliotheksbeschreibungen Zacharias Conrads und Teile mit persönlichem Inhalt, außerdem die Passagen Johann Friedrichs, nachdem er sich auf der Rückreise aus England von seinem Bruder getrennt hatte, um eine zweite Tour durch die Niederlande zu unternehmen.

Eine der ersten Rezension der gedruckten Tagebücher in Uffenbach 1754. 
besonders auf historischem Gebiet interessiert, also auch an den historischen Hilfswissenschaften wie Münz- und Siegelkunde. 115 Johann Friedrich konnte sich anhand der Herangehensweise an diese Wissenschaften - Autopsie und Empirie insofern schulen, als dass er sich immer wieder auf seinen eigenen Vorlieben Mathematik, Physik, Kunst und Kunsthandwerk - auf diese beiden Vorgehensweisen berief.

Nach einer intensiven Vorbereitung der Fahrt mit Hilfe der in der eigenen Bibliothek vorhandenen Bücher und Zeitschriften, in denen über Sammlungen und Bibliotheken der zu besuchenden Städte berichtet wird, besuchte Zacharias Conrad systematisch alle öffentlichen und privaten Einrichtungen, deren Eigentümer ihm und Johann Friedrich die Türen öffneten. Bei den einzelnen Visiten ging Zacharias Conrad methodisch die Bestände durch. Zuerst beschrieb er den Zustand der Sammlung, danach suchte er nach seltenen Handschriften und Drucken und machte sich Notizen über diese, teilweise exzerpierte er sogar einzelne Textstellen. Gab es einen gedruckten Bestandskatalog, erwarb er ihn. War er in einer Bibliothek, dessen Besitzer nicht zuließ, dass er sich die wichtigsten Handschriften und frühen Drucke notierte, hatte er eine Technik entwickelt, sich in seiner Jackentasche heimlich auf einer kleinen Tafel Notizen zu machen. Im Tagebuch selbst verzeichnete er penibel diejenigen Bibliotheken und Sammlungen, die er nicht aufsuchen konnte, sei es, dass der Eigner ihn nicht einließ, oder dass dieser verstorben und die Bibliothek verkauft worden war. ${ }^{116}$ Zurückgekehrt nach Frankfurt am Main verarbeitete Zacharias Conrad die Reisenotizen gründlich zu einem durchgehenden Tagebuch und vervollkommnete und verbesserte so die gedruckten Reisebeschreibungen und Berichte bezüglich der Sammlungen. Diese Tagebuchaufzeichnungen benötigte er vor allem zu seinem vergleichenden Studium der Urkunden und historischen Manuskripte.

Johann Friedrich hingegen besuchte während der Fahrt die verschiedenen Manufakturen und ging in ähnlicher Weise wie sein älterer Bruder vor. Was ihn hauptsächlich an den Produktionsstätten interessierte, waren die verschiedenen Herstellungstechniken, besonders wenn es sich um neue oder ihm noch unbekannte Verfahren handelte. Ähnlich wie sein Bruder in den Bibliotheken beobachtete er genau, ließ sich Unbekanntes erklären und beschrieb das Gesehene

115 Der ältere Bruder besaß u. a. ein eigenes Münzkabinett; vgl. Franke 1965,1, S. 1252-1259; hier werden die Sammlungsgebiete von Zacharias Conrad aufgezählt wie z.B. Autogramme und Münzen.

116 S. Uffenbach 1753-1754. 
in seinem Tagebuch. ${ }^{117}$ Weitere Gebiete, die ihn auf der Reise immer wieder interessierten, waren die Architektur und Technik, hier besonders die Ingenieurkunst der „Fontainenanlagen“ in den verschiedenen Gärten. ${ }^{118}$ Auch besah er sich die Festungsanlagen im niederländischen Naarden, um sein Auge und Wissen in der Kunst des Festungsbaus weiter zu schulen. ${ }^{119}$

Wie schon auf der gesamten Reise geschehen, besuchte Johann Friedrich nicht nur die für seine Interessensgebiete relevanten Sehenswürdigkeiten. Er erwarb immer wieder Gegenstände für seine verschiedenen Sammlungsgebiete. So besuchte er während der beiden Aufenthalte in Amsterdam des Öfteren den Feinmechaniker Conrad Metz (1690-1742), um bei ihm Zirkel und astronomische Instrumente $\mathrm{zu}$ erwerben. ${ }^{120}$ Auch Bücher und Druckgraphik erstand er in Amsterdam, beispielsweise im Verlagshaus „In de Visscher“: „einige Kupferstiche unter andern die Erstellung der Antiquitätenkammer von dem König in Franckreich in etlich sehr großen Plättern vor 15 f." "121

Nach dieser ersten größeren Reise hielt sich Johann Friedrich ungefähr ein Jahr in seiner Heimatstadt auf, um dann Ende 1712 seine Studien in Straßburg wieder aufzunehmen. In seinem „Elsasser und Schweitzer Reis-Diarium von Franckfurt biss Turin exclusive“ ist Johann Friedrichs Anreise nach Straßburg und sein etwa zweijähriger Aufenthalt ebendort ausführlich beschrieben. ${ }^{122}$ Die vom 21. Oktober bis zum 28. November dauernde Fahrt führte ihn unter anderem nach Stuttgart, wo er sich neben dem Schloss und dessen Garten auch den Neubau des Schlosses

117 Es können hier nur diejenigen Textstellen herangezogen werden, in denen Johann Friedrich seine Reise durch die Niederlande beschreibt, nachdem sein Bruder ihn am 9. April 1711 verlassen hatte, um über Düsseldorf nach Frankfurt am Main zurückzukehren. Nur hier kann man die eigene Vorgehensweise beobachten, da es bei der gemeinsamen Reise nicht deutlich werden kann, welcher Teil des Manuskripts von seiner oder seines Bruders Hand stammt (Cod. Ms. Uffenbach 25/III, S. 767-924).

118 Vgl. Cod. Ms. Uffenbach 25/III, S. 775-779 (Hemstede), S. 782-785 (Ceist), S. 786-788 (Soesdyck), S. 793-794 (Het Loo, das er am 6. Mai 1710 mit seinem älteren Bruder schon einmal besucht hatte [s. Uffenbach 1753-1754, Bd. 2, S. 373-377], jetzt aber von dem schlechten Zustand des Gartens, der Menagerie und besonders der Wasseranlagen enttäuscht war.), S. 795-800 (Voorst) usw.

119 Cod. Ms. Uffenbach 25/III, S. 789-791.

120 Cod. Ms. Uffenbach 25/III, S. 771-774 und 816, vgl. Meyerhöfer 1995.

121 Vgl. das Kapitel „Der Sammler Uffenbach“.

Cod. Ms. Uffenbach 25/III, S. 774, 816 und 840.

122 Das Manuskript ist der erste Band von „Johann Friedrich von Uffenbach, ausführliches Tagebuch über seine Reisen im Elsass, in der Schweitz, Italien, Frankreich und Niederland, vom 21. Oct. 1712 - 30 Mai 1716“ von insgesamt vier Bänden (Cod. Ms. Uffenbach 29 I IV).

Während der gesamten Zeit begleitete ihn sein Diener Ernst Friedrich Spies. 
Ludwigsburg gründlich besah. ${ }^{123}$ Er hielt sich danach mehr als zwei Wochen bei seinem älteren Bruder in der Universitätsstadt Tübingen auf, in der er sich die verschiedenen Stifte der Universität zeigen ließ. Nach einer Besichtigung des Durlacher und des Rastatter Schlossbaus erreichte er am 28. November Straßburg, wo er sich zuerst im „Wirtshaus zum Geist“ an der Nikolausbrücke einmietete. Von dort aus suchte er sich ein festes Quartier und bezog schließlich in der Fasanengasse zwei Zimmer.

Erst eine Woche später widmete sich Johann Friedrich zum ersten Mal dem Straßburger universitären Leben. Am 5. Dezember schrieb er sich bei dem Rektor der Universität, dem Mediziner Johannes Saltzmann (1679-1738), ein. ${ }^{124}$ Unter dem Datum des 13. Dezember 1712 befindet sich in dem betreffenden Diarienband die lateinisch gedruckte Einschreibungsurkunde, die der ihm in seinem Haus überreichte. Uffenbach schreibt hierzu: „Den 13. Decembris 1712 ging ich [...] zu dem rectori magnifico H. Doctor Salzmann in medicina, so auch ein junger und artiger man ist, mich bey der Universität einschreiben zu lassen. [...] Zuletzt wieß er mir die statuta academia, die ich nicht angesehen, weil sie immer fast ganz mit anderem über einkahmen, und thät ihm handgelöbtnuß, darvor ihm $12 \mathrm{rh}^{125}$ gegeben, und gieng wieder meiner weg. Sonst war ich der erste frembde, so sich bei ihm in librum illustrium virorum hatte einschreiben laßen $[\ldots]$....126

Über seine juristischen Studien während des zweijährigen Aufenthalts in Straßburg erfährt der Leser aus dem Tagebuch allerdings wenig. Uffenbach schildert in erster Linie seine Besuche in Sammlungen, Bibliotheken und von Konzerten, sowie mehrere Fahrten durch das Elsass und den Breisgau. ${ }^{127}$ Daneben

Johann August Corvinus [Stecher], Vues de la Residence de Louisbourg : Underschiedliche Prospect u. Grundriss des hertzoglich würtembergischen Residenz-Schlosses Ludwigsburg, Augsburg 1730 (GR 2 Bibl. Uff. 448).

124 S. Knod 1897, Bd. I, S. 13, Nr. 165 mit Anm. 2.

125 Reichstaler.

126 Vgl. Cod. Ms. Uffenbach 29/I, S. 108 mit der beigebundenen Urkunde: „Anno recuperatae per CHRISTUM salutis MDCCII (Tinte) die „Vto Xbris“ (Tinte) nomen suum Rectorem Academiae Argentoratensis est professus: Et Reipublicae huius Magistratui fidem: Rectori obedientiam: Professoribus et Praeceptoribus observatiam: Civibus humanitatem: vitam denique totam Academiae legibus convenientem promisit „Dnus Johannes Fridericus ab Uffenbach, Moeno-Francofurtensis.“ (Tinte) Johannes Saltzmann, Med.Doct. et Anat. 1.1. Ord. 3.t. Universitatis Rectorum (Tinte)“; s.a. Polaczek 1922, S. 99-100 mit Anm. 57: „Uffenbach hatte sich übrigens $\mathrm{zu}$ Unrecht in die Matricula serenissimorum et illustrissimorum eingetragen. Der Rektor machte nachträglich die Anmerkung: „Hic tantum est patricius."

127 Vgl. auch Polaczek 1922, der einige Transkriptionen zur Straßburger Zeit aus dem Tagebuch abdruckt. 
erfährt man, dass Uffenbach in Straßburg ebenfalls größere Anschaffungen für seine Sammlungen tätigte. So erwarb er z. B. den Nachlass des Straßburger Architekten und Stadtbaumeisters Johann Jacob Arhardt (1613-1674) bei dem Buchhändler Spohr. ${ }^{128}$

Es scheint gerade so gewesen zu sein, als ob Uffenbach das Studium der Kultur und Künste als wichtiger empfand als das der Jurisprudenz. Die Vorlesungen der Professoren besuchte er kaum, statt dessen bezahlte er einen Einpauker, der ihn ab Januar 1713 auf die mündliche Prüfung vorbereitete; er schrieb, dass er ihn „monatsweiße im hauß zu mir zu kommen accordirte vor einen alten Louis d'or, täglich eine stunde". 129

Am 22. Juni 1714 wurde er unter dem Dekanat des Juristen Johann Heinrich Feltz (1665-1737) zum Lizentiaten der Rechte erhoben. Im Tagebuch wird das zweitägige mündliche Examen ${ }^{130}$ bei den Professoren Feltz, Johann Heinrich Boeckler (1681-1733) und Johann Georg Schertz (1678-1754) ausführlich beschrieben, das er als eine große Qual empfand. ${ }^{131}$ In den folgenden zwei Monaten schrieb er seine „Dissertatio Juridica Inauguralis exhibens Quaestiones quasdam de Assertionibus Morientium“", ${ }^{132}$ die er anhand von neun Streitfragen behandelte. Seine Dissertation reichte er am 11. August bei den Dozenten ein. ${ }^{133}$ Er ließ seine Schrift in 500 Exemplaren bei dem Straßburger Johannes Beck drucken $^{134}$ und verteilte sie einen Tag vor seiner Disputation, am 31. August 1714, an die Professoren und Prüfer (Abb. 2). ${ }^{135}$ Die öffentliche Verteidigung am 1. September schildert er folgendermaßen: „Das auditorium war angefüllt voll curieuser Leute, und die Herren professores, so alle drei opponirten, dachten mich

S. Sors 2019, hier bes. S. 163-165.

Der Nachlass befindet sich heute zum größten Teil in der SUB Göttingen unter den Signaturen Cod. Ms. Uffenbach 1, Cod. Ms. Uffenbach 3 und Cod. Ms. Uffenbach 40c.

Desweiteren verwahrt die Kunstsammlung der Universität Göttingen vier Landschaftszeichnungen von Arhardts Hand (Inv. Nrn. H475, H485, H 486 und H 487).

Cod. Ms. Uffenbach 29/I, S. 114. Die Verabredung erfolgte am 31. Dezember 1712.

130 Die Prüfung begann am 19. Juni 1714, s. Knod 1897, Bd. II, S. 553, Nr. 799.

131 Cod. Ms. Uffenbach 29/I, S. 365-370.

132 „Juristische Inaugural-Dissertation über einige Rechtsfragen, die sich aus den Aussagen Sterbender ergeben können."

133 Cod. Ms. Uffenbach 29/I, S. 384.

134 Lebensdaten unbekannt.

Cod. Ms. Uffenbach 29/I, S. 384-387. Uffenbach übergab Beck am 14. August das Manuskript, der ihm die Fahnen zur Korrektur am 28. August vorlegte (Cod. Ms. Uffenbach 29/I, S. 391-392).

135 Uffenbach scheint seine Dissertation als unwichtig angesehen zu haben, da sich weder in seiner Bibliothek noch im ausgearbeiteten Tagebuch eines der 500 Exemplare befindet. Auch das Manuskript hat er nicht aufbewahrt. 
zu fassen, aber sie stachen daneben und ich zog mich heraus besser als ich es selbst vermeinte, und drüber das ganze auditorium lachen machte. Der Krieg währete biß halbweg $1 \mathrm{uhr}$, da er ein ende nahm [...]“..136

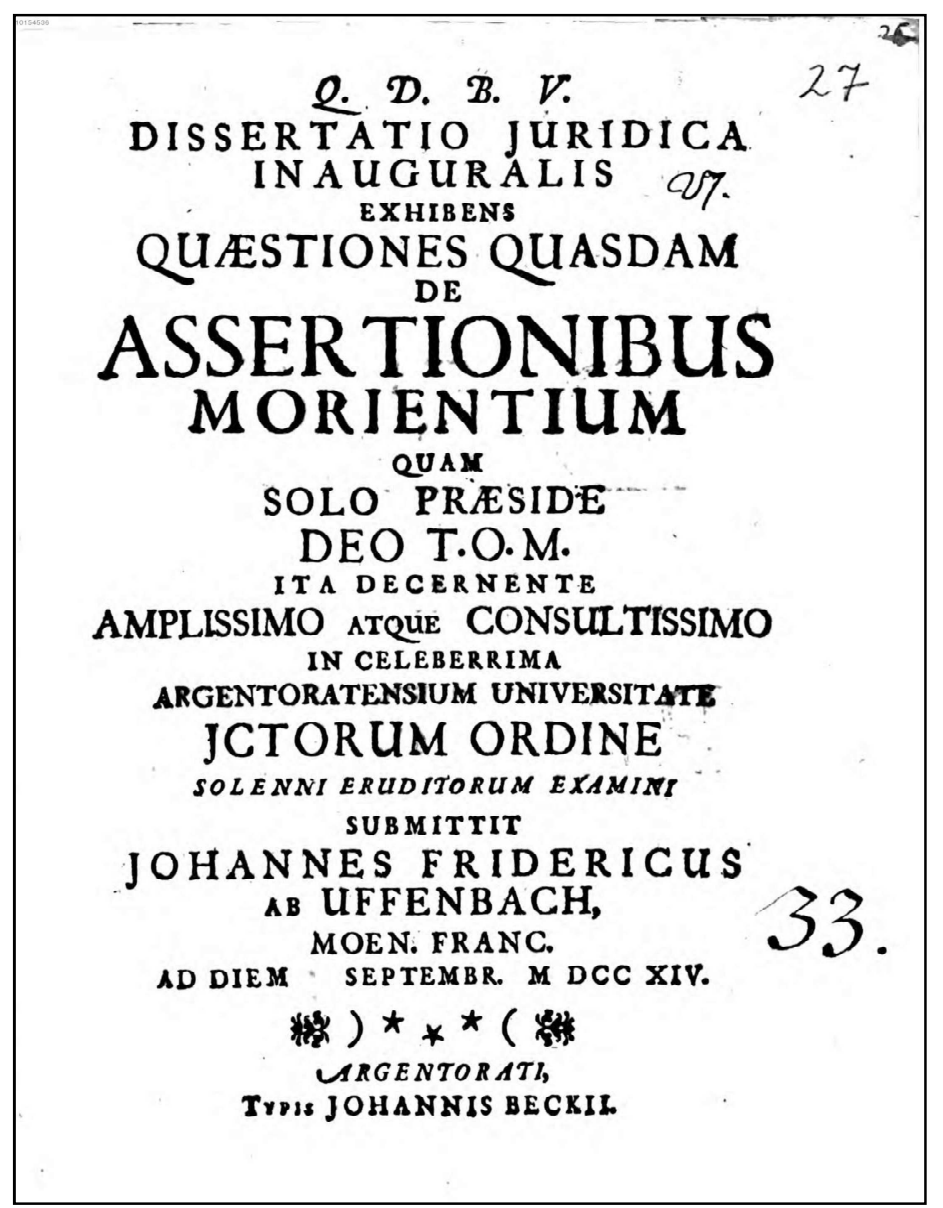

Abb. 2 Titelblatt der Dissertation Uffenbachs

Nach Ablegen seines Examens begab Uffenbach sich auf eine zweijährige „Grand Tour"137 durch die Schweiz, Italien, Frankreich und die Spanischen Niederlande, von der er ausführlich in seinen Diarien berichtet. ${ }^{138}$ Er legte dabei

136 Cod. Ms. Uffenbach 29/I, S. 393.

137 Der Begriff „Grand Tour“ wurde erstmals 1760 in der französischen Übersetzung von Richard Lassels „The Voyage of Italy, or a Compleat Journey through Italy. In Two Parts“ verwendet; s.a. Kat. Ausst. London 1996, S. 13 und Kat. Nr. 51;

Uffenbach besaß die zweite französische Ausgabe: Richard Lassels, Voyage d'Italie p., Tom 1 - 2, Paris 1682 ( $8^{\circ}$ Bibl. Uff. 467-468).

Eine Begriffsbestimmung gibt Leibetseder 2013.

138 Vom Manuskript der Reise durch Italien und Frankreich bis einschließlich Paris liegt eine 1970 angefertigte, maschinenschriftliche Transkription von Alste Horn-Oncken in der 
die für seine Zeit übliche Route zurück: Von Straßburg reiste er in die Schweiz, wo er sich vom 18. Oktober bis zum 20. Dezember 1714 aufhielt. Sein Hauptinteresse in Städten wie Basel, ${ }^{139}$ Zürich, ${ }^{140}$ Bern und Genf waren die Architektur und die Bibliotheken; ebenso suchte er die dort lebenden Gelehrten mit deren Sammlungen auf. ${ }^{141}$ Nach einer anstrengenden und als gefährlich beschriebenen Überquerung des Mont Cenis-Passes erreichte er am 28. Dezember Turin, ${ }^{142}$ von wo er am 7. Januar 1715 in Richtung Mailand abfuhr. ${ }^{143}$ Hier machte er für etwa zwei Wochen Station, um dann über Pavia, Piacenza, Parma, Mantua, Verona, Vicenza und Padua am 2. Februar nach Venedig zu gelangen. ${ }^{144}$

Mit der Lagunenstadt und ihrem Karneval hatte er in Italien ein erstes großes Reiseziel erreicht. Er besuchte während seines fünfwöchigen Aufenthalts die verschiedenen Veranstaltungen wie z. B. das tägliche Maskentreiben auf dem Markusplatz, die Bälle, Komödien und Theaterstücke, außerdem mehrere eigene Konzertaufführungen Antonio Vivaldis (1678-1741). Neben dem Karneval galt sein Interesse aber auch - wie in allen anderen Städten, die er aufsuchte - der Architektur und den verschiedenen Sammlungen. ${ }^{145}$ Nachdem der venezianische Karneval vorüber war und Uffenbach alles gesehen hatte, was ihn interessierte, und einen ersten Ballen mit erworbenen Gegenständen nach Frankfurt am Main abgeschickt hatte, reiste er am 12. März 1715 ab.

Sein nächstes großes Ziel war Rom, wo er am 30. März eintraf. Seine Route dorthin verlief über Padua, Ferrara, Bologna, Ancona, Loreto und Spoleto. ${ }^{146}$ So gelangte er auf der Via Flaminia nach Rom, wo er an der Piazza di Spagna im Wirtshaus „al monte d'oro“ ein Quartier für seinen dreimonatigen Aufenthalt fand. ${ }^{147}$ Diesen unterbrach er vom 22. April bis zum 11. Mai, um einen Abstecher nach Neapel und Pozzuoli mit seinen Thermen und Antiken zu machen. ${ }^{148}$

Abteilung Spezialsammlungen und Bestandserhaltung der SUB Göttingen ( $8^{\circ}$ Uffenbach 29 A) vor.

139 S. Horn-Oncken 1973.

140 S. Horn-Oncken 1971.

141 Cod. Ms. Uffenbach 29/I, S. 440-648.

142 Cod. Ms. Uffenbach 29/II, S. 1.

Der Mont-Cenis war im 17. und 18. Jahrhundert neben dem Brenner der wichtigste Pass über die Alpen; vgl. Schudt 1959, S. 145, Kat. London 1996, S. 100, Kat. Nr. 50.

143 Cod. Ms. Uffenbach 29/II, S. 33.

144 Cod. Ms. Uffenbach 29/II, S. 82-134.

145 Cod. Ms. Uffenbach 29/II, S. 134-245.

146 Cod. Ms. Uffenbach 29/II, S. 246-374.

147 Cod. Ms. Uffenbach 29/II, S. 374-730, und 29/III, S. 1-351. 
Das ausgiebige Programm in Rom galt in erster Linie den Besuchen der Sammlungen in den Palazzi und Villen mit den Gärten, der eingehenden Besichtigung der Kirchen und ihrer angrenzenden Gebäude, vor allem aber St. Peter und dem Vatikan, und der Betrachtung der antiken Stätten. Zudem besuchte er ausgiebig die Kupferstecher, Buchhändler und Verleger, überdies Mechaniker und Erfinder optischer und mechanischer Instrumente. ${ }^{149}$ Er hatte auf seiner Reise von Venedig nach Rom und vor Ort so viele und so schwere Gegenstände wie Bücher, Graphik und optische Geräte erworben, dass er kurz vor seiner Abreise nochmals einen großen Ballen Gepäck nach Frankfurt am Main versenden ließ.150

Am 25. Juni verließ er Rom in Richtung Florenz erst spät nachts, da er die hohen Temperaturen umgehen wollte, die tagsüber in der Campagna herrschten. Nach einem kurzen Aufenthalt in Siena, erreichte er Florenz am 30. Juni und blieb für eine Woche, um sich die Sehenswürdigkeiten der Stadt, besonders die Sammlungen der Palazzi Vecchio und Pitti, anzuschauen.151 Nach kurzen Unterbrechungen der Weiterfahrt in Livorno, Pisa, Lucca, Genua und der Überquerung des Mont Cenis, die im Sommer leichter zu bewältigen war, erreichte er mit Genf am 28. Juli wieder den Ausgangsort seiner jetzt beendeten italienischen Reise. ${ }^{152}$

Ein weiteres Reiseziel war Frankreich, wobei Paris das wichtigste Ziel dieser Tour war. Am 16. August verließ er Genf, um über Lyon, wo er sich zwei Wochen aufhielt, ${ }^{153}$ Rouanne, Nevers und Orleans in die französische Hauptstadt zu reisen. ${ }^{154}$ Auf einer Station dieses Reiseabschnitts, in Gien, erfuhr Uffenbach durch einen seiner französischen Reisegefährten vom Tod des französischen Königs Ludwig XIV (1638-1715), der am 1. September 1715 gestorben war. Im Reisetagebuch vermerkte Uffenbach unter dem 5. September: „Unser gascon und reißgefährte hatte hier wieder seine bekante von welchen er mit der uns sehr verdrießlichen und unvermutheten zeitung zurückkahme daß der konig Louis XIV nach einem nicht alzu langen lager mit todt gewiß und sicher abgegangen, wie

Mit Beginn des 18. Jahrhunderts hatten sich die meisten Gasthöfe an und um diesen Platz herum angesiedelt, vgl. Schudt 1959, S. 160.

148 Cod. Ms. Uffenbach 29/II, S. 537-728; s.a. Horn-Oncken 1978.

149 S.a. Meyerhöfer 1995, S. 116-117.

150 Cod. Ms. Uffenbach 29/III, S. 329-331.

151 Cod. Ms. Uffenbach 29/III, S. 360-522.

152 Cod. Ms. Uffenbach 29/III, S. 523-677.

153 Cod. Ms. Uffenbach 29/IV, S. 4-34.

154 Cod. Ms. Uffenbach 29/IV, S. 35-59. 
sehr es uns schmerzete, den in aller welt so berühmten und beschriehenen monarchen nicht mehr zu sehen, ist sehr leicht einzubilten."155

Nach der etwa vier Wochen dauernden Anreise erreichte er am 11. September Paris, um sich insgesamt sieben Monate, bis zum 11. April 1716, hier aufzuhalten und die wichtigsten Sammlungen, Bibliotheken und die Architektur zu besichtigen; abermals spielten Konzerte, Opern ${ }^{156}$ und Theater, ${ }^{157}$ auch Besuche von Jahrmärkten, auf denen Komödien gespielt wurden, ${ }^{158}$ eine wichtige Rolle. ${ }^{159}$ Nach anfänglichen Schwierigkeiten, eine für die Reisekasse erschwingliche Unterkunft zu finden, mietete er sich am 14. September in der ,rue de sepulchre a l'hotel d'allemagne“" zwei Zimmer für einen ihm genehmen Preis. ${ }^{160}$ Neben den Besichtigungen der Kirchen, Paläste und Gärten in Paris ${ }^{161}$ betrachtete er die

155 Cod. Ms. Uffenbach 29/IV, S. $44+45$.

156 Z. B. Cod. Ms. Uffenbach 29/IV, S. 171-174, 182, 188, 260, 540-541, 577. 578-579, 580583 (öffentlicher Opernball), 602, 617, 619, 620-621 (öffentlicher Opernball), 638-639, 661-662.

157 Cod. Ms. Uffenbach 29/IV, S. 178-180, 201, 210-211.

158 Z. B. „nach dem weit vor der statt gelegenen foire St Laurent“ (Cod. Ms. Uffenbach 29/IV, S. 174-177, 195-198, 235, 424, 485, 574, 575, 593, 601) oder ,die izo angefangene foire de St germain“ (Cod. Ms. Uffenbach 29/IV, S. 602-604, 612, 613-614, 616, 621, 623, 624, 634, 640, 643, 644, 647, 650, 652-653).

159 Cod. Ms. Uffenbach 29/IV, S. 59-692.

160 Cod. Ms. Uffenbach 29/IV, S. 73-74.

161 Z. B.: Tuillerien-Palast mit seinem Garten (Cod. Ms. Uffenbach 29. IV, S. 74-76, 192, 294-295, 297-300, 359-366),

Place Vendôme mit einzelnen Palästen (Cod. Ms. Uffenbach 29/IV, S. 77-79. 289-294), die heute zerstörte Kirche der Kapuzinerinnen (Cod. Ms. Uffenbach 29/IV, S. 79-80),

Palais Royal mit Garten (Cod. Ms. Uffenbach 29/IV, S. 80-81, 267-269),

Hotel de Soubise von Kardinal Rohan mit der Bibliothek (Cod. Ms. Uffenbach 29/IV, S. 409-412),

Place Dauphine mit Pont Neuf (Cod. Ms. Uffenbach 29/IV, S. 83, 524, 606-610),

„place royale“ (Dem heutigen Place des Vosges; Cod. Ms. Uffenbach 29/IV, S. 381-382),

Invalidendom und -haus (Cod. Ms. Uffenbach 29/IV, S. 111-119),

Place Victoires (Cod. Ms. Uffenbach 29/IV, S. 193-195),

Notre Dame de Paris mit Kloster (Cod. Ms. Uffenbach 29/IV, S. 234, 537-539),

Rathaus (Cod. Ms. Uffenbach 29/IV, S. 370-374),

Sorbonne mit der Bibliothek (Cod. Ms. Uffenbach 29/IV, S. 486-491; vgl. Bode 1961, S. 3-5),

„anatomie en cire“ mit den vielen und sehr natürlich wirkenden künstlichen Präparaten (Cod. Ms. Uffenbach 29/IV, S. 546-551),

Palais Luxembourg, wo er die Medici-Galerie von Peter Paul Rubens ausführlicher beschreibt (Cod. Ms. Uffenbach 29/IV, S. 518-522),

„,collegium de quatre nations“ mit der Bibliothek Mazarine (Cod. Ms. Uffenbach 29/IV, S. 527-534; vgl. Bode 1961, S. 5-7),

„,bibliotheque des advocats“ (Cod. Ms. Uffenbach 29/IV, S. 535-537; vgl. Bode 1961, S. 25-26), 
verschiedenen umliegenden Schlösser und Gärten vor allem wegen ihrer Architektur und der Wasserspiele. ${ }^{162}$ Zusätzlich suchte er auch kleinere Gärten

das Gebäude der Oper mit der Maschine zum Heben und Senken des gesamten Parterres (Cod. Ms. Uffenbach 29/IV, S. 626-631 mit Zeichnung der Anlage; vgl.: Meyerhöfer 1996, S. 133, Nr.58 und Kat. Magdeburg 1998, S. 135, Kat. Nr. II/22),

Sainte Chapelle (Cod. Ms. Uffenbach 29/IV, S. 539, 559-560),

die noch nicht fertiggestellte „eglise de l'oratoire“ mit der berühmten Bibliothek [Cod. Ms. Uffenbach 29/IV, S. 238-243. Vgl. Bode 1961, S. 18-19. In der Bibliothek sah er auch die Büchermaschine nach Agostino Ramelli, von der sich sein älterer Bruder, Zacharias Conrad, eine Kopie hatte anfertigen lassen, vgl. Ramellis Buch: Schatzkammer der Mechanischen Künste, Leipzig 1620, 111. Kapitel, S. 292-293 (2 Bibl. Uff. 193)],

die Abtei St.Germain des Prés mit der Bibliothek (Cod. Ms. Uffenbach 29/IV, S. 257-259, 510-511, 512-518),

das Dominikanerkloster (Cod. Ms. Uffenbach 29/IV, S. 261-264, vgl. Bode 1961, S. 2021),

das „kloster des feuillants“ (Cod. Ms. Uffenbach 29/IV, S. 300-303; vgl. Bode 1961, S. 15-16),

das „kloster der petits peres“ (Cod. Ms. Uffenbach 29/IV, S. 326-330, vgl. Bode 1961, S. 21-22),

das „,kloster de recolets“ mit der bekannten Bibliothek (Cod. Ms. Uffenbach 29/IV, S. 346347, vgl. Bode 1961, S. 24, ,recolets“ = Franziskaner),

die Kirche St. Eustache (Cod. Ms. Uffenbach 29/IV, S. 367-368),

die am Rathaus gelegene Kirche St. Gervais (Cod. Ms. Uffenbach 29/IV, S. 374-375),

das Kloster des Minimes mit Bibliothek (Cod. Ms. Uffenbach 29/IV, S. 383-385. Vgl.

Bode 1961, S. 23-24),

das Kloster der Coelestiner mit Bibliothek (Cod. Ms. Uffenbach 29/IV, S. 392-395, vgl. Bode 1961, S. 16-18),

die ,abbaye de St. victor mit der großen Bibliothek (Cod. Ms. Uffenbach 29/IV, S. 398401; vgl. Bode 1961, S. 12-13),

das „,college de louis le grand, oder dem jesuitter collegio“ mit Bibliothek (Cod. Ms. Uffenbach 29/IV, S. 436-441; vgl. Bode 1961, S. 7-9),

das ,"collegio der bernhardiner“ (Cod. Ms. Uffenbach 29/IV, S. 442-443),

die Kirche St. Nicolas du Chardonnet (Cod. Ms. Uffenbach 29/IV, S. 454-4589,

das Karmeliterfrauenkloster (Cod. Ms. Uffenbach 29/IV, S. 458-460),

das Benediktinerinnen-Kloster Val des Grace (Cod. Ms. Uffenbach 29/IV, S. 460-464),

die Abtei St. Genevieve mit der renommierten Bibliothek und Sammlung und das benachbarte Hauses mit der Bibliothek Colberts (Cod. Ms. Uffenbach 29/IV, S. 464-475, 523-524, Colberts Bibliothek s. S. 466-468, vgl. Bode 1961, S. 9-12),

das Kloster der Cordeliers mit Bibliothek (Cod. Ms. Uffenbach 29/IV, S. 509-510),

die Kirche St. Sulpice (Cod. Ms. Uffenbach 29/IV, S. 545-546),

der „Kirche des Barnabites“ (Cod. Ms. Uffenbach 29/IV, S. 560-561),

die Kirche „St sauveur a la rue St denys“ (Cod. Ms. Uffenbach 29/IV, S. 620).

162 Z. B.: Versailles (Cod. Ms. Uffenbach 29/IV, S. 84-109, 122-130),

Marly (Cod. Ms. Uffenbach 29/IV, S. 130-139, 151-156),

St. Cloud (Cod. Ms. Uffenbach 29/IV, S. 140-141, 163-169),

St. Germain (Cod. Ms. Uffenbach 29/IV, S. 156-158),

Meudon (Cod. Ms. Uffenbach 29/IV, S. 158-163),

Vincennes (Cod. Ms. Uffenbach 29/IV, S. 183-187),

Sceaux (Cod. Ms. Uffenbach 29/IV, S. 232-234). 
auf, wie das im „fauxbourg St Antoine“ gelegene Gartenhaus „des mons titons“. 163

Erst am 4. Dezember 1715 konnte er durch Vermittlung des königlichen Bibliothekars Jean Boivin (1683-1727) die „bibliothecam regiam“ besichtigen, deren Bestände er trotz des schlechten persönlichen Führers ausführlich zu beschreiben versucht. ${ }^{164}$ Neben den Büchern und seltenen Manuskripten studierte er das Medaillen- und Edelsteinkabinett. Hier konnte er auch die ehemalige Graphiksammlung des Abbé Michel de Marolles (1600-1681) sehen: „ein ander zimmer war ganz voll von lauter kupferbücher, so die berühmte collection des abbé marolles geweßen davon der catalogus noch getruckt, und welche er gar theuer an den könig verkaufft hat, alle bände waren gar schön von rothem saphian mit gold, und die sachen selbst nach den materien in gar guter ordnung, bey dem nicht allein die erschreckliche menge, sondern auch die auserlesenheit der abtrucke admirirt, und gerne etliche monat allein alhier zu gebracht hätte. “165

Ein Gebäudekomplex, der ihn besonders interessierte, war der Louvre. ${ }^{166}$ Zum einen konnte er hier die Räumlichkeiten der französischen ,academie des sciences“" sehen zum anderen diejenigen der ,academie des peintures“. Allerdings war er von dem Tagungsraum der königlichen Akademie der Wissenschaften wegen der Nüchternheit der Ausstattung enttäuscht, erwartete er doch ,viele machinen und curiositäten“ - darunter die technischen Neuerungen -, die er von den Schriften der Akademiemitgliedern kannte. ${ }^{167}$ Zudem war es ihm möglich, an einer der öffentlichen Akademiesitzungen teilzunehmen. ${ }^{168}$

Dagegen bereitete ihm die ,,academie des peintures“ großes ,,vergnügen.“169 Auch die nur zweimal im Jahr stattfindende öffentliche Sitzung der ,academie des inscriptions“ ließ ihn in den Louvre eilen. ${ }^{170}$ Zusätzlich interessierte er sich für die

\footnotetext{
163 Cod. Ms. Uffenbach 29/IV, S. 447-454.

164 Cod. Ms. Uffenbach 29/IV, S. 401-408; vgl. Bode 1961, S. 1-3.

165 Cod. Ms. Uffenbach 29/IV, S. 404; vgl. das Buch in der Bibliothek Uffenbach: Michel de Marolles, Catalogue de livre d'estampes et de figures en taille douce, Paris 1666 ( $8^{\circ} \mathrm{Bibl}$. Uff. 527).

166 Cod. Ms. Uffenbach 29/IV, S. 192, 201-210, 274-277, 277-280.

167 Cod. Ms. Uffenbach 29/IV, S. 201-210, hier bes. 201-202.

168 Cod. Ms. Uffenbach 29/IV, S. 277-280. Vgl. das Kapitel 8 „Die wissenschaftliche Gesellschaft.“

169 Cod. Ms. Uffenbach 29/IV. S. 256-257.

170 Cod. Ms. Uffenbach 29/IV, S. 274-277.
} 
dort aufbewahrten vielfältigen königlichen Sammlungen, die er an verschiedenen Tagen inspizierte und sich von den Bewahrern zeigen ließ. ${ }^{171}$

Er konnte nach mehreren vergeblichen Versuchen am 28. Dezember 1715 durch die Vermittlung des deutschen Apothekers Spizler ${ }^{172}$ die etwa 220 Stücke umfassende Sammlung der Städte- und Fortifikationsmodelle besichtigen, die in der großen Galerie des Louvre aufbewahrt wurde. Als Architekt und Ingenieur war hier für ihn die Art der Stadt- und Befestigungsanlagen durch die Zeiten hinweg von großem Interesse, besonders aber diejenigen, die er selbst gesehen hatte oder diejenigen, die in der neuesten Manier erbaut worden waren. ${ }^{173}$

Dem unter Ludwig XIV. gebauten Observatorium widmete Uffenbach wegen seines Interesses an der Astronomie spezielle Aufmerksamkeit. ${ }^{174}$ Er konnte hier endlich die Erfindungen sehen, die bei seinem Besuch in der Akademie der Wissenschaften besprochen worden waren. In seinem Tagebuch beschreibt Uffenbach die Architektur Charles Perraults (1628-1703), die ihm weniger für ein Observatorium sondern eher für ein Bollwerk oder Souterrain angemessen erschien. ${ }^{175}$ Er ließ sich von dem Astronomen Philippe de la Hire (1640-1718) durch das Gebäude führen. De la Hire zeigte Uffenbach die Sammlung der dort aufbewahrten, naturwissenschaftlichen Geräte der Akademie der Wissenschaften, nachdem er ihn durch seine eigenen Zimmer im Observatorium mit Bibliothek und selbstgeschliffenen Linsen geführt hatte. Hier betrachtete Uffenbach ausgiebig die Instrumente, die ihn besonders interessierten: Instrumente der Kriegs- und Ingenieurkunst, des verarbeitenden Gewerbes und vor allen der Astronomie. ${ }^{176}$

Neben seiner eigenen Beschreibung der Örtlichkeiten verweist er immer wieder auf die 1713 erschienene „Description de la ville de Paris et de tout ce qu'elle continent de plus remarquable“177 des Abbé Germain Brice (1652-1727), den er in Paris auch persönlich kennenlernen konnte und der ihm seine

Cod. Ms. Uffenbach 29/IV, S. 244-249, 250-255, 265-267, 310-312, 316-324.

Mit Bewahrern sind die Verwalter der Sammlungen gemeint.

172 Lebensdaten unbekannt.

173 Cod. Ms. Uffenbach 29/IV, S. 562-572.

174 Cod. Ms. Uffenbach 29/IV, S. 475-485.

175 Cod. Ms. Uffenbach 29/IV, S. 482: „Ich konnte mich übrigends über die entsezliche hohe und massive gewolbe des haußes nicht genug verwundern deren festigkeit keiner festung bey kommet [...] so daß es inwendig nathürlich als die großen gefangüße so in opern und theatris offters vorgestellet werden aus siehet."

176 Cod. Ms. Uffenbach 29/IV, S. 475-485.

1778 Bibl. Uff. 476-478. 
Kunstsammlung öffnete. ${ }^{178}$ Eigene Darstellungen Uffenbachs findet man immer dann in seinen Diarien, wenn er Gebäude oder Begebenheiten vorstellt, die nicht in den gedruckten Beschreibungen verzeichnet waren. Ansonsten greift er immer wieder auf Brice zurück: „,...] dem [Einem Reisegefährten] allmählig der lusten weiter in paris nach curiositäten, und sehenswürtigen sachen nach anleitung des brice in seiner description, zu fahren verginge, ob wohlen wir uns fürgenommen, diese description ganz durch zu gehen, bey welcher meinung ich jedoch bliebe, und auch ohne gesellschafft fort zu fahren mich entschloße."179

Durch die Vermittlung von Brice, der, wie es scheint, ihn in die Pariser Sammlerkreise einführte, konnte er die Sammlung und die Bibliothek des Abbé Jean-Paul Bignon (1662-1743) besuchen, dessen Bücheranordnung nach der Chronologie des Erscheinungsdatums er sehr denkwürdig fand. Dagegen hebt er dessen Sammlung an astronomischen Geräten heraus. ${ }^{180}$ Eine Antikensammlung, die er ausführlich beschrieb, war die des Père Bernard de Montfaucon (16551741) in der Abtei von St. Germain de Prés. ${ }^{181}$ Auch ihn besuchte er zusammen mit Germain Brice. Weitere Privatsammlungen, wie die Antikensammlung des Abbé Fauvel, ${ }^{182}$ das chemische Labor, die Bibliothek und das Kuriositätenkabinett des Apothekers und Mitglieds der französischen Akademie Claude-Joseph Geoffroy (1685-1752), ${ }^{183}$ die Bibliothek Nicolas-Joseph Foucault (1643-1721), ${ }^{184}$ die des Abbé Louis Du Four de Longuerue (1652-1733), ${ }^{185}$ mit dem er über die Eigenarten anderer Bibliophiler und deren Bibliotheken diskutierte, die Bibliothek mit großer Antiken- und Medaillensammlung von Charles César Baudelot de Dairval (1648-1722), ${ }^{186}$ die Gemälde-, Antiken- und Medaillensammlung des Abbé Francois de Camps (1643-1723), ${ }^{187}$ die Bibliothek des Gelehrten und

Cod. Ms. Uffenbach 29/IV, S. 211, 235-236.

Cod. Ms. Uffenbach 29/IV, S. 391.

Cod. Ms. Uffenbach 29/IV, S. 280-283.

Eine Kurzbeschreibung des Kabinetts, siehe: https://curiositas.org/cabinet/curios1444 vom 11.12.2018.

Cod. Ms. Uffenbach 29/IV, S. 386-388, 397-398.

Lebensdaten unbekannt.

Cod. Ms. Uffenbach 29/IV, S. 336-341.

Cod. Ms. Uffenbach 29/IV, S. 375-380.

Cod. Ms. Uffenbach 29/IV, S. 493-497.

Cod. Ms. Uffenbach 29/IV, S. 497-499.

Cod. Ms. Uffenbach 29/IV, S. 502-509.

Eine Kurzbeschreibung des Kabinetts, siehe: https://curiositas.org/cabinet/curios1267 vom 30.10.2018.

Cod. Ms. Uffenbach 29/IV, S. 553-557. 
ehemaligen Bibliothekars Colberts Etienne Baluze (1630-1718) $)^{188}$ und die Gemälde- und Kuriositätensammlung des Malers Benoit konnte er besichtigen. ${ }^{189}$

Als er die Bibliothek mit der Medaillen- und Pastensammlung des Juristen Nicolas Henrion (1663-1720) besuchte, zeigte ihm dessen Tochter ihre selbstgefertigten Pasten. ${ }^{190}$ Die Qualität der Stücke war nach seiner Meinung so hoch, dass er für seine eigene kleine Sammlung zehn Abdrücke orderte. ${ }^{191}$

Ein „cabinet von physicalischen und mathematischen sachen“, welches Uffenbach wegen der Schriften des Besitzers unbedingt sehen wollte, war jenes von Pierre Le Lorrain, Abbé de Vallemont (1649-1721).192 Er besuchte ihn am 11. Dezember 1715 und beschrieb ihn ,in seinem schmuzigen schlaffrock [als] ziehmlich obscur, alt und gewaltig hasenhafft."193 Auch seine Sammlung bezeichnet er als enttäuschend, nachdem er sie durchsehen durfte: ,[...] was ich hier gesehen, worunter überhaupt aber nichts remarquirt so nicht allen mathematischen anfängern zur genüge bekannt ist." 194 Am nächsten Tag gelang es ihm, auch die Bibliothek mit Münz- und Medaillenkabinett im Haus „des praesidenten de la moignon“" zu besichtigen. ${ }^{195}$

Beim Besuch des Kuriositätenkabinetts von Herrn Goutard, dessen Sammlung ihm ,,angerühmet worden“, war er sehr enttäuscht, da ihm alles, was der Besitzer

Eine Kurzbeschreibung des Kabinetts, siehe: https://curiositas.org/cabinet/curios1566 vom 30.10.2018.

188 Cod. Ms. Uffenbach 29/IV, S. 590-593.

189 Wahrscheinlich Antoine Benoist (1628-1717);

Cod. Ms. Uffenbach 29/IV, S. 614-616.

Eine Kurzbeschreibung des Kabinetts, siehe: https://curiositas.org/cabinet/curios1279 vom 11.12.2018.

190 Paste $=$ Abdruck von geschnittenen Steinen, Medaillen etc. in einer Teigmasse aus feinem Gips oder Schwefel.

191 Cod. Ms. Uffenbach 29/IV, S. 499-502, hier bes. 501, S. 526-527.

192 Uffenbach besitzt mehrere Bücher von ihm: Description de l'aimant qui s'est formé à la pointe du clocher neuf de Chartres, avec plusieurs expériences curieuses sur l'aimant et sur d'autres matières de physique, Paris 1692 ( $8^{\circ}$ Bibl. Uff. 437); La Physique occulte, ou Traité de la baguette divinatoire et de son utilité pour la découverte des sources d'eau des minières des trésors cachés, des voleurs et des meurtriers fugitifs, etc., Amsterdam 1693 ( $8^{\circ}$ Bibl. Uff. 421); La Sphère du monde, selon l'hypothèse de Copernic, démontrée et comparée au système de Copernic et de Tycho Brahe, Paris 1707 ( $8^{\circ}$ Bibl. Uff. 393); Eloge de Sébastien le Clerc, dessinateur et graveur du cabinet du roi. Paris 1715 ( $8^{\circ} \mathrm{Bibl}$. Uff. 529).

Eine Kurzbeschreibung des Kabinetts, siehe: http://curiositas.org/cabinet/curios1458 vom 30.10.2018.

193 Cod. Ms. Uffenbach 29/IV, S. 432-436, hier S. 432.

194 Cod. Ms. Uffenbach 29/IV, S. 436.

195 Chrétien-Francois I ${ }^{\text {er }}$ de Lamoignon (1644-1709);

Cod. Ms. Uffenbach 29/IV, S. 443-447. 
ihm vorlegte und mit vielen Worten lobte, als gewöhnlich und schlecht schien. ${ }^{196}$ Der Besuch bei dem Jesuiten Stephan Chamillard (1656-1730) in dem Kloster in der rue St. Antoine fiel für Uffenbach zu kurz aus, da er dessen Münz- und Medaillenkabinett und auch Antiken wegen ,einer leiche“ nicht in Ruhe studieren konnte. ${ }^{197}$

Am 24. September besuchte er die Kirche von St. Denis vor allem wegen der Ausstattung zu den Trauerfeierlickeiten zum Tod Ludwigs XIV. ${ }^{198}$ Die Kirche selbst beschreibt er als ,,irregulair, alt gotisch und schlecht“. ${ }^{199}$ Auch die Trauerausstattung sagte ihm nicht $\mathrm{zu}$, da sie nicht prächtig, künstlerisch und vor allem nicht wertvoll, sondern nur aus Stoff, Pappe und Papier war. Am 24. Oktober 1715 fuhr Uffenbach nochmals zur Kirche St. Denis, um das „,castrum doloris“ für den verstorbenen König Ludwig XIV. zu betrachten. ${ }^{200}$ Am Vortag hatten die Exequien für den König stattgefunden, allerdings war Johann Friedrich wegen der angekündigten Menschenfülle nicht hingegangen. Wieder beschreibt er die Ausstattung als „ein rechter bettel stath“201, da das ,zeug. so vielereley war, dann balt hingen ein stück schlecht tuch balt eines von flanell und dergleichen so schändlich vor ein koniglich begrabtnuß ehrenfalß aussahe.“202

Wie schon bei seinem Straßburger Aufenthalt beschäftigte sich Uffenbach nicht nur mit Besichtigungen der großen Sehenswürdigkeiten oder den Besuchen von Theatern, Opern und Konzerten, sondern suchte sich in Paris einen Lehrer, der sein Lautenspiel verbessern sollte. So besuchte ihn am 5. Oktober 1715 ,der berühmte lautenist Gallot“", mit dem er regelmäßigen Unterricht verabredete ${ }^{203}$ und dessen Instrumentensammlung er sich ansah. Hier beeindruckten ihn

196 Cod. Ms. Uffenbach 29/IV, S. 653-655.

Goutard lässt sich weiter nicht aufschlüsseln.

197 Pierre Chamillart (1664-1733);

Cod. Ms. Uffenbach 29/IV, S. 674-675.

Eine Kurzbeschreibung des Kabinetts, siehe:: https://curiositas.org/cabinet/curios1584 vom 30.10.2018.

198 Ludwig XIV. war am 1, September 1715 verstorben.

Cod. Ms. Uffenbach 29/IV, S. 141-150.

199 Cod. Ms. Uffenbach 29/IV, S. 141.

200 Cod. Ms. Uffenbach 29/IV, S. 214-217.

201 Cod. Ms. Uffenbach 29/IV, S. 215.

202 Cod. Ms. Uffenbach 29/IV, S. 215.

203 Cod. Ms. Uffenbach 29/IV, S. 180.

Es handelt sich bei Gallot um den Lautenspieler Gallot „le jeune“, der nach 1716 in Paris verstarb. Sein Vorname ist nicht bekannt. Er entstammte einer damals berühmten Pariser Lautenspieler-Familie; vgl. New Grove Bd. 19 (Tiomkin-Virdung), S. 131. 
besonders die beiden Lauten von den deutschen Instrumentenbauern Laux Maler (1485-1552) und Hans Frei (um 1450-1523). ${ }^{204}$

Wie auch in den zuvor besuchten Städten nahm er seine Gänge zu den verschiedenen Buchhändlern und Musikalienhändlern auf. ${ }^{205}$ So traf er am 25. Oktober den königlichen Flötenspieler Jacques-Martin Hotteterre „Le Romain“ (1674-1763), „Ordentlicher Kammermusiker des Königs“, der ihm auf verschiedenen Holzblasinstrumenten vorspielte. ${ }^{206}$ Uffenbach erwarb von ihm dessen 1713 in Paris herausgegebenen „Principes de la flûte traversière“. ${ }^{207}$ Auch bei dem „berühmten fluten macher rippert“208 wurde Uffenbach vorstellig, um zwei Flöten für seinen Bruder Wilhelm zu bestellen. ${ }^{209}$ Am 4. Januar 1716 suchte er die beiden erneut auf, um zum einen bei Rippert nach den bestellten „flutes traverses“ zu fragen, ${ }^{210}$ zum anderen kaufte er bei Hotteterre neue Musikalien und ersuchte ihn, ihm auf der Musette vorzuspielen. ${ }^{211}$

Die verschiedenen Buchhändler waren ständige Anlaufpunkte, wie diejenigen in der ,rue St jaques“, ,, au pont de notre dame“, ,,an der großen gallerie an dem louvre“ oder am ,gay des augustins, wo man einen alten bücher kram am anderen und schöne sachen umb billigen preiß aber mit nicht wenig mühe auszusuchen findet, denn an catalogues ist hier nicht zu dencken, ich traffe jedoch verschiedene alte gute bücher an, so vor billigen preiß erkauffte." 212 Auch suchte er die Drucker und Verleger Nicolas de Fer (1646-1720)213 und Gerard Scotin (1671-1716) auf, um bei de Fer den neuesten Stadtplan von Paris und von Scotin die aktuellen Ansichten von verschiedenen Pariser Gebäuden zu erwerben. ${ }^{214}$ Bei Scotin erwarb er eine Anzahl von Kupfern, die er bedauerlicherweise nicht näher

204 Cod. Ms. Uffenbach 29/IV, S. 180, 388-390.

205 Cod. Ms. Uffenbach 29/IV, S. 401 (Musikalienhändler Ballard).

206 Vgl. zu Hotteterre: House 1991, hier bes. S. 56-59, und Herzog 1999.

207 Cod. Ms. Uffenbach 29/IV, S. 221-223. Das Buch trägt die Signatur: $4^{\circ}$ Bibl. Uff. 26.

208 Jean Jacques Rippert (vor 1696-1716).

209 Cod. Ms. Uffenbach 29/IV, S. 493.

210 Cod. Ms. Uffenbach 29/IV, S. 575, 593-594 (17. Januar 1716); am 7. Februar 1716 konnte er die bestellten Traversflöten endlich abholen (Cod. Ms. Uffenbach 29/IV, S. 605).

211 Cod. Ms. Uffenbach 29/IV, S. 575-576.

Mit Musette ist eine Piccolooboe gemeint.

212 Cod. Ms. Uffenbach 29/IV, S. 82-83.

213 Nicolas de Fer war Kartograph und Verleger.

214 Cod. Ms. Uffenbach 29/IV, S. 83, 211, 391; vgl. die verschiedenen Ansichten in „Großes Kupfer-Volumen zu allen Theilen der Reisz Diariorum“ (Cod. Ms. Uffenbach 8, Bl. 91, 93-96).

Bei Nicolas de Fer erwarb er auch dessen 1708 herausgegebenen, aus 46 Illustrationen bestehenden Band: Les beautès de la France ( $2^{\circ}$ Bibl. Uff. 21$)$. 
charakterisiert. ${ }^{215}$ Bei der Witwe von Sébastien le Clerc (1637-1714) kaufte er „,seine heraus gegebene bücher, so alle sehr schön eingebunden.“216 Bei „laurent seneuse au gay des augustins, le fils“, kaufte er „etliche mathematische bücher.“217 Bei dem Buchhändler Charles Moette (1672-1754) ${ }^{218}$ „,der die meisten mathematischen sachen verleget“, fand Uffenbach „,verschiedenes so auf meiner liste von büchern notirt hatte." 219 Der Buchhändler Caillieau konnte ihm den gerade erschienenen ,traittè des ponts“ verkaufen. ${ }^{220}$

Pierre Jean Mariette (1694-1774) ,a la colonne d'hercule“, „den ich vor den besten zu meiner liebhaberey gefunden“, 221 suchte er einige Male auf und erwarb mehrfach Bücher bei ihm,222 und konnte dessen Sammlung an Druckgraphik einsehen: „dinstag, den 19 [Oktober 1715] [...] ginge also zu dem buchführer Mariette der mir unter anderen schönen wercken auch eine ganze complete collection von rembrands kupferstichen in einem fürtrefflichen band daran er über 40 jahr gesammelt und vielmahls aus 20 exemplaren das beste heraus gewehlt und hierzu destinirt, diese collection war wie leicht zu dencken incomparabel, und kunte ich mich daran nicht satt sehen, wie im gleichen an dem ganzen werck oder versammlung aller kupferstücken von callot so in 2 bänden medien fol sauber gebunden waren, das dem erstern an schönheit und fürtrefflichkeit nichts

215 Cod. Ms. Uffenbach 29/IV, S. 391.

216 Cod. Ms. Uffenbach 29/IV, S. 423.

217 Cod. Ms. Uffenbach 29/IV, S. 552-553; auch konnte er für seinen älteren Bruder, Zacharias Conrad dort einige Manuskripte preiswert kaufen (Cod. Ms. Uffenbach 29/IV, S. 557). Im Auftrag Geysels aus Nürnberg kaufte er verschiedene Bücher (Cod. Ms. Uffenbach 29/IV, S. 666-667).

218 S. über Charles Moette: http://data.bnf.fr/12497166/charles_moette/ vom 28.09.2016.

Vielleicht hat er u.a. folgende, bei Moette verlegte Bücher bei dieser Gelegenheit gekauft: Gabriel Philippe de LaHire, L' Ecole des Arpenteurs : ou l'on enseigne toutes les Pratiques de Geometrie, qui sont necessaires à un Arpenteur ; on y ajoûté un abregé du Nivellement, avec les proprietez des eaux, [et] les manieres de les jauger ou mesurer ..., Paris $1692\left(8^{\circ}\right.$ Bibl. Uff. 131); Mathurin Jousse, L’art de charpeterie, Paris 1702 (2 Bibl. Uff. 481)

219 Cod. Ms. Uffenbach 29/IV, S. 588.

220 Cod. Ms. Uffenbach 29/IV, S. 689. Das Buch befindet sich in der Bibliothek Uffenbach: Hubert Gautier, Traitè des ponts : ou il est parlè de ceux Romains et de ceux des modernes, ... des projets de ponts, des matériaux dont on les construit, Paris 1716 ( $8^{\circ}$ Bibl. Uff. 1$)$.

221 Cod. Ms. Uffenbach 29/IV, S. 232, 391.

Pierre Jean Mariette: Buchhändler, Herausgeber, Graphikhändler und Kunstwissenschaftler, vgl. Lugt 1956, Nrn. 1852, 2097, 2098.

Uffenbach besitzt verschiedene Werke, die bei Mariette erschienen waren.

222 Cod. Ms. Uffenbach 29/IV, S. 120-121, 259, 304-306.

Beispielsweise die Bücher: Traité des Pierres Gravées, Paris 1750 (2 Bibl. Uff. 498); Description sommaire des Desseins des Grands Maitres ... du Cabinet de Feu M. Crozat, Paris 1741 ( $8^{\circ}$ Bibl. Uff. 788); Veues des plus beaux Bastimens de France, Paris o.J. (2 ${ }^{\circ}$ Bibl. Uff. 27). Auf die letzt genannte Veröffentlichung, genauso wie auf le Fers ,Les beautès de la France“, weist er in seinem Tagebuch auch mehrere Male hin. 
nachgabe. Ohne dieße hatte er eben dergleichen ganze collectiones von paul veronese raphael urbino, le clerc und dergleichen mehr, zu welchen versammlung sein vater den anfang und dießer die vollendung gemacht, so daß ich wohl sagen kan, man sehe in dießer liebhaberey großer fürsten und königen cabineten und finde nicht was man hier bei einander siehet, wie vordem auch von anderen curiositäten so wohl als auch antiquitäten sprache, daß kein kabinett in europa dem seinigen an auserleßenheit bey kommen müste [...]."223 Allerdings konnte Johann Friedrich dem Sammler und Händler nichts abkaufen, da er ,ungemein theuer ist.“ 224 Er sah bei Mariette auch dessen ,großen geschriebenen catalogum von ganzen wercken derer berühmtesten kupferstecher", den er für seine wissenschaftlichen Interessen gerne kopiert hätte, ${ }^{225}$ was der Buchführer aber nicht zuließ.

Weitere Anlaufpunkte waren die verschiedenen Maler, die in Paris lebten und arbeiteten. Unter anderem ging Uffenbach am 23. November $1715 \mathrm{zu}$ dem Portraitmaler Francois de Troy (1645-1730), den er wegen seiner als ,inventiös angegeben und wohl gemacht" beschriebenen Bilder lobte. ${ }^{226}$ Danach war er bei Hyacinthe Rigaud (1659-1743), „dießem aller berühmtesten der hießigen mahler.“227 Uffenbach schreibt über diesen Aufenthalt: „er [Rigaud] selbsten ist ein mittelmäßiger man von alter und statur der ohnerachtet daß er schrecklich stottert, ungemein hochmüthig ist, und auch jederzeit besuch hat von leuten die ihm admiriren und wollen mahlen und arbeiten sehen, wie denn izo auch etliche franzoßen zu gegen waren die über jeden pinsul strich den er thate ein solch fates und abgeschmacktes lobens führten daß es mir vor üblichkeit aus dem magen stieße, ich konte mich ohnmöglich lang verweilen, deßwegen bekahme einen kaltsinnigen und genädigen abschied von dießem farben mazen." 228

Den Bildnismaler Nicolas Largillière (1656-1746) suchte er zwei Tage später, am 25. November, auf; über seinen Besuch schreibt er: „,ich ginge also von hier nach dem berühmten mahler largilliere, der ein schönes neues hauß bauen laßen, und darinnen gar bequehme und propre wohnung hat, er zeigte mir mit vieler hofflichkeit, eine menge von portraits so er gemacht, und darinnen er besonders

Cod. Ms. Uffenbach 29/IV, S. 304-305.

Cod. Ms. Uffenbach 29/IV, S. 305.

Vgl. das Kapitel 7 „Uffenbachs Schriften zur Druckgraphik.“

Cod. Ms. Uffenbach 29/IV, S. 331-333.

Cod. Ms. Uffenbach 29/IV, S. 333-334.

Hyacinthe Rigaud war zu Lebzeiten der berühmteste französische Portraitmaler. Von ihm stammt das große Staatsportrait von Ludwig XIV. von 1701.

Cod. Ms. Uffenbach 29/IV, S. 334. 
glücklich reussirt, [...] in welchen alle die hände als sein hauptwerck fürtrefflich schön waren, er läßet es sich aber auch wohl bezahlen auf den selbigen fuß wie oben von den anderen gemeldet, nehmlich 600 livres vor eins mit händen, und 200 vor die anderen. Seine mahlerey ist sonsten überaus fleißig ausgeführt, und gar wohl ausgesonnen, oder reich von inventionen, was die zeichnung aber betrifft, habe ich hier und da etliche schnize gesehen, die mir nicht gefallen."229

Bei seinem Besuch des Glasmalers und -machers Benoit Michu († 1730) kaufte er für seine Laterna magica etliche Gläser „,mit grotescken figuren.“230 Auch den Miniaturmaler „Arlan“ [sic], der eine große Gemäldesammlung besaß, suchte er auf. ${ }^{231}$ Als er die Bibliothek Mazarine besichtigte, ${ }^{232}$ konnte er im gleichen Gebäudekomplex den Historienmaler Jean Jouvenet (1644-1717) kennenlernen. ${ }^{233}$ Zudem wurde er bei dem Witwer der „berühmten poetin mahlerin und künstlerin cheron“ ${ }^{234}$, „Mons. la hay“, vorstellig, um deren eigenhändige Bilder und auch die Gemäldegalerie zu betrachten. ${ }^{235}$ Dabei stellte sich heraus, dass Jacques Le Hay ${ }^{236}$ gleichzeitig sowohl mit Antiquitäten als auch Bildern und Büchern handelte. Uffenbach erwarb bei ihm ein Buch von dessen Frau, Elisabeth Sophie Chéron. ${ }^{237}$ Uffenbach besuchte ebenfalls den Maler und Händler mit alter Kunst „,mons. Tiffeine“.238 In der „rue des gesores“ kaufte er bei einem „gibs gießer oder bilder macher“ zwei bronzierte Gipse. ${ }^{239}$ Bei dem königlichen Zeichner und Ornamentstecher Jean Bérain (1678-1726), der sich gegenüber seinem Besucher „gar groß und vornehm“ verhielt, wollte Uffenbach für seine Interessen an der Architektur dessen gestochene Ornamentvorlagen erwerben, die ihm aber insgesamt zu teuer waren, da Bérain sein Werk in kleinere Bücher eingeteilt hatte, die lediglich aus vier Blättern bestanden. ${ }^{240}$

Cod. Ms. Uffenbach 29/IV, S. 345.

Cod. Ms. Uffenbach 29/IV, S. 511-512, hier 511.

Jacques Antoine Arlaud (1668-1743/46); Cod. Ms. Uffenbach 29/IV, S. 522-523.

S.o. zu den Besuchen der Pariser Bibliotheken.

Cod. Ms. Uffenbach 29/IV, S. 534.

Elisabeth Sophie Chéron (1648-1711).

Cod. Ms. Uffenbach 29/IV, S. 541-545.

Lebensdaten unbekannt.

Bei dem Buch handelt es sich um: Essays de Pseaumes et Cantiques mis en vers et enrichis de figures, Paris 1694 ( $8^{\circ}$ Bibl. Uff. 551).

Cod. Ms. Uffenbach 29/IV, S. 656-659.

Cod. Ms. Uffenbach 29/IV, S. 667.

Cod. Ms. Uffenbach 29/IV, S. 610-611.

Uffenbach besitzt von Bérain ein 4 Blätter umfassendes Heft mit Ornamententwürfen, in: $2^{\circ}$ Bibl. Uff. 417 (12).
} 
Bei einer „berühmten künstlerin im trehen, einer meisters tochter, nahmens moubois“ 241 wollte Uffenbach für sein Interesse am Drechseln neue Drehbänke und auch Drechslertechniken studieren und erproben. Nachdem er ihre „ungemein zart und propre“ hergestellten elfenbeinernen und hölzernen Gegenstände und auch ihre Maschinen gesehen hatte, musste er aber feststellen, dass er sowohl die Techniken als auch die Art der Drehbänke schon kannte. ${ }^{242}$

Auch hier in Paris besuchte er wieder die verschiedenen Manufakturen, um sich die neuesten Techniken zeigen zu lassen. Am 24. Oktober fuhr er in die berühmte königliche Teppichmanufaktur ${ }^{243}$ und in eine Glasbläserei, die er aber wegen der schlechten Qualität der Produkte enttäuscht wieder verließ.244 Auch stattete er der berühmten Gobelinmanufaktur einen Besuch ab, wobei er sich die Herstellung der Gobelins genau erklären ließ.245 Am selben Tag, dem 7. Dezember 1715, ging er noch in die nebenan liegende „laccir fabrique“ für Leder und Stoffe. ${ }^{246}$ Der Besuch bei einem Vergolder bereitete ihm dagegen wenig Vergnügen, da er dessen Kenntnisse für seine eigenen handwerklichen Arbeiten nutzen wollte, der Mann aber seine Arbeitsgeheimnisse nicht preisgab. 247

Wie schon in Rom suchte er gute Instrumente zum Zeichnen und für die Astronomie. Am 19. Oktober 1715 ging er $\mathrm{zu}$ dem Ingenieur und Instrumentenmacher Pierre Daimant Le Maire ${ }^{248}$ und ließ sich von ihm dessen „wohl gemachte mathematische gestecke von silber und meßing“ zeigen, die Uffenbach mit seiner eigenen Sammlung an Zirkeln, Reißfedern etc. verglich. Le Mairs Preise waren ihm aber zu hoch, bis auf einen ,ganz kleinen silbernen zirckel“" und einen „transporteur von dünnen horn“, das heißt einen Winkelmesser, erwarb er nichts. ${ }^{249}$ Bei einem zweiten Besuch bei Le Mair traf Uffenbach den von ihm geschätzten Mathematiker Jacques Ozanam (1640-1718), von dem er

241 Uffenbach meint hier die Tochter von dem Kunstdrechsler Jean Maubois (Lebensdaten unbekannt).

242 Cod. Ms. Uffenbach 29/IV, S. 648-649.

243 Cod. Ms. Uffenbach 29/IV, S. 217-219.

244 Cod. Ms. Uffenbach 29/IV, S. 219-220.

245 Cod. Ms. Uffenbach 29/IV, S. 416-421.

246 Cod. Ms. Uffenbach 29/IV, S. 421-423.

247 Cod. Ms. Uffenbach 29/IV, S. 579-580.

248 Es handelt sich dabei um den Pariser Mathematiker und Ingenieur Pierre Daimant Le Maire (1672-1750)); vgl. die gedruckte Adresse im Pariser Tagebuch (Cod. Ms. Uffenbach 29/IV, S. 590).

249 Cod. Ms. Uffenbach 29/IV, S. 312-313, 370, 573; vgl. Meyerhöfer 1995, S. 117, 128 Nr. 34n, S. 130, Nr. 36k. 
aber wegen dessen Aufschneiderei und Liederlichkeit enttäuscht war. ${ }^{250}$ Bei weiteren Besuchen dort kaufte er sich ,einen [weiteren] transporteur von horn durchsichtig gemacht, als welche zu den operstionen gar bequehm sind, weil man alle linien dadurch sehen kann auf dem papier" und ein Lineal. ${ }^{251}$

Auch besuchte er den Mathematiker Jean Pigeon d'Osangis (1654-1739), 252 um dessen ,gar künstlich und sonderbahr gemachte machine, ein systeme copernis mouvant, zu sehen." ${ }^{253}$ Uffenbach kaufte sich sogleich die von Pigeon 1714 herausgegebene Beschreibung und einen Kupferstich von dem kopernikanischen Planetensystem. ${ }^{254}$ Von dem ,mathematischen instrumenten macher butterfield au gay de l'orloge" war er dagegen sehr enttäuscht. Alles, was er bei Michael Butterfield (1635-1724), diesem ,alten, murrischen und verdrießlichen engelländer", sehen konnte, genügte seinem Qualitätsanspruch nicht, auch konnte Uffenbach bei ihm keine seiner Schriften erwerben. ${ }^{255}$ Ähnlich erging es ihm bei dem Sohn des Uhrmachers René Grillet ${ }^{256}$, der sich Bidon nannte. ${ }^{257}$ Dieser hatte „bey weitem seines vattern wißenschaft nicht.“ Auch erwarb Uffenbach keine gedruckten Schriften oder Instrumente von Grillet. ${ }^{258}$ Dagegen kaufte er bei dem Instrumentenmacher Chapetot ${ }^{259}$, „,der ein feiner höfflicher alter man war“, zum einen eine Nivellierwaage, ${ }^{260}$ zum anderen einen Winkelmesser ${ }^{261}$ und ließ sich von

Cod. Ms. Uffenbach 29/IV, S. 587-588.

Von Ozanam besitzt Uffenbach: L’Usage du Compas de Proportion, Den Haag 1691 ( $8^{\circ}$ Bibl. Uff. 186); Traité de Fortification, Den Haag 1694 ( $8^{\circ}$ Bibl. Uff. 29); Cour de Mathematique, 5 Bde., Paris 1697 ( $8^{\circ}$ Bibl. Uff. 24-28); Recreations mathematiques et physiques, 2 Bde., Amsterdam 1698 ( $8^{\circ}$ Bibl. Uff. $22+23$ ); Methode facile pour arpenter ou meurer toutes sortes de superficies, Paris 1699 ( $8^{\circ}$ Bibl. Uff. 163); Usage de l'instrument universel, Paris 1700 ( $8^{\circ}$ Bibl. Uff. 194).

Nach dem Tod von Ozanam erschienen noch: La perspective theorique et pratique, Paris 1720 ( $8^{\circ}$ Bibl. Uff. 916); Methode de lever les plans et les cartes de terre et de mer, Paris 1750 ( $8^{\circ}$ Bibl. Uff. 725).

251 Cod. Ms. Uffenbach 29/IV, S. 638.

252 Cod. Ms. Uffenbach 29/IV, S. 603-604, 646-647.

253 Cod. Ms. Uffenbach 29/IV; S. 524-526, hier S. 524.

254 Jean Pigeon, Description d'une sphere mouvante par le moyen d'une pendule, d'un Globe monté d'une façon particuliere, [et] d'un nouveau Planisphere pour les distances [et] grosseurs des Planetes / Le tout selon l'hypothese de Copernic. Expliquée [et] démonstrée par ..., Paris 1714 ( $8^{\circ}$ Bibl. Uff. 38). Der Kupferstich befindet sich zum Tagebuchtext angebunden.

255 Cod. Ms. Uffenbach 29/IV, S. 584-585.

256 Lebensdaten unbekannt.

257 René Grillet, Curiosités mathemathiques de l'invention, Paris 1673 (4º Bibl. Uff. 300).

258 Cod. Ms. Uffenbach 29/IV, S. 585-587.

Vgl. zu René Grillet: http://history-computer.com/People/GrilletBio.html vom 11.12.2018. 
ihm die Geräte zeigen und erklären, die dieser nach Ozanam und anderen gebaut hatte. ${ }^{262}$ Ein „,sehr großes und schönes polyhedrum“ erwarb er bei „Mons. faugerais, a la fleur de lys couronné“.263 Desweiteren kaufte er gegen Ende seines Aufenthaltes bei einem Kupferstichhändler ,einen conischen spiegel mit denen gehörigen figuren dazu. “264

Anfang April 1716 begann Uffenbach seine Sachen zu packen, um wieder in seine Heimatstadt zurückzukehren. ${ }^{265}$ Am 8. April belud er seine „kasten“ und brachte sie zum Zoll und auch zur Spedition. ${ }^{266}$ Nachdem er an den nächsten Tagen sich von seinen verschiedenen Bekannten verabschiedet hatte und seine Koffer für die Fahrt bereit waren, verließ er am 11. April Paris in Richtung Brüssel. ${ }^{267}$ Über Antwerpen, Löwen, Maastricht und Köln kehrte er am 29. Mai 1716 nach Frankfurt am Main zurück.

\subsection{Privates und öffentliches Leben in Frankfurt am Main}

Nach Beendigung seiner Grand Tour im Mai 1716 richtete sich Uffenbach wieder in seinem Haus am Großen Kornmarkt Nr. 13 ein. Ein öffentliches Amt oder andere Verpflichtungen, die ihn von seiner ,über alles hochgeschätzte[n] ruhe, und ungebundenheit"“268 abgehalten hätten, übernahm er nicht, ehe er 1744 nach dem Tod seines Vetters Nikolaus von Uffenbach (1682-1744), in den Rat der Stadt gewählt werden konnte. ${ }^{269}$

Seine Bibliothek, besonders aber die wissenschaftliche Instrumenten- und Kunstsammlung, waren durch die Ankäufe auf den langjährigen Fahrten um viele Stücke vermehrt worden. Ein weitere Vergrößerung der Bibliothek hatte schon

Cod. Ms. Uffenbach 29/IV, S. 688. Vgl. Inventar der wissenschaftlichen Geräte Nr. 10; Meyerhöfer 1996, S. 125, Nr. 10; s. Anhang, S. 370.

Cod. Ms. Uffenbach 29/IV, S. 622-623, 634-636, 688.

Cod. Ms. Uffenbach 29/IV, S. 557-668, hier 668. Wahrscheinlich handelt es sich dabei um eines der Polyeder, die im Inventar der wissenschaftlichen Geräte unter den Nummern 159 und 160 geführt werden; s. Anhang, S. 396.

Cod. Ms. Uffenbach 29/IV, S. 686. Wahrscheinlich einer der beiden im Inventar der wissenschaftlichen Geräte, die unter den Nummern 142 und 143 geführt sind; s. Anhang, S. 400.

Cod. Ms. Uffenbach 29/IV, S. 676.

Cod. Ms. Uffenbach 29/IV, S. 687.

Cod. Ms. Uffenbach 29/IV, S. 691-692.

Zitiert nach Arnim 1928,3, S. 29. Der Brief Uffenbachs vom 9. Juni 1736 befindet sich nicht in den Akten des Universitätsarchivs Göttingen, die von der Donation handeln (Signatur: Kur. 4 V d6/2).

Vgl. Kapitel 5 „Geschichte der Schenkung nach Göttingen.“ 
1715 in seiner Abwesenheit stattgefunden, als sein älterer Bruder wegen eigener Raumnot ihm die Abteilungen zur Mathematik und Physik überließ, die für Zacharias Conrad nicht den Stellenwert hatten wie die historischen Werke. ${ }^{270}$ Johann Friedrich legte zum Handgebrauch für seine Sammlungen ein „Kurtzes Verzeichnüs derer Mathematischer Physicalischer und Kupfer-Bücher wie auch des Vorraths einiger hiezu gehöriger Instrumenten mein Johann Friedrich von Uffenbach“ an (Abb. 3), das er bis kurz vor seinem Tod im Jahr 1769 vervollständigte. ${ }^{271}$ 1965,2 .

271 Dieses Verzeichnis gehörte nicht zur Göttingen Donation. Es befindet sich heute in der StUb Frankfurt am Main unter der Signatur: Ms. Ff. J. F. v. UFFENBACH 1 und ist das einzige Manuskript von Uffenbach, das diese Bibliothek besitzt. Aus diesem Exemplar wurden von verschiedenen Schreibern der 1736 nach Göttingen versandte Katalog in grünem goldgepresstem Einband (= Cod. Ms. Uffenbach 47), das erste Supplement vom 15. Oktober 1736 (= Cod. Ms. Bibl. Arch. A. 34c/2) und die zweite Ergänzung vom 12. Oktober 1763 (= Cod. Ms. Bibl. Arch. A 34c) abgeschrieben. Alle drei Manuskripte befinden sich in der Abteilung Spezialsammlungen und Bestandserhaltung der SUB Göttingen, der dazu gehörige Schriftverkehr kann eingesehen werden im Universitätsarchiv Göttingen unter der Signatur: Kur. 4 V d6/2. 


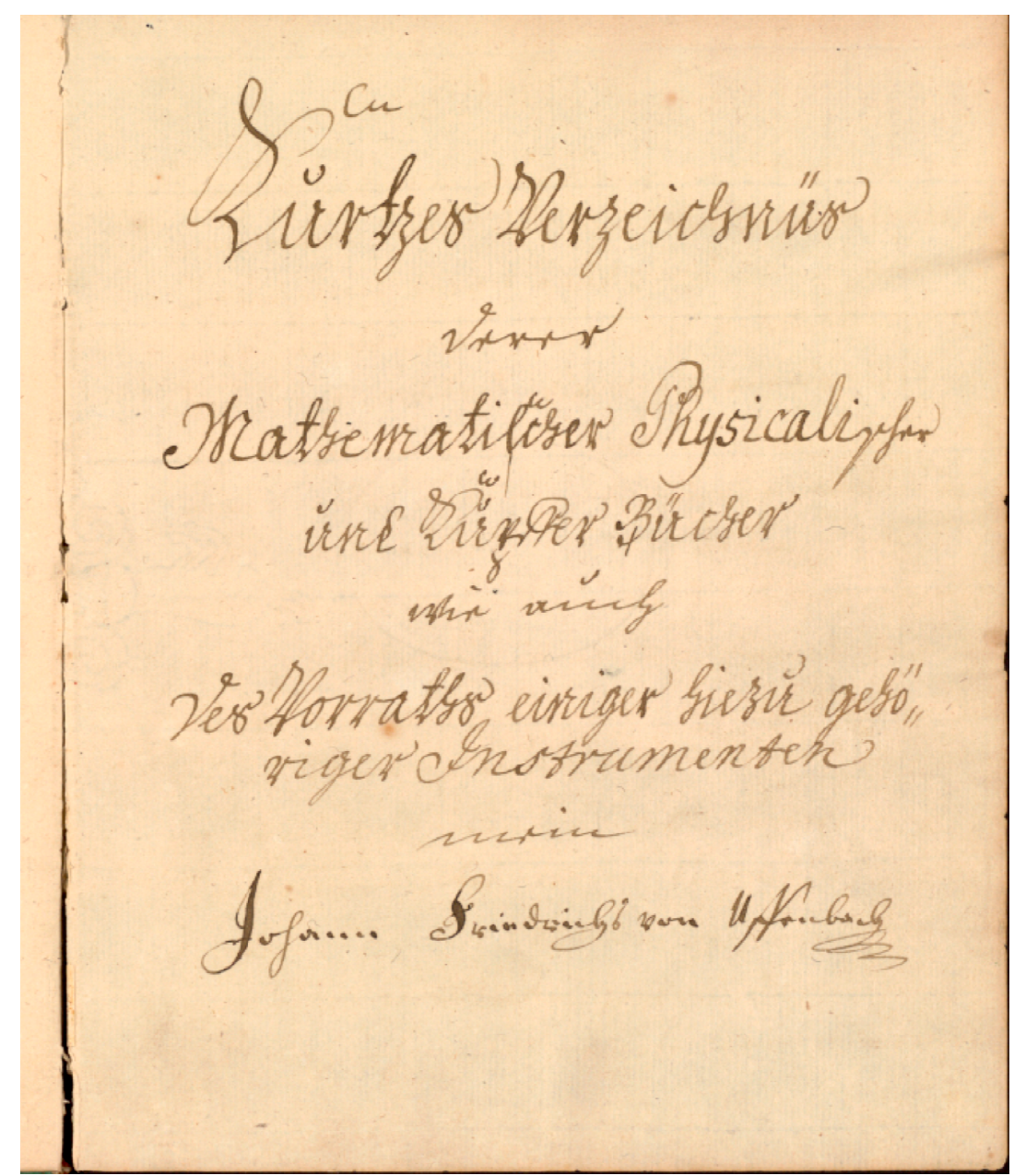

Abb. 3 Titelblatt von Johann Friedrich von Uffenbach „Kurtzes Verzeichnüs derer Mathemathischer Physicalischer und Kupfer-Bücher, in: Cod Ms. Uffenbach 47

Im Jahr seiner Eheschließung mit Anna Elisabeth Lehnemann, 1717, trat Uffenbach, der schon während seiner Studienzeit als ein großer Musikliebhaber und -förderer aufgefallen war, ${ }^{272}$ als „Stifter und Erhalter dem grossen Collegii Musici“" in Frankfurt am Main bei, wie der Komponist Georg Philipp Telemann (1681-1767) in einem Brief vom 7. Februar 1718 vermerkt. ${ }^{273}$ Telemann selbst war einer der Gründer des Collegium Musicum, das sich stets im Hause Frauenstein, der Patriziergesellschaft Uffenbachs, getroffen hat. ${ }^{274}$

272 In seiner Straßburger Studentenzeit hatte er schon einen kleinen privaten Musikzirkel aufgebaut, in dem man sich jede Woche traf, um zu musizieren.

273 Der Namen ist in einer Brief wiedergegebenen Liste aufgeführt.

Zum „Collegium Musicum“ s. ausführlich Israel 1876, hier bes. S. 13 + 14. Cahn gab 1986 einen reprographischen Nachdruck von Israels Schrift heraus.

274 Telemann war in seiner Frankfurter Zeit gleichzeitig der Verwalter der Patriziergesellschaft Frauenstein, vgl. http://www.stadtgeschichte-ffm.de/artikel/telemann.html vom 08.07.2016. 
Von Ende Juni bis Mitte August 1718 unternahm Uffenbach mit einer zwölfköpfigen Reisegesellschaft, der auch seine beiden Brüder und seine Schwester angehörten, eine kleinere Fahrt durch die Niederlande. ${ }^{275}$ Über Düsseldorf, Kaiserswerth, Duisburg, Wesel, Emmerich, Arnheim und Zutphen traf die Gruppe nach einer sechstägigen Anreise am 5. Juli 1718 in Utrecht ein, wo man drei Tage verweilte und sich neben der Stadt mit dem Dom und der Universität auch Fabrikationsstätten z.B. für Stärke, Seide und Fingerhüte ansah.

Von Utrecht aus erreichte die Gesellschaft am 8. Juli Amsterdam, eines der Hauptreiseziele. Dort nahm man bis zum 20. Juli Quartier und besah sich die Sehenswürdigkeiten, wie z.B. das Stadthaus, die verschiedenen Kirchen und Synagogen, sowie die Armen-, Waisen- und Tollhäuser. Daneben kehrte man aber auch bei Handwerkern ein, wie beispielsweise einem Bearbeiter von Schildpatt und einem Kattundrucker, ${ }^{276}$ und besuchte verschiedene Privatsammler. Über Haarlem ging es mit einer dreitägigen Unterbrechung in der Universitätsstadt Leyden, in der die Gruppe die Universitätsbibliothek, das Observatorium und die Anatomie, betrachtete, weiter nach Den Haag. Auch hier besichtigten sie einige Sehenswürdigkeiten, so etwa das Haus des Prinzen Maurits, den Hof der Generalstaaten und die Grote Kerk.

Über Delft, Rotterdam und Breda reiste die Gruppe anschließend in die Südlichen Niederlande. Ab dem 1. August hielt sie sich dann für fünf Tage in Antwerpen auf. Neben dem Stadthaus, der Groten Kerk mit den Rubensaltären, ${ }^{277}$ dem Beginenhof mit seinen 230 Bewohnerinnen und der Druckerei Plantin galt ihre Aufmerksamkeit dem Jesuitenkolleg mit der am 18. Juli des Jahres abgebrannten Jesuitenkirche: ,[...] Die Jesuiter Kirch ist sonst die Principalste und kostbahrste nicht allein dießer Stadt sondern auch im gantzen Landt gewesen, in dem alle pilaren darinnen mit dem schönsten marmor biß oben bekleidet geweßen. Da aber durch ein den 18. Juli dießes Jahr [= 1718] entstandenes Donnerwetter undt starckes Blitzen die Kirche biß auf das äußerliche gantz in die Aschen gelegt, undt zugleich die darinn geweßene treffliche Gemählde von Rubens verlohren gangen, ware weiter nichts mehr als das kostbare frontispicium so von der alten Herrligkeit ein Zeug ist."278 In Antwerpen suchte die Gesellschaft erneut Fabrikationsstätten auf, wie z.B. eine Schuhfabrik für goldene und silberne Pantoffeln.

Cod. Ms. Uffenbach 46; s.a. Schmidt 1969, Molen 1994, besonders Molen 2017.

Kattundrucker sind Handwerker, die Baumwollgewebe farbig bedrucken.

Es handelt sich um die Onze-Liewe-Vrouwe-Kathedrale mit den drei Rubens-Altären.

Cod. Ms. Uffenbach 46, S. 194-195. 
Am 5. August ging es über Mecheln mit seinem Beginenhof, der Jesuitenkirche und dem Erzbischöflichen Hof weiter nach Brüssel, wo man sich für drei Tage einquartierte. Brüssel bot mit dem Stadthaus, den Zunfthäusern, dem Schloss, der Groten Kerk ${ }^{279}$ und der Jesuitenkirche ein reichhaltiges architektonisches Spektrum. Für die beiden älteren Brüder Uffenbach eröffnete sich mit dem großen Angebot an Buchhandlungen wieder einmal die Möglichkeit, einen Tag ihres Brüsseler Aufenthalts diesen zu widmen und einzukaufen. Am 9. August fuhr die Reisegruppe über Tirlemont, St. Trond, Oreye für zwei Tage nach Lüttich. Dort besuchte man wieder die Sehenswürdigkeiten, wie die verschiedenen Kirchen, den Bischöflichen Palast und das Rathaus. Am 12. August begab sich die Gesellschaft nach Viset, um sich mit der Fähre über die Maas setzen zu lassen. Für drei Tage weilten sie in Burscheid, um dort in den heißen Quellen zu baden. Von der Kaiserstadt Aachen aus, wo sie dem Dom und den dort aufbewahrten Reliquien einen Besuch abstatteten, ging es am 15. August weiter nach Köln. Für zwei Tage sahen sie sich die großen Kirchen an. Von hier aus ging es zurück nach Frankfurt am Main.

Nach dieser kürzeren Reise durch beide Niederlande widmete sich Uffenbach in seinen „müßigen Nebenstunden“ der Niederschrift des Singspiels „Der von Londinen geliebte und ungeliebte Pharasmanes, König von Iberien“, das er 1720 mit eigenen Zeichnungen der Prospekte fertiggestellt hatte (Abb. 8 und 9), ${ }^{280}$ und der Herausgabe seines 1726 erschienenen Buches „Poetischer Versuch, worinnen die Nachfolge Christi in Betrachtung seiner heilsamen Lehre und heiligen Lebens durch Sinn-Bilder erkläret und zu einem Harmonischen Kirchen-Jahrgange nach

$279=$ Gemeint ist die Sint-Michielskathedraal.

280 Cod. Ms. Uffenbach 18, Arnim 1930,1 und Arnim 1930,2.

Es handelt sich bei diesem deutschen Operntext um eine dramatische Bearbeitung der etwas veränderten „Geschichte der Schlontina und des Pharasmanes“ nach dem Roman „Die Römische Octavia“ des Herzog Anton Ulrich von Braunschweig-Lüneburg (1633-1714). Die Oper sollte am Braunschweiger Hof aufgeführt werden. Für die Komposition sollte der dortige Kapellmeister Georg Capar Schürmann (1672-1751) verantwortlich zeichnen. Ob es zu einer Aufführung dieser Oper kam, geht aus den erhaltenen Briefen Schürmanns nicht hervor (s. Cod. Ms. Uffenbach 20 II, p. 476-479, 603-614). Die Transkription der Briefe in: Schmidt 1933, Bd. I, S. 65-66, 91-99 und 158-159; dort ordnet Schmidt die eventuelle Aufführung der Oper zeitlich in das Jahr 1729 ein; Bd. II, S. 16-18.

Am 23. Januar 1732 führt Uffenbach den Text mit den Zeichnungen der Gesellschaft mit den Worten vor: ,[...] Nechst dießem zeigte bey Gelegenheit unserer / alhier befindlichen italienischen Opera meine vor / Zeiten gemachte Opera Pharasmanes betittult / worin nebst der Poesie auch alle Scenen sehr / mühesam nach dem Alter und der gehorigen / Bauart derer orientalischen Völcker, wie auch ihrer / damahligen Kleidung und Sitten, gemahlet und / entworfen hatte, welches ehedeßen eine Arbeit / vor den braunschweig luneburgischen Hof, und das / aldorten befindliche Theatrum geweßen. Woran / mehr Fleiß, als ein Vorwurff dießer Art verdie- / net, gewendet hatte. [...]“ (Vgl. Cod. Ms. Uffenbach 14/IV, S. 489). 
Anleitung aller Sonn- und Festtäglichen Evangelien entworffen wird“, das er mit einer Widmung an den Herzog August Wilhelm (1662-1731) und die Herzogin Elisabeth Sophie Marie (1683-1767) von Braunschweig-Lüneburg versah. Sämtliche 73 Radierungen des Bandes waren von Uffenbach entworfen und gestochen worden (Abb. 4-7).281

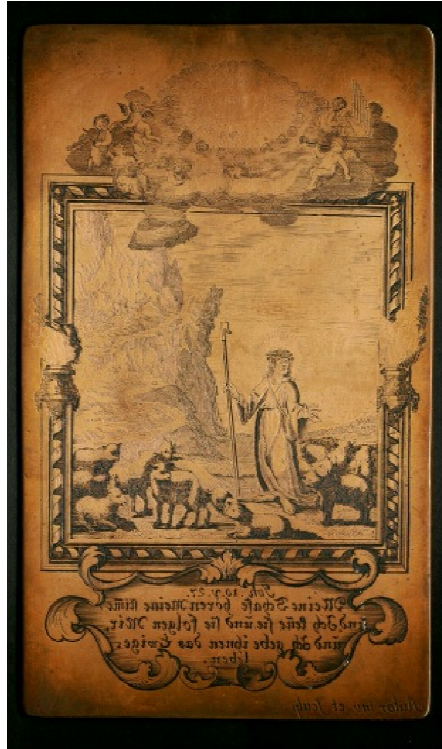

Abb. 4 Uffenbachs Titelkupfer zu „Poetischer Versuch, worinnen die Nachfolge Christi in Betrachtung seiner heilsamen Lehre und heiligen Lebens durch Sinn-Bilder erkläret"“

Kunstsammlung der Universität Göttingen Inv. Nr. DP 5

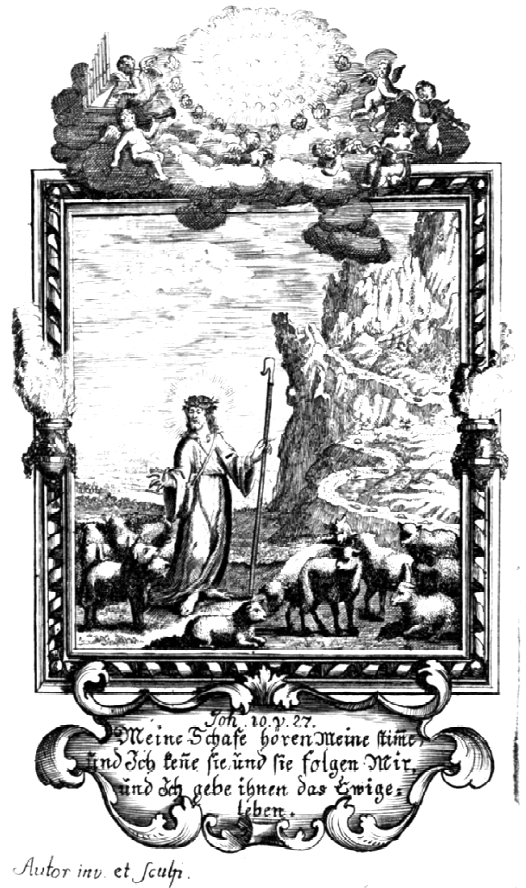

Abb. 5 Frontispiz zu ,Poetischer Versuch, worinnen die Nachfolge Christi in Betrachtung seiner heilsamen Lehre und heiligen Lebens durch Sinn-Bilder erkläret"“ 


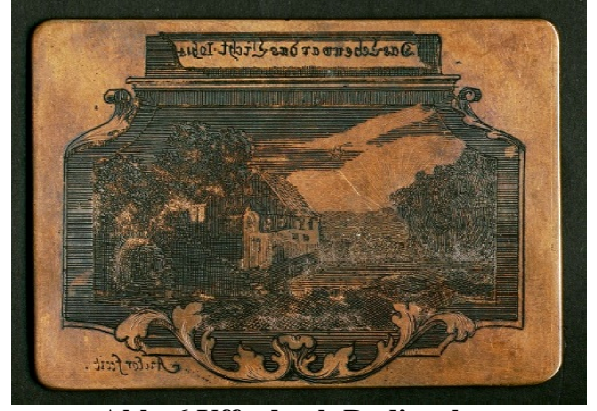

Abb. 6 Uffenbach Radierplatte zu „Poetischer Versuch, worinnen die Nachfolge Christi in Betrachtung seiner heilsamen Lehre und heiligen Lebens durch Sinn-Bilder erkläret" ${ }^{\text {“ }}$ Kunstsammlung der Universität Göttingen Inv. Nr. DP 45

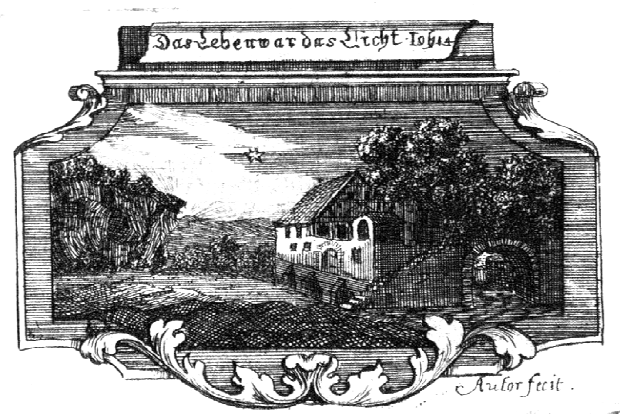

Abb. 7 Titelkupfer zum ,I. AdventsSonntag“, in: ,Poetischer Versuch, worinnen die Nachfolge Christi in Betrachtung seiner heilsamen Lehre und heiligen Lebens durch Sinn-Bilder erkläret"“

Zwei Jahre später, von Juli bis August 1728, unternahm er eine Fahrt durch „die Hessischen in die Braunschweig-Lüneburgischen Lande“,282 um am musikliebenden Braunschweiger Hof den Hofkapellmeister Georg Caspar Schürmann (1672/73-1751) aufzusuchen, mit dem er zuvor schon einen längeren Briefwechsel gepflegt hatte. ${ }^{283}$ Uffenbach wollte persönlich die Vertonung und die Aufführung seines Singspiels „Pharasmanes“ durch Schürmann vorantreiben.

283 Vgl. die Briefe Schürmanns in: Cod. Ms. Uffenbach 20/II, B1. 476-479 (2 Briefe) und 603614 (9 Briefe) und Nagel 1911,1, bei dem die Briefe teiltranskribiert sind. 


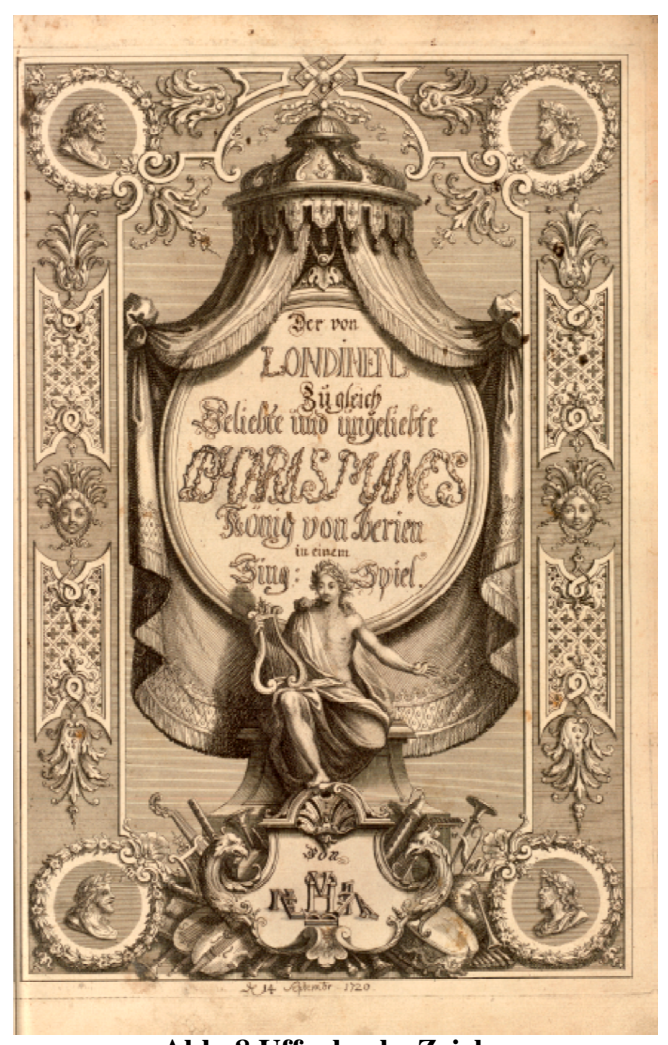

Abb. 8 Uffenbachs Zeichnung für das Titelblatt seines Singspiels „Pharasmanes“"

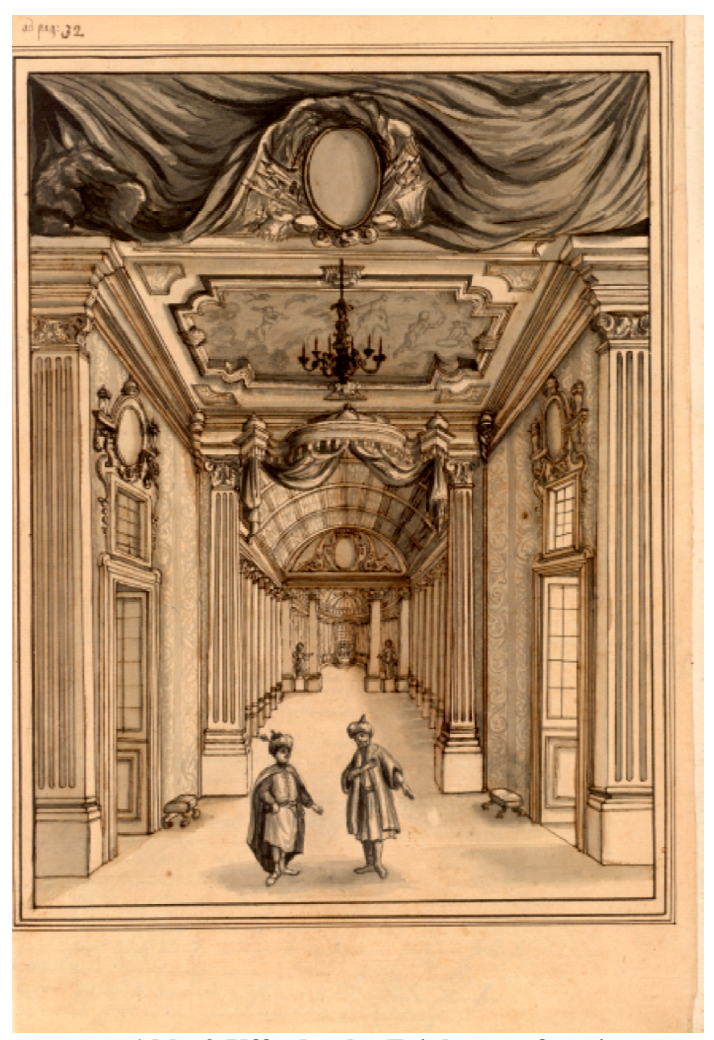

Abb. 9 Uffenbachs Zeichnung für eine
Szene in dem Singspiel ,Pharasmanes“
In Cod. Ms. Uffenbach 18 zu S. 32

in: Cod. Ms. Uffenbach 18

Er nutzte diese Fahrt aber auch, um Bekannte in Kassel aufzusuchen, die er schon 1710 bei einer Reise mit seinem älteren Bruder kennengelernt hatte. Auch besuchte er die Sehenswürdigkeiten von Braunschweig, Salzdahlum ${ }^{284}$ und Hannover. Wieder waren es nicht nur Architektur, Gärten oder Sammlungen und Kabinette, die ihn interessierten, sondern er besuchte ebenfalls wie auf allen Fahrten die zahlreichen Manufakturen und Kunsthandwerker.

Bereits 1725 hatte er zusammen mit fünf anderen Frankfurter Bürgern eine „Wissenschaftliche Gesellschaft zur Pflege von Natur und Kunst“ gegründet. Eines der Ziele dieser Gesellschaft war es, Erfindungen anderer für die Allgemeinheit zu verbessern und Möglichkeiten zu suchen, diese nutzbringend anzuwenden. 285

Vgl. zu Salzdahlum um 1710: Querfurt 1710.

285 Cod. Ms. Uffenbach 13 I-V, vgl. das Kapitel 8 „Die wissenschaftliche Gesellschaft.“

Bei dem Treffen der Gesellschaft am 23. Januar 1732 zeigte er u.a. sein von ihm verfasstes Opernmanuskript „Pharasmanes“. Er schreibt dazu in den Protokollen: „Nechst dießem zeigte bey Gelegenheit unserer alhier befindlichen italienischen Opera meine vor Zeiten gemachte Opera Pharasmanes betittult worin nebst der Poesie auch alle Scenen sehr mühesam nach dem Alter und der gehorigen Bauart derer orientalischen Völcker, wie auch 
Eine weitere Fahrt, von der sich ein ausführliches Tagebuch erhalten hat, ist seine neuntägige Reise durch die Pfalz im Jahre 1731.286 Er legte anscheinend Wert darauf, nicht als Frankfurter Patrizier erkannt zu werden. Folglich fuhr er ohne seinen Diener und nicht mit eigener Kutsche sondern in einem Postwagen, am 4. September ,unerkant morgends frühe wie ein Handwerkspursch in meiner Wanderschafft" von Frankfurt ab,287 um bei dem Mannheimer Hofschreiner und „Schildkrottarbeiter“ Franz Zeller ${ }^{288}$ seine eigene Verarbeitungstechnik des Schildpatts zu vervollkommnen.289 Uffenbachs Route verlief über Darmstadt, Bensheim und Weinheim nach Mannheim, wo er am nächsten Morgen eintraf.

Nachdem er erfolglos versucht hatte, durch einen Bekannten Zeller zu treffen, begann er mit seinem üblichen ,,architektonischen Rundgang“ durch die Stadt. Besondere Beachtung fanden dabei der auf Quadraten aufgebaute Grundriß der Stadt mit den zweistöckigen Gebäuden und das im Bau befindliche Schloss, welches er ausführlich beschreibt. Erst am nächsten Tag gelang es ihm Franz Zeller aufsuchen, der als Hofschreiner im Schloss arbeitete. Dieser bat ihn wegen Zeitmangel am Nachmittag wiederzukommen. Uffenbach fand dadurch die Möglichkeit, ausgiebig das Innere des Schlosses zu betrachten und das Neue aufzuzeichnen, wie beispielsweise den Verschluss der großen Fensterflügel oder die Dachkonstruktion des Mittelbaues. ${ }^{290}$ Am späten Nachmittag traf er dann in der Schreinerei Franz Zeller an, der ihn in seine Geheimnisse der Schildpattverarbeitung einweihte. Uffenbach musste ihm versprechen, dass er diese Handwerksgeheimnisse für sich behielt, was er so ernst nahm, dass er die

ihrer damahligen Kleidung und Sitten, gemahlet und entworfen hatte, welches ehedeßen eine Arbeit vor den braunschweig luneburgischen Hof, und das aldorten befindliche Theatrum geweßen. Woran mehr Fleiß, als ein Vorwurff dießer Art verdienet, gewendet hatte." (Cod. Ms. Uffenbach 13/IV, S. 489).

286 Cod. Ms. Uffenbach 33, s.a. Arnim 1928,2.

Im Folgenden soll die Reiseroute und die Sehenswürdigkeiten, die Uffenbach betrachtet hatte, geschildert werden, da anhand dieser kurzen Fahrt ein sehr guter Einblick in die Interessensgebiete des Frankfurters gegeben werden kann.

287 Cod. Ms. Uffenbach 33, S. 189.

288 U. a. schuf der pfälzische Hofschreiner Franz Zeller (Lebensdaten unbekannt) die Parkettböden im Schloss von Mannheim und für das Appartement der Kurfürstin Elisabeth Augusta (1721-1794) in Schloß Schwetzingen.

289 Vgl. Cod. Ms. Uffenbach 13/IV, S. 439-446, wo der Besuch bei Zeller ausführlich geschildert wird. Dieser Teil fehlt in Cod. Ms. Uffenbach 33.

Zu Franz Zeller vgl. Arnim 1928,2, S. 44, Anm.12.

290 Zu den Fensterflügeln: Cod. Ms. Uffenbach 33, S. 205-206 mit Zeichnung; zu der Dachkonstruktion: Cod. Ms. Uffenbach 33, S. 208-209; vgl. Arnim 1928,2, S. 16-19. 
Verarbeitungsmethoden nicht in sein ausgearbeitetes Tagebuch aufnahm, sondern auf einem separaten Papier notierte. ${ }^{291}$

Nachdem er in Mannheim alles erreicht hatte, weswegen er sich auf die Reise gemacht hatte, nahm er am nächsten Tag eine Postkutsche nach Heidelberg, wo er den Uhrmacher Johann Wille aufsuchte, ${ }^{292}$ um dessen Maschinen und Uhren zu sehen und ausführlich in seinem Tagebuch zu beschreiben. ${ }^{293}$ Gemeinsam mit Wille suchte Uffenbach das Jesuitenkolleg auf, um sich von Pater Heinrich Hillmann (1685-1760) die Sammlung der von ihm geschliffenen optischen Gläser zeigen $\mathrm{zu}$ lassen. Uffenbach, der selbst optische Linsen schleifen und polieren konnte, da er sich eine, „zur bequemer Schleif- und Polirung aller Arten sogenannten optischer Gläser schicklich eingerichtete Maschine“294 angeschafft hatte, war von der mangelnden Qualität der Linsen, Polyeder und Prismen des Pater Hillmann überrascht. Außerdem ließ er sich von Hillmann, der zuvor in Mainz als Professor der Mathematik tätig war, über den Verbleib der großen Brennspiegel und Gläser informieren, die dieser zusammen mit Heinrich Ludwig Muth (1673-1754) geschliffen hatte. ${ }^{295}$ Neben den optischen Geräten und Linsen besaß das Heidelberger Jesuitenkolleg eine „Menge mathematischer, physicalischer und mechanischer Instrumenten“, die Uffenbach ausführlich beschreibt. ${ }^{296}$ Nachdem der Jesuitenpater ihn zügig durch diese Sammlung geführt hatte, besuchte Uffenbach noch das große Fass im Keller des Schlosses, wovon er einen Kupferstich mit der Ansicht desselben erwarb, den er an das Manuskript anbinden ließ.

Den folgenden Tag nutzte er zu einem Ausflug nach Schwetzingen. Er konnte wegen Anwesenheit des Kurfürsten lediglich das Schloss von außen und den Garten ,artig und nach der neusten Art sehr angenehm angeleget“ betrachten, wobei ihn die technischen Einrichtungen der großen Fontäne als Architekt und Ingenieur zu einer genauen Beschreibung veranlaßten. ${ }^{297}$ Auch das Gebäude der

291 Vgl. das Treffen der wissenschaftlichen Gesellschaft am 29. November 1731, an dem Uffenbach den Mitgliedern die verschiedenen Verfahren Zellers erläutert (Cod. Ms. Uffenbach 13/IV, S. 439-446).

292 Zu Will[e] (Lebensdaten unbekannt) vgl. Arnim 1928,2, S. 48/49, Anm. 36.

293 Cod. Ms. Uffenbach 33, S. 213-217, Arnim 1928,2, S. 22-25.

294 Vgl. Uffenbach 1771, S. 60, Nr. 158. S.a. das Kapitel 8.4.1 „Die Beiträge von Johann Friedrich von Uffenbach.“

295 Zu Heinrich Ludwig Muth s.a. das Kapitel 8 „Die wissenschaftliche Gesellschaft.“

296 Cod. Ms. Uffenbach 33, S. 219-226, Arnim 1928,2, S. 26-30.

297 Cod. Ms. Uffenbach 33, S. 231-233, Arnim 1928,2, S. 33-34.

Vgl. das Kapitel 8 „Die wissenschaftliche Gesellschaft“, wo auf Pumpen und -anlagen eingegangen wird. 
Orangerie mit all seinen Innenräumen und deren Ausstattung schilderte er detailliert. An seinem letzten Tag, dem 10. September, wollte Uffenbach in Mannheim nochmals Zeller aufsuchen, um sich weitergehend in dessen Verarbeitungstechniken des „Schildgrotts“ einweisen zu lassen. Da dieser ihn aber auf den Abend vertröstete, studierte er zuerst eingehend die neu errichteten Festungswerke der Stadt und den Neubau des Jesuitenkollegs, bevor er zu dem Schreiner ging, der jedoch wieder keine Zeit für ihn aufbringen konnte. Die Heimreise am nächsten Tages verlief per Kutsche über Obersheim, Frankental nach Worms, wo er einen kurzen Halt zu einem Rundgang durch die Stadt nutzte, die er bis auf das kürzlich erbaute Schloss als ,in allen sehr reichsstättisch und klein“ empfand. Nach einem Besuch der 1725 eingeweihten lutherischen Dreifaltigkeitskirche fuhr er mit der Kutsche über Oppenheim, Gerau und Mörfelden nach Frankfurt zurück. ${ }^{298}$

$\mathrm{Ab} 1725$ beschäftigte sich Uffenbach neben den intensiven Sitzungsvorbereitungen für die wissenschaftliche Gesellschaft mit der Zusammenstellung seines pietistischen Werkes „Gesammelte Nebenarbeit in gebundenen Reden, worinnen, nebst einer poetischen Auslegung des Sinnbildes Cebetis, des Thebaners, verschiedene moralische Schriften zur Ausbesserung menschlicher Sitten, enthalten, und nebst einer Vorrede von der Würde der Singgedichte, mit dessen Genehmhaltung, an das Licht gestellet", welches 1733 in Hamburg erschien. Die Druckplatte von Matthäus Merian mit der Tabula Cebetis besitzt Uffenbach selbst. Er hat sie oben in der Mitte gelocht, um sie aufhängen zu können (Abb. 10 und 11). ${ }^{299}$

Vgl. Cod. Ms. Uffenbach 33, s.a. Arnim 1928,2.

Uffenbach 1733.

Matthäus Merian, Tabula Cebetis, 361 x $280 \mathrm{~mm}$, Kunstsammlung der Universität Göttingen Inv. Nr.: DP 1 


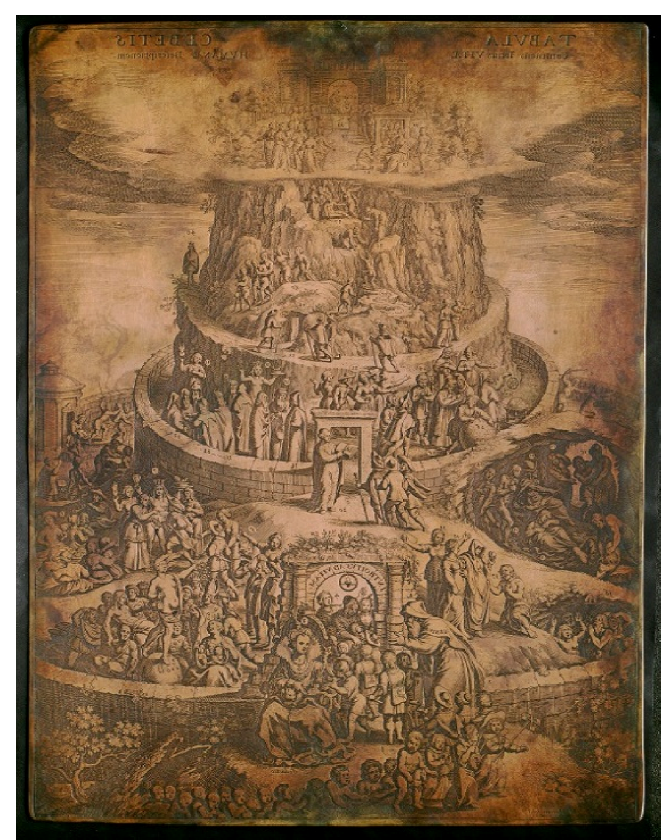

Abb. 10 Matthäus Merian, Tabula Cebetis, Kunstsammlung der Universität Göttingen Inv. Nr.: DP 1

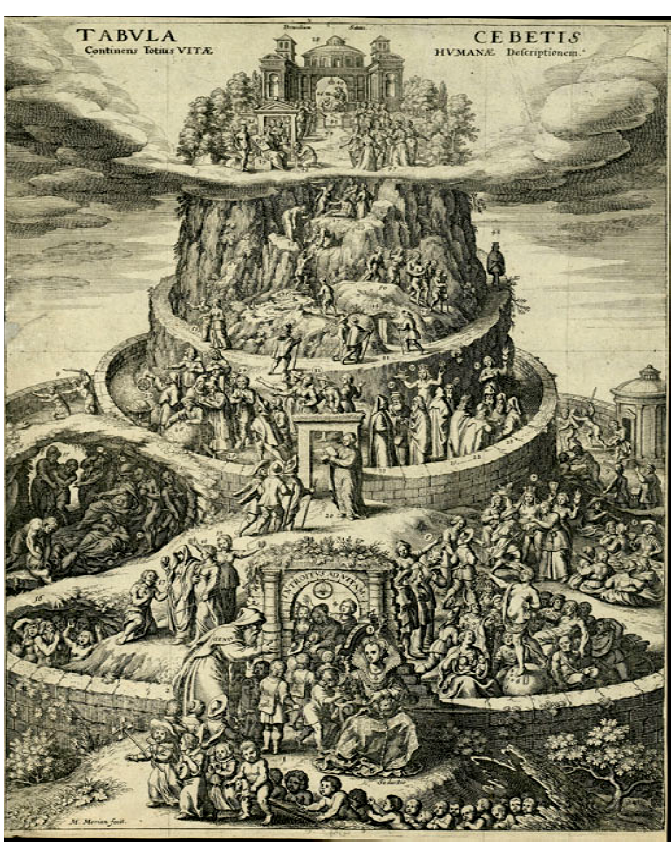

Abb. 11 Matthäus Merian, Tabula Cebetis, In: ,Gesammelte Neben-Arbeit in gebundenen Reden, Worinnen, nebst einer Poetischen Auslegung des Sinnebildes Cebetis des Thebaners", vor $\mathrm{S} .1$

In diesem Jahr versuchte der Frankfurter Rat Uffenbach zu unbezahlten und zeitraubenden Tätigkeiten heranzuziehen. Das durch kaiserliche Resolution vom 14. Mai 1732 gegründete Bürger-Kolleg der Einundfünfziger hatte ihn zum Mitglied auf Lebenszeit gewählt, dem Uffenbach sich eigentlich nicht entziehen konnte. Das Kolleg war zur umfassenden Kontrolle der Magistratshandlungen eingerichtet worden, vor allem derjenigen der Finanzen. ${ }^{300}$ Er hätte mit Übernahme dieser Verpflichtung die finanzielle Amtsführung seiner patrizischen Standesgenossen in Bezug auf das gesamte Bauwesen überwachen müssen, woran ihm nicht gelegen sein konnte, weshalb er sein Amt nicht antrat.

Da er sich dem Amtsantritt nur durch einen hohen auswärtigen Titel endgültig entziehen konnte, stiftete er am 28. Juli 1736 einen Großteil seiner Sammlungen im juristischen Sinne der neugegründeten Georgia-Augusta zu Göttingen. Für seine Donation wurde er am 22. März 1737 vom englischen König Georg II. August (1683-1760) mit dem Patent eines „Königlich Großbrittanisch 
Churfürstlich Braunschweigisch Lüneburgischen Artillerieobristlieutenants“ ausgezeichnet. ${ }^{301}$

Durch den Tod seines ledig gebliebenen, jüngeren Bruders Wilhelm im Jahre 1735 übernahm Johann Friedrich dessen Bücher und die kleine graphische Sammlung, darunter viele Portraitstiche. ${ }^{302}$ Dadurch erfuhr seine Bibliothek einen weiteren, größeren Zuwachs. Es ist anzunehmen, dass auch die wissenschaftlichen Geräte und die Musikinstrumente des jüngeren Bruders in seine Sammlung gekommen sind. ${ }^{303}$

Johann Friedrich ließ sich, nachdem er sein Haus am Großen Kornmarkt Nr. 13 verkauft hatte, zwischen 1736 und 1740 ein großes Palais auf der Zeil neben dem großen Gasthof „Rotes Haus“ erbauen. ${ }^{304}$ In einem Schreiben vom 9. Juni 1736 an den Königlichen Commissarius der Göttinger Universität, den Juristen Gottfried Mascow (1698-1760), berichtet Uffenbach erstmals über den Hausbau: ,[...] und würde vorzüglich Euer Exzellenz Gutfinden, mich personlich zu Göttingen sehen zu laßen, allerdings nachleben, wenn durch ein großes Bauwesen, das seit vier Wochen unternommen, nicht daran verhindert würde. Es begehret dieses meine Gegenwart ohnumgänglich, solte es aber, wie ich hoffe, bald zur Richtigkeit gebracht sein [...].“305

301 Vgl. das Kapitel 5 „Geschichte der Schenkung nach Göttingen.“

302 Die Portraitsammlung befindet sich heute ebenfalls im Kupferstichkabinett der Kunstsammlung der Georg-August-Universität Göttingen.

S.a. die Biographie Wilhelms im Kapitel 8.4.6 „Die wissenschaftliche Gesellschaft“ und die Trauerrede Uffenbachs im Anhang, S. 606-612.

303 Dies lässt sich aufgrund der heutigen Quellenlage nicht eindeutig entscheiden.

304 Bedingt durch die französische Besetzung Frankfurts während des Siebenjährigen Krieges wurde seit 1760 auf Veranlassung des Königsleutnants François de Théas, Comte de Thoranc (1719-1794) die Stadt nach französischen Vorbild in Quartiere eingeteilt und die einzelnen Häuser mit Nummern versehen. Das Palais Uffenbach erhielt die Hausmarke D 26 Zeil No. 54; s.a. Dietz 1897, S. 96.

305 Zitiert nach Arnim 1928,1, S. X. Vgl. Kapitel 5 „Geschichte der Schenkung nach Göttingen.“

Ein Verwandter Uffenbachs, Wilhelm Ernst Schedel, drückte in einem Brief aus Paris vom 18.2.1737 seine Freude über den Bau des Palais auf der Zeil aus (Cod. Ms. Uffenbach 20/I, p. 200-201).

In einem Brief des Johann Daniel Geysel, datiert vom 8. Mai 1738 (Cod. Ms. Uffenbach 20 I, p. 102v) heißt es: „Daß Sie [gemeint ist Uffenbach], da Sie von außen keine / Anderl. Veruche zu befürchten hatten, Sie sich dergleichen / freywillig, durch Verkauffung dero Hauses und Erbauung / eines andern, selbst zugezogen, kan ich deßwegen eben / nicht stacheln, weil ich einen solchen Baugeist habe, / daß wann mich der Himmel zu einem Fürsten gemacht / hätte, ich Städte eingerissen und anders aufgebauet haben / würde." Weiter unten: „... à propos da Sie im Bauen begriffen sind, so / fällt mir ein, bey Ihnen anzufragen, ob Sie / Herrn Schüblers in Nürnberg schöne Wercke so / Er in Architectonischen, Optischen, Mechanischen / und Gnomonischen Curiositaeten 
Es handelte sich um ein dreistöckiges, traufenständiges, weißes Gebäude mit Mittelrisalit und einem zweigeschossigen Speicherdach (Abb. 12). Als Architekt und Baumeister fertigte er die Pläne des Hauses selbst an. Er hatte sich als Autodidakt sowohl auf seinen ausgedehnten Reisen als auch durch seine ausgesuchte Bibliothek, die die einschlägigen Werke zur Architektur beinhaltete, hierin ausgebildet. ${ }^{306}$ Johann Bernhard Müller (1715-1777) beschreibt das Gebäude 1747 folgendermaßen: „Das ihm [= Gasthaus „Rotes Haus“] zur Seite stehende Uffenbachische Haus ist ein Muster von der neuen Bau Art und zeiget von dem feinen Geschmack seines Herrn Besitzers und Erbauers.“307 Müller meint mit der Bezeichnung „,neue Bauart“, dass es im französischen Stil des Rokoko erbaut worden war.

Das Haus steht heute nicht mehr. Auf diesem und den angrenzenden Grundstücken wurde von 1891 bis 1895 das Gebäude der Frankfurter Hauptpost errichtet. 308 Johann Georg Battonn beschreibt 1871 das Uffenbachische Haus als „ein schönes Gebäude von Stein“.309 Er hält weiter fest, dass das Haus als eine

herausgegeben / und theils in Augsb theils in Nb gedruckt worden, / besitzen, weil darinn vieles zu guten Gedancken / Anlaß geben kann.“

Mit Schübler ist Johann Jacob Schübler (1689-1741) gemeint, von dem Uffenbach mehrere Bücher zur Architektur besaß: Perspectiva pes picturae, das ist: Kurtze und leichte Verfassung Der Practicabelsten Regul, zur Perspectivischen Zeichnungs-Kunst, 2 Bde., Nürnberg 1719 ( $2^{\circ}$ Bibl. Uff. $\left.44+45\right)$; Synopsis Architecturæ Civilis Eclecticæ, oder Kurtzer Entwurff von denen nöthigen Partial-Begriffen, welche in der Antiquen Geometria Elementari, durch das nutzliche Diagramma Quadrangulare den gantzen Umfang der CivilBau-Kunst vorstellig machen, vornemlich aber in gegenwärtigen Zwölff Tabellen nach einem Fundamentalen Methodo die regulairen Maximen anzeigen, die bey Verfertigung ... eines Adelichen Wohn-Haußes erfordert werden ... / ... in möglichste Deutlichkeit verfasset, inventirt, und gezeichnet, Nürnberg 1732 ( $2^{\circ}$ Bibl. Uff. 477); Sciagraphia artis lignariae d.i. Zimmermanns Kunst p., Augsburg 1736 ( $2^{\circ}$ Bibl. Uff. 439; 20erley Ausgaben von zierlichen meubles und beyzierden der architectur, Augsburg ( $2^{\circ}$ Bibl. Uff. 442).

306 In den Reisetagebüchern beschreibt Uffenbach immer wieder auf das Genaueste nicht nur die Architektur als solches, sondern auch die Konstruktion und Baustoffe.

In der wissenschaftlichen Gesellschaft zeigte er u. a. anhand eines Modells, wie man an einer Brücke einen ,Schwiebbogen“ ausführt (Cod. Ms. Uffenbach 13/II, S. 159-160 mit Zeichnungen).

307 Müller 1747, S. 44; mit den angesprochenen anderen Haus ist das Gasthaus „Rotes Haus“ gemeint.

Vgl. Pütter 1765, S. 224 Anm.

3081834 hatte der Fürst von Thurn und Taxis den Gasthof „Rotes Haus“ erworben. Er ließ es zum Sitz der Generalpostdirektion und für den Betrieb des Oberpostamtes Frankfurt umbauen.

Auch dieses Gebäude ist in der Zwischenzeit abgerissen worden. Auf den Grundstücken steht heute ein Einkaufszentrum.

309 Battonn 1871, S. 114, weiter schreibt er: [...], das 1809 einen neuen Aufsatz erhielt, und dadurch ein vierstöckiges Haus wurde. [Das Dörr'sche, jetzt Böhler'sche Haus.].

Eine Photographie aus dem 19. Jahrhundert mit der Kaiserlichen Oberpostdirektion, dem ehemaligen Hotel „Rotes Haus“, zeigt das benachbart gelegene, jetzt vierstöckige Haus. 
Besonderheit ,einen 2 Stock durchlaufenden Saal [besaß], in welchem dessen berühmte Bibliothek aufgestellt war.“310 Johann Friedrich bewahrte zumindest seit 1764 seine Bücher und wissenschaftlichen Instrumente in zwei separaten Räumen im dritten Stock des Hauses auf. ${ }^{311}$ Battonn verwechselt hier die Bibliothek von Johann Friedrich mit derjenigen von Zacharias Conrad, dessen Bücherschatz aber nie in dem Palais auf der Zeil gestanden haben kann, da dieser schon 1734 - zwei Jahre vor Baubeginn des Palais` - gestorben und seine Bibliothek verkauft worden war. ${ }^{312}$ Auch besaß der ältere Bruder nie ein Haus auf der Zeil, sondern bewohnte das Elternhaus in der Großen Eschenheimer Gasse. ${ }^{313}$

Ein Grundriss des Gebäudes oder Angaben über die Größe des Grundstücks haben sich nicht erhalten. ${ }^{314}$ Lediglich eine Zeichnung der Straßenfront von Johann Heinrich Wicker (1723-1786) veranschaulicht, wie das Gebäude zu Lebzeiten Uffenbachs ausgesehen hat. Auch ein Gemälde des Frankfurter Malers Johann Ludwig Morgenstern (1738-1819) aus dem Jahre 1793 zeigt das Uffenbachische Haus in einer Ansicht der Zeil von Osten her in Richtung Hauptwache, bevor es durch den nachfolgenden Eigentümer aufgestockt wurde. ${ }^{315}$

Das Haus ging nach dem Tod des letzten Uffenbach im Jahre 1799 in den Besitz der Stadt Frankfurt am Main über, von der es der Handelsmann Arbauer erkaufte und 1809 ein weiteres Stockwerk aufsetzen ließ.

310 Battonn 1871, S. 114.

311 In einem Brief vom 16. April 1764 schreibt Uffenbach nach Hannover (Universitätsarchiv Göttingen Kur. 4 V d6/2, Bl. 184v): “[...], was in denen heute in Augenschein genommenen zwey Zimmern des 3ten Stockes meiner Behausung aufbewahret und angeordnet ist.“

Vgl. den Brief vom 1. April 1769 des hannoverschen Residenten in Frankfurt am Main, Friedrich Ludolph von Hugo, in dem dieser über die Aufstellung der Sammlung berichtet (Universitäts-Archiv Göttingen Kur. 4 V d6/2, Bl. 228).

312 Vgl. ausführlich zum Sammler und Gelehrten Zacharias Conrad von Uffenbach: Franke 1965,1 .

313 Dieser Irrtum wird in der nachfolgenden Literatur übernommen, z.B. Kat. Frankfurt 1982,2, S. 46 oder im Oktober 2016 von Howard Hotson in dem Online-Portal „cabinet“ der Universität Oxford (https://www.cabinet.ox.ac.uk/zacharias-conrad-von-uffenbach-1710 vom 27.07.2018).

314 Beim Brand des Stadtarchivs Frankfurt am Main im Jahre 1944 wurden zwei Drittel der Bestände des Instituts für Stadtgeschichte zerstört. $\mathrm{Zu}$ diesen gehörten unter anderen sämtliche Hausakten, so dass sich keinerlei differenzierte Angaben über die innere Gestaltung des Hauses machen lassen.

Auch im Nachlaß Uffenbachs in der SUB Göttingen befinden sich keine Pläne oder detaillierte Innenansichten des Gebäudes.

315 Johann Ludwig Morgenstern, Frankfurt am Main: Nordseite der westlichen Zeil vom Roten Haus bis zum Weidenhof, 1793, (Abb. 12).

S. Abbildung in: Heckmann/Michel 1982, S. 158. 


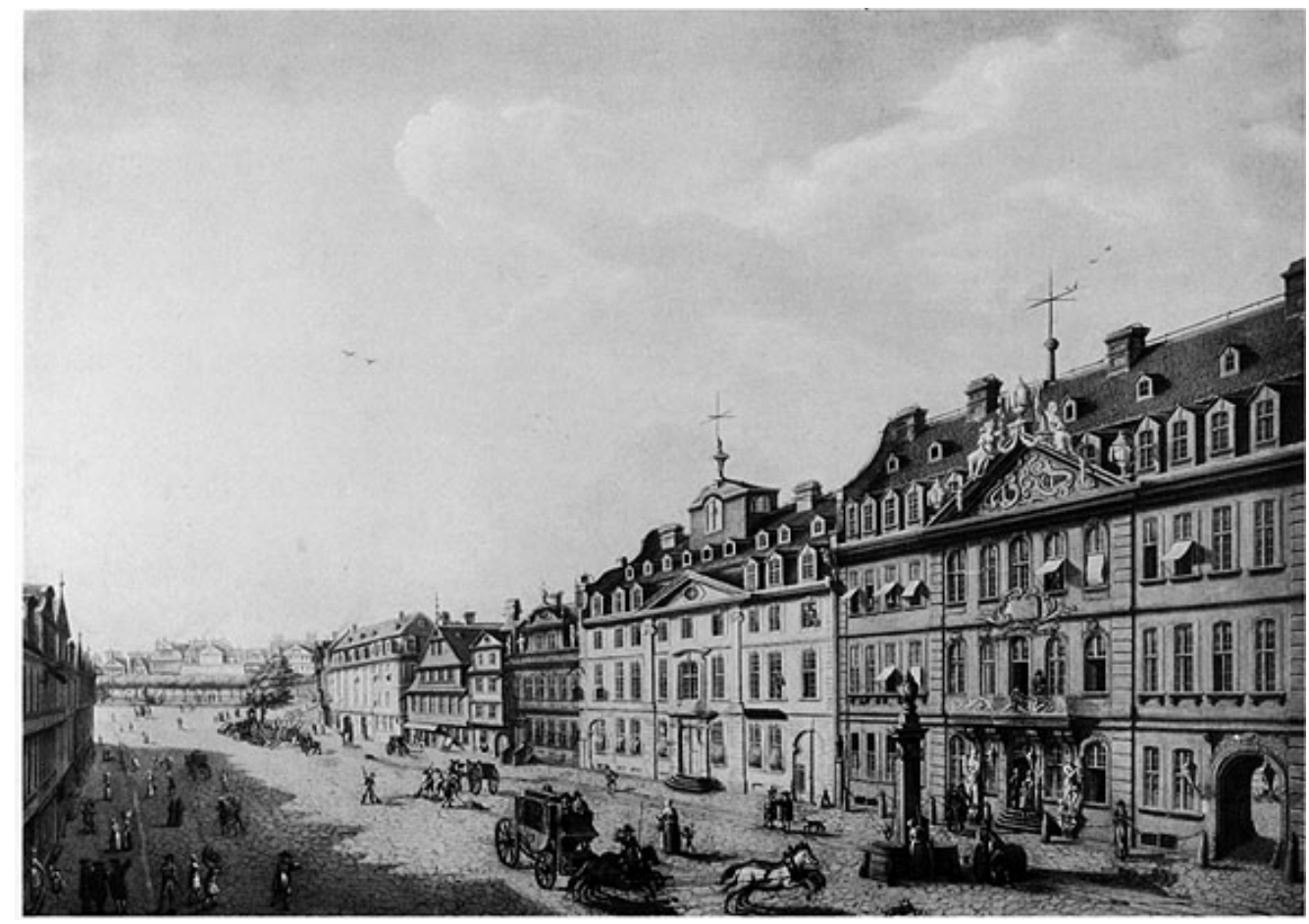

Abb. 12 Johann Ludwig Ernst Morgenstern, Frankfurt am Main -

Nordseite der westlichen Zeil vom Roten Haus bis zum Weidenhof, 1793, Historisches Museum Frankfurt am Main

Neben seinem Stadtpalais besaß Johann Friedrich noch ein großes Landgut mit Weinanbau, das im kurmainzischen Flörsheim am Main lag. Durch seine Vermählung mit Anna Elisabeth Lindheimer im Jahre 1717 war es in seinen Besitz gekommen. Er bemerkte im Protokoll der wissenschaftlichen Gesellschaft vom 16. Juli 1728: „[...] die Veranlaßung dazu hatte mir vor etlichen Jahren, nach Auferbauung dieses frey liegenden Landhauses, die angenehme und überaus weite Aussicht in das angränzende flache Land, die vielen gangbahren Landstraßen, und der vorbey gehende Fluß, gegeben. “316 Mit „Auferbauung“ ist der Umbau des Obergeschosses und Daches des Haupthauses gemeint. ${ }^{317}$ Das Anwesen liegt im sogenannten Ersten Viertel direkt innerhalb der Stadtmauer

316 Cod. Ms. Uffenbach 13/II, S. 314. Vgl. auch Preußner 1949, S. 160, der schreibt, dass Uffenbach schon 1716 den Plan gefaßt hatte, sich ein Refugium auf dem Land in Flörsheim zu erbauen. Desweiteren Uffenbach 1733, S. 85-90, wo er über „Das Landleben“ schreibt.

317 Da sich über dem heutigen Eingang zum Kellergewölbe noch die Jahreszahl 1661 findet, kann Uffenbach das Haus nicht von Grund auf selbst erbaut haben.

Vgl.: „http://www.flörsheim-1656.de/html/das_von_uffenbach-sche-faber-anwesen.html“ vom 26.04.2016.

Ich danke herzlich Herrn Bernd Blisch, Stadthistoriker und Bürgermeister von Flörsheim am Main, für seine bereitwillige Hilfe und Unterstützung.

Das Herrenhaus existiert noch heute. Im 19. Jahrhundert wurde es zu einer Gaststätte umgebaut. Seit 2014 hat das Anwesen einen neuen Besitzer, der es grundlegend saniert. 
mit Blick zum Main. ${ }^{318}$ Die Grundstücke, die zu diesem Anwesen gehörten, waren rund um Flörsheim verteilt. ${ }^{319}$ Im Jahre 1729 erwarb Johann Friedrich ein Stück Land hinzu, das direkt an das seines Hauses stieß. ${ }^{320}$ Uffenbach hat das Anwesen 1758 für 2050 fl. an den Kurmainzer Rat Jacob Daniel von Gall verkauft (1723-1783). ${ }^{321}$

Allerdings schrieb ihm noch am 17. Juni 1758 aus Amsterdam der Frankfurter Kunsthändler und Auktionator Johann Christian Kaller (1725-1794), der für Uffenbach als Kommissionär arbeitete, über seine Schwierigkeiten, den Wein von dem Flörsheimer Landgut bei den Weinhändlern abzusetzen. ${ }^{322}$ Da nicht anzunehmen ist, dass Uffenbach den in Flörsheim produzierten Wein auf dem Grundstück seines Frankfurter Stadtpalais' lagerte, muss er zumindest zu diesem Zeitpunkt das Gut noch besessen haben. Auch finden sich im „Commercium Epistolicum“ keinerlei Briefe oder Hinweise, die die Belange des Landgutes wie zum Beispiel den Verkauf betreffen.

Heute Obermainstraße 6.

Archiv der Stadt Flörsheim am Main, Gerichtsprotokollbuch 1674-1718, p. 118: „Dienstag den 4. January 1718 Er klagt sich Meister Ullrig Krämmer ein 1/2 Morgen alten Weingarten oben ahm Wickererweg stost auf den Wickerepfat gefl. unden Johannes Schirstein oben $\mathrm{zu} \mathrm{H}$ von Uffenbach so er von hans Jacob Cluin erkauft auf und für bahres Gelt $60 \mathrm{fl}$. beneben $2 \mathrm{Alb}$. gottespfännig, drey Maß Wein verkauft sonst hier frey und segen."

Archiv der Stadt Flörsheim am Main, Protokollbuch Nr. 8, S. 129: „Donnerstag, den 19. May 1729, Nachdeme der Edell Veste Herr H. Friedrich von Uffenbach die Ahnzeig tun laßen wie das er undter Dato d. 8. April lauffenden Jahr von denen hiesigen undt undt [!] hernach beschrieben gemeins Leute als Johannes Bernhardt, Hans Jacob Dubeck, undt Sebastian Flauck aus dießen dreyen habenden Hofreithen zusamen erkauft ein Stück zu seinem Garten, alhier in Flörsheim im Ersten Viertel gelegen, deßen Breithung ist unten ahn Johannes Bernhardts geschieth 6 Schu, 8 Zoll oben ahn des H Kauffers Hofreith 13 Schu ist nach der 10 Schuher Ruth gerechnet 123 Ruthen 4 Schu 7 Zoll, umb und für $41 \mathrm{Rh}$ 15 al. 4 1/3 pf. bahres gelt sonsten für frey und Eigen es ist auch aus undt für behalten da gemeldter Bernhardt seine Schäuer ableg undt anderst gebauwet wirdt das als dann da selbige 1 1/6 Schuck [!] von des H Kauffers Stein und die lang durchgefürthe Mauer weichen soll ist dann hiermit gerichtlich Imitirt.“

1 Das Wappen der Familie von Gall - ein durch ein Tor springendes Pferd - befindet sich über dem Hauseingang.

Vgl. https://www.flörsheim-1656.de/html/das_von_uffenbach-sche_-faber--_anwesen.html vom 17.05.2019.

SUB Göttingen, Cod. Ms. Uffenbach 20/II., p. 301v + 302r: „[301v] ... die von Euerhochedelgeboren mit bekommenen Weinproben / habe noch in kleinern Botellien gefüllt und an verschiedene / vornehme Weinhändler versuchen lasen, welche mir / bey Ihrer Ehre versichert haben, daß dergleichen Sorten / von Wein unmöglich hier zu angesetzen Preiß könten / abgesetzt werden, und so einst wenigstens 1/3 davon zu / accordieren, wäre nichts zu thun, Ich habe ihnen zum vorausgesagt, [302r] daß solches nicht geschehen würde, doch wolte deßhalb schreiben / und um daß allereußerste anfragen, warum nicht von / dem Stück 38er \& 53er. in Erwarthung Beliebiger nachricht / habe die Ehre nebst meiner unterthänigsten Empfehlung / mit aller erdenklich Hochachtung zu verharren." 
Uffenbach hat sich mit seiner Familie und Freunden häufiger in Flörsheim aufgehalten. Er verfertigte für die Hausandacht eigens einen zweibändigen Kirchenjahrgang, ${ }^{323}$ wie es die Pflichten eines „Hausvaters“ vorsahen, der sich um das Wohlergehen seiner Familie und seiner Angestellten kümmern musste. Den Anlass hierfür beschrieb er im Vorbericht: „Der offtere Aufenthalt auf meinem unter andern Glaubensgenossen gelegenen Landgute hat mich wie billig erinnert die eingefallene Sonn und Festage mit Ehrerbiethung $\mathrm{zu}$ begehen, und denenjenigen, so auch alda um mich sind $\mathrm{zu}$ anstößigen Gedancken keine Gelegenheit zu geben. “324

Das Landgut mit den angrenzenden Gebäuden wurde von Uffenbach zweimal in Kupfer gestochen. ${ }^{325}$ Er hatte 1723 seinem ehemaligen Reisegefährten und langjährigen Briefpartner Johann Daniel Geysel ${ }^{326}$ in Nürnberg einen Abzug einer der Platten mit der Ansicht des Landgutes zugeschickt. Geysel schreibt dazu am 5. Oktober 1723: „Die mir übersandte Probe eines in Kupffer gestochenen Prospects von dero Landtguth, hat mir recht wohl gefallen und wünsche auch bald die übrigen zu sehen.“327 Die Kupferplatte mit der Ansicht Flörsheims von Osten hat sich nicht erhalten, dagegen besitzt die Kunstsammlung der Universität Göttingen die Platte mit der Ansicht des Ortes von Westen (Abb. 13). ${ }^{328}$

323 „Der genesenen Vernunft zufällige Gedancken über alle Sonn und Festtägliche Evangelia in einem Harmonischen Jahrgange verfaßet und vor 1 oder 2 Soprani Theils mit einem begleitenden Instrumente Theils mit bloßem Basse in müßigen Stunden zu einer Haus Andacht in Music gebracht von Joh: Frid: von Uffenbach“ ( $2^{\circ}$ Bibl. Uff. 562 und 563). $2^{\circ}$ Bibl. Uff. 562, S. 3.

325 Ph. Friedrich Gwinner beschreibt die beiden Blätter als ,zwei Ansichten des Fleckens Flörsheim am Main von der Morgen- und Abendseite gestochen, wovon das letztere I.F. ab U. Fecit.“ (Gwinner 1862, S. 266.).

326 Lebensdaten unbekannt.

327 Cod. Ms. Uffenbach 20/II, p. 632-633, hier 632r.

328 Kunstsammlung der Universität Göttingen, Inv. Nr.: DP 16, Kupferstichplatte, ca. 168 x 222 mm, u. 1. signiert: I.F. ab. U. fecit, o.M. gelocht, verso Buchtitel für ein Dittionario Italiano Francese Latino Tedesco.

Die Kunstsammlung selbst besitzt keine Abzüge der beiden Platten.

Preußner 1949, S. 179 gibt eine Abbildung eines Abzuges von der Ansicht von Osten, allerdings ohne weitere Angaben. 


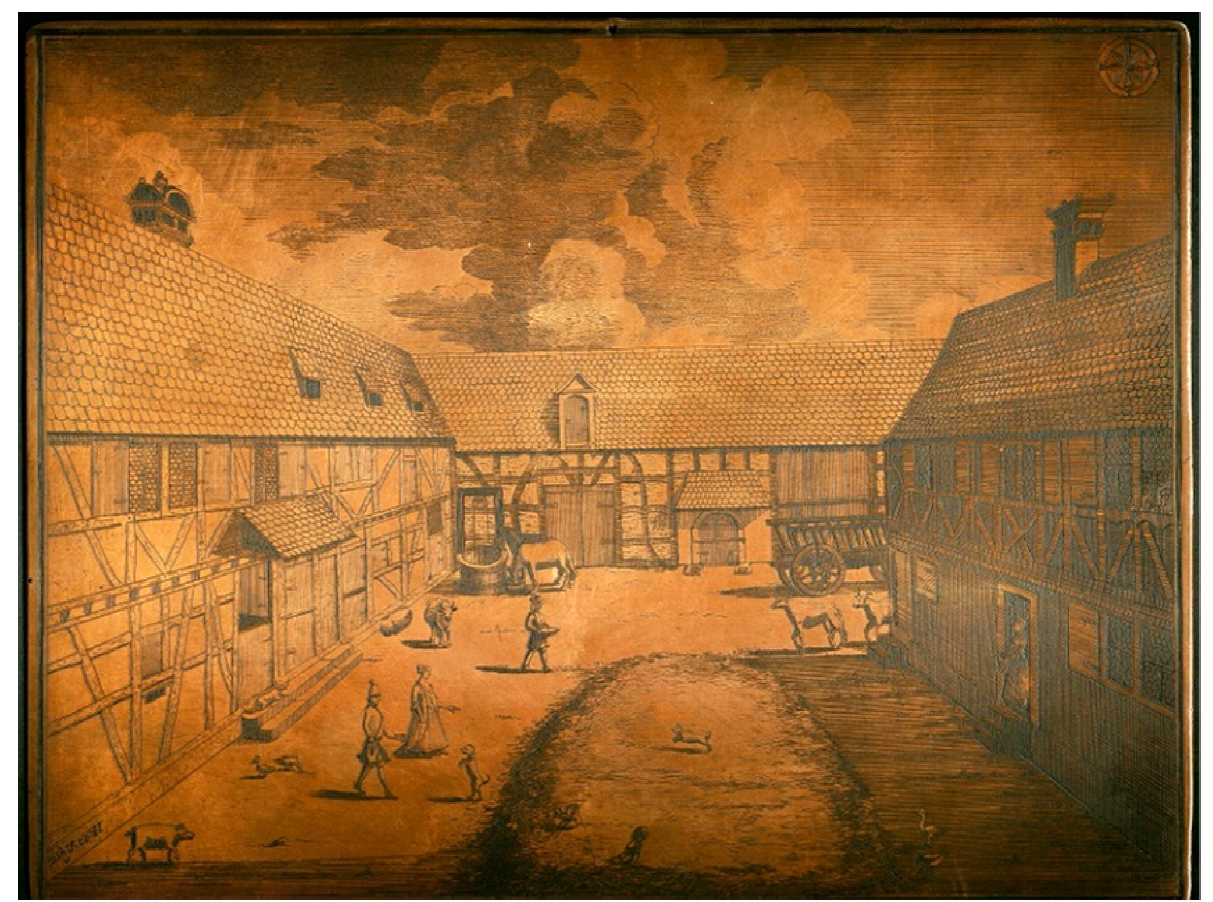

Abb. 13 Johann Friedrich von Uffenbach, Ansicht des Flörsheimer Landgutes, Kunstsammlung der Universität Göttingen Inv. Nr. DP 16

Nach Uffenbachs Stiftung nach Göttingen und der Erlangung des hohen auswärtigen Titels konnte ihn der Rat der Stadt Frankfurt am Main nicht mehr für ihre Dienste verpflichten. Dieser bat Uffenbach aber 1740, die Bauleitung für die Instandsetzung der am 16. Dezember 1739 eingestürzten Mainbrücke zu übernehmen. ${ }^{329}$ Am Abend dieses Tages war der Kreuzbogen zusammengebrochen, und der anstoßende Flößerbogen wurde gespalten und zeigte Risse, außerdem war einer der Schüttbogen stark gefährdet. 330 Von 1740 bis 1744 leitete Uffenbach den Umbau der Alten Mainbrücke. Er verfasste während dieser Tätigkeit einen 273 Folioseiten umfassenden Bericht mit dem Titel ,Zuverlässige Nachricht und Beschreibung von dem Brücken Bau zu Frankfurt am mayn wie solcher von dem Jahr 1741 biß zu dessen vollbringung 174[4] ${ }^{331}$ von Tag zu Tage geführet und angeordnet und gegenwärtiger Endwurff davon unter der hand verfaßet worden von Joh. Friedrich von Uffenbach der Königl. und Churbraunschweigischen Artillerie Obristlieutnant“; mehrere eigenhändige Zeichnungen waren beigefügt. 332 In seiner Sammlung

Zum Umbau der Alten Mainbrücke durch Uffenbach siehe: Jung 1895,1; besonders: Müller 1912; Arnim 1928,1, S. VIII; Schmidt 1960

330 Die Namen der einzelnen Bogen ergeben sich aus ihrer Funktion: Der Kreuzbogen war der das Kruzifix tragende, über die Schüttbogen wurden die Fäkalien in den Main gegossen und der Flößerbogen war für die Durchfahrt der Flöße bestimmt.

331 Die letzte Jahreszahl wurde von Uffenbach nicht mehr ausgefüllt.

332 Zur Geschichte dieses Umbaus und der Rolle Uffenbachs dabei: Müller 1912. 
wissenschaftlicher Geräte verwahrte er „Ein Modell von der hölzernen Interimsbrücke, worunter 1740 die von Quadersteinen über den Maynfluß, ohne Hinderung der freyen Uberfahrt der schwersten Lastwagen, von dem Hrn von Uffenbach erbauet worden." 333 Bei der Grundsteinlegung am Kreuzbogen, die am 28. Mai 1742 stattfand, legte man in denselben eine Flasche 1741er Weißwein, eine Flasche Rotwein, einen Krönungsdukaten, eine silberne Krönungsmünze, beide von Frankfurter Prägung, ein Milchbrot für 2 Kreuzer, sowie eine Kupferplatte mit der von Uffenbach verfassten Inschrift: „Pontem ornamentum et commodum emporii Moeno-Francofurtensis senio et injuria aëris fluminisque aestnosi die 16 Decembr. 1739 corrutum ex fundamento tribus fornicibus una cum suis pilis noviter erigi et primum hunce lapidem auspiciis divinis poni iussit nobilissimus et amplissimus senatus Moeno-Francofurtensis anno salutis millesimo septingentesimo quadragesimo secundo. Praetore Joh. Christophoro ab Ochsenstein; consulibus Joh. Carolo a Kayb scabino, Jacobo Mentzel senatore, Carolo Greis senatore. Molem operis moderante Joh. Frederico ab Uffenbach, M. Britanniae regi in legione tormentaria protribuno.“"334

Neben seiner Tätigkeit als Leiter der Erneuerung der Alten Mainbrücke wurde er im November 1740 vom Rat der Stadt als Obergutachter für die Errichtung der neuen, repräsentativen Kaiserstiege im Römer eingesetzt, die anläßlich der Wahl und Krönung Kaiser Karls VII. (1697-1745) erbaut werden sollte. ${ }^{335}$

Seine Fähigkeiten als Ingenieur konnte Uffenbach abermals 1742 beweisen. Er war von dem spanischen Wahl-Gesandten Cristóbal Gregorio VI. Portocarrero de Montijo (1693-1763), als Organisator und Gestalter der großen Feuerwerke am 18. November 1741, zum Namenstag der spanischen Königin Elisabeth (16921766), und am 25. Mai 1742 anläßlich der Kaiserkrönung Karls VII. angestellt worden. ${ }^{336}$

Die Akten des Frankfurter Bauamts sind im 2. Weltkrieg durch Brand verloren gegangen.

Vgl. Meyerhöfer 1995, S. 143. Das Modell hat sich nicht erhalten.

Zum Umbau der Brücke ausführlich auch: Wolff/Jung 1896, Bd. II, S. 270-275, hier bes. S. 273-273.

Vgl. Jung 1742, Bd.1, S. 19, Wolff/Jung 1896 hier bes.: Bd. II/1898, S. 166-167 und Schomann 1982, S. 194 und 195, wo die „Neue Stiege im Römer“" sowohl von außen als auch von innen abgebildet ist.

S. „Abbildung derer Feuerwercke und Illuminationen so in den Jahren 1741 und 1742 auf Befehl des außerordentlichen Hispanischen Gesandten Herrn Grafen von Montijo zu Franckfurt am Mayn bey der Wahl und Kroenung Ihrer Kayserl: Majestät Carl des VII, angegeben, zu Werck gerichtet, abgebrandt und gezeichnet Joh: Friedrich von Uffenbach“ (gr. ${ }^{\circ}$ Bibl. Uff. 462). Es handelt sich hierbei um einen Band, den Uffenbach aus den Kupfern zusammengestellt hat, die von den Feuerwerken und Illuminationen durch die Augsburger Stecher Jacob Wagner (1704-1770), Hieronymus Sperling (1695-1777) und 
Nach dem Tod seines Cousins Nikolaus von Uffenbach (1682-1744) wurde der Platz im Rat der Freien Reichsstadt Frankfurt am Main für Johann Friedrich frei, da immer nur ein Familienmitglied dorthin gewählt werden durfte. Mit der 47. Wahl wurde er am 15. September 1744 auf dieses hohe und gut dotierte Amt berufen. 1748 wurde er zum Wahlherrn auf der zweiten Bank, 1749 jüngerer Bürgermeister und im Jahre 1750 wiederum als Wahlherr auf der zweiten Bank gewählt. Seit dem 6. Dezember 1751 war er Schöffe und erhielt folglich - durch das kaiserliche Privileg vom 8. August 1743 - den Titel „Wirklicher Kaiserlicher Rat“.337 1752 wurde er zum Wahlherrn auf der ersten Bank und 1762 zum älteren Bürgermeister berufen. Von 1765 bis 1767 war er erneut Wahlherr auf der ersten Bank. 1768, ein Jahr vor seinem Tod, schied Uffenbach aus dem Rat der Stadt aus. ${ }^{338}$

Johann Friedrich von Uffenbach hatte sich schon im Juni 1743 mit dem Mannheimer Bildhauer Paul Egell ((1691-1752), dessen Arbeiten er von seinem Besuch des Mannheimer Schlosses im Jahre 1731 her kannte, ${ }^{339}$ in Verbindung gesetzt, um sich von ihm eine Portraitbüste in Alabaster anfertigen zu lassen. Die beiden Briefe Egells im Commercium Epistolicum ${ }^{340}$ zeigen aber, dass ein Auftrag wegen der für Uffenbach zu hohen Preisforderungen von Paul Egell nicht zustande kam.

Die Wahl in den Rat der Stadt Frankfurt am Main 1744 nahm Johann Friedrich Armand von Uffenbach dann zum Anlass, sich von Johann Georg Dathan (17011749) in einem repräsentativen Portrait darstellen zu lassen, wobei er sich vor

Gustav Andreas Wolffgang (1692-1775) angefertigt wurden. Der Titel ist nicht gedruckt, sondern wurde von Uffenbach oder einem Schreiber in brauner Tinte geschrieben. Es handelt sich insgesamt um sechs überformatige, daher gefaltete Blätter. S.a. „Gesammelte Vorbilder von Lustwercken und Illuminationen nach Angabe von I.F.v.U. (gr $2^{\circ}$ Bibl. Uff. 537). In diesem Band sind die sechs Kupfer mit anderen noch einmal versammelt.

Zu den Feuerwerken vgl. Jung 1742, Bd. 1, S. 209-211 und Jung 1742, Bd. 2, S. $102 \mathrm{ff}$.

Vielleicht hat Uffenbach bei dem zweiten Feuerwerk die Hilfe von Johann Daniel Blümel, Mechanicus und Feuerwerker aus Straßburg, in Anspruch genommen. Ein Brief Blümels, der in diese Richtung weist, befindet sich Commercium Epistolicum; vgl. Cod. Ms. Uffenbach 20/II, B1. 652-653; Transkription s. Anhang, S. 521-522.

337 Zum Titel des „Wirklichen Kaiserlichen Rates“ vgl. Voelcker 1932, S. 56.

338 Krug 1846, S. 17; Jung 1895,1, S. 132; Arnim 1928, S. XI; nach Hirsching 1812, S. 75 schon 1714; nach Meusel 1815, S. 175 schon 1741; Schmidt 1960; zum Frankfurter Rat und der Wahl bes.: Koch 1983, S. 24-28.

339 Vgl. Cod. Ms. Uffenbach 33 und Arnim 1928,2.

340 Cod. Ms. Uffenbach 20/II, p. 413-414, vgl. Döry 1958 mit den Transkriptionen der beiden Briefe. 
dem Hintergrund der Alten Mainbrücke während der von ihm geleiteten Instandsetzungsarbeiten darstellen lässt (Abb. 14). ${ }^{341}$

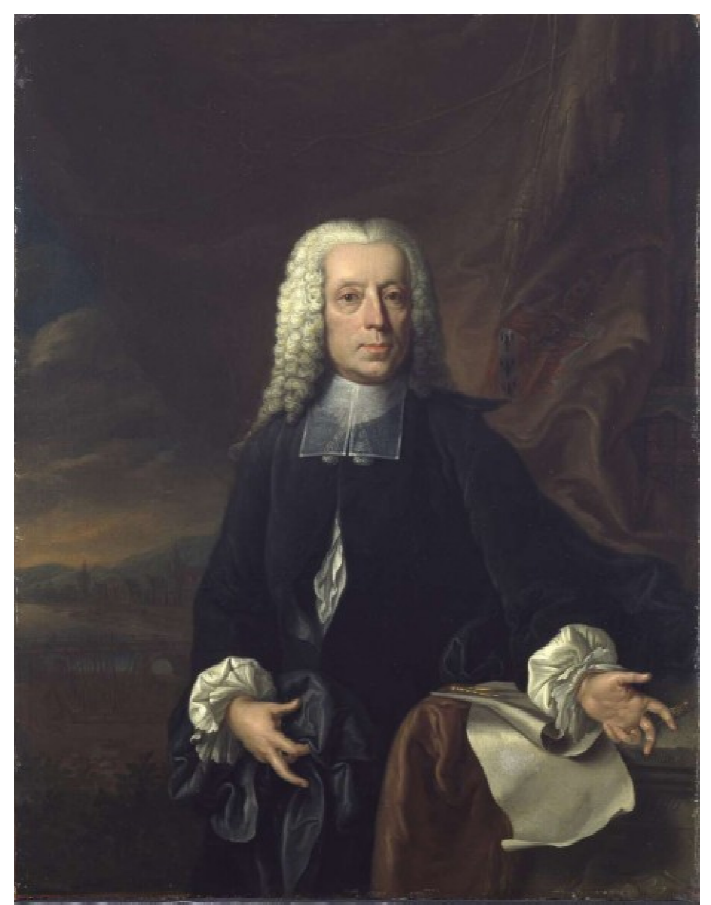

Abb. 14 Johann Georg Dathan; Johann Friedrich von Uffenbach, Historisches Museum Frankfurt am Main Inv. Nr. B 604

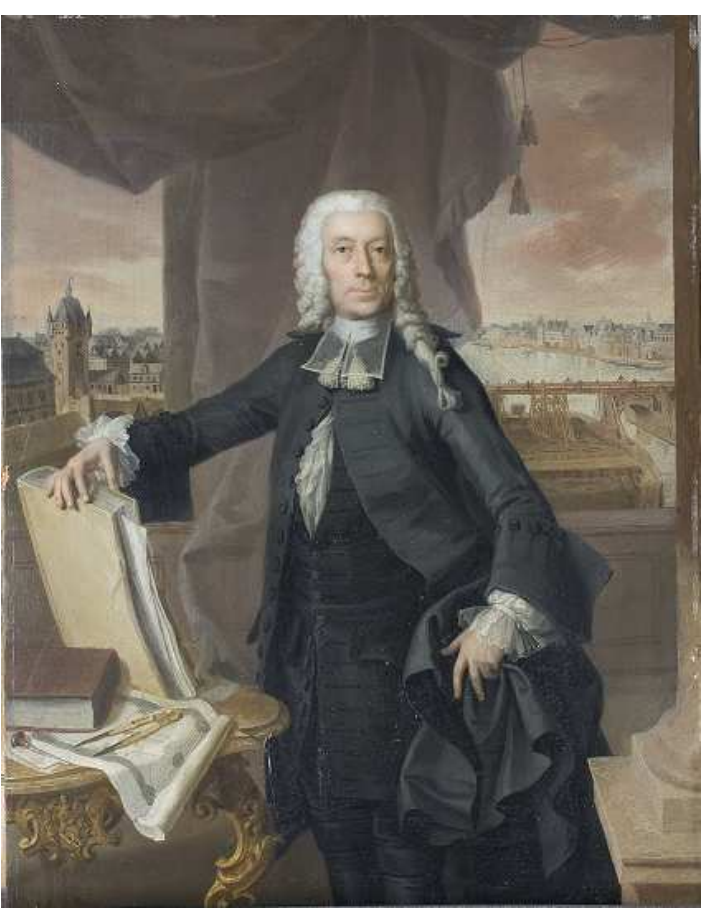

Abb. 15 Unbekannt: Johann Friedrich von Uffenbach, Kunstsammlung der Universität Göttingen Inv. Nr. GG 126

Uffenbach hatte dem zu dieser Zeit in Speyer ansässigen Maler Dathan nicht ein einziges Mal als Modell für sein Bildnis gesessen. Stattdessen verhandelte er zwischen 1745 und 1748 per Brief ${ }^{342}$ mit dem Künstler und sandte ihm zwei schon vorhandene Portraits. Das eine, heute verlorene Gemälde stammte von dem Wiener Künstler Franz Christoph Janneck (1703-1761), der sich zwischen 1735 und 1740 in Frankfurt aufgehalten hatte. ${ }^{343}$ Anhand des anderen Halbfigurenbildes

341 Historisches Museum Frankfurt am Main, Inv. Nr.: B 604. Bez. unten rechts: G. Dathan fe. 1746, Öl auf Holz, 42 x $32 \mathrm{~cm}$. Auf der Rückseite die Inschrift: Joh. Friderich ab Uffenbach, Joh. Baltaseris filius M. Britaniae Regi in Legione Formentaria Protribunas Postea Reipubl. Patriae Moeno Francofurtensis Proto Scabinus et Senator. natus 6. Maji MDCLXXXVII. Provenienz: Bis 1775 Maria Magdalena von Uffenbach, geb. von Bertram; Auktion 15.5.1775; 1850 Vermächtnis Frau Sänger, geborene Prehn an die Stadt; 1877 Übernahme durch Historisches Museum. Vgl. Kat. Frankfurt 1956, S. 17-18, Nr.44; Kat. Frankfurt 1957, S. 176 mit Abb.; Kat. Frankfurt 1982,2, S. 46 und Meyerhöfer 2000,2. Vgl. Cod. Ms. Uffenbach 20/II, p. 373-383.

343 Ehemals Museum Wiesbaden.

Das Leinwandgemälde (34 x $25 \mathrm{~cm}$ ) stammte aus der Sammlung der Frankfurter Johann Christian Gerning (1745-1802) und Johann Isaak von Gerning (1767-1837), kam 1824 
von unbekannter Hand ist die Abhängigkeit des Frankfurter Gemäldes, das Dathan 1746 datiert hat, von diesem deutlich zu sehen. Dieses Vorbild hatte die Witwe Uffenbachs 1770 dem Vermächtnis nach Göttingen beigefügt und es befindet sich heute in der Kunstsammlung der Georg-August-Universität Göttingen (Abb. 15). ${ }^{344}$

Nachdem Uffenbach am 24. Juni 1740 bereits in die Deutsche Gesellschaft zu Göttingen mit der Matrikelnummer 16 durch den Philologen Johann Matthias Gesner (1691-1761) aufgenommen worden war, ${ }^{345}$ wurde er am 19. Mai 1751 als Auswärtiges Mitglied der Mathematischen Klasse der eben gegründeten Königlichen Sozietät der Wissenschaften zu Göttingen eingetragen. ${ }^{346} \mathrm{Er}$ war damit eines der ersten zugelassenen auswärtigen Mitglieder. ${ }^{347}$ Vermutlich war einer der in Göttingen vorherrschenden Gründe, in Uffenbach sein Stiftungsversprechen an die Universitätsbibliothek wach zu halten.

Im Jahre 1755 wurde Uffenbach erneut als Architekt und Gutachter tätig. Als Freund der Familie legte er am 17. April 1755 seine Stellungnahme über den geplanten Umbau des Goethehauses am Großen Hirschgraben durch Johann Caspar Goethe (1710-1782) und die damit verbundenen Handwerkerkosten vor. ${ }^{348}$

Kurz vor der offiziellen, rechtlichen Eintragung der Schenkung 1764 nach Göttingen ${ }^{349}$ versuchte Uffenbach, Teile derjenigen Bereiche, die nicht an die Universitätsbibliothek Göttingen gehen sollten, an den dänischen Hof zu geben. Aus den Berichten von 1763 und 1764 des Königlich Dänischen Legationsrates

durch Vermächtnis an das Museum Wiesbaden und gilt schon seit 1959 als verschollen, vgl. Emmerling 1959, S. 140, Anm. 1.

344 Göttingen, Kunstsammlung der Georg-August-Universität, Inv. Nr.; GG 126 Unbezeichnet, vor 1746, Öl auf Kupfer, 41 x $31 \mathrm{~cm}$. Auf der Rückseite die Inschrift: J. Frideric. Armand ab Uffenbach. M. Brittanniae Regi in legione Tormentaria Pro Tribunus. Postea Reipublicae Patriae Moeno Francofurtensis Proto Scabinus et Senator Natus d. 6. Maji Anno MDCLXXXVII. Provenienz: 1770 Legat der Witwe Uffenbachs, Maria Magdalena geb. von Bertram, an die Universitätsbibliothek Göttingen.

Vgl.: Kat. Göttingen 1926, Nr. 96; Emmerling 1953; Emmerling 1959; Kat. Göttingen 1987, S. 181, Nr. A 13 und Meyerhöfer 2000,2.

Arnim 1928,1, S. XI; Arnim 1928,3, S. 33; Suchier 1916, S. 60

346 Hirsching 1812, Arnim 1928,3, S. 33, Arnim 1928,4, S. 169, 188 und 224 (im „Verzeichnis der Mitglieder, geordnet nach den einzelnen Wissenschaftsgebieten“ unter: „Technik und Technologie").

Vgl. Brief Gesner vom 26.11.1751 in Cod. Ms. Uffenbach 20/I, p. 20-21.

Vgl. Arnim 1928,4, S. 5: „Beschränkte sich die Stiftungsurkunde vom 13. Juni 1751 nur auf eine ganz geringe Mitgliederzahl (1 Präsident, 1 Sekretär, 3 Ordentliche, 9 Auswärtige, 3 Außerordentliche Mitglieder und 6 Ordentliche Zuhörer), ...“

348 Wolff/Jung Bd. III/1914, S. 171-207.

349 Vgl. Kapitel 5 „Geschichte der Schenkung nach Göttingen.“ 
Johann Friedrich Moritz (1717-1771) in Frankfurt an seinen Auftraggeber, den dänischen Minister des Äußeren Johann Hartwig Ernst Graf von Bernstorff (1712-1772) ist ersichtlich, dass Johann Friedrich von Uffenbach Kontakte zum dänischen Hof suchte, um als Mathematiker in die Königlich dänische Sozietät der Wissenschaften aufgenommen zu werden. Als Gegenleistung bot er dem dänischen Hof Stücke aus seinem Naturalienkabinett an. In einem Brief des Legationsrates vom Ende des Jahres 1763 an Bernstorff heißt es: „Den Werth der offerirten Naturalien zu bestimmen, dürfte mir um so schwerer fallen, als derley Stücke gemeiniglich nach ihrer rarität und dem pretio affectionis ästimiret zu werden pflegen. " 350 Moritz machte Bernstorff weitere Hoffnungen auf die übrige Sammlung Uffenbachs, da er im selben Brief schreibt: ,[...] wann nicht zugleich auf die übrige rare Sammlungen dieses Mannes einige Rücksicht in der guten Hofnung genommen werden sollte, daß er alle, oder doch eine von solchen auf eine raisonable Weise nach Copenhagen destiniren mögte, wann seine ambition auf eine angenehme Weise gerühret werde.“

Neben seiner Akademiemitgliedschaft versprach Uffenbach sich von seiner Schenkung nach Frederiksborg ein Exemplar des 1758 erschienenen Werkes von dem Nürnberger Kupferstecher Franz Michael Regenfuß (1712-1780) „Auserlesne Schnecken Muscheln und andre Schaalthiere“.351 Im Januar 1764 übergab Uffenbach Moritz ,ein Kästlein mit denen bereits bemerckten Naturalien, worinnen sich das von dem geschickten Ebenisten verfertigte, sehr fein eingelegte Kästlein befindet. Es ist dieses von besonderer Kunst und Schönheit. Der Grund stickt auf ein angenehmes violet, und auf allen Seiten ist es mit dem schönsten Blumenwerck nach dem Leben eingelegt, also daß man solches für ein Gemählde, nicht aber für eingelegte Arbeit achten sollte. Bey denen Naturalien befindet sich das einberichtete große Stück goldschweren Granad, nebst 2 verpetschirten ledernen Beutel mit gediegenem Mercurio aus Ungarn. Es hanget demnach von höchsten Befehlen $a b$, mit was für Gelegenheit nunmehro die Übersendung besagten, etwann 8 Pfd. schweren Kästleins geschehen sollte.“352

350 Alle Briefstellen von Moritz an Bernstorff sind zitiert nach Bobé 1938, S. 54-57, hier S. 54.

351 Franz Michael Regenfuß, Auserlesne Schnecken Muscheln und andre Schaalthiere auf allerhoechsten Befehl Seiner Koeniglichen Majestaet nach den Originalen gemalt, in Kupfer gestochen und mit natuerlichen Farben erleuchtet $=$ Choix de coquillages et de crustaces peints d'apres nature graves en taille douce et illumines de leurs vraies couleurs, Kopenhagen 1758.

Das Buch befindet sich nicht in der Bibliothek Uffenbach. 
Am 31. Januar 1764 berichtete Moritz nach Dänemark, dass Uffenbach bei ihm vorstellig geworden sei, um ihn zu bitten, „daß er zum Lustre der doch meist ausgestorbenen von Uffenbachischen Familie die allerhöchste königliche Begnadigung mit einem Orden erhalten mögte."353 Uffenbach stellte Moritz weitere Schenkungen nach Dänemark in Aussicht, falls ihm diese Ehre zuteilwerden würde. Moritz vermutete sogleich, dass es sich um ,seine rare Sammlungen von Handzeichnungen berühmter Mahler und vollständige Collection von Kupferstichen“354 handeln würde. Uffenbachs Wunsch nach einem hohen dänischen Orden wurde jedoch nicht gewährt. Auch kam das Kupferstichkabinett nicht nach Dänemark. Uffenbach wurde 1764 als Dank für sein Geschenk - das „,sehr fein eingelegte Kästlein“ - das Diplom eines Mitgliedes der Königlichen dänischen Sozietät der Wissenschaften überreicht. ${ }^{355}$

Der Sammler muss weiterhin Kontakte nach Dänemark gepflegt und dem Naturalienkabinett in Frederiksborg wiederholt Stücke übereignet haben. Spätestens im März 1765 hat er eine weitere Kiste nach Kopenhagen geschickt, da am 23. dieses Monats der dänische Hofdreher Lorenz Spengler (1720-1807) ${ }^{356}$ ihm in einem Brief über das Auspacken der Kiste und Einsortieren der Naturalien in das Kabinett in Frederiksborg berichtete. ${ }^{357}$ Am 4. Mai 1765 bedankte sich auch der dänische Oberhofmarschall, Christian Friedrich Graf von Moltke (17361771), für die Übersendung dieser Stücke. ${ }^{358}$ Inwieweit sich Uffenbach doch noch einen dänischen Orden erhoffte, kann nur vermutet werden.

Bobé 1938, S. 56.

Bobé 1938, S. 56.

355 Das Diplom findet sich weder in den Göttinger Akten noch in den Archivbeständen in Frankfurt am Main.

356 Spengler war Bildhauer, Naturforscher und Schriftsteller. In der Bibliothek Uffenbach befindet sich die Schrift Spenglers: Praktische Anzeige wie die ... eisernen Stubenöfen mit wenigen Kosten zu einen weit nützlichern Gebrauch einzurichten wären, Kopenhagen 1750 ( $8^{\circ}$ Bibl. Uff. 773). Spengler schreibt auch in seinem Brief, dass er dem ,vortrefflichen und weit berühmten physicalischen Cabinet" Uffenbachs gerne etwas beisteuern würde. 


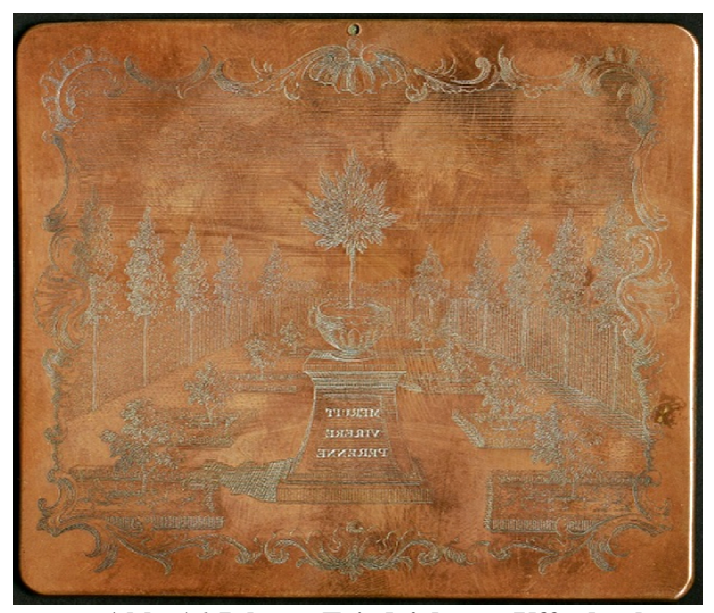

Abb. 16 Johann Friedrich von Uffenbach, Druckplatte für Dedikationsillustration, Kunstsammlung der Universität Göttingen Inv. Nr. DP 9

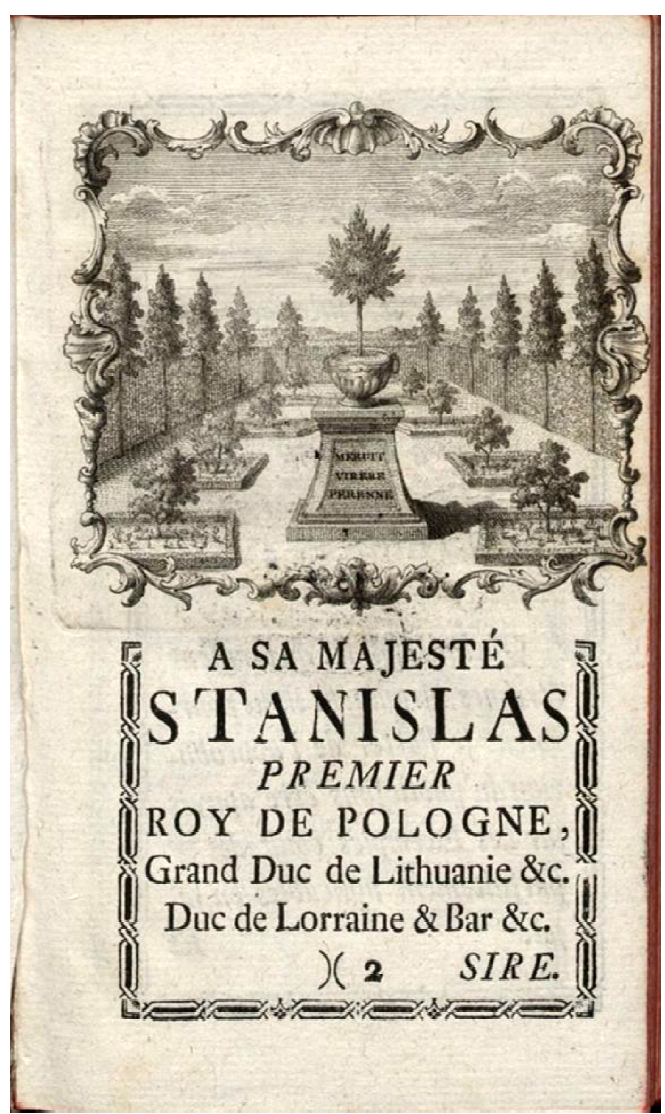

Abb. 17 Johann Friedrich von Uffenbach, Vorzüglichkeiten des Hochbejahrten Standes, Titelkupfer zur Dedikation

Im Alter von 78 Jahren wurde er 1765 wieder als Übersetzer und auch als Herausgeber tätig. Der Göttinger Medizinprofessor Georg Gottlob Richter (16941773) hatte am 17. September 1764 den lateinischen Vortrag „de commodis sene et utis“ vor der Akademie in Göttingen gehalten. ${ }^{359}$ Uffenbach übersetzte diese Schrift ins Deutsche und gab sie anonym 1765 unter dem Titel „Vorzüglichkeiten des Hochbejahrten Standes“360 heraus. Die vierseitige, französische Dedikation ist an den 88-jährigen polnischen Exilkönig Stanislaus I. Leszynski (1677-1766) gerichtet, der im lothringischen Lüneville residierte und den Uffenbach, wie er schrieb, persönlich nicht kannte (Abb. 16 und 17). Der Exilkönig bedankte sich

359 Göttingische Anzeigen von gelehrten Sachen 119. Stück, S. 961 . 964, Göttingen 1764.

360 Uffenbach 1765; vgl. Meusel 1815, S. 175.

Auf der ersten Seite der französischen Dedikation befindet sich die Radierung einer ornamental gerahmten Ansicht eines barocken Gartens, in dessen Vordergrund auf einem Postament mit der Inschrift: MERUIT / VIRERE / PERENNE [Er verdient es, ewig in Blüte zu stehen] eine Schale mit einem kleinen Bäumchen steht. Die Druckplatte zu dieser Radierung, die von Uffenbachs Hand stammt, befindet sich heute in der Kunstsammlung der Georg-August-Universität Göttingen. 82 x 98 mm, o.M. gelocht, nicht signiert, Inv. Nr.: D9. 
am 28. September 1765 bei Uffenbach. ${ }^{361}$ Richter selbst schickte am 20. September 1765 einen Dankesbrief an Uffenbach für die Übersetzung. ${ }^{362}$

Im Jahre 1767 wurde Uffenbach noch einmal für den Frankfurter Rat mit einem Gutachten betraut und tätig. Es ging hierbei um eine Stellungnahme zur Errichtung einer Malerakademie in Frankfurt am Main. Die Frankfurter Künstler waren immer noch in der Malerzunft gebunden, waren somit Handwerker wie die zur selben Zunft gehörenden Lackierer, Anstreicher und Vergolder. 363

Zuvor hatten am 2. April 1767 neun Maler beim Rat eine Eingabe vorgelegt, in der sie um die Entlassung aus der Zunft baten, um sich in einer zu gründenden Malerakademie ausbilden zu können. ${ }^{364}$ Bei den Künstlern handelte es sich um Franz Lippold (1790-1768), Justus Juncker (1703-1767), dessen Sohn Isaak Juncker (1727-1789), Christian Georg Schütz d.Ä. (1718-1791), Wilhelm Friedrich Hirt (1721-1772), Johann Volckmar Paderborn (1726-1776), Johann Daniel Bager (1734-1815), X. Honnête (1735-1793) ${ }^{365}$ und Georg Melchior Kraus (1737-1806). Daraufhin veranlasste der Stadtrat den Schöffen von Uffenbach, der von den Malern als Präses der Akademie vorgesehen worden war, ein Gutachten über den Nutzen einer solchen Institution zu verfassen.

Uffenbach äußerte sich am 11. April in einem vierseitigen Schreiben positiv zu dem Ansinnen der Künstler. Hatte er doch auf seinen ausgedehnten Reisen z.B. die großen Malerakademien von Venedig, Rom und Paris - für die Künstler wertvolle Einrichtungen - kennengelernt. Auch wehrte er sich in seinem Gutachten gegen die Vermutung des Rates, eine Malerakademie würde den öffentlichen oder Stiftungskassen finanzielle Belastungen bringen, da die Maler schon jetzt eine kostenpflichtige Zeichenschule eingerichtet hätten. Sowohl der vorgeschlagenen Ordnung als auch dem Antrag der Künstler, den „Präses“ der Akademie selbst zu bestimmen und Uffenbach selbst zu diesem zu machen, stimmte er zu. Aufgrund dieses Gutachtens beschloss der Rat am 25. Mai die

Cod. Ms. Uffenbach 20/I, p. 355.

Warum Uffenbach die Übersetzung dem polnischen Exilkönig dediziert, geht aus den Quellen nicht hervor.

362 Cod. Ms. Uffenbach 20/I, p. 32-33.

363 Die Künstler, die in der Freien Reichsstadt Frankfurt am Main ansässig waren, versuchten auch vorher schon immer wieder, sich vom Zunftzwang zu befreien. Jeder vorhergehenden Anstrengung war aber durch den Rat nicht stattgegeben worden, vgl. Kat. Frankfurt 1982,1, S. 26-27, wo ein kurzer Abriß der verschiedenen Versuche gegeben wird.

364 Vgl. Valentin 1889, Valentin bearbeitet die Dokumente des ISG Frankfurt; s.a. Kat. Frankfurt 1982,1, S. 27 und Kat. Frankfurt 1982,2, S. 122-123.

S. vollständige Transkription im Anhang, S. 286-289. Vgl. Gwinner 1862, S. 296; nach Gwinner lautet der Vorname Honnêtes Jean Francois. 
Errichtung einer Akademie mit der Einschränkung, dass der Präses vom Rat bestimmt werden sollte.

$\mathrm{Zu}$ einem der Antragsteller hatte Uffenbach als Gutachter ein besonderes Verhältnis. Es handelt sich um Christian Georg Schütz d.Ä., aus Flörsheim stammend, der Ortschaft, in der das Landgut Uffenbachs gelegen hatte. ${ }^{366}$ Uffenbach hatte damals das Talent des jungen Schütz erkannt und ihn - nach Christian Ludwig von Hagedorn $(1712-1780)^{367}$ - zu dem Frankfurter Freskenmaler Hugo Schlegel (1684-1737)368 in die Lehre geschickt. Uffenbach besaß von Schütz „Eine schöne Landschaft, wobey Flörsheim am Mayn vorgestellet wird" "369 wobei zu vermuten ist, dass Uffenbach selbst diese Ansicht bei dem Künstler in Auftrag gegeben hatte.

Johann Friedrich Armand von Uffenbach verstarb am 10. April 1769 in seinem Haus auf der Zeil und wurde am 13. April auf dem Frankfurter Peterskirchhof beigesetzt. ${ }^{370}$ Der Frankfurter Leichenbitter Johann Gottfried Guaita (1710/111775) hielt die Leichenpredigt. 371

Schon am 20. April meldet der Göttinger Bibliotheksleiter Christian Gottlob Heyne (1729-1812) in den „Göttingische Anzeigen von gelehrten Sachen“: „Den 10ten April ist der Herr J. Fr. von Uffenbach, Schöffe und Senator der freyen Reichsstadt Frankfurt, Mitglied der hiesigen K. Societät der Wissenschaften, in seinem 82. Jahre verschieden. Unsre Universität wird sein Andenken stets mit Dankbarkeit verehren, da er ihr durch seine $\mathrm{zu}$ andrer Zeit angezeigte

366 S. Kapitel 4 ,Lebenslauf des Johann Friedrich Armand von Uffenbach“.

367 Hagedorn 1755, S. 247-248.

368 Vgl. Gwinner 1862, S. 253.

369 Uffenbach 1771, S. 35, Nr. 132. Desweiteren hatte er von Schütz einen Deckel für ein Gemälde Sprangers malen lassen (Vgl. Uffenbach 1771, S. 31-32, Nr. 73.)

Ausführlich zu Schütz: Kat. Frankfurt 1991,2, Kat. Flörsheim 1992.

370 ISG Frankfurt, Totenbuch der Evangelischen Kirche in Frankfurt am Main, p. 198: (s. Transkription im Anhang, S. 284), Arnim 1928, S. XI.

Das Grab Uffenbachs besteht heute nicht mehr. Der Petersfriedhof lag direkt an der Stadtmauer, 1508 geweiht, 1828 geschlossen; vgl. Heckmann/Michel 1982, S. 28.

371 Ehemaliger Dominikanermönch, konvertierte 1738, erwarb das Bürgerrecht und ließ sich als Privatlehrer, Verfasser von antiklerikalen Streitschriften und Leichenbitter in Frankfurt nieder (vgl.: https://www.frankfurt.de/sixcms/detail.php?id=771547\&_ffmpar[_id_inhalt]=4555682 vom 24.11.2017).

Die Leichenpredigt verzeichnet in: Katalog der Leichenpredigten und sonstiger Trauerschriften im Institut für Stadtgeschichte Frankfurt am Main und im Freien Deutschen Hochstift Frankfurt, Goethe-Museum, bearb. von Rudolf Lenz, Stuttgart 1999 (= Marburger Personalschriften-Forschungen 26). 
ansehnliche Stiftung für hiesige Bibliothek einen so großen Beweiß seiner Zuneigung gegeben hat." 372

Auch die Königliche Societät der Wissenschaften zu Göttingen widmet in ihrer Sitzung vom 9. Dezember 1769 Uffenbach ein Gedenken, von welchem in den „Göttingische Anzeigen von gelehrten Sachen“ vom 4. Januar 1770 berichtet wird: „Sie vermisst, unter ihren auswärtigen Mitgliedern, den Hrn. Johann Friedrich von Uffenbach, Kaiserlichen Rath, Exconsuln, Protoscabinen, und Senatorn der freyen Reichsstadt Frankfurt; von dessen Stärke in verschiedenen, besonders mathematischen Wissenschaften, setrener [sic; seltener] Einsicht in den schönen Künsten, eignen glücklichen Versuchen darin, mit Geschmack und Auswahl gemachten Sammlungen, wesentlichen Verdiensten um die Republik, edlem, menschlichfreundlichen Charakter, und berühmtem Vermächtnisse an unsere Universität, Hochachtung und Erkenntlichkeit sprachen. Sein Name wird bey uns ewig unvergeßlich seyn."373

\subsection{Geschehnisse nach dem Tod von Johann Friedrich von Uffenbach}

Nach dem Tod Uffenbachs kam es zwischen der Witwe Uffenbachs, Maria Magdalena geb. von Bertram, und einer Nichte Uffenbachs, der verwitweten Landjägermeisterin von Veltheim, geb. von Lindheim, und der Universität zu Göttingen zu fast zweijährigen Auseinandersetzungen betreffs der Herausgabe eines Großteils der Sammlungen von Johann Friedrich. ${ }^{374}$ Danach wurde der übrige Teil seines privaten Eigentums 1771 versteigert. Für diesen Zweck ließ die Witwe einen „Catalogus von Original-Handzeichnungen, Gemählden und Statuen, nebst einigen Naturalien, wie auch optischen und technischen Maschinen“ zusammenstellen und herausgegeben, in dem die zur Versteigerung stehenden Stücke beschrieben werden. ${ }^{375}$

Im Vorwort des Auktionskataloges werden die Gegenstände kurz charakterisiert, wobei den beiden großen Klebebänden mit Handzeichnungen, die Uffenbach selbst angelegt hatte, besondere Aufmerksamkeit gilt. Es heißt dort: „Da der wohlseel. Sammler ein so großer Kenner der Kunst [der Zeichnung] war, 
so hat man sich nicht unterfangen von denenjenigen Zeichnungen, welchen Derselbe nicht Selbsteigenhändig die Nahmen beygesetzt, den Künstler zu erforschen und anzuzeigen; [...]." 376 Auch nimmt die Beschreibung der insgesamt 232 Zeichnungen in den beiden Foliobänden etwa die Hälfte des 63 Seiten starken Oktavbuches ein. Sie bilden den ersten Abschnitt des Auktionskataloges.

Im zweiten Abschnitt werden 216 Nummern mit „Gemählde, Migniature, Craion, Wasserfarb und Glasmahlerey“ und 20 Nummern „An Emaillen=Mahlereyen“ dargestellt. Im dritten Abschnitt mit insgesamt 164 Nummern, der mit „Figuren. Statuen. Bas=reliefs.“ überschrieben ist, werden nicht nur diese Art von Gegenständen aufgenommen. Hier finden auch die Beschreibungen der vier Sammlungsschränke mit Naturalien, einer Schleif- und Poliermaschine für optische Linsen und zweier Drechselbänke mit jeweiligem Zubehör und von dem ehemaligen Besitzer gearbeiteter Stücke ihren Platz.

Die nur dreitägige Auktion im Uffenbachischen Haus auf der Zeil dauerte vom 6. bis zum 8. Mai 1771. Der öffentlich bestellte Auktionator hielt sich nicht an die Reihenfolge des gedruckten Kataloges. Die Versteigerung begann mit der Nummer 84 des dritten Abschnitts „Figuren. Statuen. Bas=Reliefs.“ Insgesamt erbrachte die Auktion lediglich 751 Gulden und 43 Kreuzer, wobei weder die beiden Zeichnungsbände noch viele der Gemälde verkauft wurden. Das „Vergantungs=Register“ der Gegenschreiberei des Frankfurter Rates belegt, dass die schleppende Vergantung 377 fast nur von Frankfurter Bürgern wahrgenommen wurde. ${ }^{378}$ Es sind die bekannten Frankfurter Patriziernamen, wie Bernus, Ettling, Gerning, Goethe, Neufville und Städel unter den Ersteigerern. Auch der Frankfurter Sammler und Kunstschriftsteller Heinrich Sebastian Hüsgen (17451807) erwarb Gemälde, Kleinplastik und Statuen. Auffällig an der Versteigerung ist der geringe Verkauf an Gemälden. Vielleicht hatte die Witwe die Auktion gestoppt, handelte es sich doch um die repräsentative Ausstattung des Hauses auf der Zeil, welches sie selbst noch bewohnte.

Die Witwe Uffenbachs verstarb im Frühjahr 1775. Daraufhin wurde von den Erben - unter anderen der „ultimus familiae“, Johann Friedrich von Uffenbach (1725-1799) - wieder eine öffentliche Auktion im Haus auf der Zeil anberaumt. Für diese Vergantung wurde der Katalog von 1771 überarbeitet und neu

\footnotetext{
376 Uffenbach 1771, Vorwort.

377 Ein im 18. Jahrhundert in Süddeutschland übliches Wort u.a. für Versteigerung oder Auktion. Vgl. Ketelsen/Stockhausen 2002, S. 14.

378 Signatur: ISG Frankfurt Vergantungs-Register 1771/Uffenbach. Die vollständige Transkription des Gegenschreiberbuches der Auktion s. Anhang, S. 290-305.
} 
herausgegeben. ${ }^{379} \mathrm{Ihm}$ wurden hinzugefügt ein Großteil des Schmuckes der Verstorbenen und des zum Haushalt gehörenden, wertvollen Silbergeschirrs. ${ }^{380} \mathrm{Im}$ Vorwort sind wieder die beiden Klebebände mit Zeichnungen herausgehoben, und im Katalog wird jede Nummer detailliert erklärt.

Bei der am 15. Mai begonnenen Versteigerung, die mit Unterbrechungen bis zum 2. Juni 1775 dauerte, kam schließlich der gesamte bewegliche Besitz zum Aufruf, der sich im Uffenbachischen Haus befand. ${ }^{381}$ Mehr als die Hälfte der versteigerten Objekte sind nicht im Auktionskatalog verzeichnet. Anhand des Gegenschreiberbuches des Frankfurter Rates kann man die Menge der Objekte und den Verlauf der zwölf Werktage währenden Auktion sehr gut verfolgen. ${ }^{382}$ Neben den Möbeln, Haushaltsgegenständen, Pflanzen, weiterem Schmuck und Silberwaren kamen einige Musikinstrumente und die gesamte Sammlung an

379 Uffenbach 1771.

380 Uffenbach 1775.

381 Die Versteigerung wurde in den „Ordentliche wochentliche Franckfurter Frag= und Anzeigungs=Nachrichten, No. XL, Freytags, den 12. May 1775, Extraordinairer_Anhang No. 40. 1775.“ wie folgt angekündigt: „Montag den 15ten May und folgende Tage, werden in des seel. Herrn Schöf von Uffenbachs Behausung auf der Zeil eine auserlesene Sammlung von Handzeichnungen und Gemählden, allerhand Pretiosen und Silbergeschirr, wie auch verschiedene Curiositäten, wovon die Catalogi bey denen Herren Ausruffern Fayh und Helm zu bekommen sind, sodann ausser denen in dem Catalogo bemerckten Stücken verschiedenes schönes Gewehr, eine französische Bettlade mit einem grünem seidenen Vorhang benebst andern Bettladen, ein Armsessel benebst 6. Stühlen und 6. darzu gehörige Tabourets [= Fußschemeln] mit grünem Sammet=Plüsch überzogen, ein Cannapee mit sauber genäheter Arbeit, 6. nußbaumene mit Rohr geflochtene Stühle, nußbaumene Kleider= und Geräth=Schränck, 2. besonders schöne Schräncke, an welchem einen 2. Glasthüren und an dem andern eine Mahlerey befindlich, verschiedene Schreib= und Spieltisch, 6. auf einander gesetzte Kisten=Schränk mit Glasthüren, ein fein laquirter vollständiger Nachttisch, grosse Spiegel mit verguldener und schwartzen Rahmen, 2. grosse eiserne Kisten, doppeltes Camingezeug mit allem Zugehör, ein grosser gläserner Cronen=Leuchter, 6. gute und 4. schlechte Wandleuchter, 2. grosse gläserne Hauß=Laternen, benebst allerhand Bouteillen und Gläser, ein grosser Wandleuchter mit 2. Lichter von gelben Blech, eine kleine Uhr auf einem Gestell, ein inwendig perpectivisches Kästgen von Schildkrot, eine kleine Haußspritz, etwas Kupfer, Meßing, Eisenwerck, Porcellain und Aufsätz, an den Meißtbietenden öffentlich verkauft, der Anfang aber mit denen Gemählden gemacht werden.“

Am zweiten Tag der Auktion, 16. Mai 1775, wurde erneut eine leicht veränderte Annonce in den Frankfurter Nachrichten veröffentlicht: „In des seel. Herrn Schöff von Uffenbach Behaussung auf der Zeil wird anheute den 16ten dieses mit öffentlicher Verganthung derer Gemählden fortgefahren, darauf aber folgende Stücke verkaufft werden, als die schon bemerckte Sammlung von Original Handzeichnungen, [...], 2. Schaberacken, wovon die eine mit Silber bordirt ist, Schlittengeläut, ein grosser Vorrath gebunden und ungebundener Noten, benebst einem Dudelsack von Sammet mit goldenen Borden, einige Flöten und Music=Pulten, kleine Canonen und verschiedene alte Mobilien.“

382 Signatur: ISG Frankfurt Einundfünfzigerkolleg - Gegenschreiberbücher- 3079 [Verganthungs-Buch, angefangen den 1ten 7 bre 1774 und gehet bis d. 30. May 1775, No. 5.] Die vollständige Transkription des Gegenschreiberbuches der Auktion s. Anhang, S. $306-355$. 
Musikalien zum Aufruf, für deren Zusammenstellung Johann Friedrich in Frankfurt bekannt war. ${ }^{383}$ Es werden hier erstmals auch verschiedene, nicht näher klassifizierte Konvolute Druckgraphik versteigert. ${ }^{384}$ Diese erst kurz vor seinem Tod erworbene Druckgraphik fehlt im „Index Titulorum“385, konnte also von Johann Friedrich nicht mehr aufgenommen werden. Ebenso wurden ,etliche Handzeichnungen“ sowie die beiden Klebebände mit Handzeichnungen versteigert, wobei diese an den Bankier und Zeichnungssammler Johann Goll van Franckenstein I. (1722-1785) gingen. ${ }^{386}$

Diese Auktion fand entgegen der ersten einen regen Zuspruch und war sehr erfolgreich. Wie bei der Auktion von 1771 waren es hauptsächlich Frankfurter Bürger, die als Ersteigerer auftraten. Bei den Käufern der Kunstgegenstände sind es Namen wie Gogel, Hüsgen, Pasquay, Lindheimer und Lersner. Aber auch Frankfurter Künstler erwarben Gemälde und Kleinkunst - beispielsweise Johann Daniel Bager oder Johann Andreas Benjamin Nothnagel (1729-1804). Insgesamt erbrachte die zweite, sehr erfolgreiche Auktion die Summe von 10.047 Gulden und 47 Kreuzer.

Mit dieser Vergantung waren diejenigen Mobilien aus Uffenbachischem Eigentum, die nicht nach Göttingen kamen, restlos versteigert. Durch die Tatsache, dass sich diese Gegenstände nicht oder kaum mehr eruieren lassen, kann nur anhand der Auktionskataloge und der erhaltenen Gegenschreiberbücher ${ }^{387}$ eine quantitative Analyse derselben vorgenommen werden.

383 Verganthungs-Buch No. 5, p. 236a (2 Violinen, 3 Flöten, 1 Flaschenett), 240a + b (21 Partien mit Musikalien, Kantaten, Opern und Oratorien). S. Anhang, S. 340.

In den Frankfurter Nachrichten No.41, Anhang vom 15. Mai 1775 wird die Auktion folgendermaßen angezeigt: „In des seel. Herrn Schöff von Uffenbach Behaussung auf der Zeil wird anheute den 16ten dieses mit öffentlicher Verganthung derer Gemählden fortgefahren [...] ein großer Vorrath gebunden- und ungebundener Noten, benebst einem Dudelsack von Sammet mit goldenen Borden, einige Flöten und Musikpulten u.a. “ [Zitiert nach: Frankfurter Nachrichten 1775,2]; Israel 1876, S. 57, dazu: „Unter diesen Noten befanden sich (laut Anzeige in No.44, Anhang) 'die vortrefflichsten Opern'.“

384 Verganthungs-Buch No. 5, p. 226b. Es handelte sich um fünf Partien ,allerhand Kupferstich“, „2 Bücher mit Kupferstich“ und „1 Band mit Wappen Calender“. Desweiteren ein Kupferstich mit der Ansicht des Petersdom in Rom und diverse Landkarten, S. Anhang, S, 316-317.

385 Kunstsammlung der Universität. S. Anhang S. 413-458.

386 Verganthungs-Buch No. 5, p. 227a. S. Anhang, S. 318.

387 Nicht bei Ketelsen/Stockhausen 2002 aufgenommen. 


\section{Geschichte der Schenkung nach Göttingen}

\subsection{Uffenbach als Vollstrecker des Testaments von Zacharias Conrad}

Als im Januar 1734 Zacharias Conrad von Uffenbach verstarb, übernahm Johann Friedrich die Vollstreckung des Testaments für die Erben. 388

Ein langjähriger Briefpartner des älteren Bruders war der Memminger Superintendent Johann Georg Schelhorn (1694-1773). Der erste Brief scheint von Zacharias Conrad 1725 an Schelhorn geschickt worden zu sein. ${ }^{389}$ Schelhorn wurde Zacharias Conrad von Uffenbach ein enger Vertrauter, persönlich getroffen haben die beiden sich aber nie. Es wurden insgesamt über sechzig Briefe in neun Jahren ausgetauscht, in denen sie sich nicht nur über Manuskripte und Briefe bedeutender Wissenschaftler austauschten; auch die familiären Umstände Uffenbachs wurden besprochen; so 1733 die gegen den Willen Zacharias Conrads und seiner Gattin stattgefundene Entführung der ersten Tochter, Sybilla Charlotte (1712-1746), durch ihren späteren Ehemann Ferdinand von Üchtritz ${ }^{390}$ und der Tod der zweiten, erst zwanzigjährigen Tochter Anna Sibylla (1713-1733). ${ }^{391}$

In einem an Schelhorn gerichteten Brief vom 30. September 1732 bestimmt Zacharias Conrad seinen Memminger Vertrauten dazu, den schriftlichen Nachlaß $\mathrm{zu}$ verwalten und zu verwerten; außerdem hatte er Schelhorn ,principem inter amicos locum“ angeboten. ${ }^{392}$ Am 17. Februar 1734, etwas über einen Monat nach dem Tod seines Freundes, bat Schelhorn Johann Friedrich förmlich um die eigenhändigen Manuskripte, die ihm der Verstorbene zugedacht hatte, um „die völlige Ausfertigung und publication seiner commentariorum de vita propria“ machen zu können. ${ }^{393}$ Anfang April 1734 hat Johann Friedrich das Legat an Schelhorn übersendet. ${ }^{394}$

Die Geschichte der Stiftung Johann Friedrich von Uffenbachs nach Göttingen erschien stark gekürzt in: Meyerhöfer 2000,1.

Vgl. ausführlich über die Verbindung: Braun 1930, bes. S. 70-72 mit den transkribierten Briefen.

Lebensdaten unbekannt.

Vgl. auch den Nachruf Johann Friedrich Armands auf Zacharias Conrad im Commercium Epistolicum (Cod. Ms. Uffenbach 20/I, B1. 199a-c).

Exzerpt des Briefes in: Cod. Ms. Uffenbach 20/I, B1. 185.

Cod. Ms. Uffenbach 20/I, B1. 179-181; s. Franke 1965,1, S. 1324, Braun 1930, S. 530-531.

Cod. Ms. Uffenbach 20/I, B1.***, Braun 1930, S. 539-540. 


\subsection{Die Veräußerung der Bibliothek des Zacharias Conrad von Uffenbach}

Die größte Mühe und langwierigste Arbeit hatte Johann Friedrich mit der Vergantung der verbliebenen Bücher und Manuskripte, die nach dem ersten großen Verkauf zu Lebzeiten Zacharias Conrads im Jahre $1730^{395}$ übriggeblieben waren. Noch 1734 ließ Johann Friedrich die 14-seitige Zusammenstellung „Apparatus epistolicus Bibliothecae Uffenbachianae“ drucken, in der die große Briefsammlung zum Verkauf angeboten wurde. Die über 20.000 Briefe gingen zwischen September und dem Ende des Jahres 1735 an den langjährigen Korrespondenten Zacharias Conrads, den Hamburger Professor und Hauptpastor von St. Katharinen Johann Christoph Wolf (1683-1739). ${ }^{396}$

Im folgenden Jahr, 1735, ließ Uffenbach von dem Frankfurter Buchhändler Franz Varrentrapp (1706-1786) einen vierbändigen Katalog der Bücher erstellen und drucken.397 Varrentrapp hat auch die Verauktionierung der Bücher übernommen, die ab dem 7. März 1735 im Hause Zacharias Conrads stattfand. Uffenbach schreibt am 23. September 1734 an Schelhorn: ,[...] auf den Schluß gekommen, eine offentliche auction zu unternehmen, [...], so hat der hiesige buchhändler Frantz varrentrapp einen neuen und in die kürtze gebrachten [Katalog] der preße übergeben, dieweil das gantze vorhaben durch ihn zu stande gebracht werden soll." ${ }^{398}$

Die weder an Schelhorn oder Wolf angebotenen Codices wurden aber nicht im Katalog erwähnt und auch nicht auf der Auktion aufgerufen. Johann Friedrich wollte den verbliebenen Rest der Handschriften an bekannte Wissenschaftler veräußern, was aber anscheinend nicht gelang. 1747 ließ er einen Katalog mit dem Titel „Catalogus manuscriptorum codicum bibliothecae Uffenbachianae Francofurti ad Moenum typis Balthasaris Diehlii MDCCXLVII“399 drucken und versandt ihn an verschiedene Sammler und Bibliotheken, so auch 1748 an die Hamburger Stadtbibliothek. Der Bruder des 1739 verstorbenen Johann Christoph Wolf, Johann Christian (1690-1770), der die Stelle des Hamburger

\footnotetext{
395 Vgl. Uffenbach 1729.

Vgl. Franke 1965,1, S. 1315-1324, der den Verkauf detailliert schildert.

396 Vgl. Franke 1965,1, S. 1325.

Johann Christoph Wolf vermachte die Sammlung zusammen mit seinen eigenen Autographen 1739 der Hamburger Stadtbibliothek.

397 Vgl. Uffenbach 1735.

398 Braun 1930, S.560. Der Brief befindet sich in der Bayerischen Staatsbibliothek München in dem Band: Cod. germ. Mon. 5458/II.

399 Uffenbach 1747.
} 
Stadtbibliothekars innehatte, zeigte Interesse an der Übernahme des gesamten Bestandes für die Bibliothek. Er kaufte für die geringe Summe von 1000 Talern die insgesamt 1162 Handschriften. Diese trafen im Juni 1749 in 14 Kisten verpackt in der Hansestadt ein. 400

Die sich über mehr als zehn Jahre hinziehende Veräußerung der Hinterlassenschaft Zacharias Conrads verursachte bei Johann Friedrich ein großes Unbehagen, weil zum einen der Erlös des Verkaufs nicht die erhoffte Summe erbracht hatte. Zum anderen wurde so die mit viel Eifer und finanziellem Aufwand zusammengetragene Bibliothek des älteren Bruders, die weit über die Grenzen der Stadt Frankfurt am Main berühmt gewesen war, vollkommen aufgelöst. 401

Dies waren zwei der ,inneren“ Beweggründe, weshalb er sich einen Platz für seine Sammlungen suchte, damit diese bei seinem Tod nicht in alle Winde zerstreut würden und seine Erben mit dem Verkauf nicht ähnliche Schwierigkeiten haben würden. Ein weiterer Anlass könnte die 1734 gegründete Universität in Göttingen selbst gewesen sein, galt sie doch als eine der aufstrebenden, der Aufklärung verpflichteten Ausbildungsstätten.

\subsection{Uffenbachs Bindungen an Frankfurt am Main}

Ein von außen an ihn herangetragener Beweggrund für seine Donation waren seine Verpflichtungen der Stadt Frankfurt am Main gegenüber. Johann Friedrich hatte vor 1744 keine Möglichkeit, ein hohes, gut dotiertes, innerstädtisches Amt zu bekleiden, da immer nur ein Familienmitglied Angehöriger des Rats sein durfte. In seinem Fall war dies sein Vetter Nikolaus von Uffenbach (*1682), der 1744 verstarb und so den Weg frei machte für Johann Friedrich, der mit der 47. Wahl am 15. September 1744 in den Stadtrat gewählt wurde. ${ }^{402}$

Bereits elf Jahre zuvor im Jahre 1733 hatte ihn das Bürger-Kollegium der Einundfünfziger zum Mitglied gewählt, aber Uffenbach trat seine Mitgliedschaft nicht an. Dieses Kollegium, das sich aus Vertretern der gesamten Bürgerschaft zusammensetzte, hatte die Überwachung der Gegenschreibereien zur Aufgabe und mußte vom Rat in allen finanziellen Entscheidungen angehört werden. Außerdem übte es die Kontrolle über den Siebener-Ausschuß aus, der die Verträge und

\footnotetext{
$400 \quad$ Vgl. Krüger 1978.

401 Vgl. Bogeng 1922, Bd. I, S. 256-258, Franke 1965.

402 Vgl. Krug 1846, S. 17.
} 
Akten des Rates zu begutachten hatte. ${ }^{403}$ Uffenbach hätte mit der Übernahme dieses anstrengenden, auch unbezahlten Amtes auf Lebenszeit in dem BürgerKollegium der Einundfünfziger die finanzielle Amtsführung seiner patrizischen Standesgenossen in Bezug auf das gesamte Bauwesen überwachen müssen. Daran konnte ihm nicht gelegen sein.

Da er sich weigerte, sein Amt pflichtgemäß zu übernehmen, versuchte der Frankfurter Rat, ihn durch eine Klage beim Reichshofrat in Wien zum Eintritt zu zwingen. Die Klage führte aber zu keinem Erfolg. In einem Brief vom 9. Juni 1736 schreibt Uffenbach an den Königlichen Commissarius der Göttinger Universität, den Juristen Gottfried Mascow (1698-1760): „Es sind nunmehr 2 1/2 Jahr daß von dem Ausschuße hießiger impetrantischer Bürgerschaft vermöge neuer Kayßerl. ordnungen zur Aufsicht über alles civil und militar bauwesen erkieset worden, und da diese höchst beschwehrliche Stelle ohne Entgeld nach platonischer reichsstättischer Art zeit lebens betretten und meine über alles hochgeschätzte ruhe, und ungebundenheit dadurch kränken solte, so wiedersetzte mich mit allen kräften. Ich wurde aber ohnerachtet zweyfacher lossprechung von hießiger Obrigkeit bey einem hochpreißl. Reichshofrathe zu Wien zum zweyten mahl auf das heftigste angeklaget, so daß ich gezwungen wurde, entweder mein vaterland, gegenseitigem begehren nach $\mathrm{zu}$ raumen, oder mich durch die bewerbung eines Militar caracters zu retten. “ 404

Uffenbach, der von weiteren Ämtern in den Stadtbehörden auch in Zukunft befreit sein wollte, begab sich auf die Suche nach einem hohen auswärtigen militärischen Rang, der ihn von solchen Aufgaben befreien konnte. In dem Brief an Mascow heißt es weiter: „Meine von Jugend auf getriebene Studien, und die nachher gefolgte 2 jährige Feldübung bey frantzöschen expeditionen ${ }^{405}$, wie nicht weniger das Hochfürstl. Darmstättische und etlicher generalen zeugnüs und vorschreiben an den Kayßerl. HofKriegsrath brachten mich auch balde zum Zweck, und ich erhielte das Kayßerl. patent, jedoch nicht in der Form als es gebetten und gewünscht hatte. Denn weil darin nicht mehr als die Kayßerl. Genade über das praedicat eines Stückhauptmanns, und nicht die gewöhnliche

Vgl. zur Aufgabe des Bürger-Kollegiums der Einundfünfziger: Koch 1986,1 und Kat. Frankfurt 1986, Bd. 2, S. 36-39.

404 Zitiert nach Arnim 1928,3, S. 29. In Arnim 1928,1, S. IX + X ist dieser Brief als Ganzes transkribiert. Das Schreiben Uffenbachs befindet sich nicht, wie Arnim 1928,1, S. IX schreibt, in den Akten des Universitätsarchivs Göttingen, die von der Donation handeln (Signatur: Kur. 4 V d6/2).

405 Hiermit meint der Autor u.a. seine Besuche des französischen Heerlagers vor Freiburg im Breisgau, das er im Oktober 1713 besichtigte, vgl. Cod. Ms. Uffenbach 29/I, S. 254-275. 
Formul der würcklichkeit enthalten war, so getrauete nicht damit zum vorschein zu kommen [...].“406 Uffenbach bekam zwar das Patent eines Kaiserlichen Hauptmannes der Artillerie, da mit dem Titel aber kein wirkliches militärisches Amt verbunden war, genügte dieser nicht, um ihn vor den Diensten in Frankfurt am Main zu schützen. Uffenbach benötigte also einen höheren auswärtigen Rang, der mit einer tatsächlichen Dienstverpflichtung verbunden war.

Der Syndikus der Göttinger Universität, der aus Frankfurt am Main gebürtige Heinrich Christian von Senckenberg (1704-1768), und der Göttinger Philologe Christoph August Heumann (1681-1764) hatten im März 1735 während der zweiten großen Auktion der Bücher Zacharias Conrads, schon zuvor bestehende Verbindungen zu Johann Friedrich von Uffenbach vertieft. Die Bekanntschaft mit Senckenberg kann durch dessen Herkunft aus Frankfurt am Main angenommen werden. Auch verfolgte dieser die Entwicklung der von Uffenbach gegründeten wissenschaftlichen Gesellschaft, nahm sogar selbst an einigen Sitzungen teil. 407 Heumann und Johann Friedrich haben schon vor dem Tod des älteren Bruders in Briefkontakt gestanden. Ein Schreiben Heumanns vom 21. September 1733 befindet sich im Commercium Epistolicum Uffenbachs - dort bedankt sich Heumann für die Übersendung dieses zweiten, von Johann Friedrich veröffentlichten Buches, das er neben das erste stellen wolle. ${ }^{408}$ Nach dem Ableben von Zacharias Conrad hatte sich Uffenbach im Februar 1734 an Heumann gewandt, um ihm die restliche Bibliothek seines Bruders für die Universität zum Kauf anzubieten. ${ }^{409}$

Bei einem Besuch im Uffenbachischen Hause werden Senckenberg und Heumann die Büchersammlung Johann Friedrichs gesehen und bemerkt haben, dass diese Spezialbibliothek eine sehr gute Ergänzung zu den Bülowschen Büchern sein könnte, die schon 1732 der sich noch in Gründung befindenden Universität vermacht worden waren. ${ }^{410}$ Aus dem Kontakt zu den beiden

406 Zitiert nach Arnim 1928,3, S. 29.

407 Er berichtete den Gesellschaftsmitgliedern am 6. Dezember 1737 über die feierliche Eröffnung der Georgia-Augusta und über seine dort gehaltene Dissertation über „Mayenblumen“ (vgl. Cod. Ms. Uffenbach 13/V, S. 688-696).

408 Vgl. Cod. Ms. Uffenbach 20/I, B1. 34-35.

Bei den beiden Büchern handelt es sich um Uffenbach 1726 und Uffenbach 1733.

409 Vgl. den Brief Heumanns an Münchhausen vom 8. Februar 1734, abgedruckt in: Bodemann 1885, S. 231-232.

410 Die Bibliothek des Hannoveranischen Adeligen Joachim Heinrich Freiherr von Bülow (1650-1724) umfasste 30687 Traktate in 8912 Bänden. Bülow hatte schon zu Lebzeiten an eine Stiftung seines Bücherschatzes gedacht. Zuerst sollte die Bibliothek der Lüneburger Ritterakademie vermacht werden; er entschied sich aber wegen des immer schlechter werdenden Rufes der Akademie für eine Stiftung an die Universität Helmstedt, falls seine 
Göttingern muß sich der Plan Uffenbachs entwickelt haben, seine Bibliothek mit der Graphiksammlung und den wissenschaftlichen Instrumenten der Göttinger Universität zu vermachen.

\subsection{Ablauf der Schenkung}

Seine Schenkungsabsicht kündigt Uffenbach der Leitung der Universität in einem ersten Brief am 30. Mai 1736 an, in dem er die Schwerpunkte der eigenen Sammlung beschreibt: ,[...] Es bedarf also Euere täglich mehr emporsteigende werkstatt der weisheit nichts weniger als die Beyhülfe eines ohnmächtigen fremdens meiner Art, und ich würde verspottens werth seyn, wenn zu diesem Absehen auf nachfolgende Gedancken gerathen wäre. Selbige gehen kürtzlich dahin, daß ich meinen kleinen, jedoch mit vieler mühe und kosten gesammelten vorrath von mathematischen und physicalischen Büchern nebst denen dazu dienlichen instrumenten nach meinem dem willen Gottes nach erfolgtem Ableben Euerer verwahrung als eigenthümlich wittmen, und $\mathrm{zu}$ gemeinem Nutzen und Gebrauch stiften mögte [...]“, und weiter unten zum graphischen Kabinett ,[...] Ich habe nechst diesem etwas weiter alhier anzufügen nicht nöthig, jedennoch kan nicht umhin des Anhangs in mehr gedachtem Bücherverzeichnüs zu gedencken, welche eine Sammlung von einzeln und gantzen Kupferwerken enthält. Ich bescheide mich dabey gar wohl, daß sie weder zur Mathesi noch der Naturlehre gehören, nichts destoweniger aber einen Ziehrath abgeben, der, weil er viele kosten veruhrsachet, eines platzes wohl werth seyn mögte [...].“411

Uffenbach hebt in seinem Schreiben die drei Teilgebiete seiner Sammlung heraus, die er der Göttinger Universität zu stiften beabsichtige: seine Bücher und wissenschaftlichen Instrumente und als weiteren, einzeln betonten Punkt sein graphisches Kabinett.

Die Schenkung sollte zwar zu Lebzeiten erfolgen, aber erst nach dem Tod des Eigentümers in Kraft treten. Dieses Nießbrauchsrecht, das Uffenbach als Bedingung stellte, weil er seine Bibliothek als Arbeitsinstrument weiter benötigte, sorgte in Göttingen für Unruhe. Die Verantwortlichen in Göttingen versuchten ihn

Erben den Nachlaß nicht selber verwalten wollten. Die Erben des kinderlosen Bülow waren drei Vettern, die einer Überführung nach Göttingen im Jahre 1734 zustimmten, vgl. ausführlich: Wolf 1983.

411 Zitiert nach der handschriftlichen Kopie dieses Schreibens im Universitätsarchiv Göttingen Kur. 4 V d6/2, Bl. 43-44; abgedruckt in Arnim 1928,3, S. 24-25.

Mit „Bücherverzeichnüs“ ist Cod. Ms. Uffenbach 47 gemeint. Das Verzeichnis seiner Bücher und der wissenschaftlichen Instrumente hatte er durch den Göttinger Syndikus Senckenberg nach Göttingen bringen lassen. 
davon abzubringen. Noch am 20. April 1736 schreibt Heumann an Uffenbach hinsichtlich einer Stiftung zu Lebzeiten: „Erstlich kan solchergestalt alles nach dero Gefallen beßer regiret, und die ganze Einrichtung aufs beste gemachet werden. Zum anderen haben Ew. HochEdelgeb. auf diese Weise selbst das Vergnügen, zu sehen, mit was für Hochachtung nicht nur die Academie, sondern auch der Königl. Herrn Minister. Excellenz Dero Don gratuit ${ }^{412}$ aufnehmen werden. Ja es ist nicht zu zweifeln, es werde selbst Sr. Königl. Maj. bey dieser Gelegenheit Dero Person bekant werden, und höchstgedachte Maj. auf den, der um Ihre Universität sich auf eine so ausnehmende Art verdient machet, einen besondren Gnadenblick wenden. Drittens und letztens ist es der höchsten Billigkeit gemäß, ut gloria tibi hinc debita vivus et praesens fruaris ${ }^{413}$, und daß Sie würcklich die Freude genießen, zum Bono publico ${ }^{414}$, mithin zur Ehre Gottes, eine so ansehnliche Stiftung gemachet zu haben. “415

Uffenbach ging auf diesen Vorschlag nicht ein, so verlockend er auch von Heumann vorgetragen wurde, da er u.a. die Bibliothek für seine Studien zur Architektur brauchte. Wie oben ausgeführt, setzte er am 30. Mai 1736 die Universität Göttingen offiziell von seiner Schenkungsabsicht in Kenntnis. Schon im April des Jahres hatte er durch den Göttinger Syndikus Senckenberg eine Kopie seines Bibliothekskataloges mit dem Titel: „Kurtzes Verzeichnüs derer Mathematischer Physicalischer und Kupfer-Bücher, wie auch des Vorraths einiger hiezu gehöriger Instrumenten, mein Johann Friedrich von Uffenbach“ an die Bibliothek gesandt. ${ }^{416}$

Auf das Schreiben Uffenbachs vom 30. Mai reagierte das Göttinger „concilium academicum“, das Mascow eigens einberufen hatte, sehr schnell: am 6. Juni sandte es eine Abschrift des Schenkungsbriefes an die Hannoverschen Geheimen Räte und meldete seine Bereitwilligkeit, ,per notarium et testes“417 die Donation zu akzeptieren. ${ }^{418}$ Das offizielle Dankesschreiben an Uffenbach datiert vom 11. Juni 1736; es war von dem Göttinger Philologen und Leiter der 
Universitätsbibliothek Johann Matthias Gesner (1691-1761) aufgesetzt worden. ${ }^{419}$ In diesem werden die Bedenken und Wünsche einzelner Universitätsmitglieder, die auf eine Nutzung der Stiftung schon zu Lebzeiten gedrängt hatten, vollständig zurückgenommen. Auch wurde Uffenbach zugesagt, dass seine Schenkung gesondert aufgestellt und benannt werden würde. ${ }^{420}$

Da das „,concilium academicum“ unter Mascow aber mit der Absichtserklärung einer Schenkung durch Uffenbach nicht zufrieden war und Befürchtungen hegte, dass der Stifter oder die Erben sich an diese Schenkungsabsicht nicht halten würden, drängten sie auf eine gerichtliche Eintragung. Es sollte nach Art der Bülowschen Donation ein „Instrumentum publicum" 421 formuliert werden, in dem Uffenbach eine ausdrückliche Versicherung abgibt, dass es sich um eine „donatio inter vivos“422 handele. Zu diesem Zweck beauftragte Mascow den Syndikus von Senckenberg, Uffenbach seine Aufwartung zu machen. Selbst der Kurator der Universität, Gerlach Adolf von Münchhausen (1688-1770), bittet Uffenbach in einem privaten Brief vom 4. Juni 1736 um die gerichtliche Eintragung der Schenkung: ,also ist nichts weiter übrig, als daß Ew. Wohlgeb. die gutheit habe, dieses zu dero unsterblichen nachruhm gereichende werk zur legalen und beständigen richtigkeit und gewißheit befordern, und zu solchen ende entweder die vorhabende donationem inter vivos von dero schönen Bibliothèque entweder aldort in loco judicialiter ${ }^{423}$ verrichtet, und davon anhero hinlengliche Nachricht ertheilen, oder aber, wenn Sie solches in der stille verrichtet haben wollen, eine tour nach Gottingen thun, und daselbst den actum legali modo vor sich gehen laßen." 424 Der Stifter konnte oder wollte aber auf diese Forderungen nicht eingehen, da er vor seinen patrizischen Standesgenossen in Frankfurt die Schenkung nicht bekannt machen wollte. Ein offizielles Schenkungsdokument hätte aber beim Rat der Stadt eingereicht werden müssen. Auch wollte Uffenbach keine Reise nach Göttingen unternehmen.

Arnim 1928, 3, S. 25 erwähnt dieses Schreiben ohne Quellenangabe, es befindet sich aber weder im Commercium Epistolicum Uffenbachs (Cod. Ms. Uffenbach 20) noch in den Akten des Göttinger Universitätsarchivs.

420 Die Bibliothek wurde mit der Extra-Signatur „Bibl. Uff.“ versehen und nach der Ordnung aufgestellt, die Uffenbach mit seiner eigenen Aufstellung und dem Katalog mit den Supplementen vorgegeben hatte.

421 „öffentliches Schriftstück“.

422 „Schenkung zu Lebzeiten“.

423 ,an seinem Ort [= Frankfurt am Main], gemäß den Formen des Rechts“.

424 Cod. Ms. Uffenbach 20/I, B1. 318-319. 
Daraufhin wurde in Göttingen eine Schenkungsakte entworfen, die Uffenbach am 28. Juli 1736 unterschrieb. ${ }^{425}$ Darin ist festgelegt, dass er seine mit viel Mühe und Kosten zusammengetragenen Sammlungen der Georgia-Augusta übergeben und auch alle noch hinzukommenden Gegenstände mit dem Vorbehalt des Nießbrauches zur Donation dazugeben wolle. Auch bestimmt er darin, dass die Schenkung in Göttingen separat und öffentlich aufgestellt werden müsse.

Gemeinsam mit der unterschriebenen Urkunde sandte er einen Begleitbrief, in dem er um die absolute Geheimhaltung der Schenkung bittet. ${ }^{426}$ Mit einer Vollmacht der Göttinger Universität versehen begab sich der Hannoversche Geheime Kanzlei-Sekretär Johann Eberhard Mejer ${ }^{427}$ zur Königlichen Justizkanzlei in Hannover, um die Donation am 10. September der gerichtlichen Insinuation $\mathrm{zu}$ unterziehen. ${ }^{428}$ Merkwürdigerweise mußte Uffenbach am 28. Oktober Mejer eine persönliche Vollmacht zu der Insinuation ausstellen, also etwa 1/1/2 Monate nachdem diese schon vollzogen war, obwohl laut Schenkungsakte vom 28. Juli 1736 diese Ermächtigung im Allgemeinen schon erteilt war. ${ }^{429}$

Mit der Eingabe Mejers wäre der Schenkungsakt an sich abgeschlossen gewesen. Allerdings stellte sich 1740 bei nochmaliger Durchsicht der Akten heraus, dass Hannover nur die briefliche Absichtserklärung vom 30. Mai 1736 hatte insinuieren lassen, nicht aber die unterschriebene Urkunde Uffenbachs vom 28. Juli. Der Prorektor der Universität, der Theologe Magnus Crusius (16971751) setzte die Räte in Hannover am 10. April 1740 von dieser Unstimmigkeit in Kenntnis. 430 Es läßt sich nur über die Gründe spekulieren, weshalb Mejer im September 1736 der Justizkanzlei in Hannover nicht Uffenbachs Urkunde vom 28. Juli zur Insinuation vorgelegt hatte, sondern lediglich die nicht rechtsförmige Absichtserklärung vom 30. Mai. Die gerichtliche Eintragung der eigentlichen Schenkungsurkunde erfolgte in Hannover am 29. April 1740, worauf das

\footnotetext{
425 Universitäts-Archiv Göttingen Kur. 4 V d6/2, B1. 50-53. S. Anhang, S. 356-358.

426 Universitätsarchiv Göttingen Kur. 4 V d6/2, B1. 54-65.

427 Lebensdaten unbekannt.

428 Universitätsarchiv Göttingen Kur. 4 V d6/2, B1. 20-21.

Der Begriff „Insinuation“ (lat. Insinuatio, dt. offen-, uffen-, apenbaren oder verkynden) hat seine Wurzeln im römischen Recht und wurde weit bis ins 19. Jahrhundert verwendet. Die Insinuation bezeichnet $u$. a. eine öffentliche Mitteilung oder die Kundgabe und Verkündigung einer Willenserklärung vor einem Gericht zum Zwecke der Publizität, Beurkundung und amtlichen Registrierung, z.B. um eine Wirksamkeit einer Schenkung zu erreichen (vgl. Sellert 2012).

429 Universitätsarchiv Göttingen Kur. 4 V d6/2, B1. 69-70.

430 Universitätsarchiv Göttingen Kur. 4 V d6/2, B1. 92-93.
} 
„concilium academicum“ in Göttingen die Schenkung am 30. Mai 1740 offiziell akzeptierte. ${ }^{431}$

Gleichzeitig mit der Schenkung standen sowohl die Wünsche als auch die Bedingungen Uffenbachs zur Diskussion, die zur Erlangung des hohen Militärcharakters führen sollten, der ihn von den anstrengenden Frankfurter Diensten befreien konnte. Zwar versichert er in seinem Brief an Mascow vom 9. Juni 1736: „Ubrigends soll diese Sache mit meinem Antrag oder Stiftung gantz keinen Zusammenhang haben, und solche es gehe wie es wolle, auf das kräftigste verbleiben. “432 Dennoch versprach sich der Donator durch seine Stiftung, dass der englische König Georg II. August (1683-1760) seinem Antrag auf einen hohen militärischen Titel aufgrund der Schenkung gewogener sein könnte. Schon Münchhausen versichert in seinem Schreiben vom 4. Juni 1736, ,er werde alles mögliche anwenden, um ihn [= Uffenbach] in puncto eines Charakters völlige satisfaction zu geben." 433 Anscheinend wollte der König Uffenbach nur mit dem Prädikat eines „Kriegscommissarius“ ausstatten. Der Frankfurter Patrizier versuchte u.a. über Heinrich Christian von Senckenberg die hannoverschen Räte zu beeinflussen. Senckenberg berichtet in einem Brief vom 22. Juli 1736 über den Fortgang der Verhandlungen bezüglich eines höheren Titels. ${ }^{434}$ In diesem Schreiben gibt Senckenberg Uffenbach zwei Möglichkeiten vor, wie Hannover sich die für ihn so wichtige Befreiung von Diensten in Frankfurt am Main vorstellte. Zum einen bot man ihm den Titel eines „Artillerie-Obristlieutenants“ an, zum anderen aber, dass man den Titel des „Kriegscommissarius“ dadurch heben wolle, dass man ,per Rescriptum Regis“435 dem Frankfurter Magistrat melden wolle, dass Uffenbach tatsächlich in die Königlichen Dienste eingetreten wäre. Uffenbach entschied sich für die erste Variante, weil er vermeiden wollte, dass für ihn unangenehme Fragen bezüglich des Titels und vielleicht auch der Stiftung gestellt würden.

Allerdings baten die hannoverschen Räte König Georg II. erst am 1. Februar 1737 um die Veränderung des Titels vom „Kriegscommissarius“ zum „Caracter eines Artillerie- oder Ingenieur-Obristlieutenants“ ohne Gehalt und Funktion. ${ }^{436}$ Der Brief aus London mit der Erteilung des „Character[s] Unsers Artillerie

\footnotetext{
431 Universitätsarchiv Göttingen Kur. 4 V d6/2, B1. 12-19.

432 Zitiert nach Arnim 1928,1, S. IX + X.

433 Vgl. Cod. Ms. Uffenbach 20/I, B1. 318-319.

434 Cod. Ms. Uffenbach 20/I, B1. 83-84.

435 „durch Königlichen Bescheid“.

436 Universitätsarchiv Göttingen Kur. 4 V d6/2, B1. 71-74.
} 
Obristlieutenants“ und der Urkunde für Uffenbach trägt das Datum des 22. März 1737. ${ }^{437}$ Etwa zur gleichen Zeit wurde die Göttinger Universitätskasse von den Hannoverschen Räten aufgefordert, die Schreibgebühren zur Ausfertigung des königlichen Patents zu übernehmen. ${ }^{438}$

Johann Friedrich von Uffenbach wurde damit in den Stand eines „Königlich Großbrittanisch Churfürstlich Braunschweigisch Lüneburgischen Artillerieobristlieutenant" erhoben und konnte folglich nicht mehr für niedere und unbezahlte Dienste im Rat der Stadt Frankfurt am Main herangezogen werden.

Eigentlich wäre damit der gesamte Vorgang der Donation zu einem vorläufigen Ende gekommen - zur Zufriedenheit Uffenbachs und auch der Göttinger Universität und der Hannoverschen Räte. Schon am 15. Oktober 1736 hatte der Stifter ein „Erstes Supplement zu dem Bücher-Verzeichniß der Göttingischen Stiftung mein Joh. Fried. von Uffenbach. 1736. d. 15. Octobr.“ übersandt. ${ }^{439}$ Als nach dieser Ergänzungsliste zum Katalog 440 keine weiteren Supplemente durch Uffenbach der Göttinger Universitätsverwaltung zugestellt wurden, beauftragten die Hannoverschen Räte Ende September 1738 ihren Residenten ${ }^{441}$ in Frankfurt, Friedrich Philipp von Atzenheim (1702-1765), Uffenbach aufzusuchen und im Geheimen nachzuforschen, ob dieser noch seine Stiftungsabsicht verfolgte und die Sammlung sich vermehrt hätte.

Nachdem Atzenheim bis Anfang Dezember 1738 immer noch keinen Bericht abgegeben hatte, wurde er erneut von Hannover dazu aufgefordert. ${ }^{442}$ Atzenheim scheint sich bis Anfang 1740 nicht um diese Sache gekümmert zu haben. Nach nochmaliger Anordnung liefert er sowohl am 6. als auch am 9. Februar einen ausführlichen Bericht über den Zustand der Sammlung: ,[...] da erwehnter Obrist Lieutenant von Uffenbach von angeregter Donation mir im Vertrauen mit dem Anfügen Nachricht gegeben, weilen er bekanntlich wegen des neu erbauten Haußes große occupationes, ingleichen viele Ausgaben deßfallß gehabt, daß er gedachte Büchern und Instrumentae mit einigen Zusätzen bißhero nicht derogestalten vermehren können, wie es wohl würde geschehen seyn, wenn er

\footnotetext{
437 Universitätsarchiv Göttingen Kur. 4 V d6/2, Bl. 75 (nur der Brief).

438 Universitätsarchiv Göttingen Kur. 4 V d6/2, B1. 76-77.

439 Universitätsarchiv Göttingen Kur. 4 V d6/2, B1. 372-375.

440 Cod. Ms. Uffenbach 47.

441 Mit „Resident“ wird ein weisungsbefugter Bevollmächtigter einer Regierung in einer anderen Hauptstadt genannt.

442 Universitätsarchiv Göttingen Kur. 4 V d6/2, B1. 78- 83.
} 
berührten Bau nicht vorgenommen [...]." "443 Außerdem meldet er, dass Uffenbach, den Atzenheim mit einem „caracter eines honet homme“ kennzeichnet, seiner ersten Frau, Anna Elisabeth ${ }^{444}$, von der Stiftung erzählt hätte und diese in vollem Umfang damit einverstanden gewesen sei, und dass die Sammlung in einem eigenen Raum aufbewahrt sei. Weiterhin schreibt der Resident, dass Uffenbach: „[...] einem vertrauten Freund von der Donation zu dem Ende Eröffnung gethan, daß derselbe vor die Auslieferung von Obigen mit Sorge tragen könnte." Aufgrund dieser Nachricht forderten die Hannoverschen Räte eine Vollmacht und eine Kopie des Uffenbachischen Kataloges von der Göttinger Universität für Atzenheim, damit dieser im Todesfall des Stifters sofort auf die Sammlung zugreifen könne. Noch im selben Monat gingen Vollmacht und Kopie in zwei verschiedenen Schreiben über Hannover nach Frankfurt mit der Maßgabe, dass Atzenheim absolutes Stillschweigen über die Donation halten solle, damit Uffenbach nicht verärgert würde. ${ }^{446}$

Um Uffenbach die Göttinger Universität weiterhin gewogen zu halten, nahm die „Deutsche Gesellschaft zu Göttingen“ ihn am 24. Juni 1740 als viertes der Ehrenmitglieder auf; Johann Matthias Gesner hatte ihn schon zuvor am 4. April von diesem Vorhaben informiert. ${ }^{447}$ Nachdem aber Uffenbach keine weiteren Supplemente zu seinem Katalog nach Göttingen geschickt hatte, wurde Gesner 1741 von den Geheimen Räten in Hannover dazu aufgefordert, die Korrespondenz mit dem Frankfurter wieder aufzunehmen, was allerdings nur selten gelang. Im Jahre 1747 beantwortete der Göttinger Prorektor Albrecht von Haller (17081777) ein Schreiben aus Hannover, in dem Fragen über die Weiterführung der Korrespondenz und den Zustand der Uffenbachischen Sammlung gestellt wurden. So berichtete er in seinem Brief vom 13. März, dass Uffenbach seit sechs Jahren keinen Briefverkehr mit Gesner geführt hätte. Er, Haller, hätte den Frankfurter Patrizier aber in diesem Jahr besucht und von ihm die Versicherung bekommen, dass dieser die inzwischen erfolgten Zukäufe der Göttinger Bibliothek melden würde. ${ }^{448}$

\footnotetext{
443 Universitätsarchiv Göttingen Kur. 4 V d6/2, B1. 86v.

444 Geb. Lindheimer, verw. Lehnemann (1680-1752).

445 Universitätsarchiv Göttingen Kur. 4 V d6/2, B1. 86-89, hier 86v.

Uffenbach hatte den Frankfurter Kaufmann Albert Adolf Diesterweg 1740 von der Stiftung unterrichtet.

446 Universitätsarchiv Göttingen Kur. 4 V d6/2, B1. 90-91, 94-103.

447 Cod. Ms. Uffenbach 20/I, B1. 4-5.

448 Universitätsarchiv Göttingen Kur. 4 V d6/2, B1. 112-114.
} 
Nach weiteren sporadischen und erfolglosen Versuchen durch mehrere Mitglieder der Universität, mit Uffenbach in Kontakt zu kommen, um in Erfahrung zu bringen, ob die Sammlung erweitert worden war, kam es $1751 \mathrm{zu}$ einer weiteren Bemühung, in Uffenbach die Erinnerung an seine Göttinger Stiftung wach zu halten. Als eines der ersten außerordentlichen Mitglieder wurde Uffenbach in die Mathematische Klasse der eben gegründeten „Königlichen Sozietät der Wissenschaften zu Göttingen“ aufgenommen, wozu ihm Gesner im November des Jahres gratulierte. ${ }^{449}$ Auch diese erneute Auszeichnung führte nicht zu einer regelmäßigen Korrespondenz zwischen Frankfurt und Göttingen. ${ }^{450}$ Nach dem Tod seines Vetters Nikolaus von Uffenbach im Jahre 1744 hatte er sich in den Frankfurter Rat wählen lassen und damit ein hohes und gut dotiertes Amt innerhalb der Freien Reichsstadt inne. ${ }^{451}$ Er war somit auch nicht mehr auf den auswärtigen Titel angewiesen. Uffenbach sah vielleicht auch keinen Grund mehr, ein Großteil des zukünftigen Erbes seiner Frau nach Göttingen zu geben.

Erst nach Gesners Tod 1761 kam es wieder zu Bemühungen um die Stiftung Uffenbachs. Im Oktober 1762 baten die Hannoverschen Geheimen Räte um die Übersendung von Kopien der Stiftungsakten. Der Prorektor Christian Wilhelm Franz Walch (1726-1784) übersandte im November des Jahres ein Verzeichnis der Akten. ${ }^{452}$ Auch trat man ein Jahr später wieder direkt mit dem Stifter in Verbindung. Der Kontakt war durch den Siebenjährigen Krieg, 1756 bis 1763, und die Besetzung Frankfurts durch die Franzosen zum völligen Stillstand gekommen. Während die Göttinger Universität die beste Möglichkeit darin sah, dass der Frankfurter Resident Atzenheim einen ersten Versuch zur Wiederaufnahme der Beziehungen unternehme, sah der Kurator von Münchhausen die bis dahin inoffizielle Ernennung Christian Gottlob Heynes (1729-1812) zum ersten Bibliothekar im Jahre 1763 als die beste Gelegenheit an, die durch den Tod Gesners und die Kriegswirren unterbrochene Korrespondenz wieder zu beleben. Zusätzlich schickte man Uffenbach verschiedene in Göttingen verfaßte Schriften. Uffenbach, der 1755 wieder geheiratet hatte und dessen zweite Frau $^{453}$ von der Stiftung nach Göttingen nichts wusste, reagierte auf die Schreiben aus Göttingen und Hannover überrascht. Ein Brief des Donators nach Hannover ${ }^{454}$

\footnotetext{
449 Cod. Ms. Uffenbach 20/I, B1. 20-21.

450 Weder im „Commercium Epistolicum“ Uffenbachs noch in den Akten des Universitätsarchivs Göttingen finden sich Hinweise auf eine Korrespondenz.

451 S. weiter oben.

452 Universitätsarchiv Göttingen Kur. 4 V d6/2, B1. 120-135.

453 Maria Magdalena, geb. von Bertram (1721-1775).

454 Universitätsarchiv Göttingen Kur. 4 V d6/2, B1. 140-142.
} 
wird dort wie folgt resümiert: „Es äußert der Herr von Uffenbach in seinem Schreiben vom 28. Aug. 1763.

1.) er habe geglaubet, die Schenkungs-Sache sey in völlige Vergeßenheit gerathen, weil er seit so geraumer Zeit davon nichts gehöret, sondern 2.) vielmehr in dem hiesigen Calender seine Benennung in der Militaer-Reihe, worin er $2 \mathrm{Jahr}$ gestanden, übergangen, mithin deßen anerbotenen Samlung $\mathrm{zu}$ gering und nichtachtungswürdig gehalten sey. Wie dem auch 3.) verschiedene Rechtsgelehrte dafür hielten, daß die einem Judici incompetenti ${ }^{455}$ geschehene Insinuation keine rechtliche Kraft habe." ${ }^{456}$

Die Hauptargumente aus Münchhausens Antwort vom 22. September werden wie folgt zusammengefaßt: „Nun müste 1.) Der Krieg die Correspondentz mit den Göttingschen Professoren nothwendig unterbrochen, da Franckfurt in französischen Händen war. Vor dem Kriege ist aus Menagement dem Donanti nicht angemuthet, mit Einsendung der Designationis accessionum ${ }^{457}$ fortzufahren, da er es unterließe. 2.) Werden in hiesigen Raats-Calender nur die würklich dienende und nicht einmahl die in pension stehende Generals und Officiers wohnhaft gemachet, daher es keine Aufhebung der Übereinkunft involviret, daß der Herr von Uffenbach darin übergangen ist. Man wird es 3.) mit denjenige auszumachen haben, die nach seinem Tode die Schenkung anfechten Secundum communiorem opinionem Ictorum ${ }^{458}$ ist sie zu Recht beständig. Eine Donatio ad pias causas erfordert überdem per L. 34. Cod. de Donationibus keine Insinuation, und die Scholae, mithin auch Academiae, werden die Instrumento Pacis Westphalicae Art. 5. §. 25. den bonis ecclesiasticis, und also den piis institutis beygezehlet. Man könte in einem Antwortschreiben, die wegen des vieljährigen Silentii und Calenders gemachte Zweifel den Herrn von Uffenbach zu benehmen suchen, und zugleich äußern, daß man es mit denjenigen auszumachen haben würde, der die Schenkung dermahleins anfechtet." “459

Uffenbachs Reaktion auf den energischen Ton Münchhausens und den überzeugenden Inhalt des Schreibens, dass die Schenkung auf jeden Fall weiterbestehen würde und stets als eine schmerzliche Lücken schließende

„,nicht zuständigen Richter“.

Universitätsarchiv Göttingen Kur. 4 V d6/2, Bl. 138-139.

Hierbei meint Uffenbach die Jenaer Dissertation Paul Wilhelm Schmidts von 1761: De insinuatione quingentos solidos excellentis, coram judice incompetente haud suscipienda.

457 „Liste der Neuerwerbungen“.

458 „nach allgemeiner Auffassung der Rechtsgelehrten“.

459 Universitätsarchiv Göttingen Kur. 4 V d6/2, B1. 143-147.
} 
Bereicherung der Bibliotheksbestände angesehen werden würde, war die Zurücknahme sämtlicher Einwände gegenüber seinen Verpflichtungen. Außerdem schickte er am 12. Oktober ein zehnseitiges Supplement, in dem alle seit 1736 angeschafften Bücher verzeichnet waren. ${ }^{460}$ Münchhausens Danksagung erfolgte am 21. des Monats. Dort lobt er nicht nur Uffenbachs guten Willen, sondern geht hauptsächlich auf die von Uffenbach geäußerten rechtlichen Einwände gegen die Schenkung ein und versucht sie erneut $\mathrm{zu}$ zerstreuen. Auch versucht Münchhausen, Uffenbach die für Hannover und Göttingen so wichtige Insinuation der Stiftung vor dem Frankfurter Rat nahezubringen. ${ }^{461}$

Um Uffenbach weiterhin gewogen zu halten, erhielt er sowohl Schreiben der Hannoverschen Räte und der Göttinger Bibliotheksverwaltung als auch einen Besuch des Frankfurter Residenten. Der Patrizier suchte einer Begegnung mit Atzenheim aus dem Wege zu gehen und entschuldigte sich ihm gegenüber immer wieder wegen dringender Geschäfte beim Frankfurter Rat, so dass Atzenheim am 31. Oktober 1763 unangemeldet bei ihm vorsprach. Uffenbach führte den Residenten notgedrungen in die beiden Zimmer im zweiten Stock des Hauses auf der Zeil und zeigte ihm die Bibliothek und die anderen, zur Stiftung gehörenden Gegenstände. Atzenheim schreibt in einem Brief vom 1. November nach Hannover, dass die Ordnung der Bibliothek sehr gut sei, und Uffenbach, nachdem er ihn mit den vortrefflichsten Worten gelobt hätte, habe erkennen lassen, dass er zu einer Eintragung der Stiftung vor dem Frankfurter Rat bereit sei. ${ }^{462}$

Nach der quasi geheimen, vor über zwanzig Jahren nur in Hannover erfolgten Insinuation der Schenkung wurde die offizielle Eintragung der Donation an die Georgia-Augusta beim Frankfurter Rat am 21. Februar 1764 vollzogen. Kurze Zeit später wurde in Göttingen bei einem Vergleich mit den ,im Stillen“ vor der hannoverschen Justizkanzlei insinuierten Dokumenten von 1736 und 1740 festgestellt, dass Uffenbach vergessen hatte, die Kupferstichsammlung gesondert zu erwähnen. Deshalb wurde Uffenbach von dem Hofrat und Professor für Staatsrecht Johann Stephan Pütter (1725-1807), der sich gerade in Frankfurt am Main aufhielt, um ein Ergänzungsprotokoll gebeten. Dieses Schriftstück mit der erweiterten Schenkung wurde am 21. April 1764 beim Frankfurter Rat eingetragen. ${ }^{463}$

\footnotetext{
460 Cod.Ms.Bibliotheks-Archiv A 34c.

461 Universitätsarchiv Göttingen Kur. 4 V d6/2, B1. 152-156.

462 Universitätsarchiv Göttingen Kur. 4 V d6/2, B1. 167-168.

463 Universitätsarchiv Göttingen Kur. 4 V d6/2, B1.184-188.
} 
Mit diesem juristischen Akt war die Uffenbachische Stiftung nach Göttingen offiziell. Schon am 15. März veröffentlichen die „Göttingische Anzeigen von gelehrten Sachen" in einem zweiseitigen Artikel folgende Lobeshymne auf Uffenbach und seine Schenkung: „Die hiesige Universitätsbibliothek, welche durch die unerhörte Vorsorge ihres erlauchten Curators ${ }^{464}$ täglich mehr und mehr bereichert wird, so daß unsere Universität auch in diesen Stücken den blühendsten Universitäten in Deutschland gleich kommen, in Ansehung des Gebrauchs aber vieles voraus haben dürfte, hat durch die besondere Freygebigkeit und Geneigtheit des Kayserlichen Raths, Exconsuls Protoscabinus und Senators zu Frankfurt, auch Obristlieutenants in Königl. Großbr. und Churfürstl. Br. Lüneb. Diensten, Herrn Johann Friedrich von Uffenbach, einen ansehnlichen Zuwachs zu gewarten, indem solcher seinen ganzen beträchtlichen Bücher- Kupfer- und Instrumentenvorrath durch eine gerichtliche Schenkung unter Lebendigen derselben zugewendet und sich davon nur den Gebrauch auf seine Lebenszeit vorbehalten hat. Es ist zwar diese Schenkung bereits vor einigen Jahren geschehen, allein es hat uns von dankbarer Bekanntmachung derselben bisher der Wille des Herrn Donatoris zurückgehalten. Es besteht dieselbe besonders in einer schönen Sammlung von mathematischen und physicalischen, vorzüglich aber Kunst- und zur Bildnerey (Iconographie) gehörigen Büchern; ingleichen in einer vortrefflichen Sammlung von einzelnen Kupferstücken und Kupferstückwerken, auch Handzeichnungen, dergleichen vielleicht von wenigen Privatpersonen in Deutschland zusammen gebracht seyn möchte, und wovon die Wahl sowohl, als die methodische Einrichtung und Rangirung, ingleichen die beygefügten Handschriften, Verzeichnisse, auch eignen Handzeichnungen des Herrn von Uffenbach ein immerwährendes Andenken seiner seltenen Kenntnisse und Einsichten seyn werden. Hiezu kommt noch ein beträchtlicher Vorrath von mathematischen, mechanischen, gnomonischen, optischen und andern Instrumenten und Modellen. Wir wünschen aufrichtig, daß uns der eigenthümliche Gebrauch dieser schätzbaren Sammlung durch ein hohes und gesegnetes Alter des Herrn von Uffenbach noch in die späteste Zeit entzogen werden möge." 465

Ebenfalls 1764 hielt Christian Gottlob Heyne in Göttingen am 2. Juli auf Veranlassung der Hannoverschen Geheimen Räte eine programmatische Rede „De efficaci ad disciplinam publicam privatamque vetustissimorum poetarum

\footnotetext{
464 Gemeint ist Gerlach Adolf von Münchhausen.

465 Göttingische Anzeigen von gelehrten Sachen, 32. Stück, S. 249-250, Göttingen 1764.
} 
doctrina", in der der Stifter gefeiert wurde. 466 Heyne hatte in Folge seiner Ernennung zum Ersten Bibliothekar einen regen Briefverkehr mit Uffenbach aufgenommen.

Nach dem Tod Atzenheims wurde als Hannoverscher Resident in der Freien Reichsstadt Frankfurt am Main Anfang 1766 Friedrich Ludolph von Hugo ${ }^{467}$ eingesetzt. In einer der ersten Weisungen vom 23. Februar dieses Jahres wurde er aufgefordert, er solle sich von der Witwe Atzenheims sämtliche Akten betreffend der Stiftung Uffenbach aushändigen lassen, und er wurde beauftragt ,die Freundschaft mit Uffenbach zu cultiviren und vigilanz zu bezeigen, damit nichts dieser donation widriges, wie man zwar hoffet, vorgehen möge." 468 Der neue Resident meldet in einem Brief vom 15. März zum einen, dass er die Akten ausgehändigt bekommen hätte, zum anderen, dass er Bedenken betreffs eines Zuwachses der Stiftung hege, nachdem Uffenbach 1755 ein zweites Mal geheiratet habe: „Da die Ehefrau nach dem Frankfurter Recht außer dem Eigentum des in jetziger Ehe errungenen Vermögens nur den Nießbrauch dessen, was vor der Ehe vorhanden gewesen ist, zu hoffen hat, so steht zu vermuthen, daß sie, um ihr demnächst $\mathrm{zu}$ erlangendes Eigenthum $\mathrm{zu}$ vergrößern, alle außerordentlichen Ausgaben $a b=$ und dahingegen zur möglichsten Sparsamkeit anzurathen bemühet seyn wird." ${ }^{69}$ Von Hugo war deshalb Anfang April auch offiziell von Göttingen aus mit allen Vollmachten ausgestattet worden, um im Todesfall des Stifters sofortigen Zugriff auf die gesamte Schenkung zu haben. Außerdem hatte er neuere Abschriften des Kataloges und der beiden Supplemente erhalten. ${ }^{470}$

Uffenbach hatte weiterhin Bücher für sich angekauft und diese ebenfalls für die Göttinger Bibliothek vorgesehen, denn er sandte am 12. November 1766 eine weitere vierseitige Liste mit dem Titel „Neuere und seit einigen Jahren angeschaffte Vermehrungen der Göttingischen Stifftung, ein solche nach deren Absätzen des erstern übergebenen catalogi eingeschrieben worden." 471 Mit dieser Zusammenstellung der Erweiterungen seit 1763 wurde für die Göttinger

„Von der Wirksamkeit der Lehren der urältesten Dichter im öffentlichen und Privatleben zu festigen." Abgedruckt in: Heyne 1785.

S. Pütter 1765, S. 224.

467 Lebensdaten unbekannt.

468 Universitätsarchiv Göttingen Kur. 4 V d6/2, Bl. 197-198.

469 Universitätsarchiv Göttingen Kur. 4 V d6/2, B1. 199-201.

470 Universitätsarchiv Göttingen Kur. 4 V d6/2, B1. 197-219.

471 in: Cod. Ms. Bibliotheks-Archiv A 34c.
} 
Bibliotheksverwaltung und auch für die Hannoverschen Räte erkennbar, dass der Stifter die von Hugo geäußerten Bedenken nicht teilte.

Anfang April 1769 meldete von Hugo wiederum Bedenken bezüglich der Ansprüche der Ehefrau an, da Johann Friedrich von Uffenbach wegen Körperschwäche kurz vor seinem Tode stehe. Er schlug vor, dass man einen gemeinsamen Bekannten ${ }^{472}$ vorschicken solle, der die Räume, in der die Stiftung aufbewahrt wurde, verschließen und versiegeln und die Schlüssel an sich nehmen solle; zu diesem Vorgehen wurde ihm am 4. April die Erlaubnis gegeben. ${ }^{473}$ Nachdem Uffenbach am 10. April verstorben war, setzt von Hugo sich in zwei Briefen mit Hannover in Verbindung. ${ }^{474}$ Zum einen meldet er den Exitus, zum anderen informiert er über die Anfechtung der Donation durch die Witwe und eine Nichte Uffenbachs, die verwitwete Landjägermeisterin Catharina Charlotte von Veltheim, geb. von Lindheim (1704-1784) ${ }^{475}$, die durch den Rechtsanwalt und Hessisch-Darmstädtischen Geheimen Rat Heinrich Carl von Barkhaus gen. von Wiesenhütten (1725-1793) vertreten wurde.

Die offizielle Mitteilung durch die Witwe an den Kurator von Münchhausen, dass Johann Friedrich von Uffenbach verstorben war, datiert erst vom 17. April. ${ }^{476}$ Von Münchhausens Beileidsschreiben vom 24. April an die Witwe brachte auch die Stiftung Uffenbachs in Erinnerung. ${ }^{477}$ Am selben Tag gab er die Order an die Königliche Sozietät der Wissenschaften zu Göttingen, den Tod Uffenbachs öffentlich bekanntzumachen. Von Seiten der Sozietät geschah dies aber erst mehr als ein halbes Jahr später, am 4. Januar 1770.478 Die Bibliotheksverwaltung hingegen hatte schon am 20. April 1769 in den „Göttingische Anzeigen von gelehrten Sachen“ die kurze, von Heyne verfaßte Nachricht veröffentlichen lassen: „Den $10^{\text {ten }}$ April ist der Herr J. Fr. von Uffenbach, Schöffe und Senator der freyen Reichsstadt Frankfurt, Mitglied der hiesigen K. Societät der Wissenschaften, in seinem 82. Jahre verschieden. Unsere Universität wird sein Andenken stets mit Dankbarkeit verehren, da er ihr durch seine zu andrer Zeit

\footnotetext{
472 Nicht namentlich genannt.

473 Universitätsarchiv Göttingen Kur. 4 V d6/2, B1. 227-231.

474 Universitätsarchiv Göttingen Kur. 4 V d6/2, B1. 232-237.

475 Catharina Charlotte von Lindheim war die Tochter von Johann Jost von Lindheim (16621744) und Anna Sybilla von Uffenbach (1675-1735), der Schwester Johann Friedrichs.

476 Universitätsarchiv Göttingen Kur. 4 V d6/2, B1. 256-257.

477 Universitätsarchiv Göttingen Kur. 4 V d6/2, B1. 258-259.

478 Universitätsarchiv Göttingen Kur. 4 V d6/2, B1. 260-261.

Göttingische Anzeigen von gelehrten Sachen 2. Stück, S. 9-10, Göttingen 1770.

S. a. weiter unten.
} 
angezeigte ansehnliche Stiftung für hiesige Bibliothek einen so großen Beweis seiner Zuneigung gegeben hat." 479

Heyne und Pütter machten sich schon die ersten Gedanken über den Transport nach Göttingen und die Aufstellung der Sammlung dort. ${ }^{480}$ Zur Überführung der Sammlungen sollte es aber vorerst nicht kommen. Wie oben erwähnt, hatten zwei Erben die Ansprüche Göttingens vor dem Frankfurter Magistrat angefochten. Es waren damit die von Hugo geäußerten Befürchtungen von 1766 und 1769 eingetreten, sodass von Hugo am 21. April 1769 vor dem Magistrat einen ersten „Einwurf“ gegen die Erben eingelegt hatte. ${ }^{481}$ Zusätzlich meldet er am 2. Mai 1769 nach Hannover, dass an die Frankfurter Behörden Erbschaftssteuer zu bezahlen wäre, er aber wiederum einen „Einwurf“ des Inhalts gemacht hätte, dass diese Steuer nicht anfallen würde, da es sich um eine Schenkung an die Öffentlichkeit handeln würde. Er teilt auch mit, dass er bis jetzt noch nicht die Schlüssel der beiden Zimmer habe, aber hoffe, dass sie ihm demnächst ausgehändigt werden würden. ${ }^{482}$ Am 27. des Monats kann von Hugo zum einen die erfreuliche Mitteilung machen, dass der Frankfurter Magistrat auf die Erhebung der Steuern verzichten würde, zum anderen aber die Anfechtung der Witwe und der Cousine weiter bestehen würde. ${ }^{483}$

Nach einer Anfrage aus Hannover vom 15. Juli bezüglich des Verlaufes der juristischen Auseinandersetzung schreibt von Hugo am 22. Juli, dass der Veltheimische Anwalt immer größere Schwierigkeiten mache und auch angefangen habe, der Witwe Uffenbach zuzusetzen. Er schlage deshalb vor, dass man vor dem Frankfurter Schöffenrat eine gerichtliche Auslieferung der Schenkung anstrengen solle. ${ }^{484}$ Auf diesen Vorschlag hin bekommt am 29. Juli von von Hugo den Auftrag der Hannoverschen Räte, einen Brief mit der Bitte um gerichtliche Freigabe der Sammlung beim Frankfurter Rat einzureichen, zusammen mit der Aufforderung, die Gegenstände so schnell wie möglich an sich zu bringen. ${ }^{485}$ Der Resident meldet in einem Antwortbrief vom 8. August, dass die Erben untereinander in Streitigkeiten gekommen seien, und sich die Auslieferung aus diesem Grunde verzögern würde. In einem Postskriptum fügt er hinzu, dass

\footnotetext{
479 Göttingische Anzeigen von gelehrten Sachen, 47. Stück, S. 440, Göttingen 1769.

480 Universitätsarchiv Göttingen Kur. 4 V d6/2, B1. 248-253.

481 Universitätsarchiv Göttingen Kur. 4 V d6/2, B1. 242-245.

482 Universitätsarchiv Göttingen Kur. 4 V d6/2, B1. 262-264.

483 Universitätsarchiv Göttingen Kur. 4 V d6/2, B1. 272-273.

484 Universitätsarchiv Göttingen Kur. 4 V d6/2, B1. 279, 282-283.

485 Universitätsarchiv Göttingen Kur. 4 V d6/2, B1. 284-287.
} 
der Frankfurter Rat der Witwe Uffenbach auferlegt hätte, die Sammlung herauszugeben. Dem Brief liegt eine Kopie des Ratserlasses vom 7. August 1769 von von Hugos Hand bei. ${ }^{486}$

Aber schon am 15. August mußte der Resident erneut von Streitigkeiten zwischen den Erben berichten, aufgrund derer der Teil der Donation, der nach der zweiten Heirat 1755 von Uffenbach angeschafft worden war, durch die Erben als Pfand in Beschlag genommen würden. ${ }^{487}$

Mit diesen Nachrichten konnten sich die Göttinger Bibliotheksverwaltung und die Hannoverschen Räte wenigstens des ersten Teils der Stiftung sicher sein. Deshalb wurde von Hugo am 19. August angewiesen, sich beim Älteren Bürgermeister der Stadt Frankfurt zu bedanken und ihm die Zusicherung zu geben, dass man sich in einem ähnlichen Fall Frankfurt gegenüber gleichermaßen kulant verhalten würde. 488 Am 4. September 1769 wurde der Witwe Uffenbach durch Ratserlass aufgetragen, dem Hannoverschen Residenten von Hugo diejenigen Stücke gegen Bescheinigung herauszugeben, die vor ihrer Eheschließung, also vor 1755, angeschafft worden seien. Außerdem solle sie ein gesondertes Verzeichnis der nach der Eheschließung hinzugekommenen Bücher und Gegenstände anfertigen. Mit einer Kopie dieses Dekrets kündigt von Hugo am 9. September den Hannoverschen Räten an, dass die beiden versiegelten Zimmer von einem Angestellten der Frankfurter Gerichtskanzlei im Beisein aller Betroffenen geöffnet werden würden und die „Extradition“ damit beginnen könne. ${ }^{489}$ Dies geschah dann tatsächlich am 11. September. Von Hugo schreibt einen Tag später nach Hannover, dass man mit den Stücken aus dem Hauptkatalog von $1736^{490}$ begonnen hätte und einige Frankfurter Gerichtsdiener, denen nach von Hugos Meinung eine Gratifikation zu bezahlen wäre, beim Heraussuchen der Stücke helfen würden, denn: „In der Erwartung, daß die Bücher und übrige Donations Stücke, zu folge des von dem Donatore dem Haupt Catalogo beygefügten Vorberichts, in der nehmlichen Ordnung, wie sie verzeichnet worden, würden aufgestellet seyn, machten wir uns insgesamt die Hoffnung in wenig Tagen das Auslieferungs Geschäfte zu Stande bringen zu können, wir fanden aber alles in großer Confusion, wodurch dann diese Arbeit, weil jedes Buch erst in dem nicht einmahl nach Alphabetischer Ordnung

\footnotetext{
486 Universitätsarchiv Göttingen Kur. 4 V d6/2, B1. 291-296.

487 Universitätsarchiv Göttingen Kur. 4 V d6/2, Bl. 288-290.

488 Universitätsarchiv Göttingen Kur. 4 V d6/2, B1. 297-298.

489 Universitätsarchiv Göttingen Kur. 4 V d6/2, B1. 299-302.

490 Cod. Ms. Uffenbach 47.
} 
eingerichteten Catalogo mit vieler Mühe aufgesuchet werden muß, ungemein beschwehrlich gemachet.“491

Nachdem sich Hannover bereit erklärt hatte, den Frankfurter Gerichtsdienern eine Gratifikation zukommen $\mathrm{zu}$ lassen, ${ }^{492}$ drängten sie auf eine rasche Versendung der Stücke nach Göttingen. ${ }^{493}$ Von Hugo berichtet am 23. September über den Verlauf der Arbeiten im Hause Uffenbach. Wegen der großen Unordnung hätte man anhand des Originalverzeichnisses der Bibliothek ${ }^{494}$ und des Göttinger Kataloges von 1736 die Bücher herauszusuchen. Außerdem sei er, von Hugo, jetzt daran gegangen, die wissenschaftlichen Instrumente zusammenzutragen, da sich gerade der Mathematiker und Mechaniker Bianchi ${ }^{495}$, der Uffenbach und dessen Sammlung von mehreren Besuchen her kenne, wegen der Messe in Frankfurt aufhalte. Bianchi könne bei der sachgerechten Verpackung sehr gut helfen. Daneben geht es in dem Brief von Hugos um die gerichtlichen Kosten der Extradition, die etwa 40 Gulden betragen würden. ${ }^{496}$ Hannover ist mit der Arbeit von Hugos zufrieden und überweist ihm am 30. September den entsprechenden Betrag aus der Klosterkasse zu Hannover für die Gerichtskosten, nicht aber für die Gratifikation der Gerichtsdiener, da diese jetzt doch durch die Witwe und die Nichte zu bezahlen seien. ${ }^{497}$

Am 14. Oktober kann von Hugo Hannover darüber informieren, dass alle Stücke aus dem Katalog von 1736 und dem ersten Nachtrag bis auf das gesamte graphische Kabinett und 14 unauffindbare Bücher mit dem Fuhrmann Kühnemund nach Göttingen auf dem Weg wären. Bezüglich der graphischen Blätter schreibt er:,Jene haben noch in etwas zurückbleiben müßen, weilen der seel. Schöf von Uffenbach, wie von ihm in seinem Original Catalogo mit eigener Hand angemercket worden damit, in deßen letzteren Lebens Jahren, eine andere Einrichtung und Ordnung zu treffen vor gut gefunden hat, mithin zweifelhaft ist, ob bey denen in dem anfänglichen Catalogo nur überhaupt angeführten XVII Bänden von Kupferstücken nicht neue während der Ehe angeschaffte Stücke mit

\footnotetext{
491 Universitätsarchiv Göttingen Kur. 4 V d6/2, B1. 305-306, hier 305v.

492 Die nach Meinung der Räte aber die Witwe und die Nichte zu bezahlen hätten.

493 Universitätsarchiv Göttingen Kur. 4 V d6/2, B1. 303-308.

494 Gemeint ist das Handexemplar Uffenbachs in der StUB Frankfurt am Main: Ms. Ff. J.F.v.UFFENBACH 1.

495 Vornamen und Lebensdaten unbekannt.

496 Universitätsarchiv Göttingen Kur. 4 V d6/2, B1. 310-313.

497 Universitätsarchiv Göttingen Kur. 4 V d6/2, B1. 309 (Bescheinigung der Klosterkasse), 314-315 (Brief).
} 
eingerücket worden sind." ${ }^{498}$ Der erste Teil der Sammlung mit 421/2 Zentnern Gewicht erreichte Göttingen in zwei Lieferungen, am 21. Oktober und am 22. November 1769, und wurde wegen Platzmangels zwischenzeitlich im medizinischen Auditorium gelagert. 499

Die Erbstreitigkeiten sollten sich in der Folgezeit aber noch intensivieren. Anscheinend wollte der Veltheimische Anwalt die Kupferstichsammlung endgültig dem Erbe seiner Mandantin zukommen lassen. Daraufhin hat von Hugo am 21. und am 24. Oktober zwei Eingaben gegen dieses Vorhaben beim Frankfurter Schöffenrat gemacht. ${ }^{500}$ Die Entscheidung wurde wiederum durch Eingaben und „Einwürfe“ der Erben bis zum 13. Dezember verzögert. An diesem Tag beschloß der Schöffenrat, dass alle Bücher und Gegenstände, die im Katalog von 1736 verzeichnet sind, an die Georgia-Augusta auszuliefern seien. Außerdem hätten die beiden Erbparteien - Frankfurt und Göttingen - innerhalb von acht Tagen jene Gegenstände, die nach 1736 durch den Verstorbenen angeschafft worden waren, durchzusehen und $\mathrm{zu}$ taxieren, da ansonsten dies auf Kosten derselben „ex officio“ geschehen würde. ${ }^{501}$ Aber keiner der beiden Erbparteien kümmerte das Dekret vom 13. Dezember offenbar nicht.

Von Hugo meldet am 27. Januar 1770 nach Hannover, dass er Anfang des Jahres erneut einen „Einwurf“ beim Frankfurter Schöffenrat hätte machen müssen, um die Sache voranzutreiben. ${ }^{502}$ Dieser „Einwurf“ veranlaßte den Rat, den Erben nochmals aufzuerlegen, dass sie die Taxierung sofort vorzunehmen hätten. Von Hugo erwähnt in diesem Schreiben, dass es gar nicht so sehr die Witwe Uffenbach sei, die die Verzögerungen verursacht hätte, sondern der Veltheimische Anwalt. Weiter kann er berichten, dass die Separierung der Stücke am 19. Januar abgeschlossen und bei der Taxierung ein Wert von insgesamt 2500 Gulden festgelegt worden war. Daraufhin wären ihm, von Hugo, endlich die Gegenstände ausgeliefert worden, die vor der Ehe angeschafft worden waren also alles, was im Katalog von 1736 und dem ersten Supplement vom 15. Oktober $1736^{503}$ verzeichnet war. Es handelte sich dabei hauptsächlich um das graphische Kabinett, das von Hugo zunächst in einem Zimmer seiner Wohnung aufbewahrte;

\footnotetext{
498 Universitätsarchiv Göttingen Kur. 4 V d6/2, B1. 318-319, hier 318v.

499 Universitätsarchiv Göttingen Kur. 4 V d6/2, B1. 357-358 (Bericht Heynes betreffend die Übersendung der Schenkung).

500 Universitätsarchiv Göttingen Kur. 4 V d6/2, B1. 324-328.

501 Universitätsarchiv Göttingen Kur. 4 V d6/2, B1. 339-340.

502 Universitätsarchiv Göttingen Kur. 4 V d6/2, B1. 331-334.

503 Cod. Ms. Uffenbach 47 und Universitätsarchiv Göttingen Kur. 4 V d6/2, B1. 372-375.
} 
er schreibt in seinem Brief vom 27. Januar dazu: „In Ansehung der Kupferstiche und Handzeichnungen brachte ich, da das durante matrimonio ${ }^{504}$ hierin verwendete Quantum nicht klar zu machen stunde, es bey den Parteyen durch zureden und Vorstellungen dahin, daß sie mir die gantze Samlung, welche an Kupferstichen 36 Bände, folglich 19 Bände mehr enthält, als in denen nach Göttingen gesandten Verzeichnißen angemercket sind, verabfolgeten, wobey ich besonders den von der Schöffin von Uffenbach darunter bezeigten guten Willen und ihre löbliche Gesinnung gegen die Universitaet bestens anzurühmen, mich umso mehr für verbunden erachte, als es gar deutlich in die Augen fält, daß sothane Samlung während der Ehe ungemein starck angewachßen seyn müsse, mithin selbige, wegen ermangelndes Beweises bey dieser Rubric einen ansehnlichen Schaden erleiden werde. Hiernächst erhielte ich auch noch verschiedene meistens von dem seel. Schöff selbst gestochene und zum Theil zu deßen poetischen Werckgen von der Nachfolge Christi gehörenden Kupfer Platten, davon weder in der Donations Urkunde noch in denen Designationen Erwehnung geschehen ist." 505 Von Hugo beschreibt in dem Brief zusätzlich den Versuch des Veltheimischen Anwalts, den zweiten Teil der Donation an sich zu bringen, weshalb er, von Hugo, eine weitere Eingabe beim Rat machen wolle, damit dies verhindert würde. ${ }^{506}$

Diese Eingabe datiert vom 30. Januar. Von Hugo informiert den Frankfurter Rat in diesem Schreiben sowohl über die Auslieferung des gesamten ersten Teils der Schenkung als auch über die Tatsache, dass der zweite Teil eigentlich übergeben werden könne, da die Separierung und die Taxierung schon geschehen waren. Er bittet dabei um einen positiven Bescheid des Rates, ${ }^{507}$ dem dieser am 28. Februar nachkam. ${ }^{508}$ Allerdings kam es nochmals zu Schwierigkeiten, da ein Gutachten der Juristischen Fakultät der Universität Halle zur Uffenbachischen Erbschaftssache der Witwe das Recht zusprach, den zweiten Teil der Donation zu behalten. ${ }^{509}$ Dieses Gutachten benutzte der Veltheimische Anwalt, um

505 Universitätsarchiv Göttingen Kur. 4 V d6/2, Bl. 331-334, Zitat: 332v-333r.

506 Ebendort.

Die Kupferplatten haben sich erhalten. Sie befinden sich heute im graphischen Kabinett der Göttinger Universitätskunstsammlung. Bei dem angesprochenen Werk handelt es sich um Uffenbachs „Poetischer Versuch, worinnen die Nachfolge Christi in Betrachtung seiner heilsamen Lehre und heiligen Lebens durch Sinn-Bilder erkläret und $\mathrm{zu}$ einem Harmonischen Kirchen-Jahrgange nach Anleitung aller Sonn- und Festtäglichen Evangelien entworffen wird." aus dem Jahre 1726.

507 Universitätsarchiv Göttingen Kur. 4 V d6/2, B1. 346-347.

508 Universitätsarchiv Göttingen Kur. 4 V d6/2, B1. 348-349.

509 Universitätsarchiv Göttingen Kur. 4 V d6/2, B1. 344-355.
} 
Widerspruch gegen die Herausgabe der Gegenstände einzulegen. Von Hugo konnte den Anwalt und auch die Witwe Uffenbach überzeugen, dass die Donation nach Göttingen gehöre, wie er in einem Schreiben vom 14. April nach Hannover meldet. ${ }^{510}$ So kam es am 18. April zu einem zweiten Beschluss des Frankfurter Rates, in dem der zweite Teil der Sammlung zur Auslieferung an von Hugo freigegeben wird. 511

Zwei Tage später wurden von Hugo sämtliche Stücke der Donation, die nach 1736 und nach der zweiten Heirat angeschafft worden waren, gegen Quittung herausgegeben. Von Hugo berichtet am 21. April nach Hannover, dass er sämtliche Gegenstände und Bücher in seiner Wohnung hätte, aber: „Einige wenige nicht viel importierende Stücke fehlen zwar, hingegen ist verschiedenes, das in denen nach Göttingen geschickten Verzeichnißen nicht befindlich ist, vorhanden, unter andere 2 schöne große Globi, ein kostbarer großer Brennspiegel und etliche mathematische Instrumente, der ansehnlichen Vermehrung von Büchern und Kupferstichen nicht einmahl zu gedencken. "512 Weiter unten schreibt er: „Bey der letzten Extradition lies sie [Witwe Uffenbach] mir auch ein sehr gut getroffenes Portrait von dem seel. Schöff, welches in der Bibliothec aufgestellet gewesen, [...] verabfolgen. “513

Am 2. Mai kamen die ersten acht Ballen der Lieferung des zweiten Teils der Donation aus Frankfurt am Main in Göttingen an. ${ }^{514}$ Der Rest, „vier Ballen und zwey Verschläge“, erreichte Göttingen vor dem 11. Juni, da der Prorektor Georg Ludwig Böhmer (1715-1797) und Heyne in einem gemeinsamen Brief an diesem Tag nach Hannover melden konnten, dass nun alles am Orte wäre und auch schon die Überprüfung des Bestandes vorgenommen worden wäre. ${ }^{515}$ Dieser Teil der Schenkung wurde wie schon der Vorherige provisorisch im medizinischen Auditorium untergebracht.

\footnotetext{
510 Universitätsarchiv Göttingen Kur. 4 V d6/2, B1. 344-345.

511 Universitätsarchiv Göttingen Kur. 4 V d6/2, B1.352.

$512 \mathrm{Zu}$ den beiden Globen und den wissenschaftlichen Instrumenten vgl. Meyerhöfer 1997.

513 Universitätsarchiv Göttingen Kur. 4 V d6/2, B1.350 - 352, Zitate: 350v + 351r.

Das Portrait Uffenbachs, das von der Hand eines unbekannten Malers stammt, befindet sich heute in der Kunstsammlung der Universität Göttingen, Öl auf Kupfer, 41 x 31 cm. Vgl. Kat. Göttingen 1987, S.181, Nr.A13 mit Abb.

514 Universitätsarchiv Göttingen Kur. 4 V d6/2, B1.394 - 395.

515 Universitätsarchiv Göttingen Kur. 4 V d6/2, B1.402 - 406.
} 


\subsection{Aufstellung der Schenkung in Göttingen im Jahre 1770}

Christian Gottlob Heyne und Johann Stephan Pütter machten sich schon kurz nach dem Tode Uffenbachs erste Gedanken über die Aufstellung der Sammlung in der Göttinger Bibliothek. ${ }^{516}$ Sowohl in London als auch in Hannover stellte man diesbezüglich ebenfalls Überlegungen an - lange bevor die Donation tatsächlich in Kraft trat. ${ }^{517}$ Am 31. Mai 1769 gaben die Hannoverschen Räte der Göttinger Bibliotheksverwaltung die Weisung, dass die Bücher in der Bibliothek der Paulinerkirche und die wissenschaftlichen Instrumente und Modelle ,in einem der Auditorien“ aufzustellen wären. ${ }^{518}$ Als der erste Teil der Schenkung Ende 1769 nach Göttingen kam, wurde er, wie oben beschrieben, zwischenzeitlich wegen Platzmangels im medizinischen Auditorium auf Tische und in Regale verteilt. 519

Nachdem aber auch der zweite Teil der Schenkung durch den Frankfurter Rat freigegeben worden war, erbaten die Hannoverschen Räte am 27. April 1770 Pläne, wie sich die Göttinger Bibliotheksverwaltung die Aufstellung der Objekte in den Räumen der Bibliothek unter Berücksichtigung der Auflagen des verstorbenen Donators vorstelle. ${ }^{520}$ Heyne reichte am 21. Mai in Hannover den von dem Göttinger „OberbauCommissarius“ Johann Michael Müller (1723-1777) ausgearbeiteten „Bau- und Kosten-Anschlag, Was die Anordnung von Ansätzen an die Vier freistehenden Repositorien auf dem Nördlichen grossen Bibliothekssaale an Materialien und Arbeit erfodern dürfte" ein, um Platz für die Bücher zu schaffen, die der Uffenbachischen Sammlung weichen mußten.521 Schon am 25. des Monats bekam Müller sowohl die Anweisung, die nötigen Ansätze an die Repositorien, das heißt zusätzliche Repositorien, bauen zu lassen, als auch eine Zuweisung aus der Universitätskasse über die Summe von 172 Reichstalern und 13 Kreuzern.522 Die Aufstellung der Donation Uffenbach erforderte aber größere Umbaumaßnahmen.

Dem oben erwähnten Schreiben von Böhmer und Heyne vom 11. Juni liegt auch ein weiterer „Bau- und Kosten-Anschlag, was nachgesetzte Neue Anordnung

\footnotetext{
516 Brief vom 20. Mai 1769 (Universitätsarchiv Göttingen Kur. 4 V d6/2, B1.248 - 251).

517 Universitätsarchiv Göttingen Kur. 4 V d6/2, B1. 266-267 (Hannover, 20. Mai 1769), 269270 (London, 19. Mai 1769).

518 Universitätsarchiv Göttingen Kur. 4 V d6/2, B1. 274-274.

519 Universitätsarchiv Göttingen Kur. 4 V d6/2, B1. 357-358.

520 Universitätsarchiv Göttingen Kur. 4 V d6/2, B1. 355.

521 Universitätsarchiv Göttingen Kur. 4 V d6/2, B1. 392-395.

522 Universitätsarchiv Göttingen Kur. 4 V d6/2, B1. $391+396$.
} 
der Universitäts Bibliothek an Materialien und Arbeit erfodern [sic] dürften“ bei. ${ }^{523}$ Die von Hannover am 14. Juni bewilligte Summe über 220 Reichstaler und 28 Kreuzer wurde für die Neugestaltung der Querwand des östlichen Saales der Bibliothek und die Aufstellung der Bücher und des graphischen Kabinetts verwendet. $^{524}$ Die wissenschaftlichen Instrumente und Geräte verblieben weiterhin im medizinischen Auditorium, was die Hannoverschen Räte am 26. Juni bewilligten. ${ }^{525}$

Um die Bücherbestände aus der Sammlung Johann Friedrich von Uffenbachs kenntlich zu machen, beantragte Heyne am 23. August in Hannover die Anfertigung eines Stempels mit der Aufschrift: „Bibl. Gotting. Acad. ex donat. Uffenbach 1769“, mit dessen Eindruck jedes Buch versehen werden sollte. ${ }^{526}$ Außerdem sollte nach Heyne eine Druckerei damit beauftragt werden, Rückenschilder für die Bücher mit dem Aufdruck „Bibl. Uff.“ und der jeweiligen Numerierung herzustellen. Diese beiden Anschaffungen wurden von den Hannoverschen Räten am 27. August bewilligt. ${ }^{527}$

Die Umbaumaßnahmen müssen im September oder Oktober 1770 abgeschlossen worden sein, denn aus dieser Zeit stammt eine „Nachricht von dem neuen auf der Universitäts Bibliotheck gemachten Arragement [!], um die Uffenbachische Donation aufzustellen, "528 worin die Anordnung der Bücher und des graphischen Kabinetts erklärt wird. Die Mappen mit der Sammlung loser Druckgraphik und Zeichnungen wurden in drei Kommoden einsortiert, die in die Fensternischen eingebaut worden waren. Die Blätter konnten so bequem auf den Kommoden eingesehen werden.

Mit der Signierung und der Aufstellung der Bücher und der wissenschaftlichen Instrumente und Modelle in der zweiten Hälfte des Jahres 1770 war die sich über 34 Jahre hinziehende Donation des Frankfurter Patriziers Johann Friedrich von Uffenbach für den Universitäts-Kurator Gerlach Adolf von Münchhausen und die Göttinger Bibliotheksverwaltung endlich zu einem guten Abschluss gekommen.

Universitätsarchiv Göttingen Kur. 4 V d6/2, B1. 398-399.

524 Universitätsarchiv Göttingen Kur. 4 V d6/2, B1. 397 (Bewilligungsbescheid) + B1. 400 (Anweisung an die Universitätskasse).

525 Universitätsarchiv Göttingen Kur. 4 V d6/2, Bl. 401.

526 Der Stempel befindet sich heute noch in der Abteilung Spezialsammlungen und Bestandserhaltung der SUB Göttingen.

527 Universitätsarchiv Göttingen Kur. 4 V d6/2, B1.413-415 (Heynes Brief und Bewilligung).

528 Cod. Ms. Uffenbach Bibl. Arch. A, 1b 29.
} 


\section{Der Sammler Johann Friedrich von Uffenbach}

Die in verschiedene Interessensgebiete zu gruppierenden Sammlungen Johann Friedrich Armand von Uffenbachs haben sich zu einem größeren Teil durch seine Stiftung nach Göttingen erhalten. Zur Stiftung gehören sein Kupferstichkabinett mit etwa 9.400 Blatt Druckgraphik ${ }^{529}$ und etwa 1000 Zeichnungen, das heute in der Göttinger Universitätskunstsammlung aufbewahrt wird,530 und seine Bibliothek mit insgesamt 2289 überwiegend naturwissenschaftlichen Werken, die sich heute in der Abteilung Spezialsammlungen und Bestandserhaltung der Staatsund Universitätsbibliothek Göttingen befindet. $\mathrm{Zu}$ diesem Teil der Stiftung gehören auch die Manuskripte, die meist von Uffenbachs Hand stammen. ${ }^{531}$ Die heutige Signierung und Aufstellung der Bibliothek entspricht derjenigen Uffenbachs, die man an dem bis 1769 vervollständigten „Kurtzes Verzeichnüs derer Mathematischer Physicalischer und Kupfer-Bücher wie auch des Vorraths einiger hiezu gehöriger Instrumenten mein Johann Friedrich von Uffenbach“" nachvollziehen kann. ${ }^{532}$ Anhand des Verzeichnisses erkennt man die auf seine Interessensgebiete spezialisierte Büchersammlung, die sich nach folgenden Gebieten - jeweils in den unterschiedlichen Größen - unterteilt: „Libri matematici, Libri physici et technici, Libri Topographici et Itenarii, Einige geschriebene Sachen, Samlung derer großen Bänden mit einzeln Kupfer und Libri Iconographici."

Die „Libri Iconographici“ sind von dem Sammler in der Ordnung hinter seine Kupferbände gesetzt worden, da diese Werke diejenige gebundene Druckgraphik enthalten, die sein graphisches Kabinett ergänzen, wobei es ihm nicht um den Inhalt der Bücher ging. 533

529 Nimmt man das eigenhändige Strichverzeichnis Uffenbachs „Index Titulorum“ zur Hand, das er bis zu seinem Lebensende benutzt und immer wieder korrigiert hat, ergibt sich die genaue Anzahl von 9415 Blättern. Zu diesem Verzeichnis s. weiter unten Kapitel 6.2.2 „Die Ordnung des graphischen Kabinetts" und Anhang, S. 413-458.

Das Kupferstichkabinett wurde zuerst der Bibliothek unterstellt. Erst im Jahre 1845 wurde es dem Kunstgeschichtlichen Seminar übergeben; ich danke Katja Mikolajczak für den Hinweis, s.a. Kempen 1951, S. 11-15.

531 Vgl. Kapitel 2 ,Überblick über die vorhandenen Quellen.“

532 Vgl. StUb Frankfurt am Main Ms. Ff. J. F. v. UFFENBACH 1 und SUB Göttingen Cod. Ms. Uffenbach 47, Cod. Ms. Bibl. Arch. A. 34c/2 und Cod. Ms. Bibl. Arch. A 34c. Vgl. Cod. Ms. Uffenbach 47, p. 136r. 
Ein dritter, umfangreicher Teil mit wissenschaftlichen Geräten kam ebenfalls mit der Stiftung nach Göttingen. ${ }^{534}$ Die Geräte wurden 1770 mit den anderen Teilen in der Bibliothek eingelagert. Es waren insgesamt 229 Geräte, ${ }^{535}$ die Uffenbach numerisch in dem von ihm selbst geschriebenen Verzeichnissen aufgeführt hatte. ${ }^{536}$

Er besaß weitere wissenschaftliche Geräte und „technische Maschinen“, die nicht nach Göttingen gelangt sind und auch nicht der Stiftung angehörten. Diese wurden auf der Auktion am 6. Mai 1771 angeboten, die seine zweite Frau veranlasst hatte.

\subsection{Die Gemäldesammlung}

Die Sammlung weiterer Gegenstände und Kunstwerke, die Uffenbach zusammengetragen hatte und die nicht zur Göttinger Stiftung gehörten, läßt sich ganz oder teilweise rekonstruieren. So kann man seine Gemälde-, Statuen- und Naturaliensammlungen nur noch anhand des Auktionskataloges vom 6. Mai 1771 und der beiden Gegenschreiberbücher von 1771 und 1775, zumindest quantitativ, rekonstruieren. ${ }^{537} \mathrm{Im}$ Gegensatz zur Druckgraphik lassen sich die genauen Umstände des Erwerbs dieser Gruppe anhand der Quellen wie z. B. der Briefe 538 nicht nachweisen.

Seine Sammlung an Bildern umfasste laut dem Auktionskatalog von $1771^{539}$ insgesamt 246 Stücke, wobei hier nicht nur Gemälde sondern auch Miniaturen,

Vgl. das Kapitel 5 „Geschichte der Schenkung nach Göttingen“.

Einzelne Nummern sind mit Unternummern versehen.

Vgl. Cod. Ms. Bibl. Arch A 34a: Uffenbachische Instrumente. Es wurde nach 1770 nach Eintreffen der Sammlung angefertigt, spätestens vor der Übergabe der Geräte an Georg Christoph Lichtenberg (s. Anhang, S. 359-412) und Meyerhöfer 1995 und Lichtenberg 2017.

Bis auf fünf Instrumente, die heute im I. Physikalischen Instituts der Universität Göttingen aufbewahrt werden, lässt sich von den wissenschaftlichen Geräten nichts mehr auffinden bzw. mit Sicherheit nachweisen.

Einen größeren Teil der wissenschaftlichen Geräte wurde am 26. Oktober 1791 an Georg Christoph Lichtenberg übergeben, der sie in seiner Göttinger Wohnung in der Gotmarstraße 1 in einem gesonderten Raum aufstellte (vgl. Lichtenberg 2017). Es handelt sich bei diesem Zimmer um das Balkonzimmer (gekennzeichnet mit „A“); vgl. Cod. Ms. Lichtenberg VII, Q1 (B1.56) und Kat. Darmstadt 1992, S. 315, Kat. Nr. 663, Abb. auf S. 316. Den anderen, kleineren Teil stellte man am 29. Oktober 1791 in der Modellkammer der Bibliothek auf.

Vgl. Transkription im Anhang, S. 290-355; Uffenbach 1771 und Uffenbach 1775.

Vgl. Cod. Ms. Uffenbach 20.

Uffenbach 1771, S. 27-41. 
„Wasserfarbbilder“, Glasmalereien und Emailbilder dazugehören. ${ }^{540}$ In den Gegenschreiberbüchern der Auktionen von 1771 und 1775 sind sich noch weitere Gemälde verzeichnet, die sich in Uffenbachs Besitz befunden haben. ${ }^{541}$ Einige wenige, auf den Auktionen fehlende Bilder kann man anhand der erhaltenen Korrespondenz ${ }^{542}$ und der Protokolle der wissenschaftlichen Gesellschaft nachweisen. 543

Versucht man sich einen Überblick über Uffenbachs 163 Gemälde zu machen, die zur Versteigerung kamen, lassen sich folgende drei Aussagen treffen:

Uffenbachs Geschmack entsprach dem seiner Frankfurter Standesgenossen. Neben den meisten Gemälden, die keinem Künstler zugeordnet sind, sind es in erster Linie - geht man nach den im Auktionskatalog genannten Namen - Werke der niederländischen und flämischen Schulen des 16. und 17. Jahrhunderts, wie Willem van Bemmel (1630-1708) ${ }^{544}$, Anthonis van Dyck (1599-1641)545, Joos de Momper (1564-635) $)^{546}$, Peter Neefs (1570-1651) ${ }^{547}$, Abraham Bloemaert (1564$1651)^{548}$, Gerrit van Honthorst (1592-1656) $)^{549}$, Bonaventura Peeters (1614$1652)^{550}$, Gerard de Lairesse $(1640-1711)^{551}$, Hendrik van Steenwijk (ca. 1580-

540 Hier zeigt sich wieder, dass Uffenbach seine Sammlung technischer Interessen wegen zusammengebracht hatte. Über die Technik der Emailmalerei ließ er sich von Johann Georg Kißner ein Buch aus Paris besorgen: Jacques Philippe Ferrand, L'art du feu ou de peindre en Email: Dans lequel on decouvre les plus beaux Secrets de cette Science; Avec des Instructions pour peindre et appreter les couleurs de Mignature dans leur perfection, Paris 1721 ( $8^{\circ}$ Bibl. Uff. 294). Dieses Buch zeigte Kißner am 9. November 1730 der anwesenden wissenschaftlichen Gesellschaft; vgl. Cod. Ms. Uffenbach 13/IV, p. 56. Auch wurde auf fast jeder Sitzung über die verschiedenen künstlerischen Techniken gesprochen und praktische Versuche angestellt.

541 Vgl. Gegenschreiberbuch 1771, S. 58-59; Gegenschreiberbuch 1775, S. 222b und 225a; s. Anhang, S. 301-302, S. 307 und S. 312-313.

542 Vgl. Cod. Ms. Uffenbach 20.

543 Vgl. Cod. Ms. Uffenbach 13 I-V.

544 Uffenbach 1771, S. 29, Nr. 27.

545 Uffenbach 1771, S. 28, Nr. 7, S. 33, Nr. 105, S. 33, Nr. 110.

546 Uffenbach 1771, S. 36, Nr. 151.

547 Uffenbach 1771, S. 30, Nrn. $60+61$.

548 Uffenbach 1771, S. 28, Nr. 22.

549 Uffenbach 1771, S. 34, Nr. 115.

550 Uffenbach 1771, S. 34, Nr. 121.

551 Uffenbach 1771, S, 35, Nr. 127.

Von Gerard de Lairesse direkt oder in deutscher Übersetzung besaß Uffenbach auch mehrere gedruckte Werke. Neben „Des Herrn Gerhard de Lairesse ... Grosses MahlerBuch“, 2 Bde. Nürnberg 1728-30“ (4 Bibl. Uff. 621, $1+2)$ und „Neueröffnete Schule der Zeichenkunst“, Leipzig 1745 ( $2^{\circ}$ Bibl. Uff. 487) besonders sein „Opus tam ipsa manu incisorum, quam inventorum“, Amsterdam o.J. (2 ${ }^{\circ}$ Bibl. Uff. 505). 
ca. 1649) $)^{552}$, Pieter Neefs (1620-nach 1675) $)^{553}$, David Teniers (1610-1690) $)^{554}$, Frederik de Moucheron (1634-1686) ${ }^{555}$, Gillis van Valckenborch (1570-1622) ${ }^{556}$, Paul Bril (1554-1626) ${ }^{557}$, Johannes Coesermans ${ }^{558}$, Jan de Hens ${ }^{559}$, der „Schule des Rubens“ 560 , der „Schule von Rembrand“561 oder „im gousto von Rembrand" 562 .

Eine weitere, sehr große Gruppe bilden die Werke der Künstler der Frankfurter Schule des 18. Jahrhunderts, die mit Uffenbach besonders verbunden waren. ${ }^{563}$ Es sind Künstler wie Johann Melchior Roos (1663- 731)564, Christian Ludwig von Löwenstern (1701-1754)565, Justus Juncker (1703-1767) $)^{566}$, Johann Georg Trautmann (1713-1769)567, Georg Christian Schütz d. Ä. (1718-1791)568, August Querfurt (1696-1761)569, Franz Hochecker (1730-1782) $)^{570}$, Johann Conrad Seekatz (1719-1768) 571 aber auch der einer älteren Generation zugehörige Georg Flegel (1566-1638) 572 .

Werke von Künstlern anderer Epochen oder Länder besaß Uffenbach nur wenige, wie z. B. Lucas Cranach (1472-1553)573, Hans Holbein d.J. (1497/98-

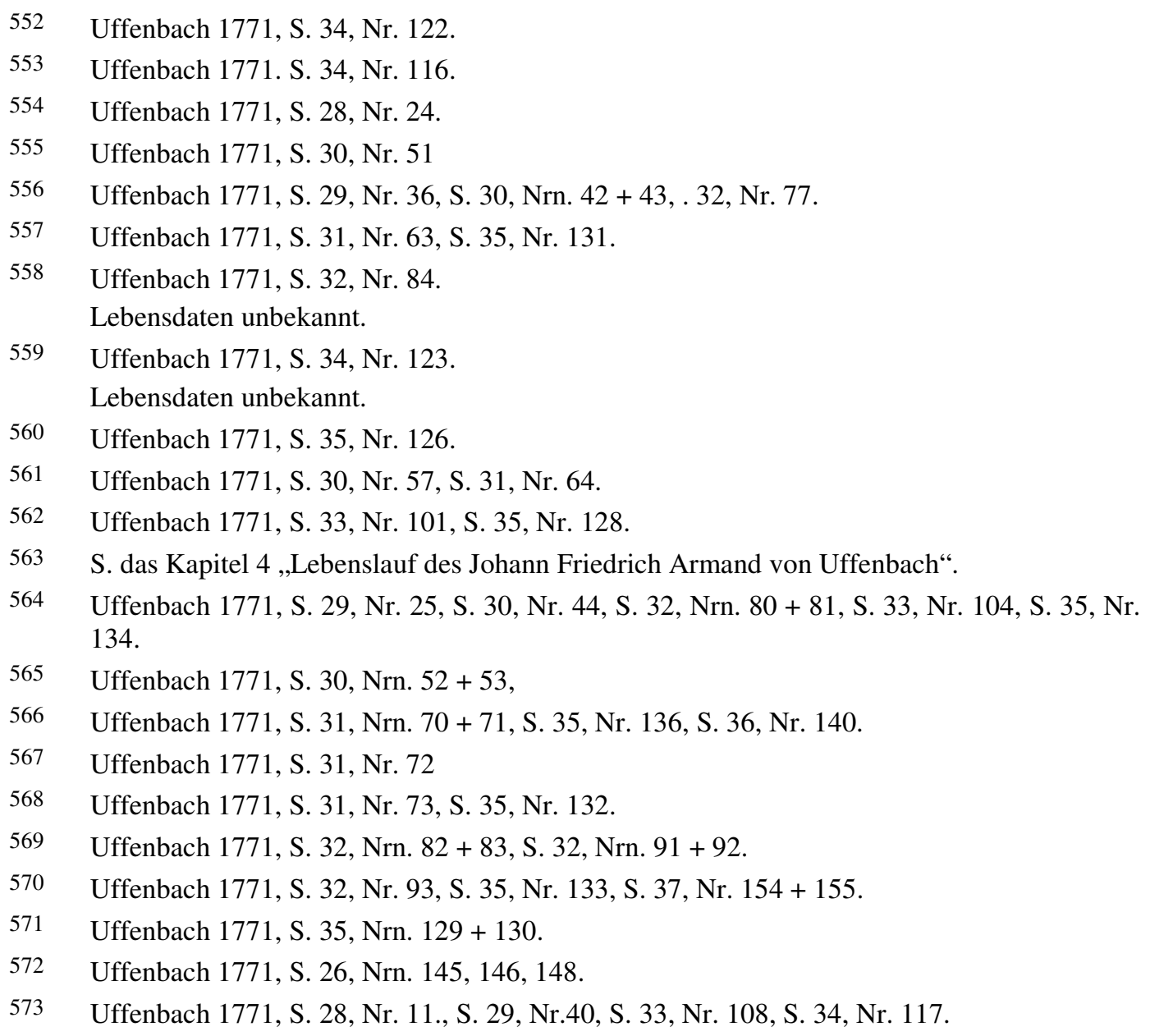

Uffenbach 1771, S. 34, Nr. 122.

Uffenbach 1771. S. 34, Nr. 116.

Uffenbach 1771, S. 28, Nr. 24.

Uffenbach 1771, S. 30, Nr. 51

Uffenbach 1771, S. 29, Nr. 36, S. 30, Nrn. $42+43$, . 32, Nr. 77.

Uffenbach 1771, S. 31, Nr. 63, S. 35, Nr. 131.

Uffenbach 1771, S. 32, Nr. 84.

Lebensdaten unbekannt.

Uffenbach 1771, S. 35, Nr. 126.

Uffenbach 1771, S. 30, Nr. 57, S. 31, Nr. 64.

Uffenbach 1771, S. 33, Nr. 101, S. 35, Nr. 128.

S. das Kapitel 4 ,Lebenslauf des Johann Friedrich Armand von Uffenbach“.

Uffenbach 1771, S. 29, Nr. 25, S. 30, Nr. 44, S. 32, Nrn. $80+81$, S. 33, Nr. 104, S. 35, Nr. 134.

Uffenbach 1771, S. 30, Nrn. $52+53$,

Uffenbach 1771, S. 31, Nrn. $70+71$, S. 35, Nr. 136, S. 36, Nr. 140.

Uffenbach 1771, S. 31, Nr. 72

Uffenbach 1771, S. 31, Nr. 73, S. 35, Nr. 132.

Uffenbach 1771, S. 32, Nrn. $82+83$, S. 32, Nrn. $91+92$.

Uffenbach 1771, S. 32, Nr. 93, S. 35, Nr. 133, S. 37, Nr. $154+155$.

Uffenbach 1771, S. 35, Nrn. $129+130$.

Uffenbach 1771, S. 26, Nrn. 145, 146, 148.

Uffenbach 1771, S. 28, Nr. 11., S. 29, Nr.40, S. 33, Nr. 108, S. 34, Nr. 117. 
1543) $)^{574}$, Hans Rottenhammer (1564-1625) 575 , Jacques Courtois, gen. Le Bourguignon(1621-1675) $)^{576}$ oder Luca Antonio Colomba (1674-1737) ${ }^{577}$.

\subsection{Das graphische Kabinett}

\subsubsection{Erwerb der Sammlung}

Beim Erwerb seiner losen und gebundenen Druckgraphik ging Johann Friedrich unterschiedliche Wege. Zum einen hatte er in seiner Heimatstadt Frankfurt am Main mit seinen Messen schon sehr gute Voraussetzungen Druckgraphik zu erwerben, da dort viele Verleger und Händler anwesend waren. Zum anderen kaufte er zumindest den Grundstock seiner Sammlung auf seinen ausgedehnten Reisen. ${ }^{578}$ Immer wenn er in einer größeren Stadt war, sei es in Rom, Venedig, Straßburg, Paris, London, Amsterdam, Den Haag oder Antwerpen, suchte er die verschiedenen Händler auf, um die Bestände durchzusehen und, falls der Preis stimmte, Graphik zu erstehen.

Beim Besuch von Amsterdam 1710 gingen die beiden Brüder, Zacharias Conrad und Johann Friedrich, am 20. Mai ,in Nic.[olas] Vischers Konst en Caertwynckel“, in welchem Johann Friedrich ,sehr viele schöne Kupferstiche von alten Meistern um billigen Preis kauffte."579 Auf der Rückreise von England besuchte Johann Friedrich am 27. April und am 26. Mai 1711 nochmals „Visschers Winckel und kaufte einige Kupferstiche.“ 580

\footnotetext{
$574 \quad$ Uffenbach 1771, S. 29, Nr. 32, S. 30, Nrn. $58+59$.

575 Uffenbach 1771, S. 33, Nr. 109.

576 Uffenbach 1771, S. 34, Nrn. $112+113$.

577 Uffenbach 1771, S. 36, Nr. 143.
}

Der Künstler war von 1735 bis 1737 in Frankfurt und fertigte während dieser Zeit u. a. das Deckengemälde in der Rotunde des Palais Thurn und Taxis an. Wahrscheinlich kaufte Uffenbach also direkt von Colomba „Ein Stück von einem Plavong, auf dito [auf Tuch].“ Vgl. Kapitel 4 ,Lebenslauf des Johann Friedrich Armand von Uffenbach“.

579 Uffenbach 1753-1754, Bd. II, S. 416-417.

Der Verlag und Handel „In de Visscher“ war schon im 17. Jahrhundert von Nicolaes Visscher (1618-1679) gegründet worden. Nach seinem Tod übernahmen sein Sohn Nicolaes Visscher II (1649-1702) und seine Frau Elisabeth Verseyl das Geschäft, das nach deren Tod 1726 von Andries de Leth (1662-1731) weitergeführt wurde. Bei ihm erwarb Uffenbach die Bücher und Druckgraphik. Nach dem Tod von Andries de Leth übernahm dessen Sohn, Hendrik de Leth (1703-1766) die Handlung, mit dem Uffenbach noch 1750 korrespondierte (Vgl. Cod Ms. Uffenbach 20/II, Bl. 349.

In der SUB Göttingen befinden sich mehrere Werke des Verlagshauses aus Uffenbachs Besitz.

580 Cod. Ms. Uffenbach 25/III, S. 774, 816 und 840. 
Uffenbach hat aber den Kontakt zu Visschers Kunsthandel nach seiner Rückkehr nach Frankfurt nicht abbrechen lassen. Anfang 1750 hatte er Hendrick de Leth (1703-1766), derzeitigen Inhaber von Visschers Winckel, wegen preiswerten Erwerbs von Graphik angeschrieben. Hendrick de Leth antwortete ihm in einem Brief, dass Uffenbach Kupferstiche und Radierungen zu den Preisen seines Vaters von vor 40 Jahren nicht mehr bekommen könnte. De Leth führt dabei die Künstler an, an denen es Uffenbach besonders gelegen war: Rembrandt, Dürer, Callot und Le Clerc. Bei Rembrandt gibt de Leth sogar ein Beispiel an: ,[...] nu 5 a 6 ja tien dukaten, en dat voor namentlyk de Prente van Rembrand, Wantte geven tegen Woordig voor Een goede Druk, voor het Pourtret van Burgemeister Six 90 ja 100 Guldens [...]." ${ }^{\text {(581 }}$

Das Beispiel zeigt sehr gut, wie Uffenbach üblicherweise beim Erwerb von Graphik vorgeht. Einmal geknüpfte Verbindungen, die er auf seinen Reisen aufgenommen hatte, verfolgte er von Frankfurt am Main aus weiter. Leider wird weder in den Tagebüchern noch, wie in diesem Fall, in den Briefen detailliert über den Kauf von einzelnen Blättern gesprochen. Es heißt nur allgemein „sehr viele schöne Kupferstiche“ oder „einige Kupferstiche.“

Wie im Kapitel 4 „Lebenslauf des Johann Friedrich Armand von Uffenbach“ schon beschrieben, war Uffenbach während seiner Grand Tour bei seinem Pariser Aufenthalt mehrere Male bei Pierre Jean Mariette. Zwar wollte er Bücher des Verlages und lose Druckgraphik erwerben, das Kunsthaus Mariette war ihm aber zu teuer. ${ }^{582}$

Uffenbach hatte zudem in einzelnen Städten Agenten, die ihm immer wieder von zu veräußernden Graphiksammlungen berichteten. Er hatte auf seiner Grand Tour durch Italien den Nürnberger Kaufmann und Münzsammler Johann Daniel Geysel $^{583}$ in Rom kennengelernt ${ }^{584}$ und nach seiner Rückkehr einen regen Briefkontakt mit ihm aufgebaut. ${ }^{585}$ Geysel war 1715 in seine Heimatstadt zurückgekehrt, siedelte dann um 1750 nach Venedig über, da seine Briefe ab dieser Zeit von dort adressiert sind. Uffenbach hatte Geysel 1750 angeschrieben,

Cod. Ms. Uffenbach 20/II, B1. 349

Sinngemäß: „Sie können jetzt fünf bis sechs ja zehn Dukaten ausgeben und das nämlich für einen Druck von Rembrandt, wenn Sie aber einen guten Abzug von dem Portrait von Bürgermeister Six haben wollen, muss man 90 bis 100 Gulden dafür bezahlen.“

582 Cod. Ms. Uffenbach 29/IV, S. 304-305.

583 Lebensdaten unbekannt.

584 Vgl. Cod. Ms. Uffenbach 29/II, S. 534 und 29/III, S. 574.

585 Vgl. die Briefe Geysels in Cod. Ms. Uffenbach 20/I und 20/II und im Anhang S. 542-555. 
um nachzufragen, ob Geysel in Venedig Druckgraphik für ihn erwerben könne. Im September des Jahres antwortet Geysel Uffenbach und schildert ihm dabei den Graphikhandel in Venedig: „Was demnach die alte Kupferstiche betrifft, so sehe aus dem was Sie davon welchen, daß Sie von dem hisigen Zustand noch keinen rechten Begriff haben. Hier fehlt es an Liebhabern von Kupferstichen und Zeichnungen so wenig, daß vielmehr alles verkaufft wird, was von alten Sachen nur zum Vorschein kommt, und ist kein alter Kupfer und Papierkrämer in gantz Venedig zu finden (dann ich kenne sie alle) welcher dergl Sachen besässe und froh seyn möchte wann Nachfrage darum geschähe.

Alle Sonn- und Feyertags sind alle Läden in der Mercaria neml die lange Straße so von der Rialtobrücken biß an den Marcusplatz gehet. geschlossen; hingegen findet man alda die Bretter der Boutiquen mit Kupferstiche und Handrissen an vielen Orten ganz tapezirt; Diese habe sieben Jahr lang, wann es das Wetter permittirt, dann bey Regenzeit legen sie nicht aus fleißig besucht aber kaum 7. Blat gefunden, die das Porto werth wären, solche hin aus zu schicken, indessen kaufen diese Leute doch immer soviel, daß sie nur viel zu bekommen wünschten, um zum Verkauff ausstellen zu können und verschiedene leben die ganze Woche von dem, was sie an Sonn- und Feyertägen an dieser Wahr gewinnen. Blätter, die Sie suchen, findet man hier nicht, dann wann bey ein Sterbfall ein Loch aufgehet, so sind diese Antiquari wie die Schürhunde so geschickt solches gleich zu erfahren, und jedermann verkaufft ihnen gern, weil sie gut und böses mit einander kauffen. Aber diese wissen die Geister zu prüfen, sie suchen alle guten Blätter heraus, und tragen solche zu erst zum Engl Consul Mr. Smith ${ }^{586}$ der am meisten dafür giebt; was sie da nicht anbringen, tragen sie zu dem Zanetti ${ }^{587}$, der läßt nicht ungekaufft, was nur halb gut ist, mithin kommt nichts zu die Mercerie als was diese beide ausschlissen. “588

Im selben Brief versucht Geysel Uffenbachs kritische Meinung über den in Venedig arbeitenden Kupferstecher und Verleger Joseph Wagner (1706-1780)589

586 Consul Joseph Smith (ca. 1674-1770), Resident Englands in Venedig, Förderer von Canaletto. Vgl. Kat. Frankfurt 1989.

587 Anton Maria Zanetti (1660-1767), Sammler, Mäzen, Kunsthändler, Karikaturist, Zeichner und Stecher, vgl. Kat. Frankfurt 1989, S. 31-32.

588 Cod. Ms. Uffenbach 20/II, B1. 111r, s. Anhang S. 547-548.

589 Der Kupferstecher Wagner baute ab 1739 in Venedig einen Verlag und eine Stecherschule auf. Er gab unter seinem Namen auch die Blätter seiner Schüler heraus (Vgl. Holland, Hyacinth, "Wagner, Joseph" in: Allgemeine Deutsche Biographie 40 (1896), S. 521-522 [Online-Version]; URL: https://www.deutschebiographie.de/gnd121772624.html\#adbcontent vom 28.02.2017).

Von „Wagener“ besaß Uffenbach nach seinem Verzeichnis 36 Stiche, vgl. Anhang, S. 456. 
zu widerlegen: „Sie sagen Wagner ahme die Frantzosen nach, kömme ihnen aber noch lange nicht bey. Auch hier sind Sie mit Ihrer Erlaubniß irrig. Mit Wagner hat es eben die Bewandniß als mit dem Picart ${ }^{590}$, wieviel Stücke findet man nicht mit Picart Sculpsit, unerachtet er dabey weder Radiernadel noch Grabstichel angesetzt hat, sondern lediglich unter seinem Verlag, von seinen Scholaren gemacht worden sind. [...] so will Ihnen wenigst ein oder zwey Stück mit senden, so Wagner, nach des geschulten Amiconi ${ }^{591}$ Gemählden mit eigener Hand gezeichnet, radiret und gestochen hat, und zweiffle, ob Sie Ihn sodann denen neüen oder nochlebenden Frantzosen nachstehen werden. “"592

Nach dem Tod des Leipziger Professors und Graphiksammlers Johann Friedrich Christ (1701-1756) im Jahre 1756, mit dem Uffenbach seit 1750 in schriftlichem Kontakt gestanden hatte, ${ }^{593}$ versuchte er, Graphik aus dessen Besitz zu ersteigern. So hatte Uffenbach 1758 aus der Leipziger Zeitung erfahren, dass die Sammlung Christ versteigert werden sollte und sich den Auktionskatalog594 schicken lassen. Nach Durchsicht des Kataloges hat Uffenbach sich mit dem Verleger Bernhard Christoph Breitkopf (1695-1777) in Verbindung gesetzt, mit der Bitte für ihn als Kommissionär bei der Auktion aufzutreten, was Breitkopf Uffenbach zusagte. ${ }^{595}$ Uffenbach gibt ihm schriftlich genaue Anweisungen, was Breitkopf ersteigern solle: „Ohneracht deßen könte mich entschließen die Samlung käuflich an mich zu bringen, wenn vor allen dingen der preiß eines wercks das ich unbesehens begehre, gantz billig und thulich seyn könte, worüber also nachricht er warte. Ubrigends wäre mir am liebsten, wenn vun dem gantzen vorrath nur die stücke von pag 14 an: Ecole de rome $\mathrm{p} \mathrm{p}$ biß pag. 79. wo der artickel: estampes en livres p p angehet billig mässig allein erhalten könnte.“596

Bernard Picart (1673-1733).

Von Picart besaß Uffenbach nach seinem Verzeichnis 21 Stiche, vgl. Anhang, S. 444.

Jacopo Amigoni (1675-1752), Lehrer von Joseph Wagner.

592 Cod. Ms. Uffenbach 20/II, Bl. 111r + v.

593 Cod Ms. Uffenbach 20/I, B1. 285-298, Transkription s. Anhang, S. 254-267.

Den Kontakt begann Uffenbach mit seinem Brief vom 30. April 1750 (Cod Ms. Uffenbach 20/I, Bl. 285-289, s. Anhang S. 556-562).

Zu Christ s. Müller 2006.

594 Catalogue D'Une Grande Collection D'Estampes Des Meilleurs Maitres D'Italie, De Flandres, De France Et D'Allemagne Du Feu Mr. Christ Celebre Professeur De L'Academie De Leipsic, Leipzig 1757 ( $8^{\circ}$ Bibl. Uff. 800).

595 Cod. Ms. Uffenbach 20/II, B1. 296, s. Anhang, S. 570.

596 Cod. Ms. Uffenbach 20/II, Bl. 297r. Transkription s. Anhang, S. 571.

Es handelt sich hier um das Konzept des Briefes, den Uffenbach an Breitkopf geschickt hat und vor dem 3. April 1758 verfasst worden sein muss, da das Antwortschreiben Breitkopfs auf diesen Tag datiert ist (Cod. Ms. Uffenbach 20/II, Bl. 296). 
Uffenbach war also gewillt, die gesamte Sammlung Christ zu ersteigern, allerdings nur zu einem geringen Preis. Wenn aber eine Aufteilung stattfinden würde, wäre er besonders an der italienischen Graphik interessiert - ebenfalls nur zu einem angenehmen Preis.

Uffenbach arbeitete den Katalog gründlich durch. Besonders bei den dort angebotenen Büchern findet man viele rote Unterstreichungen. Überprüft man die angestrichenen Werke mit denen, die in der Bibliothek Uffenbachs vorhanden sind, ist es auffällig, dass sich sämtliche Bücher schon in seinem Besitz befinden. Allerdings kann man nicht davon ausgehen, dass Uffenbach die Werke auf der Auktion Christs erworben hat. Zum einen befinden sich unter den angestrichenen Titeln Bücher, die er schon lange vorher gekauft hatte. Die Werke der Bibliothek Uffenbach - geht man nach den Signaturen - sind heute noch in der Reihenfolge so aufgestellt, wie der Eigentümer sie erworben und nach Gebieten geordnet hatte. Zum anderen zeigen dies zum Beispiel die 52 Blätter mit Illustrationen von Ovids Metamorphosen nach Hendrik Goltzius (1558-1617), die Uffenbach erst 1762 über Johann Christian Kaller ${ }^{597}$ in Amsterdam erworben hat. ${ }^{598}$ Uffenbach nahm den Auktionskatalog der Sammlung Christ also auch als Richtschnur für seine eigenen Interessen.

Der Frankfurter Kunsthändler und Auktionator Johann Christian Kaller wurde für Uffenbach 1758 und 1762 in Amsterdam tätig. Der Sammler hatte im Juni 1758 Kaller Kommission erteilt, nach Druckgraphik von Antoine Masson (16361700) und Theodor van Thulden (1606-1669) und weiteren Büchern Ausschau zu halten. Der erfolgreiche Kaller schreibt in seinem Brief vom 17. Juni 1758: „Euer hochedelgeborene gnädigst ertheilte Commissiones in Büchern und Kupferstichen, habe sogleich bey meiner ankunfft getrachtet, ein und anderes davon in Handen zu bekommen, weil es aber meißtens piecen welche sehr rar zu haben, als das portrait von Gouillaume Brisacier599 \& Petrus Dapuis ${ }^{600}$, durch Masson, und 7 Historien von Ulisses in 58 Blättern von Theodor van Thulden gestochen, unter dem titul Le traveaus d'Ulyssse: welche Hirschberg601 Ierem

\footnotetext{
597 Lebensdaten unbekannt. Zu Johann Christian Kaller vgl. Ketelsen/Stockhausen 2002, Bd. 1, S. 30-31.

598 Die Blätter befinden sich heute im graphischen Kabinett der Kunstsammlung der Universität Göttingen Inv. Nr. 4401-4405.

Die Transkription des Briefes s.a. Anhang, S. 525.

599 = Guillaume Brisacier (1654-1658), französischer Finanzminister.

$600=$ Pierre Dupuis (1610-1682), Stillebenmaler.

601 Kommissionär, Vornamen und Lebensdaten unbekannt.
} 
Doctor Ehrenreich ${ }^{602}$ zu senden die Ehre habe. weilen vor kurtzen auff eine noch einmall zum Vorschein gekommene manier 8 Anatomische Piecen heraußgegeben worden, so habe couriositet wegen zwey davon beygelegt solten Euerhochedelgeborene gefallen tragen die übrigen auch zu haben, so will dero Befehlen erwarthen zu gleich auch bemelten, ob die übrige Masson welche noch höher als diese im Preis zu stehen kommen dannoch kauffen darff. Ich wünschte gerne wohlfeilere Preyße zu besorgen, allein wann man etwas von hießigen Kunsthändlern kaufen will, so wissen die Leute nicht genug zu fordern, und laßen sich alles theuer bezahlen, besonders Stücke die man wenig finden kan." Unter Kallers Unterschrift befindet sich das Postscriptum der Rechnung: „Nota 2 portrait von Masson. f 5,30, Le Traveaus d’Ulyss: 58 piecen, von Thulden 7,30, 2 anatomie piecen, von Admiral 4.-, f 17:-.“603

Bei den „Admiral“ handelt es sich um den Amsterdamer Radierer und Schabkünstler Jan L'Admiral (1699-1733), der in seiner Zeit für seine Schabkunstblätter - schwarz-weiß und farbig - bekannt war.

Uffenbach erwarb die 58 Blätter „Les Travaux d'Ulysse“ von Theodor van Thulden, die bei Mariette in Paris 1663 erschienen waren. ${ }^{604}$

Im Juli 1762 beauftragte Uffenbach Kaller, in Amsterdam nach Blättern von Hendrik Goltzius mit Szenen aus Ovids Metamorphosen und nach Druckgraphik von Jacques Callot (1592-1635) zu suchen. Kaller war auch hier erfolgreich, wenn er in dem Brief vom 6. Juli 1762 meint: „Euer Excellentz haben mich mit zwey comiss: beEhreth, wegen welchen die Freyheit genommen diesean dieselben abzutragen; und nachricht zu geben, das die Verwandlungen Ovidii von $\mathrm{H}$ Goltzius bey einem hiesigen Kunsthändler zu bekommen seyn die Zahl bestehet in 52 blat und so guth + schön von druck, als wann solche erst von der Presse gekommen, der allereußerste Preyß ist 52 so das vor jegliches blat ein gulden gerechnet wird. weil mir nun dieser Preys etwas hoch düncket, und doch nichts davon kan abgedungen werden, so wolte vorhero anfragen, ob ich auch Euer Excellentz gewesen wäre ihn davon zu behalten, so sind davon die der Lieferung geben, das man vergeblich einer schönen collection suchen wird. die Heyligen auff das gantze Jahr von Callot sind auch vor Fl. 18 zu haben, allein man will

602 = Johann Matthias Ehrenreich (um 1700/1704-1769), Frankfurter Arzt, kaiserlicher Rat und Kunstsammler.

603 Cod. Ms. Uffenbach 20/II, p. 301-302, s. Anhang s. 523-524.

604 Die Blätter befinden sich gebunden heute in der SUB Göttingen unter der Signatur: $2^{\circ}$ Bibl. Uff. 516. 
keinen Monath davon abgeben, und alle 12 Monath zu kauffen, ob Sie schon auch extra schön seyn, darff ich ebenfals auff mich nehmen."605

Uffenbach stimmte dem Ankauf zu. Heute befinden sich insgesamt 54 Blätter der Ovid-Serie nach Entwürfen von Hendrik Goltzius aus Uffenbachs Besitz im Graphischen Kabinett der Kunstsammlung der Universität Göttingen. Vergleicht man die 52 insgesamt erschienenen Blätter der Serie mit den 54 Blättern, die sich in der Kunstsammlung erhalten haben, fallen Unterschiede auf. Zum einen fehlen aus der Serie drei Blätter606, zum anderen befinden sich fünf Doubletten im Göttinger Bestand. Kaller hatte für Uffenbach also nicht die ganze Serie erworben. Wahrscheinlich hatte Kaller in Amsterdam die Serie nicht kollationiert und die fehlenden bzw. doppelten Blätter nicht bemerkt. Die Serie „Les Images de tous les Saincts et Saintes du mois“ von Jacques Callot aus dem Jahre 1636 befindet sich gebunden in der Göttinger Bibliothek. ${ }^{607}$

Ebenfalls im Jahre 1762 nahm Uffenbach schriftlich mit der Nürnberger Künstlerfamilie Dietzsch Kontakt auf. Am 20. September fragt Uffenbach sowohl nach Gemälden als auch nach alter Druckgraphik. Am 29. September 1762 antwortet ihm Johann Israel Dietzsch (1710-1769): ,[...] haben auch die Gnade zu erwehnen daß Ew. Hochwolgebohren Liebhaber von Kupferstichen, so von alten Berühmten Meistern, und schon bereits eine große Sammlung besitzen, wir auch Willens nach unseren anzuschaffen die Sammlung vollkommen zu machen. So haben wir gehorsamst zu vermelden, daß wir sämtliche Brüder608 uns eine große Menge Kupferstiche, von denen alten berühmten Meistern zusamgetragen, und bißweilen an Liebhaber wieder einige verkauffen, werden also eine partie der besten aussuchen solche wohl einbacken nebst einer Nota der nechsten Preiße durch H. Ebermair an Ew. Hochwolgebohren über senden, nach Dero hohen gefallen etwas auszuwählen, daß unanständige aber mit gelegenheit an uns zu senden."609 Am 2. November kündigt Dietzsch an, dass er den Kommissionär Ebermair610 „ein Kästlein mit 130. der schönsten und rarsten Kupfer Stiche eingehändigt, welcher Folge mit erster gelegenheit an Ew. Hochwolgebohrne Gnaden über senden wird. Die Kupferstiche sind hinten am eck alle numerirt und wir aus

Cod. Ms. Uffenbach 20/II, B1. 303r + v, s. Anhang S. 525.

„Das silberne Zeitalter“, „Das bronzene Zeitalter“ und „Das eiserne Zeitalter“.

Unter der Signatur: $8^{\circ}$ Bibl. Uff. 819.

Gemeint sind: Georg Friedrich (1717-1755), Johann Albert (1720-1784), Johann Jakob (1713-1786) und Johann Sigmund Dietzsch (1707-1775), alle Zeichner, Kupferstecher und Maler in Nürnberg.

609 Cod. Ms. Uffenbach 20/II, B1. 318r + v.

610 Vornamen und Lebensdaten unbekannt.
} 
beygelegter Specification von jeden der nechste Preiß zu versehen sein."611 Der Erwerb des Konvoluts zog sich bis ins Jahr 1763 hin. Aufgrund eines Missverständnisses wegen des Gesamtpreises - Uffenbach versuchte den Preis zu drücken ${ }^{612}$ - konnte der Handel erst im März 1763 vollzogen werden. Am 6. März erklärte sich Dietzsch dazu bereit, die 76 Nummern mit insgesamt 87 Blättern zum Preis von 60 Gulden statt der verlangten 78 Gulden 45 Kreuzer abzugeben, und Uffenbach sollte „den über Rest der Kupferstiche mit gelegenheit zurück senden.“613 Aus der rein numerischen Liste kann man ersehen, wie viel ein Blatt Druckgraphik kostete. Die Preise lagen zwischen 15 Kreuzern und 3 Gulden pro Stück.

Uffenbach nutzte auch seine Kontakte, die er schon in seiner Heimatstadt knüpfen konnte. Der aus einer alten Frankfurter Familie stammende Stein- und Gemmenschneider Peter Heß (1709-1782)614 war 1746 von den hessischen Landgrafen nach Kassel berufen worden. Uffenbach hatte mit seinem Brief vom 7. November 1750 Kontakt zu Heß aufgenommen, um von ihm zu erfahren, wie es ihm in Kassel erging, und auch nach Leimrezepten für Pietra dura zu fragen. ${ }^{615}$ Im Winter 1750 hatte Uffenbach durch seinen Verwandten Veltheim diesen Brief überbringen lassen. Uffenbach wollte sich über Kunst und Kunsthandel in Kassel informieren lassen. Heß, der ihm mit am 4. Januar $1751^{616}$ antwortete, beschreibt die verschiedenen Sammlungen in Kassel und den Handel mit Druckgraphik, der $\mathrm{He} ß$ zu teuer erschien.

Erst Ende 1762 oder Anfang 1763 nimmt Uffenbach wieder Kontakt zu Heß auf. In einem Antwortschreiben des Kasseler Steinschneiders vom 24. Januar $1763^{617}$ geht es um den Nachlass des Generals von Donop ${ }^{618}$, der zum Verkauf stand. Heß beschreibt die Sammlung Donop folgendermaßen: „[...] der Hoffmeister hatt mir die gantze Sammlung der Kupferstiche gezeiget: worüber mich verwundert, so wohl über dero viel als Schönheit. Sie sind alle in großen Folianten von 4 biß 5 finger dick in frantz band eingebunden, und jeder Band von denen besten alten meister die einer zu haben sind angefült; außer was noch in den

\footnotetext{
611 Cod. Ms. Uffenbach 20/II, B1. 319r.

612 Vgl. den Brief von Dietzsch vom 23. Februar 1763 (Cod. Ms. Uffenbach 20/II, B1. 320).

613 Cod. Ms. Uffenbach 20/II, B1. 321v. Die Transkription der Liste.

614 S. Gwinner1862, S. 205.

615 Cod. Ms. Uffenbach 20/II, B1. 416-420, s. Anhang, S. 537-541.

616 Cod. Ms. Uffenbach 20/I, B1. 445-446, s. Anhang S. 527-529.

617 Cod. Ms. Uffenbach 20/II, B1. 328-329, s. Anhang S. 530-531.

618 Wahrscheinlich ist der Hessen-Kasselsche Oberstleutnant, Landrat und ritterschaftliche Deputierte Friedrich Ulrich von Donop (Lebensdaten unbekannt) gemeint.
} 
großen portefeille Stückweiß apart Vorrath ist deren nicht viel weniger als der Folianten sind. In Summa sie füllen ein gantzes nicht gar kleines Zimmer aus welches einer kleinen Bibliotheque ähnlich siehet". 619

$\mathrm{Heß}$ scheint mit dieser Äußerung Uffenbachs Interesse an der Sammlung an Druckgraphik geweckt zu haben, denn Heß berichtet am 19. März $1763^{620}$ weiter: „,...] was Ich von der Verlaßenschafft des H General von Donop erfahren können: so berichte undertähnig daß ein Catalogus ${ }^{621}$ über die Kupferstiche getrückt wird: sein Bruder welcher jetz hier und der Erbe sind haben vor sich eine Quantität von Handriße und Kupfer so schon lange in die Familie gehören vor selben behalten, die übrigen so noch in Zehen = Taußent:Zweyhundert: und 22 Stück bestehen sollen zusammen verkaufft werden, sobald der Catalogus fertig werden solchen Ehwg überschicke, den Preiß davon hatt man mir noch nicht bestimen wollen; Vieleicht werden sie erst einen und den anderen Liebhaber sin Geboht erwarten umb sich darnach zu richten. so viel habe von ihm vernommen daß der liebhaber so sie kauffen wolte selbe persönlich in Augenschein nehmen müste."622

Etwa einen Monat später, am 11. April 1763,623 schreibt Heß, dass der Verkaufskatalog gedruckt worden war, aber: „[...] habe mich aber nicht wenig gewundert als ihn durchsehen daß kaum der 3 oder 1/2 Theil der Kupferstiche darin stehet und ist es lange nicht die große Sammlung so ich von anfang gesehen habe, auch fehlt die völlige Sammlung von Rembrand welche doch sambt dem Bürgermeister Sicsx dabey waren, und die besten Italienischen Meister: In Summa das beste werden sie vor sich behalten oder schon verkaufft haben. Den Preiß davon hatt man mir noch nicht gesagt, aber sie werden es hoch gering halten, weil es Sachen vor ein Statsminister sind werden sie es auch statsmäßig wollen bezahlt haben."624 Desweiteren bietet Heß Uffenbach seine Dienste an, falls der Sammler tatsächlich Interesse daran zeigen würde.

Am 28. Mai $1763^{625}$ revidiert Heß sein vorhergehendes Schreiben, wenn er bemerkt, nachdem er die Erlaubnis der Erben zur kompletten Durchsicht der Sammlung bekommen hatte: ,[...] ich dann gefunden daß die besten noch vorhanden und die Rembrand alle da sind auch die besten Italienischen Meister

\footnotetext{
619 Cod. Ms. Uffenbach 20/II, B1. 328v, s. Anhang, S. 530.

620 Cod. Ms. Uffenbach 20/II, B1. 330-331, s. Anhang, S. 531-533.

621 Der Katalog befindet sich nicht in der Bibliothek Uffenbach.

622 Cod. Ms. Uffenbach 20/II, B1.330 r+v, s. Anhang, S. 531.

623 Cod. Ms. Uffenbach 20/II, B1. 332, s. Anhang, S. 532.

624 Cod. Ms. Uffenbach 20/II, B1. 332 r+v, s. Anhang, S. 532.

625 Cod. Ms. Uffenbach 20/II, B1. 333 + 334, s. Anhang, S. 535-536.
} 
als Raphael Urbin und ander mehr welche im Catalog under dem Nahmen Ecole de flamande: de Rome de venise etc marquirt sind: darin alle die besten Meister selbigen Orts verstanden werden." $626 \mathrm{He} ß$ nennt als Preis der Erben einen Gulden pro Stück Druckgraphik, schränkt aber den Erfolg eines Kaufes ein, indem er einen eventuellen Käufer, den englischen Gesandten Walpole ${ }^{627}$, nennt. Heß bietet sich auch an, weiter für Uffenbach in dieser Sache vorzugehen, allerdings scheint Uffenbachs Interesse am Erwerb dieser Sammlung im Ganzen oder in Stücken erloschen zu sein, denn es hat sich kein weiteres Schreiben von Heß in dieser Angelegenheit im Commercium Epistolicum ${ }^{628}$ erhalten.

Der Briefwechsel zwischen Uffenbach und Peter Heß zeigt auf eindrucksvolle Weise, wie Uffenbach seine druckgraphische Sammlung erworben hat. Einmal geknüpfte Kontakte verfolgte er von seiner Heimatstadt Frankfurt am Main weiter. Wenn einer seiner Agenten von einer zu veräußernden Sammlung hörte oder Uffenbach vom Tod eines Besitzers informiert worden war, versuchte er eine handschriftliche Aufstellung oder, wenn vorhanden, den gedruckten Verkaufskatalog zu bekommen. Falls für ihn einzelne Blätter, Teile oder sogar die ganze Sammlung eine Ergänzung der eigenen bedeutete, war es für Uffenbach nur noch eine Frage des zu bezahlenden Preises. Grundsätzlich kann man bei ihm feststellen, dass er nur dann Druckgraphik erwarb, wenn sie preisgünstig war. Zum einen kann man das anhand seiner Besuche bei Graphikhändlern während seiner Grand Tour beobachten - als Bespiel wären hier die Besuche bei dem Pariser Händler Mariette zu nennen ${ }^{629}$-, zum anderen zeigen das die Kontakte zu seinen Agenten in den verschiedenen Städten.

\subsubsection{Die Ordnung des graphischen Kabinetts}

In einem Brief von 1750 an den obengenannten Johann Friedrich Christ gibt Uffenbach Auskunft über die Art, wie er seine Sammlung druckgraphischer Blätter sortiert hatte: „damit ich aber einen kleinen vorgeschmack von der beschaffenheit meiner Sammlung gebe, so ist solcher von der begierde den anfang den wachsthum und die blüte der Kupferstecher Kunst zu sehen und darlegen zu können entstanden, daher meine blätter alle nach denen meistern, und zwar in

Cod. Ms. Uffenbach 20/II, B1. 333 r+v, s. Anhang, S. 535.

Vornamen und Lebensdaten unbekannt.

Cod. Ms. Uffenbach 20 I + II.

Vgl. das Kapitel 4 „Lebenslauf des Johann Friedrich Armand von Uffenbach“.
} 
alphabetischer ordnung liegen, welchem loco proemii eine Zahl von Kupfern vorgehet, die alle erdenckliche arten derselben zeigen." 630

Uffenbach hatte den Hauptteil seiner Blätter nach alphabetischer Ordnung, die nicht stringent nach Erfinder oder Stecher unterschied, auf hellblauen Pappen aufgeklebt und diese in Mappen eingelegt. Außerdem hatte er eine nach Drucktechniken geordnete Anzahl von Blättern in eigenen Mappen geordnet, die er der eigentlichen Sammlung vorangestellt hatte. Vergleicht man seine Ordnung zum Beispiel mit der von Christ von 1757 - geht man dabei nach der Reihenfolge von dessen Auktionskatalog - fällt ein großer Unterschied auf. ${ }^{631}$ Christs Sammlung war zuerst nach Kunstlandschaften und dann nach Schulen geordnet. Uffenbach dagegen kümmerte sich nicht um diese klassische Ordnung sondern nur um die einzelnen Künstler, wobei ihn noch nicht einmal die verschiedenen Kunstlandschaften oder Schulen interessierten.

630 Cod. Ms. Uffenbach 20/II, B1. 286v. Eine Transkription des gesamten Briefes befindet sich im Anhang, S. 556-562, hier bes. S. 556.

631 Christ 1757, S. 14-76. 


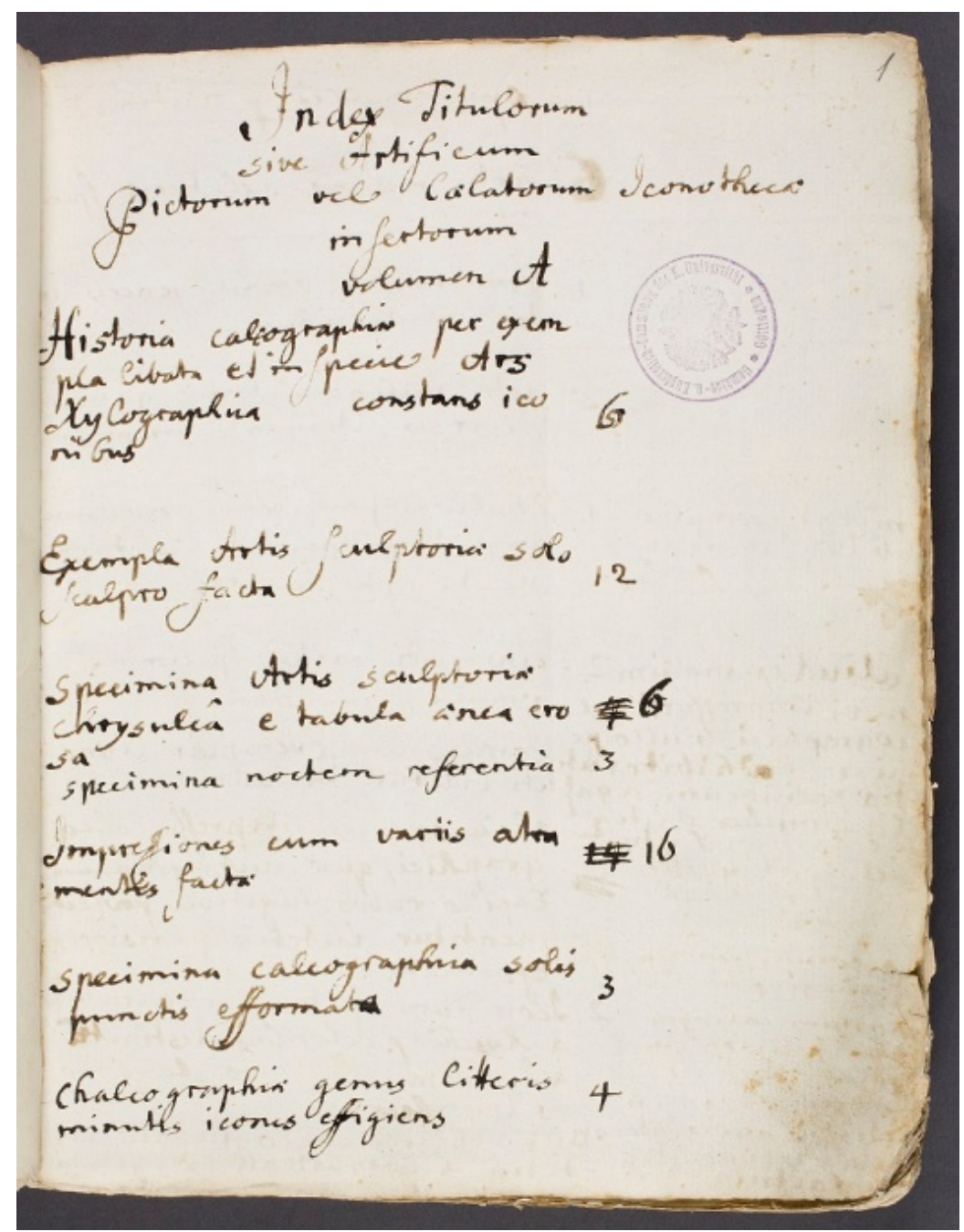

Abb. 18 Titelblatt des Index Titulorum,

Kunstsammlung der Universität Göttingen

Betrachtet man seinen „Index Titulorum sive Artificum Pictorum vel Caelatorum Iconothecae insertorum"632 ist diese Ordnung weiter spezifiziert (Abb. 18). Uffenbach hat diesen Index sein gesamtes Sammlerleben benutzt. Es handelt sich um ein reines Strichverzeichnis, das von ihm nach folgenden Kriterien unterteilt ist:

Namen der Künstler mit Monogrammen, wenn bekannt

Anzahl der Blätter

Anzahl der Bildnisse eines Künstlers.

Immer wenn Blätter von einem Künstler erworben worden waren, wurde die alte Zahl durchgestrichen und durch die neue Anzahl ersetzt. Drei Künstler, die

632 Der Band wird heute im Kupferstichkabinett der Kunstsammlung der Universität Göttingen aufbewahrt. S. Anhang, S. 127-161. 
Uffenbach besonders schätzte, waren Albrecht Dürer (1471-1528) ${ }^{633}$, Jacques Callot (1592-1635)634 und Rembrandt (1606-1669)635. Die ersten beiden Seiten des Verzeichnisses sind für Uffenbachs Sammlerverständnis aufschlussreich: Er hatte der alphabetischen Ordnung etwa 60 Blätter vorangestellt, die die unterschiedlichsten Drucktechniken repräsentieren. Vom Holzschnitt über Radierung bis hin zu Mezzotinto und Naturdruck sind jeweils Beispiele auf hellblauen Blättern aufgeklebt und mit lateinischen Überschriften versehen worden. In der Übersetzung heißt es beispielsweise: „Geschichte des Kupferstichs und insbesondere des Holzstichs durch Beispiele illustriert“636 oder „Beispiele der Bildhauerkunst, die allein nur durch Meißel (Messer) gemacht sind"“637 usw.

Diese Blätter waren u.a. die Grundlage, die er für seine Beschäftigung mit dem Manuskript der „Uhrsprünglichen Historie der gesamten Bildkunst auf Papier“ benötigte. ${ }^{638}$ Schon vor 1732 hatte er dieses 30-seitige Manuskript verfasst, das er in drei Sitzungen seiner bürgerlichen wissenschaftlichen Gesellschaft vortrug. ${ }^{639}$ Bevor er aber dort mit seinem ersten Referat beginnt, erklärt er: „Die weil nun vermuthet daß auch dieße Materie denen Anwesenden nicht unangenehm fallen mögte, indem jede Sätze mit Exempel derer Bilder erlaütern, und die Sachen selbsten aus meiner kleinen Bilder Versammlung darzeigen konnte." ${ }^{640}$

Sowohl die Blätter mit den Drucktechniken als auch die der alphabetisch aufgeführten Künstler hatten für Uffenbach Beispielcharakter, dienten also nicht allein dem Stolz des Besitzers.

So vermerkt er auch immer wieder in seinen Tagebucheintragungen, wenn ein von ihm besuchter Sammler zu viel Aufsehen um sein graphisches Kabinett macht, sei es bei der Anzahl der Blätter eines Künstlers, die Anordnung oder gar die Zustände und Erhaltung der Graphik.

Betrachtet man dagegen das Uffenbachische Kabinett, fällt auf, dass für ihn solche Dinge erst an zweiter Stelle standen. Viele seiner Blätter weisen häufig

633 Die Blätter Dürers sind in Kat. Göttingen 1997 behandelt.

634 Die Druckgraphik Callots befindet sich in erster Linie gebunden in der Göttinger Bibliothek.

635 Die Blätter Rembrandts sind in Kat. Göttingen 1993 behandelt.

636 Historia calcographia per exem- / pla libata et in specie Ars / Xylographica constans ico- / nibus.

637 Exempla Artis sculpturiae solo / sculpro facta.

638 Vgl. das Kapitel 7.1 „Die „Uhrsprüngliche Historie der gesamten Bildkunst auf Papier“.

639 Cod. Ms. Uffenbach 13/IV, p. 504-516, p. 553-573 und p. 591-604.

640 Cod. Ms. Uffenbach 13/IV, p. 503. 
Flecken, Risse, Knickspuren und auch Fehlstellen auf (Abb. 19-23). Erste Zustände waren von geringerem Interesse, das zeigt zum Beispiel, dass Uffenbach sich sogar jene Druckgraphik aus dem Verlagshaus von Hieronymus Cock (15181570) kaufte, bei der Hendrick Goltzius (1558-1617) die Verlegermarke Cocks ausradiert hatte und seine eigene Marke eingesetzt hatte. ${ }^{641}$

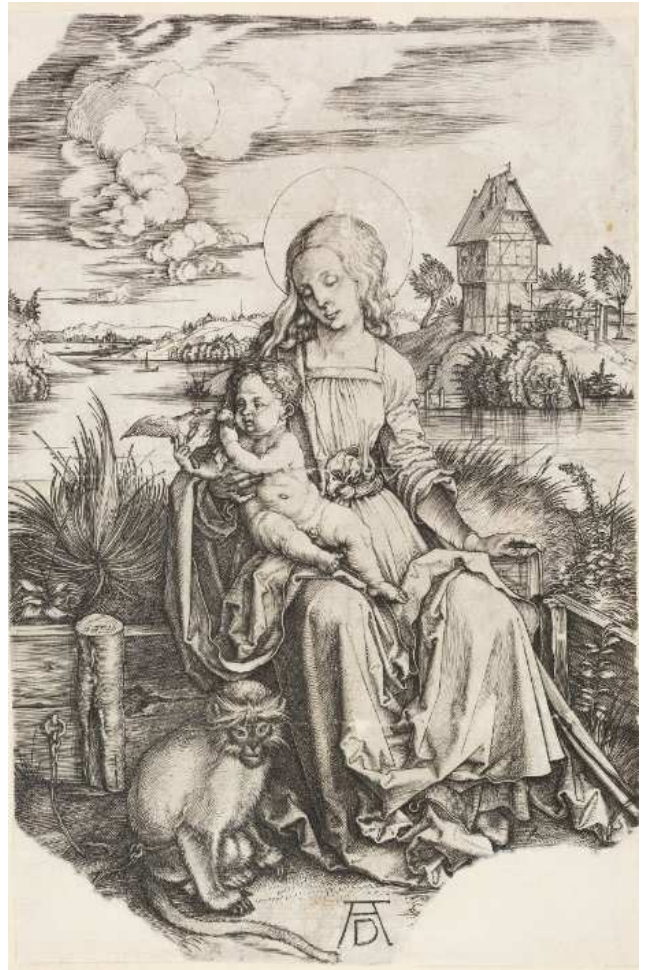

Abb. 19 Albrecht Dürer, Madonna mit der Meerkatze, Kunstsammlung der Universität Göttingen Inv. Nr.: D 884 Mit Fehlstellen

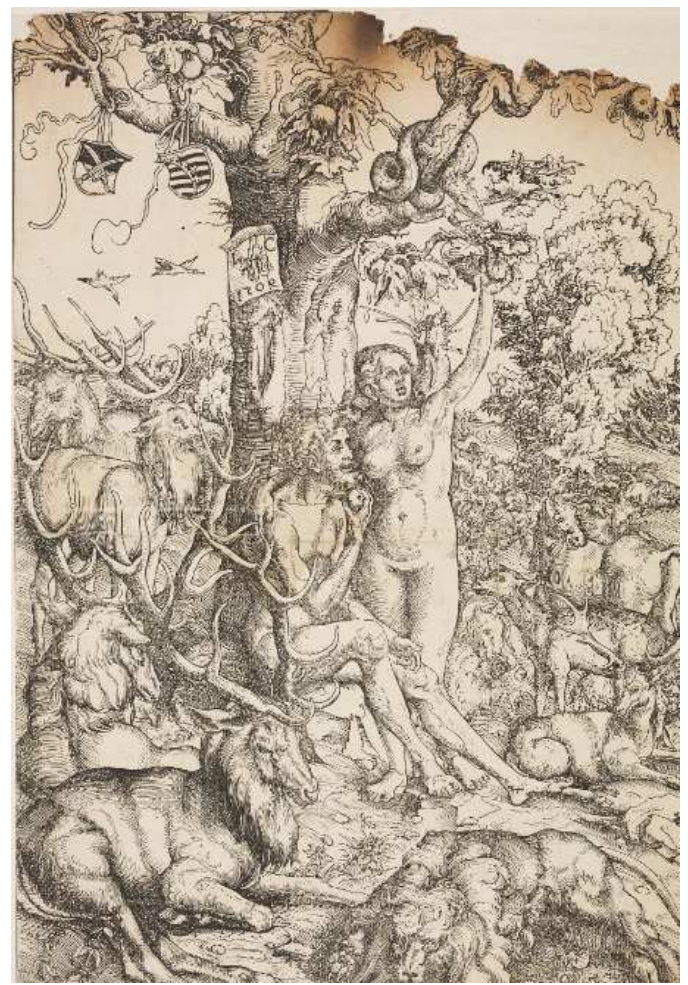

Abb. 20 Lucas Cranach, Adam und Eva im Paradies, Kunstsammlung der Universität Göttingen Inv. Nr.: D 762 Mit Brandspuren

641 Vgl. zu Cock und Goltzius: Timothy A. Riggs, Hieronymus Cock. Printmaker and publisher in Antwerp at the sign of four winds, New York 1977. 


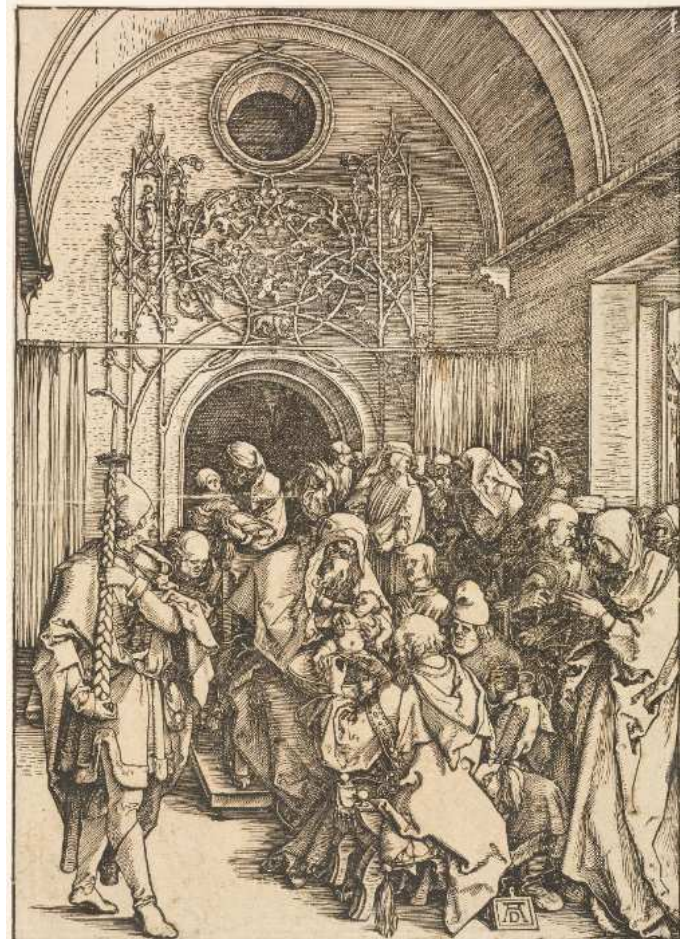

Abb. 21 Albrecht Dürer, Die Beschneidung Christi, Kunstsammlung der Universität Göttingen Inv. Nr.: D 831

Mit Knickspuren des Papiers

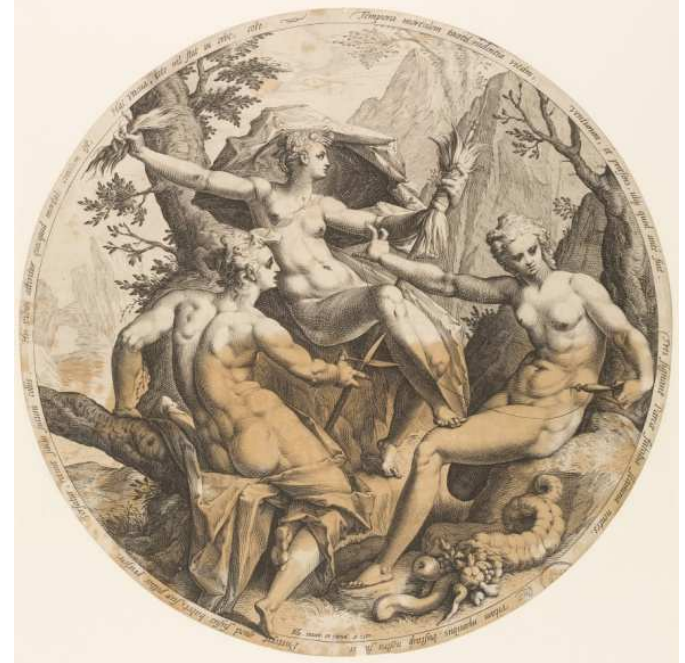

Abb. 22 Hendrick Goltzius, Die drei Parzen, Kunstsammlung der Universität Göttingen Inv. Nr.: D 5189 Stockfleckig

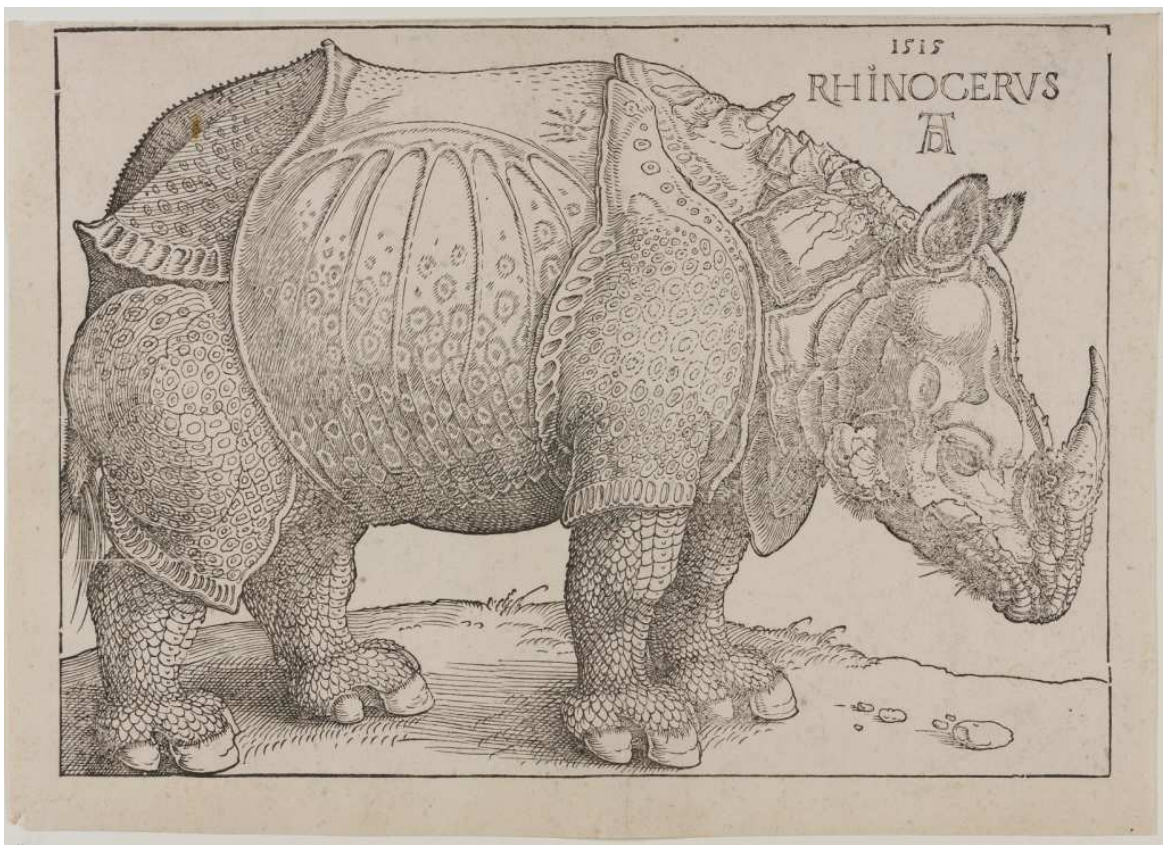

Abb. 23 Albrecht Dürer, Das Rhinozeros, Kunstsammlung der Universität Göttingen D 871 Mit ausgebrochenen Stegen der Holzplatte

Es ist auffällig, dass Uffenbach immer dann viele Blätter besaß, wenn sie seinen wissenschaftlichen Interessen entsprachen: 
Deutsche Holzschnitte von Albrecht Dürer und seinem Umkreis. ${ }^{642}$

Niederländische und Antwerpener Kupferstiche aus den Verlagen von Hieronymus Cock und Philips Galle (1537-1612), sowie von Künstlern und Stechern wie Hendrick Goltzius, Cornelis Cort (1533-1578), Dirck Coornheert (1522-1590) und Maerten van Heemskerk (1498-1574), verschiedenen Mitgliedern der Stecherfamilie Sadeler und Rembrandt Harmensz. van Rijn, von dem er sogar eine Druckplatte ${ }^{643}$ besitzt (Abb. 24), etc.

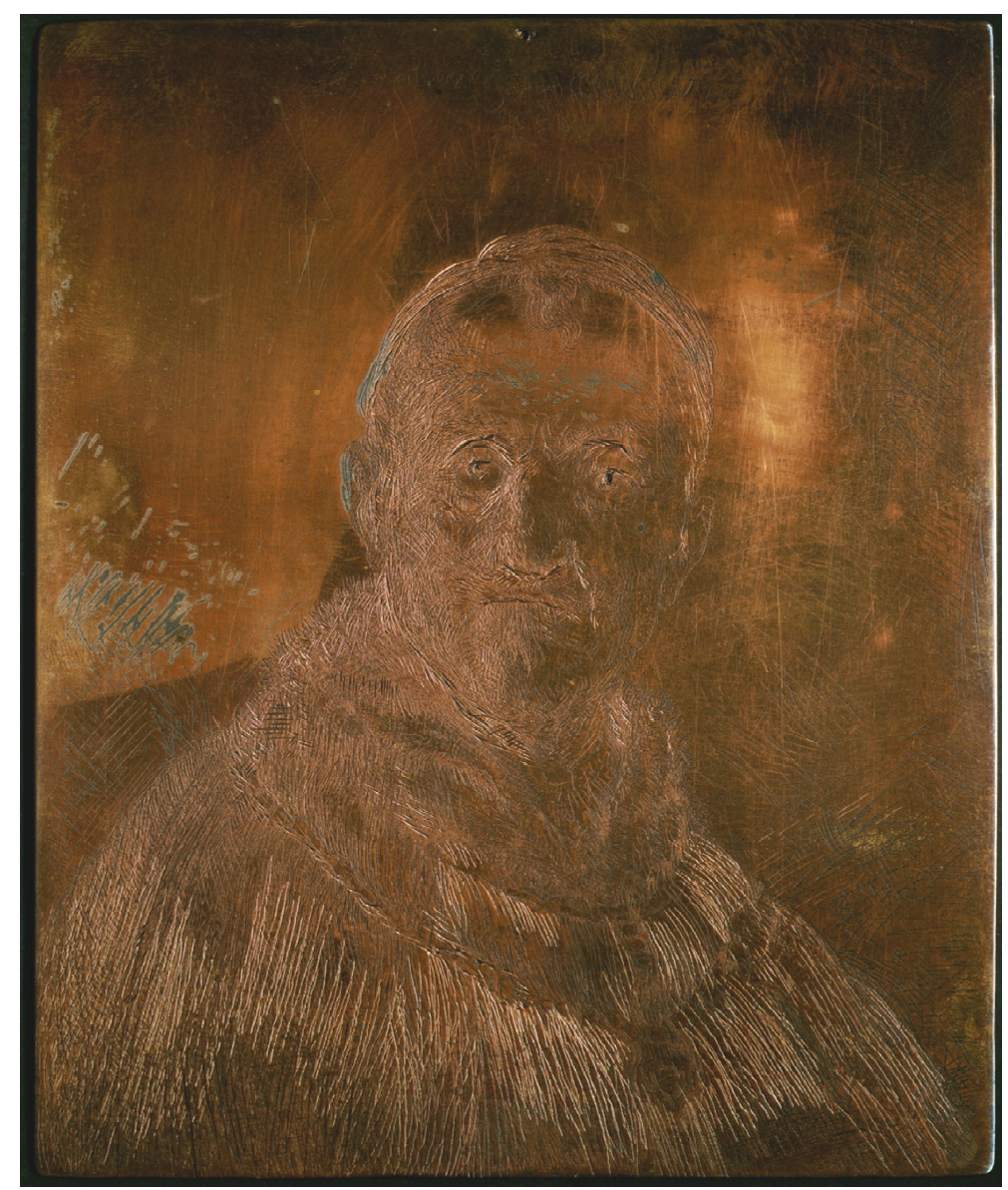

Abb. 24 Rembrandt , Der erste Orientalenkopf, Kunstsammlung der Universität Göttingen DP 7

\subsection{Die Zeichnungssammlung}

Innerhalb des Uffenbachischen graphischen Kabinetts hatten die etwa 1.000 zur Stiftung gehörenden Zeichnungen für den Sammler einen geringeren Stellenwert als die Druckgraphik. Das bezieht sich nicht nur auf die Quantität, sondern auch auf die Aufmerksamkeit und die wissenschaftliche Neugier, die 
Uffenbach dem Medium der Zeichnung widmete. So hatte er ausführliche Verzeichnisse seines druckgraphischen Kabinettes und ein Künstlerlexikon nach Monogrammen auf Druckgraphik angelegt und daneben zusätzlich noch eine Geschichte der graphischen Künste verfasst. Dagegen findet man weder ein Inventar oder einen von Uffenbach verfassten Aufsatz über die Zeichenkunst. Auch zeigte er bei keiner Sitzung der wissenschaftlichen Gesellschaft Zeichnungen aus seiner Sammlung.

Die nach Göttingen verbrachten Zeichnungen hatte der Frankfurter Sammler in sieben Bänden aufbewahrt; dort waren die Blätter entweder lose eingelegt oder auf Pappen aufgeklebt. In der dies bezüglich auskunftgebenden Textstelle eines Briefes von dem Göttinger Juristen Johann Stephan Pütter und dem Leiter der Göttinger Universitätsbibliothek Christian Gottlob Heyne vom 20. April 1769 nach Hannover heißt es: ,,[...] und den Zeichnungen in 7. Bänden würde die größte Sorgfalt dahin anzuwenden seyn, daß kein einzeln Blatt zerstreuet würde, verlohren gieng oder auch nur in Unordnung gerieth, da alles systematisch rangirt ist." "644 Eine Briefstelle Uffenbachs gibt Auskunft darüber, wie viele Zeichnungen er 1750 besaß und in welchem System er diese aufbewahrt hatte: ,[...] die Handzeichnung, deren Zahl bey 500 stücke von denen alten und besten mahlern ist, liegen ohnangehefftet in großen real portefeuilles von hellblauem papier, [...]."645

Zwei Bände mit insgesamt 232 Zeichnungen wurden nicht nach Göttingen übersandt, obwohl sie zur Stiftung gehört hätten, da sie in der Kopie des ersten Uffenbachischen Bibliothekskataloges ${ }^{646}$ schon erwähnt werden. Er beschreibt dort die beiden Bände, die schon vor 1736 angelegt worden sein müssen und in die die Blätter eingeklebt waren: „Ein sehr großer von blauem imperial Pappier in Jugden gebundener Band, von großen Handzeichnungen allesamt von denen berühmtesten Italienischen und Brabandischen Mahlern verfertiget.“ - und - „Ein Atlas Band in Jugden mit kleinern dergleichen Handzeichnungen." ${ }^{647}$ Allerdings scheint Uffenbach die beiden Bände immer wieder ergänzt oder umgruppiert zu haben, da eine Zeichnung mit der Jahreszahl „1764“ versehen war.648 Im ersten Band befanden sich 75 Bögen mit 162, im zweiten 45 mit 70 Zeichnungen. Beide

\footnotetext{
644 Universitätsarchiv Göttingen Kur. 4 V d6/2, B1. 252-253.

645 Es handelt sich hierbei um einen Auszug aus einem Brief an den Leipziger Johann Friedrich Christ (Cod. Ms. Uffenbach 20/II, Bl. 286v).

646 Cod. Ms. Uffenbach 47.

647 Cod. Ms. Uffenbach 47, S. 134v.

648 Uffenbach 1775, S. 28, Bogen-Nr. 37: „Drey nackende Männer nach Lebensgrösse auf grauem Grund in schwarz und weiß sehr meisterhaft gezeichnet, mit der Beyschrift: desine d'après nature à l'Academie Royal à Paris, par G. M. Kraus 1764.“
} 
Bände hatte Uffenbach mit eigenen Titelzeichnungen auf blauem Grund versehen. Im Auktionskatalog heißt es zu dem Blatt im ersten Band (Abb. 25): „Es stellet auf blauem Pappier ein Zimmer vor, darinnen nebst einigem Beywesen ein Mahler und ein Zeichner in ihrer Arbeit beschäftiget sind, zwey Männer heben eine große Tafel in die Höhe, worauf folgende Aufschrift:

\section{Progymnasmata \\ Artis Pictoriae \\ \& Graphices}

quae ingenii acumen auctorum

celebrium testantur

Pericula varii argumenti

in studium cultoribus

\& oblectamentum Fautoribus scientibus

(quamvis frigidiusculum Imperitis)

$$
\text { congesta } 649
$$

an der Wand des Zimmers hänget das Gemählde der Pallas, und in der Ferne zeiget sich in einem Nebenzimmer die Bildhauerkunst." "650 Die Titelzeichnung des zweiten Bandes wird beschrieben: ,[...] die abermal einen Saal vorstellet, darinnen die Künstler arbeiten, in welchen die Minerva kommt, einen Kranz in der Hand haltend, um den vorzüglichen Fleiß derer Künstler zu belohnen." 651

649 „Vorschule / der Malerei / und graphischen Künste / die Zeugnis ablegt von der Geistesschärfe berühmter Künstler / als Probestücke zu verschiedenen Gegenständen / um den Fleiß der Liebhaber zu unterstützen und die Freunde der Wissenschaft zu erfreuen / (auch wenn sie den Unerfahrenen etwas spröde vorkommen mögen) / zusammengebracht.“ 


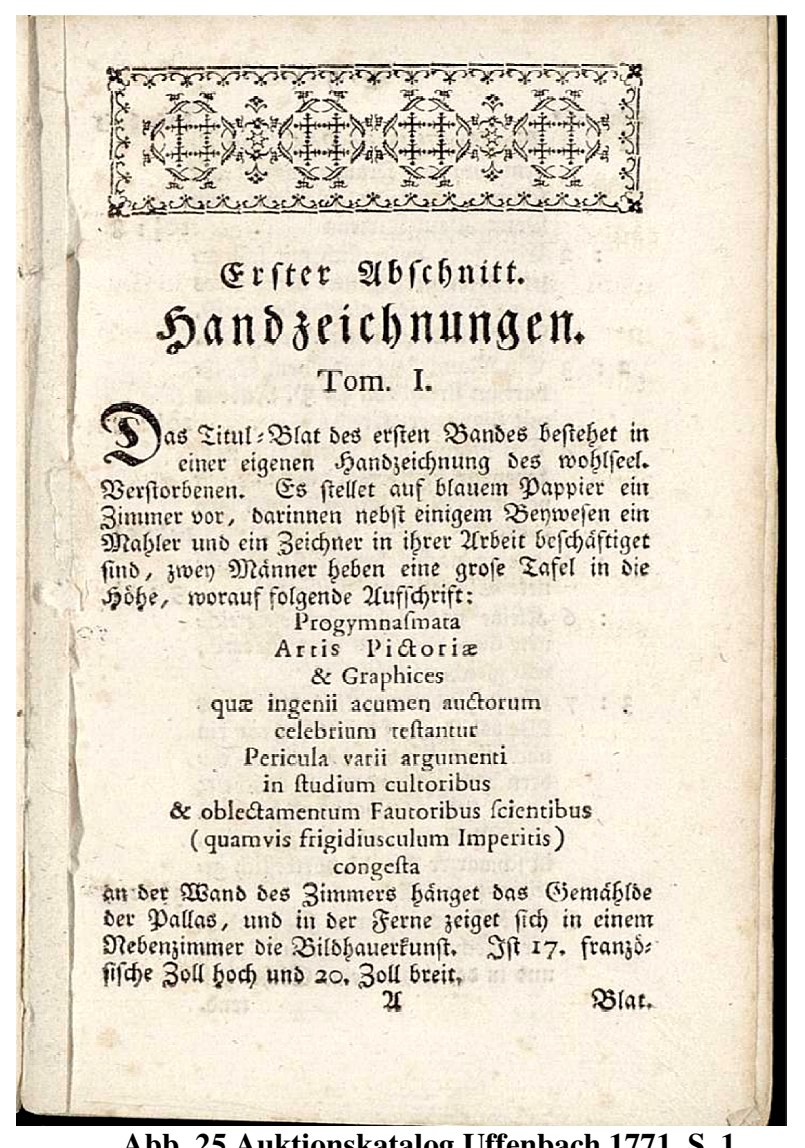

Abb. 25 Auktionskatalog Uffenbach 1771, S. 1

Bei den Künstlern, deren Zeichnungen sich nach Uffenbachs Zuschreibungen in den beiden Bänden befanden, handelte es sich hauptsächlich um Deutsche, Niederländer und Flamen, weniger um Italiener. Es tauchen Namen auf wie Peter Paul Rubens (1577-1640), Jan Lievens (1607-1674), Hendrik Goltzius (15581617), Albrecht Dürer (1471-1528), Lucas Cranach (1472-1553), Nicolaes Berghem (1620-1683), Jan van Kessel (1626-1679), Pieter Janz. Saenredam (1597-1665), die Familie van de Velde, Philips Wouwerman (1619-1668), Jacob van Ruysdael (1628-1682), die Familie Merian, Barthel Beham (1502-1540), Allaert van Everdingen (1621-1675), Paul Bril (1554-1626), Anthon van Dyck (1599-1641), Joachim von Sandrart (1606-1688), Lucas van Valkenborch (15351597), Balthasar Denner (1685-1749), Abraham Bloemart (1566-1651), Domenichino (1581-1641), Johann Heinrich Schönfeld (1609-1684), Guido Reni (1575-1642), Govaert Flinck (1615-1660), Bartholomäus Spranger (1546-1611), Carlo Saraceni, gen. Veneziano (1585-1620), Romeyn de Hooghe (1645-1708), Johann Rottenhammer (1564-1625), Adriaen Brouwer (1605-1638), Wilhelm Schellincks (1627-1678), Gillis d'Hondecoeter (175/80-1638), Jacopo Bassano (1510-1592), Michelangelo (1475-1564), Herman Saftleven (1609-1685), Jacques de Gheyn (1565-1629), Rembrandt (1606-1669), Gerard de Lairesse 
(1640-1711), Georg Melchior Kraus (1737-1806), Johann Friedrich Reiffenstein (1719-1793) und Johann Israel Dietzsch (1681-1755).

Beide Zeichnungsbände, die die Witwe Uffenbach bei der Auslieferung nach Göttingen zurückgehalten hatte, kamen 1771 auf die erste große Auktion, wurden aber nicht versteigert. Erst nach dem Tod der Witwe Uffenbachs 1775, als der gesamte bewegliche Besitz des Palais' auf der Zeil zum Aufruf kam, kaufte der bedeutende Amsterdamer Zeichnungssammler Johann Goll van Franckenstein (1722-1785) die beiden Bände für 445 Gulden.652 Weder die beiden Titelblätter, noch die Zeichnungen haben sich bis heute identifizieren bzw. auffinden lassen. ${ }^{653}$

Hatte Uffenbach diese beiden Bände in seinem Inventar besonders hervorgehoben und konnte der Auktionator in den Versteigerungskatalogen von 1771 und 1775 darauf verweisen, dass die Künstlernamen durch den Verstorbenen selbst auf die Blätter oder Pappen verzeichnet worden waren, so fehlt jeder Anhaltspunkt, wie er seine nach Göttingen gekommene Zeichnungssammlung systematisiert hatte. Vergleicht man die in den beiden Klebebänden verzeichneten Künstlernamen mit denjenigen, die in den sieben Mappen vertreten waren, fällt auf, dass es sich dort um Blätter von vielen Künstlern handelt, die dort als die „Großen“ bezeichnet werden.

Geht man davon aus, dass er die beiden Bände in ihrer Anordnung immer wieder verändert hat - wie oben erwähnt, befand sich ein datiertes Blatt von 1764 darunter -, so betrachtete Uffenbach diese für ihn aus dem Gesamtbestand herausragenden Zeichnungen als eine Annäherung an die von ihm verfolgte Systematik - nämlich das Verhältnis von Zeichnung zu Gemälde und Druckgraphik.

Seine sammlerischen Interessen gegenüber den zeichnenden Künsten lassen sich nur indirekt nachvollziehen. Der Erwerb der Blätter ist aus seinem Briefwechsel oder seinen Tagebüchern nicht nachvollziehbar. Immer wieder spricht Uffenbach in seinen Diarien von Besuchen bei Händlern von Druckgraphik in den verschiedenen europäischen Städten oder er berichtet darüber, dass er bei den Künstlern direkt eingekauft hatte. Kein Wort findet sich über den Kauf von Zeichnungen. Genauso verhält es sich mit den Äußerungen in seinem Briefverkehr. Im wissenschaftlichen Austausch ging es immer nur um 
Künstlermonogramme, die verschiedenen Drucktechniken oder die Aufbewahrung und Systematisierung einer Sammlung von Drucken. 654

Betrachtet man nochmals auf der Titelzeichnung des ersten Zeichnungsbandes die Aufschrift auf der Tafel, die von den beiden Männern hochgehalten wird, wird das Verständnis Uffenbachs gegenüber der Zeichnungskunst deutlich. ${ }^{655}$ Johann Friedrich sah in Zeichnungen eine Vorstufe, die die Künstler zur Anfertigung von Gemälden oder Druckgraphik benötigten. Es waren lediglich Probestücke oder Übungen, um dem Maler oder Graphiker den Geist zu schärfen und die Hand zu üben. Dies wird besonders deutlich, wenn man in seinem Gutachten von 1764 zur Gründung einer Malerakademie in Frankfurt am Main die Äußerung liest: „Die Zeichnungskunst ist bekantlich die Seele der gantzen Bildkunst, die nicht ausgelernet werden kan. Sie stärcket unsere Urtheilskraft, sie würcket das in allen menschlichen Geschäften hochnützliche gesunde Augenmaas, [...]."656 Daraus erschließt sich, dass Uffenbach seine eigene Sammlung als Fleißarbeit des Liebhabers und als Freude für den Freund der Wissenschaft ansah. Auch befand er die Zeichnung für ein ungeübtes Auge als wenig anschaulich.

Es lässt sich aus dieser Betrachtung Uffenbachs bezüglich der Kunst der Zeichnung ableiten, warum er seiner Sammlung von Zeichnungen weniger Beachtung schenkte als beispielsweise der Druckgraphik. Legte er hier viel Wert auf eine strenge Ordnung mit Hilfe eines fast bis zuletzt akkurat geführten Kataloges, gibt es keinen Hinweis darauf, wie er dort verfuhr. Widmete er hier der Erforschung der druckgraphischen Techniken und auch der Künstlermonogramme viel Zeit und Energie und dachte er sogar an eine Veröffentlichung seiner Gedanken zur Geschichte dieser Techniken als Einleitung für sein projektiertes Buch über die Künstlermonogramme, so gibt es dort keine Äußerungen über die Entwicklung der Zeichnungen oder deren Technik. Interessant in diesem Zusammenhang ist auch, dass Johann Friedrich von Uffenbach andere Zeichnungssammler, die er auf seinen ausgedehnten Reisen durch Europa in ihren Kabinetten besuchte, immer dann mit einem gewissen Unverständnis, auch einer gewissen Spöttelei, in seinen Tagebüchern beschreibt, wenn diese ihre Zeichnungssammlung als etwas Einmaliges, Besonderes oder die einzelnen Blätter als abgeschlossene Kunstwerke ansahen.

Vgl. den ausführlichen Briefwechsel mit dem Leipziger Professor Johann Friedrich Christ (1701 - 1756) in: SUB Cod. Ms. Uffenbach 20/II, S. 285-298.

655 S. weiter oben mit der Übersetzung in der Anmerkung.

656 ISG Frankfurt am Main: Handwerker Akten Nr. 618 (ehemals Ugb C 31 Z Nr. 2): Maler Akademie, B1.27-28 r + v; s. Anhang, S. 7 - 10, hier S. 9. 
Mit seinem ganzen Verständnis von Zeichnung zeigt sich Uffenbach als typischer Vertreter seiner Zeit. Die meisten Kunstsammlungen, die er gesehen hatte, bestanden zum großen Teil aus Gemälden und Statuen. Waren Zeichnungen vorhanden, werden diese zwar von den Eigentümern gezeigt und in seinen Tagebüchern vereinzelt erwähnt, aber das Hauptaugenmerk galt den ausgeführten Kunstwerken. Ähnliches kann auch bezüglich der Privatsammlungen von Frankfurter Bürgern ausgesagt werden. In den Frankfurter Auktionskatalogen findet man zwar auch Zeichnungen, aber diese werden nur summarisch erwähnt, während jedes Gemälde einzeln beschrieben wird. ${ }^{657}$

Die nach Göttingen verbrachten Zeichnungen, die Johann Friedrich von Uffenbach in seinem Leben zusammengetragen hatte, lassen sich also von des Besitzers Interesse her als der Versuch einer rationalen Systematik begreifen, die er für die Rangfolge von Zeichnung im Verhältnis zu Druckgraphik und Gemälden hat.

\subsection{Die Sammlung der wissenschaftlichen Geräte}

Johann Friedrich von Uffenbach besaß eine große Anzahl von wissenschaftlichen Instrumenten, die er für seine Interessen und Tätigkeiten angekauft und auch teils selbst angefertigt hatte. Das Verzeichnis ${ }^{658}$, das nach der vollständigen Überbringung der Geräte aus Frankfurt am Main nach Göttingen also 1770 oder kurze Zeit später - angefertigt wurde, zählt insgesamt 230 Nummern ${ }^{659}$, wobei einzelne Nummern mit Unternummern versehen sind.

Es handelt sich, folgt man den Überschriften, um „Werckzeuge und Erfindungen zur Arithmetik“660 mit sechs Nummern, „Allgemeine geometrische Instrumente"661 mit 33 Nummern, „Instrumente zur Mechanik“662 mit 21

Eine Ausnahme dieser Regel ist der Uffenbachische Auktionskatalog, in dem die Zeichnungen der beiden Bände einzeln besprochen werden. Es taucht aber auch im gleichen Katalog die summarische Aufzählung von Zeichnungen und Druckgraphik auf; vgl. Uffenbach 1775 und das Gegenschreiberbuch der Auktion (s. Anhang, S. 36 und S. 38).

Zu den Frankfurter Kunstsammlungen vgl. Schmidt 1960.

Das Inventar befindet sich in der SUB Göttingen mit der Signatur: Cod. Ms. Bibl. Arch. A 34a (Transkription s. Anhang, S. 78-126.).

659 Im Verzeichnis ist als letzte Nummer 229 eingetragen. Der Schreiber hatte aber die Nummer 192 zweimal vergeben.

660 Cod. Ms. Bibl. Arch. A 34a, p. 1, s. Anhang, S. 86.

661 Cod. Ms. Bibl. Arch. A 34a, p. 2, s. Anhang, S. 87.

662 Cod. Ms. Bibl. Arch. A 34a, p. 11, s. Anhang, S. 100. 
Nummern, „Zur Optic und Perspectiv gehörige Instrumente“663 mit 107 Nummern, „Instrumente zu der Gnomonik“664 mit 25 Nummern, Instrumente „Zur Architectur und Artillerie“665 mit fünf Nummern und um „Einige zu der Naturforschung und Lehre gehörige Stücke“ mit 33 Nummern. 666

Die größte Gruppe bilden die Instrumente zur „Optic und Perspectiv“ mit 107 Nummern, wobei hier Mikroskope, Teleskope, Fernrohre und -gläser gemeint sind. Im Gebrauch dieser Geräte kannte sich Uffenbach so gut aus, dass er z.B. in der von ihm gegründeten wissenschaftlichen Gesellschaft immer wieder solche Instrumente vorführte oder für Versuche benutzte, auch hielt er 24 Referate zur Geschichte und den neuesten Forschungen zur Astronomie. 667

\subsubsection{Erwerb der Sammlung}

Auf seinen langjährigen Reisen durch die Niederlande, England, Frankreich, Italien und Deutschland erwarb Uffenbach viele seiner wissenschaftlichen Geräte ${ }^{668}$, was sich anhand der erhaltenen Tagebuchmanuskripte verfolgen läßt. ${ }^{669}$

Aus diesen Berichten erfährt der Leser, welches sammlerische und wissenschaftliche Interesse Uffenbach gehabt hat. Aufgrund seiner Vorliebe für die mechanischen und optischen Künste beschreibt er seine Aufenthalte bei Mechanikern von wissenschaftlichen Geräten und führt genau Buch über seine Ausgaben, die er bei diesen tätigt. Aufgrund dieser Aufzeichnungen ist es möglich, die Gerätesammlung Uffenbachs zum großen Teil zu rekonstruieren. In diesem Zusammenhang muss auch seine ausführliche Korrespondenz ${ }^{670}$ herangezogen werden. Im Folgenden sollen nur einige Beispiele aufgezeigt werden.

Uffenbach war auf seiner Reise durch England 1710/11 von dem Optiker und Instrumentenmacher John Marshall (1663-1725) u.a. in die Kunst des

\footnotetext{
663 Cod. Ms. Bibl. Arch. A 34a, p. 13, s. Anhang, S. 193.

664 Cod. Ms. Bibl. Arch. A 34a, p. 22, s. Anhang, S. 117.

665 Cod. Ms. Bibl. Arch. A 34a, p. 24, s. Anhang, S. 121.

666 Cod. Ms. Bibl. Arch. A 34a, p. 25, s. Anhang, S. 122.

667 S. Kapitel 8.4.1 „Die Beiträge von Johann Friedrich von Uffenbach.

668 S. Transkription im Anhang, S. 78-126.

S. Meyerhöfer 1995 und Lichtenberg 2017. Der Abschnitt zu den Uffenbachischen Instrumenten, den Thomas Nickol (= Lichtenberg 2017) bearbeitet hat, greift auf Meyerhöfer 1995 zurück.

669 Vgl. das Kapitel 2.2 „Die Reiseberichte“.

670 Cod. Ms. Uffenbach 20 I + II.
} 
Linsenschleifens eingeführt worden. Neben einem Tubus, das heißt einem Fernrohr, und einem Perspektiv des Instrumentenbauers ${ }^{671}$ befand sich in der Sammlung eine Linse, die er selbst bei Marshall geschliffen hatte. ${ }^{672}$ Uffenbach besaß in Frankfurt eine "zur bequemer Schleif- und Polirung aller Arten sogenannten optischer Gläser schicklich eingerichtete Machine". 673

Sobald er sich in einem Geschäft bzw. einer Schleiferei eines Optikers befand, wollte er nicht nur alle Geräte sehen und von diesen Stücke erwerben, sondern er wollte gleichzeitig seine eigenen Fertigkeiten vervollständigen. Als er sich 1715 in Rom aufhielt, besuchte er am 8. April „den berühmten, und wegen seiner geschliffenen Gläßer wegen sehr bekanten Opticum, Giuseppe Campani. “674 Die Tochter des achtzigjährigen, als ein ,unvermögender und kindischer Man“ 675 beschriebenen Campani zeigte ihm im „Laboratorium“ die Tubi, Objektive und Mikroskope, die Uffenbach aber alle zu teuer waren, obwohl diese, wie er bemerkt, sehr gut gearbeitet waren. Allerdings wollte er von Campani unbedingt ein Instrument für seine Sammlung erwerben und kaufte ,eines der wohlfeilsten Stücke“, ein Theater-Perspektiv ,in Cocus gefaßt, in einem bunt gebeizten Futteral“.676 Die Tochter zeigte ihm auch die Werkstatt und die Schleif- und Poliermaschinen, mit denen Campani seine Linsen anfertigte, dieser war aber nicht bereit, Uffenbach in seine Schleif- und Poliertechniken einzuführen, worüber sich der Sammler und Dilettant wunderte und ärgerte.

Der römische Optiker und Glasschleifer Carlo Antonio Buttieri677 zeigte ihm am 17. Juni 1715 , auch eine auseinander gelegte und in vielen Stücken bestehende camera obscura portatilis, dadurch zu zeichnen, so mir der Erfindung nach wohlgefallen, und sie vor 12 Scudi erkauffte, weil sie sehr compendieus

Vgl. Instrumenten-Inventar Nr. 63 und 76 (S. Anhang, S. 103-104 und S. 105).

Vgl. Instrumenten-Inventar Nr. 162 (S. Anhang, S. 116-117).

Vgl. Uffenbach 1771, S 60, Nr. 158.

Giuseppe Campani (1635-1715).

Vgl. Cod. Ms. Uffenbach 29/II, p. 416/17.

Vgl. Cod. Ms. Uffenbach 29/II, p. 416/17.

Giuseppe Campani (1635-1715).

676 Vgl. Instrumenten-Inventar Nr. 87 (S. Anhang, S. 106).

677 Lebensdaten unbekannt, tätig um 1700 in Rom
} 
konte zusammen gelegt werden." 678 Von Buttieri besaß Uffenbach außerdem noch ein in Buchsbaum gefaßtes Theaterperpektiv. ${ }^{679}$

Neben Campani und Buttieri besuchte Uffenbach in Rom noch andere Erbauer von Instrumenten. Beim Besuch des Optikers und Geistlichen Antonio Chiarelli680 am 23. Juni 1715 sah er sich ebenfalls sämtliche Instrumente und erwarb einen Tubus ,in einem sauberen spanischen Rohr mit einem Micrometro gemacht“ nach neuester Erfindung von Chiarelli, zusammen mit einer Beschreibung in italienischer Sprache. 681

Neben der Astronomie und Optik interessierte sich Johann Friedrich Armand von Uffenbach auch für Arithmetik und Geometrie. Bei seinem Aufenthalt in Paris 1715 erwarb er bei dem „Ingenieurs und Instrumen Macher“ le Mair682 einen „Transporteur von dünnen Horn“683, das heißt einen Winkelmesser, und einen silbernen Zirkel. ${ }^{684}$ Desweiteren bestellte er in Paris bei dem Instrumentenmacher Chapetot am 28. Februar 1716 einen Winkelmesser ${ }^{685}$ und eine Nivellierwaage ${ }^{686}$, beides holte er kurz vor seiner Abreise am 10. April ab. ${ }^{687}$

Eines der hölzernen Modelle, auf die Uffenbach als Ingenieur und Architekt sehr viel Wert legte, war das der Herrenhäuser Wassermaschine von dem britischen Architekten William Benson (1682-1754), also der Pumpenanlage für die große Fontäne.688 Auf seiner „Spazierfarth durch die Hessische in die

S. Cod. Ms. Uffenbach 29/III, p. 303-304, bes. p.304;

Instrumenten Inventar Nr. 102; Mayer 1813, Inv. Nr. O 116; nach der Übernahme durch Weber 1831 wird die Camera obscura weggeworfen, da sie defekt war (S. Anhang, S. 109).

Wann Uffenbach das Perspektiv erwarb, läßt sich nicht feststellen, wahrscheinlich aber auch auf dieser Reise;

Instrumenten Inventar Nr. 86; Mayer 1813, Inv. Nr. O 162; bei Webers Übernahme 1831 wird es ausgesondert (S. Anhang, S. 106).

Lebensdaten unbekannt, nach Uffenbach aus Vicenza stammend.

S. Cod. Ms. Uffenbach 29/III, p. 332-341, bes. p. 336-337;

in seinen eigenen Inventar verzeichnet Uffenbach das Fernrohr als von Buttieri gemacht, hier muß er sich irren, da die Beschreibung des Gerätes sowohl im Tagebuch als auch im Inventar fast wörtlich übereinstimmen (vgl. Cod. Ms. Uffenbach 47, p. 185v und 186r); Instrumenten Inventar Nr. 73; Mayer 1813, Inv. Nr. O 150; das Rohr wird von Weber 1831 übernommen, nach 1831 verliert sich aber jede Spur (S. Anhang, S. 105).

S. Cod. Ms. Uffenbach 29/IV, p. 312-313.

Instrumenten-Verzeichnis Nr. 34 (S. Anhang, S. 94).

Instrumenten-Verzeichnis Nr. 36k (S. Anhang, S. 97).

Instrumenten-Verzeichnis Nr. 10 (S. Anhang, S. 88).

Instrumenten-Verzeichnis Nr. 33b (S. Anhang, S. 92).

S. Cod. Ms. Uffenbach 29/IV, p. 634-636 und 688.

S. Instrumenten-Inventar Nr. 39 (S. Anhang, S. 101);

S. a. Lange-Kothe 1969, S. 119-151. 
Braunschweig-Lüneburgischen Lande“ im Jahre $1728^{689}$ besichtigte Uffenbach am 29. August das Schloß Herrenhausen, nachdem er zuvor den Architekten, „den hießigen Baumeißter Herrn Böhm“ in Hannover aufgesucht hatte.

Der Kurfürstlich Hannoversche Hof-Architekt Johann Christian Böhm (16781730) zeigte und erklärte ihm ,,ein Modell von der großen Wasserkunst, welche der seel. König zu Herrenhaußen auf Angeben eines Engländers Master Benson aufrichten laßen“, die Uffenbach aber auch nach Besichtigung des Originals in Herrenhausen nicht verstand. Er bestellte bei einem Bekannten in Hannover, dem Geheimsekretär Mohr († 1733), ein Holz-Modell und bat um einige erklärende Zeichnungen (Abb. 26 und 27). ${ }^{690}$ Böhm selbst fertigte die Zeichnungen an, von wem das Modell stammte, kann nicht belegt werden.

Modell und Zeichnungen führte Uffenbach dann am 15. Dezember 1729 in seiner von ihm in Frankfurt gegründeten Wissenschaftlichen Gesellschaft vor. ${ }^{691}$

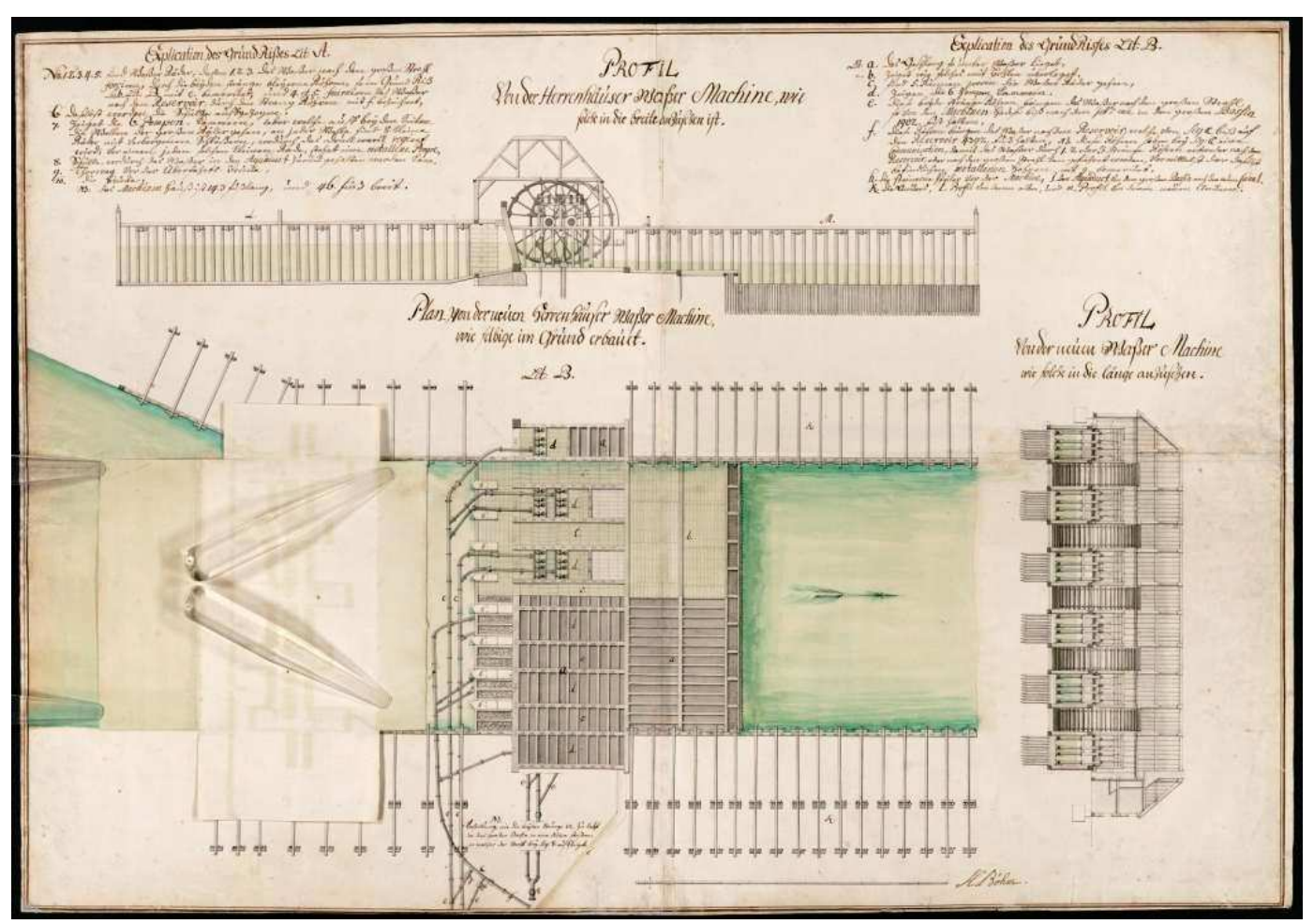

Abb. 26 Johann Christian Böhm, Profil von der Herrenhäuser Waßer Machine ohne die aufgelegten Zeichnung der Pumpenanlage, 73 x 104 cm, in: SUB Göttingen Cod. Ms. philos 26d

689 In: Cod. Ms. Uffenbach 33, hrsg. von Max Arnim, Göttingen 1928,1.

690 Instrumenten-Inventar Nr. 39 (S. Anhang, S. 101).

691 Vgl. Cod. Ms. Uffenbach 13 I-V, hier bes. Bd. III, p. 330-339. 


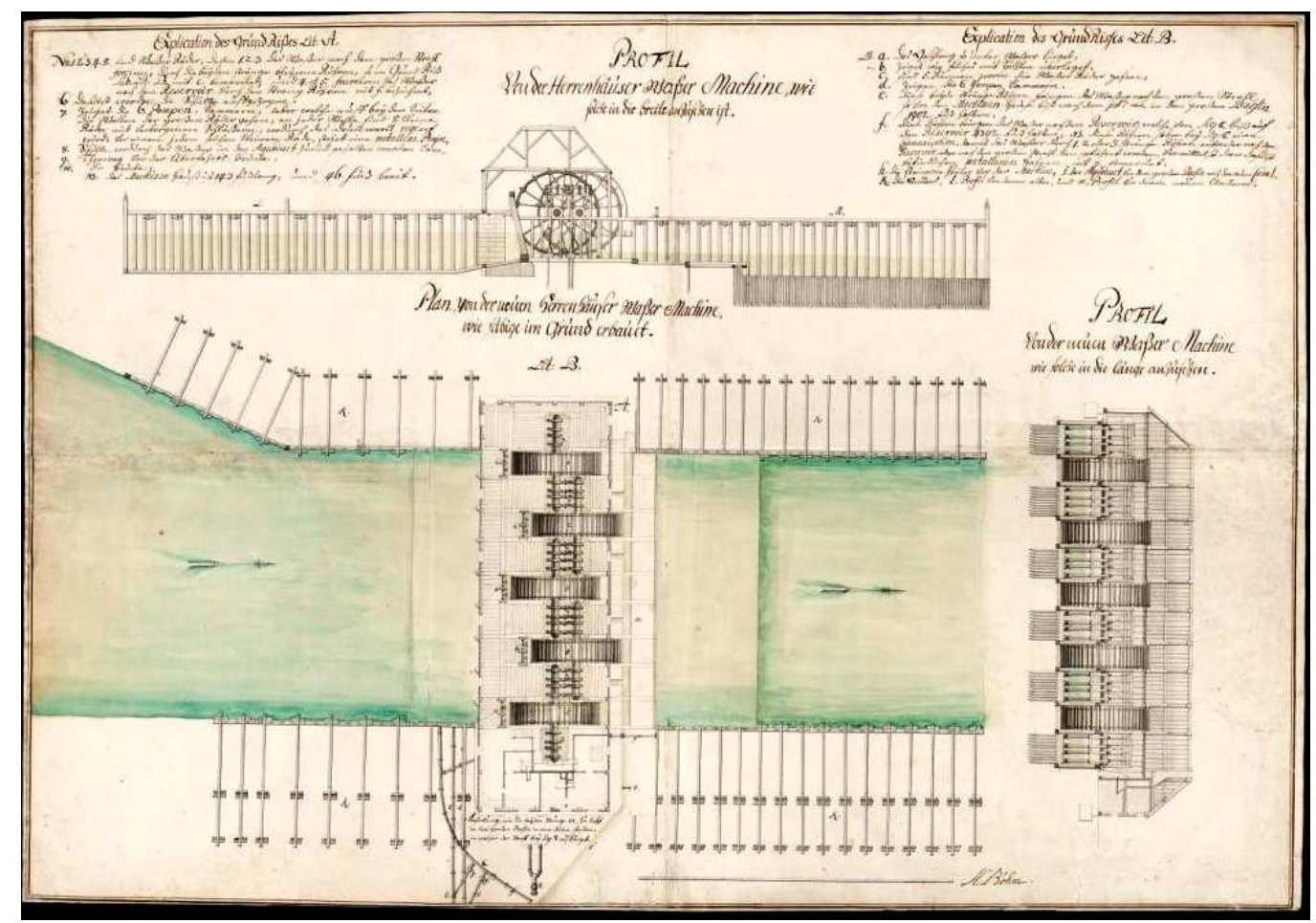

Abb. 27 Johann Christian Böhm, Profil von der Herrenhäuser Waßer Machine mit der aufgelegten Zeichnung der Pumpenanlage, 73 x 104 cm, in: SUB Göttingen Cod. Ms. philos 26d

Zum einen erklärte er dort die Wasserspiele und die Pumpenanlage für die große Fontäne von Herrenhausen ausführlichst, zum anderen verglich er diese mit den anderen großen Wassermaschinen von London und Marly und kam zu dem Schluß, daß er auf seinen Reisen nie eine größere und wirkungsvollere Fontäne gesehen noch in der Literatur beschrieben gefunden habe. In dem Protokollband befinden sich zusätzlich vier Zeichnungen der Anlage, die Uffenbach nach den Zeichnungen Böhms kopiert hatte. Die Originalzeichnungen (Abb. 26 und 27) befinden sich ebenfalls noch im Besitz der Universitätsbibliothek Göttingen, ${ }^{692}$ während das Modell heute nicht mehr vorhanden ist. ${ }^{693}$ Lichtenberg hatte das Modell nicht mit übernommen, sondern es wurde mit anderen größeren

692 Sie befinden sich unter der Signatur Cod. Ms. philos. 26d. Es sind insgesamt sieben farbige Zeichnungen, wovon zwei mit J C Böhm signiert sind. Die eine, ca. 73 x $104 \mathrm{~cm}$ groß, zeigt die gesamte Pumpenanlage an der Leine von der Seite, im Querschnitt und von oben, wobei bei dieser Ansicht die Abbildung der Wasserräder über die Fundamente mit den Röhren als Extrablatt im Klappmechanismus geklebt wurde. Die andere, ca. 36 x $25 \mathrm{~cm}$ groß, erklärt die Funktion des Wellenschlosses. Die fünf restlichen Zeichnungen wiederholen die Abbildungen des großen Blattes als Einzeldarstellungen.

Lange-Kothe 1960,2 wusste nicht, daß die in diesem Band versammelten Zeichnungen aus dem Besitz von Johann Friedrich Armand von Uffenbach stammen.

693 Die Pumpe wird beschrieben im „Kurtzes Verzeichnüs derer Mathematischer Physicalischer und Kupfer Bücher wie auch des Vorraths einiger hiezu gehöriger Instrumente mein Johann Friedrich von Uffenbach“ (Cod. Ms. Uffenbach 47) in der Rubrik Instrumente zur Mechanica (p. 167r): „Ein vollständiges Modell, nebst Abrißen und Beschreibungen der großen Waßerkunst zu Herrhaußen, in einem besondern Kasten.“ 
Instrumenten in der sogenannten Modellkammer aufgestellt; wann es ausgemustert wurde, läßt sich nicht feststellen.

Zusammenfassend läßt sich über den Besitzer dieser Instrumentensammlung sagen, daß er nur solche Geräte erwarb, die für ihn von direktem Nutzen als Ingenieur, Architekt und Astronom waren. Es befanden sich keine Stücke in dieser Sammlung, die Uffenbach nur wegen der Merk- und Denkwürdigkeit oder Seltenheit angeschafft hatte, sondern fast nur solche, die auf dem neuesten Stand der Technik waren, wie z.B. das Teleskop von Dollond, das selbst Lichtenberg als wichtig ansah. 694

Neben den genannten Teilsammlungen besaß Uffenbach „Figuren. Statuen. Bas-Reliefs.“ unterschiedlichster Materialien 695 und ein kleines Kabinett mit Mineralien und Muscheln. ${ }^{696}$ Diese Stücke wurden 1771 auf der Frankfurter Auktion angeboten. Wie er zu diesen Sammlungsstücken kam, lässt sich weder anhand der Korrespondenz noch anhand der Tagebücher nachweisen.

\subsection{Schriftliche Sammlungen}

Eine andere Art des forschenden Sammelns von Johann Friedrich von Uffenbach sind seine schriftlichen Verzeichnisse, die er über Jahre hinweg angelegt hat. Als „schriftliche Sammlungen“ sollen hier selbst angelegte Lexika verstanden werden, die er aufgrund der Rarität der Objekte, Betrügereien der Händler oder fehlender finanzieller Mittel zusammengestellt hat.

Uffenbach hatte als Architekt und Drechsler ein schriftliches Verzeichnis mit dem Titel „Alphabetisches Verzeichnüs derer ausländischen Bäume und Hölzer von allerley Arten so viel derer aus denen Schriften gelehrter Kräuter Verständigen wie auch Reisebeschreiber zu unserer Bekantschaft gekommen und in entfernten Welttheilen als ASIA AFRICA und AMERICA anzutreffen seyn mögen. $\mathrm{Zu}$ gemein nützigen, vornehmlich aber technischen Gebrauch gesamlet und entworfen“" angefangen. 697

Instrumenten-Verzeichnis Nr. .61 (S. Anhang, S. 103); Lichtenbergs Inventar, B1. 44v in roter Kreide "synd wichtig"; dies bezieht sich auf das Dollondsche Teleskop und auf einen Tubus (Instrumenten-Verzeichnis Nr. 62, S. Anhang, S. 103); heute noch im Besitz des I. Physikalischen Instituts der Georg-August-Universität Göttingen, Inv. Nr. H 101.

Uffenbach 1771, S. 42-57.

696 Uffenbach 1771, S. 57-60.

697 Cod. Ms. Uffenbach 40.

Vgl. Kapitel 8 „Die wissenschaftliche Gesellschaft des Johann Friedrich von Uffenbach.“ 
Wie bei seinen anderen Sammlungsabteilungen hat er sich „Einige der vornehmsten gedruckten Wercke deren man sich zu nachfolgendem verzeichnüße bedienet" 698 und deshalb sich die für diesen Zweck geeignete Literatur besorgt oder ausgeliehen, wie z.B. Johannes Hübners „Curieuses und reales Natur- KunstBerg- Gewerck- und Handlungs-Lexikon“699, Johann Michael von Loens „Neue Sammlung der merckwürdigsten Reisegeschichten“700, Charles de Rochforts „Histoire naturelle et morale des Iles Antilles de $1^{\text {‘Amerique }}{ }^{701}$ oder Willem Pisos „De Indiae utriusque re naturali et medica libri quatuordecim. “702

Geht man davon aus, dass Uffenbach seine Sammlungen als Lehrinstrumente für sich selbst, aber auch für andere angelegt hat, ${ }^{703}$ zeigt sich diese Vorgehensweise, sich soweit theoretisch in eine Materie einzuarbeiten, dass man jederzeit praktisch arbeiten könnte, nicht nur im Falle des Verzeichnisses der ausländischen Hölzer.

Weiter gilt dies für sein Kenntnisse an der Fortifikation, die er auf seinen Reisen und mit Hilfe seiner, nicht nur auf diesem Gebiet immer auf den neuesten Stand gebrachten Bibliothek stets auffrischt. ${ }^{704}$ Kann dieses für die Fortifikation belegt werden, gilt dies ganz allgemein für die Architektur und das hierzu benötigte Ingenieurwissen.705 In diesem Zusammenhang ist es erwähnenswert, dass Uffenbach am 2. Dezember 1729 im Hause seines Bruders Wilhelm der anwesenden wissenschaftlichen Gesellschaft einen Aufsatz über die verschiedenen Längenmaße mit dem Titel vortrug: „Zusammenlese derjenigen Vorschläge, so verschiedene Gelehrte zu der Ausfindung einer durchgängigen Länge, das Schu und Ellen Maas darnach zu bestimmen oder einen sogenanten

698 Cod. Ms. Uffenbach 40, p. Vv.

699 Leipzig $1727 ; 8^{\circ}$ Bibl. Uff. 430.

$700 \quad$ Frankfurt und Leipzig 1749; $4^{\circ}$ Bibl. Uff. 634-636.

$701 \quad$ Rotterdam 1665; $4^{\circ}$ Bibl. Uff. 398.

702 Amsterdam 1658; nicht in der Bibliothek Uffenbach vorhanden.

703 Zum Beispiel führte er in der wissenschaftlichen Gesellschaft seine schriftlichen Sammlungen in eigenen Beiträgen vor.

704 So besitzt er in seiner Bibliothek: Alessandro de Groote, Neovallia dialogo sopra la fortificatione, Monaco 1617 ( $2^{\circ}$ Bibl. Uff. 454); Johann Sebastian Grubern, Neuer und gründlicher Unterricht von der heutigen Fortification und Artillerie; in zwey Bücher verfasset, worinnen in dem Ersten bey der Fortifucation gehandelt wird, was so wol in Auferbauung, als Attaquirung und Defendirung einer Vestung in acht zu nehmen ...; in dem andern aber bey der Artillerie wird gewiesen, wie deren gebräuchliche Sorten in allen gebührend $\mathrm{zu}$ verfertigen ...; nebst einem Bericht von Zubereitung einiger ErnstFeuerwercks-Kugeln. Allen curiösen Liebhabern dieser Wissenschaften zum besten kurtz und deutlich aufgesetzet, und zum Druck befördert durch ..., Nürnberg 1700 ( $8^{\circ}$ Bibl. Uff. 134); etc.

Vgl. das Kapitel 4 „Lebenslauf des Johann Friedrich Armand von Uffenbach.“ 
modum universalem, angegeben."706 Diese Diskussion, die Uffenbach vorstellte, sollte erst nach seinem Tod durch die französische Nationalversammlung im Jahre 1790 beendet werden, als diese die Vereinheitlichung der Maße in Angriff nahm.

Aber nicht nur theoretisch setzte Uffenbach sich mit der Architektur auseinander. Wie zuvor bereits geschildert, ${ }^{707}$ war Uffenbach ab 1740 als Bauleiter beim Wiederaufbau der Alten Mainbrücke 708 und als Obergutachter bei der Erneuerung der Kaiserstiege im Frankfurter Römer ${ }^{709}$ tätig.

Uffenbach hielt desweiteren sechs Referate zur Herstellung des Porzellans. ${ }^{710}$ $\mathrm{Zu}$ diesem Thema hatte der französische Physiker René Antoine Ferchault de

706 Vgl. Cod. Ms. Uffenbach 13/III, S. 286-295;

folgende Bücher hat Uffenbach zur Ausarbeitung dieses Aufsatzes benutzt: (287) das zuerst genannte Buch von Eisenschmid besitzt Uffenbach nicht; Willebrordo Snellius, Eratosthenes Batavus, de Terrae ambitus vera quantitate a ..., Lugduni Batavorum 1617 (4 Bibl. Uff. 156); Johann Baptista Ricciolus, Geographiae \& Hydrographiae reformatae libri 12, Bononiae 1661 ( $2^{\circ}$ Bibl. Uff. 80); Allain Mallet in: La Geometrie pratique de l'Ingenieur, ou l'art de mesurer, Straßburg 1723 (4 Bibl. Uff. 110); John Harris, Lexicon Technicum, or an Universal English Dictionary of arts and sciences, 2 Bde., London 1710 ( $2^{\circ}$ Bibl. Uff. 156, 157); Johann Baptista Ricciiolus, Almagestum novum Astronomiam veterem novamque complectens observationibus aliorum, et propriis novisque Theorematibus, Problematibus, ac Tabulis promotam in tres tomos distributam, 2 Tle., Bononiae 1651 ( $2^{\circ}$ Bibl. Uff. 78, 79); Julius Reichelt Dissertatio Mathematica de Pede Argentoratensium, Straßburg 1676 (4 Bibl. Uff. 188:6); Andreas Alexander, Kurtzer Bericht von Gebrauch des Proportional-Zirkels, Nürnberg 1662 (4 Bibl. Uff. 243); Memoires de l'Academie Royale de Sciences, Année 1714, Paris ( $8^{\circ}$ Bibl. Uff. 55); Vitruvius, de Architectura Lib.X, Argent. 1543 (4 Bibl. Uff. 521); Vitruvius Germaniae, des aller namhaftesten römischen Architekti M. Vitruvii Pollionis Zehen Bücher von der Architektur und künstlichen Bauen. Erstmals verteütscht und in Truck verordnet durch D. Gualtherum H. Rivium, Basel 1614 ( $2^{\circ}$ Bibl. Uff 133); Marinus Mersennus, Minimi Cogitata Physico-Mathematica, in quibus tam naturae quam artis effectus admirandi certissimis demonstrationibus explicantur, Paris 1644 (4 ${ }^{\circ}$ Bibl. Uff. 128); Wolfgang Schmidt, Das erst Buch der Geometria: ein kurtze Unterweisung, was und warauff Geometria gegründet sey / Aus bewerten Leren gemelter freyen Kunst ..., 4 Tle., Nürnberg 1539 (4 Bibl. Uff. 153 und 293); Erasmus Bartholinus, De Naturae mirabilibus, Hafniae 1674 (nicht in der Bibliothek Uffenbachs); Johann Georg Leutmann, Instrumenta Meteorognosiae inserventia, Wittenberg 1725 ( $8^{\circ}$ Bibl. Uff. 288).

707 S. Kapitel 4 ,Lebenslauf des Johann Friedrich Armand von Uffenbach.“

708 Vgl. Müller 1912.

709 Wolff/Jung 1896 hier bes.: Bd. II/1898, S. 166-167.

710 „Umständliche Nachricht wie das feine Porcellan in Indien zu bereidet werde“ (Cod. Ms. Uffenbach 13/V, S. 233-245),

„Fortgesetzte Beschreibung wie das indianische Porcellan verfertiget werde“ (Cod. Ms. Uffenbach 13/V, S. 297-308),

„Fernere Nachricht wie das indianische Porcellan gemacht wird“ (Cod. Ms. Uffenbach 13/V, S. 361-374.),

„Vorschläge wie das indianische Porcellan in unsern Landen nachzumachen wäre“ (Cod. Ms. Uffenbach 13/V, S. 385-400),

„Weiterer Verfolg derer Vorschläge, wie das indianische Porcellan in unseren Landen mit eben der Schonheit und allen andern Eigenschaften nach zu machen wäre“ (Cod. Ms. Uffenbach 13/V, S. 429-437), 
Réaumur (1683-1757) zwei Aufsätze in den „Memoires de l'Academie royale des Sciences“ in der zweiten Hälfte der 1720er Jahre veröffentlicht. ${ }^{711}$ Uffenbach hatte dessen Aufsätze frei übersetzt, um sie der Gesellschaft vortragen zu können. Drei dieser Vorträge handeln von der Geschichte und Herstellung des Porzellans in China und drei, wie das „Porcellan in unseren Landen mit eben der Schonheit und allen andern Eigenschaften nach zu machen wäre. "712 Zur Veranschaulichung zeigte er immer wieder entsprechende Gegenstände, wie Quarzstein aus Dresden, chinesisches Porzellan, oder auch dessen Nachahmungen aus St.Cloud und Paris. Darüber hinaus konnte er erste Versuche der Hanauer Porzellanmanufaktur zeigen, die unter seiner Anleitung Experimente in der Herstellung von Porzellan gemacht hatte. ${ }^{713}$

In Bezug auf die Herstellung von Porzellan lässt sich sagen, dass er sich nicht nur theoretische Kenntnisse aneignete, sondern mit Interesse die europäischen Versuche - z.B. auf seinen Reisen zu den Manufakturen von St. Cloud und Hanau - beobachtet, um die Anwendbarkeit und den Nutzen von Porzellan zu überprüfen.

Ebensolches lässt sich über seine Referate über Schildkröten und der Verarbeitung derer Panzer sagen. Sowohl Literatur als auch einzelne Objekte dienen ihm dazu, seine eigenen Arbeiten beim Schildkrötpressen und -drehen besser ausführen zu können. ${ }^{714}$

„Fortsetzung derer Vorschläge wie das indianische Porcellan in unsern Landen nachgemacht werden könte“ (Cod. Ms. Uffenbach 13/V, S. 453-461).

711 Vgl. $8^{\circ}$ Bibl. Uff. 55-89.

René Antoine Ferchault de Réaumur, Idée générale des différentes manières dont on peut faire la Porcelaine et quelles sont les véritables matières de celle de la Chine, in: Mémoires de mathématique et de physique tiréz des registres de l'Académie Royale des Sciences 1727, S. 185-283 ( $8^{\circ}$ Bibl. Uff. 52/53).

Ders., Second mémoire sur la porcelaine ou suite des principes qui doivent conduire dans la composition des porcelaines de différents genres et qui établissent les caractères des matières fondantes qu'on ne peut choisir pour tenir lieu de celle qu'on employe à la Chine, in: Mémoires de mathématique et de physicque tiréz des registres de l'Académie Royale des Sciences 1729, S. 325-343 ( $8^{\circ}$ Bibl. Uff. 52/53).

712 Cod. Ms. Uffenbach 13/V, S. 429.

713 Cod. Ms. Uffenbach 13/V, S. 501.

Wahrscheinlich hatte Uffenbach durch Philipp Jacob Behaghel Kontakte zu der Hanauer Porzellanmanufaktur knüpfen können. Ein Mitglied der Familie, Daniel Behaghel (1625 1698), gehörte zu den Initiatoren der 1661 gegründeten Manufaktur.

Vgl. Kapitel 8 „Die wissenschaftliche Gesellschaft des Johann Friedrich von Uffenbach“. 


\section{Uffenbachs Schriften zur Druckgraphik}

Bei den eigenhändigen Texten haben sich vier Manuskripte erhalten, die Johann Friedrich von Uffenbach zur Druckgraphik verfasst hat und in denen seine Intentionen des Sammelns deutlich werden.

Zum einen handelt es sich um eine „Uhrsprüngliche Historie der gesamten Bildkunst auf Papier"715 zum anderen um zwei Lexika mit den Titeln „Monogrammata oder Zeichen derer Mahler und Kupferstecher so noch ungedeutet oder unbekant sind“716 und „Alphabetisches Verzeichnüs Aller Mahler Bildhauer Und Kupferstecher Worinnen Ihre Nahmen, Geburt Vaterland, Handzeichen, Und Übrige Lebensumstände, Wie Auch Angezogene Schriftstellen Anderer Bücher So Über Ihre Wercke Urtheilen, $\mathrm{Zu}$ Finden Sind. Zusammengetragen Von J. F. Von U."717 Zu diesen drei Manuskripten muss noch ein lateinischer Text dazu gezählt werden. ${ }^{718}$

\subsection{Die „Uhrsprüngliche Historie der gesamten Bildkunst auf Papier"}

Johann Friedrich von Uffenbach nutzte sein graphisches Kabinett mit den nach seiner Ordnung zusammengebrachten Blättern zur Niederschrift einer Geschichte der druckgraphischen Techniken. In drei einzelnen Kapiteln beschreibt er dort nach der Chronologie ihres Entstehens jeweils die Techniken des Holzschnitts, des Kupferstichs und der Radierung (Abb. 28). ${ }^{719}$

715 Cod. Ms. Uffenbach 20/II, B1. 255-185 (Konzept), Cod. Ms. Uffenbach 13/IV, p. 504-516, p. 553-573 und p.591-604 (Transkription s. Anhang, S. 163-200).

716 Cod. Ms. Uffenbach 50.

717 Cod. Ms. Uffenbach 36.

718 Cod. Ms. Uffenbach 36a, B1. 15-16. (Transkription s. Anhang, S. 207-211).

719 Cod. Ms. Uffenbach 20/II, B1. 255-185 (Konzept), Cod. Ms. Uffenbach 13/IV, p. 504-516, p. 553-573 und p.591-604 (Transkription s. Anhang, S. 163-200). 


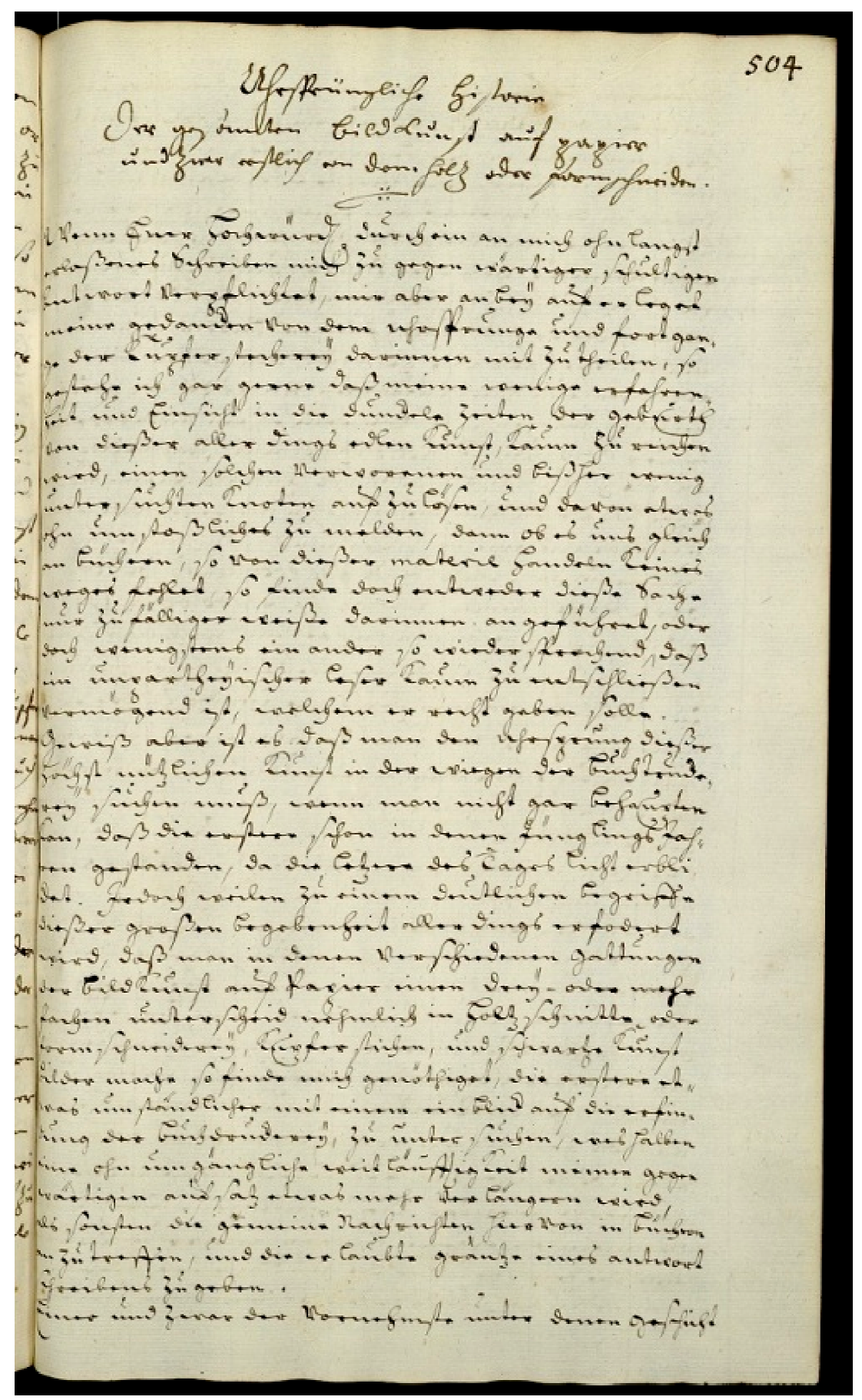

Abb. 28 Manuskript Uhrsprüngliche Historie,

Cod. Ms. Uffenbach 13/IV, p. 504

Um die Geschichte der graphischen Künste verfassen zu können, konnte Uffenbach sich sowohl auf sein geübtes Auge verlassen als auch auf seine auf dieses Gebiet spezialisierte Bibliothek stützen.

Sowohl seine Heimatstadt Frankfurt am Main mit ihren alljährlichen Messen, auf denen u.a. viel Graphik gehandelt wurde, als auch seine ausgedehnten Reisen, auf denen er viele Händler mit Druckgraphik und viele Bibliotheken und Sammler 
mit graphischen Kabinetten besucht hatte, nutzte Uffenbach zur Schulung seines „graphischen Auges“.720 Desweiteren stand er im brieflichen Kontakt mit Sammlern und Wissenschaftlern, wie z.B. dem Leipziger Johann Friedrich Christ, mit denen er sich über Druckgraphik und deren Techniken austauschen konnte. Um sich praxisnah dem Thema Druckgraphik zu nähern, fertigte Uffenbach beispielsweise selber Kupferstiche und Radierungen an. ${ }^{721}$

Um sich zu informieren, besaß Uffenbach die einschlägigen Werke zur Geschichte der Graphik von deren Ursprung bis zu seinen Zeiten. Neben Sandrarts Werk „l'Academia Tedesca oder Teutsche Academie der Bau- Bildund Mahler-Künste“722 und Vasaris Büchern „Delle vite de' più eccellenti pittori, scultori et architetti“ und „Effigie di celebri pittori, scultori et architetti“723, die er immer wieder zitiert oder paraphrasiert, benutzte er die einschlägige in- und ausländische Literatur, die er zum großen Teil selbst besaß.724

Ein Hauptaugenmerk der insgesamt drei Kapitel von der Geschichte der graphischen Künste ist Uffenbachs Auseinandersetzung mit den Anfängen der einzelnen Drucktechniken. Es geht ihm stets um den Ursprung jeder einzelnen Technik, die die verschiedenen Autoren ihren eigenen Landsleuten zuschreiben, worüber er sich immer wieder beschwert und versucht, dies aus seiner Sicht richtigzustellen.

\subsection{Die beiden Lexika der Monogramme}

Die „Uhrsprüngliche Historie der gesamten Bildkunst auf Papier“ sollte als einleitender Abschnitt bei einer Veröffentlichung für sein über Jahre hinweg angelegtes Lexikon der Künstlermonogramme ${ }^{725}$ dienen.

Um streng wissenschaftlich arbeiten zu können, hat Uffenbach aus diesem Grund zwei verschiedene Register angelegt, die er bis zu seinem Lebensende

720 S. Kapitel 4 „Lebenslauf ...“ und Kapitel 6 „Der Sammler Johann Friedrich von Uffenbach“.

721 Vgl. seine beiden Ansichten des Landgutes in Flörsheim und die Illustrationen seines Buches „Poetischer Versuch“ (= Uffenbach 1726).

722 Joachim Sandrart, L'Academie Tedesca, oder Teutsche Academie der Bau-, Bild-, und Mahler-Künste, 2 Tle., Nürnberg 1675 + 1679 ( $2^{\circ}$ Bibl. Uff. 345-346).

723 Giorgio Vasari, Delle vite de' più eccellenti pittori, scultori et architetti, Bologna 1648, 1663 (4 Bibl. Uff. 414-416) und ders., Effigie di celebri pittori, scultori et architetti, Firenze 1629 ( $8^{\circ}$ Bibl. Uff. 544).

724 S. Anhang, Anm. 471 in der Transkription „Uhrsprüngliche Historie der gesamten Bildkunst auf Papier“, wo die Literatur genannt ist, die Uffenbach benutzt hat. Cod. Ms. Uffenbach 50. 
benutzte: Zum einen den Oktavband „Monogrammata oder Zeichen derer Mahler und Kupferstecher so noch ungedeutet oder unbekant sind“ (Abb. 29 und 30), ${ }^{726}$ zum anderen einen Querquartband „Alphabetisches Verzeichnüs Aller Mahler Bildhauer Und Kupferstecher Worinnen Ihre Nahmen, Geburt Vaterland, Handzeichen, Und Übrige Lebensumstände, Wie Auch Angezogene Schriftstellen Anderer Bücher So Über Ihre Wercke Urtheilen, $\mathrm{Zu}$ Finden Sind. Zusammengetragen Von J. F. Von U.“ (Abb. 31 und 32) ) $^{727}$

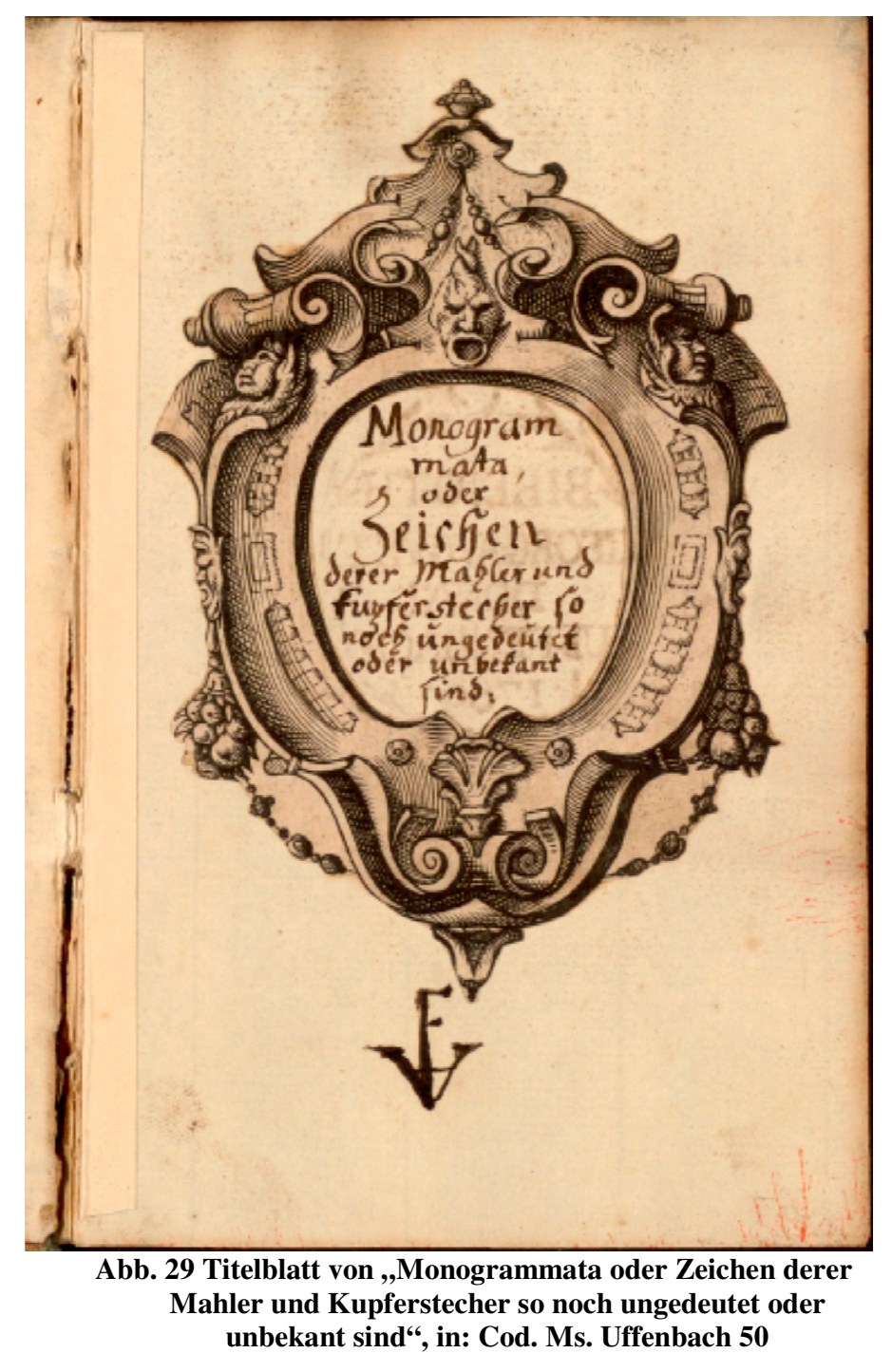




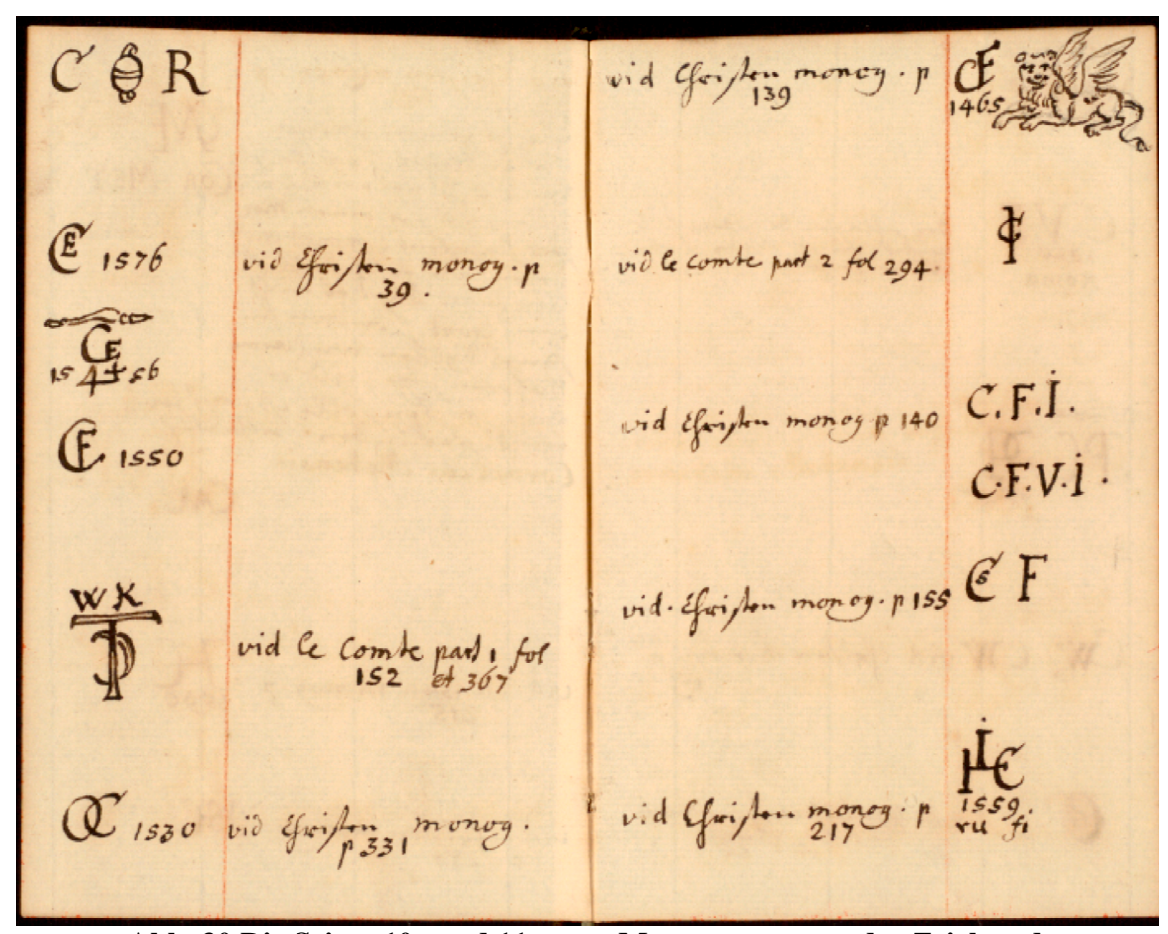

Abb. 30 Die Seiten 10v und 11r aus „,Monogrammata oder Zeichen derer Mahler und Kupferstecher so noch ungedeutet oder unbekant sind“", in: Cod. Ms. Uffenbach 50

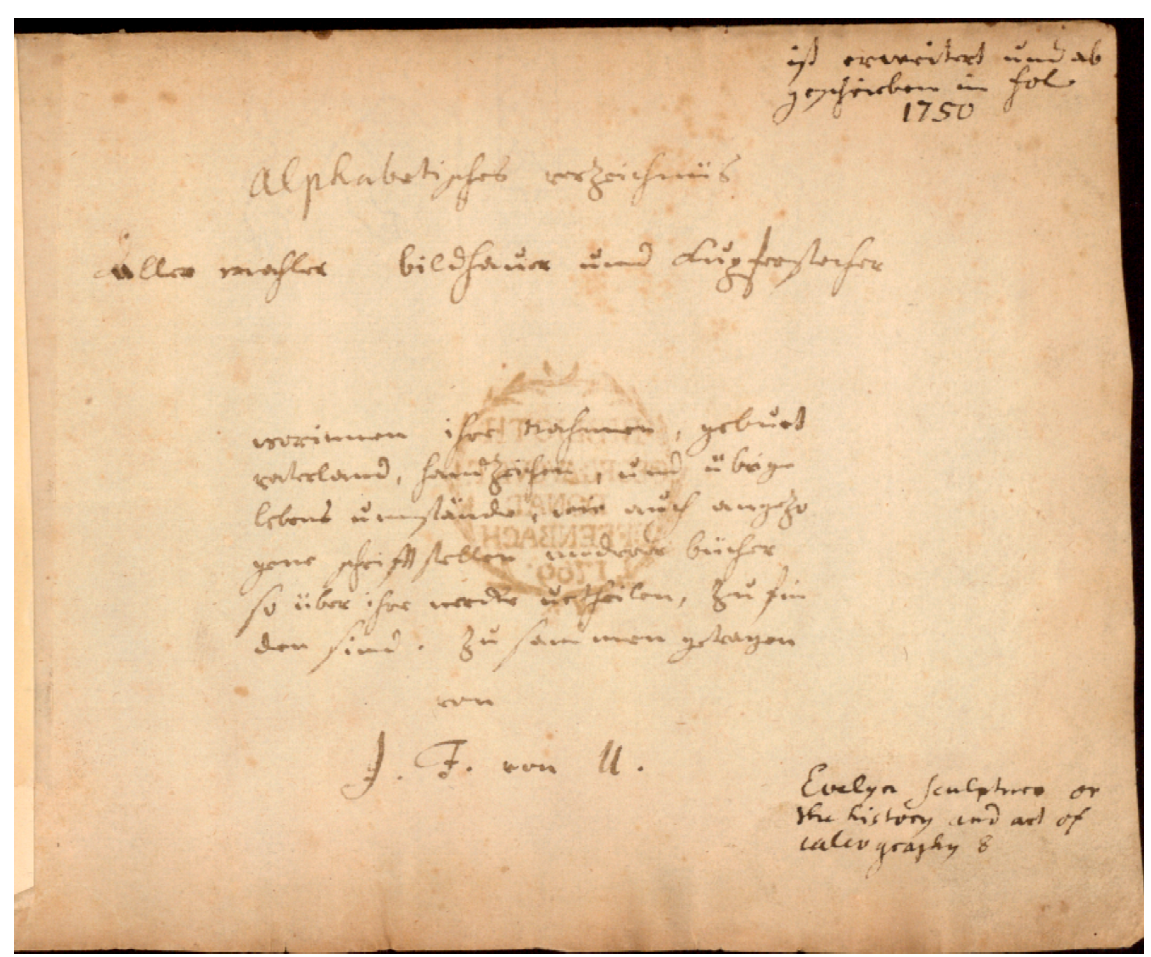

Abb. 31 Titelblatt von ,Alphabetisches Verzeichnüs Aller Mahler Bildhauer Und Kupferstecher“", in: Cod. Ms. Uffenbach 36 


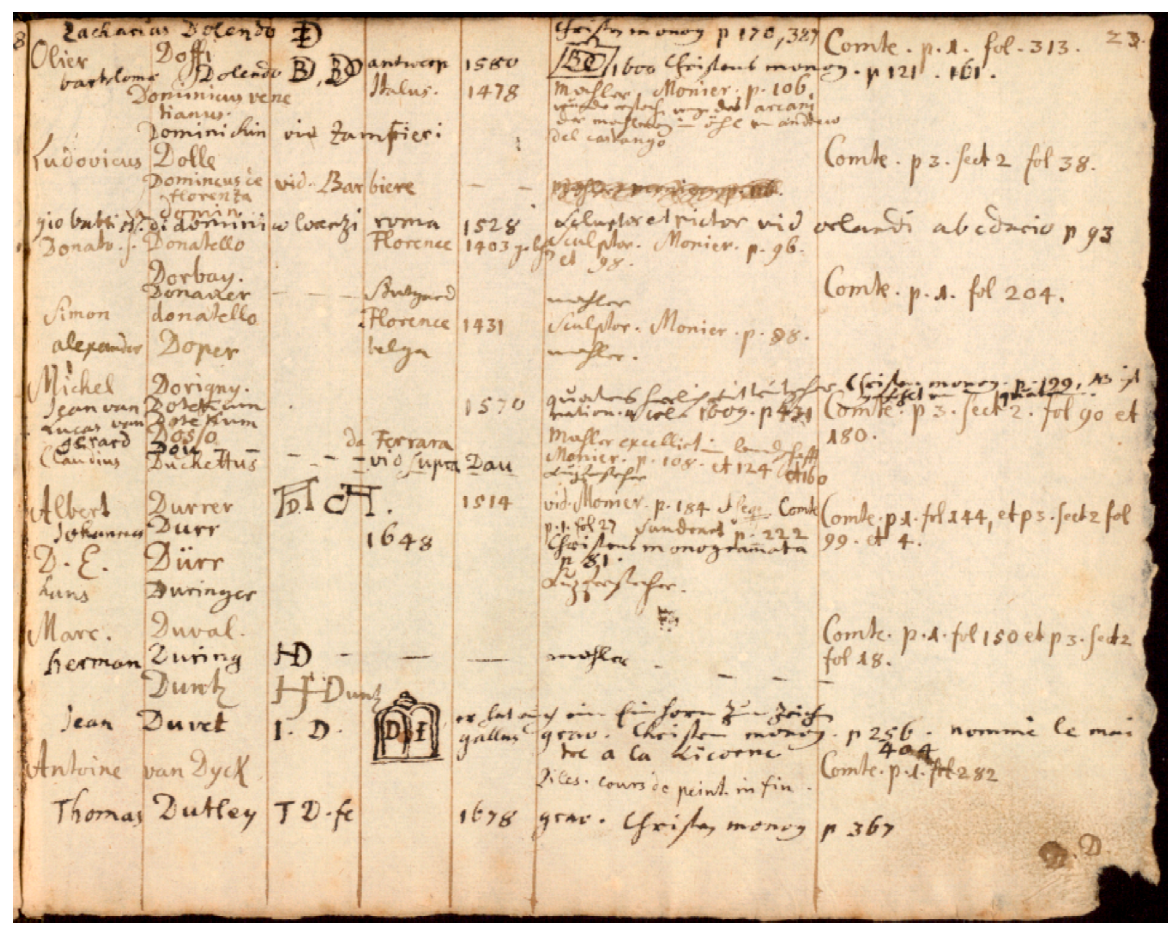

Abb. 32 Seite aus dem „Alphabetisches Verzeichnüs Aller Mahler Bildhauer Und Kupferstecher“", in: Cod. Ms. Uffenbach 36, S. 23

In den „Monogrammata“ hatte sich Uffenbach aus Büchern und bei den ausgiebigen Kabinettbesuchen während seiner Reisen die Monogramme mit der jeweiligen Quelle notiert und wenn möglich den identifizierten Namen des Künstlers davor oder dahinter gesetzt (Abb. 30).

Beim „Alphabetischen Verzeichnüs“ ging er wesentlich ausführlicher vor. Neben den Namen und Zeichen kommen jetzt noch sämtliche Fakten hinzu, die Uffenbach bekannt waren und vor allem gibt er die Quellen an, die er verwendet hatte. Er unterteilte das Verzeichnis in sieben Spalten; „Vornahme, Nahmen, Zeichen, Städte, Jahre, Urtheile“ und „Arbeit“. Insgesamt ist das Verzeichnis alphabetisch nach den Nachnamen der Künstler sortiert (Abb. 32). ${ }^{728}$

Von diesem Werk hat Uffenbach 1750 eine Reinschrift anfertigen lassen. Auf der Titelseite des Querquartbandes hat Uffenbach oben rechts vermerkt: „,ist erweitert und abgeschrieben in fol. 1750.“ (Abb. 31) Er hatte den Querquartband korrigiert und Verweise angebracht, wie z.B. auf p. 12v: „Michelange Buonarottes vid. Angelo. NB es muß aber hirher copirt werden.“ Die Reinschrift gehörte nicht zur Stiftung nach Göttingen und ist verschollen.

728 Bei beiden Manuskripten konnte Uffenbach in erster Linie auf seine Spezialbibliothek zurückgreifen. 
Wie ernsthaft er seine Arbeit an dem Monogrammistenlexikon und dessen Veröffentlichung verfolgte, erkennt man an Uffenbachs siebenseitigem Artikel in der Wochenzeitschrift „Hamburgische Berichte von neuen Gelehrten Sachen auf das Jahr 1736“.729 In dem Beitrag geht es um eine mögliche Auflösung eines ligierten Künstlermonogramms auf einem Altar in einer nicht genannten Schlosskirche nahe Nürnberg. In erster Linie schildert er aber der interessierten Öffentlichkeit seine ,auf meinen 10 und mehr jährigen Reisen“ zusammengetragenen „2 besondere umständliche Register der Mahler Bildhauer und Kupferstecher nicht ohne Mühe gesamlet, nachher auch meine Nachrichten durch vielen Briefwechsel mit Verständigen der Kunst ergäntzet, und in einige Ordnung gebracht. "730 In einer Anmerkung erklärt er sogar die Ordnung der zwei Register: „einen kleinen Begriff von deren Einrichtung zu geben, dienet daß das größere in Tabellen Form geschrieben sey, davon der erste Spalt die Vornamen, 2. die Zunamen, 3. die Handzeichen, 4. die Vaterländer, 5. die Geburts und Sterbens Jahre, 6. Schriftstellen aus Büchern wo ihre Arbeit beurteilet wird, 7. die Oerter wo von ihrer Arbeit zu sehen, enthalten. Das kleinere Register begreiffet nur die Handzeichen und Namen allein, und sind nach der Aehnlichkeit der Züge und Buchstaben zusammen gebracht."731

Im weiteren Text des Beitrages gibt Uffenbach anhand von vier ligierten Monogrammen, die er ,zum beßern Begriffe alhier in Stämpfel geschnitten

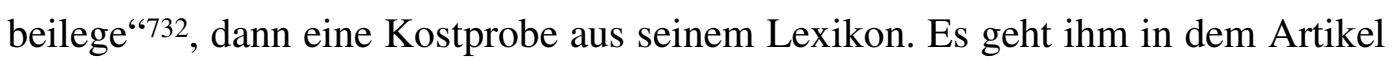
vordergründig um die Auflösung von Monogrammen, Uffenbachs eigentliches Ziel ist es, die interessierte Öffentlichkeit von der Existenz seiner Lexika zu informieren und sie so auf eine Drucklegung vorzubereiten.

$\mathrm{Zu}$ einer Veröffentlichung des Lexikons kam es aber nicht mehr, da bereits der Braunschweiger Maler Anton Friedrich Harms (1695-1745) 1742 sein Buch „Table historiques et chronologoque des plus fameux peintres anciens et moderns"733 publiziert hatte und dann im Jahre 1747 Johann Friedrich Christ sein Buch „Anzeige und Auslegung der Monogrammatum“734 in Leipzig

729 Uffenbach 1736.

Der wesentlich ausführlichere Briefentwurf in: Cod. Ms. Uffenbach 36a, Bl. 8r - 11r (Transkription s. Anhang, S. 212-217).

730 Uffenbach 1736, S. 108.

731 Uffenbach 1736, S. $108+109$.

732 Uffenbach 1736, S. 109.

733 Harms $1742\left(2^{\circ}\right.$ Bibl. Uff. 491).

734 Johann Friedrich Christ, Anzeige und Auslegung Der Monogrammatum, einzeln und verzogenen Anfangsbuchstaben der Nahmen, auch anderer Züge und Zeichen, unter 
herausgebracht hatte. Uffenbach hatte zwar, wie er selbst immer wieder schreibt, sein Monogrammlexikon in jahrelanger mühsamer Arbeit zusammengetragen, aber die Bücher von Harms und Christ hatten in seinen Augen das eigene Werk überflüssig gemacht. Uffenbach schreibt dazu in seinem Brief vom 30. April 1750 an Christ: „Niehmahlen bin ich begieriger einem neuen Druck zu sehen gewesen, aber auch niehmahlen bestürtzter, denn es sind nunmehr bey 36 Jahren da ich eben dergleichen arbeit mühsam angefangen, auf meinen langwührigen reißen vermehret, und in ruhigern Jahren durch briefwechsel ergäntzet habe, alles zu dem Absehen, daß wann es zu schickliche weiße gediehen seyn würde, es zu gemeinen Nutzen derer Liebhaber durch den Druck an Tag zu bringen. Wie sehr aber war ich verwundert als mir erstlich Harms am Braunschweigischen Hofe mit seinen chronologischen oder historischen mahler tabellen, und kurtz drauf Eurer Hochedelgeb tüchtige Arbeit ${ }^{735} \mathrm{zu}$ vorkamen, und mich also meiner Mühe überhoben." 736

Allerdings scheint Uffenbach 1763 eine Veröffentlichung nochmals ins Auge gefasst zu haben. In einem französischen Briefkonzept Uffenbachs an den Leipziger Verleger und Buchhändler Philipp Erasmus Reich (1717-1787) heißt es, dass er bis auf das lateinische Vorwort ${ }^{737}$ alles zusammengetragen hätte und dieses in Kürze ebenfalls fertiggestellt wäre. ${ }^{738}$

In diesem Vorwort begründet er dann, warum er sich der Mühe unterzogen hatte, das Lexikon zusammen mit einer Geschichte der graphischen Künste zu verfassen.

Einer der Anlässe für ihn, weshalb er eine Geschichte der graphischen Künste schrieb, war, dass ihm beim Studium der europäischen Literatur zu diesem Thema immer wieder auffiel, dass die Namen der Künstler falsch geschrieben oder unterschiedliche Namen für einen Künstler genannt wurden. Desweiteren stellte er bei der vergleichenden Lektüre fest, dass die verschiedenen Autoren die

welchen berühmte Mahler, Kupferstecher, und andere dergleichen Künstler, auf ihren Wercken sich verborgen haben, ... aus den ersten Wercken selbst, jetzt von neuem genommen, Leipzig 1747 ( $8^{\circ}$ Bibl. Uff. 789).

Zu Christ s. Müller 2006.

735 Christ veröffentlichte 1754 auch eine französische Ausgabe: Johann Friedrich Christ, Dictionnaire des Monogrammes, Chiffres, Lettres Initiales, Logogryphes, Rebus etc., Paris 1754 ( $8^{\circ}$ Bibl. Uff. 799).

736 Cod. Ms. Uffenbach 20/II, p. 285r.

737 Cod. Ms. Uffenbach 36a, B1. 15-16. S. Anhang, S. 207 - 211.

738 Cod. Ms. Uffenbach 20/II, p. 338-339, hier 338r; ,,[...] Quant a notre propos en question, je puis vous assurer certai- / nement, que la Msct. soit tout achevé, copiè et mis au / net pour etre emploiè a l'usage destinè, exeptè un avant / propos [...]." 
Erfindung der einzelnen Drucktechniken in einer Art „landsmännischen Prahlerey“ jeweils in ihrem Heimatland ansiedelten.

Innerhalb seiner Geschichte der Graphik setzte er sich deshalb, wie er in seinem Vorwort schreibt, auch mit den zwei Autoren auseinander, die sich seiner Meinung nach als erste und „vornehmste“ über den Ort der Entstehung der Techniken Gedanken gemacht und dadurch alle späteren Verfasser beeinflusst hatten: Giorgio Vasari mit „Delle vite de' più eccellenti pittori, scultori et architetti“ und „Effigie di celebri pittori, scultori et architetti“739 und Joachim von Sandrart mit „l'Academia Tedesca oder Teutsche Academie der Bau- Bild- und Mahler-Künste“740.

Anhand seiner akribisch geführten Register und auch seiner Geschichte der graphischen Künste verkörpert Johann Friedrich von Uffenbach einen Sammlertypus, dem es nicht mehr einzig um das Sammeln und Ordnen geht, sondern der seine Sammlung mit Hilfe der eigenen Bibliothek und Besuchen anderer Sammlungen dazu benutzt, ein eigenes wissenschaftliches Werk zu verfassen. Die mehrfache Veröffentlichungsabsicht zeigt ihn auch als einen Mann, der nicht nur für sich im Stillen arbeitet und forscht, sondern die von ihm gewonnenen Erkenntnisse der Gelehrtengemeinschaft zur Verfügung stellen will. Eine gewisse Öffentlichkeit erreichte er mit seinem wissenschaftlichen Werk in der Frankfurter wissenschaftlichen Gesellschaft, in der er seine verschiedenen Forschungsgebiete, aber besonders seine Kenntnisse zur Graphik und zu den graphischen Techniken vorstellen konnte.

739 Giorgio Vasari, Delle vite de' più eccellenti pittori, scultori et architetti, Bologna 1648, 1663 (4 Bibl. Uff. 414-416) und ders., Effigie di celebri pittori, scultori et architetti, Firenze 1629 ( $8^{\circ}$ Bibl. Uff. 544).

740 Joachim von Sandrart, 1'Academia Tedesca oder Teutsche Academie der Bau- Bild- und Mahler-Künste, 2 Tle., Nürnberg 1675 ( $2^{\circ}$ Bibl. Uff. 345); ders., dass., IIter Haupt-Theil, Nürnberg 1679 ( $2^{\circ}$ Bibl. Uff. 346). 


\section{Die wissenschaftliche Gesellschaft des Johann Friedrich von Uffenbach}

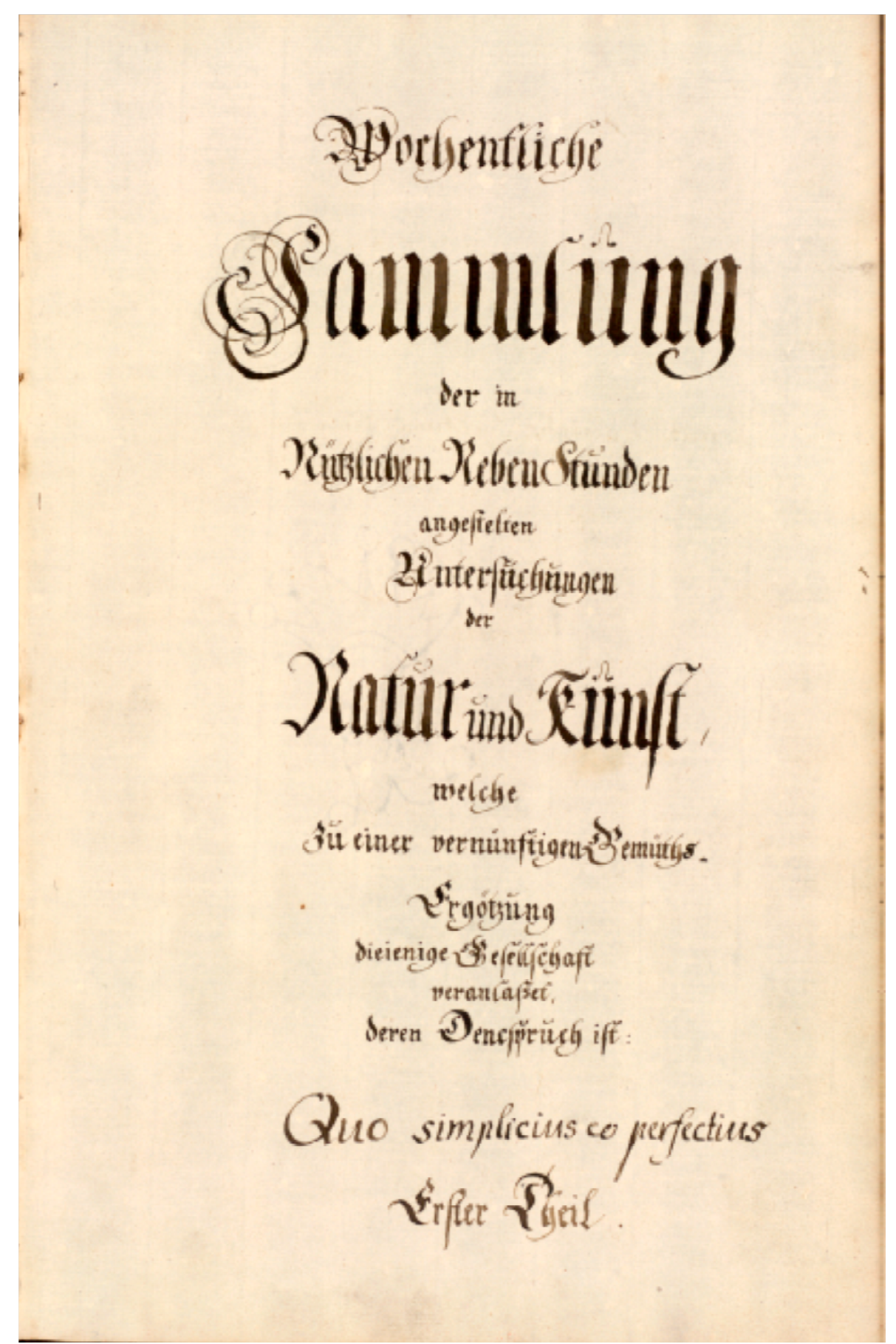

Abb. 33 Titelblatt des ersten Protokollbandes der Wissenschaftlichen Gesellschaft in: Cod. Ms. Uffenbach 13/I 
In der Entwicklung der deutschen Gelehrten Gesellschaften, die in der ersten Hälfte des 17. Jahrhunderts begann, muß man zwischen den Sprachgesellschaften und den naturwissenschaftlich orientierten Gesellschaften unterscheiden. ${ }^{741}$ Den Sprachgesellschaften - wie der 1617 in Weimar gegründeten „Fruchtbringenden Gesellschaft“ oder der vom Nürnberger „Pegnesischen Blumenorden“ von 1644 ging es zum einen um die Stärkung und Verbesserung der hochdeutschen Sprache und zum anderen um die Pflege der deutschen Dichtkunst. Die naturwissenschaftlich orientierten Gesellschaften, - wie z.B. die 1652 in Schweinfurt gegründete „Leopoldina“ - hatten es sich zur Aufgabe gemacht, den Austausch ,zum Wachstum der Heilkunde, zum Vorteil für den Nächsten und zur Erforschung der Wahrheit" ${ }^{\text {"742 }} \mathrm{zu}$ pflegen. Auch die von Gottfried Wilhelm Leibniz (1646-1716) 1700 gegründete „Sozietät der Wissenschaften“ oder andere Institutionen, waren stets Einrichtungen, die an einen königlichen oder fürstlichen Hof gebunden waren.

Dagegen war die von Johann Friedrich von Uffenbach im November 1725 gegründete „Gesellschaft zur Untersuchung und Pflege von Natur und Kunst“ vollkommen unabhängig, da sie nicht an einen Hof gebunden war. Sie war die erste wissenschaftliche Gesellschaft auf Frankfurts Boden und eine der frühesten bürgerlichen in Deutschland. ${ }^{743}$

Die Gemeinschaft bestand zu Anfang aus insgesamt sechs Frankfurter Bürgern: dem Kaufmann Albert Adolf Diesterweg (1681-1744), dem Geschäftsmann Philipp Jacob Behaghel (1688-1732), dem Arzt und Stadtphysicus Johann Georg Kißner744 (1673-1734), dem Arzt Konrad Hieronymus Eberhard genannt Schwind $^{745}$ (1653-1744) und den beiden Brüdern Wilhelm (1698-1735) und Johann Friedrich von Uffenbach. Im Jahre 1733 trat noch der Frankfurter

741 Vgl. den guten Überblick insgesamt bei Dülmen 1996, Im Hof 1982 und Kat. Göttingen 2009.

742 Zitiert nach Dülmen 1996, S. 26.

743 Vgl. Schindling 1994 mit der angeführten umfangreichen Literatur. Er kennt die Frankfurter gelehrte Gesellschaft nicht. Diese wurde aber schon zu Lebzeiten Uffenbachs in Artikeln über ihn erwähnt, vgl. Strodtmann 1757.

Auch Im Hof 1982 erwähnt die Gesellschaft nicht. Vgl. Braungart 1989, S. 160.

Vgl. Voelcker 1937, S. 194-199. Preußner 1949, S. 174-179 und Lange-Kothe 1960. Voelcker gibt eine erste allgemeine Charakterisierung der wissenschaftlichen Gesellschaft ab; Preußners Bemerkungen sind auf die Musik bezogen, während Lange-Kothe die Gesellschaft abschätzig als „Kaffeekränzchen“ beschreibt.

Vgl. auch Kitmeridis 2015, S. 84.

744 Vgl. Kallmorgen 1936, S. 252.

745 Voelcker 1932, S. 195; Kallmorgen 1936, S. 322. 
Materialienhändler Johann Friedrich Ettling746 (1712-1786) dem Kreis bei. Drei Mitglieder verstarben während des Bestehens der Gesellschaft: am 6. August 1732 Philip Jacob Behaghel, am 29. Dezember 1734 der Arzt Dr. Johann Georg Kißner und am 24. Juni 1735 Wilhelm von Uffenbach. Auf alle drei Verstorbenen hielt Uffenbach während einer der nachfolgenden Sitzungen ein langes Ehrengedächtnis. ${ }^{747}$

Ungefähr ein Jahr lang traf sich der Kreis wöchentlich, noch ohne festgelegte Regeln und ohne Protokolle der einzelnen Sitzungen anzufertigen. Erst am 25. Oktober 1726 übertrug man Johann Friedrich von Uffenbach „,das Ampt eines Schreibers"748, damit ,unsere Bemühung auf solche Weise [nicht] der Vergeßenheit ohnfehlbar zu theil werden würde“.749 Diese Aufgabe besaß er während des gesamten Bestehens der Gesellschaft. Er protokollierte nicht nur minuziös den Verlauf der Sitzungen, sondern verdeutlichte häufig das Gesagte über die behandelten Gegenstände durch eigene Zeichnungen (Abb. 34).

746 Ettling ersteigerte auf der Uffenbachischen Auktion von 1775 diverse Gegenstände, vgl. Gegenschreiberbuch 1775, S. 223b (Nrn. 47 und 48); S. 224a (Nrn. 68 und 77); S. 224b (Nrn. 83 und 83), S. 225a (Nrn. 116, 117 und 120), S. 225b (Nr. 135), S. 226b (Nr. 2), S. 227a (Nr. 18) [s. Anhang, S. 30, 31, 33, 34, 37, 38].

Zur Slg. Ettling vgl.: Hüsgen 1780, S. Voelcker 1937, S. 302, Schmidt 1960, unter dem Stichwort „Sammlung Ettling (1776).

$\mathrm{Zu}$ den Materialisten allgemein: Zedler Bd.19, Sp. 2026, Stichwort: Materialist (http://www.zedler-

lexikon.de/index.html?c=blaettern\&seitenzahl=1061\&bandnummer=19\&view=100\&l=de vom 19.08.2016), Kallmorgen 1936, S. 64-65.

747 Siehe: Auf Philip Jacob Behaghel am 22. August 1732 (Cod. Ms. Uffenbach 13/IV, S. 611622), auf Dr. Johann Georg Kißner am 18. März 1735 (Cod. Ms. Uffenbach 13/V., S. 473481) und auf Wilhelm von Uffenbach am 29. November 1735 (Cod. Ms. Uffenbach 13/V, S. 536-543, s. Anhang, S. 299-305).

748 Cod. Ms. Uffenbach 13 I, Vorbericht, S. III (s. Anhang, S. 284).

749 Cod. Ms. Uffenbach 13 I, Vorbericht, S. II (s. Anhang, S. 284). 


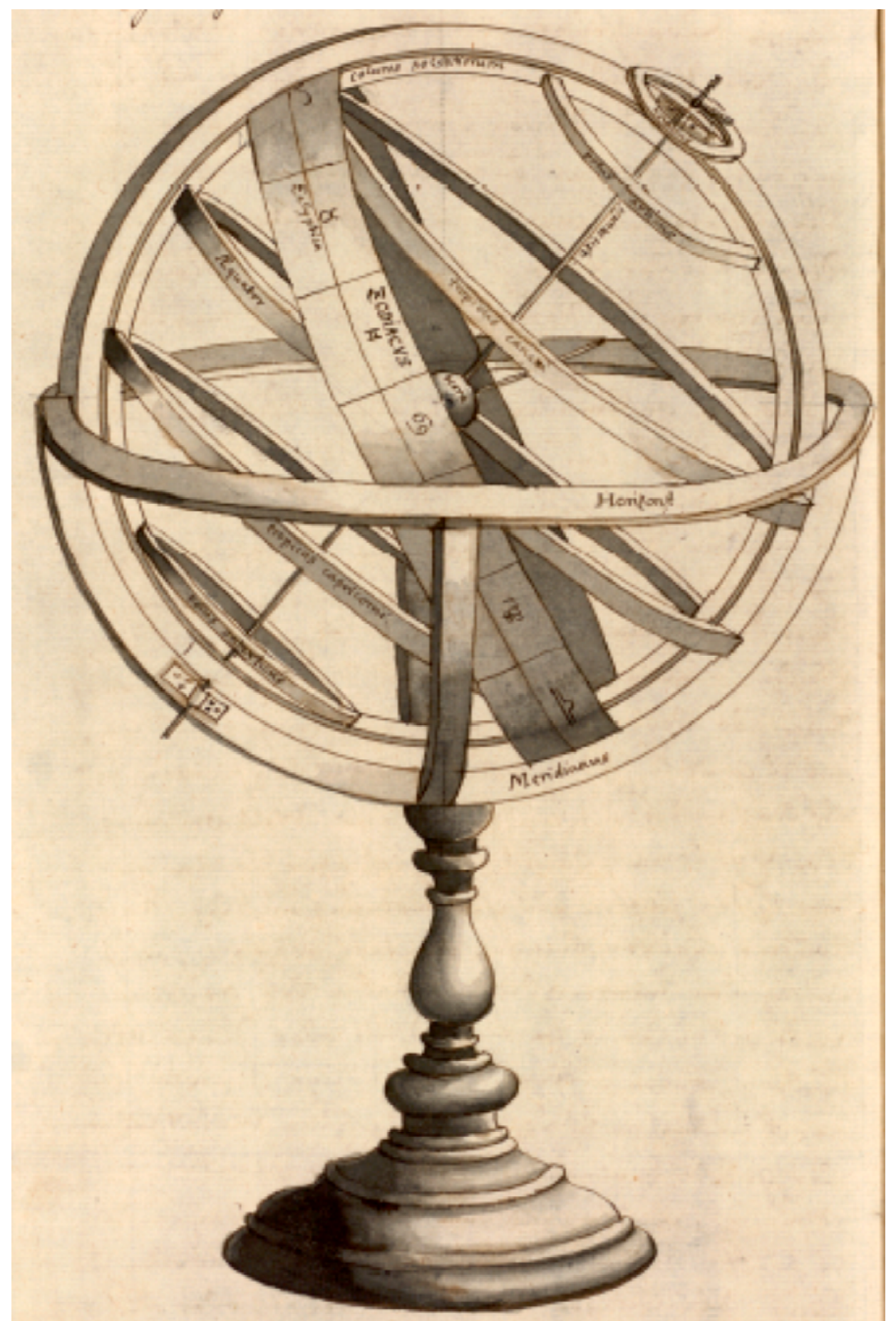

Abb. 34 Johann Friedrich von Uffenbachs eigenhändige Zeichnung einer Armillarsphäre in: Cod. Ms. Uffenbach 13/I, S. 52

Insgesamt haben sich fünf in grünes Leder gebundene Bände mit Protokollen erhalten (Abb. 33). ${ }^{750}$ Alle tragen sie den Titel: „Wochentliche Sammlung der in

750 Cod. Ms. Uffenbach 13 I-V (VII + 254 S. und 3 Tafeln, IV + 336 S. und 2 Tafeln nebst 2 Kupferstichen, IV + $462 \mathrm{~S}$. und 8 Tafeln nebst 5 Kupfern, IV + 746 S. und 3 Tafeln nebst 2 Kupfern und 1 Druckbeilage, III + 794 S. und 6 Tafeln nebst 1 Kupfer und 6 Druckbeilagen), eine Transkription der Ordnung der wissenschaftlichen Gesellschaft und 
Nützlichen Neben Stunden angestelten Untersuchungen der Natur und Kunst, welche zu einer Gemüths- Ergötzung dieienige Gesellschaft veranlasset, deren Denckspruch ist: „Quo simplicius eo perfectius“. 751

Es handelt sich um die ausführlichen Protokolle der Sitzungen vom 25. Oktober 1726 bis zum 3. Juli 1739. ${ }^{752}$ Mit dem letzten schriftlich belegten Treffen scheint die Gesellschaft aber nicht erloschen zu sein. Zwar haben sich keine weiteren detaillierten Sitzungsberichte erhalten, aber Uffenbach vermerkte nachträglich am Rand des Berichtes vom 6. Juli 1736: „,...], und nachher bey unserer Gesellschaft 1740 den 15 July zu Werck gerichtet worden ist [...]." 753 Wahrscheinlich sind die Abstände der Zusammenkünfte immer größer geworden und die Themen, die besprochen wurden, ähnelten vorangegangen so sehr, dass, wie in diesem Falle, wenn Neues zu Bekanntem dazukam, dieses nur noch in einer Anmerkung zu einem bestehenden Protokoll vermerkt wurde. Ein Beleg, dass es noch einen sechsten, umfangreichen Protokollband gegeben hat, befindet sich im zweiten Band in einer Randbemerkung zu einem der behandelten Punkte; dort heißt es auf Seite 185: ,vid tom 4 p.434 und tom 6. p.682““754 Dieser Band hat sich nicht erhalten. ${ }^{755}$

Traf sich die Gesellschaft in den Anfangsjahren im Wochenrhythmus, kann man nach 1733 ein gewisses Erlahmen feststellen. Immer wieder konnten einzelne Mitglieder die Termine nicht einhalten und so entstanden längere Pausen. Schon im November 1731 hatte deshalb die Gesellschaft bestimmt, dass man nur noch

die Vorworte der Protokollbände von Uffenbachs Hand befinden sich im Anhang S. 588596.

Eine Liste aller Zusammenkünfte mit Datum und bei welchem Mitglied das Treffen stattfand, findet sich im Anhang, S. 575-587.

Normalerweise benutzte Uffenbach grüne Ledereinbände nur dann, wenn es sich um eigene Manuskripte handelte; dann ließ er allerdings auch sein Wappen in Gold auf Vorder- und Rückseite prägen, was hier bei allen Bänden fehlt.

751 Je einfacher, desto besser.

Vgl. die Zeichnung Uffenbachs, die das Zimmer in seinem Hause zeigt, in dem sich die Gesellschaft traf. An dem Schirm des Deckenleuchters erkennt man das aufgeschriebene Motto (Cod. Ms. Uffenbach 13/I, S. 65). Siehe Abb. 35.

752 Der erste Band umfaßt die ausführlichen Protokolle der Zeit vom 25. Oktober 1726 bis zum 6. Juni 1727, der zweite die vom 18. Juli 1727 bis 30. Juli 1728, der dritte die vom 29. Oktober 1728 bis 26. März 1730, der vierte die vom 17. Mai 1730 bis 19. Dezember 1732 und der fünfte Band die vom 9. Januar 1733 bis 3. Juli 1739.

753 Cod. Ms. Uffenbach 13/V, S. 631.

754 Cod. Ms. Uffenbach 13/II.

755 Dieser sechste Protokollband ist nicht nach Göttingen gekommen. Er erscheint auch weder im Verzeichnis der Uffenbachischen Bücher (Cod. Ms. Uffenbach 47) noch in den drei Supplementen (Bibl. Arch. A 34 C). Auch im Frankfurter Institut für Stadtgeschichte lässt sich der Band nicht nachweisen. 
vierzehntägig zusammenkommen sollte. Uffenbach beklagte die Unterbrechungen genauso wie die geringe Anzahl der Mitglieder. Stets versuchte man, neue Teilnehmer zu gewinnen; außer bei dem Frankfurter Materialienhändler Ettling, der 1733 als ordentliches Mitglied der Gesellschaft beitrat, gelang dies aber nicht.

So wurde z.B. am 16. November 1731 im Hause Eberhards folgendermaßen über den Mangel an Zuwachs diskutiert: ,[...], so haben wir jedoch nach vieler angewandten Mühe so viel erfahren daß denen meisten, eine Spiel, Trinck Rauch oder Schwätzgesellschaft weit mehr Ansehnlichkeit als ein vernünftiger Zeitvertreib habe und derer Liebhaber von Künsten und Wißenschaften es alhier nicht mehr oder kaum so viel gebe als zahlreich die Gesellschaft derer Musen ehedeßen geweßen [...]."756 Ein anderer möglicher Grund, weshalb man keine weiteren Mitglieder fand, war die für die konservativen, streng getrennten Frankfurter Gesellschaftsschichten nicht nachvollziehbare Aufhebung der Standesunterschiede innerhalb der Wissenschaftlichen Gesellschaft. Es wurde ausdrücklich von den Mitgliedern bestimmt, dass es keine geben sollte. ${ }^{757}$

Jedes Mitglied hatte mehr oder weniger ein Spezialgebiet gefunden, welches er der Gesellschaft in seinem Hause vorführte. Johann Friedrich von Uffenbach beschreibt dies mit den Worten: ,[...] wobey auferlegter Maßen einen kurtzen Bericht von der Astronomie zu geben den Anfang machte, und mich billiger Maßen beschwehrte, daß die vorige $\mathrm{H}$ mir so zu reden, alle Elemente zu ihre Betrachtung weg genommen, da $\mathrm{H}$ Diesterweg durch seinen besondern Schmelzofen sich das Feuer erwehlt, H Behagel mit denen Experimenten der Antlia $^{758}$ die Luft, H Doct. Kißner nach Anleitung seines schönen Naturalien Cabinets ${ }^{759}$ gleichsam die Erde, und leztlich H Eberhard mit seinen Truckwercken und andern Waßermachinen das Waßer, da wir beyde übrige nun als Gebrüder zu kurtz gekommen, so habe ich meines Orts mir den Himmel erlesen, wohin ich mich auf 2 guten Flügeln nehmlich der Rechenkunst und Optic zu schwingen getraut, [...]." 760 Uffenbachs jüngerer Bruder Wilhelm hatte sich die Sparte des Handwerkers und Amateurs herausgegriffen. Traf sich die Runde bei ihm, führte er nützliche Maschinen, wie z.B. Dreh- und Hobelbänke, oder seltene Bücher vor, die sich in seinem Besitz befanden.

\footnotetext{
756 Vgl. Cod. Ms. Uffenbach 13/IV, S. 425.

757 S.u. in diesem Kapitel, wo auf die Statuten der Gesellschaft eingegangen wird.

758 Hiermit sind die Versuche mit der Luft- bzw. Vakuumpumpe gemeint, die Behaghel immer wieder der Gesellschaft vorführte.

759 Uffenbach verfasste auf das Naturalienkabinett Kißners ein Lobgedicht, abgedruckt in: Uffenbach 1733, S. 209-222.

760 Cod. Ms. Uffenbach 13/I, S. 40.
} 
Die Verteilung der Teilnehmer auf die vier Elemente veranlaßte Uffenbach, ein dramatisches Singspiel zu verfassen mit dem Titel: „Der um das Vorrecht angestelte Wettstreit der Vier Elementen wurde in einer derer Zusammenkünften von der Löblichen Gesellschaft deren Wahlspruch ist: Quo simplicius eo perfectius. Zur Gemüthsergetzung in einer Serenata aufgeführt von derselben Schreibern“, welches er am 23. Juni 1730 in seinem Haus aufführte. ${ }^{761}$ Den Text unterlegte er dabei mit den Noten italienischer Arien.

Der erst 1733 hinzugekommene Ettling zeigte als Materialienhändler seltene Waren aus seinem Kontor, wie besonders bearbeitetes Elfenbein oder Schildkrötpanzer. ${ }^{762}$

Allerdings hielten sich die Mitglieder nicht die ganzen Jahre hindurch an ihre „verteilten“ Rollen. Ein roter Faden, der sich durch alle Zusammenkünfte zog, war das Interesse aller an der Kunst und den damit verbundenen Kunsttechniken. Uffenbach selbst trug in drei längeren Referaten eine Entwicklungsgeschichte der Drucktechniken mit dem Titel „Uhrsprüngliche Historie der gesamten Bildkunst auf Papier“ den Mitgliedern vor. ${ }^{763}$

Auch wurden immer wieder Rezepte von Farben und Firnissen unter den Mitgliedern ausgetauscht oder seltene Verfahren gezeigt oder vorgeführt. Als Beispiel sei ein Versuch mit Bleiweiß genannt, den Uffenbach am 19. Februar 1734 erklärte. ${ }^{764}$

Neben den genannten Themen diskutierte die Gesellschaft über Flora und Fauna, das Klima und die Medizin. Tagesereignisse, wie z.B. der zugefrorene Main und die Folgen dieser Begebenheit ${ }^{765}$ oder eine Viehseuche in den hessischen Ländern, ${ }^{766}$ waren immer wieder Themen der Diskussion. An der Erörterung bezüglich der Viehseuche, die in erster Linie das Hornvieh betraf, ist

761 Cod. Ms. Uffenbach 13/IV, S. 23-30. Der Text findet sich abgedruckt in: Uffenbach 1733, S. 387-392.

Am 24. April 1740 wird in Frankfurt „ein Drama von denen 4 Elementen“ aufgeführt. Wahrscheinlich handelt es sich um die öffentliche Aufführung von Uffenbachs Singspiel, vgl. Israel 1876, S. 30.

762 S. weiter unten Kapitel 8.4.7 „Die Beiträge von Johann Friedrich Ettling.“

763 Vgl. Meyerhöfer 1997.

Cod. Ms. Uffenbach 13/IV, S. 503-516, 553-573 und 591-604.

Auf die Geschichte der graphischen Künste soll weiter unten noch ausführlich eingegangen werden. Die Transkription s. Anhang, S. 163-200.

764 Cod. Ms. Uffenbach 13/V, S. 248-249.

Siehe weiter unten.

765 Cod. Ms. Uffenbach 13/III, S. 63 (14. Januar 1729), S. 170 (25. März 1729).

766 Cod. Ms. Uffenbach 13/III, S. 256. 
die von den Mitgliedern vertretene Meinung bemerkenswert. In der Öffentlichkeit wurde diese Seuche als ein von Gott gesandtes Naturwunder angesehen, während die Mitglieder der Gesellschaft anhand von schriftlichen und mündlichen Berichten erst einmal den örtlichen Verlauf der Seuche über Bayern nach Hessen und die Art der Krankheit bestimmten. Zum Schluss verneinte man, dass die Seuche Gott gegeben sei, und betonte, dass es eine normale Erkrankung des Viehs sei, die schon zuvor mehrfach aufgetreten war.

Zusammengefaßt hatte es sich die Gesellschaft zur Untersuchung und Pflege von Natur und Kunst zur Aufgabe gestellt, Methoden und Erfindungen auf ihre Brauchbarkeit für die Allgemeinheit $\mathrm{zu}$ überprüfen und, falls erforderlich, $\mathrm{zu}$ verbessern. Die Intention war also eine auf die Praxis gerichtete. Es ging der Gesellschaft darum, die Welt zu begreifen als einen Ablauf von Regeln, die es zu erforschen galt. Die Mitglieder versuchten, die Natur und die sie umgebenden Dinge wissenschaftlich zu ergründen. Man glaubte zwar noch an die göttliche Schöpfung, hinterfragte diese aber immer wieder; das „Wie“ stand im Vordergrund.

\subsection{Johann Friedrich von Uffenbachs „Vorberichte“}

Der Schreiber Uffenbach hatte es sich zur Aufgabe gemacht, die Vorworte, oder wie er sie nannte die „Vorberichte“, für die einzelnen Protokollbände zu verfassen. ${ }^{767}$ Jede dieser Einleitungen ist datiert. Die erste schrieb er noch 1726 , also in dem Jahr, als die Gemeinschaft beschlossen hatte, ihre Zusammenkünfte für sich und die Nachwelt zu protokollieren. ${ }^{768}$ Die zweiten, dritten und vierten Vorberichte formulierte er jeweils nach Vollendung der Protokolle, die in den jeweiligen Band eingebunden werden sollten, am 15. Oktober 1728, am 24. April 1730 und am 22. Dezember 1732. Dem fünften Band fehlt ein Vorwort, es sind aber die dafür vorgesehenen Seiten schon vom Buchbinder eingeheftet worden und Uffenbach hatte die drei leeren Blätter mit dem üblichen Titel „Vorbericht“ überschrieben. Ob Uffenbach den sechsten Band mit einem Vorwort versehen hat, kann nicht festgestellt werden, da dieser verschollen ist. ${ }^{769}$

767 Der vollständige Wortlaut der Vorberichte und auch der Ordnung der Gesellschaft befinden sich im Anhang, S. 282-290.

768 Es konnte nicht festgestellt werden, ob Uffenbach diesen Vorbericht vor oder nach den Treffen 1726 geschrieben hat, da dieser nicht mit einem Tagesdatum versehen wurde. S.o. 
Im ersten Vorwort legte er Bericht ab über das Zustandekommen der Gesellschaft und auch deren Absichten. Als Grund und Ansporn, eine bürgerliche Akademie zu gründen, führte er unter anderem seine eigenen Beobachtungen bei den Besuchen sowohl der königlichen Akademien in Paris und London als auch der Akademien Italiens an, so schreibt er: „,...] wenn viele die kurtze Lebenszeit ein müthige Hand an die verborgene Kunst anlegen, sie in die Entdeckung derselben mit mehr ausrichten, als ein einziger Lehrbegieriger allein vermag, eben als wie die zusammen gesetzte Kraft vieler Hände eine sonst unbewegliche schwehre Last leichte und gleichsam unvermerckt fort bringen. "770

Seinen Besuch der Räumlichkeiten der französischen Akademie am 21. Oktober 1715, die im Louvre beheimatet war, beschreibt er in seinem Reisediarium folgendermaßen: „Auf dießes zimmer aber kahme in ein großes und höheres so aber ganz simpel meublirt und mit einem großen tisch, worum viele stühle stunden, bestellet, und dießes war der ort alwo die die academie des sciences pflegt zu sammen zu kommen, ich hatte hiervon anfänglich eine sehr große opinion, und dachte viele machinen und curiositäten $\mathrm{zu}$ sehen, allein ich wunderte mich sehr, als auch nicht das geringste von dergleichen alhier ansichtig, und mir ein lehres zimmer gezeigt wurde. "771 Als er dann aber einige Tage später an einer der für das Publikum geöffneten Sitzungen der „academie des sciences“ teilnahm, beschrieb er das Procedere in seinem Tagebuch ausführlich. ${ }^{772}$ Der positive Eindruck, den diese Sitzung wegen der Struktur und vor allem der Diskussionen auf ihn hinterließ, zeigt sich unter anderem an den Statuten der Frankfurter Gesellschaft. ${ }^{773}$

Die Mitglieder informierten sich zudem über die 1725 in St. Petersburg gegründete Akademie der Wissenschaften. Uffenbach hatte sich von dieser schon 1725 und 1726 durch den in St. Petersburg lebenden Christian Friedrich Gross ausführlich berichten lassen. ${ }^{774}$ Auch Kißner pflegte schriftliche Kontakte dorthin und berichtete beispielsweise im Dezember 1727 der Gesellschaft über die

\footnotetext{
770 Cod. Ms. Uffenbach 13/I, S. I, s. Anhang S. 589-590.

771 Cod. Ms. Uffenbach 29/IV, S. 202-203.

772 Cod. Ms. Uffenbach 29/IV, S. 277-280.

773 S.u.

774 Christian Friedrich Gross $(\dagger$ 1742) war Professor für Morallehre und Mitglied der Petersburger Akademie der Wissenschaften. Er war der Bruder des russischen Diplomaten Heinrich Gross(1713-1765). Vgl.: https://frinru.ilrt.bris.ac.uk/text/french-russiandiplomacy-antiokh-kantemir\%E2\%80\%99s-address-king-george-ii-and-his-diplomatic-andother\#_ednref17, Anm. 17 vom 01.07.2016.

Vgl. die vier Briefe von Gross in: Cod. Ms. Uffenbach 20/I, B1. 92a-97.
} 
Entwicklung der Petersburger Akademie. ${ }^{775}$ Desweiteren bezog Uffenbach die von der Londoner, Pariser und auch von der Petersburger Akademie herausgegebenen Schriften. ${ }^{776}$

Die Ziele der Zusammenkünfte der wissenschaftlichen Gesellschaft beschreibt er im ersten Vorwort folgendermaßen:

„nichts anders zu ihrem Absehen, als wochentlich etliche müßige Stunden nützlicher und vernünftiger als es gemeiniglich bey straffbahrem Geschwätze und Richten unserer Nechsten, ja bey noch verderblicherem Zeitverlust des Spielen geschihet, zu einer löblichen Gemüthsergetzung anzuwenden,“

„um nicht allein darinnen die lobenswürtige Erfindungen anderer, deren Tagregister durch offentlichen Truck bekant worden zu untersuchen, und vieleicht solche zu unseres Vaterlandes Nutzen brauchbahr zu machen, sondern auch unsere eigene noch unbekante einander mitzutheilen, und uns zu belehren;"777

„Wir achten also den Vorwurff, daß viele Sachen nicht neu seyen, wenig, dieweil die Untersuchung von anderer Erfindungen unser Hauptzweck geweßen, noch weniger aber wird uns der Unverständigen Tadel anfechten, welche ihr Spiel und unnützes Gewäsche in Gesellschaften unserer Bemühung mit einem Hohnlachen vorziehen. " 778

Im dritten Vorbericht greift er die Ziele der Gesellschaft nochmals auf: „Wenige suchen das, was unser Entzweck ist, nehmlich der Kunst mit allerley Handgriffen und kleinen Nachrichten behülfflich zu seyn, zu forderst aber solche zu unsere Belehr- und Belustigung der Vergeßenheit zu entreißen."779

Wichtig ist hier der Wahlspruch, den sich die Gesellschaft gegeben hatte: „Quo simplicius eo perfectius.“ Die Mitglieder hatten die Vereinigung mit diesem Motto überschrieben, um deutlich zu machen, dass es ihnen nicht um die Vorführung eigener Erfindungen, sondern um die Vereinfachung und Verbesserung schon gemachter ging. Diese sollten, falls möglich und nützlich, der Allgemeinheit zur Verfügung gestellt werden. Im zweiten Vorbericht wird dieses Anliegen nochmals bekräftigt: „Vielmehr an Anderer schönen Erfindungen zu

Cod. Ms. Uffenbach 13/II, S. 98.

Nicht in der Bibliothek Uffenbach vorhanden. Er hat die Zeitschriften auseinandergenommen und in sein „Repertorium physico mathematico technicum“ (Cod. Ms. Uffenbach $10 \mathrm{I}+\mathrm{II}$ ) die Artikel aufgenommen, die ihn interessierten.

Cod. Ms. Uffenbach 13/I, S. II, s. Anhang S. 590-591.

Cod. Ms. Uffenbach 13/I, S. III, s. Anhang S. 591.

Cod. Ms. Uffenbach 13/III, S. I + II, s. Anhang S. 593-594. 
ergetzen, und etwa hier und dar Mängel zu berühren, oder auch Verbeßerungen zu versuchen, damit denen Künsten und Handarbeiten, wie sie dem menschlichen Leben ohnentbehrlich sind, also vieleicht auch durch unsere Bemühung mehr Anleitung zu einer Aufnahme und Wachsthum an Hand gegeben werde.“780

Auch die Begründung, warum die Gesellschaft ihre Sitzungen protokolliert, wird in der ersten Einleitung gegeben. ${ }^{781}$ Nachdem sich die wissenschaftliche Gesellschaft im November 1725 gegründet hatte und ein Jahr regelmäßig alle 14 Tage zusammenkam, ohne Berichte zu verfassen, befürchteten die Mitglieder, dass ihr Unterfangen der Vergessenheit unterliegen würde, wenn man die Ergebnisse der einzelnen Zusammenkünfte nicht schriftlich festhalten würde. So möchte man also mit den Akademien gleichziehen, die ihre Sitzungsberichte der Öffentlichkeit gedruckt zur Verfügung stellen. Ist die Frankfurter Gesellschaft auch nur ein mit Anstrengungen unternommener Versuch, in der freien Reichsstadt eine bürgerliche Akademie zu begründen, sollen die Bemühungen aber doch der interessierten Nachwelt erhalten bleiben.

In jedem Vorbericht entschuldigt sich der Schreiber Uffenbach für seine „unzulängliche Schreibart als auch die Flüchtichkeit und den Unfleiß in meinem Abzeichnen." 782

Schon beim zweiten Vorwort vermerkt er, dass die Abstände der Zusammenkünfte größer werden würden, weshalb der Zeitraum, den der zweite Band umfassen würde, größer sei als der erste. Im Vorbericht des dritten Bandes, in dem dieser Vermerk wieder aufgegriffen wurde, erfolgt eine Begründung: „Wolte man uns aber um die Uhrsache deßelben fragen, so wüste keine hauptsächlichen anzugeben, als dass der erste Eifer in der Untersuchung der über reichen Nathur und Kunst nunmehr etwas kältlicher zu werden angefangen." 783 Noch im vierten Band sah sich Uffenbach gezwungen, Entschuldigungsworte für die längeren Pausen zwischen den einzelnen Sitzungen zu finden, die das Fortkommen der Gesellschaft wieder verlangsamt hätten, wenn er schreibt: „Die meiste Uhrsache hiervon mögte wohl die Schwäche unserer Zahl, und die besorgliche fernere Verringerung derer Mitglieder seyn, wenn ich auch gleich des Umstandes, daß sich ein Bronnen erschöpfen und die Pfeile verschießen laßen, nicht gedächte. Währender Zeit daß gegenwärtiger Band erwachsen, haben wir

Cod. Ms. Uffenbach 13/II, S. III, s. Anhang, S. 592.

781 Cod. Ms. Uffenbach 13/I, S. II, s. Anhang, S. 590-591.

782 Cod. Ms. Uffenbach 13/I, S. III, s. Anhang, S. 285.

783 Cod. Ms. Uffenbach 13/III, S. I, s. Anhang, S. 287.
} 
bekanter Maßen den ersten Verlust an dem frühezeitigen Ableben des Seel $\mathrm{H}$ Behagels erleiden müßen. Wäre unsere anitzo in Trauer gesetzte Gesellschaft zahlreicher, so würde man solches dabey so viel nicht mißen. Allein wo wenig ist, da wird der Abgang um desto eher mercklich, zumahlen da die Ersetzung einer solchen Stelle so gar schwehr fallen will." 784

\subsection{Die Statuten der wissenschaftlichen Gesellschaft}

Uffenbach stellt in dem ersten Vorwort heraus, dass sich die Mitglieder „durch gewiße Gesetze die ich hier unter anfügen wollen, genauer und unzertrenlicher verbunden“ fühlen. ${ }^{785}$ Dazu gehörten neben der Festsetzung der „Ordnung der Gesellschaft", die sich im ersten Band der Sitzungsprotokolle befindet ${ }^{786}$, die Einrichtung einer Kasse mit eigenem Kassenwart.

Die sechs Gründungsmitglieder beschlossen am 14. Oktober 1726 einstimmig, eine Reihe von Regeln „zu Erhaltung guter Ordnung.“ Im ersten Punkt wurden Rhythmus, Tag und Stunde der Zusammenkünfte festgelegt. Man traf sich freitags - im Winter alle acht Tage um 16 Uhr und im Sommer alle vierzehn Tage um 17 Uhr. Zu Zeiten der Frankfurter Messe, die zweimal im Jahr veranstaltet wurde, sollten wegen der dort abzuwickelnden Geschäfte keine Zusammenkünfte stattfinden. Der zweite Punkt betraf den Ort der Unterredungen. Durch das Los wurde eine Reihenfolge festgelegt, an die sich die Mitglieder die gesamten Jahre hielten. Als dritter Punkt wurde demjenigen auferlegt, bei dem die nächste Zusammenkunft stattfinden sollte, den anderen vorher rechtzeitig das $\mathrm{zu}$ erörternde Thema mitzuteilen, damit diese sich entsprechend vorbereiten konnten. Auch sollten, so im vierten Ordnungspunkt, immer ausreichend Schreibutensilien bereitliegen. Die fünfte Anordnung nahm auf die unterschiedliche gesellschaftliche Position der einzelnen Mitglieder Bezug. So wurde beschlossen, dass es innerhalb der wissenschaftlichen Gesellschaft keine Rangunterschiede geben sollte, gehörten der Akademie doch zwei Stände an, der des adeligen Patriziers und der der bürgerlichen Ärzte und Großkaufleute. ${ }^{787}$ Der sechste und letzte Punkt der Ordnung betraf das Ende einer jeden Sitzung, welches auf 20 Uhr festgesetzt wurde.

Cod. Ms. Uffenbach 13/IV, S. I, s. Anhang, S. 288.

785 Cod. Ms. Uffenbach 13/I, S. II, s. Anhang, S. 284.

786 Cod. Ms. Uffenbach 13/I, S. IV u. V, s. Anhang, S. 282-283.

787 Vgl. Koch 1986,2 und Kat. Frankfurt 1986, Bd. II, S. 42-43, Kat.Nr. III.14.
} 
Sollte sich eines der Mitglieder nicht an die beschlossenen Regeln halten, musste dieses eine Strafgebühr in die Kasse einzahlen, deren Inhalt u.a. zur Entlohnung mittelloser Wissenschaftler verwendet wurde, die an den Treffen der Gesellschaft teilnahmen. So besuchte der Kasseler Hofmathematiker und Professor der Optik Heinrich Ludwig Muth (1673-1754) am 19. März 1734 die Gesellschaft im Hause Kißners. ${ }^{788}$ Die Kasse hatte der jeweilige Gastgeber zu überwachen, als Kassenaufsicht wurde Albert Adolf Diesterweg bestellt, der am Jahresende den Inhalt überprüfte.

Diese Statuten waren für die Mitglieder durch die ganzen Jahre hinweg bindend. Nur der Wochentag und der Turnus der Zusammenkünfte wurden verändert. So wurde am 9. Dezember 1729 festgelegt, dass man sich abwechselnd freitags und mittwochs treffen solle, da Philipp Jacob Behaghel sonst an keinem Treffen mehr teilnehmen könnte, weil er das Amt des Frankfurter Almosenpflegers übernommen hatte, das ihn freitags in Anspruch nahm. Wegen der immer länger werdenden Pausen zwischen einzelnen Sitzungen beschloß man am 16. November 1731, dass man sich auch in den Wintermonaten nur noch alle 14 Tage treffen solle.

\subsection{Die Wirkung der Gesellschaft nach außen}

Innerhalb der Freien Reichsstadt wurde die Gesellschaft zwar zur Kenntnis genommen, als Institution konnte sich diese private Akademie nicht etablieren wie oben schon ausgeführt. Die Gründungsmitglieder blieben unter sich, bis auf den Materialienhändler Johann Friedrich Ettling konnten keine neuen Mitglieder gewonnen werden. Ab 1735 nahmen wiederholt einige wenige Frankfurter Gäste an den Sitzungen teil, wie der Kunstsammler Heinrich Jakob von Häckel (16821760) 789 und der in Frankfurt geborene Syndikus der Göttinger Universität Heinrich Christian von Senckenberg (1704-1768) ${ }^{790}$, die beide mehrere Male den Treffen beiwohnten. Häckel zeigte einige Militaria und beschrieb Experimente

788 Vgl. Cod. Ms. Uffenbach 13/V, S. 270-285.

Über Muths Forschungen und Beobachtungen wurde während der Sitzungen des Öfteren diskutiert. Einige der Teilnehmer, wie Eberhard und Johann Friedrich von Uffenbach kannten Muth auch persönlich und standen in regem Briefkontakt mit ihm (Vgl. die acht Briefe Muths an Uffenbach in: Cod. Ms. Uffenbach 20/II, S. 2-25c).

Siehe im Anhang, S. 272-281 die Liste der Treffen der Gesellschaft, wo auch die Besucher vermerkt sind.

790 Senckenberg war von 1735 bis 1738 in Göttingen, vgl. Pütter 1765, S. 79-85, Kriegk 1869, S. 14-35. 
mit Sprengstoff. ${ }^{791}$ Senckenberg unterrichtete den Frankfurter Kreis am 6. Dezember 1737 bezüglich der Eröffnung der Göttinger Universität und seines dort gehaltenen Referates über die „Mayenblumen. "792 Eine ideelle Unterstützung fand die wissenschaftliche Gesellschaft in dem bei den Sitzungen selbst nie anwesenden Frankfurter Bankier und Sammler Heinrich von Ucheln (16821746). ${ }^{793}$ Er schickte wiederholt Gemälde und kunsthandwerkliche Objekte zur Betrachtung und Begutachtung ${ }^{794}$, denn er stand mit zwei der Mitglieder, Konrad Hieronymus Eberhard und Johann Friedrich von Uffenbach, in persönlichem Kontakt.

Über die Grenzen Frankfurts hinaus erlangte der wissenschaftliche Kreis eine gewisse Bekanntheit. Dies kam zum einen durch briefliche Kontakte und persönliche Bekanntschaften der einzelnen Mitglieder zu Stande, zum anderen durch die Besuche von Technikern, Kunsthandwerkern und Professoren, wie z.B. Heinrich Ludwig Muth aus Kassel. 795

Die Gesellschaft wurde auch im Ausland bekannt. Am 4. November 1729 verlas Albert Adolf Diesterweg den Brief des in London lebenden Arztes Hampe, einem Vetter Diesterwegs, der um Abschriften der Protokolle bat. Hampe wollte sie der „Englischen Königlichen Sozietät der Wissenschaften“ vorstellen, in der er gerade Mitglied geworden war. Auch wollte er veranlassen, dass Teile der Niederschriften in den „Memoirs of the Royal Society“ abgedruckt würden. ${ }^{796}$ Die

So am 26. Januar 1736 (Cod. Ms. Uffenbach 13/V, S. 579-580).

Cod. Ms. Uffenbach 13/V, S. 688-689.

793 Uffenbach verfasste ein Lobgedicht auf das „Gemäldezimmer“ von Uchelns, abgedruckt in: Uffenbach 1733, S. 223-225; desweiteren finden sich ebda.: „Ein Schreiben an denselben“ (S. 226-227), die italienische Erklärung der Zeichnung, die Uffenbach in von Uchelns „Kunstbuch“ gezeichnet hatte (S. 228), das italienische Vorwort für das „Kunstbuch“ (S. 229) und zwei Antwortschreiben in Reimform (S. 230-231).

Uchelns Gemäldesammlung wurde am 20. Mai 1744 versteigert. Der Titel des gedruckten Versteigerungskataloges lautet: Specification derjenigen kostbahren Gemählden welche allhier in des Herrn Gerichts Substitui Frießen Behaußung auf der kleinen Gallen Gaß aus dem berühmten Uchelischen Mahlerey-Cabinet an den meistbietenden gegen gleich baare Bezahlung öffentlich sollen vergantet werden, Frankfurt am Mayn, gedruckt mit Waldowischen Schriften.

Vgl. Schmidt 1960, Sammlung Ucheln (1727).

794 So am 28. Januar 1729 (Cod. Ms. Uffenbach 13/III, S. 81), 4. Februar 1729 (Cod. Ms. Uffenbach 13/III, S. 90), 18. März 1729 (Cod. Ms. Uffenbach 13/III, S. 143-144), 17. Mai 1730 (Cod. Ms. Uffenbach 13/IV, S. 5), 8. Dezember 1730 (Cod. Ms. Uffenbach 13/IV, S. 69-70), 15. Dezember 1730 (Cod. Ms. Uffenbach 13/IV, S. 80-81), 4. März 1735 (Cod. Ms. Uffenbach 13/V, S. 449-450), 27. Januar 1736 (Cod. Ms. Uffenbach 13/V, S. 583584), 15. März 1737 (Cod. Ms. Uffenbach 13/V, S. 674) und 1. Mai 1739 (Cod. Ms. Uffenbach 13/V, S. 747).

795 Vgl. die Liste der Treffen im Anhang, S. 272-281.

796 Vgl. Cod. Ms. Uffenbach 13/III, S. 256. 
Abschrift zumindest des ersten Bandes wurde sofort veranlasst. Schon am 2. Dezember 1729 konnte Wilhelm von Uffenbach diese Kopie der Schriften der versammelten Gesellschaft vorlegen, die ein Frankfurter Maler namens Koch angefertigt hatte. 797 Wie die „Englische Königliche Sozietät der Wissenschaften“ auf die Kopie reagiert hat, konnte nicht festgestellt werden, da bei den Zusammenkünften nicht mehr darüber gesprochen wurde.

\subsection{Die Beiträge der einzelnen Mitglieder}

Insgesamt wurden in den fünf erhaltenen Bänden 192 Sitzungen protokolliert, die immer abwechselnd in den Räumlichkeiten der einzelnen Mitglieder stattfanden. Bei Johann Friedrich von Uffenbach traf man sich 37, bei Albert Adolf Diesterweg und Conrad Hieronymus Eberhard jeweils 36, bei Johann Georg Kißner und Wilhelm von Uffenbach jeweils 29, bei Philipp Jacob Behaghel 16 und bei dem erst 1733 hinzugekommenen Johann Friedrich Ettling neun Mal.

\subsubsection{Die Beiträge von Johann Friedrich von Uffenbach}

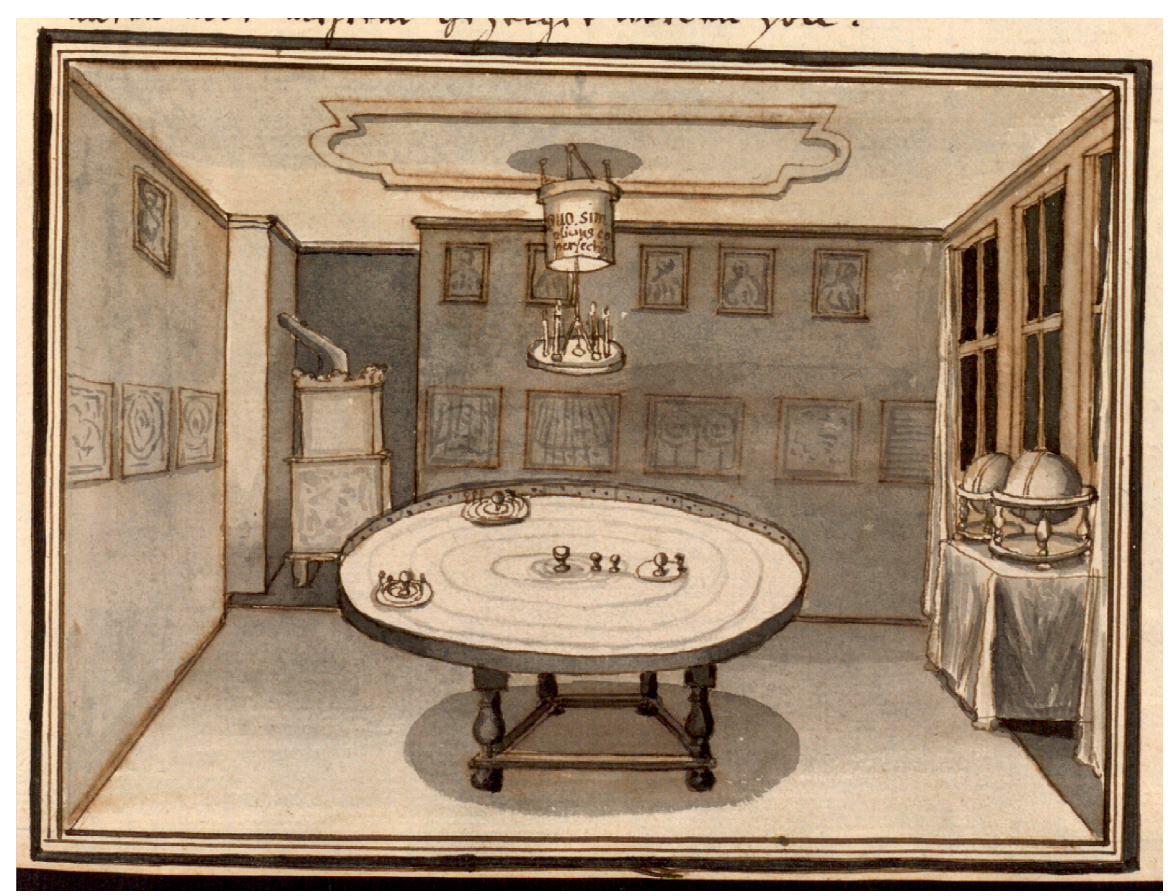

Abb. 35 Uffenbachs Zeichnung des Zimmers in seinem Haus, wo sich die Gesellschaft traf, in: Cod. Ms. Uffenbach 13/I, S. 65

797 Vgl. Cod. Ms. Uffenbach 13/III, S. 281.

In Frankfurt am Main lebte in dieser Zeit, nach Gwinner 1862, S. 258, nur ein Maler dieses Nachnamens, Georg Anton Koch (1685-1757). 
Als Erster soll der Initiator der Gesellschaft, Johann Friedrich von Uffenbach, mit seinen Themenschwerpunkten vorgestellt werden. Er hatte sich, wie oben ausgeführt, „,en Himmel erlesen, wohin ich mich auf 2 guten Flügeln nehmlich der Rechenkunst und Optic zu schwingen getraut."798 Uffenbach hielt eine lange Reihe von Referaten zur Astronomie. Dabei handelt es sich insgesamt um 24 Lesungen, die sich in 24 Kapiteln auf insgesamt 311 Seiten Text mit einigen eigenhändigen Illustrationen in den Protokollen befinden. Er konnte bei der Vorbereitung auf eigene Geräte und die umfangreiche Literatur zur Astronomie aus seiner Bibliothek zurückgreifen. 799 Über einen Zeitraum von etwas mehr als vier Jahren, Dezember 1726 bis Februar 1731, unterrichtete Uffenbach die Teilnehmer bei den Zusammenkünften in seinem Haus über die Geschichte der Astronomie und die neuesten Ergebnisse astronomischer Forschung.

Die Kapitelüberschriften in den Protokollen lauten:

„Kap. 1: Von dem Lobe und Alter der Astronomie. ${ }^{800}$

Kap. 2: Von denen Gelegenheiten so die Astronomie aufgebracht, und derselben Werckzeug. ${ }^{801}$

Kap. 3: Von der Altenmeinung, betreffendt die Welt=Ordnung. ${ }^{802}$

Kap. 4: Mängel der Ptolmaeischen Meinung von dem Weltgebäude, und Beschreibung der Copernicanischen. ${ }^{803}$

Kap. 5: Von denen Einwürffen die denen Copernicanern gemacht werden. ${ }^{804}$

Kap. 6: Von der Tychonischen Weltordnung. ${ }^{805}$

Kap. 7: Von dem Zusammenhang und der beständigen Ordnung unseres Weltgebäudes. ${ }^{806}$

Cod. Ms. Uffenbach 13/I, S. 40.

Das Verzeichnis der wissenschaftlichen Geräte, von Uffenbach selbst verfasst, hat sich in der Göttinger Handschriftenabteilung erhalten. Die Geräte wurden bis auf 22 Nummern am 26. 10.1791 an den Göttinger Professor Georg Christoph Lichtenberg (1742-1799) übergeben, der die Geräte, 198 Nummern, in seiner Wohnung deponierte und damit mit seinen Studenten experimentierte. Vgl. Cod. Ms. Bibl. Arch. A 34a und Meyerhöfer 1995. S. Anhang, S. 78-126.

2. Dezember 1726, Cod. Ms. Uffenbach 13/I, S. 41-47.

2. Dezember 1726, Cod. Ms. Uffenbach 13/I, S. 47-60.

2. Dezember 1726, Cod. Ms. Uffenbach 13/I, S. 60-65.

17. Januar1727, Cod. Ms. Uffenbach 13/I, S. 109-117.

17. Januar 1727, Cod. Ms. Uffenbach 13/I, S. 117-123.

7. März 1727, Cod. Ms. Uffenbach 13/I, S. 173-179. 
Kap. 8: Von der Entfernung, Größe, und künstlichen Ausmeßung der Welt Cörper. ${ }^{807}$

Kap. 9: Von der geglaubten Würckung und dem Einfluß der Sterne auf unserer Erde. ${ }^{808}$

Kap. 10:Von denen Fixsternen. ${ }^{809}$

11. Kap.: Von unserm Fixsterne der Sonnen. 810

12. Kap.: Von dem Planeten Mercurio. ${ }^{811}$

13. Kap.: Von der Venus. ${ }^{812}$

14. Kap. Von dem Planeten Mars. ${ }^{813}$

15. Kap.: Von dem Planeten Jupiter nebst seinen Trabanten. ${ }^{814}$

16. Kap.: Von dem Planeten Saturno. 815

17. Kap.: Von denen ungewöhnlichen Planeten oder denen Cometen. ${ }^{816}$

18. Kap.: Von unserm Neben Planeten dem Mond. 817

19. Kap.: Von denen Finsternüßen. 818

20. Kap.: Von der Erde als einem Planeten. ${ }^{819}$

21. Kap.: Von der Eintheilung der Erden durch Zirckel und Linien in gewiße Flächen. 820

22. Kap.: Von denen Dingen so über dem Erdeboden sind und sich zu tragen. ${ }^{821}$

7. März 1727, Cod. Ms. Uffenbach 13/I, S. 179-186.

6. Juni 1727, Cod. Ms. Uffenbach 13/I, S. 218-237.

6. Juni 1727, Cod. Ms. Uffenbach 13/I, S. 237-246.

21. Oktober 1727, Cod. Ms. Uffenbach 13/II, S. 33-54 und den „Verfolg des 10ten Kapitels von denen Fixsternen“" am 19 Dezember 1727, Cod. Ms. Uffenbach 13/II, S. 109-122.

30. Januar 1728, Cod. Ms. Uffenbach 13/II, S. 157-171.

19. März 1728, Cod. Ms. Uffenbach 13/II, S. 236-243.

19. März 1728, Cod. Ms. Uffenbach 13/II, S. 243-249.

3. Dezember 1728, Cod. Ms. Uffenbach 13/III, S. 21-26.

4. Februar 1729, Cod. Ms. Uffenbach 13/III, S. 94-109.

18. März 1729, Cod. Ms. Uffenbach 13/III, S. 145-154.

12. August 1729, Cod. Ms. Uffenbach 13/III, S. 238-251.

15. Dezember 1729, Cod. Ms. Uffenbach 13/III, S. 312-320.

3. Februar 1730, Cod. Ms. Uffenbach 13/III, S. 392-403.

23. Juni 1730, Cod. Ms. Uffenbach 13/IV, S. 9-22.

15. Dezember 1730, Cod. Ms. Uffenbach 13/IV, S. 86-114. 
23. Kap.: Von denen Dingen so auf dem Erdeboden sind und geschehen. ${ }^{822}$

24. Kap.: Von denen Dingen so unter der Erdenfläche sind, und sich begeben." 823

Bevor er über die neuesten Forschungen in der Astronomie referierte, hielt er sechs Vorträge zur Geschichte dieses Faches. Immer wieder nutzte er seine astronomischen Geräte, um die Thesen seiner Vorträge zu unterstreichen. Insgesamt kann man anhand der Texte sagen, dass Uffenbach den Versuch unternommen hat, ein Gesamtbild über Geschichte und Stand der Astronomie zu geben. $\mathrm{Ob}$ er eine Veröffentlichung seiner Astronomievorlesungen in Betracht zog, konnte nicht festgestellt werden. Allerdings sprechen der Umfang und die Ausführlichkeit der Texte für ein solches Projekt.

Neben dem allgemeinen Abriß zur Astronomie behandelte Uffenbach aber auch eigene Beobachtungen. Am 5. Februar 1734 beschrieb er ein astronomisches Phänomen, das er im Sommer 1733 am 23. August um 21.06 Uhr beim Aufenthalt in seinem Flörsheimer Landhaus beobachtet hatte. Es handelte sich um einen Vollmond mit einem zweifarbenen Hof, einem Halo, den er den Mitgliedern mit einer eigenhändigen Zeichnung veranschaulichte (Abb. 36). ${ }^{824} \mathrm{Um}$ die Erscheinung näher bestimmen zu können, griff er auf verschiedene Zeitungsartikel und die Bücher seiner Bibliothek zurück. ${ }^{825}$

19. Januar 1731, Cod. Ms. Uffenbach 13/IV, S. 175-206.

16. Februar 1731, Cod. Ms. Uffenbach 13/IV, S. 234-259.

28. Februar 1731, Cod. Ms. Uffenbach 13/IV, S. 278-300.

Cod. Ms. Uffenbach 13/V, S. 223. Mit dem eingeklebten Flugblatt einer ähnlichen Begebenheit im Jahre 1666 zu Straßburg zu Seite 226.

Johann Jacob Scheuchzer, Physica, oder Natur-Wißenschaft, 2 Bde., Zürich 1711 ( $8^{\circ}$ Bibl. Uff. 358); Martin Gotthelf Löscher, Dissputatio Physica de halone solis, Wittenberg 1725 (4 Bibl. Uff. 191:1 [11]); Johann Friedrich Weidler, Selectas aliquot observationes coelestas ..., Wittenberg 1723 (4 Bibl. Uff. 191:1 [13]). 


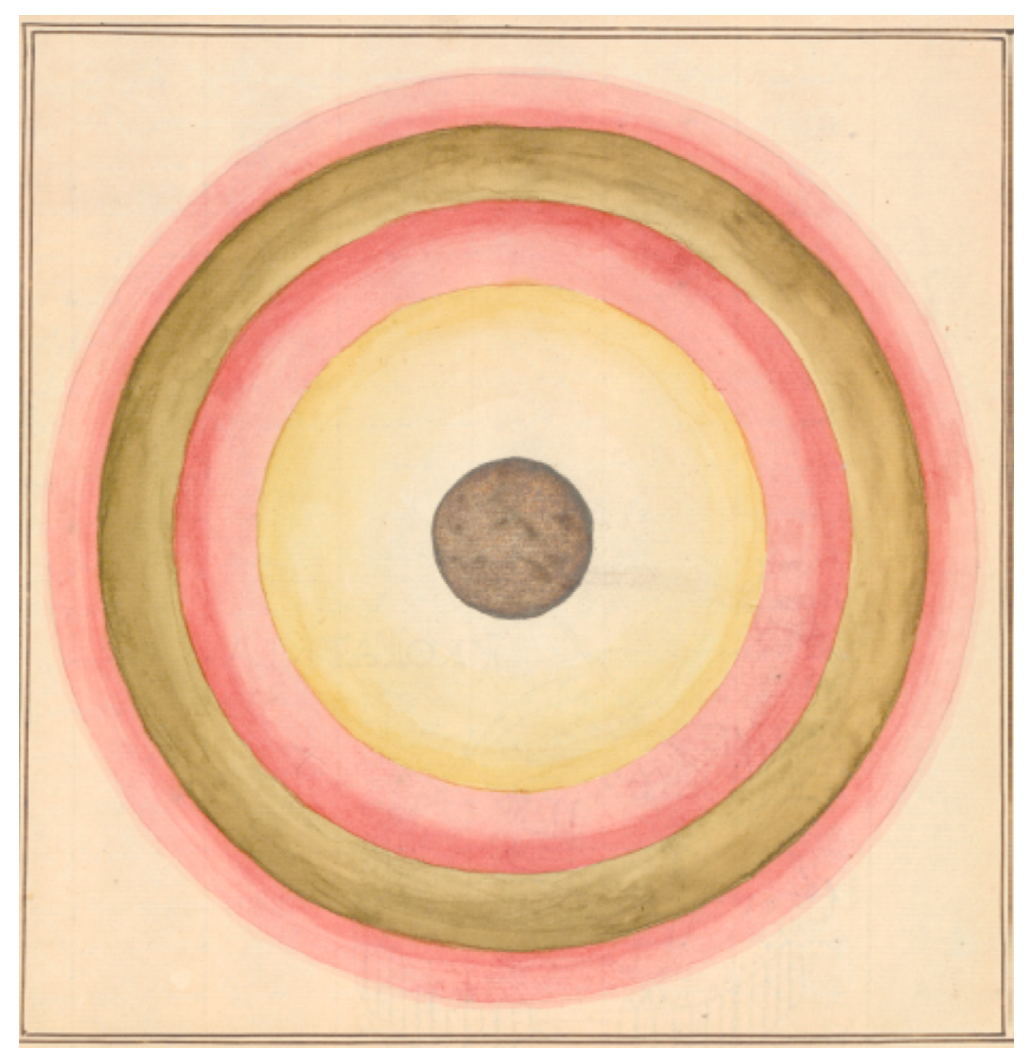

Abb. 36 Uffenbachs Zeichnung zu dem Halo, den er beobachtet hatte, in: Cod. Ms. Uffenbach 13/V, S. 223

Uffenbach war als Astronom aber nicht nur Theoretiker und Laienastronom sondern auch Praktiker. So hatte er das Schleifen von Linsen schon in seiner Hallenser Studienzeit 1706 bis 1709 erlernt. In seinem französischen Tagebuch vermerkte er: ,[...] unterwegs traffe ich einen alten ehrlichen bekanten teutschen he Reuß so vor dießem zu halle wohl gekant, und da mich im Glasschleiffen alda informiert."826 Auch auf seinen ausgedehnten Reisen kaufte er nicht nur optische Geräte, sondern versuchte auch von den Mechanikern deren Techniken zu erlernen. ${ }^{827}$

Um in seiner Heimatstadt weiterhin dieser Technik nachgehen zu können, besaß er eine ,zur bequemer Schleif- und Polirung aller Arten sogenannten optischer Gläser schicklich eingerichtete Machine“, 828 welche er der Gesellschaft

828 Vgl. Uffenbach 1771, S. 60, Nr. 158: „Eine zur bequemer Schleif- und Polirung aller Arten sogenannten optischer Gläser schicklich eingerichtete Maschine mit ansehnlichem Vorrath feiner und dicker noch unbearbeiteter Gläser, nebst verschiedenen zum Schleifen und Poliren nöthigen kleinen Werkzeug, und mit folgenden ansehnlichen kupfernen fein polirten und bestens conservirten Schleif=Schüsseln versehen, als 16 Stück, deren jedes aus einer concaven und einer convexen accurat auf einander passenden Schüssel bestehet, wovon jede mit einer Schraubemutter [!] versehen ist, um sie vermittelst derselben auf die 
zweimal, 1730 und 1732, vorführte. ${ }^{829}$ Die Maschine hatte er selbst nach den Angaben des Schwarzenauer Mechaniker Johann Melchior Kinet ${ }^{830}$ und von Johann Conrad Kanz ${ }^{831}$ angefertigt, welcher ein Hofrat von Graf Casimir von Sayn-Wittgenstein in Berleburg (1687-1741) war. Der in seiner „müßigen Zeit“ ebenfalls als Schleifer und Dreher tätige Kanz arbeitete eng mit Kinet zusammen, mit dem einige andere Gesellschafter, wie Albert Adolf Diesterweg, Konrad Hieronymus Eberhard und Wilhelm von Uffenbach, sowohl in brieflichen Kontakt standen als auch Geräte bei ihm bestellten und bauen ließen.

So konnte Uffenbach selbst gebaute optische und astronomische Geräte vorstellen, wie z.B. „2 ovale geschlifene Lese oder Vergrößerungsgläser vor blöde Augen“, die er selbst in Schiltkröt gefaßt hatte ${ }^{832}$ oder seinen 1737 gefertigten „tubum von 4 Gläser und 11 Schuen rheinländisch lang“, nach einem englischen

Schraube der Schleifmaschine zu befestigen, jedes paar obgenannter Schüsseln ist von der andern sowohl der Grösse als Concav- und Convexité unterschieden, das kleinste paar hat 2 Zoll im Durchschnitt, und das gröste paar ist 12. Zoll gros; ferner findet sich noch hiebey 6 Concav-Schüsseln von verschiedener Grösse, davon die gröste 9 Zoll breit ist, sämtlich auf gleiche Art wie die vorhergehende mit Schraubenmuttern versehen und aufs feinste ausgeschliffen; desgleichen endlich 3 auf ähnliche Art verfertigte Plan=Schüsseln, eine von Kupfer, die andere von Meßing, und die dritte von Zinn, wobey sich noch ein in Meßing ausgeschnittenes Maas derer verschiedenen Concav- und Convex-Schüsseln nach der Rheinländischen Abmessung befinden, nebst annoch zwey Stangen=Cirkel.“

Auf die Auktion 1771 kam als Nr. 163 (S. 61-62) auch: „Eine ansehnliche Parthie geschliffener und fein polirter optischer Gläser, von verschiedener Grösse, worunter sich folgende befinden, als a) 63 Stück auf beyden Seiten convex geschliffen, von verschiedener Grösse à 5-1 Zoll im Durchschnitt, ingleichen von verschiedenen foco, die grösten von 6 Schuh bis auf die kleinen von etwa 2 Zoll. b) 19 Stück Plan-convexe Gläser von gleichfalls verschiedener Grösse und verschiedenem foco. c) 22 Stück Plan-concav geschliffene gleichfalls von verschiedener Grösse und foco von 2 Schuh bis auf einige Zoll. d) 7 Stück concav-convex oder menisci von ebenfalls verschiedener Grösse. e) Etlich und vierzig fein geschliffene lentes oder Linsen zu Vergrösserungsgläser von verschiedener Grösse, davon die kleinste einen Stecknadelsknopf bis zu denen grösten, so eine Erbse gros sind. f) 41 paar rund geschliffener in der Mitte durchbohrter runde Glasplättgen 2 Zoll im Durchschnitt, wovon in der einen Glasplatte jedesmahl sechs runde Hohlungen zum microscopalischen Gebrauch eingeschliffen sind. g) 4 Plättgen dito, davon jedes mit sechs eingeschliffenen Hohlungen versehen, und 9 dito ganz flach ohne Hohlung. h) 10 Stück geschliffener Hohlspiegel 3 Zoll im Durchschnitt sämtlich belegt. i) 12 Stück verschiedentlich geschliffener Gläser, darunter sich ein grünes und 2 ovale befinden, und endlich k) ein Polyhedron nebst einem noch nicht zu End bebrachten Microscopio.“

16. Dezember 1730 (Cod. Ms. Uffenbach 13//IV, S. 83-85) und 29. Februar 1732 (Cod. Ms. Uffenbach 13/IV, S. 496-499).

830 Lebensdaten unbekannt.

Zwischen Kinet und Uffenbach herrschte zwischen 1726 und 1735 ein reger Briefverkehr, vgl. u.a. die zwölf Briefe in: Cod. Ms. Uffenbach 20/II, S. 127-155, in denen mehrfach Drehbänke, Schleifmaschinen, Pumpen und Blasebälge thematisiert werden.

Auch zwischen Kanz und Uffenbach gab es einen regen Briefverkehr zwischen 1729 und 1741, vgl. Cod. Ms. Uffenbach 20/I, S. 492-508 und 20/II, S. 156-167. 
Vorbild, sowie sein hierzu gebautes Gestell. ${ }^{833}$ Schon 1733 hatte er einen Vortrag halten können mit dem Titel: „Nachricht wie verfertigte Glasschleiferschahlen auf neu gemachte Spindeln, oder Schleifmühlen so anzuordnen, daß sie vollkommen rund, und als ob sie darauf abgedrehet worden, laufen." $834 \mathrm{Um}$ sich auf das Referat vorbereiten zu können, konnte er wie immer auf seine Bibliothek und die Briefe Kinets zurückgreifen..$^{835}$

Neben optischen Geräten führte er die von ihm entwickelten oder erworbenen Sonnenuhren den Mitgliedern vor, so eine horizontale Gartensonnenuhr in Form einer antiken Vase, auf der er diverse Schlangen, Kröten und Eidechsen als Verzierung angebracht und den Stundenzeiger als eine sich in die Höhe reckende, züngelnde Schlange aus Eisen gestaltet hatte. ${ }^{836}$ Eine weitere von ihm gebaute horizontale Sonnenuhr in Form eines stehenden Cupidos mit einer Schreibtafel stellte er am 4. April 1737 vor. ${ }^{837}$ Eine gerade erworbene „Universalsonnenuhr“, die der Astronom Johann Beyer (1673-1751) in Hamburg als eine Halbhohlkugel angefertigt und ihm mit einer gedruckten Beschreibung verkauft hatte, war ein Objekt, das er am 9. März 1736 in seinem Haus der Gesellschaft vorstellte. ${ }^{838}$

Uffenbach hat sich nicht nur aus eigenem Interesse und innerhalb der Gesellschaft mit der Astronomie intensiv auseinandersetzt, sondern war auch außerhalb ein angesehener Ansprechpartner. So verlas er in den Sitzungen am 4.

4. April 1737, Cod. Ms. Uffenbach 13/V, S. 680. Das Fernrohr kann in der Inventarliste der Uffenbachischen Geräte nicht nachgewiesen werden, wahrscheinlich hat der Erbauer es weggegeben.

10. Juli 1733, Cod. Ms. Uffenbach 13/V, S. 140-155 mit zwei eigenhändigen Zeichnungen. Vgl. Cod. Ms. Uffenbach 20/I, Bl. 506.

Johann Georg Leutmann, Neue Anmerckungen vom Glasschleifen, Wittenberg $1719\left(8^{\circ}\right.$ Bibl. Uff. 283); Johann Kunkel, Ars Vitraria, oder Glasmacherkunst, Frankfurt 1689 (4 Bibl. Uff. 369)

Neu-eröffnete Kunst- und Schatzkammer rarer und neuer Curiositäten, Hamburg 1702, p. 942 ( $8^{\circ}$ Bibl. Uff. 341); Johann Juncker, Dissertatio Inauguralis Chymico-Medica de calce viva, Halle 1733 (nicht in der Bibliothek Uffenbach).

Kinets Briefe s. o. Anm. 830.

10 Juli 1733. Eine Zeichnung der Sonnenuhr befindet sich als Randabbildung neben dem Text (Cod. Ms. Uffenbach 13/V, S. 158).

837 Cod. Ms. Uffenbach 13/V, S. 683-684 mit Zeichnung.

838 Im Verzeichnis der Bücher und Instrumente Uffenbachs (Cod. Ms. Uffenbach 47, p. 180v) heißt es zu diesem Instrument: „Eine universale Sonnen Uhr in einer halben Kugel zu Hamburg von Bayern verfertiget, in einem hölzernen schwarzen Gehäuse“; vgl. Meyerhöfer 1995, S. 143. 
Juli und am 10. August 1731 drei detaillierte Briefe nach Cleve mit Erläuterungen zum Bau und Einrichten von Sonnenuhren. ${ }^{839}$ Sie tragen die Überschriften:

„1. Sonnen Uhren auf sehr leichte und ganz mechanische Art überall zu machen und zwar erstlich von der Mittagslinie;

2. Große verticale Sonnenuhren nach mittag, oder dergleichen angränzenden gegenden leicht zu verzeichnen;

Große Sonnenuhren an senckelrechte Wände gegen abend und morgen zu verzeichnen.“

Insgesamt lässt sich über die Versuche Uffenbachs zur Astronomie, Gnomonik und deren Instrumente aussagen, dass er sich bei beiden sowohl als Theoretiker als auch als Praktiker auf diesen Gebieten beweisen konnte.

Neben den optischen und mechanischen Geräten, die zur astronomischen Beobachtung dienten, führte er die Teilnehmer auch in die Welt des Mikrokosmos ein. Mit den Mikroskopen unterschiedlicher Mechaniker, die sich in seiner Sammlung befanden, stellte er immer wieder Versuche an. Im August 1729 erklärte er am Mikroskop Versuche nach Louis Joblot (1645-1723) ${ }^{840}$, wobei er die Ergebnisse Joblots bei den Experimenten mit Pfeffer und Muskatblüten nicht nachvollziehen kann. ${ }^{841}$ Noch im selben Jahr zeigte er in seinem bei Dirk Metz (ca. 1674-1742) in Holland gekauften Mikroskop 842 ein von dem Pariser „Occulisten“843 John Thomas Woolhouse (1666-1734) erfundenes „Augenbürstchen“, welches ihm Johann Georg Kißner zu diesem Zweck gegeben hatte. ${ }^{844}$ Bei dieser Sitzung verglich er einige Mikroskope unterschiedlicher Optiker miteinander. Er legte dasselbe Augenbürstchen unter verschiedene

Cod. Ms. Uffenbach 13/IV, S. 367-388 und 413-421 mit mehreren eigenhändigen Zeichnungen. Die Entwürfe für die beiden Briefe befinden sich im Commercium Epistolicum (Cod. Ms. Uffenbach 20/II, B1. 104-124).

840 Louis Joblot, Description \& Usage de plusieurs nouveaux Microscopes, Paris $1718\left(4^{\circ}\right.$ Bibl. Uff. 24).

841 12. August 1729, Cod. Ms. Uffenbach 13/III, S. 233.

842 Vgl. Instrumenten-Inventar Nr. 100 (S. Anhang, S. 108-109): „Ein schmal längliches und roth ledernes Kästgen mit einem / holländischen Microscopio, zu vielerley Gebrauch, / zu Amsterdam von Dietrich Metz verfertiget.“

843 Augenarzt.

844 15. Dezember 1729, Cod. Ms. Uffenbach 13/III, S. 310-311 mit Zeichnung.

$\mathrm{Zu}$ „Augenbürstchen“ s. Busch 1830, S. 79: „Zum Scarificiren (= Schröpfen) der Augenlider bedienten sich die Aerzte des Alterthums eines Instrumentes von der Form eines kleinen Löffels, [...] Woolhouse empfahl zu diesem Zwecke ein Bürstchen (Augenbürste, Augenkratzer. S. Blepharoxystrum.) oder einen Pinsel aus den langen, stachelichten Spitzen der Gersten- oder Rockenähren [...].“ 
Mikroskope: eines von Edward Culpeper (1670-1737) aus London, ${ }^{845}$ eines von John Marshall (1663-1725) daselbst, ${ }^{846}$ und eines von Pieter van Musschenbroeck (1692-1761) aus Leiden. ${ }^{847}$ Dabei konnten die Mitglieder feststellen, dass das Mikroskop von Dirk Metz aus Amsterdam wegen der Schärfe das Beste war. ${ }^{848}$

Ein weiteres Gebiet, mit dem sich Uffenbach in der Gesellschaft intensiv beschäftigte, war die Druckgraphik. In insgesamt drei längeren Vorträgen führte er eine Entwicklungsgeschichte der Drucktechniken mit dem Titel „Uhrsprüngliche Historie der gesamten Bildkunst auf Papier“849 vor. Den ersten Vortrag, gehalten am 29. Februar 1732, widmete er dem Holz- oder Formschneiden als der ältesten Drucktechnik. ${ }^{850}$ Am 16. Mai 1732 folgte ein Zweiter über das Kupferstechen. ${ }^{851}$ Das dritte und letzte Referat datiert vom 4. Juli 1732 und behandelte die „Etzkunst“, das Radieren. ${ }^{852}$ Dabei konnte er wie schon zuvor auf seine umfangreiche Bibliothek und sein ansehnliches Kupferstichkabinett zurückgreifen. Er selbst schreibt hierzu: „Die weil nun vermuthet daß auch dieße Materie denen Anwesenden nicht unangenehm fallen mögte, indem jede Sätze mit Exempel derer Bilder erlaütern, und die Sachen selbsten aus meiner kleinen Bilder Versammlung darzeigen konte [...]." ${ }^{653}$

Schon 1728 bei der Zusammenkunft am 19. März im Hause Uffenbachs unterhielt man sich über den Ursprung des Holzschnitts. ${ }^{854}$ Der Hausherr legte dabei einige Beispiele vor, genannt sei hier „Neues Testament mit schonen Figuren 1523 Augsb. bey Hanß Schönberger fol.“855

Vgl. Instrumenten-Inventar Nr. 99 (S. Anhang, S. 108): „Ein dergl. [= Mikroskop aus Messing] kleineres, von Culpepper in London gemacht, nebst einem / ledernen Köcher, worinn das Glas zur Betrach= / tung des Umlaufs des Geblüts, verwahret ist. “

Vgl. Instrumenten-Inventar Nr. 90 (S. Anhang, S. 107): „Ein großes Microscopium nach Marshalls Art, mit blau / laccirten Röhren, auf einem schwarzen Kästgen, / worinn das Zugehör, wovon doch die Porte Objecte / nebst anderen Stücken fehlen.“

847 Das Mikroskop von Musschenbroeck läßt sich anhand des Inventars nicht identifizieren.

848 15. Dezember 1729, Cod. Ms. Uffenbach 13/III, S. 310-311.

Die vollständige Transkription befindet sich im Anhang, S. 163-200.

Cod. Ms. Uffenbach 13/IV, S. 503-516.

Cod. Ms. Uffenbach 13/IV, S. 553-573.

Cod. Ms. Uffenbach 13/IV, S. 591-604.

Cod. Ms. Uffenbach 13/IV, S. 503.

Cod. Ms. Uffenbach 13/II, S. 257.

Uffenbach meint hier: Das Buch des Neuen Testaments teutsch mit schoenen Figuren, Augsburg 1523, gedruckt bei Hans Schönsperger. Er hatte sich die Bibel Schönpergers aus der Bibliothek seines älteren Bruders Zacharias Conrad ausgeliehen, vgl. Uffenbach 1729, Bd. 1, S. 4, Nr. 17. 
Dass er sich schon vor seinen Referaten mit der Geschichte der graphischen Techniken auseinandergesetzt hat, bewies er auch am 9. Dezember 1729. Eberhard zeigte bei der Zusammenkunft in seinem Haus der Gesellschaft eine neue Art des Mehrfarbendrucks. Uffenbach betrachtete die gezeigten Vorlagen, äußerte kurz seine Vermutung, wie der Drucker vorgegangen sein könnte, und verwies auf seine geplanten Referate über die verschiedenen Druckverfahren. 856

Ein Jahr nachdem Uffenbach die Vorträge zur Geschichte der graphischen Künste abgeschlossen hatte, griff er das Thema anläßlich einer Ankündigung eines Kräuterbuches des Erfurter Arztes Johann Hieronymus Kniphof (17041763) nochmals auf und präsentierte am 10. Juli 1733 den Mitgliedern einen Probebogen des Buches (Abb. 37). ${ }^{857}$ Dies sollte in dem Erfurter Verlag von Johann Michael Funcke (1678-1749) erscheinen. ${ }^{858}$ 


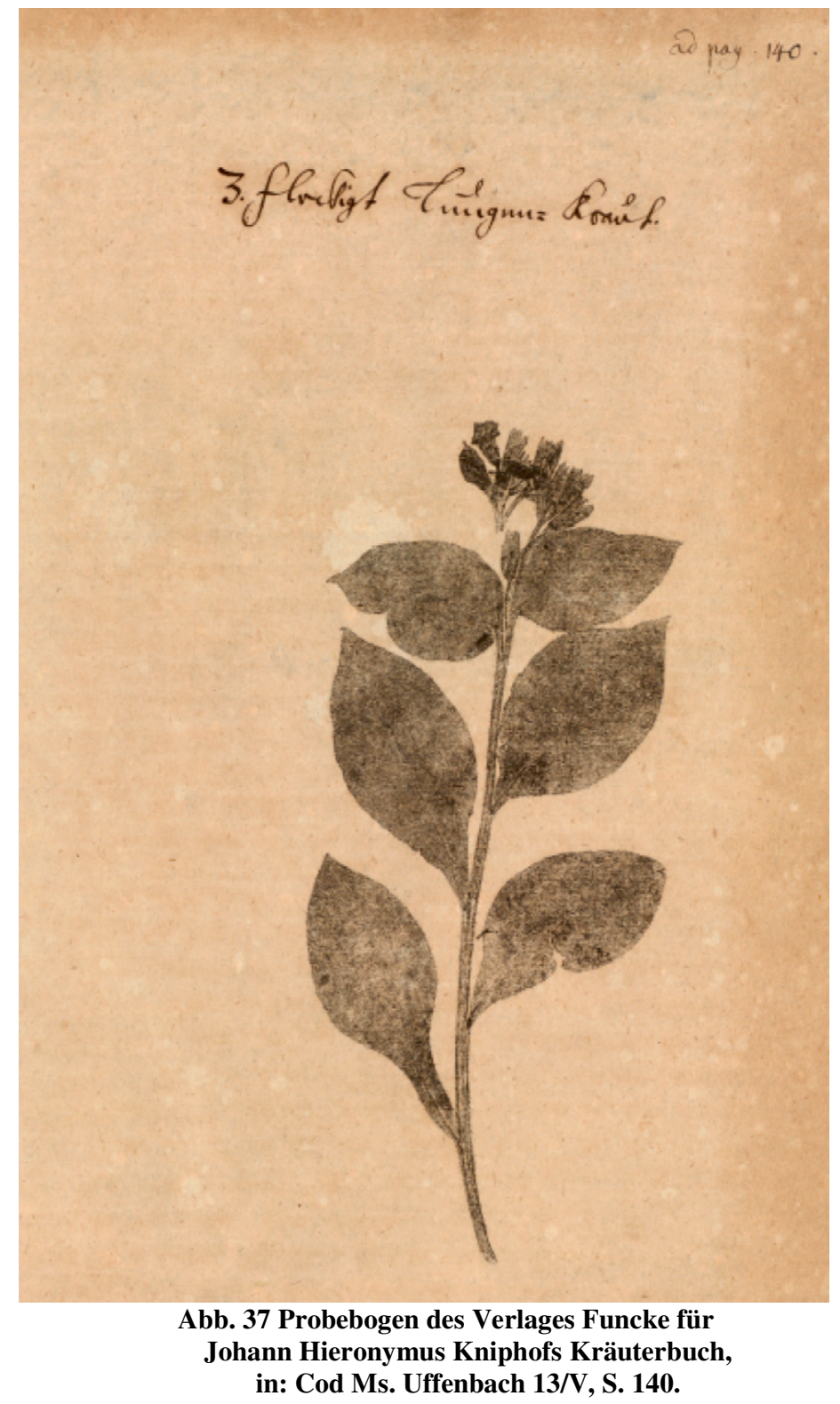

Laut Ankündigung des Verlages handelte es sich um ein neues Verfahren, Abbildungen der Kräuter zu drucken, indem man diese direkt in die Druckerfarben eintaucht und auf das Papier drückt. Uffenbach zitierte die gedruckte Anzeige der Kräuterbücher auszugsweise: „der erste tomus dieser Botanica in Originali, wovon bereits 200 Stück fertig, hält alle Officinali, der Verleger hat von seinem unverdroßenen Fleiße die Hoffnung daß diese Kraüter zu drucken, auf gleiche Art mit der Zeit seine Verbeßerung finden wird wie die Buchdruckerey nach und nach zu größerer Vollkommenheit gelangt ist, und weil die Figuren lauter Abdrucke von lebendigen Kraütern sind, dergleichen Buch noch keine Nation weder in einer von ihren kostbahrsten Bibliothecken noch auch in denen berühmtesten Buchläden aufweisen kan, und mit sehr großer Mühe und 
Kosten gemacht wird, so daß vielen zu kostbahr fallen will etliche hundert auf einmahl zu nehmen, so hat sich der Verleger resolvirt die in vorgemeldetem 1ten tomo befindliche Kraüter denen Liebhabern zu liebe einzel abzudrucken und zu verkaufen etc:"859 Uffenbach bezweifelte, dass Kniphof und Funcke dieses Verfahren entwickelt hätten und konnte dieses unter Zuhilfenahme der Reisebeschreibung von Balthasar de Monconys ${ }^{860}$ und den eigenen Eintragungen in seinem niederländischen Reisetagebuch ${ }^{861}$ beweisen. Monconys beschreibt in seinem eigenen Tagebuch von 1664 eine Vorstufe des Druckverfahrens mit Hilfe von Ruß: „Den 2. September lehrete mich bey dem Herrn Thevenot ein Däne nahmens Monsieur Walquenstein eine Art allerhand Kräuter auff Papier abzudrucken, und zwar also, daß man sie an dem Feuer oder Lichte einer Lampe anräuchern lässet, dann zwischen zwey Papiere legt, und mit einem Glätter oder Faltzbeine drüber hinstreichet." 862 In Uffenbachs niederländischem Reisetagebuch von 1716 heißt es: „Zuletzt zeigete man uns ein Buch in folio fingersdick, darinnen die rahrsten Kraüter, als wenn sie lebeten, oder auf das accurateste in Kupfer gestochen wären, zu sehen waren. Man sagte dabey daß solche Abdrucke in einer Geschwindigkeit und ohne Verletzung der Pflanze, wenn sie auch noch in der Erden stünden, zu machen seyen. Denn man nehme nur ein gewißes Pulver streuete es auf die Pflanze und drucke sie ganz sachte auf das Papier so stellete sich die Figur auf das accurateste dar, so daß sich auch die allerzartesten Fibrae ordentlich zeigeten.“ 863

Er versprach den Anwesenden, dass er bei einem späteren Treffen in seinem Hause das Druckverfahren selbst vorführen werde. Um hinter das Geheimnis des Verfahrens zu kommen, benötigte Uffenbach ein knappes Jahr und führte schließlich am 28. Mai 1734 die Ergebnisse seiner Versuche vor. ${ }^{864}$ Dabei griff er nochmals die Urheberschaft der Erfindung Kniphofs auf und verwarf sie vollends. Dabei kamen ihm der Wolfenbütteler Arzt Franz Ernst Brückmann (1697-1753) und der Kasseler Professor Heinrich Ludwig Muth mit ihren schriftlichen Äußerungen zu dieser mutmaßlichen Erfindung zu Hilfe. Uffenbach zitierte die

859 Cod. Ms. Uffenbach 13/V, S. 139-140, s. Anhang S. 501.

860 Balthasar de Monconys, Voyages, 4 Bde., Paris 1695 (8 Bibl. Uff. 456-459).

861 Vgl. Uffenbach, Reisdiarium, Cod. Ms. Uffenbach 25/III, S. 363 (Kabinett des Professors Herman in Leiden).

862 Balthasar de Monconys, Des Herrn de Monconys Beschreibung seiner Reisen, übersetzt von Christian Juncker, Leipzig 1697, S. 880 (4 Bibl. Uff. 404).

Balthasar de Monconys (1611-1665).

Melchisedech Thevenot (1620-1692).

Vgl. Cod. Ms. Uffenbach 29/III, S. 363 (Cabinet des Professors Herman in Leiden).

Cod. Ms. Uffenbach 13/V, S. 310-315, s. Anhang, S. 202-206. 
wichtigsten technischen Anweisungen aus einem gedruckten Brief von Brückmann und zeigte danach seine eigenen Versuche mit der Materie, ${ }^{865}$ die er ausführlich beschreibt und kommentiert (Abb. 38). Dabei stellte er fest, dass dieses Druckverfahren sich nur für Kräuter eignet, „die rauh und nervigt sind“"866, während ,glatte und polirte Blätter“867 sich nicht oder nur wenig eignen, da sie wenig Binnenstrukturen wie Blattadern oder eine raue Oberfläche aufweisen.

865 Vgl. Cod. Ms. Uffenbach 13/V, S. 313. Es handelt sich hierbei um einen eingebundene Seite mit acht verschiedenen aufgedruckten Pflanzenblättern in drei verschiedenen Farben (olivgrün, rotbraun und dunkelgrün) von Uffenbachs Hand.

866 Cod. Ms. Uffenbach 13/V, S. 315, s. Anhang S. 506.

867 Cod. Ms. Uffenbach 13/V, S. 314, s. Anhang S. 505. 


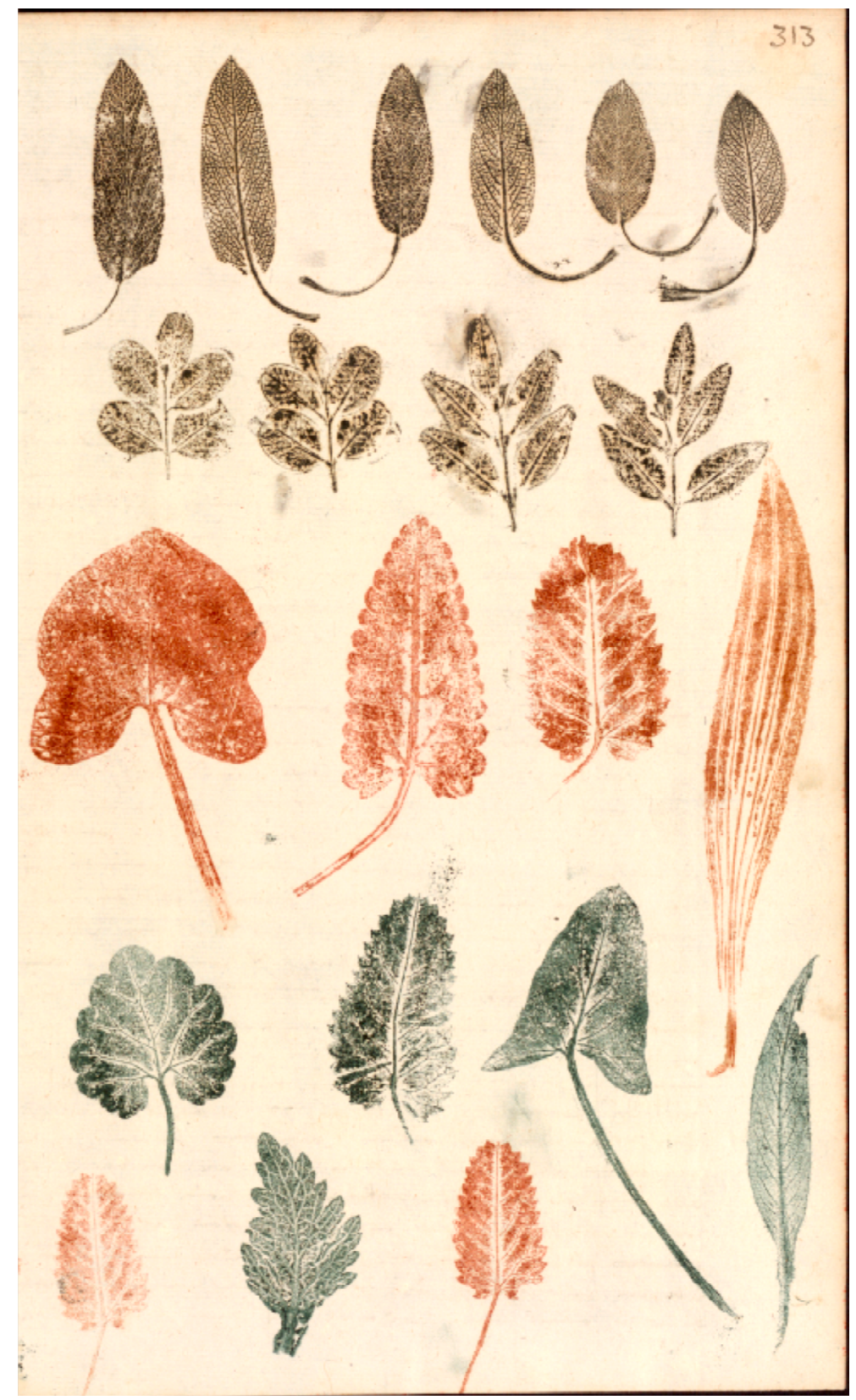

Abb. 38 Uffenbachs eigene Versuche mit dem Naturdruckverfahren in: Cod. Ms. Uffenbach 13/V, S. 313

Aber nicht nur mit dem Direktdruck machte Uffenbach eigene Versuche sondern auch im Anfertigen von Kupferstichen. Eine der ersten Kupferplatten, die er 1723 arbeitete, war sein Musikalienexlibris (Abb. 39). ${ }^{868}$ 


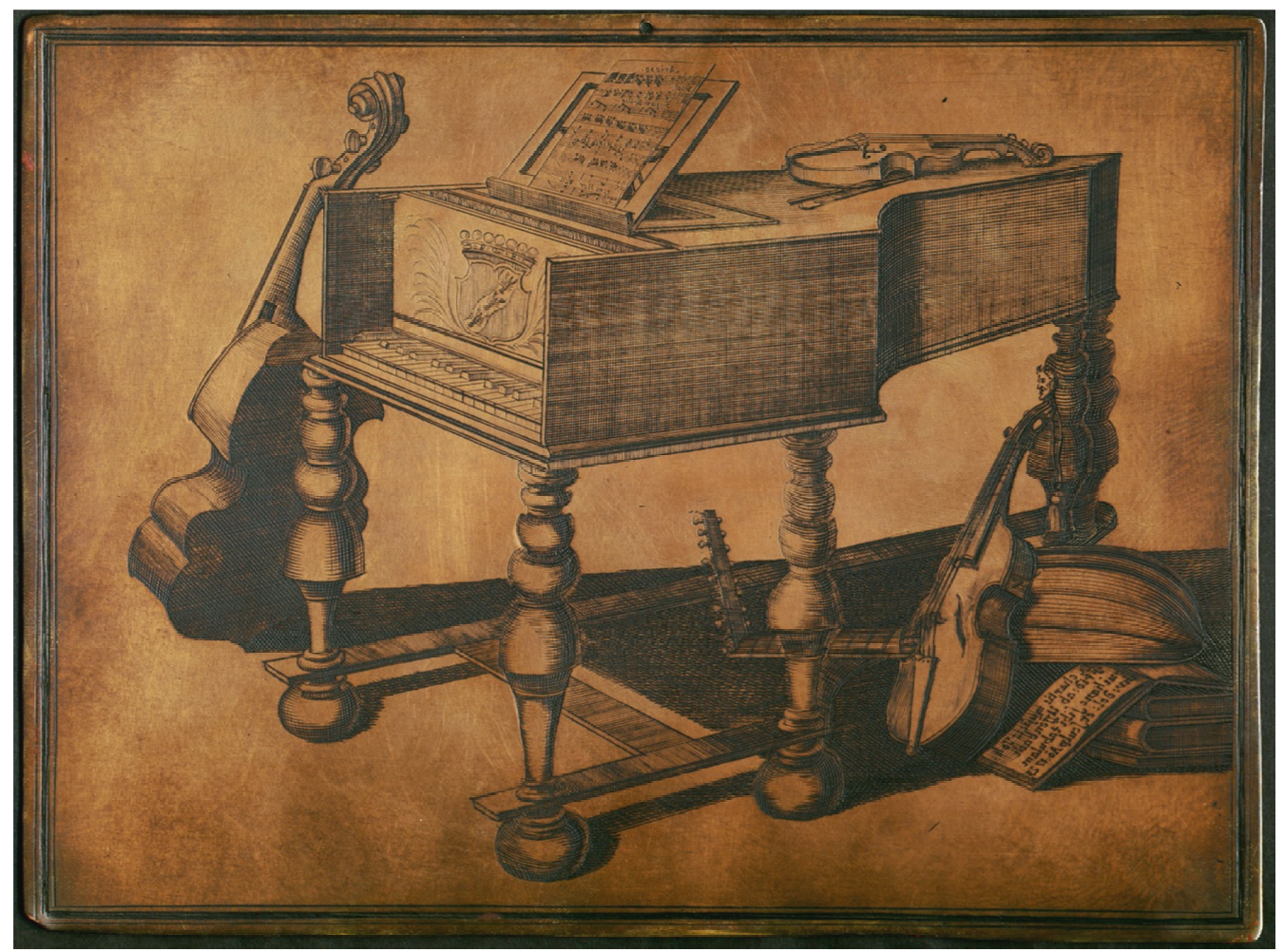

Abb. 39 Das eigene Musikalienexlibris von Uffenbach selbst gestochen Kunstsammlung der Universität Göttingen Inv.Nr. DP 10

In einem Schreiben seines langjährigen Nürnberger Briefpartners, des Kaufmanns und Sammlers Johann Daniel Geysel ${ }^{869}$, heißt es: ,[...] zu der neüen Liebhaberey des Kupfferstechens gratulire herzl, und hat mir die Probe recht wohlgefallen; Wo Sie hierinn fortfahren, zweifle nicht, daß Sie à grand Pas zu der Perfection kommen sollen p.“870 Allerdings schreibt Geysel auch: „Darff ich indessen so frey seyn, Ihnen meine Gedancken davon zu eröfnen, so kan ich nicht umhin, zu welchen daß so viel aus dem Abdruck ersehe, so sind Sie noch nicht gewohnt, durch den Spiegel auf die Platte zu zeichnen, um den Umriß zu machen, sondern bedienen sich noch der gemeinen Art der Kupfferstecher nemlich des sogenannten Ciligirens. "871 Uffenbach hatte Geysel einen Abdruck von der Platte geschickt und Geysel bemerkte sofort den Anfängerfehler der Seitenverkehrung, den Uffenbach gemacht hatte.

Lebensdaten unbekannt.

Kunstsammlung der Georg-August-Universität Göttingen, Inv. Nr. DP 10.

870 Cod. Ms. Uffenbach 20 II, B1. 405v, s. Anhang, S. 248.

Die beiden kannten sich von der Grand Tour Uffenbach durch Italien, vgl. Cod. Ms. Uffenbach 29/II, S. 354 und 29/III, S. 574.

871 Cod. Ms. Uffenbach 20 II, B1. 405v, s. Anhang, S. 248. 
Dieser Fehler unterlief ihm 1727 nicht mehr. Am 19. Dezember des Jahres zeigte er der wissenschaftlichen Gesellschaft das große Exlibris, das er für seinen älteren Bruder Zacharias Conrad entworfen und angefertigt hatte. ${ }^{872}$ Er schreibt im Protokollband: „Dieweil ich auch schließlich bey gegenwärtiger Versamlung meine verwichen zu Stande gebrachte Arbeit, so eine in Kupfer gebrachte Vorstellungen meines ältern Bruders Bibliotheque ist, vorzeigen, und die Abtrucke denen mitheilen wollen, als habe einen derer auch alhier beyzufügen nicht vor unschicklich erachtet (Abb. 41 und 43). ${ }^{873}$ Hier, wie auch bei den beiden weiteren Exlibris (Abb. 40 und 42) mit je einer Ansicht der Bibliothek des Bruders, sind die Abzüge von den Druckplatten seitenrichtig, da die Überschriften über den Abteilungen der Bibliothek zu lesen sind. ${ }^{874}$ Eines dieser beiden anderen Exlibris führte er am 3. Februar 1730 vor. ${ }^{875}$

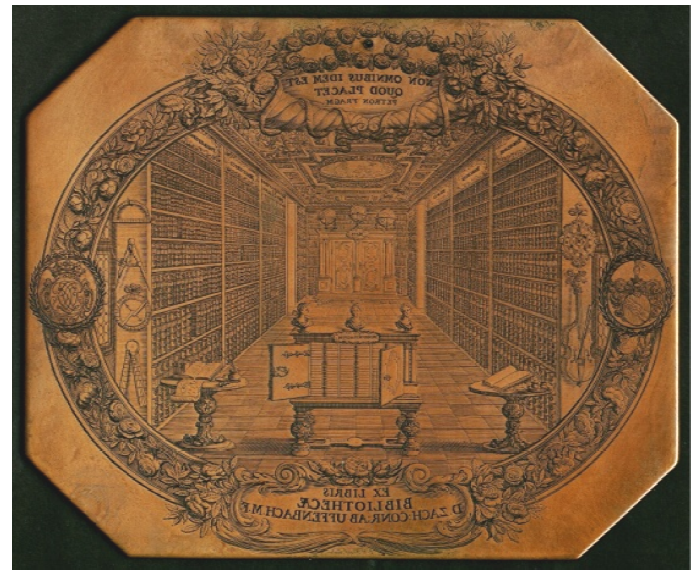

Abb. 40 Das kleine Exlibris von Zacharias Conrad von Uffenbach, Kunstsammlung der Universität, Göttingen Inv.Nr. DP 8, $68 \times 85$ mm

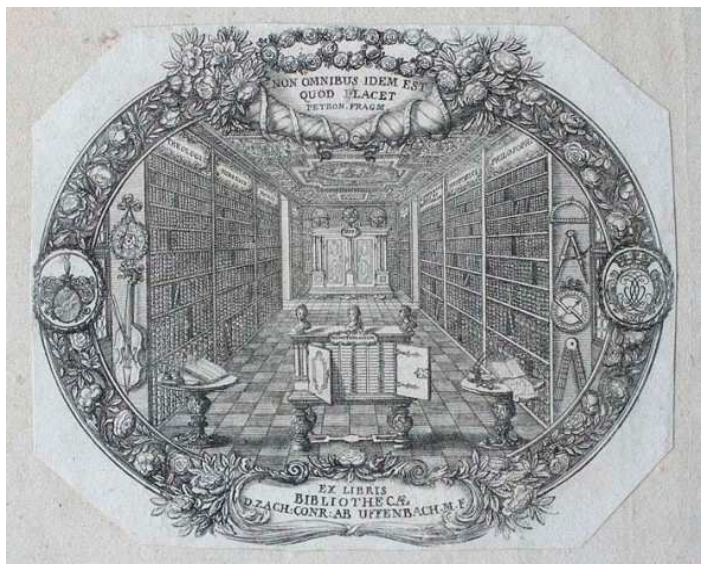

Abb. 41 Abzug des großen Exlibris von Zacharias Conrad von Uffenbach, in: Cod. Ms. Uffenbach 13/II, S. 125

872 Kunstsammlung der der Georg-August-Universität Göttingen, Inv. Nr. DP . 6.

873 Cod. Ms. Uffenbach 13/II, S. 125.

Die Abbildung ist auf S. 125 unten aufgeklebt. Es handelt sich hierbei um das sogenannte große Kupfer der Bibliothek von Zacharias Conrad von Uffenbach: Fratri carissim. ca qua potuit manu deliniavit et sculps Germanus I. F. ab U. 1727. 


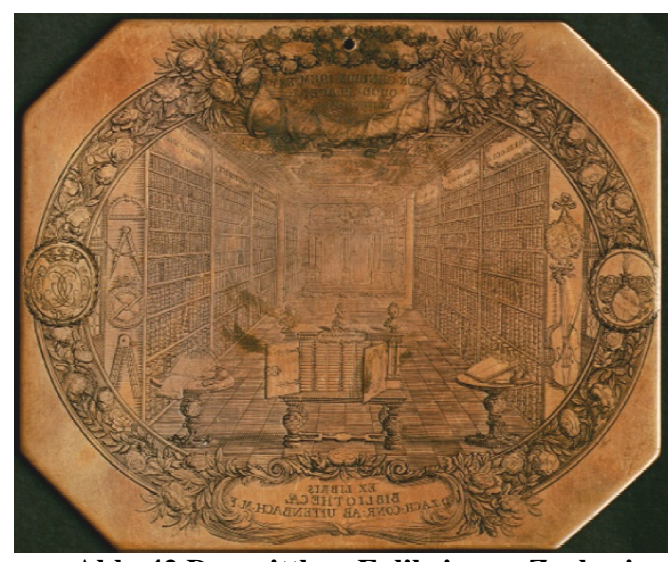

Abb. 42 Das mittlere Exlibris von Zacharias Conrad von Uffenbach, Kunstsammlung der Universität Göttingen Inv.Nr. DP 89, $85 \times 102 \mathrm{~mm}$

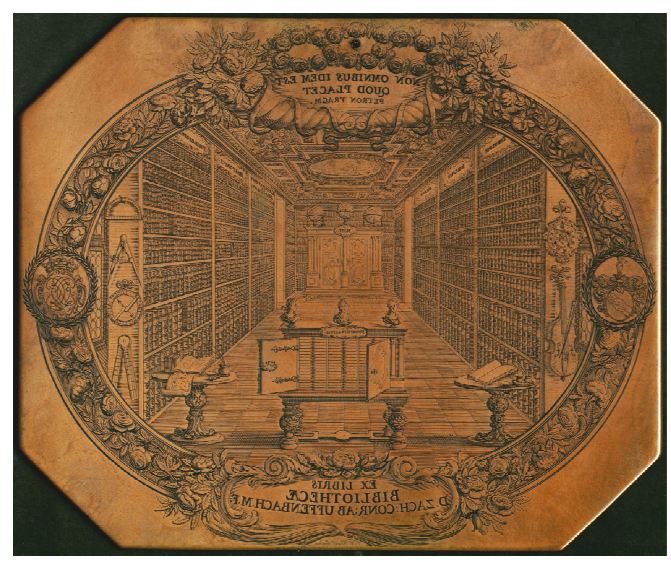

Abb. 43 Das große Exlibris von Zacharias Conrad von Uffenbach, Kunstsammlung der Universität Göttingen Inv.Nr. DP 6, $127 \times 154 \mathrm{~mm}$

Ein weiteres Thema der Gesellschaft waren die verschiedenen Techniken und Arbeitsweisen der bildenden Künste: Bei nahezu jeder Sitzung wurden Rezepte für Firnisse, Farben, Lacke, Tinten, Malgründe etc. ausgetauscht und wurden von den Mitgliedern selbst erprobt. ${ }^{876}$ Bei einem Referat über die Versuche mit dem Verhalten von Bleiweiß im Winter, wobei Uffenbach auf die zu ihrer Zeit bekannte Wachsbossiererin Anna Maria Braun, geb. Pfründt (1642-1713) und ihre speziellen Verfahren zu sprechen kam: „War die Versamlung unserer gewöhnlichen Gesellschaft bey H Diesterweg, woselbst ich etwas zur Betrachtung darlegete welches das vorige Mahl $\mathrm{zu}$ thun vergessen hatte, obsolchen gleich damahlen bey die Hand gestellet. Ich hatte nehmlich bey dem Anbrechen der verwichenen harten Kälte mir vorgenommen etwas Bleyweis mit Waßer auf einem Steine klahr abzureiben, und dieses hernach recht harte durchfriehren zu lassen, um es künftig bey vorkommender Wachspoussier Arbeit nach Angebung eines verständigen Künstlers zu dem Färben des Wachses zu gebrauchen, und besagte Materie dadurch vor der gelben Farbe, die sie mit der Zeit insgemein anziehet, zu bewahren, als welchen Kunstgriff die ehedeßen alhier berühmt gewesene Wachspoussiererin Braunin im Brauch gehabt, und dadurch den Bestand ihres weisen und fleischfarben Wachses erhalten haben soll."877 Bei derselben Zusammenkunft erklärte Konrad Hieronymus Eberhard die Zubereitung des gebrannten Beinschwarz, einer Farbe, die auf ähnliche Weise hergestellt wird, wie das oben erwähnte Bleiweiß.

Vgl. den Versuch mit Bleiweiß, den Uffenbach 1734 den Mitgliedern erklärte, s. Anhang, S. 295-297.)

877 Cod. Ms. Uffenbach 13/V, S. 248-249. 
Uffenbach hielt am 13. März 1733 einen Referat über einen Sarg, der bei Rüsselsheim vom Main freigeschwemmt worden war, und den er anfänglich als römisch oder heidnisch einstufte, jetzt aber doch für christlich. Der Aufsatz trägt den Titel: „Beschreibung eines steinernen Todten-Sargs bey Rüsselheim am Mayn. “878 Die wissenschaftliche Vorgehensweise Uffenbachs kann anhand dieses Referates exemplarisch aufgezeigt werden. Er macht genaue Ortsangaben und Fundumstände, zieht einen Vergleich mit zwei Sandsteinsärgen, die er auf seiner Fahrt durch England 1710 gesehen hatte, und datiert aufgrund dieser Analyse den Rüsselsheimer Sarg als christlich. Anschließend hielt er einen längeren Exkurs über die Bestattungsgewohnheiten im Mittelalter und beschrieb Bestattungsgewohnheiten in Luft, Erde und Wasser verschiedener Völker zu verschiedenen Zeiten und erwähnte in diesem Zusammenhang kurz den Kannibalismus. Seine Kenntnisse stützte er zum einen auf gedruckte Reisebeschreibungen, ${ }^{879}$ zum andern auf die Schriften der Antike.

In seinen „Nebenarbeiten“, wie Uffenbach sie immer wieder nennt, beschäftigte er sich mit verschiedenen handwerklichen Tätigkeiten. Eine solche Nebenarbeit war die im 18. Jahrhundert beliebte Bearbeitung des Panzers von Schildkröten. Er zeigte in den Sitzungen, die in seinem Hause stattfanden, immer wieder von ihm erworbene oder selbst gepresste und derartige gedrechselte Arbeiten. Zu diesem Zweck besaß Uffenbach „Eine grosse und eine kleine zur Bearbeitung des Schildkrots stark von Eisen verfertigte Presse." ${ }^{880}$

Am 3. Dezember 1728 führte er einen ,in Holland verfertigter, und mit einer schiltgrottenen Hülse überaus künstlich überzogener Lauffer Stock“ vor, den er auf der letzten Frankfurter Messe erworben hatte, und beschreibt ihn im Protokoll ausführlich, wobei er seine eigenen Kenntnisse der Bearbeitung einfließen ließ. ${ }^{881}$ Als weitere Objekte präsentierte er am 18. März 1729 ein Gesangbuch, dessen Vorder- und Rückseite er mit einer Schildkrötplatte versehen hatte, die für ihn von dem Frankfurter Goldschmied Harter ${ }^{882}$ montiert wurde; 883 und am 28. Mai 1734 umgebende Luft-Kreys, Nürnberg 1680 (4 Bibl. Uff. 367).

880 Die Pressen werden als Nr. 161 im Auktionskatalog von 1771 aufgeführt, allerdings in der Auktion nicht aufgerufen. Auch in der Auktion von 1775 tauchen sie nicht mehr auf. Vgl. Uffenbach 1771 S. 61, Uffenbach 1775 und die Gegenschreiberbücher(s. Anhang, S, 24). Cod. Ms. Uffenbach 13/III, S. 28-30. Der vollständige Text befindet sich als Transkription im Anhang, S. 293-294.

882 Lebensdaten unbekannt.

883 Cod. Ms. Uffenbach 13/III, S. 161.
} 
einen Toilettespiegel „mit Schildgrottenem Rahmen“, den er wegen seiner feinen Arbeit daran mit Stolz zeigte; 884 und am 3. Dezember 1734 zwei von ihm aus Schildkrötenpanzer getriebene Spielteller mit Silbereinlegearbeiten ${ }^{885}$ und schließlich am 3. Juli 1739 einen Stockknauf aus Perlmutt und Schildkröt mit Goldeinlegearbeiten. ${ }^{886}$

Allerdings ist er nicht nur der stolze Besitzer und Amateur in der Bearbeitung, sondern zeigt erneut hier sein wissenschaftliches Interesse am Material und an der entsprechenden Bearbeitungstechnik. In zwei längeren Vorträgen ging es ihm zum einen um die naturwissenschaftliche Beschreibung der Schildkröten, zum anderen um die Nutzung und Bearbeitung des Panzers beim Drechseln und Pressen. ${ }^{887}$ Die Manuskripte der Vorträge tragen die Überschriften „Historische Beschreibung derer Schildkrotten“888, gehalten am 28. Oktober 1735, und „Fortgesetzte Nachricht von Schildgrotten“889, gehalten am 9. März 1736. Das Thema beschäftigte ihn aber schon länger. Am 17. Januar 1727 erklärte er ein erstes Mal die Beschaffenheit von Schildkrötenpanzern und der darüber gespannten Haut. ${ }^{890}$ Im September 1731 hatte Uffenbach eine Reise nach Mannheim unternommen, um bei dem Mannheimer Hofschreiner Franz Zeller ${ }^{891}$ seine Kenntnisse in der Bearbeitung von Schildkrötenpanzern zu verfeinern. ${ }^{892}$ Seine dortigen Erlebnisse und die Künste Zellers trug er am 29. November 1731 der Gesellschaft vor. ${ }^{893}$ Auch wenn andere Mitglieder, wie der Materialienhändler Johann Friedrich Ettling am 5. März 1734, Schildkrötenpanzer zeigten, die dieser aus Venedig zugesendet bekommen hatte, konnte Uffenbach sein Fachwissen beitragen. An diesem Abend erklärte er der Runde den Unterschied zwischen Wasser- und Landschildkröten und zwischen europäischen und außereuropäischen. 894

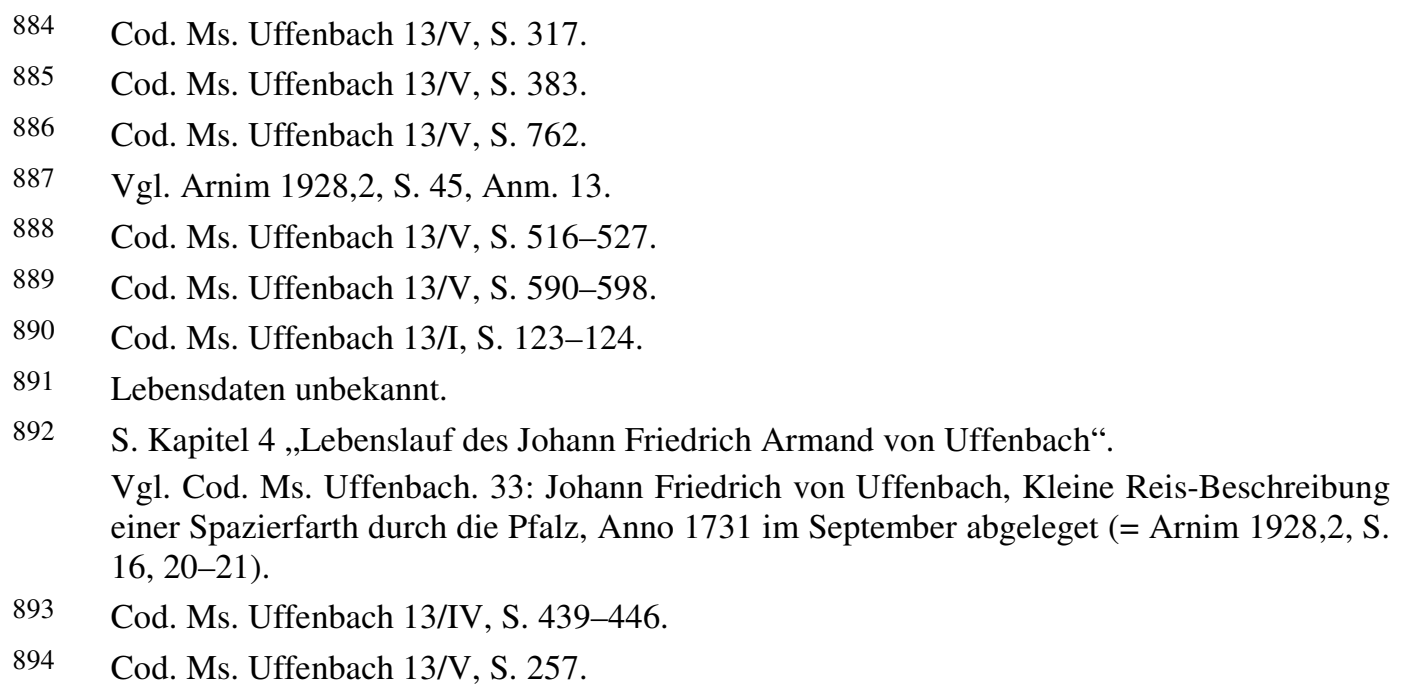


Eine weitere „Nebenarbeit“ war die Beschäftigung mit Prinzmetall, einer Legierung ,aus sechs Theilen Kupffer und einem Theile Zinn“.895 Prinzmetall diente im Kunsthandwerk als preiswerte Alternative zu Gold. Kennengelernt hatte es Uffenbach bei dem Gesellschaftstreffen bei Albert Adolf Diesterweg am 11. Februar 1729, als dieser Prinzmetall vorgeführt und ein Rezept zur Verfügung gestellt hatte. ${ }^{896}$ Uffenbach experimentierte unter Anleitung eines früheren Besuchers der Gesellschaft ${ }^{897}$ mit Namen Schloßer ${ }^{898}$ mit der Legierung und ihrer Verarbeitung und konnte eineinhalb Jahre später, am 8. Dezember 1730, eine von ihm angefertigte Tabaksdose vorführen, bei der die Zarge aus Prinzmetall gefertigt war, Deckel und Boden bestanden aus Perlmutt. ${ }^{899}$ Zwei Wochen später, am 22. Dezember 1730, als das Treffen im Hause Diesterwegs stattfand, präsentierte Uffenbach einen von ihm gegossenen und ziselierten Stockknauf.900 Auch bei dieser Nebenarbeit handelt er nach dem Grundsatz der Gesellschaft, die Dinge theoretisch und praktisch zu ergründen und die Ergebnisse den Mitgliedern $\mathrm{zu}$ zeigen und zu erklären, was man bereits bei seiner Beschäftigung mit Schildkrötenpanzern beobachten konnte.

Uffenbach beschäftigte sich ebenfalls mit dem im 18. Jahrhundert sehr beliebten Drechseln von Holz und Elfenbein. Zu diesem Zwecke besaß er „Eine vollständige mit allen dazu gehörigen Instrumenten aufs reichlichste versehene und vollkommen unbeschädigte Drehbank“ und „Eine Bassig- und OvalDrehbank, bey welcher 7 meßingerne und 5 stählerne Patronen, desgleichen 2 meßingerne Schraubenköpf, nebst 29 Stück dazu gehörigen Stahl sich befinden."901 Diese beiden Drehbänke hatte er in seinem Haus in einer nicht beheizbaren Kammer untergebracht, wo er sie der Gesellschaft am 3. Februar 1730 vorführte und detailliert anhand des Buches „L'Art de Tourner“ von Charles

$\mathrm{Zu} \quad$ Prinzmetall

lexikon.de/index.html?c=blaettern\&id=261526\&bandnummer=29\&seitenzahl=0281\&suppl ement $=0 \&$ dateiformat=1\%27) vom 20.09.2016 = Zedler, Bd.29 (Pr - Pz), Sp. 535.

896

897

898

899

900

901

Cod. Ms. Uffenbach 13/III, S. 109.

15. Dezember 1729, Cod. Ms. Uffenbach 13/III, S. 306-339.

Vornamen und Lebensdaten unbekannt.

Cod. Ms. Uffenbach 13/IV, S. 72.

Cod. Ms. Uffenbach 13/IV, S. 121.

Noch 1762 wollte er über seinen in Amsterdam lebenden Kommissionär Johann Christian Kaller eine weitere Drehbank erwerben lassen (Cod. Ms. Uffenbach 20/II, p. 384, s. Transkription im Anhang, S. 224).

Beide Drechselbänke wurden 1771 als Nr. 159 und Nr. 160 zur Auktion gebracht; vgl.: Uffenbach 1771, S. 61 und Gegenschreiberbuch 1771, S. 61, (s. Anhang, S. 24). 
Plumier (1646-1704) erklärte. ${ }^{902}$ Außerdem präsentierte er Gegenstände, die er selbst gedrechselt hatte. Am 4. April 1737 zeigte er das Buch „40 Kunst-Stücke im Drehen“ des Regensburger Silber- und Elfenbeindrechslers und Künstlers Johann Martin Teuber (tätig um 1727-1740), das von dessen Meisterstücken handelt. ${ }^{903}$ Am 14. März 1738 konnte er schließlich ,,zwei ovale Elfenbeinplatten für Tabacsdosen und ein elfenbeinernes Zahnstocherbüchsgen“904, welche er im selben Jahr in Frankfurt von Teuber gekauft hatte, der Gesellschaft vorführen. Teuber erwähnte beim Kauf auch eine spezielle Art des Drechselns, um damit drei-, vier- oder sechseckige Säulen auf einer normalen Drehbank zu drehen, was Uffenbach so lange beschäftigte, bis er mit Hilfe eines anderen Frankfurter Drechslers der Sache auf den Grund gekommen war und in der Folge den Mitgliedern erklären konnte (Abb. 44). ${ }^{905}$

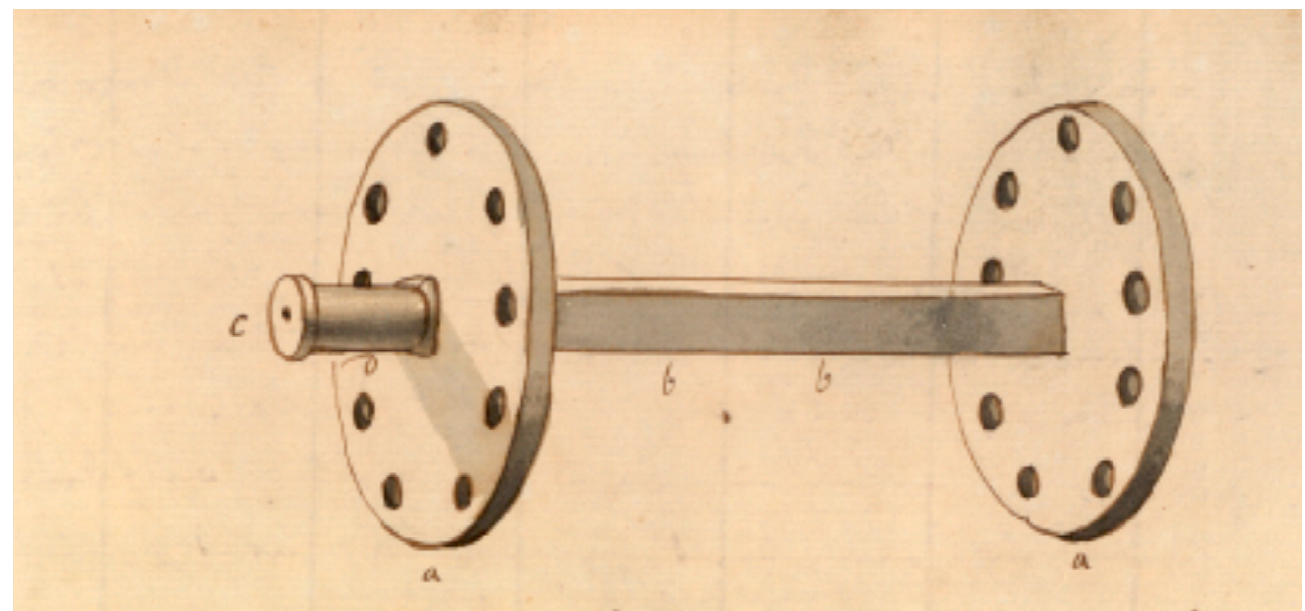

Abb. 44 Uffenbachs Zeichnung zu seinem Vortrag über das Drechseln von ,eckigen Säulen“ in: Cod. Ms. Uffenbach 13/V, S. 718

Für seine Tätigkeit als Drechsler aber besonders für diejenige als Architekt ${ }^{906}$ versuchte Uffenbach, ein „Alphabetisches Verzeichnüs derer ausländischen Bäume und Hölzer von allerley Arten so viel derer aus denen Schriften gelehrter Kräuter Verständigen wie auch Reisebeschreiber zu unserer Bekantschaft

902 Vgl. Cod. Ms. Uffenbach 13/III, S. 420-424, mit Zeichnungen der Maschine in der Kammer S. 421, und weiteren S. 423, S. 424.

Charles Plumier, L'Art de Tourner, ou de faire on perfection toutes sortes d'ouvrages au tour, Lyon 1701 ( $2^{\circ}$ Bibl. Uff. 293).

903 Johann Martin Teuber, 40 Kunst-Stücke im Drehen, Regensburg 1736 (4 Bibl. Uff. 603).

904 Vgl. Teubers Buch und Kupferstich (s.o.), dort Num. 15.

905 Vgl. Cod. Ms. Uffenbach 13/V, S. 717-718 mit Zeichnung.

906 S. Kapitel 4 ,Lebenslauf des Johann Friedrich Armand von Uffenbach“. 
gekommen und in entfernten Welttheilen als ASIA AFRICA und AMERICA anzutreffen seyn mögen. $\mathrm{Zu}$ gemein nützigen, vornehmlich aber technischen Gebrauch gesamlet und entworfen"907 anzulegen. Er legte es am 13. März 1733 den Mitgliedern vor.908 Das Manuskript war die Folge seines Versuchs, ein Kabinett mit ausländischen Hölzern anzulegen, das er der Gesellschaft ebenfalls zeigte. Da ihm dies im Laufe der Jahre, wie er vermerkt, zu teuer wurde - er hatte bis zu diesem Zeitpunkt nur 37 verschiedene Hölzer zusammengebracht - und einige Händler ihm Fälschungen verkauft hatten, beschränkte er sich auf das Anlegen eines beschreibenden Lexikons aller außereuropäischen Hölzer. Ein weiterer Grund, dass er ein Lexikon - also ein schriftliches Kabinett - angelegt hat, besteht darin, dass Uffenbach zur Vergegenwärtigung der Objekte nicht mehr das Original sondern nur noch die genaue Beschreibung benötigte. Er hatte 1729 das Buch „Nachricht von dem Holz-Cabinet welches anno 1729 in die Dresdenische Naturalien-Kammer geliefert worden" $" 909$ erworben, was ihn reizte, ein eigenes Kabinett von Hölzern anzufertigen, jedoch: „,...] weil aber gedachtes Cabinet [das von Dresden] und alle andere die bey Liebhabern auf meinen Reißen gesehen in nichts anderst als inheimischen [!] Höltzern bestanden, so fiele mein Lusten vortzüglich auf fremde Gattungen worin aber ohneracht aller meiner großen Bemühung niehmahlen habe zu stande kommen können, angesehen eine solche Verwirrung in Nahmen, auch eine dergestaltige Unrichtigkeit und Unwißenheit darinnen überall ist, daß es schier eine Unmöglichkeit seyn will nur ein Register derer Arten Höltzer zu machen.“910 Allerdings scheint er das Projekt 1733, vier Jahre nach Beginn des Sammelns, schon wieder aufgegeben zu haben, da die Namen, Bezeichnungen und Beschreibungen in der von ihm benutzten Literatur falsch waren oder ein und dieselbe Holzsorte von verschiedenen Autoren mit unterschiedlichen Namen genannt werden.

Uffenbach hatte auf seinen Reisen immer wieder eingehend „Wassermaschinen“ studiert.911 Dass er sich mit dieser Materie theoretisch und praktisch beschäftigt hat, zeigt eine Vorführung eines Modells der Herrenhäuser

\footnotetext{
907 Cod. Ms. Uffenbach 40.

908 Cod. Ms. Uffenbach 13/V, S. 72-73.

909 Lignophilus (= Christian Clodius), Zuverläßige Nachricht von demjenigen Holtz-Cabinet, Welches am 3.Jenner dieses 1729. Jahres In Ihro Königl. Majestät in Pohlen und Churfl. Durchl. zu Sachsen Vortreffliche Naturalien-Cammer geliefert worden. Nebst einem Verzeichniß aller und ieder darinnen befindlichen Holtz-Arten, in Latein. und Teutscher Sprache., Dreßden und Leipzig, Im Hekelischen Buchladen, 1729 (8 Bibl. Uff. 403, ist aber an Cod.Ms.Uff.40 angebunden).

910 Cod. Ms. Uffenbach 13/V, S. 72-73.

911 Vgl. das Kapitel 4,,Lebenslauf des Johann Friedrich Armand von Uffenbach“.
} 
Wassermaschine am 15. Dezember 1729 vor der Gesellschaft. ${ }^{912}$ Es handelt sich um eine ausführliche Beschreibung der Pumpentechnik, die im Protokollband mit vier detaillierten Zeichnungen versehen ist, die Uffenbach nach den Originalen des Kurfürstlich Hannoverschen Hof-Architekten Johann Christian Böhm (16781730) eigenhändig angefertigt hatte (Abb. 26 und 27). Uffenbach verglich in seinem Vortrag die Herrenhäuser Fontaine mit denen von Marly, London, Meudon und Rom und kam zu dem Schluss, dass der Strahl in Hannover der größte wäre. ${ }^{913}$ Er führte die detaillierte Erläuterung der Herrenhäuser Wassermaschine am 3. Februar 1730 fort. ${ }^{914}$

Überblickt man die verschiedenen Gebiete, mit denen sich Johann Friedrich von Uffenbach beschäftigte, kann man feststellen, dass er nicht nur als Theoretiker arbeitete, sondern sich auch immer als Praktiker zeigte. Sowohl bei der Beschäftigung mit der Astronomie, als auch mit der Graphik, dem „Schilkrottpressen“, dem Drechseln und Ziselieren sehen wir ihn gleichermaßen als Theoretiker und Praktiker. Besonders bei der Astronomie und der Graphik wird dies deutlich. Auf der einen Seite die intensive Auseinandersetzung mit der Theorie - Geschichte der Astronomie und Geschichte der graphischen Künste auf der anderen Seite die praktische Umsetzung - eigene Himmelsbeobachtungen, darüber hinaus die Herstellung von optischen Linsen und eigene Versuche in den druckgraphischen Techniken bis hin zur Veröffentlichung von eigenhändig angefertigten Kupferstichen.

\subsubsection{Die Beiträge von Philipp Jacob Behaghel}

Der Kaufmann Philipp Jacob Behaghel wurde am 26. Juli 1688 in Frankfurt am Main geboren. Er und Johann Friedrich Armand von Uffenbach kannten sich schon von ihrer Schulzeit am Frankfurter Stadtgymnasium her. Behaghel entstammte einer aus Flandern eingewanderten Familie, die durch Tuch- und Spezereienhandel reich geworden war. Er selbst betrieb den Handel mit

913 Folgende Bücher hat Uffenbach benutzt: Jacob Leupold, Theatrum Machinarum Generale, Schau-Platz des Grundes Mechanischer Wissenschaften, Leipzig 1724 (2 Bibl. Uff. 251); Johann Friedrich Weidler, Tractatus de Machinis hydraulicis toto terrarum orbe maximis Marlyensi et Londinensi et aliis rarioribus similibus: In quo mensurae prope ipsas machinas notatae describuntur, et de viribus earum luculenter disseritur. Cum figuris aeri incisis, Wittenberg1728 (4 Bibl. Uff. 191:1). Bei der Lektüre des letztgenannten Buches stellte Uffenbach fest, dass die Herrenhäuser Fontaine keine Erwähnung findet, worüber er sich wundert, da sie die größte sei, die er kennen würde.

914 Vgl. Cod. Ms. Uffenbach 13/III, S. 403-418, mit eigenen Zeichnungen auf S. 406, 408, 409, 410, 413, 414, 416, 417a.
} 
Florettseiden- und Seidenwaren.915 Er verstarb am 6. August 1732 an einer Lähmung, die in den Protokollen der wissenschaftlichen Gesellschaft als „paralysis specialissima organi memoriae“ bezeichnet wird. ${ }^{916}$ Behaghel war verheiratet, der Name der Gattin und eventuelle Nachfahren sind nicht bekannt. Am 22. August 1732 hielt Uffenbach eine längere Trauerrede auf das Gründungsmitglied. 917

Behaghels Hauptgebiet innerhalb der wissenschaftlichen Gesellschaft waren Versuche und Vorführungen auf dem Gebiet der Luft- und Vakuumpumpen. Er besaß neben Pumpen eine ,,aus Holland überkommene und von Musschenbroek verfertigte Haucksbeeische Machinen, die Experimenten des Lichts und Electricität verschiedener Cörper betreffend."918

Als sich am 1. September 1726 die Mitglieder in seinem Haus trafen, führte er mit seiner Vakuumpumpe acht verschiedene Versuche durch, die die gesamte Sitzung dauerten und von Uffenbach genau protokolliert wurden. ${ }^{919}$ Zuerst erklärte Behaghel seine Vakuumpumpe unter Zuhilfenahme eines Werkes ${ }^{920}$ von Francis Hauksbee (ca.1666-1713), um danach das erste Experiment mit einer Porzellanschale voller Wasser vorzuführen. Es folgten die Versuche mit einer halbvollen Wasserkugel und der Lunge eines Ferkels. Sowohl die Wasserkugel als auch die Lunge implodierten, bei dem Versuch mit dem Wasser in der Schale konnte nichts beobachtet werden. Daraufhin zeigte er zwei Experimente mit lebenden Tieren, einer Maus und einem Sperber, die beide in der Vakuumpumpe

915 Mit Florettseide ist Seide gemeint, die aus den minderwertigen äußeren Fasern des Seidenkokons gewonnen wird: Vgl. Stichwort „Seide“, in: http://woerterbuchnetz.de/Meyers/?sigle=Meyers\&mode=Vernetzung\&lemid=IS08029\#XI S08029 vom 29.08.2016.

916 Cod. Ms. Uffenbach 13/IV, S. 120.

917 Cod. Ms. Uffenbach 13/IV, S. 611-622.

918 Cod. Ms. Uffenbach 13/II, S. 2f., mit einer Zeichnung Uffenbachs der Vakuumpumpe auf S. 3.

Vgl. Francis Haucksbee, Physico-Mechanical Experiments on various subjects, London 1709 (4 Bibl. Uff. 390) und: Willem Jacob Gravesande, Physices elementa Mathematica, Experimentis confirmata, T. I. II, Leiden 1720 (4 Bibl. Uff. 391 und 392), und: Pieter van Musschenbroeck, Pet epitome Elementorum Physico-Mathematicorum, Leiden 1726 ( $8^{\circ}$ Bibl. Uff. 167).

Willem Jacob Gravesande (1688-1742).

Pieter van Musschenbroeck (1692-1761).

919 Cod. Ms. Uffenbach 13/I, S. 7-13.

920 Vgl. das Buch: Francis Hauksbee, Physico-Mechanical Experiments on various Subjects, London 1709 (4 Bibl. Uff. 391 und 392). 
starben. ${ }^{921}$ Für die beiden letzten Versuche an diesem Abend legte Behaghel zuerst eine geöffnete Taschenuhr unter die Vakuumglocke. Die Uhr tickte im Vakuum weiter. Es folgte ein Versuch mit rotem Phosphor, wie ihn Hauksbee in seinem Buch beschreibt. Unter Lufteinfluss leuchtete der rote Phosphor unruhig, im Vakuum verstärkte sich die Leuchtkraft, umso mehr Luft aus der Vakuumglocke herausgezogen wurde. In den weiteren Sitzungen der Gesellschaft, die in den Räumlichkeiten Behaghels stattfanden, führte dieser immer wieder Versuche mit der Vakuumpumpe vor. 922

Am 29. Oktober 1728 erklärte Behaghel „Geräte zur Electritität der Cörper“923 und führte der Gesellschaft Versuche mit der Maschine nach Hauksbee vor. ${ }^{924}$ Diese Versuche setzte Behaghel in der Sitzung vom 28. Dezember 1729 fort. ${ }^{925}$

Ein Weiteres seiner Interessensgebiete war die Pflanzenkunde. Am 20. Dezember 1726 zeigte er einen von ihm angestellten Versuch, bei dem er Blumenzwiebeln in einer mit Wasser gefüllten Flasche im Zimmer zum Treiben gebracht hatte. ${ }^{926}$ Von ihm selbst gesammeltes Berg-Ruhrkraut (Gnaphalium montanum) führte er am 4. Juni 1728 vor, auf das sich in der Zwischenzeit Käfer gesetzt hatten, die den Blüten der Pflanze ähnlich sahen. ${ }^{927}$ Auch praxisbezogene Tipps wurden ausgetauscht: Einer, der am 29 Oktober 1728 besprochen wurde, war die Verwendung von Trester als Bodendünger.928 Der Anbau von Wein und die Düngung der Reben mit Horn wurden am 29. August 1729 diskutiert. ${ }^{929}$ Am

921 In der nächsten Sitzung am 20. Dezember 1726, die in seinem Haus stattfand, zeigte Behaghel den Mitgliedern den Sperber, den er in Spiritus eingelegt hatte (Cod. Ms. Uffenbach 13/I, S. 72).

922 20. Dezember 1726 (Cod. Ms. Uffenbach 13/I, S. 78); 31. Januar 1727 (Cod. Ms. Uffenbach 13/I, S. 136-139); 14. März 1727 (Cod. Ms. Uffenbach 13/I, S. 187-192); 18. Juli 1727 (Cod. Ms. Uffenbach 13/II, S. 2-6); 14. September 1727 (Cod. Ms. Uffenbach 13/II, S. 79-80); 19. Februar 1728 (Cod. Ms. Uffenbach 13/II, S. 207-212); 4. Juni 1728 (Cod. Ms. Uffenbach 13/II, S. 293-294); 17. Dezember 1728 (Cod. Ms. Uffenbach 13/III, S. 41-43); 18. Februar 1729 (Cod. Ms. Uffenbach 13/III, S. $120+123$ ); 1. April 1729 (Cod. Ms. Uffenbach 13/III, S. 175-177); 28. Dezember 1729 (Cod. Ms. Uffenbach 13/III, S. 350); 3. März 1730 Cod. Ms. Uffenbach 13/III, S. 430-436).

Cod. Ms. Uffenbach 13/II, S. 2.

924 Cod. Ms. Uffenbach 13/II, S. 2-4.

Pieter van Musschenbroek, Epitome Elementorum Physico-Mathematicorum, Leiden 1726 ( $8^{\circ}$ Bibl. Uff. 167). 
17. Dezember 1728 erklärte Behaghel die Wirkung von Frost auf Haselsträucher. 930

Daneben wurden auf seinen Sitzungen Rezepte für Farben ausgetauscht. So zeigte er am 20. Dezember 1726 der Gruppe eine rote Farbe, die das von der Kermeslaus gewonnene Karminrot nachahmt. ${ }^{931}$ Behaghel hatte die Farbe nach einem Rezept von Claude Boutet angefertigt. ${ }^{932}$ Am 31. Januar 1727 wurde das Gespräch über dieses Rezept noch einmal aufgenommen. ${ }^{933}$

Das Gebiet der Farben war erneut Thema am 9. Januar 1728, als Behaghel verschiedenfarbige Flüssigkeiten vermischte, um der Gesellschaft den Farbwechsel und die Farbversuche nach Christian Wolffs Buch „Allerhand nützliche Versuche, dadurch zu genauer Erkäntnis der Natur und Kunst der Weg gebahnet wird" vorzuführen. 934

Bei einem der letzten Treffen in seinem Haus, am 28. Dezember 1729, führte Behaghel seine Versuche zur „Laccierkunst“ vor. ${ }^{935}$

Fasst man seine Interessensgebiete zusammen, war Behaghel ein von der Physik Begeisterter. Das zeigen seine Versuche zur Elektrizität und zum Vakuum, aber auch das Experiment mit dem Farbwechsel bei der Vermischung von Flüssigkeiten.

\subsubsection{Die Beiträge von Albert Adolf Diesterweg}

Albert Adolf Diesterweg wurde 27. Februar 1681 in Siegen geboren und heiratete am 15. Juni 1705 Anna Christine Heeser (1681-1757). ${ }^{936}$ Er hatte nicht

Cod. Ms. Uffenbach 13/II, S. 38.

Cod. Ms. Uffenbach 13/I, S. 73.

Lebensdaten unbekannt.

Uffenbach, der sich für Farb- und Firnißrezepte interessierte, hatte zwei Ausgaben des Werkes: Traité de la peinture en migniature, aux Pastels \& autre, La Haye $1708\left(8^{\circ} \mathrm{Bibl}\right.$. Uff. 395) und Grundmäßige kurtze und sehr deutliche Anweisung zum Mignatur-Machen, o.O. 1702 (angebunden an $4^{\circ}$ Bibl. Uff. 425).

Cod. Ms. Uffenbach 13/I, S. 133.

Cod. Ms. Uffenbach 13/II, S. 133-135.

Christian Wolff, Allerhand nützliche Versuche, dadurch zu genauer Erkäntnis der Natur und Kunst der Weg gebahnet wird: Denen Liebhabern der Wahrheit mitgetheilet, 3 Bde., Halle 1721-23 ( $8^{\circ}$ Bibl. Uff. 347-349).

Uffenbach hatte in Halle bei Wolff studiert. Nachdem dieser 1723 an die Marburger Philipps-Universität wechseln musste, nahm Uffenbach u.a. wegen einer transportablen Camera obscura zweimal brieflich Kontakt mit ihm auf (Cod. Ms. Uffenbach 20/I, B1. 261265 und 511-512).

Cod. Ms. Uffenbach 13/III, S. 351. 
das Frankfurter Bürgerrecht, sondern besaß lediglich Beisassenschutz.937 In Frankfurt war er als Händler für Manufakturwaren tätig. ${ }^{938}$ Diesterweg war mit seiner Heimatstadt immer noch eng verbunden, so bestellte er um die Jahreswende 1728/29 für 500 Gulden zwei Feuerspritzen für Siegen, worüber er am 11. Februar 1729 der wissenschaftlichen Gesellschaft berichtete. ${ }^{939}$ Er verstarb in Frankfurt am Main im Jahre 1744.

Das Gründungsmitglied Diesterweg wurde von der Gesellschaft zum Schatzmeister bestimmt. Seine Aufgabe war es, am Ende eines jeden Jahres den Inhalt der Gesellschaftskasse zu überprüfen, in die die Mitglieder Strafgebühren einzahlen mussten, wenn sie zu spät kamen. Aus dieser Kasse wurden dann mittellose Wissenschaftler bezahlt, die die Gesellschaft besuchten. ${ }^{940}$

Wie der Schriftführer der wissenschaftlichen Gesellschaft, Johann Friedrich von Uffenbach, im ersten Protokollband vermerkt, hatte „H Diesterweg durch seinen besondern Schmelzofen sich das Feuer erwehlt.“941 Diesterweg führte in der allerersten Sitzung am 25. Oktober 1726 diesen Schmelzofen vor ${ }^{942}$, weshalb Uffenbach ihm das Element Feuer zuordnete. Allerdings kam Diesterweg nur noch einmal auf Schmelzöfen zu sprechen, als ein Brief des Schwarzenauer Mechanikers Johann Melchior Kinet ${ }^{943}$ in der Sitzung vom 22. August 1732 erörtert wurde. ${ }^{944}$

Dagegen war eines der Hauptgebiete Diesterwegs allgemein die Physik und hier besonders alles, was mit physikalischem Druck zu tun hatte. In mehreren Sitzungen führte er Versuche mit verschiedenen Pumpen vor, so am 30. Juli 1728

$936 \quad$ Vgl.: $\quad$ http://gedbas.genealogy.net/person/show/1136365435 und http://gedbas.genealogy.net/person/show/1136368771 vom 25.11.2016.

937 ISG Frankfurt am Main, Ratssuplikationen, Signatur 1.704, Bd. III. Dort sein Gesuch um Beisassenschutz.

Unter einem Beisassen versteht man einen Bürger einer Stadt mit eingeschränktem Bürgerrecht; vgl.: Justinian von Adlerflycht, Das Privatrecht der freien Stadt Frankfurt, In systematischer Ordnung vorgetragen, Frankfurt 1824, S. 11, §11, wo ausführlich der Beisassenschutz erörtert wird, und: http://drw-www.adw.uni-heidelberg.de/drwcgi/zeige?index=lemmata\&term=beisasse vom 14.03.2017.

938 Voelcker 1932, S. 116.

Nach Schmidt 1960, Sammlung Diesterweg (1767), besaß er eventuell ein eigenes Kabinett, da Hüsgen 1790, S. XIV eine Sammlung Diesterweg erwähnt.

939 Cod. Ms. Uffenbach 13/III, S. 46.

940 S. „Die Statuten der wissenschaftlichen Gesellschaft““, s. Anhang, S. 282.

941 Cod. Ms. Uffenbach 13/I, S. 40.

942 Cod. Ms. Uffenbach 13/I, S. 1-2.

943 Lebensdaten unbekannt.

944 Cod. Ms. Uffenbach 13/IV, S. 609. Hier am Rand auch die Bemerkung; „Vgl. Bd. I, pag. 2 über den selben Gegenstand.“ 
einen mit einer Wasserpumpe ${ }^{945}$ und beim Treffen am 11. Februar 1729 berichtete er neben der Bestellung der zwei Feuerspritzen für seine Heimatstadt Siegen anhand eines Modells über ein hölzernes Saug- und Hebewerk für Wasser. ${ }^{946}$

Für Johann Friedrich von Uffenbach waren die Ausführungen von Diesterweg zu Pumpen von Interesse, da er sich selbst mit dieser Technik auseinandersetzte. ${ }^{947}$

Ein weiteres Gebiet, mit dem sich Diesterweg intensiv beschäftigte, waren Barometer und Thermometer. Insgesamt viermal unterrichtet er die Gesellschaft über verschiedene Luftdruckmesser. ${ }^{948}$ So hält er beispielsweise am 25. März 1729 einen Vortrag mit dem Titel „Bewegungsgründe des Quecksilbers in denen Barometris“949 und am 27. März 1733 zitiert er aus Andreas Elias Büchners „Miscellanea physico-medico-mathematica“950 über die Erfindung eines leuchtenden Barometers nach Samuel Morland (1625-1695). ${ }^{951}$ Johann Friedrich von Uffenbach fand den Bericht über diese Erfindung so wichtig, dass er ihn in seine „Ausgezogenen Schriftstellen“952 aufnahm.

Nach dem Tod von Philipp Jacob Behaghel im Jahre 1732 hatte Diesterweg von dessen Witwe die Lichtmaschine und die Vakuumpumpe, beide nach den Angaben von Francis Hauksbee angefertigt, übernehmen können. Diesterweg führte damit Behaghels Versuche fort. So unternahm er einen ersten Versuch am 9. Januar 1733, ${ }^{953}$ weitere folgten am 27. März $1733^{954}$ und am 19. Februar 1734. ${ }^{955}$

Cod. Ms. Uffenbach 13/II, S. 330-331.

Cod. Ms. Uffenbach 13/III, S. 115-117.

Weitere Versuche mit Pump- und Hebewerken am 13. Dezember 1726 (Cod. Ms. Uffenbach 13/I, S. 66-70), am 22. August 1732 (Cod. Ms. Uffenbach 13/IV, S. 605-606) und am 7. Januar 1735 (Cod. Ms. Uffenbach 13/V, S. 408).

S.o. Kapitel 8.4.1 „Die Beiträge von Johann Friedrich von Uffenbach“.

25. Oktober 1726 (Cod. Ms. Uffenbach 13/I, S. 3), 25. März 1729 (Cod. Ms. Uffenbach 13/III, S. 165-169), 14. März 1732 (Cod. Ms. Uffenbach 13/IV, S. 516) und 27. März 1733 (Cod. Ms. Uffenbach 13/V, S. 88-92),

Cod. Ms. Uffenbach 13/III, S. 165-169.

Andreas Elias Büchner, Miscellanea physico-medico-mathematica: oder angenehme, curieuse und nützliche Nachrichten von Physical- $u$. Medicinischen, auch dahin gehörigen Kunst- und Literatur-Geschichten, welche in Teutschland und andern Reichen sich zugetragen haben oder bekannt worden sind, Erfurt 1727.

Cod. Ms. Uffenbach 13/V, S. 88-92.

Ausgezogene Schriftstellen aus Büchern, So zur Erlaüterung der Naturlehre, Mathematic und künstlichen Handarbeit etwas beytragen, angefangen 1733 [Cod. Ms. Uffenbach 9, S. 207-216 (Num. 64 "Barometrum Morlandinum“)].

Cod. Ms. Uffenbach 13/V, S. 6.

Cod. Ms. Uffenbach 13/V, S. 87.

Cod. Ms. Uffenbach 13/V, S. 251-252 und 255. 
Diesterweg besaß wie das Gesellschaftsmitglied Johann Georg Kißner ein eigenes, umfangreiches Mineralienkabinett. Am 21. März 1727 hielt er mit Hilfe eigener Sammlungsstücke einen längeren Vortrag über das Wachstum der Mineralien.956 Die Reaktion der Zuhörenden fasst Uffenbach im Protokollband folgendermaßen zusammen: „Es enthält dießer vorhergehende Aufsatz so viele wichtige Sätze daß die löbl. Geselschaft ihre Gedancken ohne Weitläuftigkeiten nicht eröfnen kan, und sich dannenher vorbehält solche unter der Hand künftig beyzubringen, um dadurch zu erweißen ob die Anfänge des Wachsthums aller Geschöpfe und mithin der Grundsatz aller Weltweisheit mehr vernunftmäßig nach mechanischen als geistlichen Lehren erwießen werden könne." "957 Diesterwegs Vortrag berührte demnach das religiöse Weltbild, das es vernunftmäßig zu überprüfen und eventuell zu verwerfen galt. Am 4. Januar 1732 griff Diesterweg das Thema nochmals auf, als er „gediegene Eisenstufen“958 aus seiner Heimat, dem Sieger Land, zeigte. Das Thema der Entstehung der Erze und Mineralien führte Diesterweg am 23. März 1736 fort, als er der Gesellschaft aus seinem Kabinett verschiedene Erz- und Quarzstufen zeigte und dazu einen Vortrag über deren Entwicklung hielt. ${ }^{959}$ Auch am 6. Dezember 1737 griff er - anlässlich einer erneuten Vorführung von Mineralien - die Materie in einem Vortrag über „Muthmaßliche Gedancken von der Eigenschaft eines unterirdischen Feuers“ auf. ${ }^{960}$

Neben seinen naturwissenschaftlichen Interessen führte Diesterweg die Gesellschaft zusätzlich in das Gebiet der Kartographie ein. Uffenbach beschreibt ihn in dem Protokoll vom 18. März 1735 als ,ein[en] Liebhaber der Geographie und der eine starcke Anzahl derer besten Landkarten zusammen gebracht [hat]."961 Einen ersten Eindruck der Qualität des Kartenmaterials, die Diesterweg besaß, bekam die Gesellschaft am 7. Mai 1728, wobei die Mappe mit Karten von Johann Christoph Müller (1673-1721), die in Augsburg bei Michael Kauffer (1673-1727) erschienen war, im Protokoll Erwähnung findet. ${ }^{962}$ Beim Treffen am 956 Cod. Ms. Uffenbach 13/I, S. 193-199.
957 Cod. Ms. Uffenbach 13/I, S. 199.
958 Cod. Ms. Uffenbach 13/IV, S. 465.
Zu gediegenem Eisen vgl. Johann Samuel Schröter, Mineralogisches und bergmännisches
Wörterbuch über Nahmen, Worte und Sachen aus der Mineralogie und Bergwerkskunde, 2
Bde., Frankfurt 1789, Bd. 2, S. 307-317.
Cod. Ms. Uffenbach 13/V, S. 604-607.
960 Cod. Ms. Uffenbach 13/V, S. 690-696.
961 Cod. Ms. Uffenbach 13/V, S. 467.
962 Cod. Ms. Uffenbach 13/II, S. 276-278.
Titel der Kartensammlung: „Mappa Chorographica novissima et completissima Totius
Regni Bohemiae In Duodecim Circulos Divisae : Cum Comitatu Glacensi Et Districtu
Egrano Adiunctis Circumiacentium Regionum Partibus Conterminis ; ex accurata totius 
10. Dezember 1728 zeigte Diesterweg erneut Landkarten. Hier hob der Schreiber Uffenbach besonders die Karte der Grafschaft Hanau von Friedrich Zollmann ${ }^{963}$ hervor, die gerade bei Johann Christoph Homann (1703-1730) in Nürnberg herausgegeben worden war. 964

Am 7. Juli 1730 führte Diesterweg zwei englische Landkartenbände vor, zum einen den "Atlas minor or a set of sixty two new and corrected maps of all parts of the world. by Herman Moll, London 1729". Diesterweg lobte die Karten wegen ihrer Präzision. Zum anderen zeigte er einen 1720 erschienenen Band von Thomas Templeman ${ }^{965}$ mit dem Titel: „A new survey of the globe”, den Uffenbach als Vorbild für andere Kartenmacher beschreibt. ${ }^{966}$ Diesterweg legte am 22. Dezember 1730 erneut eine gerade erworbene Landkarte von Philipp Johann von Strahlenberg (1677-1747) vor. Es handelte sich um ,die vor einiger Zeit neu heraus gekommene Landkarte der großen Tartarey, so ein in Siberien lang in Verhaft geweßener, und mit dem verstorbenen Konig verreißter Schwedischer Officier, nahmens von Strahlenberg verfertiget, solche auch mit einer besondren Beschreibung in $4^{\circ}$ unter dem Titul: Das Nord- und Ostliche Theil von Europa und Asia. 1730 Stockholm erlaütert. So wohl die Karte selbst die gar umständlich und groß war, als auch die übrigen Kupfer in dem Buche von Antiquitäten unbekanten Gegenden, 2 feuerspeyenden Bergen, Krüften Monumenten, und der gleichen, sind alle wohl gestochen und das Werck eine schöne Ausbeßerung der Geographie, indem man bißher von dießer Gegend wenig oder nichts gewußt. Es sind auch die Meerstrande so wohl als auch die Gränzen gegen andere Länder weit anderst gestaltet, als wie sie in denen bißherigen Charten gehabt [...].“967

Regni perlustratione et geometrica dimensione Mandato Caesaro institutâ in hanc formam redacta et ad usum commodum nec non omnia et singula distinctius cognoscenda XXV Sectionibus exhibita.“

963 Lebensdaten unbekannt.

964 Cod. Ms. Uffenbach 13/III, S. 34-35.

Titel der Karte: ,S[acri] R[omani] IMP[erii] COMITATUS HANAU proprie sic dictus cum singulis suis Praefecturis, ut et Comitatus SOLMS, BÜDINGEN et NIDDA cumreliqua WETTERAVIA et vicinis Regionibus ; Cum Privilegio Sac. Caes. ut \& Reg Maiest Polon. / per FR. ZOLLMANN.“

965 Lebensdaten unbekannt.

966 Cod. Ms. Uffenbach 13/IV, S. 36-38.

Hermann Moll (1654-1732). Der “Atlas Minor" ist eines der Hauptwerke Molls und ab 1719 in mehreren Auflagen erschienen ist.

Der vollständige Titel des Bandes von Templeman: „A new survey of the globe: or, An accurate mensuration of all the empires, kingdoms, countries, states, principal provinces, counties, \& islands in the world, London 1720." 
Hermann Molls Karten wurden von Diesterweg bevorzugt, denn er zeigte am 22. Juni 1731 die von diesem 1729 angefertigte Karte von „New England, New York, New Jersey and Pensilvania“, die Uffenbach im Protokoll wegen ihrer Präzision lobt. 968

Wie alle Mitglieder der wissenschaftlichen Gesellschaft richtete Adolf Albrecht Diesterweg seine Aufmerksamkeit auch auf die Kunst und die damit verbundenen Techniken. $\mathrm{Ob}$ es um künstlich gemalten Marmor, ${ }^{969}$ die Zubereitung von Goldfarbe, ${ }^{970}$ um einen Straßburger Farbenhändler, der besonders durch seine intensive blaue Farbe bekannt geworden war, ${ }^{971}$ um einen Firniß nach Engelbert Kämpfer (1651-1716), ${ }^{972}$ um Rezepte für verschiedenfarbige Firnisse ${ }^{973}$ oder um das Trocknen verschiedener Farben und Firnisse auf Holztäfelungen ${ }^{974}$ ging, immer wieder wurden bei den Treffen im Haus von Diesterweg diese Themen besprochen.

Das besondere Interesse innerhalb der Gesellschaft an künstlerischen Techniken zeigt sich auch daran, dass Diesterweg am 13. Februar 1728 die Ergebnisse eigener Farbexperimente in einem längeren Vortrag vorstellte. ${ }^{975}$ Ein weiteres Referat über „Die Natur der Farben“ hielt er am 22. August 1732.976

Der Titel der Beschreibung: „Das Nord- und Östliche Theil von Europa und Asia, in so weit solches das gantze Russische Reich mit Sibirien und der grossen Tatarey in sich begriffet. in Verlegung des Autoris, Stockholm 1730.“

Titel der Karte: „Nova Descriptio Geographica Tattariae Magnae ...“

Der erwähnte Bericht von Engelbert Kämpfer in: Engelbert Kämpfer, Amoenitatum Exoticarum Politico-Physico-Medicarum Fasciculi V Quibus continentur Variae Relationes, Observationes \& Descriptiones Rerum Persicarum \& Ulterioris Asiae multa attentione, in peregrinationibus per universum Orientem, collectae ab ...., Lemgo 1712, S. 276.

Cod. Ms. Uffenbach 13/III, S. 428-430.

Cod. Ms. Uffenbach 13/V, S. 724.

Cod. Ms. Uffenbach 13/II, S. 196-203.

Cod. Ms. Uffenbach 13/IV, S. 607-608. 


\subsubsection{Die Beiträge von Conrad Hieronymus Eberhard, gen. Schwind}

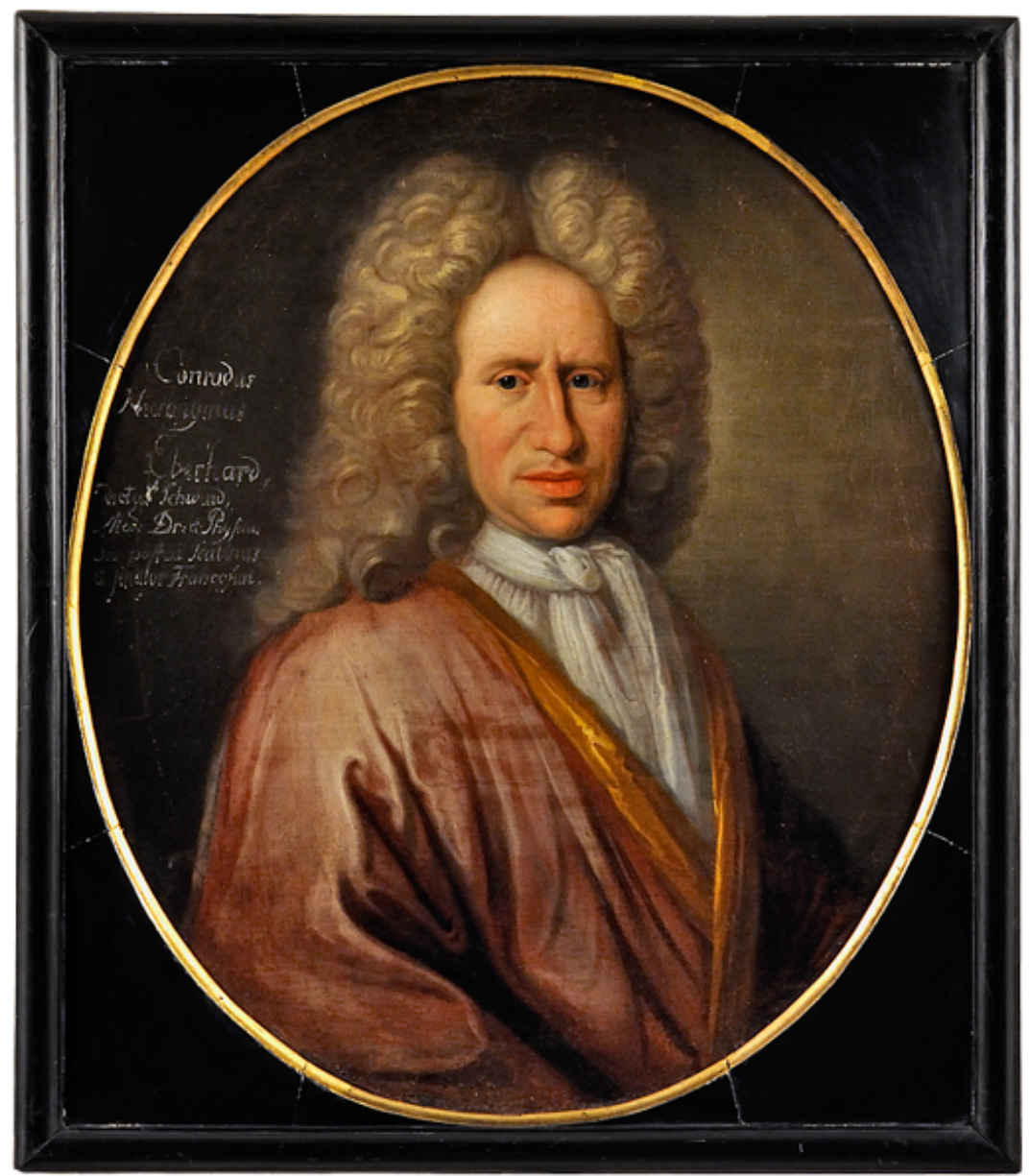

Abb. 45 Unbekannt, Conrad Hieronymus Eberhard, gen. Schwind, Frankfurt am Main, Dr. Senckenbergische Stiftung, Portraitsammlung

Der Mediziner Conrad Hieronymus Eberhard, gen. Schwind wurde am 29. November 1653 in Frankfurt am Main geboren. Von 1670 bis 1673 studierte er Medizin in Jena, konnte aber aus familiären Gründen - nach dem Tod seines Vaters 1673 musste er dessen Handelsgeschäft übernehmen - erst 1680 in Leiden sein Studium fortsetzen und 1682 in Utrecht abschließen. 1691 wurde er in die „Gesellschaft Frauenstein“ aufgenommen, in dieser Patriziergesellschaft war auch Johann Friedrich von Uffenbach Mitglied. 1688 wurde er zum Pfleger des 1679 eröffneten Schwind'schen Armen- und Waisenhauses berufen, dessen Verwaltung er 1699 übernahm. Seit dem 1. Mai 1700 fungierte er zusätzlich als Pfleger im Hospital zum Heiligen Geist. Ab 1706 wurde Eberhardt zudem mit wechselnden Aufgaben im Rat der Stadt beauftragt. 1718 wurde er zum Ältesten Schöffen und Wirklichen Kaiserlichen Rat ernannt. Das Amt des Älteren Bürgermeisters hatte er 1719 und 1725 inne, das Amt des stellvertretenden Bürgermeisters 1721 und 
1727. Eberhard verstarb am 2. Juli 1744. ${ }^{977}$ Seine Schwester Anna Elisabeth ${ }^{978}$ war mit dem Arzt Johann Erasmus Kißner (1645-1678) verheiratet, dem Vater von Johann Georg Kißner.

Wie Uffenbach im Vorwort zu seiner eigenen Geschichte der Astronomie schreibt, hatte Eberhard „mit seinen Truckwercken und andern Waßermachinen das Waßer [erwehlt]“.979 In seinen Referaten berichtete Eberhard über die verschiedenen Pumpen und Spritzen und die neuesten Erfindungen. Dabei zeigte er der Gesellschaft kleinere und größere Modelle davon; in den Protokollen sind immer wieder entsprechende Zeichnungen zwischen die Texte gesetzt. ${ }^{980}$ Einen Vortrag mit Versuch widmete Eberhard am 10. Januar 1727 der Erfindung eines Brunnens des griechischen Mathematikers und Ingenieurs Heron von Alexandria $\left(†\right.$ 62). ${ }^{981}$ Die „,fonte Heronis“ war am 17. Februar 1735 nochmals Thema, als ein Gast namens Heckel, über den nichts Näheres bekannt ist, der Gesellschaft beiwohnte und den Mitgliedern eine gerade erfundene Wasserpumpe erklärte. ${ }^{982}$

Neben den Pumpen und Hebewerken stehen die künstlerischen Techniken und Materialien im Vordergrund von Eberhards Interessen. Hier sind es besonders Firnis-, Leim- und Lackrezepte, die Eberhard der Gesellschaft anhand

977 Vgl. Kallmorgen 1936, S. 252 und http://www.senckenbergische-portraitsammlung.de/26Conrad+Hieronymus+Eberhard+gen.+Schwind.html vom 28.10.2016.

S.a. Johann Philip Fresenius, Gedächtnis-Rede, welche bey Beerdigung des Wohlgebohrnen Herrn, Herr Conrad Hieronymus Eberhard, genant Schwind [,,,] den zweyten Julii 1744 [,,,] gehalten, Franckfurt am Mayn 1745, s. hier der ausführliche Lebenslauf S. 32-36.

978 Lebensdaten unbekannt.

979 Cod. Ms. Uffenbach 13/I, S.40.

980 22. November 1726 (Cod. Ms. Uffenbach 13/I, S. 31), 10. Januar 1727 (Cod. Ms. Uffenbach 13/I, S. 108-109), 9. Mai 1727 (Cod. Ms. Uffenbach 13/I, S. 213-216), 24. Oktober 1727 (Cod. Ms. Uffenbach 13/II, S. 24-28), 12. Dezember 1727 (Cod. Ms. Uffenbach 13/II, S. 100-102), 23. April 1728 (Cod. Ms. Uffenbach 13/II, S. 270-274), 5. Juli 1728 (Cod. Ms. Uffenbach 13/II, S. 308-312), 12. November 1728 (Cod. Ms. Uffenbach 13/III, S. 12), 9. Dezember 1729 (Cod. Ms. Uffenbach 13/III, S. 299-300), 8. Dezember 1730 (Cod. Ms. Uffenbach 13/IV, S. 74-75), 12. Januar 1731 (Cod. Ms. Uffenbach 13/IV, S. 159-161), 8. Juni 1731 (Cod. Ms. Uffenbach 13/IV, S. 353), 5. Dezember 1732 (Cod. Ms. Uffenbach 13/IV, S. 663), 27. Februar 1733 (Cod. Ms. Uffenbach 13/V, S. 57), 19. Juni 1733 (Cod. Ms. Uffenbach 13/V, S. 134-136), 22. Januar 1734 (Cod. Ms. Uffenbach 13/V, S. 217-218), 9. April 1734 (Cod. Ms. Uffenbach 13/V, S. 292-293), 12. November 1734 (Cod. Ms. Uffenbach 13/V, S. 378), 27. Januar 1736 (Cod. Ms. Uffenbach 13/V, S. 582-586) und 15. März 1737 (Cod. Ms. Uffenbach 13/V, S. 664669).

981 Cod. Ms. Uffenbach 13/I, S. 108-109.

Zum Heronsbrunnen vgl.: http://schueltz.com/heronkurz.html vom 29.10.2016.

982 Cod. Ms. Uffenbach 13/V, S. 443-448. 
von Beispielen vorführte. ${ }^{983}$ So erläuterte er am 22. November 1726 anhand eines Kupferstichs, der seinen Schwiegervater zeigte und „ungemein schön in schwarze Kunst vorgebildet" $" 984$ war, wie man einen besonderen Firnis aufträgt, sodass die Oberfläche gleichmäßig glänzend wirkt. Es handelt sich dabei um ein Firnisrezept sowohl für Druckgraphik als auch für Druckplatten. ${ }^{985}$ Dasselbe Thema griff er nochmals am 10. Januar 1727 anhand einiger Portraits aus seinem Besitz auf.986 Am 9. Dezember 1729 berichtete Eberhard über einen Firnis, der mit Sandrak ${ }^{987}$ hergestellt worden war. Das Rezept war erstmals 1728 im „Compendieuses und stets-währendes Handbuch des galanten und curieusen Frauenzimmers“ unter dem Stichwort „Türckischer Firniß“988 veröffentlicht worden. Firnisrezepte waren für die Gesellschaft so interessant, dass Eberhard am 12. Januar und am 23. Februar 1731 einen zweiteiligen Vortrag „Ausführliche Beschreibung des Laccirens“ hielt, dessen Niederschrift dem vierten Band der Protokolle im Anhang beigebunden wurde. 989

Wie alle Mitglieder zeigte Eberhard neu erworbene Gemälde und druckgraphische Blätter. Im Protokoll zum 5. Dezember 1732 heißt es entsprechend: „Hierauf zeigte der Hausherr verschiedene ohnlängst zufällig vor ein gar geringes erhaltene und erkaufte gute Gemälde, als ein kleines gar nathürlich abgemahlten aufliegenden Calender, eine Landschaft, ein Bauernstückgen und dann einen gantzen Pack von wohl behaltenen schönen Kupferstücken oder meisterlichen Portraiten durch van Dyck gemahlt und Lombart in London sehr sauber in Kupfer gebracht, welches alles er in einem hießigen Ausrufe vor ein Spottgeld erstanden, [...].“990 Bei den Portraits, die Eberhard der Gesellschaft vorlegte, handelt es sich um eine Folge von zwölf

22. September 1726 (Cod. Ms. Uffenbach 13/I, S. 36-38), 10. Januar 1727 (Cod. Ms. Uffenbach 13/I, S. 102), 9. Dezember 1729 (Cod. Ms. Uffenbach 13/I, S. 297-298), 25. Januar 1730 (Cod. Ms. Uffenbach 13/I, S. 378-392), 17. Mai 1730 (Cod. Ms. Uffenbach 13/II, S. 2), 19. November 1728 (Cod. Ms. Uffenbach 13/III, S. 13-18), 8. Dezember 1730 (Cod. Ms. Uffenbach 13/IV, S. 72-73), 12. Januar 1731 (Cod. Ms. Uffenbach 13/IV, S. 163 mit dem Referat im Anhang S. 711-730), 8. Juni 1731 (Cod. Ms. Uffenbach 13/IV, S. 351352, 27. Januar 1736 (Cod. Ms. Uffenbach 13/V, S. 584).

Cod. Ms. Uffenbach 13/I, S. 38.

985 Cod. Ms. Uffenbach 13/I, S. 36-38.

986 Cod. Ms. Uffenbach 13/I, S. 103.

987 Cod. Ms. Uffenbach 13/III, S. 298.

„Sandrak“ ist das Harz des Sandarakbaumes (Tetraclinis articulata).

Compendieuses und stets-währendes Handbuch des galanten und curieusen Frauenzimmers, Leipzig 1728, S. 83.

988 Ebendort

989 Cod. Ms. Uffenbach 13/IV, S. 711-730.

990 Cod. Ms. Uffenbach 13/IV, S. 662. 
Damenportraits, die „Folge der Gräfinnen“ genannt, die Pierre Lombard (16131641) in seiner Londoner Zeit nach Gemälden von Anton van Dyck (1599-1641) gestochen hatte.

Zusammenfassend lässt sich über Conrad Hieronymus Eberhard, gen. Schwind sagen, dass er ein Mann war, der an neuen Erfindungen auf dem Gebiet der Pneumatik interessiert war. Daneben interessierte er sich wie alle Mitglieder der Gesellschaft für die Techniken und Methoden bei der Herstellung von Kunst und Kunstgewerbe.

\subsubsection{Die Beiträge von Johann Georg Kißner}

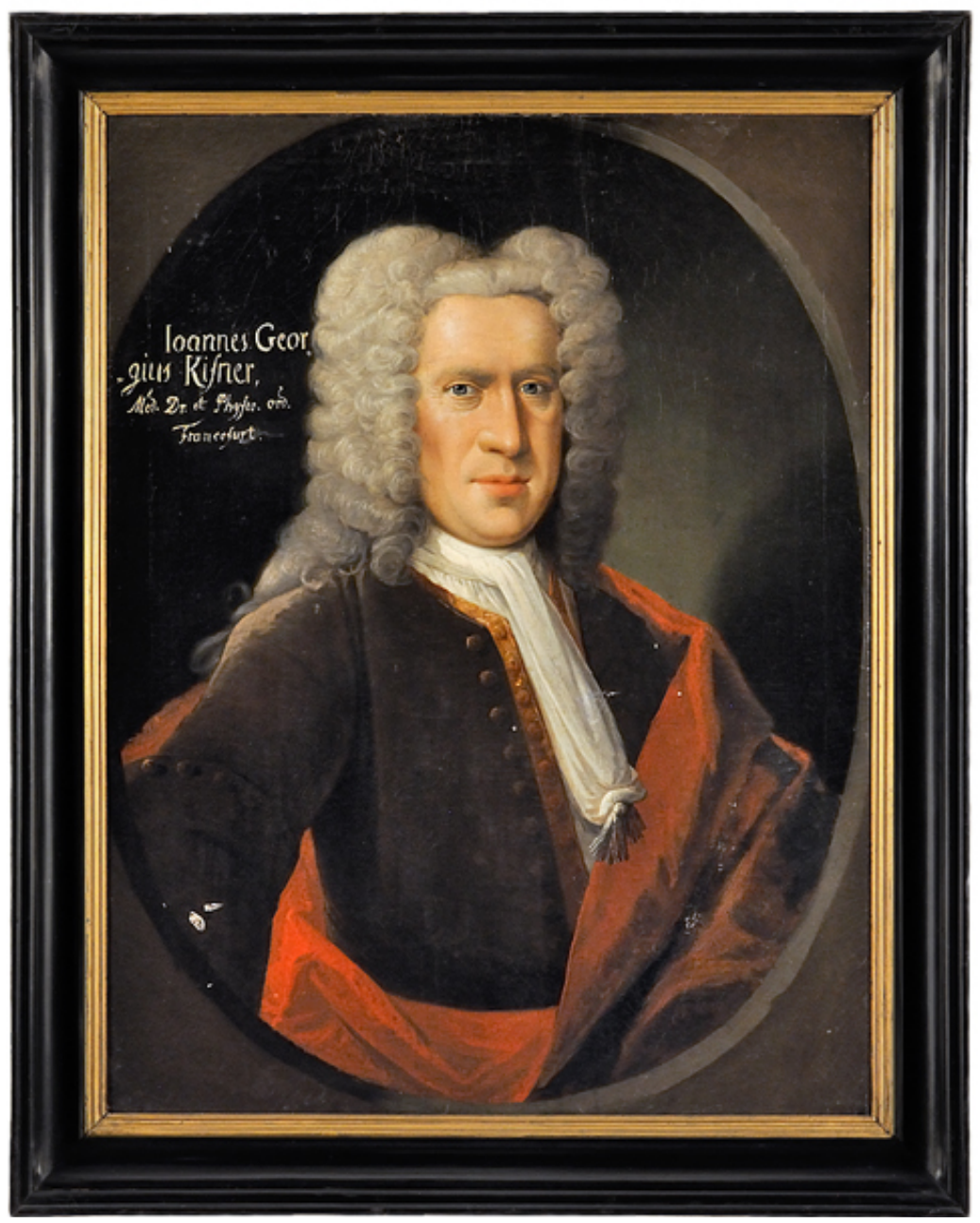

Abb. 46 Georg Anton Koch, Johann Georg Kißner

Frankfurt am Main, Dr. Senckenbergische Stiftung, Portraitsammlung 
Der Arzt und Stadtphysicus Johann Georg Kißner ${ }^{991}$ wurde 1673 als Sohn des Arztes Johann Erasmus Kißner (1645-1678) und seiner Frau Anna Elisabeth, einer Schwester des Frankfurter Physicus Primarius und Älteren Bürgermeisters Conrad Hieronymus Eberhard, gen. Schwind in Frankfurt geboren. Kißner war verheiratet $^{992}$ und hatte mindestens einen Sohn, den Mediziner Johann Christian (1717-1781), der zudem Administrator der Senckenbergischen Stiftung ${ }^{993}$ war.

Nach der Promotion Kißners im Jahr 1699 in Leiden praktizierte er als Arzt ab 1701 in Frankfurt. Von 1707 bis 1709 war er zudem Pfleger am Hospital zum Heiligen Geist. 1715 wurde er zum dritten, 1728 zum zweiten und 1734 zum ersten Stadtphysicus ernannt. Er gehörte zum Kreis der Gründer der wissenschaftlichen Gesellschaft um Uffenbach. Die Gesellschaft traf sich insgesamt zu 29 Sitzungen in seinem Haus. Die letzte Zusammenkunft der Gesellschaft in seinem Hause fand am 23. Juli 1734 statt. Kißner verstarb während des Bestehens der Gesellschaft am 31. Dezember 1734. ${ }^{994}$ Johann Friedrich von Uffenbach hielt eine ausführliche Gedächtnisrede auf ihn am 18. März 1735 in Diesterwegs Räumen. ${ }^{995}$

Es sind besonders drei Gebiete, die Kißner den Mitgliedern in seinen Vorträgen darstellte: Medizin, Chemie und das eigene Mineralienkabinett. Johann Friedrich von Uffenbach bemerkt zu Kißner und dessen Sammlung: „H Doct. Kißner [hat] nach Anleitung seines schönen Naturalien Cabinets996 gleichsam die Erde [gewählt]." "997 Besonders das Kabinett steht im Mittelpunkt der Zusammenkünfte in seinem Haus. ${ }^{998}$ Aber auch sein Beruf als Arzt ${ }^{999}$ und die damit verbundenen

S.a. „http://www.senckenbergische-portraitsammlung.de/33-Johann+Georg+Kissner.html“ vom 20.05.2016.

992 Namen und Lebensdaten der Gattin sind unbekannt.

993 Zur Senckenbergischen Stiftung vgl:: http://www.senckenbergische-stiftung.de/diestiftung.html vom 14.02.2017.

994 Zum Leben Kißners vgl. Kallmorgen 1936, S. 322.

995 Cod. Ms. Uffenbach 13/V., S. 473-481.

996 Auf das Naturalienkabinett von Kißner verfaßt Uffenbach ein Lobgedicht. Es ist nachzulesen in: Uffenbach 1733, S. 209-222.

Vgl. Schmidt 1960, Sammlung Kissner (1727).

997

998

999

Cod. Ms. Uffenbach 13/I, S. 40.

Cod. Ms. Uffenbach 13/I, S. 17-24; 13/I, S. 82-87, 13/I, S. 201-205, 13/II, S. 7, 13/II, S. 9-19, 13/II, S. 81-92, 13/II, S. 137-148, 13/II, S. 214-223, 13/III, S. 5-7, 13/III, S. 34, 13/III, S. 125-127, 13/III, S. 189-204, 13/III, S. 269-279, 13/III, S. 356, 13/III, S. 439, 13/IV, S. 451-452, 13/III, S. 27, 13/IV, S. 626-629, 13/V, S. 9-23 und 13/V, S. 341-352.

Cod. Ms. Uffenbach 13/I, S. 16, 13/I, S. 146-154, 13/I, S. 200, 13/II, S .284-291, 13/III, S. 49-61, 13/III, S. 63, 13/III, S. 264, 13/III, S. 354-355, 13/III, S. 377, 13/III, S. 439-453, 13/IV, S. 41-55, 55, 13/IV, S. 122-124, 13/IV, S. 125-143, 13/IV, S. 166-167, 13/IV, S. 217-226, 13/IV, S. 303-318, 13/IV, S. 354, 13/IV, S. 395-404, 13/IV, S. 453-463, 13/V, S. 6-8, 13/V, S. $209,13 / \mathrm{V}$, S. 284-285. 
biologischen und chemischen Untersuchungen sind Gegenstand seiner Berichte. ${ }^{1000}$ Sowohl zum Mineralienkabinett als auch zu seinen naturwissenschaftlichen Vorträgen lieferte Kißner ausführliche Manuskripte häufig mit eigenen, erläuternden Zeichnungen -, die in die Protokollbände eingebunden wurden.

Sein Mineralien- und Fossilienkabinett war weit über die Grenzen Frankfurts bekannt. So beschreibt Johann Georg Keyßler (1693-1743) in seinen „Neuesten Reisen“ von 1741: „Liebhaber von Naturalien finden bey Herrn D Joh Georg Kißner eine schöne Sammlung von Ertzen, Salibus terris, gemmis, lignis fossilibus, lapidibus, marmoribus und Petrefactis."1001 Die Naturaliensammlung Kißners blieb nach seinem Tod erhalten. Sein Schwager, Konrad Hieronymus Eberhard gen. Schwind, war zum Kurator und Verwahrer der Sammlung, die er von Kißners Witwe übernommen hatte, bestellt worden. Er ordnete die Stücke neu in Schuber und Kästen und legte einen eigenen Katalog an. ${ }^{1002}$

Aus seiner Sammlung zeigte Kißner bei der Sitzung am 14. Dezember 1731 eine Sammlung von einhundert antiken und modernen Marmorproben, die er sich durch die Vermittlung von Domenico Silvio Passionei (1682-1761), zu dieser Zeit apostolischer Nuntius in Wien, aus Rom hatte schicken lassen. ${ }^{1003}$ Anlass für das Anlegen einer eigenen Marmorsammlung war Uffenbachs Lapidarium „,von allen Gattungen antiquer Marmor“", das Kißner am 3. Dezember 1728 in dessen Haus gesehen hatte. ${ }^{1004}$ Uffenbach hatte sein Kabinett zum eigenen Bedauern in der Zwischenzeit verkauft. Er schreibt in einem Zusatz zu Kißners Ausführungen: „Jedoch weil ich die meinige ehedeßen in der Absicht überlaßen, mir andere von denen romischen Lapidariis und zwar die gröste Gattung, welche die gegenwärtige im Umfange noch eines so groß übertreffen, kommen zu laßen, so kan ich mir den Verlust mit Zeit und Gelegenheit vieleichte wieder ersetzen."1005 Als Architekt hatte Uffenbach ein großes Interesse an unterschiedlichsten Gesteinsproben, die er bezüglich Farbe oder Härte für einzelne Bauzwecke prüfen musste.

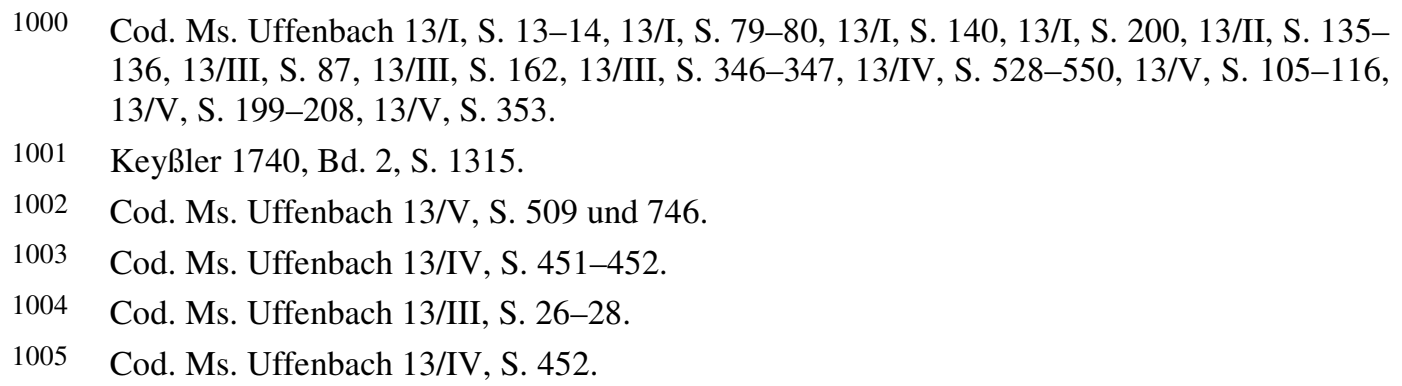


Als Arzt interessierte Kißner sich besonders für die Entwicklung der Embryonen im Mutterleib. In mehreren Sitzungen unterrichtete er die Mitglieder der Gesellschaft darüber. So begann er am 9. November 1730 ein längeres Referat über die Entstehung und Entwicklung der Knochen eines Kindes, das er mit erläuternden Zeichnungen illustrierte. ${ }^{1006}$ Zuvor hatte er schon am 14. Februar 1727 einen acht Wochen alten, in Konservierungsflüssigkeit eingelegten Fötus und am 28. März 1728 zwei getrocknete Embryonen gezeigt. ${ }^{1007}$ Sein Referat setzte er am 9. Februar und am 9. März 1731 fort. ${ }^{1008}$ Auch „Von der Circulation des Geblüthes in einem noch nicht gebohrnen Kind“ und über „Ein anatomisches Problema, ob nehmlich zwischen einer schwangeren Frauen und ihrer Frucht ein reciprocquer Umblauf des Geblütes seye?“ berichtete er in zwei längeren Vorträgen. ${ }^{1009}$

Neben Experimenten mit Phosphor, ${ }^{1010}$ Salmiak $^{1011}$ und Weinstein ${ }^{1012}$ beschäftigte Kißner sich immer wieder mit Versuchen oder Untersuchungen zur Herstellung von Farben. So zeigte er am 14. Februar 1727 drei von ihm künstlich erzeugte Farben. ${ }^{1013}$ Die Herstellung der Farbe Scharlach bzw. Karminrot war sogar zweimal Thema. Eine erste Erläuterung mit dem Titel „Die Natürliche Historie und Beschreibung des Pohlnischen Cocci Radicums“ gab er am 28. März 1732.1014 Das Referat dauerte die gesamte Sitzung und das eigenhändige Manuskript mit einem eingelegten Kupferstich umfasst 22 Seiten des Protokollbandes. Bei der Coccus Radicum handelt es sich um die Polnische Karminschildlaus, aus der die scharlachrote Farbe gewonnen wurde. Am 19. März 1734 griff er mit dem Vortrag über „Die Untersuchung des Carmins“, den er mit einigen eigenen Proben demonstrierte, das Thema nochmals auf. 1015

Johann Georg Kißner hatte in der wissenschaftlichen Gesellschaft die Stellung des Mediziners, Chemikers und insbesondere des Paläontologen inne. Sein Mineralien- und Fossilienkabinett war für Kißner von identischer Bedeutung in

\footnotetext{
1006 Cod. Ms. Uffenbach 13 IV, S. 41-45.

1007 Cod. Ms. Uffenbach 13/I, S. 154 und 200.

1008 Cod. Ms. Uffenbach 13 IV, S. 217-226 und 303-318.

1009 Cod. Ms. Uffenbach 13 IV, S. 395-404 und S. 453-463.

1010 Cod. Ms. Uffenbach 13/I, S. 13 und S. 80,

1011 Cod. Ms. Uffenbach 13/I, S. 200 und Cod. Ms. Uffenbach 13/V, S. 105-116.

1012 Cod. Ms. Uffenbach 13/V, S. 199-206.

1013 Cod. Ms. Uffenbach 13/I, S. 140.

1014 Cod. Ms. Uffenbach 13/IV, S. 528-550.

1015 Cod. Ms. Uffenbach 13/V, S. 273-283.
} 
den Mußestunden wie für Johann Friedrich von Uffenbachs die graphische Sammlung.

\subsubsection{Die Beiträge von Wilhelm von Uffenbach}

Der jüngere Bruder Johann Friedrichs gehörte ebenfalls zum Gründerkreis der wissenschaftlichen Gesellschaft. Diese traf sich insgesamt zu 29 Sitzungen in seiner Wohnung. Auffällig an den Abenden in seinem Hause ist, dass die anderen Mitglieder, aber besonders Johann Friedrich, viele Beiträge lieferten. Auch wurde in Wilhelms Haus mehr über allgemeine tagespolitische Themen gesprochen.

Er verstarb überraschend am 24. Juni 1735. Die letzte Zusammenkunft in seinem Hause fand noch am 13. Mai 1735 statt. Am 29. November des Jahres hielt Uffenbach ein Ehrengedächtnis auf seinen Bruder im Hause Diesterwegs. ${ }^{1016}$ Bevor auf die einzelnen Themen Wilhelms eingegangen wird, soll an dieser Stelle eine Kurzbiographie anhand der Totenrede gegeben werden, weil Wilhelm von Uffenbach ansonsten in der Literatur nicht erwähnt ist.

Wilhelm von Uffenbach wurde am 16. September 1689 als dritter und jüngster Sohn von Balthasar von Uffenbach und dessen Frau, Anna Sybilla, geboren. Nach einer von Krankheit gezeichneten Kindheit wurde er im September 1706 für vier Jahre an das Gymnasium Ernestinum in Gotha geschickt. Im Jahre 1711 ging er zum Studium der Jurisprudenz nach Tübingen und wechselte 1713 nach Straßburg, wo seit 1712 schon sein Bruder Johann Friedrich studierte. Vom Herbst 1717 an hielt er sich für ein Jahr in Leiden auf, um dort sein juristisches Studium abzuschließen. An seinen Leidener Aufenthalt schloß sich eine zweijährige Grand Tour durch die Niederlande, Brabant, Frankreich und die Schweiz an. Ab 1720 lebte er ununterbrochen, abgesehen von einigen kürzeren Reisen ${ }^{1017}$, bis zu seinem Tod in Frankfurt am Main. Da er wie auch seine beiden Brüder durch das Erbe seiner Eltern finanziell unabhängig war, musste er keinem „Broterwerb“ nachgehen und konnte sich ganz auf seine „Nebenbeschäftigungen“ konzentrieren. Er beschäftigte sich in erster Linie mit der Musik, dem Kunsthandwerk, wie z.B. dem Drechseln, und der Pflege seiner Bibliothek. Durch

1016 Cod. Ms. Uffenbach 13/V, S. 536-543. Es handelt sich hierbei um eines der wenigen biographischen Zeugnisse zu Wilhelm von Uffenbach (S. Anhang, S. 299-305).

1017 Vgl. die im Lebenslauf von Johann Friedrich erwähnten „Spazierfarthen“ (Kapitel 4.4). 
den Umstand, dass Wilhelm unverheiratet blieb, übernahm Johann Friedrich nach dessen Tod u.a. die Bibliothek mit der graphischen Portraitsammlung. ${ }^{1018}$

Wie oben erwähnt, hatte Wilhelm von Uffenbach innerhalb der wissenschaftlichen Gesellschaft die Rolle des Amateurs übernommen. Allein in drei aufeinanderfolgenden Sitzungen erklärte er ausführlich seine Dreh- und Hobelbänke, von denen er eine nach den exakten Angaben des Schwarzenauer Mechanikers Johann Melchior Kinet eingerichtet hatte. ${ }^{1019}$ Dabei konnten die Mitglieder zum einen die Maschinen selbst zum anderen die Werkstücke bewundern, die Wilhelm von Uffenbach darauf angefertigt hatte. Er beschrieb dabei immer wieder genau den Herstellungsprozess der Werkstücke, wie zum Beispiel einer von ihm gedrechselten Kugel. Es ging aber dem AmateurKunsthandwerker nicht nur um den Herstellungsprozeß sondern auch um das Material der Objekte. Am 9. November 1726 hielt er das kurze Referat „Von der Natur der Hölzer zum Drehen." 1020

Auch seine auf einem Rollstuhl befestigte Camera obscura zeigte Wilhelm von Uffenbach mehrere Male. Am 17. Oktober 1727 erklärte er zuerst den Rollstuhl, 1021 am 16. November 1730 führte er die auf den Rollstuhl montierte Camera obscura vor, 1022 was er am 10. August 1731 wiederholte, da er Veränderungen an der Camera obscura vorgenommen hatte. ${ }^{1023}$ Beim letzten

1018 Während der Sitzungen der Gesellschaft im Hause Wilhelms von Uffenbach werden immer wieder Bücher erwähnt, nach denen Wilhelm seine Versuche und Erläuterungen erarbeitet hat und die sich nun in der Bibliothek Johann Friedrichs finden. Beispielsweise die zweite Auflage von Johann Bernhard Fischer von Erlachs „Entwurf einer Historischen Architectur", Leipzig 1725 (2 Bibl. Uff. 5).

Die Portraitsammlung Wilhelms befindet sich heute als ein Teil der Stiftung Johann Friedrichs im Kupferstichkabinett der Kunstsammlung der Georg-August Universität Göttingen.

$\mathrm{Ob}$ anderes Gut aus der Verlassenschaft Wilhelms an Johann Friedrich von Uffenbach übergegangen ist, kann nicht festgestellt werden.

1019 Cod. Ms. Uffenbach 13/I, S. 25-31 (9. November 1726), S. 88-95 (3. Januar 1727), S. 159-163 (21. Februar 1727).

Vgl. den Brief Kinets vom 12. Mai 1726 im Commercium Epistolicum (Cod. Ms. Uffenbach 20/II, p. 127-128), in dem Kinet die Einrichtung der Maschine beschreibt.

Kinet arbeitete nicht nur für Wilhelm von Uffenbach sondern auch für Johann Friedrich, Diesterweg und Eberhardt.

1020 Cod. Ms. Uffenbach 13/I, S. 29-31.

1021 Cod. Ms. Uffenbach 13/II, S. 22

1022 Cod. Ms. Uffenbach 13/IV, S. 57-59.

1023 Cod. Ms. Uffenbach 13/IV, S. 410-412.

Dabei wurde das Buch von Willem Jacob Gravesande, Essai de Perspective, La Haye 1711 ( $8^{\circ}$ Bibl. Uff. 180) benutzt. 
Treffen, am 13. Mai 1735, zeigte er der Gesellschaft und anwesenden Gästen noch einmal in seiner Wohnung die transportable Camera obscura. ${ }^{1024}$

Ein weiteres Fach, dem er wie sein Bruder Johann Friedrich ebenfalls seine Aufmerksamkeit schenkte, war die Musik. Genau wie dieser besaß er eine kleinere Sammlung an Musikinstrumenten, von denen er die selteneren oder „merkwürdigen“ vorführte. So hatte er sich 1729 ein stehendes Klavier von einem Frankfurter Instrumentenbauer gekauft. Im Januar 1730 erklärte er es den Teilnehmern ${ }^{1025}$ und gab ein Hauskonzert in der darauffolgenden Sitzung in seinen Räumen als Abschlußveranstaltung des Winterhalbjahres. ${ }^{1026}$

Wilhelm von Uffenbach führte immer wieder rare Bücher aus seiner Bibliothek vor. So sah sich die Gesellschaft beispielsweise am 4. April 1727 die Publikation „Theuerdancks Abentheuerliche Geschichte“ von 1517 an,1027 über das im Protokoll vermerkt ist: ,[...] zeigte man uns die erste und rahre Edition des so genanten Theuerdancks in fol, die so wohl an Bildern als Buchstaben miteinander von dem berühmten Formschneider Scheufling in Buchsbaum geschnitten wurden, welches aus denen vielen am Rand befindlichen Zügen und Ziehrathen erhellet, und nach der ersten Art der Buchtruckerey, wo nehmlich alle Buchstaben aneinander hangend in einer Taffel geschnitten und nicht jeder absonderlich wie heutzutag üblich aufgetragen werden, eingerichtet ist. Es hat solche Schönberger in Nurnberg anno 1517 in gros fol ausgeleget." Am Seitenrand steht ergänzend die Notiz: „Dieße Nachricht ist aus der Vorrede des lang hernach gefolgten Antruckes in fol genommen."1028

Die „Historische Baukunst“ von Johann Bernhard Fischer von Erlach(16561723) ${ }^{1029}$ war an einem der Abende, am 2. Dezember 1729, Thema. ${ }^{1030}$ In der Sitzung wurde zum einen über die Druckqualität - „Ob nun zwar wie es scheinet, die Platten nachmahls in fremde Hände gekommen und stärcker abgetruckt, auch also schwächer und blaßer gegen der ersten Auflage, ausgefallen“1031 - und zum

1024 Cod. Ms. Uffenbach 13/V, S. 492.

1025 Cod. Ms. Uffenbach 13/III, S. 361-367 mit verschiedenen Zeichnungen.

1026 Cod. Ms. Uffenbach 13/III, S. 455.

1027 Maximilian I., Theuerdancks Abentheuerliche Geschichte, Nürnberg durch Hanßen Schönberger 1517 ( $2^{\circ}$ Bibl. Uff. 355) und: ders., Theuerdancks gedenckwürdige Historia, Frankfurt 1596 ( $8^{\circ}$ Bibl. Uff. 591).

1028 Cod. Ms. Uffenbach 13/I, S. 207.

1029 Johann Bernhard Fischer von Erlach, Historische Baukunst in Abbildung unterschiedener berühmter Gebäude des Alterthums, Leipzig 1725 ( $2^{\circ}$ Bibl. Uff. 5).

1030 Cod. Ms. Uffenbach 13/III, S. 280-281.

1031 Cod. Ms. Uffenbach 13/III, S. 280. 
anderen über „die Einbildungskraft des H Verfaßers“1032 diskutiert. Die Gesellschaft war sich einig darüber, dass die Einbildungskraft Fischer von Erlachs „,vieles zu gesezet, sie sich eben aus den Resten der alten Scribenten nicht gar wohl erweißen laßen wird."1033 Die Mitglieder folgen also der Vorstellung Fischer von Erlachs nicht.

Wilhelm von Uffenbach besaß einen umfangreichen Folianten mit gestochenen Portraits, der am 17. Oktober 1727 als letzter Programmpunkt vorgestellt wurde. ${ }^{1034}$ Im Protokoll heißt es: ,Zu letzte sahen wir noch einen großen Folianten voll schöner Kupferstücke und Abbildungen von berühmten Künstlern Mahlern Baumeistern und Handarbeitern, deren der $\mathrm{H}$ Eigenthümer eine ziehmliche Anzahl, gleichwie auch an Portraits großer H, Gelehrten, und Kriegs und Civil Bedienten, alle in gleichmäßigen saubern porte feuille hat."1035

Neben den oben genannten Dingen führte Wilhelm immer wieder nützliche oder „denck- und merckwürdige“ Möbelstücke und Ausstattungsstücke seines Hauses vor, so zum Beispiel ein Fensterrollo, 1036 ein Schrankbett (Abb. 47), 1037 ein Reiseservice für Tee und Kaffee in einem Kasten, einen klappbaren Wandtisch, ${ }^{1038}$ ein Lesepult, das nach den Angaben von Agostino Ramelli (15311600) angefertigt worden war, ${ }^{1039}$ einen mondsichelförmigen Rolltisch, den Wilhelm als Speisetisch verwendete, ${ }^{1040}$ eine besondere Art von Holztritten, die bei unebenem Boden nicht so leicht umkippten, ein verstellbares Notenpult, ${ }^{1041}$ zwei auseinandernehmbare Reiseleuchter aus Messing, einen zerlegbaren „Caffe Offen"1042 und zwei kartesianische Leuchter. ${ }^{1043}$

\footnotetext{
1032

1034 Cod. Ms. Uffenbach 13/II, S. 23.

Johann Friedrich von Uffenbach konnte die Portraitsammlung nach dem Tod von Wilhelm übernehmen, heute in der Kunstsammlung der Universität Göttingen.

1035 Cod. Ms. Uffenbach 13/II, S. 23.

1036 23. Januar 1728, Cod. Ms. Uffenbach 13/II, S. 151-153.

1037 12. März 1728, Cod. Ms. Uffenbach 13/II, S. 224-227.

Im Protokoll vermerkt Johann Friedrich auf S. 224: „[...], welche ich nachmahls in meinem zu Flörsheim befindlichen Landhauße mit guter Gemächlichkeit nach geahmet.“

1038 Beides am 12. November 1728, Cod. Ms. Uffenbach 13/III, S. 7-10.

1039 3. Juni 1729, Cod. Ms. Uffenbach 13/III, S. 209-211.

Vgl. Agostino Ramelli, Schatzkammer mechanischer Künste, Leipzig 1620 ( $2^{\circ}$ Bibl. Uff. 193); Nicolas Grollier de Serviere, Recueil d'ouvrages curieux de Mathematique et de Mechanique, Lyon 1719 (4 Bibl. Uff. 311).

1040 23. Januar 1732, Cod. Ms. Uffenbach 13/IV, S. 468.

1041 Beides am 13. Februar 1733, Cod. Ms. Uffenbach 13/IV, S. 28-29.

1042 Beides am 1. Oktober 1734, Cod. Ms. Uffenbach 13/V, S. 355-356.
} 


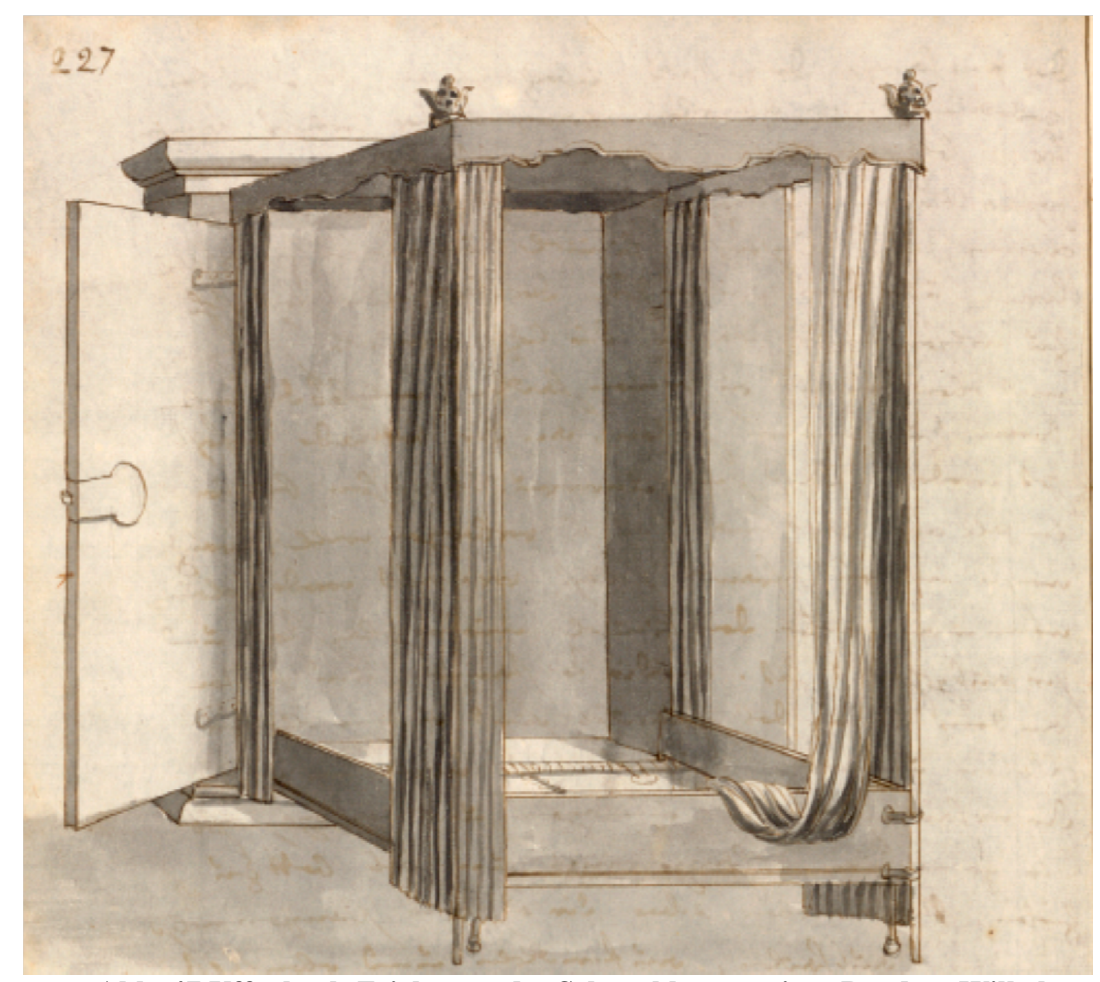

Abb. 47 Uffenbach Zeichnung des Schrankbettes seines Bruders Wilhelm in: Cod. Ms. Uffenbach 13/II, S. 227

Überblickt man die Gebiete, mit denen sich Wilhelm von Uffenbach beschäftigt hat, fällt auf, dass er anders als die übrigen Mitglieder kein ausgesprochenes Fachgebiet hatte sondern eher als Liebhaber rarer und nützlicher Dinge angesehen werden muss.

\subsubsection{Die Beiträge von Johann Friedrich Ettling}

Mit dem „Materialisten“ Johann Friedrich Ettling1044 konnte 1733 das einzige neue Mitglied der wissenschaftlichen Gesellschaft gewonnen werden. Der 1712 in Frankfurt geborene Ettling hatte eine große Materialwarenhandlung in der Neuen Kräme in Frankfurt am Main. Er besaß eine große Kunstsammlung mit Gemälden und Arbeiten auf Papier, daneben aber auch ein Naturalienkabinett. Philipp Friedrich Gwinner beschreibt 1862 dessen Sammlung als „eine der bedeutendsten, welche Frankfurt jemals besessen, [sie] zählte 528 Oelgemälde der deutschen und niederländischen Schule [...], außerdem viele Kupferstiche und Radirungen, 
worunter das Werk Rembrandt's fast vollständig; auch Statuen, Basreliefs, Bronze etc.“ Innerhalb der Gesellschaft wurde diese Sammlung kaum besprochen. Da Ettling Junggeselle geblieben war, gingen nach seinem Tod im Jahre 1786 seine Sammlungen an seine Schwester. ${ }^{1045}$

Ettling besuchte die wissenschaftliche Gesellschaft interessehalber erstmals am 8. Mai 1733 im Hause von Johann Georg Kißner, wobei Ettling einen vollkommen ausgelösten Schildkrötenpanzer vorführte. ${ }^{1046}$ Das erste Treffen in seinem Haus fand am 6. November des Jahres statt, bei dem Ettling als neues Mitglied begrüßt wurde. ${ }^{1047}$ Hier zeigte er aus seiner eigenen Sammlung ,alle erdenckliche Gattungen von denen so genanten Bezoarsteinen, nebst allen daraus bereideten Arzeneyen und Vermischungen."1048 Um die Bezoarsteine - auch Magensteine genannt - der Gesellschaft näher bringen zu können, hielt er einen Vortrag mit dem Thema „Historische Untersuchung des Bezoarsteins nach allen Gattungen"1049

Überblickt man seine Beiträge, die er innerhalb der Gesellschaft hielt, lässt sich kein besonderes Spezialgebiet Ettlings feststellen. Neben seiner eigenen Sammlung nutzte Ettling die Waren seines Geschäfts. So führte er zum Beispiel „das Cranium eines Seekalbes“, 1050 eine in Spiritus eingelegte Sepia, ${ }^{1051}$ Kerzen aus der Fertigung italienischer Klöster, ${ }^{1052}$ feines italienisches Wachstuch für Mäntel, ${ }^{1053}$ Trinkgläser aus Murano, ${ }^{1054}$ Halbedel- und Edelsteine von guter und schlechter Qualität, ${ }^{1055}$ orientalische Perlenschnüre im Vergleich mit Imitaten aus Murano ${ }^{1056}$ und echten und falschen Mastix vor. ${ }^{1057}$ Außerdem zeigte er einen

Gwinner 1862, S. 534, Anm. 6.

Die Sammlung Ettling lässt sich nicht mehr rekonstruieren, da nach dem Tod der Schwester das Erbe nochmals unter deren vier Kindern aufgeteilt und dann einzeln verkauft wurde.

1046 Cod. Ms. Uffenbach 13/V, S. 97-98.

1047 Cod. Ms. Uffenbach 13/V, S. 182-195.

1048 Cod. Ms. Uffenbach 13/V, S. 184.

1049 Cod. Ms. Uffenbach 13/V, S. 185-193.

Bei Bezoarsteinen oder -kugeln handelt es sich um verhärtete Verklumpungen von Haaren, die z.B. von Greifvögeln oder Katzen im Magen gebildet und nach längerer Zeit wieder ausgewürgt werden.

1050 25. Juni 1734, Cod. Ms. Uffenbach 13/V, S. 325.

Bei ,cranium“ oder „granium“ handelt es sich um einen Schädel.

1051 25. Juni 1734, Cod. Ms. Uffenbach 13/V, S. 326-328.

1052 25. Juni 1734, Cod. Ms. Uffenbach 13/V, S. 336.

1053 21. Januar 1735, Cod. Ms. Uffenbach 13/V, S. 412.

1054 21. Januar 1735, Cod. Ms. Uffenbach 13/V, S. 413.

1055 1. April 1735, Cod. Ms. Uffenbach 13/V, S. 489-491.

1056 29. Mai 1736, Cod. Ms. Uffenbach 13/V, S. 618. 
faustgroßen, zerschlagenen Pferdeblasenstein, vier kreisrunde Magensteine eines Pferdes, das „granium“ eines Seerosses, das er von einem Freund aus der Nachlassenschaft eines Amsterdamer Materialienhändlers hatte ersteigern lassen, einen ausgetrockneten Fisch mit Horn namens Remora ${ }^{1058}$, einen ausgetrockneten Affen, ein ineinandergewachsenes Rhinozeros-Horn, einen kleinen „Schiltgrottenpanzer“, dessen Schuppen ganz frei lagen und nur an einer Stelle angewachsen waren, ein zartes Seegewächs sowie ausgetrocknete Vogelköpfe mit großen Schnäbeln. ${ }^{1059}$

Am 27. Dezember 1737 legte er der Gesellschaft zwei Gemälde des Wiener Malers Philipp Ferdinand Hamilton (1666-1750) vor, die Jagd- oder Tierstücke vorstellten. ${ }^{1060}$ Hamilton war im 18. Jahrhundert ein sehr beliebter Tier- und Stillebenmaler. Ettling hatte die Gemälde von Hamilton aus Wien zur weiteren Spedition zugeschickt bekommen. Uffenbach beschreibt die Gemälde: „Beyde waren einer Größe, ohngefehr 2 Schu breit und 1 1/2 hoch, und stelleten nach dieses bekanten großen Meisters Art, Jagd oder Thierstücke vor, welche von gantz ungemeiner Zartigkeit und mit erstaunlichen Gedult gemahlet waren. Die getödete übereinander liegende Thiere und Gevögel zeigeten die pure Nathur, und sind auch allem Vermuthen nach darnach verfertiget. So fein aber immer mehr der Pinsel schiene, so hatten doch die anwesende Kunstverständige etwas wieder die Haltung der gantzen Mahlereyen in ihren Coloritten einzuwenden, als welche ein wenig hart und krell abstechend heraus kame.“

Ein besonderes Interesse Ettlings lag auf der Verarbeitung von Korn, was ebenfalls mit seinen Geschäften zu tun hatte. So zeigte er am 22. Januar $1734 \mathrm{im}$ Hause Eberhards eine von ihm erfundene kleine Kornwaage mit verschiedenen Meßbechern. ${ }^{1061}$ In seinen eigenen Räumen hielt er am 21. Januar 1735 einen Vortrag über eine „Maschine von Fruchtböden“1062 und eine „Scheuermaschine zum Reinigen von Korn“,1063 am 27. Dezember des Jahres führte er ein Modell einer Panstermühle vor ${ }^{1064}$ und am 6. Dezember 1738 griff er das Thema in

1057 27. Dezember 1737, Cod. Ms. Uffenbach 13/V, S. 700.

1058 Fische der Gattung Remora sind so genannte Schiffshalter. Dabei handelt es sich um Fische, die am Kopf eine aus der ersten Rückenflosse gebildete Saugplatte besitzen, mit denen sie sich an größere Wirtsfische anheften können.

1059 6. Dezember 1738, Cod. Ms. Uffenbach 13/V, in S. 724-741.

1060 Cod. Ms. Uffenbach 13/V, S. 696-697.

1061 Cod. Ms. Uffenbach 13/V, S. 219.

1062 Gemeint ist hiermit ein Aufbewahrungsschrank für Obst.

1063 Cod. Ms. Uffenbach 13/V, S. 417-421.

1064 Cod. Ms. Uffenbach 13/V, S. 698-699. 
seinem Vortrag „Beschreibung aller Theile und Werckzeuge einer Mahlmühle“ nochmals auf. 1065

Die Beiträge des „Materialisten“ Ettling sind eng mit seinem Beruf als Materialienhändler verknüpft, da er häufig Maschinen zum Bearbeiten von Korn oder seltene Waren aus seinem Kontor zeigte. Auffällig wenig erfahren die Mitglieder der Gesellschaft über dessen eigene große Kunstsammlung.

\subsection{Resümée}

Zusammenfassend beurteilt stellt die 1725 von Johann Friedrich Armand von Uffenbach gegründete wissenschaftliche Gesellschaft, deren fünf erhaltene Protokollbände den Titel „Wochentliche Sammlung der in Nützlichen Neben Stunden angestelten Untersuchungen der Natur und Kunst, welche zu einer Gemüths- Ergötzung dieienige Gesellschaft veranlasset, deren Denckspruch ist: Quo simplicius eo perfectius“ tragen, für die erste Hälfte des 18. Jahrhunderts ein Novum dar. Diese erste bürgerliche Gesellschaft bestand bis Mitte des Jahres 1740, 1066 wenn nicht sogar weit darüber hinaus, da sich im zweiten Band der Protokolle auf Seite 185 die Randnotiz mit dem Hinweis auf einen wohl mehr als 682 Seiten starken, heute verschollenen, sechsten Band befindet. 1067

Der Gründer Uffenbach hatte auf seinen ausgiebigen Reisen durch Westeuropa die verschiedensten Akademien und deren Veranstaltungen besucht und sich durch diese anregen lassen, auf Frankfurts Boden etwas Ähnliches zu etablieren. Während des Bestehens informierten sich die Mitglieder über Neugründungen von Akademien, wie beispielsweise die Akademie der Wissenschaften in St. Petersburg, die 1724 von Zar Peter dem Großen (1672-1725) initiiert worden war. ${ }^{1068}$

Bei einer Panstermühle handelt es sich um eine Wassermühle, deren unterschlächtiges Wasserrad mit Hilfe von sogenanntem Pansterzeug je nach Wasserstand gehoben und gesenkt werden kann.

1065 Cod. Ms. Uffenbach 13/V, S. 730-741.

1066 S. Randnotiz in Cod. Ms. Uffenbach 13/V, S. 631.

1067 S. Cod. Ms. Uffenbach 13/II, S. 185: „vid tom 4. p.434 / und tom 6. p.682.“

Dieser sechste Protokollband ist nicht nach Göttingen gekommen. Er erscheint auch weder im Verzeichnis der Uffenbachischen Bücher (Cod. Ms. Uffenbach 47) noch in den drei Supplementen (Bibl. Arch. A 34 C).

1068 Vgl. die vier Briefe von dem Professor für Morallehre und Mitglied der Petersburger Akademie Christian Friedrich Gross († 1742) in: Cod. Ms. Uffenbach 20/I, Bl. 92a-97 und Cod. Ms. Uffenbach 13/II, S. 98. 
Betrachtet man sich die Gebiete, wie Astronomie, Physik, Chemie, Botanik, Kunst etc., mit denen sich die Mitglieder beschäftigten, sind Entsprechungen zu den Akademien beispielsweise in Paris und London festzustellen. Die Frankfurter Gesellschaft unterscheidet sich aber von den anderen darin, dass sie sich nie an einen fürstlichen oder königlichen Hof gebunden hat, sondern immer eigenständig und unabhängig blieb. Das genaue Gegenteil ist die 1652 von vier Ärzten in Schweinfurt gegründete „Academia Naturae Curiosorum“, die im August 1677 von Kaiser Leopold I. offiziell bestätigt und zehn Jahre später von ihm mit Privilegien ausgestattet wurde. Seitdem lautete ihr offizieller Namen: „Sacri Romani Imperii Academia Caesareo-Leopoldina Naturae Curiosorum“ oder in Kurzform: „Leopoldina.“1069

Zudem kann man hinsichtlich der Wirkung der Wissenschaftlichen Gesellschaft nach außen ebenfalls Vergleiche zu etablierten Akademien anstellen. Innerhalb Frankfurts stieß die Gesellschaft durchaus auf Interesse, auch wenn nur ein neues, dauerhaftes Mitglied in Gestalt von Johann Friedrich Ettling gefunden werden konnte. Immer wieder besuchten Frankfurter Wissenschaftler oder Sammler, wie Heinrich Jakob von Häckel oder Heinrich Christian von Senckenberg, die Sitzungen oder sendeten wie im Falle Heinrich von Uchelns Objekte zur Begutachtung.

Ebenso erlangte die Wissenschaftliche Gesellschaft einen gewissen Bekanntheitsgrad außerhalb Frankfurts. Sporadisch nahmen auswärtige Wissenschaftler an den Sitzungen teil, wie der Laubacher Mediziner Strich, der Kölner Räuspling, der als Erfinder eines Probierofens zum Überprüfen von Münzen vorgestellt wurde, der Wiesbadener Arzt Fleischmann und der Kasseler Heinrich Ludwig Muth. Sogar im Ausland war die Frankfurter Gesellschaft ein Begriff. 1729 wurde von dem in London lebenden Arzt Hampe, einem Vetter Albert Adolf Diesterwegs, eine Abschrift der Protokolle angefordert, damit Hampe diese der Englischen Königlichen Sozietät der Wissenschaften vorstellen konnte. 1070

Betrachtet man sich die Forschungs- und Wissensgebiete der einzelnen Mitglieder, wurden von ihnen in erster Linie schon veröffentlichte Erfindungen überprüft oder mit eigenen Verbesserungen vorgestellt. Alle Mitglieder hatten sich dem Prinzip der Gesellschaft „Je einfacher, desto besser“ verschrieben. Es

1069 Heute: Deutsche Akademie der Naturforscher.

Vgl.: $\quad$ https://www.leopoldina.org/de/ueber-uns/ueber-dieleopoldina/akademiegeschichte/akademiegeschichte-tabellarisch/ vom 24.01.2017.

1070 Vgl. Cod. Ms. Uffenbach 13/III, S. 256. 
kam aber ebenso vor, dass völlig eigenständige Erfindungen zu einzelnen Themen gemacht wurden. Hierzu zählen die Versuche Uffenbachs mit Bleiweiß und die Erfindung einer Kornwaage von Ettling.

Neben den einzelnen Hauptgebieten durchzieht ein roter Faden die Interessensgebiete. Alle Mitglieder behandelten die Themen Kunst- und Kunstpraktiken. Hier war es besonders Johann Friedrich Armand von Uffenbach, der mit seinem großen Thema Druckgraphik und ihre Techniken hervortrat. Er und die anderen stellten aber auch verschiedene Verfahren der Kunst und des Kunstgewerbes vor, so z. B. häufig Farb- und Firnisrezepte für alle Bereiche der bildenden Kunst. 


\section{Welchem Typus von Sammler gehört Johann Friedrich von Uffenbach an?}

Betrachtet man sich Sammlungen, die seit der Zeit um 1500 bis etwa 1700 entstanden sind, fällt als ein entscheidendes Sammlungskriterium auf: Die Eigentümer versuchen, sich von jedem Teil der Welt aus den verschiedensten Bereichen von Natur und Kunst ein Exemplar zu verschaffen, also den Makrokosmos im Mikrokosmos zu besitzen. ${ }^{1071}$ Bei den Sammlern herrscht die Meinung vor, dass sie durch die Betrachtung der verschiedensten Gegenstände die Ordnung der Welt begreifen können. Natur, Kunst und Wissenschaft verschmelzen dabei zu einer Einheit. Die Amsterdamer Ausstellung „De wereld binnen handbereik, Nederlandse kunst- en rariteitenverzamelingen“1072 zeigte dies 1992 exemplarisch an niederländischen Sammlungen. Einen großen Teil der dort behandelten Sammlungen hat Johann Friedrich von Uffenbach auf der Grand Tour mit seinem älteren Bruder Zacharias Conrad besucht. So konnte er seinen Blick also dort für Kunst- und Wunderkammern schulen. Auch auf seiner eigenen Kavalierstour durch die Schweiz, Italien und Frankreich besuchte er immer wieder Sammlungen dieses Typus‘. ${ }^{1073}$

Um 1700 erfolgt - ausgelöst durch die beginnende Aufklärung - ein langsamer Wechsel von den Kunst- und Wunderkammern hin zu spezialisierten Sammlungen. Es geht jetzt den Sammlern nicht mehr darum, die Welt im Ganzen zu erforschen und zu erkennen, sondern die Eigentümer fangen an, die Objekte aus Natur und Kunst zu separieren und in einzelne Abteilungen zu gliedern, um die einzelnen Exemplare zu untersuchen.1074 Auch für diese Art des Zusammentragens konnte Uffenbach auf seinen ausgedehnten Reisen aber auch in seiner Heimatstadt Frankfurt am Main ${ }^{1075}$ Beispiele finden und untersuchen. Als direktes Vorbild kann hier sein älterer Bruder Zacharias Conrad herangezogen

1071 Vgl. Schlosser 1908, Alsop 1982, Impey/MacGregor 1986, Bergvelt 1993, Bredekamp 1993, Elsner/Cardinal 1994, MacGregor 1994, Kat. Bonn 1994, Pomian 1998, Kat. Braunschweig 2000, Kat. Innsbruck/Wien 2006.

1072 Kat. Amsterdam 1992.

Vgl. auch Pomian 1998. S.o.

1073 S. das Kapitel 4.3 „Werdegang und größere Reisen.“

1074 Einen kurzen Überblick über die Genese und den Wandel der Kunst- und Wunderkammern in Spezialsammlungen gibt Beßler 2015, ausführlicher s. die Literatur in Anm. 1071.

1075 Vgl. Schmidt 1960, Kat Frankfurt 1982, 2, Kat. Frankfurt 1988 und Kat. Frankfurt 2012. 
werden. ${ }^{1076}$ Zacharias Conrad hatte in seinem Leben eine der größten Privatbibliotheken mit dem Spezialgebiet Historie aufgebaut. Bücher zur Mathematik und Physik, die in diese Richtung nicht gehörten, schied er aus und überließ sie 1725 seinem jüngeren Bruder Johann Friedrich.1077 Als weitere Beispiele sei hier nur auf die Sammlungen der Mitglieder der Frankfurter wissenschaftlichen Gesellschaft Johann Georg Kißner und Konrad Hieronymus Eberhard genannt Schwind verwiesen, die beide Spezialsammlungen mit Steinen, Mineralien, Muscheln etc. aufgebaut hatten. ${ }^{1078}$ Für Uffenbach ebenfalls vorbildlich war die Kunstsammlung des Frankfurter Bankiers Heinrich von Ucheln. ${ }^{1079}$ Ucheln hatte sich in seinem Sammlerleben auf das Zusammentragen von Gemälden spezialisiert. Sein Gemäldekabinett umfasste eine für Frankfurter Patrizier übliche Spezialisierung auf niederländische Künstler des 16. und 17. Jahrhunderts und eine größere Abteilung an deutschen insbesondere Frankfurter Malern des 17. und 18. Jahrhunderts. ${ }^{1080}$

Besonders auf seinen Reisen hatte Uffenbach die Möglichkeit, die unterschiedlichsten Sammlungen und ihre Eigentümer kennenzulernen. Hatte er durch seine gemeinsame Reise durch Niederdeutschland, die Niederlande und England von 1709 bis 1711 mit seinem Bruder Zacharias Conrad verschiedenste Typen von Sammlungen kennengelernt, ${ }^{1081}$ konnte er auf seiner eigenen Grand Tour durch die Schweiz, Italien und Frankreich von 1712 bis $1716^{1082}$ seine Kenntnisse und auch seine Vorstellungen der eigenen Kollektionen verfeinern. ${ }^{1083}$ Dies wird in seinen Tagebüchern besonders deutlich, da er nicht nur die denk- und merkwürdigsten Dinge der Sammlungen beschreibt, sondern häufig auch Kommentare zur Qualität abgibt. An dieser Stelle sei nur auf seine Charakterisierung der Sammlung Mariette ${ }^{1084}$ und auf seinen Besuch bei dem

Zu Zacharias Conrad von Uffenbach vgl. Franke 1965,1 und Franke 1965,2.

Vgl. das Kapitel 4 ,Lebenslauf des Johann Friedrich Armand von Uffenbach.“.

Vgl. das Kapitel 8.4.5 „Die Beiträge von Johann Georg Kißner“ und das Kapitel 8.4.4 „Die Beiträge von Conrad Hieronymus Eberhard gen. Schwind.“.

Vgl. Kapitel 8 „Die wissenschaftliche Gesellschaft des Johann Friedrich von Uffenbach“.

Vgl. Ucheln 1744 und das Kapitel 8 „Die wissenschaftliche Gesellschaft des Johann Friedrich von Uffenbach“.

Z.B. die umfangreichen Sammlungen in Schloss Saltzdahlum, das er 1710 mit seinem Bruder Zacharias Conrad besichtigt hatte, und nochmals 1728 nochmals aufsuchte. Vgl. Kapitel 4 „Lebenslauf des Johann Friedrich Armand von Uffenbach“.

Vgl. u.a. Kat. Braunschweig 1994.

Cod. Ms. Uffenbach 29/I-IV.

S. Kapitel 4 „Lebenslauf des Johann Friedrich Armand von Uffenbach“.

S. Kapitel 4 ,Lebenslauf des Johann Friedrich Armand von Uffenbach“. 
Abbé Louis Du Four de Longuerue ${ }^{1085}$ hingewiesen. Uffenbach vermerkt zu diesem am 15. Dezember 1715 in seinem Tagebuch: ,,...] er führte mich in sein zimmer also wir eine gute weile von allerhand außwärtigen gelehrten und bibliothequen sprachen, von welchen allen er eine sonderliche wißenschaft bezeigte. "1086 Die Diskussion konnte Uffenbach nur deshalb führen, weil er selbst viele dieser Bibliotheken besucht hatte. Dies gilt aber nicht nur für seine Kenntnisse Bibliotheken betreffend sondern allgemein für alle Sammlungsgebiete, mit denen er sich in seinen „Mußestunden“ beschäftigte.

Uffenbachs Sammlungsgegenstände umfassen hauptsächlich folgende Gebiete: ein druckgraphisches Kabinett zusammen mit einer kleinen Zeichnungssammlung, das Bestandteil seiner Spezialbibliothek war, und eine Sammlung von wissenschaftlichen Geräten zur Arithmetik, Geometrie, Mechanik, Optik und Perspektive, Gnomonik und Naturforschung. ${ }^{1087}$ Es handelt sich also nicht um eine Universalsammlung, wie man es von Kunst- und Wunderkammern behaupten kann, sondern um eine speziell auf Uffenbachs Person zugeschnitte Ansammlung von Gegenständen.

Vier Sammlungsgebiete, die Gemälde, die Zeichnungen, die Skulpturen und Reliefs ${ }^{1088}$ und das kleine Naturalienkabinett ${ }^{1089}$, haben bei Uffenbach nicht den Stellenwert wie die oben genannten. Man erfährt bei allen in Uffenbachs Briefen, den Protokollen der wissenschaftlichen Gesellschaft oder den Tagebüchern nichts über den Erwerb, die Qualität oder den Umfang der Stücke. Die Gemälde, Skulpturen und Reliefs scheinen lediglich als Ausstattungsstücke des Palais` auf der Zeil gedient zu haben, das Naturalienkabinett war ebenfalls nur Teil der patrizischen Repräsentation bzw. ein kleiner Versuch mit dem umfangreichen Naturalienkabinetten von Johann Georg Kißner und Albert Adolf Diesterweg gleich zu ziehen. Wie erwähnt, waren die etwa 1000 Zeichnungen, die er besaß, von geringerem Stellenwert als beispielsweise die Druckgraphik, da Uffenbach Zeichnungen für nicht abgeschlossene Werke hielt. ${ }^{1090}$

Ein weiterer Punkt, der Uffenbach von zeitgenössischen Sammlern und ihren Vorgängern unterscheidet, ist sein Streben danach, sein eigenes Wissen an andere weiterzugeben und selbst neues Wissen für sich zu erwerben. Sowohl das

\footnotetext{
1085 S. Kapitel 4 „Lebenslauf des Johann Friedrich Armand von Uffenbach“.

1086 Cod. Ms. Uffenbach 29/IV. S. 497.

1087 Ausführlicher dazu s. Kapitel 6 „Der Sammler Johann Friedrich von Uffenbach“.

1088 Uffenbach 1771, S. 42-57.

1089 Uffenbach 1771, S. 57-60.

1090 Vgl. das Kapitel 6.3 „Die Zeichnungssammlung.“
} 
langjährige Bestehen der von ihm initiierten wissenschaftlichen Gesellschaft als auch sein ausgiebiger Briefverkehr mit Partnern in ganz Europa belegen dies. Insbesondere seine wissenschaftliche Neugier, sich Neues anzueignen, aber auch dieses Wissen mitzuteilen, zeigen besonders seine ausführlichen Vorträge in der wissenschaftlichen Gesellschaft. Konnte Uffenbach in der Anfangszeit noch auf sein vorher schon erarbeitetes Wissen zurückgreifen - wie z.B. auf das Gebiet der Astronomie, das er in ausführlichen Vorträgen über einen Zeitraum von mehr als vier Jahren vorstellte, oder das Gebiet des Schleifens von optischen Linsen und Bauens von optischen und astronomischen Geräte -, musste er sich später in für ihn neue Bereiche einarbeiten. Dies kann besonders bei seinen Kenntnissen zur Druckgraphik gezeigt werden. Hatte Uffenbach in den einzelnen Sitzungen immer wieder sein Wissen bezüglich der Druckgraphik gezeigt, referierte er 1732 seinen Gesellschaftsmitgliedern in drei langen Vorträgen seine Geschichte der graphischen Künste. Er griff das Thema anlässlich einer angeblichen Erfindung einer neuen Drucktechnik - der des Naturdrucks - noch im selben und im darauffolgenden Jahr auf. Bevor er seine Referate hielt, hatte er sich sowohl einen Probedruck besorgt, eigene Versuche mit dieser Technik gemacht, als auch Briefpartner, seine Reisetagebücher und die Bücher seiner Bibliothek konsultiert. In seinen Beiträgen konnte er dann praktisch die Vor- und Nachteile dieser Technik aufzeigen und nachweisen, dass die angeblich neue Erfindung schon Jahre vorher in den Niederlanden gemacht worden war.

Zusammenfassend lässt sich der Frankfurter Patrizier Johann Friedrich Armand von Uffenbach als ein Vertreter eines neuen Sammlertypus‘ einordnen. Er war eben nicht der Connaisseur des ,,in der barocken Tradition verhafteten Typus des Universalsammlers"1091, der seine Stücke zum Vergnügen und zur Repräsentation sammelte, sondern die Dinge, die er zusammentrug, dienten ihm als Grundlage für seine wissenschaftlichen Interessen. Dies zeigt besonders seine Stiftung an die eben gegründete Georgia Augusta in Göttingen, in der nur solche Gegenstände Bibliothek mit graphischem Kabinett und wissenschaftliche Geräte - beinhaltet sind, mit denen er sich sein Leben lang intensiv beschäftigte.

1091 Hier irrt Cilleßen 2015, S. 252. 


\section{Literaturverzeichnis}

Das Literaturverzeichnis enthält alle Titel, die im Text und in den Anmerkungen zitiert werden. Darüber hinaus habe ich auch solche Titel aufgenommen, die mir bei der Konzeption der Arbeit und der Entwicklung der Fragestellung geholfen haben. aber im einzelnen nicht zitiert werden. Die Literatur wird in den Fußnoten durch Autor und Erscheinungsjahr bzw. Ausstellungs- und Bestandskataloge durch Ort und Erscheinungsjahr nachgewiesen.

Abbildung Feuerwercke $=$ Abbildung derer Feuerwercke und Illuminationen so in den Jahren 1741 und 1742 auf Befehl des außerordentlichen Hispanischen Gesandten Herrn Grafen von Montijo zu Franckfurt am Mayn bey der Wahl und Kroenung Ihrer Kayserl: Majestät Carl des VII. angegeben, zu Werck gerichtet, abgebrandt und gezeichnet Joh: Friedrich von Uffenbach.

Ackermann 1986 = Hans Christoph Ackermann, The Basle Cabinets of Art and Curiosities in the Sixteenth and Seventeenth Centuries, in: Impey/MacGregor 1986, S. 62-68.

Ahnsehl 1987 = Peter Ahnsehl, Zum Konzertschaffen Christoph Graupners, in: Bill 1987, S. 1-26.

Albrecht 1994 = Peter Albrecht, Braunschweig als kultureller Mittelpunkt in der zweiten Hälfte des 18. Jahrhunderts, in: Wolfenbütteler Beiträge, Aus den Schätzen der Herzog August Bibliothek, hrsg. von Paul Rabe, Bd. 9, Wiesbaden 1994, S. 31-54.

Alvensleben 1929 = Udo von Alvensleben, Herrenhausen, Die Sommerresidenz der Welfen, Berlin 1929 (= Kunstwissenschaftliche Studien Bd. II).

Alsop 1982 = Joseph Alsop, The rare Art Traditions, The History of Art Collecting and Its Linked Phenomena, whereever 
these have appeared, New York 1982 (= Bollingen Series XXXV)

Anonym 1790 = Beschreibung der Feyerlichkeiten bey der Wahl und Krönung eines deutschen Kaysers oder eines römischen Königs, nebst einer kurzen Erzählung von den Rechten eines deutschen Kaysers, Frankfurt am Mayn 1790.

Anonym 1791 = Kurzgefaßter Bericht von den bey der Wahl und Krönung eines römischen Kaysers gewöhnlichen Feierlichkeiten, ingleichen über Deutschlands Reichsverfassung, Kaiserwahl und Krönung aus der Geschichte und dem Staatsrecht gezogen, Frankfurt und Leipzig 1791.

Anonym $1840=$ Geschichte der Grafschaft Erbach und biographische Nachrichten über die Herren und Grafen zu Erbach von den ältesten bis zu den neuesten Zeiten, Erbach 1840.

Arndt 1986 = Karl Arndt, Die Göttinger Universitäts-Kunstsammlung, Geschichte und Aufgabe, Sonderdruck aus GEORGIA AUGUSTA November 1986, Nachrichten der Universität Göttingen.

Arnim 1928,1 = Max Arnim, Johann Friedrich Armand von Uffenbach's Tagebuch einer Spazierfarth durch die Hessische in die Braunschweig-Lüneburgischen Lande (1728), nach der unveröffentlichten Göttinger Handschrift hrsg. und eingeleitet von Max Arnim, Göttingen 1928.

Arnim 1928,2 = Max Arnim, Johann Friedrich Armand von Uffenbachs Reise durch die Pfalz 1731, hrsg. von Max Arnim, Mannheim 1928, (= Mannheimer Altertumsverein, Kleine Schriften / Heft 2).

Arnim 1928,3 = Max Arnim, Johann Friedrich Armand v. Uffenbachs Schenkung an die Göttinger Universitäts-Bibliothek (1736- 
1770), in: Beiträge zur Göttinger Bibliotheks= und Gelehrtengeschichte, hrsg. und den Teilnehmern der 24. Versammlung deutscher Bibliothekare gewidmet von der Universitäts-Bibliothek, Göttingen 1928 (= Vorarbeiten zur Geschichte der Göttinger Universität und Bibliothek, hrsg. vom Universitätsbund Göttingen, 5. Heft).

Arnim 1928,4 = Max Arnim, Mitgliederverzeichnisse der Gesellschaft der Wissenschaften zu Göttingen (1751-1927), in ihrem Auftrag zusammengestellt, Göttingen 1928.

Arnim 1930,1 = Max Arnim (Hrsg.), Johann Friedrich von Uffenbach, Pharasmanes, Ein Singspiel in 15 Bühnenbildern von ..., nach der unveröffentlichten Göttinger Handschrift hrsg. von Max Arnim, Berlin 1930.

Arnim 1930,2 = Max Arnim, Joh. Friedr. von Uffenbachs „Pharasmanes“. Ein unveröffentlichtes Singspiel aus dem Jahre 1720, in: Alt-Frankfurt, Geschichtliche Zeitschrift für Frankfurt und seine Umgebung, 3.Jg./1930, S. 119120.

Arnswaldt 1909 = W. C. von Arnswaldt, Die Uffenbach in Frankfurt, in: Frankfurter Blätter für Familien=Geschichte, hrsg. von Karl Kiefer, 2.Jg., Frankfurt am Main 1909, S. 42-44.

Battonn 1871 = Johann Georg Battonn, Oertliche Beschreibung der Stadt Frankfurt am Main, aus dessen Nachlasse hrsg. von dem Vereine für Geschichte und Alterthumskunde zu Frankfurt a.M. durch den zeitigen Direktor desselben L.H. Euler, sechstes Heft, die Beschreibung des übrigen Theils der Neustadt enthaltend, Frankfurt am Main 1871.

Bauer 1983 = Michael Bauer, Christoph Weigel (1654-1725), Kupferstecher und Kunsthändler in Augsburg und Nürnberg, Frankfurt am Main 1983 (= Sonderdruck aus dem „Archiv für 
Geschichte des Buchwesens“ Bd. XXIII, Lief. 4-6, Frankfurt am Main 1982).

Beck 1981 = Hans-Ulrich Beck, Anmerkungen zu den Zeichnungssammlungen von Valerius Röver und Goll van Franckenstein, in: Nederlands Kunsthistorisch Jaarboek 1981, Bd. 32, S. $111-125$.

Becker 1836 = Carl Ferdinand Becker, Systematisch chronologische Darstellung der musikalischen Literatur von der frühesten bis auf die neueste Zeit. Nebst biographischen Notizen über die Verfasser der darin aufgeführten Schriften und kritischen Andeutungen über den innern Werth derselben, 1. Lieferung, Dresden 1836.

Becker 1937 = Josef Becker, Die Bibliothek des Zacharias Konrad von Uffenbach, in: Festschrift Georg Leyh, 1877-1737, Aufsätze zum Bibliothekswesen und zur Forschungsgeschichte, Leipzig 1937, S. 129-148.

Beckmann 1777 = Johann Beckmann, Anleitung zur Technologie oder zur Kenntnis der Handwerke, Fabriken und Manufakturen vornehmlich derer, die mit der Landwirthschaft, Polizey- und Cameralwissenschaft in nächster Verbindung stehen. Nebst Beyträgen zur Kunstgeschichte, Göttingen 1777.

Beckmann 1978 = Johann Beckmann, Vorbereitung zur Waarenkunde, oder zur Kentniß der vornehmsten ausländischen Waaren, mit einem Nachwort von Günter Grundke, Leipzig 1978 (Reprint der Ausgabe Göttingen 1724, 1796, 1800).

Beckmann 1990 = Johann Beckmann, Vorrath kleiner Anmerkungen über mancherley gelehrte Gegenstände, Auszugsweiser Abdruck der Ausgabe Göttingen 1795, 1803, 1806, hrsg. von Manfred Beckert, Leipzig 1990.

Bergvelt 1993 = Ellinoor Bergvelt, Debora J. Meijers, Mieke Rijnders (Hrsg.), Verzamelen, Van Rariteitenkabinet tot Kunstmuseum, Heerlen 1993. 
Beutler $1981=$ Ernst Beutler, Am Großen Hirschgraben, Goethes Vater, Schwester und Mutter, Zürich und München 1981.

Bill 1987 = Oswald Bill (Hrsg.), Christoph Graupner, Hofkapellmeister in Darmstadt, 1709-1760, Mit Beiträgen zu Graupners Leben und Werk, Mainz 1987 (= Beiträge zur Mittelrheinischen Musikgeschichte, hrsg. von der AG für mittelrheinische Musikgeschichte, Bd. 28), Mainz 1987.

Bill 1987,1 = Oswald Bill, Dokumente zum Leben und Wirken Christoph Graupners in Darmstadt, in: Bill 1987, S. 73-212.

Bobé 1938 = Louis Bobé, Beziehungen Frankfurts zu Kopenhagen in der Goethezeit, in: Archiv für Frankfurts Geschichte und Kunst, IV. Folge, 5. Bd., 1. Heft, Frankfurt am Main 1938, S. 45-61.

Bode 1961 = Hermann Bode, Nachrichten über Pariser Bibliotheken, Aus einem Reisetagebuch des Johann Friedrich Armand von Uffenbach, Göttingen 1961 (Mss.).

Bodemann 1885 = Eduard Bodemann, Zur Gründungsgeschichte der Universität Göttingen. Heumann's Correspondenz mit dem Geh. Rat G. A. v. Münchhausen, in: Zeitschrift des historischen Vereins für Niedersachsen, hrsg. unter Leitung des Vereins-Ausschusses, Jahrgang 1885 und 47. Nachricht über den historischen Verein für Niedersachsen, Hannover 1885.

Boetticher 1966 = Wolfgang Boetticher, Uffenbach, Johann Friedrich Armand von, in: Die Musik in Geschichte und Gegenwart, Allgemeine Enzyklopädie der Musik, hrsg. von Friedrich Blume, Bd. 13, Syrinx-Volksgesang, Volksmusik und Volkstanz, Kassel, Basel Paris et. al. 1966, Sp. 1019-1021.

Bogeng 1913 = Gustav Adolf Erich Bogeng, Über Zacharias Conrad von Uffenbachs Erfahrungen und Erlebnisse bei der Benutzung deutscher, englischer, holländischer 
öffentlicher Büchersammlungen in den Jahren 17091711, in: Beiträge zum Bibliotheks- und Buchwesen, Paul Schwenke zum 20. März 1913 gewidmet, hrsg. von A. Hortzschansky, Berlin 1913, S. 30-46.

Bogeng 1922 = Gustav Adolf Erich Bogeng, Die Großen Bibliophilen, 3 Bde., Leipzig 1922.

Bothe 1929 = Friedrich Bothe, Geschichte der Stadt Frankfurt am Main, 3. erw. Aufl., Frankfurt am Main 1929 (Reprint Frankfurt am Main 1977).

Braun 1930 = Friedrich Braun, D. Johann Georg Schelhorn's Briefwechsel, mit einer Einleitung und Erläuterungen herausgegeben, München 1930 (= Schriftenreihe zur bayerischen Landesgeschichte, hrsg. von der Kommission für bayerische Landesgeschichte bei der Bayerischen Akademie für Wissenschaften, Bd. 5).

Braungart 1989 = Wolfgang Braungart, Die Kunst der Utopie, Vom Späthumanismus zur frühen Aufklärung, Stuttgart 1989.

Bredekamp 1993 = Horst Bredekamp, Antikensehnsucht und Maschinenglauben, Die Geschichte der Kunstkammer und die Zukunft der Kunstgeschichte, Berlin 1993 (= Kleine Kulturwissenschaftliche Bibliothek Bd. 41).

Brednow $1966=$ Walter Brednow, Beinamen in wissenschaftlichen Gesellschaften und Zirkeln, Ein Beitrag zur anthropologischen Bedeutung der cognomina, in: Archiv für Kulturgeschichte 48. Bd., Köln-Graz 1966, S. 242-261.

Brilli 1989 = Attilio Brilli, Reisen in Italien, Die Kulturgeschichte der klassischen Italienreise vom 16. bis 19. Jahrhundert, Köln 1989.

Busch 1830 = Encyclopädisches Wörterbuch der medicinischen Wissenschaften, hrsg. v. D.W.H. Busch, C.F.v. Gräfe et. al., 4. Bd. (Attrahentia - Band.), Berlin 1830. 
Cahn 1986 = Peter Cahn (Hrsg.), Karl Israel, Frankfurter Concert-Chronik von 1721-1780, Reprographischer Nachdruck der Ausgabe von 1876 mit einem Vorwort, Anhang und Register (= Edition Peters Nr.8602), Frankfurt-New York-London 1986.

Canisius 1999 = Claus Canisius, Goethe und die Musik, München 1999.

Capitani 1993 = François de Capitani, Wissenschaft und Sozietätsbewegung im 18. Jahrhundert, in: Wissenschaft, Gesellschaft und politische Macht, hrsg. von Erwin Neuenschwander, Basel 1993, S. 57-68.

Christ $1747=$ Johann Friedrich Christ, Anzeige und Auslegung der Monogrammatum, einzeln und verzogenen Anfangsbuchstaben der Nahmen, auch anderer Züge und Zeichen, unter welchen berühmte Mahler, Kupferstecher und andere dergleichen Künstler, auf ihren Wercken sich verborgen haben, Leipzig 1747.

Christ $1750=$ Johann Friedrich Christ, Dictionnaire des monogrammes, chiffres, lettres, initials, logogryphe, rébus sous lequels le plus célèbres peintres, graveurs et dessinateurs ... ont dessiné leurs noms, Paris 1750.

Christ 1757 = Catalogue D'Une Grande Collection D'Estampes Des Meilleurs Maitres D'Italie, De Flandres, De France Et D'Allemagne Du Feu Mr. Christ Celebre Professeur De L'Academie De Leipsic, Leipzig 1757.

Cilleßen 2015 = Wolfgang P. Cilleßen, ,mit grossen Kosten succesive gesammelte schöne Collectiones“, Herzog Anton Ulrich von Sachsen-Meiningen und das Frankfurter Kunstleben um 1750, in: Anton Ulrich 1687-1763, Herzog von Sachsen-Meiningen, Ein Leben zwischen Eigensinn und Leidenschaft (= Südthüringer Forschungen, $\mathrm{Bd}$. 34), Meiningen 2015, S. 233-280. 
Daston / Park 2001 = Lorraine Daston, Katherine Park, Wonders and the Order of Nature, 1150 - 1750, New York 2001.

Dietz $1897=$ Alexander Dietz, Frankfurter Bürgerbuch, Geschichtliche Mittheilungen über 600 bekannte Frankfurter Familien aus der Zeit vor 1806, Frankfurt am Main 1897.

Döry 1958 = Baron Ludwig Döry, Paul Egell und Johann Friedrich von Uffenbach, in: Mannheimer Hefte 1958, 2, S. 19-21.

Döry 1962 = Baron Ludwig Döry, Balthasar Neumann und die Brüder von Uffenbach, in: Stifter-Jahrbuch Bd. VII, hrsg. von Helmut Preidel, München 1962, S. 247-256.

Donner-von Richter 1901 = Otto Donner-von Richter, Philipp Uffenbach 15661636 und andere gleichzeitig in Frankfurt a. M. lebende Maler, in: Archiv für Frankfurts Geschichte und Kunst, hrsg. von dem Verein für Geschichte und Alterthumskunde zu Frankfurt am Main, 3. Folge, 7.Bd/1901, Frankfurt am Main 1901, S. 1-220.

Dreier $1986=$ Franz Adrian Dreier, The Kunstkammer of the Hessian Landgraves in Kassel, in: Impey/MacGregor 1986, S. 102-109.

Duchardt 1991 = Heinz Duchardt, Frankfurt am Main im 18. Jahrhundert, in: Frankfurt am Main, Die Geschichte der Stadt in neun Beiträgen, hrsg. von der Frankfurter Historischen Kommission, Sigmaringen 1991 (= Veröffentlichungen der Frankfurter Historischen Kommission Bd. XVII), S. 261-302.

Dülmen 1982 = Richard van Dülmen, Die Aufklärungsgesellschaften in Deutschland als Forschungsproblem, in: Die Bildung des Bürgers, Die Formierung der bürgerlichen Gesellschaft im 18. Jahrhundert, hrsg. von Ulrich Herrmann (= Geschichte des Erziehungsund Bildungswesens in Deutschland hrsg. von Ulrich Herrmann, Bd. 2) Weinheim und Basel 1982, S. 81-99. 
Dülmen, 1996 = Richard van Dülmen, Die Gesellschaft der Aufklärer, Zur bürgerlichen Emanzipation und aufklärerischen Kultur in Deutschland, Frankfurt am Main 1996².

Eitner 1904 = Robert Eitner, Biographisch-bibliographisches Quellenlexikon der Musiker und Musikgelehrten der christlichen Zeitrechnung bis zur Mitte des 19. Jahrhunderts, 10 Bde., Leipzig 1900-1904, Bd. 10, Leipzig 1904.

Elsner/Cardinal 1994 = John Elsner, Roger Cardinal (Hrsg.), The Culture of Collecting, Cambridge MA 1994.

Emmerling 1953 = Ernst Emmerling, Die Gemälde Johann Georg Dathans, in: Pfälzer Heimat, 4. Jg./1953, Heft 2, S. 33-37.

Emmerling 1959 = Ernst Emmerling, Johann Georg Dathan und Johann Friedrich von Uffenbach, in: Pfälzer Heimat, 10. Jg./1959, Heft 4, S. 138-140.

Engelke 1908 = Bernhard Engelke, Johann Friedrich Fasch, Versuch einer Biographie, in: Sammelbände der Internationalen Musikgesellschaft, Jg. X/1908/09, S. 263-283.

Exner $1878=$ Wilhelm Franz Exner, Johann Beckmann, Begründer der technologischen Wissenschaft, Vortrag gehalten im k.k. österreich. Museum für Kunst und Industrie, Wien 1878 (Reprint mit einem Anhang von Ulrich Troitzsch, Hoya 1989).

Fabian 1977,1 = Bernhard Fabian, Göttingen als Forschungsbibliothek im achtzehnten Jahrhundert. Plädoyer für eine neue Bibliotheksgeschichte, in Raabe 1977, S. 209-239.

Fabian 1977,2 = Ursula Fabian, Deutsche Reisende des 18. Jahrhunderts in englischen Bibliotheken, in: Raabe 1977, S. 91-117. Fachlexikon 1992 = Fachlexikon abc Forscher und Erfinder, hrsg. von HansLudwig Wußing, Hans Dietrich, Walter Purkert und Dietrich Tutzke, Thun, Frankfurt am Main 1992.

Fechner 1977 = Jörg-Ulrich Fechner, Die Einheit von Bibliothek und Kunstkammer im 17 . und 18. Jahrhundert, 
dargestellt an Hand zeitgenössischer Berichte, in: Raabe 1977, S. 11-31.

Feulner 1938 = Adolf Feulner, Frankfurt/M, aufgenommen von der Staatl.

Bildstelle, beschrieben von Adolf Feulner, Berlin 1938.

Fichards Geschlechtergeschichte $=$ Johann Karl von Fichard's Geschichte der Geschlechter von Frankfurt a.M., Fasz. Nr.306 / Uffenbach, msct. im Institu für Stadtgeschichte Frankfurt am Main.

Findlen 1994 = Paula Findlen, Possessing Nature, Museums, Collecting, and Scientific Culture in Early Modern Italy (= Studies on the History of Society and Culture, ed. by Victoria E. Bonnell and Lynn Hunt, Nr. 20), Berkely et. al. 1994

Forkel 1792 = Johann Nicolaus Forkel, Allgemeine Litteratur der Musik oder Anleitung zur Kenntniß musikalischer Bücher, Systematisch geordnet und nach Veranlassung mit Anmerkungen und Urtheilen begleitet, Leipzig 1792.

Franke $1965,1=$ Konrad Franke, Zacharias Conrad von Uffenbach als Handschriftensammler. Ein Beitrag zur Kulturgeschichte des 18. Jahrhunderts, in: Börsenblatt für den Deutschen Buchhandel Frankfurter Ausgabe - Nr. 51, 29. Juni 1965, S. 1235-1338 (auch in: Archiv für Geschichte des Buchwesens Bd. VI).

Franke 1965,2 = Konrad Franke, Zacharias Conrad von Uffenbach als Sammler von Antiquitäten, Autogrammen und Münzen, in: Archiv für Frankfurts Geschichte und Kunst Bd. 49., Frankfurt am Main 1965, S. 87-98.

Frankfurt Chronik 1964 = Frankfurt Chronik, hrsg. und verlegt von Waldemar Kramer, Frankfurt am Main 1964.

Frankfurter Biographie $=$ Frankfurter Biographie, Personengeschichtliches Lexikon, i.A. der Frankfurter Kommission, hrsg. von 
Wolfgang Klötzer, bearb. von Reinhard Frost und Sabine Hock, 2 Bde., Frankfurt am Main $1994+$ 1996 (= Veröffentlichungen der Frankfurter Historischen Kommission XIX / 1 + 2).

Frankfurter Hausblätter 1881 = Frankfurter Hausblätter, Aus Vergangenheit und Gegenwart, hrsg. von Franz Rittweger, Frankfurt am Main 1881, N.F.1, No.5, S. 39-40 und No. 6, S. 48.

Frankfurter Nachrichten 1775,1 = Ordentliche wochentliche Franckfurter Frag= und Anzeigungs=Nachrichten, No. XL, Freytags, den 12, May 1775, Extraordinairer_Anhang No. 40. 1775 .

(Quelle:

https://babel.hathitrust.org/cgi/pt?id=njp.321010804 61096; view=1up;seq=425 vom 10.05.2016).

Frankfurter Nachrichten 1775,2 = Ordentliche wochentliche Franckfurter Frag= und Anzeigungs=Nachrichten, No. XLI, Dienstags, den 16, May 1775, Extraordinairer_Anhang No. 41. 1775 .

(Quelle:

https://babel.hathitrust.org/cgi/pt?id=njp.321010804 61096;view=1 up;seq=425 vom 10.05.2016).

Gall 1989 = Lothar Gall, Bürgertum in Deutschland, Berlin 1989.

Gerber 1792 = Ernst Ludwig Gerber, Historisch-biographisches Lexicon der Tonkünstler, welches Nachrichten von dem Leben und den Werken musikalischer Schriftsteller enthält, Leipzig 1790-92 (2 Teile), Teil 2, 1792.

GGA = Göttingische Anzeigen von Gelehrten Sachen, unter der Aufsicht der Königl. Gesellschaft der Wissenschaften, Göttingen $1753 \mathrm{ff}$.

Goethe Gedenkausgabe = Johann Wolfgang Goethe, Gedenkausgabe der Werke, Briefe und Gespräche, hrsg. von Ernst Beutler, 24 Bde. + 3 Erg.Bde., Zürich und Stuttgart 1948-1971.

Goethe Werke = Johann Wolfgang Goethe, Sämtliche Werke, Briefe, Tagebücher und Gespräche, hrsg. von Dieter Borchmeyer, 
Martin Ehrenzeller, Karl Eibl et. al., 40 Bde., Frankfurt am Main.

Goldschmidt 1915 = Hugo Goldschmidt, Die Musikästhetik des 18. Jahrhunderts und ihre Beziehungen zu seinem Kunstschaffen, Zürich und Leipzig 1915.

Gundelach 1957 = Ernst Gundelach, Die Königlichen Commissarien, Prorectoren und Rektoren der Georg-August-Universität zu Göttingen, 1734-1957, Göttingen 1957.

Grosse/Jung 1972 = Hans Grosse und Hans Rudolf Jung (Hrsg.), Georg Philipp Telemann, Briefwechsel, Sämtliche erreichbare Briefe von und an Telemann, Leipzig 1972.

Großpietsch 1994 = Christoph Großpietsch, Graupners Ouverturen und Tafelmusiken, Studien zur Darmstädter Hofmusik und thematischer Katalog $(=$ Beiträge zur Mittelrheinischen Musikgeschichte, hrsg. von der AG für mittelrheinische Musikgeschichte, Bd. 32), Mainz 1994.

Grote 1994 = Andreas Grote (Hrsg.), Macroscosmos in Microcosmo. Die Welt in der Stube. Zur Geschichte des Sammelns 1450 bis 1800 (= Berliner Schriften zur Museumskunde Bd. 10), Opladen 1994.

Gwinner $1862=\mathrm{Ph}$. Friedrich Gwinner, Kunst und Künstler in Frankfurt am Main vom dreizehnten Jahrhundert bis zur Eröffnung des Städel'schen Kunstinstituts, Frankfurt am Main 1862 (Reprint Leipzig 1975).

Gwinner $1867=$ Ph. Friedrich Gwinner, Zusätze und Berichtigungen zu Kunst und Künstler in Frankfurt am Main vom dreizehnten Jahrhundert bis zur Eröffnung des Städel'schen Kunstinstituts, Frankfurt am Main 1867 (Reprint Leipzig 1975).

Hagedorn 1755 = Christian Ludwig von Hagedorn, Lettre à un Amateur de la Peinture, avec des Eclaircissemens historiques sur 
un Cabinet et les Auteurs des Tableaux qui le composent, Dresden 1755.

Hagedorn 1797 = Christian Ludwig von Hagedorn, Briefe über die Kunst von und an ..., hrsg. von Torkel Baden, Leipzig 1797.

Hansert 1992 = Andreas Hansert, Bürgerkultur und Kulturpolitik in Frankfurt am Main. Eine historisch-soziologische Rekonstruktion, Mit einer Einführung von Ulrich Oevermann, Frankfurt am Main 1992 (= Studien zur Frankfurter Geschichte, hrsg. von Wolfgang Klötzer und Dieter Rebentisch, Bd. 33).

Harms 1742 = Antoine Frederic Harms, Table historiques et chronologoque des plus fameux peintres anciens et modernes, Braunschweig 1742.

Hartmann/Füchsel 1937 = Karl Julius Hartmann und Hans Füchsel (Hrsg.), Geschichte der Göttinger Universitäts=Bibliothek, verfaßt von Göttinger Bibliothekaren, Göttingen 1937.

Haymann 1743 = Christoph Haymann, Kurzgefaßte Geschichte der vornehmsten Gesellschaften der Gelehrten von den ältesten Zeiten an bis auf die gegenwärtige, aus glaubwürdigen Nachrichten verfertiget, Leipzig 1743.

Heckmann/Michel 1982 = Herbert Heckmann und Walter Michel, Frankfurt mit den Augen Goethes, Frankfurt am Main 1982.

Heilmann 1996 = Peter Norbert Heilmann, Die kommerzielle Herstellung von Werken mit Naturdrucken, Versuch einer Rekonstruktion des Herstellungsverfahrens, in: Gutenberg-Jahrbuch 71. Jg./1996, S. 176-181.

Heller 1991 = Karl Heller, Antonio Vivaldi, Leipzig 1991.

Helmolt 1976 = Christa von Helmolt, Die Uffenbachs, Nachrichten von einer berühmten Frankfurter Familie, in: Frankfurter Allgemeine Zeitung, Zeitung für Frankfurt, Nr. 267, 26. November 1976. 
Hermann 1753 = Johann Georg Hermann, Leben des Herrn Zacharias Conrad von Uffenbach ..., Ulm 1753.

Herzog 1999 = Katrin Herzog. Hotteterre „Le Romain“, Sonnenkönig der Traversflöte, o.O. 1999, in: http://www.carpediemrecords.de/de/ordinaire/ hotteterre.htm (08.12.2000).

Heyden 1869 = Eduard Heyden, Der Frankfurter Chronist Achilles August v. Lersner, Frankfurt am Main 1860 (= Neujahrs-Blatt den Mitgliedern des Vereins für Geschichte und Alterthumskunde zu Frankfurt am Main dargebracht im Januar 1860).

Heyne 1785 = Christian Gottlob Heyne, Opuscula Academica collecta et animadversionibus locupletata, Göttingen 1785, Vol.1, S. 179-181.

Hirsching 1812 = Friedrich Carl Gottlob Hirsching's Historisch-Litterarisches Handbuch berühmter und denkwürdiger Personen, welche in dem 18. Jahrhunderte gestorben sind, 17 Bde., 1794-1815, 15. Bd., 1. Abt., Leipzig 1812, S. 71-76.

Hochheimer 1993 = Willy Hochheimer, Materialsammlung zur Geschichte der Malerfamilie Schütz aus Flörsheim am Main, Flörsheim am Main 1993.

Höffner 1992 = Corinna Höffner, Frankfurter Privatsammlungen, Stifter und Bestände - Eigenart und Umfang Frankfurt am Main 1992 (= Wiss. Hausarbeit an der J.W.GoetheUniversität Frankfurt, Fachbereich Klass. Philologie und Kunstwissenschaften - Fach: Kunstpädagogik, Frankfurt am Main 1992)

Hoffmeister 1885 = Jacob Hoffmeister, Gesammelte Nachrichten über Künstler und Kunsthandwerker in Hessen seit etwa 300 Jahren, Hannover 1885.

Holst $1930=$ Niels von Holst, Die Frankfurter Kunstcabinette des 18. Jahrhunderts, in: Alt-Frankfurt, Geschichtliche 
Zeitschrift für Frankfurt und seine Umgebung, 3.Jg./1930, S. 49-52.

Holst 1931 = Niels von Holst, Frankfurter Kunst- und Wunderkammern des 18. Jahrhunderts, ihre Eigenart und ihre Bestände, in: Repertorium für Kunstwissenschaft, Bd. 52/1931, S. $34-58$.

House 1991 = Delpha LeAnn House, Jacques Hotteterre „le Romain“: A study of his life and compositional style, Chapel Hill N.C. 1991 (Microfilm).

Horn-Oncken 1969 = Alste Horn-Oncken, Eine Bergwerksbesichtigung zu Beginn des 18. Jahrhunderts, Aus dem Tagebuch von Johann Friedrich A. von Uffenbach, in: Technikgeschichte Bd. 36, Düsseldorf 1969, S. 103110.

Horn-Oncken 1971 = Alste Horn-Oncken, Ein Frankfurter in Zürich, in: Neue Zürcher Zeitung Nr. 182, 21. April 1971, S. 19.

Horn-Oncken 1973 = Alste Horn-Oncken, Besuch in Basel, in: Neue Zürcher Zeitung Nr. 604, 30. Dezember 1973, S. 42.

Horn-Oncken 1978 = Alste Horn-Oncken, Ausflug in elysische Gefilde, Das europäische Campanienbild des 16. und 17. Jahrhunderts und die Aufzeichnungen J.F.A. von Uffenbachs, Göttingen 1978 (= Abhandlungen der Akademie der Wissenschaften in Göttingen, Philologisch-Historische Klasse, 3. Folge, Nr. 111).

Hüsgen $1780=$ Heinrich Sebastian Hüsgen, Nachrichten von Franckfurter Künstlern und Kunst-Sachen enthaltend das Leben und die Werke, aller hiesiger Mahler, Bildhauer, Kupfer- und Petschier-Stecher, Edelstein-Schneider und Kunst-Gießer. Nebst einem Anhang von allen was in öffentlichen und Privat Gebäuden, merckwürdiges von Kunst-Sachen zu sehen ist, Franckfurt am Mayn 1780. 
Hüsgen $1790=$ Heinrich Sebastian Hüsgen, Artistisches Magazin, enthaltend das Leben und die Verzeichnisse der Werke hiesiger und anderer Künstler. Nebst einem Anhang von allem Was in öffentlichen und Privat-Gebäuden der Stadt Franckfurt Merckwürdiges von Kunst Sachen, Naturalien Sammlungen, Bibliotheken und MünzCabinetten $\mathrm{zu}$ sehen ist. Wie auch einem Verzeichnis aller hiesigen Künstler Portraiten. Mit einer Menge historischer Nachrichten, so aus ächten Original-Quellen geschöpft sind von ..., Franckfurt am Mayn 1790.

Hunter 1986 = Michael Hunter, The Cabinet Institutionalized: the Royal Society’s 'Repository' and its Background, in: Impey/Macgregor 1986, S. 159-168.

Im Hof 1982 = Ulrich Im Hof, Das gesellige Jahrhundert, Gesellschaft und Gesellschaften im Zeitalter der Aufklärung, München 1982.

Impey/MacGregor 1986 = Oliver Impey und Arthur MacGregor (Hrsg.), The Origins of Museums. The Cabinet of Curiosities in Sixteenth- and Seventeenth-Century Europe, Oxford $1986^{2}$.

Israel $1876=$ Carl Israel, Frankfurter Concert-Chronik von 1713-1780, Frankfurt am Main 1876 (= Neujahrs-Blatt des Vereins für Geschichte und Alterthumskunde zu Frankfurt am Main für das Jahr 1876).

Jöcher $1751=$ Christian Gottlieb Jöcher, Allgemeines Gelehrten-Lexicon: Darinnen die Gelehrten aller Stände ... vom Anfange der Welt bis auf ietzige Zeit ... Nach ihrer Geburt, Leben, ... Schrifften aus den glaubwürdigsten Scribenten in alphabetischer Ordnung beschrieben werden, 4 Bde., Leipzig 1750-91, Bd. 4, Leipzig 1751. 
Jung 1742 = Johann David Jung, Merckwürdiges Diarium sowohl von der Wahl und Crönung Ihro Kayserl. Majestät Karls des VII., Als auch der Crönung Ihro Majestät der Kayserin Maria Amalia, wie solche mit ausserordentlichem Pracht in Franckfurt am Mayn vollzogen worden, 2 Bde, Frankfurt am Main 1742 und 1743.

Jung 1895,1 = Rudolf Jung, Johann Friedrich von Uffenbach, in: Allgemeine Deutsche Biographie, hrsg. durch die Historische Commission bei der Bayrischen Akademie der Wissenschaften, 56 Bde., Leipzig 1875-1912 (Reprint Berlin 1971), 39. Bd., Leipzig 1895 S. 132134.

Jung 1895,2 = Rudolf Jung, Zacharias Conrad von Uffenbach, in: Allgemeine Deutsche Biographie, hrsg. durch die Historische Commission bei der Bayrischen Akademie der Wissenschaften, 56 Bde., Leipzig 1875-1912 (Reprint Berlin 1971), 39. Bd, Leipzig 1895, S. 135137.

Jung 1900 = Rudolf Jung, Johann Friedrich v. Uffenbach (1687-1769), in: Frankfurter Zeitung und Handelsblatt Nr. 68 / 10. III. 1900.

Kallmorgen 1936 = Wilhelm Kallmorgen, Siebenhundert Jahre Heilkunde in Frankfurt am Main, Frankfurt am Main 1936.

Kat. Amsterdam 1992 = Amsterdams Historisch Museum, De wereld binnen handbereik, Nederlandse kunst- en rariteitenverzamelingen, 1585-1735, hrsg. von Ellinoor Bergvelt und Renée Kistemaker, 2 Bde., Zwolle 1992.

Kat. Berlin 1981 = Staatliche Museen zu Berlin, Preußischer Kulturbesitz, Die Brandenburgisch - Preussische Kunstkammer, Eine Auswahl aus den alten Beständen, Redaktion: Josephine Hildebrand, Christian Theuerkauff, Berlin 1981. 
Kat. Braunschweig $1994=$ Herzog Anton Ulrich-Museum Braunschweig, „Seltenheiten der Natur als auch der Kunst“, Die Kunst- und Naturalienkammer auf Schloß Salzdahlum, Text v. Alfred Walz, Braunschweig 1994.

Kat. Bruchsal 1981 = Schloß Bruchsal, Barock in Baden-Württemberg, Vom Ende des Dreißigjährigen Krieges bis zur Französischen Revolution, hrsg. vom Badischen Landesmuseum Karlsruhe, 2 Bde., Karlsruhe 1981.

Kat. Darmstadt 1992 = Mathildenhöhe Darmstadt, Georg Christoph Lichtenberg, 1742-1799, Wagnis der Aufklärung, hrsg. vom Land Hessen, Ministerium für Wissenschaft und Kunst; Hessische Kulturstiftung et. al., München - Wien 1992.

Kat. Flörsheim 1992 = Heimatmuseum Flörsheim am Main, Christian Georg Schütz der Ältere, bearb. von Kurt Wettengl (= Kleine Schriften des Historischen Museums Frankfurt/M. Bd. 46), Frankfurt am Main 1992.

Kat. Frankfurt 1956 = Historisches Museum, Stadt Frankfurt am Main, Kunst und Kultur von der Reformation bis zur Aufklärung, bearb. von Wolfram Prinz, Hans Stubenvoll und Gerhard Bott, Frankfurt am Main 1956.

Kat. Frankfurt 1957 = Historisches Museum, Stadt Frankfurt am Main, Gemälde des ..., bearb. von Wolfram Prinz, hrsg. zum Jahrestag des hundertjährigen Bestehens der Städtischen Gemäldesammlung im Historischen Museum, Frankfurt am Main 1957.

Kat. Frankfurt 1982,1 = Städtische Galerie im Städelschen Kunstinstitut Frankfurt am Main, Frankfurter Malerei zur Zeit des jungen Goethe, hrsg. von Klaus Gallwitz, Frankfurt am Main 1982.

Kat. Frankfurt 1982,2 = Historisches Museum, Stadt Frankfurt am Main, Stadt und Natur, Frankfurt um 1780, Das Buch der 
gleichnamigen Ausstellung des Historischen Museums November 1982 - Juni 1983, bearb. von Cornelia Rühlig und Jürgen Steen, Frankfurt am Main 1982.

Kat. Frankfurt 1986 = Historisches Museum, Stadt Frankfurt am Main, Wahl und Krönung in Frankfurt am Main, Kaiser Karl VII., 1742-1745, hrsg. von Rainer Koch und Patricia Stahl, 2 Bde., Frankfurt am Main 1986.

Kat. Frankfurt 1988 = Historisches Museum, Stadt Frankfurt am Main, Katalog zu der Abteilung „Bürgerliche Sammlungen in Frankfurt, 1700-1830“, bearb. von Viktoria Schmidt-Linsenhoff und Kurt Wettengl, Frankfurt am Main 1988.

Kat. Frankfurt 1989 = Schirn Kunsthalle, Frankfurt am Main, Die Sammlung des Consul Smith, Meisterwerke Italienischer Zeichnung aus der Royal Library, Windsor Castle, Von Raffael bis Canaletto, Text von Frances Vivian, München 1989.

Kat. Frankfurt 1991,1 = Historisches Museum, Stadt Frankfurt am Main, Brücke zwischen den Völkern - Zur Geschichte der Frankfurter Messe, hrsg. von Rainer Koch, 3 Bde., Frankfurt am Main 1991.

Kat. Frankfurt 1991,2 = Freies Deutsches Hochstift - Frankfurter GoetheMuseum, Frankfurt am Main, Christian Georg Schütz der Ältere, 1718-1791, Ein Frankfurter Landschaftsmaler der Goethezeit, bearb. von Petra Maisak, Frankfurt am Main 1991.

Kat. Frankfurt 1999,1 = Historisches Museum, Stadt Frankfurt am Main, Erde, Sonne, Mond \& Sterne. Globen, Sonnenuhren und astronomische Geräte im Historischen Museum Frankfurt am Main, bearb. von Reinhard Glasemann, Frankfurt am Main $1999 \quad(=$ Schriften des Historischen Museums Frankfurt am Main, Bd. 20). 
Kat. Frankfurt 1999,2 = Historisches Museum, Stadt Frankfurt am Main, „Franckfurt bleibt das Nest“, Johann Wolfgang Goethe und seine Vaterstadt, hrsg. von Patricia Stahl unter Mitarb. von Roland Hoede und Andreas Thiel, Frankfurt am Main 1999.

Kat. Frankfurt $2000=$ Historisches Museum, Stadt Frankfurt am Main, „Aus Auffrichtiger Lieb Vor Franckfurt", Patriziat im alten Frankfurt, bearb. von Andreas Hansert, hrsg. von der Cronstett- und Hynspergischen Evangelischen Stiftung und dem Historischen Museum Frankfurt, Frankfurt am Main 2000.

Kat. Frankfurt 2002 = Haus Giersch, Museum Regionaler Kunst, Frankfurt am Main, Sammlerin und Stifterin, Henriette Amalie von Anhalt - Dessau und ihr Frankfurter Exil (= Kataloge des Haus Giersch - Museum Regionaler Kunst, hrsg. im Auftrag der Stiftung Giersch von Manfred Großinsky, Bd. 5), Frankfurt am Main 2002.

Kat. Frankfurt 2012 = Historisches Museum, Stadt Frankfurt am Main, Frankfurter Sammler und Stifter, Eine Dauerausstellung des historischen museums frankfurt $(=$ Schriften des historischen museums frankfurt, Bd. 32, hrsg. von Jan Gerchow), Frankfurt am Main 2012.

Kat. Göttingen 1926 = Kunstsammlung der Universität Göttingen, Katalog der Gemäldesammlung der Universität Göttingen, bearb. von Wolfgang Stechow, Göttingen 1926.

Kat. Göttingen $1987=$ Kunstsammlung der Universität Göttingen, Die niederländischen Gemälde, mit einem Verzeichnis der Bilder anderer Schulen, bearb. von Gerd Unverfehrt, Göttingen 1987.

Kat. Göttingen 1993 = Kunstsammlung der Universität Göttingen, Rembrandt, Schwarz - Weiss, Meisterwerke der Radierkunst aus 
der Kunstsammlung der Universität Göttingen, hrsg. von Gerd Unverfehrt, Göttingen 1993.

Kat. Göttingen 1997 = Kunstsammlung der Universität Göttingen, Dürers Dinge, Einblattgraphik und Buchillustrationen Albrecht Dürers aus dem Besitz der Georg-AugustUniversität Göttingen, hrsg. von Gerd Unverfehrt, Göttingen 1997.

Kat. Göttingen (CD-ROM) 1999 = Kunstsammlung der Universität Göttingen, Katalog der Zeichnungen - Kunstsammlung der Universität, Hrsg. von der Kunstsammlung der Universität Göttingen, München 1999 (CD-ROM).

Kat. Göttingen 2000 = Kunstsammlung der Universität Göttingen, Zeichnungen von Meisterhand, Die Sammlung Uffenbach aus der Kunstsammlung der Universität Göttingen, hrsg. von Gerd Unverfehrt, Göttingen 2000.

Kat. Göttingen 2016 = Kunstsammlung der Universität Göttingen, Copy.Right,

Adam von Bartsch. Kunst - Kommerz Kennerchaft, hrsg. von Stephan Brakensiek, Anette Michels und Anne-Katrin Sors, Petersberg 2016.

Kat. London 1996 = Tate Gallery, London, Grand Tour, The Lure of Italy in the Eighteenth Century, ed. by Andrew Wilton and Ilaria Bignamini, London 1996.

Kat. Magdeburg 1998 = Kloster Unser Lieben Frauen, Magdeburg, Telemann und Frankreich, Frankreich und Telemann, hrsg. von Ralph-Jürgen Reipsch und Wolf Hobohm, Ochtersleben 1998.

Kat. Nürnberg 1980 = Germanisches Nationalmuseum, Nürnberg, Nützliche Anweisung zur Zeichenkunst, Illustrierte Lehr- und Vorlagenbücher aus den Beständen der Bibliothek des ..., bearb. von Gerlind Werner, Nürnberg 1980 $(=$ Bestandsverzeichnisse der Bibliothek des Germanischen Nationalmuseums I.). 
Kat. Potsdam 1986 = Staatliche Schlösser und Gärten Potsdam - Sanssouci, Neues Palais, Friedrich II. und die Kunst, Ausstellung zum 200. Todestag, 2 Bde., Potsdam 1986.

Kat. Wolfenbüttel 1989 = Herzog August Bibliothek Wolfenbüttel, Maß, Zahl und Gewicht, Mathematik als Schlüssel zu Weltverständnis und Weltbeherrschung, Konzeption: Menso Folkerts, Eberhard Knobloch, Karin Reich, Weinheim $1989 \quad$ (= Ausstellungskataloge der Herzog August Bibliothek Nr. 60).

Kaufmann 1998 = Thomas DaCosta Kaufmann, Höfe, Klöster und Städte, Kunst und Kultur in Mitteleuropa, 1450-1800, Köln, 1998.

Kempen 1951 = Wilhelm van Kempen, Die Pflege der Kunstgeschichte an der Georg-August-Universität zu Göttingen, in: Mitteilungen des Universitäts-Bundes 1951, Heft 1, Jg.XXVII.

Ketelsen/Stockhausen 2002 = Thomas Ketelsen und Tilman von Stockhausen, Verzeichnis der verkauften Gemälde im deutschsprachigen Raum vor 1800; the provenance index of the Getty Research Institute, 3 Bde., München 2002

Keyßler 1740 = Johann Georg Keysler, Neueste Reisen durch Deutschland, Böhmen, Ungarn, die Schweiz, Italien und Lothringen, 2 Bde., Hannover 1740 und 1741.

Keyßler 1751 = Johann Georg Keysler, Neueste Reisen durch Deutschland, Böhmen, Ungarn, die Schweiz, Italien und Lothringen, 2 Bde., Hannover 1751.

Keyßler 1776 = Johann Georg Keysler, Neueste Reisen durch Deutschland, Böhmen, Ungarn, die Schweiz, Italien und Lothringen, 2 Bde., Hannover 1776.

Kind-Doerne 1986 = Christiane Kind-Doerne, Die Niedersächsische Staats- und Universitätsbibliothek Göttingen, Ihre Bestände und 
Einrichtung in Geschichte und Gegenwart, Mit einem Beitrag von Klaus Haenel über die Handschriftenabteilung, Wiesbaden 1986 (= Beiträge zum Buch- und Bibliothekswesen, hrsg. von Max Pauer, Bd. 22).

Kitmeridis $2015=$ Panagiotis Kitmeridis, Popularisierung der Naturwissenschaften am Beispiel des Physikalischen Vereins Frankfurt, Dissertation Hamburg 2015

Kleiner $1940=($ Salamon $)$ Kleiners Florirendes Frankfurt, hrsg. von Fried Lübbecke, Frankfurt 1940.

Knod 1897 = Urkunden und Akten der Stadt Strassburg, hrsg. mit Unterstützung der Landes- und der Stadtverwaltung, Abth. 3: Die alten Matrikeln der Universität Strassburg 1621 bis 1793 / bearb. von Gustav Carl Knod, Bd. 1: Die allgemeinen Matrikeln und Bd. 2: Die Matrikel der medicinischen und juristischen Facultät, Straßburg 1897

Koch 1983 = Rainer Koch, Grundlagen bürgerlicher Herrschaft, Verfassungs- und sozialgeschichtliche Studien zur bürgerlichen Gesellschaft in Frankfurt am Main (1612-1866), Wiesbaden $1983 \quad(=$ Frankfurter Historische Abhandlungen, hrsg. von Lothar Gall, Werner Gembruch, Notker Hammerstein etc., Bd. 27).

Koch 1986,1 = Rainer Koch, Grundzüge der Frankfurter Verfassungsgeschichte bis zur Mitte des 18. Jahrhunderts in: Kat. Frankfurt 1986, Bd. 1, S. 22-33.

Koch 1986,2 = Rainer Koch, Bürger, Beisassen, Fremde, Juden - Zur Herrschaftsordnung der Freien Reichsstadt Frankfurt am Main im 18. Jahrhundert, in: Kat. Frankfurt 1986, Bd. 1, S. 35-43.

Kölsch 2002,1 = Gerhard Kölsch, Die Gemäldesammlung der Prinzessin Henriette Amalie von Anhalt - Dessau sowie ihre 
weiteren Sammlungen im Überblick, in: Kat. Frankfurt 2002, S. 70-89.

Kölsch 2002,2 = Gerhard Kölsch, Frankfurt und die Niederlande Wechselwirkungen zwischen Kunst und Sammlertum im 18. Jahrhundert, in: Kat. Frankfurt 2002, S. 90-98.

Kracauer 1910 = Isidor Kracauer, Die Vorbereitungen Frankfurts zur Wahl und Krönung Karls VII., in: Alt-Frankfurt, Vierteljahrschrift für seine Geschichte und Kunst, Jg. II/1910, Frankfurt am Main, S. 69-81.

Kriegk 1869 = Georg Ludwig Kriegk, Die Brüder Senckenberg. Eine biografische Darstellung; Nebst einem Anhang über Goethe's Jugendzeit in Frankfurt am Main, Frankfurt am Main 1869.

Krug 1846 = Friedrich Krug, Diarium der Frankfurter Raths-Wahlen nach der durch Allerhöchste Kaiserliche Resolution vom 22. Nov. 1725 neu vorgeschriebene Wahl-Ordnung durch die Kugelung; oder Chronologisches Verzeichnis aller Raths-Glieder vom 11. März 1725 an, mit Angabe ihres Geburtstages, der versch. Würden, welche und wann sie dieselben bekleideten, so wie ihres Todestages, Frankfurt am Main 1846.

Krüger $1978=$ N. Krüger (Hrsg.), Supellex epistolica Uffenbachii et Wolfiorum. Katalog der Uffenbach-Wolfschen Briefsammlung, Hamburg 1978.

Lange-Kothe 1960,1 = Irmgard Lange-Kothe, Die naturwissenschaftlichtechnische Gesellschaft in Frankfurt, 1725-1739, in: Archiv für Frankfurts Geschichte und Kunst Bd. 47, Frankfurt 1960, S. 31-44.

Lange-Kothe 1960,2 = Irmgard Lange-Kothe, Die Wasserkunst in Herrenhausen, in: Hannoversche Geschichtsblätter N.F. Bd. 13, Hannover 1960, S. 119-151. 
Laurencich-Minelli 1986 = Laura Laurencich-Minelli, Museography and Ethnographical Collections in Bologna during the Sixteenth and Seventeenth Centuries, in: Impey/MacGregor 1986, S. 17-23.

Leibesteder 2013 = Leibetseder, Mathis: Kavalierstour - Bildungsreise - Grand Tour: Reisen, Bildung und Wissenserwerb in der Frühen Neuzeit, in: Europäische Geschichte Online (EGO), hg. vom Leibniz-Institut für Europäische Geschichte (IEG), Mainz 2013-08-14. URL: http://www.ieg-ego.eu/leibetsederm-2013-de URN: urn:nbn:de:0159-2013070226 [2018.08.25].

Lersner 1734 = Achill. Augusti von Lersner, Nachgehohlte, vermehrte, und continuirte Chronica der weitberühmten freyen Reichs-, Wahl- und Handels-Stadt Franckfurth am Mayn, oder Zweyter Theil der Ordentlichen Beschreibung der Stadt Franckfurth, erw. durch Georg August von Lersner, Franckfurth am Mayn 1734.

Leweke 1988 = Wendelin Leweke, Berühmte Frankfurter, 57 Begegnungen mit der Geschichte, Frankfurt am Main 1988.

Lichtenberg 2017 = Georg Christoph Lichtenberg, Gesammelte Schriften: historisch-kritische und kommentierte Ausgabe, hrsg. von der Akademie der Wissenschaften zu Göttingen und der Technischen Universität Darmstadt, , Dd. 6; Vorlesungen zur Naturlehre, bearb. von Thomas Nickol, Göttingen 2017.

Loen 1749 = Johann Michael von Loen, Des Herrn von Loen gesammelte Kleine Schrifften: Besorgt und heraus gegeben von J.(ohann) C.(aspar) Schneidern, Frankfurt, Leipzig, 1749-1751, 3 Bde.

Loen $1751=($ Johann Michael von Loen $)$ Des Herrn von $L^{* *}$ moralische Gedichte, hrsg von Naumann, Franckfurt und Leipzig 1751, S. 124-127. 
Lotz $1940=$ Arthur Lotz, Das Feuerwerk, Seine Geschichte und Bibliographie, Beiträge zur Kunst- und Kulturgeschichte der Feste und des Theaterwesens in sieben Jahrhunderten, Leipzig 1940.

M. = Joseph Meder, Dürer-Katalog, Ein Handbuch über Albert Dürers Stiche, Radierungen, Holzschnitte, deren Zustände, Ausgaben und Wasserzeichen, Wien 1932.

MacGregor 1986 = Arthur MacGregor, The Cabinet of Curiosities in SeventeenthCentury Britain, in: Impey/Macgregor 1986, S. $147-158$.

MacGregor 1994 = Arthur MacGregor, Die besonderen Eigenschaften der "Kunstkammer", in Grote 1994, S. 61-106.

Major 1674 = Johann Daniel Major, Unvorgreiffliches Bedencken von Kunst- und Naturalien-Kammern insgemein, Kiel 1674

Mann 1977 = Gunter Mann, Johann Christian Senckenberg, sein Medizinisches Institut und seine Bibliothek im 18. Jahrhundert in Frankfurt am Main, in: Raabe 1977, S. 301-316.

Meidinger 1846 = Heinrich Meidinger, Nachträgliches. [über ein Portrait des Johann Friedrich Armand von Uffenbach], in: Frankfurter Gemeinnützige Chronik, 6. Jhg., März 1846, Nr.6, S. 50.

Meiners 1804 = E. Meiners, Göttingische akademische Annalen, Erstes Bändchen, Hannover 1804.

Meusel 1815 = Johann Georg Meusel, Lexikon der vom Jahr 1750 bis 1800 verstorbenen teutschen Schriftsteller, 15 Bde., Leipzig 1802-1815, 14. Bd., Leipzig 1815.

Meyer $1894=$ Wilhelm Meyer (Hrsg.), Die Handschriften der Universitätsbibliothek Göttingen, Bd. 3, Berlin 1894 (Verzeichniss der Handschriften im Preußischen Staate. 1,1.), S. 278-299: Johann Friedrich von Uffenbach's (1687-1769) Nachlass.

Meyerhöfer 1995 = Dietrich Meyerhöfer, Lichtenberg und die Sammlung der wissenschaftlichen Geräte des Frankfurter Patriziers 
Johann Friedrich Armand von Uffenbach, in: Lichtenberg-Jahrbuch 1995, hrsg. i.A. der Lichtenberg-Gesellschaft von Wolfgang Promies u.

Ulrich Joost, Ober-Ramstadt 1996, S. 113-160.

Meyerhöfer 1997 = Dietrich Meyerhöfer, Johann Friedrich Armand von Uffenbach und ,unser teutscher Appelis Albert Dürern“ in: Kat. Göttingen 1997, S. 396-404.

Meyerhöfer 2000,1 = Dietrich Meyerhöfer, Johann Friedrich von Uffenbach Sammler, Forscher, Stifter, in: Kat. Göttingen 2000, S. 11-29.

Meyerhöfer 2000,2 = Dietrich Meyerhöfer, Johann Friedrich von Uffenbach. Der Patrizier als Privatgelehrter, in: Kat. Frankfurt 2000, S. $118-125$.

Meyerhöfer 2016 = Dietrich Meyerhöfer, Lernen und Reisen - Kaufen und Sammeln - Forschen und Mitteilen: Johann Friedrich Armand von Uffenbach, in: Kat. Göttingen 2016, S. 169-179.

Meyers Konversations-Lexikon $=$ Meyer Großes Konversations-Lexikon, Ein Nachschlagewerk des allgemeinen Wissens, 21 Bde., 6. Aufl., Leipzig und Wien 1904-1909.

Mizler 1752= Lorenz Mizlers Musikalische Bibliothek oder Gründliche Nachricht nebst unpartheyischem Urtheil von alten und neuen musikalischen Schrifften und Büchern, worinn alles, was aus der Mathematik, Philosophie und den schönen Wissenschaften zur Erläuterung und Verbesserung sowohl der theoretischen als auch der praktischen Musik gehöret, nach und nach beygebracht wird, Dritter Band, Leipzig 1752, S. 377-408.

Molen 1994 = Johan R. ter Molen, Een bezichtiging van het poppenhuis van Petronella Brabdt-Oortman in de zomer van 1718, in: Bulletin van het Rijksmuseum, Rijksmuseum 
Amsterdam, Jg. 42/1994, Nr.2, S. 120-136, 168170.

Molen 2017 = Johan R. ter Molen, Een plezierreis in de zomer van 1718, De familie Von Uffenbach in de Nederlanden, Zwolle 2017.

Morawietz 1981 = Kurt Morawietz (Hrsg.), Glanzvolles Herrenhausen, Geschichte einer Welfenresidenz und ihrer Gärten, Hannover 1981.

Müller 1747 = Johann Bernhard Müller, Beschreibung des gegenwärtigen Zustandes der Freien Reichs- Wahl- und Handelsstadt Franckfurt am Mayn, Franckfurt am Main 1747.

Müller 1912 = Bernard Müller, Johann Friedrich von Uffenbach und der Umbau der Mainbrücke 1740-1744, in: Alt-Frankfurt, Vierteljahrschrift für seine Geschichte und Kunst, Jg. IV, Frankfurt am Main 1912, S. 1-16.

Müller 1916 = Bernard Müller, Bilderatlas zur Geschichte der Stadt Frankfurt am Main, hrsg. von der Städtischen Historischen Kommission, Frankfurt am Main 1916.

Müller 2006 = Hans-Peter Müller, Johann Friedrich Christ, in: Jubiläen 2006, Personen, Ereignisse, Universität Leipzig, hrsg. Rektor der Universität Leipzig, Leipzig 2006, S. 109-113

Muensterberger $1995=$ Werner Muensterberger, Sammeln, Eine unbändige Leidenschaft, Psychologische Perpektiven, Aus dem Amerikanischen von H. Jochen Bußmann, Berlin 1995.

Musik-Lexikon $=$ Die Musik in Geschichte und Gegenwart, Allgemeine Enzyklopädie der Musik, hrsg. von Friedrich Blume, 20 Bde., Kassel-Basel-Paris-London-New York, 1994-2008. 
Nagel $1908=$ Willibald Nagel, Das Leben Christoph Graupner's, in: Sammelbände der Internationalen

Musikgesellschaft, Jg. X/1908/09, S. 568-612.

Nagel 1910 = Willibald Nagel, Gottfried Grünewald, in: Sammelbände der Internationalen Musikgesellschaft, Jg. XII/1910/11, S. 99-107.

Nagel 1911,1 = Willibald Nagel, Deutsche Musiker des 18. Jahrhunderts im Verkehre mit J. Fr. A. von Uffenbach, in: Sammelbände der Internationalen Musikgesellschaft, Jg. XIII/1911/12, Heft 1, Okt. Dez. 1911, Leipzig 1911, S. 69-106.

Nagel 1911,2 = Willibald Nagel, Neues über Joh. Friedr. A. v. Uffenbach, in: Frankfurter Zeitung und Handelsblatt Nr.353 / 21. XII. 1911.

Nagler 1849 = Georg Kaspar Nagler, Neues allgemeines Künstlerlexikon: oder Nachrichten von dem Leben und den Werken der Maler, Bildhauer, Baumeister, Kupferstecher, Formschneider, Lithographen, Zeichner, Medailleure, Elfenbeinarbeiter etc., 22 Bde., München 1835-1852, Bd. 19, München 1849.

Neickelius 1727 = Caspar Friedrich Neickelius, Museographia oder Anleitung zum rechten Begriff und nützlicher Anlegung der Museorum oder Raritäten-Kammern, mit einigen Zusätzen und dreyfachem Anhang vermehret von Johann Kanold, Leipzig und Breßlau 1727.

New Grove $=$ The New Grove, Dictionary of Music and Musicians, ed. by Stanley Sadie, 20 Bde., London 1980.

Niedersächsische Nachrichten $1731=$ Niedersächsische Nachrichten von Gelehrten neuen Sachen auf das Jahr MDCCXXXI, Hamburg 1731.

Noack 1954 = Friedrich Noack, Erbach, Friedrich Karl, Graf zu, in: Die Musik in Geschichte und Gegenwart, Allgemeine Enzyklopädie der Musik, hrsg. von Friedrich Blume, 
Bd. 3, Daquin - Fechner, Kassel, Basel Paris et. al. 1954, Sp. $1471-1473$.

Olmi 1986 = Giuseppe Olmi, Science - Honour - Metaphor: Italian Cabinets of the Sixteenth and Seventeenth Centuries, in: Impey/MacGregor 1986, S. 5-16.

Oppitz 1992 = U. D. Oppitz, Artikel: Uffenbach, Zacharias Conrad (von), in: Handwörterbuch zur Deutschen Rechtsgeschichte, hrsg. von Adalbert Erler und Ekkehard Kaufmann et. al., 34. Lieferung, Tisch - Untereigentum, Berlin 1992, Sp.411-413.

Petzoldt 1967 = Richard Petzoldt, Georg Philipp Telemann, Leben und Werk, Leipzig 1967.

Plomb 2003 = Michiel C. Plomb, Zeichnungen von Meisterhand. Die Sammlung Uffenbach aus der Kunstsammlung der Universität Göttingen., in: The Burlington Magazine, Vol. 145, No. 1208, Art in Italy (Nov. 2003), S. 802-803.

Polaczek 1922 = Ernst Polaczek, Das Straßburger Tagebuch des Johann Friedrich von Uffenbach aus Frankfurt (1712-1714), in: Elsaß-Lothringisches Jahrbuch, 1. Bd., Berlin und Leipzig 1922, S. 68-122.

Pomian 1998 = Krzysztof Pomian, Der Ursprung des Museums, Vom Sammeln, Aus dem Französischen von Gustav Roßler, Berlin 1998.

Predeek 1928 = Albert Predeek, Bibliotheksbesuche eines Gelehrten Reisenden im Anfange des 18. Jahrhunderts, in: Zentralblatt für Bibliothekswesen, 45.Jg, Leipzig 1928, S. 221-265, 342-354, 393-407.

Preisendanz 1918,1 = Karl Preisendanz, Zum römischen Buchhandel (1715), in: Zentralblatt für Bibliothekswesen, 35. Jg., Leipzig 1918, S. 27.

Preisendanz 1918,2 = Karl Preisendanz, Aus zwei Schweizer Bibliotheken 1714, in: Zentralblatt für Bibliothekswesen, 35. Jg., Leipzig 1918, S. 262-257. 
Preisendanz 1920 = Lili Preisendanz, Musikalisches aus einem Reisetagebuch, in:

Neue Musikzeitung Nr. 41, Stuttgart 1920, S. $118-122$.

Preußner 1949 = Eberhard Preußner, Die musikalischen Reisen des Herrn von Uffenbach, Aus einem Reisetagebuch des Johann Friedrich A. von Uffenbach aus Frankfurt a. M. 1712-1716, Kassel 1949.

Preußner 1950 = Eberhard Preußner, Die bürgerliche Musikkultur, Ein Beitrag zur deutschen Musikgeschichte des 18. Jahrhunderts, Kassel und Basel 1950².

Pütter 1765 = Johann Stephan Pütter, Versuch einer academischen GelehrtenGeschichte von der Georg-Augustus-Universität zu Göttingen, Göttingen 1765, 1788.

Pütter 1788 = Johann Stephan Pütter, Versuch einer academischen GelehrtenGeschichte von der Georg-Augustus-Universität zu Göttingen, Zweyter Theil: von 1765 bis 1788, Göttingen 1788.

Querfurt 1710 = Tobias Querfurt, Kurtze Beschreibung des Fürstl. Lust=Schlosses Saltzdahlum, Braunschweig ca. 1710.

Raabe 1977 = Paul Raabe (Hrsg.), Öffentliche und Private Bibliotheken im 17. und 18. Jahrhundert, Raritätenkammern, Forschungsinstrumente oder Bildungsstätten, Bremen und Wolfenbüttel 1977 (= Wolfenbütteler Forschungen, hrsg. von der Herzog August Bibliothek Bd. 2).

Robbins Landon 1993 = H. C. Robbins Landon, Vivaldi, Voice of the Baroque, New York 1993.

Rohlfing $1998=$ Helmut Rohlfing, Uffenbach-Bibliothek (Bibliotheca Uffenbachiana), in: Handbuch der Historischen Buchbestände in Deutschland, hrsg. von Bernhard Fabian, Bd. 2.1, Niedersachsen A - G, hrsg. von Paul Raabe, bearb. von Alwin Müller-Jerina, Hildesheim - Zürich - New York 1998, S. 254-255. 
Rott 1917,1 = Hans Rott, Kunst und Künstler am Baden-Durlacher Hof bis zur Gründung Karlsruhes, Karlsruhe 1917.

Rott 1917,2 = Hans Rott, Die Reise des Frankfurters Joh. Friedr. von Uffenbach über Durlach nach Rastatt und die Besichtigung des dortigen Schlosses (1712), in: Zeitschrift für die Geschichte des Oberrheins, N.F., Bd. XXXII, Heidelberg 1917, S. 137-143.

Saur 1658 = Abraham Saur, Vermehrtes Stätte-Buch: oder Außführliches und auß vielen bewehrten alten und neuen Scribenten zusammen in ein Corpus gebrachte Beschreibung der fürnehmsten Stätte/Plätz und Vestungen/ meißtens in Europa, auch theils in andern Theilen der gantzen Welt, verfaßt und fortgesetzt durch Hermann Adolphum Authes, Franckfurt 1658.

Scheidel $1867=$ Sebastian Alexander Scheidel, Geschichte der Dr. Senckenberg'schen Stiftshäuser, Frankfurt am Main 1867 (= Neujahrs-Blatt des Vereins für Geschichte und Alterthumskunde zu Frankfurt am Main für das Jahr 1867).

Schellenberg 1928 = Kurt Schellenberg, Der Borheck-Bau und seine Vorläufer, Beitrag zur Grundrißgeschichte der Göttinger Universitätsbibliothek, 1767-1787, in: Beiträge zur Göttinger Bibliotheks $=$ und Gelehrtengeschichte, hrsg. und den Teilnehmern der 24. Versammlung deutscher Bibliothekare gewidmet von der Universitäts-Bibliothek, Göttingen 1928 (= Vorarbeiten zur Geschichte der Göttinger Universität und Bibliothek, hrsg. vom Universitätsbund Göttingen, 5. Heft), S. 55-74.

Schepelern $1986=$ H. D. Schepelern, Natural Philosophers and Princely Collectors: Worm, Paludanus, and the Gottorp an Copenhagen Collections, in: Impey/MacGregor 1986, S. 121-127. 
Schleuning 1989= Peter Schleuning, Das 18. Jahrhundert: Der Bürger erhebt sich (Geschichte der Musik in Deutschland), Reinbek bei Hamburg $1989^{2}$.

Schindling 1994 = Anton Schindling, Bildung und Wissenschaft in der frühen Neuzeit, 1650 - 1800 (= Enzyklopädie deutscher Geschichte, hrsg. von Lothar Gall, Bd. 30), München 1994.

Schlichte 1979 = Joachim Schlichte, Thematischer Katalog der kirchlichen Musikhandschriften des 17. und 18. Jahrhunderts in der Stadt- und Universitätsbibliothek Frankfurt am Main (Signaturengruppe Ms. Ff. Mus.), (= Kataloge der Stadt- und Universitätsbibliothek Frankfurt am Main, Bd. 8) Frankfurt am Main 1979.

Schlosser 1927 = Julius Schlosser, Zur „Philosophie“ des Kunstsammelns, in: Präludien, Vorträge und Aufsätze, Berlin 1927, S. 404-409.

Schmidt 1933 = Gustav Friedrich Schmidt, Die frühdeutsche Oper und die musikdramatische Kunst Georg Caspar Schürmann's, 2 Bde., Regensburg 1933, 1934.

Schmidt 1960 = Ulrich Schmidt, Die privaten Kunstsammlungen in Frankfurt am Main von ihren Anfängen bis zur Ausbildung der reinen Kunstsammlung, Diss. masch. Göttingen 1960.

Schmidt 1969 = Helga Schmidt, Johann Friedrich Armand von Uffenbachs Bibliotheksreise von Brüssel nach Köln im Jahre 1716 (Aus seinem „Reiß Diarium“), Mit einem Nachtrag aus einem Tagebuch von 1718 (=Hausarbeit der Diplom-Prüfung für den gehobenen Dienst an wissenschaftlichen Bibliotheken an der Evangelischen Bibliotheksschule Göttingen 1969 (Mss.).

Schnapper-Arndt 1915 = Gottlieb Schnapper-Arndt, Studien zur Geschichte der Lebenshaltung in Frankfurt am Main während des 
17. und 18. Jahrhunderts, auf Grund des Nachlasses von ... hrsg. von Karl Bräuer, 2.Teil: Quellen und Materialien, Frankfurt 1915 (= Veröffentlichungen der Historischen Kommission der Stadt Frankfurt am Main, II, 2.T1.).

Schrotzenberger $1884=$ Robert Schrotzenberger, Francofurtensia, Aufzeichnungen zur Geschichte von Frankfurt am Main, 2.Aufl., Frankfurt am Main 1884, S. 255.

Schudt 1959 = Ludwig Schudt, Italienreisen im 17. und 18. Jahrhundert, Wien München 1959 (= Römische Forschungen der Bibliotheca Hertziana Bd. XV).

Schwedt $1983=$ Georg Schwedt, Zur Geschichte der Göttinger Universitätsbibliothek, Zeitgenössische Berichte aus drei Jahrhunderten, zusammengestellt von ..., Göttingen 1983.

Schomann 1982 = Heinz Schomann, Kaiserkrönung, Wahl und Krönung in Frankfurt nach den Bildern der Festbücher, Dortmund 1982 (= Die bibliophilen Taschenbücher Nr.290).

Seidel 1953 = Werner Seidel, Baugeschichte der Niedersächsischen Staats- und Universitätsbibliothek in Göttingen 1734 - 1953, Göttingen 1953, (= Hainbergschriften Bd. 11).

Sellert 2012 = Wolfgang Sellert, Insinuation, in: Handwörterbuch der deutschen Rechtsgeschichte, 2. Aufl., Berlin 2012, 2.Bd, Sp. $1256-1259$.

Simmank 1977 = Gerhard Simmank, Auf den Spuren der Malerfamilie Schütz, in: Genealogisches Jahrbuch, hrsg. von der Zentralstelle für Personen- und Familiengeschichte, Bd. 16/17, Neustadt an der Aisch 1977, S. 49-98.

Simon 1858 = G. Simon, Die Geschichte der Dynasten und Grafen zu Erbach und ihres Landes, Frankfurt am Main 1858.

Sors 2019 = Anne-Katrin Sors, Tieck, Fiorillo und Uffenbach - Zum Einfluß niederländischer und deutscher Kunst auf die frühe 
Romantik an der Göttinger Universität nebst sammlungsgeschichtlichen Funden zum Erwerb des Arhardtschen Nachlasses, in Niederdeutsche Beiträge zur Kunstgeschichte, Neue Folge, Band 4 (= Beiträge zur alten Malerei und zum Sammeln von Kunst, hrsg. von Johannes Wiegand), hrsg. Von Katja Lembke, Jochen Luckhardt und Rainer Stamm, Petersberg 2019, S. 160-171.

Stagl 2002 = Justin Stagl, Eine Geschichte der Neugier, Die Kunst des Reisens 1550 - 1800, Wien - Köln - Weimar 2002.

Stieda 1907 = Wilhelm Stieda, Auktionen, in: Festgaben für Wilhelm Lexis, dargebracht von G. Adler, G. Arendt, L. v. Bortkiewicz, Jena 1907, S. 304-335.

Stille 1957 = Ulrich Stille, Hannover in Reisebeschreibungen des 18. und 19. Jahrhunderts, in: Hannoversche Geschichtsblätter, N.F. Bd. 10, Hannover 1957, S. 235-274.

Stock $1745=$ Johann Adolph Stock, Kurtzgefaßte Franckfurther Chronik, Franckfurt am Main 1745.

Streich 1977 = Gerhard Streich, Die Privatbibliothek als Handwerkszeug des Gelehrten im 18. Jahrhundert, dargestellt am Beispiel Göttingens, in: Raabe 1977, S. 241-299.

Strodtmann 1757 = Johann Christoph Strodtmann, Des neuen Gelehrten Europa, 11. Theil, S. 544-554.

Suchier 1916 = Die Mitglieder der Deutschen Gesellschaft zu Göttingen von 1738 bis Anfang 1755, in: Zeitschrift des Historischen Vereins für Niedersachsen, Jg. 81, Hildesheim 1916, S. 44-123.

Talbot 1985 = Michael Talbot, Antonio Vivaldi, Der Venezianer und das barocke Europa, Leben und Werk, aus dem Englischen übertragen von Konrad Küster, Stuttgart 1985.

Theuerkauff 1986 = Christian Theuerkauff, The Brandenburg Kunstkammer in Berlin, in: Impey/MacGregor 1986, S. 110-114. 
Turner 1986 = Gerard l'E. Turner, The Cabinet of Experimental Philosophy, in: Impey/Macgregor 1986, S. 214-222.

Ucheln 1744 = Specification derjenigen Kostbahren Gemählden welche allhier den 20ten May Anno 1744. Nachmittags und folgende Tage in des Herrn Gerichts Substituti Frießen Behaußung auf der kleinen Gallen Gaße Aus dem berühmten von Uchelischen Mahlerey=Cabinet an den meistbietenden gegen gleich baare Bezahlung öffentlich sollen vergantet werden, Frankfurt am Main 1744.

Uffenbach $1714=$ Johann Friedrich von Uffenbach, Dissertatio Juridica Inauguralis exhibens Quaestiones quasdam de Assertionibus Morientium, Argentorati (Straßburg) 1714.

Uffenbach 1726 = Johann Friedrich Armand von Uffenbach, Poetischer Versuch, worinnen die Nachfolge Christi in Betrachtung seiner heilsamen Lehre und heiligen Lebens durch Sinn-Bilder erkläret und zu einem Harmonischen Kirchen-Jahrgange nach Anleitung aller Sonn- und Festtäglichen Evangelien entworffen wird, Wolffenbüttel 1726 oder Frankfurt a.M. 1726.

Uffenbach 1729 = Zacharias Conrad von Uffenbach, Bibliotheca Uffenbachiana universalis sive catalogus librorum tam typis quam manu exaratorum quos summo studio hactenus collegit Zach. Conradus ab Uffenbach, nunc vero ob rationes in proloquio deductas, venale prostant, 4 Bde., Frankfurt am Main 1729-1731.

Uffenbach 1733 = Johann Friedrich Armand von Uffenbach, Gesammelte NebenArbeit in gebundenen Reden, Worinnen, nebst einer Poetischen Auslegung des Sinnebildes Cebetis des Thebaners, verschiedene Moralische Schrifften, zur Ausbesserung menschlicher Sitten, enthalten, Und nebst einer Vorrede von der Würde derer Singe- 
Gedichte, Mit dessen Genehmhaltung an das Licht gestellt, Hamburg 1733.

Uffenbach $1735=($ Franz Varrentrapp$)$, Bibliotheca Uffenbachiana, seu catalogus librorum, quos summa industria, magna cura maximisque sumptibus ex variis regionibus collegit scabinus republicae Francofurtensis Zachar. Conradus ab Uffenbach, quorum publica habebitur auctio in aedibus defuncti die VII. Martii 1735 per Franciscum Varrentrapp, Tomus I-IV, Francofurti ad Moenum apud Franciscum Varrentrapp. MDCCXXXV.

Uffenbach 1736 = Johann Friedrich Armand von Uffenbach, in: Hamburgische Berichte von neuen Gelehrten Sachen auf das Jahr 1736 (Hrsg. von Johann Peter Kohl), den 10. Februar, Nr. XII, Hamburg 1736, S. 105-111.

Uffenbach $1747=($ Zacharias Conrad von Uffenbach $)$ Catalogus manuscriptorum codicum bibliothecae Uffenbachianae Francofurti ad Moenum typis Balthasaris Diehlii MDCCXLVII.

Uffenbach 1753-1754 = Johann Georg Schellhorn (Hrsg.), Herrn Z. C. v. Uffenbach merkwürdige Reisen durch Niedersachsen, Holland und Engelland, in 3 Theilen, hrsg. von Johann Georg Schelhorn, Frankfurt/Leipzig/Ulm 1753-1754.

Uffenbach 1754 = Freymüthige Nacheichten von Neuen Büchern, und andern zur Gelehrtheit gehörigen Sachen, Eilfter Jahrgang, 1754, Zürich 1754, S. 12-13.

Uffenbach 1765 = Anonym [= Johann Friedrich Armand von Uffenbach $]$, Vorzüglichkeiten des hochbejahrten Standes für andere Alter des menschlichen Lebens, In einem Vortrage zur Erbauung des Gemüthes und Widerlegung unvorsichtiger Vorurtheile abgefasset., Franckfurt am Mayn 1765. 
Uffenbach 1771 = Catalogus von Original-Handzeichnungen, Gemählden und Statuen, nebst einigen Naturalien, wie auch optischen und technischen Maschinen, welche der wohlseel. Herr Johann Friedrich von Uffenbach hinterlassen, und durch öffentlichen Verkauf an den Meißtbietenden in desselbigen Behausung auf der Zeil Lit. D. Nro. 26. den 6ten May 1771 und folgende Tage gegen gleich baare Bezahlung überlassen werden sollen, Franckfurth am Mayn o.J.

Uffenbach $1775=$ Catalogus von Original-Handzeichnungen, Gemählden, Pretiosis und Silbergeschirr, welche des wohlseel. Herrn Johann Friedrich Armand von Uffenbachs gewesenen Schöffs und des Raths, wie auch Kayserlichen würkl. Raths leztlich wohlseel. verstorbene Frau Wittib hinterlassen und durch öffentlichen Verkauf an den Meistbietenden in der Behausung auf der Zeil Lit. D. No. 26 den 15ten May 1775 und folgende Tage gegen gleich baare Bezahlung überlassen werden sollen, Franckfurt am Mayn o.J.

Valentin $1889=$ Veit Valentin, Frankfurter Akademiebestrebungen im achtzehnten Jahrhundert, in: Archiv für Frankfurts Geschichte und Kunst, 3. Folge, 2. Bd., Frankfurt am Main 1889, S. 290-312.

Valentin 1906 = Caroline Valentin, Geschichte der Musik in Frankfurt am Main vom Anfange des XIV. bis zum Anfange des XVIII. Jahrhunderts, Frankfurt am Main 1906.

Valter 1995 = Claudia Valter, Studien $\mathrm{zu}$ bürgerlichen Kunst- und Naturaliensammlungen des 17. und 18. Jahrhunderts in Deutschland, Aachen 1994.

Vierhaus 1982 = Rudolf Vierhaus, Kulturelles Leben im Zeitalter des Absolutismus in Deutschland, in: Die Bildung des Bürgers, Die Formierung der bürgerlichen 
Gesellschaft im 18. Jahrhundert, hrsg. von Ulrich Herrmann (= Geschichte des Erziehungs- und Bildungswesens in Deutschland hrsg. von Ulrich Herrmann, Bd. 2) Weinheim und Basel 1982, S. 1137.

Voelcker 1932 = Heinrich Voelcker [Hrsg.], Die Stadt Goethes, Frankfurt am Main im XVIII. Jahrhundert, Frankfurt am Main 1932.

Waetzoldt 1921 = Wilhelm Waetzoldt, Deutsche Kunsthistoriker, 2 Bde., Leipzig 1921 und 1924.

Wanger 1994 = Bernd Herbert Wanger, Kaiserwahl und Krönung im Frankfurt des 17. Jahrhunderts. Darstellung anhand der zeitgenössischen Bild- und Schriftquellen und unter besonderer Berücksichtigung der Erhebung des Jahres 1612, Frankfurt am Main 1994 (= Studien zur Frankfurter Geschichte, hrsg. von Wolfgang Klötzer und Dieter Rebentisch, Bd. 34).

Wellmer 1900 = Arnold Wellmer, Um einen Titel, Eine merkwürdige Erbschaftsgeschichte aus dem alten Frankfurt. Nach aktenmäßigen Quellen, in: Frankfurter Zeitung und Handelsblatt 11. II. 1900.

Werner/Beuermann $1986=$ Thomas Werner und Gustav Beuermann, Die historische Sammlung des I. Physikalischen Institutes der Georg-August-Universität Göttingen, Ausstellungskatalog anläßlich der 250-Jahrfeier der Georg-August-Universität im Jahre 1987, Göttingen 1986.

Wöhlke $1940=$ Franz Wöhlke, Lorenz Christoph Mizler, Ein Beitrag zur musikalischen Gelehrtengeschichte des 18. Jahrhunderts, Würzburg 1940 (= Phil. Diss. Berlin 1940 und Bd. 3 der Schriftenreihe „Musik und Geistesgeschichte“, hrsg. von Arnold Schering). 
Wolf 1983 = Hans-Werner Wolf, Joachim Heinrich Freiherr von Bülow oder die Anfänge der Göttinger Universitätsbibliothek, aus „göttingen im august '71“, in: Schwedt 1983, S. 4954.

Wolff 1896 = Carl Wolff, Rudolf Jung, Die Baudenkmäler in Frankfurt am Main, 3 Bde., Frankfurt a.M. 1896, 1898, 1914

Wolf 1990 = Jürgen Rainer Wolf (Hrsg.), Grafschaft Erbach - Schönberg, 14591944, Bd. 1: Familienpersonalien, Landesverwaltung und Hausvermögen, bearb. von Klaus Peter Decker, Hugo Spengler, Harald Lönnecker und Jürgen Rainer Wolf, Darmstadt 1990 (= Repertorien des Hessischen Staatsarchivs Darmstadt 30/1, Abt. F 21).

Wolff/Jung 1896 = Carl Wolff und Rudolf Jung, Die Baudenkmäler in Frankfurt am Main, 3 Bde., Frankfurt 1896, 1898, 1914.

Zedler $=$ Johann Heinrich Zedler, Grosses vollständiges Universal Lexicon Aller Wissenschaften und Künste, welche bißero durch menschlichen Verstand und Witz erfunden und verbessert worden, 68 Bde., Halle - Leipzig 1731 1754.

Zinner 1956 = Ernst Zinner, Deutsche und Niederländische Astronomische Geräte des 11.-18. Jahrhunderts, München 1956. 


\section{Abbildungsverzeichnis}

Abb. 1 Das Wappen der Familie von Uffenbach in: Cod. Ms. Uffenbach 29/I ........ 29

Abb. 2 Titelblatt der Dissertation Uffenbachs ....

Abb. 3 Titelblatt von Johann Friedrich von Uffenbach „Kurtzes Verzeichnüs derer Mathemathischer Physicalischer und Kupfer-Bücher, in: Cod Ms.

Uffenbach 47 57

Abb. 4 Uffenbachs Titelkupfer zu „Poetischer Versuch, worinnen die Nachfolge Christi in Betrachtung seiner heilsamen Lehre und heiligen Lebens durch Sinn-Bilder erkläret“ Kunstsammlung der Universität Göttingen Inv. Nr. DP 5.

Abb. 5 Frontispiz zu „Poetischer Versuch, worinnen die Nachfolge Christi in

Betrachtung seiner heilsamen Lehre und heiligen Lebens durch Sinn-

Bilder erkläret“" 60

Abb. 6 Uffenbach Radierplatte zu „Poetischer Versuch, worinnen die Nachfolge Christi in Betrachtung seiner heilsamen Lehre und heiligen Lebens durch Sinn-Bilder erkläret“ Kunstsammlung der Universität Göttingen Inv. Nr. DP 45.

Abb. 7 Titelkupfer zum „I. Advents-Sonntag“, in: „Poetischer Versuch, worinnen die Nachfolge Christi in Betrachtung seiner heilsamen Lehre und heiligen Lebens durch Sinn-Bilder erkläret".

Abb. 8 Uffenbachs Zeichnung für das Titelblatt seines Singspiels „Pharasmanes“ in: Cod. Ms. Uffenbach 18

Abb. 9 Uffenbachs Zeichnung für eine Szene in dem Singspiel „Pharasmanes“

In Cod. Ms. Uffenbach 18 zu S. 32

Abb. 10 Matthäus Merian, Tabula Cebetis, Kunstsammlung der Universität

Göttingen Inv. Nr.: DP 1

Abb. 11 Matthäus Merian, Tabula Cebetis, In: „Gesammelte Neben-Arbeit in gebundenen Reden, Worinnen, nebst einer Poetischen Auslegung des Sinnebildes Cebetis des Thebaners", vor S. 1 .... 66

Abb. 12 Johann Ludwig Ernst Morgenstern, Frankfurt am Main - Nordseite der westlichen Zeil vom Roten Haus bis zum Weidenhof, 1793, Historisches Museum Frankfurt am Main 
Abb. 13 Johann Friedrich von Uffenbach, Ansicht des Flörsheimer Landgutes, Kunstsammlung der Universität Göttingen Inv. Nr. DP 16

Abb. 14 Johann Georg Dathan; Johann Friedrich von Uffenbach, Historisches

Museum Frankfurt am Main Inv. Nr. B 604 ............................................... 76

Abb. 15 Unbekannt: Johann Friedrich von Uffenbach, Kunstsammlung der Universität Göttingen Inv. Nr. GG 126 76

Abb. 16 Johann Friedrich von Uffenbach, Druckplatte für Dedikationsillustration, Kunstsammlung der Universität Göttingen Inv. Nr. DP 9 80

Abb. 17 Johann Friedrich von Uffenbach, Vorzüglichkeiten des Hochbejahrten

Standes, Titelkupfer zur Dedikation 80

Abb. 18 Titelblatt des Index Titulorum, Kunstsammlung der Universität Göttingen 128

Abb. 19 Albrecht Dürer, Madonna mit der Meerkatze, Kunstsammlung der Universität Göttingen Inv. Nr.: D 884 Mit Fehlstellen.

Abb. 20 Lucas Cranach, Adam und Eva im Paradies, Kunstsammlung der Universität Göttingen Inv. Nr.: D 762 Mit Brandspuren. 130

Abb. 21 Albrecht Dürer, Die Beschneidung Christi, Kunstsammlung der Universität Göttingen Inv. Nr.: D 831 Mit Knickspuren des Papiers.

Abb. 22 Hendrick Goltzius, Die drei Parzen, Kunstsammlung der Universität Göttingen Inv. Nr.: D 5189 Stockfleckig ...

Abb. 23 Albrecht Dürer, Das Rhinozeros, Kunstsammlung der Universität Göttingen D 871 Mit ausgebrochenen Stegen der Holzplatte.....

Abb. 24 Rembrandt, Der erste Orientalenkopf, Kunstsammlung der Universität Göttingen DP 7

Abb. 25 Auktionskatalog Uffenbach 1771, S. 1

Abb. 26 Johann Christian Böhm, Profil von der Herrenhäuser Waßer Machine ohne die aufgelegten Zeichnung der Pumpenanlage, 73 x 104 cm, in: SUB Göttingen Cod. Ms. philos 26d.

Abb. 27 Johann Christian Böhm, Profil von der Herrenhäuser Waßer Machine mit der aufgelegten Zeichnung der Pumpenanlage, 73 x 104 cm, in: SUB Göttingen Cod. Ms. philos 26d

Abb. 28 Manuskript Uhrsprüngliche Historie, Cod. Ms. Uffenbach 13/IV, p. 504 149 
Abb. 29 Titelblatt von „Monogrammata oder Zeichen derer Mahler und Kupferstecher so noch ungedeutet oder unbekant sind“, in: Cod. Ms. Uffenbach 50

Abb. 30 Die Seiten 10v und 11r aus „Monogrammata oder Zeichen derer Mahler und Kupferstecher so noch ungedeutet oder unbekant sind“, in: Cod. Ms. Uffenbach 50

Abb. 31 Titelblatt von „Alphabetisches Verzeichnüs Aller Mahler Bildhauer Und Kupferstecher“, in: Cod. Ms. Uffenbach 36

Abb. 32 Seite aus dem „Alphabetisches Verzeichnüs Aller Mahler Bildhauer Und Kupferstecher“, in: Cod. Ms. Uffenbach 36, S. 23.

Abb. 33 Titelblatt des ersten Protokollbandes der Wissenschaftlichen Gesellschaft in: Cod. Ms. Uffenbach 13/I

Abb. 34 Johann Friedrich von Uffenbachs eigenhändige Zeichnung einer

Armillarsphäre in: Cod. Ms. Uffenbach 13/I, S. 52

Abb. 35 Uffenbachs Zeichnung des Zimmers in seinem Haus, wo sich die

Gesellschaft traf, in: Cod. Ms. Uffenbach 13/I, S. 65

Abb. 36 Uffenbachs Zeichnung zu dem Halo, den er beobachtet hatte, in:

Cod. Ms. Uffenbach 13/V, S. 223

Abb. 37 Probebogen des Verlages Funcke für Johann Hieronymus Kniphofs

Kräuterbuch, in: Cod Ms. Uffenbach 13/V, S. 140.

Abb. 38 Uffenbachs eigene Versuche mit dem Naturdruckverfahren in:

Cod. Ms. Uffenbach 13/V, S. 313

Abb. 39 Das eigene Musikalienexlibris von Uffenbach selbst gestochen

Kunstsammlung der Universität Göttingen Inv.Nr. DP 10

Abb. 40 Das kleine Exlibris von Zacharias Conrad von Uffenbach,

Kunstsammlung der Universität, Göttingen Inv.Nr. DP 8, 68 x 85 mm ... 186

Abb. 41 Abzug des großen Exlibris von Zacharias Conrad von Uffenbach, in:

Cod. Ms. Uffenbach 13/II, S. 125

Abb. 42 Das mittlere Exlibris von Zacharias Conrad von Uffenbach,

Kunstsammlung der Universität Göttingen Inv.Nr. DP 89,

$85 \times 102 \mathrm{~mm}$ 
Abb. 43 Das große Exlibris von Zacharias Conrad von Uffenbach, Kunstsammlung der Universität Göttingen Inv.Nr. DP 6, 127 x $154 \mathrm{~mm}$

Abb. 44 Uffenbachs Zeichnung zu seinem Vortrag über das Drechseln von „eckigen Säulen“ in: Cod. Ms. Uffenbach 13/V, S. 718

Abb. 45 Unbekannt, Conrad Hieronymus Eberhard, gen. Schwind, Frankfurt am Main, Dr. Senckenbergische Stiftung, Portraitsammlung ...

Abb. 46 Georg Anton Koch, Johann Georg Kißner Frankfurt am Main, Dr.

Senckenbergische Stiftung, Portraitsammlung....

Abb. 47 Uffenbach Zeichnung des Schrankbettes seines Bruders Wilhelm in:

Cod. Ms. Uffenbach 13/II, S. 227. 
ANHANG

ZU

JOHANN FRIEDRICH VON UFFENBACH.

SAMMLER - STIFTER -

WISSENSCHAFTLER 


\section{Hinweise zur Transkription:}

/ = Zeilensprung

$[\ldots]=$ nicht transkribierter Text

[?] $=$ schlecht oder unlesbare Textstellen

[!] = steht in dieser Schreibweise im Original so geschrieben

$(\quad)$ Seitenzahlen

Die Groß- und Kleinschreibung ist der heutigen Schreibweise annähernd angeglichen.

Die Zeichensetzung des Originaltextes wurde weitgehend beibehalten.

Abkürzungen im Originaltext wie z.B. Wortendungen wurden aufgelöst.

"ij" und "y" sind in der Transkription "y"

Wird ein Zitat im laufenden Text angegeben wird in der Anmerkung folgendermaßen zitiert:

Bibl. Uff. = Bibliothek Uffenbach oder Cod. Ms. Uffenbach $=$ Handschriften im Besitz Uffenbachs oder eigenhändige, von ihm verfasste, oder Bibl. Arch. = Bibliotheks-Archiv. Diese drei Signaturengruppen befinden sich in der Handschriftenabteilung der Niedersächsischen Staats- und Universitätsbibliothek Göttingen,

Uni. Arch. = Archiv der Georg-August-Universität zu Göttingen.

ISG Frankfurt am Main = Institut für Stadtgeschichte Frankfurt am Main.

UB Frankfurt am Main = Universitätsbibliothek J.C. Senckenberg, Frankfurt am Main. 
13LEBEN UND SAMMLUNGEN 


\subsection{Eintragungen in den Taufbüchern und Totenbüchern der Evangelischen Kirche}

$\underline{\text { ISG Frankfurt am Main Tauf- und Totenbücher der Evangelischen Kirche in }}$ $\underline{\text { Frankfurt am Main }}$

Taufbuch der Evangelischen Kirche in Frankfurt am Main 1686-1690, p. 130v:

Dienstags d. 10. dito [Mai 1687]

H Johann Balthasar Uffenbach B.[ürger] u. Handelsmann alhier, uxor Fr. Anna Sibylla, ein Sohn Johann Friedrich, sub Herr Johann Friedrich Ammelburg, B. und Handelsmann alhier.

Taufbuch der Evangelischen Kirche in Frankfurt am Main 1686 - 1690, p. $375 v$ :

Donnerstags, den 26. dito [September 1689]

Herr Johann Balthasar Uffenbach, Bürger und Handelsmann; Frau Anna Sibylla, uxori, geb. Mayerin; einen Sohn, Wilhelm, sub Johann Wilhelm Lehnemann $\mathrm{p}$.

[am linken Rand der Vermerk: + 1735 [Zeichen für Venus od. Freitag] 24 Jun denat]

Taufbuch der Evangelischen Kirche in Frankfurt am Main 1667-1675, p. 495v:

Dienstags, 17. Augusti [1675]

Hr. Johann Balthasar Uffenbach, Bürger und Handelsmann, uxor Frau Anna Sibylla, eine Tochter Anna Sibylla, sub Frau Anna Sibylla; Wegl. Hrn. Johann Mayers, Bürgers und Handelsmanns Seel. Wittib, Ihr Mutter.

Totenbuch der Evangelischen Kirche in Frankfurt am Main 1668-1772, p. 198:

Donnerstag, d. 13 do [April 1769]

von Uffenbach, S. T. Herr Johann Friedrich Armand, Ihro Röm. Kayßerl. Major, würckl. Rath, ältester Schöff und des Raths alhier: 
bapt. [Zeichen für Mars od. Dienstag] 10. May 1687.

cop. [Zeichen für Jupiter od. Donnerstag] 6. Aug. 1717.

vid. [Zeichen für Sonne od. Sonntag] 5. Nov. 1752.

cop. [Zeichen für Saturn od. Samstag] 29. Sept. 1755. 


\subsection{Das Gutachten aus dem Jahre 1767 von Johann Friedrich von Uffenbach zur Gründung einer Malerakademie in Frankfurt am Main}

ISG Frankfurt am Main: Handwerker Akten Nr. 618 (ehemals Ugb C $31 \mathrm{Z}$ Nr.2): Maler Akademie, B1.27-28 r + v1092

Im Jahre 1767 verfasste Johann Friedrich von Uffenbach für den Frankfurter Rat dieses Gutachten. Es ging um eine Stellungnahme zur Errichtung einer Malerakademie in Frankfurt am Main. Die Frankfurter Künstler waren in der Malerzunft gebunden, gehörten also zur selben Zunft wie Lackierer, Anstreicher und Vergolder.

(27r) Es haben am abgewichenen 7ten dieses ${ }^{1093}$ alhie- / Bige Kunstmahler bei Einem HochEdlen Rahte [!] mit / 9 Unterschriften eine so betittulte unterthänige Vor- / stellung und Bittschrift, sie von denen neuerlich auf- / erlegten Artickeln zu befreyen, und ihnen eine Zeich- / nungs Schule, oder Academie genägigst [!] zu erlauben / und solche zu bestätigen, überreichet, worüber das / venerirliche1094 Raths Conclusum also ergangen: daß / man in Scabinatu diesen Vorfall überlegen, und / indeßen des H Schöffen von Uffenbachs Gutachten hier- / über erfodern solle. Ein solches um gehorsamst zu / befolgen, ermangele nicht meine wenige Gedancken / ohnmasgeblich in folgendem darzustellen.

Ohnstreitig1095 ist die ächte Kunstmahlerey von dem / grauesten Alter her durch eine große Reyhe von / Kayßern, Konigen und Regenten für eine der an- / gesehensten freyen Künsten erkant und geachtet, auch / mit besondern Genaden Bezeugungen beehrt, mithin / daß deren Zugethanen in dießem langen Besitze nir/ gends ein niederer Handwercksmäßiger Zwang und / Einschränckung zu gemuthet worden, welchen verklei- / nerlichen Einfall vor etlichen Jahren bey uns ohnfehl- / bar niemand anders als verschiedene Nahrungseif- / ferer und alzu gemeinsüchtige oder scheelsehende Pro- / fessionisten, ohne die übrige Gesellschaft, wie billig, dar- / über vernehmen zu laßen, wieder rechtlich auf die

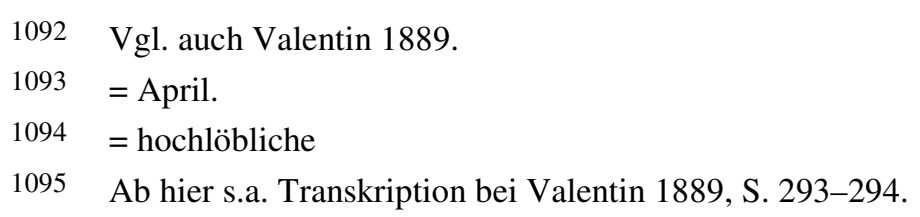


Bah- / ne gebracht. Wird es also denen wahren Kunst- / mahlern, deren wir verschiedene in unserer Statt ha- / ben, zu verdencken seyn, wenn sie, wie geschehen, um / wieder Einsetzung in ihren angefochtenen Ehrenstand

(27v) und um die Ausnahme von denen neuen lästi- / gen Artickeln, die weder dem aerario noch dem pu- / blico das mindeste, wohl aber denen geschwohrnen / Vorstehern ofters etwas eintragen, unterthanig $\mathrm{zu} /$ bitten? Ich solte es nicht dencken, und dafür halten / es seye ihnen pro petito zu willfahren. Einen Ein- / wurf aber höre ich doch in diesem und andern Vor- / fällen von patriotisch gesinnet seyn Wollenden sehr / hoch treiben, und kläglich anzuführen, daß nehmlich / unser Vaterland sich ohne Einschränckung von Hand- / wercks Artickeln der Übersetzung in allen Professionen / und Ständen für Zulauf sich zu erwehren nicht fä- / hig seyn würde, und der Nahrungsmangel einrei- / Ben, am Ende aber die milde Stiftungen überschwem- / met werden dürften. Allein ich muß mich wundern / daß eben dieser Umstand, der allen Herrschaften und / Regierungen bey dem Anwachs ihrer Staaten ein be- / sonders Vergnügen und Freude ist, bey uns nach klein- / stättischer Art im Gegentheile als eine Noth und Furcht / betittult und angesehen werden will. Man blicke / nur 50 Jahre in das Vergangene, und beleuchte von / nur so kurtzer Zeit die Erweiterung unserer itzigen / Umständen, so wird man allerdings unsern merck- / lichen Wachstum (Gott Lob) leichtlich erkennen. Nichts / desto weniger haben wir (Gott sey abermahl Danck) / nichts von Noth und Übersetzung zu klagen. Wer / alhier nur Kopf und Hände brauchen will, findet / Nahrung. Ubermuth, Müßiggang und Unachtsam- / keit aber leitet zum Darben. Allein ich habe der- / mahlen nur die Mahler für mir, die denen mil- / den Stiftungen gewißlich weniger als andern dro/ hen; wenn nur die wenige Achtung und Einsicht für

(28r) sothane Kunst bey unsern Mitbürgern nicht so / gar geringe wäre, und sie an das Hungertuch / verwiese. Ein Mahler ist ein ehrgeitzig Geschöpfe / mit Einbildungen beladen; er höret, wie anderer / Orten die Kunst belohnet werde, er packt ein, und / setzt seinen Stab weiter, und läßet die milde / Stiftungen unbegräncket. [!] Wenn aber in einem / Staate sich alles vergrößert und wächset, so ist sich / leichtlich vorzustellen, daß das Armuth darinnen / es ebenfalls thue. Die Stiftungen aber haben durch / eben den Anwachs der Beytragenden, die sich vermeh- / ret, auch mehr Zuschuß zu Erhaltung der Armen zu / gewarten, ohne zu gedencken, daß bey einer Anzahl / vermögender Einwohner die Höchste Fürsehung / auch unverhoft mildthätige Hertzen zu einer auser- / ordentlichen Freygebigkeit erwecket, wie wir nur in / unsern heutigen kürtzlich abgewichenen Zeiten aus / derer edelmüthigen Abgaben und Stiftungen, zum Exempel: der 
Rothischen, Werlinischen, Lind- / heimischen, Bachischen, von Cronstattischen und an- / dern zu erinnern haben.

Der andere Vorwurf in oben benanter Bittschrift / enthält das Ansuchen und Gutheißen und Schutz / ihrer, derer Mahler, bereits angefangenen Zeichnungs / Schule, oder nach itziger fast durchgängiger Mode, der / sogenannten Academie. Ein lobliches Vorhaben, so / dem aerario nicht im mindesten leid thut, aus eige- / nen Mitteln in der Stille bestritten werden soll, un- / serer in diesem Vorfalle ehedem sehr berühmten / Statt eine wahre Ehre bringet, und überhaupt man- / chen thätigen Nutzen und Vortheil schaffet. Die Zeich- / nungskunst ist bekantlich die Seele der gantzen / Bildkunst, die nicht ausgelernet werden kan. Sie stär- / cket unsere Urtheilskraft, sie würcket das in allen

(28v) menschlichen Geschäften hochnützliche gesunde Augen- / maas, sie macht der lernenden Jugend Sitzfleisch / und bringet, wie die Studia überhaupt, den rühm- / lichen Vortheil: quod emolliat mores, nec sineat esse / feros. Ist der letztere Umstand bey unserer Hand- / wercksgesellschaft, welche der Obrigkeit bißher so man / ihr Unlust veranlaßet, nöthig und gut, so hätte man / das Ansuchen ohne Bedencken zu billigen, und es in / erbothenen Schutz zu nehmen, will doch auch manche / Handwercker in diese Schule zu gehen gereitzet wer- / den, wenn sie wohl thun wollen. Ich kan ihnen al- / so meinen Beyfall nicht entziehen, nur aber wün- / schete ich der vorhabenden Sache auch eine glückliche / Dauer, worinnen auch in Betracht des nöthigen Auf- / wandes halben ein Zweifel will irre machen. Ins- / gemein haben die Künstler Cassen die Auszehrung, wo- / rinnen sie aber ihr getrostes Unternehmen verhoffend- / lich curiren wird, und welches man ihrem Begehren / überlaßen kan. ${ }^{1096}$

Das letztere Ansuchen in erwehnter Bittschrift betrift / das praesidium ihrer Gesellschaft, nehmlich des Mitglie- / des Eines Hochedlen Rahtes [!], und hierüber fallen sie in / ihrer Auswehlung und Vorschlag zu meiner Verwunde- / rung auf meine Wenigkeit. Ich kan mir dabey / wohl vorstellen, daß der geglaubte Ruf von mei- / ner Liebe für Künste mir diese vorzügliche Ehre zu / gezogen, und ich werde mir auch Kraft dieser, und dem / Bestreben meinen Mitbürgern mich Dienst bereit zu be- / zeigen den Antrag nicht entgegen seyn laßen, ob- / wohlen es ein tüchtigerer und munterer beßer als / ich verrichten mögte.

Schließlich finde an der Beylage von Gesetzen und Re- / geln, so die Gesellschaft zu halten sich vorgenommen nichts / zu errinnern oder für anstößig

1096 Bis hier s.a. Transkription bei Valentin 1889, S. 293-294. 
zu achten. Womit al- / so seine Schuldigkeit und Befolgung des aufgetragenen / Gutachtens geleistet zu haben vermeinet. salv. melior.

ffurt d 11 Aprill 1767

J.F. von Uffenbach

Scab. 


\title{
13.3Das Gegenschreiberbuch der Auktion von 1771
}

\author{
$\underline{\text { ISG Frankfurt am Main Vergantungs-Register 1771/Uffenbach, p. 27-63. } 1097}$
}

„Vergantungs=Register / über die / von / Titl: Frau Schöf von Ufenbach [!] / gegebene / Mahlereyen, und Statuen / angefangen d 6e May 1771.“

Das Gegenschreiberbuch richtet sich nach dem gedruckten Auktionskatalog von $1771^{1098}$, d.h., daß die Seitenzählung identisch ist. Die einzelnen Druckseiten des Kataloges wurden in das Gegenschreiberbuch mit eingebunden. Auf den ersten 27 Seiten des Auktionskataloges werden die Zeichnungen der beiden, zur Auktion gekommenen Klebebände einzeln vorgestellt. Da die Bände aber nicht versteigert wurden, sind diese Seiten des Gegenschreiberbuches leer. In der Transkription wurden die Seiten ausgelassen, von denen kein einziger aufgeführter Gegenstand verkauft wurde.

Die drei-tägige Auktion dauerte vom 6. bis zum 8. Mai 1771. Der Auktionator hielt sich nicht an die Reihenfolge des gedruckten Kataloges. Die Versteigerung begann mit der Nummer 84 des dritten Abschnitts „Figuren. Statuen. Bas-reliefs.“ Insgesamt erbrachte die Vergantung 751 Gulden, 43 Kreuzer, wobei weder die beiden Zeichnungsbände noch viele Gemälde verkauft wurden. ${ }^{1099}$

Die Seiten des Manuskripts besitzen fünf Unterteilungen:

1.: Nummer im Auktionskatalog.

2.: Kurzbeschreibung des Gegenstandes.

3.: Name des Käufers.

4. und 5.: Preis in Gulden und Kreuzer.

[Deckblatt, o.1.] 1771

1097 Das Gegenschreiberbuch galt bis heute als verschollen. Ich danke Achim Reichel, ehemals Institut für Stadtgeschichte Frankfurt am Main, herzlich für seine Bemühungen.

1098 Uffenbach 1771.

1099 Die Frankfurter Währung war eine reine Silberwährung und wurde in Gulden zusammengesetzt, wobei ein Gulden (fl.) 60 Kreuzern (kr. oder xr.) entsprach, vgl. Kölsch 2002,1, in: Kat. Frankfurt 2002, S. 85. 
Vergantungs=Register / über die / von / Titl: Frau Schöf von Ufenbach [!] / gegebene / Mahlereyen, und Statuen / angefangen d 6e May 1771
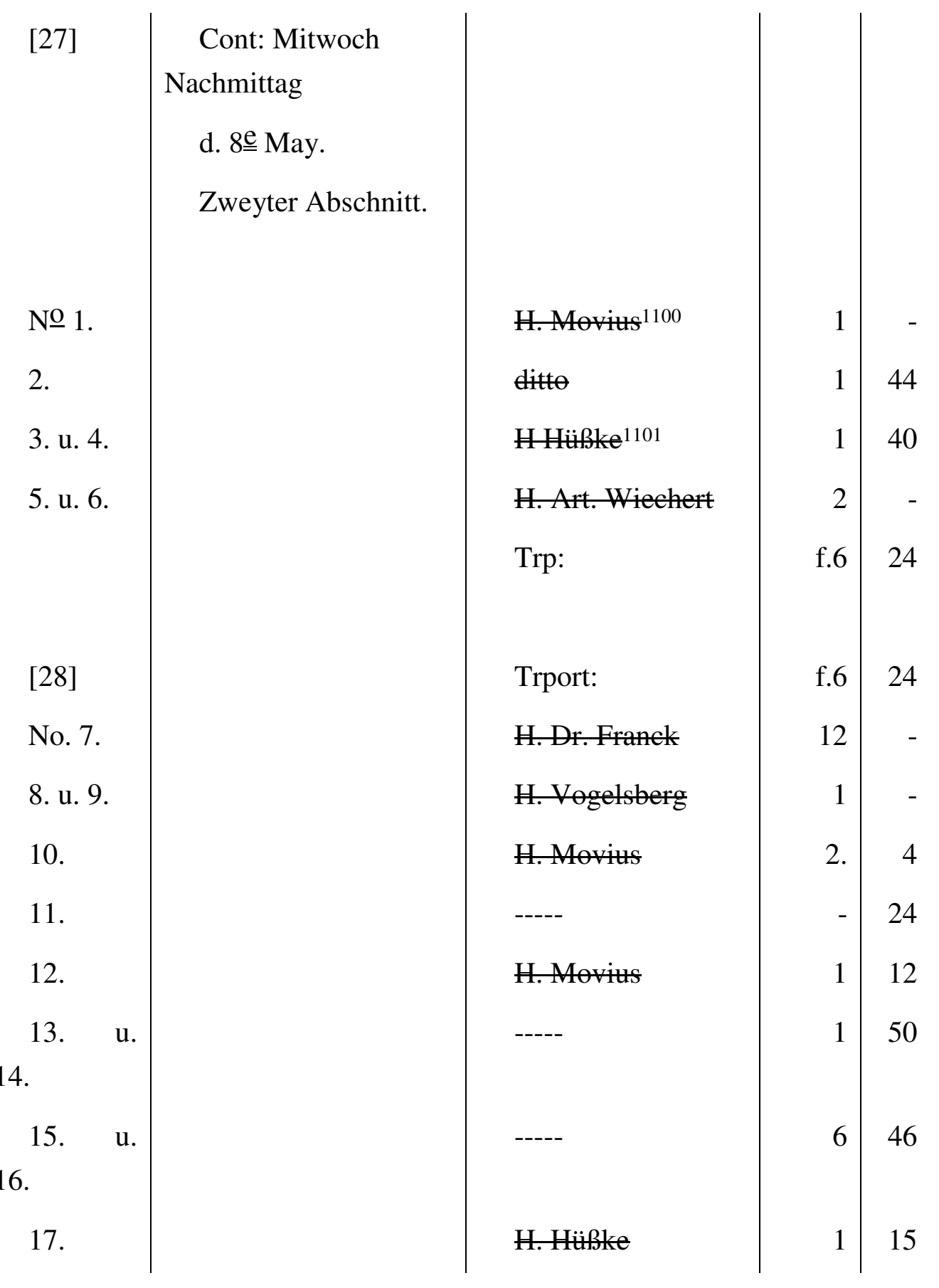

$1100=$ Mevius, Georg Friedrich (1727-1798).

Nach Schmidt 1960, Art. „Sammlung Nothnagel (1765)“ war Mevius ein Maler und Kunsthändler; in Gwinner 1862 ist allerdings ein Mevius nicht verzeichnet.

$1101=$ Der Frankfurter Sammler und Kunstschriftsteller Heinrich Sebastian Hüsgen (17451807). 


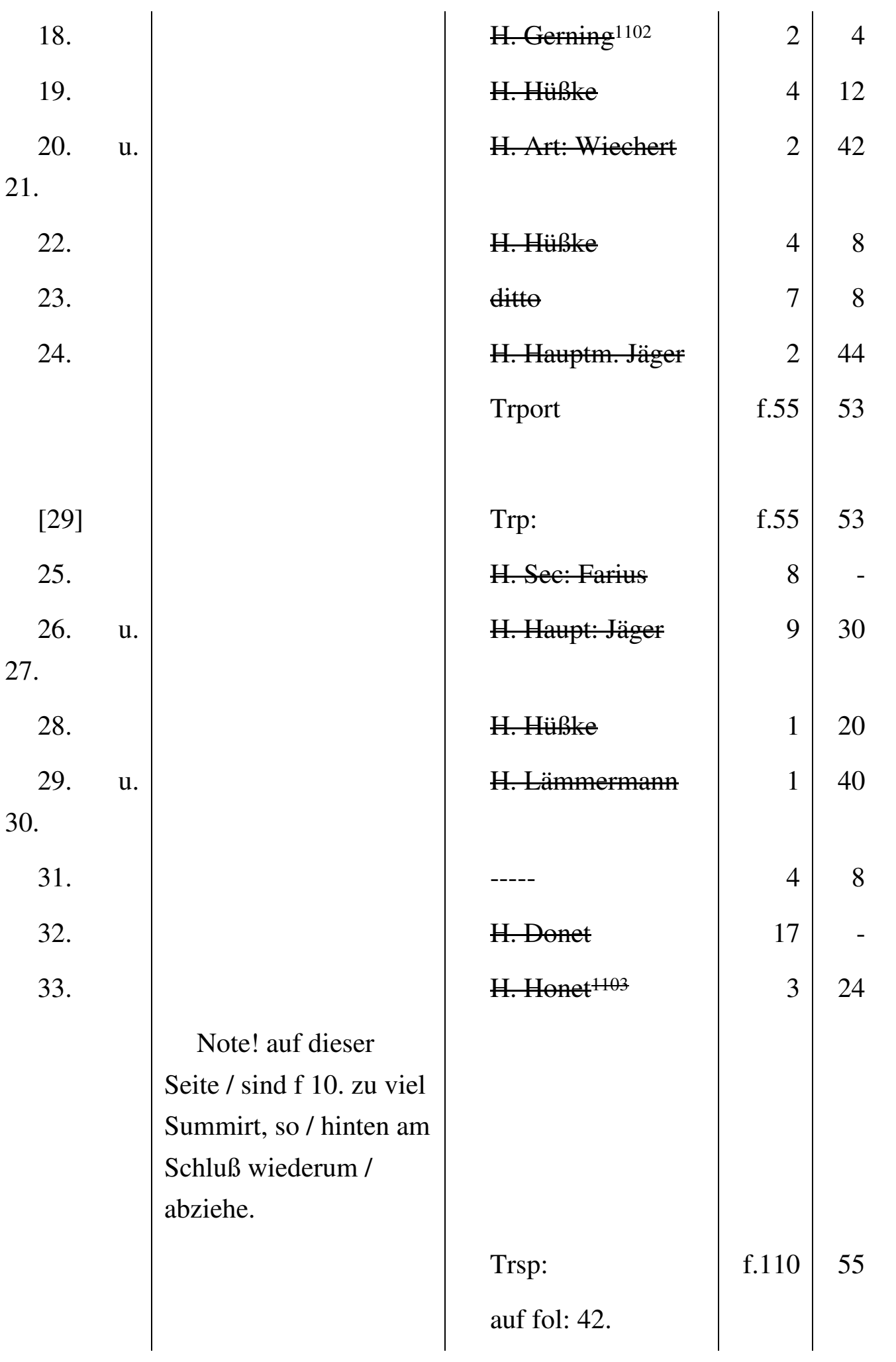

1102 = Der Frankfurter Sammler Johann Christian Gerning (1744-1802), sein Vater, der Handelsmann Peter Florens Gerning (1695-1764), stammte aus Bielefeld und lebte seit 1732 in Frankfurt, vgl. Schmidt 1960. Die Sammlung Gerning kam nach dem Tod des Besitzers in das heutige Museum Wiesbaden.

1103 Jean Francois Honnête (1735-ca.1793). 


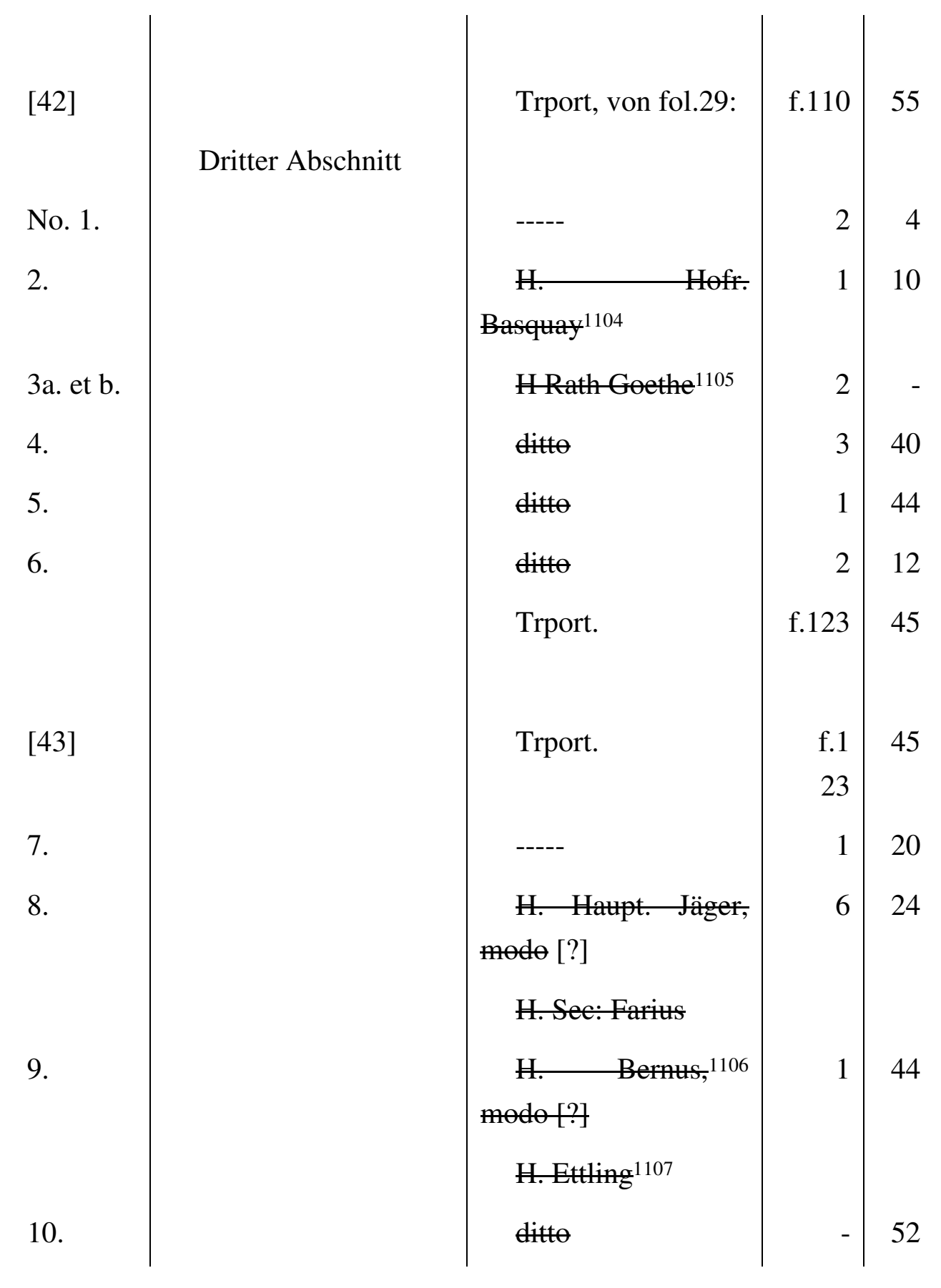

1104 Es handelt sich hierbei vermutlich um den anhalt-dessauischen Leibarzt Dr. Peter Pasquay (1719-1777), der mit Elisabeth Bernus verheiratet war, vgl. Schmidt 1960.

1105 Es handelt sich hier um den Vater Johann Wolfgangs von Goethe, den Juristen Johann Kaspar Goethe (1710-1782), vgl. auch Schmidt 1960, dessen Angaben zum Besitz Goethes allerdings nicht zu verwenden sind.

1106 Vielleicht der Bankier Heinrich Bernus (gest. 1781), die Familie stammte ursprünglich aus Piacenza und kam im 17. Jahrhundert von Lüttich nach Frankfurt, der Familie gehörte seit 1696 der Saalhof, vgl. Schmidt 1960. Nach Gwinner 1862, S.534 wurde die Sammlung des Handelsmannes Jacob Bernus im Jahre 1781 unter Leitung von Hüsgen versteigert, der auch den Auktionskatalog verfaßt hatte.

1107 Es handelt sich hier um den Frankfurter Handelsmann Johann Friedrich Ettling (17121786), der ab 1733 auch Mitglied der wissenschaftlichen Gesellschaft Uffenbachs war; vgl. auch Schmidt 1960. 


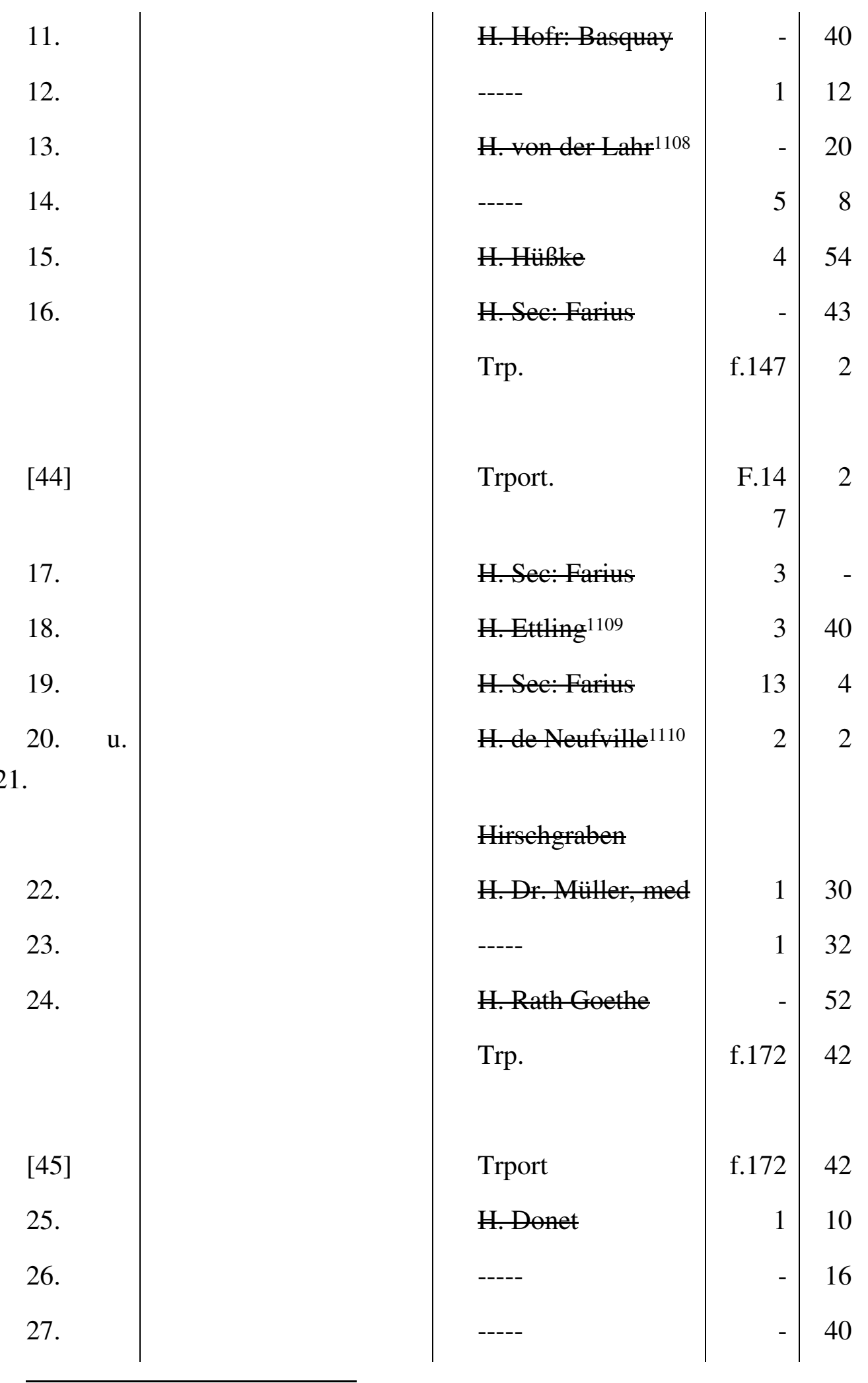

1108 Nach Schmidt 1960 gab es im Frankfurt des 18. Jahrhunderts eine Kunstsammlung und Bibliothek der Familie von der Lahr.

1109 Es handelt sich hier um den Frankfurter Handelsmann und Mitglied der wissenschaftlichen Gesellschaft, Johann Friedrich Ettling (1712-1786), vgl Schmidt 1960.

1110 Frankfurter Bankiersfamilie, aus Antwerpen stammend, seit 1573 in Frankfurt ansässig; vgl. Schmidt 1960. 


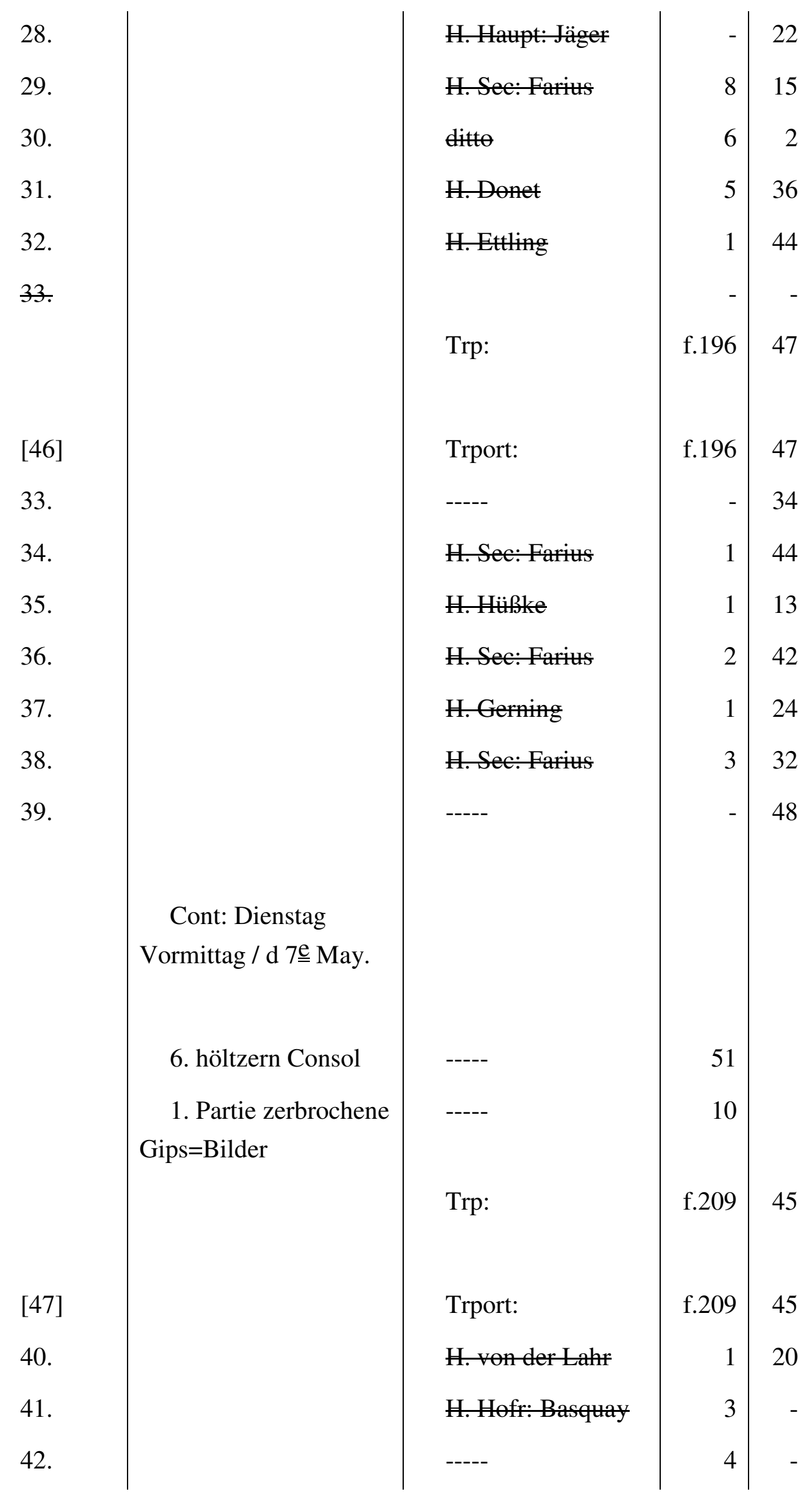




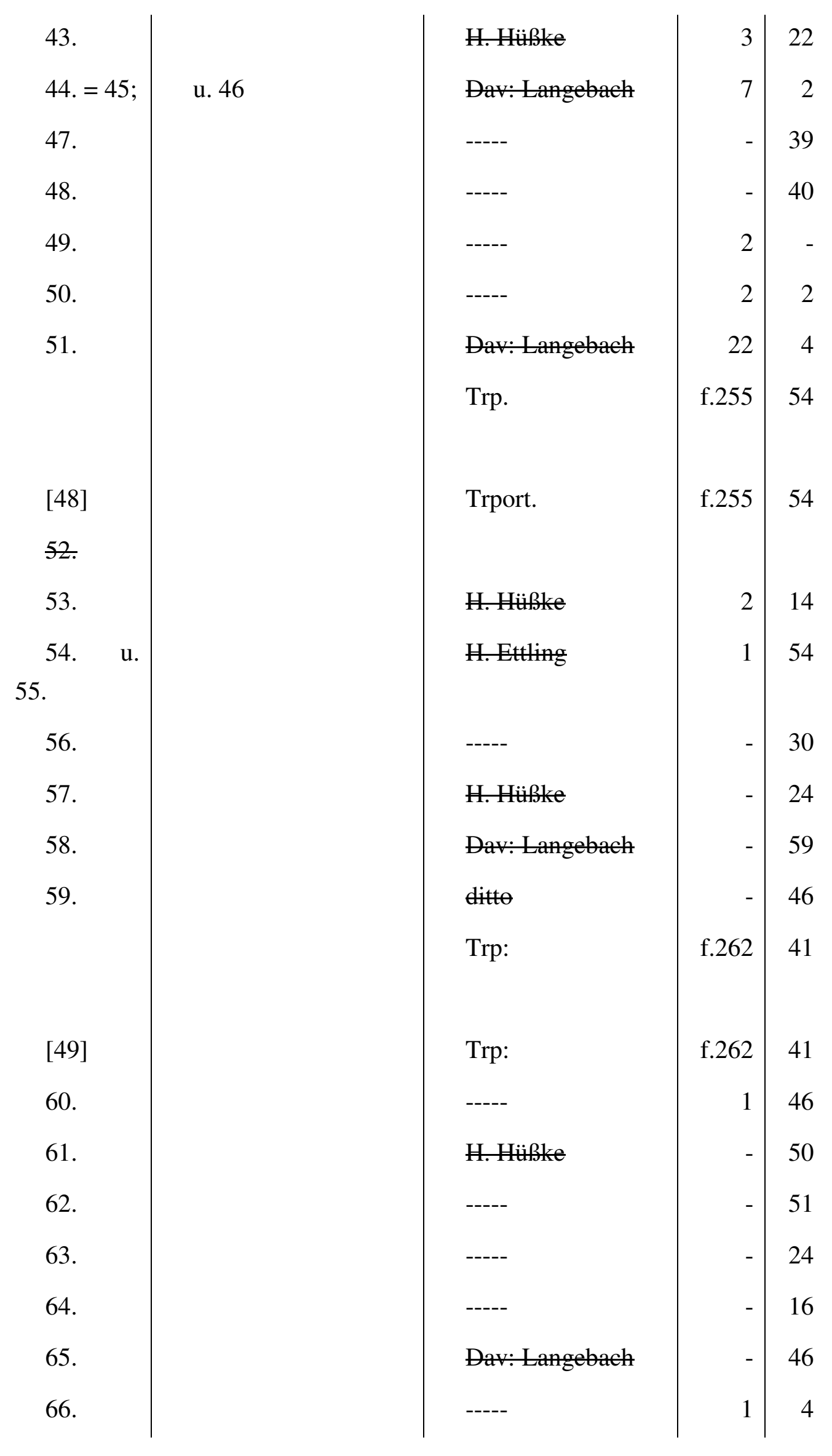




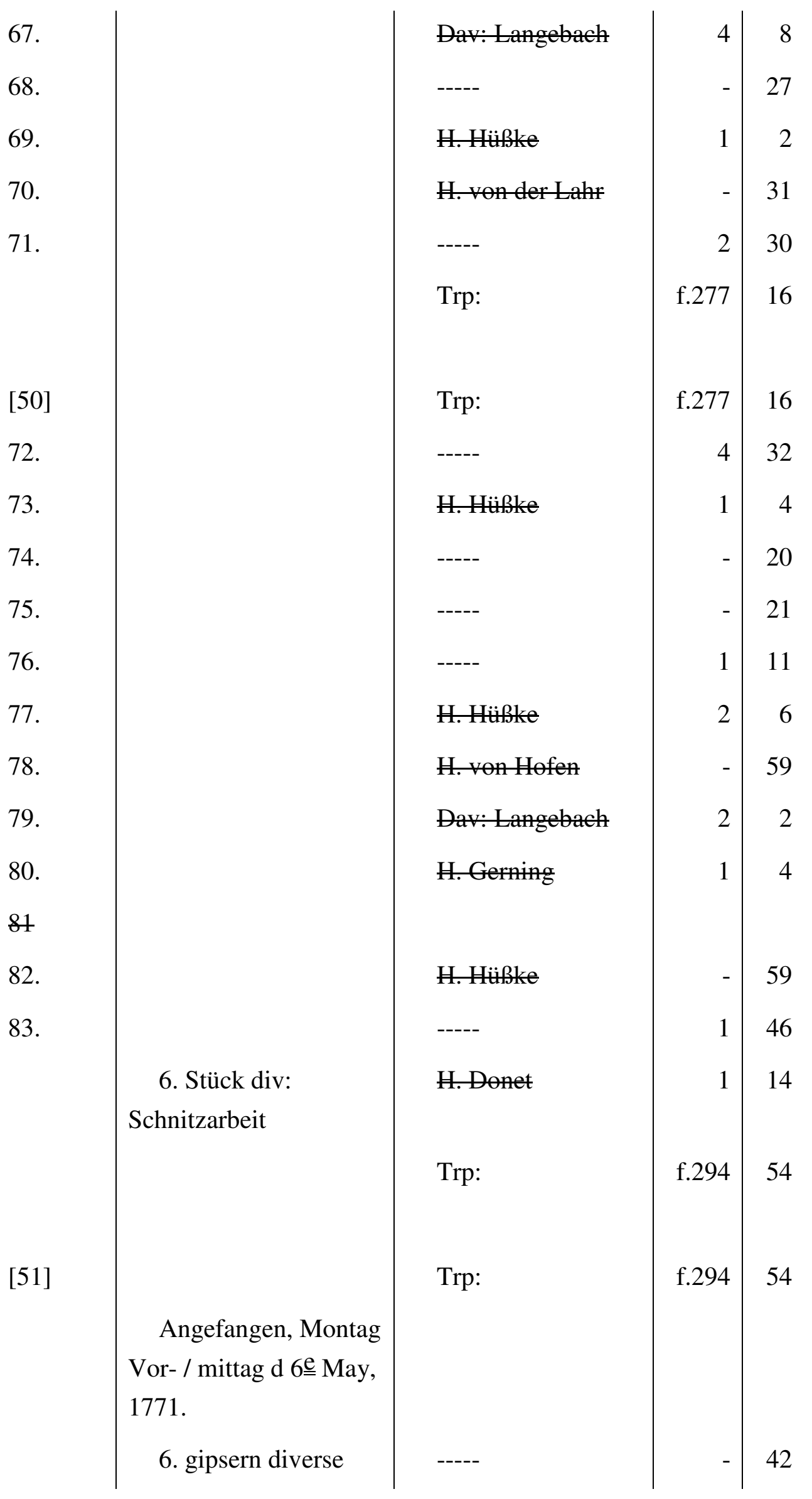




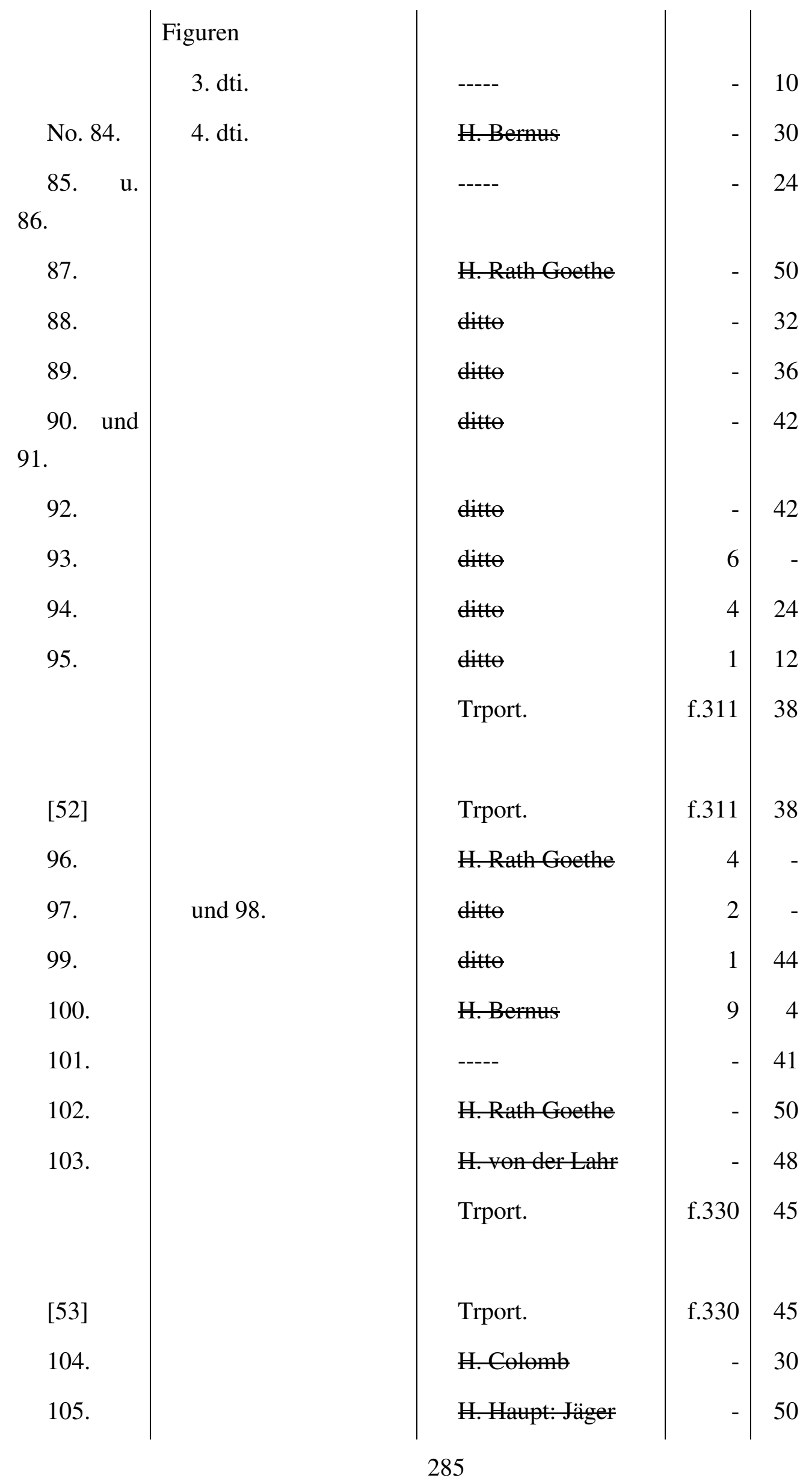




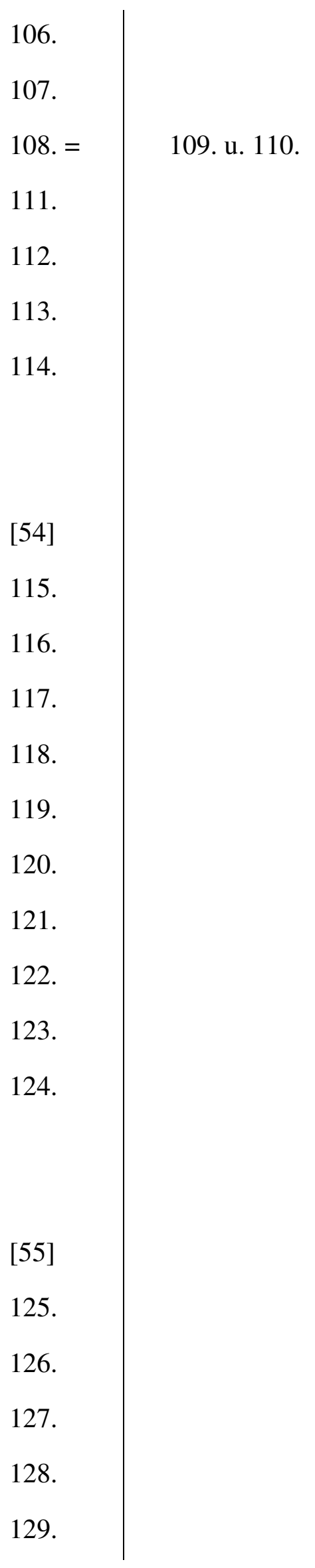

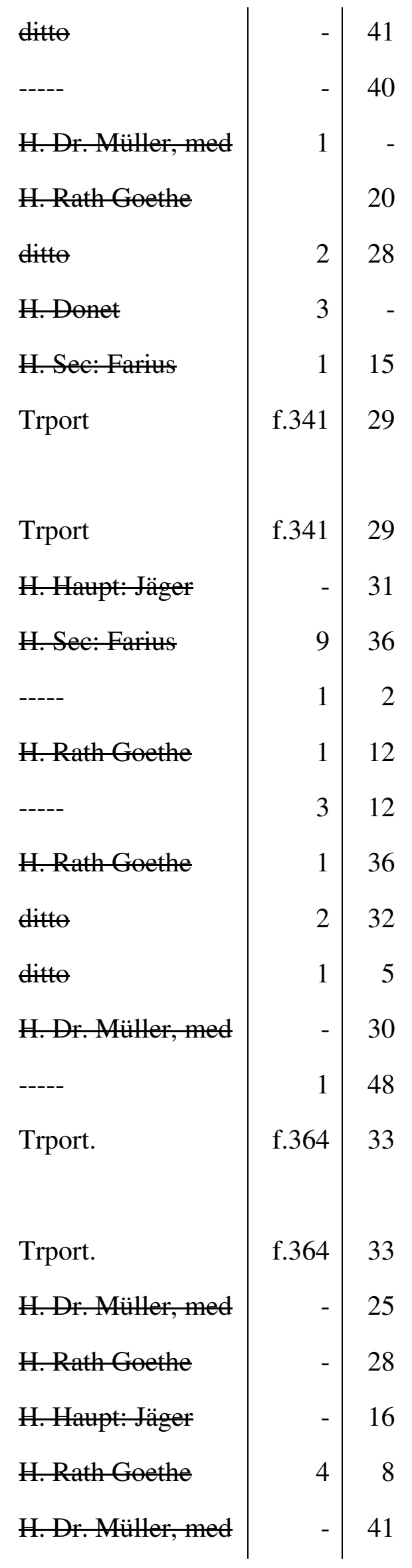




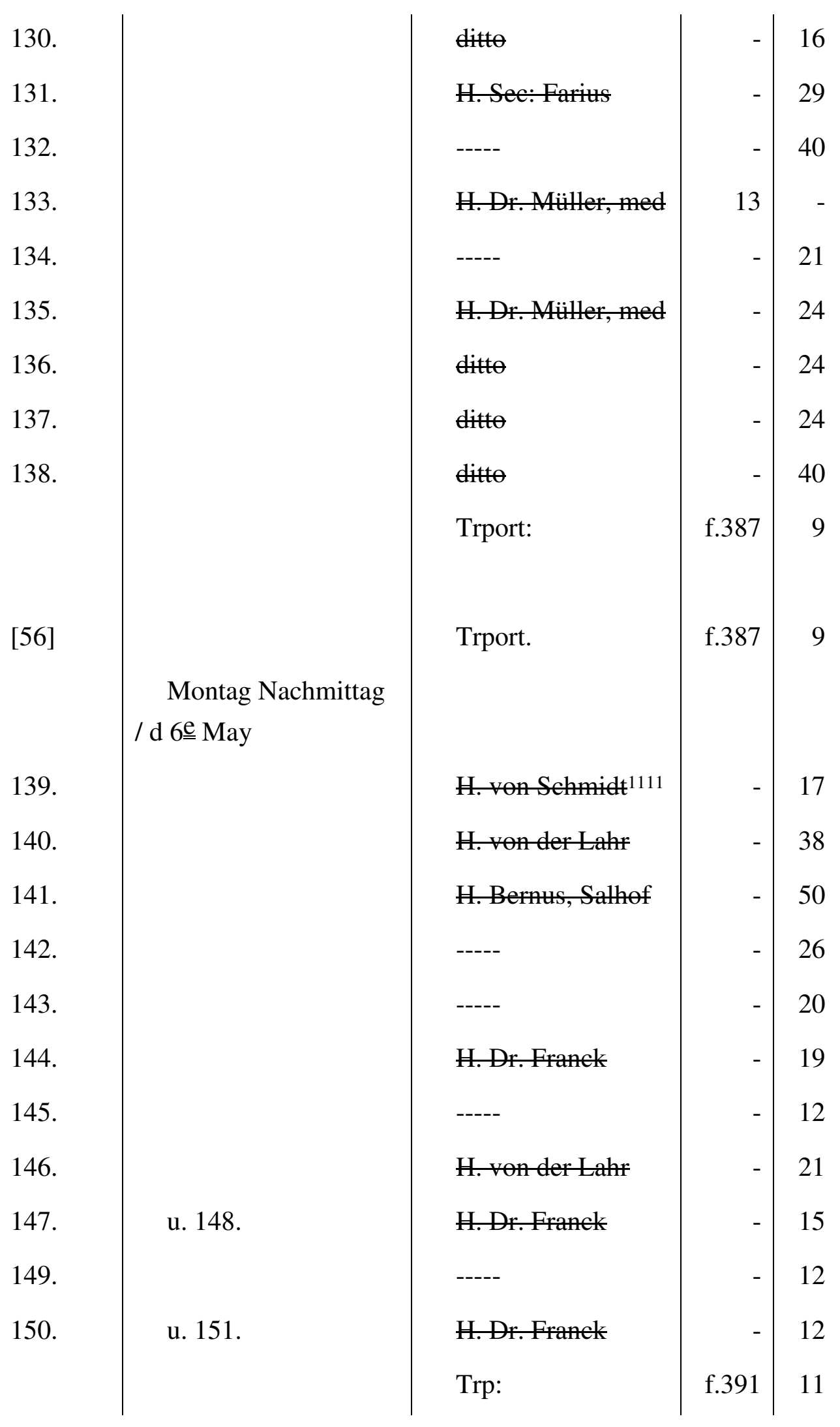

1111 Wahrscheinlich Friedrich Samuel von Schmidt, Herr von Rossan und Hullhausen (17371796), der seit 1771 Baden-Durlachischer geheimer Legationsrat und Resident war, vgl. Schmidt 1960. 


\begin{tabular}{|c|c|c|c|}
\hline [57] & & Trp: & f.391 \\
\hline 152 & $\begin{array}{l}\text { u. } 153 . \\
\text { 2. dti. }{ }^{1112} \text { von Gips }\end{array}$ & $\begin{array}{l}\text { H. von der Lahr } \\
\text {----- }\end{array}$ & - \\
\hline 154. & $\begin{array}{l}\text { Dienstag Nachmittag } \\
\text { / d. } 7 \underline{\text { e May }}\end{array}$ & H. von Hofen & 6 \\
\hline 157. & & ----- & 3 \\
\hline \multirow[t]{11}{*}{156.} & & H. Danckert & 9 \\
\hline & $\begin{array}{l}\text { 1. Kistgen in Form } \\
\text { eines Buchs mit } \\
\text { geschnittenen Steinen }\end{array}$ & $\begin{array}{l}\text { H Hiltenbrandt auf } \\
\text { dem Markt }\end{array}$ & 25 \\
\hline & 3. grose Muscheln & H. Danckert & 2 \\
\hline & $\begin{array}{l}\text { 2. dti. und } 1 . \\
\text { Corallenzincken }\end{array}$ & H. Ettling & 3 \\
\hline & 12. div: dti. & H. Danckert & 1 \\
\hline & Muschlen & & \\
\hline & 12. div: dti. & ditte & 1 \\
\hline & 5. Stück & H. von Hofen & 1 \\
\hline & div:Naturalien & & \\
\hline & 17. Stück dti. & H. Danckert & 2 \\
\hline & & Trp: & f. 447 \\
\hline \multirow[t]{2}{*}{ [58] } & & Trport & f. 447 \\
\hline & $\begin{array}{l}\text { 1. schw. eingelegte / } \\
\text { Dose, und noch / } \\
\text { verschiedene Curi- / }\end{array}$ & H. Hofr. Basquay & 2 \\
\hline
\end{tabular}




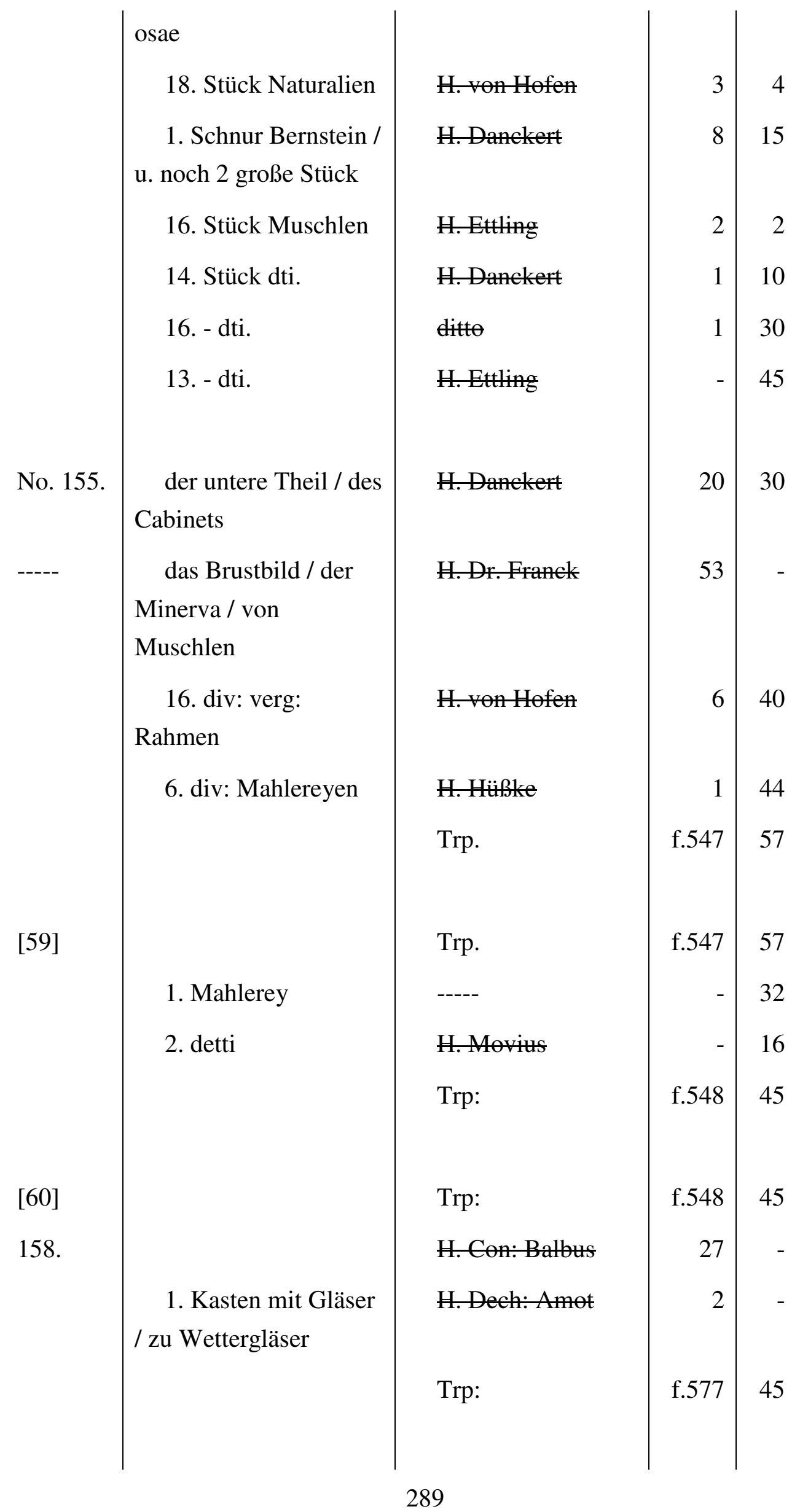




\begin{tabular}{|c|c|c|c|c|}
\hline [61] & & Trp: & f.577 & 45 \\
\hline 159. & Drehbanck & H. Honet & 56 & - \\
\hline 160. & & H. Dech. Amot & 16 & - \\
\hline \multirow[t]{11}{*}{162.} & 1. Laute & H. Rath Geethe & 8 & 30 \\
\hline & 1. dto. & H. Bernus & 2 & 12 \\
\hline & 1. dto. & H. Hiltenbrandt, & 1 & - \\
\hline & & auf / dem Marckt & & \\
\hline & 1. Violine & H. von der Lahr & 7 & - \\
\hline & 1. dto. mit Schildkrot & H. Henet & 2 & 32 \\
\hline & 1. Clavicordium & H. Otten ${ }^{1113}$ & 10 & 4 \\
\hline & 2. Violinen & H. Colomb & 2 & 4 \\
\hline & 1. Hand u. Basretg. & H. Bernus & 1 & 2 \\
\hline & 1. Ditto & H. Hiltenbrandt & 1 & - \\
\hline & & Trp: & f.685 & 9 \\
\hline \multirow[t]{4}{*}{ [62] } & & Trport: & f. 685 & 9 \\
\hline & $\begin{array}{l}\text { Mittwoch } 1114: \text { : M: } \\
\text { d 8 } \underline{\underline{e}} \text { May. }\end{array}$ & & & \\
\hline & 1. Kistgen mit / & H. Hüßke & 7 & - \\
\hline & $\begin{array}{l}\text { Elfenbeinern / Flöten, } \\
\text { nebst / Fagot }\end{array}$ & & & \\
\hline \multirow[t]{5}{*}{163.} & 12. Stück ge- / & H. Städel ${ }^{1115}$, im & 5 & - \\
\hline & schlifene Gläser & Torb [?] & & \\
\hline & 12. detti & H. Hüßke & 6 & - \\
\hline & 12. detti & H. Ettling & 3 & - \\
\hline & 12. detti & ----- & 3 & 4 \\
\hline
\end{tabular}

1113 Vielleicht aus der Familie Baron von Otten; vgl. Schmidt 1960.

1114 Als Abkürzungszeichen.

1115 Wahrscheinlich der Frankfurter Handelsmann und Bankier Johann Friedrich Städel (17281816), Stifter des nach ihm benannten Kunstinstituts, vgl Gwinner 1862, S. 555-563. 


\begin{tabular}{|c|c|c|c|c|}
\hline & 15. detti ${ }^{1116}$ & H. Städel & 4 & - \\
\hline Lit: B. & 19. detti & ----- & 7 & 4 \\
\hline Lit: C. & 22. detti & ----- & 5 & 4 \\
\hline Lit: D. & 7. detti & H. Ettling & 1 & 24 \\
\hline Lit: E. & 20. detti & H. Goll1117 & 2 & 10 \\
\hline ---- & 21. detti & $\operatorname{ditt\theta }$ & 3 & 8 \\
\hline Lit: F. & 13. detti & H. Hofr. Basquay & 1 & - \\
\hline et & 12. detti & $\operatorname{ditt\theta }$ & - & 40 \\
\hline G: & 58. ditto & ditte & 4 & - \\
\hline Lit: H. & 4. detti & H. Hüßke & 2 & 44 \\
\hline --- & 3. detti & ----- & 2 & 20 \\
\hline --- & 3. detti & H. Ettling & 2 & 8 \\
\hline & & Trp: & f.744 & 55 \\
\hline [63] & & Trport: & f.744 & 55 \\
\hline Lit: J. & $\begin{array}{l}\text { 11. geschlifene } \\
\text { Gläser }\end{array}$ & H. Hüßke & 2 & - \\
\hline Lit. K. & 1. Microscopio & $\operatorname{ditte}$ & 4 & 40 \\
\hline No.164. & 6. Taflen, mit folio & ----- & 2 & 28 \\
\hline & 5. detti & ----- & 1 & 24 \\
\hline & 3. detti & ----- & 1 & 12 \\
\hline & 3. detti & ----- & - & 31 \\
\hline & 3. detti & ----- & - & 24 \\
\hline & 2. detti & H. Gerning & - & 40 \\
\hline & 2. detti & ditte & - & 40 \\
\hline & 2. detti & H.Hüßke & - & 15 \\
\hline
\end{tabular}

1116 Bis hierhin eine geschweifte Klammer, davor „Lit: A.“

1117 = Johann Goll van Franckenstein I (1722-1785). 


\begin{tabular}{|l|l|r|r}
$\begin{array}{l}\text { 2. Metall Spiegel / u. } \\
\text { 4. farb: Gläser }\end{array}$ & H. Hofr. Basquay & 1 & 30 \\
2. Polier-Kolben & & 1 & 4 \\
$\begin{array}{l}\text { 1. Perspectiv, und / } \\
\text { 1. alt Wetterglaß }\end{array}$ & H. Städel & fl.76 & 43 \\
& & 1 & \\
hier von geht ab, an & & 10 & - \\
fol. 29. / alwo fl. 10. zu & & fl.75 & 43 \\
viel sumirt: & $\underline{\text { Sma }}$ & 1 &
\end{tabular}




\subsection{Das Gegenschreiberbuch der Auktion von 1775}

ISG Frankfurt am Main Einundfünfzigerkolleg - Gegenschreiberbücher- 3079 Verganthungs-Buch, angefangen den 1ten 7 bre 1774 und gehet bis d. 30. May $\underline{1775, \text { No.5.], p. 222b-242a. }{ }^{1118}}$

Verganthungs-Buch No. 5, Angefangen den 1ten 9bre. 1774. und gehet bis d. 30 e May 1775 ,

Die Nummerierung der Gegenstände in dem Gegenschreiberbuch richtet sich nach dem gedruckten Auktionskatalog von 17751119, der eine redigierte Neuauflage des Auktionskataloges von 1771 war. ${ }^{1120}$ Die meisten Objekte, die zum Aufruf kamen, sind im Auktionskatalog nicht aufgenommen worden und so mit keiner Nummer verzeichnet. Bei dieser Versteigerung kamen die gesamten Mobilien der verstorbenen Witwe von Uffenbach unter den Hammer. Sie dauerte 12 Werktage und ergab eine Gesamtsumme von 10047 Gulden und 50 Kreuzer. 1121

Die Seiten des Manuskripts besitzen fünf Unterteilungen:

1.: Nummer im Auktionskatalog.

2.: Kurzbeschreibung des Gegenstandes.

3.: Name des Käufers.

4. und 5.: Preis in Gulden und Kreuzer.

1118 Das Gegenschreiberbuch galt bis heute als verschollen. Ich danke Achim Reichel, ehemals Institut für Stadtgeschichte Frankfurt am Main, herzlichst für seine Bemühungen.

$1119=$ Uffenbach 1775 .

$1120=$ Uffenbach 1771.

1121 Die Frankfurter Währung war eine reine Silberwährung und wurde in Gulden zusammengesetzt, wobei ein Gulden (fl.) 60 Kreuzern (kr. oder xr.) entsprach, vgl. Kölsch 2002,1, in: Kat. Frankfurt 2002, S. 85. 
[222b] 1775. Montag d. 15e May, sind der S.T. / Wohlseel. Frau Schöf von Uffenbach, gebohren / von Bertram, ihre hinterlaßene Mahlereyen / Praetiosa, Silber Werck, und Effecten \& $c^{\mathrm{a}}$ / wie solche folgender Maßen beschrieben, / an den Meißtbietenden öffentl. verkauft, / und losgeschlagen worden, als nemlich. ${ }^{1122}$

Muntirt

\begin{tabular}{|c|c|c|}
\hline $\begin{array}{l}3 \text { Blumen Stück } \\
1 \text { ovale Mahlerey } \\
\text { und }\end{array}$ & ----- & - \\
\hline noch 3 Detti & Bender jun. & - \\
\hline 2. Detti unter glas & Gogel & 1 \\
\hline 2 große Ditto & Bender jun. & 1 \\
\hline 3. Detti & Ditto & - \\
\hline 3. Detti & Ditto & - \\
\hline 2. Detti & Schnitter & 2 \\
\hline 2. Ditto & Bender jun. & 2 \\
\hline 1. Ditto & Movius 1123 & 1 \\
\hline 1. Ditto & Ditte & 1 \\
\hline 2. Detti & Dr.Beinhauer & 1 \\
\hline 2. Detti & Hisque & 2 \\
\hline im Catalogo 2ter & & \\
\hline Ab-/ schnitt pag.29.1124 & & \\
\hline
\end{tabular}

1122 In den Frankfurter Nachrichten No.41, Anhang vom 15. Mai 1775 wird die Auktion folgendermaßen angezeigt: „Versteigerung des Nachlasses vom seel. Herrn Schöff von Uffenbach - darunter Gemälde, ein großer Vorrath gebunden- und ungebundener Noten, benebst einem Dudelsack von Sammet mit goldenen Borden, einige Flöten und Musikpulten u.a.“ [Zitiert nach: Israel 1876, S. 57]. Weiter schreibt Israel: „Unter diesen Noten befanden sich (laut Anzeige in No. 44, Anhang) 'die vortrefflichsten Opern'.“ Die hier genannten Gegenstände sind im gedruckten Auktionskatalog von 1775 [= Uffenbach 1775] nicht aufgeführt.

$1123=$ Mevius, Georg Friedrich

$1124=$ Uffenbach 1775. 


\begin{tabular}{|c|c|c|c|c|}
\hline No. 1 & 1. Portrait & Gogel & 22 & - \\
\hline \multirow[t]{2}{*}{2} & 1 Klein Stück & ------- & - & 30 \\
\hline & & Transport & 38 & 37 \\
\hline $223[a]$ & & Transport & 38 & 37 \\
\hline No.3. & 1 Klein Stück & ----- & - & 37 \\
\hline 4. & Die Erweckung & Pager Mahler & 1 & 8 \\
\hline & Lazari & & & \\
\hline 5. & 1. Portrait König in / & Gogel & 1 & 22 \\
\hline & Schweden & & & \\
\hline 6. & Die Beschneidung & Movius & 2 & 28 \\
\hline & Christi & & & \\
\hline 7. & 1. Italienisches & Hofr Paque & 1 & 56 \\
\hline & Stück & & & \\
\hline 8. & 1. Kniestück & Schäfer & 1 & - \\
\hline 9. & 1. liegende Venus & Gogel & 6 & - \\
\hline $10 \& 11$. & Zwey unterirdische & Geyß farthor & 1 & 5 \\
\hline & Hölen & & & \\
\hline 12.1125 & 1 Klein Hündgen & & & \\
\hline 13. & 1. Brust Bild & Hisque & - & 40 \\
\hline 14. & die Cleopatra u & & & \\
\hline 15. & ein Landschäftgen & Movius & 4 & - \\
\hline 16. & 1. alter Kopf u. & & & \\
\hline 17. & 1. antique & Jgfr Büttnern & 1 & 4 \\
\hline & Landschaft & & & \\
\hline 18. & die heilige Familie & Mr. Colomb & 2 & 24 \\
\hline 19. & Eine Landschaft & Movius & 2 & 44 \\
\hline
\end{tabular}

1125 Die Nummer „12“ zusammen mit Nummern „,10“ und „11“. 


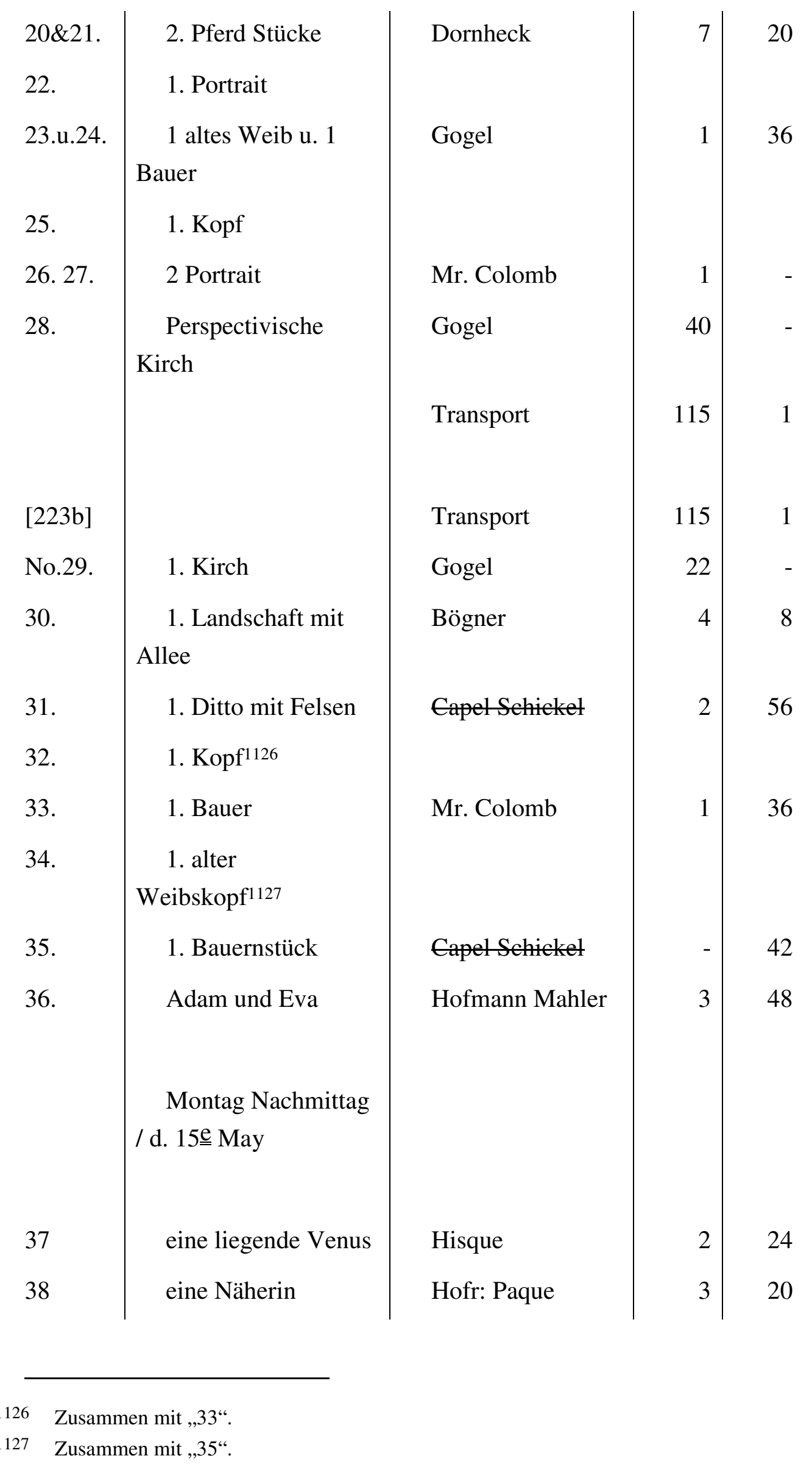




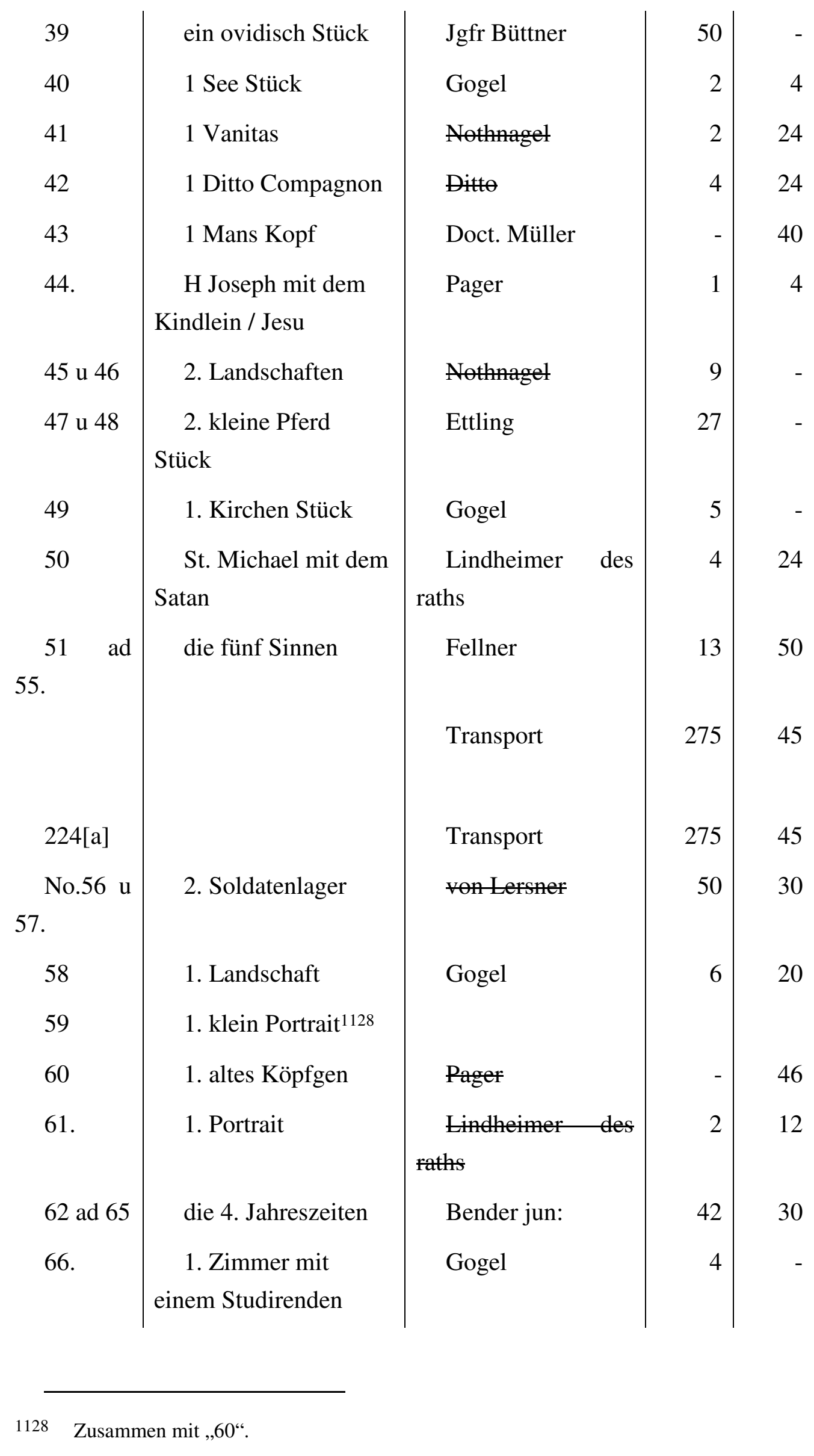




\begin{tabular}{|c|c|c|c|}
\hline 67. & 1. Ditto & Ditto & 3 \\
\hline 68. & 1. klein Portrait & Ettling & 5 \\
\hline 69. & $\begin{array}{l}\text { 1. Stück mit einem } \\
\text { Pferd }\end{array}$ & Bender jun. & 3 \\
\hline 70. & $\begin{array}{l}\text { 1. Christusbild mit } \\
\text { dem Creutz }\end{array}$ & Gogel & 6 \\
\hline 71. & Adam und Eva & Nothnagel & 18 \\
\hline 72. & $\begin{array}{l}\text { 1. Portrait Churfürst } \\
\text { Johannes / von Sachsen }\end{array}$ & Doct Müller & - \\
\hline 73. & $\begin{array}{l}\text { Johannes der } \\
\text { Evagelist }\end{array}$ & Gogel & 15 \\
\hline 74 u 75 & 2. Bataillen Stücke & Nothnagel & 50 \\
\hline 76. & die heilige Familie & Gogel & 2 \\
\hline 77. & 1. kleine Kirch & Ettling & 55 \\
\hline 78. & 1. große Bataille & Gogel & 15 \\
\hline 79 u 80 & $\begin{array}{l}\text { 2. Stück mit Speisen } \\
\text { und / Geschirr }\end{array}$ & Hoffman Mahler & 19 \\
\hline 81. & 1 klein Portrait & Gogel & 2 \\
\hline 82. & 1. Nacht Stück & Hiemynus [?] & 1 \\
\hline & & Transport & 581 \\
\hline$[224 b]$ & & Transport & 581 \\
\hline 83 u 84 & 2. Landschaften & Ettling & 34 \\
\hline 85 & 1. runde Landschaft & Movius & 4 \\
\hline 86. & $\begin{array}{l}\text { 1. Landschaft } \\
\text { Flörsheim }\end{array}$ & Bender jun. & 22 \\
\hline & $\begin{array}{l}\text { Dienstag Vormittag/ } \\
\text { d. 16 } \underline{\text { e May }}\end{array}$ & & \\
\hline
\end{tabular}




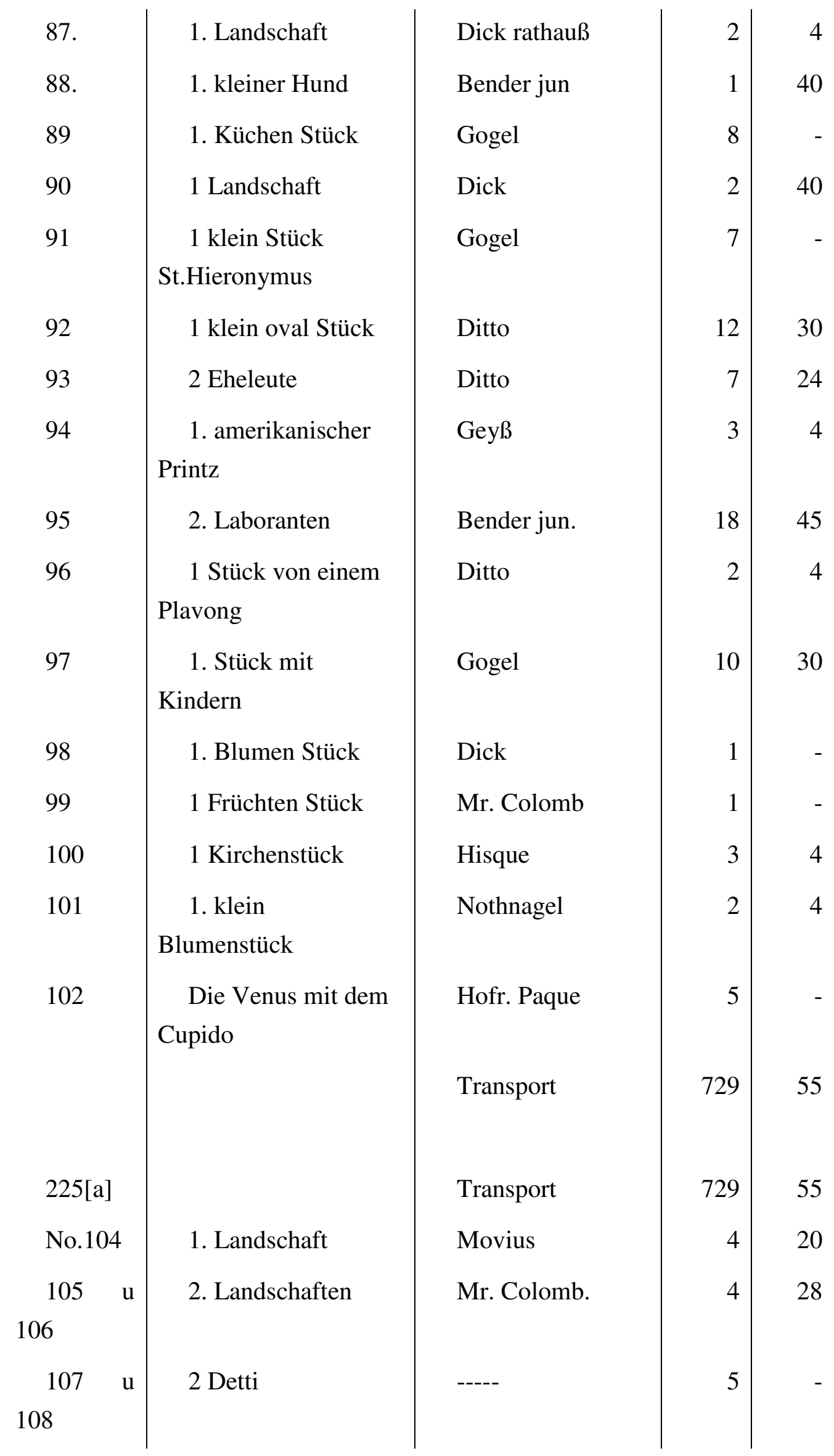




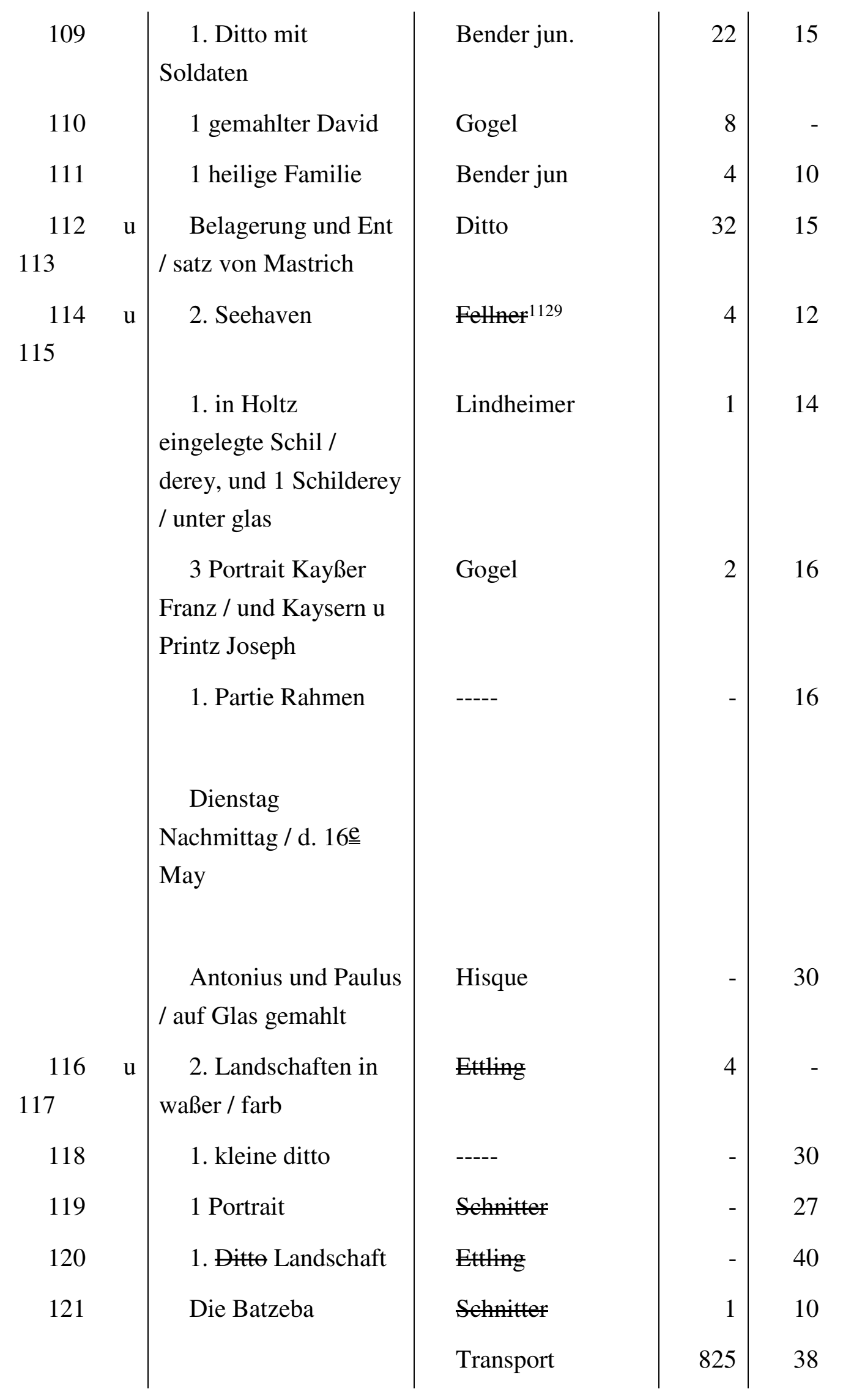

1129 [vielleicht auch Heltner] 


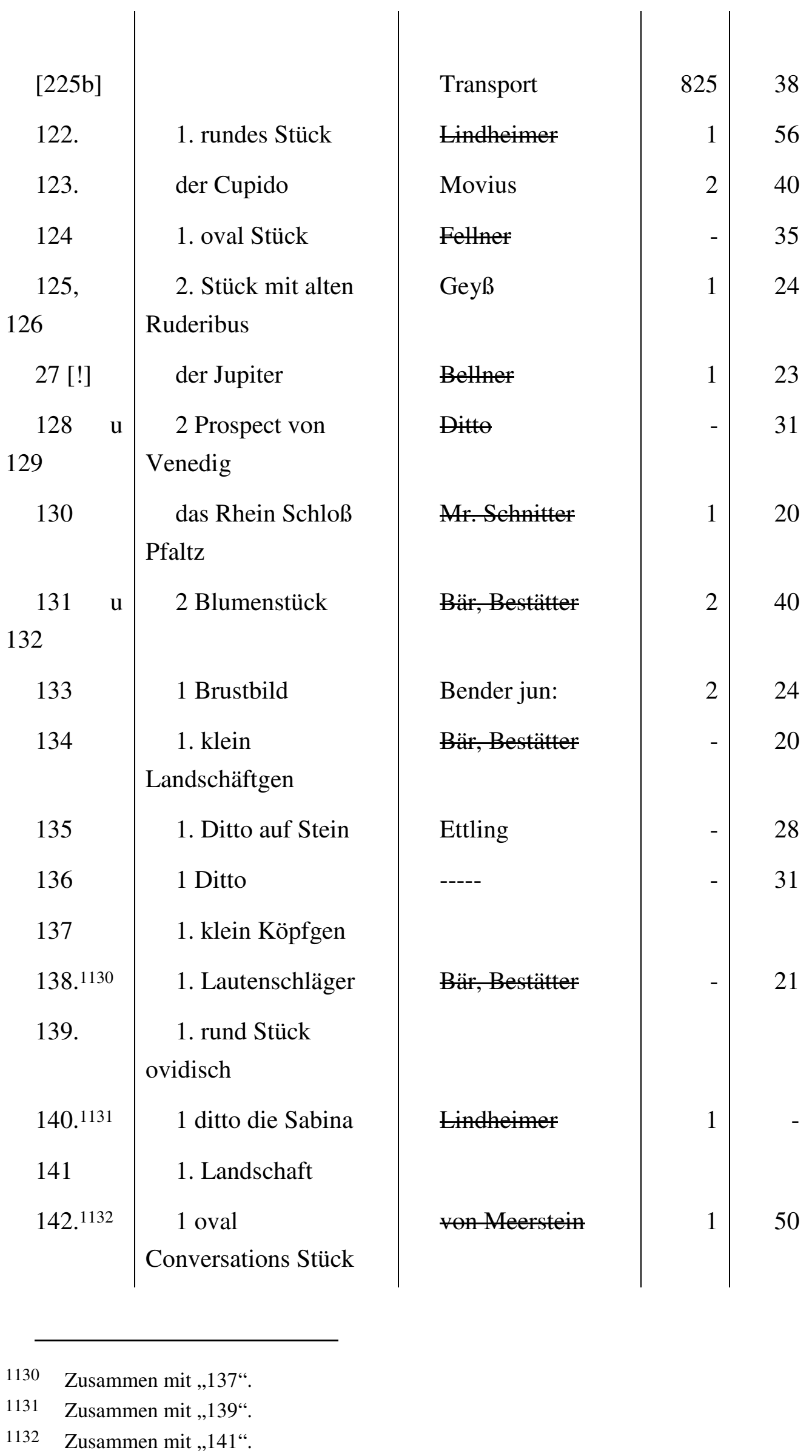




\begin{tabular}{|c|c|c|c|c|}
\hline 143. & $\begin{array}{l}\text { 1. oval Portrait vom } \\
\text { Kaiser VII }\end{array}$ & & & \\
\hline $144 .{ }^{1133}$ & $\begin{array}{l}1 \text { klein } \\
\text { Landschäftgen }\end{array}$ & Hisque & 1 & 12 \\
\hline 145. & $\begin{array}{l}\text { 1. lachendes } \\
\text { Köpfgen }\end{array}$ & & & \\
\hline 146.1134 & 1. Portrait & ----- & 4 & 34 \\
\hline 147. & $\begin{array}{l}\text { 10. eingefaßte } \\
\text { Portraits }\end{array}$ & Bär, Bestätter & 4 & 4 \\
\hline 148. & 1. Portrait & & & \\
\hline 149.1135 & 1. klein ditto & Hisque & - & 36 \\
\hline & & Transport & 855 & 27 \\
\hline $226[a]$ & & Transport & 855 & 27 \\
\hline 150 & bis auf 153.4 Stück & Weischeubel [?] & - & 41 \\
\hline 154. & die Geburt Christi & Geyß & 6 & - \\
\hline 155. & $\begin{array}{l}1 \text { Venus mit der } \\
\text { Feder }\end{array}$ & ----- & - & 32 \\
\hline 156. & $\begin{array}{l}\text { Isaac mit seinem } \\
\text { Sohn Jacob }\end{array}$ & Hisque & 1 & 14 \\
\hline 157. & $\begin{array}{l}\text { 1. Marienbild von } \\
\text { silber / getrieben }\end{array}$ & Hoffman jubl: & 3 & 16 \\
\hline 158. & $\begin{array}{l}1 \text { gedrähtes [!] } \\
\text { Portrait }\end{array}$ & Hisque & - & 12 \\
\hline 159. & $\begin{array}{l}\text { 1. silb. getriebenes } \\
\text { Stück / der Mercurius }\end{array}$ & Goldschmidt & 3 & 30 \\
\hline 160. & 1. Ditto vergoldt & Ditto & 2 & 4 \\
\hline 161. & 1. von Kupfer & Hisque & 2 & 32 \\
\hline
\end{tabular}




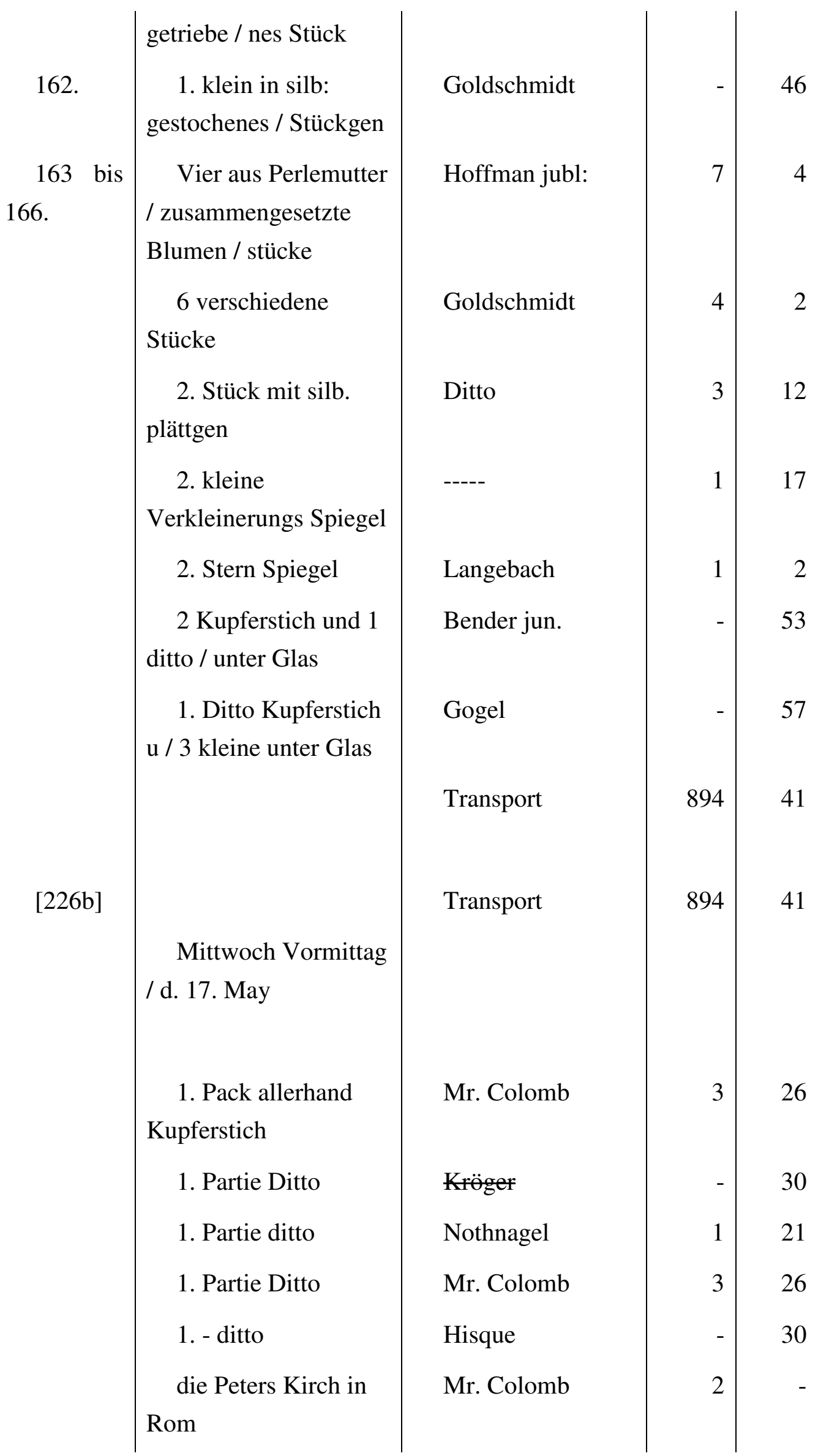




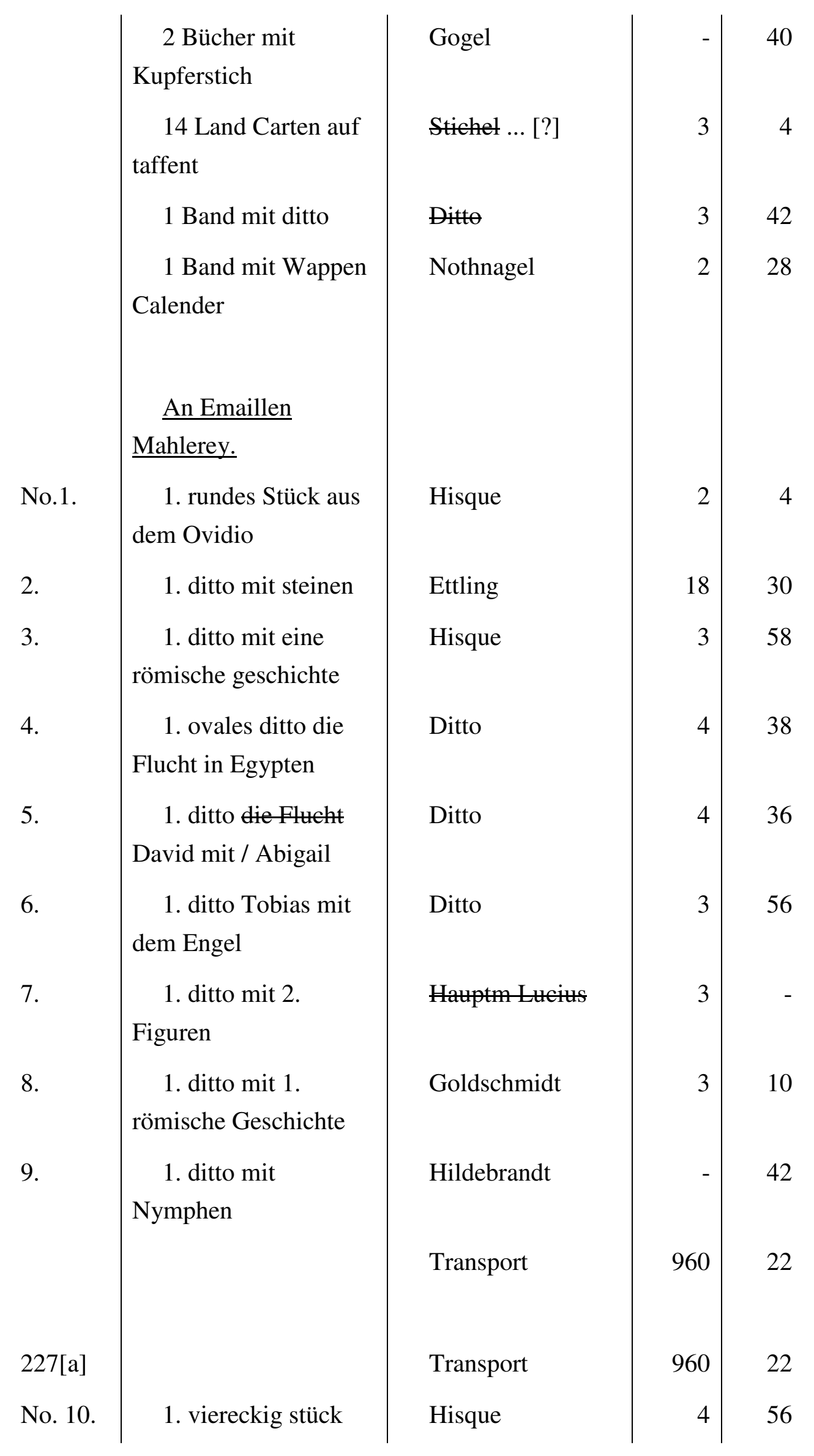




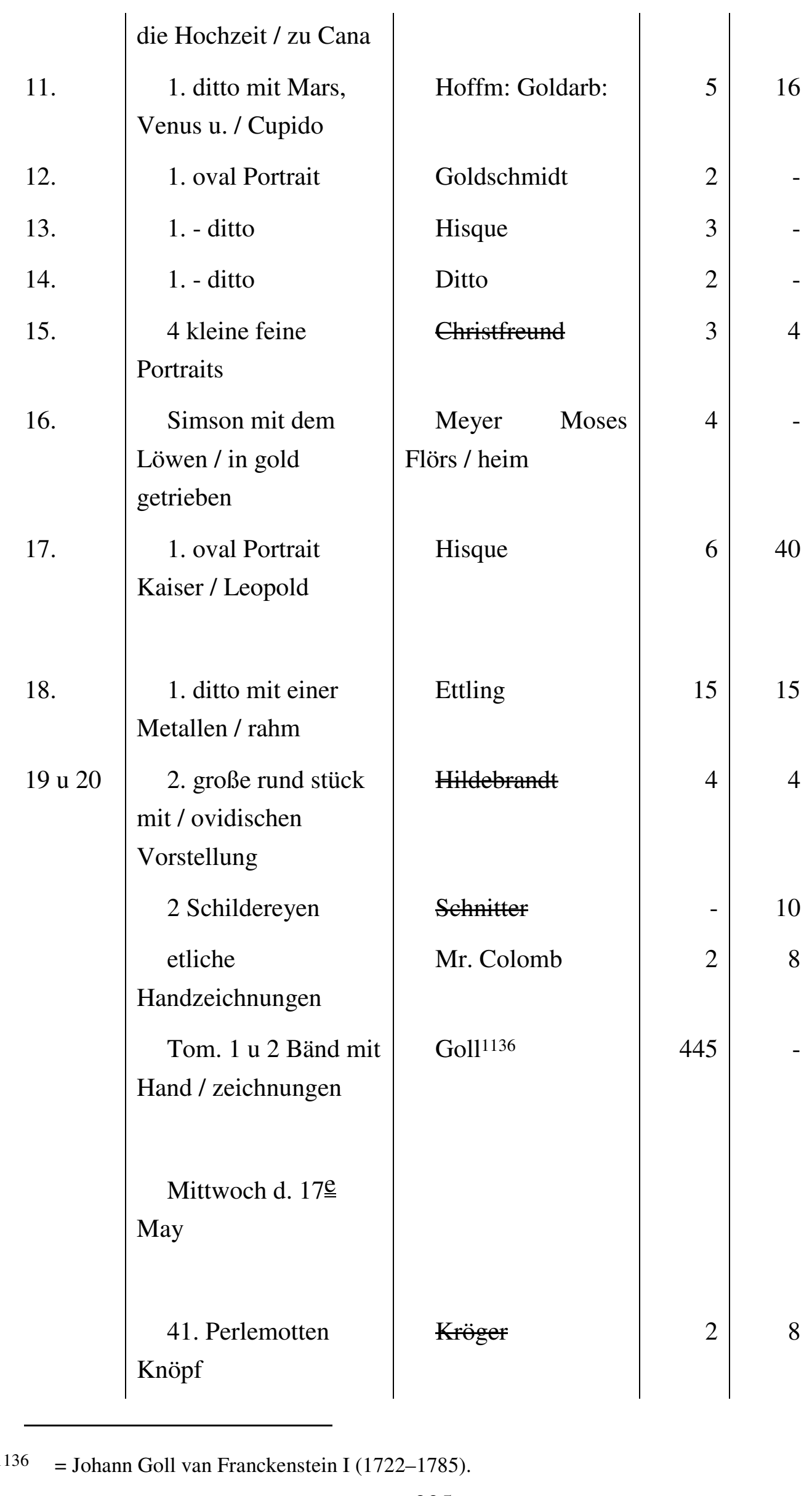




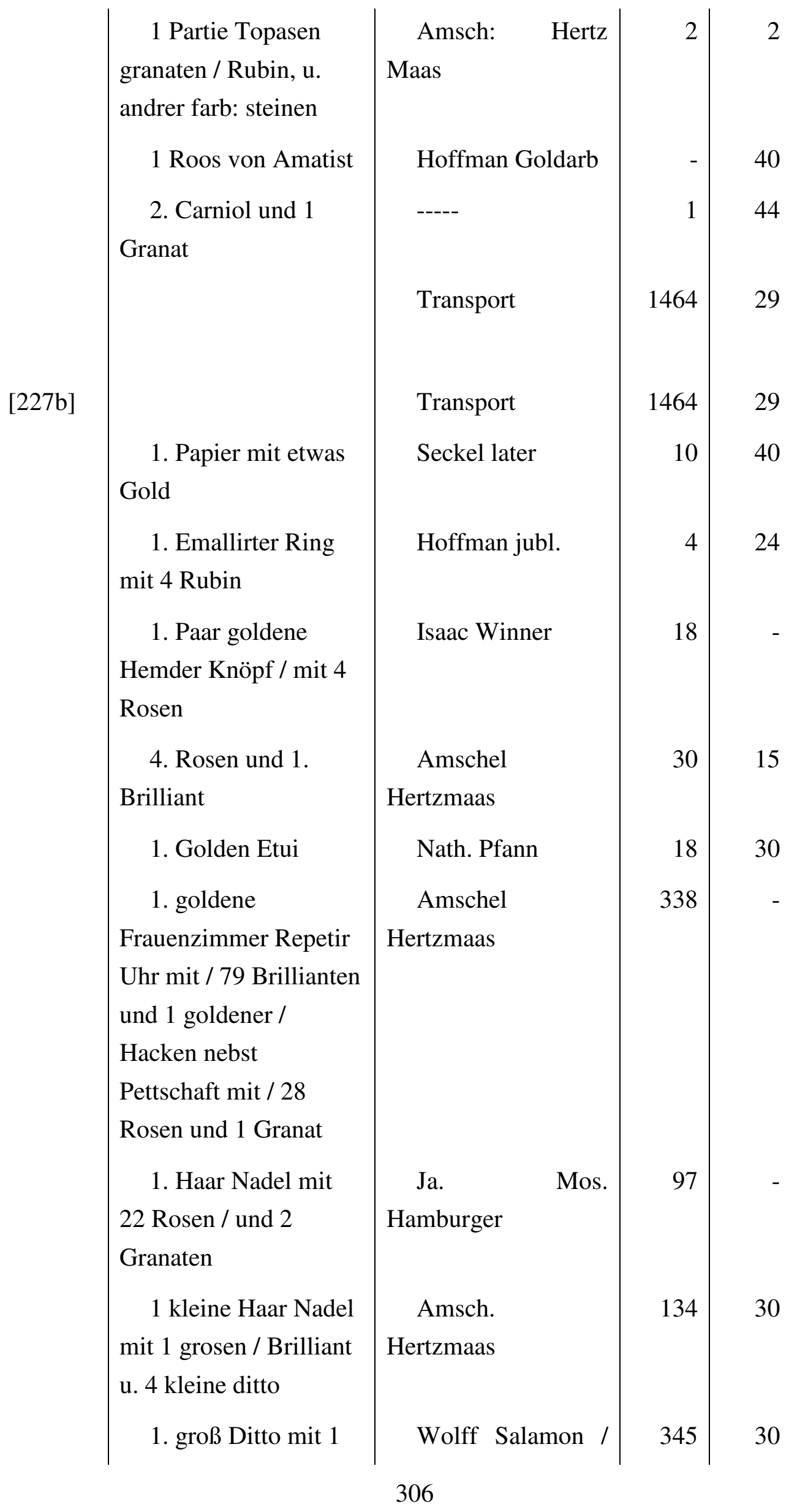




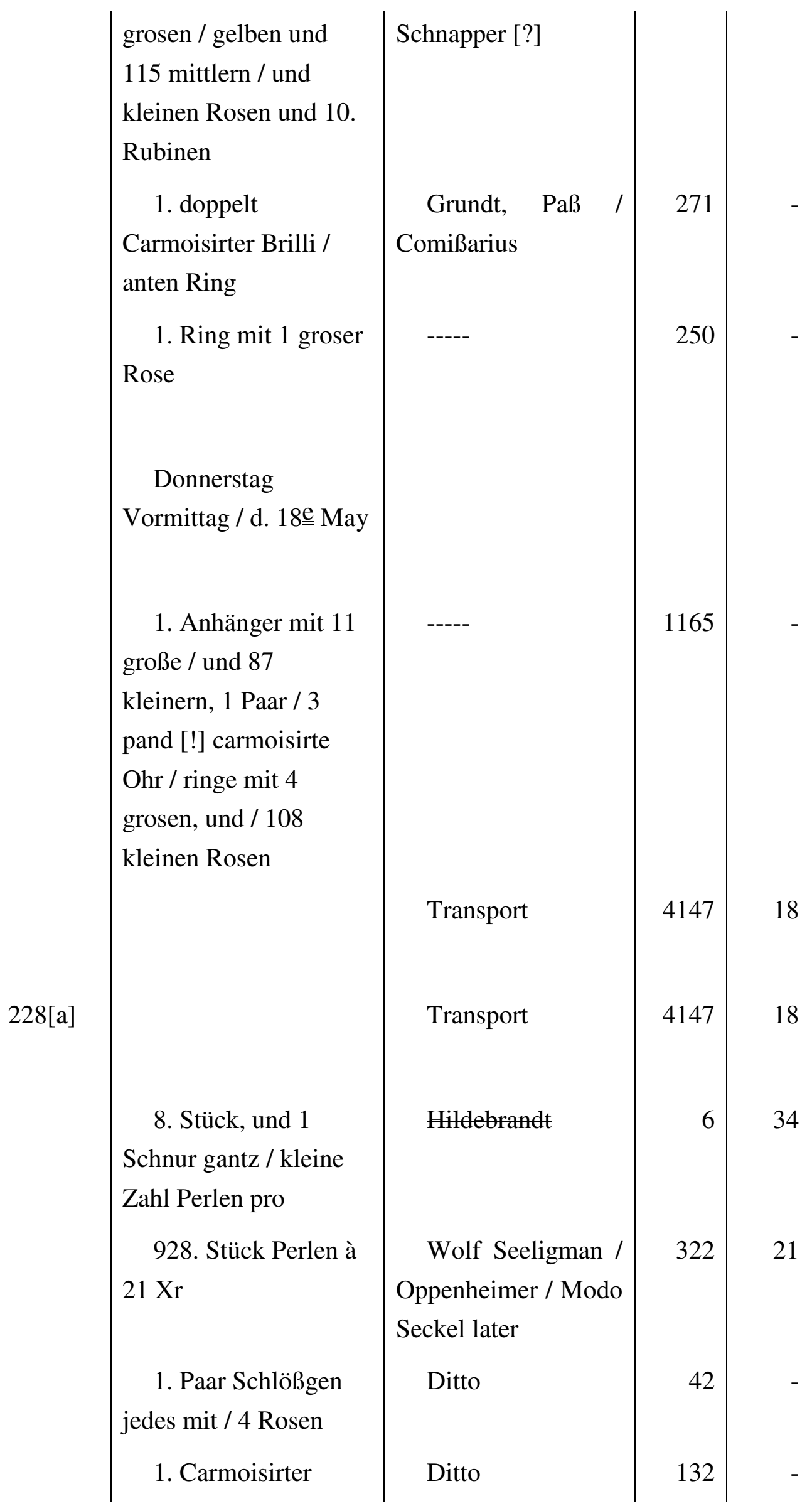




\begin{tabular}{|c|c|c|}
\hline $\begin{array}{l}\text { Brillianten / Ring mit } 1 \\
\text { grosen und / } 2 \text { kleinen } \\
\text { Smaragden }\end{array}$ & & \\
\hline $\begin{array}{l}\text { 1. Carmo. } \\
\text { Brillianten Ring / mit } \\
\text { 1. grosen Saphir }\end{array}$ & Isaac Winner & 207 \\
\hline $\begin{array}{l}\text { 1. golden blau } \\
\text { Emaillirte dos }\end{array}$ & von Hilten & 207 \\
\hline $\begin{array}{l}\text { 1. Schreib Tafel von } \\
\text { Jaspis mit / } \\
\text { Goldringfuß }\end{array}$ & Goldschmidt & 84 \\
\hline $\begin{array}{l}\text { 16. Stück } \\
\text { carmoisirter Knöpf / } \\
\text { mit 112. Rosen in } \\
\text { goldgefaßt / die untern } \\
\text { Theile von Silber / und } \\
\text { Vergold }\end{array}$ & Seckel later & 450 \\
\hline $\begin{array}{l}\text { 1. Schild Kroten das } \\
\text { mit Gold / eingelegt } \\
\text { und golden Garnier }\end{array}$ & von Hilten & 14 \\
\hline $\begin{array}{l}\text { 1. Agaten dos in } \\
\text { gold gefast }\end{array}$ & $\begin{array}{l}\text { Mos. Michel } \\
\text { Oppenheimer }\end{array}$ & 44 \\
\hline $\begin{array}{l}\text { 1. golden Emaillirte } \\
\text { Minutten / Uhr mit } \\
\text { Einem Brillianten / } \\
\text { Zeiger }\end{array}$ & $\begin{array}{l}\text { Brentano / Ngbe } \\
\text { Hof }\end{array}$ & 100 \\
\hline $\begin{array}{l}\text { 1. Goldener Stock } \\
\text { Knopf oben / mit } 1 \\
\text { großen Granat carmoi / } \\
\text { sirt mit } 8 \text { Brillianten, } \\
\text { und / } 8 \text { Rubinen, u. im } \\
\text { Bügel / } 7 \text { Rosen }\end{array}$ & von Hilten & 165 \\
\hline & Transport & 5922 \\
\hline
\end{tabular}




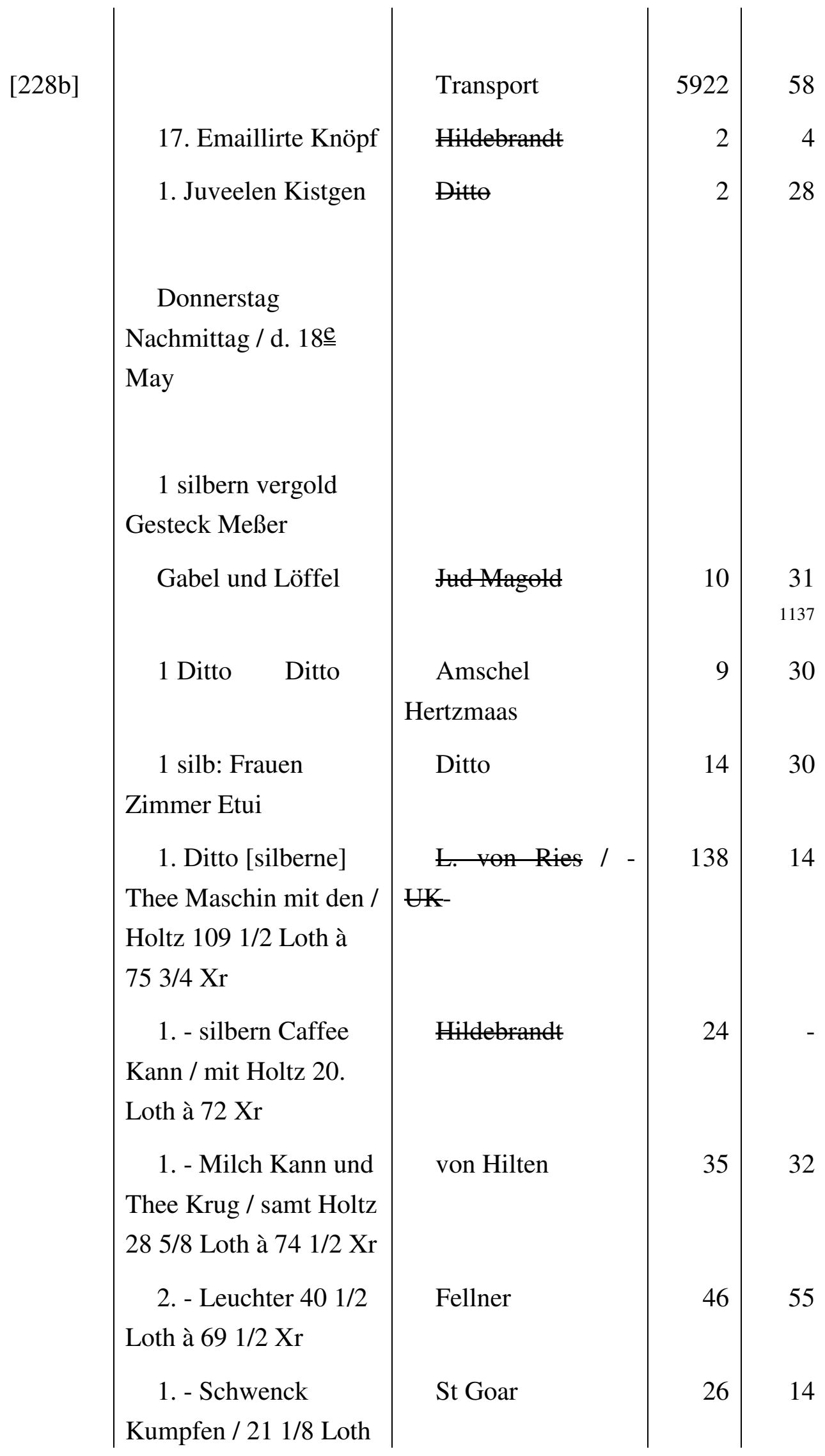

1137 Die Summe wurde eingerahmt und aus der Zählung herausgenommen. 


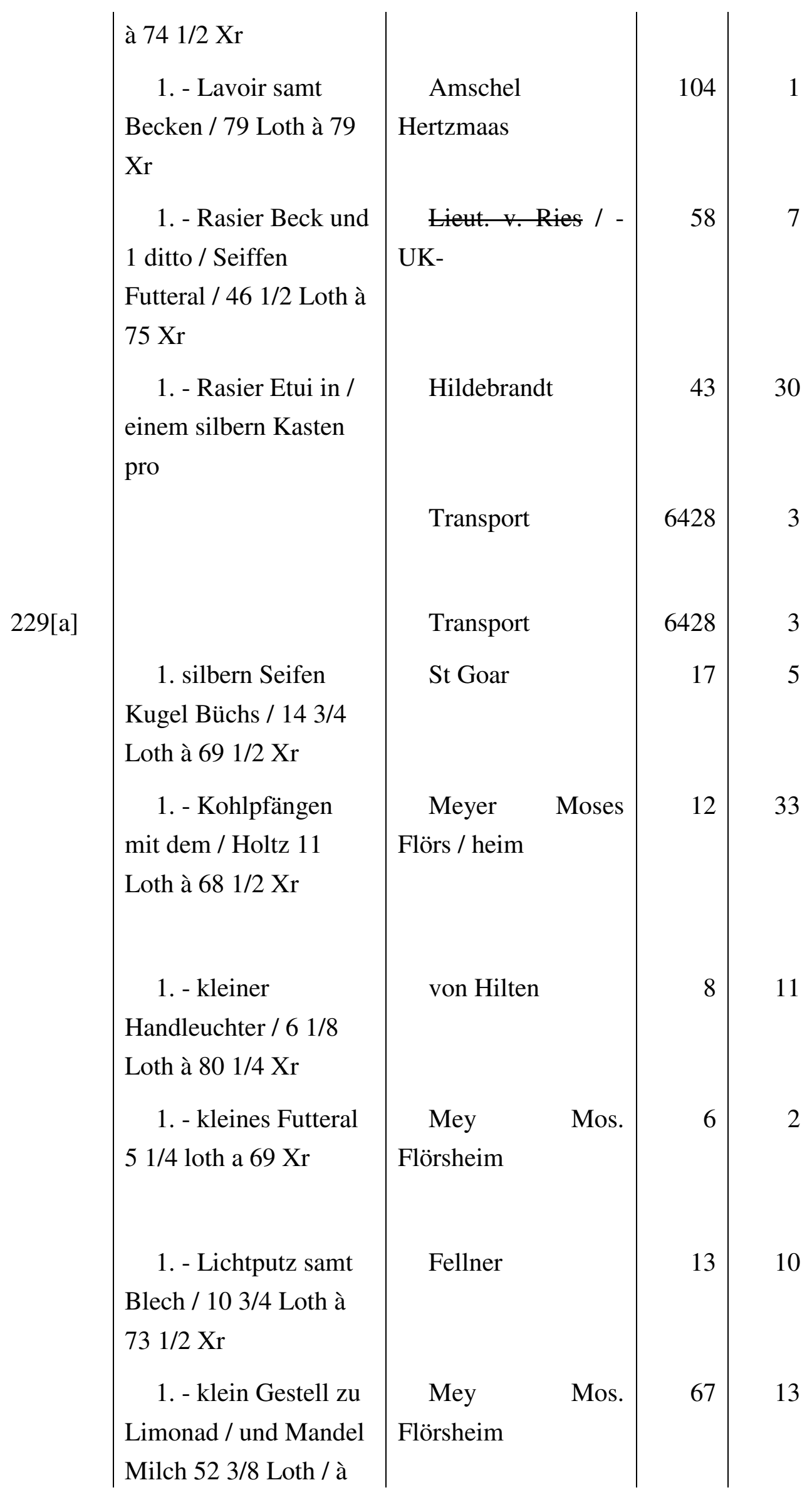




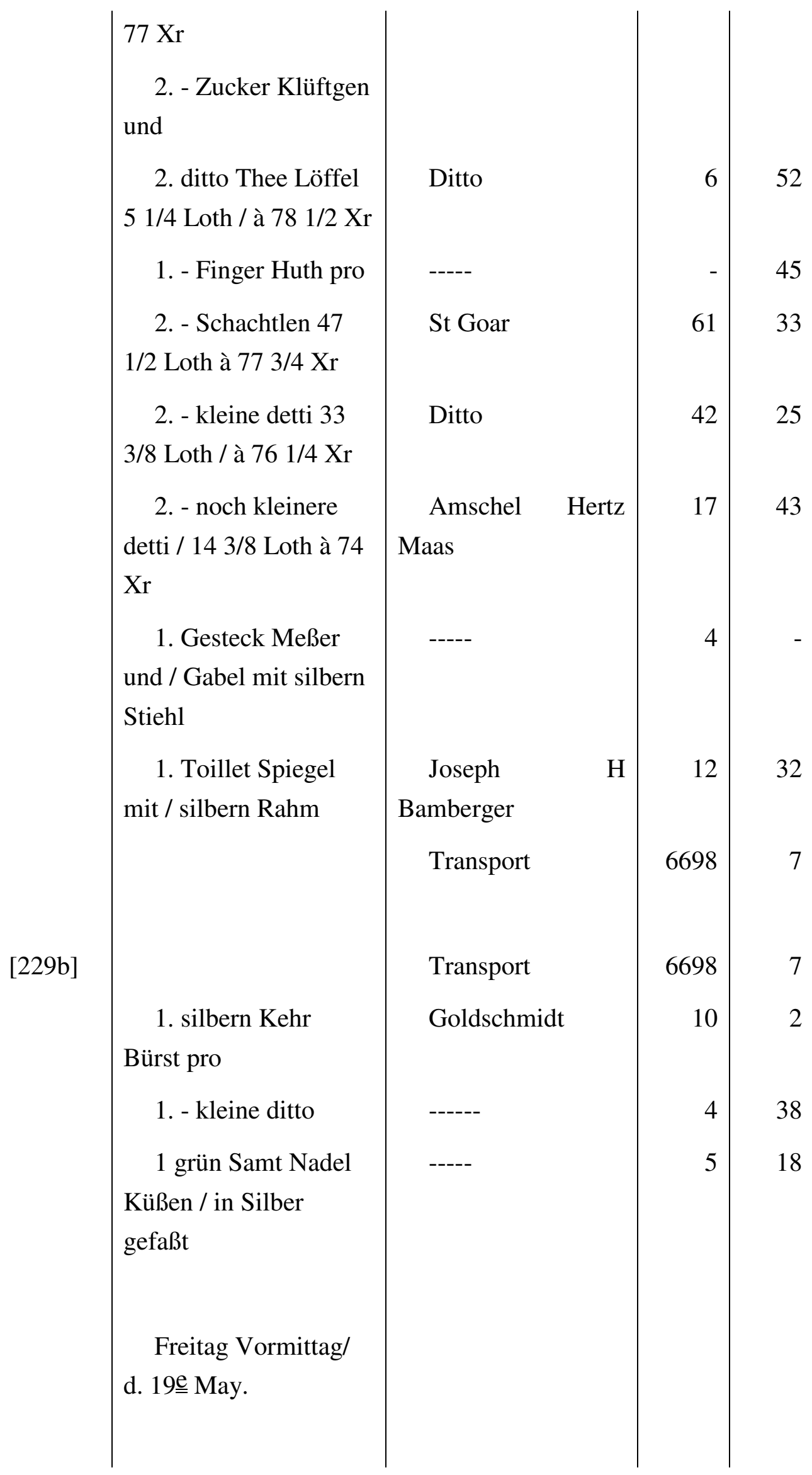




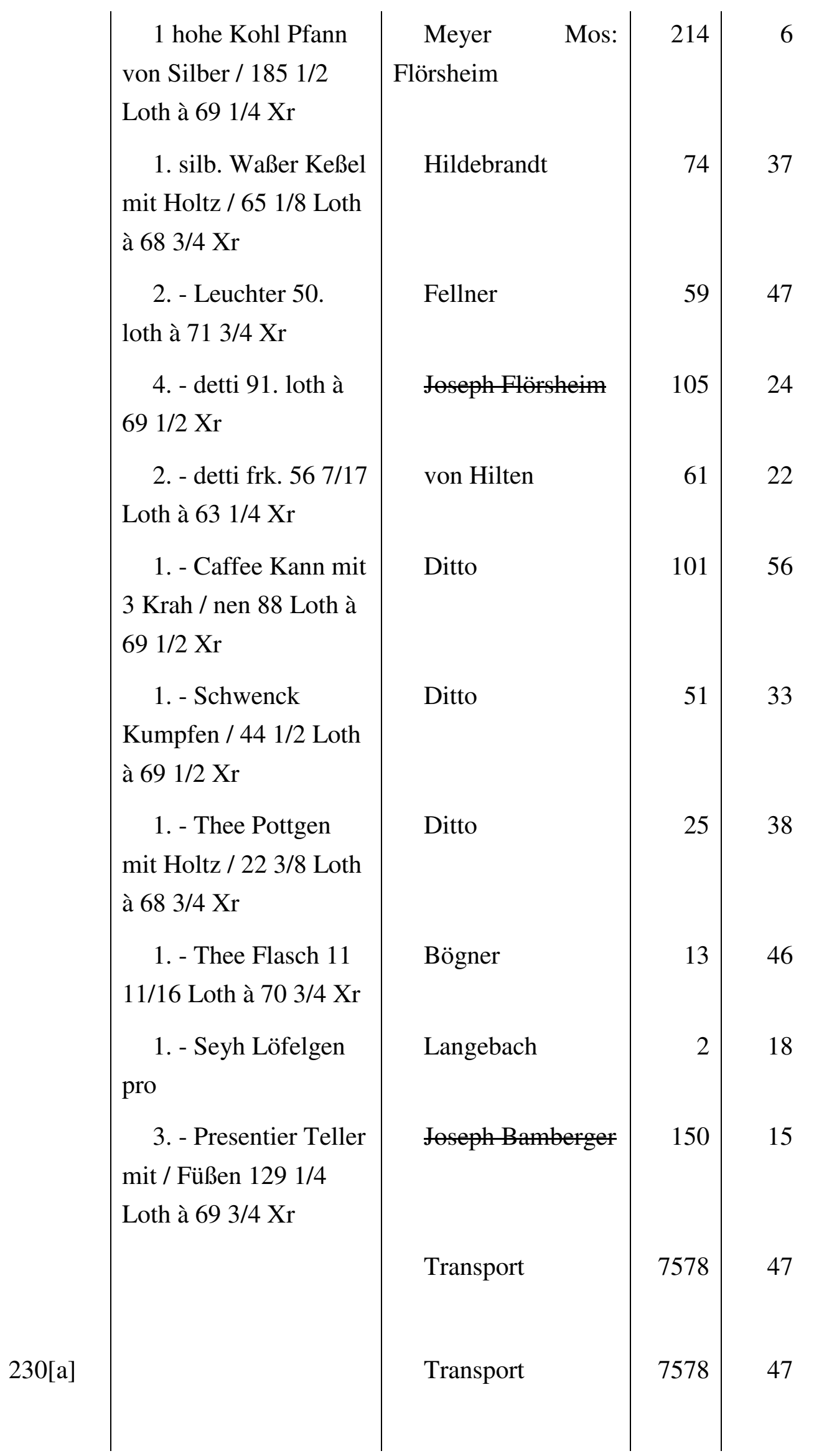




\begin{tabular}{|c|c|c|}
\hline $\begin{array}{l}\text { 1. silb. große } \\
\text { Suppen Kumpfen / mit } \\
\text { Deckel und Schüßel / } \\
\text { nebst } 1 \text { Vorleg Löfel in } \\
\text { wendig verdoldt / } 185 \\
\text { 1/4 Loth à } 74 \text { 1/2 Xr }\end{array}$ & Jgfr Büttnern & 230 \\
\hline $\begin{array}{l}\text { 1. - ditto mit Ditto } \\
\text { Ditto / 185. loth à } 75 \\
\text { Xr }\end{array}$ & Ditto & 231 \\
\hline $\begin{array}{l}1 \text { - Seause Kümpgen } \\
\text { in / wendig vergoldt / } \\
22 \text { 1/4 Loth à } 83 \text { 3/4 Xr }\end{array}$ & Langebach & 31 \\
\hline $\begin{array}{l}\text { 1. - ditto dto } 22 \text { 1/8 } \\
\text { Loth à } 88 \mathrm{Xr}\end{array}$ & Ditto & 32 \\
\hline $\begin{array}{l}\text { 1. - Senff Kängen } \\
\text { nebst Löfel / inwendig } \\
\text { vergold / } 13 \text { 11/16 Loth } \\
\text { à } 80 \text { 3/4 Xr }\end{array}$ & von Hilten & 18 \\
\hline $\begin{array}{l}\text { 4. - Saltz Fäßer } 30 \\
\text { 1/8 loth à } 701 / 4 \text { Xr }\end{array}$ & Fellner & 35 \\
\hline 1. - Vorleg Löfel & Hauptm Lucius & \\
\hline $\begin{array}{l}1 \text { - ditto } 30 \text { 3/4 Loth } \\
\text { à } 82 \text { 1/4 Xr }\end{array}$ & Ditte & 42 \\
\hline $\begin{array}{l}\text { 2. Crystallen } \\
\text { Flaschen zu Eßig / und } \\
\text { Baumöhl in silb. gefaßt }\end{array}$ & von Hilten & 26 \\
\hline $\begin{array}{l}1 \text { silb. Zucker Streu } \\
\text { Büchs / } 11 \text { 5/16 Loth à } \\
86 \text { 3/4 Xr }\end{array}$ & Lvon Ries-UK & 16 \\
\hline $\begin{array}{l}\text { 1. silb. groß Tauf } \\
\text { Becken samt / Kann } \\
146 \text { 3/8 Loth à } 71 \text { Xr }\end{array}$ & $\begin{array}{l}\text { Amschel Hertz } \\
\text { Maas }\end{array}$ & 173 \\
\hline 1. silb. Lichtputz pro & Langebach & 3 \\
\hline
\end{tabular}




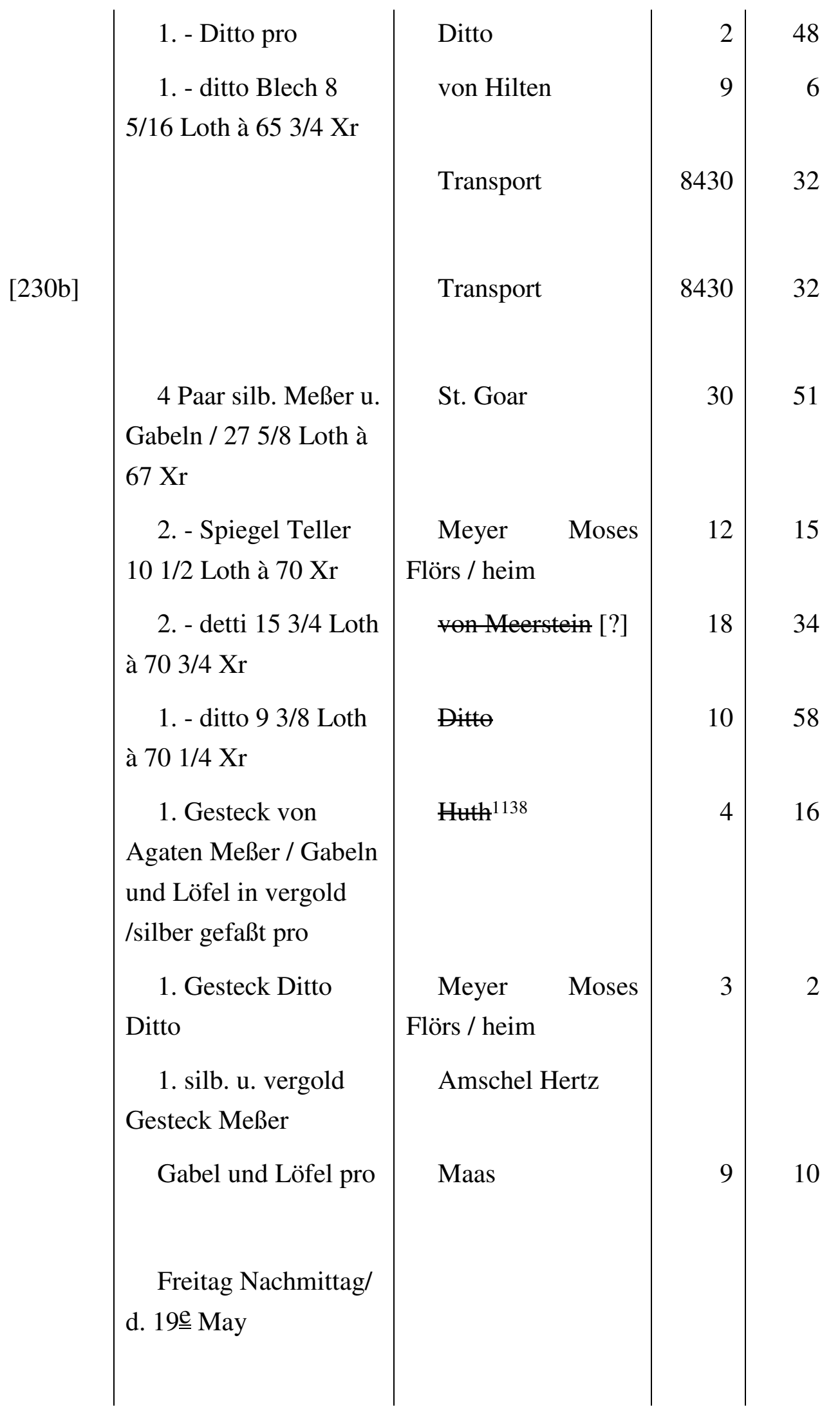

1138 Wahrscheinlich der Frankfurter Handelsmann Johann Georg Huth (1735-1815), sein Kunsbesitz wurde 1816 versteigert, vgl. Schmidt 1960. 


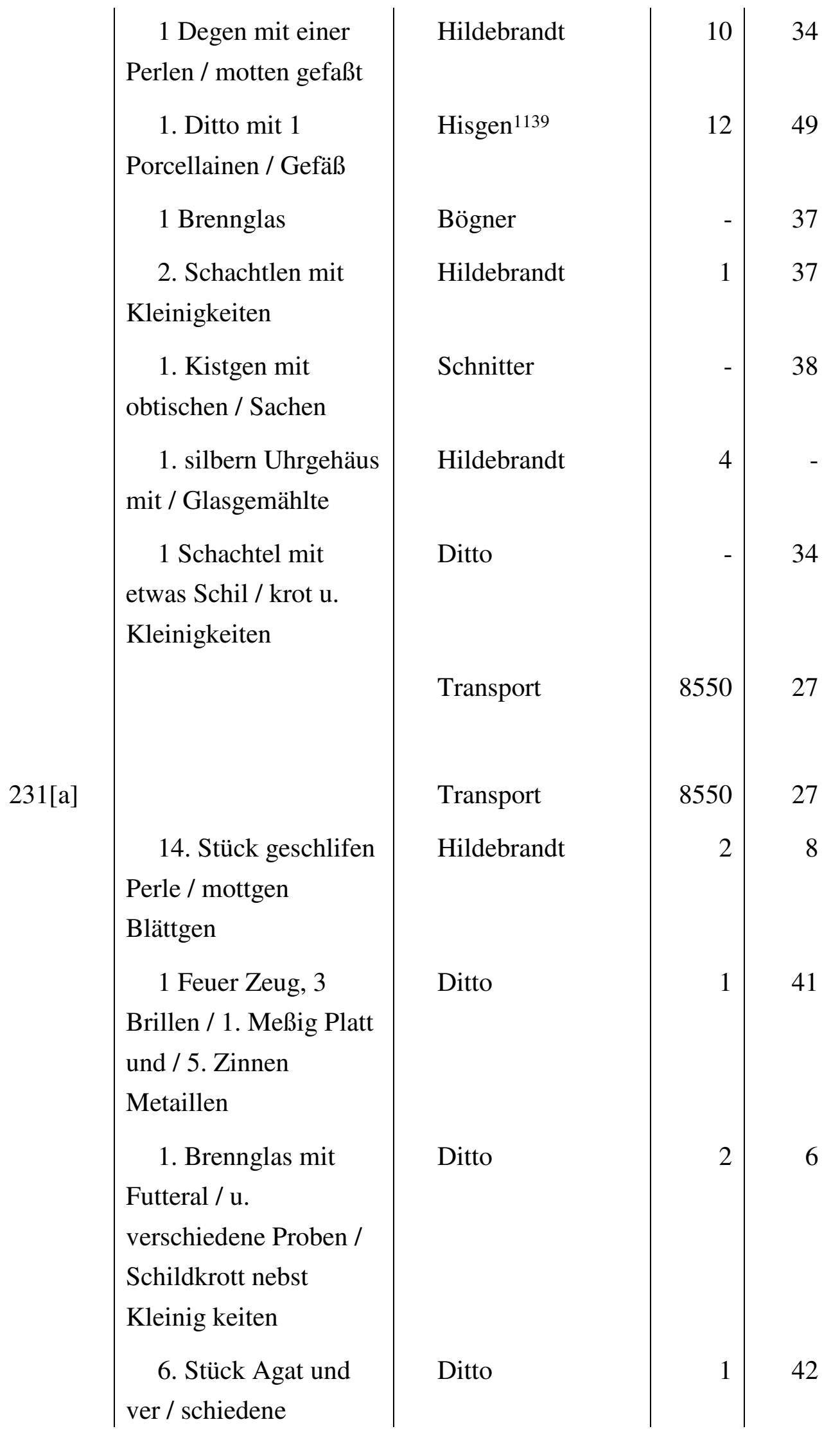

1139 Es handelt sich um den Sammler und Kunstschriftsteller Heinrich Sebastian Hüsgen (17451807). 


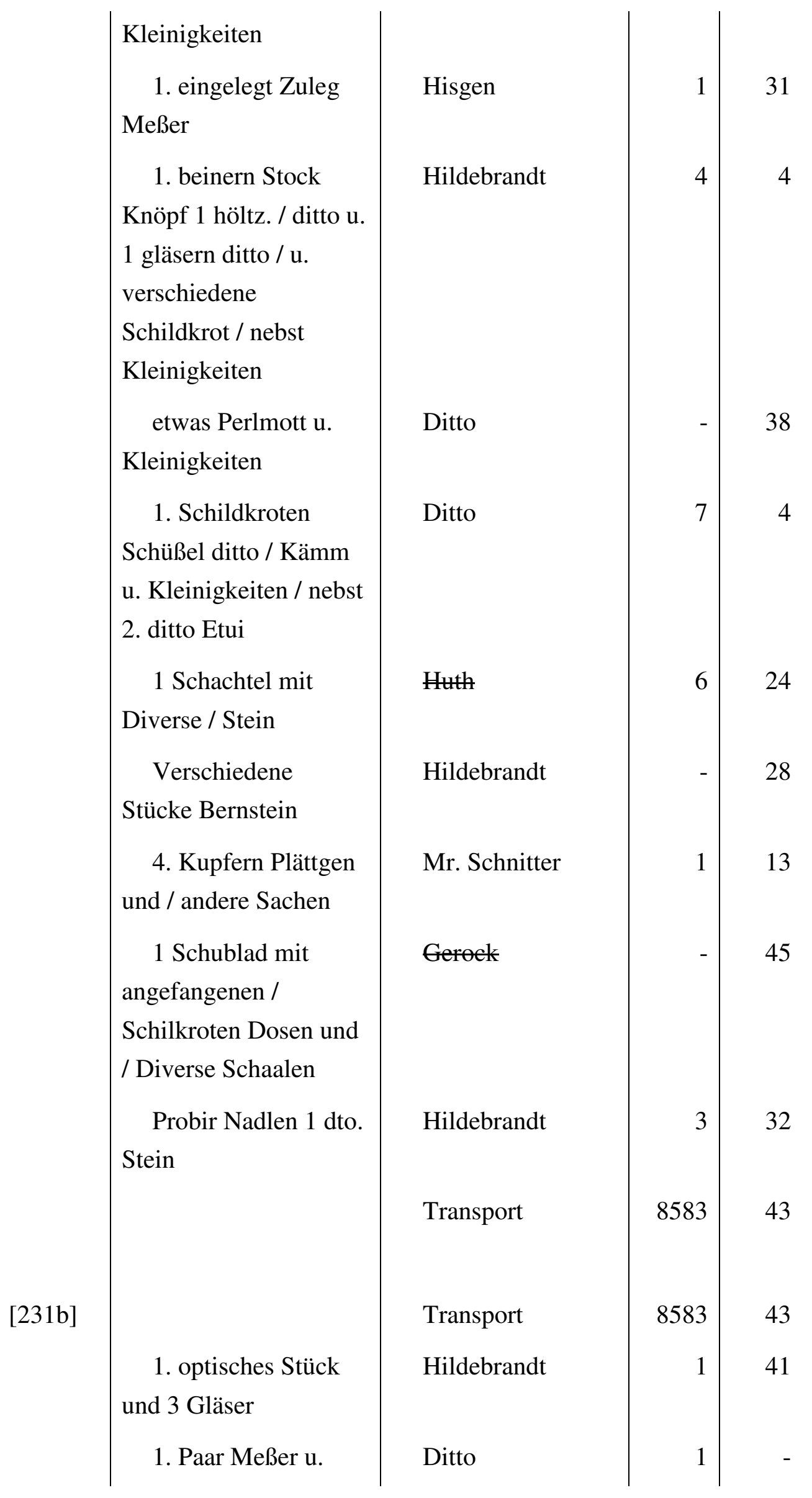




\begin{tabular}{|c|c|c|}
\hline $\begin{array}{l}\text { Gabeln und / } 2 \\
\text { Hobeleisen u. } 3 \text { Stein }\end{array}$ & & \\
\hline $\begin{array}{l}\text { 2. steinern Büchsgen } \\
\text { mit etwas / Gold }\end{array}$ & Moses Kahn & 5 \\
\hline $\begin{array}{l}\text { etl. Ohrringe u. } \\
\text { Kleinigkeiten }\end{array}$ & Schnitter & - \\
\hline $\begin{array}{l}2 \text { silb. Büchsgen } 3 \\
\text { 3/8 loth à } 74 \mathrm{Xr}\end{array}$ & Hildebrandt & 4 \\
\hline $\begin{array}{l}26 \text { 1/8 loth } \\
\text { Bruchsilber à } 72 \mathrm{Xr}\end{array}$ & Ditto & 31 \\
\hline $\begin{array}{l}\text { 1. Schränckgen mit } \\
\text { Schubladen }\end{array}$ & Ditto & 4 \\
\hline $\begin{array}{l}1 \text { Chatoul worinen } 1 \\
\text { Silber u / vergold } \\
\text { Chocolate Service / } 62 \\
\text { Loth à } 1231 / 2 \mathrm{Xr}\end{array}$ & $\begin{array}{l}\text { Brentano / in } \\
\text { Nbge Hof }\end{array}$ & 127 \\
\hline 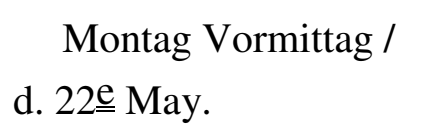 & & \\
\hline $\begin{array}{l}\quad 3 \text { alte Brillen und } \\
\text { verschie / dene } \\
\text { Kleinigkeiten }\end{array}$ & ----- & - \\
\hline $\begin{array}{l}\text { etliche Dosen u. } \\
\text { Kleinigkeiten }\end{array}$ & ---- & - \\
\hline $\begin{array}{l}1 \text { eilfen beinern } \\
\text { gedrehte / Dose }\end{array}$ & Hisgen & 2 \\
\hline 1 höltzern ditto & Gebhard & - \\
\hline $\begin{array}{l}1 \text { türckisch Zuleg } \\
\text { Meßer }\end{array}$ & Hisgen & - \\
\hline 1 Microscopium & Langebach & - \\
\hline 2 kleine silbern & Brentano & 7 \\
\hline
\end{tabular}




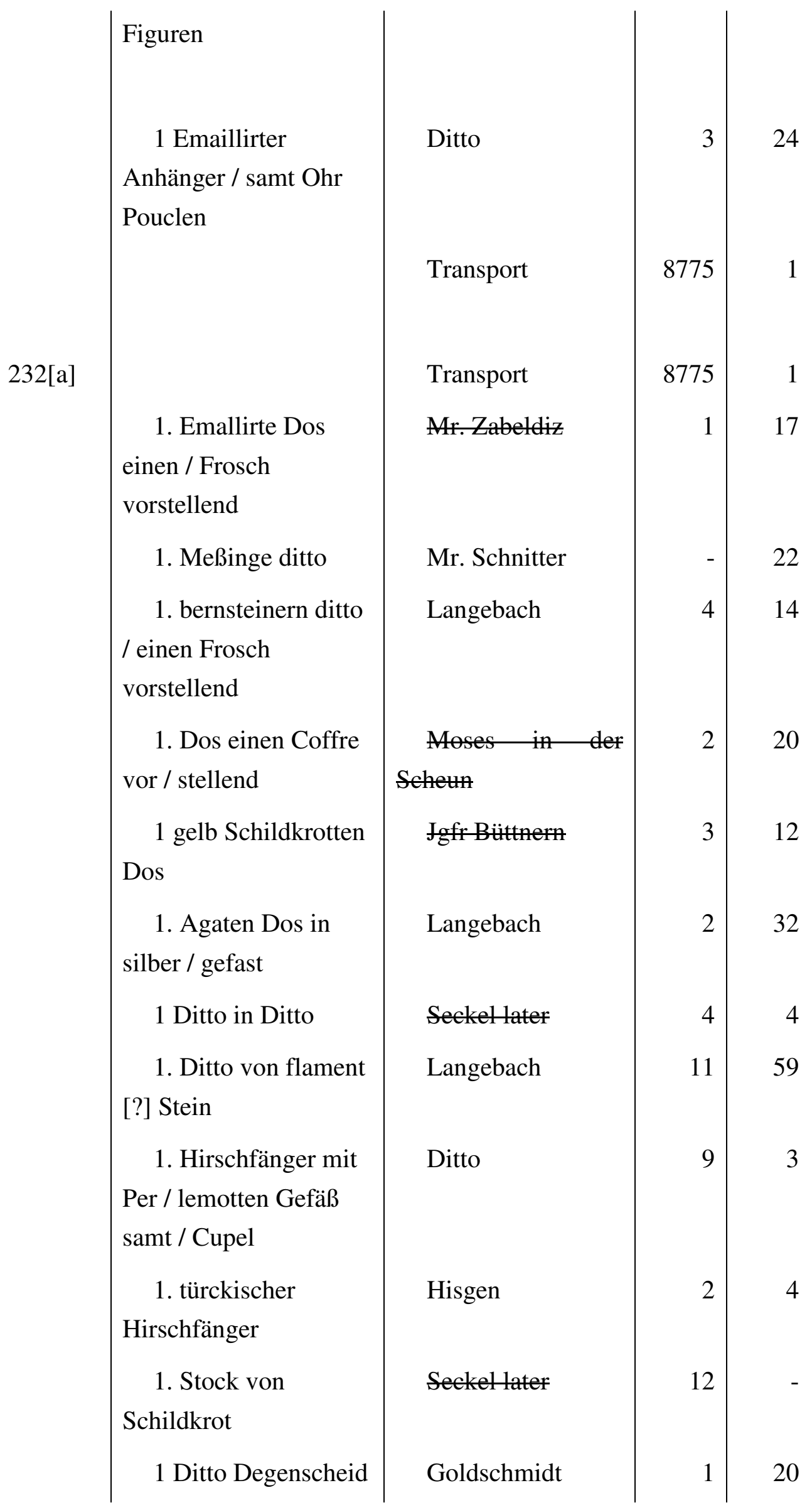




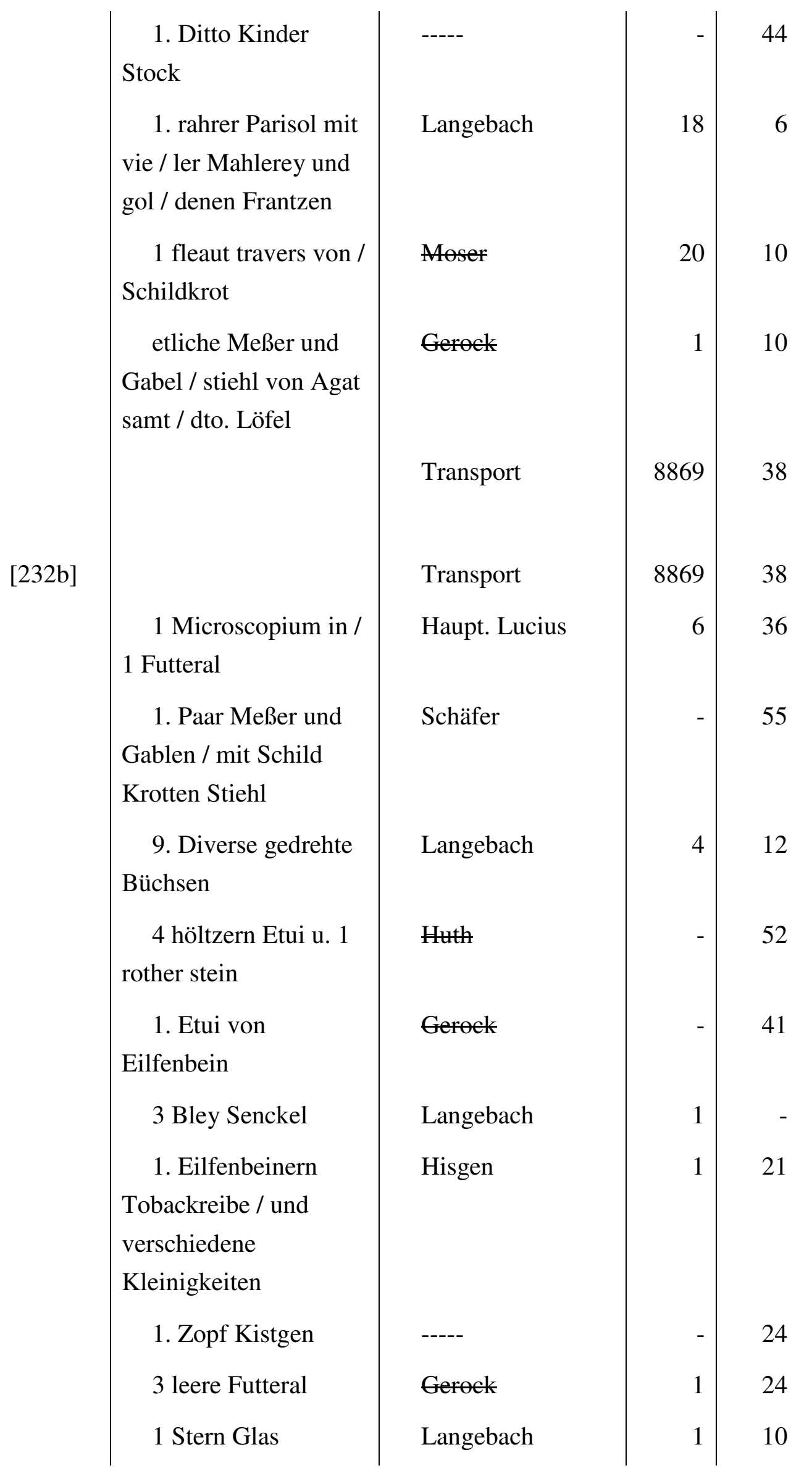




$\left|\begin{array}{l}\text { 1 Kistgen mit Leder } \\ \text { bezogen / mit gepreßt } \\ \text { Schildkrott / u. } \\ \text { Curiositäten } \\ \text { 1. Brennglas in } \\ \text { Schildkrott / gefaßt u. } \\ \text { 1. Carniol } \\ \text { Montag Nachmittag } \\ \text { / d. 22 } 2 \text { May } \\ \text { Keller / mit 5 Flaschen } \\ \text { u. } 2 \text { Gläser } \\ \text { samt / Zugehör } \\ \text { 12 Stängelgläser mit } \\ \text { golden / ranft } \\ \text { 10. kl. Stutzgläser } \\ \text { mit ditto }\end{array}\right|$

Ditto

13

Ditto

Langebach

$10 \quad 40$

Ditto

46

Haupt. Jäger

Transport

40

Transport

Brentano

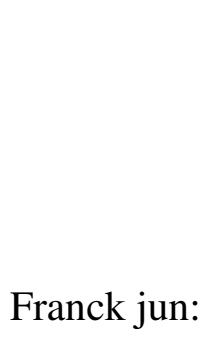




\begin{tabular}{|c|c|c|c|c|}
\hline \multirow{4}{*}{\multicolumn{2}{|c|}{$\begin{array}{l}\text { 2 Schreibtaflen } \\
\text { 1. Feld Apotheck } \\
1 \text { Ditto u: 1 laquirt } \\
\text { Kistgen }\end{array}$}} & Langebach & 1 & 44 \\
\hline & & Lieut. von Ries & 1 & 5 \\
\hline & & ----- & - & 49 \\
\hline & & & & \\
\hline & 3 Pettschaft & Brentano & 2 & 40 \\
\hline & 1 Kistgen zu & Ditto & - & 31 \\
\hline & Reversino & & & \\
\hline & 1. Leichen Sarg und & Wegner Cath. & & \\
\hline & & & & \\
\hline & Schreibtafel & Pfaff & 1 & 4 \\
\hline & 1 Schreib Tafel mit & ----- & - & 37 \\
\hline & 1 Schloß / u 1 Pfeif & & & \\
\hline & 1 Grillen Spiehl und & Haupt. Jäger & - & 53 \\
\hline & ein / Knöbel Spiehl & & & \\
\hline & 1 laquirt Seifen & Ditte & - & 31 \\
\hline & Kugel, 1 Pfei / fen & & & \\
\hline & Kopf u. 1 Büchs von / & & & \\
\hline & Purpur Holtz & & & \\
\hline & 1 Büchsgen mit & Langebach & 5 & 26 \\
\hline & einer golden / und & & & \\
\hline & silbern Metaillen & & & \\
\hline & & Transport & 8951 & 22 \\
\hline [233b] & & Transport & 8951 & 22 \\
\hline & 1 Brill & ----- & - & 19 \\
\hline & 2 Schächtelgen u: 3 & Langebach & - & 31 \\
\hline & Büchsgen & & & \\
\hline & 1 höltzern Schraub & Huth & 1 & 5 \\
\hline & Thaler / 1 Perspectif & & & \\
\hline & und allerhand / & & & \\
\hline & Kleinigkeiten & & & \\
\hline & 1. Flacon, 1 kupfern & Gold Schmidt & 1 & 31 \\
\hline
\end{tabular}




\begin{tabular}{|c|c|c|}
\hline $\begin{array}{l}\text { Plättgen / } 1 \text { Brill u. } 1 \\
\text { Portraitgen }\end{array}$ & & \\
\hline $\begin{array}{l}1 \text { Perlemotten } \\
\text { Meßer, } 1 \text { Flacon / mit } \\
\text { Silber und } 1 \text { Sack Spie } \\
\text { / gel in Silber gefaßt }\end{array}$ & Haupt. Jäger & 3 \\
\hline $\begin{array}{l}1 \text { Maasstab in } 1 \\
\text { Meßinfutte / ral, } 1 \text { Etui, } \\
1 \text { Mesing / büchs, } 1 \\
\text { ditto Insatzgewicht / } \\
\text { und Kleinigkeiten }\end{array}$ & St Goar & 1 \\
\hline $\begin{array}{l}1 \text { seiden gestickter } \\
\text { Camin / Crantz }\end{array}$ & Ditto & 4 \\
\hline $\begin{array}{l}1 \text { Gesteck Meßer } \\
\text { und Gabel / von } \\
\text { Bernstein, } 2 \text { Stock / } \\
\text { Knöpf u. } 2 \text { laquirte } \\
\text { Thee Flasch }\end{array}$ & Mr. Schnitter & 1 \\
\hline 3 türckisch Meßer & Langebach & 4 \\
\hline $\begin{array}{l}\quad 3 \text { Rohr zu } \\
\text { Perspectif, } 3 \text { Kling / } \\
\text { und 2. Gablen, 1 Feuer } \\
\text { / zänglen nebst etl. } \\
\text { Spinnen [?] }\end{array}$ & Goldschmidt & 1 \\
\hline $\begin{array}{l}\qquad 1 \text { Büchs mit } \\
\text { Perlenmott Marquen / } \\
\text { und } 1 \text { ditto mit beinen } \\
\text { Marquen }\end{array}$ & Jgfr Büttnern & 2 \\
\hline $\begin{array}{l}2 \text { Reibeisen } 1 \text { Jacht } \\
\text { [?] und / Kleinigkeiten }\end{array}$ & Kröger & - \\
\hline $\begin{array}{l}\quad 1 \text { beinern } \\
\text { Strickscheid u. } 1 \text { dto. / } \\
\text { Schaufel nebst } \\
\text { Kleinigkeiten }\end{array}$ & Huth & 1 \\
\hline
\end{tabular}




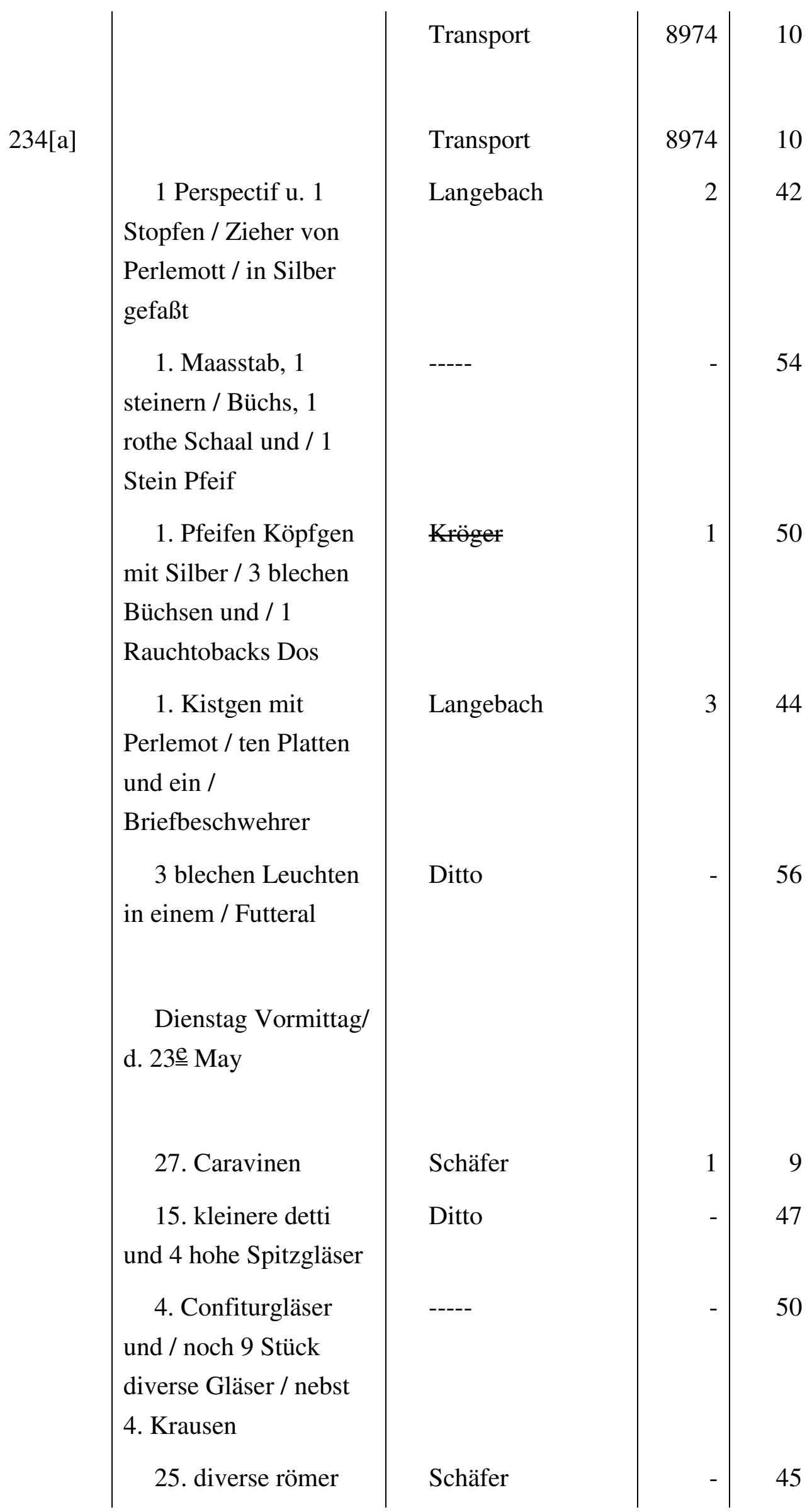




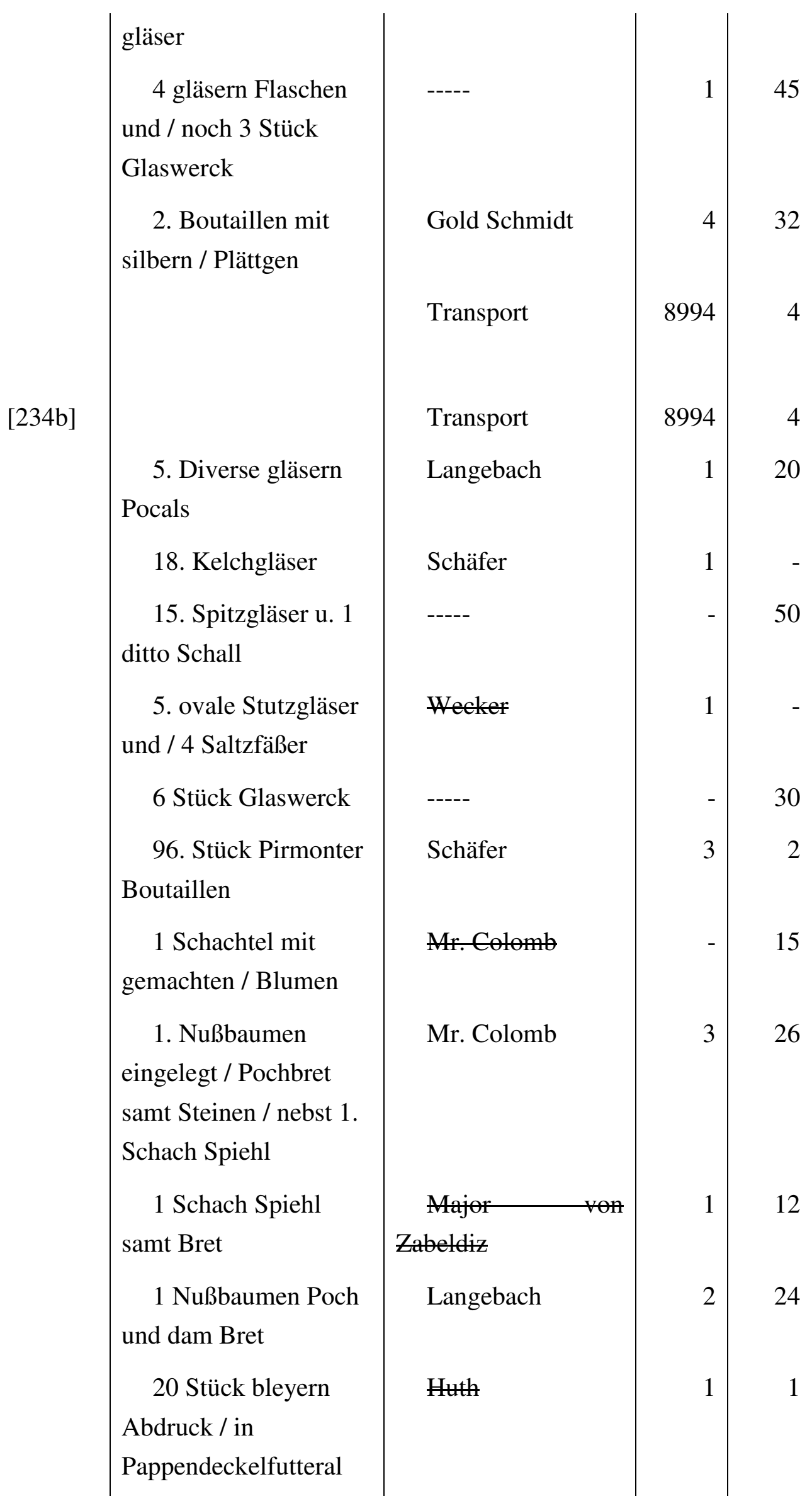




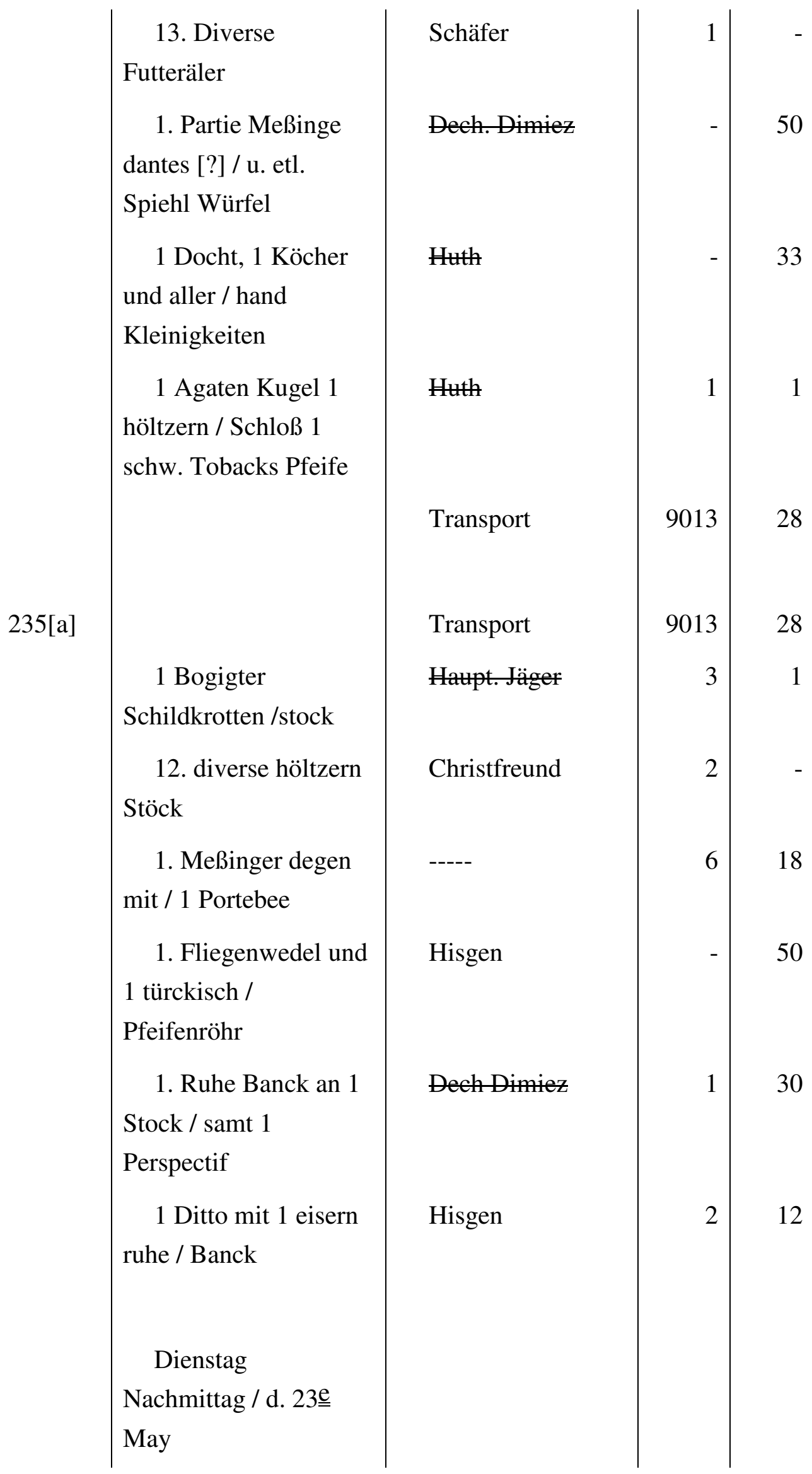




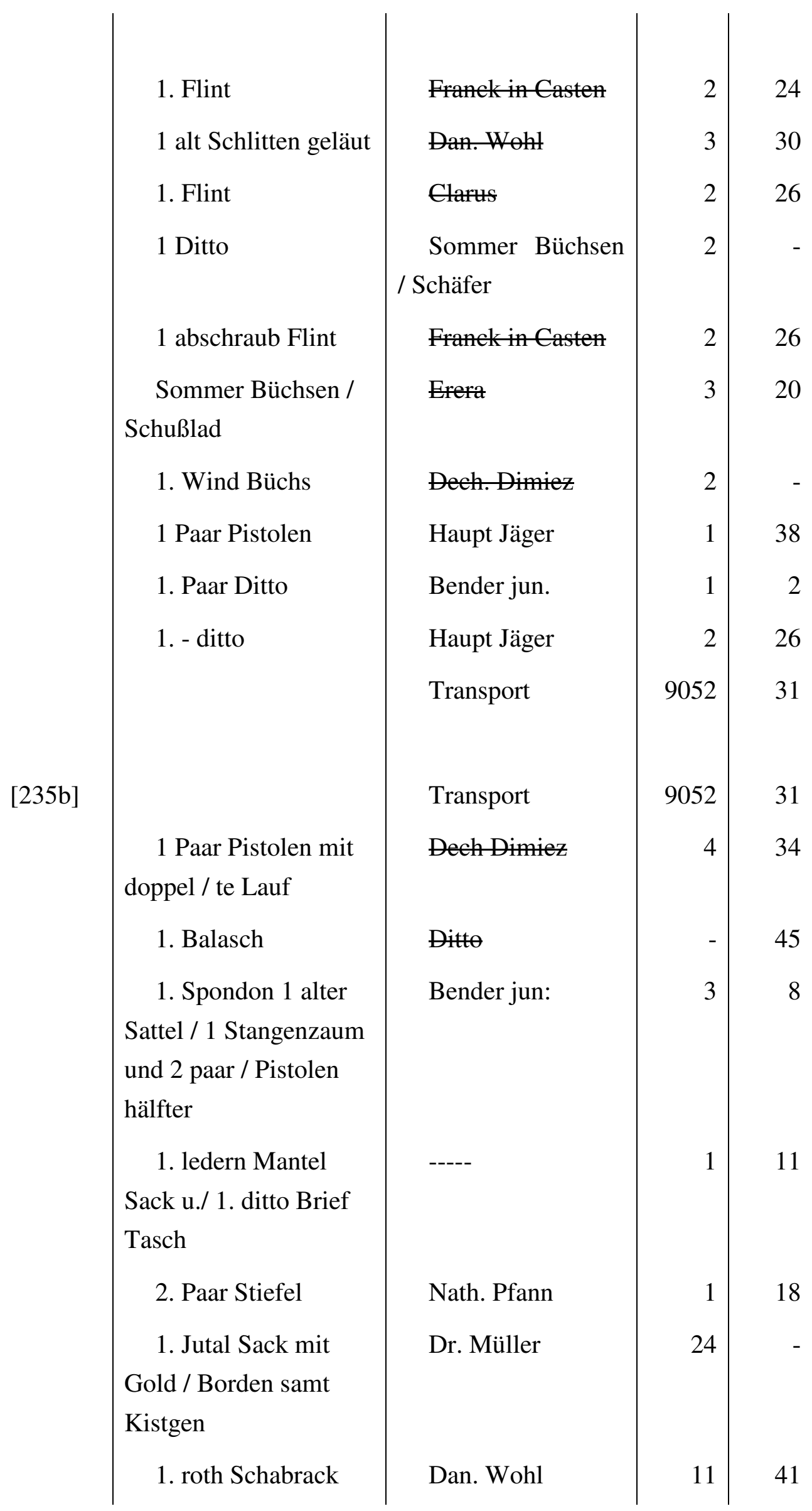




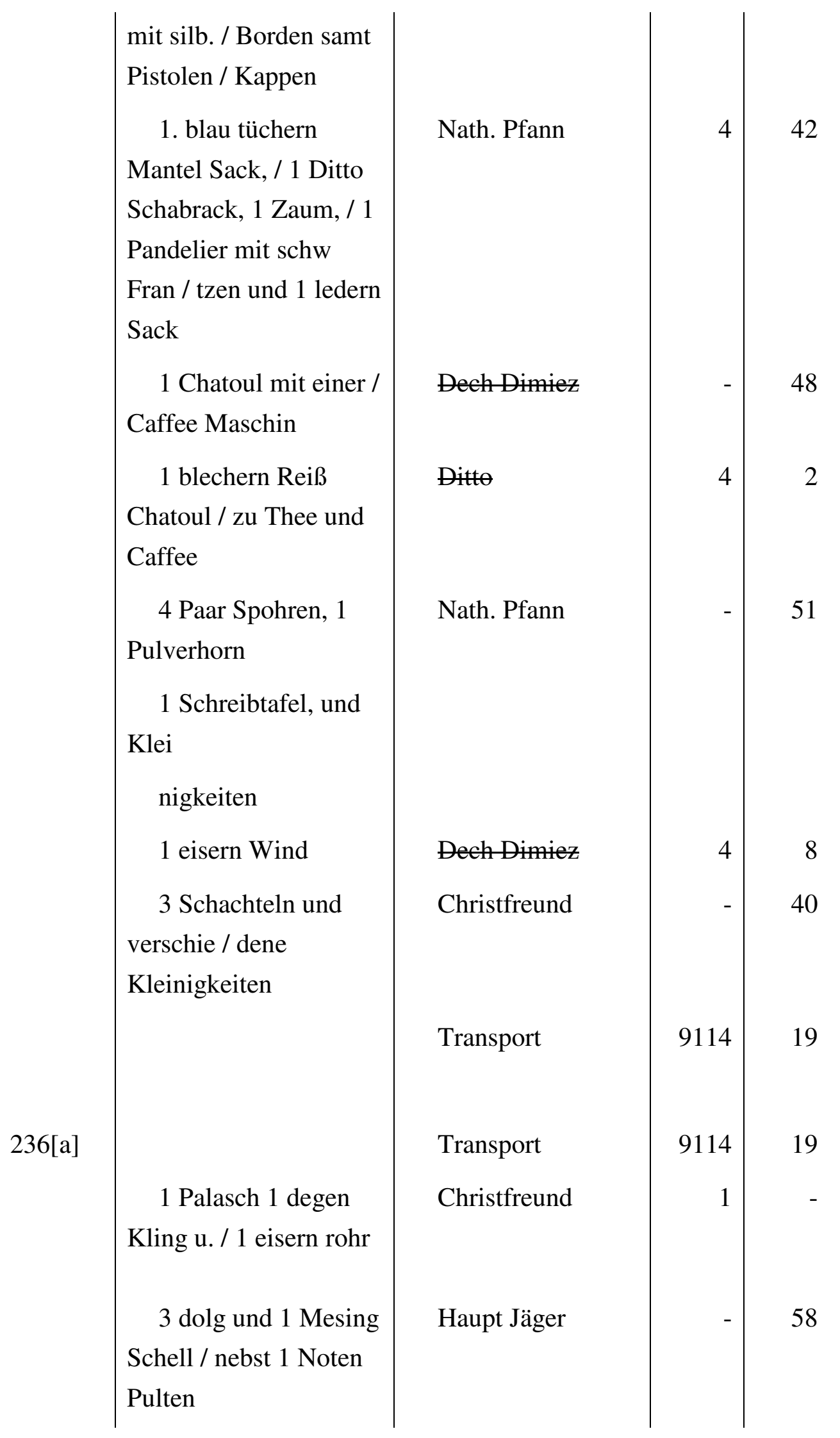




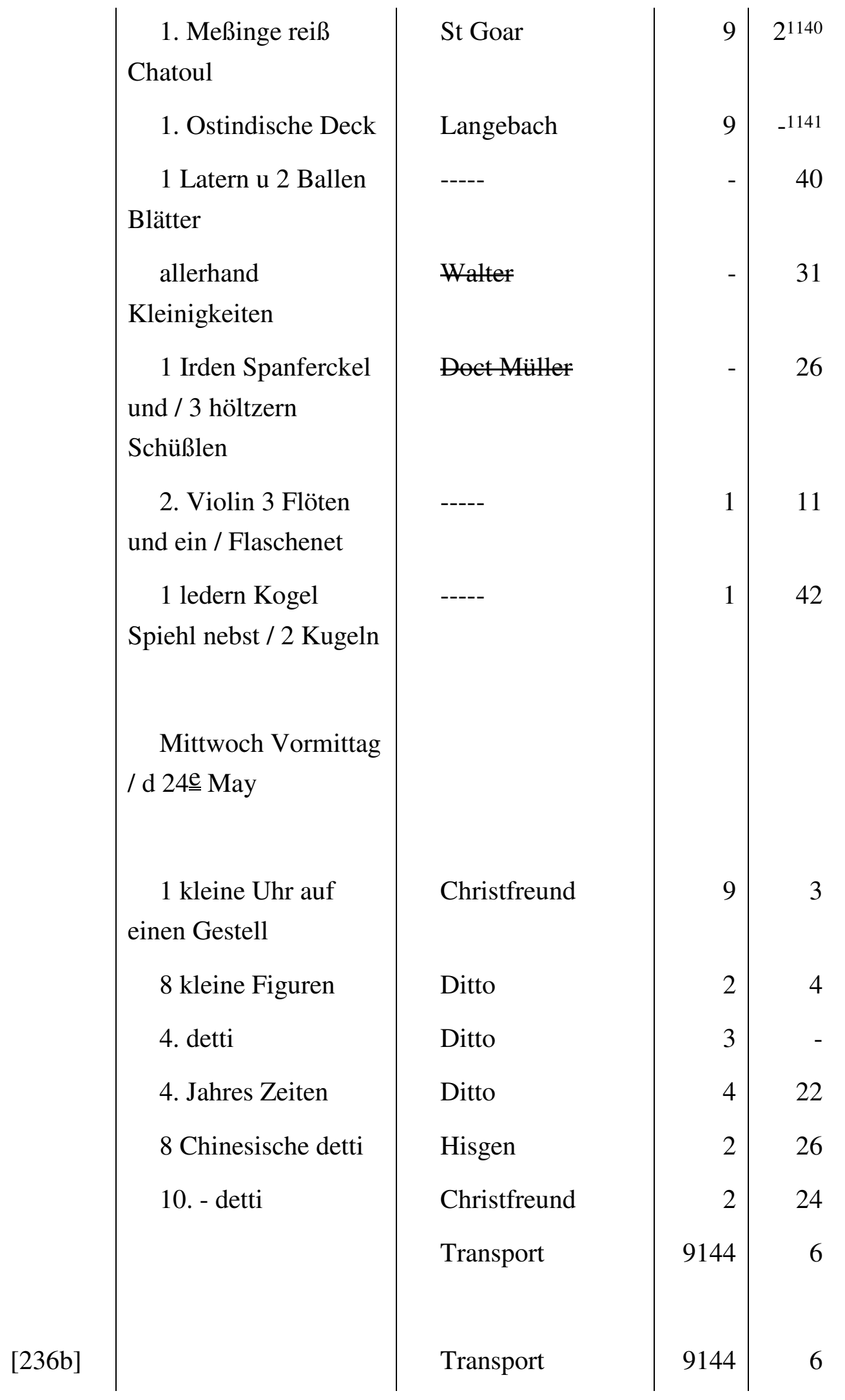

1140 Die Summe wurde eingerahmt und aus der Zählung herausgenommen.

1141 Die Summe wurde eingerahmt und aus der Zählung herausgenommen. 


\begin{tabular}{|c|c|c|c|}
\hline $\begin{array}{l}6 \text { kleine hendger [?] } \\
\text { und / } 1 \text { laquirt } \\
\text { Schüßelgen }\end{array}$ & Christfreund & 2 & 14 \\
\hline $\begin{array}{l}1 \text { klein Porcell. } \\
\text { aufsatz von / 5. stück }\end{array}$ & Haupt Jäger & - & 38 \\
\hline $\begin{array}{l}8 \text { Detti kl. } \\
\text { aufsätzger }\end{array}$ & Christfreund & 1 & 31 \\
\hline 6 Detti Ditto & Haupt: Jäger & - & 56 \\
\hline 10. detti ditto & Ditto & - & 31 \\
\hline 9. Detti Ditto & Mad Diefenbach & - & 43 \\
\hline $20-\quad$ Ditto & Christfreund & 1 & 9 \\
\hline $\begin{array}{l}\quad 4 \text { Chinesische } \\
\text { Figuren und / } 3 \text { andere } \\
\text { Detti }\end{array}$ & Hisgen & 3 & 12 \\
\hline $\begin{array}{l}13 \text { Figuren von Tera } \\
\text { Sigilata }\end{array}$ & Mad Diefenbach & 2 & 6 \\
\hline 3 Figuren & Huth & 1 & 21 \\
\hline 2 detti & ----- & - & 42 \\
\hline 1 Ditto & Christfreund & 3 & 8 \\
\hline $\begin{array}{l}1 \text { höltzern aufsatz } \\
\text { mit } 2 \text { Figuren }\end{array}$ & Hisgen & 1 & 18 \\
\hline 1 Metallen Pferd & Ditto & 11 & 4 \\
\hline $\begin{array}{l}\text { 1 Porcell. aufsatz à } \\
\text { 6. Stück }\end{array}$ & Fr. Rath Eichhorn & 5 & 28 \\
\hline 1. Ditto à 2. stück & Ditto & 3 & 4 \\
\hline $\begin{array}{l}1 \text { Porcell. aufsatz à } 4 \\
\text { stück }\end{array}$ & Haupt. Jäger & 3 & 2 \\
\hline 1. Ditto à 3 stück & $\begin{array}{l}\text { Mad Eichhorn } \\
\text { Transport }\end{array}$ & $\begin{array}{r}1 \\
9187\end{array}$ & $\begin{array}{r}4 \\
17\end{array}$ \\
\hline
\end{tabular}




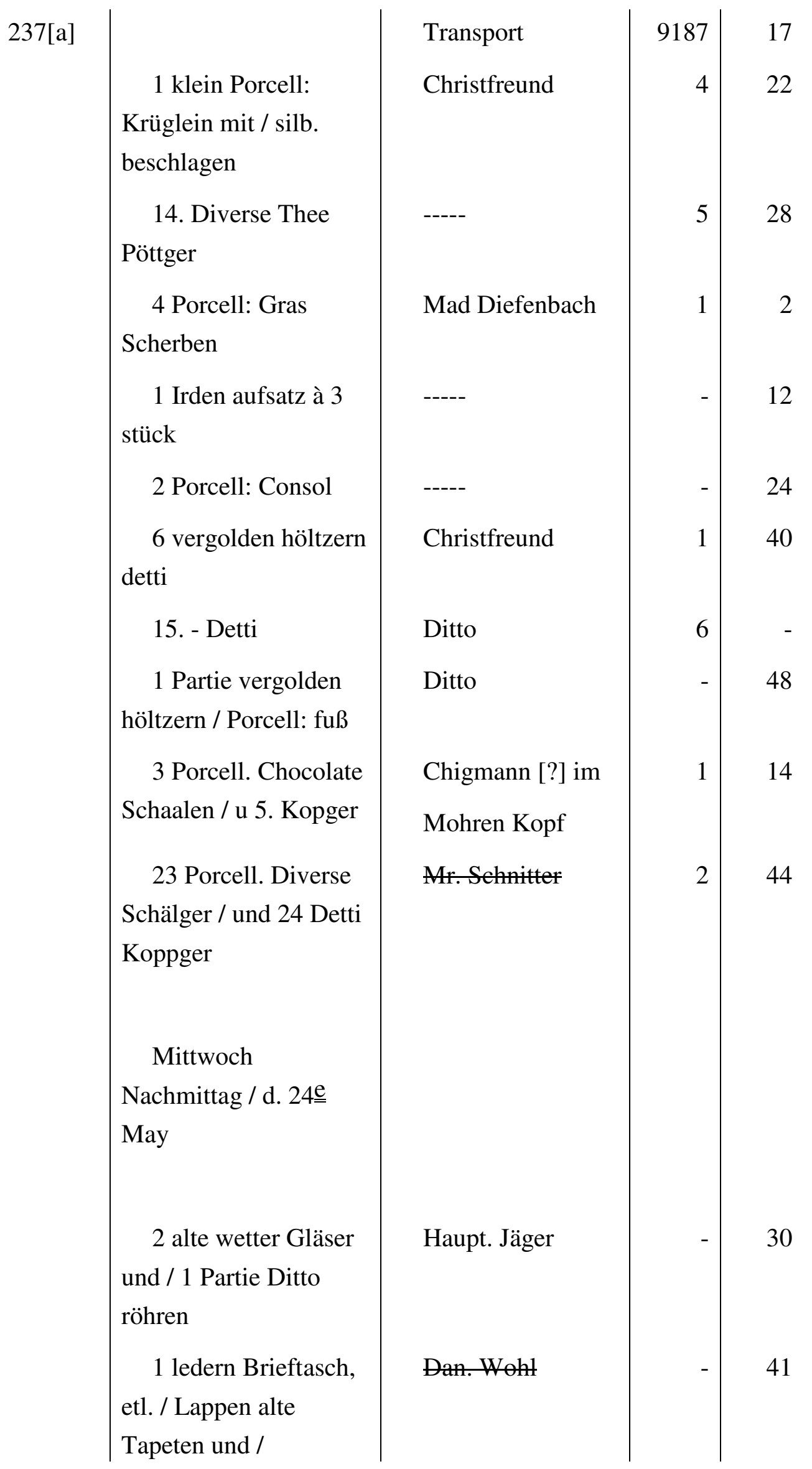




\begin{tabular}{|c|c|c|c|c|}
\hline & Kleinigkeiten & & & \\
\hline & 1 türckischer Teppig & Haupt. Jäger & 2 & 38 \\
\hline & 1 Partie Fuß Jacken & Ditto & 2 & 42 \\
\hline & Matten / alt wachstuch & & & \\
\hline & $\mathrm{u}$ alte tapeten & & & \\
\hline & 9 rester tapeten und & ----- & 2 & 18 \\
\hline & 1 hunds / hauth & & & \\
\hline & & Transport & 9220 & - \\
\hline \multirow[t]{22}{*}[237\mathrm{b}]{} & & Transport & 9220 & - \\
\hline & 5 rester Fuß Matten & Hauptm Jäger & 4 & 26 \\
\hline & 1. frantzen stiehlgen & ----- & - & 31 \\
\hline & und / 1 Klippel Küßen & & & \\
\hline & 1 Ledern & Dan. Woht & - & 54 \\
\hline & Schreibzeug 2 höltzern & & & \\
\hline & / wandleuchter 1 alt & & & \\
\hline & Schild / Krotten Stock & & & \\
\hline & u Kleinigkeiten & & & \\
\hline & 1 Poch Bret und 1 & Weyland & - & 48 \\
\hline & dam bret / und & & & \\
\hline & vergolden verzierung & & & \\
\hline & 1 Chatoul von & Schild in ...gaß [?] & 7 & 4 \\
\hline & Schildkrot & & & \\
\hline & 1 fein Laquirter & Mad. Rumpel & 7 & 54 \\
\hline & vollständiger / & & & \\
\hline & Nachttisch & & & \\
\hline & 1 laquirt Kistgen & ----- & - & 27 \\
\hline & 1 Eck Tabolett & Erera & 1 & 8 \\
\hline & 1 Schachtel mit & ----- & - & 21 \\
\hline & Scheibenglas & & & \\
\hline & 4 gläsern & Chigmann [?] & 2 & 58 \\
\hline
\end{tabular}




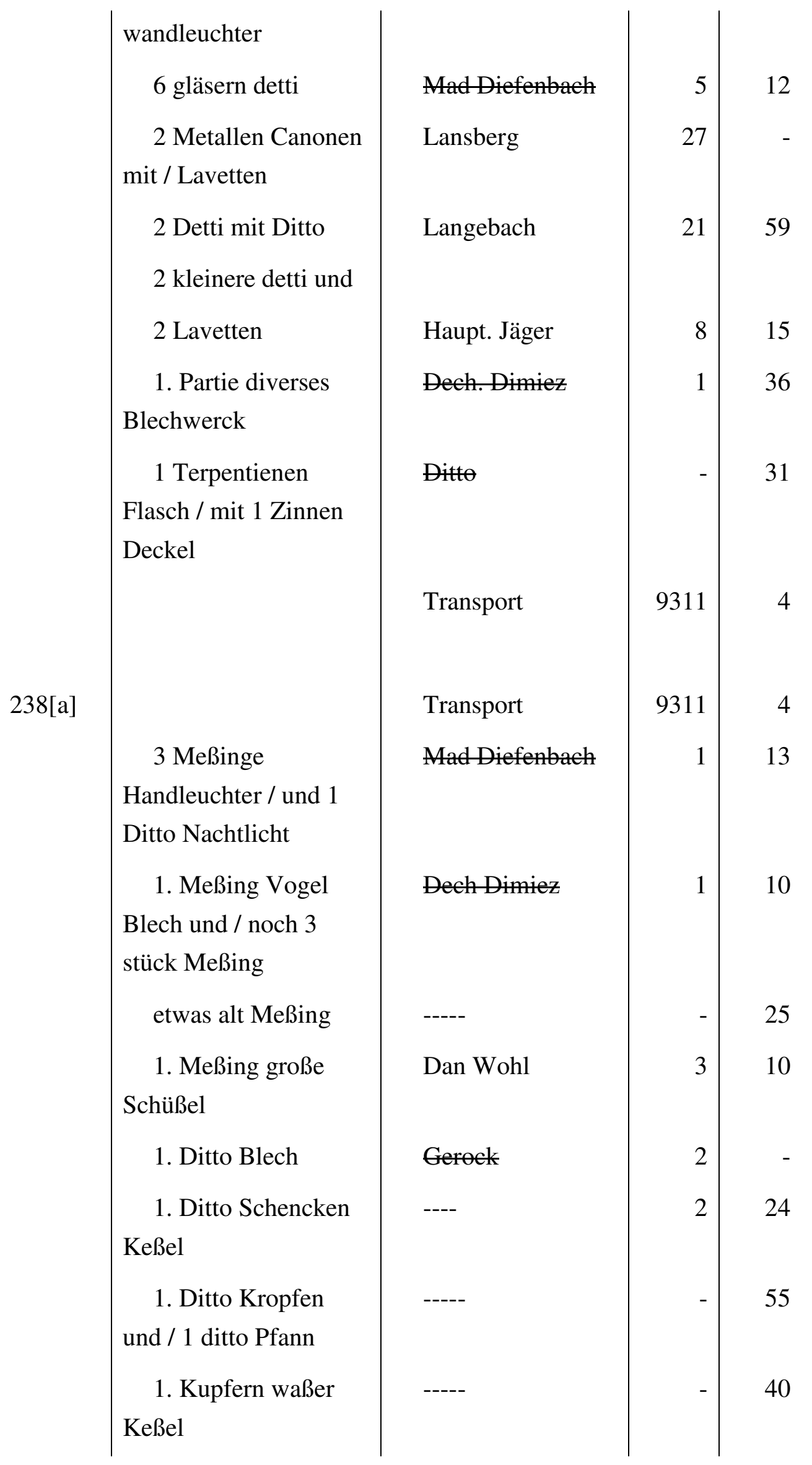




\begin{tabular}{|c|c|c|c|c|}
\hline \multirow{4}{*}{\multicolumn{2}{|c|}{\begin{tabular}{|l}
1 Ditto Schencken \\
Keßel \\
1. Ditto Brennzeug \\
1. Ditto Platt \\
etl. Meßinge \\
wandschrauben / und \\
Meßing
\end{tabular}}} & Dan Wohl & 3 & 6 \\
\hline & & Dech. Dimiez & 3 & 28 \\
\hline & & Dan Wohl & 2 & 56 \\
\hline & & St. Goar & 2 & 2 \\
\hline & $\begin{array}{l}\text { Freitag Vormittag / } \\
\text { d. } 26 \underline{\underline{\mathrm{e}} \text { May }}\end{array}$ & & & \\
\hline \multirow{8}{*}[238b]{} & $\begin{array}{l}1 \text { Mahler Gestell } \\
\text { und / Kleinigkeiten }\end{array}$ & Nath. Pfann & - & 43 \\
\hline & $\begin{array}{l}1 \text { grün samt trag } \\
\text { Küßen }\end{array}$ & Langebach & 1 & $\begin{array}{r}15 \\
1142\end{array}$ \\
\hline & $\begin{array}{l}1 \text { alt grau Plüschen } \\
\text { Deck u. / } 1 \text { Eichen } \\
\text { Kästgen }\end{array}$ & Bender Sen. & 1 & 6 \\
\hline & & Transport & 9336 & 22 \\
\hline & & Transport & 9336 & 22 \\
\hline & $\begin{array}{l}1 \text { gros Vorhang } \\
\text { Schloß, alt / Meßing } \\
\text { und eisen werck }\end{array}$ & Dan. Wohl & 4 & 34 \\
\hline & $\begin{array}{l}\text { 1. eisern Brat Pfann, } \\
1 \text { ditto / Deckel, } 1 \\
\text { Bratroost, } 2 \text { Zeichen / } \\
\text { eisen u. alt Eisen }\end{array}$ & Kröger & 1 & 5 \\
\hline & 1 Kleiner Bräter & Jgfr Büttnern & 1 & 30 \\
\hline
\end{tabular}

1142 Die Summe wurde eingerahmt und aus der Zählung herausgenommen. 


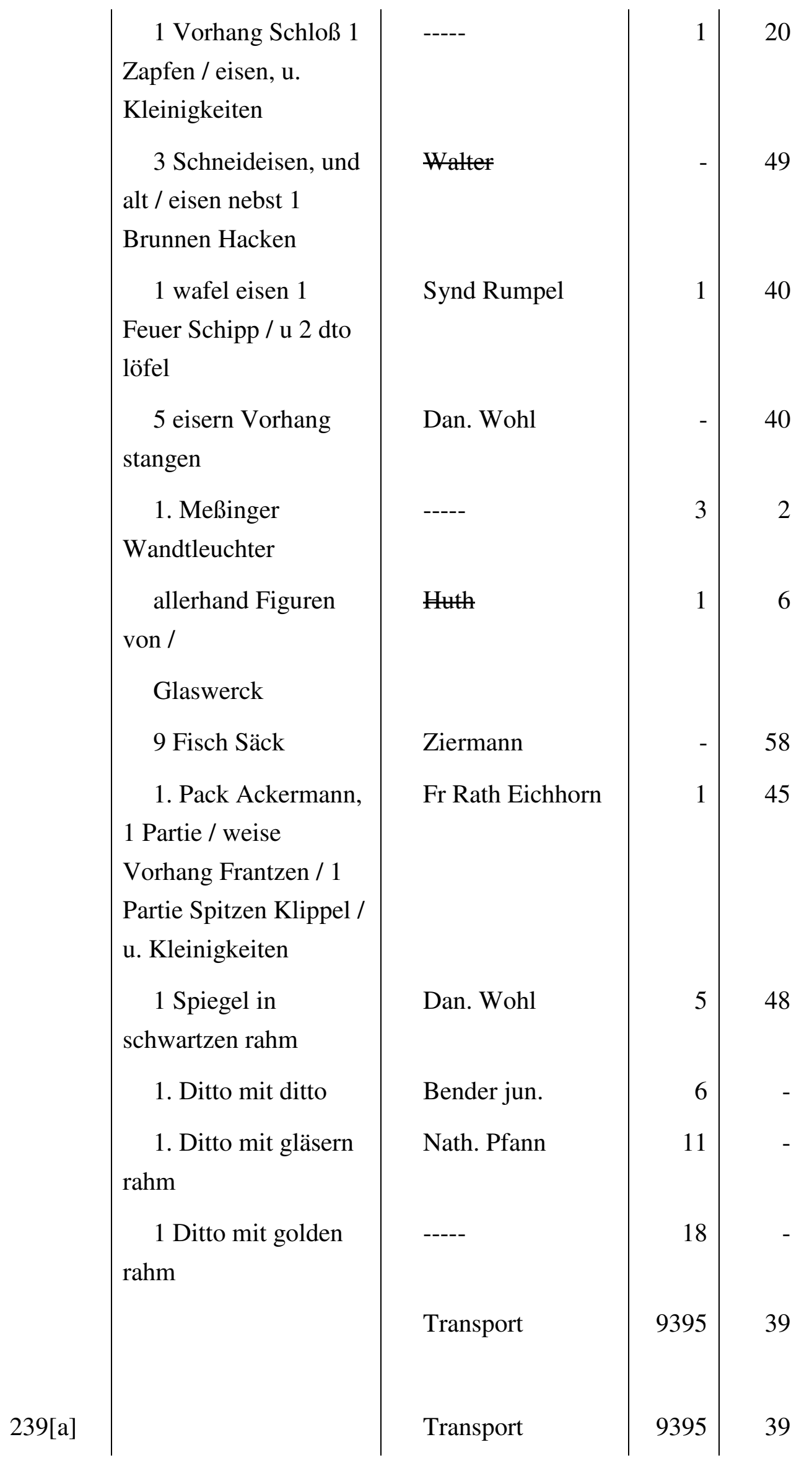




\begin{tabular}{|c|c|c|c|}
\hline $\begin{array}{l}\text { 1. Spiegel mit } \\
\text { vergolder Rahm }\end{array}$ & $\ldots[?]^{1143}$ & 20 & 40 \\
\hline 1. Ditto Ditto & Mad. Diefenbach & 21 & 40 \\
\hline 2. Nußb. Gueridon & ----- & 1 & 7 \\
\hline 2. - Detti & ----- & - & 45 \\
\hline 1. - Gadrillen Tisch & ----- & 4 & 32 \\
\hline 1 Laquirter Tisch & Mad. Diefenbach & 2 & 36 \\
\hline $\begin{array}{l}\text { 1. Nußb. arbeits } \\
\text { Tischgen }\end{array}$ & von Lersner & 2 & 18 \\
\hline $\begin{array}{l}1 \text { - Spiegeltisch mit } \\
\text { grün / Tuch bezogen }\end{array}$ & Fr. Rath Eichhorn & 9 & 30 \\
\hline $\begin{array}{l}1 \text { Schwarz Laquirter } \\
\text { Schreib / Tisch }\end{array}$ & ----- & 4 & 16 \\
\hline $\begin{array}{l}\text { 1. Nußb. Schreib } \\
\text { Tisch }\end{array}$ & $\begin{array}{l}\quad \text { M. } \\
\text { Flörsheim } \\
\text { 1144 }\end{array}$ & 3 & 40 \\
\hline 1. Ditto Ditto & ----- & 4 & 16 \\
\hline $\begin{array}{l}\text { 1. Arm Seßel mit } \\
\text { grünem / Mocad } \\
\text { bezogen }\end{array}$ & St. Goar & 8 & 21 \\
\hline $\begin{array}{l}3 \text { Seßel Stiehl mit } \\
\text { blau / Seiden } \\
\text { überzogen }\end{array}$ & Nath. Pfann & 4 & 56 \\
\hline $\begin{array}{l}\text { 6. Detti mit grünem } \\
\text { / Mocad bezogen }\end{array}$ & Langebach & 31 & 17 \\
\hline $\begin{array}{l}6 \text { Detti mit rohr } \\
\text { beflochten }\end{array}$ & $\begin{array}{l}\text { M. } \\
\text { Flörsheim } 1145\end{array}$ & 18 & 4 \\
\hline $\begin{array}{l}\text { 1. Zahl Tisch und } 1 \\
\text { anderer Tisch }\end{array}$ & Kröger & - & 40 \\
\hline
\end{tabular}




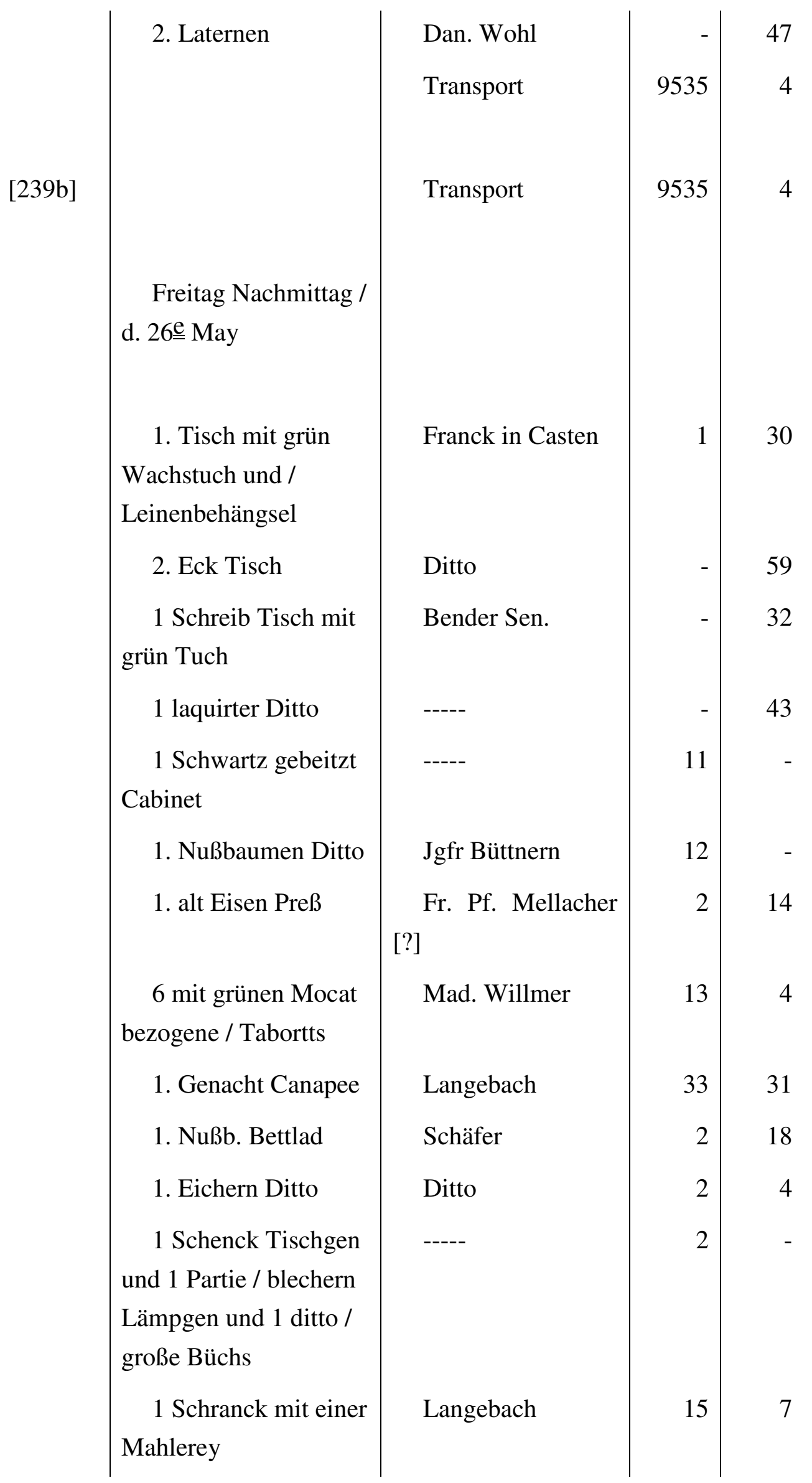




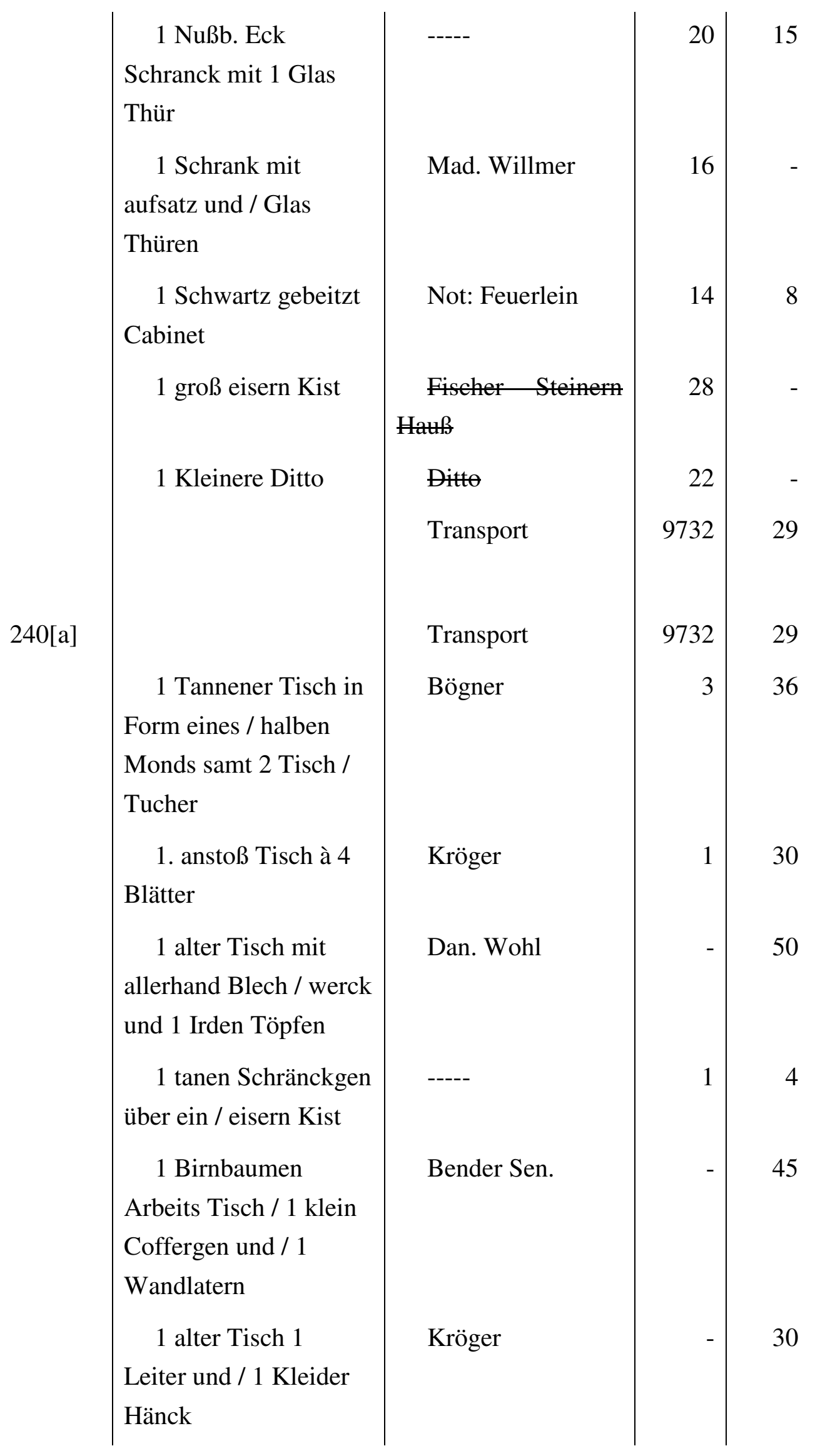




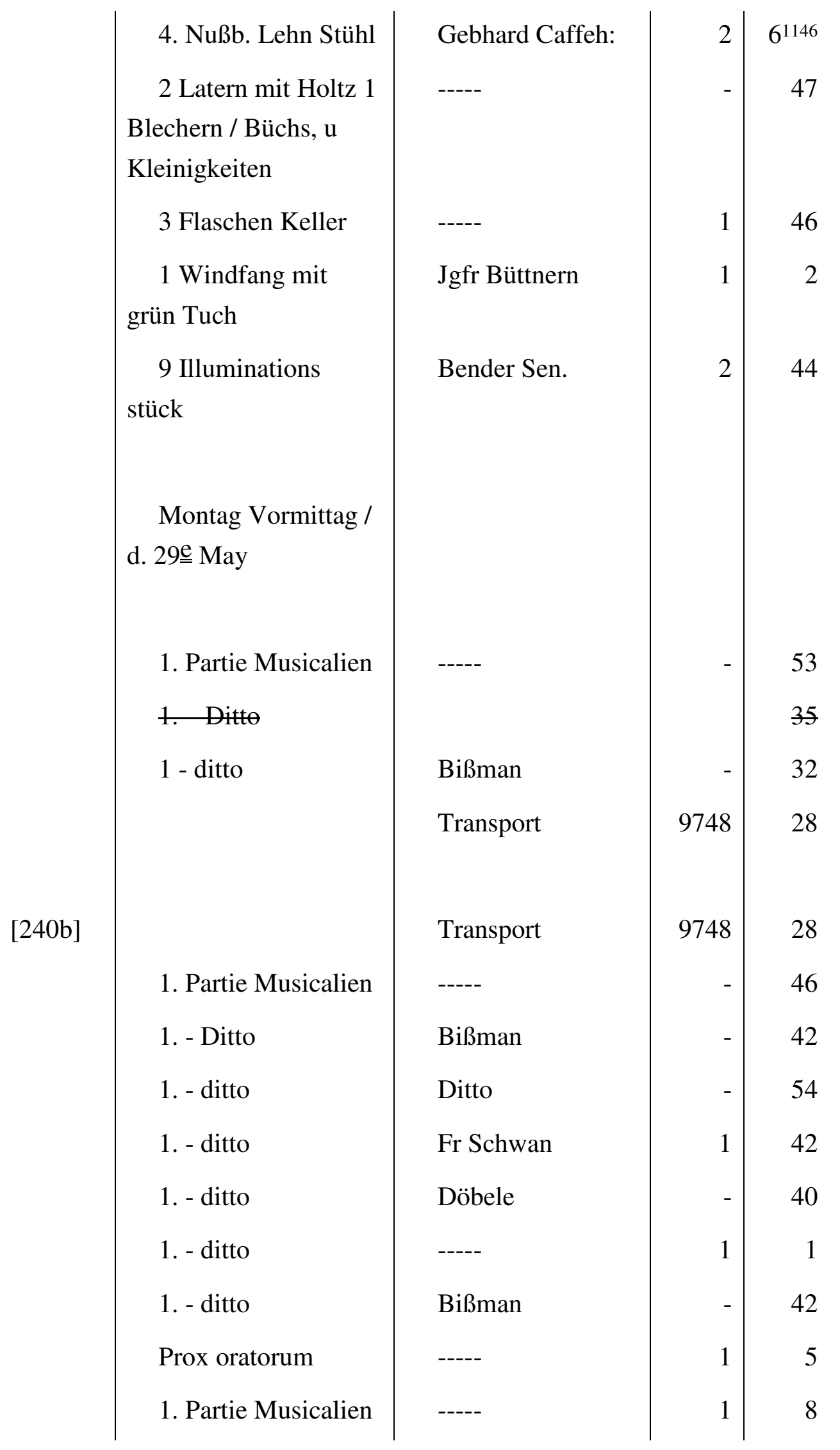

1146 Die Summe wurde eingerahmt und aus der Zählung herausgenommen. 


\begin{tabular}{|c|c|c|c|c|}
\hline \multirow{5}{*}{\multicolumn{2}{|c|}{$\begin{array}{l}\text { 1. Partie Musicalien } \\
\text { Bijcher }\end{array}$}} & Bißman & - & 48 \\
\hline & & Kröger & - & 39 \\
\hline & & ----- & 1 & 48 \\
\hline & & Brentano & 1 & 16 \\
\hline & & & & \\
\hline & 1. - ditto & Ditto & - & 46 \\
\hline & 1. - ditto & ditto & 1 & 20 \\
\hline & 1 Partie opera & Ditto & 4 & 10 \\
\hline & 1. - ditto u Cantaten & ditto & 1 & 1 \\
\hline & 1. - Musicalien & Ditto & 3 & 8 \\
\hline & 4 Music Pulten und & Ditto & 1 & 30 \\
\hline & 4 ditto / Leuchter & & & \\
\hline & 1. Tisch mit Pulten & ditto & - & 42 \\
\hline & 1. Tisch & Gerock & 1 & 4 \\
\hline & 1. Ditto & Ditto & 1 & 1 \\
\hline & & Transport & 9776 & 21 \\
\hline $241[a]$ & & Transport & 9776 & 21 \\
\hline & 1. große Haus & Brentano & 5 & 4 \\
\hline & Latern & & & \\
\hline & 1. Ditto in Hauß & Fr. v. Barkhausen & 19 & 45 \\
\hline & 1. Statue in $\mathrm{Hau} ß$ & Ditto & 2 & 4 \\
\hline & 1 Hauß Spritz samt & Ditto & 13 & - \\
\hline & Schlauch & & & \\
\hline & 1. gläsern Cronen & Ditto & 22 & 15 \\
\hline & Leuchter & & & \\
\hline & 3 Porcell: aufsätz & Ditto & 6 & 16 \\
\hline & 2 Brandt Reutel [?], & Ditto & 4 & 8 \\
\hline & 1 Kluft / und 1 & & & \\
\hline & Blasbalg & & & \\
\hline
\end{tabular}




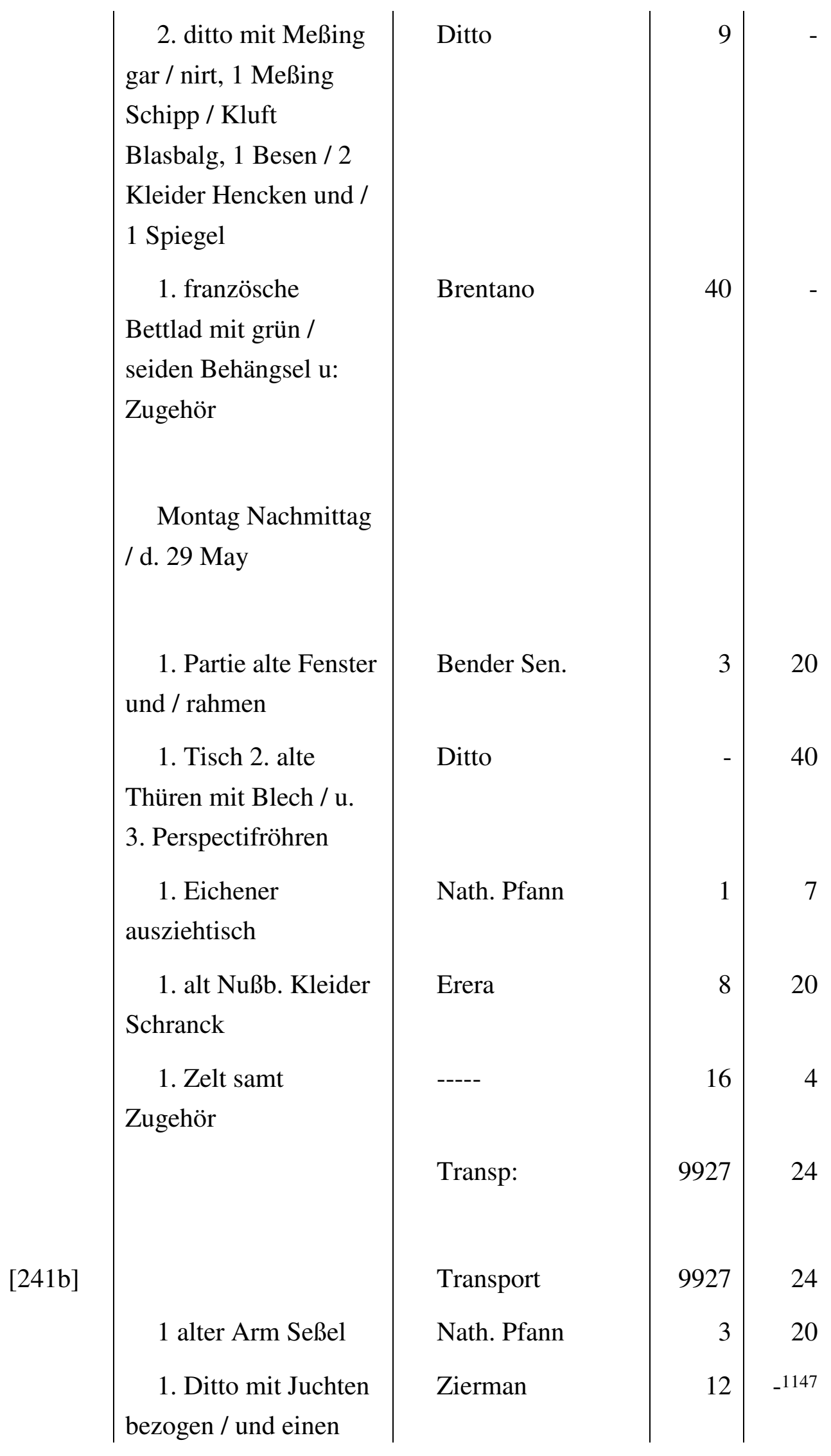

1147 Die Summe wurde eingerahmt und aus der Zählung herausgenommen. 


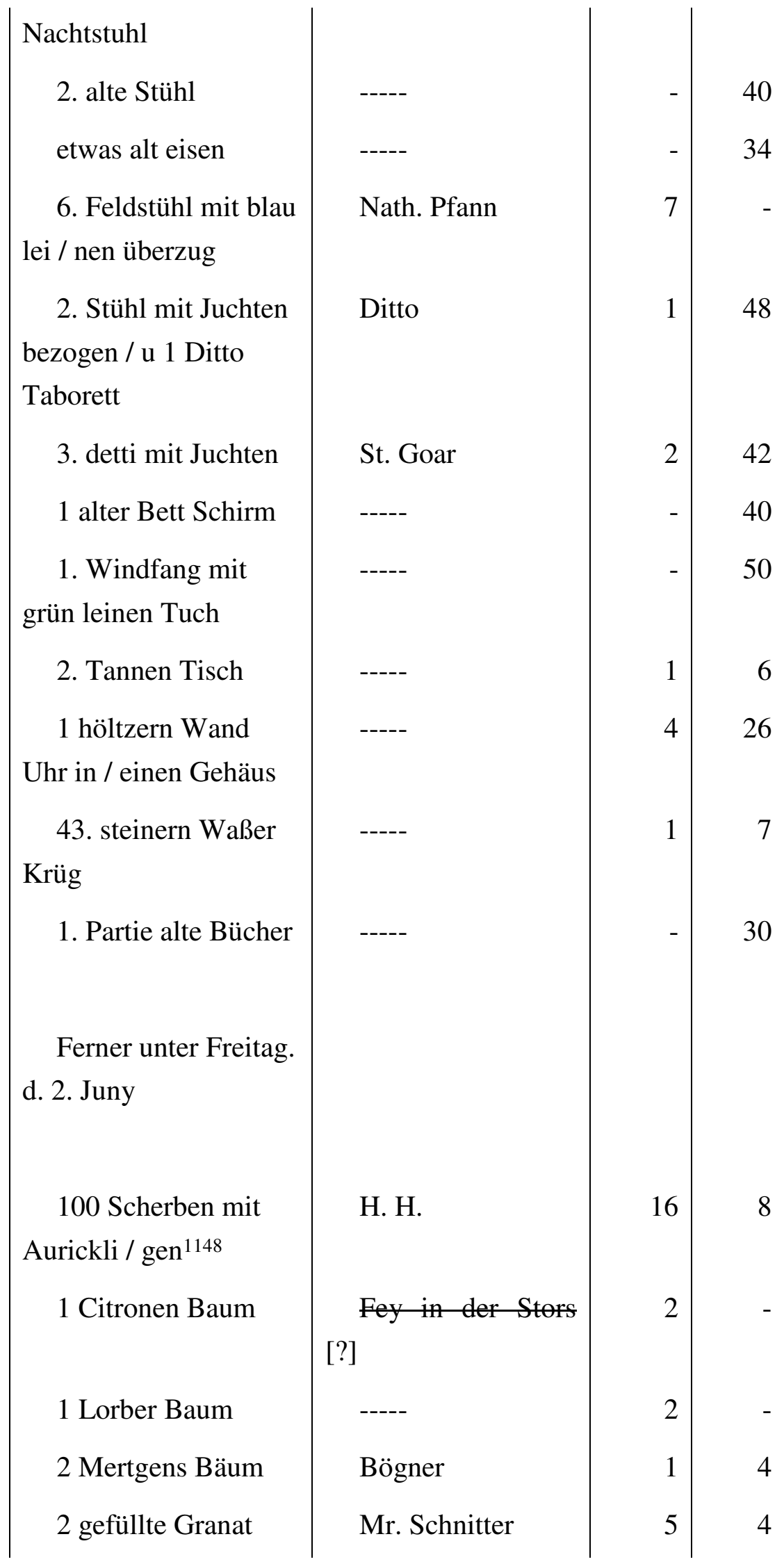

$1148=$ Primelpflanze. 


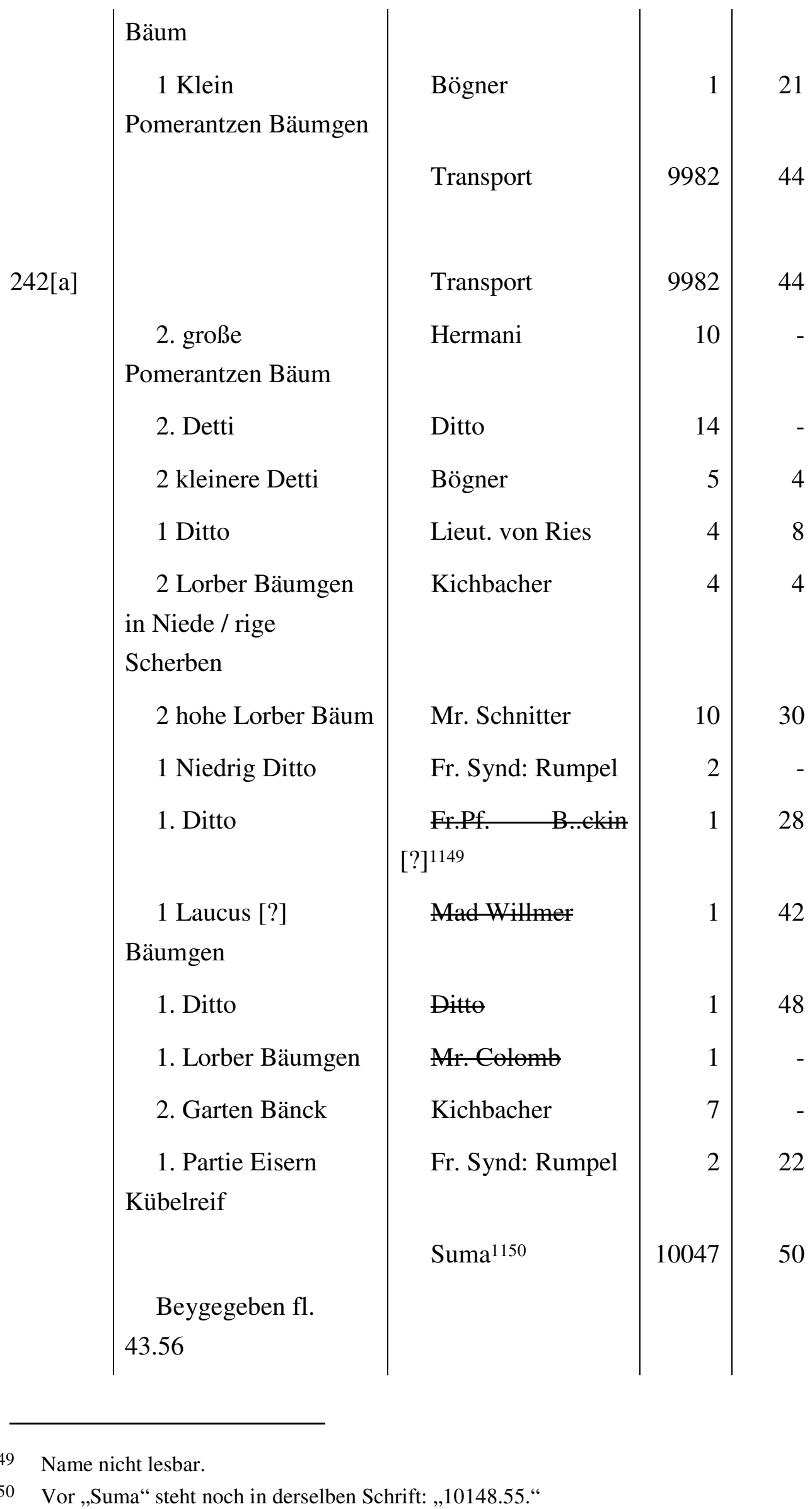




\title{
13.5Die offizielle Schenkungsakte an die Georgia - Augusta in Göttingen vom 28. Juli 1736
}

\author{
Universitäts-Archiv Göttingen Kur. 4 V d6/2, B1. 50-53.
}

Johann Friedrich von Uffenbach unterzeichnete am 28. Juli 1736 die Urkunde, mit der er seine Schenkung an die Bibliothek der Georgia - Augusta in Göttingen bekräftigte.

„Ich Endes unterschriebener uhrkunde und bekenne hiermit,

Demnach in reife und gründliche Erwegung gezogen, es auch die fast tägliche Erfahrung sattsam bezeiget, welchergestalt öfters, wo nicht mehrentheils ansehnliche, auch mit großer Mühe und Kosten, nach und nach angeschaffte privat Bibliothequen, nach des Besitzers Absterben, in solcher Erben Hände gerathen, die aus mannigfaltigen Uhrsachen und Umständen einigen wahren Gebrauch davon zu machen, und solche zum fortwährenden Andenken, auch nach der Intention und Wunsch deßen, welcher zu deren acquisition und Sammlung weder Fleiß noch Geld gesparet, zu conserviren und beysammen zu behalten, weder fähig noch gemeinet sind, folglich durch Auctionierung dieselbe dergestalt unglücklich los zu schlagen und zu distrahiren pflegen, daß öfters kaum der dritte oder halbe Theil desjenigen Capitals, so zu deren Anschaffung angewendet worden, davor erlanget und herausgebracht wird; Ich aber wegen meines seit vielen Jahren mit nicht geringen Kosten, Sorgfalt und Fleiß gesammelten und ziemlich angesehenen Vorraths von Mathematischen und Physicalischen Büchern, auch hierzu dienlichen Instrumenten, auf deren Vermehrung ich auch täglich bedacht bin, in ebenmäßige Besorgung und daß, nach meinem in Gottes Händen stehenden Ableben, solche eben dergleichen unglücklichen Zufall haben möge, gerathen;

Als habe, damit diese meine Mathematische und Physicalische Bibliotec, Kupfer Stiche und Instrumenta, samt allen dem, was ich noch darzu zur Vermehrung anschaffen werde, samt und sonders nach meinem Tode conserviret und dem publico mit deren immerwährenden öffentlichen Gebrauch ein wahrer Nutzen dardurch gestiftet, hauptsächlich aber Gottes Ehre befördert werden möge, aus allerdings ungezwungenen und freyen Muth, auch eigener Bewegniß, auf vorher gepflogene sattsame und reifliche Erwegung, den Entschluß gefaßet, mehr 
erwehnte meine völlige Mathematische und Physicalische Bibliothec, zugehörige Instrumenta und Kupfer=Stiche, samt künftiger Vermehrung, nichts davon ausgeschloßen, an die Königliche GrosBrittanische und Churfürstlich Braunschweig=Lüneburgische neu angelegte Georg August Universität zu Göttingen, zu einem beständigen Andenken, durch eine unwiederufliche Schenkung unter denen Lebendigen, wie hiermit und kraft dieses ausgefertigten Donations-Instruments, in beständiger Form Rechtens beschiehet, und zwar also und dergestalt zu überlaßen und abzutretten, daß von nun an ich obwohlbesagte Universitaet als Eigenthümer darvon hiermit und Kraft dieses erkenne und halte, mir aber, bis zur Zeit meines in Gottes Händen stehenden seeligen Absterbens, den Gebrauch derselben ausdrücklich vorbehalte, der löblichen Universität hingegen, nach solchem meinem Ableben die Potestaet, solche meine unwiederruflich geschenkte Bibliothec nach ihren Gefallen von hier aus nach Göttingen ungehindert und ohne einige Contradiction meiner Erben zu transportiren überlaße; welche sie sodann in Separirte Repositoria zum öffentlichenn und immerwährenden Gebrauch aufstellen, und zu meinem Andenken deren conservation sich aufs beste und nachdrücklichste recommendiret seyn laßen werden; Allermaßen ich nun eben in solcher Absicht der löblichen Universitaet durch Herrn Profeßorem und Syndicum Doct. Senckenberg den darüber von mir treulich gefertigten Catalogum ${ }^{1151}$ allbereits einhändigen laßen, nicht minder diese meine reifliche Intention und beschehene Schenkung in einem besondern an dieselbe abgelaßenen Schreiben de dato Franckfurth dem 30. May a. c. ${ }^{152}$ derselben zu erkennen gegeben, welche dieselbe auch in einer deßfalls an mich aus Göttingen anhero erlaßenen Antwort, sub dato den 11. Junii a. c. mit vieler Danknehmigkeit bereits acceptiret. So erklähre mich hiermit nach mahlen dabey unwiederruflich bis an mein Ende zu beharren, begebe mich aller deßfalls hierwieder habenden Exceptionen überhaupt, und insonderheit des iuris revocandi ex capite supervenientium liberorum ${ }^{1153}$, und weiter mir aus vielen erheblichen Ursachen die gerichtliche Insinuation dieser Schenkung allhier coram Amplißimo Senatu1154 zu Franckfurth, zu bewerkstelligen bedenklich; So übertrage hiermit und Kraft dieses, mehrerwehnter löbl. Universitati donatariae die völlige Vollmacht und Gewalt

\footnotetext{
1151 Cod. Ms. Uffenbach 47.

1152 Uffenbach meint hier das erste offizielle Schreiben, in dem er seine Schenkung ankündigt (Universitätsarchiv Göttingen Kur. 4 V d6/2, B1.43 - 44; abgedruckt in Arnim 1928,3, S. 24-25).

1153 „Rechtes, die noch zusätzlich hinzukommenden Bücher von der Schenkung auszunehmen“. 1154 ,vor dem [Frankfurter] Senat“.
} 
cum clausula substituendi1155, die Insinuation apud acta bey Königl. GrosBrittanittanisch und Churfürstl. Braunschweig Lüneb. Hoher Landes=Regierung, oder Justiz=Kantzelley, wo sie es selbst vor diensam erachten wird, in meinem Nahmen, mittelst Überreichung dieses meines Original Donations-Instruments, $\mathrm{zu}$ verrichten, oder per mandatarium ${ }^{1156}$ verrichten $\mathrm{zu}$ laßen, welches alles ich hiermit, als wenn es von mir selbst geschehen, vor genehm halten will. Alles treulich und sonder Gefehrde.

Uhrkundlich habe mich eigenhändig unterschrieben und mein Petschaft beygedruckt. So geschehen

Frankfurt, den $28^{\text {ten }}$ July 1736 Johann Friedrich von Uffenbach.“

1155 ,in einer Form, die alle weiteren Vollmachten überflüssig macht“.

1156 „durch Beauftragten“. 


\title{
13.6Das Uffenbachische Instrumenten-Inventar
}

\author{
$\underline{\text { SUB Göttingen Cod. Ms. Bibl. Arch. A 34a. }}$
}

\subsubsection{Darstellung des Uffenbachischen Instrumenten- Inventars $\underline{1157}$}

Die Aufzählung der wissenschaftlichen Geräte umfaßt insgesamt 27 Seiten und zwei Vorsatzblätter mit der Größe von ca. 32,5 x 19,5 cm. Sie wurden in einen Papp-Einband mit Lederrücken eingebunden. Ein zweiseitiger Brief des Göttinger Mathematikers Abraham Gotthelf Kästner (1719-1800) vom 16. September 1784 liegt lose bei. ${ }^{1158}$

Das Verzeichnis wurde nach der vollständigen Überbringung der Geräte aus Frankfurt am Main nach Göttingen, also nach 1770 angefertigt. Der Übersichtlichkeit halber wurde hier das Dokument verwendet, das alle wissenschaftlichen Geräte Johann Friedrich von Uffenbachs in einem Manuskript verzeichnet.

Es wurde folgendermaßen eingeteilt: Werckzeuge und Erfindungen zu Arithmetik (p. 1); Allgemeine geometrische Instrumente (p. 2-10); Instrumente zur Mechanik (p. 11-12); Zur Optik und Perspectiv gehörige Instrumente (p. 1321); Instrumente zu der Gnomonik (p. 22-24); und Einige zu der Naturforschung und Lehre gehörige Stücke (p. 25-27). Dem Verzeichnis zugrunde liegen die Geräte selbst, aber auch drei Teilinventare. Zum einen wurden die Beschreibungen des ersten Inventars „Kurtzes Verzeichnüs derer mathematischer physicalischer und Kupffer Bücher wie auch des Vorraths einiger hiezu gehöriger Instrumente mein J. F.'s v. Uffenbach" ${ }^{1159}$, die von den Instrumenten handeln, fast wörtlich übernommen, zum andern konnte der Schreiber auf drei Supplemente ${ }^{1160}$ zurückgreifen, die noch zu Uffenbachs Lebzeiten angefertigt worden waren.

\footnotetext{
1157 S.a. Meyerhöfer 1995.

1158 In dem Brief bestätigte Abraham Gotthelf Kästner, daß er die „Corpora regularia“ (Nr. 116) ausgeliehen hatte und diese noch länger für seine Vorlesungen und Untersuchungen behalten wollte.

1159 Cod. Ms. Uffenbach 47, p. 165r-193r.

1160 In: Cod. Ms. Bibl. Arch. A 34c.
} 
Das erste, schon den größten Teil der Bücher und Geräte beschreibende Inventar, eine Abschrift des eigenen, von Uffenbach benutzten Kataloges ${ }^{1161}$, wurde etwa 1734 zusammengetragen und mit der Schenkungsurkunde nach Göttingen übergeben. Schon am 15. Oktober 1736 übersandte der Stifter das erste Supplement, das zweite erst im Jahr 1763 und das dritte im November 1766. Hinzu kamen noch die Nachträge des Hannoverschen Residenten in Frankfurt, Friedrich Ludolph von Hugo, die dieser beim Sichten und Verschicken der Stiftung nach Göttingen in dem Haus von Uffenbach angefertigt hatte. ${ }^{1162}$

Die Seiten des hier vorliegenden Inventars wurden jeweils in vier Spalten unterteilt. Die erste Spalte dient der Nummerierung, außerdem wurde vor den Zahlen vermerkt, wohin der Gegenstand abgegeben oder verbracht wurde: Ein „L.“ bedeutet Lichtenberg, während das „M.“ die Modellkammer der Göttinger Universitätsbibliothek bezeichnet. Einige der Nummern haben vorweg keinen Vermerk; entweder fehlten diese Gegenstände bei der Übergabe an Lichtenberg, wie die Aufzählung auf dem zweiten Vorsatzblatt in einer anderen Schrift vermerkt, oder es wurde, wie bei den Nummern 219 und 222, mit spitzer Feder darüber gesetzt ,,auf der Bibliothek“. Die Geräte dieser beiden Nummern 219 und 222, zwei Globen des Nürnberger Instrumentenbauers Johann Gabriel Doppelmayer (1677-1750). und eine Armillar-Sphaere wurden zu den Büchern und Kupferstichen der Stiftung Uffenbach gestellt. ${ }^{1163}$

Die zweite Kolumne wurde mit „Catal.“ überschrieben und bezieht sich zum einen auf den Katalog von 1734, wobei die Zählung der Seiten im vorliegenden Verzeichnis etwas eigentümlich ist. Sie erfolgt nicht nach recto und verso, sondern die jeweils gegenüberliegenden Seiten des Kataloges sind mit 'a' und 'b' gekennzeichnet. Zum anderen wurde auf die als Nachträge bezeichneten Supplemente Uffenbachs zurückgegriffen. Die dritte Rubrik, „Frkfurth. Verzeich.“ oder „Frkt. Verz.“1164 betitelt, verzeichnet die Listen und Ergänzungen des Frankfurter Residenten von Hugo,1165 während die vierte Spalte einer Benennung des Gegenstands vorbehalten ist. Auffällig ist hierbei, dass der Verfasser meist wörtlich die Beschreibungen Uffenbachs und Hugos übernimmt.

1161 UB Frankfurt am Main, Signatur: Ms. Ff. J.F.v.UFFENBACH: „Catalog der von v. Uffenbach der Universität Gottingen gestifteten Schätze.“

1162 Ebenfalls in: Cod. Ms. Bibl. Arch. A 34c.

1163 Der Hinweis, daß die drei Stücke zur Bibliothek Uffenbach gestellt wurden, befindet sich in: Cod. Ms. Lichtenberg VII, Q:2, B1. 52r und 52v.

$1164=$ Frankfurter Verzeichnis.

1165 In: Cod. Ms. Bibl. Arch. A 34c. 
Ein weiteres, fast identisches Verzeichnis der Sammlung befindet sich im Besitz der SUB Göttingen. ${ }^{1166}$ Es trägt die Überschrift: „B. Verzeichnis dessen was aus dem Uffenbachischen Apparat zu der physischen Instrumentensammlung von Herrn Hofrath Lichtenberg ist abgegeben worden. Octob. 1791.“ Auch hier befinden sich am Anfang jedes Apparats eine Nummer, die sich auf Lichtenbergs Übernahme bezieht. Es handelt sich um ein kurzzeitig später erstelltes Verzeichnis, welches genau nach dem hier transkribierten abgefaßt wurde, da die Instrumente, die in die Modellkammer abgegeben worden waren - insgesamt 23 Nummern-, nicht mehr beschrieben sind, sondern grundsätzlich als „In der Modellkammer" oder „sind in die Modellkammer gegeben worden“ gekennzeichnet sind. Sogar die falsche Zählung aus dem hier beschriebenen wurde übernommen. ${ }^{1167}$ Auch die Geräte, die bei der Verbringung nach Göttingen gefehlt haben, sind nicht mehr beschrieben, sondern nur als „fehlet“ gekennzeichnet. Bei einigen Instrumentenbezeichnungen befinden sich Vermerke Lichtenbergs über den Zustand des jeweiligen Geräts. ${ }^{168}$ Ein wichtiger Zusatz findet sich aber in dieser Zusammenstellung. Lichtenberg übernahm am 16. Oktober 1791 ebenfalls das auf Kupfer gemalte Portrait Johann Friedrich Armand von Uffenbachs. ${ }^{169}$ Das Bild fügte die Witwe Uffenbachs, Maria Magdalena, der Stiftung bei. Es befindet sich heute in der Kunstsammlung der Georg - August Universität Göttingen. ${ }^{1170}$

Lichtenberg bestätigte den Empfang der Gegenstände folgendermaßen: ,(B1.53r) [...] Daß ich alle oben verzeichnete Instrumente / empfangen habe bescheinige ich / hiemit. Göttingen d. 26 Oct. 1791. / Lichtenberg“.

\subsubsection{Verbleib der Sammlung}

Nach dem Tod von Lichtenberg im Jahre 1799 wurden sowohl die Geräte aus dessen Nachlass als auch die aus der Stiftung Uffenbach von dem Nachfolger,

1166 In Cod.Ms. Lichtenberg VII, Q:2, B1. 38-53.

1167 Vgl z.B. die Nr. 173, die auch hier zweimal vorhanden ist.

1168 Es soll in den Fußnoten jeweils mit „Lichtenberg“ gekennzeichnet werden.

1169 Cod.Ms. Lichtenberg VII, Q:2, B1. 38-53.

Unbezeichnet, Kupfer 41 x $31 \mathrm{~cm}$; auf der Rückseite die Inschrift: J. Frideric. Armand ab Uffenbach. M. Brittanniae Regi in legione Tormentaria Pro Tribunus. Postea Reipublicae Patriae Moeno Francofurtensis Proto Scabinus et Senator Natus d. 6. Maji Anno MDCLXXXVII.

1170 S.a. Kunstsammlung der Universität Göttingen, Die niederländischen Gemälde, mit einem Verzeichnis der Bilder anderer Schulen, bearb. von Gerd Unverfehrt, Göttingen 1987, S. 181, Nr. A 13. 
dem Physiker Johann Tobias Mayer (1752-1830), übernommen. In einer Bestätigung vom Oktober $1800^{1171}$ heißt es: [B1.9] „Daß ich die in den Catalogen A $[=$ Lichtenbergs physicalische Instrumente $], \quad \mathrm{B}[=$ Verzeichnis des Uffenbachischen Apparats], C $[=$ Anhang zu Lichtenbergs physicalische Instrumente], verzeichneten Instrumente des physicalischen Apparats, mit Ausschluß derjenigen, welche in dem Catalog C1172 unter Nro 7. 23. 194. 195. 196. [...] vorkommen, und deren zuerst genante fünf Stück noch von dem seel. Lichtenberg an den $\mathrm{H}$. Obristlieutnant Müller, [...] geliehen worden, richtig empfangen habe, solches wird hiedurch von mir bescheiniget. Göttingen im October 1800. JohTob Mayer.“

Bei den fünf Instrumenten handelt es sich um:

,$[B 1.10][\ldots] \underline{\text { In dem Catalog B }}$

Nro. 7. Ein Astrolabium von le Fevre zu Paris

Nro 23. Ein andres von einem halben Circul

Nro 194, 195, 196 Modelle von einer Canone, Haubize u. Mörser.

Diese Stücke besitzt Hr. Obristl. [G.W.] Müller, und sind Scheine darüber vorhanden.“

In dem Verzeichnis befindet sich auch bei den jeweiligen Nummern mit Rötel eingetragen „OberL M.“.

Ein „Post Scriptum“ vom 27. Mai 1802, von dem Göttinger Universitätsbaumeister Georg Heinrich Borheck (1751-1834) verfasst, zeigt außerdem, dass die Geräte in das Museum, das heißt in die frühere Modellkammer, überbracht wurden. Weiterhin wurden zwei Schränke angefertigt, die die mathematischen Instrumente aufbewahren sollten, damit der Göttinger Mathematiker Bernhard Heinrich Thibaut (1775-1832) diese mitbenutzen konnte.

In dem „Katalog des Physikalischen Apparats, verfertigt von Johann Tobias Mayer im Jahre 1813“ werden noch 204 Instrumente aus der Sammlung Uffenbach beschrieben. ${ }^{1173}$ Allerdings sind zu diesem Zeitpunkt schon einige der Geräte defekt. Mayer übernimmt die Uffenbachischen Beschreibungen der

1171 In Cod. Ms. Lichtenberg VII, Q:2, B1. 9 und 10.

1172 Hier irrt sich Mayer in der Bezeichnung. Es handelt sich um den Katalog „B“, also dem Verzeichnis der Uffenbachischen Geräte.

1173 Das Inventar befindet sich heute im I. Physikalischen Institut der Georg-August-Universität Göttingen (Inv. Nr.: H 1); s.a. Anmerkungen in der Transkription, wo als „Mayer 1813“ auf die Instrumente hingewiesen wird. 
Instrumente fast wörtlich und versieht die Instrumente mit neuen Inventarnummern, die sie schon von vornherein näher klassifizieren. Er stellt auf dem zweiten Blatt des Verzeichnisses folgende Aufstellung voran, wobei die Seitenzahlen von späterer Hand hinzugefügt wurden:

Bezeichnungen der einzeln / Stücke.
Allgemeine
Eygenschaften
der
A. (p. 1)

Körper

Statica et Mechanica

S. (hieher gehören auch die Acustica) (p.

8)

Hydrostatica

H. (p. 48)

Aerometrica

AE. (p. 58)

Pyrometrica

P. (p. 87)

Hygrometrica

Hg. (p. 103)

Optica

O. (p. 106)

Electrica

E. (p. 141)

Galvanica

G. (p. 166)

Magnetica

M. (p. 169)

Chemica

C. (p. 176)

Arithmetica

Ar. (p. 191)

Geometrica

Ge. (p. 193)

Gnomonica

Gn. (p. 209)

Astronomica

Astr. (p. 214)

Als Wilhelm Eduard Weber (1804-1891) sein Amt 1831 in Göttingen antrat, fand eine erneute Revision statt. Auf der Titelseite des Inventars von Mayer befindet sich in roter Tinte folgender Vermerk: „Revidirt nach des Hofraths J. T. Mayers / Tode, bey der gerichtsseitig geschehenen / Uebergabe an den Professor Weber. / im October 1831. / laut des am Ende des Catalogs / befindlichen Protocolls.“ 
Bei der Durchsicht der Sammlung, die vom 11. bis zum 18. Oktober 1831 vorgenommen wurde, aktualisierten Weber und der Universitäts-Rat G.H. Oesterley ${ }^{1174}$ mit Hilfe des Unteraufsehers Modell Prospector Apel den Zustand der Sammlung, wobei die 204 Uffenbachischen Geräte teilweise defekt oder beschädigt sind. In dem zweiseitigen Übernahmeprotokoll vom 18. Oktober 1831 heißt es u.a.:

„,(p. 220) [...] 1. daß sämtliche Stücke, bey welchen / nicht bemerkt ist, daß sie fehlen, ge $=/$ brochen oder defect befunden worden $/$ in brauchbarem Zustande vorhanden / sind.

2. daß die mit roter Dinte geschriebenen / Bemerkungen und Zusätze von dem / unterzeichnenden Commissarius hin $=$ / zugesetzt sind, die übrigen mit Bley, / Feder und schwarzer Dinte geschriebe $=$ / nen aber, von der Hand des Hofraths / Mayer u. einige wenige von der / des Inspectors Apel herrühren.

3. daß die Bemerkung: repositum 1. / bezeichnet, daß diese zwar vorhande= / nen Sachen, nach Anzeige des Pro= / fessors Weber, bey den Vorlesungen / nicht gebraucht werden, indessen doch / aufzubewahren sind; die mit repos.2. I bezeichneten Stücke aber, als gänzlich / unbrauchbar betrachtet werden müssen.

4. daß die Notizen über den Verbrauch / einiger Sachen, von dem Inspec $=/$ tor Apel mitgetheilt sind. [...]".

Am 10. Februar 1832 bekam Weber vom Königlich Großbrittanisch=Hannoverschen Universitäts-Curatorium in Hannover die schriftliche Erlaubnis, die Geräte, die im Mayerschen Inventar von ihm mit dem Vermerk ,repos.2“ versehen wurden, entweder auszusondern oder als Vorrat für andere Instrumente zu benutzen. ${ }^{1175}$

Im Oktober 1838 wurde eine erneute Revision durchgeführt, nachdem Weber als einer der „Göttinger Sieben“ seines Amtes enthoben worden war und eine Überweisung der Sammlung an Georg Carl Justus Ulrich (1798-1879) stattfand. Diese Durchsicht wurde im Inventarverzeichnis mit grüner Tinte kenntlich gemacht. Jetzt sind kaum noch Geräte Uffenbachs intakt und einige waren zwischenzeitlich auch entfernt worden.

In zwei weiteren Verzeichnissen der Instrumente und Werkzeuge des Instituts für Experimentalphysik aus dem Jahr 1849, die beide von der Hand Wilhelm

1174 Georg Heinrich Oesterley d.J. (1774-1847).

1175 Der Brief befindet sich im I. Physikalischen Institut der Georg-August-Universität Göttingen, Inv. Nr. H 11, Wilhelm Weber, Rescripte Sept.1831 - Dec.1837. 
Webers nach dessen Rückkehr nach Göttingen stammen, sind nur noch 16 Gerätenummern mit den Instrumenten aus der Sammlung Uffenbach in Verbindung $\mathrm{zu}$ bringen. ${ }^{1176}$ Die beiden Inventare haben folgende Titel: I. Inventarium des Instituts für die Experimentalpysik. Ostern 1849, und II. Vorrath an Werkzeug , Utensilien und Materialien des Instituts für die Experimentalphysik. Ostern 1849.1177

Zwischen 1838 und 1849 muß noch eine Überprüfung der Sammlung stattgefunden haben. Nach der Amtsenthebung Webers war Johann Benedikt Listing (1808-1882) die Leitung des Instituts übertragen worden. In dem Mayerschen Inventar finden sich in türkisblauer Tinte Abkürzungen wie z.B. „L.“ oder „List.“, die sich nur auf Listing beziehen können. Da nach der Rückkehr Webers 1849 das Institut auch geteilt wurde, und Weber das Institut für Experimentalphysik und Listing das Institut für mathematische Physik übernahm, könnte es sein, dass auch die Sammlung geteilt wurde. Dabei könnten mehrere Geräte aus der Sammlung Uffenbach dem Institut für Mathematische Physik ${ }^{1178}$ zugeordnet worden sein.

Die ,auf der Bibliothek“ aufgestellten drei Instrumente, zwei große Globen des Nürnberger Instrumentenbauers Johann Gabriel Doppelmayer (Nr.219) und eine Armillar-Sphaera (Nr.222) befanden sich noch im Mai 1835 im Besitz der Bibliothek.

In einem mit „Anhang II. Verzeichniß der in dem Bibliotheks-Gebäude vorhandenen beweglichen Geräthschaften, aufgenommen im May 1835 von dem Bibliothecar Hofrat Denecke.“ heißt es: „,(B1.2r) In dem obern Stocke, [...] In dem kleinen rechts von dem vorigen / ablaufenden Sale - I. - (Dichtersal) / 2 alte Globen und 1 Armillar= / Sphäre.“.1179

Zwei solche Globen Doppelmayers, beide 1728 datiert, werden auch heute noch in der Bibliothek aufbewahrt. Sie kamen 1986 aus dem Besitz des Geographischen Instituts dorthin. Es konnte nicht festgestellt werden, woher sie ursprünglich stammen. Bei dem einem handelt es sich um einen GLOBUS TERRESTRIS bei dem anderen um einen GLOBUS COELESTIS NOVUS. Vielleicht sind es die beiden unter Nr.219 des Inventars bezeichneten. Die unter

1176 In den Anmerkungen der Transkription mit „Weber 1849“ gekennzeichnet.

1177 Beide Verzeichnisse befinden sich im I. Physikalischen Institut der Georg-AugustUniversität Göttingen und tragen die Inventar-Nummern $\mathrm{H} 2$ und $\mathrm{H} 8$.

1178 Das heutige Institut für Theoretische Physik in Göttingen.

1179 In Cod. Ms. Bibl. Arch. B 10a. 
Nr.222 beschriebene Armillar-Sphaere konnte nicht mehr ausfindig gemacht werden. Ihre Spur verliert sich nach 1835 .

Genauso verhält es sich mit den Geräten, die in der Modellkammer Platz fanden. Es handelte sich um meist große Instrumente, wie z.B. die Camera Obscura in einer Tragsänfte (Nr.103), oder um größere architektonische Modelle, wie das Modell der großen Wasserkunst zu Herrenhausen (Nr.39), die Lichtenberg zu groß waren oder ihn für seine Belange nicht interessierten.

Bis zum heutigen Tag lassen sich fast keine Instrumente der Uffenbachischen Schenkung nachweisen. Im I. Physikalischen Institut sind es insgesamt fünf Gerätenummern, die mit Sicherheit aus Uffenbachs Sammlung stammen; es handelt sich dabei um ein Teleskop von John Dollond ${ }^{1180}$, ein kleines Spiegelfernrohr ${ }^{1181}$, ein kleiner, in Gold gefaßter Magnet an einen hölzernen Gestell1182, Magnetsand von Musschenbroek ${ }^{1183}$ und ein Magneteisenstein mit Armierung im Messinggehäuse ${ }^{1184}$, vielleicht auch einer der Zerrspiegel ${ }^{1185}$.

Hinweise zur Transkription

In den Anmerkungen sind Bücher aufgezählt, die Uffenbach entweder in den Instrumentenbeschreibungen nennt oder von den Instrumentenbauern oder Wissenschaftlern außerdem noch besitzt; die in runde Klammern gesetzten Signaturen verweisen auf die Bibliothek Uffenbach, die in der Handschriftenabteilung der SUB Göttingen aufbewahrt wird. Zum anderen sind die ausführlicheren Beschreibungen des Kataloges von 17341186 und der Supplemente aufgeführt, wobei es sich bei „Katalog 1734“ um dieses erste Inventar handelt. Weiter wurden die Ergänzungen Lichtenbergs, die dieser in seinem Inventar der Uffenbachischen Geräte ${ }^{1187}$ vermerkt hat, hinzugefügt; dabei

1180 Verzeichnis-Nr. 61, heute Inv. Nr. H 101.

John Dollond (1706-1761).

1181 Verzeichnis-Nr. 62, heute Inv. Nr. H 102.

1182 Verzeichnis-Nr. 199, heute Inv. Nr. H 107, wobei der Originalmagnet gestohlen und durch eine Kopie aus Messing ersetzt wurde.

1183 Verzeichnis-Nr. 207, heute Inv. Nr. H 110.

Pieter van Musschenbroek (1692-1761).

1184 Verzeichnis-Nr. 197, heute Inv. Nr. H 108; s.a. Werner/Beuermann 1986, S. 22-23, Abb. 8.

1185 Verzeichnis-Nrn.141 und 142, heute Inv. Nrn. H 98 und H 99.

1186 Cod.Ms.Uffenbach 47.

1187 In Cod. Ms. Lichtenberg VII, Q:2, B1. 38-53: „Verzeichniß dessen was aus dem Uffenbachischen Apparat zu der physischen Instrumentensammlung von Herrn Hofrath Lichtenberg ist abgegeben worden. Oktob. 1791.“ Dieses Inventar ist genauso eingeteilt 
soll der Zusatz „Lichtenberg:“ auf dieses Inventar hinweisen; zum einen soll auch das Inventar des Johann Tobias Mayer von $1813^{1188}$ mit aufgenommen werden als „Mayer 1813“, zum anderen die beiden Inventare von Wilhelm Weber, gekennzeichnet als „Weber I“ und „Weber II“1189. Des Weiteren wurden in den Anmerkungen Erklärungen, in eckige Klammern gesetzt, hinzugefügt.

\subsubsection{Transkription des Kataloges der Uffenbachischen Instrumente}

(1.Vorsatzblatt) D. Uffenbachische / Instrumente.

(2.Vorsatzblatt) Die Instrumente, vor welchen in diesem Verzeichnis ein $\underline{\underline{L}}$ steht / und welche roth unterstrichen sind, hat Herr Hofr. Lichten= / berg den 26. Oct. 1791. von der Universitäts=bibliothek in / Empfang genommen.

Die Instrumente, vor welchen in diesem Verzeichnis ein / $\underline{\underline{M}}$. steht, sind in der Modellkammer den 29. Oct. 1791. / aufgestellt worden.

Folgende Instrumente haben bey der Übergabe an Hn. / Hofrath Lichtenberg gefehlt.

S.8. ‥ Ein stählerner Haar Zirkel mit einer Schraube. p.

i. Ein einfacher Zirkel von Dirk Metz ${ }^{190}$ in Amsterdam p.

1. Ein messingener Zirkel mit 3 Füssen. p.

S.13. Nro. 71. Ein Tubus von 4 Fuß mit schwarzer Fischhaut. pp

S.14. Nro. 77. Ein perspectiv von 1 1/2 Fuß mit schwarzer Fischhaut pp

S.16. Nro. 111. Ein hölzernes Instrument zu der Perspectiv-Zeichnung. pp

wie das hier vorgestellte, nur daß die fehlenden Instrumente nicht mehr beschrieben sind, sondern lediglich als ,fehlt" gekennzeichnet sind. Außerdem wurden die Geräte, die in der Modellkammer abgestellt wurden nur noch als „In der Modellkammer“ und diejenigen, die in die Bibliothek kamen, als ,auf der Bibliothek; bey Uffenbach's Bibliothek.“ verzeichnet.

1188 S.o.

1189 S.o.

1190 Dirk Metz (ca. 1674-nach 1742). 
S.17. Nro. 116. Die Corpora regularia auf 72 Arten, von steifen Papier gemacht $\mathrm{pp}^{1191}$

S.18. Nro. 127. Ein kleines Brennglaß, 2 Zoll im Diameter, im Elfenbein gefasst.

S.20. Nro. 150. Ein Verkleinerungs Spiegel von 6-7 Zoll im Diameter pp.

S.27. Nro. 227. Rothes Glas - von Cambridge.

- - Nro. 228. Blaues Glas - von Cambridge.

- - Nro. 229. Glaß aus der Kirche zu Gouda.

(p. 1) Werckzeuge und Erfindungen zur / Arithmetik.

No Catal. $\quad$ Frkfurt. [Erklärung des Gegenstandes]

Verzeichn.

1192

L 1. pag. 166a. I, n. 116. Ein Kästgen mit Rechnungsstäben von Sr.

Grillet ${ }^{193}$ in Paris. ${ }^{1194}$

L 2. ib. - n. $117 . \quad$ Bacilli Neperiani. ${ }^{1195}$

1191 Wie der beiliegende Brief von Abraham Gotthelf Kästner vom 16. September 1784 zeigt, hatte er sich diese Körper ausgeliehen.

Mayer (S. 1): A.1, Einige geometrische Körper von Pappe [mit dem Hinweis bei der Revision von 1831: sind in 3 Kasten 78 Stück.].

$1192=$ Frankfurter Verzeichnis. Dieses ist von dem Hannoverschen Residenten in Frankfurt, Friedrich Ludolph von Hugo, geschrieben worden, als er die Geräte 1769 von der Witwe Uffenbachs übernommen hat.

1193 René Grillet (Lebensdaten unbekannt, tätig 2. Hälfte 17. Jahrhundert).

1194 Katalog 1734, p. 165v: „vid: Curiosités mathematiques par Grillet Paris $4 .^{\circ} 1673$. und Leupold Theatr: arith: geometr: fol: tab: VI.“ [= René Grillet, Curiositez mathematiques de l'invention du ..., Paris 1673 (4 Bibl. Uff. 300) und Jacob Leupold, Theatrum arithmeticogeometricum. Das ist Schauplatz der Rechen- und Messkunst, darinnen enthalten dieser beiden Wissenschaften nöthige Grundregeln und Handgriffe, Leipzig 1727 ( $2^{\circ}$ Bibl. Uff. 257)].

Mayer 1813, S. 191, Inv. Nr. Ar 1.

1195 Katalog 1734, p. 165v: „zu dergleichen Gebrauch von Holz.“ [= Nepersche Rechenstäbe; die Bacilli Neperiani sind nach ihrem Erfinder John Napier (Neper, Nepper, Nepair) benannt (1550-1617); er gilt als Erfinder der Logarithmen; die Neperschen Rechenstäbe dienen zur mechanischen Ausführung der Multiplikation und Division, die ihren Nutzen nach Erfindung der Logarithmen verloren.].

Mayer 1813, S. 191, Inv. Nr. Ar 2. 

L 3. p. 166b
- n. 118.
Ein Kästgen von
von Buchsbaum
mit
Rechenstäben. ${ }^{1196}$

L. 4. ib

- n. 119.

Ein besonders

zusammen gelegtes

Spielbrett $\mathrm{zu}$ einem un= / bekannten

algebraischen Spiele, nebst dazu ge= / hörigen Karten. ${ }^{1197}$

L. $5 . \quad$ ib. $\quad-120$

Ein eiserner Wagbalken, nebst einer kupfernen Schaale, / und Gegengewicht zu verschiedenen Ausrechnungen / dienlich, von der Erfindung des Hrn Cassini. ${ }^{1198}$

L. 6. 2.ter

Nachtrag

Kleine bacilli Neperiani ${ }^{1199}$ in einem schwarzen Futteral. ${ }^{1200}$

(p. 2) Allgemeine geometrische Instrumente.

No Catal. $\quad$ Frkt.Verz. [Erklärung des Gegenstandes]

1196 Katalog 1734, p. 165v: ,vid: Leupold. Theatr: arithm: geom: fol: tab: V. fig: 7.“ [= Jacob Leupold, Theatrum arithmetico-geometricum. Das ist Schauplatz der Rechen- und Messkunst, darinnen enthalten dieser beiden Wissenschaften nöthige Grundregeln und Handgriffe etc., Leipzig 1727 ( $2^{\circ}$ Bibl. Uff. 257)].

Mayer 1813, S. 191, Inv. Nr. Ar 3;

1197 Mayer 1813, S. 191, Inv. Nr. Ar 4.

1198 Katalog 1734, p. 165v: ,vid: Journal des Scavans tom: 4. 8. Amsterdam p: 259. und Bions mathem: Werck-Schule 4. Nürnberg. tab: 10." [Journal des Scavans = Journal des Scavans hoc est Ephemerides eruditorum (nicht mehr in der Bibliothek Uffenbach vorhanden); Bions Werck-Schule $=$ Nicolai Bion, Neu-eröffnete Mathematische Werck=Schule oder Gründliche Anweisung wie die Mathematische Instrumenten nicht allein schicklich und recht zu gebrauchen ..., übersetzt von J.G.D. [= Johann Gabriel Doppelmayer] Nürnberg 1712 (4 Bibl. Uff. 306);

bei „Cassini“ handelt es sich um den Astronomen und Direktor der Pariser Sternwarte Giovanni Domenico Cassini (1625-1712).

Weiterhin befindet sich ein Brief Doppelmayers, ohne Ort und Datum, mit der genauen Beschreibung der Waage von Cassini im ersten Band des „Commercium Epistolicum“ [Cod. Ms. Uffenbach 20/I, B1. 345r-347v, hier bes. 347r + v.];

Die Waage hatte Uffenbach über seinen ehemaligen Reisegefährten Johann Dabiel Geysel 1723 bei Doppelmayer in Auftrag gegeben, vgl. Cod. Ms. Uffenbach 20/II, p. 632r (s. Anhang).

Mayer 1813, S. 24, Inv. Nr. S 21; mit dem Vermerk der Revision von Weber 1831 in roter Tinte ,repot.2“, auch ist die Beschreibung durchgestrichen.

1199 [= Rechenstäbe].

1200 Mayer 1813, S. 191, Inv. Nr. Ar 5. 
L. 7. p. $170 b$

II, n. 15.

Ein Astrolabium von einem halben Zirkel, mit Lineal, $\mathrm{Di}=/$ optern und der Bussole ${ }^{1201}$ / von le Fevre ${ }^{1202}$ zu Paris. / in einem schwarz ledernen Futeral, nebst einem / Gestell von Hanbüchen Holz. ${ }^{1203}$

L. $8 . \quad$ ib. - n. 9 .

Eine mensula Praetoriana ${ }^{1204}$ mit einer in Grade eingeteil $=/$ ten messingenen Einfassung, nebst einem Bretgen / mit Bley überzogen ${ }^{1205}$, Und einem langen mes $=$ / singenen Lineal mit Dioptern ${ }^{1206}$, Von [Jacob] Leupold ${ }^{1207} /$ In einer Schieblade. ${ }^{1208}$

L. $9 . \quad$ p. $171 \mathrm{a}-$ n. 8

Eine dergl.[eichen] ohne messingene Einfassung, mit einem / zusammengelegten schwarzen Gestelle, und mes= / singenen Gewinde. ${ }^{1209}$

1201 [= Magnetnadel].

1202 Vornamen und Lebensdaten unbekannt.

1203 Katalog 1734, p. 170r: „Ein Astrolabium von einem halben Zirckel mit Lineal Dioptern, und der Bussole [= Magnetnadel] welche auch herauszunehmen und als ein Declinir Compass zu gebrauchen, an welchem die Magnet Nadel außer dem Gebrauch fest gestellt werden kan. Von Le Febvre zu Paris gemacht. in einem besondern schwartz ledernen Futeral. Wozu ein Gestell als ein 3. Fuß von Hanbügen Holtz mit Eisen beschlagen, gehöret. Welches leztere zu Flörsheim stehet.“ [In Flörsheim befand sich das Landgut von Johann Friedrich Armand von Uffenbach.].

Mayer 1813, S. 193, Inv. Nr. Ge 1; mit dem Vermerk der Revision von Weber 1831 in roter Tinte ,rep. 1“.

1204 Geometrischer Tisch nach dem Mathematiker, Instrumentenbauer und Astronomen Johannes Praetorius [= Johann Richter (1537-1616)].

1205 Lichtenberg (B1. 39r.): ,(so beschadiget ist Lichtenberg)“.

1206 Katalog 1734, p. 170v: ,einen stahlernen Radier Kolben, und einen besondern starcken meßingen Gewinde. wozu der vorgemeldete 3. Fuß als ein Statif dienen kan, oder ein andrer schwartz angestrichener Fuß, [am Rand in anderer Schrift: fehlt. S. sie Frkft. Nota.] welcher eigendlich dazu gemacht, gebraucht werden kan“.

1207 Katalog 1734, p. 165v: ,in Leipzig verfertiget.“ Jacob Leupold (1674-1727).

1208 Mayer 1813, S. 193, Inv. Nr. Ge 2; mit dem Vermerk der Revision von Weber 1831 in roter Tinte ,rep. 1“.

1209 Mayer 1813, S. 193, Inv. Nr. Ge 3; mit dem Vermerk der Revision von Weber 1831 in roter Tinte ,rep. 1“. 
L. 10 ib.

- n. 14.

L. 11. p. 171b.

- n. 16.

NB L. p. 174.

- n. 18.

12.

L. 13. p. 176b. - n. 71 .

L. 14. ib.

I, n. 153.

L. 15 . p. 177a.

- n. 150.

L. 16. ib.

- n. 151.
Ein messingenes Instrument, die Winkel abzunehmen / in einem schwarz ledernen Futteral, Von / Chapetot ${ }^{1210}$ zu Paris. ${ }^{1211}$

Ein viereckigtes messingenes Instrument zum Auf / und Abnehmen der Winkel, in einem braun / ledernen Futteral, mit einem besondern $\mathrm{Ge}=$ / winde, in eben dergl.[eichen] Köcher. ${ }^{1212}$

Ein messingenes Instrument, die Winkel abzunehmen $^{1213}$ / das zugleich $\mathrm{zu}$ einer Setzwage dient. ${ }^{1214}$

Ein großer proportional Zirkel, in Kupfer gestochen / und auf Holz gezogen. ${ }^{1215}$

Ein Senkelwerckzeug Von Holz mit Messing versehen / die Mensula praet.[oriana] über einen begehrten Punct / zu stellen. ${ }^{1216}$

Eine Meßlatte von Messing. ${ }^{1217}$ von Eisen. ${ }^{1218}$

1210 Vornamen und Lebensdaten unbekannt,

1211 Katalog 1734, p. 165v: ,vid. Leupolds Theatrum geometric. fol: tab: 26. fig: 5. \& 6.“ [= Jacob Leupold, Theatrum arithmetico-geometricum. Das ist Schauplatz der Rechen- und Messkunst, darinnen enthalten dieser beiden Wissenschaften nöthige Grundregeln und Handgriffe etc., Leipzig 1727 ( $2^{\circ}$ Bibl. Uff. 257)].

Mayer 1813, S. 193, Inv. Nr. Ge 4; mit dem Vermerk der Revision von Weber 1831 in roter Tinte ,rep. 1“.

1212 Mayer 1813, S. 193, Inv. Nr. Ge 5; mit dem Vermerk der Revision von Weber 1831 in roter Tinte ,rep. 1“.

1213 Lichtenberg (B1. 39r): ,(dessen Gebrauch ich nicht daran finde L).“

1214 Mayer 1813, S. 194, Inv. Nr. Ge 10; das Gerät ist von Mayer zwar noch in das Inventar aufgenommen worden, von ihm aber schon mit dem Vermerk „unbrauchbar“ versehen worden.

1215 Mayer 1813, S. 194, Inv. Nr. Ge 11; mit dem Vermerk der Revision von Weber 1831 in roter Tinte ,rep. 1“.

1216 Lichtenberg (B1. 39v): „(liegt bey No. 8 wozu es gehöret L.)“; Mayer 1813, S. 194, Inv. Nr. Ge 12.

1217 Mayer 1813, S. 194, Inv. Nr. Ge 13; mit dem Vermerk der Revision von Weber 1831 in roter Tinte ,fehlt“.

1218 Mayer 1813, S. 194, Inv. Nr. Ge 14. 
L. 17. ib.

- n. 152.

nach

Rheinl[ändischen] Schuhen. ${ }^{1219}$

(p. 3) Allgemeine geometrische Instrumente.

No Catal. $\quad$ Frkt.Verz. [Erklärung des Gegenstandes]

L. 18. 2.ter

Nachtrag

L. 19. ib.

L. 20. ib.

L. 21. ib.

L. 22. Cat. p. $175 b$.

L. $23 . \quad-$ p. 177a.

L.22.

1226

1219 Mayer 1813, S. 194, Inv. Nr. Ge 15.

1220 Mayer 1813, S. 172, Inv. Nr. M 25.

1221 Mayer 1813, S. 194, Inv. Nr. Ge 16.

1222 Mayer 1813, S. 195, Inv. Nr. Ge 17.

1223 Lichtenberg (B1. 39v): ,(worin einige Stücke fehlen L.)“; Mayer 1813, S. 195, Inv. Nr. Ge 18.

1224 Mayer 1813, S. 195, Inv. Nr. Ge 19.

1225 Mayer 1813, S. 195, Inv. Nr. Ge 20.

1226 Hier und bei der folgenden Nummer hat sich der Schreiber geirrt. Er wiederholt die Nrn. 22-23.
Ein englischer Declinir Compass, an dessen einer Seite / ein Niveau von besonderer Einrichtung. 1220

Ein messingener Quadrant mit einem Hang Per $=$ / pendicul. ${ }^{1221}$

Ein messinges besonders Instrument um Ovale von / dem centro an tiefer parallel zu reißen. ${ }^{1222}$

Ein Futteral, in Gestalt eines Buchs, mit üblichen Reiß=/ zeug. ${ }^{1223}$

Ein zwey Schuh langes Lineal von Messing, worauf ver= / schiedene verjüngte Maasstäbe gestochen. ${ }^{1224}$

Ein Lineal $2 \quad 1 / 2$ Schuh lang von Ebenholz. ${ }^{1225}$

Ein roth ledernes Besteck, mit einem zusammen $\mathrm{ge}=$ / legten Maasstabe, Bleyfeder von Elfenbein, / und einer 
Schere. ${ }^{1227}$

L. 23. 3ter Nachtr. /

Ein Astrolabium von einem halben Zirkel, p. 13a. mit messin $=/$ geren Linealen mit Dioptern und Gewinde. ${ }^{1228}$

L. 24. ib. Ein Futteral von rothem Leder, worin a) ein $b e=/$ sonderer Zirkel mit einer großen krumm / gebogenen Schraube, b) eine Reißfeder, / c) ein Zirbelfuß zum punctieren, d) ein / Federmesser ${ }^{1229}$, e) eine Copirnadel mit zwo / Spitzen. ${ }^{1230}$

L. 25. ib.

Eine Setzwage von Messing. ${ }^{1231}$

L. 26. ib.

Ein großer Zirkel von Messing, nebst zwey hinein $=/$ passenden Stücken, nh $[=$ nehmlich] einer Reißfeder, und / Fuß zum Bleystift. ${ }^{1232}$

L. 27. ib.

Ein dergl.[eichen] nebst zwey hineinpassenden krum gebog= / ene stählernen Enden. ${ }^{1233}$

L. 28. ib.

Ein dergl.[eichen] zum Abtheilen dienlich. ${ }^{1234}$

(4) Allgemeine geometrische Instrumente

No Catal. $\quad$ Frkt.Verz. [Erklärung des Gegenstandes]

1227 Mayer 1813, S. 195, Inv. Nr. Ge 21; mit dem Hinweis von Mayer in schwarzer Feder „Bleifeder fehlt“.

1228 Mayer 1813, S. 195, Inv. Nr. Ge 22; mit dem Hinweis von Mayer ,(von Joseph Czech)“.

1229 Lichtenberg (B1. 40r): ,(fehlet)“.

1230 Mayer 1813, S. 195, Inv. Nr. Ge 23; mit dem Vermerk der Revision von Weber 1831 in roter Tinte zu den Unternummern a und d ,fehlt“.

1231 Mayer 1813, S. 195, Inv. Nr. Ge 24.

1232 Lichtenberg (B1. 40r): ,(woran die Schraube fehlet L.)“; Mayer 1813, S. 195, Inv. Nr. Ge 25.

1233 Mayer 1813, S. 195, Inv. Nr. Ge 26.

1234 Lichtenberg (B1. 40r.): ,Von Christoph Schisler zu Augsburg 1565 gemacht.“; Mayer 1813, S. 196, Inv. Nr. Ge 27. 
L. 29. 3ter Nachtr. /

p. 13.

L. $30 . \quad$ ib. p. 14 .

L. 31. ib.

L. 32 ib.

L.

L. 33. Cat. p. 171.

$171 b$.
Ein messingenes verguldetes Instrument dessen Benen $=/$ nung und Gebrauch unbekannt. 1235

Ein Instrument ${ }^{1236}$ von Messing, vermuthlich $\mathrm{zu}^{1237}$ Beobach $=$ / tung der Sonnenfinsternisse dienlich, / in einem mit grünen Pergament bezog $=$ / enen Kästgen. ${ }^{1238}$

Ein Instrument von Nußbaumholz mit verschiedenen / messingenen Schrauben dessen Benennung / unbekannt. (Ein Storchschnabel) ${ }^{1239}$

Noch ein dergleichen. ${ }^{1240}$

II, n. 20

Sechs Gefach mit

geometrischen Instrumenten

1. Gefach. ${ }^{1241}$

a. Ein Instrument zum Auf und Abnehmen der Winkel, / von Messing, und einer Scheibe von Ebenholz, / nebst einem Compasse. Vid. Leupoldi Theatr. ge $=$ / ometr. Tab. 43 Fig.I. 1242

b. Eine kleine Nivellir Waage in schwartzen Futeral, von / Chapetot zu Paris

1235 Lichtenberg (B1. 40r): ,(Ritteri Astrolabium L.)“; Mayer 1813, S. 196, Inv. Nr. Ge 28.

1236 Darüber steht in einer anderen Schrift: Astrolabium.

1237 Darüber steht in einer anderen Schrift: Ritteri.

1238 Lichtenberg (B1. 40r): ,(Ist ein Microscop)“; Mayer 1813, S. 210, Gn 17; mit dem Vermerk von Mayer in schwarzer Tinte ,,von Denne in London“.

1239 In einer anderen, spitzeren Schrift, vielleicht dieselbe wie bei Anm.2 „Ritteri“; Lichtenberg (B1. 40v): ,(ein Storchschnabel L.); Mayer 1813, S. 196, Inv. Nr. Ge 29; mit dem Vermerk von Mayer mit Bleistift ,defect“.

1240 Mayer 1813, S. 196, Inv. Nr. Ge 30; mit dem Vermerk von Mayer mit Bleistift „,defect“.

1241 Mayer 1813, S. 197-204, Inv. Nr. Ge 31; mit der Beschreibung von Mayer in schwarzer Tinte „Ein großes geometrisches Besteck, mit vielerley besonderer Instrumenten, in einem braun lackierten Kasten mit 6 Gefachen.“

1242 = Jacob Leupold, Theatrum arithmetico-geometricum. Das ist Schauplatz der Rechen- und Messkunst, darinnen enthalten dieser beiden Wissenschaften nöthige Grundregeln und Handgriffe etc., Leipzig 1727 ( $2^{\circ}$ Bibl. Uff. 257). 
gemacht.

175a.

c. Ein Senkel, von Eisen gedrechselt, in einem hölzern / Futeral. ${ }^{1243}$

$177 \mathrm{a}$.

d. Eine Meßschnur in einer eisernen Kugel, insgemein ein / Pferdemaaß genannt.

ib.

e. Ein messingener Quadrant mit zusammengelegten Lineal / und Dioptern, nebst Senkel zu Stücken und Mör= / sern zu richten.

ib.

f. Ein besonders Messing verguldetes Instrument, in / einem schwarz ledernen Futeral um allerley / Oval Figuren zu ziehen.

179a.

g. Ein Declinir Compaß in einem messingeren Gehäuse, des=

(p. 5) Allgemeine geometrische Instrumente.

No Catal. $\quad$ Frkt.Verz. [Erklärung des Gegenstandes]

L.

34.1246 p. $172 b$. sen Nadel etwas über 2 Zoll lang ist, und / auf dessen Deckel eine horizontal Uhr gesto $=/$ chen. Von Muth ${ }^{1244}$ verfertiget. ${ }^{1245}$

2. Gefach.

a. Ein kleiner messingener Winckelhacken mit 4 / unterschiedenen gestochenen Maasstäben / von Metz in Amsterdam verfertiget.

1243 Mit dem Vermerk der Revision von Weber 1831 in roter Tinte „fehlt“.

1244 Heinrich Ludwig Muth (1673-1754), Kassler Hofmechanicus und Professor der Optik, Zeitgenosse und Briefpartner Uffenbachs, der ihn auch in Kassel besucht. Außerdem besucht Muth einmal die von Uffenbach gegründete Wissenschaftliche Gesellschaft.

1245 Mit dem Vermerk der Revision von Weber 1831 in roter Tinte „fehlt“.

1246 Vor allen Unternummern eine Klammer. 
ib.

ib.

p. 174a.

ib.

ib.

p. $174 b$.

ib.

ib.

p. $175 a$.

p. $175 b$.

ib. b. Eine Reisfeder, deren Hintertheil lang zu einem / Copirstiften angeordnet ist, von eben den $=/$ selben. ${ }^{1247}$

c. Eine dergl.[eichen] deren Gegenend eine Stechnadel abgiebt, / blinde Linien zu reißen, die abgeschraubt / werden kan, und worin eine Copir $\mathrm{Na}=/$ del verborgen ist, von eben demselben.

d. Eine Reißfeder, mit einem langen bassigt gefeilten / Stiel. ${ }^{1248}$

e. Ein dergl.[eichen] an deren andern Seite ein Punctirrädgen / angebracht ist.

f. Ein Punctirrädgen mit einer elfenbeinernen gedrechselt / Handhabe.

g. Ein Federmesser mit einem viereckigten messingen $=/$ nen Hefte. ${ }^{1249}$

h. Ein kleiner Taster Zirkel von Messing, aus London. ${ }^{1250}$

i. -------- noch kleiner, ebenfals aus London. ${ }^{1251}$

k. Ein zusammengelegter messingener Maasstab, von Braun= / schweig. ${ }^{1252}$

1. Zwey messingene Röhrgen, mit Schieber, zu Bleystift / und Röthel.

m. Zwo Reißfedern von Messing, an einem dergleichen / Handgriff, weit und nah zu stellen, um paralel / Lin

1247 Mit dem Vermerk von Mayer mit Bleistift ,,verbraucht“.

1248 Lichtenberg (B1. 41r): ,anderen Ende ein Bley Rohr.“

1249 Mit dem Vermerk von Mayer mit Bleistift ,,verbraucht“.

1250 Mit dem Vermerk von Mayer in schwarzer Tinte „fehlet“.

1251 Lichtenberg (B1. 41r): ,fehlet.“; mit dem Vermerk der Revision von Weber 1831 in roter Tinte in Mayer 1813 ,ist vorhanden“.

1252 Lichtenberg (B1. 41r): (Rheinländischer F).“ 
(p. 6) Allgemeine geometrische Instrumente

No Catal. $\quad$ Frkt.Verz. [Erklärung des Gegenstandes]

Linien zu ziehen, von Dirk Metz zu Amster $=/$ dam. ${ }^{1253}$

p. $175 b$.

n. Ein Transporteur von dünnen Horn, von la Maire / zu Paris. ${ }^{1254}$

p. 176a.

o. Ein großer Transporteur besonderer Art, mit einem Lineal und besondern Gradbogen, zur $\mathrm{Ab}=$ / theilung der Secunden dienlich.

ib.

p. Ein kleiner Transporteur gemeiner Art, von Pierre / Sevin 1255 in Paris.

ib.

q. Ein Winkelhacken von Messing.

ib.

r. Eine kleine Setzwage von Holz, mit Messing beschlagen.

p. $177 \mathrm{~b}$.

s. Ein messingener Artillerie Maasstab.

t. Ein Artillerie Maasstab von gebeitzten Holz, mit Silber / beschlagen.

\section{Gefach.}

L. 35 . p. $171 b$.

a. Ein Oval Zirkel, bestehend in einem kleinen Lineal, / so sich auf einem Creutze mit 2 Schiebern / beweget, von Messing.

p. $172 \mathrm{a}$. b. ----------, bestehend in einem Line $=/ \mathrm{al}$, darüber 2 eingeschliffene Schieber mit / einem Seidenfaden geschoben, und mit 2 dazu $=/$ gehörigen messingenen Reisfedern die Ovale / gezogen werden, von Conr.[ad]

1253 Mit dem Vermerk der Revision von Weber 1831 in roter Tinte in Mayer 1813 ,fehlen“.

1254 Lichtenberg (B1. 41v): „,(beschädiget L.).“; in Mayer 1813 mit dem Vermerk von Mayer selbst mit Bleistift ,verbraucht“.

1255 Pierre Sevin (tätig zwischen 1662 und 1685). 
Metz zu Amsterdam.

ib.

c. Eine besondere Art von Winkel Instrument, so auch zur / Artillerie und Stereometrie dient, ohngefehr / in der

Gestalt eines Proportionalzirkels, / von Conr.[ad] Metz in Amsterdam verfertiget. S. J.F.v.Uffenbach Holl. u. Engl. Reiß Dia= / rium MS IV. To. III. p. $773 .{ }^{1256}$

d. Ein

(7) Allgemeine geometrische Instrumente.

No Catal. Frkt.Verz. [Erklärung des Gegenstandes]

p. $172 \mathrm{a}$.

d. Ein Parallel Lineal von Ebenholz, mit messingenen / Armen, und 4 starken Schrauben das / Werkzeug in einer beliebigen Weite fest / zu stellen Von Dirk Metz in Amsterdam. ${ }^{1257}$

p. $174 \mathrm{~b}$.

e. Ein Proportional Zirkel einen Fuß lang, von Mes $=/$ sing. ${ }^{1258}$

f. Jobst Byrgii ${ }^{1259}$ Proportional Zirkel mit verschobenen / Gewinde. S. Leupold Theatr. geometr. tab.16.1260

1256 S. Cod. Ms. Uffenbach 29/IV, p. 771-774, wo sowohl der Kauf am 27. April 1711 als auch die genaue Beschreibung des Gerätes und eine Bedienungsanleitung geschildert wird (Cod. Ms. Uffenbach 25/III. Außerdem befindet sich im vierten Band des Tagebuches als Nr. CXXXXIII eine Zeichnung des Gerätes von Uffenbachs Hand (Cod. Ms. Uffenbach 25/IV);

in Mayer 1813 mit dem Vermerk von Mayer selbst mit Bleistift ,,verbraucht“.

1257 In Mayer 1813 mit dem Vermerk der Revision von Weber 1831 in roter Tinte ,fehlt“.

1258 In Mayer 1813 mit dem Vermerk der Revision von Weber 1831 in roter Tinte ,fehlt“.

1259 Katalog 1734, p. 174v: „Jobst Burgii“ [= Jobst Bürgi (Burgi, Byrgi, lat. Byrgius) (15521632) Verfertiger von Himmelsgloben und astronomischen Instrumenten, seit 1579 Hofuhrmacher des Landgrafen Wilhelm IV. von Hessen (1532-1592).].

1260 = Jacob Leupold, Theatrum arithmetico-geometricum. Das ist Schauplatz der Rechen- und Messkunst, darinnen enthalten dieser beiden Wissenschaften nöthige Grundregeln und Handgriffe etc., Leipzig 1727 ( $2^{\circ}$ Bibl. Uff. 257). 
p. 166a.

p. $174 \mathrm{~b}$.

p. $176 b$.

ib.

p. $173 b$ /

$174 a$. g. Ein besonderes Proportional Lineal mit Schiebern / von Buchsbaum, und mit Messing beschlagen, / nach des Engländers Gunther ${ }^{1261}$ Erfindung. / S. Edm. Gunther's Works. Lond. 1673. 4‥1262 Ro. Padridge / Descript. of a double Scale. Lond. 1648 $8^{\circ} .{ }^{1263}$ Ley $=/$ bourn's Gunthers line. Lond. 1702.1264 Leupold / Theatr. arith. geom. tab.X. ${ }^{1265}$

h. Ein messingenes Instrument, die Winkel aufzu $=$ / nehmen, das zugleich eine Setzwage abgibt. / S. Leupold Theatr. geom. tab.27. f.1.1266

i. Eine messingene runde Büchse, in der ein pergamen $=/$ tenes Maaß aufgewickelt ist, von allerley / Schuhen und Ellen. ${ }^{1267}$

k. Ein kleines Lineal von Buchsbaum.

1. Ein klein Besteck, in einem viereckigten Futteral mit / roth Leder bezogen, worinn 2 Zirkel mit / Einsätzen, ein Handzirkel 3 Zoll lang, ein / Winkelhacken, der als ein Zirkel dient, und wor $=/$ auf verschiedene

1261 Edmund Gunter (1581-1626).

1262 = The Works of Edmund Gunter containing the description and use of the sector, crossstaff, bow, quadrant and other instruments, with a canon of artificial sines and tangents to a radius of 100.000 parts and the logarithms from an unite to 10.000 etc. The $\mathrm{V}$. edition. Corrected by William Leybourn, London 1673 (nicht in der Bibliothek Uffenbach vorhanden).

1263 Uffenbach besitzt folgende Ausgabe dieses Werks: Seth Partridge, The description and Use of an instrument, called the Double Scale of Proportion by which instrument all questions in Arithmetrick, Geometry ... may be most accurately and speedily performed, without the assistance of either pen or compasses, London 1692 ( $8^{\circ}$ Bibl. Uff. 115).

1264 Nicht in der Bibliothek Uffenbach vorhanden.

1265 = Jacob Leupold, Theatrum arithmetico-geometricum. Das ist Schauplatz der Rechen- und Messkunst, darinnen enthalten dieser beiden Wissenschaften nöthige Grundregeln und Handgriffe etc., Leipzig 1727 ( $2^{\circ}$ Bibl. Uff. 257);

in Mayer 1813 mit dem Vermerk von Mayer selbst mit Bleistift ,verbraucht“.

1266 = Jacob Leupold, Theatrum arithmetico-geometricum. Das ist Schauplatz der Rechen- und Messkunst, darinnen enthalten dieser beiden Wissenschaften nöthige Grundregeln und Handgriffe etc., Leipzig 1727 (2 Bibl. Uff. 257).

1267 Lichtenberg (B1. 42r): ,(fehlet). 
verjüngte Maasstäbe gestochen / sind, ein Transporteur, mit verjüngten / Maasstabe aus England, eine Copiernadel, / ein gar kleines Federmesser, ein Parallel / Lineal von Ebenholz. ${ }^{1268}$

(8) Allgemeine geometrische Instrumente.

No Catal. Frkt.Verz. [Erklärung des Gegenstandes]

L. 36 .

p. $172 b$.

ib.

ib.

p. $172 b$.

p. 173a.

p. 173a.

\section{Gefach.}

a. Ein großer messingener Zirkel, mit einem Fuß / zu Kreiden Spitzen, von Messing

b. Ein doppelter Zirkel zur Theilung, davon die kleine Spi=/ tze den 3ten Theil zeigen, von Messing

c. ------------ davon die kleinen Spitzen den / halben Theil zeigen, von Mess.[ing] 1269

d. Ein einfacher 3. Zoll langer Zirkel in London gemacht ${ }^{1270}$

e. Ein einfacher messingener Zirkel, mit dem Namen: Jac. / Luswerg ${ }^{1271}$ Mutinensis Romae 1674.

f. vier bis 5 Zoll lang, über des $=/$ sen Spitzen ein rundes messingenes Futteral / geschraubt wird, nebst einem stählernen Schlüßel / das Gewinde fest zu schrauben. ${ }^{1272}$

1268 In Mayer 1813 mit dem Vermerk von Mayer selbst mit Bleistift ,defect“.

1269 In Mayer 1813 mit dem Vermerk von Mayer selbst mit Bleistift ,,verbraucht“.

1270 In Mayer 1813 mit dem Vermerk der Revision von Weber 1831 in roter Tinte ,fehlt“.

1271 Giacomo Luswerg aus Modena (1636-1689).

1272 Lichtenberg (B1. 42v): ,(dieser fehlet.)“ 
p. $172 b$.

ib.

p. $173 b$.

p. 173a.

p. $175 \mathrm{a}$.

p. 173a.

ib.

p. $175 a$. g. Ein Zirkel mit ausgebogenen Oberschenkeln, um ihn mit / einer Hand auf und zu zuthun, von Dirk Metz / in Amsterdam. ${ }^{1273}$

h. Ein stählerner Haar Zirkel mit einer Schraube, in / London gemacht. ${ }^{1274}$

i. Ein einfacher Zirkel, von Dirk Metz in Amsterdam nicht / gar 2 Zoll lang, dessen eine Spitze zugleich / eine Reisfeder ist. 1275

k. Ein einfacher Zirkel, einen Zoll lang von Silber. ${ }^{1276}$

1. Ein messingener Zirkel mit 3 Fussen, in London gemacht

m. Ein einfacher holländischer Zirkel, von Messing.

n. --------- dessen eine Spitze auszunehmen / mit 2 Füssen zu Bleystift und Röthel, Reisfeder / Punctirrädgen, und Ausscheide Messer, von Mess.[ing] ${ }^{1277}$

o. Ein messingener Zirkel, in einem runden messingenen $/$ Futte $=$

(9) Allgemeine geometrische Instrumente.

No Catal. Frkt.Verz. [Erklärung des Gegenstandes]
1273 In Mayer 1813 mit dem Vermerk von Mayer selbst in schwarzer Tinte „fehlt“.

1274 In Mayer 1813 mit dem Vermerk von Mayer selbst in schwarzer Tinte „fehlt“.

1275 In Mayer 1813 mit dem Vermerk von Mayer selbst mit Bleistift ,verbraucht“.

1276 Katalog 1734, p. 172v: ,zu Paris von le Mair gemacht“;

in Mayer 1813 mit dem Vermerk von Mayer selbst in schwarzer Tinte ,fehlt“.

1277 In Mayer 1813 mit dem Vermerk der Revision von Weber 1831 in roter Tinte „fehlt“. 
Futteral geschraubt, auf welchen ein Maasstab / gezeichnet, und darinn eine Bleyfeder befind $=/$ lich ist. ${ }^{1278}$

p. $175 b$.

p. Ein messingener Zirkel von Dirk Metz aus Amster $=$ / dam, mit Reisfeder, Punctirrad, und Bley= / stiftfuß.

q. Ein einfacher messingener Zirkel.

p. $174 \mathrm{~b}$.

r. Ein einfacher verguldeter Zirkel, dessen Gewind fest / zu schrauben.

p. $177 b$.

1280

s. Ein messingener Stangen Zirkel mit verschiedenen $S c h u h=/$ maßen. ${ }^{1279}$

t. Eine Radiernadel, mit elfenbeinern Heft ${ }^{1281}$

p. $174 b$.

u. Ein Bürstgen, die Zirkel zu reinigen, an dessen / Handhebe ein kleine messingene Spadel be $=/$ findlich ist. ${ }^{1282}$

L.37.

5.Gefach.

p. 177a.

a. Ein ganzes Scheiben Instrument, mit Dioptern, Lineal, / Bussole ${ }^{1283}$, und dem dazu gehörigen Gewinde, von / Messing, wie ohngefehr bey Leupold Theatr. / geometr. tab.43. ${ }^{1284}$

p. 176a.

b. Ein Astrolabium von einem ganzen Zirkel, mit Schiebern / Dioptern, und Bussole ${ }^{1285}$ nebst Gewinde, wozu der / Fuß, der bey der kleinern Mensula

\footnotetext{
1278 In Mayer 1813 mit dem Vermerk der Revision von Weber 1831 in roter Tinte ,fehlt“.

1279 In Mayer 1813 mit dem Vermerk von Mayer selbst mit Bleistift „,verbraucht“.

1280 Katalog 1734 auf S. 173v. als: „Eine Copier Nadel mit Elfenbeinern / Heffte.“

1281 In Mayer 1813 mit dem Vermerk von Mayer selbst mit Bleistift ,verbraucht“.

1282 Fehlt in der Aufzählung in Mayer 1813.

1283 [= Magnetnadel].

1284 = Jacob Leupold, Theatrum arithmetico-geometricum. Das ist Schauplatz der Rechen- und Messkunst, darinnen enthalten dieser beiden Wissenschaften nöthige Grundregeln und Handgriffe etc., Leipzig 1727 (2 Bibl. Uff. 257).

1285 [= Magnetnadel].
} 
praetor.[iana] $]^{1286} /$ gedacht worden, dienet.

ib.

c. Ein dergleichen von einem halben Zirkel mit Linealen, / Dioptern, und Gewinde, zu eben dem Fuß. ${ }^{1287}$

p. $177 b$.

d. Ein messingener proportional Zirkel, mit aufgeschraub $=/$ ten Dioptern, und einem Gewinde.

p. $171 b$.

e. ------------- mit aufgeschraubten Transporteur, / Dioptern, und der Bussole ${ }^{1288}$, nebst einem Gewind / von Muth verfertiget.

(10) Allgemeine geometrische Instrumente.

No Catal. Frkt.Verz. [Erklärung des Gegenstandes]

p. $175 b$.

f. Ein Schrittzehler auf 10000 Schritte eingetheilt, / von Messing verguldet, und silbernen / Schräubgen, in einem blechernen Futte $=$ / ral, zu Fuß, und Wagen zu gebrauchen. 1289

ib. g. Ein großes messingenes Punctirrad mit einer / hölzernen Handhebe.

L.38. 6.Gefach.

p. $171 \mathrm{~b}$.

a. Zwey hölzerne Dreyecke, vermittelst eines Lineals $\mathrm{pa}=/$ rallel Linien $\mathrm{zu}$ ziehen. ${ }^{1290}$

p. 174a.

b. Ein Parallellineal, 12 Zoll lang von Buchsbaum, / mit messingenen Ärmen.

1286 Lichtenberg (B1. 43r): „No. 8“.

1287 In Mayer 1813 mit dem Vermerk von Mayer selbst mit Bleistift ,,verbraucht“.

1288 [= Magnetnadel].

1289 Mayer 1813, S. 27, Inv. Nr. S 28.

1290 In Mayer 1813 mit dem Vermerk der Revision von Weber 1831 in roter Tinte „eins fehlt“. 
p. $177 \mathrm{a}$.

p. 176a.

p. $174 \mathrm{~b}$.

ib.

p. $175 b$.

p. $176 b$.

ib.

(11) Instrumente zur Mechanik.

No Catal. $\quad$ Frkt.Verz. [Erklärung des Gegenstandes] c. Ein 1-2 Fuß langes Parallellineal von Holz, roth / gebeitzt, auf Messing beschlagen.

d. Ein elfenbeinern Lineal, mit einem hölzernen Anschlag / winckelrechte Linien zu ziehen. ${ }^{1291}$

e. Ein Lineal von Elfenbein, 9 Zoll lang.

f. Ein Lineal von Buchsbaum, 13 Zoll lang. g. ---------- von Ebenholz, 1 1/2 Fuß lang.

h. Der Rheinländische Fuß in 1000 Theilen, auf einem mes $=/$ singenen Lineal, mit allerley verjüngten / Maasstäben, von Muth ${ }^{1292}$ verfertiget.

i. Eine Pergament Rolle, worauf all Schuhe und Ellen $=/$ maaße accurat verzeichnet sind, auf ei= / nem roth lackirten Stöckgen.

k. Ein Instrument krumme Linien abzutragen, oder / Figuren, so auf beyden Seiten gleich seyn / sollen, zu entwerfen, bestehend aus einem / biegsamen Lineal von Fischbein, so ver= / mittelst messinger Schieber nach Belieben / zu stellen ist, von Dirk Metz in Amster / dam. gleiche gilt für die Nummern $38 \mathrm{e}-\mathrm{h}$.

1292 Lichtenberg (B1. 43v): ,zu Franckfurth“. 
nebst

Abrissen

und

Beschreibungen der großen / Wasserkunst zu Herrenhaußen. ${ }^{1293}$

M.40. ib.

Eine Maschine mit 6 Bücherpulten, welche als ein Rad / gedrehet, die Pulte allezeit in horizontalen / Stande erhält.

M.41. ib.

I, n. 121.

M.42 ib.

n. 122.

M.43 ib.

n. 123.

M.44. ib.

M.45 p. 168a.

M.46. ib.

n. 125.

M.47. ib.

n. 126.

M.48

ib.

n. 127.
Ein klein Modell einer Stuben Thüre, so sich zu beyden Seiten / nach Gefallen aufmachen und verschließen läßt.

Ein kleines Nußbaumenes Schränkgen, woran die Thüre / auf gleiche Art eingerichtet ist.

Ein kleines hölzernes Modell von Wagenseils Wasser $=$ / schild, oder Maschine über Wasser zu gehen.

Ein dergl.[eichen] Modell einer horizontalen Windmühle.

I, n. 115. Ein Modell eines Wagens, welcher ohne Pferde fortge $=/$ trieben wird.

Zwey kleine runde Büchsen, wodurch eine Walze geht, den / Nutzen der einen verborgenen Sperrkegel / zu beweisen. ${ }^{1294}$

Ein schwarz lacquirtes Uhrengehäuse, von London, worinn ein jede hineingehengte Uhr einen Wecker $a b=/$ giebt.

Ein Stundenglaß einer Sanduhr, so die Minuten zeigt.

1293 Uffenbach zeigte im Dezember 1729 dieses Modell in der von ihm gegründeten wissenschaftlichen Gesellschaft (Cod.Ms.Uffenbach 13/III, p. 330-339: Zeichnungen von Uffenbach selbst und ausführliche Beschreibung). Er hatte die Wassermaschine des Engländers Benson 1728 auf Vermittlung des Geh. Secretärs Mohr bewundert. Mohr hatte ihm auch das Modell und die Abrisse der Wassermaschine besorgt. Während das große Modell weggeschmissen wurde, befinden sich die sieben Zeichnungen noch im Besitz der SUB Göttingen (Cod. Ms. philos 26d, s.a. weiter oben).

1294 Katalog 1734, p. 167v: „Zwey kleine runde Büchßen, wodurch eine Waltze gehet, um den Nutzen der inwendig verborgenen Sperrkegel zu beweisen.“ 
M.49. ib. $\quad$ n. 114 .

Ein von Blech und Eisen gekünstelter Arm, an dem alle / Finger bewegt, festgestellt, und wieder loß= / gelassen werden können, in Nürnberg vor mehr / als 100 Jahren, von Bümmel $^{1295}$ verfertiget. ${ }^{1296}$

M.50. p. $168 . \quad$ n. $128 . \quad$ Ein Spatzierstock aus London, worinn eine Fischangel verborgen ist.

L.51. ib. $\quad$ n. 130 Abbildung der äußeren und innere Theile eines menschlichen / Ohres aus Elfenbein zu Halle gemacht. 1297

L.52. ib. IV,n. 3. Eine Maschine den Tact in der Musik anzugeben, von der / Erfindung des $\mathrm{Hr}$ Feuillets zu Paris. ${ }^{1298}$

(12) Instrumente zur Mechanik.

No Catal. $\quad$ Frkt.Verz. [Erklärung des Gegenstandes]

M.53 p. 168b. II, n. 6. Ein Bücherpult aus einem Stück Holz gemacht $\mathrm{p}$.

L.54. ib. $\quad$ n. 5. Ein holzerner Blaßbalg, der ohnabläßig fort blä= / set. ${ }^{1299}$

L.55. p. 169a. I, n. 132. Ein ledernes Küssen, so mit Wind gefüllt, und so gut / als ein anderes gebraucht

1295 Vornamen und Lebensdaten unbekannt.

1296 Katalog 1734, p. 167v und 168r: „Ein von Blech und Eisen gekünstelter Arm, an dem alle Finger nach Belieben beweget, festgestellt, und mit einem Druck wieder hergestellt werden, vor diejenigen zu gebrauchen, die durch Zufälle um den rechten Arm gekommen sind, in Nurnberg vor mehr als 100. Jahren, von Bümmel verfertiget.“

1297 Mayer 1813, S. 39, Inv. Nr. S 70.

1298 Uffenbach hatte sich das „Cronometre“ auf seiner Reise durch Frankreich im Jahre 1715/16 gekauft. Eine Zeichnung des Instruments befindet sich in den Aufzeichnungen der wissenschaftlichen Gesellschaft, die Uffenbach in Frankfurt am Main gegründet hatte (Vgl. Cod. Ms. Uffenbach 13/II, p. 250-254 mit Zeichnungen und der Beschreibung);

von Raoul Auger Feuillet (1653/60-1710) gibt es folgendes Buch zu diesem Instrument: Choreographie ou l'art de decrire la danse, Paris 1700 [nicht in der Bibliothek Uffenbach]; Mayer 1813, S. 41, Inv. Nr. S 74.

1299 Mayer 1813, S. 62, Inv. Nr. AE 32; mit dem Vermerk der Revision von Weber 1831 in roter Tinte ,repos. 2“; außerdem ist die Beschreibung durchgestrichen. 
werden kan. ${ }^{1300}$

$\begin{array}{lll}\text { M.56. ib. } & \text { II, n. 7. } & \begin{array}{c}\text { Ein kleines Modell der Dresdenischen } \\ \text { Maschinen Tafel. }\end{array} \\ \text { M.57. ib. } & \text { I, n. 113. } & \text { Ein Gliedermann. }{ }^{1301} \\ \text { M.58 ib. } & \text { II, n. 13. } & \begin{array}{l}\text { Ein kleines Modell eines Theatri, dessen so } \\ \text { genanntes / par terre in weniger Zeit von } \\ \text { der Höhe des / Theatri zu stellen. - nach der } \\ \text { Erfindung / des P. [Sebastien] Truchet }\end{array} \\ & & \text { zu Paris. }\end{array}$

L.59 ib. I, n. 133. Zwey kleine messingene Flaschenzüge, mit dazu ge $=/$ hörigen Seilen. ${ }^{1303}$

L.60. ib. $\quad$ n. 13. Eine Wage mit einer Spiralfeder, in einem eiser= / nen Cylinder. ${ }^{1304}$

M.60b 3.ter Nachtr. /
p. 15, n. 25 .
Ein Modell von einer Wasserkunst

M.60c n. 26

Ein Modell einer Rammelmaschine.

13) Zur Optic und Perspectiv gehörige / Instrumente.

No Catal. Frkt.Verz. [Erklärung des Gegenstandes]

L.61. zweyt.Nachtr

Ein Tubus von 5 Schuhen, durch Dollond ${ }^{1305}$ in London, mit / Polirter Fischhaut überzogen. ${ }^{1306}$

1300 Mayer 1813, S. 72, Inv. Nr. AE 75.

1301 Katalog 1734, p. 168v am Rand: „kommt unten p. 189 noch einmal vor.“; und auf p. 189r: „Ein hölzerner von denen Mahlern genante Gliederman über halbe Menschen Größe zu dem jetzo erwehnten Zeichnen dienlich.“

1302 Sébastien Truchet (1657-1729).

1303 Mayer 1813, S. 30, Inv. Nr. S 37, wobei hier nur von einem Flaschenzug die Rede ist.

1304 Mayer 1813, S. 25, Inv. Nr. S 25; in Weber 1849 II noch vorhanden.

1305 John Dollond (1706-1761), Optiker, erfand eine Verbesserung in der Kombination der Okulargläser bei dioptrischen Fernrohren, außerdem konstruierte er ab 1758 dioptrische Fernrohre, die Bilder ohne störende farbige Ränder lieferte. 1757 verfertigte er aus Flint- 
L.62. Cat. p. 186b. I.n. 2.

L.63. ib. n. 3 .

L.64. p. 186a. n. 4.

L.65. ib. $\quad$ n. 5 .

L.66. ib. $\quad$ n. 10 .

L.67. 3ter Nachtr.

L.68. Cat. p. 186b. I, n. 11 .
Ein englischer Tubus von 8 Schuh, in buntgefärbten / Röhren, und Einfassung in Cocus. ${ }^{1307}$

Ein dergleichen, von gleicher Länge und Gestalt, von / Marshall in London. ${ }^{1308}$

--------- von ohngefehr 14 Schuh, mit grünem Leder bezo $=/$ gen, und schwarz laccirten Einfassungen, 1708 / in Halle gemacht. ${ }^{1309}$ von 12 Schuh mit grünem Leder, zu Frei= / singen gemacht. ${ }^{1310}$ von 9 Fuß. ${ }^{1311}$ über 8 Fuß lang, mit schwarzem Chagrin 1312 / bezogen. ${ }^{1313}$

bezogen, zu / Augsburg gemacht. ${ }^{1314}$

und Crownglas zusammengesetzte Objektive, welche die ungleiche Brechbarkeit der Lichtstrahlen korrigierten und den Namen achromatische erhielten.

1306 Lichtenberg (B1. 44v): „Synd wichtig“ (in roter Kreide, bezieht sich auf Nr.61 und 62); Mayer 1813, S. 133, Inv. Nr. O 139. Das Fernrohr befindet sich heute noch im Besitz des I. Physikalischen Instituts der Georg-August-Universität Göttingen und hat die Inv. Nr. H 101.

1307 Mayer 1813, S. 133, Inv. Nr. O 140; mit dem Vermerk der Revision von Weber 1831 in roter Tinte „repos 1“.

1308 Mayer 1813, S. 133, Inv. Nr. O 141; mit dem Vermerk der Revision von Weber 1831 in roter Tinte „desgl.“ [dies bedeutet ebenfalls Repositum 1].

John Marshall (1663-1725).

1309 Mayer 1813, S. 133, Inv. Nr. O 142; mit dem Vermerk der Revision von Weber 1831 in roter Tinte „desgl.“ [dies bedeutet ebenfalls Repositum 1].

1310 Katalog 1734, p. 185v: ,,in Bayern“; Mayer 1813, S. 133, Inv. Nr. O 143; mit dem Vermerk der Revision von Weber 1831 in roter Tinte ,desgl.“ [ dies bedeutet ebenfalls Repositum 1].

1311 Katalog 1734, p. 185v ist ein anderer Tubus aufgeführt. Es heißt aber am Rand: ,ist mit einem Tubo von 9 Fuß verkauft. S. die Frkt. Not.“; Mayer 1813, S. 133, Inv. Nr. O 144; mit dem Vermerk der Revision von Weber 1831 in roter Tinte „desgl.“ [dies bedeutet ebenfalls Repositum 1].

1312 Chagrin $=$ narbiges Leder.

1313 Lichtenberg (B1. 44v): ,zu Augsburg gemacht.“; Mayer 1813, S. 133, Inv. Nr. O 145; mit dem Vermerk der Revision von Weber 1831 in roter Tinte „desgl.“ [dies bedeutet ebenfalls Repositum 1].

1314 Mayer 1813, S. 133, Inv. Nr. O 146; mit dem Vermerk der Revision von Weber 1831 in roter Tinte „desgl.“ [dies bedeutet ebenfalls Repositum 1]. 
L.69. ib. $\quad$ n. 6 . von 5 Fuß, mit schwarzen Chagrin bezogen, / und hornenen Einfassungen, der 2 Objecti $=$ / ve hat ${ }^{1315}$, in London gemacht. 1316

L.70. ib. $\quad$ n. 8 . von $4 \mathrm{Fu}$, mit französischen Papier be $=/$ zogen, und roth lacquierten Einfassungen. ${ }^{1317}$

71. p. 187a. $\quad$ n. 7. Fischhaut, und Ein= / fassung von Messing, in London gemacht.

L.72. ib. n. 9 . von $4 \mathrm{Fu}$, mit grün Pergament, zu / Freysingen gemacht. 1318

L.73. p. 186a. n. 72 . von $3 \mathrm{Fu}$, in einem Spanischen Rohr, von / Buttieri1319 in Rom, mit einem Micrometro. ${ }^{1320}$

L.74. 3ter Nachtr. von 2 1/2 Fuß, mit rothem Leder bezogen. ${ }^{1321}$

L.75. 2ter Nachtr. von $3 \mathrm{Fu}$, roth laccirt, u.[nd] Einfassung von Horn. ${ }^{1322}$

1315 Katalog 1734, p. 186r: „um ihn auch zu 3. Schuh Länge zu gebrauchen“.

1316 Mayer 1813, S. 133, Inv. Nr. O 147; mit dem Vermerk der Revision von Weber 1831 in roter Tinte „,desgl.“ [ dies bedeutet ebenfalls Repositum 1].

1317 Mayer 1813, S. 134, Inv. Nr. O 148; mit dem Vermerk der Revision von Weber 1831 in roter Tinte „repos 1“.

1318 Katalog 1734, p. 186v: „in Bayern“; Mayer 1813, S. 134, Inv. Nr. O 149; mit dem Vermerk der Revision von Weber 1831 in roter Tinte „,desgl.“ [dies bedeutet ebenfalls Repositum 1].

1319 Carlo Antonio Buttieri (tätig um 1700 in Rom).

1320 Katalog 1734, p. 185v und 186r: „Ein besonderer Tubus von 3 Schuh in einem Spanischen Rohr, von Buttieri in Rom dergestallt verfertiget, daß man im Durchsehen sogleich die Entfernung des Objectes und deßen natürliche Größe bestimmen kan, vermittelst eines darin befindlichen Micrometri, und einer auf der letzten Röhre angebrachten Tabelle, wozu die Beschreibung des Gebrauchs in msct: in 8 gehört so bey obigen optischen Sachen liegt."

Mayer 1813, S. 134, Inv. Nr. O 150.

1321 Mayer 1813, S. 134, Inv. Nr. O 151; mit dem Vermerk der Revision von Weber 1831 in roter Tinte ,repos 1“.

1322 Mayer 1813, S. 134, Inv. Nr. O 152; mit dem Vermerk der Revision von Weber 1831 in roter Tinte „,desgl.“ [dies bedeutet ebenfalls Repositum 1]. 
(14) Zur Optik - gehörige Instrumente.

No Catal. $\quad$ Frkt.Verz. [Erklärung des Gegenstandes]

L.76. p. 187a. I, n. 12. Ein Perspectiv, von 1 1/2 Fuß, mit bunter Fischhaut, und / silberner Einfassung. 1323

77. ${ }^{1324}$ ib. $\quad$ n. 13. von 1 1/2 Fuß, mit schwarzer Fischhaut, und mes $=/$ singener Einfassung, in London gemacht. ${ }^{1325}$

L.78. ib. n. 36 . von $1 \mathrm{Fu} \beta$, in einer beinernen Röhre, darinn / zugleich ein Microscopium, und Polyhedrum ver= / borgen. ${ }^{1326}$

L.79. p. $187 b . \quad$ n. 39 . Röhren. ${ }^{1327}$

L.80. p. 187a. $\quad$ n. 35 . 4 Zoll lang, in schwarz gebeitzten Elfenbein / gefasst, in einem buchsbaumenen Futeral. ${ }^{1328}$

L.81. ib. 37 . 3 Zoll lang, mit schwarzer Fischhaut, und mes $=/$ singener Einfassung, in London gemacht. ${ }^{1329}$

L.82. p. $187 b . \quad$ n. 38 . von 3 Zoll, in einer schwarz gebeizten Elfenbei- / nern Röhre, in Amsterdam von Arend / Borins ${ }^{1330}$ gemacht. 1331 S. Vorblatt: fehlte bei der Übergabe an Lichtenberg.

1325 Katalog 1734, p. 186v: „Tubus“.

1326 Mayer 1813, S. 134, Inv. Nr. O 154; mit dem Vermerk der Revision von Weber 1831 in roter Tinte ,repos 2 “ und der Text ist durchgestrichen.

1327 Mayer 1813, S. 134, Inv. Nr. O 155; mit dem Vermerk der Revision von Weber 1831 in roter Tinte „rep. 2“ und der Text ist durchgestrichen.

1328 Mayer 1813, S. 134, Inv. Nr. O 156.

1329 Mayer 1813, S. 134, Inv. Nr. O 157; mit dem Vermerk der Revision von Weber 1831 in roter Tinte ,rep. 2“ und der Text ist durchgestrichen.

1330 Lebensdaten unbekannt.

1331 Mayer 1813, S. 134, Inv. Nr. O 158; mit dem Vermerk der Revision von Weber 1831 in roter Tinte ,repos. 2“ und der Text ist durchgestrichen.
} 
L.83. ib. $\quad$ n. $40 . \quad \begin{gathered}----- \\ \text { Pappe. } 1332\end{gathered}$
von 3 Zoll, in Röhren von

L.84. ib. $\quad$ n. $41 . \quad$------ $11 / 2$ Zoll lang, in einer silbern bassigt ge $=$ / drechselten Röhre, zu Augsburg gemacht. ${ }^{1333}$

L.85. ib. $\quad$ n. 42 Ein Theatern Perspectiv, mit schwarz verguldeten Leder / bezogen, in einem hölzernen Futteral, zu / Paris gemacht. ${ }^{1334}$

L.86. ib. $\quad$ n. 43 . ------ etwas kürzer, und dicker, in Buchsbaum ge $=/$ faßt, und in Rom von Buttieri gemacht. ${ }^{1335}$

L.87. ib. $\quad$ n. 44. in Cocus gefaßt, in einem bunt gebeizten / Futteral, in Rom von Campani ${ }^{1336}$ gemacht. ${ }^{1337}$

L.88. 2ter Nachtr. Ein vollständiges Microscopium, in einem braunen Kästgen / von indianischem Holz. ${ }^{1338}$

L.89. ib.

Ein vollständiges Universal Microscopium, in einem schwarz / gebeizten Kästgen. ${ }^{1339}$

15) Zur Optik - gehörige Instrumente.

1332 Mayer 1813, S. 134, Inv. Nr. O 159; mit dem Vermerk der Revision von Weber 1831 in roter Tinte ,desgl.“ [bedeutet ebenfalls Repositum 2].

1333 Lichtenberg (B1. 45r): ,(fehlen die Gläser darin L.)“; Mayer 1813, S. 135, Inv. Nr. O 160; mit dem Vermerk der Revision von Weber 1831 in roter Tinte „desgl.“ [bedeutet ebenfalls Repositum 2].

1334 Mayer 1813, S. 135, Inv. Nr. O 161; mit dem Vermerk der Revision von Weber 1831 in roter Tinte „desgl.“ [bedeutet ebenfalls Repositum 2].

1335 Mayer 1813, S. 135, Inv. Nr. O 162; mit dem Vermerk der Revision von Weber 1831 in roter Tinte „desgl.“ [bedeutet ebenfalls Repositum 2].

1336 Giuseppe Campani (1635-1715).

1337 Mayer 1813, S. 135, Inv. Nr. O 163; mit dem Vermerk der Revision von Weber 1831 in roter Tinte „desgl.“ [bedeutet ebenfalls Repositum 2].

1338 Lichtenberg (B1. 45v): ,(davon die eine Linse zerbrochen L.)“; Mayer 1813, S. 131, Inv. Nr. O 132 und von Mayer selbst der Hinweis ,untauglich“; mit dem Vermerk der Revision von Weber 1831 in roter Tinte „,das Kästchen fehlt“.

1339 Lichtenberg (Bl. 45v): ,(fehlet ein Schraube L.)“; Mayer 1813, S. 131, Inv. Nr. O 133; mit dem Vermerk der Revision von Weber 1831 in roter Tinte „repos. 2“ und der Text ist durchgestrichen. 
No Catal. $\quad$ Frkt.Verz. [Erklärung des Gegenstandes]

L.90. p. 182b. I, n. 15. Ein großes Microscopium nach Marshalls Art, mit blau / laccirten Röhren, auf einem schwarzen Kästgen, / worinn das Zugehör, wovon doch die Porte Objecte / nebst anderen Stücken fehlen. ${ }^{1340}$

L.91. ib. $\quad$ n. 52 . Ein kleineres Microscopium compositum, auf 3 messin= / genen Füßen, und einem Tischgen, nach Ceru= / bins Art. ${ }^{1341}$

L.92. p. 183a. n. 20 . Ein roth lackirtes einfaches Microscopium mit allerley / Saamen. ${ }^{1342}$

L.93. p. 183b. n. 22. Ein einfaches Microscopium, in Cocus gefaßt, von Muth / gemacht. ${ }^{1343}$

L.94. ib. $\quad$ n. $47 . \quad$ Ein einfaches kleines Microscopium, auf einem roth lackir $=$ / ten Füßgen, mit einer messingenen Nadel. ${ }^{1344}$

L.95. p. $184 b . \quad$ n. 23 . Ein kleines Microscopium, mit hölzerner Einfassung, und / messingenen Schieber, fürnehmlich um Haar $\mathrm{zu} /$ besehen gemacht. ${ }^{1345}$

1340 Mayer 1813, S. 131, Inv. Nr. O 134; mit dem Vermerk der Revision von Weber 1831 in roter Tinte ,repos. 2“ und der Text ist durchgestrichen.

1341 Mayer 1813, S. 131, Inv. Nr. O 135; mit dem Vermerk der Revision von Weber 1831 in roter Tinte ,repos. 2“ und der Text ist durchgestrichen.

1342 Mayer 1813, S. 129, Inv. Nr. O 122; mit dem Vermerk der Revision von Weber 1831 in roter Tinte ,repos. 2“ und der Text ist durchgestrichen.

1343 Katalog 1734, p. 183r: „Ein einfaches Microscopium in Cocus gefaßt worinne sehr kleine versteinte Spitzen von pinno marino, so in der Schweitz gefunden worden, liegen, von Herrn Muth gemacht.“; Mayer 1813, S. 129, Inv. Nr. O 123.

1344 Mayer 1813, S. 129, Inv. Nr. O 124; mit dem Vermerk der Revision von Weber 1831 in roter Tinte „defect; repos. 2“ und der Text ist durchgestrichen.

1345 Mayer 1813, S. 129, Inv. Nr. O 125; mit dem Vermerk der Revision von Weber 1831 in roter Tinte ,repos. 2“ und der Text ist durchgestrichen. 
L.96. ib. $\quad$ n. 24 .

Ein einfaches Microscopium in Holz gefaßt, in dessen / Handhebe der dazu gehörige Stift verborgen / ist. ${ }^{1346}$

L.97. ib. $\quad$ n. 25. Ein ganz kleines Microscopium in Elfenbein gefasset, / um Samen Körner darin zu besehen. ${ }^{1347}$

L.98. p. 185b. $\quad$ n. $56 . \quad$ Ein schwarz Chagrines viereckigtes Kästgen, mit einem vollständigen / messingenen Microscopio, Gläsern, und allen / Zugehör in London von Scarlet ${ }^{1348}$ gemacht. 1349

L.99. ib. $\quad$ n. 57.

Ein dergl.[eichen] kleineres, von Culpepper ${ }^{1350}$ gemacht, nebst einem / ledernen Köcher, worinn das Glas zur Betrach $=/$ tung des Umlaufs des Geblüts, verwahret ist. ${ }^{1351}$

L.100. ib. $\quad$ n. 54. Ein schmal längliches und roth ledernes Kästgen mit einem / holländischen Microscopio, zu vielerley Gebrauch, / zu Amsterdam von Dietrich Metz verfertiget. ${ }^{1352}$

(16) Zur Optik - gehörige Instrumente.
No Catal.
Frkt.Verz.
[Erklärung des Gegenstandes]

1346 Lichtenberg (B1. 45v): ,(ist zerbrochen L.)“; Mayer 1813, S. 129, Inv. Nr. O 126; mit dem Vermerk der Revision von Weber 1831 in roter Tinte ,repos. 2“ und der Text ist durchgestrichen.

1347 Mayer 1813, S. 129, Inv. Nr. O 127; mit dem Vermerk der Revision von Weber 1831 in roter Tinte ,repos. 2 “ und der Text ist durchgestrichen.

1348 Edward Scarlett (um 1688-1743).

1349 Mayer 1813, S. 132, Inv. Nr. O 136; Weber 1849 I, Inv. Nr. 191.

1350 Katalog 1734, p. 185r.: ,in London“. Edward Culpeper (1670-1737).

1351 Lichtenberg (B1. 46r): „fehlt“ [vor der Beschreibung des Instruments mit Bleistift eingetragen].

Mayer 1813, S. 132, Inv. Nr. O 137; mit dem Vermerk der Revision von Weber 1831 in roter Tinte „defect; rep. 2“ und der Text ist durchgestrichen.

1352 Mayer 1813, S. 132, Inv. Nr. O 138. 

L.101. p. 183b. $\quad$ I, n. 18 Eine Camera obscura erecta, in einem 2 Schuh großen / hölzernen Kästgen. ${ }^{1353}$

L.102. p. $185 b$ n. 16 .

Eine besondere Camera obscura portatilis, die in Rom / von Buttieri gemacht, mit Stangen, messin= / gene Capsul, Spiegel, seidenen gefütterten / Decken, $\mathrm{pp}^{1354}$

M.103 p. 188b. IV,n. 1. Eine vollständige und besondere Camera obscura, in / einer Trag Senfte, mit Zugehör, nach / Gravesande Angabe. ${ }^{1355}$

L.104. p. 189 b. I, n. 50 .

\author{
Eine Camera obscura, zum Abzeichnen \\ naher Objecte, das / in einem viereckigten \\ Behälter, von einer / spanischen Wand \\ gemacht, bewerckstelliget / wird. ${ }^{1356}$
}

1353 Mayer 1813, S. 127, Inv. Nr. O 115; mit dem Vermerk der Revision von Weber 1831 in roter Tinte „rep. 2“ und der Text ist durchgestrichen.

1354 Katalog 1734, p. 185r: ,Eine besondere Camera obscura portatilis, die man im Sacke nachtragen, auf dem Felde als ein großes Gehäuße aufrichten, und alle Gegenden abzeichnen kan, in Rom von Buttieri gemacht, mit Stangen, meßingen Capsul, Spiegel, seidenen gefütterten Decken, und anderem Zugehör.“; Mayer 1813, S. 127, Inv. Nr. O 116; mit dem Vermerk der Revision von Weber 1831 in roter Tinte „defect u. repos. 2“ und der Text ist durchgestrichen.

1355 Katalog 1734, p. 188r und 188v: ,Ein vollständige und besondere Camera obscura in einer Tragsenfte alßo angeordnet, daß man mit dem oben darauf zu sitzenden Thürgen alle Gegenden nach begehrter Größe, und Erhebung des Augen Punckts auf Pappier zeichnen, das lincke rechts verkehren, verkleinern und vergrößern, auch alle ordentlich dargestellte Kupfer oder Gemählde zu Platfonds oder verkürtzete Bilder von oben und unten anzusehen, formiren kan. Nach Gravesande seiner Angabe in dem Anhang von dem traitè de la perspective. 8. a la haye. nebst einigen Verbeßerungen so der Autor in Briefen, welche dabey befindlich deswegen comunicirt weil die Kupfer in besagtem Buche ganz falsch gestochen. Hiernechst ist in dieser Machine noch eine Art von Cameris obscuris von unten auf angebracht, welche die Bilder auf ein matt geschliffenes Glas, das in dem Tischgen verborgen ist werfen, und zu ganz nahen Objectiv als in einen Zimmer dienlicher als die erste ist, nebst allem Zugehör, so in dem inwendigen Stuhle verwahret ist.“ [Gravesandes traité de la perspective $=$ Wilhelm Jacob 's Gravesande, Essai de perspective, La Haye 1711 ( $8^{\circ}$ Bibl. Uff. 180); der darin enthaltene Anhang lautet: Usage de la Chambre Obscure pour le dessin]. Willem Jacob's Gravesande (1688-1742).

1356 Mayer 1813, S. 127, Inv. Nr. O 112; mit dem Vermerk der Revision von Weber 1831 in roter Tinte ,repos. 2“ und der Text ist durchgestrichen. 
L.105. 3ter Nachtr.

L.106. Cat. p. 183a. I, n. 21 .

L.107. p. $183 b$.

n. 85 .

L.108. 3ter Nachtr.
Eine Camera obscura zum Abzeichnen in Gestalt eines / großen Buches in Schweinsleder. ${ }^{1357}$

Ein Modell eines Auges, auseinander zulegen, in einem / runden braunen Gehäuse, von Muth gemacht. 1358

Ein dergl.[eichen] in einem künstlich gedrechselten Futteral / von Cocusnuß, aus Nürnberg. ${ }^{1359}$ p. 15 , n. 23

111. Cat. p. 189b. II, n. 4. 1361

L.109. p. 183b.

I, n. 17.
Das von Joh.[ann] Beyer in Hamburg neu inventirte $\mathrm{Mo}=/$ dell von dem menschlichen Auge in einem / schwarzen Kasten. ${ }^{1360}$

Ein hölzernes Instrument zu der Perspectiv Zeichnung / nach Albrecht Dürers Angabe, in seinen Wer= / ke von der Geometrie, so zugleich als ein ge $=/$ meines Reißbret dienen kan. ${ }^{1362}$

Eine Laterna magica mit messingen Gehäuse in Leyden / von Musschenbroeck gemacht, nebst einem Kästgen / mit gemahlten Gläsern. ${ }^{1363}$

1357 Mayer 1813, S. 127, Inv. Nr. O 113; mit dem Vermerk der Revision von Weber 1831 in roter Tinte „,defect; repos. 2“ und der Text ist durchgestrichen.

1358 Mayer 1813, S. 126, Inv. Nr. O 106.

1359 Mayer 1813, S. 126, Inv. Nr. O 107.

1360 S.a.: Johann Beyer, Beschreibung eines Modells vom menschlichen Auge, Hamburg o.J. (4 Bibl. Uff. 321);

Mayer 1813, S. 126, Inv. Nr. O 108.

Johann Beyer (1673-1751).

1361 Die Zahl 109, die an sich kommen müsste, ist durchgestrichen und 111 darübergesetzt. Außerdem ist vorn vermerkt, daß dieses Gerät bei der Übergabe an Lichtenberg fehlte.

1362 Albrecht Dürer, Underweysung der messung, Nürnberg 1525 (2 Bibl. Uff. 183). Albrecht Dürer (1471-1528).

1363 Lichtenberg (B1. 46r): „defect“ [vor die Beschreibung mit Rötel gesetzt]; Mayer 1813, S. 138, Inv. Nr. O 188; mit dem Randvermerk von Mayer in schwarzer Tinte „Diese drey Zauberlaternen [ $=$ die beiden folgenden Inv.Nrn. ebenfalls Laterae Magicae] sind alle wieder hergestellt worden, sodaß sie nun wieder guten Effect thun.“ 
L.110. ib. $\quad$ n. 51 .

Eine dergl.[eichen] von weissen Blech, mit vielen Bildern. ${ }^{1364}$

(17) Zur Optik - gehörige Instrumente.

No Catal. $\quad$ Frkt.Verz. [Erklärung des Gegenstandes]

L.112. p. 184a. I, n. 70. D. [Christoph] Wren's Maschine zum Perspectivzeichnen, nebst einem / Parallelogrammo. ${ }^{1365}$

L.113. ib. $\quad$ n. 79. Ein Velum mesopticum mit Gestell, eisernen Rahmen zum / Flor und Glas, nebst einem besondern höl= / zernen Pult, die Figuren von dem Glas / auf Pappier zu zeichnen. ${ }^{1366}$

L.114. ib. $\quad$ n. 77. Ein besonderes Parallelogrammum von Ebenholz mit / Messing beschlagen, von Metz in Amsterdam. ${ }^{1367}$

L.115. ib. $\quad$ n. 78 . Ein Parallelogrammum von Messing, nach Scheiners / Angabe. 1368

Pieter van Musschenbroeck (1692-1761).

1364 Lichtenberg (B1. 46r): ,defect“ [vor die Beschreibung mit Rötel gesetzt].

1365 Katalog 1734, p. 183v: „Doct: Wrens Machine zum Perspectiv Abzeichnen wie es in transactionibus angl: ann: 1673 . vol: 8. p. 6079. und in Monconys voyage suite de la $2^{\text {de }}$ partie p: 130. zu finden, nebst einem Parallelogrammo." [Eine Kopie der Beschreibungen mit Zeichnungen, beides von Uffenbachs Hand, befindet sich im vierten Band seiner „Reis Diarii durch Nieder Sachsen, Holl- und Engelland“ (Cod. Ms. Uffenbach 25/IV, p. 447r457v); außerdem besitzt Uffenbach von Balthasar de Monconys, Monconys Beschreibung seiner Reisen, übers. von Christian Juncker, Leipzig 1697 (4 Bibl. Uff. 404); die „transactionibus angl:“ = Philosophical Transactions: giving some Accompt of the present Undertakings, Studies, and Labours of the Ingenious in many considerable parts of the World, herausgegeben in London];

Christopher Wren (1632-1723).

Lichtenberg (B1. 26v): ,(Ist incomplet L)“;

Mayer 1813, S. 128, Inv. Nr. O 117; mit dem Vermerk von Mayer „Ist incomplet“.

1366 Lichtenberg (B1. 46v): „,(dieses fehlet gänzlich, das Instrument ist auch nicht vollständig L.); Mayer 1813, S. 128, Inv. Nr. O 118; mit dem Vermerk der Revision von Weber 1831 in roter Tinte ,repos. 2“ und der Text ist durchgestrichen.

1367 Mayer 1813, S. 128, Inv,Nr. O 119.

1368 Katalog 1734, p. 183v: ,vid: deßelben Pantographice seu ars delineandi fol: paro: oder 4. Romae 1631.“ [= Christoph Scheiner, Pantographice, seu ars delineandi res quaslibet per 
116. p. $187 b . \quad$ n. 71 .

Die Corpora regularia auf 72 Arten, von steifen $\mathrm{Pa}=/$ pier gemacht, $\mathrm{zu}$ perspectivischen und an $=/$ dern Gebrauche dienlich. ${ }^{1369}$

L.117. p. $183 b . \quad$ n. 82 .

Die 24 Römischen Buchstaben von Holz geometrisch ge $=/$ macht, und verguldet, zum Perspectivzeich=/ nen brauchbar. ${ }^{1370}$

M.118 2ter Nachtr.

Ein viereckigtes Brett, mit 144 Quadrathölzern Bretg.[en] / so halb schwarz gefärbet, zur Erfindung al= / lerley Compartimenten von Fußböden, nach / Douat Methode $\mathrm{pp}^{1371}$

L.119. Cat. p. 182. n. 1. Ein großes Brennglaß auf feinem Fuße mit einem / Vitro collectivo. ${ }^{1372}$

L.120. ib. 14 .

Ein concav belegter Spiegel, auf einem roth lackierten / Gestelle. ${ }^{1373}$

L.122. 2ter Nachtr. Ein convexer ${ }^{1375}$ Brennspiegel in schwarz 1374 lackirten Rahme / der auch schwarz foliirt ist. 1376

parallelogrammum lineare seu cavum, mechanicum, mobile ..., Rom 1631 (zweimal vorhanden: $2^{\circ}$ Bibl. Uff. 264 und $4^{\circ}$ Bibl. Uff 730)];

Christoph Scheiner (1573-1650).

Mayer 1813, S. 128, Inv. Nr. O 120; mit dem Vermerk der Revision von Weber 1831 in roter Tinte „repos. 2“ und der Text ist durchgestrichen.

1369 Fehlte bei der Übergabe an Lichtenberg. Zu diesem Zeitpunkt hatte sich Abraham Gotthelf Kästner die Corpora regularia ausgeliehen [S. den Brief vom 16. September 1784 im gleichen Volumen];

vielleicht identisch mit: Mayer 1813, S. 1, Inv. Nr. A.1: „Einige geometrische Körper von Pappe“; mit dem Vermerk der Revision von Weber 1831 in roter Tinte „sind in 3 Kasten 78 Stück“.

1370 Mayer 1813, S. 128, Inv. Nr. O 121.

1371 In Cod. Ms .Bibl. Arch. A 34 C im zweiten Nachtrag (1766), p. 4r: Ein 4 eckendes Bret mit 144 quadrat holzernen Bretgen, so halb schwartz gefärbet, zur Erfindung allerley Compartimenten von Fusböden nach Anleitung des in Paris in $4^{\circ}$ gedruckten Buches: Douat Methode pour faire une infinitè de desseins differens pp 1722 [= Dominique Douat, Sebastien Truchet, Methode pour faire une infinitè de desseins differens avec carreaux mipartius de deux couleurs par une ligne diagonale ..., Paris 1722 ( $4^{\circ}$ Bibl. Uff. 14)].

Dominique Douat (geb. 1681, Sterbedaten unbekannt), Sebastien Truchet (1657-1729).

1372 Mayer 1813, S. 119, Inv. Nr. O 74.

1373 Mayer 1813, S. 111, Inv. Nr. O 27.

1374 Nr.121 wurde vergessen. 
L.123. 3ter Nachtr.

Ein großer Brennspiegel von 22 Zoll, in einer schwarz / gebeitzten Rahme. ${ }^{1377}$

(18) Zur Optik - gehörige Instrumente.

No Catal. Frkt.Verz. [Erklärung des Gegenstandes]

L.124. p. $183 \quad$ I, n. 49 Ein hohler gläßerner Brennspiegel, in einer hölzern / Einfassung, mit einer Handhebe, 8 Zoll im / Diametro. ${ }^{1378}$

L.125. ib. $\quad$ n. $64 . \quad$---------- 6 Zoll im Diam.[etro]. 1379

L.126. ib. $\quad$ n. 46 Ein Brennglaß in Zinn gefaßt, mit einer Hand= / hebe, 8 Zoll im Diam.[etro]. ${ }^{1380}$

L.127. p. $185 . \quad$ n. 29

Ein kleines Brennglaß, 2 Zoll im Diam.[etro] in Elfenbein / gefaßt. ${ }^{1381}$

L.128. p. $189 . \quad$ n. 48 . Ein Brennglaß 4 Zoll im Diam.[etro] mit einer elfenbeinen / Einfassung. ${ }^{1382}$

L.129. 3ter Nachtr.

p. 14, n. 21 .

Ein Brennglaß ohne Einfassung, ohngefehr 8 Zoll im / Durchschnitt. ${ }^{1383}$

L.130. ib., n. 22

Ein dergl.[eichen] kleineres. ${ }^{1384}$

L.131. Cat. p. 183.

I, n. 66.

Ein gläserner viereckigter Vergrößerungsspiegel / 1 Schuh groß, mit schwarzer Rahme. ${ }^{1385}$

\footnotetext{
1375 Darunter in Klammern und anderer Schrift: „concaver“.

1376 Mayer 1813, S. 111, Inv. Nr. O 28.

1377 Mayer 1813, S. 111, Inv. Nr. O 29.

1378 Mayer 1813, S. 111, Inv. Nr. O 30, mit dem Vermerk von Mayer in schwarzer Tinte „untauglich“.

1379 Mayer 1813, S. 112, Inv. Nr. O 31.

1380 Mayer 1813, S. 119, Inv. Nr. O 66.

1381 Lichtenberg (B1. 47r): „fehlt“ (in roter Tinte).

1382 Mayer 1813, S. 119, Inv. Nr. O 67.

1383 Mayer 1813, S. 119, Inv. Nr. O 68.

1384 Mayer 1813, S. 119, Inv. Nr. O 69.

1385 Mayer 1813, S. 112, Inv. Nr. O 32.
} 
L.132. ib.

n. 19.

L.133. p. 184.

n. 69.

L.134. ib.

n. 70 .

L.135. ib.

n. 110.

L.136. p. 182.

n. 62 .

L.137. ib.

n. 63.
Ein schwarzes ovales Futteral mit einem Vergös $=$ / serungs, und gemeinen Spiegel, gegen über. ${ }^{1386}$

Ein runder Vergrösserungs Spiegel, ohne Rahme, / 6 Zoll im Diam.[etro]. ${ }^{1387}$

Eine ovale Dose mit hornen Zarchen, deren Deckel / ein Brennglas, und der Boden ein Plan= / spiegel ist. ${ }^{1388}$

Ein herzenformig Dösgen, deren Zarche von Bein, der / Deckel von rothen Glas, und der Boden ein / Planspiegel ist. ${ }^{1389}$

Ein viereckigter metallener Planspiegel, 1 Schuh groß / mit schwarzer Rahme. ${ }^{1390}$

Ein dergleichen runder metallener hohler, ohne Rahme / 1 Schuh im Diam.[etro]. ${ }^{1391}$

(19) Zur Optik - gehörige Instrumente.

No Catal. $\quad$ Frkt.Verz. [Erklärung des Gegenstandes]

L.138. p. 182. $\quad$ I, n. 48 Ein runder metallener ${ }^{1392}$ Planspiegel, mit einer Handhebe / in Indien gemacht. ${ }^{1393}$

L.139. p. 184 n. 68. Ein ovaler metallener Spiegel, plan geschliffen, ohne / Rahme. ${ }^{1394}$

L.140. p. 183. n. 67. Ein gläserner viereckigter Spiegel, so verzerrte $\mathrm{Ge}=$ / sichter darstellet, in

1386 Mayer 1813, S. 107, Inv. Nr. O 10.

1387 Mayer 1813, S. 112, Inv. Nr. O 33.

1388 Mayer 1813, S. 107, Inv. Nr. O 5.

1389 Mayer 1813, S. 107, Inv. Nr. O 6.

1390 Mayer 1813, S. 107, Inv. Nr. O 7; mit dem Vermerk von Mayer in schwarzer Tinte „untauglich“".

1391 Mayer 1813, S. 112, Inv. Nr. O 34,; Weber 1849 I, Inv. Nr. 211.

1392 Lichtenberg (B1. 47v): „Ein runder kupferner Plan=Spiegel [...]“.

1393 Mayer 1813, S. 107, Inv. Nr. O 8; in Weber 1849 II noch vorhanden.

1394 Mayer 1813, S. 107, Inv. Nr. O 9; in Weber 1849 II noch vorhanden. 
schwarzer Rahme. ${ }^{1395}$

L.141. p. $188 . \quad$ n. 53

Ein cylindrischer metallener Spiegel, mit schwarz gebeitz $=/$ ten Gestelle, nebst 45 großen auf steif $\mathrm{Pa}=/$ pier gemahlten verzerrten Bildern. ${ }^{1396}$

L.142. ib.

n. 59.

L.143. ib.

n. 58.

L.144. ib.

n. 60 .

L.145. ib.

n. 61.

L.146. ib.

n. 80 .

L.147. ib.

n. 81.
Ein metallener Conus Spiegel, nebst 13 auf Pappe / gezogenen und gemahlten Bilder in ihrer / Verzerrung. ${ }^{1397}$

Dreyzehn in die Länge verzerrte Bilder, die sich in / einem gemeinen Planspiegel, oder auf / einen gewißen Augen Punckt, natürlich prae $=/$ sentiren. ${ }^{1398}$

Ein Conus von gelbem Blech, an dessen äußern und innern / Seiten verzerrte Bilder aufgezogen sind, die / sich in besagter Art nathürlich darstellen. 1399

Ein von gelbem Bleche gemachte Pyramide, auf deren / innern und äußern Seiten dergleichen Bil= / der gemacht sind, $\mathrm{zu}$ dem vorigen Gebrauch. ${ }^{1400}$

Jac: Leupolds ${ }^{1401}$ Machina anamorphotica zu cylindrischen / Figuren. ${ }^{1402}$

------- Maschine zu den conischen Bildern. ${ }^{1403}$

1395 Mayer 1813, S. 114, Inv. Nr. O 39, mit dem Vermerk von Mayer in schwarzer Tinte ,(Eigentlich ein cylindrischer Hohlspiegel). Hiezu eine Zeichnung, einen Scherenschleifer vorstellend.“

1396 Katalog 1734, p. 187v: „die sich in gehöriger Gestalt darin darstellen.“; Mayer 1813, S. 114, Inv. Nr. O 40.

1397 Katalog 1734, p. 187v: „,die sich wohl proportionirt darinnen darstellen.“; Mayer 1813, S. 114, Inv. Nr. O 43.

1398 Mayer 1813, S. 125, Inv. Nr. O 102.

1399 Mayer 1813, S. 125, Inv. Nr. O 104.

1400 Mayer 1813, S. 125, Inv. Nr. O 105.

1401 Katalog 1734, p. 188r: ,von Leipzig“.

1402 Mayer 1813, S. 115, Inv. Nr. O 45, ohne den Hinweis von Mayer auf Uffenbach.

1403 Mayer 1813, S. 115, Inv. Nr. O 46, ohne den Hinweis von Mayer auf Uffenbach. 
L.148. ib.

n. 111.

Eine schwarz und gold lackirte Schnupftabacks Rappe, wo $=/$ rauf ein dergleichen in die Länge verzerr $=/$ tes Bild gemahlet ist. 1404

(20) Zur Optik - gehörige Instrumente.

No Catal. Frkt.Verz. [Erklärung des Gegenstandes]

L.149. 2ter Nachtr.

150. 3ter Nachtr.

L.151. Cat. p. 185a. I, n. 30 .

L.152. ib.

n. 31.

L.153. ib.

n. 33 .

L.154. p. 183.

n. 65 .

L.155. p. 184

n. 74 .

L.156. ib.

n. 75 .
Ein Gestell mit einem grosen Concavglaß, zu einem bey / den Mahlern betittelten Verkleinerungs $=/$ spiegel, in einer schwarz lackirten Einfas $=$ / sung, und Gebrauches Einrichtung. ${ }^{1405}$

Ein Verkleinerungs Spiegel, von 6 biß 7 Zoll im Diam.[etro] / in einer schwarz gebeitzten Rahme. ${ }^{1406}$

Eine grüne concave Brille, in Leder gefaßt, zum / Verkleinern vor Mahler. ${ }^{1407}$

Zwey Brillen Futterale von Schildkröte. ${ }^{1408}$

Ein uraltes schwarz ledernes Futteral, mit 2 großen / Lesegläsern, so wegen ihres Alters auf $=$ / gehoben. ${ }^{1409}$

Ein Leseglas auf seinem Gestelle. ${ }^{1410}$

Ein gläsernes Prisma, in einem Futteral. ${ }^{1411}$

Glase. ${ }^{1412}$

\footnotetext{
1404 Mayer 1813, S. 125, Inv. Nr. O 103.

1405 Mayer 1813, S. 120, Inv. Nr. O 82.

1406 Fehlte bei der Übergabe der Instrumente an Lichtenberg.

1407 Mayer 1813, S. 120, Inv. Nr. O 81.

1408 Mayer 1813, S. 119, Inv. Nr. O 70.

1409 Mayer 1813, S. 119, Inv. Nr. O 71.

1410 Mayer 1813, S. 119, Inv. Nr. O 72.

1411 Mayer 1813, S. 121, Inv. Nr. O 84.
} 
L.157. Suppl. n. 112.

L.158. Cat. p. 184 . n. 76. 1414

$\begin{array}{ll}\text { L.159. p. } 185 a . & \text { n. } 27 .\end{array}$

L.160. ib. 1417

L.161. ib.

n. 26.

L.162. ib.

n. 32 .

L.163. ib.

n. 34. langes Prisma, von etwas dunkler

Materie. ${ }^{1413}$

Ein kleines Polyhedrum, mit einer roth lackirten Einfassung. ${ }^{1415}$

Ein großes Polyhedrum, mit viele viereckigten Flächen / 3 Zoll im Diam.[etro] ungefaßt. ${ }^{1416}$

ungefaßt. ${ }^{1418}$

Ein sehr dickes planoconvex Glaß, fast eine halbe $\mathrm{Ku}=$ / gel, 4 Zoll Durchschnitt. ${ }^{1419}$

Ein Objectivglaß zu einem Tubo astronomico von 16 / Fuß Foco, das Hr. v. Uffenbach zu London / bey Marschall gemacht, nebst dem Oculare / das dazu gehört. ${ }^{1420}$

Ein Conus von dichtem Glase, dessen Basis 3 Zoll Diam.[etro] / in Messing gefaßt, um Regenbogen, und Far= / ben $\mathrm{zu}$ demonstriren. ${ }^{1421}$

(21) Zur Optik - gehörige Instrumente.

No Catal. $\quad$ Frkt.Verz. [Erklärung des Gegenstandes]

1412 Katalog 1734, p. 184r: ,in einem Futterale“; Mayer 1813, S. 121, Inv. Nr. O 85.

1413 Mayer 1813, S. 121, Inv. Nr. O 86, ohne den Hinweis von Mayer auf Uffenbach.

1414 Darunter steht: „NB. hat gefehlt.“

1415 Mayer 1813, S. 116, Inv. Nr. O 54.

1416 Mayer 1813, S. 116, Inv. Nr. O 55, mit dem Vermerk von Mayer in schwarzer Tinte „untauglich“.

1417 Darunter steht: „s. auch n.167.“

1418 Katalog 1734, p. 184r: ,etwas größer als das vorige.“; Mayer 1813, S. 117, Inv. Nr. O 56.

1419 Mayer 1813, S. 119, Inv. Nr. O 75; in Weber 1849 II noch vorhanden.

1420 Mayer 1813, S. 120, Inv. Nr. O 78.

1421 Mayer 1813, S. 122, Inv. Nr. O 91, mit dem Vermerk von Mayer in schwarzer Tinte ,(Chrystallglas) untauglich“; in Weber 1849 II noch vorhanden. 
L.164. 3ter Nachtr.

p. $15 . n .31$.

L.165. n. 28a.

L.166. n. 28b.

L.167. Cat. p. 186a. I, n. 55.
Ein besonders geschliffenes dickes Glas von 4 Zoll / im Durchschnitt. ${ }^{1422}$

Eine Lens convexo-convexa von preußischen Bernstein. ${ }^{1423}$

Ein kleines Glas zu einem Microscopio von Hartsoecker / in Duisburg geschliffen. ${ }^{1424}$

Ein Polyhedrum mit viereckigten Flächen, mit einer / Einfassung, als ein Conus von Buchsbaum. ${ }^{1425}$

(22) Instrumente zu der Gnomonik.

No Catal. Frkt.Verz. [Erklärung des Gegenstandes]

L.168. p. 179a. I, n. 83. Ein Declinircompas, in einem viereckigten hölzernen / Kästgen mit Messing beschlagen, dessen / Nadel 3 1/2 Zoll lang ist, aus London. ${ }^{1426}$

L.169. ib. $\quad$ n. 84. Ein Sonnenuhrring, von Messing in einem schwarz / chagrinen Futteral, von Metz in Amster $=/$ dam gemacht. ${ }^{1427}$

1422 In BA A 34 C, Supplement 3: ,deßen Gebrauch unbekandt.“; Mayer 1813, S. 120, Inv. Nr. O 79, mit dem Vermerk von Mayer in schwarzer Tinte „zum Vorrath“.

1423 Mayer 1813, S. 119, Inv. Nr. O 76; in Weber 1849 II noch vorhanden.

1424 Mayer 1813, S. 119, Inv. Nr. O 77, mit dem Vermerk von Mayer in schwarzer Tinte ,zum Vorrath“.

Nicolaas Hartsoecker (1656-1725).

1425 Mayer 1813, S. 116, Inv. Nr. O 53.

1426 Mayer 1813, S. 172, Inv. Nr. M 26.

1427 Katalog 1734, p. 178v: ,vid. Bions mathem: Werck Schul 4. tab: 27. fig: 1. \& 2.“ [= Nicolai Bion, Neu-eröffnete Mathematische Werck=Schule oder Gründliche Anweisung wie die Mathematische Instrumenten nicht allein schicklich und recht zu gebrauchen ..., übersetzt von J.G.D. [= Johann Gabriel Doppelmayer] Nürnberg 1712 (4 Bibl. Uff. 306)]; Mayer 1813, S. 209, Inv. Nr. Gn 1. 
L.170. p. $179 b . \quad$ n. 86 .

Eine Magnetnadel in einem messingenen versilberten / runden Gehäuse, welche nach dem Schatten / eines dabey aufgerichteten Stiftes die Stunden / zeiget, von Muth gemacht. ${ }^{1428}$

L.171. ib. $\quad$ n. 87. Eine hölzerne rothe Capsul in Form einer Sackuhr / darin eine kleine Horizontaluhr und Magnet $=$ / nadel befindlich, von Coulomb ${ }^{1429}$ gemacht. ${ }^{1430}$

L.172. ib. n. 88. Ein Meßing verguldetes Messer, mit dergl.[eichen] Scheide / auf dessen cylindrischer Handhebe eine Sonnen= / uhr ${ }^{1431}$, auf der Scheide aber der berühmtesten / Örter Polhöhen gestochen. ${ }^{1432}$

L.173. ib. $\quad$ n. 89. Eine Sonnenuhrscheibe von Messing, auf Deutschlands / Polhöhen gerichtet, nach der Erfindung Hr. / Holzheues von Ulm. ${ }^{1433}$

L.173. ib. $\quad$ n. 90 Eine universal Sonnenuhr, von eben $[!]$ demselben, wozu / eine auf Messing gestochene Tabelle ge $=$ / höret. ${ }^{1434}$

L.174. ib. $\quad$ n. 91 . von Pappe, von dergleichen Erfindung. ${ }^{1435}$

1428 Mayer 1813, S. 172, Inv. Nr. M 27.

1429 Vielleicht Charles Augustin de Coulomb (1736-1806).

1430 Mayer 1813, S. 172, Inv. Nr. M 28.

1431 Lichtenberg (B1. 49v): ,(worin ein kleines Perspectivo darin das eine Glas fehlet L.)“.

1432 Lichtenberg (B1. 49v): „(ist falsch, das Wechseln der Sonne in ein anderes Zeichen L.)“. Außerdem noch der Zusatz ,von Michael Benner in Augsburg“; Mayer 1813, S. 209, Inv. Nr. Gn 2.

1433 Bei „Holzheu“ handelt es sich um Johannes Conrad Holzheu (Lebensdaten unbekannt); die Vorlage zu der Sonnenuhrscheibe stammt aus: Heliotropium gnomonicum, oder: Neuerfundene und unbetrügliche Universal-Sonnenuhr ..., Inventirt und an das Licht gegeben von Johannes Conrad Holtzheu, Ulm 1720 ( $8^{\circ}$ Bibl. Uff. 290). Uffenbach hatte u.a. einen ausführlichen Schriftverkehr mit Johann Conrad Holzheu über dessen Instrumemt (vgl. Commercium Epistolicum, Bd.I, p. 389-413 (Cod. Ms. Uffenbach 20); Mayer 1813, S. 209, Inv. Nr. Gn 3.

1434 Mayer 1813, S. 209, Inv. Nr. Gn 4. 

L.175. p. 180a.
n. 92 .
Ein großer hölzerner Cylinder mit einer Sonnen $=/$ uhr. ${ }^{1436}$
L.176. in.
n. 93.
Ein dergleichen kleiner. ${ }^{1437}$
L.177. ib.
n. 94.
Ein hölzerner Stern auf einem Postement mit ver= / schiedenen Sonnenuhren. ${ }^{1438}$

(23) Instrumente zur Gnomonik.
No Catal.
Frkt.Verz.
[Erklärung des Gegenstandes]

L.178. p. 180a.

I, n. 95 .

L.179. ib.

n. 96.

L.180. ib.

n. 97.

L.181. p. $180 b$.

n. 98.

\begin{abstract}
Eine viereckigte Capsul von Pappe, worin eine ver= / ticale und horizontale Uhr, nebst dem $\mathrm{Com}=$ / $\mathrm{pa}$ und dazu dienlichen immerwährenden $\mathrm{Ca}=/$ lender befindlich, bey Mich.[ael] Funcken in Erfurt / ausgegeben. ${ }^{1439}$
\end{abstract}

Ein halber Circkel mit Graden, und einem Weißer, nebst / einem Compaß von Holz, die Declinatio $=/$ nes der Wänd zu suchen horizontaliter. ${ }^{1440}$

Ein ganzer Circkel mit einem eisernen Senckel, die / Reclinationes $\mathrm{zu}$ finden verticaliter. ${ }^{1441}$

Ein einzelner Quadrant auf Holz

1435 Katalog 1734, p. 179v: ,zu welchen allen ein besonderer Tractat des Erfinders: Heliotropium gnomonicum 8. Ulm 1720. dienet.“; Mayer 1813, S. 209, Inv. Nr. Gn 5.

1436 Mayer 1813, S. 209, Inv. Nr. Gn 6.

1437 Mayer 1813, S. 209, Inv. Nr. Gn 7.

1438 Mayer 1813, S. 209, Inv. Nr. Gn 8.

1439 Mayer 1813, S. 209, Inv. Nr. Gn 9. Johann Michael Funcke (1678-1749).

1440 Katalog 1734, p. 179v: ,vid: Bions mathemat. Werckschule 4. tab: 24. fig: 1.“ [= Nicolai Bion, Neu-eröffnete Mathematische Werck=Schule oder Gründliche Anweisung wie die Mathematische Instrumenten nicht allein schicklich und recht zu gebrauchen ..., übersetzt von J.G.D. [= Johann Gabriel Doppelmayer] Nürnberg 1712 (4 Bibl. Uff. 306)]; Mayer 1813, S. 210, Inv. Nr. Gn 10.

1441 Mayer 1813, S. 210, Inv. Nr. Gn 11; mit dem Vermerk der Revision von Weber 1831 in roter Tinte „fehlt“. 
gezeichnet. $^{1442}$

L.182. ib.

n. 99.

Hevelii ${ }^{1443}$ kleines Instrument von Holz mit einer / aufgespannten Saiten, die Mittagslinie / zu finden. ${ }^{1444}$

L.183. ib. $\quad$ n. 100 Eine große Setzwage mit dem Senkel. ${ }^{1445}$

L.184. ib. n. 101. Clavii Instrument alle Sonnenuhren practice $\mathrm{zu} /$ verzeichnen, von Holz in ziemlicher Größe. ${ }^{1446}$

L.185. ib. $\quad$ n. 102. ---------- auf etwas veränderte Art im Kleinen, / von Messing und Holz. ${ }^{1447}$

L.186. ib.

n. 103.

Eine große horizontale Probier Uhr, deren Zeiger / ein aufgespannter Faden ist. ${ }^{1448}$

L.187. ib.

n. 104. Eine runde hölzerne Scheibe mit der Polaruhr. ${ }^{1449}$

L.188. p. 181a. n. 105 .

Ein hölzernes mit Papier bezogenes Instrument, / Sonnenuhren [an] alle Wände practice $\mathrm{zu} /$ reißen, und die 12 himmlische Zeichen ein $=/$ zutragen. ${ }^{1450}$

L.189. ib n. 106.

Ein immerwährender Calender von silbernen kleinen / Scheibgen, in einem schwarzen Futteral eines / Cr.[euzer] groß. ${ }^{1451}$

1442 Mayer 1813, S. 210, Inv. Nr. Gn 12.

1443 = Johannes Hewelke (1611-1687).

1444 Mayer 1813, S. 210, Inv. Nr. Gn 13.

1445 Mayer 1813, S. 13, Inv. Nr. A 36.

1446 Katalog 1734, p. 180r: „,vid: Bions mathemat. Werckschule 4 tab: 25. fig: 4. \& 5.“ [= Nicolai Bion, Neu-eröffnete Mathematische Werck=Schule oder Gründliche Anweisung wie die Mathematische Instrumenten nicht allein schicklich und recht zu gebrauchen ..., übersetzt von J.G.D. [= Johann Gabriel Doppelmayer] Nürnberg 1712 (4 Bibl. Uff. 306)]; Mayer 1813, S. 210, Inv. Nr. Gn 14.

1447 Mayer 1813, S. 210, Inv. Nr. Gn 15.

1448 Mayer 1813, S. 210, Inv. Nr. Gn 16.

1449 Katalog 1734, p. 180r: ,,auf einem eisernen Rohr befestiget, welches an die Zeiger derer vertical Uhren zu stecken, um solche practice überall zu machen.“; Lichtenberg (B1. 50r): „(ist nicht im completen Stande L.)“; Mayer 1813, S. 210, Inv. Nr. Gn 18.

1450 Mayer 1813, S. 210, Inv. Nr. Gn 19.

1451 Mayer 1813, S. 210, Inv. Nr. Gn 20. 
L.190. ib.

n. 107

Eine kleine portatile verticale Sonnenuhr, als in einem / Büchelgen. ${ }^{1452}$

(24) Instrumente zu der Gnomonik.

No Catal. $\quad$ Frkt.Verz. [Erklärung des Gegenstandes]

L.191. p. 181a. I, n. 198. Eine universal Sonnenuhr in einer halben Kugel zu / Hamburg von Bayern ${ }^{1453}$ verfertiget, in / einem hölzernen schwarzen Gehäuse. ${ }^{1454}$

L.192. ib. $\quad$ n. 109 Eine kleine messingene Sternenuhr. ${ }^{1455}$

Zur Architectur und Artillerie.

M.192 2ter Nachtr.

Ein Modell von der hölzernen . [!] Interimsbrücke, worunter / 1740 die von Quadersteinen über den / Maynfluß, ohne Hinderung der freyen Uber= / fahrt der schwertsen Lastwagen, von dem / Hrn von Uffenbach erbauet worden.

M.193 3ter Nachtr. Ein großes Modell von einer Papiermühle. p. 15.n. 24 .

L.194. 2ter Nachtr. Ein regelmäßiges verjüngtes Modell von einer halben / Canone $\mathrm{zu} 24$ Pfund $^{1456}$ Eisen, auf der Lavette / mit Protzwagen, und Backzeug. ${ }^{1457}$

1452 Mayer 1813, S. 211, Inv. Nr. Gn 21.

1453 Gemeint ist Johann Beyer (1673-1751).

1454 Mayer 1813, S. 211, Inv. Nr. Gn 22.

1455 Mayer 1813, S. 211, Inv. Nr. Gn 23.

1456 Als Abkürzungszeichen.

1457 Lichtenberg (B1. 51r): „OberL M“ (in roter Kreide, vornan gesetzt; gilt ebenfalls für Nrn.195 und 196); Mayer 1813, S. 102, Inv. Nr. P 58; Weber 1849 I, Inv. Nr. 19. 
L.195. ib. von einer Haubitze auf ihrer /

Lavette. ${ }^{1458}$

L.196. ib. von einem Mörser nach fran= / zösischer Art auf seiner Lavette. ${ }^{1459}$

(25) Einige zu der Naturforschung und Lehre / gehörige Stücke.

No Catal. Frkt.Verz. [Erklärung des Gegenstandes]

L.197. p. 191. I, n. 136. Ein armirter großer Magnetstein, biß 8 Pfund ${ }^{1460}$ ziehend. ${ }^{1461}$

L.198. ib. $\quad$ n. $137 . \quad$ Ein dergleichen armirter, über 2 Pfund ${ }^{1462}$ ziehend. ${ }^{1463}$

L.199. ib. $\quad$ n. 138. Ein sehr kleiner armirter, und in Gold gefaßter Magnetstein, / von ungewöhnlicher Stärke nach seiner Proportion, / an einem kleinen hölzernen Gestelle. ${ }^{1464}$

L.200. 3ter Nachtr. Ein armirter Magnet. ${ }^{1465}$

L.201. ib. Ein artificieller Magnet, nebst einem kleinen messinge $=/$ nen Keßel zum Gewicht. ${ }^{1466}$

L.202. Cat. p. 191. n. 139 Ein Westindischer unarmirter Magnet, der $\mathrm{zu}$ einer Sphäre / geschliffen werden sollen. ${ }^{1467}$

1458 Mayer 1813, S. 102, Inv. Nr. P 59,; Weber 1849 I, Inv. Nr. 18.

1459 Mayer 1813, S. 102, Inv. Nr. P 60; der Hinweis von Mayer auf Uffenbach fehlt; Weber 1849 I, Inv. Nr. 20.

1460 Als Abkürzungszeichen.

1461 Mayer 1813, S. 170, Inv. Nr. M 8,; Weber 1849 I, Inv. Nr. 166.

1462 Als Abkürzungszeichen.

1463 Mayer 1813, S. 170, Inv. Nr. M 9.

1464 Mayer 1813, S. 170, Inv. Nr. M 10; Weber 1849 I, Inv. Nr. 167.

1465 Vielleicht Mayer 1813, S. 170, Inv. Nr. M 14.

1466 Mayer 1813, S. 170, Inv. Nr. M 11, mit dem Vermerk von Mayer in schwarzer Tinte ,untauglich“.

1467 Mayer 1813, S. 169, Inv. Nr. M 1. 
L.203. ib.

L.204. ib.

n. 141.

L.205. p. $192 b$.

n. 145.

L.206. ib.

n. 146.

L.207. 3ter Nachtr.

L.208. Cat. p. 192a. II, n. 10.

I, n. 142.

Ein

dergl.[eichen]

unarmirter

Norwegischer. ${ }^{1468}$

Drey ${ }^{1469}$ kleinere unarmirter, in einer

Schachtel mit Feil= / Spänen. ${ }^{1470}$

Verschiedene hohle eiserne Kugeln, Ringe, und andres / $\mathrm{zu}$ magnetischen Experimenten. ${ }^{1471}$

2 große und 20 kleine ledige Magnet Nadeln zu eben / dergleichen. ${ }^{1472}$

Magnetsand von Musschenbroeck. ${ }^{1473}$

Ein großer See Compaß1474, wie er auf holländ- und englischen / Schiffen bräuchlich ist, in einem viereckigten / Kasten. ${ }^{1475}$

L.209. ib.

1, ก. 142

Ein dito kleinerer in einem runden Gehäuse mit messin= / genen Ringen und Capsul. ${ }^{1476}$

L.210. ib.

II, n. 2.

Eine gläserne Kugel mit einer Magnetnadel, die Inclini= / rung derselben zu erforschen. ${ }^{1477}$

L.211. 3ter Nachtr.

Phosphorische Steine von Bononien. ${ }^{1478}$

1468 Mayer 1813, S. 169, Inv. Nr. M 2.

1469 Darunter steht durchgestrichen: „Zwey.“ Auch in Katalog 1734, p. 191r sind unter dieser Nummer nur zwei Magnete erwähnt.

1470 Mayer 1813, S. 169, Inv. Nr. M 3; Weber 1849 I, Inv. Nr. 3.

1471 Mayer 1813, S. 169, Inv. Nr. M 5.

1472 Mayer 1813, S. 169, Inv. Nr. M 6.

1473 Mayer 1813, S. 170, Inv. Nr. M 7, kein Hinweis von Mayer auf Uffenbach.

1474 Lichtenberg (B1. 51v): ,(Peil Compas. S)“.

1475 Mayer 1813, S. 173, Inv. Nr. M 32; mit dem Vermerk der Revision von Weber 1831 in roter Tinte „repos. 2“ und der Text ist durchgestrichen.

1476 Mayer 1813, S. 173, Inv. Nr. M 33; Weber 1849 I, Inv. Nr. 162.

1477 Mayer 1813, S. 173, Inv. Nr. M 29.

1478 Mayer 1813, S. 106, Inv. Nr. O 1: „Zwey bononische Steine, oder Luftmagnete, noch nicht calcinirt.“ 
(26) Einige zu der Naturforschung und Lehre / gehörige Stücke.

No Catal. Frkt.Verz. [Erklärung des Gegenstandes]

L.212. p. 191. II, n. 22. Eine Windbüchse zu Breslau verfertiget, Die Wind= / pumpe fehlet. ${ }^{1479}$

L.213. 3ter Nachtr.
p. $14 . n .19$
Ein Sprachrohr von weißem Blech. ${ }^{1480}$

L.214. ib.

$$
\text { p. } 15 . \text {.n. } 20
$$

Ein ${ }^{1481}$ Hörrohr von Messing. ${ }^{1482}$

L.215. Cat. p. 192a. I, n. 143. Ein kleines hölzernes Modell von dem Coctore papinia $=/$ no. ${ }^{1483}$

$\begin{array}{lll}\text { L.216. p. 192b. } & \text { n. } 144 . \\ \text { L.217. p. 193a. } & \text { n. } 129 .\end{array}$

Drey gläserne Wasserproben. ${ }^{1484}$

Ein Spazierstock, worin ein Barometer verborgen wer $=/$ den kan, die Höhe der Berge zu messen / nach Scheuchzers Angabe. ${ }^{1485}$

L.218. ib. II, n. 12. Ein Modell des Copernicanischen Systematis, inwendig mit / Räderwerck so versehen, daß es zugleich ei= / nen Calender abgeben, und alle Darstel $=$ / lungen der Erdbewegungen zeigen kan / nach M.[agister] Seilers zu Leipzig

1479 Mayer 1813, S. 61, Inv. Nr. AE 22: „Ein Windbüchse zu Breslau gemacht. mit doppeltem Lauf, die Pumpe ist im Kolben versteckt.“; Weber 1849 I, Inv. Nr. 9.

1480 Mayer 1813, S. 41, Inv. Nr. S 75; mit dem Vermerk von Mayer in schwarzer Tinte ,wie ein Ammonshorn“" und dem Zusatz abn der Seite ,ist grün gestrichen worden“.

1481 Lichtenberg (B1. 52r): ,(Parabolisches)“.

1482 Mayer 1813, S. 41, Inv. Nr. S 77.

1483 Katalog 1734, p. 191v: „,oder Topfe die Beine weich zu kochen.“; Mayer 1813, S. 99, Inv. Nr. P 45; mit dem Vermerk der Revision von Weber 1831 in roter Tinte ,defect“.

1484 Lichtenberg (B1. 52r): ,(eine ist zerbrochen L.)“; in Mayer 1813 nicht auffindbar.

1485 Katalog 1734, p. 192v: „von Zürch.“ Mit dem Schweizer Arzt, Naturforscher und Historiker Johann Jacob Scheuchzer (1672-1733) hatte Uffenbach persönlichen Kontakt auf seiner Reise durch die Schweiz 1714 aufgenommen.

Mayer 1813, S. 68, Inv. Nr. AE 60; mit dem Vermerk der Revision von Weber 1831 in roter Tinte ,zerbrochen“ und der Text ist durchgestrichen. 
Erfindung. ${ }^{1486}$

219. 3ter Nachtr.

1487

p. 13.n. 1 .

L.220. Cat. p. 193a. I, n. 105.

L.221. p. $193 b$.

I, n. 105.
Ein paar Globi von Doppelmayer in Nürnberg. ${ }^{1488}$

Zwey kleine Globi, 4 Zoll im Diam.[etro] von Coronelli in Vene $=/$ dig gemacht. ${ }^{1489}$

Zwey dergl.[eichen] in einem Futteral, daran das inwendige / Theil des letztern den Himmelsglobum abbil $=$ / det, in dem Erdglobo aber eine Sphaera ar= / milliaris steckt, nebst einem kleinen messingen / Systemate copernicano, in erwehntes Futteral / zu stecken. ${ }^{1490}$

1486 Mayer 1813, S. 213, Inv. Nr. Astr. 1.

Magister Seiler, Erklärung und Gebrauch des Copernicanischen Systematis, o.o., o.J. ( $8^{\circ}$ Cod. Ms. Uffenbach 44).

1487 Darüber in anderer Schrift: ,,auf der Bibliothek“.

1488 Lichtenberg (B1. 52r): ,auf der Bibliothek; bey Uffenbach's Bibliothek.“ (in roter Tinte, der Eintrag, um was es sich für ein Gerät handelt fehlt).

Außerdem besitzt Uffenbach mehrere Bücher von Johann Gabriel Doppelmayer wie z.B.: Atlas coelestis, in quo mundus spectabilis ..., Nürnberg 1742 (Gr. ${ }^{\circ}$ Bibl. Uff. 472); Neue und gründliche Anweisung, wie nach einer Methode Grosse Sonnen-Uhren auf jeden ebenen Flächen ... richtig zu verzeichnen, in vier Teilen dargelegt, Nürnberg 1719 ( $2^{\circ}$ Bibl. Uff. 90); Ausführliche Erklärung über zwey neue Homännische Charten als über das Systema Solare et Planetarium Copernico-Hugenianum, Nürnberg 1707 (4 Bibl. Uff. 109 und 263).

In dem ersten Band des „Commercium Epistolicum“ Uffenbachs befindet sich ein Brief Doppelmayers, ohne Ort und Datum, mit dem Verzeichnis seiner bis 1720 edierten Werke und einer genauen Beschreibung des eisernen Waagbalkens (arithmetische Waage) nach der Erfindung von Giovanni Domenico Cassini [s.o. und Cod. Ms. Uffenbach 20/I].

Die SUB Göttingen besitzt zwei Globen Doppelmayers aus dem Jahre 1728. Bei dem einem handelt es sich um einen GLOBUS TERRESTRIS bei dem anderen um einen GLOBUS COELESTIS NOVUS. Die SUB hat diese beiden Globen 1986 von Geographischen Institut der Universität übernommen. Es könnte sich um die beiden Globen aus Uffenbachs Besitz handeln.]

1489 Uffenbach besitzt u.a. folgendes Buch von Vincenzo Coronelli (1650-1718): Epitome cosmografica, o compendiosa introduttione all' astronomia, geografia, \& idrografia per l'uso, dilucidatione, e fabbrica delle sfere, globi, planisferj, astrolabj, e tavole geografiche, Colonia 1693 ( $8^{\circ}$ Bibl. Uff. 302);

Mayer 1813, S. 213, Inv. Nr. Astr. 2.

1490 Lichtenberg (B1. 52v): ,(letztes ist nicht vorhanden L.)“; Mayer 1813, S. 213, Inv. Nr. Astr. 3. 
(27) Einige zu der Naturforschung und Lehre / gehörige Stücke.

No Catal. Frkt.Verz. [Erklärung des Gegenstandes]

222. p. 193b. III

1491

III. Eine Sphaera armilliaris, 1 1/2 Schuh im

L.223. ib.

I, n. 154. Zween stumpfe Coni von Pappe, worinn die Himmels $=/$ Kugel abgebildet ist, nach Harprechts / Angabe. ${ }^{1492}$

L.224. p. 192b. I, n. 147. Einige geschliffene und rohe Kieselsteine aus dem Rhein. ${ }^{1493}$

L.225. ib. $\quad$ n. 148 Verschiedene Satyrici aquatici von Glas, nebst dem Deckel / von Terra Sigillata zu der Flasche. ${ }^{1494}$

L.226. p. 193a. n. 149. Der Fuß eines Stengelglases, den ein Schottländischer / Edelmann, Cherbourn, entzweygesungen. ${ }^{1495}$

227. 3ter Nachtr.

p. $15 . n .28 \mathrm{c}$.

Rothes Glas von den alten München auf der Bibliothek zu / Cambridge. ${ }^{1496}$

228. ib.n. 28d.

Blaues Glas von eben denselben. ${ }^{1497}$

1491 Darüber in anderer Schrift: ,,auf der Bibliothek“; Lichtenberg (B1. 52v): ,auf der Bibliothek; bey Uffenbach's Bibliothek." (in roter Tinte; der Eintrag, um was es sich für ein Gerät handelt, fehlt).

1492 Mayer 1813, S. 213, Inv. Nr. Astr. 4.

Vornamen und Lebensdaten von Harprecht unbekannt.

1493 Mayer 1813, S. 106, Inv. Nr. O 3.

1494 In Mayer 1813 nicht auffindbar.

1495 Katalog 1734, p. 191v: „Der Fuß eines abgebrochenen starcken Kehlglaßes aus London den ein Schottländischer Edelman Nahmens Cherbourn nebst etl: dergleichen in meiner Gegenwart entzwey gesungen wie mein Holl und Engelländisch Reiß Diarium msct: tom. 2. p: 2700: mit mehrern besagt, und wie von dieser Mögligkeit des Morhofs tract: de Scyphovitreo personum fracto nachzuschlagen." [= Daniel Georg Morhoff, Stentor, seu de scypho vitrio personum fracto, Kiloni 1682 (4 Bibl. Uff. 389)],

Mayer 1813, S. 41, Inv. Nr. S 79; mit dem Vermerk der Revision von Weber 1831 in roter Tinte ,repos. 2“ und der Text ist durchgestrichen.

1496 S.o., hat bei der Übergabe an Lichtenberg gefehlt.

1497 S.o., hat bei der Übergabe an Lichtenberg gefehlt. 
229. ib.n. 28e.

Glas aus der Kirche zu Gouda. ${ }^{1498}$

1498 S.o., hat bei der Übergabe an Lichtenberg gefehlt. 


\subsection{Das eigenhändige Inventar der Druckgraphik}

\section{$\underline{\text { Kunstsammlung der Georg - August - Universität Göttingen, }}$}

Ca. 22,5 X 18,0 cm, Feder mit brauner Tinte, zwei verschiedene Hände, Heftbindung in braunem Pappeinband insgesamt 109 beschriebene Blätter (vorne drei, hinten ein unbeschriebenes Blatt), jedes Blatt in der Mitte geknickt (zur Bindung hin die Künstlernamen, außen die Anzahl der Blätter), mit starken Gebrauchsspuren.

Es handelt sich hier um das Inventar der Graphik und auch der Künstlerbildnisse aus der Sammlung von Johann Friedrich von Uffenbach. Das Inventar ist aufgeteilt nach Künstlernamen, alphabetisch sortiert, und die Anzahl der Werke eines jeden Künstlers. Es ist zu beobachten, daß Uffenbach mit dem Inventar intensiv gearbeitet hat. Immer wenn ein Werk oder mehrere zur Sammlung dazu kamen, hat er die Anzahl verbessert, indem er entweder über die alte Zahl darüber schrieb oder die Zahl durchgestrichen hat und die neue daneben setzte.

In der Transkription wurden die Verbesserungen und Durchstreichungen des Autors bei der Anzahl der Blätter jedes Künstlers weggelassen. Zusammengeschriebene Großbuchstaben sind als Ligaturen zu denken. Kommazeichen hinter bzw. vor der Anzahl der Blätter und Bildnisse sind im Original Abstände.

\section{$[1 \mathrm{r}]$}

Index Titulorum / sive Artificum / Pictorum vel Caelatorum Iconothecae / insertorum $^{1499}$

\section{Volumen A}

Historia calcographia per exem- / pla libata et in specie Ars / 6 Xylographica constans ico- / nibus 1500

1499 Index der Titel sowohl der Künstler, der Maler wie auch der Kupferstecher, die zu der Bildersammlung gehören.

1500 Geschichte des Kupferstichs und insbesondere des Holzstichs durch Beispiele illustriert [schon im Register von vor 1736 erwähnt, Text s.u. in Anm.]. 
1501 Beispiele der Bildhauerkunst, die allein nur durch Meißel (Messer) gemacht sind [schon im Register von vor 1736 erwähnt, Text s.u. in Anm.].

1502 Beispiele der Bildhauerkunst, die aus einer erzenen Tafel von goldener Farbe herausgekratzt worden sind [Kupfertafeln ?] [schon im Register von vor 1736 erwähnt, Text s.u. in Anm.].

1503 Beispiele, die sich auf die Nacht beziehen [noch nicht im Register von vor 1736].

1504 Abdrücke, die mit verschiedenen schwarzen Farben (atramentum) gemacht sind [schon im Register von vor 1736 erwähnt, Text s.u. in Anm.].

1505 Kupferstiche, die nur aus Punkten bestehen [schon im Register von vor 1736 erwähnt, Text s.u. in Anm.].

1506 Art des Kupferstichs, der mit kleinen Buchstaben Bilder darstellt [schon im Register von vor 1736 erwähnt, Text s.u. in Anm.].

1507 Gehämmerte Sache von Lutma [schon im Register von vor 1736 erwähnt, Text s.u. in Anm., hier wird der Vorname mit "Jani" angegeben].

Janus Lutma d.J. (1624-1685) gilt als Erfinder einer von ihm „Pous mallei“ genannten Punktiemanier.

1508 Beispiele der schwarzen Kupferstichkunst [schon im Register von vor 1736 erwähnt, Text s.u. in Anm.].

1509 Kombination aller Arten der Kupferstichkunst [schon im Register von vor 1736 erwähnt, Text s.u. in Anm.].

1510 Beispiel der Kunst des schwarzen Kupferstichs, das mit verschiedenen Schwarzmitteln gedruckt ist [schon im Register von vor 1736 erwähnt, Text s.u. in Anm.].

1511 Beispiel der Kupferstecherkunst nach der neuen englischen Art, welches Ölbilder vor sich herträgt (Ölbilder als Vorbild hat) [schon im Register von vor 1736 erwähnt, Text s.u. in Anm.]. 
alia species impressi calco / graphici, quae autographum / lapillo

rubro fugitive projectum / mentitur Lutetiae parisorum / eformata ${ }^{1514}$

Icon dura matris, praeparatum / a Ryschio p. coloribus distinctam /

a J. Ladmiral, novo plane mo- / do impressum ${ }^{1515}$

nova species calcographia Lu- / tetiae a Demarteau excogitatae ${ }^{1516}$

[1v, linke Seite]

inventi exemplar1517 / ab I B Jakson anglo / executum p. vene- / tiis 1518

aliud exemplum 1519 / novi impressorii cal- / cographici nullo pe- / nicillo adhibito Lute- / tiae parisiorum a gal- / lo Boucher dicto et / Demarteau factum / et a pictore et / sculptore Mayny / inventa 1520

altorum specimen ${ }^{1521}$ / calcographiae ${ }^{1522}$

1512 Beispiele der gleichen Kunst, die Augsburger Sachen nachmachen [schon im Register von vor 1736 erwähnt, Text s.u. in Anm.].

1513 Chinesischer Stich in Holz gestochen so wie er aussieht [im Register von vor 1736 noch nicht erwähnt].

1514 Andere Abzüge in Kupferstich, welche die schnell in Rötel hingeworfene Handzeichnung vorspiegeln, in Paris gemacht [im Register von vor 1736 noch nicht erwähnt].

1515 Perlmuttbild, hergestellt zum ersten von Ryschius mit verschiedenen Farben, zum zweiten von J. Ladmiral, auf deutliche neue Art eingedrückt [im Register von vor 1736 noch nicht erwähnt].

Ryschius $=$ Frederik Ruysch (1638-1731), niederländischer Anatom und Botaniker.

Jan Ladmiral (1669-1773) war Mitarbeiter von Jakob Christoph Le Blon (1667-1741). Ladmiral half ihm bei seinen Versuchen zum Drei- und Vierfarbendruck.

1516 Neue Art des Kupferstichs von Demarteau in Paris erdacht [im Register von vor 1736 noch nicht erwähnt].

Gilles Demarteau (1722-1776) fertigte und publizierter Stiche in Crayonmanier.

1517 Steht links von chalcographiae genus novum anglicum ...

1518 Ich habe ein Beispiel gefunden, das von dem Engländer I.B. Jakson ausgeführt p. in Venedig [im Register von vor 1736 noch nicht erwähnt].

John Baptist Jackson (1701-ca.1780) englischer Holzschneider, der auch clair obscur- und Farbholzschnitte angefertigt hat.

1519 Steht neben ejusmodi artis ....

1520 Ein anderes Exemplar eines neuen Kupferstichabdruckverfahrens, wobei kein Grabstichel (penicillo) angewendet worden ist, zu Paris von dem Franzosen Boucher empfohlen und von Demarteau durchgeführt und von dem Maler und Bildhauer Mayny erfunden [im Register von vor 1736 noch nicht erwähnt].

Francois Boucher (1703-1770), französischer Maler, Zeichner und Kupferstecher

1521 Steht neben mentitur Lutetiae ...

1522 Anderer (Leute) Beispiele der Kupferstichkunst [im Register von vor 1736 noch nicht erwähnt]. 
novum calcogra 1523 / phiae specimen sin- / gulare ${ }^{1524}$

novum specimen 1525 / artis melanocelatoria / halae Saxonum a

$\mathrm{Bau}\left[\mathrm{se}\right.$ ?] factum ${ }^{1526}$

[2r] Ordo Pictorum / et caelatorum voluminis A

Joh. ab Ach

sistens cum

chartas effigie 2

21

Philip. Adler patricius Noric. / falso communiter paticina dictus

Adam AElsheimer, AE vel / AAE

cum

effigie 3

$[2 \mathrm{v}]$

Nicol. ab Aest

antonio dell Agata

Franc. Albanus bonon

Cherubin Albert ABC vel / BA

[3r]

Henr. Aldegrafe, Susatiensis / AG

115 cum

effigie 3

Alesandri vid. Scataglia

J. Aliamet, parisinus

Gerard Altzenbach

Amiconi, venezianus

$[3 v]$

Carl Gustav ab Amling

1523 Steht neben Icon dura matris ...

1524 Einzigartiges neues Beispiel der Kupferstecherkunst [im Register von vor 1736 noch nicht erwähnt].

1525 Steht neben nova species ...

1526 Ein neues Beispiel der Schwarzkunst angefertigt von Bau[se] in Halle zu Sachsen [im Register von vor 1736 noch nicht erwähnt].

Johann Friedrich Bause (1738-1814) Kupferstecher. 
Jost Ammon vel Amman / XA vel I.A. vel AL 9

Andr. Andreanus bologn. / dictus: il piccolo Albert, vel / Albert le 85 petit, AAA, AA, AA

Petrus Aquila Romanus / sacerdos $\quad 2$

$[4 \mathrm{r}]$

Pompejo Aquilano sive dell / Aquila 1

Marius Arconius, romanus 1

N. de l' Armesin 1

$[4 \mathrm{v}]$

Joseph Caesar Arpinas $\quad 2$ cum effig. 2

$\begin{array}{ll}\text { Petr. Aubry } & 7\end{array}$

$\begin{array}{ll}\text { Claudius Audran } & 37\end{array}$

R. Audenard 4

$[5 r]$

I van den Avele $\quad 4$

P Aveline 1

$\begin{array}{ll}\text { Petr. van Avont } & 25\end{array}$

$[5 \mathrm{v}]$ leer

[6r] volumen B

Theodor Badens cognomine / Anshelm, AB $\quad 4 \quad$ cum effigie 1

Franc. von Babylon $\quad 2$

Elias Back $\quad 2$

J. Balechon, parisinus 9

[6v]

Petr. de Baillieu

1 cum effig. 1

$\begin{array}{lll}\text { P. Baltens vulgo Custos } & 1 & \text { cum effig. } 1\end{array}$

Lazarus Baltus 
$[7 \mathrm{r}]$

Baccius Bandinellus

Joh. Franc. Barbari dictus / il Guercin da cento

2 cum effig. 1

Joh. Batista Barbé

$4 \quad$ cum effigie

Domenico Bariera

2

Frid. Barrocius

6

F. Bartolozzi, venetus

$[7 \mathrm{v}]$

Petr. Sanctus Bartolus 3

Joh. Barra 2

H. Bary 3

F. Basan, parisinus $\quad 8$

le Bas, Sculptor parisinus $\quad 15$

[8r]

I. Bassanus

22 cum effig. 1

Francois Basset, gallus $\quad 1$

$\begin{array}{ll}\text { Steph. Baudot } & 2\end{array}$

Joh. Wilh. Bauer

58 cum effig. 1

J. F. Bause, Saxo Halensis / sculptor 10

J Bauvarlet $\quad 5$

Nicolas Bazin $\quad 2$

$[8 v]$

Nic. Beatrix, lotharing. / N.B.L.F. 6

Dominicus Beccafumi / TB 1

Joh. Becket 1

[9r]

Joh. Sebald Beham, Noricus / HSB

195 cum effig. 3

Joachim Franc. Beich 
Bellange, eques

Steph. de la Bella

P. van Bemmel

$[9 v]$

A. Benoist

Bentleen, HB

N. Berchem

[10r]

S. Bernard

Theod. Bernard, amstelod. / T.B.

Petr. Berretinus cordo- / nensis

[11v]

Beringerode

P. van Berge

Horatius Bertelli

[11r]

Michel Betz MB

Nicolo Billy Romanus

Jacob Binck 15IB29

Biscai

Franc. Bonaventura Bisius

[11v]

Blanchard

S. Blesendorf

A. Blockland

[12r]

Abrah. Bloemart

Michel le Blond
10 cum effig. 2

5 cum effig. 1

16

2

1

11

13

1 cum effig. 2.

1

1

1

3

1 cum effigie 1

79 cum effig. 3

24 cum effigie 
A. Blooteling

$[12 \mathrm{v}]$ vol. BO

Franc. van Bockholt 1

Pierre Bodart gallus $\quad 3$

$\begin{array}{ll}\text { Gabriel Bodenehr, august. } & 8\end{array}$

Franc. Böhm 2

Elias du Bois, gallus

[13r]

Renat. Boivin, andega- / vensis, BR 8

$\begin{array}{ll}\text { Robert Boissart } & 12\end{array}$

Hieronymus Bollman 2

$[13 \mathrm{v}]$

Joh. Boll, HB

35 cum effig. 2

Adam Schelde van Bolswert / AB 31

Jul. Bonasone vel Bonazo- / nio. Iul B. vel IBF vel Ba / vel B Bol 22 inv. vel $\mathrm{B}^{1527}$

Louis Bonnet $\quad 9$

$[14 \mathrm{r}]$

Petr. van der Borcht 10 cum effig. 2

Horatius Borganius, $\mathrm{HB}^{1528}$ vel H B. $\quad 8$

Hieronymus Boss $\quad 2 \quad$ cum effig 1

$[14 \mathrm{v}]$

Cornel. Boss vel Buss. vel / Bux CB vel CEB 2

Robert Bossart 11 cum effig. 1

$\begin{array}{ll}\text { Abrah. Bosse, AB } & 25\end{array}$

C. L. du Bose 1

1527 In einem Würfel.

1528 Darunter 1516. 
L. J. Bosse. Sp.

[15r]

I. Boscher 10

Samuel Botschild

$4 \quad$ cum effig. 1

Boucharion NB 2

Boucher, parisinus 4

C. Boul 1

[15v]

Jean Boulenger

Sebast. Bourdon

Gerhard Bouttats

D. Boutemie

[16r]

A. Bouys 1

Joh. Boxberger. B. 1

[16v] vol. BR

Baccus Brandinus 1

$\begin{array}{ll}\text { Joh. Brauwer } & 2\end{array}$

B. Brasser 1

$\begin{array}{ll}\text { Petr. Brebiette } & 7\end{array}$

C. v. Breem 5

Balt. Bremberg 1

F. Brentel 1

Joh. Bricaeio 1

$[17 \mathrm{r}]$

Paul Brill

74 cum effig. 1

$\begin{array}{ll}\text { Brinckmann / pictor palatinus } & 12\end{array}$

$\begin{array}{lll}\text { Crispin van Broek } & 1 & \text { cum effig. } 1\end{array}$ 
Crispin van Broil, CVB

$[17 v]$

Hans Brosamer 1

Adrian Brouwer $\underline{\mathrm{AB}}$

14 cum effig. 2

Carolus le Brun

$[18 \mathrm{r}]$

$\begin{array}{ll}\text { Hans Brunn } & 10\end{array}$

$\begin{array}{ll}\text { Isac et Franciscus Brunn argentiensis } & 9\end{array}$

Franc. Brunner FB vel FB / vel FB 20

Fridericus Brunet 1

Nicol. et Abrah. de Bruyn / DNB. N D B. N B. AVDB / ABD vel 86

A. D. B

$[18 v]$

Theodor de Bry. T.D.B

18

Hans Burkmayer HB / vel H. B. vel 1529

$5 \quad$ cum effig. 1

Mich. Angel. Buonarotus / MA vel M A B

17 cum effig. / pri- /mae

Chartae /

annexae

G. P. Busch berolinensis

1

[19r]

Jacob de Bye

$[19 v]$ volum Ca

Adrian van der Cabel

F. N. de la Cave 1

Paul Caliary. veronens. / P. C. P. 22 cum effig. 1

Jaques Callot, lotharing. 113 cum effig. 4

[20r]

1529 Kurzzeichen, nicht darstellbar. 
Dionysius Calvaert 1

$\begin{array}{ll}\text { Josephus Cameratta } & 2\end{array}$

Marc Antonio Caninius 1

$\begin{array}{ll}\text { Petr. Candidus } & 5\end{array}$

P. C. Canot 1

Simon Cantarinus, pesarensis $\quad 2$

Antonius Capellan 1

[20v]

Hanibal Caracci. A. C. P. / Augustin Caracci Ag. C 31 cum effig. 1

M. Salvator Carmona 2

Guido Carpioni 1

$\begin{array}{lll}\text { Polydorus da Carravaggio } & 27 & \text { cum effig. } 2\end{array}$

Jacobus Carraldus vel Car- / raglio 1

Laurentius Cars 3

$[21 \mathrm{r}]$

Bernh. Castellus, januensis / nvel genovensis / BC. vel B C I, vel 17 CB

Joh. Benedict. Castiglione / genov. GB

23 cum effig. 1

Johannes Cattini venezianus 4

Joh. Battist. de Cavalleriis sen / Domenico Lorenzo 1

[21v] volumen Ce

Joh. Franc Censensis 1

Philip Champaigne $\quad 2$

Nicol. Chaperon. N. C. f. 2

[22r]

Chardin 1

$\begin{array}{ll}\text { Charpentier, parisinus } & 9\end{array}$

Louis de Chastillon 1 
Guilielm. Chateau 3

$\begin{array}{ll}\text { Chedel } & 3\end{array}$

$[22 \mathrm{v}]$

$\begin{array}{ll}\text { F. Chereau } & 7\end{array}$

Elisabeth Cheron $\quad 5$

Chevillet gallus 1

Chinesium Exemplaria ligno / uti apparet incisa 6

Franc. Choveau vel Chauveau / vel Cheaubeau CF 1

Domin. Ciaripellus 1

Fabritius Clarus 1

[23r]

Henr. Cleef vel Clivensis / et Justus Cleef HVC

10 cum effig. 2

$\begin{array}{ll}\text { Sebast. le Clerc } & 138\end{array}$

Jean le Clerc le jeune $\quad 2$

Nicol. Clock 1

$[23 v]$

Petr. Clouwet 1

[24r] vol CO

Herman Cobbert HC 2

$\begin{array}{ll}\text { C. N. Cochin } & 13\end{array}$

Mathias, Petrus, Hieronymus / et Gonzale Cock 18 cum effig. 3

Jacobus Coulemans 1

$\begin{array}{ll}\text { Anton Coget } & 22\end{array}$

$[24 v]$

Richard Colin $\quad 1 \quad$ cum effig. 1

Johannes Collin

$\begin{array}{ll}\text { Adrian Collaert, AC, AC, AC. } & 79\end{array}$

Franc. Collignon 1 
[25r]

AEgidius Coninxloi seu / Coninxlogensis

8 cum effig. 1

Cornelius Cornelius vel Corne- / lisan Harlemensis CC

13 cum effig. 1

Anton Corregio

2 cum effig 1

$[25 v]$

Cornel. Cort C. C. ${ }^{1530}$

20 cum effig. 1

Joh. August Corvinus, augustan.

1

Georg Corvinus 1

Ludovicus Cossimus me- / tensis

Joh. Couvay, JC

[26r]

Nol. Coypel

$3 \quad$ cum effig 1

Lucas Cranach seude Craen / CL, ${ }^{1531}$ L. V. C. 1532

71 cum effig 1

Theodor Cruger

2

Dirk Cuerenhert, VC, DC

9 cum effig. 2

$[26 v]$

J. de la Croix

Dominicus Custos

[27r] leer

$[27 v]$ volum. D.

Augustin Suecus 1

$\begin{array}{ll}\text { C. van Dalen } & 10\end{array}$

Ludovic. Danet 3

Dancker Danckerts 2

1530 Als weitere Signatur ein Haus.

1531 Es folgen die Zeichen der Schlange und des Drachen.

1532 Mit zwei Wappen. 
Pierre Daret

[28r]

Jacob Dassonville

J. Daullè, parisinus

H. David, anglus 5

Demarteau

A. Demarcenay

L. Deplaces 6

Delafosse 1

$\begin{array}{ll}\text { Diacre } & 31\end{array}$

W. E Dieterich 1

$\begin{array}{ll}\text { J. C. Dietsch Norimbergensis } & 17\end{array}$

$[28 v]$

Abrah. Diepenbeck

2 cum effig. 1

L. Dignon 1

Wilh. Dillich, archit. 1

Antonius Dieu, gallus $\quad 4$

[29r]

B. Dolendo 1

Zach. Dolen 1

Dominichin vid. Zampieri

$\begin{array}{ll}\text { N. Dorigny } & 19\end{array}$

$\begin{array}{ll}\text { Abraham Drebber A. B. } & 8\end{array}$

P. Drevet 5

vol. Du

E. Dubois vid. Bois

Duchange, parisinus 
$[29 v]$

Claudius Duchettus 1

$\begin{array}{ll}\text { Claudius Duflos } & 31\end{array}$

Dupin, gallus 1

Stephanus Durocher 5

Nicol. Dupnys 5

[30r]

Albert Durer, AD, $1516^{1533}$ / et quidem hujus imagines aeri in- / cisae

94 cum effig. / patris et filii / 9

quibus annexae in duplo ob rarita- / tem operis 4

Ejusdem buxo vel ligno incisa / inter quas currus triumphalis Imp / 107 cum effig. 1 Maximiliani unius chartae numerum / obtinet

Joh. Dürr 2

Cornelius Dusart 1

$[30 v]$

Anton van Dyck

Daniel van den Dyck

[31r] volumen E

J. J. Ebersbach 2

$\begin{array}{ll}\text { Gerard Edelinck } & 11\end{array}$

$\begin{array}{ll}\text { Egbert } & 1\end{array}$

Egel, Sculpt. palatin 1

$[31 v]$

Gabriel Ehinger

Emanuel Eichel, august. $\quad 2$

Maria Clara Eimartin 1

1533 Im Schild. 
G. C. Eimart

l'Empereur, Echevin de paris

Chr. Engelhard

[32r]

Hans Ersamus EH vel HE / vel H E.

Franc. Erdinger

Ulrich Ermendingert, VE

$[32 v]$

Joh. et Hubert ab Eyck / de Bruggen

[33r] vol. F

J. Faber Londinensis

Raymond la Fage

Faithorne

J. Falck

A. Faldoni

P. C. la Fargue

$[33 v]$

Paul Farines vel Farina / P. F.

Petr. Fehr

A. J. de Fehrt

Meynert Felissen

Cyrus Ferrus

S. Fessard

Fiamingo vid Flamingo

[34r]

Odoardus Filialetti

Filleul parisinus

Petr. Firens 5 
Eduart Fischer, londinensis $\quad 1$

Michael Flamingo 1

J. F. Fleischberger 1

$[34 v]$

$\begin{array}{ll}\text { Paul Flint, norimb. } & 16\end{array}$

Flipard, parisinus 3

P. Floding, suecus $\quad 2$

Franc. Floris, FF. $\quad 36$ cum effig. 2

$[35 \mathrm{r}]$

Joh. Batist. Fontana / I.B.F. $\quad 8$

Forest, gallus 1

$\begin{array}{ll}\text { J. Foucheron } & 4\end{array}$

Fosse vid Delafosse

$\begin{array}{ll}\text { Paul Francischi } & 7\end{array}$

$\begin{array}{ll}\text { J. Foucheron } & 2\end{array}$

Vicentius Franceschini / romanus 1

$[35 \mathrm{v}]$

A. Franck. ${ }^{1534}$

J. F. Franck, FFranck f. $\quad 1 \quad$ cum effig. 3

Battista Francus, venet. / B F V F

Jean Charles Francois Lotha- / ringus 2

Jacob Frey 3

Hieronymus Frezza $\quad 2$

[36r]

Simon Frisius 3

Fritsch, hamburgens $\quad 3$

1534 Als Signatur ein Federmesser. 
[36v]

$\mathrm{Ph}$. Fruitiers

Fruminet

Adam Fuchs, norimber- / gensis

Sebast. Furck, SF, S F

[37r]

Paul Fürst

Petr. Furmius

Joh. Fyt

$[37 \mathrm{v}]$ leer

[38r] vol. G

R. Gaillard

P. Gallays

Jean Battiste Galestruzzi

Ganiere

Philip. Cornelius et Theodor / Galle

134 cum effig. 1

R. Gaywood, angel. / R G.

$[38 v]$

Marcus Geerards

Claude Gellé

1 cum effig. 1

S. T. Gerike

1

Gersaint Mercator / et Cimelipola parisinus

S. Gesner, Tigurinus

[39r]

Jacob de Gheyn DG, DG

37 cum effig. 1

C. G. Geyser

J. Gilbert 
Gillot 2

J Glauber 1

Albert Glockenton 1

Glume, berolensis 4

[39v] volumen Go

$\begin{array}{ll}\text { Petr. Goos } & 26\end{array}$

Jean Goeree, amslod $\quad 40$

Goethe 2

A Goetiers 1

[40r]

$\begin{array}{ll}\text { J. Gole } & 2\end{array}$

Hubert. Henr. Julius, Jacob / et Conrad Goltzius HG, Iul G. 107 cum effig. 5

H. Goudt, nobil. battav. 6

Josias Goupy londinensis $\quad 2$

G. van der Gouwen 2

$[40 v]$

Goyen 3

Joh. Andr. Graf 1

Jacob Grandhomme JG / I. G van Vliet 3

[41r]

Paul Gratianus $\quad 1$

Christoph Greuter 1

Frederic Greuter 2

Joh. Franciscus Grimaldi / bolognes $\quad 5$

$\begin{array}{lr}\text { Simon Grimm, august. } & 8\end{array}$

[41v]

Hans Baldung Grien de / Weyersheim, HBG 18

Joh Grignon 1 
J. Gronsveld 1

Abrah. de Groos

Guarana, venetus 4

$[42 \mathrm{r}]$

Guelard

René Guermeau 2

Raphael Guidi romanus 1

Hans Guldenmund 1

Petr. a Gunst, amstelod 24

[42v] leer

[43r] vol. H

Gabriel Haas, argentin. / G H fecit 6

Johannes Hackaert 1

W. Haecht 1

Pietre et Theodor van Haerlem $\quad 3$ cum effigie

$[43 v]$

de Hagedorn / consil. Polon. 13

$\begin{array}{ll}\text { Joh. Jacob Haid august. } & 37\end{array}$

E. Hainzelmann 16

I. v. Halbeck 1

$\begin{array}{ll}\text { J. Halbou } & 2\end{array}$

[44r]

$\begin{array}{ll}\text { J. Housard } & 1\end{array}$

Catharina Heckelin 1

Leonhard Heckenauer

G de Heer 1 
$[44 v]$

Isac van Heiden, IHV 31

Joseph Heintz

15 cum effig. 2

Elias Heiss

[45r]

Martin. Hemskerk, MH, MMhe, /AH, ME, MHV

156 cum effig. 2

G. Hendriks

1

Joh. Daniel Hertz augustan.

5

$[45 \mathrm{v}]$

Cornelius Hevissen, C1536T ${ }^{1535}$

G. D. Heuman 3

vol. Hi

Petr. Hiis vel Huis, P H 1

[46r]

Laurentius dela Hire $\quad 2$

Nic. et Franc. Hogenberg / monachiens $\quad 14$

Johannes Hogenberg 3

Hans Holbein $\mathrm{HH} \quad 30$ cum effig. 2

$[46 v]$

Wencelaus Hollar W.H. $\quad 145$ cum effig 2

Cornel Holstein 3

Henr, Wilh, et Abrah. Hondi- / us Hn. HH 10 cum effig. 3

$[47 r]$

Roman de Hooghe 19

G. de Hondecouter 2

David, Hieronym. et Lambrecht / Hopfer. DH, DH, IH, / I H, IH, 45 cum effig. 1 LH, L H ${ }^{1536}$

1535 Über "1536" ein "A" mit einem Kreuz. 
Magdalena Horthemels / juct.

$[47 v]$

Wolfgang Huber W. H.

Joh. Henr. Huber Tiguren- / sis 1

J. van Huchtenburg 3

Georg Hufnagel

1 cum effig.

duplici 1

J. Houbraken

8

J. Houvel

[48r]

Frider. Hulsius

[48v] vol. J

I. B Jackson

L. Jacob, parisen

Cornel. Jansen vel Jansin

$8 \quad$ cum effig 1

Christoph Jegher

[49r]

Jean Jenet

Petrus, Gerard et Arnold de / Jode, G I

49 cum effig. 4

Etienne Jeaurat

J. A. Inniger Noricus

[49v]

Clement de Jonghe

Jacob Jordans

$4 \quad$ cum effig. 3

Jean Jouvenet

2 cum effigie 1

[50r]

Petrus Isach

1536 Zwischen den Ligaturen jeweils noch Zeichen, die hier nicht darstellbar sind. 
- Israel -

Petrus Isselburg

$[50 \mathrm{v}]$ volumen K

Matheus Kager, MK, M K

David Kanel

Karolus

Henr. de Keyser

1 cum effig. 1

[51r]

Lucas, Wolfgang et Bartolom. / Kilian, L.K.A, AY, IA, KA, BK 122 cum effig 2

A Khol

Klauber, augustanus

Joh. Jacob Kleinschmidt

$[51 v]$

David Klöcker ab Ehrenstrahl

1 in 3 cum effig. 1

Blätter

S. Knob

AD Kocker

1

I. L. Kraft

1

Joh. Ulrich Kraus

16

G. M. Kraus

1

[52r]

Ludwig Krügelein

Melchior Küsel

Sybilla Küselin filia

$[52 \mathrm{v}]$ leer

[53r] vol. L

Petr. de Laar, vulgo Bam- / bozzo. P D L. fec.

22 cum effig 1

G. Ladame G. L. f. 
D. v. Ladder, DVLadder.

$[53 \mathrm{v}]$

Joh. Ladespeldrik, VLE

F. Ladomin

Anton Laffrei, sequamnus

[54r]

Lairesse vid. Larisse

Georg Lalleman

Stephan van Lamswerde

N. Lancret

[54v]

Joh. Landersel

Joh. Lanfranco

2 cum effig. 1

Nicolas de Largilliere

8 cum effig. 1

$[54 \mathrm{a} \mathrm{r}]^{1537}$

Gerard Larisse

7 cum effig. 1

de Larmessin

8

Michel Lasne, ML

[54a v]

Petrus Lastman

Hans Sebald Lautensack

Conr. Lauwerts

N. le Fevre

[55r]

Lepicie

Thomas de Leu

Johan Leypold

1537 Fehler in der nachträglich erfolgten Zählung. 
$[55 \mathrm{v}]$

P. C. Leigebel 1

D. Lilly, anglus 2

il Conte Pietro Liberi 1

[56r]

Joh. Lis 2

G. Lichtensteger, Noricus $\quad 32$

Joh. Baltasar Lidel 1

Littret 2

[56v]

Joh. Livius vel Livens / I L $\quad 7 \quad$ cum effig. 1

Renatus et Michael Lochem / vel Lochon, RL 1

Loder 1

Baro de Loevenstern $\quad 2$

$[57 \mathrm{r}]$

Loire 6

Pierre Lombart $\quad 1 \quad$ cum effig 3

Claude Lombart 1

Lommelin 1

$\begin{array}{lc}\text { Franciscus Londonio mila- / nese } & 12\end{array}$

Petrus Longhi, venetus $\quad 3$

D. E. Lons 1

Lucas van Leyden, L, L, ${ }^{1538} \quad 90 \quad$ cum effig. 4 $[57 \mathrm{v}]$

Ant. Franc. Luccini 6

Michael Luccensis vel / Lucchese MF, 15MFL51 2

Joh. Georg Lukher 1

1538 Das erste "L" mit Kreis oder Herz, das zeite als Kreuzform. 
[58r]

Lunin 1

H. van Luyk

Johannes Luyken $\quad 2$

$[58 \mathrm{v}]$ vol. M

P. Maes 1

$\begin{array}{ll}\text { Major, battavus } & 12\end{array}$

[59r]

Carolus et Philip. de Mallery $\quad 11$ cum effig. 1

Carl van Mander KM, KM $\quad 28$ cum effig 3

Andr. Mantegna, AMF / aM, AM $\quad 8 \quad$ cum effig. 1

$[59 v]$

Diana, Andreas, Adam / Diana ${ }^{1539}$, AMT, A M, / Georgius Ghisi 18

Mantua vel / Mantovano / GM, GMF, GF, GMF, GGM, / GMAF

Hans Rudolf Manuel HRM / RM, MR. 1

Carolus Marattus $\quad 5 \quad$ cum effig. 1.

[60r]

Georg de Mareès 1

Michael Marieschi venetus 1

J. Mariette 3

$\begin{array}{ll}\text { Marinus } & 2\end{array}$

Vincentius Mariottus 1

Marcenay vid Demarcenay

$[60 v]$

Augustinus Venetianus de Ma- / sis, vel Musis AV, AVI, VA, / 16 AL V, AVPE

1539 Im Schild. 
Masquellier gallus $\quad 1$

Anton Masson $\quad 5$

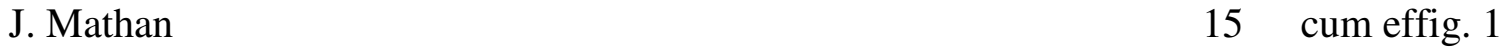

$[61 \mathrm{r}]$

Ludovicus Mathiolus 1

Henricus Mauperchè $\quad 1$

Christoph et Jost Maurer / CM, MC, MC, CM

3 cum effig.

J. Maurer Londinensis 1

W. C. Mayer Cassellanus 2

Ch. de Meckel 2

Israel von Meck, Mechenic, vel / Menz, to bockolt tegens in / 1 westphalia I V M to bockolt

N. v. d. Meer 1

$\begin{array}{ll}\text { Conrad Meier } & 23\end{array}$

[61v]

Claudius Mellan. Mell. 18

Melar 3

Hans Memmeling, HM ${ }^{1540} \quad 3$

$[62 \mathrm{r}]$

Joh. Batt. Mercatus 1

Mathaeus, Caspar et Anna Sybil- / la Merian MM 73 cum effig. 3

Theodor Jonas von Merlen 1

Cornel Metzger, CORMET 1

$[62 v]$

$\begin{array}{ll}\text { N. Metelli } & 4\end{array}$

$\begin{array}{ll}\text { Anton. Franc. van der Meulen } & 8\end{array}$

1540 Darüber ,1542“. 
C. H. van Meurs 1

Dietericus et Conrad et Felix Meyer 5

cum effig. 2

$[63 r]$ vol. Mi

Petr. et Nicol. Mignot DM / DvE 24

Joh. Mirevelt

1 cum effig. 3

Joseph Maria Mitellus / GM

$[63 v]$

Renaldus et Daniel Mytenius / vel Mytens

1 cum effig. 2

Hieronym. Mocetus

le Moine, gallus

2

F. de Moitte gallus

2

Petr. van Mol

P. F. Mola

[64r]

$\begin{array}{ll}\text { I. Molenaer } & 2\end{array}$

Pietro Monaco / venetus 1

$\begin{array}{ll}\text { Moncornet } & 8\end{array}$

Jacob et Barthol Montagna 3

Nic. de la Plate Montaigne 1

Joseph a Montalegre

$[64 \mathrm{v}]$

Paul Morelse PM, PML 1

L. Morin

Gillis et AEgidius Mostaert 44 cum effig. 1.

Johannes Moucheron

$[65 r]$

$\begin{array}{ll}\text { Michael Mozyn } & 7\end{array}$ 
Hieronym Mucianus, ${ }^{1541}$

Herman, Battista, Johan / Mull HML, BM, / et Joh. Petr. Muller 27 PM

$[65 v]$

T. van Munickhuysen 1

Johannes Mussard 1

[66r] vol. N

$\begin{array}{ll}\text { Robert Nanteuil } & 20\end{array}$

J. Galiot Nardois 3

Michael Natalis M. N 2

J M. Nattier 2

$[66 v]$

$\begin{array}{ll}\text { H. Nauwinx } & 16\end{array}$

J. van Neck 1

$\begin{array}{ll}\text { Jacob Nefs } & 2\end{array}$

[67r]

E. Nessenthaler 2

F. van Neyschoot 2

Nicolai 1

$\begin{array}{llll}\text { G. Nieuland } & 7 & \text { cum duplice }\end{array}$ effigie

$\begin{array}{ll}\text { P. E. Nilson } & 35\end{array}$

$\begin{array}{ll}\text { Petr. Nolpe PN, PN } & 12\end{array}$

Elias Nunzer

$[67 v]$ leer

[68r] vol. O

Ochterfeld 1

1541 Als Signatur zwei kämpfende Hähne. 
Joh. Oertel 1

Oeser / acad. lips. pict. director 1

M. Olstreich Sculpt. dresdens $\quad 4$

$\begin{array}{ll}\text { J. Ossenbeek } & 2\end{array}$

F. v. Orley 1

$\begin{array}{ll}\text { A van Ostade } & 22\end{array}$

[68v]

$\begin{array}{ll}\text { Petr. Oueradt } 3 & 3\end{array}$

$\begin{array}{ll}\text { J. Ouvrier } & 1\end{array}$

[69r] vol. P

Joh. Batt. Paggius, florentinus 3

Palamedes Palamedessen $\quad 1 \quad$ cum effig. 1

$\begin{array}{ll}\text { Jacob Palma } & 8\end{array}$

$[69 v]$

Wilh. Paneels 2

F Parmegian dictus Maz- / zuoli 3 cum effig. 1

Bernh. Passarus vel Passarotus / B P, BP 2

[70r]

Crispin. et Magdalena de / Pas vel Passe CPV, CP 68

Gio Battista Pasqualinus $\quad 1$

$\begin{array}{ll}\text { Jean le Pautre } & 21\end{array}$

Joh. Peak, anglus ${ }^{1542}$

$\begin{array}{ll}\text { Georgio Pecini } & 7\end{array}$

Pelletier. parisinus $\quad 3$

Martin Pepyn $\quad 1 \quad$ cum effig. 1

[70v]

Lucas Pennis, roman dictus / Factor LP, L P, LPR $4 \quad$ cum effig. 1

1542 Keine Zahlenangabe von Blättern. 
Georg Penz GP, PG.

Stephan du Perac A P F

[71r]

Camillus Percaccinus vel / Procaccinus

Petrus Perret

Joh. Persellus

Franc. Perrier FP

$[71 v]$

Gabriel, Adam et Nicolaus / Perelle

Petr. Persoy

Perjecouter

[72r]

Pietro Perugino

Baltasar Perutius, Senensis / vel Peruzzi Bal. Sen.

Bonaventura et Johannes Peters

1 cum effig. 1

1 cum effig. 1

Petite, parisinus

2

$[72 v]$

J. A. Pfeffel

P. Piazza a castro franco

Piazetta, venetus

Joh. Piccard

Julius Pipi dictus Romanus

7 cum effig. 1

Piranesi

[73r]

Nicol. Andreas et Johan. Pi- / sanus

N. Pitau

Joh. Marcus Pitteri / venetus

dela Plate vide Montaigne 
F Playe 6

$\begin{array}{ll}\text { Martin Pleyinck } & 7\end{array}$

Pietro del Po 1

Corneille Poelenburg $\quad 3 \quad$ cum effigie 2

$[73 v]$

Nicol. et Franc. Poilly 23

Paul Pontius

9 cum effigie 3

M Pool, amstelod.

[74r]

Anton Pordenone 5

Andrea Potesta 3

Joh. le Potre vid Pautre

Nicol. Poussin

29 cum effig. 1

$[74 v]$

G. M. Preisler, Noricus 12

$\begin{array}{ll}\text { v. Prenner } & 7\end{array}$

Franc. Bolognensis vel dictus / Abbas Primaticcio, vel Francesco / 6 Bolognese, Abbas Sancti Martini / SMB, FB, A P M A, fra bol inv. [75r]

Joh. Baltasar Propst 5

J. Prou 1

Puys vid Dupuys

J. Punt, amstelodamen- / sis 1

Richard Purcill, anglus $\quad 2$

$[75 v]$ leer

[76r] vol Q

Petr. Quast, PQ, PQ 35

Herman Hendric Quater 1 
$[76 \mathrm{v}] \underline{\mathrm{vol} \mathrm{R}}$

Joh. de Ram

Raphael Urbin vid Sancio

Donatus Rascicholi 1

Marcus Ravignanus, de Ra- / venna, R, MR, AMR 1 $[77 \mathrm{r}]$

Marcus Anton. Raymondi / AMFT ${ }^{1543}$, MFB s. 13

$\begin{array}{ll}\text { Frederic Reclam } & 8\end{array}$

Casparus Rem, belga 1

F. Reiffstein Consilia- / rius Reg. Dan. 1

Rembrand van Rhyn / RH van Rhin. 181 cum effig. 3 [77v]

Guido Rheni, eques bonon. / G R B F, BC eques, G R, G R F 8 cum effig. 1 Remigius de Puzzuolo, capucinus 1

Joseph de Ribera dictus Espanolet / ARB, SHP, JR 12

[78r]

Abrah. de Richter et / Christian Richter, CR 8

Joh. Elias Ridinger august. $\quad 8$

Paulus Rietter 1

$\begin{array}{ll}\text { J Rigauld, parisinus } & 20\end{array}$

E B dela Rocque 1

J. H. Rode

Roettiers 1

Hans Rogel HR ${ }^{1544}$

1543 Vor diesem Kürzel ein Bilderrahmen mit Halterung als Zeichen.

1544 Dahinter das Zeichen eines Messers. 
$[78 v]$

Julius Romanus, alias Pipi / vid. Pipi

Theodor Rombouts

Salvator Rosa

70 cum effig. 1

Rosbach, lipsiens

2

Henr. Roos

[79r]

Joh. Rottenhammer 1

Joh. Ludw. Roullet 2

Egidius Rousselet 3

$[79 v]$

Petrus Paul Rubens P. P. R.

101 cum effig. 5

Hieronym. de Rubeis vel Rosso / vel Roux dictus 1

AEgidius Rucholle

[80r]

Princeps Rupertus palatinus / Friderici V Regis Boh. filius, R ${ }^{1545}$ p. 3 AE 1658

Wilhelm Rücker / mogunt. calcograph 1

$\begin{array}{ll}\text { Georg. Philip. Rugendas } & 73\end{array}$

Martin Ruotta vel Rota / sebenzanus, MR dd. 5

[80v]

$\begin{array}{ll}\text { Ruysdale } & 18\end{array}$

$\begin{array}{ll}\text { P. Rysbrak } & 6\end{array}$

$[81 \mathrm{r}] \underline{\mathrm{vol} \mathrm{S}}$

Laurentius Sabadinus 1

Andr. Sacchi, romanus $\quad 1$

Aegidius, Raphael, Justus, Johan- / nes, et Gilles Sadeler / E S., R 209 cum effig. 2

1545 Darüber eine Krone. 
S., IS, ISV, I S.

Hans Saerbrun H. S. ${ }^{1546}$

$[81 \mathrm{v}]$

Herman et Corn. Saftleven / vel Sachtleven 3 cum effig. 2

J. G. Saiter augustanus 1

$\begin{array}{ll}\text { Saintnon gallus } & 9\end{array}$

Ant. Salamanca A S, MAT / ATS. 4

Ventura Salimbeni V S I 2

Salvator 1

Joseph Salviati

[82r]

Horatius Samachius $\quad 2$

vol San.

Raphael Urbin Sancio $\quad 49$ cum effig 2

Joh. Jacob et Joachim von / Sandrart et Susanna Maria / filia 29

[82v]

Joh. Sanredam, SHS, F S 26

Santerre $\quad 8 \quad$ cum effig. 1

Andreas del Sarto, A S $4 \quad$ cum effig. 1

[83r]

Joh. C. Sartorius 2

J Savage 1

Jacob et Ruland Savery $\quad 9 \quad$ cum effig 2

$[83 v]$

Joh. Georg. Sauter 1

[84r] volum SC

1546 Darunter das Zeichen eines Messers. 
Petrus Scalberge 1

J L. Schaerer 1

$\begin{array}{ll}\text { P. Scataglia venetus } & 9\end{array}$

Hans Schauflig, Schuffel, Schuf- / ling, et Scheffelt, HS ${ }^{1547}, 15$ $\mathrm{HS}^{1548}$, H S ${ }^{1549} / \mathrm{HS}^{1550}$

M. Schedel 1

$\begin{array}{lll}\text { Petr. Schenk, amstelod. } & 61 & \text { cum effig } 1\end{array}$

$[84 \mathrm{v}]$

Raphael Schiaminosa / RSA, RA. F 28

A Schiavon cel Sciavon 1

Laurentius Schilling / francofurtensis $\quad 2$

Georg. Frid. Schmidt, argentin. 13

Joh. Smith, Londinensis

Christoph Schmidt 1

F. L. Sehmidtner Schmitner 2

[85r]

Schmutzer vindobonensis 1

Petr. Franc. Michael et Abrah. / Sneyers $\quad 2$ cum effig 2

$\begin{array}{lll}\text { Joh. Henr. Schönfeld } & 5 & \text { cum effig } 1\end{array}$

Martin de Schoen dictus le- / tudesque MCS, M C S 14 cum effig 1

Erard Schörer, ES 1524

$[85 \mathrm{v}]$

Ant. Schonians 1

Petr. van Schuppen 1

$\begin{array}{lll}\text { Cornel Schut } & 8 & \text { cum effig } 1\end{array}$

1547 Darunter das Zeichen eines Grabstichels.

1548 Darüber das Zeichen einer Schere.

1549 Dazwischen das Zeichen einer Schaufel.

1550 Davor das Zeichen eines Grabstichels. 
[86r]

$\begin{array}{ll}\text { Christian Schuvaert } & 1\end{array}$

Wilhelm Schwan bruns- / vicensis 1

L. W. Schwaneburg, Gschw. 1

$\begin{array}{ll}\text { G. Scotin, parisinus } & 7\end{array}$

[86v] leer

[87r] volumen SE

Gerard et Daniel Seghers 17

J. A. Schweikart norimber- / genis 13

J. G Seiler 6

Franc. von Sen 1

$[87 \mathrm{v}]$

$\begin{array}{ll}\text { Mecarinus de Senis } & 10\end{array}$

B. S. Setletsky 1

J. A Seupel, argentorat $\quad 7$

Martin Sichelbein, M. S., MS 1

[88r]

Corn. van Sichem, VS / CHS 8

$\begin{array}{ll}\text { Franc. et L. Silvestre } & 17\end{array}$

Baltasar Silvius $\quad 2$

$[88 \mathrm{v}]$

C. Simoneau 5

$\begin{array}{llll}\text { Snellinck } & 1 & \text { cum effig } 2\end{array}$

Virgilius Solis, VS, VS, VIS / VFS, V S, V S 181 cum effig. 1

$\begin{array}{ll}\text { Martin von Somer } & 14\end{array}$

P. van Sompel 2

de Son 1

D. Sornique / parisinus 2 
[89r]

$\begin{array}{ll}\text { Petr. Soutman } & 11\end{array}$

Soubeyran sculpt / parisin 6

M. Speer 2

H. Sperling 1

Fr. Spierre 3

$[89 v]$

$\begin{array}{ll}\text { Georg Spirinx } & 2\end{array}$

Julio Maria Spisanelli vel / Spisani, Mspil 4

Gabriel Spitzel

[90r]

$\begin{array}{lll}\text { Bartholom. Spranger } & 20 & \text { cum effig } 2\end{array}$

Hans Springelskle HSK 1

volum St

$\begin{array}{ll}\text { Stampaert } & 1\end{array}$

[90v]

Dietricus van der Staven / D S. ${ }^{1551}$, D S. ${ }^{1552}$

$\begin{array}{ll}\text { J. Steen } & 2\end{array}$

Franciscus van den Steen $\quad 1$

D Steidner 1

[91r]

Godfried Stein $\quad 8$

$\begin{array}{ll}\text { Jacob Stella } & 22\end{array}$

Stephanus. senior et junior / SF 62

1551 Dazwischen das Zeichen eines fünfzackigen Sterns.

1552 Dazwischen das Zeichen eines vierzackigen Sterns. 
[91v]

Petr. Stephanonius P S.

2

Benedetto Stefani

1 cum effig. 1

P. de Stetten, patricius aug.

1

M. Steudner

3

A. Stock

1

E. A. Stockmann

4

Stoopendaal sculptor / batavus

1

Stör

1

[92r]

Joh. a Strada vel Stradanus

86 cum effig 1

Lorenz Strauch

4

Lambert Suavius L. S.

14 cum effig. 1.

[92v]

J. Surugne, parisinus

Frider. Lambert et Johannes / Sustris

J. Suyderhoef

[93r] leer

[93v] volumen $\mathrm{T}$

[93r] leer

$[93 \mathrm{v}]$ volumen T

P. Tanjè

N. Tardieu

Anton Tempesta, A T, AT, TE, / I T F,

David Teniers, DT

10 cum effig

[94r]

Petrus Testa, PT

$8 \quad$ cum effig 3

Ludovicus Tetelin 
Guilielmus Therlho

[95r]

Henr Thilens, HT

Joh. Thomas

Philip. Thomasinus 3

S. Thomasin, gallus

[95v]

Joh. Jacob Thurneisen

5 cum effig. 1

Theod. van Thulden TvT

Domenico Tiepolo

Titian vid Vecelli

NB. Tintoretto ${ }^{1553}$

Joh. Baronius Tolosani 1

Henr. Toman, de Zürch 1

[96r]

Franc. Tortebat 1

Elisabetha Catherina de / Tournay 1

Wendel Traudt 3

H. Troschel 3

[96v]

Troger 1

Elisabeth Claire Tournay $\quad 2$

$\begin{array}{ll}\text { Tourniere } & 1\end{array}$

1553 In spitzer Feder von anderer Hand geschrieben. 
$\begin{array}{ll}\text { J. Trouvain } & 9\end{array}$

de Troy 1

J Troyen 1

[97r]

Philip Turpinus 1

Martin Tyrof $\quad 5$ cum effigie

$[97 \mathrm{v}]$ volum U. V.

$\begin{array}{ll}\text { Franc. Vaccarius } & 10\end{array}$

Perin del Vago $\quad 1 \quad$ cum effig. 1

$\begin{array}{ll}\text { W. Vaillant WW } & 19\end{array}$

[98r]

S. Vallée 2

Gerard Valck, amstelod 6

Joh. Franc. et Jacobus Vale- / sius vel Valegio VLo, VAL 2

Gio Batista Vanni 3

J. Vanloo 1

D. Vauguer 9

Lucas van Uden $\quad 4$

$[98 \mathrm{v}]$

Otto, Gilbert, et Octavius / van Veen, Voen, sivo Ven- / nius 2 cum effig. 2

$\begin{array}{lll}\text { Titianus Vecelli } & 23 & \text { cum effig. } 2\end{array}$

van Velde Johan. et Esais $\quad 52$

M. S. Venekin 1

[99r]

Hadrianus van Venne AV 1 cum effig. 1

Gio Francesco Venturini 1

N. Verkoelie 6

$\begin{array}{ll}\text { Vermeulen } & 7\end{array}$ 
[99v]

Versegraf, VG ${ }^{1554}$

Philip Uffenbach PUL, PU 3

Lucas van den Uhde

1 cum effig. 1

[100r] volumen Vi

$\begin{array}{ll}\text { J. v. Vianen } & 11\end{array}$

AEneas Viens, parmensis / AE V, E V, AE V P, AE V P. AEV. 4

Franc. Villamena F V F RV / VR 8

$[100 v]$

David van Vinckboons / D v Boons. 10

Leonhard da Vinci $\quad 1 \quad$ cum effig. 1

Thomas Vincidor 1

$[101 \mathrm{r}]$

Corn. et Vicol de Visscher

73 cum effig. 1

Vivares

8

Vivien

$[101 v]$

J. G van Vliet

Henr. Ulrich

17 cum effig. 1

Jonas Umbach

6

[102r] volum. VO

Robert van Voerst

1 cum effigie

Alexander Voet

1

Simon Vouet

9 cum effig. 2

Bernhard Vogel, augustan.

Voyès gallus

1554 Davor ein Zeichen, das wie eine Spirale aussieht, in der nächsten Zeile ein Bilderrahmen mit VG. 
$[102 v]$

Herman a Vollenhofen 1

Martinus, Paulus, Guillielmus / Simon et Cornelius de Voss / M. 127 cum effig. 6 V.S.

Lucas Vosterman L AE

18 cum effig. 4

Vouerman vid Wouerman

[103r]

Sebastian Vrancx

7

Adrian Vries

14 cum effigie

H. Using, Hvsing

2

Raphael Urbin vid. Sancio

J van Utenwael XW

[103v]

M. van Uylenbroek / M V WY

[104r] volum W

Hans Waechtelein, W

Jeremias Wachsmut

6

Joh. Erhard Wagener argento- / ratensis

Wagener

Anton et Joh. de Waterloo / AW

James Wattson anglus

[104v]

Watteau

Wauerman vid Vouerman

Conrad Wauman 
[105r]

Hadrianus de Weert, HW

Hans Weigel

Joh. Christoph Weigel

[105v]

Nicol. Weilborn / N W

F. E. Weirotter

Jacob Weis coloniensis

Adrian van der Werff

Johannes v. Weert

Arnold van Westerhout

volum. WI

J. H. Wicker

[106r]

Jeronymus Wienes, I W F 4

Anton. Johan, et Hieronymus / Wierx A W., Ie W. 36

$\begin{array}{ll}\text { J. G Wille } & 7\end{array}$

Michael Willman M W 6

6 cum effig 2

$[106 \mathrm{v}]$

W. Wilson 2

T. van der Wilt 1

Jodocus von Wingen / I a W $\quad 6 \quad$ cum effig 2

Adam Ludwig Wirsing / norimbergensis 1

[107r]

Fridericus de Wit 6

H. Witdonc 3

1555 Vor dem "I" ein Pfeil nach rechts. 
Michel Wohlgemut

Jeremias Wolff

$[107 v]$

Joh. Georg et Georg Andreas / Wolfgang A W.

Philip Wouerman

Anton de Woormatiis vel / Worms, WA, AVV

[108r]

F de Wyngarde

[108v] volum Z

Bernard Zaech

Theodor et Matheus Zagel / M Z

Dominicus Zampieri bono- / niensis dictus Dominichin / D [109r]

Reimerus Zeeman

Ludovicus Ziegler

Jost Ammon Zimmerman

A. Zingg, vindebonensis

Frider. Vincentius et Tad- / deus Zuccarus

Andreas Zucchi venetus

A. van Zylvelt
103 5

10

1 cum effigie

5

9

3 cum effig. 1

3 
14MONOGRAMMLEXIKON 


\title{
14.1,Uhrsprüngliche Historie der gesamten Bildkunst auf Papier“ und zwei Referate zum Naturdruck
}

\author{
SUB Göttingen Cod. Ms. Uffenbach 13/IV, S. 503-516, 553-573, 591-604.
}

Naturdruck: SUB Göttingen Cod. Ms. Uffenbach 13/V, S. 139-140, 310-315.

In der wissenschaftlichen Gesellschaft hielt Uffenbach einen sich über mehrere Sitzungen ziehenden Vortrag über die „Uhrsprüngliche Historie der gesamten Bildkunst auf Papier“. In insgesamt drei längeren Referaten führte er eine Entwicklungsgeschichte der Drucktechniken vor. Die erste Abteilung, gehalten am 29. Februar 1732, widmete er dem Holz- oder Formschneiden als der ältesten Druckart. ${ }^{1556}$ Am 16. Mai 1732 folgte ein Aufsatz über das Kupferstechen. ${ }^{1557}$ Das dritte und letzte Referat datiert vom 4. Juli 1732 und behandelt die „Etzkunst“, das Radieren. ${ }^{1558}$ Dabei konnte er auf seine umfangreiche Bibliothek und sein Kupferstichkabinett zurückgreifen. Er selbst schreibt hierzu: „Die weil nun vermuthet daß auch / dieße Materie denen Anwesenden nicht unangenehm / fallen mögte, indem jede Sätze mit Exempel derer / Bilder erlaütern, und die Sachen selbsten aus mei- / ner kleinen Bilder Versammlung darzeigen konte [...]." ${ }^{1559}$ Die drei vorbereitenden Manuskripte der Vorträge befinden sich im Commercium Epistolicum. ${ }^{1560}$

\subsubsection{Von dem Holz- oder Formschneiden}

Den ersten Teil referierte Johann Friedrich von Uffenbach am 29. Februar 1732 in der wissenschaftlichen Gesellschaft. ${ }^{1561}$

(503) [...] Nach allen dießen Unterredungen, und Vorzeig- / ung der vorher gedachten Stücken, hatte ich einen klei- / nen historischen Aufsatz, von dem Uhrsprunge und / Fortgange der Kupferstecherey und was dießer Kunst / mehr

\footnotetext{
1556 Cod. Ms. Uffenbach 13/IV, S. 503-516.

1557 Cod. Ms. Uffenbach 13/IV, S. 553-573.

1558 Cod. Ms. Uffenbach 13/IV, S. 591-604.

1559 Cod. Ms. Uffenbach 13/IV, S. 503.

1560 Cod. Ms. Uffenbach 20/II, S. 255-285.

1561 Cod. Ms. Uffenbach 13/IV, S. 503-516.
} 
anhanget, entworffen, und solchen als ein / Antwortschreiben an einen sichern Geistlichen in dem / Elsaß eingereicht, ihn auch in 3 Brieffe oder Theile / abgesondert, als erstlich von der Formschneider- / kunst oder denen Holzschnitten, so dann von dem Kupfer- / stechen, und letztlich von dem Etzen und der so genan- / ten schwarzen Kunst. Die weil nun vermuthet daß auch / dieße Materie denen Anwesenden nicht unangenehm / fallen mögte, indem jede Sätze mit Exempel derer / Bilder erlaütern, und die Sachen selbsten aus mei- / ner kleinen Bilder Versammlung darzeigen konte / so nahme dieses Mahl das erste Schreiben oder die / historische Erzehlung der Formschneider Kunst und der / Erfindung derer Holzschnitten, wie auch derenselben / verschiedene Gattung vor, wozu es zugleich Gelegen- / heit gabe von Erfindung der Buchtruckerey, als einer / aus der Formschneiderey hergefloßenen großen / Kunst zusprechen, und eines und das andere aus mei- / nes älteren Bruders Bibliotheque anzuziehen, so zu / dießer Materie nicht undienlich war. Es lautete / aber das erste Schreiben folgender Maßen:

(504) Uhrsprüngliche Historie / der gesamten Bildkunst auf Papier / und zwar erstlich von dem Holz oder Formschneiden. ${ }^{1562}$

1562 An dieser Stelle werden alle Autoren mit ihren Büchern in voller Länge nach alphabetischer Reihenfolge erwähnt. Dabei sollen die Bücher mit ihren Signaturen ergänzt werden, die in der Bibliothek Uffenbach nachweisbar sind. Diejenigen von Uffenbach benutzten Werke, die nicht aus seinen eigenen Beständen stammen, hatte er bei seinem älteren Bruder, Zacharias Conrad, einsehen können. Im folgenden werden die Titel mit Namen und Jahreszahl abgekürzt.:

Heinrich Conrad Arend, Das Gedechtniß der Ehren eines derer vollkommnesten Künstler seiner und aller nachfolgenden Zeiten, Albrecht Dürers, Goslar 1728 ( $8^{\circ}$ Bibl. Uff. 533);

Filippo Baldinucci, Cominciamento e progresso dell'arte dell'intagliare in rame, Firenze 1686 ( $2^{\circ}$ Bibl. Uff. 310);

Abraham Bosse, Sentiments sur la distiction des diverses manieres de la Peinture, Dessein et Gravure, Paris 1649 ( $8^{\circ}$ Bibl. Uff. 412);

Abraham Bosse, Radier-Büchlein, Handelt von der Etzkunst, Nürnberg 1669 ( $8^{\circ}$ Bibl. Uff. 447);

Marcus Zuerius Boxhorn, De Typographiacae artis inventione \& inventoribus, Lugduni Batavorum 1640;

Florent le Comte, Cabinet de Singularités d'Architecture, Peinture et Gravure, 3 Bde., Brüssel 1702 ( $8^{\circ}$ Bibl. Uff. 537-539);

Johann Gabriel Doppelmayer, Historische Nachricht von den Nürnbergischen Mathematicis und Künstlern, Nürnberg 1730 ( $2^{\circ}$ Bibl. Uff. 249);

John Evelyn, Sculptura, or the History and Art of Chalcography and Engraving in Copper, London 1662 ( $8^{\circ}$ Bibl. Uff. 435);

Andre Felibien, Principes de 1'Architecture, Sculpture et Peinture, Paris 1697 (4 Bibl. Uff. 40);

Andre Felibien, Entretiens sur les Vies et sur les Ouvrages des plus excellens Peintres anciens et modernes, 4 Bde., London 1715 ( $8^{\circ}$ Bibl. Uff. 530-531);

John Harris, Lexicon Technicum, or an Universal English Dictionary of Arts and Sciences, 2 Bde., London $1708+1710$ ( $2^{\circ}$ Bibl. Uff. 156-157); 
Arnold Houbraken, De groote Schouburgh der Nederlantsche Konstschilderers en Schilderessen, 3 Bde., Amsterdam 1718-1721 ( $8^{\circ}$ Bibl. Uff. 523-525);

Hadrianus Junius, Batavia. In qua praeter Gentis et Insulae Antiquitatem Originem, Decora, Mores, aliaque ad eam Historiam pertinentia, declaratur, quae fuerit vetus Batavia, quae Plinio, Tacito, Ptolomaeo cognita, quae etiam genuina inclytae Francorum nationis fuerit sedes. Leiden 1588;

Johann Kenkel, Allerhand Academische Figuren in schwartze Kunst gebracht, Regensburg o.J. ( $2^{\circ}$ Bibl. Uff. 314$)$;

Johann Hieronymus Kniphof, Botanica in originali. Das ist: Lebendig Kräuter-Buch, Erfurt 1734;

Giovanni Pietro Maffei, I. P. Maffeii Historicarum Indicarum libri XVI. Selectarum, item, ex India Epistolarum, eodem interprete, libri IV, Coloniae Agrippinae 1589;

Michel Maittaire, Annales Typographici ab Artis Inventae Origine ad Annum MD., HagaeComitum $1719+1722$;

Bernhard von Mallinckrodt, De ortu et progressu artis typographicae, Coloniae Agrippinensium 1639

Karel van Mander, Het Schilderboek, Amsterdam 1618 (4º Bibl. Uff. 418);

Michel de Marolles, Catalogue des livres d'estampes et de figures en taille-douce, Paris 1666 ( $8^{\circ}$ Bibl. Uff. 527);

Emanuel van Meteren (Meteranus), Eigentlich und volkomene Historische Beschreibung des Niederlendischen Krieges, Arnhem 1614-1630;

Balthasar de Monconys, Voyages de M. ..., 4 Bde., Paris 1695 ( $8^{\circ}$ Bibl. Uff. 456-459);

Balthasar de Monconys, Beschreibung seiner nach Asien und in das gelobte Land, nach Portugall, Spanien, Italien ... gethanen Reisen, übersetzt von Christian Juncker, Leipzig 1697 (4 Bibl. Uff. 404);

Pierre Monier, The History of Painting, Architecture, Sculpture, Graving, and of those who have excell'd in them, London 1699 (8 Bibl. Uff. 526);

Gabriel Naude (Gabriel Naudaeus), Addition a l'histoire de Louis XI, contenant plusieurs recherches curieuses sur l'histoire de ce roy, Paris 1630;

Pellegrino Antonio Orlandi, Abcedario Pittorico, Bologna 1719 (4 Bibl. Uff. 422);

Guido Panciroli, Rerum deperditarum et noviter inventarum, lib. 8, Amberg 1607 ( $8^{\circ} \mathrm{Bibl}$. Uff. 735);

Georg Pasch (Paschius), De novis Inventis, quibus facem praetulit Antiquitas, Lipsiae 1700 ( $4^{\circ}$ Bibl. Uff. 608):

Mathis Quadt von Kinckelbach, Teutscher Nation Herrlichkeit: ein außführlich Beschreibung des gegenwärtigen alten, und uralten Standts Germaniae, Cölln 1609;

Joachim Sandrart, L'Academie Tedesca, oder Teutsche Academie der Bau-, Bild-, und Mahler-Künste, 2 Tle, Nürnberg 1675 + 1679 (2 Bibl. Uff. 345-346);

Johann Saubert, Historia bibliothecae Norimbergensis, Nürnberg 1643;

Petrus Scrivenius (= Pieter Schrijver), Laure-Cranz voor Laurens Coster van Harlem, eerste vinder van de boeck-druckery, Haerlem 1628;

Nicolaus Serarius, Moguntiacarum res ab initio usque ad ... archipiscopus, ac electorum, dominum D. Joannem Schwichardum, Libri Quinque, Moguntiae 1604;

Leonhard Christoph Sturm, Der geöffnete Ritterplatz, 3 Bde., Hamburg 1706, 1711, 1715, 1723 ( $8^{\circ}$ Bibl. Uff. 276-278);

Giorgio Vasari, Delle vite de'più eccellenti Pittori, 4 Tle., Bologna 1648 (4 Bibl. Uff. 414 - 416);

Giorgio Vasari, Effigie di celebri Pittori, Scultori, \& Architetti, Firenze 1629 ( $8^{\circ}$ Bibl. Uff. 544);

Isaac Vossius,, Variarum observationum liber, London 1685.

Christoph Weigel, Abbildung der gemein-nützlichen Haupt-Stände, von Regenten und ihren so inFriedens- als auch Kriegszeiten zugeordneten Bedienten an, biß auf alle Künstler 
Wenn Euer Hochwürden durch ein an mich ohnlangst / erlaßenes Schreiben mich zu gegenwärtiger schultigen / Antwort verpflichtet, mir aber an bey auferleget / meine Gedancken von dem Uhrsprunge und Fortgan- / ge der Kupferstecherey darinnen mitzutheilen, so / gestehe ich gar gerne daß meine wenige Erfahren- / heit und Einsicht in die dunckelen Zeiten der Geburth / von dießer aller dings edlen Kunst, kaum zu reichen / wird, einen solchen verworrenen und bißher wenig / untersuchten Knoten aufzulösen, und davon etwas / ohn umstoßliches zu melden, dann ob es uns gleich / an Büchern, so von dießer Materie handeln keines / weges fehlet, so finde doch entweder dieße Sache / nur zufälliger Weiße darinnen angeführet, oder / doch wenigstens einander so wiedersprechend, daß / ein unpartheyischer Leser kaum $\mathrm{zu}$ entschließen / vermögend ist, welchem er recht geben solle.

Gewiß aber ist es daß man den Uhrsprung dießer / höchst nützlichen Kunst in der Wiegen der Buchtrucke- / rey suchen muß, wenn man nicht gar behaupten / kan, daß die erstere schon in den JünglingsJah- / ren gestanden, da die letzere das Tageslicht erbli- / cket. Jedoch weilen zu einem deutlichen Begriffe / dießer großen Begebenheit allerdings erfordert / wird, daß man in denen verschiedenen Gattungen / der Bildkunst auf Papier einen drey- oder mehr- / fachen Unterschied nehmlich in Holtzschnitte oder / Formschneiderey, Kupferstichen, und schwartze Kunst / Bilder mache so finde mich genöthiget, die erstere et- / was umständlicher mit einem Blick auf die Erfin- / dung der Buchdruckerey, zu untersuchen, weshalben / eine ohnumgängliche Weitlaüftigkeit meinen gegen- / wärtigen Aufsatz etwas mehr verlängern wird, / als sonsten die gemeine Nachrichten hiervon in Büchern / anzutreffen, und die erlaubte Gräntze eines Antwort / Schreibens zu geben.

Einer und zwar der Vornehmste unter denen Geschicht-

(505) schreibern betreffend die Zeichen und Mahler Kunst / nahmens Georg Vasari ${ }^{1563}$ in seinem sonst gelehrten Wer- / cke von dem Leben der berühmten Mahler Bilthauer / und Baumeister, die meiste Scribenten und Lieb- / haber in dießer Kunst aus einer Neigung vor seine / Landsleute, auf die Gedancken gebracht, daß der / florentinische Gold und Silberschmid Masofinigner- / ra1564 durch seine schlechte papierne Abtrucke von Zieh- / rathen, die er auf seine Spangen Buckeln, Schnallen / und anderes Geräthe gestochen, den ersten obwohl

und Handwercker, nach jedes Ambts- und Beruffs-Verrichtungen, meist nach dem Leben gezeichnet und in Kupfer gebracht, Regensburg 1698 ( $4^{\circ}$ Bibl. Uff. 370.

1563 (1511-1574); Vasari 1648, Vasari 1629.

1564 Maso Finiguerra (1426-1465). 
/ geringen und gantz zufälligen Anlas zu der Kupfer- / stecherey gegeben habe, von dem es ein anderer floren- / tinischer Goldschmidt Baccio Bandinelli1565, und letzlich / Andrea Mantegna ${ }^{1566}$ und Marc Anton Raymondi1567 in / Rom abgesehen und die Kunst zu mehrerer Vollkomen- / heit gebracht wie er solches umständlich in gedachten / seinem Buche delle vite de piu excelllenti pittori etc / parte terza meiner Edition in $4^{\circ}$ Bologna 1647. p.299.seq. ${ }^{1568} \mathrm{zu}$ behaupten suchet, und nachmahls die / Erfindung der Holtzschnitte ebenfalß denen Italienern / zuschreibet. Da nun der erste Zunder zu der Er- / neuerung aller Bildkunst in Italien entglommen / auch daselbst von allen andern Ländern den herrlichsten / Schein von sich gegeben, so haben die meisten angrän- / zende Liebhaber als Spanier Franzosen und Engellän- / der kein Mißtrauen gehabt, dieße Sätze vor gantz / richtig und wahr anzunehmen, und solche biß auf / den heutigen Tag fort zupflantzen, zu mahl da das / Vorurtheil ihnen keinen Zweifel gelaßen, daß dieße / welsche Köpfe zu einer so großen Erfindung nicht / die geschicktesten und tüchtigsten geweßen seyn solten / ohneracht deßen aber hat in denen vorigen Zeiten / ein tapferer Verfechter der teutschen Nation nah- / mens Mathis Quaden ${ }^{1569}$ in seinem Wercke: Teutscher / Nation Herrlichkeit welche ich in $4^{\circ} \mathrm{zu}$ Cölln 1609 / getruckt besitze pag.425 bereits nebst andern / das Hertze gefaßet, dieße entzogene Ehre, ihren / vermeinten Eigenthümern wieder beyzulegen, / und die Teutschen vor die glückliche Erfinder so- / thaner Kunst auszugeben welchem verschiedene

(506) seiner Landsleute, hauptsächlich aber Sandrat ${ }^{1570}$ in / seiner teutschen Mahler Accademie fol Nurmb. 1675. / 2ter Theil 1tes Buch p.205 u. 218. ritterlich

1565 Bei Baccio Bandinelli (1493-1560) unterliegt Uffenbach einem Irrtum, den er von Le Comte, 3.Bd., p. 229 übernimmt. Der Florentiner Goldschmied heißt richtig Baccio Baldini (1486-1487); s.a. Hagedorn 1797, p. 150f. (= Fragment eines Auffsatzes von Johann Friedrich Christ, p. 149-154).

Nach seinem eigenhändigen Inventar besitzt Uffenbach fünf Blätter von Baccio Bandinelli, heute werden dem Künstler keine Blätter aus dem Besitz Uffenbachs zugeschrieben.

1566 (1431-1506).

Nach seinem eigenhändigen Inventar besitzt Uffenbach acht Blätter von Andrea Mantegna heute werden ihm 38 Blätter zugeschrieben.

1567 (1475-1534).

Nach seinem eigenhändigen Inventar besitzt Uffenbach 13 Blätter von Marc Anton Raymondi; heute werden ihm 24 Blätter zugeschrieben.

1568 Vasari 1648.

1569 (1557-1613); Quadt 1609.

Uffenbach schreibt in seinem Manuskript, daß er dieses Buch besitzen würde, es läßt sich aber in der SUB Göttingen nicht nachweisen. Vermutlich benutzte er das Exemplar seines älteren Bruders.

1570 Joachim Sandrart (1606-1688); (Sandrart 1675). 
gefol- / get, und den vorangezogenen Vasari mit seinen / eigenen Worten gleichsam wiederleget, in dem / er ihm die Wiedersprechungen seiner Meinung / nach vorrucket. Nun wäre in einer Begebenheit / derer dunckelen Zeiten kein beßerer Richter als wen / wir die Arbeiten der Teutschen und Italienischen / Meister mit Jahrzahlen und unterschriebenen Nah- / men aufweißen könten, gleich wie aber von / denen ersten getruckten Büchern bekant ist, daß die / jenige worinnen gar keine Jahrzahl noch Ortes ge- / dacht, die ältesten und dießelbe seyen, so vor denen / mit gedachten Umständen an das Licht gekommen, / wie solches Joh. Saubertus ${ }^{1571}$ in historia biblioth. / Norimb. und viele andere erwießen, also gehet / es auch mit denen ersten Holtzschnitten, manche / Liebhaber haben dergleichen, wenn sie solche nach / denen Jahren geleget, nach denen datirten die / Stelle angewießen, da ihnen doch der Vorrang wie / gedachten Büchern gehöret, allein als Richter in un- / serer vorhabenden Streitsache sind sie nicht anzu- / führen, dannenher man auf solche bedacht seyn muß / worinnen des Meisters Nahme, oder Zeichen, und et- / wa die Jahrzahl eine Entscheidung geben kan, und / dießer hat der angezogene Mathis Quadt nebst San- / draten verschiedene erwehnet, welche ich gleich- / falß mit wenigen anführen werde, wenn vor- / laüfig in der Kürtze von der Erfindung der Buch- / trucker Kunst werde gesprochen haben, als welchen / Ausschnitt in dießer Sache ohnmöglich entrathen / kan, in dem die ersten Bücher mehrentheils mit / Figuren in Holtzschnitten versehen sind, und dieße / letztern wahrscheinlich den Anlas zu denen erstern / gegeben haben. Ich werde also mit denen Holtzschnitten / den Anfang machen, und derselben verschiedene / Gattungen erwehnen, hiernechst aber von aller- / ley Arten der Kupferstichen, so dann von dem Etzen / und endlich von der schwartzen Kunst, wie nicht we-

(507) niger von einigen mit Farben gedruckten Bildern / als denen jüngsten der Erfindung nach, reden.

Die Frage: wer das erste Buch gedruckt ist von vielen / Jahren her so öfters aufgeworffen, wiedersprochen / und abgehandelt worden, daß ich nothwendig ein / gantzes Buch, gleichwie schon vielfaltig geschehen, da- / von schreiben müßte, wenn ich eines jeden Meinung / alhier gedencken wolte, da aber eben dieße Frage / nur ein Nebenword in meiner gegenwärtigen / Untersuchung ist, so werde meine Erzehlung so / kurtz als möglich zusammen faßen. Alle Gelehrte / wie auch alle Nachrichten oder Spuhren so man biß- / her ausgefunden geben einhellig ohngefehr, das / Jahr 1440 nach Christi Geburth vor die Geburths- / zeit der 
Buchdruckerey an, in Benennung aber des / Orths, wo es geschehen, ist eine gar große Mißhel- / ligkeit entstanden, die Städte Haerlem, Maynz, / Strasburg, Venedig, Rom und Paris ja wer weiß / noch mehrere streiten alle um dieße Ehre, die doch / der Wahrheit nach nur einer, oder nach dem man / es einsiehet, etwa zweyen gebühren kan. Und / wenn wir der gelehrten Wercke so von dießer / Sache geschrieben worden, anführen wolten, so / müßte man allerdings mit unpartheyischen den / Ausspruch geben, daß einjeder aus blinder Neigung / vor seine Landesleute vieleicht mehr gesprochen / als er mit Wahrheit erweisen kan, daß die ersten / Drucker so mit eintzelnen Buchstaben wie heut zu / Tage üblich gedruckt haben, Guttenberg 1572 und / Faust ${ }^{1573}$ zwey Maynzische Einwohner und gute Freun- / de die das große Werck in Gesellschaft unter- / nommen, geweßen, dann dießes kan mit Zuziehung / der erstern Drucken selbsten nicht geleugnet wer- / den, welche mit besondern Fleiße und Ordnung / Maitaire ${ }^{1574}$ in seinen Annalibus Typo Graphicis / $4^{\circ}$ Hang. 1719. 3.vol. nach dem Alter und wie sie / an Tag gekomen beschrieben. Inzwischen wieder-

(508) sprechen die Holl. und Niederländische Scribenten / zwar dieße Wahrheit nicht, allein sie behaupten / jedoch, daß vor erwehnte Künstler die Sache an / Costeri1575 zu Haerlem gedruckten Büchern, und / zwar insbesondere an einen Donat so Alexan- / dri Galli Doctrinale 1442 betittult, abgesehen, / und nachmahls durch die Erfindung der eintzelen / Buchstaben verbeßert hätten, gleich wie man / hierüber mit meheren dasjenige so Petrus Scri- / verius ${ }^{1576}$ wie auch Marcus / Zuerius Boxhorn ${ }^{1577}$ De Typographiae Artis Inventione / Hadrianus Junius ${ }^{1578}$ In Historia Bataviae Cap.XVII / Meteranus ${ }^{1579}$ und viele andere geschrieben, nachle/ sen kan. Welchen der vorerwehnte Quaden 1580 in / Teutscher Nation Herrlichkeit noch mit dießen Um- / ständen beystimmet, daß Faust ein Diener bey Cos- / ter in Haerlem geweßen, ihme in der Christnacht / die Formen und anderes Geräthe zum Drucken / in Fauste [?] gestohlen und sich damit nach Maynz / gemacht, auch nachmahls mitzurathen seines Ge- / sellen des Guttenbergs die Kunst zu weitere Voll- / kommenheit gebracht hätte. Gleich wie aber dießes / Vorgeben sind, die er

\footnotetext{
1572 Johannes Gensfleisch, genannt Gutenberg (ca. 1400-1468).

1573 Johannes F(a)ust (ca. 1400-1466).

1574 Michael Maittaire (1668-1747); Maittaire 1719.

1575 Lauren Jansz. Coster (ca. 1370-ca. 1440).

1576 Pieter Schrijver (1576-1660); Scrivenius 1628.

1577 Marcus Zuërius van Boxhorn (1612-1653); Boxhorn 1640.

1578 Hadrianus Junius (1511-1575); Junius 1588, cap. XVII.

1579 Emanuel van Meteren (1535-1612); Meteren 1614.

1580 Quadt 1609.
} 
mit keinem Beweisthü- / mern und bloß durch seine Aussage erhärten / will, so pflichtet man vielmehr andern Gelehr- / ten die gründlicher von der Sache gesprochen, / als dem Gabriel Naudaeo ${ }^{1581}$ in addition a l'historie / de Louis XI Paris $8^{\circ} 1630$, Serrario ${ }^{1582}$ lib. I Rerum / mognetiaerum Cap.37. Mallingrot ${ }^{1583}$ de ortu et / progressu artis typograph. und vielen andern / Inn und Ausländern, bey. Zumahlen da es ihnen / an Beweisthümern nicht fehlet, die auch Obrig- / keiten in Genaden Briefgen gegeben, gleich wie / des Kayser Maximiliani I. Privilegio so daß / vorerwehnten Faustens Enckel über Bücher / gegeben worden, und darin ausdrücklich seines / Anherrns als Erfinder der Kunst gedacht wird.

(509) Ein gleiches beweißet auch Accursius 1584 aus der Biblio- / theca vatienna, woraus er Wercke anführet / die Anno 1442. Guttenberg (zum Jungen) equestris / dignitatis vir zu Maynz habe drucken laßen.

Ob ich nun zwar nach dießem kleinen Ausschweiffe / von Erfindung der Buchdruckerey nicht nöthig / hätte, ein meheres davon zu berühren so kan doch / nicht unerinnert laßen was die Annales cole- / niensis und verschiedene andere Gelehrten davon / melden, daß nehmlich der Erfinder ein Teutscher / nahmens Schäfer oder Schoifer geweßen. / Gleich wie nun dießes abermahl ein neuer Nahme / davon noch nichts gesprochen zu seyn scheinet / so bleibet doch unserer erstes behaupten noch / gantz feste, in dem dießer Schoifer ein Tochter- / man des Faustens gewesen, so bald nach der / Erfindung seines Schwiegervaters mit Hand / anleget und sich auch auf Büchern als Ver- / leger mit genennet hat. Allein zu unserm / Vorhaben werden alle dießelbe so keine Bilder / oder Holtzschnitte gehabt, nichts beytragen, dannen / her mich allein auf dergleichen Bücher beziehen / will, welche insonderheit der oben angeführte Mai- / taire ${ }^{1585}$ in seinen Annalibus typographicis um- / ständlich erzehlet, und davon viele in meines / ältern Bruders Zach. Conrad von Uffenbachs / Bibliotheques selbsten durchsuchet, in keinem / einzigen aber bey denen Holtzschnitten ein Zeichen / oder Nahmen des Formschneiders vor 1500. ge- / funden. Die Verzeichnung dießes Vorraths / kan man in seinen gedruckten Catalogo und zwar tomo 2. Appendice 2 sistenti incuna- / bula artis typographicae ${ }^{1586}$ nachsehen unter wel- /

\footnotetext{
1581 Gabriel Naude (1600-1653); Naude 1630.

1582 Nicolaus Serarius (1555-1609); Serarius 1604.

1583 Bernhard von Mallinckrodt (1591-1664); Mallincrodt 1639.

1584 Bonus Accursius (1182/85-1260/63), Philologe und Drucker in Mailand.

1585 Maittaire 1719.

1586 Maittaire 1722.
} 
chen allen kein würtiger Exembel als an denen / Blättern gefunden, so er aus Costeri erstem / Buche de Spegel onsere behoutnas, Speculum

(510) Salvationis nostra zu erhalten das Glücke ge- / habt. Es ist bekant daß dießes erstes und sehr un- / vollkomenes Buch auf dem Rathause zu Haerlem / denen Reißenden gezeigt, wie auch in einem an- / dern Exemblare zu Horn auf der Kirchen Biblio- / theques bewahret wird, und hierinnen findet man / mehr Bilder und Holtzschnitte als Text oder Worte / daher einige auf die Gedancken gekomen daß Lau- / recjanz ${ }^{1587}$ [sic!] oder Lorentz Coster selbsten ein Formschnei- / der geweßen seyn müße. Ob nun zwar dießes / aus seinen von Scriverio ${ }^{1588}$ beschriebenen Lebens- / laüffe nicht erhellet als der ihn nur als einen / Küster der großen Haerlemischen Kirchen, und / daher Costerum genant angiebt so kan doch beydes / meines Erachtens wohl beysamen stehen, gleich wie / noch heutzutage an vielen Orten der Ver- / waltung von Handwercksleuten oder Künstlern ge- / schiehet, wenn man aber die zwar rauhe und / schlecht abgetruckte, aber doch nicht übel gezeichne- / te Bilder des erwehnten Buches ansiehet, so kan / es mir gantz wahrscheinlich vorkomen, daß / Coster die Formschneiderkunst als ein Nebenwerck / getrieben, und vieleicht von andern schon erler- / net habe. Ist dießes Probstück aber schon anno / 1440. ohngefehr gemacht worden, was will Vasari ${ }^{1589}$ / doch mit seinen italienischen Meistern, die lange / nach der Zeit erst aufgekomen ausrichten, wenig- / stens hat er keine solche alte Bücher von seinen / Landsleuten, oder auch eintzeln Stücke aufzuwei- / ßen, dannenher wohl ohnstreitig die Kunst in Holtz / zu schneiden denen teutschen Erfindern als deren / Probstücke noch vor Augen liegen, gebühret. Was aber die Kupferstücke betrift, darin könte wohl / Vasari ${ }^{1590}$ nicht gar unrecht haben, allein wir verspah- / ren dieße Untersuchung biß dahin da wir das / nöthige von denen Holtzschnitten werden erwehnet / haben. In dem wir aber inzwischen an denen

(511) erstern Büchern die Buchstaben sehr schlecht, die Bilder / hergegen weit meisterlicher sehen so weiß ich nicht / warum man nicht sagen könne daß die Holtz- / schnittebilder weit älter als die Buchtruckerey seye / und jene zu dießer Gelegenheit gegeben habe müße / dann obgleich der mehr erwehnte Scriverius 1591 in / Costers Lebenslaufe umständlich behaupten will, daß ein Finger oder Pitschierring mit etlichen / Buchstaben dem Erfinder Anlas zu der Kunst ge- /

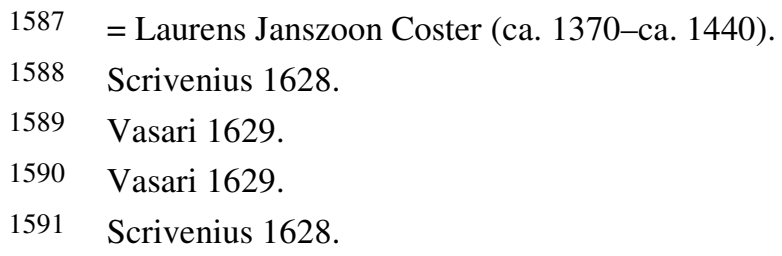


geben habe, so kan er doch wahrscheinlich aus kei- / ner andern Uhrsache auf das Holtzschneiden derer / Schriften, als durch seine Erfahrenheit Bilder zu / schneiden gekomen seyn, obgleich der Pitschier- / ring seine erstere Gedancken veranlaßet haben / mag. Allein da wir uns bey Muthmaßungen / nicht aufzuhalten haben, so will nur noch mit we- / nigen etlicher ersten Drucken aus meines Bruders / Bibliotheques wobey Bilder befindlich gedencken. / Als ein vol in fol. von dem Ciruroirus durch Joh. / Gruniger ${ }^{1592}$ gedruckt und vollendet zu Arasburg / uf dinstag nach peter und paulstag anno domini / 1397.1593 Bey dießer Jahrzahl man sich vieleicht über / das Alter eines gedruckten und mit Figuren ver- / sehenen Werckes wundern mögte, allein weil der Ver- / leger gemeldet, und man deßen Lebensjahren / wohl weiß, so erhellet gar balde daß in der / Jahrzahl geirret und etliche $\mathrm{C}$ oder hundert aus- / versehen weg gelaßen worden, gleich wie man / sich auch an verschiedene andere alte Bücher so / gar von ann. 1100, und dergleichen Erwehnung / thun, nicht stoßen darf, welche entweder aus / eben einen solchen Druckfehler, oder vieleicht weil / das Manuscript, wo von sie abgedruckt worden / so alt, und von solchem Schluße geweßen, also / betitult worden. || processus Belials gegen Christus / opus quod finit faustissimi quod \& neis figuris / (Buchstaben) antonius Sorg1594 in urbe augustensi / feliciter atque dignisssime perfecit an: Dom: 1481. $\|$

(512) Die guldin Bulle und Kuniglich Reformacion ge- / truckt zu Arasburg. Joh. Prussz anno Dom: 1485. / $4^{\circ}$ Die teutsche Bibel von Anton Koburgern gedruckt / mit Figuren anno 1483. fol. || Bernhard von Brey- / denbachs Reysen gen Jerusalem durch Erhart / Reuwiek von Utricht ynn der Statt Maynz getruckt / im Jar 1486. || Herbarius gedruckt durch Hansen / Schonsperger zu Augsburg 1488. fol. || Cento novelle / hundert newe Fabeln gedruckt in Augsburg von / Anton: Sorg. 1490. fol. || Liber Chronicarum etc: im- / pressit Norimb. Anton Koberger, adhibitis viris / mathematicis pingendique arte peritissimis Micha- / el Wohlgemut et Wilhelm Pleydenwurf etc. quo- / rum Figura inserto sunt consumatum an. 1493. fol / max. und eben dießes teutsch wie auch noch ein / ander mahl teutsch von 1496. Allein genug hievon / um nicht allzu weitlaüffig bey einer klahren Sache / zu seyn, zumahlen die Bücher allmählig zu denen / Jahren von $1500 \mathrm{zu}$ gehen, und keines Formschneiders / darin gedacht worden außer dem letztern, welche / die erste geweßen darin Nahmen in einen alten / Druck erwehnt

\footnotetext{
1592 Johannes Grüninger (ca. 1455-ca. 1532).

1593 Johannes Grüninger (Drucker), Biblia cum concordatiis veteris et novi testamenti, Straßburg 1497.

1594 Anton Sorg (tätig als Buchdrucker in Augsburg zwischen 1475 uns 1493).
} 
gefunden. Es gehet also hiermit / als wie Sambertus in der Beschreibung der nuremb. / Biblioteque ${ }^{1595}$ von denen Büchern sagt, daß man nicht / leicht vor 1466 eins mit des Druckers Nahmen / oder dem Orte finden werde weil damahls der / Brauch noch nicht wie in folgenden Zeiten geweßen. / Woher also Sandrart in seiner Mahler Academie1596 / erweißen will daß an teutsche Holtzschnitte / lang vor Durern gehabt, kan ich nicht sagen, / wann er anderst nicht auf erwehnte alte Bücher / sich beziehet, woraus man jedoch den eigendlichen / Erfinder der Kunst nicht errathen kan. Wolte / man aber mit Muthmaßungen noch weiter / ausschweifen, so könte man sagen daß solche / von denen Sineser zu uns in Europa gekommen / wäre dann daß man gar weit ältere gedruckte

(513) Bücher mit Bilder in Holtz geschnitten von selbiger / Nation habe ist eine gantz ausgemachte Sache, allein / wie dieße Wißenschaft sich nachmahls mehr aus- / gebreitet und zu uns gekomen, wolte ich eben / nicht wie Maffejus in Historia Indiae. Lib VI fol / 2561597 und Vossius In variarum observat. Capitel 14. / p.81 1598 gethan, beschrieben, viel weniger aber be- / haupten daß die Kunst von dorten erstlich in Teutsch- / land und dann anderwärts hingekomen seye, wie / Pancirollus lib. II. Rerum memorabilium seu de- / perditarum tit. XII. ${ }^{1599}$ traumet. Genug daß ich meines / Erachtens wahrscheinlich erwiesen daß die Teutschen / sie nicht von denen Italienern oder andern bekom- / men. Es hat aber solche nicht herrlicher zu blühen / angefangen, als durch die belobte Hand unseres / teutschen Appelis den Albert Dürern ${ }^{1600}$, da er 1498. / seine Offenbahrung Johannis, die er 1511. zum 2ten / Mahl gedruckt, nebst vielen andern Kunststücken / herausgegeben. Es dienen aber jedoch dieselben / keinesweges zum Beweis nach meinem Erachten / daß das Holtzschneiden von denen Teutschen auf / die Italiener gekomen, dann ob gleich Dürer seine / in Holtz geschnittene Passion 1510. in 13. halben Bogen / und 1511. in 37. kleinen Stücken, heraus gegeben so / folget doch nicht daraus wie Sandrart in der Mah- / ler Academie 2ten Theil 2tes Buch p.205.1601 erwehnet / daß weil dießes überall belobte Werck zu Venedig /

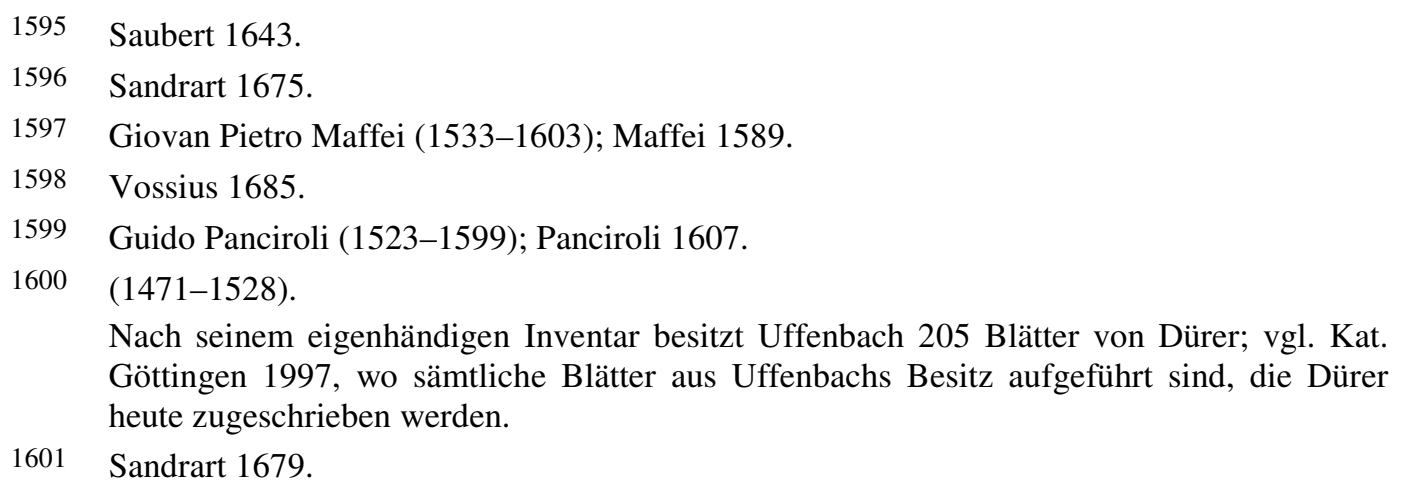


auf dem Marcus Platz feil geleget, und von Marco / Antonio ${ }^{1602}$ begierig und theuer erkauft, auch also / bald in groben Kupferstichen mit Dürers Zeichen / nach gemacht worden, daß daraus erhelle daß / damahls denen Italienern das Holtzschneiden in / dießer Vollkomenheit noch müßte unbekant gewe- / ßen seyn, und sie also keines Weges vor die Er- / finder dießer Kunst angegeben werden können, / dann wie es noch gantz unausgemacht bleibet / wer in Teutschland eigendlich zu erst dieße Kunst

(514) getrieben, so läßet sich auch eben so wenig erwei- / ßen, ob es in Welschland nicht um / eben die Zeit auch geschickte Formschneider gege- / ben habe. Dann Marc Antonii Werck war nach / dem eigenen Geständnus Sandrarts 1.c. kein Holtz- / schnitt, sondern ein grober und unvollkommener / Kupferstich, so daß dieße Begebenheit uns keines / Weges einen Beweiß in dem Vorzugsrecht be- / treffend die Erfindung der Holtzschnitte geben / kan, obwohlen man solchen aus andern ange- / führten Stücken haben kan. Gleich wie nun dieße / Kunst angeführter Maßen lang in Teutschland / vor denen Italienern getrieben worden, so ist / doch nicht zu leugnen, daß Hugo da Carpi ${ }^{1603}$ um / die Jahre 1530. der erste geweßen der das so ge- / nannte Mezzo Tinto, oder Chiaro oscuro eine / Art von Holtzschnitten mit Farben und weißer / Erhohungen gedruckt zu erst verfertiget habe, / gleich wie solches an einem Stücke worauf eine / Sybilla lesend, und ein Kind mit einer Fackel / dabey stehend zu erweißen ist. Es sagt zwar San- / drart in seinen 2ten Theil der teutschen Mahler / Academie fol.2191604 abermahl bey dießer Gelegen- / heit daß sich die Italiener auch dieße Erfindung / fälschlich an maßeten, die weil man der gleichen / mit der Jahrzahl 1503. in denen Cabinetten einiger / Liebhaber fände. Da er aber nicht allein dießer / Liebhaber Nahmen verschweiget, über das auch / keinen Beweisthum hinzusetzet daß sie eigendlich / von Teutschen gemacht worden, so sehe ich nicht wie / man seinen Angeben Glauben beymeßen könne. / Dann mit eben dem Rechte womit er sie ohne Auf- / schrift eines Meisters oder deßelben Zeichen, vor / teutsch ausgiebt, kan man sie auch vor Italienisch / halten, weil man um dieße Zeit verschiedene / Bücher zu Rom und Venedig mit Holtzschnitten und

(515) Ziehrathen gedruckt, mithin auch Formschneider da- / selbst gehabt hat. Ich kan also Sandrarts und an- / dere Behauptung vor nichts anderst als eine

\footnotetext{
1602 Marcantonio Raimondi (ca.1475-ca.1534).

1603 Ugo da Carpi (1480-1523).

Nach seinem eigenhändigen Inventar besitzt Uffenbach kein Blatt von Ugo da Carpi, heute werden ihm vier Blätter zugeschrieben.

1604 Sandrart 1679.
} 
lächerliche / Liebe vor ihre Landsleute und keine Wahrheit an- / sehen, biß ich durch Mezzo tinto Stücke mit teutschen / Nahmen und Jahrzahlen eines andern überwießen / werde. Es werden aber der gleichen Bilder mit / 2 oder mehr besondern in Holtz geschnittenen Stöcken / die eine Figur vorstellen gedruckt, auf deren ersten / die Umriße der Figur allein geschnitten und schwartz / gedruckt worden, auf denen 2ten aber die hohe / Lichter oder Schraffierungen der Bilder wiederum / allein mit einer weißen Farbe angelegt sind. / Wenn nun das schwartze erst gedruckt ist, so wer- / den die Stöcke mit denen hellen Lichtern abermahl / darauf gelegt und wieder unter die Preße ge- / bracht, wo durch als dann dieße Mezzo tinto Stücke / zu Wege gebracht werden, welche wie gedacht / anfänglich Hugo da Carpi, nach ihm aber verschie- / dene andere insonderheit Andrea Andreano $^{1605}$ / und Andrea Mantegna1606 sehr meisterlich verferti- / get. Gleichwie aber in allen Wißenschaften die / Anfänge schlecht und die folgende aus Übungen / beßer sind, so ging es auch mit dießer Kunst / der Mezzo tinto Stücken, wie ingleichen mit / dem gesamten Formschneiden, welche letztere / Albert Durer unleugbahr zu einer großen Voll- / kommenheit gebracht, obwohlen nach ihm einige / andere Meister insonderheit in Franckreich und / Teutschland aufgekommen, die in ihren Zügen / fast zärter und lieblicher sind zu mahlen in de/ nen Creutzschraffirungen, als worin bey Holtz- / schnitten die größte Kunst und Gedult bestehet. / Zu unsern Zeiten, nach dem das Kupferstechen / so gemein worden, obwohlen sie dieses vor jenem

(516) zum voraus hat, daß man 50000 und mehr Abtrücke / ohn Verletzung der Stämpfel machen kan, da die / Kupferplatten kaum etliche taußend aushalten, / und daß man über das den besondern Kupferdrucker- / lohn dabey erfahren könne, die weil die Stöcke ins- / gemein mit denen Buchdrucker Lettern zu gleich / aufgesetzt und abgedruckt werden. Und dießes / seye genug von denen Holtzschnitten, worauf mit / nechstem eine kurtze Historie des Kupferstechens / folgen soll.

\footnotetext{
1605 Andrea Andreani (ca.1540-1610), Verleger von Ugo da Carpi.

Nach seinem eigenhändigen Inventar besitzt Uffenbach 85 Blätter von Andreanis Hand, nach heutigem Stand sind es vier Blätter.

1606 Andrea Mantegna.
} 


\subsubsection{Von dem Kupferstechen}

Am 16. Mai 1732 in den Räumen von Wilhelm von Uffenbach folgte der zweite Teil seines Vortrages. ${ }^{1607}$

(552) [...] Bey dießer Gelegenheit laße ich der anwesenden Ge- / selschaft den oben pag.504 angefangenen Entwurff / der Historie von der gesamten Bildkunst auf Papier / als eines Verfolg in einem 2ten Schreiben von dem / Kupferstechen vor, welches hier nachfolgenden Inhalts war

(553) Von dem Kupferstechen

Die hochbelobte Kunst des Kupferstechens ist an / sich selbsten so Edel und nutzbahr daß ihr durch / die Erforschung weme eigendlich dieße schätz- / bahre Erfindung zuzuschreiben, weder ein / größeres Lob, noch viel weniger ein Unwerth / daraus erwachsen kan. Jedennoch da über dieße / Sache fast so viel streitens unter denen Europae- / er entstanden, als ich in meinem vorigen von / denen Holtzschnitten erwehnet, so deucht mich / es seye noch wohl der Mühe werth die alten Ge- / schichten dießfals unpartheyisch einzusehen, und / einen richtigeren Schluß davon abzufaßen als man / meines Wißens bißher in vielen Bücherschreibern / nicht gehabt. Wenn ich aber in meiner vorigen / und bereits angezogenen Untersuchung derer / Holtzschnitten wie billig angemercket daß der / Uhrsprung dießer Kunst noch mit vieler Dunckelheit / umhüllet seye, so kan ich es dießes mahlen von der / Kupferstecherey fast noch mit größern Fuge / sagen, dann weil das Holtzschneiden schier eine / Art und Wesen mit denen erstern Bücherndru- / cken gehabt, foglich [sic!] also alle Gelehrte begierig / gemacht den Erfinder davon aufzuspühren, so / hat man durch deren Veranlaßung weit mehrere / Nachricht erhalten als man vieleicht von dem / Kupferstechen nicht aufbringen wird, angesehen / dieses letztern nur die Künstler, und etliche we- / nige Liebhaber dererselben angehet, die bey wei- / tem in solcher Anzahl sich nicht um die erste / Spuhren der Kunst bekümmert, als in dem erstern / Vorfalle geschehen, so viel man aber doch hievon / aufgezeichnet findet, so will es bey denen meisten / Nationen schier eine ausgemachte Sache seyn / daß die Italiener in dem Besitze sothaner Ehre / seyen, angesehen sie selbsten so wohl, als die

(554) Spanier Frantzoßen, Engelländer Niederländer / und anderer einhellig zu behaupten suchen daß / der florentinische Goldarbeiter Maso Finiquerra ${ }^{1608}$ /

1607 Cod. Ms. Uffenbach 13/IV, S. 552-573.

1608 Maso Finiguerra. 
erstlich unvollkommen, nach ihm aber Andrea / Mantegna, Baccio Bandinelli, oder wie ihn andere / nennen Baldini, und Marc Antonio Raymundi / in einem höhern Grade die Kunst erfunden und / getrieben, und zwar soll der erste nach Aussage / des Andr. Vassari de gli pittori etc. $4^{\circ}$ Bologn. / 1647. parte 3. fol.299. ${ }^{1609}$ gantz zufällig darauf ge- / kommen seyn, dann weil er die Gewohnheit / gehabt hätte seine mit Laubwerck und Zierathen / bestochene Arbeit an Buckeln, Spangen und / Schnallen mit geschwärtztem Öhle einzulaßen / hierauf aber ein naßes Papier zu legen, und / mit einem glatten Heffte zu überreiben damit / er die Muster zu seiner Belehrung nach dem / Verkauf seiner Sachen beybehalten könne, so / seye ihm eingefallen ob nicht auf gleiche Art / allerley Bilder in die Metalle zu stechen und hernach- / mahls so abzudrucken wären, daß man viele Copien / davon in die Welt schicken und sie vieleicht vor / Zeichnungen mit der Feder gerißen ausgeben kön- / ne. Dieser Anfang aber seye nach gedachten / Vassari Berichte ohngefehr um das Jahr 1460. / geschehen. Worauf Baccio Baldini ein eben / mäßiger Goldschmidt in Florentz die Kunst / weiter gebracht, und, weil er in dem Zeichnen / nicht gar feste geweßen, sich derer Vorbilder / eines geschickten Mahlers nahmens Sandro Botti- / celli ${ }^{1610}$ bedienet, von welchem er hernachmahls / nach Rom an den Andrea Mantegna, endlich / aber nach Bologna an den Marc Antonio Ray- / mundi gekommen seye, welche durch ihre / vortreffliche Arbeit alle Künstler in Europa / aufsehen gemacht insonderheit aber in Flandern

(555) den sogenanten Martin von Antwerpen ${ }^{1611}$ bewo- / gen, sich in dieser neuen Kunst ebenfalß zu üben / und solche in gantz Teutschland bekandt und an- / genehm zu machen, wodurch endlich verschiedene / Nürnberger ausnehmendlich aber Albert Durer / ebenfalß in dieße Liebhaberey gekomen, und / sie zu einer großen Vollkommenheit gebracht hätten. / Alles dieses schreibet und behauptet gedachter / italienischer Verfaßer Vassari, nach ihm aber / biß auf unsere eigene Zeiten viele andere Ita- / liener Frantzosen und Engelländer. Gleich / wie dann unter andern Filippo Baldinucci / in seinem Buche Comminciamento e Progresso / dell arte dell intagliare in rame $4^{\circ}$. Firenza / 1686. in dem proemio pag. 21612 ausdrücklich sagt: / quest'arte ebbe suo principio nel Secolo 1400 nella / citta di

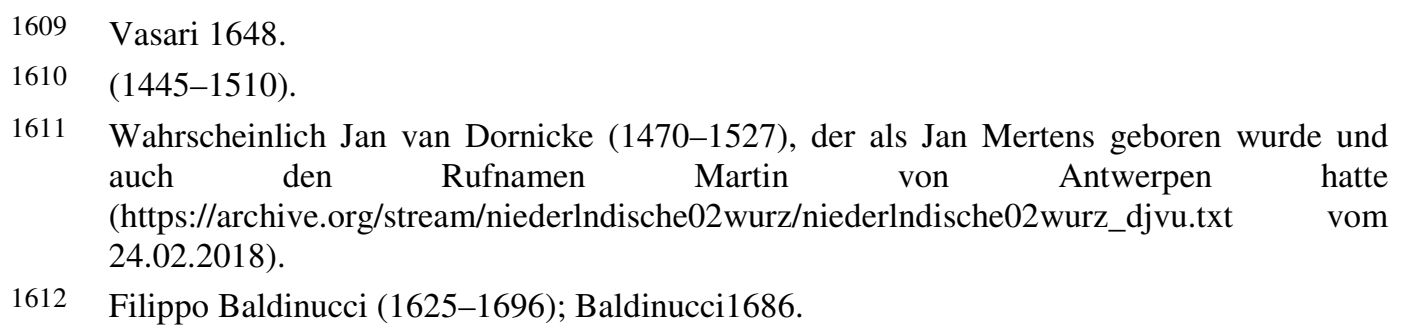


firenze mediante la persona die maso finiquerri / orefice argentiere Scultore e inttagliatore etc. Nach / dem er nun hierauf eine umständliche Erzehlung / der zufälligen Weise, wie das Kupferstechen em- / por gekommen, giebt, welche in allem mit des Vassari / seiner, als seines Vorgangers übereinkommen, so / schreibt er 1.c. ferner oservò quest invenzione baccio / baldini altro orefice fiorentino e comminciò an- / cor esso a fare il simigliante, ma per ch'egli avera / poco Disegno, facevasi assistere da Sandro Botticel- / li. Viveva in quei tempi antonio Dell Pollaiolo / il quale avendo veduto le stampe del baldini si / pose ancor egli ad intagliare in rame e fece / intagli in rame di gran lunga migliori che il / finiquerro el baldini fatti non avevano pp. / Daß ich nun dießen Scribenten alhier besonders / anführe ob er gleich, etliche wenige Umständen / ausgenommen, eben daselbe schreibet, was wir / anfanglich von Vassari gehöret, ist darum gesche- / hen weil er hauptsachlich von dem Kupferstechen

(556) geschrieben, viele andere aber vor und nach ihm / nur die Sache zufällig anführen. Mit eben / solchem Fuge könte auch des gantz neuen Verfa- / Bers des so genannten a b c darii pitoriae, / Pellegrin. Anton. Orlandi $4^{\circ}$ Bologna 17191613 ge- / dencken, wenn ich durch überhäufte Schrift- / stellen gegenwärtige Untersuchung gros machen / wolte, da aber solches gantz mein Absehen nicht / ist, so will nur noch mit wenigem, des sorgfäl- / tigen und gelehrten H. Felibiens als / eines Frantzosens, in seinen Principes de l'architecture / de la sculpture p. $4^{\circ}$ Paris 16971614 erwehnen, der / p.280 also spricht: l'invention en fut trouveé / par un orfevre qui travailloit de niellure a floren- / ce etc: Albert Durer et Lucas furent des premiers / qui perfectio nerent la maniere de graver etc. / und in seinen entretiens sur les vies des peintres / $8^{\circ}$ tom. 2 Londre 1705 p. $98^{1615}$ daselbe wiederhohlet. / Eben dieses hat ihm auch Florent le Comte, in / seinem verdrieslichen Mischmasche, so er Les / singularité d'architecture peintures etc: be- / titult, und zu Paris in 8. in 3 tom. $1700^{1616}$ gedruckt / ist, pag 31 nachgepfiffen, gleich wie dieser Scri- / bent in seinem angezogenem Wercke nicht viel / anderes als dergleichen, und zwar mit dießem / Umstande herfür gebracht, daß er alles wie Kraut / und Rüben durcheinander geschmißen. Allein / das seye von Frantzosen genug, obwohlen noch / gar viele in eben dem Tone singen. Von En- / gelländern aber haben wir nichts anders zu ge- / warten, davon nur kürtzlich

\footnotetext{
1613 Pellegrino Antonio Orlandi (1660-1727); Orlandi 1719.

1614 Andre Felibien (1619-1695); Felibien 1697.

1615 Felibien 1715.

1616 Florent le Comte (1655-1712); Comte 1702.
} 
des Harris Lexicon / technicum fol. London vol.21617 unter dem Worte / prints anführe, woselbsten also lese: in the / year 1460 one maso finiquerra a goldsmith / of florence graved his plate etc: und hierauf

(557) redet er eben so wie vorher von denen vorigen / Verfaßer gemeldet. Dießem stimmet der Enge- / llische Übersetzer von Monier histoire de la peinture / welche zu London 1699. in 8 mit dem Tittul history / of painting etc ${ }^{1618}$, bey, wenn er pag.183. / sagt graving was found out at florence by maso / finiquerra etc: afterwarts bax. bandinelli a / florentine goldsmith continned that art but / as hy was no good designer etc. Hiernechst will / noch einen dießer Nation und zwar den sehr ge- / lehrten John Evelyn in seinem schönen Werck- / gen history and art of calcography. 8. London / $1662^{1619}$ hinzufügen, der pag.36. eben dießer Mei- / nung ist, und also damit die Zeugnüße derjenen / beschließen, welche die Italiener vor die Erfin- / der des Kupferstechens angeben, ob gleich nur / der allerwenigsten so mir vorgekommen gedacht / habe. Dann da alle die erwehnte insgesamt / auf den Vassari als den Uhrheber dieses Behaup- / tens kommen, so würde es wenig zu der Sache / selbsten thun, wenn ich auch gantze Folianten / dießer Schriftstellen, die alle eines unwieder- / sprechlichen Grundes ermangeln, zusammenschriebe. / Wolte man aber fragen wo ein solcher Grund / ausfindig zu machen wäre, so würde ihm ant- / worten daß die Darlegung von alten Kupfer- / stichen mit Jahrzahlen und Nahmen das beste Licht / geben könten, allein wo soll man dieße finden? / Die Buchdrucker selbsten haben wir in meinem / vorigen erwehnt, in ihren ersten Büchern / keine Jahrzahlen und Nahmen, gesetzt, was / will man also von solchen eintzeln Blättern / wie Kupferstiche sind, erwarten? Gewiß- / lich werden die erste Künstler auch lange / Zeit ihre Arbeit ohne Zeichen oder Jahre, in / die Welt geschickt haben, ehe und bevor dießer

(558) Brauch wegen der Vielheit der Künstler hernach / aufgekommen ist. Allein ohnerachtet dießer Über- / einstimmung vieler Bücherschreiber, so hat / es jedoch einige und zwar Teutsche gegeben, / welche die Ehre dießer Erfindung denen Wel- / schen abgeschnitten und strittig gemacht, in / Meinung zu erweißen daß solche vielmehr / Teutschen als denen Italienern zu gehören, / auf solche Weise könte ich alhier vieler unserer / Landsleuten gedencken, welche insgesamt / mit harten Worten denen Welschen sothanes / unfügliches Behaupten verweißen wollen, / die weil aber der Uhrheber ihrer Vermuthungen / Sandrart in seiner

\footnotetext{
1617 John Harris (1667-1719); Harris 1710.

1618 Pierre Monier (1641-1703); Monier 1699.

1619 John Evelyn (1620-1706); Evelyn 1662.
} 
Teutschen Mahler Academie / fol Nürnb. 1675.1620 2ten Theils 2tes Buch. p.204. / und 218. gewesen, so werden wir einer Mühe / überhoben seyn alle anzuhören, wen wir / nur die angezogene Schriftstelle erwegen. / Sie lautet aber 1.c. also ${ }^{1621}$ : aldieweilen wir / uns von dem Marc Antonio samt allen be- / rühmtesten Kupferstechern aus Italien biß / zu unserer Zeit zu schreiben vorgenommen so / erachte ich vor billig deßen von Anfang zu / gedencken weil Andr. Vassari fol 297. der / wenig von unsern Teutschen gewußt solches / Lob dem Andrea Mantegna, als ob selbiger / der erste Erfinder dieser Kunst gewesen wäre / zu eignen Wille mit ermelden daß er / solche denen Goldschmieden, wenn sie auf / die Riemen oder Gürtel die mit Silber / beschlagen vermittelst des Grabstichels laub- / werck Grotescken und anderes gegraben ab- / gesehen, hernach er solche geschwärtzt und / auf naß Papier abgedruckt und also Kupfer

(559) zu stechen den Anfang erfunden habe. Darauf er- / folgends seine Wercke mit großem Lob in Kupfer / ausgehen laßen von deme dann auch nachgehends / in Teutschland Martin Schön ${ }^{1622}$ solches erlernet hätte. / Hiebey aber nun findet sich ein großer Irrthum, / weile die Ehre dießer edelen invention des Kupfer- / stechens auch etzens und Holtzschnitts mit nichten denen / Italienern sondern, wie auch das Buchdrucken zu / Strasburg 1440. denen Teutschen samtlich gebühret. / Maßen damahlen als Mantegna in dießer Kunst 1500. / den Anfang gemacht schon zuvor und wohl ehe als / er gebohren ermeldete Wißenschaft in hoher Voll- / kommenheit bey denen Teutschen floriret, wie dann / Mategna selbst sich ob Albert Durers in Kupfer ge- / brachten Passion und anderes verwundert weile / er solcher vollkommenen Handelung des Grabstichels / zu folgen nicht vermögt, zu geschweigen auch daß / Durer und Martin Schön lange vor dem Mategna / die Welt gesehen und das Israel von Mecheln ${ }^{1623}$ Werck / erst aus Teutschland in Italien gekommen durch / welche ihnen Anlaß gegeben worden selbige Exem- / plaria nach zu machen worunter Mategna / als ein Italiener zwar der erste gewesen etc. ${ }^{1624}$ / Alles dießes heißet nun zwar eine Sache ausgeben / und schreiben, aber meines Erachtens nicht er- / weißen, dann wenn der angeführte Verfaßer / dießer ersten Kupferstecher Lebens

\footnotetext{
1620 Sandrart 1675.

1621 Auf S. 558 befinden sich am Zitat von Sandrart Anführungszeichen am Anfang der Zeile, auf S. 559 am Ende der Zeile.

1622 Martin Schongauer (ca.1445/50-1491).

Nach seinem eigenhändigen Inventar besitzt Uffenbach 14 Blätter des Künstlers.

1623 Israel van Meckenem (ca.1445-1503).

Nach seinem eigenhändigen Inventar besitzt Uffenbach ein Blatt des Künstlers.

1624 Zitat Ende.
} 
oder Todes Jahre / und ihre mit Nahmen bezeichnete Blätter angere- / get hätte, so wäre in der Sache selbsten bald die / Wahrheit erschienen, aber ohne dieße höchst nöthi- / ge Umstände, kan er wenigstens mich nicht auf / seine Gedancken bringen. Wolten wir aber auf / einen beßern Grund zu kommen aller dießer Künstler / Lebenzeit ausforschen, und dadurch erfahren wel- / cher der erste geweßen seyn mögte so wäre es / zwar das sicherste Mittel hinter die Wahrheit zu / ge-

(560) gelangen, wenn wir nur gewiße Spuhren von / ihrem Lebenslaufe haben könten, alleine hierin / liegt eben die größte Schwührigkeit. Sandrart / selbsten sagt im angezogenen Wercke fol 218. / ferner: ${ }^{1625}$ Nun sind ferner vor Zeiten in Nieder- / Teutschland unterschiedliche herrliche Geister / und edele verständige Männer geweßen die / sich in dießer Kunst geübet haben von denen die / Historien und Geschichtsschreiber fast nicht, als / ihre blose Nahmen angeregt auch von ihren / Wißenschaften wohl gar still geschwiegen haben / obwohl selbige alte und kostbahre Kupferstecher / und Mahler geweßen so wir hie und dort aus / ihrem so wohl in Kupfer gestochenen als gemahl- / ten hinterlaßenen Wercke genugsam ersehen / unter andern der Israel von Mecheln und der / so genante hübsche Märten dero Kupfer wie ge- / sagt bezeugen was jeglicher vor ein guter / Meister in solcher Zeit geweßen etc. ${ }^{1626}$ Weiß dieße / nach Sandrart nicht viel von Martin de Schon, / Israel von Mech, Meckerik oder Menz wie / einige wollen, wie kan er dan behaupten daß / sie vor Mantegna, Baccio Bandini und noch / mehr vor Maso Finiquerra gelebet, ja wohl / gar verstorben seyn, und das Kupferstechen / eher als diese getrieben? Jedoch wir wollen un- / serm Verfechter teutscher Herrlichkeit weiter / hören wenn er folgends p.218 also spricht: ${ }^{1627}$ / Indem unter allen Teutschen und Italienern / wir keinen ältern finden der seinen Nahmen / durch Kupferstücke berühmt gemacht und darin deßelben gedacht, als den Israel von Mecheln, / nehmen wir Uhrsach von dem Anfang dießer / edlen Wißenschaft in Kupfer zu stechen und zu / etzen als auch in Holtz zu schneiden etwas zu melden

(561) Ob dann nun schon der kluge Georg. Vassari sich / sehr bemühet zu erweisen daß dießer Künste / Erfindungs Lob denen Italienern gebühre all / der weil zuforderst die Goldschmiede Maso Fini- / querra und Baccio Baldini zu Florentz auf die / nach damahliger Zeiten Landart geschmiedete / silberne Gürtel

\footnotetext{
1625 Auch hier wieder am Anfang der Zeile Anführungsstriche.

1626 Zitat Ende.

1627 Zitat Anfang, anfangs wieder Anführungsstriche.
} 
etc: wie dann vor dießen Zei- / ten niemand von dießen Künsten etwas gewust / hätte, so verstößt er sich doch darin gewaltig ja / er schneidet sich selbst mercklich in die Finger / durch übelen Bewust, dann in dem er sein selbst / vergeßend meldet daß als im Jahr 1511 das erste / Mahl auf St Marc. Platz zu Venedig die in Holtz / geschnittene Passion von Albrecht Durer zu ver- / kaufen geweßen habe selbige unter andern / viele der Kunst, Marc Antonio mit unabge- / wendeten Verwunderungs Auge angesehen, / und fast alle seine Bahrschaft mit dießem ihm / weit liebern Schatz vertauscht, und etc: etc: so / giebt ja gedachter Vassari als ein gebohrner / Italiener damit selbsten an Tag daß schon damahls / als dieße Kunst in Italien hat sollen gebohren / werden, selbige in Teutschland rühmlich er- / wachsen und in schöner Blüthe gestanden habe. etc:1628 / Dieße noch weiter sich erstreckende und mit / vielen pegnitz Blühmlein ${ }^{1629}$ ausgeschmückte / Beweißthümer nun sollen den guten Vassari / nach der Sandratischen Meinung gäntzlich be- / schähmen, ja dieße Gründe sind es auch die so / viele unserer Landsleute blindlings bewegen, / in ihren Wercken die Erfindung des Kupfer- / stechens denen Teutschen als was gantz ausge- / machtes zuzuschreiben, ich würde hievon gan- / tze Blätter anzufüllen Gelegenheit haben, wenn / mir die Mühe geben mögte sie nahmhaft zu

(562) machen, jedoch kan hiebey einen nicht verschwei- / gen und zwar einen Frantzosen nahmens / Bosse in seinem Tractat Sentiments sur la / Distinction de diverses manieres de peinture / 12. Paris 1699.1630 der p.74 also spricht: plusieurs / tiennent que l'origine on la restauration, crain- / te de se de sabuser, de cet art n'est que vers l'anée / 1490 et sur ce sujet je commencerai a nommer / les premiers qui l'ont mis on remis en pratique / Israel Martin Schon on le tedesques que les autres / nomment le maître au chandelier, etc. Ob / dieses nun zwar auf die teutsche Seite sich neigen / so bin ich doch der festen Meinung daß ein / jeder unpartheyischer Leser mit mir aus / denen vorher angeführten Quellen nicht eben / so gantz ungezweifelt auf des erst angezo- / genen teutschen Scribentens seiten tretten / werde. Dann ob ich gleich keines weges mei- / nes Vaterlandes Ruhm dadurch zu schmählern / suche so daucht mich doch daß die Liebe vor daßel- / bige derjenigen so ein jeder vernünftiger / vor die Wahrheit haben müße, allerdings / nachgehen solle. Wenn Marc Antonio die / Durerische Holtzschnitte damahls in Venedig / vor rechte Kunststücke angesehen und solche /

\section{Zitat Ende.}

1629 Pegnesischer Blumenorden, Nürnberger Sprachgesellschaft, 1664 gegründet.

1630 Abraham Bosse (1604-1676); Bosse 1649 [Uffenbach oder seinem Schreiber unterläuft in der Jahreszahl ein Schreibfehler, statt 1699 muß es 1649 heißen.]. 
nachgestochen, so sehe ich noch nicht daraus wie / zu erweißen stehe daß dergleichen niemahlen / vorher in gantz Italien sollen gemacht worden / seyn, vieleicht hatte sie Marc Antonio nicht / alle gesehen, vieleicht hatte er auch vor fremde / Wahren mehr Hochachtung als seine einheimische, / wie man es heutzutage noch über all siehet. / Vieleicht aber hat Sandrart die logische Argumen- / ten

(563) ten, welche der liebe Aristoteles a particulari / ad universalem mit einem Machtspruche verwirft / nicht verstanden? Und wenn nechst dießem al- / len Vassari gantz unschuldig oder vieleicht ohn / Absicht schreibet daß Finiquerra eine Art der / ersten Kupferstichen 1460. ausgehen laßen, / so meine ich es seye der Unterschied von dießen / Jahren und denen worin Durer, Marc Antonio, / Lucas von Leyden ${ }^{1631}$ und dergleichen gelebet ziem- / lich von einander, da ein Zwischenstand von / 50 Jahren ohngefehr darinnen vorkommet. / Dieße Sprünge kommen mir allerdings und / allen Vernünftigen verdächtig vor und ich / glaube nicht daß jemand zweiffeln könne / daß binnen dießer Zeit nicht werden allerley / Kunst Sachen an verschiedenen Orten zum / Vorschein gekommen seyn, die wor zwar bey / Liebhaber noch finden, allein ihr Alter wegen / Mangel der Jahr Zahl und der Meisters Nahmen / nicht errathen können. Wenn also Sandrart / nicht weiß noch wißen können, wie damahls / der Sachen eigendlicher Verlauf geweßen, / oder welcher Künstler vor dem andern ge- / lehrt oder verstorben, sintemahl uns des / Martin Schöns ${ }^{1632}$ des so genannten Bockolts ${ }^{1633}$, des Israel von Meek oder Meckenick, des / Martin Stocks ${ }^{1634}$, des Gemberlins ${ }^{1635}$, welche

1631 Lucas von Leyden (1494-1533);

Nach seinem eigenhändigen Inventar besitzt Uffenbach 90 Blätter.

1632 Martin Schongauer (ca.1445/1450-1491).

Nach seinem eigenhändigen Inventar besitzt Uffenbach 14 Blätter.

1633 Wahrscheinlich Franz von Bocholt (tätig 2. Hälfte 15. Jh.), vgl. https://www.jstor.org/stable/pdf/4169801.pdf, S. XX,4 vom 27.02.2018.

Nach seinem eigenhändigen Inventar besitzt Uffenbach ein Blatt des Künstlers.

Im Inventar zieht Uffenbach Israel van Meckenem mit Franz Bocholt zusammen, wenn er auf Bl. 61r schreibt: „Israel von Meck, Mechenic, vel / Menz, to bockolt tegens in / westphalia I V M to bockolt.“"

1634 Name nicht nachweisbar, vielleicht Marten Schott (tätig 1481-1499), Drucker in Straßburg, der 1488 „Das Buch der Geschicht des großen Alenander“ mit 28 Holzschnitten herausgab.

1635 Ein Künstler namens Gemberlein ist nicht nachweisbar.

Wahrscheinlich ist Urs Graf d. Ä. (1485-1528) gemeint, denn in der Literatur des 18. Jahrhunderts, z.B. in: Christ 1747, S. 372-373 wird die Signatur wie folgt aufgelöst: „Ein V und G, alte, Gotthische Buchstaben, stehen auf Holzschnitten zu Straßburg abgedruckt, im Jahr 1507, bey Knoblauchen, ingleichen bey demselben, im Jahr 1518, und zu Basel bey Adam Petri, i,Jahr 1519. Es wird auch dieses Zeichen ordentlich gedeutet, V. Gemberlein, oder Gamperlein," Christ bezieht sich z.B. auf ein Werk, das 1508 bei Johann Knobloch in Strassburg mit dem Titel „Passio domini nostri Jesu Christi“ von Matthias Ringmann 
alle / Teutsche geweßen seyn sollen, wie nicht we- / niger des Maso Finiquerra, Andr. Mantegna, / Baccio Baldini, und anderer Italiener Leben / Todt und Arbeit auf gewiße Mase gantz un- / bekant ist, so sehe ich sein so gar gewiß und / herrisch gethanen Ausspruch in einer so

(564) dunckeln Sache mehr vor eine übermäßige / Eigenliebe oder Neigung für sein Vater- / land als eine Wahrheit an. Wodurch er / nach meinem wenigen Urtheil seinen Lands- / leuten mehr Nachtheil als Ehre anthut. / Die Haupt Eigenschaft eines Historienschreibers / muß die Unpartheylichkeit seyn, und wenn / ihn ein blindes Vorurtheil einmahl recht offfen- / bahr verdächtig gemacht, so verliehret er das / Vertrauen in allen seinen Erzehlungen, so / gehet es nach meinem wenigen Begriffe dem / Sandrartischen Wercke, das bey mir noch lange / nicht die Würde eines ohnumstoßlichen Bewei- / ßes erlanget, ich kan dannenher alle die Be- / schreiber von Erfindungen und Erfindern, / deren wir eine große Menge im Druck haben, / nicht vor Capitel fest ansehen so bald ich dieße / oder dergleichen Eigenliebe vor ihre Landsman- / schaft antreffe. Man pfleget in Historischen / Dingen insgemein bey der Ermangelung / eines tüchtigen Beweißes die Zuflucht zu / den so genanten historischen Glauben, (fides / historica) zu nehmen, und Sachen die eben nicht / sonnenklahr erhärtert [!] werden können, dann / wahrscheinlich zu machen daß man spricht, / was der Verfaßer vor Absehen Nutzen oder / Vortheil dieses oder jenes unschuldig hinzu- / setzen gehabt hätte. Wolte man also in gegen- / wärtiger Untersuchung dieses Erwegen / ebenfalß anstellen so weiß ich nicht wohin / das Recht und die Wagschale sich neigen würde. / Vassari und andere alte Italiener beschreiben / die gar zufällige Art, so zu dem Kupferstechen / Anlas gegeben, auf einerley und meines Er-

(565) achtens unschultige Weise, und brauchen also weil / die Sache von weniger Erheblichkeit war, keine / Jahr Zahl noch Zeugnüße. Unsere Teutsche aber / verwerfen und greifen diese Sätze rittermäßig / an, ohne selbsten einen gründlichern Beweiß / zu haben, dießem nach fället die Verdächtigkeit / einer landsmännischen Prahlerey mehr auf / die letzte als die erste, und verstärcket die Mei- / nung daß es der Wahrscheinlichkeit gemäser / seye Finiquerra habe den Anfang gemacht, an- / dere aber in Italien nachmahls in Niederland / und letzlich in Nürnberg haben dieße Kunst wei- / ter zur Vollkommenheit gebracht, biß endlich / Albert Duer [!] sich als den grösten Meister darinnen / hervor gethan.

erschienen war und mit Holzschnitten eines Künstlers mit dem Kürzel V. G. ausgestattet ist, wobei es sich hier um Urs Graf handelt.

Nach seinem eigenhändigen Inventar besitzt Uffenbach weder von einem Künstler mit Namen Gemberlein noch von Urs Graf Blätter. 
Soll ich zu dießen Muthmaßun- / gen noch einige andere setzen, so komt es mir / gantz vernünftig vor daß Finiquerra bereits / müße in einen gesetzten Alter gewesen seyn / da er durch seine Abdrücke von Silberstichen / in der Welt an. 1460 nach Vassari Meldung be- / kant worden, nach dem er vermuthlich eine / Zeitlang vorher seine Silber Arbeiterey erler- / net und getrieben, gleich wie nun deßen Lebens / Zeit der jenigen Teutschen ihre, welche insge- / mein als die ersten angegeben werden ziem- / lich übertrift, so sehe ich nicht warum man / nicht glauben könne es seye die Kunst von die- / Bem auf die andern gekommen, Andrea Man- / tegna ist im 66.ten Jahr seines Alters zu Mantua / an 1517. verstorben folglich kan er wohl zu einer / Zeit mit dem Math. Zasinger ${ }^{1636}$ der 1501. eine Passion / in 12 Stücken in Kupfer herausgegeben gelebet / haben. Vor dießem beyden aber ist Martin Schön / zu Kahlenbach gebohren oder der hübsche Märten

(566) von Antwerpen bereits durch verschiedene Ar- / beit bekant gewesen welcher 1486 gestorben / auf seinen Blättern aber keine Jahr Zahl hinter- / laßen welche uns erweisen könten daß er / vor dem Finiquerra schon gearbeitet hätte. / Eben dießes müßen wir auch von andern / Teutschen, als dem so genanten Gemberlein, / dem Israel von Meckeln, dem Bocholt, dem / Martin Stock und andern sagen, als deren / eintzeln Blätter gar keine Jahr Zahl und viel- / mahls auch keine Nahmen gehabt, wenn aber / Sandrart von Durers Lehrmeister dem Michel / Wohlgemuth ${ }^{1637}$ erwehnet daß er lange vor de- / nen Italienern Holschnitte [!] und Kupferstiche / herausgegeben, so finde ich zwar in Doppel- / mayers Leben der Nürnbergischen Künstler / fol. ibid. p. $181^{1638}$ daß er daselbst an. 1434 gebohren / und $1519 \mathrm{im}$ 85ten Jahr verstorben seye, wenn / er aber seine Kupferstiche verfertiget ist / uns so sehr nicht bekant als von dem Finiquerra / daß er dergleichen schon 1460 ausgegeben. / Hiernechst aber kan nicht unberühret laßen / was Sandrart in seinen ofters angezogenem / Wercke fol 220. von einem alten teutschen / Meister der seine Arbeit mit einen H uns S. / in einander geschlungen, wie Hans Schauf- / lig ${ }^{1639}$ zu thun pflegen HS [ligiert] bemercket,

\footnotetext{
1636 Matthäus Zasinger (ca.1477-1555).

Nach seinem eigenhändigen Inventar besitzt Uffenbach ein Blatt von dem Künstler, allerdings löst er das Monogramm M Z mit „Theodor et Matheus Zagel“ auf. Im Kupferstichkabinett sind heute zwei Blätter nachweisbar.

1637 Michael Wohlgemut (1434-1519).

Nach seinem eigenhändigen Inventar besitzt Uffenbach ein Blatt von dem Künstler.

1638 Doppelmayer 1730.

1639 Hans Schäufelin (ca.1480/85-1538/40).

Nach seinem eigenhändigen Inventar besitzt Uffenbach 15 Blätter des Künstlers.
} 
anführet, / daß er nehmlich die Abbildung eines alten / Mannes bey einem jungen Mägdlein, die ihm / in den Geldbeutel greifet, mit der Jahr Zahl / 1455 in Kupfer gestochen gesehen und selbsten / beseßen habe, wären uns also die alten Zeichen / der ersten Meister mehr bekant, so würde dieses

(567) eintzige Stück die streitende Parteyen aus ein- / ander zu setzen vermögend seyn, allein da uns / die Nachrichten in dießem Stücke ungemein feh- / len, und die Liebhaber der Kunst noch auf den / heutigen Tag sich nach keinem vollständigen / oder unzweifelhaften Register richten können 1640 / so weiß ich aus dießer Nachricht noch kein Licht zu / finden. Der oben genannte Hans Scheuflig oder / Schufeln, und Scheufelein von Nordlingen oder / wie Doppelmayer ${ }^{1641}$ will von Nürnberg bürtig / kan es nicht wohl seyn in dem derselbe jünger / und 1550 daselbst verstorben. Ober er aber Hanß / Schützelein, wie mich ehedeßen ein Strasburger / Liebhaber der Kunst H Kühnast ${ }^{1642}$ bereden wollen / geheißen, kan ich vor keine Gewißheit ausgeben / noch auch wo und wann derselbe gelebet. Jedennoch / könte mit der angegebenen Jahr Zahl auch wohl / ein solcher Verstoß vorgegangen seyn, wie wir / dergleichen in meiner vorigen Untersuchung / von Holtzschnitten bey denen ersten Bücher an- / gemercket, da zu Exembel Joh. Grunigers Buch / von dem Cirurgicus anno 1397. zu Strasburg / oder beßer 1497. gedruckt $^{1643}$, wie auch Murhonis / opus calamitatum, Bapt. Mantuani $1402 \mathrm{zu}$ Stras- / burg vor 1502 gedruckt ${ }^{1644}$ erwehnet worden sinte- / mahl die dabey stehende Drucker um die letzte / und nicht die erste Zeit gelebet, gleich wie hierüber / meines Bruders Biblioth. Uffenbachianae cata- / logus. Tom 2 in append. p.101645 mit meherem / nachgeschlagen werden kan, so daß also mit der /

1640 Vgl. Cod. Ms. Uffenbach 36 und 36a: Johann Friedrich von Uffenbach, Alphabetisches Verzeichnis aller Mahler, Bildhauer und Kupferstecher; und: Cod. Ms. Uffenbach 50: ders., Monogrammata oder Zeichen derer Mahler und Kupferstecher, so noch ungedeutet oder unbekant sind.

1641 Doppelmayer 1730.

1642 Uffenbach besucht „Kühnast“ insgesamt dreimal während seines Aufenthaltes in Straßburg, am 12. September, am 6. und 14. Oktober 1714 (Vgl. Cod. Ms. Uffenbach 19/I, S. 397403, S. 432 und S. 434-436).

Wahrscheinlich handelt es sich um den Straßburger Juristen Philipp Ludwig Künast (16481717).

1643 Hieronymus Brunschwig, Das ist das Buch der Cirurgia, Hantwirchung der Wundartzny, Straßburg (Grüninger) 1497.

1644 Sebastian Murrho, Opus Calamitatum Baptistae Mantuani com Commentario, Straßburg (Schott) 1502.

1645 Bibliothecæ Uffenbachianæ Universalis, Complectens Historicos Ac Caeteros, Qui Ad Studia Historica Pertinent, Scriptores, Una Cum Appendice Duplici, Quarum Prior Supellectilem Antiquariam, Altera Incunabula Artis Typographicæ Sive Librorum Typis Exscriptorum Editiones Primas Exhibet. Zach. Conradus ab Uffenbach ... Comparavit, Nunc Vero Venalia Prostant, Bd.II, Frankfurt 1730. 
Jahr Zahl ein Druck oder Stich Fehler begangen wor- / den. Uberhaupt ist dießem nach von solchen / dunckeln Zeiten, und derselben vorgefallenen / Geschichten nichts standhaftes und ohnfehlbahres

(568) anzugeben, gleich wie Sandrat und alle seine / Anhänger berühmter Maßen von der Kupfersteche- / rey gethan. Damit ich ihm aber dieße Überei- / lung nicht allein zuschreibe, so kan ich wohl muth- / maßen daß er durch die vorher gedruckte Nach- / richten eines teutschen Bücherschreibers des mehr / angezogenen Math. Quatens teutscher Nation / Herrlichkeit 4. Cöllen 1609.1646 hiezu gebracht worden / seye. Dann dieser hochtrabende Verfaßer / meldet p.425.1647 der aller erste und der aller erste- / ste [?] Platenschneider von dem Ich hören und fin- / den kan ist F von Bocholt, und dießer und dießer soll ein / Schäfer in dem Bergischen Lande geweßen seyn / und kan man kein ältern Abtrucke dann dieses / Meisters finden etc. auf ihn erfolgten strax / Israel von Meckenich aus der Eifel bürtig / und die Litter [es folgt eine Schlangenlinie] deßen Signification ich noch mit er afren [?]; nach dießem erfolgt Martin / Stock nachher die beyde genannte zum großen / Theil überstieg. etc. ${ }^{1648}$ Die weil nun der gute / Man sich fest vorgesetzt hatte seine Landsleute / über alle zu erheben so hat er ja nichts von / andern Wercken laßen, und uns also eine ge- / schmünckete und verdächtige Nachricht, die er / doch zu seiner Zeit beßer als wir schreiben kön- / nen hinterlaßen, da aber sein schwülstiges / und mit sehr schlechtem Stoffe angefültes Buch / ohne dem in andern Sachen gar wenig Beyfall / bey der Nachwelt erhalten, so kan ich ihm auch / in dießem vorhabenden Stücke nicht recht geben / zu mahlen da ihm Sandrart selbsten ohn Wißen / eines großen Schnitzers überzeuget. Er sagt / nehmlich in seiner Mahler Academie 1.c. p. / 219. ${ }^{1649}$ daß er ein zierliches gestochenes Laubwerck

(569) von Israel von Meckeln in Kupfer besäse worunter / der Meister selbsten gestochen: to bocholt ist / gemaet in dem bisdom monster und weiter unten / seyn Nahme Israel. Hieraus ist meines Erach- / tens leicht abzunehmen, daß Quaten und gar / viele nach ihm aus einer Statt nehmlich Bocholt / einen Kupferstecher gemacht habe, und zwar / einen der ersten. Da es doch von dem Israel / von Meckeln oder Meckenick gestochen ware / dannenher auch dasjene was Sandrart von / dießem vermeinten Bockold wie vorher ge- / dacht, meldet alles falsch und irrig ist. Hätte / ich es dießes Mahl mit Italienern Frantzosen / oder andern

\footnotetext{
1646 Quadt 1609.

1647 Zitat Anfang, Anführungszeichen in jeder Zeile vorne.

1648 Zitat Ende.

1649 Sandrart 1675
} 
Ausländern zu thun, so solte es / mich nicht wundern solche Teutsche Nahmens- / verletzungen $\mathrm{zu}$ finden, allein in dießem Falle ist es mir selsamer [!] vorgekommen, als die / mancherley Verzerr und Zergliederung der / Nahmen, in denen Italienischen und Frantzöschen / Mahler Historien; solcher Art Fehler könte in- / sonderheit aus Florent le Comte Singularites / de peinture 8. Paris ${ }^{1650}$, und des Orlandi abcdario / pittorico 4. Bologna 17191651 ohnzehlige anführen, / da sie aus einen Manne zu weilen 6. unter- / schiedene, und ihrer etliche Gegentheils zu / einem zusammen geschmoltzen haben, wenn / es Zeit und Gelegenheit leiden wolte. Jedoch / sind es zu der Historie einer Wißenschaft / oder Kunst überaus schadliche Irrthümer, welche / die Liebhaber in solche Verwirrung bringen / daß man nicht weiß wer Koch oder Keller ge- / weßen. Allein da ich bereits lang genug in / dießer Untersuchung ausgeschweifet, so will

(570) weiter davon nichts gedencken, als daß es so keine / ausgemachte Sache seye wie viele davor halten / daß die Erfindung des Kupferstechens unsern / lieben Landsleuten allein zuzuschreiben seye. / Gleich wie aber dieße edele Kunst anfänglich / nur von wenigen getrieben worden, so / hat es doch nicht lange gewährt biß dergleichen / Arbeiter schier in allen Theilen Europens aufgestan- / den und sie in mehrere Vollkommenheit gebracht / haben worunter unserem Albert Durer jedes / mahlen der Preiß und der Vorzug ohnstreitig / geblieben. Sintemahl alle andere auch Italiener / selbsten wie wir oben von Marc Antonio Er/ wehnung gethan nach seinen Wercken sich ge- / übet, und um seine Vollkommenheit gebuhlet haben, wovon mit meheren Arend in Gedächt- / nus der Ehren Albert Durers 8 Goslar 1728. ${ }^{1652}$ / nachzulesen. Keiner aber hat es nach aller / Verständigen Zeugnus so weit als Lucas von / Leyden gebracht, welchen so gar verschiedene in / etlichen Stücken ihm vorziehen wollen, jedoch / ist er in dem Fleiße und der Anzahl von heraus- / gegebenen Wercken dem Durer nicht gleich ge- / kommen, deßen gesamtes Werck in Holtz Kupfer / und Zinn, als worauf er auch etliche Stücke ver- / fertiget, sich nach des Abbé Marolles de Villeloin / in 8 zu Paris $1666 .{ }^{1653}$ gedruckten Catalogo bey 400. / Stücke beträget, und an Kupfern allein 104 aus- / machet. Da hingegen von Lucas von Leyden / über 170 Kupfer, und gar keine Holtzschnitte be- / kant sind. Aus des Quatens

\footnotetext{
1650 Comte 1702.

1651 Orlandi 1719.

1652 Arend 1728.

1653 Marolles 1666.
} 
oben angeführ- / ten Buche teutscher Nation Herrlichkeit 4 Colln / 1609 p.428. ${ }^{1654}$ kan man übrigends wahrnehmen

(571) wie hoch bereits in denen alten Zeiten dieses un- / vergleichlichen Meisters Arbeit geschätzet wor- / den wenn er sagt:1655 was seine Kupferstück an/ gehet so werden derselben insgemein 100 ge- / zeilet[!] von kleinen großen und mittelbahren / durcheinander, neben diesen sind noch (aber / sehr kümmerlich zu finden) 4 oder 5 zum höchsten / welche noch unvollkommen, und dieß wird heut/ zutage das Buch Dureri genannt, und wofern / dießelbe Truck reinlich und wohl ausgedruckt / sind, beleuft sich dieß Buch ungefehrlich 100 / Goltgulten, etliche sind über 100 Frantze Cro- / nen verkauft worden etliche unter die 50. / Cronen nach dem sie frisch oder schlecht von / Papier und Truck waren. Man findet ein / klein rundes Crucifix darunter ohngefehr / eines halben Reichsthalers gros, kostet über / 2 Cronen. Seine hultzern Figuren belaufen / sich in der Zahl mehr denn noch eins so viel / und steht in gros Bedencken ob er in Hultz oder / Kupfer der artigst gewesen sey. etc. ${ }^{1656}$ Wenn / also dieser einzige Künstler der Nachwelt / seiner Zeit so viele Stücke hinterlaßen, so ist / sich leicht die Rechnung zu machen, welch eine / Menge dergleichen Kunstsachen nach und / nach zum Vorschein gekomen seyen, wovon / man keine beßere Nachricht aus dem eben / angezogenen Catalogo des Apts de Villeloin ${ }^{1657}$ / haben kan, welcher den Leser gewißlich er- / staunen machet. Es ist aber dieße Samlung / mit unerhörten Kosten von dießem großen / Liebhaber über die 400 starcke Bände bestehend / in Paris gemacht, und kurtze Zeit darauf in die / königliche Bibliothec daselbst von Ludwig dem XIV.

(572) erkauft worden, woselbst sie auch an 1715 in / einem Zimmer rings herum angefüllet mit / großer Verwunderung1658 gesehen. Wer aber dießem / Exempel auch nur im kleinen folgen wolte / wird mit mir gar bald innen werden daß ein / Verzeichnuß aller Kupferstecher, und zum Theil / Mahler höchst nöthig

\footnotetext{
1654 Quadt 1609.

1655 Das gesamte Zitat trägt auf der rechten Seite am Ende jeder Zeile Anführungsstriche.

1656 Zitat Ende.

1657 Marolles 1666.

1658 Vgl. Cod. Ms. Uffenbach 29/IV, S. 404: „Ein ander Zimmer [im Louvre] war ganz voll von lauter Kupferbücher, so die berühmte Collection des Abbé Marolles geweßen davon der Catalogus noch getruckt [= Michel de Marolles Abbé de Villeloin, Catalogue des Livres d'Estampes et de Figures en Taille-Douce, Paris 1666 ( $8^{\circ}$ Bibl. Uff. 527)], und welche er gar theuer an den König verkaufft hat, alle Bände waren gar schön von rothem Saphian mit Gold, und die Sachen selbst waren nach den Materien in gar guter Ordnung, bey welchem nicht allein die erschrecklicke Menge, sondern auch die Erlesenheit der Abdrucke admirirt, und gerne etliche Monat allein alhier zu gebracht hätte, [...].“
} 
dabey seye, welche ich aber / theils nirgends antreffen, theils auch ohn er- / achtet einer Mühe von 20. Jahren niehmahlen / tauglich zum Stande bringen können ${ }^{1659}$. Dannen- / her der vor erwehnte Apt denen Liebhabern / einen weit größern Dienst mit einen Nahmen / Catalogo, als einen Verzeichnus der Stücke nach / ihrem Inhalt gethan hätte. Er füget übrigens / als eine Vorrede den großen Nutzen der Kup- / fer an, und ist hierrinnen gantz anderer Meinung / als Georg Pasch in seinem schönen Werck De / novis inventis quorum cultui facem praetulit / antiquitas 4 Lips 1700. ${ }^{1660}$ welcher pag.793. erstlich / des angezogenen Quatens Worte ${ }^{1661}$ von der / Erfindung dießer Kunst buchstäblich nachschrei- / bet, und dazu setzet daß man noch nicht ausge- / macht habe ob sie mehr Nutzen oder Schaden / in der Welt gestiftet. Weil so viele ärger- / liche Bilder dadurch denen Wohlüstlern in / die Hände gekommen, da er dann mit denen Wor- / ten schließet: Digni qui relegentur in offici- / nas ubi piper venditur et thus. etc. Wie / armseelig aber der Schluß seye brauchet mei- / nes Wiederlegens nicht, weil die Sache in ihrem / rechten Gebrauche sich selbst verthaidiget[!]. / So viel hätte also meines wenigen Erachtens / von dem finstern Uhrsprunge des Kupferstechens

(573) zu sagen, welchem füglich eine Verzeichnung / der ersten Kupferstecher biß auf 1600 aus / meiner wenigen Erfahrung, mit ihren hin- / zugefügten Handzeichen oder Buchstaben an- / hengen könte, die weil aber dieses Mahl ohne- / dem die Gräntze einer Zuschrift überschritten, / so will es biß in das künftige verfahren, alwo / nicht nur hievon, sonder auch von verschiede- / nen Gattungen der Kupferstiche insonderheit / aber der Etzkunst, etwas weniges gedencken / werde. Ich empfehle mich schließlichen etc:

Soweit erstreckte sich dieses Mahl der ziemlich lan- / ge Inhalt meines vorgelesenen Schreibens von der / Erfindung des Kupferstechens, wobey denen Anwesenden / noch ein sicheres rahres und diese Sache betreffendes / Buch aus meines ältern Bruders Bibliotheque zeigete / nehmlich Ptolomaei opera. fol. romae $1480^{1662}$ worinnen / eine Menge großer in Kupfer gestochener Landkarten / befindlich waren, wie dieses nun an sich eine Rarität ist / und wohl ohnstreitig als die ersten Landkarten die jemahlen / in Kupfer ausgegangen anzusehen ist, so

1659 Vgl. sein Manuskript „Alphabetisches Verzeichnus aller Mahler, Bildhauer und Kupferstecher" (Cod. Ms. Uffenbach 36), s. Anhang.

1660 Pasch 1700.

1661 Quadt 1609.

1662 Hier unterläuft Johann Friedrich Armand von Uffenbach ein Irrtum. Diese lateinische Ausgabe des Claudius Ptolmaeus Cosmograophia, herausgegeben von Nicolaus Germanus, mit Kupferstichen versehen, erschien bei Peter de Turre in Rom erst 1490 und nicht schon im Jahre 1480. 
sahen wir / es dieses Mahl nur in Betrachtung der Kupferstiche und / ihrer Älte wegen an, da um solche Zeit, und also lang / vor Durern die Kunst in Italien augenscheinlich so üblich / gewesen und geblühet daß man so große Wercke von Land- / karten daselbst herausgegeben, so wird man wohl schwehr- / lich dergleichen von Teutschland aufweißen mithin also / nicht wohl leugnen können daß die Italiener recht haben / wenn sie sich der Erfindung der Kunst des Kupferstechens / rühmen. Das erwehnte Werck war übrigends bey dem / sonst bekanten Buchhändler in Rom, nehmlich apud Pe- / trum de Turre ${ }^{1663}$ verleget, und so wohl von Papier und Druck / als Stiche der Karten sehr sauber, obgleich was die Wis- / senschaft der Geographie betrift es gegen die heutigen / von keinem großen Belange seyn mag. Dieweil man / in selbigen Zeiten es in der Erden Beschreibung noch so / weit als itzo nicht gebracht hatte. [...]

\subsubsection{Von der Etzkunst}

Am 4 Juli 1732 referierte Johann Friedrich von Uffenbach den letzten Teil:1664

(590) [...] Uber alle vorher gemeldete Stücke nun laße der an- / wesenden Gesellschaft den 3ten und letzten Brief / betreffend die gesamte Bilderkunst auf Papier / und derselben uhrsprüngliche Historie für, wovon die / beyden ersten in vorigen Zusammenkünften bereits / unserer Samlung einverleibet; dieser gegen- / wärtige handelte nunmehr von der Etzkunst, oder / denen Kupferstücken so vermittelst des Scheidewas- / sers unsere neüere Künstler zu machen ersonnen / und damit die sonst sehr mühsame und lang- / weilige Arbeit des Kupferstechens mit dem Grabsti- / chel abgekürzet und erleichtert haben. Der Inhalt / davon folget hiernechst, und enthält nechst dem auch / andere Arten von Kupferstücken, die auf neuere Ma- / nier gemacht, oder auch mit Farben zu Wege gebracht worden.

\section{(591) Von der Etzkunst}

Zufolge meinem Versprechen so in meinem vorher / $\mathrm{zu}$ gesendeten Untersuchungen der uhrsprüng- / lichen Historie über die gesamte Bilderkunst / auf Papier gethan habe, fahre ich dieses Mahl / weiter fort und erwehle mir die so genannte / Etzkunst auf Kupfer und andere Metalle zu mei- / nem Vorwurf, in

1663 Pietro della Torre (gebürtig aus Como, geht nach Rom, tätig im 15. Jahrhundert), vgl.: http://www.treccani.it/enciclopedia/pietro-della-torre_res-36194768-87ec-11dc-8e9d0016357eee51_(Dizionario-Biografico)/vom 01.03.2018).

1664 Cod. Ms. Uffenbach 13/IV, S. 590-604. 
dem ich dafür halte daß ich / das nöthigste von dem Kupferstechen bereits / abgehandelt habe, gleich wie ich aber damahls / mit gutem Vorbedachte zu behaupten gesuchet / daß man den ersten Erfinder einer so nützlichen / als schönen Kunst nicht allerdings gewiß wiße, / und daß gantz zufälliger Weiße ausgesonnen / worden seye, so will ich auch dieses Mahl von / dem Kupferetzen das erstere gleichfalls darthun. / Hiernechst aber auch dabey muthmaßlich sagen, / daß sie nicht vorbedächtlich wie jene erfunden / worden, dann da einmahl die Liebhaberey Bilder / mit dem Grabstichel in Kupfer zu schneiden, in / vollen Gange ware, so legten sich alsobald viele / Meister auf diese so wohl einträgliche als liebli- / che Arbeit, keiner aber langte zu einer sattsamen / Vollkommenheit der nicht die rahre Gabe der lieben / Gedult in voller Mase besäße. Dann es ist eine / ausgemachte und bekannte Sache, daß keine Kunst / Arbeit so zärtlich so mühsam, und langweilig / seye als eben das Kupferstechen mit dem Grab- / stichel, so daß auch viele große Kenner der Mahle- / rey sie eben aus der Uhrsach verkleinern wollen, / die weil ein Künstler so lange Zeit über dem in / seinem Sinne gefaßten Uhrbilde sitzen, und Ar- / beiten müße, daß die Abschilterung davon auf / dem Kupfer hernachmahls nicht anderst als steif / und gezwungen herauskommen müße, in Gegen- / haltung einer mit dem flüchtigen Pinsel ent- / worfenen Mahlerey, wobey die Hände weit hurti- / ger

(592) ger munterer lebhafter und geistreicher das / jene vollbrächten was sich die Einbildungskraft / in ihrem ersten Feuer vorgenommen habe. Aus / welcher Uhrsache auch rechte Liebhaber die erste / Umriße oder den schlechten Entwurf auf Papier / eines großen Meisters denen hernach ausge- / fertigten Mahlereyen weit vorziehen. Wenn / nun dergleichen Liebhaber hierinnen nicht eben / gar unrecht haben, so ist doch eben daßelbe die / Gelegeheit, welche das Kupferetzen auf die / Welt gebracht. Viele Künstler hatten entweder / nicht die Gedult, oder auch die erforderliche Fertig- / keit ihrer Hand zu dem Grabstichel, und wolten / es jedoch andern hiermit begabten nachthun, so / fiele der menschliche Witz endlich auf die Gedan- / cken, ob man nicht das Kupfer mit einer hartzigten / Materie überziehe, hierin mit einen Griffel / radieren, und solche entblößete Züge nachmahls / mit aufgeschüttetem Scheide, oder Etzwaßer ein / und ausfreßen laßen könte, wodurch sodann / alle erforderliche Riße eines Bildes auf einmahl / und zwar in gar weniger Zeit zu Stande kähmen, / die Probe wurde also von verschiedenen ange- / stelt, und die Sache gantz möglich und gemächlich / erfunden, wann und von weme aber die erste / geschehen seye, das ist nunmehro eben so eine / strittige und dunckele Frage, als meine ersten / beyde von dem Holtzschneiden und Kupferstechen / Geweßen. Alles was wir in 
Geschichtschreiben / davon aufgezeichnet finden, ist lange nicht hin- / länglich eine Gewißheit zu haben, wer der erste / Arbeiter in dieser Kunst, welche die Kupfersteche- / rey selbsten zielich aus der Übung gesetzet / möge gewesen seyn. Der bereits ofters er- / wehnte Georg Vassari meldet in seinem Buche / Vite de gli pittori 4. Bologna 1647. p.299.seq. ${ }^{1665}$ / daß Francesco Permesanin ${ }^{1666}$ an 1530 derjenige / geweßen seye so mit dem Etzen den Anfang ge- / macht

(593) macht habe, allein sein beständiger Gegner San- / drart, und viele andere Teutsche nach ihm haben / meines Erachtens sattsam erwießen daß dieße / Kunst eine ziemliche Zeit vorher in Teutschland / bereits üblich war, wie man dann von Albert / Durern, der ohnstreitig vor einen der ersten in / dießer Arbeit zu halten, das Bildnus von Christo / im Öhlgarten, und die Engel mit der Passion ${ }^{1667}$ / worauf die Jahrzahl 1515. und 1516. befindlich, wie / auch ein großes Blat worauf Geschütz abgebil- / det und 1518 radirt worden ${ }^{1668}$, in denen Bilder- / sammlungen der Liebhaber aufweißen kan, welche / bereits so meisterlich geetzet sind, daß man ver- / nünftig wohl schließen kan, es müßen dieße / Stücke nicht die erste Proben sondern die Folge / von vielen andern vorher gemachten geweßen / seyn. Wenn ich aber in meinen vorigen Unter- / suchungen von Holtzschnitten und Kupferstechen / ebenfalß dieße beyde Geschichtschreiber [!], als die / vornehmsten in gegen wartig unterhanden / habenden Kunstsachen angeführt, und was das / erste betrift die Erfindung meines wenigen / Vermuthens denen Teutschen, des andern / aber denen Italienern beygeleget habe, so / so würde ich gegen die helle Wahrheit handeln wenn / ich abermahl nach der Erwehnung Albert Durers / Arbeit bey der Meinung des Vassari stehen bleiben / wolte, alhier hat Sandrart einen Beweisthum / beygebracht den kein Unpartheyischer umstoßen / und denen Welschen recht geben kan, es seye / dann Sache daß man künftig ältere geetzete / Stücke als die benennte könte vor Augen legen; / wenn wir hiernechst den teutschen Hauptver- / fechter den mehr angezogenen Math. Quaten / in seiner Herrlichkeit teutscher Nation ${ }^{1669}$ auch / über dießen Vorwurf anhören

\footnotetext{
1665 Vasari 1648.

1666 Francesco Mazzola, gen. Parmigianino (1503-1540).

Nach seinem eigenhändigen Inventar besitzt Uffenbach drei Blätter von dem Künstler.

1667 Das Schweißtuch, von einem Engel gehalten, Eisenradierung, 155 x 131 mm, M.27. Im Besitz von Uffenbach.

1668 Die große Kanone, 1518, Eisenradierung, 220 x 322 mm, M.96b. Im Besitz von Uffenbach. 1669 Quadt 1609.
} 
wollen so / sagt er in meiner Ausgabe ${ }^{1670} 4^{\circ}$ Collen. 1609 / p.431. folgendes. Ungefehrlich um das Jahr

(594) 1570 haben zween Gebrüder Joan und Lucas van / Dotecum ${ }^{1671}$ eine gantz neue und überkünstige [!] Art / von Etzen erfunden, also daß sie allerhand Figuren / Landtafeln mit allen Schriften und Littern darin / so rein, greef [!], lind und verblasen [!] in Kupfer etzen / kunten und noch künnen daß es lange Zeit von / vielen Verständigen für keine Etzung sondern / einen reinen Schnitt ist angesehen worden. / Die Kunst blieb bey ihnen gantz verborgen biß Lucas / mit Todt abgegangen sein Bruder Joan es nach / etlich Jahr seinen beyden Söhnen Baptisten und / Joannen auch offenbahret die es jetz und zu Haerlem / üben und mit geringer Arbeit viel herrlicher Ta- / feln an Tag geben. etc. Hieraus wird ein jeder / nun mehr nach dem gehörten leichtlich urtheilen / daß der Historienschreiber in dießer Sache etwas / zu kurtz komme, und zu jung seye, da wir die vor- / habende Kunst von weit ältern Jahren her geführt / und erwiesen haben. Wer aber dieße beyde / erwehnte Meister eigendlich geweßen, habe / weder in Vermanders ${ }^{1672}$ und Houbraken Schilder- / boek ${ }^{1673}$, nach andern Lebensbeschreiber der nieder- / ländischen Künstler finden können, all die weil / solches nach meinen ersten vorlaüfigen Gedan- / cken Lucas von Leyden nicht geweßen, der bereits / 1533 verstorben. Alle dieße vorhergehende Nach- / richten scheinet der gelehrte Engelländer Joh / Evelyn ${ }^{1674}$ nicht gehabt zu haben in dem er in seiner / History of Chalcography 8 London 1662 p.48 / schreibet Fran. Parmegiano may be estesmed / for one of the first that brought the use of / aqua fortis into reputation, so tender and grace / full were some of his etchings as appears in / that rare descent of the Cros, nativity ans se- / veral other pieces etc. Weil er vermuthlich / die vor erwehnte Durerische Stücke wie viele / gethan vor gestochen angesehen. Gleich wie / aber alles dießes was bißher von dem Etzen gespro- / chen worden nur allein den Uhrsprung dießer Kunst

(595) betrift, so kan man sich einbilden daß sie sich ihrer / leicht und Gemächlichkeit halber gar bald über all aus- / gebreitet habe, es ist aber dieses nicht nur allein / geschehen, sondern es hat auch dem Kupferstechen / selbst einen solchen Stoß gegeben, daß wir heut / zu Tage wenig Stücke zu sehen bekomen die

\footnotetext{
1670 Das Buch stammt nicht aus der Bibliothek Uffenbachs, wahrscheinlich besaß sein älterer Bruder ein Exemplar und der Autor meint mit „meiner Ausgabe“ die von ihm verwendete.

1671 Jan van Duetecum (tätig von 1530 bis ca. 1606) und Lucas van Duetecum (tätig 1554/1572; starb vor 1589).

1672 Mander 1618.

1673 Houbraken 1718.

1674 Evelyn 1662.
} 
alleine / mit dem Grabstichel nach alter Art verfertiget / sind. Zumahlen da die heutige Künstler insge- / mein beyde Arten mit einander zu verbinden / pflegen solcher Gestalt werden alle rechtlinigten / Schrafirungen und Umriße mehrentheils ge- / etzet, die in die Runde lauffende aber, und die / jenige so hinten starck und fornen [!] spitzig zulauffen / als denn mit dem Grabstichel nachgehohlet wenn / die erste Etzung behöriger Maßen geschehen. / Ohneracht deßen giebt es doch auch Bilder wel- / che gantz radiert vor meisterlich gehalten werden / wie Simon Fris, Rembrand ${ }^{1675}$, Callot ${ }^{1676}$, Wenzel Hollar ${ }^{1677}$ / Math. Merian ${ }^{1678}$ unter denen neuern und viele / andere ausnehmendlich gethan. Daß aber der- / gleichen gantz geetzte Stücke denenjenigen an / Kunst und Schönheit beykommen sollen welche ent- / weder allein mit dem Grabstichel verfertiget / oder mit demselben vorgemeldeter Weiße nach- / gehohlet und geendiget worden, wird nicht leicht / ein Kunsterfahrner zugeben. Jedoch hat ein / sicherer Frantzose Abrah. Bosse ${ }^{1679}$ eine solche Art / von Radirnadeln und Etzen in einen besonders / darüber geschriebenen Tractat angegeben, wo- / mit eben solche spitze zulauffende und runde / Schrafirungen könten gemacht werden, gleich / wie mit dem Grabstichel, allein es ist dieße / Weise zu arbeiten so künstlich und anstößig daß / man schier mit eben der Mühe den Grabstichel / selbsten zu behandeln erlernet. / Wenn ich nun auf solche Art in der Kürtze alhier / dasjenige so bey dem Etzen zu melden vor nöthig / erachtet angeführet habe, und mich hiernechst / er

(596) errinnern daß mich anheischig gemacht noch von / etlichen Arten von Kupferstichen, so zu unsern / neuern Zeiten ersonnen worden, Erwehnung / zu thun, so werde mich anfänglich zu der in Holland / ehedeßen aufgekommene Art Kupferstiche mit 2 / und mehr Farben abzudrucken. Man hat hiedurch / die Art der Holtzschnitten so man Chiaro oscuro / oder Mezo tinto zu nennen pfleget und anfanglich / von Hugo da Carpi wie oben errinnert verfer- / tiget worden, nachahmen wollen, und zwar so / viel ich davon muthmaßen kan, also, daß man ver- / schiedene Platten einer Größe gazu genommen, auf / einer die schwartze

1675 Rembrandt Harmenszoon van Rijn (1606-1669).

Nach seinem eigenhändigen Inventar besitzt Uffenbach 181 Blätter des Künstlers; vgl. Kat. Göttingen 1993, wo alle Blätter von Rembrandt aus Uffenbachs Besitz aufgeführt sind.

1676 Jacques Callot (1592-1635).

Nach seinem eigenhändigen Inventar besitzt Uffenbach 113 Blätter des Künstlers.

1677 Wenzel Hollar (1607-1677).

Nach seinem eigenhändigen Inventar besitzt Uffenbach 145 Blätter des Künstlers.

1678 Matthäus Merian (1593-1650).

Nach seinem eigenhändigen Inventar besitzt Uffenbach 73 Blätter von „Mathaeus, Caspar et Anna Sybilla Merian MM“.

1679 Bosse 1719. 
Schatten und Figuren allein ge- / stochen auf einer andern diejenige so roth und noch / auf andern die grün oder wie man die bereitete / Farben hat, haben sollen, gedruckt werden, wenn nun / alle dieße Platten nacheinender auf ein genäßtes / Papier abgezogen worden, so ist ein buntes und mah- / lerhaftes Bild herausgekommen, das die unerfah- / rene in nicht geringe Verwunderung gesetzet. Dergleichen Arbeit nun hat man vornehmlich in / Amsterdam an historischen Bildern Landschaften, / Bluhmen Gevögel, Anatomie, und Baukunststücken / ja allerley Vorfällen angebracht welche dem Auge / ein veränderte Lust dem Arbeiter aber keine an- / dere Bemühung gemacht, als alle Blatten [!] be- / hutsam abgewischet, und jedes mahlen auf den- / selben Papiere gar ordentlich geleget und ab- / gedrucket werden müßen, dann sonsten hätten / sich die Farben vermischet und das Bild verdor- / ben. Dieße bunte Kupferstiche haben nach- / mahlen einigen Liebhabern und Künstlern An- / las gegeben die Sachen weiter nach zu dencken / gleich wie dann ein sicherer Franckfurter ge- / schickter Mahler so sich in Amsterdam und letzlich / in London haüßlich niedergelaßen, nahmens Ms. / le Blond ${ }^{1680}$, eine gantz besondere Art von Kupfer-

(597) stichen mit Farben also abzudrucken ersonnen daß / sie ein jeder vor Gemälde würde ansehen, der / des Gegentheils nicht ausdrücklich versichert würde. / Es sind nehmlich darinnen alle Farben der Gestalt / in einander vertrieben und meisterlich ange- / bracht daß sie der geschickteste Künstler mit sei- / nen Pinsul nicht regelmäßiger durcheinander / bringen und anordnen kan, und weil er mit / dießem seinen neuen Geheimnüße sich großen / Vortheil zu machen versprache, so hat er vor / wenig Jahren eine große Werckstatt von vielen / Arbeitern zu dießer Kunst mit Hülfe einer ziehm- / lichen Anzahl vornehmer und begüterter Per- / sohnen die alle einen Beytrag zu Bestreitung / der Kosten gethan, in London aufgerichtet, die / Sache auch so weit gebracht daß man ein große / Menge dergleichen Bilder als in Öhlfarbe gemahl- / te Altar und Kirchenstücke nach Spanien und / Italien gesendet, welche da es noch gantz was / neues gewesen ihren Herrn und Teilhabern an / dießem Unterfangen die Auslage ziemlich er- / setzet. Man hat insgemein der gleichen Stücke / auf Leinwand nach dem sie mit Farben ab- / gedruckt gewesen, gezogen, und hier und dar die / höchste Lichter mit einen Pinsul und Farben er- / höhet, so dann aber einen weisen und klahren / Firnüß darüber gezogen, wodurch das Werck / ein gar schönes Ansehen erhalten. Ich meines / Orts aber hätte lieber ein Stück unaufgezogen / aus ihrer Werckstatt

1680 Michel Leblond (1587-1656).

Nach seinem eigenhändigen Inventar besitzt Uffenbach 24 Blätter von Leblond; heute werden ihm elf Blätter zugeschrieben. 
haben mögen, das aber, ob / mich gleich viel darum bemühet, doch niemahlen / erhalten, und nichts anders als die Bilder laccirt / bekommen können. Allein gleich wie dieses nur / zufälliger Weise alhier erinnere, so will nechst / dieser besondern Art von Kupferstichen, noch / einer andern gedencken, die zwar mit keinen Far- / ben gedruckt aber darinnen von denen gemei- / nen unterschieden wird daß die Schatten und

(598) Schrafirungen nicht mit Strichen und Linien, son- / dern lauter Punckten wie in dem Mignintur- [!] / mahlen brauchlich heraus gebracht werden. / Gleichwie aber die itzo genente Gattung von / Mahlerey die aller mühsamste und langweiligste / ist, so gehet es auch it dießer Manier in Kupfer / zu stechen her. Davon man in sonderheit von / frantzöschen Meistern ungemeine Proben der Ge- / dult siehet. Etliche unserer Teutschen Meister / haben solches nicht minder gezeiget, insonder- / heit der noch lebende kayßerl. Kupferstecher / H. Pfeffel ${ }^{1681}$ von welchem ein Crucifix besonders / mühesam gearbeitet besitze. Nebst dem ist mir / von einem Amsterdamer Künstler eben eine / solche schöne Arbeit im großen zu Handen gekom- / men, deren Stich nicht nur punctirt sondern / auch das Bild mit Farben abgedruckt ist, es stellet / ein nackendes Kind vor, woran alle Farben so / scharf eingetheilet die Puncten aber so meister- / lich verjüngt und vergrößert in 3 besondern / Platten weil 3erley Farben daran sind angebracht / worden, daß man die große Sorgfalt des Künst- / lers nicht genug bewundern kan. Außer dießer / mühsamen Art von Kupfer hat man noch eine / andere welche insonderheit Claude Mellan ${ }^{1682}$ ein / Frantzose gebrauchet, da er seine Bilder, so groß / sie auch geweßen nur mit einem in die runde / und einer Schneckenlinie laufenden Striche / ohne alle Umriße der Gestalt meisterlich vorge- / bildet als ein anderer mit scharfen Umrißen / und alle Creutzschrafirungen kaum thun können. / In der Sandrartischen Mahleracademie ${ }^{1683}$ finden / sich eben dergleichen schöne Vorstellungen einiger / Statuen die ein Schweitzer Kupferstecher nahmens / Thurneiser ${ }^{1684}$ dem erst gedachten nach gethan, / und ziemlich wohl damit zustande kommen, je- / doch mit dem Unterschiede daß er nicht eine / Schneckenlinie allein, wie jener an dem Bildnus

\footnotetext{
1681 Johann Andreas Pfeffel (1674-1748).

Nach seinem eigenhändigen Inventar besitzt Uffenbach drei Blätter des Künstlers.

1682 (1598-1688).

1683 Sandrart 1675.

1684 Johann Jacob Thurneysen (1636-1711); Sandrart 1675, Tafel c: Laokoon; Sandrart 1679, Tafel aa: Antinous, Tafel bb: Venus.

Nach seinem eigenhändigen Inventar besitzt Uffenbach 5 Blätter des Künstlers.
} 
(599) Christi und Maria ${ }^{1685}$ schier lebensgroß gebraucht, / angebracht, sondern vieler gleichlaufenden / Zirckel sich bedienet. Unter die gar mühsame / Arten von Kupferstichen kan auch ferner diejenige / gezehlet werden, welche einige Künstler mit / lauter ineinander laufenden über aus kleinen / Schriften gebrauchet, um damit entweder / gantze Bilder und die Haare und Peruquen der- / selben vorzustellen da mittelst das Gesicht auf / Migniatur Art punctirt worden, ich habe / derselben allerley Arten in meiner kleinen Samm- / lung theils ohne Nahmen theils von einem F. / Michael Puchler ${ }^{1686}$ gestochen, unter andern ein / ziemlich groses ecce homo in deßen Bart und / Haare die gantze Passions Historie angebracht / worden, ob nun zwar die Kunst in dergleichen / Stücken eben nicht ausnehmend groß ist, so sehe / ich doch die unerhörte Gedult als vor etwas / besonders an, und mag derohalben dieße Art / wohl unter denen verschiedenen Gattungen der / Kupferstichen mit erwehnet werden. Mehrere / Aufmercksamkeit und Lob der Kenner aber ver- / dienet noch letzlich eine besondere Manier die / ein holländischer Goldarbeiter nahmens Peter / Lutma ${ }^{1687}$ an seinen Kupferstichen sehen laßen / Dieße sind ohne Grabstichel und Etzwaßer, und / wie er selbsten auf die Abdrucke gesetzt, allein / mit dem Hammer und Punzen ohne einigen Um- / riß verfertiget. Opus mallei nennet er es / selbsten, aber gewißlich eine ungemeine mei- / sterliche Arbeit wovon sein eigenes und seines / Vaters Bildnus, dasjenige von dem holländi- / schen Poeten Vondel, und etliche andere Stücke / besitze ${ }^{1688}$, und nie genug betrachten oder bewundern / kan. Daß aber dieße Kunst einen vollkome- / nen Meister im Zeichnen und Treiben verlan- / get kan ich wohl daraus abnehmen, daß mir / kein einiger [!] seit dem vor Augen gekommen, der es

(600) dießem geschickten Lutma hat wollen oder können / nachmachen, so daß wie es scheint die damahli- / ge neue Art von Kupferstücken mit ihrem / Erfinder abgestorben. Gleich wie nun dießes / die vornehmste Gattungen derselben sind, die / ich bißher nach der Reihe erzehlet, so wüste ich / keine Art dieser Liebhaberey mehr die mir übrig / wäre als die zu unsern Zeiten ausgekomene / und nun sehr hoch getriebene so genante / schwartze Kunst. Die Handarbeit daran ist der / vorangegangenen Kupferstecherey gantz entge- / gen, dann wie man in

\footnotetext{
1685 in Kupferstichkabinett raussuchen

1686 Johann Michael Püchler (1679-1709).

Obwohl Uffenbach schreibt, daß er Werke von Püchler besitzen würde, führt er sie in seinem Inventar nicht auf.

1687 Hier irrt Uffenbach bei Nennung des Vornamens. Es handelt sich um Janus Lutma d.J. (1624-1685);

Nach seinem eigenhändigen Inventar besitzt Uffenbach 25 Blättter des Künstlers.

1688 in Kupferstichkabinett überprüfen
} 
dießer von dem hellen / immer in den Schatten und das dunckele arbeitet / so gehet man hingegen in jenen aus dem völligen / Dunckeln zu denen Lichtern, das ist die gantz eben / geglättete Kupferblatte [!] wird mit einen beson- / dern Werckzeuge, oder auch auf eigenen hiezu / angeordneten Mühlen über und über der Gestalt / überkerbet, überadert und übergangen, daß / wenn man sie so dann solte abdrucken das $\mathrm{Pa}$ - / pier davon kohlschwartz ausfallen würde, dieße / also überaus gleich und fein bereidete Platte wird / insgemein auf eine Staffeley, wie die Ohlfarben- / mahler haben, gestellet, die Zeichnung mit aller / Sorgfalt darauf gemacht, und das Bild der Gestalt / durch Schaben und Abgraben des schwartzen / Grundes herfür gebracht, daß man erst die dun- / ckelste und so weiter immer die hellere Lichter / glatt poliret biß man endlich die groste Höhen / gantz hell schabet die weil nun dieße Arbeit / weit lustiger und behender als das mühesame / Kupferstechen und Etzen von statten gehet, da / zu auch keine des Grabstichels mächtige Hand / erfordert wird, das nicht jeder Mans Thun ist, / so hat es zu unsern Zeiten der Liebhaber und / Arbeiter gar viele gegeben die sich daran ge- / macht und ihre Fähigkeit nach und nach meister- / lich gezeiget haben, sie erfordert aber einen

(601) im Zeichnen überaus festen Meister, und hat den / Mangel, daß die Abdrücke davon mühesamer / genommen werden müßen und solche bei weitem / an die Zahl nicht reichen, welche eine gestochene / oder geetzete Platte auszustehen vermag. / Die weil aber in unserer bißherigen / Untersuchung die meiste Absicht auf den Er- / finder der Kunst gegangen, so fraget es sich / auch dieses Mahl wer dießer geweßen, und / hierüber finde auch die Geschichtschreiber über / Künste ziemlich unterschieden, das sich vor / unsere kurtze Zeit, binnen welcher das Werck / den Anfang genommen, wie billig zu verwun- / dern, und daher abzunehmen ist, wie schwehr / es falle ein Licht in Künstendiesfalß zu finden / deren gebührt in weit ältern Zeiten hinauf / laufet. Sandrart in seiner Mahler Academie 1689 / fol Nurnb. 1675. 1. Theil 3 Buch. p. 101. meldet / hievon daß ein heßischer Obrist Lieutenant / nahmens von Siegen ${ }^{1690}$ an. 1648 der Erfinder / davon geweßen wie er es an etlichen Abbil- / dungen großer H[erren] sehen laßen, und von dießem / seye die Wißenschaft auf den in London sich / damahls befundenen Printz Rubrecht von der / Pfaltz ${ }^{1691}$ des unglücklichen Friderici V Königes 1692 / in Böhmen 2ten Sohn und Vice Admiral von / Engelland

\footnotetext{
1689 Sandrart 1675.

1690 Ludwig von Siegen (1609-1680).

1691 Ruprecht von der Pfalz (1619-1682).

1692 Friedrich V. von der Pfalz (1596-1632).
} 
und Churfürst Carl Ludwigs von / der Pfaltz ${ }^{1693}$ Brudern gekommen, welcher da / er ein auserordentlicher Liebhaber der Künste / und selbsten ein überaus erfahrner und ge- / chickter Arbeiter geweßen, dieße neue Hand- / arbeit zu mehrerer Vollkommenheit gebracht / habe, von dem es nachmahlen Vaillant ${ }^{1694}$ und / andere Künstler abgesehen und weiter getrie- / ben, gleich wie nun dießes Behaupten viele / unserer Teutschen Bücherverfaßer und auch / Ausländer ihrer Gewohnheit nach getreulich / nachgeschrieben, so ist es kein Wunder, daß der

(602) Ritterplatz 8 Hamb 1706. ${ }^{1695}$ in dem 1 tom. p.168. / Doppelmayer von nürnbergischen Künstler ${ }^{1696}$ / fol ibi 1730. p. 235 und viele andere eben also / sprechen, allein der oben angeführte Gelehrte / Joh. Evelyn in the history of Calcography1697 8 / London 1662. wendet zu dem gebührenden / höchsten Ruhm dieses durchlauchtigen Erfinders / die Sache der Gestalt um, daß er mit vielen Um- / ständen gantz unschuldig erweiset, wie gedach- / ter unsterblicher Künstler Printz Rubrecht die / Wißenschaft nicht nur zu erst ersonnen, son- / dern auch recht meisterlich zu seinem höchst rühm- / lichen Zeitvertreib geübet habe. Seine Worte / sind 1.c. also this obligation then we have to / his highness prince Robert Count Palatine of / Rhyne who has been pleard to cause the intru- / ment to be expressly fitted to Schew me with / his own hands how to manege and conduct / them on the plate that it might produce the / effects. und vorher Nor may I without extra- / ordinary ingratitude comeal thusillustri- / ons Name wich did comunicate it to me, / nor the obligation wich the curious have to / that heroic person who has pleasd to impart / it to the world though by so incompetent and / unworthy an instrument. Es wird hier also / keines Weges eines Vorgängers nehmlich des / angeführten Obrist Lieutenants gedacht, und / da aller sonst vermuthliche Argwohn, als ob / Standspersohnen die Künste in so weit nicht / selbsten behandelten, von dießem ungemein / fertigen und in gar vielen Wißenschaften / höchst bewanderten Erfinder von selbsten weg- / fallen, so sehe ich nicht, warum die Nachwelt / ihme das verdiente Lob entziehen will, vieleicht / aus keiner andern als der unbilligen Uhrsache / daß seine durchlauchte Geburth ihn über aller

\footnotetext{
1693 Karl I. Ludwig von der Pfalz (1617-1680).

Nach seinem eigenhändigen Inventar besitzt Uffenbach drei Blättter des Künstlers. Im Kupferstichkabinett der Kunstsammlung der Universität Göttingen befindet sich heute nur ein Blatt.

1694 Wallerant Vaillant (1623-1677).

Nach seinem eigenhändigen Inventar besitzt Uffenbach 19 Blättter des Künstlers.

1695 Der geöffnete Ritterplatz 1706.

1696 Doppelmayer 1730.

1697 Evelyn 1662.
} 
(603) Privatpersonen Ruhm hinaus setzen mögte. / Es hat aber dieser zum Exembel der Nachahmung aller seines gleichen hocherfahrne Printz viele / von seinen Probstücken der Nachwelt hinterlaßen / worauf sein Zeichen P R mit einer Fürsten Krohne / stehet, und deren ich biß in 10 Stücke selbsten aus / zu finden das Glücke gehabt. ${ }^{1698}$ Ja es meldet der vor- / hin angezogene Evelyn ${ }^{1699}$ p. 147 and I am here ready / to Shew the world in a pice of his own illustrious / touching, wich he was pleasd to honnour this work / withall, not as a venal addition to the price of / the book, though for wich alone it is most valua- / le, but a particular grace as a specimen of what / we have alledged and to adorn this present chap- / ter. Dieße Probe nun ist an einem Haupte, da- / von ich nachmahls das gantze Bild in einen großen / Real Bogen erhalten und das den Schärgen vor- / bildet, der den Johannen enthauptet, selbst dem / gelehrten Tractate ein verleibet, und das gantze / Capitel voller Zeugnus daß der Erfinder keinen an- / dern Lehrmeister als sich selbst gehabt habe. Gleich / wie ich auch nach der Hand dießen Verlauf in ver- / schiedenen Schriften absonderlich aber in Weigels / Abbildung der Künstler und Handwercker 4. Nurnb. / 1698.1700 einem Buche das gewißlich zu mehr als blo- / sen Bilder durchblättern dienet, p.205. angezo- / gen gefunden. Es ware aber diese Wißenschaft / kaum der Welt bekant so machten sich also bald / viele Künstler darüber unter denen zwar Vail- / lant ${ }^{1701}$ einer der ersten geweßen der aber hernach / durch verschiedene Amsterdamer Meister inson- / derheit aber durch den londischen John Smith ${ }^{1702}$, / wie auch verschiedenen Teutschen übertrofen / worden, gleich wie dann zu Augsburg die Kupfer- / stecherey durch diese Kunst und die Menge der Ar- / beiter abermahl einen nicht geringen Stoß erhalten ${ }^{1703}$ / und zu befürchten stehet daß sie künftig noch mehr / unbrauchbahrer dadurch werden werde. / In denen gantz letztern Zeiten haben sich auch Künstler

(604) besonders an dem letzt erwehnten Samelplatze aller / schönen Wißenschaften gefunden welche eben / diese schwartze Kunstblätter mit allerley lieblichen / Farben abzudrucken ersonnen, gleich wie mir dann / braune,

\footnotetext{
1698 Uffenbach kann mit „,selbsten aus zu finden“ nur meinen, dass er zehn Blätter von Ruprecht von der Pfalz studiert hat, denn nach seinem Register besitzt er drei Blätter des Künstlers.

1699 Evelyn 1662.

1700 Weigel 1698.

1701 Wallerant Vaillant (1623-1677).

Nach Uffenbachs Verzeichnis besitzt er 19 Blätter des Künstlers.

1702 John Smith (1652-1743).

Nach seinem Verzeichnis besitzt Uffenbach 33 Blätter des Künstlers.

1703 Kenkel o.J. Es handelt sich hierbei um die 21 Blätter der Nürnbergischen Maler-Academie. Die Vorlagen stammen von Johann Martin Schuster (1667-1738), Johann Kenkel (16881722) stach die Platten und Christoph Weigel verlegte das Werk.
} 
himmelblaue, rothe, grüne, und noch meh- / rern dergleichen also abgedrucket zur Hand gekommen / die aber weil sie vermuthlich nichts anders als / eine veränderte Einfärbung der Kupferplatten, / und die Wißenschaft so thane Farben zu zu bereiten / zum Grunde haben, keine besondere Gattung der / Kupferstücken abgeben können. Gleich wie ich / nun bißher alle Arten dießer Liebhaberey, so mir / bekant worden in der Kürtze durchgangen, und / vornehmlich derselben Uhrsprung so viel uns / davon wißend ist, berühret, als muß ich noch zum / Beschluße einer besondern Art gedencken, davon / verschiedene Stücke besitze, und worin alle Manier / in Kupfer zu arbeiten an einem Blatte ange- / bracht sind, es ist nehmlich der Grund, schwarte / Kunst die Umriße und tiefste runde Schatten / mit dem Grabstichel nach gehohlet, und die linde / gerade Züge hier und dar ohnstreitig geetzet. Die / selbe sind von einen Pariser Arbeiter wie es / scheinet aus Liebhaberey gemacht, und eben nicht / gar viel nach geahmet worden. / Sind dießem allen nach meine gegenwärtige we- / nige Nachrichten einer Aufmerckung werth, und / in Stande einen Untericht zu geben so soll mich die / daran gewandte Mühe nicht thauern, mit dem / Verzeichnus der alten Meister samt ihrer Zeichen / und erörterten Nahmen ${ }^{1704}$, so viel mir davon zu / erforschen möglich geweßen aufwarten werde / der ich übrigends $\mathrm{p} p$.

So weit erstreckte sich dieses Mahl mein Aufsatz und / Schlußrede über diese Materiae, welche der Gewohnheit / nach hier gantz einzurücken vor nöthig erachtet / die weilen es bey den vorigen Untersuchungen / von Kupfer ebenfals geschehen.

\subsubsection{Vom Drucken von Pflanzenblättern}

Nach Beendigung der Referate zur Geschichte der graphischen Künste griff Uffenbach das Thema am 10. Juli 1733 anläßlich einer angeblich neu erfundenen Drucktechnik nochmals auf. Es handelt sich um das Verfahren des Naturselbstdruckes von Pflanzenblättern auf Papier, das der Erfurter Arzt Johann Hieronymus Kniphof ${ }^{1705}$ vorgab entwickelt $\mathrm{zu}$ haben und nun ein großes Kräuterbuch durch den Erfurter Verleger und Drucker Johann Michael Funcke1706 herausgeben ließ. ${ }^{1707}$

\footnotetext{
1704 Johann Friedrich von Uffenbach, Alphabetisches Verzeichnis aller Mahler, Bildhauer und Kupferstecher ... (Cod. Ms. Uffenbach 36).

1705 Johann Hieronymus Kniphof (1704-1763).

1706 Johann Michael Funcke (1678-1749).

1707 Cod. Ms. Uffenbach 13/V, S. 139-140 mit einem Probebogen Kniphofs.
} 
(139) [...] Kame unsere gewohnliche Gesellschaft nach / einem kleinen Aufschube, bey mir zusammen / wobey ich zum Anfange eine Probe von einem / neuen Kraüterbuche das zu Erfurt bey Michael / Funcke gedruckt und von Joh. Hieronymo Kniphof / med. Doct. als eine ganz neue und besondere / Art von Abzeichnungen oder Drucken von Pflanzen / herausgegeben wird, vorzeigete; Es ist nehmlich in dem / vorhergehenden IVten Bande unserer Samlungen pag / 504 und 553 eine Untersuchung von allen Arten / von Kupferstücken derselben Erfindung und Unter- / scheid fürgekommen, welche gegenwärtige so genante / neue Gattung als ein Zusatz nicht undienlich an- / zufügen ist, die gedruckte Anzeige hievon, giebt folgen- / de Umstände zu erkennen: ${ }^{1708}$ der erste tomus dieser / Botanica in Originali, wovon bereits 200 Stück fertig, hält / alle Officinali, der Verleger hat von seinem unverdroße- / nen Fleiße die Hoffnung daß diese Kraüter zu drucken, auf / gleiche Art mit der Zeit seine Verbeßerung finden wird / wie die Buchdruckerey nach und nach zu größerer / Vollkommenheit gelangt ist, und weil die Figuren / lauter Abdrucke von lebendigen Kraütern sind, dergleichen Buch noch keine Nation weder in einer von ihren kostbahr-

(140) sten Bibliothecken noch auch in denen berühmtesten / Buchläden aufweisen kan, und mit sehr großer Mühe / und Kosten gemacht wird, so daß vielen zu kostbahr fal- / len will etliche hundert auf einmahl zu nehmen, so hat / sich der Verleger resolvirt die in vorgemeldetem 1ten tomo / befindliche Kraüter denen Liebhabern zu liebe einzel abzu- / drucken und zu verkaufen etc: ${ }^{1709}$ Einen solchen Bogen / mit etlichen Proben zeiget also dieses Mahl als eine neu / erfundene Art von Kupferstücken dar, und da, wie es / scheinet der Erfinder ein Geheimnüß aus der Sache machet / so laße aus Monconys Reißbeschreibung 4 Leipz. 1697. p. / 8801710 folgenden Unterricht vor: ${ }^{1711}$ d 2 7br lehrte mich H / Tevenot die Art allerhand Kraüter auf Papier abzudrucken / und zwar also, daß man sie an dem Feuer oder Lichte einer / Lampen anrauchen läßet, dann zwischen 2 Papiere legt und / mit einem Glätter oder Falsbeine darüber hinstreichet. ${ }^{1712} \mathrm{Ob}$ die- / ser Kunstgriff aber thulich, und derselbige den H Kniphof / brauchet seye,

\footnotetext{
1708 Am Rande des Zitats befinden sich Anführungszeichen.

1709 Zitat Ende.

1710 Monconys 1697.

1711 Am Rande des Zitats befinden sich Anführungszeichen.

1712 Zitat Ende.

Bei Monconys 1697, S. 880 heißt es: „[...] lehrete mich bey dem Herrn Thevenot ein Däne nahmens Monsieur Walquenstein die Art allerhand Kräuter auff Papier abzudrucken.“
} 
stehet zu zweifeln, obgleich seine Abdrucke / ziemlich unvollkommen aussahen. Eine andere Spuhr von / dieser Arbeit zeiget hierauf in meinem Reißediario, mscto, tom / 3. p 363, woselbst eine Beschreibung des Professoris Hermans / Cabinet von Leiden ${ }^{1713} \mathrm{zu}$ finden, und unter andern also gesagt / wird: Zuletzt zeigete man uns ein Buch in folio fingersdick, da- / rinnen die rahrsten Kraüter, als wenn sie lebeten, oder auf das ac- / curateste in Kupfer gestochen wären, zu sehen waren. Man sagte / dabey daß solche Abdrucke in einer Geschwindigkeit und ohne Ver- / letzung der Pflanze, wenn sie auch noch in der Erden stünden, zu / machen seyen. Denn man nehme nur ein gewißes Pulver / streuete es auf die Pflanze und drucke sie ganz sachte auf das / Papier so stellete sich die Figur auf das accurateste dar, so daß sich / auch die allerzartesten Fibrae ordentlich zeigeten, man machte / eine große Heimlichkeit denen etc: $\mathrm{Ob}$ nun diese Nachricht zwar / auch nicht viel Licht in diese Kunst giebt so siehet man doch / daraus, daß es nichts neues, wie $\mathrm{H}$ Kniphof behauptet, seye / und überhaupt eine Art von Abdrucken gebe, die gar un- / vollkommen herauskommet, sie seye nun gemacht wie sie / wolle, gleichwie beyliegende Probe es ausweißet. [...]“1714

Nachdem Uffenbach mit der neuen Materie sich vertraut gemacht hatte, hielt er am 28. Mai 1734 erneut einen Aufsatz über dieses neue Druckverfahren und legte ein mehrfarbiges Beispielblatt bei. ${ }^{1715}$

„(310) [...] Nach aller dieser Betrachtung zeiget der anwesenden / Gesellschaft einen andern Vorwurf, nehmlich das / Abdrucken lebendiger Kraüter und Pflanzen, wovon / nehmlich oben p.1401716 gedacht daß sie H Kniphof med. / Doct. zu Erfurt erfunden zu haben vorgegeben, und in / dem Verlag des Buchführers Funcke daselbst ein großes Kraü- / terbuch auf solche neue Art heraus zu geben willens gewe- / sen; Es wurden daselbst allerley Muthmaßungen, wie / diese Arbeit mögte angegrifen werden, erwehnet / Nachdem aber H Doct Brückman ${ }^{1717}$ zu Wolfenbüttel in / einem besonders gedruckten Sendschreiben an

1713 Über das Leben und die Sammlung des Leidener Professors Paul Hermann (Halle 1646Leiden 1695) vgl. Kat. Amsterdam 1992/Katalog, S. 41-42.

1714 Cod. Ms. Uffenbach 25/III, S. 363.

1715 Cod. Ms. Uffenbach 13/V, S. 310-315.

1716 Cod. Ms. Uffenbach 13/V, S. 140.

1717 Franz Ernst Brückmann (1697-1753). 
H Knip- / hof. 4. Wolfenb. $1733^{1718}$ das gantze Geheimnüß mit vie- / len Cautelen entdeckt, wie auch H Profess. Muth ${ }^{1719}$ / von Cassel ohnlängst die Arbeit selbsten handgreiflich / gezeiget, so konte dieses Mahl mit Darlegung des / itz gedachten Schreibens, und meiner eigenen Probe, von / der Sache etwas gewißer reden. Der getruckte Brief / ist zu weitlaüfig alhier gantz Platz zu finden, der- / wegen will nur des Umstandes, wie dergleichen / Kraüterdrucke allein gemacht werden, gedencken, / und davon heißt es demnach also: wir machen / von Kühnrus und Leinöhl eine schwartze Farbe an Con- / sistentz so dücke, daß sie nicht mehr fließe, sondern / stehe, wie sie etwa von denen Buchtruckern gebraucht / wird. Diese streichen und tragen wir mit einem / Ballen oder breiten Pinsel fein equal und aller Orten / gleich dück auf einen halben oder gantzen Bogen / Schreibpapier. NB das erste Mahl nach dem Bestreichen / zieht sich das Öhl aus der Farbe zusammen in das $\mathrm{Pa}-$ / pier, und ist der Bogen noch nicht recht $\mathrm{zu}$ gebrauchen, muß

(311) also die Farbe anfängl zu 2 biß 3 mahlen aufge- / tragen werden, ehe man den Bogen recht nutzen kan; unter / welchen ein glatt gehobeltes Brett eines Bogen gros lieget. / Auf die Farbe legen wir das grüne noch frische Kraut, Blät- / ter oder Blumen, so wir abdrucken wollen von der rechten / oder lincken Seite, welche von beyden wir am liebsten aufm [!] / Papier zu sehen verlangen, fein aus ein ander, daß nehm- / lich alle Blätter ordentlich ausgebreitet zu liegen kommen, / über die Blume wieder einen Bogen Maculaturpapier, / dann fahren und wischen wir mit der Hand gantz gelinde / darüber, so inhinuirt sich von der ausgestrichenen schwartzen / Farbe so viel in die Adern und Nerven derer Blätter, / Kraüter und Blumen als zum Abdrucken dere Gewächse / nöthig. Hoc facto, nehmen wir das Kraut von dem ge- / schwärtzten Bogen wieder ab, legen es reinlich und sauber / daß es nicht geschoben werde oder ungerade zu liegen komme / auf einen weisen Bogen Papier, über das Kraut aber / und den weisen Bogen Papier breiten wir ein paar Bogen grob / Lösch Papier, fahren mit der Hand von unten nach oben zu / über die ganze Pflanze her, doch so, daß sie nicht aufm Papier / verschoben und der Druck unordentl oder unrein werde, / nehmen so dann Maculatur und Kraut beydes ab, so prae- / sentirt sich aufm weisen Papier das Kraut Blat und Blu- / me mit allen auch den feinsten Adern, subtilsten und /

1718 Franz Ernst Brückmann, Send-Schreiben an Tit. Herrn Joh. Hieron. Kniphof, Die bequeme und nützliche Art, die Kräuter nach dem Leben abzudrucken und dieselbe nach ihrer natürlichen Gestalt und Grösse sauber abgebildet darzulegen, Wolffenbüttel 1733 (nicht in Bibl. Uff.).

1719 Heinrich Ludwig Muth (1673-1754), Briefpartner von Uffenbach, der Muth auch in Kassel besucht. 
zartesten Nerven, Costis und Poris recht lebendig reinlich / und sauber in der Größe derer nathürlichen Blätter etc: / et totius plantae habitus. Wenn man will kan man / über solchen schwartzen Druck die lebendige und nathürli- / che Farben der Kraüter und Blumen mahlen auch die Pflan- / tzen illuminiren, so wird die schwartze Druckfarbe gleichsam / statt einer Schattirung seyn, und die Pflantze desto kentlicher / machen und können hoc modo die schönste herbaria pi- / cta verfertiget werden. Zum Druck kan keine Farbe / anders als Kühnrus oder Rauch vom Succino ${ }^{1720}$ gebrau- / chet werden, denn die Erdefarben sind alle zu schwehr, / und die Waßer und Saftfarben laßen sich nicht wohl / mit dem Leinöhl vermischen. Wir haben auf mehr / als einerley Weise mit allerhand Couleuren Versuche / gemacht, aber niemahls etwas gutes oder vollkomme- / nes herausgebracht, außer daß etliche gantz einzelne Blät- / ter, und unter diesen die Folia salviae, lormini, urti- / lae. etc: am besten die Farbe von Cinober Spangrün / Berlinerblau, Ochra, Umbra, Kugellack Chrysocolla / etc: angenommen, und sich wohl abdrucken laßen. / (p.312) mit gantzen Pflanzen aber haben uns die tentirte Ex- / perimente niemahls biß dato vollkommen contentiren / wollen. Wenn die Kraüter und Blumen, so man ab- / drucken will sehr dick starck gefüllet oder kraus sind / muß man sie vorher ein paar Stunden in einem / großen Folianten oder Bücherpreße zwischen Papier ge- / legt einschrauben und preßen. Will man aber gantz / trockene Kraüter abdrucken, so müßen solche vorher erst / etliche Stunden in Waßer geweichet werden, sonst nehmen / sie die Farbe nicht wohl an. Frische und grüne Kraüter / sind zu dieser Arbeit weit beßer in dem sie die Farbe bes- / ser annehmen. Die gedürrete nehmen bald zu viel und / ofters Klumpen weiß die Farbe an, bald zu wenig oder / gar nicht, brechen leicht unter der Arbeit etc: etc: / So viel erachte nur vor nöthig aus H D. Brückmans / Schreiben alhier abschriftl einzubringen, obgleich das / folgende noch manche gute Vortheil zu dieser Arbeit / wie auch das Verzeichnüs derer jenigen Kraüter so sich / am besten, und derer so sich gar nicht abdrucken laßen / enthält. Man kan aber aus dem angeführten meines / Erachtens genugsam sehen wie diese Arbeit anzu- / greifen, und wer überhaupt die Regel in Acht nimt / daß alle glatte und gleichsam polirte Blätter ohne A- / dern und Nerven sich nicht wohl, anderer aber mit / denenselben, als insonderheit die Salbey am füglich- / sten abdrucken laßen, der brauchet weiter keine Be- / lehrung. Uberhaupt giebt die Übung die beste Anzeige / und da ich nur, wie aus hier nachfolgendem Blatte / zu ersehen eine kleine Probe gemacht, so ist mit / die Sache noch ziemlich vor einen Anfang gerathen. / Die Farbe belangend, so weiß ich nicht, warum H Brück- / man nicht alle Öhlfarben 
vor tauglich hält, mir ist / wenigstens der Versuch mit gemeinen Mahlerfarben in / Öhl gantz wohl gerathen, wenn sie nur recht fein abge- / rieben, und hauptsachlich der Bogen Papier nicht zu / dücke, und zu spahrsam damit bereitet werden, als / worauf das meiste ankomt. Nach jedem Abdruck eines / Krautes muß dieser von neuem überfahren werden,

(313) [Auf dieser Seite finden sich die Probedrucke von acht verschiedenen Pflanzenblättern in drei Farben (olivgrün, rotbraun und und dunkelgrün), die Uffenbach angefertigt hatte.]

(314) und hiezu habe einen Pinsel nicht so tüchtig als / die Finger der Hand selber gefunden, womit die / zähe Farbe sich beßer austheilen und anstreichen läs/ set, doch müßen solche jedes Mahl, ehe man die / Kraüter auf sauber Papier abziehet wohl gereiniget / werden, sonst giebt es gar leichtlich Sudeley. / Es ist hier nechst auch gar viel an der Eigenschaft der Farbe / nehmlich an ihrer Dücke oder Dünnigkeit gelegen, ist sie / zu zähe so nehmen sie die Kraüter nicht wohl $\mathrm{ab}$, ist sie / zu dünne, so giebt es zusammen fließende Glecke [!] / die hernach sehr heßlich durch das Papier schlagen. Zum / schwartzen ist die gemeine Kupferdruckerschwärtze wohl / die beste, weil sie rein ist und bald trocknet, bey an- / dern aber kan ein wohl gekochtes Leinöhl nach Mas / und Ziel ebenfalls gebrauchet werden, und solte es / mir nicht schwehr fallen ein gantzes Gewächse mit / braunen Stengel grünen Blättern, und vielfeltig ge- / färbten Blumen stückweise an ein ander zu tra- / gen. Welche Mühe aber sich der Erfurter Buchführer / Funcke wohl schwehrlich vor einen so geringen Preiß / geben wird, wie denn auch seine Abdrucke mehren- / theils sehr hingehuchelt [!] und schlecht sind. Auf solche Art / haben wir also das eben erwehnte Geheimnüs ent- / decket, und ein Proplema solvirt, worüber wir unser / damahlen allerley vergebene Gedancken gemacht hat- / ten, wie die angeführte Stell oben p 140 es mit / meherem ausweißet. Es erhellet aber aus dem gehörten / hiernechst gar leichte, daß H Kniphof mit seiner An- / zeige von einer neuen Art Kraüterbücher, die auch in / denen Breßlauer samlungen von Nathur Kunst und / Medicin. 4. oder vielmehr in der zu Erfurt durch H Büch- / man herausgegebenen Fortsetzung, Miscellanea physico / mathem. genant 4. an. 1729. p 779. bekant gemacht / und hoch angerühmet worden, ein wenig zu weit gegan- / gen, wenn er diese Abdruckungsart vor universal für / alle Kraüter angiebt. Glatte und polirte Blätter laßen / sich gar schlecht auf solche Art entwerfen, wie in vorher- / gehenden Proben die 2te Reihe, welches Buchsbaumstauten / gewesen, zu ersehen ist, daher ich muthmaße daß der vorhaben- / de Verlag eines solchen neumodischen Kraüterbuches eben 
(315) keinen gar großen Fortgang oder Beyfall gewin- / nen werde. Wolte man jedoch Fleiß und Mühe anwen- / den so könte man von einer ziemlichen Zahl Kraü- / ter, die rauh und nervigt sind, eine artige Samlung / auf solche Weise machen, die jedoch allemahl unvoll- / kommen bleiben würde. [...]“ 


\title{
14.2 Lateinischer Text von Johann Friedrich von Uffenbach, gedacht als Vorwort bei der Veröffentlichung des Monogrammlexikons mit deutscher Übersetzung
}

\author{
SUB Göttingen Cod. Ms. Uffenbach 36a, B1. 15-16.
}

[15r] / Collector cultoribus artis Salutem / Decrevi tandem (supellectilem) apparatum meum artis caelatoriae multis / abhinc annis (congestam , imprimis) imprimis autem / intervallo longin quorum itinerum (meorum) congestum in / ordinem qualemcumque redigere, ut ille faci(ole)liorem / mihi praebere possit usum, et quamvis (hoc) studium / hocce a primordiis me ad (illum) eundem finem (illum) / duxerit, anceps tamen, haesitavi semper, quem / ordinem in distribuendis chartis hisce servare / debuerim, cum normam congruentem nullam, nec / (alteram) quempiam facem praeferentem invenerim qui praecipua / desideria cultorum hujus artis mea sententia (exple) explevit. / Primum cogitavi rationem (in ordinandis) / (schedis) non nisi (scalptorum) caelatorum habere / in ordinandis schedis, et iuxta illorum nomina / illas ordine alphabetico redigere, ast cum paucos / saltem titulos et in quolibet copiam (enormen) molestam (chartorum) iconum a multis pictoribus / (in quolibet) (effict...) inventarum hoc (modo) pacto nactus fuerim, praeterea / artem ab incunabulis usque ad perfectiora incre- / menta sistere haud potuerim cum plurimi caelatores / hujus aevi pictorum veterum opera scalpro suo / denuo instauravere satius esse duxi in eligendo / ordine (et) rationem tam pictorum et inventorum quam / sculptorum habere, inde omnem curam operamque / in hoc posui ut indicem expeditum omnium / artificum (reperiam) et interpretem fidum monogrammatum / ipsorum reperiam sed (quaeso) age ubi illum invenies? / autores qui vitas pictorum celebrium ex omni / gente scripserunt effectim [?] ad manus quidem sunt, sed tantum / abest, ut illis niti et confidere possimus, nam / itali e.g. nominum germanorum vel batavarum (intantes) / mentionem facientes, haec adeo pervertunt et torquent / ut absque haesione vix comprehendi possint, quo vitio inter omnes / fere gentes galli utplurimum laborare videmus, / imaginaria quadam condecentia, adeo ut in- / ter numero illorum scriptorum vix unum evolverim / qui nomina propria exterorum vite citavit, excepto (si velis) / Bailico et Marvilico utroque in hoc momento curam / prae caeteris geren(tibus)te, id quod per parenthesin dictum / esse velim. Mirum igitur non est, quod in vitis 
[15v] / non nullis pictorum celebrium ab exteris / expositis quatuor imo plura nomina (et) / citata legi(men) sunt quae forse post investigationem / (meam acutiorem) solicitam unius ejusdem artificis / denominatione(m)s reperiuntur, (qui) appellati vel nomine proprio / vel praenomine vel natione vel agnomen- / to alio usitato (appellati sunt) (diversi imodes). In exemplum voca- / vi gallos prae reliquis (meurios) hac in re socordes et me / non fugit illorum assueta excusatio sumta a / barbarie praetensa lingua (mem) germanica et / et hujus affinium, verum si aurem, quae neu- / tram in partem movetur, judicem legimus / quaeso quae vocabula plus minus barbara ex- / istimanda cum (sermo fit) mentio fieret huchten- / burgi, hemskirchii, hirschvogelii etc: aut arti- / ficis cujusdam galli veluti, coyseveaux, Cheau- / veau, couvay, baudoux et horum similium. / Sed cum de re mea non sit de hisce longum dignoscere / illa differo paucis mentionem monogrammatum / vel signorum pictorum et caelatorum veterum facturus, for- / tassis me plus uno errore captum in re tanta dubia praebeo, nam / ducem habui neminem adeo certum, ut omnia / mihi explevisset desideria, profert equidem Sandrartus / in academia sua teutonica ${ }^{1721}$ non nulla horum signo- / rum, sequitur autorem gallus le Comte in singula / vites de peintures, paris $1700^{1722}$ in $8^{\circ}$ plurimorum sistit / cujus farraginem inconcinnam, (autor) liber germanus (script literam) / der geoffnete ritterplatz $\mathrm{z}^{1723} 8$ hamb. $1706 \mathrm{p} .188^{\mathrm{F} 1}$ ut et / italus orlandi in abcdario pittorico 4 bologna ${ }^{1724}$ / tamquam comprobatum transscripsit ast ego illam / adeo fallacem et minus aptam reperii, ut in / dicem absolutiorem (non sine gravi studio, com) / auxilio peritorum in arte quos peregrinans con- / veni, et postea commercio litterario exploravi / non levi studio (in) constituere impulsus fui / cujus ductu sequentes hasce icones, deficiente / altero perfectiori in ordinem redegi, sed nullus / dubito quin hinc inde erraverim in tenebris / nondum dijudicatis constitutus. (postremo) quod / autem attinet historiam calcographicam praefationis lo- / co huic apparatui praefixam, monendus est lector bene- / volus, quod exempla praecipua iconum ad hoc / non selegerim, malui enim illa, ${ }^{\mathrm{F} 2}$ ordini suo

1721 Joachim Sandrart, l'Academia Tedesca oder Teutsche Academie der Bau- Bild- und Mahler-Künste, 2 Tle., Nürnberg 1675 (2 Bibl. Uff. 345); ders., dass., IIter Haupt-Theil, Nürnberg 1679 ( $2^{\circ}$ Bibl. Uff. 346)

1722 Florent le Comte, Cabinet de Singularités d'Architecture, Peinture et Gravure, 3 Bde., Bruxelles 1702 ( $8^{\circ}$ Bibl. Uff. 537-9).

1723 Der geöffnete Ritterplatz, 3 Bde., Hamburg 1715, 1711, 1723 (8 Bibl. Uff. 276-8).

F1 „cum apino, in der / anleitung bilder / nützlich zu samlen / 8 nurnb. 1728“ [= Siegmund Jacob Apin, Anleitung wie man Bildnisse samlen solle, Nürnberg 1728 ( $8^{\circ}$ Bibl. Uff. 541)].

1724 Antonius Orlandi, Abededario Pittorico, Bologna 1719 (4 Bibl. Uff. 422).

F2 quae nota autorum / nondum destituta / erant.“ 
[16r] / relinquere, et rejectaneis solumodo uti, quae / sine mentione autoris nullo titulo inseri / potuerunt, hocce evolvat igitur qui vult, per seriam / alphabeticam, et invenit procul dubio alia / praestantiora exempla suo loco inserta. optassem / praeterea unicuique (titulo) membro vel articulo effi- / giem pictoris vel caelatoris praeponere potuisse / sed cum omnium copia mihi non fuit, sufficiat / in plurimis illud observasse destitutus, viribus ulterioribus / (mihi deficientibus) idem est (quod de) quorum inopiam / et parvum numerum titulorum quorundam excusare / conabor, quos locupletiores reddere potuissem, si / mihi animus fuisset discerpendi integra opera iconographica / quae potius repositorio singulari committere / quam paginis dissutis volumina iconothecae / hujus intumescere.

\section{Übersetzung 1725}

Der Sammler sagt den Freunden der Kunst seinen Gruß

Nun habe ich mich entschlossen meinen "Apparat" der Kupferstecherkunst, den ich über lange Jahre und insbesondere während der Zeit langer Reisen zusammengebracht habe, in irgend eine Ordnung zu bringen, auf daß er mir eine leichtere Benutzung ermögliche und welche Mühen ich auch von Anfang an zu diesem Zwecke aufgewendet habe, bin ich doch immer im Zweifel geblieben und habe gezögert, welche Ordnung in der Anordnung der Blätter ich einhalten sollte, denn eine passende Richtlinie oder eine $\mathrm{zu}$ verfolgende Anleitung, die hauptsächlichen Bedürfnisse der Verehrer jener Kunst meiner Ansicht nach erfüllen könnte, habe ich nicht gefunden. Zuerst habe ich mir überlegt, daß eine Reihenfolge bei der Anordnung der Blätter nicht ohne die Reihenfolge der Stechernamen gemacht werden kann, und daß die Blätter in alphabetischer Reihenfolge gemäß den Stechernamen geordnet werden sollen, aber weil die Blätter oft wenig Beschriftung tragen und ich so zu einer beschwerlichen Menge von Bildern, die von vielen Malern herstammen, gekommen bin und ich fernerhin die Kunst von ihren Anfängen bis zu Erreichung ihrer höheren Vollkommenheiten nicht habe sicherstellen können, weil viele Kupferstecher dieses Zeitalters die Werke alter Maler mit ihrem Grabstichel aufs neue vorgestellt haben, deswegen habe ich es für ausreichend angesehen die einzurichtende Ordnung auf die Reihenfolge sowohl der Maler und Erfinder wie auch der Stecher zu begründen, und deswegen habe ich mich mit aller Sorgfalt bemüht einen ausführlichen Index aller Künstler und einen treuen Dolmetscher ihrer Monogramme aufzustellen. Wo 
aber findet man so etwas? Die Schriftsteller, die die Lebensbeschreibungen der berühmten Maler aller Völker geliefert haben, liegen uns alle vor, aber es fehlt viel daran, daß wir ihnen vertrauen könnten, denn zum Beispiel die Italiener, die die Namen der Deutschen oder Niederländer erwähnen, verdrehen sie derartig, daß man sie ohne zu stutzen kaum verstehen kann. Unter nahezu allen Völkern sehen wir die Franzosen am meisten unter diesem Laster leiden (imaginaria quadam condecentia) und zwar so sehr, daß man unter ihren Schriftstellern kaum einen aufschlägt, der die Eigennamen der Ausländer richtig schreibt ausgenommen Bailicus und Marvidicus, beider Werke bediene ich mich ganz besonders, was ich aber nur in Klammern gesagt haben möchte. Es ist also nicht verwunderlich, daß in den Lebensbeschreibungen mancher berühmter Maler, die von Ausländern verfaßt worden sind, mindestens vier Namen gelesen werden können, die wohl nach sorgfältiger Untersuchung als der Namen ein und desselben Künstlers zu identifizieren sind, nämlich entweder der Eigennamen oder der Vornamen oder die Nation oder der Spitznamen. Ich nenne insbesondere die Franzosen vor allen anderen in dieser Sache nachlässig und es entgeht mir auch nicht ihre gewöhnliche Entschuldigung, die sich auf die vorgebliche Unkultiviertheit der deutschen Sprache und ihrer Verwandten stützt. Wenn man aber das Ohr als unparteiischen Richter über diese Sache befinden läßt, dann frage ich, welche Wörter mehr oder weniger barbarisch erscheinen, wenn man den Namen des Huchtenburg ${ }^{1726}$, Heemskerk ${ }^{1727}$ und Hirschvogel ${ }^{1728}$ erwähnt, oder die Namen gewisser französischer Künstler erwähnt wie Coyseveaux ${ }^{1729}$, Cheauveau ${ }^{1730}$, Couvay ${ }^{1731}$, Baudoux ${ }^{1732}$ und ähnliche. Aber da ich über diese Sache nicht des längeren befinden will, lasse ich es mit diesen wenigen Anmerkungen genug sein. Als ich ein Verzeichnis der Monogramme oder Zeichen der alten Maler und Stecher anlegte, bin ich in dieser so schwierigen Angelegenheit in mehr als einen Fehler gefallen, denn ich habe keine sichere Anleitung dazu bekommen, die mir alle meine Fragen beantwortet hätte; nun bringt Sandrart in seiner Teutschen Academie nicht wenige dieser Zeichen und diesem Autor folgt der Franzose Le Comte in seinen "singula vites de peintures,

\footnotetext{
1726 Jan van Huchtenburgh (1647-1733).

1727 Maarten van Heemskerck (1498-1574).

1728 Augustin Hirschvogel (1503-1553).

1729 Antoine Coysevox, auch Coyzevox (1640-1720).

1730 François Chauveau (1613-1676).

1731 Jean Couvay (ca. 1605-1663).

1732 François Joseph Baudoux (gest. 1788),
} 
paris $1700^{1733 " ~ u n d ~ d e r ~ d i e ~ M o n o g r a m m e ~ v o n ~ v i e l e n ~ K u ̈ n s t l e r n ~ f e s t s t e l l t ~ u n d ~ d a s ~}$ aber in einem unverdaulichen Durcheinander. Dann folgt das deutschsprachige Buch Der geöffnete Ritterplatz $8^{\circ}$ Hamburg 1706, p.188 ${ }^{1734}$ zusammen mit dem Autor Apin in der Anleitung Bilder nützlich zu samlen $8^{\circ}$ Nurnb. $1728^{1735}$ wie auch der Italiener Orlandi im Abcedario Pittorico $4^{\circ}$ Bologna ${ }^{1736}$. Er transkribiert sie, als ob er sie korrekt aufgelöst hätte, aber ich habe ihn ziemlich fehlerhaft und ungeeignet gefunden, so daß ich ein vollständigeres Verzeichnis nicht ohne schwere Mühe und die Hilfe der Kunstbeflissenen, die ich auf meinen Reisen besucht habe und mit denen ich danach einen Briefwechsel unterhalten habe, aufgestellt habe. Die Anregung, dieses Verzeichnis aufzustellen, hat mich nicht wenig Mühe gekostet und diesen Plan verfolgend habe ich angesichts des Mangels an Bildern eine andere bessere Ordnung gefunden, aber es gibt keinen Zweifel, daß ich mich öfters in Irrtümer und unentscheidbare Dinge verrannt habe. Was nun die Geschichte der Kupferstichkunst angeht, die anstelle eines Vorwortes meiner Sammlung vorangestellt wird, so muß der wohlwollende Leser darauf achten, daß ich dafür die hervorragendsten Bildbeispiele nicht ausgesucht habe. Ich wollte diese ${ }^{\mathrm{F} 1}$ nämlich lieber an ihrem Platz in der Ordnung lassen und ich habe mich nur der nicht authentischen Beispiele bedient, die, weil die Erwähnung des Autors fehlt, unter keinem Namen eingeordnet werden konnten. Wer will, kann also meine Sammlung durchsehen, gemäß der alphabetischen Ordnung, und er wird zweifellos andere hervorragendere Beispiele finden, die an ihrem richtigen Platz eingeordnet sind. Ich hätte es übrigens gerne gewünscht, einem jeden Abschnitt meiner Sammlung das Bildnis des Malers oder Stechers voranstellen zu können, aber weil ich nicht über alle Bildnisse verfüge, mag es genügen, in den meisten Fällen dieser Regel gefolgt zu sein, weil mir darüber hinausgehende Möglichkeiten fehlen; zugleich liegt mir daran, den Mangel und die geringe Anzahl der Beispiele gewisser Abteilungen zu entschuldigen, die ich versucht hätte reichhaltiger auszustatten, wenn mir der Sinn danach gestanden hätte, ganze ikonographische Werke auseinander zu nehmen, die ich aber lieber doch zusammengehalten habe, als mit den herausgetrennten Seiten die Bände meiner Bildersammlung aufzublähen.

1733 Florent le Comte, Cabinet de Singularités d'Architecture, Peinture et Gravure, 3 Bde., Bruxelles 1702 ( $8^{\circ}$ Bibl. Uff. 537-9).

1734 S.o.

1735 S.o.

1736 S.o.

F1 ,„welche noch nicht bekannt und ihrem Autor noch nicht zugewiesen sind,.“ 


\title{
14.3Johann Friedrich von Uffenbachs Aufsatzentwurf vom Januar 1736 an die Herausgeber der „Hamburgische Berichte von neuen Gelehrten Sachen“
}

\author{
SUB Göttingen Cod. Ms. Uffenbach 3a, 8r-11r $\underline{1737}$
}

Die in runde Klammern gesetzten Textstellen bedeuten, dass sie von Uffenbach durchgestrichen wurden.

[8r] An die H Verfaßer derer / gelehrten Berichten von Hamburg

Meine Herrn.

Seit deme mir derselben 51 Stück von verwiche- / nem Jahre zu Handen gekommen, bin ich bey mir / selber unschlüßig gewesen, ob ein geringer Bey- / trag, wie etwa gegenwärtiger mit Recht zu nennen / (der Mühe] so beträchtlich (genug) seyn möge, daß er eine / Stelle in deroselben überall belobten Wochenblättern / verdiene. Wenn ich aber die daselbst vorgetragene / Bitte bedencke, so daucht mich nicht daß ich un- / recht thue, derselben nach meiner wenigen Erfahren- / heit zu willfahren, und wenigstens etwas zu thun / wenn mir gleich ein mehreres und gewißeres / unmöglich ist. Es wird diesem nach in denen / angezogenen num. 51, von Nurnberg unter dem / 4ten Juny gemeldet, daß in einer nicht weit davon / entlegenen Schloßkirche ein Altarblat ziemlicher / Größe auf Holtz und Kreitengrund ungemein / fleißig und mit sehr hohen Farben gemahlt zu sehen / seye unter welchem des Künstlers Zeichen, nehm- / lich ein W, und (auf solchem) über deßen Mitten ein / T samt der Jahrzahl 1524 stehe, welchen man / vor einen durch Teutschland damahls gereißten berühmten / Italiener gehalten, der nach seiner ersten, und folg- / lich etwas harten Art zu mahlen dieses Kunststück / verfertiget haben soll, ob gleich man das beschriebene / Handzeichen biß anher nirgends in Büchern oder / Beschreibungen gefunden. Ich glaube solches auch / gar wohl, indem meines wenigen Wißens hierin- / nen noch gar keine zulängliche, ordentliche, und / (Wahr) und unpartheyische Nachricht vorhanden ist, die

1737 Der Text wurde größtenteils abgedruckt in: Hamburgische Berichte von neuen Gelehrten Sachen auf das Jahr 1736 (s. Uffenbach 1736). 
[8v] der Wahrheit oder wenigstens der Wahrscheinlichkeit / ein Genüge leisten könne. Verehrer und Lieb- / haber dieser Künsteleyen, so in ihrem Werthe kei- / nen andren, sie mögen Nahmen haben wie sie / wollen, nachgiebt, haben dahero keine geringe / Schwührigkeit etwas gewißes hievon zu reden, und / so sehr man in unserm Vaterlande bemühet ist, es / in allen Künsten und Wißenschaften denen be- / nachbahrten zu gleich zu thun, so wenig (hat) ist man / (sich) doch bißher besorget gewesen, das Ehrenwerthe / Andencken so mancher wackerer deutschen Künst- / ler auf die Nachkommenen zu erhalten. Hat man / denen, wird alhier so gleich der Einwurf lauten, / nicht gedruckte Lebensbeschreibungen wie berühmten / deutschen Künstlern genug? Allein wer solche durchblättert / wird derselben Mangelhaftigkeit gar balde erken- / nen, und die eben erwehnte Nurnbergische Anfrage giebt / uns so gleich ein Exempel hievon. Meines Wißens / hat man über gemeldete Handzeichen derer Künst- / ler noch keine hinlängliche viel weniger voll- / ständige Nachricht, obgleich in verschiedenen Wercken / zufällig hier und dar Erwehnungen und einige / Spuhren zu finden sind. Ohnstreitig nehmen sich die / Sandrartische Wercke1738 den ersten Rang in diesem / Stücke, aber nur schade daß sie in der Pegnitz / Schäferey und nach deren Schreibart verfaßet, daß / sie eine Menge sich selbst wiedersprechender Erzehlun- / gen und viel unnothiges enthalten, ja daß einem / Angst wird etwas in der Unordnung zu finden, / wenn man sich darinnen Raths erhohlen will. Nichts / getreulich nachgeschrieben, unter welchen Orlandi ${ }^{1739}$ in / seinem abcdario pittorico (4 Bologna) so zu verschiede-

[9r] ne mahlen in Bologna in quarto gedruckt worden / sich noch die meiste Mühe gegeben zu haben scheint / allein die Verketzerung derer deutschen und anderen / Nahmen macht auch dieses sonst artige Werck so / unbrauchbahr, daß man sich nicht darauf verlaßen / darf. Gleich wie ich denn erweisen kan daß er / aus eines deutschen Künstlers Tauf und Zunahmen / 5 Männer gemacht, im Gegentheil aber 3 / verschiedene andere, in einem zusammen geschmolzen, / von unglücklich angeführten Jahrzahlen und Gebuhrts- / örter nichts zu gedencken. Eben diesem Fehler sind / auch verschiedenen frantzösche Wercke unterworfen, ob / gleich de Piles ${ }^{1740}$ (und) Monier ${ }^{1741}$ und Felibien ${ }^{1742}$ mit seinen vies des

1738 Joachim Sandrart, l'Academia Tedesca oder Teutsche Academie der Bau- Bild- und Mahler-Künste, 2 Tle., Nürnberg 1675 ( $2^{\circ}$ Bibl. Uff. 345); ders., dass., IIter Haupt-Theil, Nürnberg 1679 ( $2^{\circ}$ Bibl. Uff. 346).

1739 Antonius Orlandi, Abededario Pittorico, Bologna 1719 (4 Bibl. Uff. 422).

1740 Roger de Piles, Cours de Peinture par principes, Paris 1708 ( $8^{\circ}$ Bibl. Uff. 528).

1741 Pierre Monier, Histoire des Arts qui ont rapport au Dessein, Paris 1698 ( $8^{\circ}$ Bibl. Uff. 534); ders., The history of Painting, Graving, p., London 1699 ( $8^{\circ}$ Bib. Uff. 526). 
peintres 8 Paris in 4 Bänden außer / der Unhinlänglichkeit noch leidlich ist, Florent le Comte1743 / aber mit seinen Singularites d'architecture pein- / ture p 8 Paris in 3 Bänden gar einen Irrgarten / abgiebt. \{ Zu wünschen wäre es vor diese Liebhabe- / rey, daß man von jedes Landes Künstlern und [am Rand steht: Lebens- / beschreibungen / ein gantzes / zu machen, und] / solche düchtige Nachricht hätte, wie etwa von Italie- / nern unter vielen andern Vassari1744, Lomazzo $^{1745}$, [am Rand steht: Felsina ${ }^{1746}$ ] / Scanelli ${ }^{1747}$ p von Frantzosen der vorgedachte Felibien ${ }^{1748}$, / (von) Monier ${ }^{1749}$ de $\operatorname{Piles}^{1750}$ (p) Gautier ${ }^{1751} \mathrm{p}$ von Niederländern [am Rand steht: vid. Sched. ${ }^{1752}$ ] / von Mander ${ }^{1753}$ und Houbraken ${ }^{1754}$ in seinen 3 schönen Bänden / Showburg der nederlandse Schilder p von Engelländern / unter verschiedenen andern Evelyns ${ }^{1755}$ History of chal- / cography $\mathrm{p}$ und endlich in Deutschland von Nurnberger / H Doppelmayers ${ }^{1756}$ Nurnbg. Künstler, (hatt) im Drucke / hätte so wäre leichtlich etwas ganzes, und zwar beliebter Bequemlichkeit / (Kürtze) und Mode ( willen als) ein Lexicon, (daraus zu machen.)\} / (Allein) Jedoch nach dieser unvermutheten Ausschweifung [am Rand steht durchgestrichen: in welches doch / die Handzeichen / schwehrlich aus obi- / gen Wercken zu- / sammen zu brin- / gen wären, die / mit Zuziehung / vieler Kenner / Nachricht allein / [unleserliche Zeile, weil mit Tusche nochmals durchgestrichen] / zu ergäntzen (wäre) / werden müßten.] / wird man nun wohl

1742 André Felibien, Entretiens sur les vies et les ouvrages des peintres, 4 Bde., London 1715 ( $8^{\circ}$ Bibl. Uff. 530-531); ders., Recueil historique de la vie des architectes, Paris $\left(8^{\circ} \mathrm{Bibl}\right.$. Uff. 532).

1743 Florent le Comte, Cabinet de Singularités d'Architecture, Peinture, et Gravure, 3 Bde., Bruxelles 1702 ( $8^{\circ}$ Bibl. Uff 537-539).

1744 Giorgio Vasari, Delle vite de' più eccellenti pittori, 3 Bde., Bologna 1648 (4 Bibl. Uff. 414-416); ders., Effigie di celebri pittori, scultori, et architetti, Firenze 1629 ( $8^{\circ} \mathrm{Bibl}$. Uff. 544).

1745 Giovanni Carlo Lomazzo, Trattato dell'arte della pittura, Milano 1584 (4 Bibl. Uff. 420).

1746 Felsina Pittrice, Vite de' Pittori Bolognesi, 2 Bde., Bologna 1678 (4 Bibl. Uff. 412-413).

1747 Francesco Scanelli, Il microcosmo della Pittura, Cesena 1657 (4 Bibl. Uff. 419).

1748 S.o.

1749 S.o.

1750 S.o.

1751 Hubert Gautier, L'art de laver, ou la maniere de peindre sur papier, Bruxelles $1708\left(8^{\circ}\right.$ Bibl. Uff. 216); ders., Kunst zu Tuschen, Nürnberg 1719 ( $8^{\circ}$ Bibl. Uff. 446).

1752 Dies ist der kleine Zettel 10r.

1753 Carel van Mander, Schilderboek, Amsterdam 1618 (4 Bibl. Uff. 418).

1754 Arnold Houbraken, De grote Schouburgh der Nederlandsche Konst=Schilderers, 3 Bde., Amsterdam 1718 ( $8^{\circ}$ Bibl. Uff. 523-525).

1755 John Evelyn, Sculptura or the history and art of chalcography, London 1707 ( $8^{\circ}$ Bibl. Uff. 435).

1756 Johann Gabriel Doppelmayer, Historische Nachricht von Nürnbergischen Mathematicis und Künstlern, Nürnberg 1730 ( $2^{\circ}$ Bibl. Uff. 249). 
begierig seyn zu wißen, was / ich in Ansehung des Anfangs gedachten Mahler- / zeichens vor einen Rath aus wenigen noch unvollkommenen anzugeben habe, es wird / dieser bey der Dunckelheit in dieser (? Wißenschaft) Sache

[9v] schwehr fallen, zu mahlen da ein Kenner die / Mahlerey selbsten ohnentbehrlich vor Augen haben / muß, um auch aus andern Umständen, die Gewiß- / heit seiner Aussage zu bestätigen. Dieses nothwen- / dige Stück nun fehlet mir, jedennoch weil auf / meinen 10 und mehrjahrigen Reißen ${ }^{1757} 2$ beson- / dere umständliche Register der Mahler (und) Bilt-1758 / hauer und Kupferstecher nicht ohne Mühe gesamlet / nach her auch meine Nachrichten durch vielen Brief/ wechsel mit Verständigen der Kunst (ausgebeßert) / ergänzet, und in einige Ordnung gebracht, so will / aus denenselben viererley Muthmaßungen anfüh- / ren, worunter die Eigenthümer der besagten schö- / nen Mahlerey wehlen mögen. $\mathrm{Zu}$ beßerm Begrif / meines Vortrages (habe) stelle die 4 Handzeichen so etwa / dem beschriebenen ähnlich sind, in einem Stämpfel / wie hiebey zu sehen, geschnitten vor, zum voraus aber / muß ich sagen daß diese (Tafel) Mahlerey nach der Beschreibung / ja nicht vor italienische sondern vor deutsche Ar- / beit halte, welches sie deswegen in ihrem Werthe doch / nicht verringert. Ein hergebrachtes Vorurtheil will meist / in allen Dingen nur das was fremd ist, hoch halten, / eine wahre Kentnüs aber gehet behutsamer und rich- / tiger. Die Italiener haben mehrentheils viel zu (viel) / große Einbildung von ihren Wecken gehabt, als daß / sie solche mit Handzeichen versehen hätten. Sie waren / und sind noch heutzutage insgemein der Meinung / daß der Welt ihre besondere Art zu mahlen so be- / kant wäre, daß (sie) ihre beygefügte Nahmen nicht / nöthig hätten ihren Werth zu bestätigen, ${ }^{F}$ [am Rand steht hierzu: zu geschweigen / daß das W / unter denen / Welschen Nah- / men so wenig / als in ihrer / Sprache gefunden / wird.] folglich habe ich / um dieser Uhrsachen willen einen Zweifel, ob die beschrie- / bene Tafel von einem so großen italienischen Meister ver- / fertiget worden, worin aber der Augenschein den

[10r] [es handelt sich hierbei nur um einen kleinen Zettel mit den Zeilen, die bei der großen Durchstreichung auf 9r eingefügt werden muß] wolte man alle (der) bereits geschriebenen Wercke von / dem Leben derer Künstler deren wir verschiedene recht düchtige haben, zusammen nehmen, so ließe / sich leichtlich ein vollstandiges Lexicon, dem itzigen Brauche / und der Bequemlichkeit nach, daraus machen. Ich zweifle / aber sehr daß man was ordentliches; in Ansehung

1757 Vgl. Cod. Ms. Uffenbach 36 und Cod. Ms. Uffenbach 50.

1758 Am linken Rand bei den letzten vier Zeilen ein blauer Bundstiftstrich, ein Zeichen von Wilhelm Meyer, der die Handschriften der UB HSA katalogisiert hat. 
derer / Handzeichen, wovon hier die Rede ist, daraus bringen würde / (in) indem man sie in denen meisten Büchern vergebens / suchet, und also aus der gemeinschaftlichen Mittheilung / derer erfahrnen Kenner (erwarten muß.) erlangen müßte.

[11r] sichersten Ausschlag geben kan. In Ermangelung / deßen aber theils hir (nechst) bey die der Beschreibung ähn- / lich kommende Zeichen mit, und mögte wünschen / daß die Sache mit düchtigen Lebensbeschreiber / der Mahler bekräftigen könte, woran es mir aber / wie allen Liebhabern fehlet, und worüber wir nichts / als die Übereinstimmung anderer Kenner anzu- / führen wißen. Das erste zweyfache Zeichen, num. I. ist von / einem alten Strasburger Mahler nf Baumeister nahmens Wendel Dieter- / $\operatorname{lin}^{1759}$ geführet worden, deßen in verschiedenen Bü- / chern, in sonderheit aber in Sandrart Mahler Academie ${ }^{1760}$ tom. I. p.310 nebst in Orlandi abcdario pittorico ${ }^{1761}$, und Florent le Comte / Singularites ${ }^{1762}$ p I partie p.147 Erwehnung geschie- / het. Das andere num. 2. soll ein geschickter Mahler / der einen fremden und wie mich deucht bohmi- / schen Nahmen hat, gebraucht haben, nehmlich Wences- / laus Eohoncz ${ }^{1763}$ wie mich solches ein alter und erfahr- / ner Kenner in Strasburg H Kühnast versichert. / Des 3ten num. 3. hat sich Augustin mit dem Bey- / nahmen der Schergel ${ }^{1764}$ bedienet, gleich wie mich ein / Kaufmann von Ulm, der viele Jahre mit (dießen) dergleichen / Kunststücken umgegangen, berichtet. ${ }^{\mathrm{F}}$ [am Rand steht: und wie mich sol- / ches das von / des Seel Dr Scheuch- / zer in Zürch / mitgetheiltes / Register be- / (stätiget) kräf- / tiget] Das letzte / aber oder num. 4. ist wohl dem beschriebenen am / aller nächsten wo nicht eben daßelbige, und ist das Handzeichen von Wen- / del Traudt ${ }^{1765}$, von deßen Arbeit und Lebensum- / ständen aber nicht viel zu sagen weiß, weil ihn / in wenig Büchern, (das Ze) sein Zeichen aber (vor) nur allein / (nehmlich) in IK. Neu aufgerichteten und vergrös- / serten Kunst und Werckschule ${ }^{1766}$ im 2 Banden 1707 / zu Nurnberg bey Joh. Ziegern gedruckt, gefunden. / Ich wünsche daß mit dieser wenigen und unhin- / länglichen

\footnotetext{
1759 Vgl. Cod. Ms. Uffenbach 36, p. 22v.

1760 Joachim Sandrart, l'Academia Tedesca oder Teutsche Academie der Bau- Bild- und Mahler-Künste, 2 Tle., Nürnberg 1675 (2 Bibl. Uff. 345); ders., dass., IIter Haupt-Theil, Nürnberg 1679 ( $2^{\circ}$ Bibl. Uff. 346).

1761 Antonius Orlandi, Abededario Pittorico, Bologna 1719 (4 Bibl. Uff. 422).

1762 Florent le Comte, Cabinet de Singularités d'Architecture, Peinture et Gravure, 3 Bde., Bruxelles 1702 ( $8^{\circ}$ Bibl. Uff. 537-539).

1763 Vgl. Cod. Ms. Uffenbach 36, p. 25v.

1764 Vgl. Cod. Ms. Uffenbach 36, p. 3r.

1765 Vgl. Cod. Ms. Uffenbach 36, p. 83v.

1766 I.K. vermehrte Kunst- und Werckschule, 2 Bde., Nürnberg 1705 (4º Bibl. Uff. 393-394).
} 
Nachricht denen Eigenthümern besagter / Mahlerey gedienet, und mein Anmuthen, um solche / in gegenwärtigen Gelehrten Berichten bekant zu machen / nicht für übel aufgenommen werden mögte,

[11v] welches aber, weil darinnen insgemein weit / wichtigere Dinge als diese $\mathrm{zu}$ allgemeinen Beyfalle / abgehandelt lese, fast vermuthen solte. Jeden- / noch verharre mit aller Hochachtung / meine Herren ergebener Diener / J.F.v.U. / ffurt d Jan. 1736 


\section{BRIEFE}




\subsection{Brief des Mechanikers und Feuerwerkers Johann Daniel Blümel aus Straßburg}

$\underline{\text { SUB Göttingen Cod. Ms. Uffenbach 20/II, Bl. 652-653. }}$

Der Brief von Johann Daniel Blümel ${ }^{1767} 1$ ging an den Verwandten Uffenbachs, Nikolaus von Uffenbach (1682-1744), der zu dieser Zeit Schöffe der Stadt Frankfurt am Main war. Wahrscheinlich hat ihn Nikolaus an Johann Friedrich weitergegeben, da dieser von dem spanischen Wahl-Gesandten Cristóbal Gregorio VI. Portocarrero de Montijo (1693-1763) als Organisator und Gestalter am 25. Mai 1742 anläßlich der Kaiserkrönung Karls VII. angestellt worden war.

[652r] / Strasburg, d 6ten April / 1742 / Monsieur!

Es hat mir ein gewißer Freund, welcher / gestern von Franckfurt hier arrivirt / zu verstehen gegeben, wie daß der Herr / Ambassadeur von Spanien, Monseig / le Marquis de Montijo die vergangene / Woche wieder in ffurt angelangt, und willens / ist, auf d. 1 Maj als auff Philippi wieder ein / Feuerwerck spielen zu laßen, wie Er schon d. 18ten / 9bris 1741. vor die Königin gethan, da unter andern / mir sehr gerühmet, die vortreffliche Illumina= / tiones und Gemählde so dabey unter Ew: Gnad. Di= / rection gesehen worden. Wie ich nun nicht zweifle / daß solche Direction wieder auf Sie fallen wird

[652v] So gelanget mein freundlichs Ersuchen an / Ew: Gnad: Herrn von Uffenbach, mir die / Liebe zu thun, und mich bey Ihro Excell. dem / Herrn Ambassadeur bestes zu recommendiren / Ich offerire meine Dienste im Feuerwerck, / und habe die Ehre dem Herrn von Uffenbach / zu bedeuten, daß ich in anno $1729 \mathrm{zu}$ Solothurn / in der Schweitz vor die Geburth des Dauphins / p Ordre des Herr Ambassadeurs, Monseigneur / le Marquis de Bonnac ein großes Feuer $=$ / werck abgefeurt mit allem contentement / des Herrn Ambassadeurs, wie deßen ein / solennes attestatum aufweißen kan: ich / erinnere mich auch die Ehre gehabt zu haben dem / Herrn von Uffenbach hier in Straßburg mit

[653r] dero Herrn Bruder als Sie hier studirt bey mei= / nem Sel. Vatter gesehen zu haben, da Sie in specie in der / Optica großes Vergnügen gehabt zu arbeiten / zu allen Mathematischen Wißenschaften, / großes Belieben gehabt, und

1767 Lebensdaten unbekannt. 
nimmt mich nicht Wunder / daß Dero Illuminationes und Decorationes s[ehr ${ }^{1768}$ / wohl außgefallen; Wolte der Herr von Uf[fen $]^{1769}=$ / bach mich so viel würdigen, und mit einer Ant= / wort hierauff beehren, so werden Sie dem[jenigen] ${ }^{1770 ~ / ~}$ dadurch sehr verbindlich machen, welcher $m[i t]^{1771}$ allein ersinnlichen Respect verharrt ...[?] $]^{1772}$ / des Herrn von Uffenbachs / Ergebenster Diener / Johann Blümel / Mechanicus / wohnhafft auf dem Roßmarckt / in Straßburg.

[653v] Herrn / Herrn Nicolao von Uffenbach / E. E. hochlöblichen Magistrats / zu Ffurt wohlverordneter / Schöffen und Assessori / abzugeben In / Franckfurt

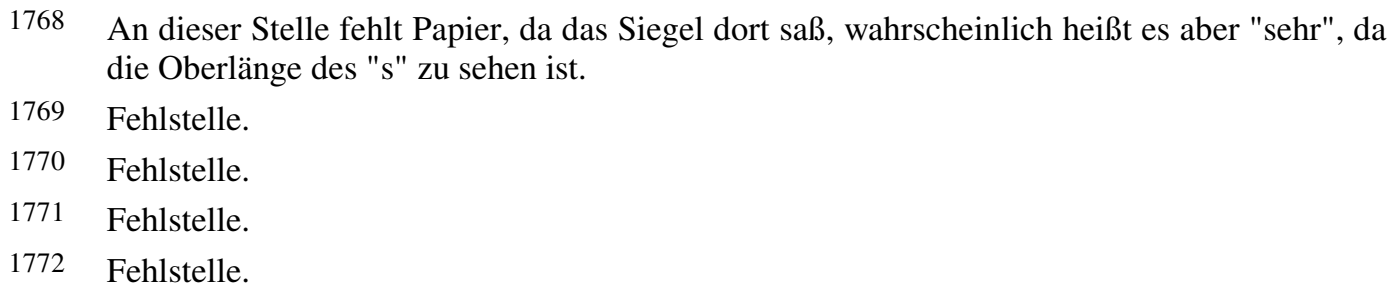




\title{
15.2Drei Briefe von Johann Christian Kaller aus Amsterdam, einer der Kommissionäre, die für Johann Friedrich von Uffenbach tätig waren.
}

\author{
SUB Göttingen Cod. Ms. Uffenbach 20/II, p. 301-304, 384.
}

In den Schreiben berichtet Johann Christian Kaller (1725-1794) u.a über seine für Uffenbach in Kommission erworbenen Druckgraphik, über den Verkauf von Wein des Flörsheimer Landgutes und von der Suche nach einer Drechelbank für Uffenbach.

\subsubsection{SUB Göttingen Cod. Ms. Uffenbach 20/II, p. 301-302, Amsterdam, 17.Juni 1758}

[301r] Hochedelgeborener / Gnädiger Herr.

Euer hochedelgeborene gnädigst ertheilte Commissiones / in Büchern und Kupferstichen, habe sogleich bey meiner / ankunfft getrachtet, ein und anderes davon in Handen / zu bekommen, weil es aber meißtens piecen welche sehr rar / zu haben, als das portrait von Gouillaume Brisacier / \& Petrus Dapuis, durch Masson, und 7 Historien von Ulisses / in 58 Blättern von Theodor van Thulden gestochen, unter / dem titul Le traveaus d'Ulyssse: welche Hirschberg Ierem / Doctor Ehrenreich zu senden die Ehre habe. ${ }^{1773}$ weilen / vor kurtzen auff eine noch einmall zum Vorschein ge- / kommene manier 8 Anatomische Piecen heraußgegeben / worden, so habe couriositet wegen zwey davon beygelegt / solten Euerhochedelgeborene gefallen tragen die / übrigen auch zu haben, so will dero Befehlen erwarthen / zu gleich auch bemelten, ob die übrige Masson welche

[301v] noch höher als diese im Preis zu stehen kommen dannoch kauffen / darff. Ich wünschte gerne wohlfeilere Preyße zu besorgen, allein / wann man etwas von hießigen Kunsthändlern kaufen / will, so wissen die Leute nicht genug zu fordern, und laßen / sich alles theuer bezahlen, besonders Stücke die man / wenig finden kan. Von den Büchern habe noch keine / Zweiffeln aber dannoch nicht Zeit meines auffenthalts / einige davon zu bekommen, von welchen den ...

1773 Diese 58 Blätter sind gebunden unter: Theodor van Thulden, Les travaux dÙlysse, dediez a Monseigneur de Liancourt, Paris 1633 (2 Bibl. Uff. 516). 
(?) biß be- / vorstehende Herbstmeß selbsten der Überbringer zu seyn / die von Euerhochedelgeboren mit bekommenen Weinproben / habe noch in kleinern Botellien gefüllt und an verschiedene / vornehme Weinhändler versuchen lasen, welche mir / bey Ihrer Ehre versichert haben, daß dergleichen Sorten / von Wein unmöglich hier zu angesetzen Preiß könten / abgesetzt werden, und so einst wenigstens $1 / 3$ davon zu / accordieren, wäre nichts zu thun, Ich habe ihnen zum vorausgesagt,

[302r] daß solches nicht geschehen würde, doch wolte deßhalb schreiben / und um daß allereußerste anfragen, warum nicht von / dem Stück 38er \& 53er. in Erwarthung Beliebiger nachricht / habe die Ehre nebst meiner unterthänigsten Empfehlung / mit aller erdenklich Hochachtung zu verharren.

Euer HochEdelgeboren / Meines Insonders Gnädigsten Herrn / Unterthanigster Diener / Johann Christian Kaller / by frans Meyer, op de Schleepers Kolk / Amsterdam, d 17 Junii / 1758

Nota / 2 portrait von Masson .. f 5,30 / Le Traveaus d’Ulyss: 58 piecen, von Thulden 7,30 / 2 anatomie piecen, von Admiral 4.- / f 17:-. / Amsterdam den 17 Junii 1758 / Kaller 


\subsubsection{SUB Göttingen Cod. Ms. Uffenbach 20/II, p. 303-304, Amsterdam, 06.Juli 1762}

[303r] Hochedelgeborener Herr / Gnädiger Herr !

Euer Excellentz haben mich mit zwey comiss: / beEhreth, wegen welchen die Freyheit genommen diese / an dieselben abzutragen; und nachricht zu geben, / das die Verwandlungen Ovidii von H Goltzius / bey einem hiesigen Kunsthändler zu bekommen seyn / die Zahl bestehet in 52 blat und so guth + schön / von druck, als wann solche erst von der Presse / gekommen, der allereußerste Preyß ist 52 so das / vor jegliches blat ein gulden gerechnet wird. / weil mir nun dieser Preys etwas hoch düncket, / und doch nichts davon kan abgedungen werden, / so wolte vorhero anfragen, ob ich auch Euer / Excellentz gewesen wäre ihn davon zu behalten,

[303v] so sind davon die der Lieferung geben, das / man vergeblich einer schönen collection / suchen wird. die Heyligen auff das gantze / Jahr von Callot sind auch vor Fl. 18 zu haben, / allein man will keinen Monath davon abgeben, / und alle 12 Monath zu kauffen, ob Sie schon / auch extra schön seyn, darff ich ebenfals / auff mich nehmen. Ich wolte mir also auch / mit wenigen warten deroselben gedancken / unterthänigst aufgebehten haben. / in nächst kommenden monath augusti werden hier / zwey schöne Cabinetter Mahlereyen verkaufft. / Von welchen die catalogi übersenden solle.

[304r] und so Euer Excellentz darinnen nach gusto / etwas findten sollten, würde es mit vielen / Vergnügen vor dieselben ankauffen. / Ich habe auch gelegenheit ein Cabinett von mehr / als 100 Stück Mahlereyen, worunter 3 Coelenburg $(\mathrm{P})$ / seyn nach franckfurt zu bringen; dahero um / gnädige erlaubnis anfragen wollen, ob ich solche / als bevollmächtigter darüber gegen Zahlung / der Schuldigengebühr öffentlich durch die ge- / schworenen aufkäuffer alda versteigern darff. / Es wäre so ein schriftlicher Gewinn vor mich dabey, / und die Liebhaber bekömmen einmal wieder etwas / recht gutes zu sehen und zu kauffen.

[304v] in tiefster Ehrerbiethung Euer Excellentz / gnädigste Zusage erwarthend, Verharrend / mit unterthänigstem Respect / Euer Excellentz / unterthönigster Diener / Johann Christian Kaller / by frans Meyer, op de Schleeperskolk / Amsterdam / 16 Juli / 1762 
15.2.3 SUB Göttingen Cod. Ms. Uffenbach 20/II, p. 384, Amsterdam 14.Juli 1762

[384r] Hochedelgebohrener Herr / Gnädiger Herr !

Euer Excellentz pardonieren daß die / freyheit unser noch zwey catalogi zu übersenden. / die darinnen befindliche schöne Mahlereyen / Zeichnungen, Kupfferstücke und zur Bewunderung / mit der Schnur aufgeschnittenen papierkunst, / haben mich solches zu unterwerfen bewogen. / Anmerckich aber ist eine inventiose Drewelbanck / dergleichen wohl nirgends anzukauffen vorhanden, / und weil mir bewußt, daß Euer Excellentz / große Liebhaberey von dieser Kunst haben, so wolte / zu gleich anfragen, ob dieselben nicht Lust / bezeugten, (wann der Preys civil wäre) / solche zu erkauffen.

[384v] Dero Befehle mit weiteren Anregungen erwarthend / habe die Ehre in Künstler submission mich / zu nennen.

Euer Excellentz / unterthänigster Diener

Johann Christian Kaller / by frans Meyer, op de / Schleepers Kolk

Amsterdam / den 14 July 1762 


\subsection{Sechs Briefe von Peter Heß, Steinschneider in Kassel}

SUB Göttingen Cod. Ms. Uffenbach 20/I, p. 445-446, Cod. Ms. Uffenbach 20/II, p. 328-334, 416-420.

Peter Hess (1709-1782) war Steinschneider, der, aus Frankfurt am Main gebürtig, ab 1746 am Hof der Hessischen Landgrafen in Kassel arbeitete. ${ }^{1774}$. Er schuf Pietra-dura-Arbeiten und war in Kassel als letzter Bearbeiter auch an der Rheinfelstafel $(1,91 \times 1,41 \mathrm{~m})$ tätig, heute im Hessischen Landesmuseum in Kassel.

Der Frankfurter Schöffe und Ältere Bürgermeister Johann Friedrich von Uffenbach war noch am 16. Juli 1762 als Zeuge für Peter Hess tätig. Hess hatte am 3. Juli des Jahres sein Haus zum Blumenstein am großen Kornmarkt verkauft, was Uffenbach in dem Währschaftsbrief - also dem Kaufbrief - bezeugt. ${ }^{1775}$

\subsubsection{SUB Göttingen Cod. Ms. Uffenbach 20/I, p. 445-446, 4. Januar 1751.}

[445r] Cassel d 4 Jan / 1751 / Hoch edel Gebohrner / Wohl Edeler Best und Hoch Weißer / Insonders großgl. Hochgeehrter Herr

Euer Excelentz gnädiges Schreiben habe durch / S Ex Herr von Fehlheim (Veltheim ?) richtig erhalten, und / bitte fästens nicht ohngnädig zu nehmen / daß mit meiner Antwort so lang verzogen / es haben es verschiedenen Umbständen es nicht zu / laßen wollen meine Antwort eher darauf zu richten. / Was nun den Stock Knopf belangt so muß selbst / gestehen daß er vieler Gefahr ausgesetzet ist, und / wann doch E. Ex. ein Plaisir von dießer eingelegten / Arbeit hätten, so hilte davor ein schöner Doßen- / deckel mit dießer Arbeit wäre doch nicht so offt / dem fallen so underworffen. Ich habe willens selbst / einen vor meine Plaisir zu machen und mit / Gelegenheit E. Ex. zu überschicken, ist er nicht anständig / so nehme solchen allezeit wieder zurück, jedoch deplacirt (?) / alles von E Ex hohen Befehl ob der Knopf oder dißes

1774 Vgl. Gwinner 1862, S. 205.

1775 ISG Frankfurt am Main, Hausurkunden 515 vom 16.7.1762, vgl.: http://www.ifaust.de/isg/rech.FAU?sid=3FC3C1AE32\&dm=1\&auft=1 vom 22.06.2019. 
[445v] resolvirt wird: daß die Hütte schon längst E Ex sind / bekand geweßen zweiffel nicht ich habe aber doch mit Gibs / viele Sachen geleimbt die sehr gehalten und war fast wie / ein Stein so hart worden: ich schicke hier noch 3 Recept die / ich hivor nicht probirt sie kommen mir aber doch gut vor. / und habe derselben noch viele in Büchern beschrieben. Den Kupfferstückhandel betreffend so glaub daß die Preiße / ziemlich hoch sind, allein die $\mathrm{H}$ haben es selbst ver..(?) / Ich habe selbst vor 1 Quart Blättgen von Callot schon $1 \mathrm{rl} /$ zahlen der Hoffmahler hätte sich wohl resolvirt E Ex / etwas zu schicken allein er fürcht es mögte ihnen etwas / ... (?) fahren verdorben werden. Er hatt seine schönste Kupffer / alle in große Folianten schön gebunden wie auch lauter große / Stück und mehrentheils von Italienische Meister, und die / ofter von Rubens sehr groß, und and. mehr. Er macht / sich ein Freude davon wann E Ex solten auf das / Frühjahr Cassell mit dero hohen Gegenwart beehren / Er besitzet auch ein Muschel Cabinet, und wie er mir sagte / so wäre es nach Zahl meher als des Mr. de Lavilette seines / ware: des Mr. de Lavilette sein Muschel Cabinet ist an den / Hertzog von Mecklenburch vor 1000 rl verkauft / worden wie mir deßen hindelaßene Frau gesagt hatt: / Von H Rath Archenholtz habe ein schönsten Emphl / an Sr Ex zu berichten und machte sich ein sonderbahre / Freude davon wann Sr Ex solten hier her kommen / er wolte verhören daß er wolte Sr Ex Sachen gegen die / Sr Ex condentren (?) und würden die Kunst Sachen in gantz

[446r] andern Stand finden als vorhero: Er hätte erst eine / Sammlung Andrequen (?) in Holland auf Ordre des Princen / gekauft, welche sehenswürdig wären, und wäre seine / Freude umb so viel vollkommener wann Sr Ex hier kommen / und bey Besichtigung der Sachen Ihre Sentiment über / die Einrichtung derselben erklärten. In deßen aber seien / dießen in allen Vorfallenheiten Sr Ex offerirte: / Was den Archidect H: Fünck belangt so ist solcher / jetz eben ein Jahr in Paris und zwar auf Kosten / unseres gnädigen Princen des H Stadthalters umb / was schönes von neüen Gebäue abzuzeichnen und / sich vollents in der Baukunst zu perfectioniren. / Er hatte hier in Amelienthal die Aufsicht über / das Bauweßen, und hatt auch würcklich 2 japan- / ische Lusthäußer ausgeführt. Jedes von $80 \mathrm{Fuß}$ lang / Selbe werden guth kostbahr ausgezirt mit Marmor / und Stocadur arbeit es soll jedes auf 30000 rl kommen. / Er hatt auch schon viele schöne Riße, dem Herrn von / Paris hier her geschickt, Wann selber aber wieder hier / kommbt weiß man noch nicht. Wann aber E Ex / etwas an ihn zu befehlen haben so kann die / Adresse überschicken. Von Antiquen / Steinen ist mir noch nichts in der Handen / kommen. Ich habe zwar bey einem Juden etwas 
[446v] einwertz gescheiden Köpffe gesehen, allein sie sind / so elend gemacht daß Bedencken trage solche E Ex zu / schicken, und will er noch darzu hoch damit hinaus / Ich werde aber sehen wann etwas schönes vorfält / solches nicht aus Händen zu laßen Ich glaube wann / E Ex: in Ffurth die Juden an der Hand bekämmen daß / manchs mahl was bey ihnen anzutreffen dann sie kaufen / offt solche Sachen umb ein Bacadell und geben es auch / darumb wieder weg dann sie verstehens nicht hier / fält dergleichen Handel nicht viel vor.

Die Taffel woran arbeite ist wie E Ex gerathen die / Festung Reinfelß und auch in der Tath ein lang- / weilige Arbeit hofte aber doch wann mir Gott das / Leben fristet solche zum Standt zu bringen womit / schlüßlich E Ex der göttlichen Gnaden Empfel / und zu dero hohen Befehl jederzeit oh- / ausgesetzt verharre / Euer HochEdlichgestre / und Herlichkeit / undertähnigster / Diener / Peter Heß Steinschneider 


\subsubsection{SUB Göttingen Cod. Ms. Uffenbach 20/II, p. 328-329, 24. Januar 1763.}

[328r] Cassel d 24 Jan / 1763 / Hochwohlgebohrner / Hochedeler Insonderes HochgeEhrter / Herr Baron

Das sehr gnädige Andencken vor meine / geringe Pershon habe aus Ehwg an mich er= / laßenen Schreiben underthänigst Ersehen, und / hatt mich über die Maßen Saulagirt auch / wegen der darin enthalten gnädigen aus / trücken beschämbt wann Ich die Erkundigung / so Ehwg wegen meines Wohlbehaltens und / das W...leiden (?) In unseren betränckten vergangenen / Zeiten so Ehwg vor mich geheget erwege: wo vor / meinen schuldigen Danck underthänigst abstatte; / und kürtzlich eine so viel benachrichten daß Gott / mir durch alle diße beängstigungen und Schrecken / glücklich durchgeholften und biß auf diße stunde / gesund und wohl erhalten: was die Verlaßen= / schafft des verstorbenen Hr G. Donop betrifft: so habe mich / darumb sogleich erkundigt bey seinem Haushoftmeister

[328v] sein Hr Bruder der General Donop und Gouveme / In Rindelen ist der Erbe, welcher nägsten Tagen / hierher kommen wird, der Hoffmeister hatt mir / die gantze Sammlung der Kupferstiche gezeiget: / worüber mich verwundert, so wohl über dero viel / als Schönheit. Sie sind alle in großen Folianten von / 4 biß 5 finger dick in frantz band eingebunden, und / jeder Band von denen besten alten meister die / einer zu haben sind angefült; außer was noch in / den großen portefeille Stückweiß apart Vorrath ist / deren nicht viel weniger als der Folianten sind. In / Summa sie füllen ein gantzes nicht gar kleines Zimmer / aus welches einer kleinen Bibliotheque ähnlich siehet: / und es war almit einer kleinen Kunstjalousie / herißen (?) dem Hr Landgraffen und dem Hr General weil / dießer eine größere und schönere connexion halte als / Er selbsten: so weil ich vom Haußhoffmeister vernommen / wird die Sammlung der Kupfer nicht vertheilt sondern zu / sammen verkaufft werden, Ich habe mir eine Abschrifft wegen / aus bethen von denen im Inventario Specificiis Folianten / der Kupfer wo die Meisters mit d Nahmen sind welche er mir / in Gefälligkeit ließe vor ... (?) allein hier Abschrifft wolt / er sich nicht verstehen, biß der Hr von Donop selbsten hier wäre da / vielleicht ein Cathalog drüber gemacht würde, und

[329r] so würde es ebenfalls mit den Mahlereyen gehalten / werden, welche gleichfals zusammen verkaufft werden, falls / Ich habe solche auch alle gesehen und sind von den besten Meister als Osdate: Tennier: Elsheimer van Dyck Rubens 
/ und viele Italiensche und holändische Meister wo Ihn solches / das Stück von 30: 40: biß 50 und 100 Luydôr gekostet hatte / Auch ist ein gantze Sammlung von dem bekanten geschir / von porclan des Rafael Urbin vorhanden welches sehr / schön und aus mehr als 200 stück bestehet. In Summa / Es wäre sehr schade wann diße drey schönen Samlungen / solten vertheilt werden. Ich werde mir angelegen seyn / laßen in künfftige zu erfahren wie es damit wird ge $=/$ halten werde umb Ehwg (=Euerhochwohlgeboren) underthänigst davon zu / benachrichten: was nun die Ruinen der Kunst / stück betrifft so ist an der Vleune (?) Gallery wie ... (?) / Bad nicht beschädigt das Model Hauß ebenfals ohn= / versehrt blieben und die beßten Kunstsachen in Kunsthäußer / als Antique Steine und Müntz Cabinet und andere / für transportiren mögliche Kunststücke schon beym Einfall / der Franttosen weggeschickt worden; hin gegen ist die cascade der / so gemachete wieder (?) kosten sehr Ricimirt, die Aue hatt Ihre / schönen Wände und viele Bäume verlohren wie auch die / Esplanate der frantz: ... (?) völlig rasirt ist, und / umb gantz Cassel herumb stehet weder Hauß Baum noch / Stauden und kennet man die Gegenten nicht mehr / maßen die Frantzosen über 90 Schantzen angelegt hatten

[329v] und haben wir hier was ... (?) vom Kriegs unglück / erfahren welche wohl leichter in ... (?) Seculis nicht / empfunden noch empfinden werde. Ich nähme aber nicht / viel gelt davor daß es nicht erfahren hätte und ... (?) / nachfahren mahl so viel daß es noch erfahren solte / Es scheint jedoch daß wir bald wieder auf dem alten Fuß / haus, unser gnädigster Hr Landgraff sind vorgestern hier / ankommen und sein Leibgarde zu Pferd und Fuß heute / hier hin gerücket: so daß wir eine wieder ... (?) zu leben / anfangen, übrigens erwarte von Ehwg die hohen / Befehle in aller underthänigkeit was Ehwg bey den / vorfallentz Kunstsachen der G Donnopischen Verlaßen= / schafft mir solte gnädigst auftragen werde welche / mit aller schuldigen Treu und Sorgfalt observiren / der ich in underthänigkeit zu Ehwg Befehl ... (?) / verharre / Euer Hochwohlgebohren / underthänigster Diener / Peter Heß Edelsteinschneider 
15.3.3 SUB Göttingen Cod. Ms. Uffenbach 20/II, p. 330-331, 19. März 1763.

[330r] Cassel d 19 Mertz / 1763 / Hochwohlgebohrner / Hochedeler Insonders HochgeEhrter / Herr Baron

Ich habe ... (?) ... (?) Ein / gängen zu thun meinen undertähnige / Schuldigkeit beobachten wollen was / Ich von der Verlaßenschafft des H General / von Donop erfahren können: so be $=/$ richte undertähnig daß ein Catalogus über / die Kupferstiche getrückt wird: sein Bruder / welcher jetz hier und der Erbe sind haben vor / sich eine Quantität von Handriße und Kupfer / so schon lange in die Familie gehören vor / selben behalten, die übrigen so noch in Zehen (?) = / Taußent:Zweyhundert: und 22 Stück bestehen / sollen zusammen verkaufft werden, sobald der / Catalogus fertig werden solchen Ehwg überschicke, / den Preiß davon hatt man mir noch nicht

[330v] bestimen wollen; Vieleicht werden sie / erst einen und den anderen Liebhaber sin / Geboht erwarten umb sich darnach zu richten. / so viel habe von ihm vernommen daß der lieb= / haber so sie kauffen wolte selbe pershönlich in / Augenschein nehmen müste: so viel ist gewiß / daß schon von seinen Sachen verkaufft worden / sein gantzes Silber Servis hatt der hannöversche / Gesande gekaufft, seine Mahlereyen haben / der Hr Landgraff besehen, ob sie solche aber kauffte / wird die Zeit lehren, sie haben dem H General / solche als schon bey seinen Lebzeiten abkauffen / wollen, ... (?) er aber alzeit 20000 rl (=Reichstaler) verlangt / hatt: seine kostbahren Möbels sollen auch / zusammen verkaufft werden: übrigens / laßen der Hr Landgraff sich sehr angelegen sein / die Künste und Handelung in flor zu bringen / sie sind alle tage im Kunsthauße und / ordiniren alles selbst, haben das selbe auch / mit vielen kostbahren Stücken vermehrt / und einig Zimmer hier ... (?) Academi an

[331r] gewißen umb junge Leuthe nach dem Leben / zeichnen zu lernen worüber der $\mathrm{Hr}$... (?) / Professor und Director ist: auch besuchen sie / jetz täglich die ...städter (?) Meße und haben / schon vor $20000 \mathrm{rl}$ Werth gekaufft laßen auch / golde und silberne Medaillen zu 20 Ducaten / schlagen denen Kaufffleuthen welche die / Meße mit guter Wahre besucht als Premium / auszutheilen, auch wollen sie im Bau= / weßen die große Pojecte Ihres Hr Großvatters / Landgraff Carls ausführen so daß es jetz / hier recht lebhafft wird: was nun Ehwg / mir in der aufgetragen Comission der / Kupferstiche betreffend gnädigst befehlen / werde mit aller schuldigsten Sorgfalt / undertähnig nachkommen und ausrichten / 
der Ich nebst niederigsten (?) complment zu / Ehwg Befehl in der Zeit verharre / Euer Hochwohlgebohren / undertähnigster Diener / Peter Heß Edelsteinschneider 
15.3.4 SUB Göttingen Cod. Ms. Uffenbach 20/II, p. 332, 11. April 1763.

[332r] Cassel d 11 April 1763 / Hochwohlgebohrner / Hochedeler Insonders HochgeEhrter / Herr Baron

Ich habe ... (?) ... (?) ein / undertähniger Gängen zu leisten den / Catalog hierbey überschicken wollen. / habe mich aber nicht wenig gewundert / als ihn durchsehen daß kaum der 3 oder 1/2 (?) / Theil der Kupferstiche darin stehet und ist / es lange nicht die große Sammlung so ich von / anfang gesehen habe, auch fehlt die völlige / Sammlung von Rembrand welche doch sambt / dem Bürgermeister Sicsx (?) dabey waren, und / die besten Italienischen Meister: In Summa das / beste werden sie vor sich behalten oder schon ver= / kaufft haben. Den Preiß davon hatt man / mir noch nicht gesagt, aber sie werden es hoch / gering halten, weil es Sachen vor ein Stats=

[332v] minister sind werden sie es auch statsmäßig / wollen bezahlt haben, seine Möbels und / übrige Sachen sind alle verkaufft ist aber / nichts wolfeil wegegangen: wan ... (?) / Ehwg zu dißer Sammlung der Kupferstiche lust / bezeichnen därft (?) solche mir gnädigst befehlen / was ich dabey thun kann werde undertähnig / observiren: oder können sich selbsten an den / Hr General oder deßen Hoffmeister adressiren / der ich in Erwartung dero hohen Befehle undertähnig verharre / Euer Hochwohlgebohrn / undertähniger Diener / Peter Heß Edelsteinschneider 
15.3.5 SUB Göttingen Cod. Ms. Uffenbach 20/II, p. 333-334, 28. Mai 1763.

[333r] Cassel d 28 May 1763 / Hochwohlgebohrner / Hochedeler Insonders HochgeEhrter / Herr Baron

Ich habe längstens eine Antwort auf / Ehwg an mich erlaßenes letztern gnädiges / Schreiben abgehen laßen wollen, weil es / aber der Hoffmeister von $\mathrm{Hr}$ General Donnop / in Rindelen erst eine Antwort über den Preiß / der Kupferstiche erwarten müßen, so habe meine / undertähnige Aufwartung erst heute da mir / derselbe die Nachricht überbracht damit machen / können: Ich muß aber zum voraus berichten daß / ich mit meinem Urtheil zu voreilig geweßen, in dem ich geglaubt es wären die besten Stücke / davon weg: der Hoffmeister mich aber versichert daß / der Hr General nicht davon genommen als ... (?) frantzösche Stück und Handzeichnungen umb seine Söhne / darnach zeichnen zu laßen; Er hatt mir auch die / Erlaubniß geben die gantze Sammlung durch / zu sehen, da ich dann gefunden daß die besten noch / vorhanden und die Rembrand alle da sind auch / die besten Italienischen Meister als Raphael Urbin / und ander mehr welche im Catalog under dem Nahmen

[333v] Ecole de flamande: de Rome de venise etc / marquirt sind: darin alle die besten Meister selbigen Orts / verstanden werden, Ich habe mich nicht wenig / dran ergetzen als sie durchsehen, aber alles zu durch / sehen war mir wegen Mangel der Zeit ohnmöglich / In den kaum d 1/3 Theil in einer Woche durchsehen können (?) / und ist es wohl der Mühe werth daß solche ein / Liebhaber vorhero durchsuchet und betrachtet: / was den Preiß betrifft so soll Stück vor Stück / ein Gulden kosten, ... (?) sind zwar Stücke viele Stücke / darunder die mehr als ein biß 2 Luydôr kosten / und der Hoffmeister versichert mich daß keines / von den allergeringsten Stücken darunder seien / Hr General weniger als 1/2 fl können: hingegen / die guten Stücke er vor 2 biß 3 Luydôr bezahlt / hätte, weilen er selbsten die corespodence mit / den auswärtigen Kunsthändeler geführt und / die Zahlung davor weggeschickt hätte: Ehwg / werden mir der gnädigen Resolution / darüber berichten ob solche ein Liebhaber davor / ausgeben wollen. Ich glaube es wird vom / Preiß noch was abgehen der Hoffmeister sagt / mir daß der Engelische Gesande Walpole / schon ein Gebott darauf gethan hätte wie viel

[334r] aber wolte er nicht sagen, man wird vieleicht / Ehwg Resolution auch erst hören wollen umb / sich darnach zu richten: was meine Wenigkeit / dahir beytragen kann werde mit aller Treue / meine undertähnigste Schuldigkeit 
observiren / womitin Erwartung einer gnädigen Antwort / zu dero hohen Befehle undertähnigst / verharre / Euer Hochwohlgebohrn / undertähniger Diener / Peter Heß Edelsteinschneider 


\subsubsection{SUB Göttingen Cod. Ms. Uffenbach 20/II, p. 416-420, ohne p. 419, 28. November 1750.}

[416r] Cassel d 28. Nobris 1750 / Hoch Edel gebohrener. Vest und hochweißer / Wohl Edeler Insonders großg. HochgeEhrter / Herr

Es ist mir Euer Excelentz Angenehmes vom 7ten / dießes richtig worden und daraus Sr Ex gnädiges / Andencken so dieselbe vor mich haben mit größten / Vergnügen ersehen, wogegen mein gehorsamsten / Danck unterthänigst abstatte. Wie auch vor die Versicherung / der Theilnehmung an meiner hiesigen Wohlfahrt / wünsche von Hertz daß der höchste Sr. Ex. bey beständigen / hohen Wohlergehen erhalten wolle. Anbey bitte / höchsten $\mathrm{zu}$ excusieren daß nicht gleich geantwortet habe. Dir / Uhrsach ware weil der Hofmahler verreißet gewesen ist. / Was nun belangt den Stockknopf so will / solchen gerne machen wann slber nur nicht presirt. / In die kurtzen Tage jetzt von dießer Arbeit viel / verhindern, auch nur 2 Tage in der Woche vor mich zu / arbeiten habe. Daß der Knopf zu starck ist nichts daran / gelegen weil er beßer zu faconiren ist als wann er / zu dünn wäre, den Preiß kann gewiß nicht bestimmen

[416v] weil nicht wißen kann wie viel Goldt mir drauf / gehet, wann Sr. Ex. bey Übergleichung des Knopfs mir / kleinen Entwurf was drauf kommen solt auf Papir setzen / wie auch die rechte Proportion des Knopfs wäre es beßer sich / darnach zu richten, sonsten versicher daß ihnen so wohlfeil / als möglich machen werde.

Belangend der Hütte so habe viereley Sorten / hier aufgeschrieben, und schicke Sr Ex ein Probe / vor 3 Sorten mit. No 1. und 2 auch 4. halte vor die / beste Art das Perlenmutter zu hütten, wann nur / die Handgriffe recht observirt werden: daß aber Sr Ex / meinen daß die Antiquen so von 2 Sorten sind auf / einander gehüttet wären so laße es $\mathrm{zu}$, daß es deren / gibt: aber mehrentheils sind sie aus einem Stück Stein / verfertiget, wo die Farben von Natur sind im Stein geweßen / die auf gehütten sind mehr aus Noth weil man / solche Stein nicht haben können oder daß die Antiquen / gebrochen geweßen und auf ein Krand [?] haben auf / gehütt [!] werden müßen. Ich habe hier welche mit / beygelegt so Ich selbsten gemacht habe, wie auf / dergleichen Steine, dießes Paquet bitte / Sr Ex versigelt / an $\mathrm{Mr}$ Duval in der Maintzergaß zu überschicken / bitte aber höchster zu pardoniren. Ich habe es nur / umb Sr Ex die Art der 2farbigten Steine zu zeigen / gethan, das ausgelegte Porto muß Mr Duval wieder / restiniren: Meine Beschäftigung betreffend / so habe bey meiner Hierkunft gleich meine 
[417r] Arbeit im Kunsthauße bekommen wo ein Sammlung / von mehr als 1400 der schönsten Erhaben geschniten / Antiquen helften in Ordnung bringen und aus bietzen [?] / und repariren müßen, und habe mit H Rath Archenholtz / Antiquarius ein gantzes Jahr zubracht, dann seite [!] des / Seelichen Herrn Todt alles in Ohnordnung gelegen. Jetzt aber / ist alles im Kunsthauße in der schönsten Ordnung und / sehenswürtig. Wir haben nicht allein die Sammlung alle / Kayser von Jul Cäsar biß auf Constantium sondern auch ihr $\mathrm{Ge}=/$ mahlin nd Prinsen wie auch alle Divinitäten und / und [!] Taußenterley Fabeln in Stein alle veritabel / Antique. In Summa es ist eine Sammlung so wenig zu / finden, anjetzo arbeite beständig an der Tafel1776 / oder sonst was vorfält von Tabaiers [!] in Stein wie es / dann immer etwas tu thun gibt und bin Gottlob / wol zufrieden in dem ein sehr Gnädigen Herrn / habe auch meine Besoldung richtig erhalte. / Herr Profesor Muth ist noch so gesund wie vor 20 Jahren / er hatt hier ein Brief an Sr. Ex mit beygelegt er sagt / mir daß er auch welche Kupferstück von Alb Dürern / hätte: was nun dem Mahler belangt so kenne / solchen schon lange ist ein brafer [!] Man der 7 Jahr / in Rom geweßen und schöne Kupfer hatt, er sagte / mir daß er Sr Ex etwas überlaßen wolte, wann selbe / selbst hier wären er könte Sr Ex viele schöne Couriosa zeigen / welche zu schicken nicht möglich wären, ich habe ihn doch so / weit gebracht daß er etwas schicken will wann nur

[417v] Sr Ex selbst ein paar Zeilen an ihn abgehen laßen. ${ }^{1777}$ Es ist / hier so viel fragens nach alten Kupfer daß dieße Leuth / gantz stoltz werden, es ist nicht allein Sr Drlch Prins / Friederich Liebhaber, sondern H General von Donop: / H General von Dieten: H Camer President von / Boreck: sammeln alle Kupferstücke, und suchen alles / auf. Ich habe hier eine Vorzeichnung von einer Sammlung / (so ein sicher Man besitzet welcher Mathematische Instrumente / macht und zuweilen was einkauft) ${ }^{1778}$ mit beygelegt / solche auch auf Begeren schicken will, übrigens wann / selbsten was gutes auftreiben kann werde mit / allem Plaisir mich bemühen Sr Ex mit meiner Wenig= / keit undertahnigst zu dienen, wie auch wann von / geschniten Stein was vorfält. Ich habe zuvor 3 Stück geschn / aber schlecht gemacht jedoch Antique, der Besitzer will aber / ein Luy d'or [!] davor haben welches sie nicht werth sind / womit schlüßlich Sr Ex der gütlichen Obhut des / Aller Höchsten Empfehle und zu dero Befehl in De= / mut

1776 Vgl. Cod. Ms. Uffenbach 20/I, Bl. 446v, wo die Tafel näher beschrieben wird.

1777 Uffenbach scheint an den Hofmahler Hochfeldt nicht geschrieben zu haben, da kein Schreiben des Künstlers im Commercium Epistolicum vorhanden ist.

1778 Hier links am Rand in der Schrift Uffenbachs "NB in fra"". 
undertähnigst verharre / Euer Hoch Adliche gestr / und Herlich / undertahnigster Diner / Peter Heß Steinschneider

[418r] Hütte so zu der Floentiner [!] / Steinarbeit oder mosaique / gebrauchtet werden / No 1. / Man nimbt von den Schreiner Ihren starcken / Leim: /dann die Schreiner haben zweyerley Leim schwachen / und starcken): Läßet Ihn wie gebräuchlich auf Kohlen / hergehen umbt so viel davon als man nöthtig [!] hat zu der / Sache die man leimen will, tuht darzu feinen Gips / wie ihn die Bildhauer zu Bilder gißen brauchen) und / rührt solchen wohl under den Leim. Machet breite / Stücke so man Leimen will wohl warm, und be=/ streichet solche damit. Läßet es hernach mit Etwas /beschwertet in der Wärme trucknen. / NB Man muß nicht mehr Leim und Gips vermißen [!] / als man nöthig hat weil er hernach nicht mehr zu Kochen ist. / No 2 / Weiße Mastix Körner (Je größer Je beßer sind sie) stecket / ein Korn auf ein Ende eines über dem Kohlfeuer / warm gemachten Draht, hält es so lang über das / Feuer biß das Mastix Korn anfährt zu Schmeltzen, alsdann / trückt man mit dem Forderfinger und Daumen / (welchen vorhero im Munde ein wenig befeuchtet worden / damit der Mastix sich nicht an die Finger anhänget) / das helle aus der Haut heraus, Schneidet hernach mit / einem Meßer das Helle von der Haut ab, verfährtet [!]

[418v] so lang biß man Körner genug ausgetrücket / als nöthig sind, Stecket hernach von dißen aus / getrücken [!] Körnerauf ein Drat hält es über ein Kohl= / feuer biß es schmeltzen will, und beschmihrt beyte / Stücke Stein (welche auf Wohl erwärmbtet seyn müßen) / damit, hält sie hernach über das Kohlfeuer daß der / Mastix wohl schmeltzet, trucket beyde Stücke gemächlich / zusammen und läßet es kalt werden. Schneidet hernach / den neben ausgetrucken Mastix mit einem Federmeßer / von dem Stein ab. NB die Mastix Körner werden / darumb von der Eusern [!] Haut abgesondert weil die Haut / verhindert daß er nicht anklebet. / No 3 /

Schwartzes Bech (wie es die Bürstenbinder verkaufen) / in einem Eisern Löffel über Kohlfeuer zergehen / laßen, hernach Ziegelmehl gantz fein gerieben / wohl drunter gerühret, hernach auf ein Naßen / Stein gantz dünn ausgegoßen: Von solchen Stücker / beschmirt man hernach dieüber dem Feuer warm / gemachte Steine damit, trucket die Stück über dem / Kohlfeuer wohl zusammen und läßet es kalt werden. / No 4 / Bech und Wachs wohl under Einander zergehen / laßen und braf undereinander gerührt hernach in in starcke / wie Sigellac fermischet beyte Stücke Stein über dem / Kohlfeuer damit beschmirhet Zusammen getruckt und / kalt laßen werden. 
[p. 419 nicht transkribiert]

[420r] Cabinet geschnittenen orientalischen Stein / Numero 1. / Alsß von Jaspis, Onyx, Sardonyx, Carniol, Lapisla= / zar, Amathisten, Agat, Caliston, alle einwärts ge= / schnitten, Götzen vorstellend, heydnische Kayßer / gantze figurel, wie auch heydnische Kayßer Köpfel / Caracterfigur, und Buchstaben, Item mit Caracter / allein, in Summa allerhand schöne heydnische Sinnbilder / und Vorstellungen, die größte von einem Guldten, wie Batzen / wie halbe Batzen, alle oval, sind auch 4. Eilig länglich in / Summa sauber schnit von Antiquen 80. Stück. Item Ein heyd= / nischer Kayßer Kopf auswärts geschnitten, in der Größ / wie ein Kopstück [!], gar schön der Grund schwartz der Kopf weiß, / antique. / No 2. Ein einwärts geschnitten Venus, mit 2. Cupido von roth und / grünen Jaspis, in der Größ 2 1/2 Zoll schön geschnitten, Eine / Palas in Onyx, weiß die Größ 2. Zoll schön geschnitten, Item / auswärts geschnittene Köpf, und kleine Figurlein von Camin $=$ / onyx, 2. von Corallen Zinck, Ein Mercurius Kopf gar / schön wie ein drei Bätzner, Item wie ein Batzen, wie / ein halber Batzen, wie Kreutzer 100. Stück, Item 34. Stück / von der allerschönsten einwärts geschnittenen antique Kay $=$ / ßer Köpf + Kayßerin Köpf, und Feldherrn, von Carniol, Amathist, Sardo= / nyx, Jaspis, Item mit Vogelstück 8. vier Eilige Stückel / in der Größ wie ein Batzen, von Bernstein, inwendig 2. Köpf / ein Städtgen, Ein Cameol, ein Pferdt, etliche Blumen, ein / Kopf von schönen Metall, Goldt gleich der Parton. / No 3. 154. Stück, einwärts geschnittene Stein, als Sardonyx, Carniol / Lapislazar, Jaspis, Crystall, Amathisten, groß wie ein / Batzen, bis auf ein Kreutzer groß, allerley heydnische / Caracter,gantze Hauß Götter, Götzen, wie auch Vögel / und

[420v] und Köpf von allen Sorten die man finden Kan. / No 4. 154 Stück, als Lapislazar, Carniol, Caliston, Jaspis, Criselet / gantze Figurlein Köpf mit Caracter, grie Größ von einem halben / Batzen, bis auf einen Pfenning, allemahl antique und orientalisch. / No 5. Lapislazar Carniol, Crystall, Jaspis, Amathist allerley / Figurlein, Köpflein, die Größ von einem halben Batzen bis auf / einen 1/2 Heller. / No 6. allerley Steinlein darin gewachsen zeigen vielerley / als Bäumlein, Berge Waßer, und Luft, Erd und Luft, $\mathrm{Ka}=/$ tzenaugenschöne ungeschnittene Carniol, 2. Milchstein, ein / Stück Bernstein, als ob ein Figur darin gewachsen wäre / Ein Stück orientalische Perl, in Größ eines 5. Kreutzer Stück / ein schön Stückel Jaspis, das mit allerhand Farben melirt / ist, in Größ eines 5. Kreutzer Stück, die Größ von den / gewachsenen Steinen von drey Bätzer Größ, bis auf / Eines Kreutzers Größ alles antique geschnitten und orien= / talisch, außer wie obgemelt 8. Stück von Bernstein. / No 7. 4. Ring einer in Silber gefaßt, die anderen 3. in Goldt. / 1. Einen schönen Mercurius Kopf der Grund schwartz, der / 
Kopf darauf blau: Onyx in Silber gefaßt. / 2. Ein schön Kayßer Köpflein, Onyx in Goldt gefaßt, der / Grund schwartz, das Gesicht braun, das Band weiß. / 3. Ein Kayßerin Köpflein Onyx crustila der Grund schwartz / das Gesicht blau die Haar und Gewand braun. / 4. Ein Operstock [!] mit einer Flamm wie brennend, von / einem Oval, welcher Farbe wie der Regenbogen hat / in Goldt gefaßt. 


\subsection{Drei Briefe von Johann Daniel Geysel an Johann Friedrich von Uffenbach}

SUB Göttingen Cod. Ms. Uffenbach 20/I, p. 108-112 und 20/II, p. 405-408, $\underline{632-633 .}$

Den Nürnberger Kaufmann und Münzsammler Johann Daniel Geysel ${ }^{1779}$ hatte Uffenbach auf seiner Grand Tour durch Italien in Rom kennengelernt ${ }^{1780}$ und nach seiner Rückkehr nach Frankfurt einen regen Briefkontakt mit Geysel aufgebaut. Geysel war 1715 in seine Heimatstadt zurückgekehrt, siedelte dann vor 1750 nach Venedig über, da seine Briefe ab dieser Zeit von dort adressiert sind.

An dieser Stelle werden nur die Schreiben in Transkription wiedergegeben, die im Text erwähnt sind.

\subsubsection{SUB Göttingen Cod. Ms. Uffenbach 20/I, p. 108-112, Venedig, September 1750}

[108r] Monsieur / mon trés honoré Patron.

Dero hoch werthes vom 19. Aug. habe mit vielen Vergnügen / erhalten und daraus anvorderst die richtige Überkunfft meiner / drey Brieffe gerne ersehen. Dieselben haben ganz und gar / nicht Ursache, wegen einiger Verzögerung bey deren Beantw(ortung) / Anregung zu thun; Massen gar wohl erkennen, daß bey Dero Um- / ständen, es nicht leicht ist seine Verrichtungen nach eigenen Wohl / und Belieben anzustellen, sondern man zu frieden seyn muß / wann man nur dann und wann ein wenig Luft bekommen / kann; ich erkenne daher auch immer mehr und mehr, die Grösse mei- / ner Glückseligkeit, da ich / frey, wie die grosse Welt / und keinem Menschen unterworffen bin, daher über die Zeit / nach eigenem Wohl disponiren und niemand, als Gottes Gewalt, / mich an Ausführung meiner Verrichtungen hindern kan. / Was dieselbe wegen der Liebhabereyen melden, so ist es aller- / dings damit beschaffen, wie Sie Schreiben, und der ehrliche Virgil / hat ganz recht gesagt: Trahit sua quemque voluptas. Das Samm- / len wird

1779 Lebensdaten unbekannt.

1780 Vgl. Cod. Ms. Uffenbach 29/II, S. 534 und 29/III, S. 574. 
demjenigen, so einen natürl Trieb dazu hat, zur andern / Natur, wie wohl man es vielmehr eine Gemüthskrankheit nennen / solte, wobey der Mensch zwar keine äußerl Beschwerde oder Schmerz / empfindet, innerlich aber beständige Unruhe und Begierde empfindet / bald

[108v] 2. / bald dieses, bald jenes zu haben. Ich bin viele Jahr in diesem Lazareth / kranck gelegen, und Sie werden sich noch wohl erinnern, daß ich in Rom / Parapihmi gehabt, deren Würckung ich mich, nicht ohne Reue und / Scham erinnern kan. Aber, Gott sey gedanckt, ich bin, obschon späth, / endlich doch zur Erkenntniß kommen; es hat mich aber viele Jahre Arbeit / und Mühe gekostet, mich davon nach und nach zu erledigen.

/: fast auf eben die Weise, wie mir gestern ein Landsmann, der sich / schon in die 18. Jahr hier auffhält, er selbst hat, wie er die Neigung / zum Theil, worein er nach und nach gerathen war, nach vieler Mühe / glückl überwunden hat und nunmehro ein vernünfftiger Spieler / genannt zu werden, obschon dieser Beynahme dem Substantiv nicht / mit Recht beygelegt könne zu werden, möglich scheint:/

und ist es eben so lange noch nicht, daß ich völlig davon frey bin. / In wenig Tägen, werde ich meinen Geburtstag feyern, da ich das 3te. Jahr / meines vernünfftigen Lebens zurücklegen und mit Gottes Hülffe / das Vierthe antreten werde. Die Warheit hat mich frey gemacht, / und von allem Trahit befreyet, aber deßwegen, bin ich kein Mysticus / kein Eremit, kein Mukler oder Fantaste worden, sondern ich bin in / Ansehung meiner Welt=Mitbürger, eben derjenige, so ich vorhero ge- / wesen, und entziehe mich niemand, denen ich nutzlich seyn kan, und / enthalte mich allein von dem Umgang derer, so mit mir nicht / gleich gesinnt sind. Das Vergnügen, so ich vor diesen in Gesellschafften / und Conversationen geführt, finde ich weit besser, sicherer und / ohne Furcht vor allen mögl Verdruß und Ungemächlichkeit, in / dem Briefwechsel oder schrifftl Unterredung mit guten Freunden. / Die Begierde allerley zu samlen ist bey mir völlig abgeschaffet, nach- / denen ich erkannt habe, daß wir nichts davon aus dieser Welt mit- / fortnehmen dürfen, hingegen sammle ich bey aller Gelegenheit, an denen / Dingen, die mir niemand wegtragen kan, die ich dereinst mit mir nehmen / und

[109r] und in der andern Welt brauchen kan, das ist: Erkenntniß / und Wahrheit. Denn, je mehr die erste hier vermehret wird, desto / besser wird sie uns beym Anfang der vollkommenen Erkenntniß / zustatten kommen: die andere aber ist und bleibt hier und vorst eben / dieselbe, und in derselben allein ist das 
Centrum alles Vergnügens / und reellen Belustigung, so der Mensch in der Welt zu geniessen / fähig ist. Ob ich nun schon von allen unnöthigen und überflüßigen / Dingen einen Abscheü habe und solche als etwas beschwehrliches / ansehe, so siehet es doch bey mir nicht aus wie in des Diogenis seiner / Vena, sondern in meinen Zimmern befindet sich nicht nur alles nothwendige / sondern, wann ich Ihnen ein Inventarium von allen darinen be- / findl Dingen senden solte, werden Sie schwerl glauben wollen, was ich / soeben mit Wahrheit geschrieben habe. Bey mir findet man etl hundert / moderne Medaillen, Blechmüntzen und andere alte Müntzen, Kupfferstiche / Landcharten, Basreliefs, Zeichnung, Praeparata anatomica, optischen Werckzeuch, aufgetruk- / net Kräuter, Samen, Blätter, Rinde, Hölzer, Muscheln, Petrifacta / Steine, Sand, Farben etc etc. Allein alle diese Sachen, können nach und / nach, ohne daß ich sie Inhanden begehre, und das meiste ohne Geld / alles hat in gewisser Masse seinen Gebrauch, nemlich observationes zu / machen, was davon hiezu gedienet hat, solt gute Freunde zu ... (?) / da mir einer bald hier bald da etwas davon träget, den Rest werde / ultra et citra montes an Liebhaber versenden, wann sich die Gelegen- / heit praesentiret, Ihnen mit ein oder andern dienen zu können. Dann alle / diese Dinge betrachte ich nun als entlehnet, und nur in gewissen Gebrauch / dienlich, wann dieser vollbracht, cedire ${ }^{1781}$ ich solche, dem der sie auch gebrauchen kan. / Opictetus hat das omnia mea mecum porto wohl verstanden, / Er hielte nichts vor ihm gehörig, als was in ihm war, das andere alles / auch sogar Weib und Kind vor entlehnet, und so ist es freylich, wann / wie die allgemeine Meinung, so die Welt oder vielmehr die Menschen in / der Welt regieret, aus dem rechten Punckt ansehen. Weil ich / nicht aus dem Hause gehe und doch gerne im Meer observat(iones) anstellen / wollte, so wußte ich geschwinden für H (?) Meer in mein Zimmer zu erlangen. / Ich ließ einen sehr grossen irdenen, inwendig glasurten Napf auf / einen

[109v] 4. / einem hölzernen Stuhl in ein Winckel meines Zimmers stehen, darein / that ich zwey ...ungen (?) von kleinern Seistermuscheln, so ich mir aus / dem Arsenal bringen lassen, wie sie sich solche alda an die alten Schiffe / Klumpen weiß aufzuhäng(en) pflegen. Ich ließ mir so viel Seewasser / holen daß ich das Gefäß bis oben anfüllen konnte. Ich eröffnete / zwey dem Winckel des Zimmers am nächsten liegende Fenster und / armdurchstreifend und auff die Fläche des Wassers wirckende Wind, / ließ mir allerley Bewegungen seheh, dabey ich Gelegenheit hatte / die so genannte Gesetze der Bewegungen bey denen

$1781=$ abtreten. 
Fluidis zu un- / tersuchen. Mein künstl Meer wurde bald leütselig, eine Menge / von verschied Wasser Insecten, davon ich vorher kein richtiges er- / blicket hatte, weil sie sich alle in dem Klumpen zwischen die Muscheln ver- / steckt hatten, langs(am) zum Vorschein, und machten mir ein angenehmes / Lustspiel, die kleine Kolonie oder Meer... (?), welche auf denen / Seistermuscheln sich aufzubauen pflegen, fiengen an Ihre Thüren zu / öffnen und ihre Nahrung zu suchen, und unerachtet ich von diesen / in Cabineten die Schaalen oder Häuser vielmahl in Cabineten gesehen / auch selbst dergl. marina \& Petrefacta gehabt, so habe ich doch nie / gewußt, wie die Einwohner aussehen, nun aber bekam ich Wunder- / dinge zu sehen. Dieses Vergnügen währte ein paar Tage, darauf nahm ein / Freund zu gefallen, eine Arbeit vor, womit 2. Täg occupiret und da- / durch verhindert war, nach mei(nem) Meer zu sehen. Weil ich das Wasser nicht / verändern lassen stürben viele aus Mangel der Lebensmittel und der / Rest war auch kranck; derowegen wollte alle in den Canal / schmeissen lassen, ich besann mich aber anderst, und brachte das Meer- / wasser, durch Zugießung einer geringen Portion süssen Wassers zur / Fermentation und Fäulung, mithin verwandelte sich mein Meer / in ein Sumpff und gab mir Gelegenheit, den Ungrund dessen was Lancisi / von denen Sümpffen und deren schädl Ausdünstung geschr zu erkennen. / Und so ist es mir gelungen eine zieml Anzahl Beobachtungen $\mathrm{zu} /$ bekommen, die wegen Ihrer Analogie bey andern ganz differenten / und hiemit gar nicht verwandt zu seyn scheinenden Dingen, / ein nüzl Licht und wichtige Spuren zu weitern Untersuchungen formiren. / Wann

[p.110r] Wann ich Ihnen eine Beschreibung, von dem was aus meinem / künstl Meer und Sumpff gelernet und abstrahiret habe, geben / sollte, würde etliche Bögen Papier solches nicht fassen können. Was ich / fast seit etl Bögen vor allerley Wahrnehmung, Versuche und dergl. / in andern Materien gemacht, darf ich nicht einmal wagen / solcher zu gedencken, aus Furcht Sie mögten mich vor was anders halten, / als ich bin, und muß ich bey mir selbst lachen und mich wundern, daß / gewahr werden, daß es Fälle giebt, da man schweigen und die / Wahrheit zu sagen nicht wagen darff \& Zweyer Entdeckungen / will ich nur hier gedencken so in voriger Woche gemacht habe, von / welchen gewiß bin, daß wann solche einem Schrifftgelehrten / gerathen wären Er davon ein gräul Lärmen in der Welt machen / und ein Hecatombe sicher würde kosten lassen. die erste Entde- / ckung betrifft eine Meerpflanze, die ich nun ganz was anders finde / und daß solche nicht in den Stall gehöret worein sie die Botanici / nach des Meisters Sournefarts Vorschrifft zu lociren pflegen. Sie heissen / solche Titanon keratophylon, mein Apotecker brachte mir solche, / und bat mich ihm den 
Nahmen zu sagen, weil ich solche nicht / wußte, Er aber just zu der Zeit kam, da ich eine lange Botanische / Epistel an ein Praelaten in Rom geschrieben, der ein grossen Botani- / schen Wurm im Kopff, eine Sammlung aber von einer Menge unge- / heüren Folianten mit aufgetrucknet Kräutern, worunter eine / grosse Zahl Meerpflanzen sind, im Cabinet hat; so offerirte mich, / wann Er ein Stückgen davon abschneiden wollte, solches in dem / Brieff zu legen, und mir den Nahmen berichten zu lassen. Er offe- / rirte sich mir die Pflanze zu verehren, weil er noch ein schöner / Exemplar davon hätte, ich wollte mich aber nicht damit beladen, / und da er anhielt solche anzunehmen, hieng ich solche an einen ledige / Nagel, so ich eben erblickte, nicht denckend daß ich solche jemals / mehr davon herunter nehmen würde, Was geschiehet? In 14 Tagen / sandte mir der Praelat obig Nahmen, nebst der Erklärung und ver- / schied Umstände, was davon geschrb und gesagt würde; Mein Apotecker / hatte ein groß Vergnügen darüber. Er war kaum aus dem Zimmer, so / kam mir der Beynahme Titanon verdächtig vor. Wie soll der / Kalck ins Meer kommen. Wer pinselt die Pflanze so gleich und oben an ? / Sagte

[110v] 6. / sagte ich bey mir selbst. Ein Gedancke producirt den andern: alle Men- / schen sind Lügner, die Botanici sind Menschen Ergo p Dieser bizarre / Syllogismus veranlaßete mich die Pflanze von dem Nagel herunter / zu langen und ihr vors erste mahl Wasser zu lehrhen. Das erste / war, daß ich soviel von dem sogenannten Kalch, womit sie über / und über beckleidet ist herunter nahm, um solche auf der Zunge / und zwischen denen Zähnen zu prüfen, sogleich gieng das Titanon / vor die Hunde. Darauf nahm ein Microscopium, von der Art, aber / nicht von der Güte, desjenigen womit uns der Pater Basile in der / Cartosa zu Napoli vor 35. Jahren so curieuse Dinge gezeiget hat, und / drehete sie nach allen Gesichtspunckten herum, und da ich alle / Kennzeichen, die der geschulte Naturforscher vitalim Donati mein / wehrter Freund an denen Corallen, denen Madregonis und dem / kiviozoon wahrgenommen erblickte, so wurde ich gewahr, daß diese Pflanze / ganz was anders seye, als wofür sie biß dato von jedermann ge- / halten worden, und mithin unter die Pflantze gehöre, so noch keinen / rechten Nahmen haben, man könnte sie eben sowohl, eine Thier- / pflanze, als ein Pflanzen-Thier nennen, aber es muß wohl erst noch / ein Schuhl Nahmen ausgedacht werden. Diese Entdeckung hat / deßwegen Ihr Werth, weil solche denen Botanicis Gelegenheit geben / wird, daß Gewächs mit mehrerer Aufmerksamkeit zu betrachten, / und was mehren erfordert wird als die Stamina und epices zu / zählen. Das ist eines. Die andere Entdeckung ist weit / importanter; ich habe neml eine gantze neüe Classe von Vegeta- / bilibes 
entdeckt, die in kein Buch beschrieben sind und vermuthl keines / Botanici Aug nach mir gesehen hat, von denen man derley mit größten / nachschlagen kan: daß auch Salomo in aller seiner Herrlichkeit nicht / beckleidet gewesen ist, als der selbigen einer. Diese Entdeckung bin / gesonnen nach einer Zeit lang und so lange geheim zu halten, biß ich / mit mehrerley auff einmahl hervor tretten kan.

Nun ist es Zeit auf die in Dero wehrtgeschätzten Schreiben enthaltenen Punckte / gehörig zu antworten. / Was

[111r] 7. / Was demnach die alte Kupferstiche betrifft, so sehe aus dem was Sie / davon welchen, daß Sie von dem hisigen Zustand noch keinen rechten / Begriff haben. Hier fehlt es an Liebhabern von Kupferstichen und / Zeichnungen so wenig, daß vielmehr alles verkaufft wird, was von / alten Sachen nur zum Vorschein kommt, und ist kein alter Kupfer und $\mathrm{Pa}$ - / pierkrämer in gantz Venedig zu finden (dann ich kenne sie alle) welcher dergl / Sachen besässe und froh seyn möchte wann Nachfrage darum geschähe.

Alle Sonn- und Feyertags sind alle Läden in der Mercaria /.neml / die lange Straße so von der Rialtobrücken biß an den Marcusplatz / gehet./ geschlossen; hingegen findet man alda die Bretter der Bou- / tiquen mit Kupferstiche und Handrissen an vielen Orten ganz / tapezirt; Diese habe sieben Jahr lang, wann es das Wetter per- / mittirt /. dann bey Regenzeit legen sie nicht aus /. fleißig besucht aber / kaum 7. Blat gefunden, die das Porto werth wären, solche hin aus zu schicken, / indessen ..fen diese Leute doch immer soviel, daß sie nur viel zu bekommen / wünschten, um zum Verkauff ausstellen zu können und verschiedene / leben die ganze Woche von dem, was sie an Sonn- und Feyertägen an / dieser Wahr gewinnen. Blätter, die Sie suchen, findet man hier nicht, / dann wann bey ein Sterbfall ein Loch aufgehet, so sind diese Anti- / quari wie die Schürhunde so geschickt solches gleich zu erfahren, und je- / dermann verkaufft ihnen gern, weil sie gut und böses mit einander / kauffen. Aber diese wissen die Geister zu prüfen, sie suchen alle guten / Blätter heraus, und tragen solche zu erst zum Engl Consul Mr. Smith ${ }^{1782}$ / der am meisten dafür giebt; was sie da nicht anbringen, tragen / sie zu dem Zanetti ${ }^{1783}$, der läßt nicht ungekaufft, was nur halb gut ist, / mithin kommt nichts zu die Mercerie als was diese beide ausschlissen / Sie sagen Wagner ${ }^{1784}$ ahme die Frantzosen nach, kömme ihnen aber noch lange / nicht bey. Auch hier

\footnotetext{
1782 = Consul Joseph Smith (ca. 1674-1770), Resident Englands in Venedig, Förderer von Canaletto. Vgl. Kat. Frankfurt 1989.

1783 = Anton Maria Zanetti (1660-1767), Sammler, Mäzen, Kunsthändler, Karikaturist, Zeichner und Stecher, vgl. Kat. Frankfurt 1989, S.31-32.

1784 Nach seinem eigenhändigen Inventar besitzt Uffenbach 36 Blätter von einem „Wagener“.
} 
sind Sie mit Ihrer Erlaubniß irrig. Mit Wagner / hat es eben die Bewandniß als mit dem Picart ${ }^{1785}$, wieviel Stücke findet / man nicht mit Picart Sculpsit, unerachtet er dabey weder / Radiernadel noch Grabstichel angesetzt hat, sondern lediglich / unter seinem Verlag, von seinen Scholaren gemacht worden sind. Sobald / ein Maß Droguerien entweder an Heckellner und Städel oder einen / andern Droguisten von hier gesandt wird, so will Ihnen wenigst ein oder / zwey

[111v] 8. / zwey Stück mit senden, so Wagner, nach des geschulten Amiconi Ge- / mählden mit eigener Hand gezeichnet, radiret und gestochen hat, / und zweiffle, ob Sie Ihn sodann denen neüen oder nochlebenden / Frantzosen nachstehen werden.

Daß ich nicht aus dem Hause gehe, stehet denen Commissionen nicht / im geringsten im Wege, dann es läßt sich in allem Rath finden, und / lassen Sie sich deßwegen in dem guten Vorsatz nicht stören, mich mit / Dero wehrten Befehlen zu beehren und zweifeln nicht, daß Sie auf / alle nur mögl Art sollen exequiret werden.

Von denen Mytalis oder Lüstermuscheln woran ich gedacht, will / ich ein paar große nebst der Perlmutter und Schildkröte zum Muster / senden. Letztere bin erstens von Rom gewärtig.

Ao. 1716 können Sie in Venedig keine Tabacks Dosen Gemählde gesehen haben, / dann damals waren Sie in Franckreich aber wohl im Jahr 1715. / Es sind noch dergl zu haben, nur mit dem Unterschied, daß solche / damals überhaupts leickicher oder passabler gemahlt gewesen / seyn. Man verkaufft sie jetzt generalement dem Dutzend nach, und / sind gar zu schlecht. Die Rosalba lebet noch, mahlt aber seit 30. Jahren / nichts mehr in Wasserfarben, sondern in truckenen Farben, lebens- / grösse Bruststücke mit gutem Gusto. Es sind übrigens dergl Mahler / und Mahlerinnen so Tabattierenstücken machen, im Überfluß mir aber / noch keines in etl Jahren zu geschickt kommen, daß ich in meiner Tabattiere / leiden möchte, und kan nicht glauben daß Ihnen mit dergl gedinet wäre.

Inn- und auswartige antique geschnittene Steine kommen hier selten vor, / und sind gleichfalls Smith und Zanetti die ersten denen dergl gebracht / wird. H Smith hat seine Collection Zeichnen und in Kupfer stechen / lassen, Gori in Florentz machet die Beschreibung dafür, wann solche / fertig, wird er sie im Druck herausgeben; Verwichenen Herbst kam H / Smith zu mir und brachte sein ganzes 
Cabinet mit sich, weil ich nicht zu / ihm gehen konnte, Er hat mir die Ehre gethan mich zum Richter und / Täuffer zu erwehlen, und schrieb er auf mein Wort die Nahmen der / Steine und der Figuren, welche ihm unbekannt waren, unter die Zeichnungen / dieses ist eine von denen kostbahrsten unter allen Samlung und wobey keiner / wann

[112r] 9. / wann Er auch noch so gute Augen hat, oder zu haben glaubt, gar ge/ mächlich betrogen werden kan, ich meine etwas modernes vor antique / zu kauffen. Hier wird in Kürzen eine Samlung von 30. in 40. Stücken / erwartet, so hirher zum Verkauff gesandt wird, weil der Besitzer das / daraus zu erlösende Geld andernorts anwenden will. Als diese Sam- / lung zu Florentz passirte, hat $\mathrm{H}$ von Stosch, Mittel gefunden, solche zu / sehen, und hat an einen hiesigen guten Freund gemeldet, daß es fast / lauter Köpffe, aber sehr schöne Stücke wären. Weil solche hier an jemand / kommen, mit dem ich wohl dran bin, so flattire mir diese Samlung / am aller ersten in meinem Zimmer mit aller Commoditaet besehen / zu können. Solte darunter was besonders finden und ich sehen, daß im / Preiß fortzukommen wäre, so will Ihnen sogleich Nachricht geben.

Es hat hier jemand etliche auff Pergament gemahlte Portrait von einigen / Fürsten und Fürstinnen des Churbayrischen Hauses; solche sind von einem / circa 1670. 1680 berühmten und bekandten teutschen Miniaturmahler / nahmens Degler, sehr kräfftig gemahlt und wohl conservirt. Der so sie hat, / braucht das Geld nicht, macht aber auch aus den Portraiten wenig, / und getrauete mir das Stück vor einen Ducaten zu bekommen.

Ob Sie keinen leichten modeam wissen, die Meermuscheln von der / rauhen Haut zu reinig(en) und ihnen den Glanz zu geben? Mir w(ürde) / es sehr lieb seyn, wann Sie mir solchen communiciren wollten / Wann Monsieur mon trés honoré Amy mich mit einer Antw(ort) / beehren wollen, so bitte solche nicht an H Streit wie lezthin / zu adressiren, sondern über den biß anneml (?) Couvert mit fol- / gender Überschrift zu machen: / A Monsieur Jean Sigismond Natter chez Monsieur Daniel / Amann. / à Venise / So bekomme den ... (?) richtig und ... (?) ohngesäumet. Womit vor / dißmahl schließend nebst gehorsamster meiner Empfelung mit vieler / Hochachtung verharre / Monsieur mon trés honoré Ami / Votre trés humb et trés obeiss. Serviteur / J.D.Geysel

Venedig d 7 bre 1750

P.S. Von der (ab hier nicht mehr lesbar, da hier der Klebefalz ansetzt) 
[405r] Monsieur Mon trés honoré Amy / d 3 7bre 1723 / Dero hochwerthes vom 16 Passim ist mir seiner / Zeit wohl worden; aus demselben habe / zu vorderst Dero beständiges Wohlseyn / mit besonderm Vergnügen ersehen. / Die angeführte Entschuldigung wegen lang Still- / schweigens sind bey mir unnöthig, und können / künfftig erspahret werden, massen ich selbst /: ob / schon nicht aus Negligence, sondern ebenfalß wei- / len Verhinderung wegen :/ ein unfleissiger / Correspondente bin; Mir ist es indessen jeder- / zeit sehr angenl. gewesen, wann durch dero / Herrn Bruder oder auch von durchreisenden / Landsleüthen, von dero gutem Wohlstandt er- / freul Nachricht bekommen; Wann von dem / Polierpulver nicht etwa 1/2 Loth haben kan, / so wird es nicht wohl möglich seyn, dahinter zu / kommen

[405v] kommen, worinn es eigentl bestehe; Solten / Sie mir aber so viel davon senden können, ver- / spreche mein möglichstes zu thun, dieses Geheim- / nuß zu deteniren; zu der neüen / Liebhaberey des Kupfferstechens gratulire / herzl, und hat mir die Probe recht wohlge- / fallen; Wo Sie hierinn fortfahren, zweifle / nicht, daß Sie à grand Pas zu der Perfection / kommen sollen p. Darff ich indessen so frey / seyn, Ihnen meine Gedancken davon zu / eröfnen, so kan ich nicht umhin, zu welchen / daß so viel aus dem Abdruck ersehe, so sind / Sie noch nicht gewohnt, durch den Spiegel / auf die Platte zu zeichnen, um den Um- / riß zu machen, sondern bedienen sich / noch der gemeinen Art der Kupfferstecher / nemlich des sogenannten Ciligirens; hierdurch

[406r] hierdurch kommt aber hernach das Kupfferstich / verkehrt heraus, und ist Ihr Clavecin damit / zu neuem Ding geworden, welches wann es / gespielt werden könnte unmöglich klingen / würde, dann der Bass zu kurz der Dyant / aber zu lang bezogen worden; Nebst deme / kan das auf der Laute liegende Instrument / nicht recht erkennen p. Ich bitte aber noch- / mahl diese meine Erinnerung nicht übel / zu nehmen p. Ihren Bruder habe willens / selbst zu schreiben, weil es aber ungewiß / ob es mir nicht an der Zeit fehlen dürffte / so ersuche Ihme nebst meine gehorsamen Empfh / zu vermelden, daß Madame de Sandrart / bedauert, daß sie das in der Academie mangelnde Kup- / fer dermahlen unmögl. verschaffen kan, indem / kein Abdruck mehr vorhanden, die Platten / aber, so über 7 Pfund (Abkürzungszeichen) schwehr in einer Kiste einge- / macht, welche sie dermahlen nicht wohl auspacken / kan 
[406v] kan; Sie verspricht aber im anstehenden Früh- / ling, ohnfehlbar solche abdrucken zu lassen. / Wäre demnach mein unmaßgebl Rath, der / Herr Bruder ließe das Buch binden und an / das Ort, wo der Defat ist einen kleinen Steg / machen, so könte solch alzeit noch commode / hineingemacht werden; der Valor war das / Werck, welcher nach ihm mitgesandten Auszug / ...(?) beträgt, können so es beleg. nur an / Herrn Johann Nicolaus Ohlenschlager und / Compangie in Fft, Conto Herrn Jacob / Blomart gegen Schein bezahlt werden / Bey dem künstl Perspectiver, der die Nahmen / und andres artig zu machen weiß, habe etl. / Abdrücke gesucht, aber er ist wie alle un- / sere oder doch die meisten Künstler, daß / ist : ein bißg liederlich, die wann sie von ihrer / regen Arbeit etwas weisen sollen, solches nicht / eher thun können, als wann man sie es erst bey / andern

[407r] andern Leüthen entlehnet haben. Summa, er / konnte mir nichts geben, hat aber versprochen / etwas zu procuiren ${ }^{1786}$. Herr Professor Doppel- / mayer führet in seiner Beschreibung der Künstler / fleissig fort, und solche villeicht auf die / Herbstmesse ans Licht treffen; Was ich bey ihme / weg verlangter Nachrichten effatuiret, weiset daß / mir vorgestern zugesandte Billet - / Was den süssen Einfall wegen der christallinen / Cronleuchter betrifft, soll mir lieb seyn, wann / hiezu etwas beytragen kan. Ich bin bey unsern / Raritaeten Krämern gewesen, und mir etliche / Muster von den Glaskörnern geben lassen, wel- / che Ihnen durch den Kutscher senden will, weil / sie sich im Brieff nicht wohl einschlagen lassen / sie sind aber etwas grösser, als die in breist (?) / gezeichnete, der Preiß davon ist sehr civil, dann / man verkaufft sechstausendt vor einen Thaler / oder das tausendt vor 15. x. (= Kreuzer). Meine Liebha- / bereyen gehen sonst noch immer ihrem Gange fort / obschon /: bey vielen Handelsgeschäfften :/ etwas langsam; / Die

[407v] Die vornehmste davon sind die Naturalien / Ich habe bereits soviel Steine zusammen gebracht / daß man mich bald mit Warheit wird stein- / reich nennen können. 2.) die Medaillen Collection / vermehret sich dann und wann mit einer / guten Piece. 3.) die zu diesen beiden Lieb- / habereyen gehörige Bücher haüffen sich auch nach / und nach. 4.) Die Samlung der Abdrücke von / antiquen Gemmis habe nicht continuiren / können, weil hier wenig Gelegenheit darzu / sich zeiget, und man selten was neües $\mathrm{zu} /$ sehen bekommt. 5.) destomehr aber vermehret / sich meine Pinacotheque, wie ich Ihnen dann / nicht bergen kan, daß ich seit kurzer Zeit / ein graülicher Kupffer Wurm worden bin. Meine Collection

1786 = besorgen. 
bestehet in 3. Classen: Die / 1.) betrifft: Portrait der Kayser König / Fürsten Graffen und Baronen; diese colli- / gire ich pianpiano, ohne mir deßwegen / viele

[408r] viele Mühe oder grosse Unkosten zu machen / und möchte ich der Zeit wohl 1500 Stücke / zusammen gebracht haben. Die 2te Classe be- / stehet: in den Portraiten derer Päpsten Car- / dinälen Bischöffen Praelaten pp zugleich derer / Theol. Glth. ${ }^{1787}$ Medicorum Philosophorum / und in Summa alles was gelehrt heissen soll / denen zum Anfang die Künstler beygefüget / habe; diese colligire mit mehrern Eyfer / und werden nicht viel von 3000 Stücken fehlen / die 3te. Classe, worauff den meisten Fleiß / wende, und worinn am weitesten gekommen, be- / stehet in den Portraiten Nürnbergischer Patri- / tiorum, und Burger, hirunter nehme ich / gelehrt und ungelehrt, Schuster, Schneider pp / Was nur in Nürnb. gebohren, oder erzogen / alda gewohnet, oder auch was von Fremden / alhier gestorben und begraben worden. / Ich glaube nicht daß ein Ort, in Teutschland / ja ich dürffte wohl sagen in ganz Europa seyn / wird

[408v] wird, daß so viel in Kupffer gestochene / Portraiten von seinen Bürgern aufwei- / sen kan; Wer solte wohl glauben, daß / ich bey 3000. Stück davon gesammlet, und / doch noch über 400 Stück hier und dar gesehen / so zur Stundt noch nicht habhafft werden / können? Ich habe mit vieler Mühe einen ac- / curaten Catalogum hierüber verfertiget / sowohl $\mathrm{zu}$ meinem als andrer hiesig Liebhaber / Gebrauch, weil durch Tausch man in der- / gleich Samlung am geschwindesten fort kommen / kan. Ich habe eine ziemliche Partie * in Duplo / solte Monsieur et trés honoré Amy in Fft / ein oder anderer Liebhaber, der dergl colli- / giret, bekannt seyn, und sie mir zur Corres- / pondentz und ...procirlich (?) Communication / verhelffen können, würde mir besonderer / Gefallen geschehen; dißmahl muß schließen / Ich verharre nebst meiner höchst. Empfl an die / Herrn Brüder, Monsieur M tres h: amy / Votre trés h et trés dedié / Servit Gueisel le fils

Nürnb d 9. Marz $\underline{1723}$

* sowohl von hiesigen als fremden

$1787=$ Gelehrten 
[632r] Nürnb d 5. 8br. 1723 / Monsieur mon trés honoré \& trés cher Amy / Dero sehr wehrtes vom 3 Pass habe mit Vergnügen / erhalten, würde auch eher darauf geantwortet haben / wann nicht durch Madame de Sandrart, mit dem / Defect so lange aufgehalten worden, welchen endl vorgestern / erhalten und hirbey folgt, anbey ersucht Sie dienstl wie / aus Versehen des Blomartisch Bedienten, durch H Ohlenschlager / 1 f weniger gefordert worden, als die Bücher betragen, wie / dero Herr Bruder aus dem mitgesandten Sandrartischen / Original aushl ersehen kan, daß besagter Gulden noch [an] / H Ohlenschlager möchte bezahlt werden, weil Sie die Bücher / in dem Preiß angesetzet, wie Ihr solche die Buchhändler bez(...? Rest fehlt) / welches dann hirmit, wie Ihr versprochen, erinnert / und ersucht haben will, besagtem Defect d Herrn Bruder / nebst meinen gehorsamen Empfel. zu zustellen. / Die mir übersandte Probe eines in Kupffer gestochenen / Prospects von dero Landtguth, hat mir recht wohl gefallen / und wünsche auch bald die übrigen zu sehen. / Herr Prof. Doppelmayer ist gestern per hazard zu mir / gekommen, da ihme dann, in dero Nahmen weg communicir- / ter Nachricht von seinen Wercken gedancket; und zugleich ein / wenig weg des Ihnen comunicirten Berichts von der Cassinischen / Waage, auf den Zahn gefühlet; allein er meint seiner Sache / gewiß zu seyn, und hat mich versichert, daß er bey dißer / Machine wenig oder gar keine Schwirigkeit finde, Er wolle / disen Winter sich darüber machen, und ein dergleichen / Waage verfertigen und Ihnen übersenden; Was daraus / werden wird, muß die Zeit lehren an meiner Erinnerung soll / es bey Ihm nicht fehlen, damit er bald Hand anlegen möge

[632v] Ich habe alhier noch keinen Glasschneider erfragen können / bey welchem dergl birnen Klocken oder Kegeln mit Facetten ge- / schliffen in guten Preiß zu haben wären. Man hat / mir zwar von einem Künstler gesagt, der sich eine Stunde / von hier aufhält, ich habe aber noch keine Zeit finden können / dahin zu kommen, werde aber in Kürzen mich dahin verfügen / und was ausgerichtet zu melden nicht unterlassen. / Herr Professor Doppelmayer hat mich ferner ersucht, / Sie in seinem Nahmen zu bitten soferne sie folgende / 3. Bücher oder auch nur 1 od 2 davon hätten, Ihm solches / auf kurze Zeit zu übersenden, Er verspricht die Resti- / tution, bald, unversehrt, und mit höchstem Danck und / oblige in dergl und allen andern Occasionen wider $\mathrm{zu} /$ dienen. Es sind aber folgende: 
1. The Continuation of the Philosophical / Translations, and Collections to the year $\underline{1720} .4^{\circ} 1788$

2. Observations Physiques \& Mathematiques envoyées / des Judes et de la Chine â l'academie Royale / des Sciences a Paris par les Peres Jesuites p / â Paris 1692. in $4^{\circ} 1789$

3. Observations Physiques \& Mathematiques / envoyées de Siam â l'academie Royale / des Sciences â Paris. 1682. $8^{\circ 1790}$

Das gütige Anerbiethen bey Gelegenheit zur / Vermehrung meiner Pinacotheque etwas / beyzutragen, erkenne mit geziemend schuldig / Danck. Mit dem Catalogo will aufwarten, sobald / damit zum Standte seyn werde. Ich muß mit / den Krebsen einerley Gang machen, und von den / Bürgern

[633r] Bürgern zu den Potentaten aufsteigen. Es werden / demnach fünff besondere Catal. zu verfertigen seyn,

1.) Die Bildnuße derer Päpste Cardinaele Erzbischöffe, / Bischöffe Praelaten etc.

2.) Die Bildnuße derer Kayser König Chur- und fürsten / (?) römische Kaiser, wie auch der Könige und fr... (Rest weggebrochen) / der Fürsten p.

3.) Die Bildnuße derer Graffen und Freyherren p. / Item derer Staats und Kriegs Ministrarum pp

4.) Die Bildnuße derer Gelehrten und Künstler, denen / als ein Anfang das Frauenzimmer beygefügt / werden soll.

5.) Die Bildnuße der Nürnbergischen Rathsherren / und Bürger p.

Dieser fünffte und letzte Catalogus ist fertig und / darff nur ins reine geschrieben werden. Der Erste (unleserlich, da weggebrochen) / ist auch fast zur Helffte fertig, und hoffe ihn jezt / anfangenden langen Nächten in Kürzen zu Ende zu / bringen; Wornach mich dann auch über die übrigen / wagen will. / Bey dem Verlust des Kästgens, worinn mein Italiaen. / Journal sich befunden, war auch das Lautenbuch daß bey M. Bloivin in Rom angefangen, worinn zwar über / etwa à 12 Stück nicht befindlich, wünschte aber doch solche / einmahl jezo zu sehen, um der besondern Maniern und Battuten willen, ob mich solcher dabey noch erinnern / könnte; wolte dahero wohl bitten, wann Sie dasjenige / Lautenbüchl noch

\footnotetext{
1788 Nicht im Besitz Uffenbachs nachweisbar.

$17894^{\circ}$ Bibl. Uff. 23/25.

$1790 \quad 4^{\circ}$ Bibl. Uff. 23/25.
} 
beyhanden, worein er Ihnen damals Stücke / geschrieben, mir solches gütigst zu communiciren. ${ }^{1791} /$ Ich

[633v] Ich will hingegen willigst mit Lautenstücken dienen / da ferne Sie von diesem charmanten Instrument noch ein / Liebhaber sindt. Ich meines Arths habe vor kurzen ange- / fangen den Generalbaß auf der Laute zu tractiren / wobey ich zwar viele Schwürigkeit aber auch viel Vergnügen / finde. Und nachdeme das Glück gehabt, mir admirable / Lauxmaler Lauthe zu überkommmen, so habe solche à la modern. / zurichten und an 13. Chöre optiren lassen, welches / auch sowohl reussirt, daß ich damit mich unter einer Compagne / von 4 biß 5. Personen kecklich wagen, und nicht fürchten / darff, überschrien zu werden. Es ist ein Optiker nahmens Keller / von hier, so in Ffort etablirt, vor kurtzen hier gewesen, und / gegen jemand gesagt: man hätte in Ffort Lauthen so mit / stählernen oder messingen Saiten bezogen wären und so / starck als ein Clavicimbel klingen. Bin curieux zu wissen / ob deme also und was es damit vor eine Beschaffenheit / habe; So mir unbeschwert zu melden ersuche p. / Ich habe etliche Concerten von Kühnel mit drey Stimmen, / als: Laute Flûte Travers und Violoncello. Laute Viol di Gamba / und Bassetgen p Dabey alle Stimmen obligat sind; Ob / Ihnen solche bekannt, oder ob Sie auch dergleich haben / möchte wohl wissen. Leztens habe eine Probe gemacht / und aus einem Trio von Kunicke, so vor 2 Flûte Traversen / und Cembalo gesezt waren, die eine Fleute in die / Laute gesezt, so zimmlich wohl reussirt, habe es / zwar seit deme mit 2. andern probirt, hat aber / nichts rechts herauskommen wollen, zum Beweiß daß / die Stücke so nicht in die Laute componirt sind, auch sich / selten dazu schicken. Allein ich dencke nicht daß ich / Sie alzu lang mit meinem Schreiben aufhalte, ich wünsche / bald die Ehre zu haben, widerum gute Nachrichten von Ihrem / Wohlseyn zu hören; Inzwischen verbleibe lebenslang / Monsieur Mon trés honoré Amy / Votre trés h \& trés obeiss Servit / J.D. Gueisel le fils 


\title{
15.5Briefentwurf von Johann Friedrich von Uffenbach an den Leipziger Professor Johann Friedrich Christ
}

\author{
$\underline{\text { SUB Göttingen Cod. Ms. Uffenbach 20/II, p. 285-289, 30. April } 1750}$
}

In dem Briefentwurf an Johann Friedrich Christ (1701-1756) schildert Uffenbach u.a. ausführlich seine geplante Veröffentlichung des Monogrammlexikons und auch die Ordnung seines Kabinetts.

[285r] Hochedelgebohrner Hochgelehrter / und Hochgeehrtester Herr.

Eine Zuschrifft von unbekanter Hand empfangen hat / nicht allezeit das Glück eines günstigen Geschickes. / ich wage es jedoch nach manchem innerlichen wieder / spruche Eure Hochedelgeb mit gegenwertigen $\mathrm{zu}$ belästigen / und denenselben für die Ausgabe des schönen werckes / von denen mahler und kupferstecher zeichen zu dancken / Niehmahlen bin ich begieriger einem neuen Druck zu / sehen gewesen, aber auch niehmahlen bestürtzter, / denn es sind nunmehr bey 36 Jahren da ich eben / dergleichen arbeit mühsam angefangen, auf mei / nen langwührigen reißen vermehret, und in ruhigern / Jahren durch briefwechsel ergäntzet habe, alles zu dem Absehen, daß wann es zu schickliche weiße gediehen / seyn würde, es zu gemeinen Nutzen derer Liebhaber / durch den Druck an Tag zu bringen. Wie sehr aber war / ich verwundert als mir erstlich Harms ${ }^{1792}$ am Braunsch / weigischen Hofe mit seinen chronologischen oder histo / rischen mahler tabellen, und kurtz drauf Eurer Hochedelgeb / tüchtige Arbeit ${ }^{1793}$ zu vorkamen, und mich also mei / ner Mühe überhoben. Ich hatte nehmlich die stolze ge / dancken mein gantzes Werck, das ohngefehr dem itz er / wehnten Harmsischen ähnlich siehet, mit eigener Hand in / Kupfer zu stechen, wie man bey andern Schrifften in / Engelland mehrmahlen gethan, allein meine

1792 Antoine Frédéric Harms, Tables historiques et chronologiques des plus fameux peintres anciens et modernes, Braunschweig 1742 ( $2^{\circ}$ Bibl. Uff. 491).

1793 Johann Friedrich Christ, Anzeige und Auslegung der Monogrammatum, einzeln und verzogenen Anfangsbuchstaben de Nahmen, auch anderer Züge und Zeichen, unter welchen berühmte Mahler, Kupferstecher u.a. dergleichen Künstler, auf ihren Wercken sich verborgen haben ... aus den ersten Wercken selbst, jetzt von neuem genommen, Leipzig 1747 ( $8^{\circ}$ Bibl. Uff. 789)

ders., Dictionnaire des Monogrammes, Chiffres, Lettres Initiales, Logogryphes, Rebus etc., Paris 1754 ( $8^{\circ}$ Bibl. Uff. 799). 
überhäufften / Berufsgeschäffte, und sonderlich das abgewichene Jahr, mach / ten mich in meinen Zirckeln, und überhaupt zu Hauße

[285v] zu einem solchen Fremdlinge, daß an dergleichen / mühsame Nebenarbeit nicht gedencken konte, so / verliehfe unvermerckt eine Zeit nach der andern / biß endlich andere vorkamen und mich derselben / gantz überhoben. Ich muß jedoch hirbey auch offen / hertzig gestehen daß die Furcht mich in eine ver / jahrte dunckele und ungewohnte Sache zu wagen / ein Theil des Verzuges geweßen. Drum ich scheute / mich immer durch einen Machtspruch ohne hin / langlichen Beweiß, wie le Comte ${ }^{1794}$ und nach ihm / italiener Engellander und Holländer blind ge / than, Knoten aufzulösen und Nüße aufzu / knacken die meinen Zähnen zu hart waren. / indeßen ist es doch billig daß einmahl die bahne ge / brochen werde, soll einmahl die Ehre so mancher / redlichen Künstler, deren Gedächtnüs schon würcklich / zerflattert, wie billig gerettet und die unächte / frantzösche und welsche Hirngespienste, wie Cormet / Hisbens, Versegraf p p aus dem register, wie itzo die / kleine Lichter aus der heiligen Rolle zu Rom gestoßen / werden. Alle rechte Kenner müßen also Eurer / Hochedelgeb vor deren rühmliche Bemühung Danck sagen / und dieselben bitten, sich nicht irre machen zu laßen / wenn hie und da ein Anfänger es für einen schlechten / Troßt halten will, daß man ihm sagt ein begehrtes / Zeichen fände sich auf alten Blättern, und weiter / nichts. Dann wie Rom nicht an einem Tag gebauet / und keine Wißenschafft anders als stufenweis em / por gekommen, so wird es auch wohl dieser gehen.

[286r] Nur schade ist es hirbey, daß der theilnehmenden / diesfalls so wenig in der Welt sind, wann ich anders / von hier auf andere Orte urtheilen soll, woselbst / die Geselschafft weit geringer als die Zahl der ehemah / ligen Musen befindlich ist. bekantlich studiret der / gelehrte Pöbel nur brodmäßig, und der meißte Theil / derer Einwohner stehet unter dem flügelstabe des mer / curii lieber als bey der Lanze der Pallas. Wann aber / die Zahl derer Liebhaber unseres vorwurffes so klein / ist, was wunder wann ich anderwärts bekantschafft / zu machen trachte und wünsche, und hirmit erfahren / endlich Eure Hochedelgeb nach einem so langen vor / trage eine Uhrsache meines Schreibens. die folgende / bestehet hauptsachlich in einer Neubegierde, umb vor / läuffig zu vernehmen, worauf eigendlich die ver / tröstung ziele welche dieselbe an etlichen arten des aus / gegangen werckes dahin geben, daß dieser oder je / ner umstand auf eine andere art künftig aus / geführet

1794 Florent le Comte, Cabinet Des Singularitez D'Architecture, Peinture, Sculpture Et Graveure, Ou Introduction A la Connoissance des plus Beaux Arts, figurés sous les Tableaux, les Statues \& les Estampes, 3 Bde., Brüssel 1702 ( $8^{\circ}$ Bibl. Uff. 537-539). 
werden solle, wann anders mein begehren / nicht zu frey bittet. hiernechst verstehe ich deutlich daß / der H verfaßer eine beträchtliche Sammlung von alten / Bildern sowohl abgedruckte als mit der Hand ge / zeichneter besitze, und da ich durch meine erfahrung / inne worden, daß man doppele (verstehe der erstern / gattung) zu bekommen nicht vermeiden kan, als / will allenfalls meinen vorrath anerbiethen, wann / ein tausch beliebig seyn mögte, worüber mich künf / tig weiter zu erklähren die Ehre haben und nehmen werde.

[286v] damit ich aber einen kleinen vorgeschmack von / der beschaffenheit meiner Sammlung gebe, so ist sol / cher von der begierde den anfang den wachsthum / und die blüte der Kupferstecher Kunst zu sehen und / darlegen zu können entstanden, daher meine / blätter alle nach denen meistern, und zwar in alphabetischer ordnung liegen ${ }^{1795}$, welchem loco proe / mii eine Zahl von Kupfern vorgehet, die alle er / denckliche arten derselben zeigen. der folgende / Schwarm ist, weil gut und schlechte meister haben / müßen, ziemlich gros, jedoch so daß man / augenblicklich das verlangte finden kan, weil / alles auf real bögen von hellblauem papier / angehefftet ist, auch keine unordnung oder / vorfall zu befürchten stehet. die Handzeichnung / deren Zahl bey 500 stücke von denen alten / und besten mahlern ist, liegen ohnangehefftet / in großen real portefeuilles von hellblauem pa / pier, als in welcher gattung von bildern heut / $\mathrm{zu}$ tage in franckreich, Engel, und holland gleichsam / eine rasende Kaufsucht ist, wie in allen dingen / eine mode tyrannisiret. wie es in franckreich als / dem orte wo ohnstreitig Künste und wissenschafften / am meisten blühen, damit aussiehet, kan man / nicht zuverläßiger, als aus gersaint catalogues raison / nès ${ }^{1796}$, derer seit wenigen Jahren nach und nach 10 stücke

[287r] heraus kommen, abnehmen, dieße Nachrichten / von allen arten gelehrter Spielsachen, sind so gründ / lich schön und unpartheylich für alle nationen, daß / man sie nicht anders als mit vergnügen durch / gehet. die Kupferstuicke haben darinnen einen großen / platz, und ein kleines Lexicon von dem leben derer / vornehmsten mahler und kupferstecher, wie auch cata / logi gantzer wercke von etlichen hauptsachlichen meistern / sind sehr nützlich, daher

1795 Vgl. Pütter 1788, S. 229: „Mit der Sammlung von Kupferstichen ist noch insonderheit folgende Veranstaltung getroffen worden. Sie war bisher in vierzig Mappen aufbewahrt; aber ohne daß dabei auf ein chronologisches System, auf die verschiedenen Schulen, oder sonst auf eine richtige alphabetische Folge Rücksicht genommen war, sondern so, daß zuweilen der Name des Erfinders, zuweilen der Name des Kupferstechers zur Richtschnur gedient hatte."

1796 Edme-Francois Gersaint, Catalogue raisonné des Tableaux, diamans, bagues de feu M. Charles Godefroy, Paris 1748 ( $8^{\circ}$ Bibl. Uff. 947). 
mich wundert daß Euer Hochedel / keine anregung davon in der vorrede ihres mehr be / sagten werckes, wo von denen Schrifftstellern dieser Kunst / gedacht wird, gemacht, und hingegen etliche Engellän / der erwehnet haben, so dieser Ehre nicht werth sind, wie / zum exempel das repertorium sculptile $\mathrm{p} \mathrm{p}^{1797}$. Ich habe / eine geraume Zeit unter diesen landsleuten zuge / bracht, und zum Eckel erfahren, daß sie, sobald etwas / in franckreich oder Teutschland in ihren Kram drinnen / das gedruckt wird, sie es so fort in ihre Sprache übersetzen / und den Uhrheber sorgfaltig verschweigen, dergleichen / grobe plagia ich verschiedene erlebet, und worunter / auch dieses repertorium gehöret, ein anders aber nahm / lich Evelyn Sculptura or the history and art of calcogra / phy 1798 verdienet mehrere achtung, und enthält gründli / che Nachrichten, ob es gleich auf bossens arbeit ${ }^{1799}$ erbauet / worden. Er ist sonsten derselbe Verfaßer so den schönen

$[287 \mathrm{v}]$ folianten, a paralell of the ancient and modern / Architecture ${ }^{1800}$ heraus gehen laßen, und muß man / ihm die verketzerungen derer Nahmen, sonderlich der / von Teutschen, welche ihnen barbarisch klingen, zu gute / halten. Thun es doch unsere Landsleute, / wie neulich bey der Ausgabe der Kern historie aller / freyen Künste ${ }^{1801}$ gesehen. der verfaßer, welcher mir / unbekant ist, muß mir nicht

1797 Pellegrino Antonio Orlandi, Repertorium sculptile-typicum: or a complete collection and explanation oft he several marks and cyphers by which the prints oft he best engravers are distinguished, with an alphabetical index of their names, places of abode, and times in which they lived, translated from the abcedario pittorico of Pellegrini Antonio Orlandi, London 1730 ( $8^{\circ}$ Bibl. Uff. 787).

1798 John Evelyn, Sculptura, or the history and art of chalcography and engraving in Copper, With an ample enumeration oft he most renowned Masters and their works, London 1662 $\left(8^{\circ}\right.$ Bibl. Uff. 435).

1799 Abraham Bosse, Sentiments sur la distiction de la peinture, dessein et garvure, Paris 1649 ( $8^{\circ}$ Bibl. Uff. 412).

ders., Radier-Büchlein, Handelt von der Etzkunst, Nemlich: Wie man mit Scheidewasser in Kupferetzen, das Wasser wie auch den harten und weichen Etzgrund machen solle; Beneben kurtzer Beschreibung wie die Kupferplatten abzudrucken, die Druckerpressen zu machen uns was ansonsten darbey in achten zu nehmen hat, Erstmals durch Abraham Bosse, berühmten Kupfferstechern zu Pariß in französischer Sprache beschrieben, Anjetzo aber in Teutscher Sprach herauß gegeben und vermehret; Sampt einer Zugabe von der Herold- Mahl- und Reißkunst mit darzugehörigen Figuren durch Andream Böcklern, Nürnberg 1669 ( $8^{\circ}$ Bibl. Uff. 447).

1800 John Evelyn, A parallel of the ancient architecture with the modern, in a collection of ten principal authors who have written upon the five orders viz. Palladio and Scamozzi, Serlio and Vignola, D. Barbaro and Cataneo, L. B. Alberti and Viola, Bullant and De Lorme, compared with one another ; the three Greek orders, Doric, Ionic, and Corinthian, comprise the first part of this treatise ; and the two Latin, Tuscan and Composita, the latter, to which is added An account of architects and architecture : in an historical and etymological explanation of certain terms particularly affected by architects. With Leon Baptista Alberti's Treatise of statues, London 1707 ( $2^{\circ}$ Bibl. Uff 139).

1801 Der Kern-Historie aller freyen Künste und schönen Wissenschaften, vom Anfang der Welt bis auf unsere Zeiten, Leipzig 1748 ( $8^{\circ}$ Bibl. Uff. 750). 
verübeln, wann ich / dafürhalte daß seine Erfahrung noch nicht / genug seye, da sich solche im irrthum derer Jahr / Zahlen so wohl als derer Nahmen aüßert, und / dem Doppelmaier ${ }^{1802}$, welchem mehr zu traue, offters / wiederspricht. was mag ihm aber die Nachricht von dem / erfinder der schwarzen kunst, nehmlich von Sichem oder Sichen ${ }^{1803}$ gesagt haben, da doch der oben er / wehnte Evelyn dieselbe dem prinzen Ruprecht von / Pfalz mit beglaubten Umständen beyleget. I ferner erweitert er den gemeinen irrthum von den / baselischen und vermeinten holbeinschen Todentanz / den merian in einer besonderen beschreibung in / Kupfer ${ }^{1804}$ gebracht, und welchen mit Augen selbsten be / dachtlich betrachtet, am ende aber derer figuren / den todt bey dem mahler gefunden mit dießer / anrede: hans hug glauber loss mohlen ston, du / must itzund mit mir davon p. ohneracht deßen soll

[288r] es holbein gemahlt, und von dem durchreißen / den Rubens in oben dem glauben bewundert wor / den seyn, das ich nirgends gelesen. Noch weiter führt / man in Nachforschung des Sandrarts ${ }^{1805}$, der bey mir / keinen historischen Glauben hat, bey erwehnung von / dem erfinder der Kupferstecherkunst, ein bekantes / bild an, so darin etwas erweisen soll, da es doch / das gegentheil zeiget, es ist daß selbe wo ein alter / man von einem entblößten weibe auf ein bettte ge / zogen wird welches sie Hand in seiner geldtasche hat / und wird pag. $90 \mathrm{im}$ Kupferstecher theil erwehnet. / mein wohlgehaltenes exemplar hat keine JahrZahl, un / ten aber die buchstaben L. C. nebst einem ausflie / Benden umgestürtzten

1802 Johann Gabriel Doppelmayr, Historische Nachricht von den Nürnbergischen Mathematicis und Künstlern: welche fast von dreyen Seculis her durch ihre Schrifften und KunstBemühungen die Mathematic und mehreste Künste in Nürnberg vor andern trefflich befördert ...; in Zweyen Theilen an das Liecht gestellet, Auch mit vielen nützlichen Anmerckungen und verschiedenen Kupffern versehen, Nürnberg 1730 ( $2^{\circ}$ Bibl. Uff. 249).

1803 Christoffel van Sichen, Bibels Tresor or sielen lusthof, Amsterdam 1646 (4 Bibl. Uff. 483).

1804 Matthaeus Merian. Todten-Tantz, Wie derselbe in der löblichen und weitberühmten Stadt Basel, Als ein spiegel menschlicher Beschaffenheit ganz künstlich gemahlet und zu sehen ist; Mit Leben, Nach dem Original in Kupffer gebracht und herausgegeben, Franckfurt 1696 (4 Bibl. Uff. 455).

1805 Joachim von Sandrart, L' Academia Todesca della Architectura, Scultura \& Pittura: Oder Teutsche Academie der Edlen Bau- Bild- und Mahlerey-Künste : Darinn enthalten Ein gründlicher Unterricht/ von dieser dreyer Künste Eigenschaft/ Lehr-Sätzen und Geheimnißen/ von den Bau-Steinen und fünferley Bau-Arten/ von den Statuen und ihrer Zugehör/ von der Erfind- und Zeichnung ... Durch langen Fleiß und Erfahrung ergriffen/ und Auf inständiges Erinnern hoher und vornehmer Personen/ allen Kunst- und TugendLiebenden zu Ehren und Nutzen; Neben Aller Egyptischen/ Griechischen/ Römischen/ Italiänischen/ Hoch- und Nieder-Teutschen/ auch anderer Alten und Neuen Virtuosen/ Leben und fürnehmsten Kunst-Werken/ beschrieben/ Auch Mit 38 Platten von der Architectur, 68 Alt-Römischen Statuen/ ganz und halben Bildern/ 74 Medaglionen/ 180 Contrafäten/ durch die Hand der bästen heutigen Künstler, 3 Bde. Nürnberg, Frankfurt 1675 ( $2^{\circ}$ Bibl.Uff. 345-347). 
Krüglein, daher es vor / ludwig krüglein, oder Lucas Ciamberlan gehalten / welches auch die tracht des alten pandalons, oder ve / netianers bezeuget, und dem alter derer bey colmar / erschienenen Kupfern nicht bey kommet. Die Zeichnung / ist ohnfehlbar dem in solchen nackenden / bildern bekanten carache zuzuschreiben, wegen des / Kupferstechers aber will nicht hartnäckig wiedersprechen daß es aber eines derer ersten blätter seye, siehet meiner / nicht glaublich aus. dießem allen ohngeachtet aber lobe / jedoch die bemühung des Kern historici ${ }^{1806}$, welche in ihrem / artigen Zusammenhange mit vergnügen gelesen. / Allein da von der erfindung dieser belobten Kunst rede

[288v] so fallt mir eine begebenheit ein, deren noch ge / dencken muß, würde auch meine unerlaubte epi / stel noch so grob. Ich lase vor etlichen Jahren in actis / physico medicis naturae curios, vol. secund. 4 novimb. / 1730 in appendice $\mathrm{p} 73$. $\mathrm{H}$ Jacob baiers doctor et prof. / med. sciagraphiam musaei ${ }^{1807}$, wo gesagt wird: habeo / autem adhuc vetustiores aliquot tabulas in germania / aere expressas luculentis indiciis literarum nostri idioma / tis et annorum queis divulgatae sunt, videlicet 1464 / et 67 quibus nescio an priores aliquae pari certudine / possint demonstrari. Haben Euer Hochedelgeb niehmahlen / hievon einige umstände vernommen? allenfalls bäthe / mir solche nachrichtlich aus, weil immer bedencken / getragen mich an den besitzer wegen der Kleinigkeit des vorwurffes mit einer Zuschrifft zu wagen. Den / Erfinder der Kunst betreffend, so habe verschiedene sehr / betrachtliche Bilder welche allenfalls ein Licht geben kön / ten, wenn man kühnlich seinen Mutmaßungen / den Zirgel wolte schießen laßen. Ich habe aber den / teutschen Fehler nehmlich die Zaghafftigkeit, und wolte / es lieber tüchtigeren Kennern als ich bin zu beurthei / len überlaßen, daher mich wohl entschließen könte / falls mein allzulang gerathener Vortrag Eurer / Hochedelgeb nicht misfiele, sie zur Einsicht zu über / senden. Insonderheit wäre mir lieb, davon Urtheil / über einen sehr mühsamen gotischen Handriß auf

[289r] Pergamen, welchen zufällig in einem buchla / den zu Brugge 1718 bekommen, gelegendlich zu / vernehmen, es stellet eine Schlacht mit vielerley Fahnen / und Waggen vor, woraus Kenner der Alterthümer / wohl etwas errathen solten. Die Zeichnung war ge / wittmet und denen Buchbinder feil gebothen umb / Riemen zum Bücherhafften zu schneiden. / Drum mein Seel Bruder in seiner bekannten Samlung / viele von dem Untergang errettet, wie ich mit dießem / gleichfalls gethan. Vielleicht möchte es Kennern der / Alterthümer gefallen, zu

1806 S.o.

1807 Johann Jacob Baier, Sciagraphia musei sui. Accedunt supplementa oryctographiae Noricae, Nürnberg 1730 (4 Bibl. Uff. 606). 
mahlen wann es nicht teutsch / ist, denn fremde Sachen haben leyder bey uns immer / mehr Achtung. Einen obwohl unnötigen Beweiß deßen / kan aus der Begebenheit mit einer alten Mahlerey, / so ohnfern Nurnberg in einer Schloßkirche bewahret, wegen / ihrer Fürtrefflichkeit für italienisch gehalten, und in den / Hamburger Berichten Num 51 Anno 1735. d 4ten Juny zur / Entscheidung beschrieben worden. Die Rettung teutscher / Ehre brachte mich damals auf, daß einen Aufsatz im / folgenden Jan. 1736 einrücken ließe der meine Gedan / ken hierüber weitläuffiger erläutert. So war es in al / ten und neuren Zeiten bey unsern Landsleuten, und / so sind manche wackere Künstler in Vergeßenheit, man / che Ausländer Stümpler aber hoch an das Brot gekommen. / Welche Erbsünde allerdings Achtung verdienet.

[289v] Allein endlich wacht mein Gewißens Scrupel / auf, daß Euer Hochedelgeb über Gebühr mit mei / nem allzulangen Vortrage behelligt. Ich bitte dero / wegen, und zwar gleich bey dem ersten Exempel / gehors. umb Vergebung so wohl dies falls, als / auch überhaupt meiner unternommenen Freyheit / wegen, und verharre mit schuldiger Hochachtung / wie auch aller Gegenbereitschafft zu dienen ohn / ausgesetzt / Eurer Hochedelgebohrnen / ergebenster Diener / Johann Friedrich von / Uffenbach

Franckfurt am Mayn / d 30 Aprill 1750. / an H Professor Christ nach / Leipzig 


\title{
15.6Antwortschreiben mit französischem Text von Johann Friedrich Christ aus Leipzig an Johann Friedrich von Uffenbach
}

\author{
$\underline{\text { SUB Göttingen Cod. Ms. Uffenbach 20/II, p. 291-295, 12. Mai } 1750}$
}

[291r] Wohlgebohrner und Hochgelahrter, / Insonders Hochgeehrtester Herr,

Es seyen nun schon viele Jahre verfloßen, da ich mich nebst dem / Herrn Grafen von Bünau, Cammerherr bey Ihro Majestät unseres / König, zu Franckfurt am Mayn befand, und nach gemachter / Bekanntschafft mit dero wohlseel Bruder auch viel / rühmliches von der Ihro Wohlgebohrn beywohnenden edlen Wis= / senschafft und vielerley annehmliches Singendes (?) verstanden / hatte, und daher wünschte, auch dieselbe zu sehen, das aber / damahls wegen dero Abwesen und Kürtze unseres Aufenthalts / in dem lieben Franckfurt nicht erhalten konnte. Desto / erfreulicher fället mir jetzt billig, daß dero mir sehr / angenehmer, umständliche Brief, dieselbe edle Wohlgewogenheit

[291v] für dero Person gegen mich bezeuget, welche jederzeit unter denen, die / Kunst und Wißenschafft lieben auch in der Entfernung gemeinschafftlich / blühen soll. Daher habe ich ingleichen die geneigte Aufnahme / meines in Eile entworffenen Büchleins von den Zeichen der Mahler p / auf ihren Werten mit Dank zu erkennen, und daßelbe mei= / nen übrigen Schrifften ferner zu gütigen Urtheil zu empfehlen.

Dieses Büchlein ist erstlich entworffen mit Geschwindigkeit zu einer Zeit, / da ich besorgen muste, das aus meinen Papieren, welcher Communication / ich verschiedenen Freunden künstlicher Werke nicht hatte versagen kön / nen, durch irgend eines anderen etwas verstümmeltes leicht im / Druck erscheinen mögte. Dann hat die Verlegerin, eine Witbe, welche den Buchhandel bißher auf redliche, gute Weise fortgeführet / hat, gleichwohl den Muth dabey nicht gefaßet, durch einen recht / feinen, ansehnlichen Druck, und mehrere Kosten, etwas das nach / Würdigkeit der Sache mehr in die Augen fiele, zu lieffern. Es hat= / te auch gleichsam noch ein anderer Band eines reichlichen Registers / der Nahmen etlicher tausend Künstler, mit Anzeige der Nation, Schulen,

[292r] Lehrmeister, Ort und Zeiten, in welchen sie gelebt haben, welche Verzeichniße be $=/$ reits ausgearbeitet bey mir liegen, und das Buch erst vollkömmlich zu aller= / ley Gebrauche geschickt und dienlich gemacht hätte, 
darzu kommen sollen. / Welches aber der Kosten halber noch zur Zeit zurückgeblieben ist. Nach dem / Drucke habe ich dann auch wohl diese unschuldige Zeichendruckerey selbst mit etwa / noch soviel neuen Zusätzen verbeßert und vermehrt, als vorhin das ganze war. / Deß allen ohngeachtet aber werden dieselbe das Büchlein, wie auch andere / viele Kenner bißher gethan und es wohl aufgenommen haben, leicht un= / füglich gemacht, und beym durchlesen und Untersuchung des angeführten nicht / unrühmlich finden. Das, worauf ich mich darinnen der Kürtze halber biß=/ weilen beziehe, ist meine Historie der Mahlerey neuerer Zeiten, und eine andere, / von Erfindung und Aufmachen des Kupferstichs, Formschneidens in Holz und / dergleichen: deßen das meiste schon zu Papier gebracht ist. Weil ich mit eben / dießem Posttage an meinen auswärtigen Gelehrten einen Articul einer Frage / eben darüber in einem eiligen Brieffe beantworte, will ich nur dieße Stelle / aus dießem Brieffe abschreiben laßen, und hier beylegen. /

Laßen übrigens dieselbe ${ }^{1808}$ sich an dero rühmlichen Vorhaben durch meine / Arbeit nicht hindern. Ich zweiffle keineswegs, daß auch dero entworffe $=/$ ne Tabellen bey allen, was ich oder ein anderer machen kan, als etwas / eigenes, schönes und sonderliches, wohl stehen, und allerhand gutes ent $=$ / halten werden, welches mir und anderen bißher unbekannt geblieben. Kenner / aber werden nebst mir daßelbe, wenn auch nur die Methode unterschieden

[292v] wäre, ein solches Werck wohl gebrauchen können, und jederzeit mit Hochach= / tung und Distinction aufbehalten, und endlich die übrigen um so mehr durch / unterschiedene Bücher erwacht werden, dieße holdfertigen Künste zu lieben. / Der Weg, welchen dieselbe hirbey halten, und dero Urtheil über Florent le / Comte ${ }^{1809}$ und andre dergleichen Arbeit zeigt wohl, daß denenselbe der / rechte Grund dießer Sache bekannt sey. Es ist hirbey in unsern teut $=/$ schen Landen allerdings etwas beschwerlich, daß dieße, welche einige Wis $=$ / senschafft, Kunst und dergleichen bey sich empfinden, nicht also, wie etwa / derer einer andren Nation zu Paris oder zu London, an einem Orte sich ver= / sammlet haben und untereinander gebrauchen können. Wie vielerley / gutes würde man durch mündliche Unterredung finden, Wann Ew / Wohlgebohren und ander wenige dergleichen, die ich die Ehre habe zu kennen, / bey uns in Sachsen wären?

Wegen meiner Sammlung an Kupfersti $=$ / chen und was dem anhängig, deßhalb dieselbe sich erkundigen, ist es wohl anders, / daß ich viel beysammen

1808 Mit „dieselbe“ ist Uffenbach gemeint.

1809 S. o. 
habe, und obschon die schönste Ordnung darinnen ist, erstlich / nach den Nationen, ferner nach den Schulen, und bey den Schulen nach der Zeit, als / die ältren, mittlern und neuern Meistern ieder Schule: dann weiter die Wercke der / berühmten Meister absonderlich, da bißweilen einer allein, als ein Raphael und dergleichen, / ein 4 biß 5. Portefeuilles allein einnimmt, in welches wieder das werck nach chro $=$ / nologischer Ordnung erstlich der Bibel und Kirchenhistorie, und dann nach der historia / fabulari und civili eingelegt ist: also zwar, daß man iedes Blat in der Menge / dießer Ordnung halber bald finden kan: so wird nur das doch bald beschwehrlich,

[293r] wegen der Weitläuffigkeit, und alles in der Ordnung zumahl mit den neuer= / kaufften zu erhalten. Weniger aber habe ich noch dazu gelangen können / daß die Exemplaria der Blätter durchaus, wo es nöthig ist, ausgelesen, allenfalls / abgezogen, gereinigt, wieder von neuem aufgezogen, und auf die Art recht in / ihre gehörige Gestalt gebracht werden, wie wohl einen Theil derselbe geschehen / ist. Daher es dann kommt, daß auch die meisten der doppelten, welche aufs ver= / schobner Auslese des besten und vollständigsten Abdrucks noch mit in den Porte= / feuilles liegen, noch nicht zusammen genommen seynd. Doch möchten sich wohl / ein oder ein paar tausend mehr oder weniger doppelte Blätter Historien guter / Hände gegenwärtig ausgeschoßen finden. Solte es sich nun zutragen, daß unter / dero doppelte allerhand zu mahl alte Blätter sich, wie ich nicht zweiffle, für= / das, die mir abgängig und zu meinen Nachrichten dienlich wären, würde ich nicht / nur gar gern aus meinen doppelten anständige dagegen geben, sondern es auch / sonst mit Dank erkennen. An Handrißen habe ich nur etliche wenige Hundert, / gleichwohl sehr und gute, zusammen gelegt. Solten sich in den Rißen oder / Kupferstichen, wie das wohl zu vermuthen ist, auch mit solchen Zeichen Blätter / finden laßen, welche in meinem Büchlein noch nicht angeführt wären, oder / da zu mahl Zeichen und mehre Deutung auf einem oder etlichen Blättern $\mathrm{zu}=$ / sammen stünden: so versteht sich, daß wir durch Übersendung solcher Blätter / allein zum ansehen, ein besondrer, angenehmer Gefallen geschehen werde. / Ich zweifle keineswegs, daß nicht das, was Ew Wohlgebh. beysammen habe, viel / schöner, feiner und ausgesuchter sey, als das weitläuffige, wohin ich diese Sache / erstreckt habe, nicht allein zu einem edlen Vergnügen Kunsterfahrener Augen, / sondern nur nehmlich zu Behulf der Historia der Mahlerey und andrer Künste, 
[293v] welche vielerley dergleichen erfordert haben. Die Catalogues eines Auctionnaires / zu Paris Nahmens Gersaint ${ }^{1810}$ vermeine ich alle bey mir gehabt und grö= / stentheils gelesen zu haben. Etliche derselben habe ich auch unter meinen Büchern gesetzt, andere aber, die mir geschienen haben geringer zu seyn, den Buchhändlern / zurück geschickt. Es ist damit also beschaffen, wie dieselbe melden, und ver= / dienen sie ihrer Güte und Artigkeit halber Achtung. Von den Zeichen der Mahler / aber bedeucht mich nicht, daß ich darinnen etwas dienliches gefunden hätte, und / das ist die einzige Ursache, weshalb sie in meinem Vorbericht zum Büchlein / der Monogrammatam nicht berührt seynd: wo allein dieselben, und auch die / fehlerhaften derselbe, angeführt seynd, welche Zeichen erklährt hatten: dahin / dann der Ritterplatz ${ }^{1811}$, das in Engelland gelehrte Repertorium ${ }^{1812}$, Agins (?) geräum= / ges Büchlein, und andres dergleichen, allerdings Gehöhr. Es ist übrigens, / was dieselbe von der Manier der Engelischen Nation melden, im Bücherschreiben / sich fremder Arbeit zu bedienen, außer Zweiffel wol gegründet. / Die kleinen Schrifften welche hier unter dem Titul einer Kannhistoria nach / und nach ans Licht trethen, währen her von einem hiesgen jungen, angehenden / Gelehrten: und sind vornehmlich entstanden aus nicht vollständig gefaßten / Anmerckungen meines Vortrags in den gewöhlichen praelectioniben über die / Litteratur und ander mit der Gelehrsamkeit verwandte Künste. Der Nahme / deßen, der dieße Stücke schreibet, ist in Verfall seines Gewerbes als Buchhändler / gerathen, und deßen Sohn war wenig Jahre mein fleißiger Zuhörer hat dießes in Gestalt / eines Journals zu schreiben angefangen, welches, da es gekauft wird, so viel ich ... (?), / dienen muß, dem Vater etwas

1810 Edme-Francois Gersaint, Catalogue raisonné des Tableaux, diamans, bagues de feu M. Charles Godefroy, Paris 1748 (8 Bibl. Uff. 947).

1811 Der geöffnete Ritterplatz, Theil 1, Worinnen die vornehmsten Ritterlichen Wissenschafften und Übungen Sonderlich was bey der Fortification, Civil-Bau-Kunst, Schiff-Fahrt, Fechten, Reiten, Jagen, Antiquen so wol als Modernen Müntzen und Medaillen Hauptsächliches zu beobachten ... an das Licht gestellet werden, Hamburg 1715 ( $8^{\circ}$ Bibl. Uff. 276); Der geöffnete Ritterplatz, Theil 2, Welcher zu Fortsetzung noch andere galante Wissenschaften, Insonderheit was bey Maschinen, Arsenalen, Antiquitäten und Bibliotequen ... zu beobachten. Welechem beygefügt die Historie der heutigen Religion und Allgemeinen Rechtsgeschichte, Hamburg 1711 ( $8^{\circ}$ Bibl. Uff. 277), Der geöffnete Ritterplatz, Theil 3, Worinnen $\mathrm{zu}$ noch mehrern galanten Wissenschaften Anleitung gegeben und zwar besonders Unterricht ertheilet wird, was bey Raritäten- und Naturalien-Kammern, BergWercken, Kaufmannschaft und Handlungen, Manufacturen und Handwercken hauptsächliches und remarquables zu bemercken vorfället; welchen begefügt ein curieuse Nachricht, Hamburg 1723 ( $8^{\circ}$ Bibl. Uff. 278).

1812 Pellegrino Antonio Orlandi, Repertorium sculptile-typicum: or a complete collection and explanation oft he several marks and cyphers by which the prints oft he best engravers are distinguished, with an alphabetical index of their names, places of abode, and times in which they lived, translated from the abcedario pittorico of Pellegrini Antonio Orlandi, London 1730 ( $8^{\circ}$ Bibl. Uff. 787). 
weniges zu dem nothdürfftigen Unterhalt monatlich reinzubringen. / In welchen Begriffe und Meynung ich denn auch diese kleine geringe Arbeit, da der

[294r] Verfaßer mich bißweilen deshalb angegangen, und nur guten Beyrath dazu und abgän= / giger Nachricht gebeten, auch etliche seiner Entwürffe geschrieben mir communicirt hat, / welche ich aber stündlicher Verrichtungen halber weder recht lesen, noch er meine mündliche / Anmerkungen und Außbeßerungen vollkömmlich hat faßen können, gern befördert habe, und / mir lieb ist, daß dieselbe diese kleinen Proben anzusehen gewürdigt haben. Es ist aber / fraglich, wegen des gleich mehr angeführten, auf den Inhalt nirgends, als auf gewiße und / zuverläßige Dinge, Rechnung zu machen: und also der rechte Grund der Sache darinnen / nicht, wohl aber an das meiste ohne viele Fehler in den Nahmen und erzehlte Dinge / zu finden. Was er von der Erfindung der Schwartzkunst meldet, ist außer Zweiffel / ein Fehler. Mit dem baselischen Todten-Tantze aber hat er ohngefehr etwas getroffen. / Denn obschon Holbein der jüngere einer gantz andern Erfindung des Todten-Tantzes / stehet in Holzschnitte ausgefertigt hat, der ich fünf oder sechserley unterschiedene Abdrücke habe, / als der zu Basel auf der Mauer gemahlet ist: so ist doch deßen auf der Mauer erste $\mathrm{Er}=$ / findung in Stellung und Trachten weder von Holbein, noch von Klauber, sondern von ei= / nem viel ältern Mahler, der zu den Zeiten des baselischen Concilii gelebt, und daßelbe / Werck zuerst gemacht hat. Wie aber dergleichen Mahlerey auf den Wänden allgemach ver=/ schwindet: so scheint wohl um 1510 ohngefehr Holbein der jüngere dieses Werck, wie aller= / dings der Ruff und die Rede unter dem Volck noch ist, wieder erneuert und übermahlt / zu haben: gleich als noch immer den Umriß seines Wesens hat, und es in gewißen= / maße zeiget, keines wegs aber also Hollhisg geblieben, wie es beynah 100. Jahr vorher / von dem Erfinder muß seyn gemacht worden. Sechzig Jahr ohngefehr hernach, im / Jahr 1568 ist die Renovation durch Hanns Hug Klauber erfolgt, wie Marioen schreibt, / und die Trachten des Mahlers genug zeigen: und im Jahr 1616 hat man das Werck wieder / erneuern laßen. Wegen des Kupferstichs mit L.C. hat diese Kern-Historie / auch außer allem Zweiffel einen Fehler gemacht, und ist derselbe, wie Ew. Wohlgebh.

[294v] mit guthem Grunde vermuthen, das Ciamberlano. Blätter mit der Jahreszahl 1464 / oder 1467 unterschrieben habe ich noch zur Zeit unter meinen Kupferstichen selbst nicht: / aber dergleichen unterschiedene wohl gesehen und angemerckt. Wie mir dann auch / der seel. H. Hofrath von Heucher ehmahls dergl. von Dreßden zugeschickt hat. Eben der= / selbe hat mir auch versichert, daß er wohl gesehen habe Blätter mit 1400 und / etlich und fünfzig beschrieben, welches 
auch Sandrart ${ }^{1813}$ schreibt. Ich habe auch aus Büchern / gute Nachricht daß schon um 1430 das Schneiden und Abdrucken des Kupferstichs frey / geübt worden, ehe und bevor an den Bücherdruck gedacht war. Die Blätter, / deren H. Dr. Cayer (?) ${ }^{1814}$ erwehnet, wo meine ich zu Altorff ehmahls bey Herrn Professore / Schwarzer gesehen und betrachtet zu haben. Jedoch war darauf, so wirlich (!) mich entsinne, / kein Zweiffel, und die Manier gering, weder ... (?) noch Israels. Ich wünschte dergl. / Blätter mit einem gothischen $\mathrm{L}$ und $\mathrm{K}$ zu finden, sintemahl Luprecht Küst als der / erste und Lehrmeister Martin Schöns in beglaubten Büchern gefunden wird.

Dero Aufsatz und den Hamburgh. Berichte, und was dazu Anlaß gegeben hat, möchte ich / wohl lesen, würde auch überhaupt für alle dergleichen Communication mit vielen / Dancke verbunden seyn: wie ich das auch jetzt bin für die überschriebene gute Nachricht / und das bezeigte Wohlwollen, dazu ich mich künftige aufs beste empfehle, / und mit herzlichem Wunsche alles Wohlergehens, und bezeige meiner Hochachtung / iederzeit beharre / Ew Wohlgebohrn / gehors. ergebenster Diener / Christ

Leipzig / am 12. May 1750

Ew Wohlgebh. werden belieben sich gefallen zu laßen und wohl anzunehmen bgdr / diesen in Eile unter allerhand Anspruch geschriebenen Brief, als auch die liederli. $A b=/$ schrifft der Beylage, welche auch in Eile wie noch inabgerichteter Studiosy mir gemacht hat.

[295r] Extrait d'une Lettre à A. de L. ce 12 de Maj. 1750

Mon histoire de la peinture moderne pourra étre mise / au net et s'imprimer ici en peu de tems. Elle est toute / arrangée en ma tête. J'en ai deja ecrit sur des cahiers / les materiaux les plus necessaires et je tiens prêt tout ce / qu'il faut pour

1813 Joachim von Sandrart, L' Academia Todesca della Architectura, Scultura \& Pittura: Oder Teutsche Academie der Edlen Bau- Bild- und Mahlerey-Künste : Darinn enthalten Ein gründlicher Unterricht/ von dieser dreyer Künste Eigenschaft/ Lehr-Sätzen und Geheimnißen/ von den Bau-Steinen und fünferley Bau-Arten/ von den Statuen und ihrer Zugehör/ von der Erfind- und Zeichnung ... Durch langen Fleiß und Erfahrung ergriffen/ und Auf inständiges Erinnern hoher und vornehmer Personen/ allen Kunst- und TugendLiebenden zu Ehren und Nutzen; Neben Aller Egyptischen/ Griechischen/ Römischen/ Italiänischen/ Hoch- und Nieder-Teutschen/ auch anderer Alten und Neuen Virtuosen/ Leben und fürnehmsten Kunst-Werken/ beschrieben/ Auch Mit 38 Platten von der Architectur, 68 Alt-Römischen Statuen/ ganz und halben Bildern/ 74 Medaglionen/ 180 Contrafäten/ durch die Hand der bästen heutigen Künstler, 3 Bde. Nürnberg, Frankfurt 1675 ( $2^{\circ}$ Bibl.Uff. 345-347).

1814 Es könnte der erste Buchstabe auch ein L oder ein B sein. 
en tirer les particularite's au'il faut pour l'ar / ranger. Je tacherai en lui donnant les agremens requis d'en / modererle volume. deux à trois tomes en $8^{\circ}$ chacun / d'un Alphabet et demi scavoront la contenir. Je me hâte / à present de parfaire quelques uns de me livres, et ce / qui m'en tient les plus au coeur, sont sans doute / mes poesies, qu'il me faut publier les premieres, comme / je pense Vous avoir ecrit quelque autre jour. Après cela / en un ou deux ans, si Dieu m'accorde, à ce que j'espe- / re, la vie et bonne santé, cette histoire et le cours de / litterature pourront se publier en peu de tems. Cepen- / dant on n'ofe rien promettre là dessus, parceque celà / depend aussi des libraires. Le dessin du Dictionaire / des Peintres à eté abandonné, parceque l'histoire sep / pleera, et de meilleure grace, a tout cela. Cependant / j'ai deja tout fait entre mes papiers un inventaire de quelques / milliers de peintres rangès selon l'Alphabet, qui fera un

[295v] tome à part, utile egalement a l'histoire dite de la / peinture, et à mon explication de Monogrammes que / j'ai augmentée après au delâ de la moitié, et dont la secon- / de edition sera plus ample en deux volumes a ce que / je crois: Mais telle pourtant, que la premiere edition / en pourra aussi sublister toujours et garder quelques / avantages à part. Tout celà sera écrit en Allemand. 


\subsection{Zusammenfassung Uffenbachs von einem Brief des Leipziger Verlegers Bernhard Christoph Breitkopf oder dessen Sohn, Johann Gottlob Immanuel Breitkopf.}

\section{$\underline{\text { SUB Göttingen Cod. Ms. Uffenbach } 20 \text { II, p. 296, 3. April } 1758}$}

In der Zusammenfassung des Briefes von Bernhard Christoph Breitkopf (1695-1777) oder dessen Sohn, Johann Gottlob Immanuel Breitkopf (1719-1794) geht es um die Auktion der Sammlung des verstorbenen Leipziger Professors Johann Friedrich Christ.

[296r] / Extract Schreibens von H. Breitkopf in Leipzig / d. d. 3. April 1758 / Die Christische Auction ist bis nach der Messe aufgeschoben, / ohne noch einen neuen Tag zu bestimmen. Die Commission / kan ganz sicher, wo nicht zu meiner Besorgung mir selbst, Herrn Philippi, Cassirern bey hiesigen Auctions- / Geschäfte, unmittelbar aufgetragen werden. Denn was an mich kommt, pflege ich demselben $\mathrm{zu}$ übergeben. / [Von Uffenbach daruntergesetzt:] Von dem buchhandler Barbe d / 7 Aprill 1758 aus Leipzig erhalten 


\subsection{Zwei Kurzschreiben bezüglich der Auktion des graphischen Kabinetts von Johann Friedrich Christ aus Leipzig}

\section{$\underline{\text { SUB Göttingen Cod Ms Uffenbach 20/II, p .297, nicht datiert. }}$}

Es geht um die Auktion der Sammlung des Leipziger Professors Johann Friedrich Christ (1701-1756), mit dem Johann Friedrich von Uffenbach in schriftlichen Kontakt gestanden hatte. Auf der Rückseite (297v) ist die Anfrage eines Verbindungsmannes Uffenbachs in Leipzig, die Vorderseite (297r) ist Uffenbachs Konzept für eine Antwort.

Den Auktionskatalog: Catalogue des estampes de Mr le Prof. Christ, Leipzig 1757 ( $8^{\circ}$ Bibl. Uff. 800) hatte Uffenbach sich aus Leipzig kommen lassen. Die Auktion fand 1758 statt.

[297r] Durch die Leipziger gelehrte Zeitung über / komme die Nachricht von einer vergantung / von Kupferstücken aus der Verlassenschafft des / Seel H. Prof. Christens, und da nachher den / catalogum durch Vermittlung guter freunde / erhalten, so kan auf keine weise glauben / daß diese collection des erwehnten Seel H. Pro / fessors gantz seye. Ich finde so viele absatze / mit strengen getheilt, daß ich aus denen stücken / urtheilen muß es seye mehr als eine Zugabe / und zwar vun (!) einem negotianten mit Kupfer / stücken dazu gekommen, da es bey vielen blät / tern ausdrücklich heißet: deux, quatre, six p / fois vun einem stück, das nimmermehr / eine liebhaberey eines besitzers seyn kann. / Ohneracht deßen könte mich entschließen die / Samlung käuflich an mich zu bringen, / wenn vor allen dingen der preiß eines wercks / das ich unbesehens begehre, gantz billig und thu / lich seyn könte, worüber also nachricht er / warte. / Ubrigends wäre mir am liebsten, wenn vun / dem gantzen vorrath nur die stücke von pag 14 / an: Ecole de rome p p biß pag. 79. wo der ar / tickel: estampes en livres p p angehet billig mäs / sig allein erhalten könte, als welche vor und nach stehen / de absätze eigendlich mein augenmerck nicht / wären. hirbey könten aber die wenige desseins pag / 6 mit unter die genommen werden, welche mir über / laßen würden.

[297v] Alles was in Catalogo stehet, gehöret zu des / sel. H. Prof Verlaßenschafft, ohngeachtet / manches etl. Mahle da ist, so von verschiedenen / Bändten (?) herkommt / Vereintzeln kann man die Kupferstiche etc: Es / müßte 
alles beysammen bleiben. Nun habe / ich schon damahls von diff. Orten $1500 \mathrm{fl}$ darauf / gebothen erhalten, solche aber nicht weg- / lassen kennen weil sie $4000 \mathrm{fl}$ werth / seyn sollen. fragt sich also was der / H Liebhaber darauf bieten will. Ich / werde es denen Erben schon so gut als möglich vorstellen. 


\section{DIE WISSENSCHAFTLICHE GESELLSCHAFT}




\subsection{Liste der Zusammenküfte der wissenschaftlichen Gesellschaft}

SUB Göttingen Cod. Ms. Uffenbach 13 I-V.

Gegründet wurde die Gesellschaft im November 1725, wobei sie fast ein Jahr

alle 14 Tage zusammentraf, ohne Protokolle abzufassen. Letztes schriftlich belegtes Treffen am 15. Juli 1740.

Am 14. Oktober 1726 gibt sich die Gesellschaft ihre Ordnung.

Seit 25. Oktober 1726 bestehen die Protokolle, bei denen Johann Friedrich von Uffenbach als Protokollant tätig war. Längere Referate stammen jeweils von der Hand des Vortragenden.

Die Treffen fanden gewöhnlich am Freitag statt, wenn es ein anderer Wochentag war, wurde dies vermerkt.

Am 9. Dezember 1729 wurde festgelegt, daß man sich abwechselnd Freitags bzw. Mittwochs treffen sollte, da Philipp Jacob Behaghel sonst an den Treffen nicht mehr hätte teilnehmen können. Er hatte das Amt des Almosenpflegers übernommen, das ihn freitags beanspruchte.

Am 16. November 1731 wurde beschlossen, daß man sich nur noch alle 14 Tage treffen sollte.

Die protokollierten Zusammenkünfte pro Jahr:

[Nov.1725 - 25.10.1726 alle 14 Tage ohne Protokolle]

$\begin{array}{lll}1726 & 9 & \text { ab } 25.10 .1726 \\ 1727 & 26 & \\ 1728 & 26 \\ 1729 & 24 \\ 1730 & 17 \\ 1731 & 19\end{array}$




$\begin{array}{ll}1732 & 15 \\ 1733 & 13 \\ 1734 & 13 \\ 1735 & 11 \\ 1736 & 9 \\ 1737 & 4 \\ 1738 & 4 \\ 1739 & 2 \\ 1740 & 1\end{array}$

Insgesamt sind in den fünf Bänden die ausführlichen Protokolle von 192 Zusammenkünften enthalten. Von dem Treffen am 15. Juli 1740 besteht nur ein Hinweis in einer Randbemerkung.

Datum Treffpunkt

Band I:

25.10.1726 Albert Adolf Diesterweg

01.11.1726 Philipp Jacob Behaghel

08.11.1726 Johann Georg Kißner

15.11.1726 Wilhelm von Uffenbach

22.11.1726 Conrad Hieronymus Eberhard

01.12.1726 Johann Friedrich von Uffenbach

13.12.1726 Albert Adolf Diesterweg

20.12.1726 Philipp Jacob Behaghel

27.12.1726 Johann Georg Kißner

9 Treffen

03.01.1727 Wilhelm von Uffenbach 


\begin{tabular}{ll} 
Datum & Treffpunkt \\
10.01.1727 & Conrad Hieronymus Eberhard \\
17.01.1727 & Johann Friedrich von Uffenbach \\
24.01 .1727 & Albert Adolf Diesterweg \\
31.01 .1727 & Philipp Jacob Behaghel \\
14.02.1727 & Johann Georg Kißner \\
21.02 .1727 & Wilhelm von Uffenbach \\
28.02 .1727 & Conrad Hieronymus Eberhard \\
07.03 .1727 & Johann Friedrich von Uffenbach \\
14.03 .1727 & Philipp Jacob Behaghel \\
21.03 .1727 & Albert Adolf Diesterweg \\
28.03 .1727 & Johann Georg Kißner \\
04.04 .1727 & Wilhelm von Uffenbach \\
09.05 .1727 & Conrad Hieronymus Eberhard \\
815 & \\
06.06 .1727 & Johann Friedrich von Uffenbach \\
\hline 816 & \\
\hline
\end{tabular}

Band II:

18.07.1727 Philipp Jacob Behaghel 1817

15.08.1727 Johann Georg Kißner

17.10.1727 Wilhelm von Uffenbach 1818

24.10.1727 Conrad Hieronymus Eberhard

\footnotetext{
1815 Messeunterbrechung.

1816 Johann Friedrich von Uffenbach "unpäßlich".

1817 Messeunterbrechung.

1818 Messeunterbrechung.
} 
Datum Treffpunkt

31.10.1727 Johann Friedrich von Uffenbach

07.11.1727 Albert Adolf Diesterweg

14.11.1727 Philipp Jacob Behaghel

21.11.1727 Johann Georg Kißner

05.12.1727 Wilhelm von Uffenbach

12.12.1727 Conrad Hieronymus Eberhard

19.12.1727 Johann Friedrich von Uffenbach

02.01.1728 Albert Adolf Diesterweg

09.01.1728 Philipp Jacob Behaghel

16.01.1728 Johann Georg Kißner

23.01.1728 Wilhelm von Uffenbach

30.01.1728 Johann Friedrich von Uffenbach

06.02.1728 Conrad Hieronymus Eberhard

13.02.1728 Albert Adolf Diesterweg

19.02.1728 Philipp Jacob Behaghel

1820

27.02.1728

05.03.1728 Johann Georg Kißner

12.03.1728 Wilhelm von Uffenbach

19.03.1728 Johann Friedrich von Uffenbach

23.04.1728 Conrad Hieronymus Eberhard
Als Gast: Zacharias Conrad von Uffenbach

26 Treffen

Als Gast: Dr. Strich ${ }^{1819}$

Zusammenkunft fällt aus 1821

1819 Aus Laubach.

1820 Donnerstag.

1821 Messeunterbrechung. 


\begin{tabular}{ll}
\multicolumn{1}{l}{ Datum } & Treffpunkt \\
07.05.1728 & Albert Adolf Diesterweg \\
21.05 .1728 & Johann Georg Kißner \\
04.06.1728 & Philipp Jacob Behaghel \\
18.06 .1728 & Wilhelm von Uffenbach \\
05.07.1728 & Conrad Hieronymus Eberhard \\
16.07 .1728 & Johann Friedrich von Uffenbach \\
\hline 822 & \\
30.07 .1728 & Albert Adolf Diesterweg \\
Band III: & \\
\hline 29.10.1728 & Philipp Jacob Behaghel \\
\hline 05.11.1728 & Johann Georg Kißner \\
\hline 12.11 .1728 & Wilhelm von Uffenbach \\
19.11 .1728 & Conrad Hieronymus Eberhard \\
03.12 .1728 & Johann Friedrich von Uffenbach \\
10.12 .1728 & Albert Adolf Diesterweg \\
17.12 .1728 & Philipp Jacob Behaghel \\
\hline &
\end{tabular}

\section{Treffen}

07.01.1729 Johann Georg Kißner

14.01.1729 Wilhelm von Uffenbach

28.01.1729 Conrad Hieronymus Eberhard

04.02.1729 Johann Friedrich von Uffenbach

1822 Treffen auf dem Uffenbachs Flörsheimer Landgut.

1823 Die Zusammenkünfte fallen wegen der Abwesenheit verschiedener Mitglieder und der Messe aus. 
Datum Treffpunkt

11.02.1729 Albert Adolf Diesterweg

18.02.1729 Philipp Jacob Behaghel

25.02.1729 Johann Georg Kißner

04.03.1729 Wilhelm von Uffenbach

11.03.1729 Conrad Hieronymus Eberhard

18.03.1729 Johann Friedrich von Uffenbach

25.03.1729 Albert Adolf Diesterweg

01.04.1729 Philipp Jacob Behaghel

13.05.1729 Johann Georg Kißner

1825

03.06.1729 Wilhelm von Uffenbach

17.06.1729 Conrad Hieronymus Eberhard

12.08.1729 Johann Friedrich von Uffenbach

29.08.1729 Philipp Jacob Behaghel

04.11.1729 Albert Adolf Diesterweg 1826

21.11.1729 Johann Georg Kißner

02.12.1729 Wilhelm von Uffenbach

09.12.1729 Conrad Hieronymus Eberhard

15.12.1729 Johann Friedrich von Uffenbach

23.12.1729 Albert Adolf Diesterweg

28.12.1729 Philipp Jacob Behaghel
Als Gast: Mag. Birnbaum $^{1824}$

Birnbaum 1824
Als Gast: Isaac Behaghel ${ }^{1827}$

Als Gast: Hr. Schlosser ${ }^{1828}$

24 Treffen

\footnotetext{
1824 Aus Frankfurt.

1825 Messeunterbrechung?

1826 Messeunterbrechung?

1827 Ein Arzt.

1828 Metallurg?
} 
Datum Treffpunkt

06.01.1730 Johann Georg Kißner

11.01.1730 Wilhelm von Uffenbach

25.01.1730 Conrad Hieronymus Eberhard

03.02.1730 Johann Friedrich von Uffenbach

17.02.1730 Albert Adolf Diesterweg

03.03.1730 Philipp Jacob Behaghel

24.03.1730 Johann Georg Kißner

26.03.1730 Wilhelm von Uffenbach

1829

Band IV:

17.05.1730 Conrad Hieronymus Eberhard

1830

23.06.1730 Johann Friedrich von Uffenbach

07.07.1730 Albert Adolf Diesterweg

09.11.1730 Johann Georg Kißner

1831

16.11.1730 Wilhelm von Uffenbach

08.12.1730 Conrad Hieronymus Eberhard

15.12.1730 Johann Friedrich von Uffenbach

Als Gast: Dr. Christian Münden ${ }^{1832}$

22.12.1730 Albert Adolf Diesterweg

1829 Sonntag.

1830 Messeunterbrechung.

1831 Messeunterbrechung?

1832 (1684-1741) Prediger und Consistorialrat, 1730 nach Frankfurt berufen.

Vgl. Frankfurter Personenlexikon: https://frankfurter-personenlexikon.de/node/582 vom 01.06.2019. 
Datum Treffpunkt

29.12.1730 Johann Georg Kißner

17 Treffen

05.01.1731 Wilhelm von Uffenbach

12.01.1731 Conrad Hieronymus Eberhard

19.01.1731 Johann Friedrich von Uffenbach

26.01.1731 Albert Adolf Diesterweg

09.02.1731 Johann Georg Kißner

16.02.1731 Wilhelm von Uffenbach

23.02.1731 Conrad Hieronymus Eberhard

28.02.1731 Johann Friedrich von Uffenbach

09.03.1731 Johann Georg Kißner

27.04.1731 Albert Adolf Diesterweg

11.05.1731 Wilhelm von Uffenbach

08.06.1731 Conrad Hieronymus Eberhard

22.06.1731 Albert Adolf Diesterweg

04.07.1731 Johann Friedrich von Uffenbach

27.07.1731 Johann Georg Kißner

Als Gast: Hr. Sühlens ${ }^{1833}$

10.08.1731 Wilhelm von Uffenbach

16.11.1731 Conrad Hieronymus Eberhard 1834

29.11.1731 Johann Friedrich von Uffenbach

14.12.1731 Johann Georg Kißner

19 Treffen

1833 Frankfurter Apotheker in der Rittergasse. In seinem Garten fand auch das Treffen statt.

1834 Messeunterbrechung? 
Datum Treffpunkt

04.01.1732 Albert Adolf Diesterweg

23.01.1732 Wilhelm von Uffenbach

15.02.1732 Conrad Hieronymus Eberhard

29.02.1732 Johann Friedrich von Uffenbach

14.03.1732 Albert Adolf Diesterweg

28.03.1732 Johann Georg Kißner

16.05.1732 Wilhelm von Uffenbach

06.06.1732 Conrad Hieronymus Eberhard

27.06.1732 Johann Friedrich von Uffenbach

Als Gast: Zacharias Conrad von Uffenbach. ${ }^{1835}$

04.07.1732 Johann Friedrich von Uffenbach

22.08.1732 Albert Adolf Diesterweg 1836

24.10.1732 Johann Georg Kißner

Als Gast: Hr. Koch ${ }^{1837}$

14.11.1732 Wilhelm von Uffenbach

05.12.1732 Conrad Hieronymus Eberhard

19.12.1732 Johann Friedrich von Uffenbach

15 Treffen

Band V:

09.01.1733 Albert Adolf Diesterweg

30.01.1733 Johann Georg Kißner

13.02.1733 Wilhelm von Uffenbach

1835 Das Treffen findet in seinem Haus statt.

1836 Johann Friedrich von Uffenbach hält Totenrede auf Philip Jacob Behagel (*26. Juli 1688), der am 6. August 1732 verstorben war. Das letzte Treffen bei Behagel war schon am 3. März 1730.

1837 Materialienhändler. 


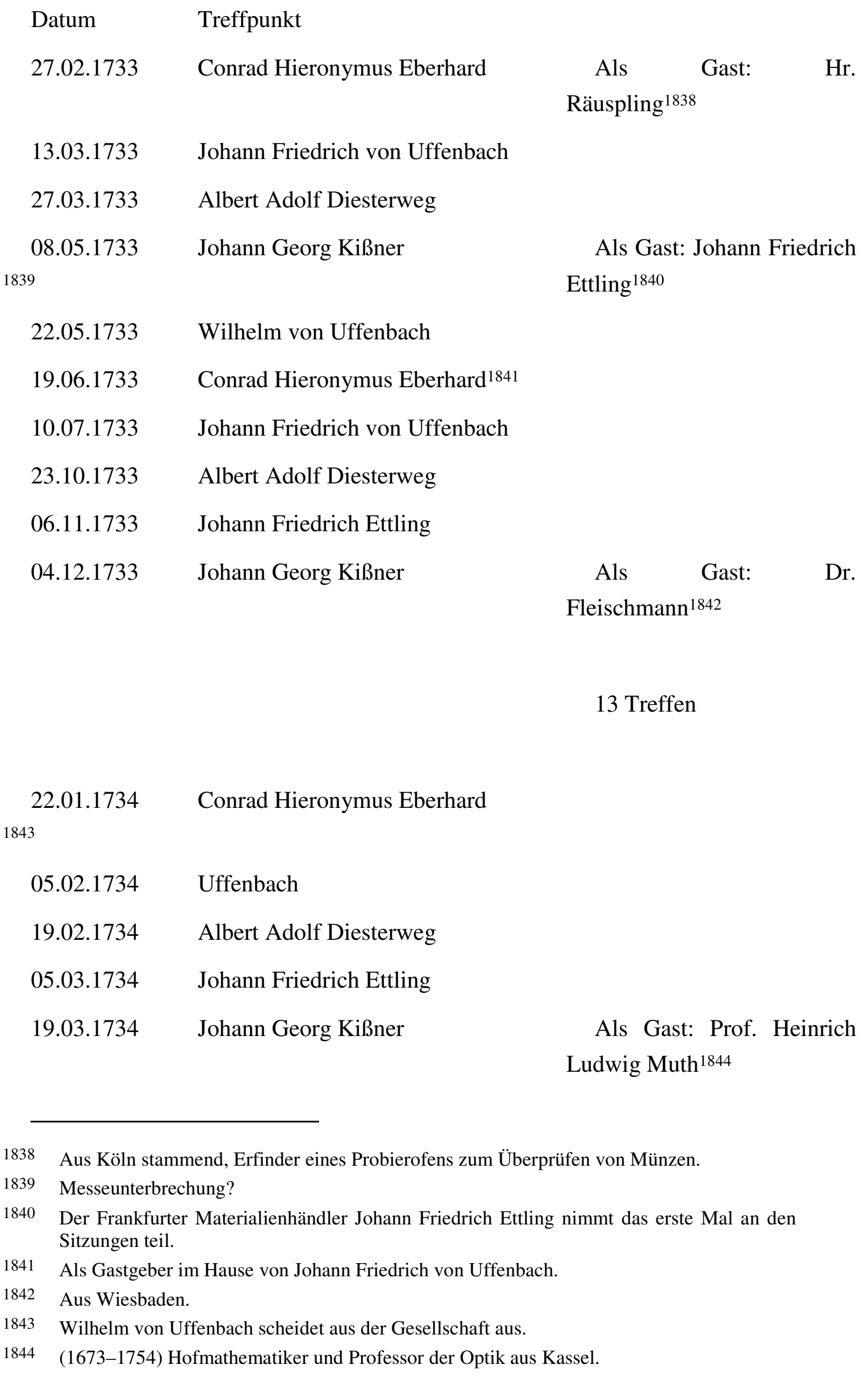




$\begin{array}{ll}\text { Datum } & \text { Treffpunkt } \\ \text { 09.04.1734 } & \text { Conrad Hieronymus Eberhard } \\ \text { 28.05.1734 } & \text { Johann Friedrich von Uffenbach } \\ \text { 11.06.1734 } & \text { Albert Adolf Diesterweg } \\ \text { 25.06.1734 } & \text { Johann Friedrich Ettling } \\ \text { 23.07.1734 } & \text { Johann Georg Kißner } \\ \text { 01.10.1734 } & \text { Wilhelm von Uffenbach }{ }^{1845} \\ \text { 12.11.1734 } & \text { Conrad Hieronymus Eberhard } \\ \text { 03.12.1734 } & \text { Johann Friedrich von Uffenbach }\end{array}$

03.12.1734 Johann Friedrich von Uffenbach

07.01.1735 Albert Adolf Diesterweg 1846

21.01.1735 Johann Friedrich Ettling

04.02.1735 Wilhelm von Uffenbach

17.02.1735 Conrad Hieronymus Eberhard

04.03.1735 Johann Friedrich von Uffenbach

18.03.1735 Albert Adolf Diesterweg 1848

01.04.1735 Johann Friedrich Ettling

13.05.1735 Wilhelm von Uffenbach
13 Treffen

Als Gast: Heinrich Jakob von Häckel ${ }^{1847}$

Als Gast: Heinrich Jakob von Häckel

Als Gast: Heinrich Jakob von Häckel

Als Gast: Heinrich Christian von Senckenberg 1849

Als Gast: Heinrich Jakob von Häckel

1845 Seit Ostern 1734 nimmt Wilhelm von Uffenbach wieder an den Treffen teil.

1846 Am 29. Dezember 1734 war Johann Georg Kißner gestorben.

1847 (1682-1760), schwedischer Baron und Kapitän, der beim letzten Rheinfeldzug mitgemacht und jetzt sein Winterquartier in Frankfurt hatte.

1848 Uffenbach hält Totenrede auf Johann Georg Kißner.

1849 (1704-1768). 
Datum Treffpunkt

10.06.1735 Conrad Hieronymus Eberhard

24.06.1735

Treffen bei Johann Friedrich von Uffenbach fällt aus. ${ }^{1850}$

28.10.1735 Johann Friedrich von Uffenbach

29.11.1735 Albert Adolf Diesterweg

1851

11 Treffen

13.01.1736 Johann Friedrich Ettling

27.01.1736 Conrad Hieronymus Eberhard

Als Gast: Heinrich Jakob von Häckel

09.03.1736 Johann Friedrich von Uffenbach

23.03.1736 Albert Adolf Diesterweg

Als Gast: Heinrich Christian von Senckenberg

29.05.1736 Johann Friedrich Ettling

15.06.1736 Conrad Hieronymus Eberhard

06.07.1736 Johann Friedrich von Uffenbach

Als Gäste: Heinrich Jakob 1852 von Häckel

Hr. Oppenheimer ${ }^{1853}$

20.07.1736 Albert Adolf Diesterweg

07.12.1736 Johann Friedrich Ettling

9 Treffen

1850 Wegen des Todes von Wilhelm von Uffenbach.

1851 Uffenbach hält Totenrede auf Wilhelm von Uffenbach; Transkription hier im Anhang.

1852 Hier die Randbemerkung, daß die Gesellschaft sich am 15.07.1740 getroffen hat (p. 631).

1853 Getaufter Jude und Reisender. 
Datum Treffpunkt

15.03.1737 Conrad Hieronymus Eberhard Als Gast: Dr. Fleischmann

04.04.1737 Johann Friedrich von Uffenbach

Als Gäste: Dr.

Fleischmann

Heinrich Christian von

Senckenberg

Heinrich Jakob von

Häckel

Als Gast: Heinrich Christian von Senckenberg

27.12.1737 Johann Friedrich Ettling

4 Treffen

24.01.1738 Conrad Hieronymus Eberhard

14.03.1738 Johann Friedrich von Uffenbach

31.10.1738 Albert Adolf Diesterweg

Als Gast: Heinrich Christian von Senckenberg

Als Gast: Peter Florens Gerning 1854

4 Treffen

01.05.1739 Conrad Hieronymus Eberhard

03.07.1739 Johann Friedrich von Uffenbach

2 Treffen

15.07.1740 $\quad ?^{1855}$

$1854 \quad(1695-1764)$

Vgl. Graphikportal: https://www.graphikportal.org/document/gpo00152429 vom 01.06.2019. 


\subsection{Die Ordnung der Wissenschaftlichen Gesellschaft und die einzelnen Vorworte der Bände I - IV}

SUB Göttingen Cod. Ms. Uffenbach 13/I, S. I-V, 13/II, S. III-IV, 13/III, S. III, 13/IV, S. I-II.

„Wochentliche Sammlung der in Nützlichen Neben Stunden angestelten Untersuchungen der Natur und Kunst, welche zu einer Gemüths- Ergötzung dieienige Gesellschaft veranlasset, deren Denckspruch ist: Quo simplicius eo perfectius“"1856

\subsubsection{Die Regeln, die sich die Gesellschaft gegeben hat:}

[IV] Ordnung der Gesellschaft

Anno 1726 d 14 8bris sind bey gehaltener Zu- / sammenkunft zu Erhaltung guter Ordnung folgende / Puncten einmüthig festgesezet und beliebet worden.

1) Soll der bestimmte Tag der Freytag seyn, im Fall / es wegen vorgefallener Geschäfte nicht aufeinan- / der angesezet werden muß, welches aber jedem der / Gesellschaft in Zeiten wißend gemacht werden soll. / Dießem nach soll dieses des Winters alle 8 Tage, und / Sommers alle 14 Tage, von denen Meß Zeiten ange- / rechnet, geschehen, welche leztere aber von aller Zusam- / menkunft ausgenommen bleiben. Die Stunde an- / langend so ist solche Winters auf 4, Sommers aber / auf 5 Uhr praecise beliebet worden, bey Straffe des / Ausbleibens a 5 Batzen, des zu spath Kommens aber / von einer Stunde 1 Batzen von 1 1/2, 2 Batzen von 2 Stunden / 3 Batzen und so fort, ohne Ausnahme. Und damit / man

2) wiße bey weme sich die Gesellschaft jedesmahlen / einzufinden hat, so ist darüber das Los gezogen wor- / den welches ausgefallen wie folget

1) bey H Diesterweg

2) bey H Behagel

1855 Vgl. das Treffen vom 6. Juli 1736. Dort wird in einer Randbemerkung dieses Treffen erwähnt (p. 631).

$1856=$ Je einfacher, desto besser. 
3) bey H Doct. Kißner

4) bey H Wilhelm von Uffenbach

5) bey H Eberhard

6) bey H Johann Friedrich von Uffenbach

[V] 3) Ist derjenige bey welchem die folgende Gesellschaft / zu halten seyn soll, verbunden zu sagen was er pro- / ponieren werde, um sich darauf zu bereiten bey Straffe / 3 Batzen

4) Soll Feder und Tinte und Papier auf dem Tische / liegen bey Straffe 2 Batzen, von welchem allen der / HausH so die Büchse jedesmahlen hat, der Executor / ohne Ansehen der Person ist.

5) Soll es bey denen Tractamenten nach bißheriger / Gewohnheit verbleiben, auch alle unnöthige Compli- / menten vermieden werden, und im Gesundheit / trincken von dem jenigen, so dem HausH der nechste / zur lincken Hand sitzet angefangen und der Reye / nach gefolget werden, im Aus und Eingehen der Thüre / auch der nechst dabey Stehende den Anfang machen / deme die übrigen nach der ohngefehren Reye folgen / sollen, bey Straffe 1 Batzens

6) Soll man um 8 Uhr von einander gehen, und / dieser Glocken Schlag von dem HausH angemeldet / werden bey Straff 1 Batzens. Welches alles nach / der Statt oder Thomglocken zu rechnen.

\subsubsection{Die Vorworte:}

\subsubsection{Band I:}

[I] Vorbericht

So viel wie die Gesellschaft dem menschlichen Leben / behülflich, und aller deßen Glückseligkeit Uhrsprung ge- / weßen seyn mag, so viel hat man auch eben derselben / in Ansehung der Beforderung von Künsten und Wißen- / schaften zu dencken. Dann nennet man dem Sprichworte / nach unser Leben kurtz, und diese hingegen lang, ja / unabsehlich, so kan es nicht fehlen, daß, wenn viele die / kurtze Lebenszeit ein müthige Hand an die verborgene Kunst anlegen, / sie in die Entdeckung derselben mit mehr ausrichten, als / ein einziger Lehrbegieriger allein vermag, eben als wie / die zusammen gesetzte Kraft vieler Hände eine sonst / unbewegliche schwehre Last leichte und gleichsam unver- / merckt fort bringen. 
Ich spahre dießem nach die Mühe / gegenwärtigen Satz mit vielen Exempeln zu beweißen, / angesehen so wohl der Nutzen als auch der Ruhm vieler / in Italien, Franckreich, Engell. und Teutschland, ja auch / andre Orten blühenden, sogenannten Academien, bekant / genug ist, und zum theil noch täglich mehr hervor leuch- / tet, zu mahlen wann väterlich gesinnte Herrschaften / zu der Aufnahme ihrer Länder und Unterthanen solchen / nicht unbedachtsam im Wege stehen wollen. Es liegen uns / derselben gedruckte Proben zur Genüge vor Augen, / und vielleicht sind solche die Gelegenheit geweßen ande- / re zu einem gleichen edelmüthigen Unternehmen auf / zu muntern, ja man mögte sie vielleicht auch als die / Uhrheber von gegenwärtigem nach dem verjüngten Mas- / stabe eingerichteten Vorhaben ansehen, das keinem andern / Entzweck als den ihrigen zum Grunde hat. Aus dießen / Reden solte man also billig muthmaßen, es würden / gegenwärtige Samlungen von Untersuchungen der Nathur / und Kunst, welche eine sichere kleine Gesellschaft wochent- / lich alhier angestellet, künftig eben so an das Licht tret- / ten gesonnen seyn, man verwundere sich aber nicht, wann / ich ihme dieße Meinung, so mit unserm Vorhaben gar nicht / über einstimmet, auf ein mahl mit einem unvermutheten

[II] Nein, benehme. Unsere denen nöthigsten Geschäften / abgebrochene Zeit, unsere hiezu gewittmete Kosten, / unsere wenige Kräfte und Einsichten, ja unser / billiger Eckel vor aufgekochten Gerüchten, und der / selben verdrießlichem Wiederkäuen, haben versichert / nichts anders zu ihrem Absehen, als wochentlich etliche / müßige Stunden nützlicher und vernünftiger als / es gemeiniglich bey straffbahrem Geschwätze und / Richten unserer Nechsten, ja bey noch verderblicherem / Zeitverlust des Spielen geschihet, zu einer löblichen / Gemüthsergetzung anzuwenden, um nicht allein da- / rinnen die lobenswürtige Erfindungen anderer, / deren Tagregister durch offentlichen Truck bekant wor- / den $\mathrm{zu}$ untersuchen, und vieleicht solche $\mathrm{zu}$ unseres / Vaterlandes Nutzen brauchbahr zu machen, sondern / auch unsere eigene noch unbekante einander mit- / zutheilen, und uns zu belehren; mögten sich nun / wieder unser Vermuthen hierunter einige finden, die / vieleicht eben so tüchtig und werth wären dem allge/ meinen Wesen wie viele andere oben erwehnte be- / kant zu machen, so nenne man unsere Vorent- / haltung derselben vielmehr eine Bescheidenheit als / einen Neid, angesehen solche niemand geringer / als uns selbsten vorkommen, und in begehrenden / Vorfällen vieleicht nicht entzogen oder verhöhlet werden / sollen.

Auf eine solche unschultige Art entstunde also an- / no 1725 im 9bris die Geburt unserer kleinen Gesell- / schaft, zu welcher ich meines wenigen Rats viele Anreg- / ung gegeben zu haben mich ohne eiteles Lob rühmen / kan; wir fuhren 
auch darinnen ohne ein Register / zu halten ein ganzes Jahr zu allerseitigem Vergnügen / alle 14 Tage fort, fanden aber daß unsere Bemühung / auf solche Weise der Vergeßenheit ohnfehlbahr zu theil / werden würde, dannen hero sie sämptl Mitglieder / nicht allein ein solches anzufangen vor höchst rath- / sam hielten, sondern sich auch durch gewiße Gesetze / die ich hier unter anfügen wollen, genauer und unzer- / trenlicher verbunden.

[III] Man truge mir dießem nach anno 1726 d 25 8bris / als in der ersten Zusammenkunft nach verbeßerter / Ordnung das Ampt eines Schreibers, um besagtes Re- / gister in Stande zu bringen, und die vorgezeigte Erfin- / dungen so wohl von Naturalien als Machinen dabey / abgezeichnet fürzustellen, ohnerachtet meiner Entschultig- / ung, auf, und ließe das Los die Abwechselung und / Ordnung der Zusammenkünften, so weiters alle / Wochen, Sommers aber alle 14 Tagen (die Meß Zeiten ganz / ausgenommen) gehalten werden solten, bestimmen, / welche hirunten zu Vermeidung aller Unordnung eben- / falß beygefüget habe. Gleich wie es mir nun zu die- / Ber Verrichtung so wohl an Zeit als Vermögen man- / gelt, so hoffe ich es werde derjenige so gegenwärtige ge- / ringe Arbeit zu Gesicht bekommt so wohl meine unzu- / längliche Schreibart als auch die Flüchtichkeit und den / Unfleiß in meinem Abzeichnen gütigst entschultigen, / immaßen wir besagter Weise keine andere Absicht / dabey gehabt, als sich allenfalls zu unserem eigenen Dienste / darinnen ersehen zu können. Wir achten also den / Vorwurff, daß viele Sachen nicht neu seyen, wenig, / dieweil die Untersuchung von anderer Erfindungen / unser Hauptzweck geweßen, noch weniger aber wird / uns der Unverständigen Tadel anfechten, welche ihr / Spiel und unnützes Gewäsche in Gesellschaften un- / serer Bemühung mit einem Hohnlachen vorziehen. / Dieses also ist alles, was ich zu einem Vorbericht hirher / zu setzen vor nöthig erachtet, außer daß ich der gemein- / schaftlichen Cassa mit wenigem gedencke, so die Ge- / sellschaft durch eine jedesmahlige kleine Beylage zu / der Belohnung einiger Künstler, die uns etwa ihre Heim- / lichkeiten gegen eine Verehrung künftig offenbahren / wolten gestiftet.

Ist dieße nun dermahlen klein, gleichwie unsere ganze / Einrichtung, so ist ihr der Wachsthum mit der Zeit nicht / versaget, und eine ausgemachte Sache daß aller An- / fang nicht groß seye, es fälle also der geneigte Leser von unserm ganzen Vorhaben ein gütiges Urtheil und bleibe dem Schreiber ge- / wogen.

Franckfurt am Mayn 1726

Johann Friedrich von Uffenbach 


\subsubsection{Band II:}

[III] Vorbericht

Nützliche Anstalten machen zu Beförderung der / Wißenschaften und Künste, ist gut, solche aber suchen / bey zu behalten und nach Vermögen fortzusetzen, ist eben / so löblich. Gegenwärtiger Band, welcher eine kurtze Vorstel- / lung desjenigen enthält, was bey wochentlicher Zusam- / menkunft einiger Liebhaber alhier vorgenommen wor- / den, kan hievon ein Zeugnuß geben, obmahlen manche / den Inhalt vor gering und unerheblich ansehen mög- / ten. Es gedencken aber dieselbe, daß wir, gleichwie der Vorbe- / richt unseres ersten Bandes derer Sammelungen mit meher- / rem zeiget, das obschon nicht eigendlich gehabt, lauter neue / und unerhörte Dinge auf die Bahne zu bringen, sondern / und vielmehr an Anderer schönen Erfindungen zu ergetzen, / und etwa hier und dar Mängel zu berühren, oder auch Ver- / beßerungen zu versuchen, damit denen Künsten und Hand- / arbeiten, wie sie dem menschlichen Leben ohnentbehrlich sind, / also vieleicht auch durch unsere Bemühung mehr Anlei- / tung zu einer Aufnahme und Wachsthum an Hand gege- / ben werde; hiernechst ist es auch noch keine ausgemachte / Sache, ob dem gemeinen Wesen mit tiefsinnig und weit / hergehohlten Hirngespinsten oder aber mit vernünftigen / Untersuchungen von gering scheinenden Kunstgriffen, und / derselben Erleichterung am meisten gedienet ist, wir be- / gnügen uns also dabey, daß wir aus dem in Eile auf- / gesetzten Inhalt dießer Blätter erweißen können, wie wir / alle Wochen einige Zeit nützlicher als viele Gesprächs und / Spielgeselschaften zu gebracht, und es in unsern Nebenstun- / den an dem Willen und der Liebe denen Künsten aufzu- / helffen nicht gefehlet, wenn man gleich die That, nach einem / andern großem Maasstabe gerechnet, bey uns nicht gefun- / den. Dieses ist alles, was ich bey der Reiffung gegenwärti- / gen zweiten Bandes unserer Sammlungen zu erinnern, / oder vielmehr zu wiederhohlen Uhrsach habe, nebst ange- / hengter Bitte mich nicht zu fragen, warum das erste halbe

[IV] Jahr unserer Zusammenkunft eine ebenso reiche / Fruchterndte, als gegenwärtige drey halbe Jahre gehabt? / Denn wann ich gleich Abwesenheiten, Geschäfte, ehrhaften / und andere Verhinderungen anführen würde, so fürchte / ja dennoch daß man dieße alle nicht vor so erheblich, als / die allmächtige Erkältung unserer Begierde halten, und / dieße letztere Uhrsache uns immer vorrücken würde. / Allein auch dießer Vorwurff soll uns verhoffendlich / nicht irren, genug ist es, wann unsere Erfindungsein- / flüße nicht strohmweiß fließen, daß solche doch noch tröpf- / len, und also dem Sprichwort nach nicht gar verlachen, / oder vertrocknen; Findet man doch ein gleiches anderen / vornehmsten und 
berühmtesten Gesellschaften anderer / Königreichen, für welchen wir nichts besonders zu haben / uns bestreben, Ihnen auch vielmehr gerne den Vorzug las- / sen, daß ihr Vorwürffe mit erheblicher als unsere, ja / daß auch ihre Beschreibung mit fleißiger und wichtiger / als dieße seye, welche denen Worten und Abzeichnungen / Stunden des Verfaßers gewesen, und seyn sollen, da- / mit wir auch in dießem Stücke unserm Wahlspruch nahe / machen mögen: Quo simplicius, eo perfectius.

Geschrieben zu Franckfurt am Mayn d 15 Octob 1728 / durch / Johann Friedrich / von Uffenbach

\subsubsection{Band III:}

\section{[I] $\underline{\text { Vorbericht }}$}

Alles hat seine Zeit. Spricht dorten die Weisheit, so / wird man ohne mein Darthun leichtlich begreiffen, daß auch / unsere Bemühung der bißherigen Gesellschaft mit zu diesem / Alles gehöre. Sie hat allerdings ihre Zeit, und zwar wie gegen- / wärtiger abermahliger Band unserer Sammlungen ausweiset, / eine etwas längere, als die ersten beyde zu ihrer Geburth ge- / habt. Wolte man uns aber um die Uhrsache deßelben fra- / gen, so wüste keine hauptsächlichen anzugeben, als daß / der erste Eifer in der Untersuchung der über reichen Nathur / und Kunst nunmehr etwas kältlicher zu werden ange- / fangen. Wer sich mit unverblendeten Augen ein wenig / in denen Geschäften der Menschen umsiehet, wird ein glei- / ches überall erblicken, der Anfang ist gemeiniglich hitzig, / der Fortgang etwas bedachter, und das Alter langsam. / Ich will aber hierdurch keines Weges sagen, daß unsere Gesell- / schaft frühzeitig grau werden, vielmehr habe ich das Vertrau- / en, daß da sie langsam zu gehen beginnt, sie auch desto / sicherer und gewißer bestehen werde. Alle ihre Untersuchun- / gen sind nichts als ein bloses Nebenwerck, das auf eine / vernünftige Gemüths Ergetzung abziehlet. Dießem nach ist / uns nicht zu verdencken, daß wichtigere Geschäften ofters / eine Pause in denen Zusammenkünften veruhrsachen. / Wer demnach gegenwärtige Samlung einzusehen sich die / Mühe nimmt, erwarte darinnen nichts anderst als was / ohne großes Nachsinnen und Fleiß hat können auf die Bahn / gebracht werden, sintemahl unser Absehen, wie in denen / ersten zwey Theilen bereits gemeldet, vielmahlen dahin ge- / gangen der gelehrten und nunmehr gar niedlich gewohn- / ten Welt durch offendlichen Druck damit belästigt zu / werden. Wenige suchen das, was unser Entzweck ist, / nehmlich der Kunst mit allerley Handgriffen und kleinen 
[II] Nachrichten behülfflich zu seyn, zu forderst aber solche / zu unsere Belehrund Belustigung der Vergeßenheit / zu entreißen. Wann aber auch dieses von dem Schrei- / ber auf eine Art geschehen, die wohl hätte umständlicher / und beßer seyn können, so verzeihe der geneigte Leser / seiner Eilfertigkeit, angesehen auch dieses sein Ampt / ob wohl nicht ohne Beschwerde, sein Nebenwerck ist. Zeit / Geschäfte und Vermögen haben es nicht anderst leiden / wollen, daher bedienet er sich desjenigen Spruches, den / er ohngefehr vor weniger Zeit in einem alten Mönchs / Chronicon msct. eingeschrieben gefunden: / Scriptor / scripsisset bene, melins si potuisset. / und versichert den Leser, daß er darinnen weder einen / Schreibmeister nach Mahler abgeben wollen, empfiehlet / sich aber zu fernern Wohlwollen, und nennet sich / mit aller Dienstbegierde

Johann Friedrich von / Uffenbach

Franckfurt am Mayn / d 24 Aprill 1730

\subsubsection{Band IV:}

[I] Vorbericht

Die Schriften unserer kleinen Gesellschaft wachsen und / vermehren sich noch immer, obgleich nicht mit dem ersten / eifrigen und geschwinden Triebe. Zeitig genug, wenn sie / nur was taugen, sagt das Sprichwort, und dieses mögte bey / der Ausfertigung gegenwärtigem vierten Theils unserer / Sammlungen wohl eintreffen. Wer sich die Mühe nimt / die vorigen gegen diesem einzusehen, wird daraus bald / erkennen, daß die Hitze, mit welcher unsere Zusammenkünf- / ten begonnen, um ein merckliches seither abgenommen, und / kältlicher worden. Es ist auch solches nicht anders mög- / lich. Damahls stunde unsere kleine Gesellschaft in der eifri- / gen Jugendblüthe, nun aber, da sie allmählig ein männli- / ches und gesetzteres Alter erreichet, so gehet es auch damit ein / wenig bedächtlicher her. Wolte man aber das angebrachte Gleich- / nüs weiter treiben, so müßte man auch nunmehr das heran- / nahende Kaltgesinnte und schläfrige Alter, ja selbsten den / darauf folgenden Abschied fürchten. In dem menschlichen Leben / ist es nicht anders, was wäre es diesem nach Wunder, wenn / unserer bißherigen Gesellschaft ein gleiches wiederführe? / Die meiste Uhrsache hiervon mögte wohl die Schwäche unserer / Zahl, und die besorgliche fernere Verringerung derer Mitglie- / der seyn, wenn ich auch gleich des Umstandes, daß sich ein / Bronnen erschöpfen und die Pfeile verschießen laßen, nicht / gedächte. Währender Zeit daß gegenwärtiger Band erwachsen, haben wir bekanter Maßen den ersten Verlust an 
dem frühe- / zeitigen Ableben des Seel H Behagels erleiden müßen. Wäre / unsere anitzo in Trauer gesetzte Gesellschaft zahlreicher, so wür- / de man solches dabey so viel nicht mißen. Allein wo wenig / ist, da wird der Abgang um desto eher mercklich, zumahlen / da die Ersetzung einer solchen Stelle so gar schwehr fallen will. / War unsere Besorgung anfänglich die enge Gränze der Verbind- / ung zu unserem vermutheten Ungemache nicht zu erweitern, / so war solche, gleich wie wir itzo sehen, gantz überflüßig. Solte man / aber in unserem geliebten Vaterlande, worin es Gott Lob an Men- / schen nicht fehlet, einen solchen Wiederwillen vor eine Beschäftigung / unserer Art sich eingebildet haben ? Wenigstens hätte man es nimmer

[II] glauben sollen, daß die brennende Begierde vor das einige Noth- / wendige, ich meyne Amtsgeschäften, Berufs und Nahrungssor- / gen Liebe zum Mühsiggange und anderem verderblichen Zeit- / vertreibe und dergleichen, nicht dann und wann etliche wenige / Stunden einer vernünftigen Unterredung über die wunder- / reiche Natur und Kunst gönnen würde; Jedennoch erfahren / wir, daß dieses letztere alhier gegen dem vorigen viel zu wenig / geachtet, ja gleichsam eckelhaft und abgeschmackt scheinen will, / wie unten pag. 425 mit meherem gesagt worden. Die / Musen finden also hier wenig Gehöre, und ihre ehemalige kleine / Zahl ist in unserm sonst ansehnlichen Aufenthalte nicht ein Mahl / zu finden. So haben wir Verbundene e ohneracht aller angewen- / deten Mühe erfahren müßen, und werden also genöthiget gegen / Willen unserem lieben Vaterlande nicht viel Ruhm diesfalls bey / zu legen. Allein wie Noth darum, wenn unsere kleine Anzahl / künftig fortfähret die Wunder des preißwürdigen Schöpfers in der / unerforschlich reichen Natur, so wohl, als in denen unzahlbahren Er- / findungen der Kunst, so viel als uns möglich ist, einzusehen, / und dieser vernünftigen, ja eigendlich menschlichen Bemühung etli- / che wenige Stunden zu wittmen.

Euch schreibe ich dieses, die ihr mit mir nicht müde werdet, auf / solche löbliche Weise euch zu ergetzen, und mit erleuchtetern Augen / als der Pöbel nicht hat, euch in der Welt umzusehen. Sorget nicht / um Vorwürffe zu dieser edelen Beschäftigung, nehmet das erste / so euch vorkommet, sehet solches nachdencklicher, als insgemein ge- / schiehet, an, so werdet ihr auch daran finden, wie wenig wir von / nathürlichen Dingen wißen, wie solten sich die blinde, und nur / auf Gewinn und Grossucht blickende Sinnen der Menschen, da- / rum bekümmern, und für allen andern, wie unbegreiflich gros / der Schöpfer auch in denen kleinsten Dingen seye. Die Weisheit / ist ein Bronnen, je mehr man daraus schöpfet, je mehr quillet / zu. Darum wird die Bekümmernüs: wo nehmen wir 
Waßer / oder Stoff her, gantz unnöthig. Sorget inzwischen nicht, daß / was ihr zur Untersuchung erwehlet, schon von andern vorher gesagt worden / und daß solche die Leser unser Samlungen nicht würdig achten mögten / Bedenckt vielmehr daß wir allein dießelbe abgeben, und unsere Absicht nicht / seye, damit die überhaüfte Unzahl der Bücher zu vermehren, ja, daß ihr mir / die Mühe der Verfaßung gegenwärtiger Schriften nur darum aufgetragen / daß ihr, nebst mir, euch zur Erinnerung und unschultigen Gemüthsergetz- / ung darin ersehen könnet. Ich wünschte hiebey nichts mehr, als daß meine / aufgetragene Pflicht ein Genüge gethan, und meine Arbeit in Nebenstunden / so verrichtet haben möge, wie ihr, und keine Auswärtige, keine Unachtsame / keine Verächter und dergleichen, es verlangen $\mathrm{zu}$ lesen. Vergebet übrigens, / wenn ihr Fehler darin antreffet, und bleibet eurem Mitverbundenen und Ver- / faßer dieser geringen Zeugnüßen unsres gesamten Fleißes mit fernerer / Wohlgewogenheit zugethan, als der sich mit aller Ergebenheit nennet

Johann Friedrich von Uffenbach

Franckfurt d 22 Decemb 1732

Für Band V hat Johann Friedrich von Uffenbach hat keinen Vorbericht mehr verfasst. 


\subsection{Die Titel der Vorlesungen zur Astronomie von Johann Friedrich von Uffenbach.}

\section{$\underline{\text { SUB Göttingen Cod. Ms. Uffenbach 13/I-IV. }}$}

Uffenbach hielt in der wissenschaftlichen Gesellschaft von Dezember 1726 bis Februar 1731 insgesamt 24 Kapitel zur Geschichte und Stand der Astronomie.

Kap. 1: $\quad$ Von dem Lobe und Alter der Astronomie. 1857

Kap. 2: Von denen Gelegenheiten so die Astronomie aufgebracht, und derselben Werckzeug. ${ }^{1858}$

Kap. 3: $\quad$ Von der Altenmeinung, betreffendt die Welt=Ordnung. ${ }^{1859}$

Kap. 4: Mängel der Ptolmaeischen Meinung von dem Weltgebäude, und Beschreibung der Copernicanischen. ${ }^{1860}$

Kap. 5: Von denen Einwürffen die denen Copernicanern gemacht werden. ${ }^{1861}$

Kap. 6: Von der Tychonischen Weltordnung. 1862

Kap. 7: Von dem Zusammenhang und der beständigen Ordnung unseres Weltgebäudes. ${ }^{1863}$

Kap. 8: $\quad$ Von der Entfernung, Größe, und künstlichen Ausmeßung der Welt Cörper. ${ }^{1864}$

Kap. 9: $\quad$ Von der geglaubten Würckung und dem Einfluß der Sterne auf unserer Erde. ${ }^{1865}$

Kap.10: $\quad$ Von denen Fixsternen. 1866

\footnotetext{
1857 02.12.1726, Cod. Ms. Uffenbach 13/I, S. 41-47.

1858 02.12.1726, Cod. Ms. Uffenbach 13/I, S. 47-60.

1859 02.12.1726, Cod. Ms. Uffenbach 13/I, S. 60-65.

1860 17.01.1727, Cod. Ms. Uffenbach 13/I, S. 109-117.

1861 17.01.1727, Cod. Ms. Uffenbach 13/I, S. 117-123.

1862 07.03.1727, Cod. Ms. Uffenbach 13/I, S. 173-179.

1863 07.03.1727, Cod. Ms. Uffenbach 13/I, S. 179-186.

1864 06.06.1727, Cod. Ms. Uffenbach 13/I, S. 218-237.

1865 06.06.1727, Cod. Ms. Uffenbach 13/I, S. 237-246.

1866 21.10.1727, Cod. Ms. Uffenbach 13/II, S. 33-54.
} 
Verfolg des 10ten Kapitels von denen Fixsternen. ${ }^{1867}$

Kap.11: $\quad$ Von unserm Fixsterne der Sonnen. ${ }^{1868}$

Kap 12.: $\quad$ Von dem Planeten Mercurio. ${ }^{1869}$

Kap. 13: $\quad$ Von der Venus. ${ }^{1870}$

Kap. 14: $\quad$ Von dem Planeten Mars. ${ }^{1871}$

Kap. 15: $\quad$ Von dem Planeten Jupiter nebst seinen Trabanten. ${ }^{1872}$

Kap. 16: Von dem Planeten Saturno. ${ }^{1873}$

Kap. 17: Von denen ungewöhnlichen Planeten oder denen Cometen. ${ }^{1874}$

Kap. 18: $\quad$ Von unserm Neben Planeten dem Mond. ${ }^{1875}$

Kap. 19: $\quad$ Von denen Finsternüßen. ${ }^{1876}$

Kap. 20: $\quad$ Von der Erde als einem Planeten. ${ }^{1877}$

Kap. 21: $\quad$ Von der Eintheilung der Erden durch Zirckel und Linien in gewiße Flächen. ${ }^{1878}$

Kap. 22: $\quad$ Von denen Dingen so über dem Erdeboden sind und sich zu tragen. 1879

Kap. 23 Von denen Dingen so auf dem Erdeboden sind und geschehen. ${ }^{1880}$

Kap. 24: Von denen Dingen so unter der Erdenfläche sind, und sich begeben. ${ }^{1881}$

19.12.1727, Cod. Ms. Uffenbach 13/II, S. 109-122.

30.01.1728, Cod. Ms. Uffenbach 13/II, S. 157-171.

1869 19.03.1728, Cod. Ms. Uffenbach 13/II, S. 236-243.

1870 19.03.1728, Cod. Ms. Uffenbach 13/II, S. 243-249.

1871 03.12.1728, Cod. Ms. Uffenbach 13/III, S. 21-26.

1872 04.02.1729, Cod. Ms. Uffenbach 13/III, S. 94-109.

1873 18.03.1729, Cod. Ms. Uffenbach 13/III, S. 145-154.

1874 12.08.1729, Cod. Ms. Uffenbach 13/III, S. 238-251.

1875 15.12.1729, Cod. Ms. Uffenbach 13/III, S. 312-320.

1876 03.02.1730, Cod. Ms. Uffenbach 13/III, S. 392-403.

1877 23.06.1730, Cod. Ms. Uffenbach 13/IV, S. 9-22.

1878 15.12.1730, Cod. Ms. Uffenbach 13/IV, S. 86-114.

1879 19.01.1731, Cod. Ms. Uffenbach 13/IV, S. 175-206.

1880 16.02.1731, Cod. Ms. Uffenbach 13/IV, S. 234-259.
} 


\title{
16.4Johann Friedrich von Uffenbach beschreibt einen Gehstock mit Schildpatthülle in der wissenschaftlichen Gesellschaft am 9. Dezember 1728
}

\author{
SUB Göttingen Cod. Ms. Uffenbach 13/III, S. 28-30.
}

Der Beschreibung fügte Uffenbach eine eigene Zeichnung dieses Stockes bei.

[28] Nach dießen Kunststiucken der Nathur [s.o.], so die artige

[29] Vermischung der Farben beliebt machet, zeigte / ich einen andere, welche nicht minder aus eben / der Uhrsache denen Augen gefället, nehmlich eine / Arbeit von Schildgrotte Schahlen, die an Glanz und Schon- / heit dem vorigen nicht allein wenig nachgabe, an / hinzugefügter Kunst aber selbige weit übertreffe / Dieses war ein in Holland verfertigter, und mit / einer schiltgrottenen Hülse überaus künstlich überzo- / gener Lauffer Stock, denen das untere Holz nicht nur / an sich selbst in seiner weitlaüffig gewundenen / und unterher abnehmenden Gestalt ein Meister- / stück der Drechslerarbeit ist, sondern auch der / Überzug von einer schiltgrottenen sehr zarten Hülße / vor ein noch weit größeres passiren kan, sinte / Mahl das Löthen so von oben biß unten aus seyn / muß, und deren nicht der geringste sichtbahr war, eine / sehr kitzlichte Arbeit ist, die Rundungen aber deßel- / ben noch ein viel erhebliches seyen wollen. Ein / jeder wird also bald errathen daß der leztere durch / die Erwärmung des Schiltgrottes geschehen, was aber / dießes von einer solchen Länge, Zartigkeit der Hülse / selbst, und der Verdünnung untenher auf sich habe / weiß derjenige am besten, der sich so vergeblich viel / Mühe in dießer Arbeit wie ich bißher, gegeben, / Es mußte H Eberhard selbsten, der ehedeßen verschiedene / große Künstler dießer Arbeit in Coppenhagen gekant / gestehen, daß dieses Kunststück ihm ein unauf- / löslicher Knoten seye, und er solches als was ganz / besonders bewundere. Es ist mir daßelbe in ver- / wichener Meße bey dem hollandischen Porcellan Hände- / ler Pfaff von ohngefehr in die Hände gerathen, woraus / es sicherlich nicht gelaßen wenn ich auch ein weit / mehres, als ich aus Mangel anderer Kenner und Lieb- / haber nicht gethan, denen hätte bezahlen sollen, ohneracht / es eben nicht zum 
besten mag behandelt, und auf / geschoben worden seyn, denen es hier und der einige

[30] Riße und Beschädigung überkommen. 


\title{
16.5Johann Friedrich von Uffenbachs Bericht zu seinen Versuchen mit Bleiweiß
}

\author{
$\underline{\text { SUB Göttingen Cod. Ms. Uffenbach 13/V, S. 248-251 }}$
}

Uffenbach beschreibt seine Experimente mit Bleiweiß am 19. Februar 1734 in der wissenschaftlichen Gesellschaft.

[248] War die Versamlung unserer gewöhnlichen Gesell- / schaft bey H Diesterweg, woselbst ich etwas zur Betracht- / ung darlegete welches das vorige Mahl zu thun verges- / sen hatte, obsolchen gleich damahlen bey die Hand gestel/ let. Ich hatte nehmlich bey dem Anbrechen der verwiche- / nen harten Kälte mir vorgenommen etwas Bley- / weis mit Waßer auf einem Steine klahr abzurei- / ben, und dieses hernach recht harte durchfriehren zu las- / sen, um es künftig bey vorkommender Wachspous-

[249] sier Arbeit nach Angebung eines verständigen Künst- / lers zu dem Färben des Wachses zu gebrauchen, und besagte / Materie dadurch vor der gelben Farbe, die sie mit der / Zeit insgemein anziehet, zu bewahren, als welchen Kunst/ griff die ehedeßen alhier berühmt gewesene Wachspous- / siererin Braunin ${ }^{1882}$ im Brauch gehabt, und dadurch den / Bestand ihres weisen und fleischfarben Wachses erhalten / haben soll. Als nun die gemeldete Farbe auf einem / offenen Geschirr der kalten Luft biß in die 4 Tagen aus- / gesezet und solche die Materie recht erhärtet hatte, fande / ich die Oberfläche derselben mit lauter artigen Zügen / Ziehrathen, und gleichsam einem formlichen Laubwerck / überzogen, welches nach seiner Bildung dem gemeinen / Kraute Salbey mit seinen Adern und übriger Beschaf- / fenheit nicht unähnlich sahe; die Einbildungskraft hatte / dabey, wie es etwa sonsten bey dergleichen Vorwürfen nöthig / ist, eben so viel nicht zu thun, immaßen die zarte und / eigendliche Abbildung dieser Pflanze einem jeden / von selbsten in die Augen fiele, und diese gab mir / Anlas zu dencken, ob gleich der Frost an vielen feuch- / ten Sachen eine gleichmäßige Wirckung thut, daß / solches doch keines Weges von ohngefehr geschehen müße. / Daß ich mich aber unterfangen mögte eigendlich $\mathrm{zu} /$ beschreiben wie die bildende Natur in ihrer geheimen / Werckstätte damit verfahre, das wäre meines Erachtens / eine

1882 Es handelt sich hierbei um Anna Maria Braun, geb. Pfründt (1642-1713), die von circa 1700 bis zu ihrem Tod in Frankfurt am Main lebte; vgl. Gwinner 1862, S.247-248. 
Kühnheit, die eben so viel Nutzen bringen würde, / als heutzutage manche cartesianische und so genan- / te corpusculare Weltweisen, mit ihren hackigten, 3 echi- / gen, und wer weiß es alle was vor Theilgen bey der / unpartheyischen Vernunft zu Wege bringen. Auf / solchen Schlag errinnere mich in manchen Büchern / berühmter Gesellschaften, und Naturkündigen gro- / Be Wetlaufugkeiten gelesen zu haben, die von aller- / ley gefrohrnen Flüßigkeiten, und der vermeinten Art / wie es damit zugegangen, handelten. Solche Maßen / behauptet einer daß die Fenster in einem sichern Pome- / rantzen Hauße über und über mit lauter Pomerantzen- / blättern und Straüchen befrohren gewesen, und / andere noch selsamere Einfälle, wie etwa hievon / in dem Giornale de letterati d'italia 12 Venez. / tom 26. p.367 ein Exempel von dem Winter von / anno $1716^{1883}$ und anderwärts mehrer davon zu finden / seyn mögten. Die Breßlauer Samlungen von Natur / und Kunstgeschichten enthalten ebenfals verschiedene / gleichmäßige Begebenheiten, davon ich aber beliebter

[250] Kürze wegen abbreche. Bey meinem gegenwärtigen / Vorwurfe kam ich übrigends auf die Gedancken, ob / dergleichen Materie auch jederzeit bey ihrer Erfriehrung / eben solche Bildung zeigen, und mich des Gegentheils / eines von ohngefehr geschehenen Zufalles überzeugen / mögte. Ich wiederhohlte demnach meine Arbeit mit / abreiben etwas weniges von neuer Bleiweis, ließe / sie aus einem porecellanen Teller wie das erste / Mahl friehren, und fande abermahl die Spuhren der / vorerwehnten Bildung ganz deutlich, und keine ande- / re. Solten denn dieses, gedachte ich hierauf alle weise Mate- / rien in dergleichen Fällen vieleichte thun? Deßwegen / machte einen Versuch mit feinen Stärckemeel [!], fande / aber darauf zwar einige sehr feine und kleine Züge, die / aber bey weitem die vorige Gestalt nicht hatten. Hätte die / damahlige Kälte nun länger angehalten, so würde in / meiner Anstellung von meherern Proben vieleichte in / dieser Erforschung weiter gekommen seyn, da mir aber / das folgende gelinde Wetter die Lehrbegierde unterbrach, / so mußte es dieses Mahl dabey bewenden laßen. In- / zwischen daucht mich doch daß dergleichen Bildungen / uns eine Muthmaßung an die Hand geben können / die vieles weit hergehohltes Vernünftlen über die bekan/ te Kraüterschiefer von verschiedenen Bergwercken in Eu- / ropa insonderheit die Eislebischen aufheben können. / Viele schreiben solche einer wircklichen Versteinerung / des Fahrenkrauts und anderer Pflanzen zu, ja sie hal- / ten gar dafür daß solche durch die allgemeine Sündflut / müßen ausgerißen, fortgeschwemmet und in die / Krüfte derer Berge in einem Leimen [?] 
eingeschloßen / erhärtet und versteinert worden seyn. Was sind aber / die weit hergehohlte Wahrscheinlichkeiten nütze, wenn wir / noch alle Tage Exempel vor Augen haben daß die Natur / dergleichen Bildungen durch ein schwelles Austrocknen / flüßiger Materien vor aller Augen bewerckstellige. / Könte dergleichen, wie an meiner Bleiweise geschehen / nicht auch in Eisleben an einer besondern Gattung / von Erden vorfallen, deren Bildungszüge alle auf / einem Vertiefen und ebenen Grunde etwas erhaben / werden. Könne als dem ein anderer Schlamm / welcher anders gefärbt als der erstere, ist, darüber, deckte / solche zu, und erhärtete unangerühret in solchem Stande

[251] so würden gewißlich eben dergleichen Figuren, wie / die besagte Steine haben, bey der Schieferung dieser / nachmahls erharteten Materie erscheinen. Mögte man / mir aber hierauf die gelehrte Einwendung und Frage / thun: Was ist das hier gebrauchte dunckele Wort, die Natur? / Und wie gehet derselben so unnöthig scheinendes Bilden / her? So würde ihm mit einem noch gelehrteren: / Ich weiß nicht, antworten. Allein genug von der / gleichen Muthmaßungen. [...]. 


\title{
16.6 Johann Friedrich von Uffenbachs Anmerkungen zu einem Verfahren des Mehrfarbendrucks
}

\author{
$\underline{\text { SUB Göttingen Cod. Ms. Uffenbach 13/III, S. 297-298 }}$
}

Uffenbach hielt das Referat in der wissenschaftlichen Gesellschaft am 9. Dezember 1729 im Haus von Conrad Hieronymus Eberhard, gen. Schwind.

[297] Nach dießer Anmerckung von lacciren brachte man / und verschiedene Gattungen von gefärbten Abtrücken / von Kupferstücken oder vielmehr schwarzer Kunst herbey / welche nunmehr mit einem besondern Kunstgriff zu / Augspurg sehr schön verfertiget, und in hießige Meßen / gebracht worden, es bestunden aber gegenwärtige Prob- / stücke, in denen Abbildungen der 5 Sinne und andern / historischen Bildern, denen eines grün, das ander ein / angenehmes rotlich braun, andere rosenfarb, noch / andere blau, gelb, und so weiter abgetruckt waren / und ein recht schönes Ansehen hatten. Ob nun wohl hir- / bei leicht zu dencken daß der sogenante Trucker Firnus / so wohl mit andern Farben als schwartz könne bereitet

[298] und abgerieben, folgends die Abtrücke mit ver- / schiedenen Farben abgezogen werden, so bilde / mir doch ein, daß hirunter ein besondrer Hand- / griff, wie auch ein ganz anderes als gekochtes / Leimöhl gebraucht werde, sintemahl dieses im Kochen / oder dem gemeinen Brennen, wie es die Trucker nen- / nen, dunckel und schwartzlicht, und also vor helle Farbe / als das hell rothe, gelbe, und dergleichen untüchtig / wird, so daß sie nothwendig ein ander Ohl so hell / und weis bleibet anwenden müßen. Vor allen andern / Proben aber war eine merckwürdig worin alle vorige / Farben zusammen an einem Stücke angebracht waren / und also schier der neuen engellandischen Erfindung / die Kupferstiche wie Ohlfarben Gemälde nach der Schat- / tirung und Colorit abzutrucken, beykahme, gleich wie / man nun vor längstens dergleichen schon in Holland nehm- / lich an solchen die mit dem Grabstichel gemacht, verferti- / get, so habe jedoch meines Wißens noch keine von schwar- / zer Kunstart gesehen, als das vermuthlich ganz andere / Umstände haben muß. Weil aber künftig bei un- / sern Zusammenkünften insonderheit von 
Kupferstücken / und derselben verschiedenen Gattungen, Verfertigung, und / Uhrsprung etwas umständlich bei zu bringen gesonnen / bin, so breche hiermit ab, und erspahre meine muthmaß- / liche Gedancken biß dahin. 


\title{
16.7Die Rede Johann Friedrich von Uffenbachs zum Tod seines jüngeren Bruders Wilhelm von Uffenbach
}

\author{
$\underline{\text { SUB Göttingen Cod. Ms. Uffenbach 13/V, S. 536-543. }}$
}

Johann Friedrich von Uffenbach hielt die Rede am 29. November 1735 vor der wissenschaftlichen Gesellschaft.

\section{[536] Ehrengedächtnüs / weyl / Herrn Wilhelms von Uffenbach}

So wohl die bißherige Üblichkeit bey unserer kleinen Gesell= / schaft, als auch der unvermuthete und abermahlen erlittene / verlust derselben errinnern [!] mich leider ! einer traurigen / Schultigkeit, die rechter einer andern fertigern Feder als der / meinigen ungeübten überlaßen zu werden verdienete. $\mathrm{Zu}=/$ mahlen da die nahe Verbindung zwischen mir und dem entris= / senen Mitgliede einen billigen Verdacht der Partheylichkeit / vorrücken mögte, wenn ich das schuldige Denckmahl deßelben / durch dieße wenige mehr als gezwungene Zeilen errichten soll. I Unsere Gesellschaft beklaget nehmlich darinnen das frühzeitige / Abscheiden weyl Herrn Wilhelms von Uffenbach. Ich wünschete / aber von Hertzen daß solches durch jemand anders als deßen / tiefgerührten Bruder geschehen mögte. Ist mir jemahlen das / Amt eines Schreibers bey unserer Zusammenkunft lästig ge $=/$ fallen, so kan es mit Grund der Wahrheit dieses Mahl gestehen; / Allein die Pflicht, welche einen Verbundenen dieser Art antreibet, / giebt keiner Ausnahme oder Entschuldigung Platz, und nöthiget / mich also eine Bemühung zu unternehmen, die nach diesen $\mathrm{Um}=/$ ständen nicht anders als gezwungen gerathen kan, gleichwie / es sonsten in allen Vorfällen meiner Schwäche gemäs eben / also geschehen. Wohlan, ich entschließe mich keine Hinter $=$ / nüs mehr anzuhören, und mir einzubilden, als ob der Verbli $=$ / chene mich weiter nicht als nur durch das Band unserer $\mathrm{Ge}=/$ sellschaft anginge, mit dem Vorsatze meine Unternehmung / desto kürtzer zu faßen, je angenehmer mein Vortrag so dann / der leyder auf die Helfte verkleinerten Anzahl unserer Mit= / glieder seyn wird.

Besagter Wohlgebohrner Herr Wilhelm von Uffenbach erblicke $=$ / te das Licht dieser mühsamen Welt in dem Jahr 1689 den / 16 7bris durch Vermittelung seiner lieben Aeltern weyl. H / Balthasars von Uffenbach des Raths alhier und Frauen $\mathrm{An}=$ / nen Sibyllen einer gebohrnen Mayern. Weiter in seine $\mathrm{Ge}=$ / 
schlechtserzehlung hinauf zu steigen, leydet der bißher einge $=$ / führte Gebrauch bey uns nicht, ein mehreres auch davon zu melden, / würde wegen allgemeiner Bekantschaft überflüßig, und nach

[537] denen Regeln des vernünftigen Wohlstandes anstößig / seyn. Er erblickete demnach auf solche Art diese Zeitlichkeit / allein in einem so baufälligen und schwächlichen Leibe, daß / damahlen kein Mensch glauben sollen, daß er sein nunmehr / erlebtes Alter erreichen könte. Krankheit und allerley be $=$ / sorgliche Anfälle begleideten seinen unvermögenden Leib von / der Geburt an biß in das siebende Jahr, da er erstlich an= / finge auf die Füße zu kommen und Fleisch genießen zu / lernen, wie etwa Kinder von 2 Jahren sonsten gewöhnlich / zu thun pflegen. Zu welchem noch dieses kam, daß er durch / einen schwehren Fall den Bau seiner Gliedmaßen dergestalt / erschüttert, daß sein sehr lang verweiltes Wachsthum $\mathrm{zu}$ ei= / ner ungewohnlichen Leibeskürtze Anlas gabe. Wie aber ei= / ne zarte Pflanze durch sorgfältige Erquäckelung zwar anfangs / wenig Ansehn und Schuß, aber um desto mehr unsichtbahre Stär= / cke erhält, so ging es auch unserm entseelten Mitgliede, der / von gedachten siebenten Jahr unvermuthet anfinge durch leb $=/$ hafte Munterkeit des Geistes und einen gegen alle fern= / er Anfälle ausdauernden Leib sich herfür zu thun, auch wei= / ter biß an seinen neulich erfolgten Abschied keiner Unpaß=/ lichkeit Platz zu geben. Da nun die Gemüthsgaben und ein / gewiß nicht kleiner Geist in einem nicht großen Leibe wäh=/ render Jugend anfingen herfür zu leuchten, so war wohl für= / nehmlich seine erste, beste und nachdrücklichste Schule, das / rühmliche Exempel seiner noch in gefeyerten Andencken / schwebenden Aeltern. Redlichkeit, und ein dieser heutigen Welt / nicht gleichender Wandel waren in einer tugendhaften Stille / die erspriesliche Fusstapfen, so sie ihren Kindern zur Nach= / ahmung zeigeten, und bey ihrem frühen Abschiede aus dieser / Welt hinterließen. Dieser ereignete sich von beyden anno 1700 / ohngefehr in 2 Tagen, und setzete unsern Verblichenen also / in einen frühen Waysenstand, nachdem sie ihme sowohl / durch Hauß als offentliche Schulen den Grund seiner darauf / erbaueten Wißenschaft mit aller Sorgfalt legen laßen. Es geschahe dieses hauptsächlich in allhießigem Gymnasio, / das der Erblichene sowohl bey ihren Lebzeiten als nachher un=/ ter der Vormundschaft, besuchet. Biß man es endlich zu seinem

[538] Nutzen zu sey erachtete Ihn anno 1706 d 8 7bris nach / Gotha in das Gymnasium, und dem H Professor Weichard / daselbst zum haußligen Unterricht und Erhaltung zu ver= / senden alwo er bey 4 Jahre verblieben, und nach abgeleg $=/$ ten verschiedenen Proben seines Fleißes anno 1710 wie $=/$ derum nach 
Hauße zu kommen befehliget worden. Wäh= / rendem diesen erstern Aufenthalt in der Fremde ließe / er schon Spuhren seiner Neigung für allerley nützliche Neben $=/$ bemühungen und für mechanische Wißenschaften blicken, die / er Zeithero immer zu unterhalten nicht nach gelaßen, und solche / Liebhabereyen auch damahlen mit nach Tübingen, alwo er / den Anfang seiner academischen Jahren gemacht, mitgenom $=/$ men. Er verreißete aber 1711 dorthin nicht allein, sondern / wegen seiner besorglichen Schwächlichkeit auf einrathen seiner / Vormünder in der Begleitung seines damahligen Hofmeisters / H Mauritz Christoph Thielens, der nunmehr in Hochfürstl Nas= / sau Usingischen Diensten als Rath und Cantzeleydirector / stehet. Des H Professor Craßens Hauß, Tisch und Unterricht / beliebte ihm für andern alda, bey welchem er auch in / die 2 Jahre verblieben, und darauf diesen Aufenthalt, / in dem Absehen sich fremder ohnentbehrlicher Sprachen zu / bemeistern, mit der Strasburger Academie verwechsel $=/$ te, alwo er sich anno 1713 im Frühjahr ohne Gesellschaft / hin wande, in Hoffnung eine ihm annehmliche an / seinem Bruder ${ }^{1884} \mathrm{zu}$ finden, welcher sich derer Studien we $=$ / gen ebenfalls dahin begeben hatte. Ein Hauß, ein Tisch / ein Lehrer, und endlich auch eine Nebenbemühung in / verschiedenen anständigen Handarbeiten, besonders aber / in der Music vergnügten sie beyde alda gantzer zwey / Jahre, worauf er nach gedachten Bruders Abreiße1885 / noch eine Frist von 2 Jahren allein verbliebe, und so / dann anno 1717 im Herbst nach Holland, und auf die hohe / Schule zu Leiden ginge, allda er ebenfalls ein Jahr / sich rühmlich aufgehalten, und hiernechst anno 1718 eine / Reiße durch selbige Lande und Brabant nach Franckreich / fürnahme. Gleichwie er aber in allen seinen Verricht $=$ / ungen nicht oben hin zu gehen gewohnt war, als wurden / auch diese jetzo gemeldete Reißen eben also abgeleget. / Ihm war nicht genug nach dem gemeinen Schlender die grös=

[539] Besten [!] und vornehmste Stätte eines Reiches allein, und / zwar dem Sprichworte nach, wie der Hahn über die Kohlen, / zu durchlaufen, sondern seine Lehrbegierde nahm sich über / all die Zeit alles und jedes aufmercksam in Augenschein / zu nehmen, deswegen er sich auch eine geraume Zeit in de $=/$ nen Provinzien Franckreichs, insonderheit aber an dem / Meerhafen von Marseille aufgehalten, und alda, wie in / allen Seestätten zu seyn ein besonderes Vergnügen gehabt. / Von hier aus reißete er durch die Schweitz nach seinem / Vaterlande, um auch alda das merckwürdigste zu betrach=/ ten, und kam 1720 über Augsburg und Nurnberg in / seiner Geburtsstatt wieder glücklich und gesund an, mit / dem

1884 Johann Friedrich meint sich hier selbst.

1885 Vgl. Tagebuch Cod. Ms. Uffenbach 29/I. 
festen Vorsatze nach der Verrichtung einiger nothwen= / digen Geschäften die übrige Reiche von Europa ebenfalls / zu durchwandern. Gleichwie es aber in dem menschlichen / Thun so beschaffen ist, daß man sich ofters Sachen vornimmt / die jedennoch wegen allerley Vorfällen nicht in das Werck / gerichtet werden, so erging es auch unserm verblichenen Mit=/ genoßen. Er finge nehmlich allmählich an die Ruhe, $d e=/$ nen mühseeligen Reißen vorzuziehen, richtete seine Haus $=$ / haltung als eine sich selbst begnügte ledige Person, / ja daß ich es sagen mag, als ein um menschliche Aus= / schweifungen wenig bekümmerter Weltweise auf das / bequehmlichste und anmuthigste ein, und fand sein / größtes Ergetzen an denen Büchern, deren er sich eine / auserlesene Zahl sonderlich von historischen, geographischen / und physicalischen anschafte, und diesen Zeitvertreib so $=/$ wohl mit einigen Handarbeiten als insonderheit der ihm / über alles gehenden Music abwechselte. Diese angenehme / und ungebundene Lebensart, welche denen wenigsten / dieser Welt zu Theil wird, nahm ihn auch dergestalt ein, / daß er an andere Dinge, worauf insgemein mensch $=/$ liche Gemüther rennen und trachten, keinen Gefallen / hatte, und sich jährlich mit einer kleinen Reiße in der / Nachbahrschaft herum, die zu weilen ziemlich weit aus $=/$ schweifete, nicht ohne Nutzen und seiner eigenen Belehr $=$ / ung erlustigte. Mittlerweile hatte das Verhängnüs / anno 1726 sich im Schertze fürgenommen, einen Schatten / einer Gesellschaft, die sich um Wercke der Natur und Kunst

[540] vernünftiger Weise bemühen solte, aufzurichten, sie / that es auch in allem Ernste an einem Orte, wo man / sonsten dergleichen Geschäften gehöre zu geben sich nicht die / Mühe giebt, und hieraus wurde wieder alles vermuthen / unsere nunmehrige Verbindung. Wie nun der Eifer eines / jeden Mitgliedes anfänglich ziemlich glühete, so war un= / ser Verstorbene einer von denen ersten mit der hiebey zu / tratten, aber auch biß zu seinem Abschiede mit so viel Ver= / gnügen darin zu seyn bezeigete, als der Anfang ihme / lieb gewesen. Welche in der That ein lobwürdiges Exempel / vor die noch übrige verbundenen seyn mögte, wenn anders / unsere unschuldige und nichts eintragende Bemühung ei=/ nes Lobes werth ist. Zufällig komt mir das Wort des Ein=/ tragens in die Feder, zufällig kan ich also auch als einen / Eifer für die Gesellschaft unseres abgetrenneten Mitgliedes / anpreißen, daß er unserer kleinen Cassa vorzüglich für $\mathrm{an}=/$ dere $\mathrm{zu}$ verstärcken sich angelegen seyn laßen. Allein / ich halte es vor überflüßig eine uns allen bekante Sache weit= / läuffiger darzuthun. Genug daß seine Liebe für unsere / Zusammenkünfte aus denen meisten seiner Aufführ= / ungen geleuchtet, und wir hätten wünschen sollen und / mögen, daß wir seiner Gesellschaft nicht so balde, nicht so / unvermuthet, und nicht so plötzlich beraubet 
werden mögten. / Das Schicksal verlangete dieses an eben dem Tage un=/ serer Zusammenkunft ${ }^{1886}$, und er tratte aus der Gesellschaft / zu eben der Zeit, da er vermuthete derselben wieder per= / sönlich beyzuwohnen. Es kam aber die muthmaßli= / che Uhrsache dieser Trennung nicht von weniger Zeit her, / denn da er fast zwey Jahre vor seinem Tode einer sichern / frantzösche Vertheidigung des gemeinen Waßers unter dem / Tittul: Vertue de l'eau commune $\mathrm{p}^{1887}$ zufällig in die Hände / bekam, fande er ein solches Belieben daran, daß er dem / Verfaßer nicht nur völligen Beyfall gabe, sondern auch / die Probe von Stund an an sich selber machte. Er fing / nehmlich an den Wein als einen Verderb der menschlichen / Natur bey Seite zu setzen, und den Tranck, welcher allen / Lebenden, wovon also auch die Menschen nicht auszunehmen, / vorzuziehen; nicht daß er es gethan, weil er weniger kostet,

[541] denn das war bekantlich seine Neigung nicht, oder das / ihn sonderliche Leibesschwachheit und Anfälle dazu ermahnet / sondern weil er glaubete eine kleine dann und wann ihn / quählende Beschwehrung, so in einem halben Kopfschmer= / tzen mit Eckel vor Speisen bestanden, gäntzlich damit zu / heben. Es thate dieses einfaltige und auf gewiße Wei=/ se heylsame Mittel auch seine Wirckung allerdings, / unser Waßerfreund wurde zusehens und vermeindlich / gesund, aber auch augenscheinlich so dücke, daß das athem $=/$ holen ziemlich belästiget wurde. Keine Bewegung wol= / te dem Übel abhelfen, und die Ansehnlichkeit des Leibes ver= / mehrte sich dermaßen, daß die Seele ihn länger $\mathrm{zu}$ bewoh= / nen nicht mehr Raum fande. Nachdencklich ist es allerdings / daß in der letzten Versamlung, so bey dem Verstorbenen / gehalten worden, meine Übersetzung von einem fast glei= / chen Zufalle von Amsterdam aus einer zu Leiden gehalte $=/$ nen Dissertation vor seinen Ohren abgelesen worden, $\mathrm{wo}=/ \mathrm{zu}$ mich doch nichts weniger als eine Muthmaßung, und / anders nichts, als ein ich weiß nicht was, veranleitet / hatte. Nicht lange darauf erschiene der für mich inson= / derheit herbe Tag seiner Trennung von dieser Welt und / unsern Augen. Es war solches der verwichene 24te Juny / nehmlich ein Freytag, der uns von andern Geschäften / befreyet um an unsere Gemüthsergetzung zu gehen, / aber auch ein Freytag, der unsern Freund aller weltlichen / Trübsalen und Unvollkommenheiten befreyet hat, nach / dem er nicht gar 46 Jahre des Alters erreichet.

1886 Freitag, 24 Juni 1735.

1887 Vielleicht: Les Vertus medicinales de l'eau commune, Paris 1730 (SUB Göttingen $8^{\circ}$ Ther 2685 [nicht in Bibl. Uff.]). 
Wir errinnern diesem nach weiter nichts von ihm / weil wir alle wißen, daß sein Umgang redlich, / seine Aufführung edelmüthig und vernünftig, sein / Reden spahrsam aber gewürtzet, und seine Liebe für / die Wißenschaften nur mit seinem Tode auslösch $=/$ lich gewesen. Seine Bücher, nebst seinen Instrumen $=/$ ten in Nebenstunden, waren daher seine vertrauteste / Lieblinge, und unsere geringe Versamlung eine seiner

[542] erwehlten Ergetzungen. Hat diese bey uns übrigen den / Entzweck um die Natur in ihren verborgenen Wegen / ferner zu erforschen, so laßet uns einen Irrthum / derselben bey dem Tode unseres Freundes wahrnehmen. / Es stirbt der jüngste unter uns zuerst, und sein $\mathrm{Schei}=/$ den lehret uns allerdings die Ungewißheit unserer $\mathrm{Ta}=/$ ge; hier ist eine Begebenheit der Natur, nach der Aufschrift / unserer Samlungen zu reden, die das menschliche Hertz / noch nicht erforschet, hier ist eine Kunst daran wie von / unserer Geburt an zu lernen haben, und so wie die $=$ / Lehrbegierde in allen unsern Thaten, sowohl als diesen / Augenblick da ich dieses ablese, blicken laßen, so / werden wir wahrhaftig klug.

Doch da ich mich entsin= / ne weder auf einer Cantzel, noch auf einem offendli= / chen Lehrgerüste zu stehen, so soll der nunmehrige jüngste / unserer Mitglieder, wie ich bin, die ältern nicht weiter / zu lehren sich unterfangen. Es wird genug, ja überflüs= / sig seyn was ich zu des Verstorbenen Denckmahl bereits / gesprochen, und wozu mich meine Pflicht nebst dem eh= / maligen versprechen verbunden. Vieleicht rücket man / mir vor ich hätte ihn als ein Bruder zu viel erhoben / und ich entsinne mich auch daß es würcklich wahr, ja / unschicklich für seinen nechsten Blutsfreund seye, allein / da ich diesem Vorwurfe gleich anfangs begegnet, und von / ihm als ein Fremder zu reden mir vorgenommen, so deucht / mich bin ich entschuldiget; hab ich ihn also einigermaßen / gelobet, so hab ich es als ein Fremder gethan, hab ich aber / seine rühmliche Eigenschaften zum Theil verschwiegen, so / hab ich als ein Bruder gesprochen. Es sey nun wie es / wolle, so geb ich denen Anwesenden bey dem Abschiede / meines letzten Bruders ${ }^{1888}$ die Versicherung, daß sie den Fehler / nicht noch einmahl von mir hören werden. Das Kleeblat / unserer brüderlichen Zahl ist zerrißen, und wer hätte den $=/$ cken sollen, daß das dürreste und schlechteste Blätgen

[543] davon am längsten stehen solte? Wenigstens habe / nimmer anderst vermuthen können, als daß der / letzt verblichene vielmehr mein Denckmahl, als ich / das seinige abzulesen genöthiget seyn werde. So / brächte es Ordnung und

1888 Sein älterer Bruder Zacharias Conrad war 1734 gestorben. 
Natur mit sich, allein auch / hirin sehen wir unser Unvermögen in der Erkent= / nüs derselben deutlich. Ihre und des Höchsten Regierers / Wege bleiben unerforschlich, und gehen so wenig nach / unserm Willen, als (ohne alle Vergleichung gesprochen) / meine Feder dieses Mahl nach mein Fürsatze dieße / letzte Schultigkeit und meinen Spruch so viel als mög=/ lich abzukürtzen. Und wie ich selbst erkenne daß ich / in diesem Geschäfte nichts tauge, so wünschet doch mit / mir daß ich eure Gedult lange hin nicht mehr mis= / brauchen, und ich in dieser Obliegenheit, die niemand / mehr als mir selber zu wieder ist, lange Jahre verscho $=$ / net bleiben möge. 


\section{Eidesstattliche Erklärung}

Hiermit versichere ich an Eides statt, dass ich die eingereichte Dissertation „Johann Friedrich von Uffenbach. Sammler - Stifter - Forscher“ selbständig und ohne unerlaubte Hilfe verfasst habe. Anderer als der von mir angegebenen Hilfsmittel und Schriften habe ich mich nicht bedient. Alle wörtlich oder sinngemäß den Schriften anderer Autorinnen oder Autoren entnommenen Stellen habe ich kenntlich gemacht. Die Abhandlung ist noch nicht veröffentlicht worden und noch nicht Gegenstand eines Promotionsverfahrens gewesen.

Göttingen, den 28. August 2019

Dietrich Meyerhöfer 